\title{
Quality of
}

\section{Surface Waters of the}

\section{United States}

1954

Parts 7-8. Lower Mississippi River Basin and Western Gulf of Mexico Basins

Prepared under the direction of S. K. LOVE, Chief, Quality of Water Branch

GEOLOGICAL SURVEY WATER-SUPPLY PAPER 1352

Prepared in cooperation with the States of Arkansas, Louisiana, New Mexico, Oklahoma, and Texas, and with other agencies

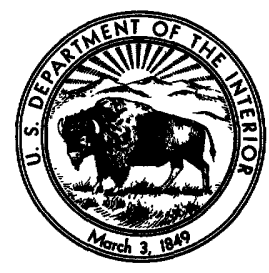


UNITED STATES DEPARTMENT OF THE INTERIOR

FRED A. SEATON, Secretary

\section{GEOLOGIGAL SURVEY}

Thomas B. Nolan, Director 


\section{PREFACE}

This report was prepared by the Geological Survey in cooperation with the States of Arkansas, Louisiana, New Mexico, Oklahoma, and Texas, and with other agencies by personnel of the Water Resources Division under the direction of:

C. G. Paulsen .......... Chief Hydraulic Engineer

S. K. Love ......... Chief, Quality of Water Branch

P. C. Benedict, regional engineer ...... Lincoln, Nebr.

J. W. Geurin, district chemist .... Fayetteville, Ark.

J. M. Stow, district chemist ... Albuquerque, N. Mex. Burdge Irelan, district chemist ......... Austin, Tex. T. B. Dover, district chemist ... Oklahoma City, Okla. 



\section{CONTENTS}

Introduction $\ldots \ldots \ldots \ldots$

Collection and examination of samples $\ldots \ldots \ldots \ldots \ldots$

Chemical quality ........................ 3

Suspended sediment ...................... 4

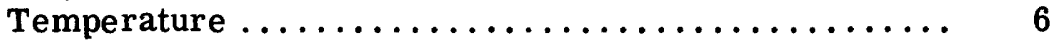

Expression of results ..................... 6

Composition of surface waters ................ 8

Mineral constituents in solution ............... 9

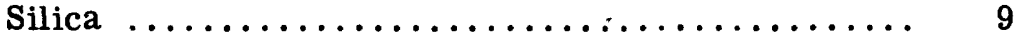

Aluminum $\ldots \ldots \ldots \ldots \ldots \ldots \ldots \ldots \ldots \ldots \ldots$

Manganese $\ldots \ldots \ldots \ldots \ldots \ldots \ldots \ldots \ldots \ldots \ldots \ldots$

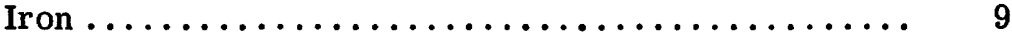

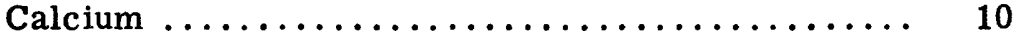

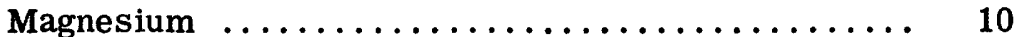

Sodium and potassium $\ldots \ldots \ldots \ldots \ldots \ldots \ldots$

Carbonate and bicarbonate ............... 11

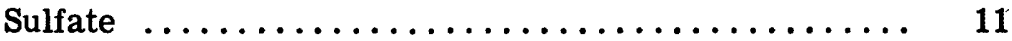

Chloride ............................. 11

Fluoride .......................... 11

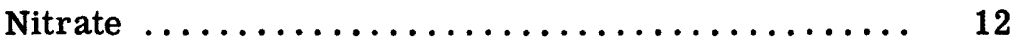

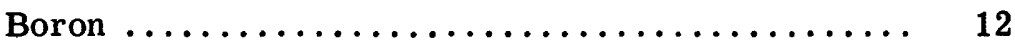

Dissolved solids ...................... 12

Properties and characteristics of water .......... 13

Oxygen consumed ..................... 13

Color ............................. 13

Hydrogen-ion concentration .............. 13

Specific conductance .................... 13

Hardness ............................. 14

Total acidity $\ldots \ldots \ldots \ldots \ldots \ldots \ldots \ldots \ldots \ldots \ldots \ldots \ldots$

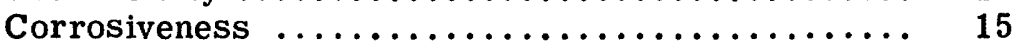

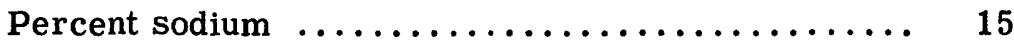

Sodium-adsorption-ratio .................. 15

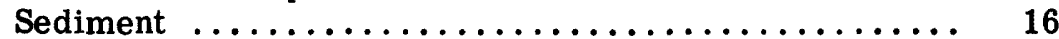

Publications .......................... 17

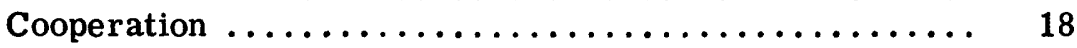

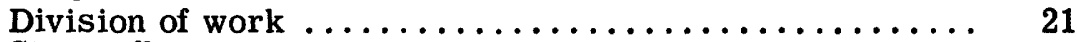

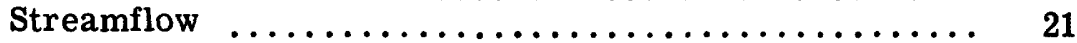

Literature cited ......................... 22

Chemical analyses, water temperatures, and suspended

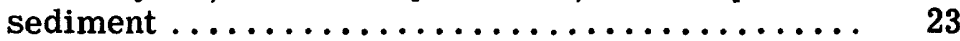

Part 7-Lower Mississippi River basin ............ 23

Mississippi River at St. Louis, Mo. (main stem) . . 23

St. Francis River basin ................ 27 
Chemical analyses, etc. --Continued

Lower Mississippi River basin--Continued

St. Francis River basin--Continued

St. Francis River at Marked Tree, Ark. ......... 27

Miscellaneous analyses of streams in St. Francis

River basin in Arkansas .................. 30

White River basin ....................... 31

War Eagle Creek near Hindsville, Ark. .......... 31

Kings River near Berryville, Ark. ............. 32

White River at Cotter, Ark. ............... 33

Buffalo River near St. Joe, Ark. ............ 35

North Fork River at Norfork Dam near Norfork, Ark. . 36

Spring River at Imboden, Ark. ............. 37

Eleven Point River near Ravenden Springs, Ark. .... 38

Strawberry River near Poughkeepsie, Ark. ........ 39

White River at Newport, Art. ............... 40

Cache River at Patterson, Ark. ............... 43

White River at Clarendon, Ark. .............. 46

Lagrue Bayou near Stuttgart, Ark. ........... 49

Little Lagrue Bayou near Stuttgart, Ark. ........ 50

Miscellaneous analyses of streams in White River

basin in Arkansas $\ldots \ldots \ldots \ldots \ldots \ldots \ldots \ldots \ldots, 52$

Arkansas River basin . .................. 54

Arkansas River below John Martin Reservoir, Colo. .. 54

Arkansas River at Arkansas City, Kans. .......... 57

Arkansas River at Ralston, Okla. .............. 61

Skeleton Creek near Lovell, Okla. .............. 64

Cimarron River at Perkins, Okla. ............. 69

Arkansas River at Sand Springs Bridge near Tulsa,

Okla. ............................... 75

Verdigris River near Lenapah, Okla........... 80

Verdigris River near Claremore, Okla. ......... 83

Verdigris River near Inola, Okla. ............ 86

Neosho River near Commerce, Okla. .......... 90

Neosho (Grand) River at Pensacola Reservoir, at

Langley, Okla. .................... 93

Neosho (Grand) River at Fort Gibson Reservoir, Okla . 95

Ute Creek near Bueyeros, N. Mex. ........... 97

Illinois River at Tenkiller Reservoir, near Gore, Okla. 101

Canadian River near Amarillo, Tex. ............. 103

Canadian River at Bridgeport, Okla. ............. 106

Little River below Hog Creek near Norman, Okla. .... 110

North Canadian River at Canton Reservoir near

Canton, Okla. .......................... 114

North Canadian River near Yukon, Okla. ......... 116

North Canadian River near Wetumka, Okla. ....... 119

Deep Fork River near Beggs, Okla. ............ 124

Canadian River near Whitefield, Okla. .......... 128 
Chemical analyses, etc. --Continued

Lower Mississippi River basin--Continued

Arkansas River basin--Continued Page

Lee Creek near Van Buren, Ark. ............ 134

Arkansas River at Van Buren, Ark. ............ 135

Mulberry River near Mulberry, Ark. ........... 140

Piney Creek near Dover, Ark. ................ 141

Illinois Bayou near Scottsville, Ark............. 142

Arkansas River at Dardanelle, Ark. ............ 143

Arkansas River at Little Rock, Ark............. 148

Arkansas River near Altheimer, Ark. ........... 152

Crooked Creek near Humphrey, Ark. ........... 156

Miscellaneous analyses of streams in Arkansas River

basin in Oklahoma and Missouri ............ 157

Miscellaneous analyses of streams in Arkansas River

basin in Arkansas ........................ 178

Red River basin ........................ 180

Salt Fork Red River near Wellington, Tex. ........ 180

North Fork Red River near Carter, Okla. ......... 183

Little Wichita River near Archer City, Tex. ....... 186

Little Wichita River near Henrietta, Tex. ......... 190

Red River near Gainesville, Tex. ............. 194

Washita River at Carnegie, Okla. ............. 198

Washita River near Durwood, Okla. ............. 202

Red River at Denison Dam near Denison, Tex. ..... 206

Kiamichi River near Belzoni, Okla. .......... 208

Little River below Lukfata Creek near Idabel, Okla. .. 210

Little River near Horatio, Ark. ............ 212

Red River at Fulton, Ark. .............. 215

Twelvemile Bayou near Dixie, La. ........... 219

Bayou Bodcau near Sarepta, La. ............. 220

Saline Bayou near Clarence, La. ............. 221

Red River at Alexandria, La. ............. 223

Ouachita River at Arkadelphia, Ark. .......... 226

Little Missouri River near Boughton, Ark. ....... 229

Smackover C reek near Norphlet, Ark. .......... 231

Ouachita River at Calion, Ark. ............. 235

Hurricane Creek near Sheridan, Ark. .......... 240

Saline River near Rye, Ark. ............... 244

Bayou Lapile near Strong, Ark. ............. 246

Ouachita River near Felsenthal, Ark. ......... 250

Cornie Creek near Junction City, Ark. .......... 254

Three Creeks near Junction City, Ark. .......... 258

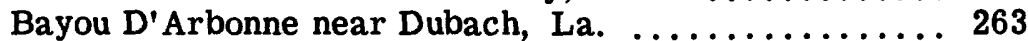

Bayou La Fourche near Crew Lake, La. ............ 264

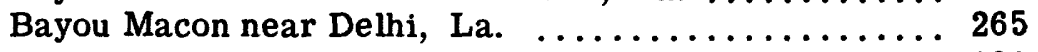

Bayou Castor near Grayson, La. ............. 266 
Chemical analyses, etc. --Continued

Lower Mississippi River basin--Continued

Red River basin--Continued

Miscellaneous analyses of streams in Red River basin in Oklahoma

Miscellaneous analyses of streams in Red River

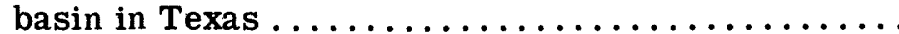

Miscellaneous analyses of streams in Red River basin in Arkansas

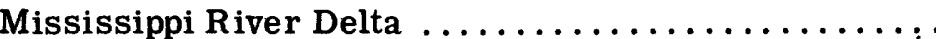

Atchafalaya River at Krotz Springs, La. .......... 282

Bayou Cocodrie near Clearwater, La. .......... 285

Vermilion River at Bancker's Ferry, La. ........ 291

Part 8-Western Gulf of Mexico basins ........... 295

Mermentau River basin ................... 295

Mermentau River near Lake Arthur, La. ....... 295

Calcasieu River basin .................... 298

Beckwith Creek near De Quincy, La. ........... 298

Calcasieu River at Moss Bluff, La. ............ 299

Sabine River basin .......................... 302

Sabine River near Emory, Tex. ............ 302

Sabine River near Tatum, Tex. ............ 305

Sabine River near Ruliff, Tex. ............. 308

Cow Bayou near Mauriceville, Tex. .......... 311

Neches River basin ...................... 314

Neches River at Evadale, Tex. ............. 314

Miscellaneous analyses of streams in Neches River basin in Texas .......................... 317

Trinity River basin ..................... 319

Trinity River near Oakwood, Tex. ........... 319

Trinity River at Romayor, Tex. ............ 322

Trinity River near Moss Bluff, Tex. .......... 325

Old River near Cove, Tex. .............. 327

Trinity River at Anahuac, Tex. .............. 329

Trinity Bay at mouth of Trinity River near Anahuac,

Tex.

San Jacinto River basin $\ldots \ldots \ldots \ldots \ldots \ldots \ldots \ldots \ldots$

San Jacinto River near Huffman, Tex. ......... 335

Brazos River basin ..................... 337

Brazos River at Possum Kingdom Dam near Graford,

Tex.

Brazos River near Whitney, Tex. ........... 339

Brazos River at Richmond, Tex. .............. 342

Miscellaneous analyses of streams in Brazos River basin in Texas

Colorado River basin ..................... 347

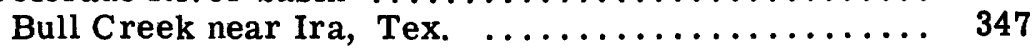

Deep Creek near Dunn, Tex. ............... 348 
Chemical analyses, etc. --Continued

Western Gulf of Mexico basins--Continued

Colorado River basin--Continued

Colorado River at Colorado City, Tex. .......... 349

Colorado River near San Saba, Tex. ........... 352

Colorado River at Austin, Tex. .............. 358

Colorado River at Wharton, Tex. ............. 360

Miscellaneous analyses of streams in Colorado

River basin in Texas ................... 362

Guadalupe River basin .................... 363

Guadalupe River at Victoria, Tex............. 363

Miscellaneous Analyses of streams in Guadalupe River

basin in Texas ......................... 366

Nueces River basin ...................... 367

Nueces River near Mathis, Tex. ............ 367

Rio Grande basin .................... 369

Rio Grande above Culebra Creek near Lobatos, Colo. . 369

Rio Grande at Embudo, N. Mex. ............ 371

Rio Chama near Abiquiu, N. Mex. ........... 375

Rio Chama near Chamita, N. Mex. ............ 379

Rio Grande at Otowi Bridge near San Ildefonso,

N. Mex. ............................ 383

Galisteo Creek at Domingo, N. Mex. ........... 389

Jemez River below Jemez Canyon Dam, N. Mex. . ... 393

Rio Grande near Bernalillo, N. Mex. . . . . . . . . . 397

Rio Grande near Bernardo, N. Mex. ........... 401

Rio Puerco below Cabezon, N. Mex. .......... 405

Chico Arroyo near Guadalupe, N. Mex. ......... 409

San Jose River at Correo, N. Mex. ............. 412

Rio Puerco at Rio Puerco, N. Mex. .............. 414

Rio Puerco near Bernardo, N. Mex. ...........4418

Rio Salado near San Acacia, N. Mex. ........... 421

Socorro main canal north at San Acacia, N. Mex. .... 423

Rio Grande at San Acacia, N. Mex. ............ 424

Rio Grande at San Antonio, N. Mex. ........... 430

Rio Grande conveyance channel below heading near

San Marcial, N. Mex. ................... 434

Rio Grande Tiffany Channel at San Marcial, N. Mex. . 437

Rio Grande conveyance channel at San Marcial,

N. Mex.

Rio Grande floodway at San Marcial, N. Mex. ...... 447

Pecos River at Puerto de Luna, N. Mex. .........453

Pecos River below Alamogordo Dam, N. Mex. ...... 459

Pecos River near Acme, N. Mex. .............461

Rio Hondo at Diamond A Ranch near Roswell, N. Mex. . 464

Pecos River near Artesia, N. Mex. ........... 468

Rio Penasco at Dayton, N. Mex. ............474

Pecos River at Dam Site 3 near Carlsbad, N. Mex. ... 476 
Chemical analyses, etc. --Continued

Western Gulf of Mexico basins--Continued

$\mathrm{R}$ io Grande basin--Continued

Carlsbad main canal at head near Carlsbad, N. Mex. .. 477

Pecos River at Carlsbad, N. Mex. ........... 478

Refinery intake canal near Loving, $\mathbf{N}$ Mex. .......4481

Pecos River east of Malaga, N. Mex. .......... 482

Pecos River at Pierce Canyon Crossing near Malaga,

N. Mex. ........................... 484

Pecos River near Red Bluff, N. Mex. ......... 487

Pecos River below Red Bluff Dam near Orla, Tex. . . 490

Pecos River below Grandfalls, Tex. ........... 492

Pecos River near Girvin, Tex. .............. 493

Miscellaneous analyses of streams in Rio Grande

basin in New Mexico ........................ 495

Index

\section{$\overline{\text { ILLUSTRATION }}$}

Figure 1. Map of the United States showing basins

Page covered by the four water-supply papers on quality of surface waters in 1954 


\title{
QUALITY OF SURFACE WATERS
}

\section{OF THE UNITED STATES, 1954}

\author{
PARTS 7-8
}

\section{INTRODUCTION}

The quality-of-water investigations of the United States Geological Survey are concerned with chemical and physical characteristics of the surface and ground water supplies of the Nation. Most of the investigations carried on in cooperation with States and other Federal agencies deal with the amounts of matter in solution and in suspension in streams.

The records of chemical analysis, suspended sediment, and temperature for surface waters given in this volume serve as a basis for determining the suitability of the waters examined for industrial, agricultural, and domestic uses insofar as such use is affected by the dissolved or suspended mineral matter in the waters. The discharge of a stream and, to a lesser extent, the chemical quality are related to variations in rainfall and other forms of precipitation. In general, lower concentrations of dissolved solids may be expected during the periods of high flow than during periods of low flow. The concentration in some streams may change materially with relatively small variations in flow, whereas for other streams the quality may remain relatively unifor $m$ throughout large ranges in discharge. The quantities of suspended sediment carried by streams are also related to discharge, and during flood periods the sediment concentrations in many streams vary over wide ranges.

The regular yearly publication of records of chemical analyses, suspended sediment, and water temperature was begun by the Geological Survey in 1941. The annual records prior to 1948 were published in a single volume for the entire country. Beginning in 1948, the records were published in two volumes, and beginning in 1950, in four volumes, covering the drainage basins shown in figure 1 . The samples for which data are given were collected from October 1, 1953 , to September 30, 1954. Descriptive statements are given ior each sampling station for which regular series of chemical analyses or sediment determinations have been made. These statements include the location of the stream-sampling station, drainage area, length of time for which records are available, extremes of dissolved solids, hardness, sediment loads, water temperature, and other pertinent data. 


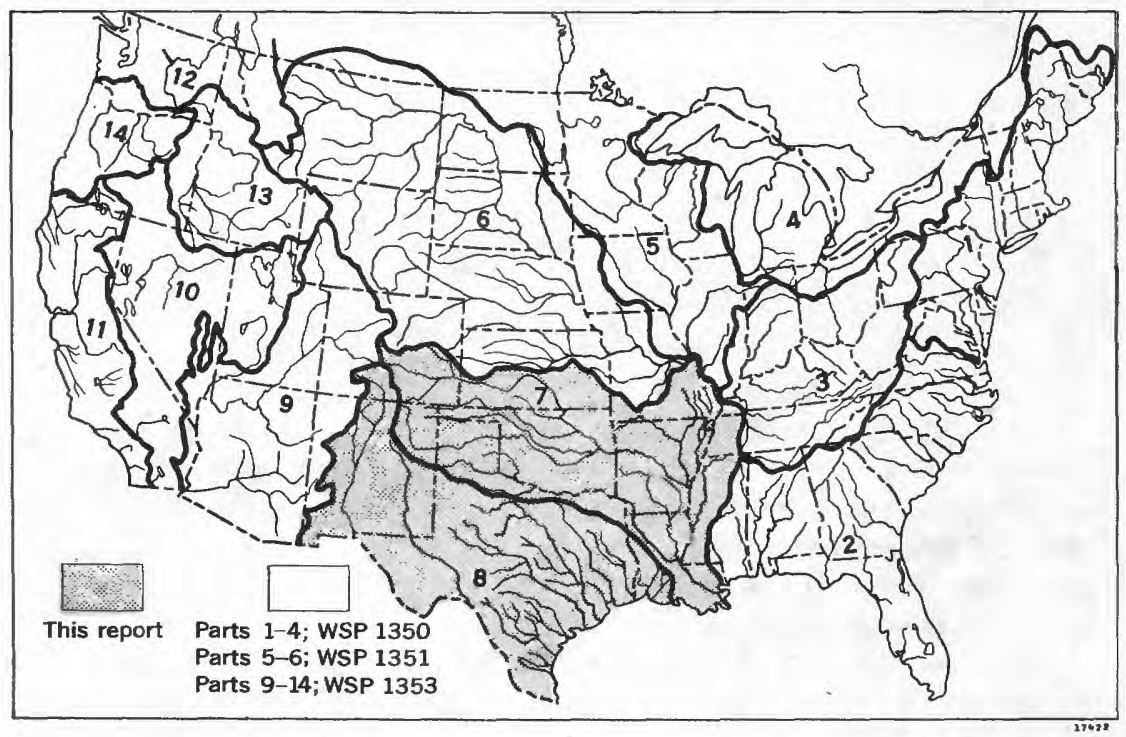

Figure 1. Map of the United States showing basins covered by the four water-supply papers on quality of surface waters in 1954. The shaded portion represents the section of the country covered by this volume; the unshaded portion represents the section of the country covered by other watersupply papers.

Records of water discharge of the streams at, or near, the samping point for the sampling period are included in most tables of analyses. The records are arranged by drainage basins, according to Geological Survey practice in reporting records of stream flow.

Beginning with the series of reports for the water year ending September 30,1951 , the order of listing station records has been changed. In this report, stations on tributary streams are listed between stations on the main stream in the order in which those tributaries enter the main stem. Stations on tributaries to tributaries are inserted in a similar manner.

During the year ended September 30, 1954, 109 regular sampling stations on 70 streams for the study of the chemical character of surface waters were maintained by the Geological Survey in the area covered by this volume. Samples were collected less frequently during the year at many other points. Water temperatures were measured daily at 96 of the regular sampling stations. Not all analyses of samples of surface water collected during the year have been included. Single analyses of an incomplete nature generally have been omitted. Also, determinations made on the 
daily samples before compositing have not been reported. Specific conductance was usually determined on each daily sample, and $\mathrm{pH}$, chloride, or other determinations were also made on many of the daily samples. As noted in the table headings these data are available for reference at the district offices listed under Division of Work, on page 19.

Quantities of suspended sediment are reported for 27 stations during the year ended September 30, 1954. The sediment samples were collected one or more times daily at most stations, depending on the rate of flow and changes in stage of the stream. Sediment samples were collected less frequently during the year at many other points. In connection with measurements of sediment discharge, sizes of sediment particles were determined at 27 of the stations. As noted under "Remarks" in the table headings, suspended-sediment concentrations also were determined from the samples collected for chemical analyses in some parts of the country. The data do not provide a reliable basis for computing the loads of suspended sediment carried by the stream but may be of value for design and operation of filtration plants utilizing these stream waters. Records of these infrequent determinations are available for reference in the district offices listed.

Material which is transported essentially in continuous contact with the stream bed is termed bed load and is not considered in this report. All other undissolved material in transport is termed suspended sediment and generally constitutes the major part of the total sediment load. At the present time no reliable method has been developed for determining bed load on a routine basis.

\section{COLLECTION AND EXAMINATION OF SAMPLES}

\section{CHEMICAL QUALITY}

Samples for chemical analyses were usually collected daily at, or near, points on streams where gaging stations are maintained for measurement of water discharge. Most of the analyses were made on 10-day composites of daily samples collected for a period of a year at each sampling point. Three composite samples were usually prepared each month by mixing together equal volumes of daily samples collected from the 1 st to the 10 th, from the 11 th to the 20th, and during the remainder of the month. For some streams that are subject to sudden and large changes in chemical composition or concentration, samples were composited for shorter periods on the basis of the concentration of dissolved solids indicated by measurements of specific conductance of the daily samples.

The samples were analyzed according to methods regularly used by the Geological Survey. These methods are essentially the same as or are modifications of methods described in recognized 
authoritative publications for the mineral analysis of water samples (Collins, 1928; Am. Public Health Assoc., 1946).

For those waters containing moderately large quantities of soluble salts, the value reported for dissolved solids is the sum of the quantities of the various determined constituents using the carbonate equivalent of the reported bicarbonate. In other analyses the value reported as dissolved solids is the residue on evaporation after drying at $180^{\circ} \mathrm{C}$ for 1 hour. Specific conductance is given for most analyses and was determined by means of a conductance bridge using a standard potassium chloride solution as reference.

\section{SUSPENDED SEDIMENT}

In general, samples were collected daily with the US D-43 depth-integrating sampler (U. S. Inter-agency, 1948, p. 70-76) from a fixed sampling point at one vertical in the cross section. The US DH-48 hand sampler was used at many stations during periods of low flow. Suspended-sediment samples, consisting of depth-integrated samples at three or more verticals in the cross section were made periodically to determine the cross-sectional distribution of the suspended concentration with respect to that at the daily sampling vertical. In streams where comparatively rapid fluctuations in transverse distribution of water discharge or sediment concentration are encountered at the sampling point, samples were taken regularly at two or more verticals to determine the average concentration across the section. During periods of high flow, samples were taken two or more times throughout the day at many sampling stations, and during periods of rapidly changing flow samples were taken hourly at some stations.

Sediment concentrations were determined by filtration or evaporation of the samples as required. At many stations the mean daily concentration for some days was obtained by plotting the instantaneous concentrations on the original or copies of the original gage-height chart. The plotted concentrations adjusted, if necessary, for cross-sectional distribution with respect to that at the daily sampling vertical, were connected or averaged by continuous curves to obtain a concentration graph. This graph represented the estimated concentration at any time and, for most periods, mean daily concentrations were deter mined from the graph. When the concentration and water discharge were changing rapidly, the day was often subdivided for this computation. For some periods when the day -to-day variation in the concentration was negligible, the data were not plotted, and the average concentration of the samples was used as the mean concentration for the day. For certain stations, when the discharge and sediment concentrations were relatively low and varied only slightly from day to day, the 
samples for a number of days were composited and the mean daily concentrations and mean daily loads are shown.

For some periods when no samples were collected, daily sediment loads were estimated on the basis of water discharge, sediment concentrations observed immediately preceding and following the periods, and sediment loads for other periods of similar discharge. The estimates were further guided by weather conditions and sediment discharge for other stations.

In many instances where there were no observations for several days, the sediment loads for individual days are not esti mated, as numerous factors influencing the quantities of transported sediment made it very difficult to make accurate estimates of sediment loads for individual days. However, estimated sediment loads for missing days in an otherwise continuous period of sampling have been included in monthly and annual totals for most streams to provide a somplete record.

In addition to the records of total quantities of sediment, rec ords of the particle sizes of sediment are included also. The particle sizes of the suspended sediments were determined periodically for many of the stations. As much of the material carried in suspension can pass through the finest sieves, the bottomwithdrawal tube method (U. S. Inter-agency, 1943, p. 82-90) was used in most of the analyses. Generally, sieves were used in the determination of particle sizes for sediments which were predominantly coarser than $0.062 \mathrm{~mm}$. Size distribution for some sediments was deter mined by a combination of sieves and pipette methods in which the size fraction $0.062 \mathrm{~mm}$ and larger was analyzed by sieves and that smaller than $0.062 \mathrm{~mm}$ was analyzed by the pipette method (Kilmer and Alexander, 1949). Native or distilled water, as noted in the tables of analyses, was used as the settling medium. In some instances, chemical dispersing agents were added to the settling medium. As settling diameters of the clay and colloidal fractions are often affected by the chemical character of the settling medium, analyses made using native water may more nearly simulate particle sizes existing in the stream. Results of analyses using distilled water or using a settling medium containing dispersing agents approximate ultimate particle sizes of the finer fractions. The concentration of sediment suspension for analysis was reduced to less than 5,000 parts per million, where necessary, by means of a sample splitter, in order to stay within limits recommended for the bottom-withdrawal tube or pipette method. The concentration of suspended sediment used in the bottom-withdrawal tube or pipette cylinder was of ten differ ent from the concentration in the or iginal suspension. The concentration at which analyses were made is indicated in the appropriate tables. 


\section{TEMPERATURE}

For most of the stations, daily water temperatures were obtained at the time that the chemical quality or sediment samples were collected. So far as practicable the water temperatures were observed at about the same time each day for an individual river station in order that the data would be relatively unaffected by diurnal variations in temperature. For most large, swiftly flowing streams the diurnal variation in water temperature is probably small, but for sluggish or shallow streams the daily range in temperature may amount to several degrees and may follow closely changes in air temperature. The thermometers used for determination of water temperature were accurate to plus or minus about $0.5^{\circ} \mathrm{F}$.

Records of thermograph observations consist of maximum and minimum temperatures for each day, and the monthly averages of the maximum daily and minimum daily temperatures.

\section{EXPRESSION OF RESULTS}

The dissolved mineral constituents are reported in parts per million. A part per million is a unit weight of a constituent in a million unit weights of water. Equivalents per million are not given in this report although the expression of analyses in equivalents per million is sometimes preferred. An equivalent per million is a unit chemical combining weight of a constituent in a million unit weights of water and is calculated by dividing the concentration in parts per million by the chemical combining weight of the constituent. For convenience in making this conversion the reciprocals of chemical combining weights of the most commonly reported constituents (ions) are given in the following table:

Constituent Factor Constituent Factor

Iron $\left(\mathrm{Fe}^{++}\right) \ldots \ldots \ldots 0.0358$

Iron $\left(\mathrm{Fe}^{+++}\right) \ldots \ldots \ldots .0537$

Calcium $\left(\mathrm{Ca}^{++}\right) \ldots \ldots .0499$

Magnesium $\left(\mathrm{Mg}^{++}\right) \ldots .0822$

Sodium $\left(\mathrm{Na}^{+}\right) \ldots \ldots \ldots . .0435$

Potassium $\left(\mathrm{K}^{+}\right) \ldots \ldots .0256$
Carbonate $\left(\mathrm{CO}_{3}^{--}\right) \ldots 0.0333$

Bicarbonate $\left(\mathrm{HCO}_{3}^{-}\right) . \quad .0164$

Sulfate $\left(\mathrm{SO}_{4}{ }^{--}\right) \ldots \ldots .0208$

Chloride $(\mathrm{Cl}-\ldots \ldots .0282$

Fluoride $\left(\mathrm{F}^{-}\right) \ldots \ldots .0526$

Nitrate $\left(\mathrm{NO}_{3}{ }^{-}\right) \ldots \ldots .0161$

Results given in parts per million can be converted to grains per United States gallon by dividing by 17.12 . A calculated quan- 
tity of sodium and potassium is given in some analyses and is the quantity of sodium needed in addition to the calcium and magnesium to balance the acid constituents.

The hardness, as calcium carbonate $\left(\mathrm{CaCO}_{3}\right)$, is calculated from the equivalents of calcium and magnesium except for a few samples for which the reported values also include equivalents of free mineral acid, aluminum, iron, and manganese when present in signif icant quantities. The hardness caused by calcium and magnesium (and other ions if significant) equivalent to the carbonate and bicarbonate is called carbonate hardness; the hardness in excess of this quantity is called noncarbonate hardness.

In the analyses of most waters used for irrigation, the quantity of dissolved solids is given in tons per acre-foot as well as in parts per million. Percent sodium is computed for those analyses where sodium and potassium are reported separately by dividing the equivalents per million of sodium by the sum of the equivalents per million of calcium, magnesium, sodium, and potassium and multiplying the quotient by 100 . In analyses where sodium and potassium were calculated and reported as a combined value, the value reported for percent sodium will include the equivalent quantity of potassium. In most waters of moderate to high concentration, the proportion of potassium is much smaller than that of sodium.

Specific conductance values are expressed in reciprocal ohms times $10^{6}$ (micromhos at $25^{\circ} \mathrm{C}$ ). The discharge of the streams is reported in cubic feet-per second (see Streamflow, p. 21) and the temperature in degrees Fahrenheit. Color is expressed in units of the platinum-cobalt scale proposed by Hazen (1892, p. 427-428). Hydrogen-ion concentration is expressed in terms of $\mathrm{pH}$ units. By definition the $\mathrm{pH}$ value of a solution is the negative logarithm of the concentration of gram ions of hydrogen. However, the $\mathrm{pH}$ meter which is generally used in Survey laboratories, determines the activity of the hydrogen ions as distinguished from concentration.

An average of analyses (arithmetical or weighted) for the water year is givenfor most daily sampling stations. An arithmetical average represents the composition of water that would be contained in a vessel or reservoir that had received equal quantities of water from the river each day for the water year. A weighted average represents approximately the composition of water that would be found in a reservoir containing all of the water passing a given station during the year after thorough mixing in the reservoir. The weighted average of the analyses is computed by multiplying the discharge for the sampling period by the quantities of the individual constituents for the corresponding period and dividing the sum of the products by the sum of the discharges. Water as represented by the weighted average is less concentrated than that represented by the average of the individual analyses for most streams because at times of high discharge the rivers generally have lower concentrations of dissolved solids.

Mean daily sediment concentrations are expressed in parts per million by weight. A part per million of sediment is computed as 
$1,000,000$ times the ratio of the weight of sediment to the weight of water-sediment mixture. Daily sediment loads are expressed in tons per day, and except for subdivided days are usually obtained by multiplying daily mean sediment concentration in parts per million by the daily mean discharge, and the appropriate conversion factor, normally 0.0027 .

Particle-size analyses are expressed in percentages finer than indicated sizes in millimeters. The size classification used in this report is that recommended by the American Geophysical Union Subcommittee on sediment terminology (Lane, et al; 1947, p. 937). Other data included as pertinent to the size analyses for many streams are the date of collection, the stream discharge and sediment concentration when sample was collected, the concentration of the suspension during analysis, and the method of analysis.

\section{COMPOSITION OF SURFACE WATERS}

All natural waters contain dissolved mineral matter. Water in contact with soils or rock, even for only a few hours, will dissolve some rock materials. The quartity of dissolved mineral matter in a natural water depends primarily on the type of rocks or soils through which the water has passed and the length of time it has been in contact with the rocks or soils. Some streams are fed by both surface runoff and underground water from springs or seeps. Such streams reflect the chemical character of their concentrated underground sources during dry periods and are more dilute during periods of heavy rainfall. Underground water is usually more highly concentrated than surface runoff as it remains in contact with the rocks and soils for much longer periods. The concentration of dissolved solids in a river water is frequently increased by drainage from mines or oil fields, by the addition of industrial or municipal wastes, or--in irrigated regions--by return drain waters.

The mineral constituents and physical properties of natural waters reported in the tables of analyses include those that have a practical bearing on the value of the waters for most purposes. The analyses generally include results for silica, iron, calcium, magnesium, sodium, potassium (or sodium and potassium together as sodium), bicarbonate, sulfate, chloride, fluoride, nitrate, boron, and dissolved solids. Aluminum, manganese, color, $\mathrm{pH}$, acidity, oxygen consumed, and other dissolved constituents and physical properties are reported for certain streams. The source and significance of the different constituents and properties of natural waters are discussed in the following paragraphs. 


\section{MINERAL CONSTITUENTS IN SOLUTION}

\section{Silica $\left(\mathrm{SiO}_{2}\right)$}

Silica is dissolved from practically all rocks. Some natural surface waters contain less than 5 parts per million of silica and few contain more than 50 parts, but the more common range is from 10 to 30 parts per million. Silica affects the usefulness of a water because it contributes to the formation of boiler scale; it usually is removed from feed water for high-pressure boilers. Silica also forms troublesome deposits on the blades of steam turbines.

\section{Aluminum (Al)}

Aluminum is usually present only in negligible quantities in natural waters except in areas where the waters have been in contact with the more soluble rocks of high aluminum content such as bauxite and certain shales. Acid waters often contain large amounts of aluminum. It may be troublesome in feed waters where it tends to be deposited as a scale on boiler tubes.

Manganese (Mn)

Manganese is dissolved in appreciable quantities from rocks in some sections of the country. Waters impounded in large reservoirs may contain manganese that has been dissolved from the mud on the bottom of the reservoir by action of carbon dioxide produced by anaerobic fermentation of organic matter. Manganese is not regularly determined in areas where it is not present in the waters in appreciable amounts. It is especially objectionable in water used in laundry work and in textile processing. Concentrations as low as 0.2 part per million may cause a dark-brown or black stain on fabrics and porcelain fixtures. Appreciable quantities of manganese are often found in waters containing objectionable quantities of iron.

Iron (Fe)

Iron is dissolved from many rocks and soils. On exposure to the air, normal basic watcrs that contain more than 1 part per 
million of iron soon become turbid with the insoluble reddish ferric oxide produced by oxidation. Surface waters, therefore, seldom contain as much as 1 part per million of dissolved iron, although some acid waters carry large quantities of iron in solution. Iron causes reddish-brown stains on white porcelain or enameled ware and fixtures and on fabrics washed in the water.

\section{Calcium (Ca)}

Calcium is dissolved from practically all rocks and soils, but the highest concentrations are usually found in waters that have been in contact with limestone, dolomite, and.gypsum. Calcium and magnesium make water hard and are largely responsible for the for mation of boiler scale. Most waters associated with granite or silicious sands contain less than 10 parts per million of calcium; waters in areas where rocks are composed of dolomite and limestone contain from 30 to 100 parts per million; and waters that have come in contact with deposits of gypsum may contain several hundred parts per million.

\section{Magnesium (Mg)}

Magnesium is dissolved from many rocks, particularly from dolomitic rocks. Its effect in water is similar to that of calcium. The magnesium in soft waters may amount to only 1 or 2 parts per million, but water in areas that contain large quantities of dolomite or other magnesium-bearing rocks may contain from 20 to 100 parts per million or more of magnesium.

\section{Sodium and potassium ( $\mathrm{Na}$ and $\mathrm{K})$}

Sodium and potassium are dissolved from practically all rocks. Sodium is the predominant cation in some of the more highly mineralized waters found in the western United States. Natural waters that contain only 3 or 4 parts per million of the two together are likely to carry almost as much potassium as sodium. As the total quantity of these constituents increases, the proportion of sodium becomes much greater. Moderate quantities of sodium and potassium have little effect on the usefulness of the water for most purposes, but waters that carry more than 50 or 100 parts per million of the two may require careful operation of steam boilers to prevent foaming. More highly mineralized waters that contain a large proportion of sodium salts may be unsatisfactory for irrigation. 
Carbonate and bicarbonate $\left(\mathrm{CO}_{3}\right.$ and $\left.\mathrm{HCO}_{3}\right)$

Bicarbonate occurs in waters largely through the action of carbon dioxide, which enables the water to dissolve carbonates of calcium and magnesium. Carbonate as such is not usually present in appreciable quantities in natural waters. The bicarbonate in waters that come from relatively insoluble rocks may amount to less than 50 parts per million; many waters from limestone contain from 200 to 400 parts per million. Bicarbonate in moderate concentrations in water has no effect on its value for most uses. Bicarbonate or carbonate is an aid in coagulation for the removal of suspended matter from water.

\section{Sulfate $\left(\mathrm{SO}_{4}\right)$}

Sulfate is dissolved from many rocks and soils--in especially large quantities from gypsum and from beds of shale. It is formed also by the oxidation of sulfides of iron and is therefore present in considerable quantities in waters from mines. Sulfate in waters that contain much calcium and magnesium causes the formation of hard scale in steam boilers and may increase the cost of softening the water.

\section{Chloride (Cl)}

Chloride is dissolved from rock materials in all parts of the country. Surface waters in the humid regions are usually low in chloride, whereas streams in arid or semiarid regions may contain several hundred parts per million of chloride leached from soils and rocks, especially where the streams receive return drainage from irrigated lands or are affected by ground-water-inflow carrying appreciable quantities of chloride. Large quantities of chloride may affect the industrial use of water by increasing the corrosiveness of waters that contain large quantities of calcium and magnesium.

\section{Fluoride (F)}

Fluoride has been reported as being present in some rocks to about the same extent as chloride. However, the quantity of fluoride in natural surface waters is ordinarily very small compared to that of chloride. Recent investigations indicate that the incidence of dental caries is less when there are small amounts of 
fluoride present in the water supply than when there is none. However, excess fluoride in water is associated with the dental defect known as mottled enamel if the water is used for drinking by young children during calcification or formation of the teeth (Dean, 1936, p. 1269-1272). This defect becomes increasingly noticeable as the quantity of fluoride in water increases above 1.5 to 2.0 parts per million.

\section{Nitrate $\left(\mathrm{NO}_{3}\right)$}

Nitrate in water is considered a final oxidation product of nitrogenous material and in some-instances may indicate previous contamination by sewage or other organic matter. The quantities of nitrate present in surface waters usually amount to less than 5 parts per million (as $\mathrm{NO}_{3}$ ) and have no effect on the value of the water for ordinary uses.

It has been reported that as much as 2 parts per million of nitrate in boiler water tends to decrease intercrystalline cracking of boiler steel. Studies made in Illinois indicate that nitrates in excess of 70 parts per million (as $\mathrm{NO}_{3}$ ) may contribute to methemoglobinemia ("blue babies") (Faucett and Miller, 1946, p. 593), and more recent investigations conducted in Ohio show that drinking water containing nitrates in the range of 44 to 88 parts per million or more $\left(\right.$ as $\mathrm{NO}_{3}$ ) may be the cause of methemoglobinemia in infants (Waring, 1949). In a report published by the National Research Council, Maxcy $(1950$, p. 271$)$ concludes that a nitrate content in excess of 44 parts per million $\left(\mathrm{as} \mathrm{NO}_{3}\right.$ ) should be regarded as unsafe for infant feeding.

\section{Boron (B)}

Boron in small quantities has been found essential for plant growth, but irrigation water containing more than 1 part per million boron is detrimental to citrus and other boron-sensitive crops. Boron is reported in Survey analyses of surface waters in arid and semiarid regions of the Southwest and West where irrigation is practiced or contemplated, butfew of the surface waters analyzed have harmful concentrations of boron.

\section{Dissolved solids}

The reported quantity of dissolved solids--the residue on evaporation--consists mainly of the dissolved mineral constituents in the water. It may also contain some organic matter and water of crystallization. Waters with less than 500 parts per million of dis- 
solved solids are usually satisfactory for domestic and some industrial uses. Waters containing several thousand parts per million of dissolved solids are sometimes successfully used for irrigation where practices permit the removal of soluble salts through the application of large volumes of water on well-drained lands.

\section{PROPERTIES AND CHARACTERISTICS OF WATER}

\section{Oxygen consumed}

The value for oxygen consumed furnishes an approximation of the oxidizable matter in the unfiltered and filtered samples and gives a partial measure of polluting materials such as sewage and oxidizable industrial wastes. Naturally highly colored waters may have relatively high oxygen consumed, although waters that are not noticeably colored may contain oxidizable material.

\section{Color}

In water analysis the term "color" refers to the appearance of water that is free from suspended solids. Many turbid waters that appear yellow, red, or brown when viewed in the stream show very little color after the suspended matter has been removed. The yellow-to-brown color of some waters is usually caused by organic matter extracted from leaves, roots, and other organic substances in the ground. In some areas objectionable color in water results from industrial wastes and sewage. Clear deep water may appear blue as the result of a scattering of sunlight by the water molecules. Water for domestic use and some industrial us es should be free from any perceptible color. A color less than 10 units usually passes unnoticed. Some swamp waters have natural color of 200 to 300 units or more.

\section{Hydrogen-ion concentration $(\mathrm{pH})$}

The degree of acidity or alkalinity of water, as indicated by the hydrogen-ion concentration, expressed as $\mathrm{pH}$, is related to the corrosive properties of water, and is useful in determining the proper treatment for coagulation that may be necessary at water-treatment plants. A pH value of 7.0 indicates that the water is neither acid nor alkaline. Waters having $\mathrm{pH}$ values progressively lower than 7.0 denote increasing acidity, whereas values progressively higher than 7.0 denote increasing alkalinity (see p. 7). The $\mathrm{pH}$ of most natural surface waters ranges between 6 
and 8 . Some alkaline surface waters have $\mathrm{pH}$ values greater than 8.0 , and waters containing free mineral acid usually have $\mathrm{pH}$ values less than 4. 5 .

Specific conductance (micromhos at $25^{\circ} \mathrm{C}$ )

The specific conductance of a water is a measure of its capacity to conduct a current of electricity. The conductance varies with the concentration and degree of ionization of the different minerals in solution and with the temperature of the water. When considered in conjunction with results of determinations for other constituents, specific conductance is a us eful determination and plays an important part in indicating changes in concentration of the total quantity of dissolved minerals in surface waters. (See p. 7 .)

\section{Hardness}

Hardness is the characteristic of water that receives the most attention in industrial and domestic use. It is usually recognized by the increased quantity of soap required to produce lather. The use of hard water is also objectionable because it contributes to the formation of scale in boilers, water heaters, radiators, and pipes, with the resultant decrease in rate of heat transfer, possibility of boiler failure, and loss of flow.

Hardness is caused almost entirely by compounds of calcium and magnesium. Other constituents--such as iron, manganese, aluminum, barium, strontium, and free acid--also cause hardness, although they usually are not present in quantities large enough to have any appreciable effect. Water that has less than 60 parts per million of hardness is usually rated as soft and suitable for many purposes without further softening. Waters with hardness ranging from 61 to 120 parts per million may be considered moderately hard, but this degree of hardness does not seriously interfere with the use of water for many purposes except for use in high-pressure steam boilers and in some industrial processes. Waters with hardness ranging from 121 to 200 parts per million are considered hard, and laundries and industries may profitably soften such supplies. Water with hardness above 200 parts per million usually requires some softening before being used for most purposes.

\section{Total acidity}

The total acidity of a natural water represents the content of free carbon dioxide, mineral acids, and salts--especially sulfates 
of iron and aluminum -- that hydrolyze to give hydrogen ions. Acid waters are very corrosive and generally contain excessive amounts of objectionable constituents, such as iron, aluminum, and manganese.

\section{Corrosiveness}

The corrosiveness of a water is that property which makes the water aggressive to metal surfaces and frequently results in the appearance of the "red water" caused by solution of iron. The disadvantages of iron in water have been discussed previously. Additionally, corrosion causes the deterioration of water pipes, steam boilers, and water-heating equipment. Many waters that do not appreciably corrode cold-water lines will aggressively attack hotwater lines. Oxygen, carbon dioxide, free acid, and acid-generating salts are the principal constituents in water that cause corrosion. In a general way, very soft waters of low mineral content tend to be more corrosive than hard waters containing appreciable quantities of carbonates and bicarbonates of calcium and magnesium.

Percent sodium

Percent sodium is reported in most of the analyses of waters collected from streams in the western part of the country where irrigation is practiced extensively. The proportion of sodium to all the basic constituents in the water has a bearing on the suitability of a water for irrigation. (See p. 7 .) Waters in which the percent sodium is more than 60 may be injurious when applied to certain types of soils, particularly when adequate drainage is not provided (Magistad and Christiansen, 1944, p. 8-9; Wilcox, 1948, p. 6).

\section{Sodium-adsorption-ratio}

Sodium-adsorption-ratio (SAR) is the relative proportion of sodium to other cations in an irrigation water.

$$
\mathrm{SAR}=\frac{\mathrm{Na}^{+}}{\sqrt{\left(\mathrm{Ca}^{++}+\mathrm{Mg}^{++}\right) / 2}}
$$

where the ionic concentrations are expressed in milliequivalents per liter (or equivalents per million for most irrigation waters).

The term is used for soil extracts and irrigation waters to ex- 
press the relative activity of sodium ions in exchange reactions with soil. SAR provides an estimate of the sodium or alkali hazard and reportedly is more significant for interpreting water quality than percent sodium because it relates more directly to the exchangeable sodium percentage the soil will attain when it and the water are in equilibrium.

The U.S. Salinity Laboratory diagram for classifying waters for irrigation divides water into four classes with respect to sodium hazard, the dividing points being at SAR values of 10,18 , and 26 . They range from low-sodium water that can be used for irrigation on almost all soils to very high-sodium water which is generally unsatisfactory for irrigation.

\section{SEDIMENT}

Fluvial sediment is generally regarded as that sediment which is transported by, suspended in, or deposited by water. Suspended sediment is that sediment which remains in suspension in water owing to the upward components of turbulent currents or by colloidal suspension. Most fluvial sediment results from the normal process of erosion, which in turn is part of the geologic cycle of rock transformation. In some instances, this normal process may have been accelerated by agricultural practices. Sediment also results from a number of industrial activities. In certain sections, waste materials from mining, logging, oil-field, and other industrial operations introduce large quantities of suspended as well as dissolved material.

The quantity of sediment, transported or available for transportation, is affected by climatic conditions, form or nature of precipitation, vegetal cover, topography, and land use. An important property of fluvial sediment is the fall velocity of the particles in transport. Particle sizes, as determined by various methods, represent mechanical diameters, which are related to sedimentation diameters indirectly. Sediment particles in the sand-size (larger than $0.062 \mathrm{~mm}$ ) range do not appear to be affected by flocculation or dispersion resulting from the mineral constituents in solution. The sedimentation diameter of clay and silt particles in suspension may vary considerably from point to point in a stream or reservoir, depending on the mineral matter in solution and in suspension and the degree of turbulencepresent. The size of sediment particles in transport at any point depends on the type of erodible and soluble material in the drainage area, the degree of flocculation present, time in transport, and characteristics of the transporting flow. The flow characteristics include velocity of water, turbulence, and the depth, width, and roughness of the channel. As a result of these variable charac- 
teristics, the size of particles transported, as well as the total sediment load, is in constant adjustment with the characteristics and physical features of the stream and drainage area.

\section{PUBLICATIONS}

Reports giving chemical analyses, suspended-sediment loads, and water temperatures of samples of surface water made by the Geological Survey have been published yearly since 1941. Records for many of the stations listed in this report for the water years ending September 30, 1941-1954 are listed below.

Numbers of water-supply papers containing records for Parts 7 and 8, 1941-1954

\begin{tabular}{c|c||c|c||c|c|c|r}
\hline Year & WSP & Year & WSP & Year & WSP & Year & WSP \\
\hline 1941 & 942 & 1945 & 1030 & 1949 & 1163 & 1953 & 1292 \\
1942 & 950 & 1946 & 1050 & 1950 & 1188 & 1954 & 1352 \\
1943 & 970 & 1947 & 1102 & 1951 & 1199 & -- & -- \\
1944 & 1022 & 1948 & 1133 & 1952 & 1252 & -- & -- \\
\hline
\end{tabular}

Geological Survey reports containing analyses of surface-water samples collected prior to 1941 are listed below. Publications dealing largely with the quality of ground-water supplies and-only incidentally covering the chemical composition of surface-waters are not included. Publications that are out of print are preceded by an asterisk.

\section{PROFESSIONAL PAPER}

*135. Composition of river and lake waters of the United States, 1924.

\section{BULLETINS}

*479. The geochemical interpretation of water analyses, 1911. 770. The data of geochemistry, 1924 .

\section{WATER-SUPPLY PAPERS}

*108. Quality of water in the Susquehanna River drainage basin, with an introductory chapter on physiographic features, 1904. *161. Quality of water in the upper Ohio River basin and at Erie,
Pa., 1906.

*193. The quality of surface waters in Minnesota, 1907.

*236. The quality of surface waters in the United States, Part 1, Analyses of waters east of the one hundredth meridian, 1909 . 
*237. The quality of the surface waters of California, 1910.

*239. The quality of the surface waters of Illinois, 1910 .

*273. Quality of the water supplies of Kansas, with a preliminary report on stream pollution by mine waters in southeastern Kansas, 1911.

*274. Some stream waters of the western United States, with chapters on sediment carried by the Rio Grande and the industrial application of water analyses, 1911.

*339. Quality of the surface waters of Washington, 1914.

*363. Quality of the surface waters of Oregon, 1914.

*418. Mineral springs of Alaska, with a chapter on the chemical character of some surface waters of Alaska, 1917.

*596-B. Quality of water of Colorado River in 1925-26, 1928.

*596-D. Quality of water of Pecos River in Texas, 1928.

*596-E. Quality of the surface waters of New Jersey, 1928.

*636-A. Quality of water of the Colorado River in 1926-28, 1930.

*636-B. Suspended matter in the Colorado River in 1925-28, 1930.

*638-D. Quality of water of the Colorado River in 1928-30, 1932.

*839. Quality of water of the Rio Grande basin above Fort Quitman, Tex., 1938.

* 889-E. Chemical character of surface water of Georgia, 1944. *998. Suspended sediment in the Colorado River, 1925-41, 1947.

1048. Discharge and sediment loads in the Boise River drainage basin, Idaho, $1939-40,1948$.

1110-C. Quality of water of Conchas Reservoir, New Mexico, 1939-49, 1952 .

Many of the reports listed are available for consultation in the larger public and institutional libraries. Copies of Geological Survey publications still in print may be purchased at a nominal cost from the Superintendent of Documents, Government Printing Office, Washington 25, D. C., who will, upon request, furnish lists giving prices.

\section{COOPERATION}

The table on p. 19 lists State and local agencies that cooperated in quality-of-water investigations in the drainage basins included in this volume. The locations of quality-of-water district or regional offices responsible for the data collected in the drainage basing are given in the table, also.

Financial assistance was furnished by the Bureau of Reclamation of the United States Department of the Interior, in the oper ation of some stations in Oklahoma and New Mexico. 


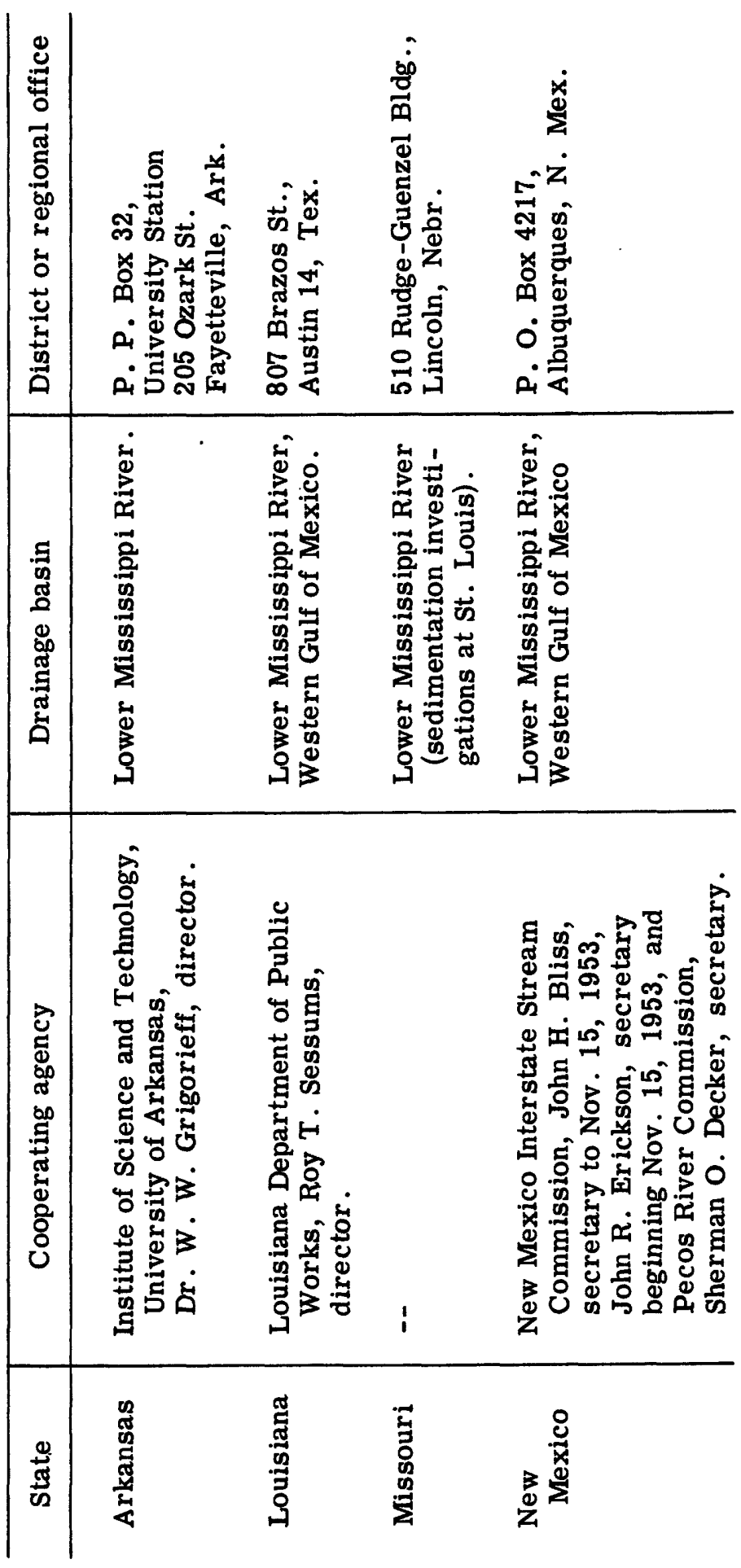




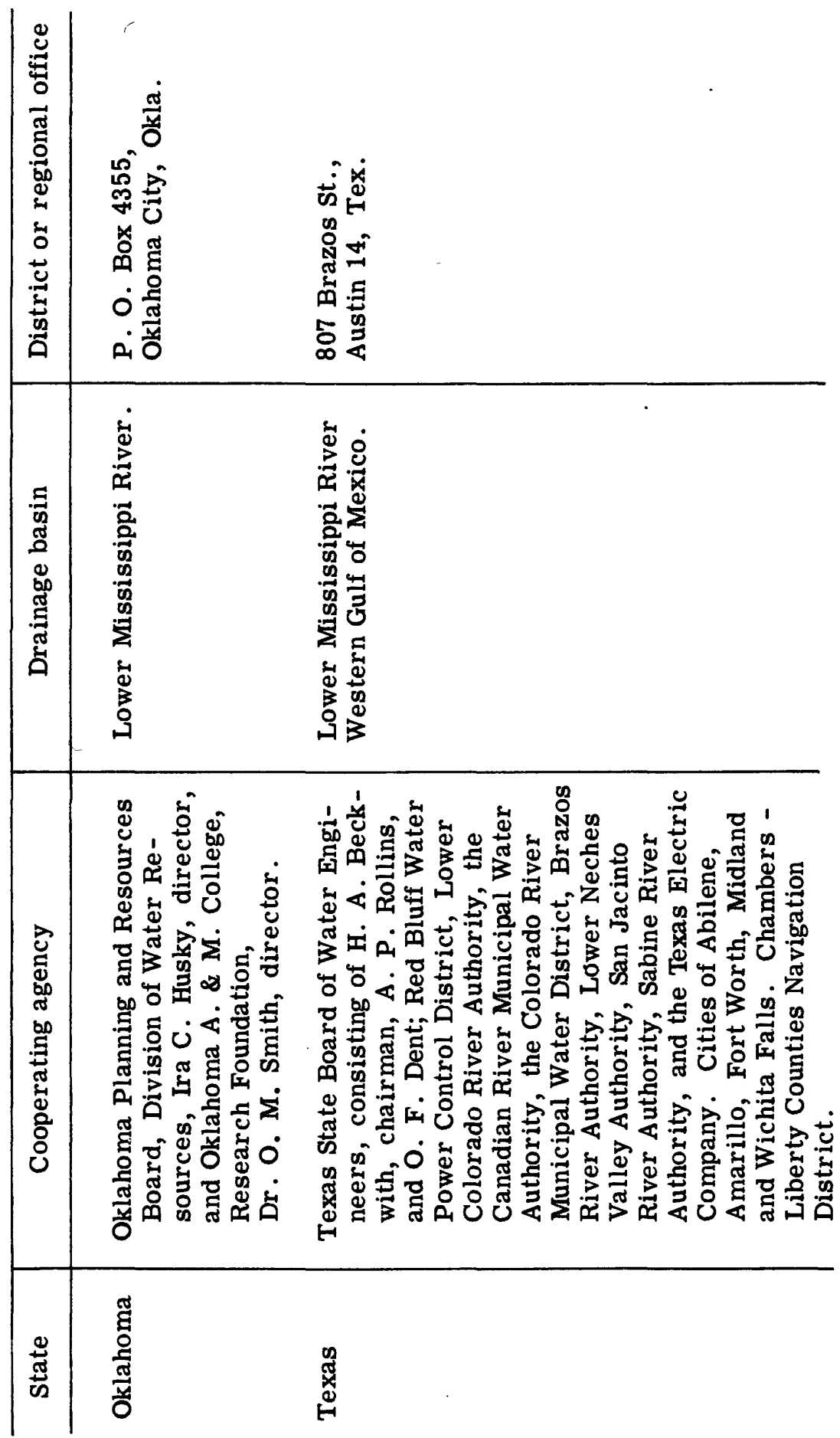


Financial assistance was also furnished by the Corps of Engineers, Department of Army, in the operation of some stations in Texas. The Corps also provided financial assistance and made determinations in their laboratory of particle-size analyses of bed material and of sediment concentrations in connection with the sedimentation investigations of the Mississippi River at St. Louis. Assistance in collecting records was given by many municipal, State, and Federal agencies

In addition to these cooperative programs, many of the stations were operated from funds appropriated directly to the Geological Survey for quality -of-water investigations. Studies of suspended-sediment loads in the middle Rio Grande in New Mexico were initated as a Federal project in 1948.

\section{DIVISION OF WORK}

The quality-of -water program was conducted by the Water Resources Division of the Geological Survey, Carl G. Paulsen, Chief Hydraulic Engineer and S. K. Love, Chief of the Quality of Water Branch. The records were collected and prepared for publication under supervision of district or regional chemists and engineers as follows: In Arkansas -- J. W. Geurin; in Missouri -- P. C. Benedict; in Oklahoma, and in the Arkansas River basin in Kansas -- T . B. Dover; in New Mexico, and in the Rio Grande and Arkansas River basins in Colorado -- J. M. Stow; and in Texas and Louisiana -- Burdge Irelan. Any additional information on file can be obtained by writing the responsible Survey district office.

\section{STREAMFLOW}

Most of the records of stream discharge, used in conjunction with the chemical analyses and in the computation of sediment loads in this volume, are published in Geological Survey reports on the surface-water supply of the United States. The discharge reported for a composite sample is usually the average of the mean daily discharges for the nor mal composite period. For analyses in which the composite periods differ from the nor mal 10 or 11-day period, the discharges reported are the averages of the mean daily discharges for the days indicated. The discharges reported in the tables of single analyses are either daily mean discharges or discharges for the time at which samples were collected, computed from a stage-discharge relation or from a discharge measurement. 


\section{LITERATURE CITED}

American Public Health Association, 1946, Standard methods for the examination of water and sewage, 9th ed., p. 1-112. Collins, W. D., 1928, Notes on practical water analysis: U. S . Geol. Survey Water Suppl y Paper 596-H.

Dean, H. T., 1936, Chronic endemic dental fluorosis: Am. Med. Assoc. Jour., v. 107, p. 1269-1272.

Faucett, R. L., and Miller, H. C., 1946, Methemoglobinemia occurring in infants fed milk diluted with well waters of high nitrate content: Jour. Pediatrics, v. 29, p. 593.

Hazen, Allen, 1892, A new color standard for natural waters: Am. Chem. Jour., v. 12, p. 427-428.

Kilmer, V. J. and Alexander, L. T., 1949, Methods of making mechanical analyses of soils: Soil Sci., v. 68, p. 15-24.

Lane, E. W., et al., 1947, Report of the Subcommittee on Terminology: Am. Geophys. Union Trans., v. 28, p. 937.

Magistad, O. C., and Christiansen, J. E., 1944, Saline soils, their nature and management: U. S. Dept. Agriculture Circ. 707, p. 8-9.

Maxcy, Kenneth F., 1950, Report on the relation of nitrate concentrations in well waters to the occurrence of methemoglobinemia: Natl. Research Council, Bull., Sanitary Engineer, p. 265, App. D.

U. S. Inter-agency Report 7, 1943, A study of methods used in measurement and analysis of sediment loads in streams, a study of new methods for size analysis of suspended sediment samples, p. 82-90; U. S. Engineer Office, St. Paul, Minn.

U. S. Inter-agency Report 8, 1948, A study of methods used in measurement and analysis of sediment loads of streams, measurement of the sediment discharge of streams, p. $70-76$; U. S. Engineer Office, St. Paul, Minn.

U. S. Salinity Laboratory Staff, 1954, Diagnosis and improvement of saline and alkali soils: U. S. Dept. Agriculture Handbook 60, p. 1-60.

Waring, F. Holman, 1949, Significance of nitrates in water supplies: Jour. Am. Water Works Assoc., v. 72, no. 2.

Wilcox, L. V., 1948, Explanation and interpretation of analyses of irrigation waters: U. S. Dept. Agriculture Circ. 784, p. 6 . 
PART 7. LOWER MISSISSIPPI RIVER BASIN

\section{MISSISSIPPI RIVER MAIN STEM}

MISSISSIPPI RIVER AT ST. LOUIS, MO.

LOCATION.--At MacArthur Bridge, 1.1 miles below gaging station, which is 15 miles downstream from the Missouri River and 180 miles upstream from the Ohio River.

DRAINAGE AREA. $--701,000$ square miles, approximately.

RECOROS AVAILABLE. --Water temperatures: October 1950 to September 1954.

Sediment records: April 1948 to September 1954

EXTREMES, 1953-54.--Water temperatures: Maximum, $84^{\circ} \mathrm{F}$ July 21, 22 ; minimum, freezing point on several days during December and January.

Sediment concentrations: Maximum daily, 2,450 ppm June 7; minimum daily, 50 ppm Jan. 24.

Sediment 10ads: Maximum daily, 1,860,000 tons June 7; minimum daily, 6,760 tons Jan. 28.

DXTREMES, 1948-54, --Water temperatures (1950-54): Maximum, 86 ${ }^{\circ} \mathrm{F}$ July 31, 1953; minimum,

freezing point on several days during winter months.

Sediment concentrations: Maximum daily, 6,420 ppm June 7, 1951; minimum daily, 38 ppm

Feb. 2, 3, 1951 .

Sediment loads: Maximum daily, 7,010,000 tons May 5, 1951; minimum daily, 4,340 tons Feb. 3, 1951 .

REMARKS.--Records of discharge for water year October 1953 to september 1954 given in WSP 1341 .

Temperature $\left({ }^{\circ} \mathrm{F}\right)$ of water, water year October 1953 to September 1954

Önce-daily measurement generally between $9 \mathrm{a} . \mathrm{m}$. and $3 \mathrm{p} . \mathrm{m} .7$

\begin{tabular}{|c|c|c|c|c|c|c|c|c|c|c|c|c|}
\hline Day & Oct. & Nov. & Dec. & Jan. & Feb. & Mar. & Apr. & May & June & July & Aug. & Sept. \\
\hline $\begin{array}{l}1 \\
2 \\
3 \\
4 \\
5\end{array}$ & $\begin{array}{l}69 \\
70 \\
69 \\
-- \\
66\end{array}$ & $\begin{array}{l}-5 \\
57 \\
-- \\
55 \\
52\end{array}$ & $\begin{array}{l}42 \\
43 \\
44 \\
44 \\
40\end{array}$ & $\begin{array}{l}-- \\
36 \\
36 \\
35 \\
36\end{array}$ & $\begin{array}{l}35 \\
36 \\
35 \\
36 \\
37\end{array}$ & $\begin{array}{l}40 \\
40 \\
38 \\
37 \\
36\end{array}$ & $\begin{array}{l}44 \\
47 \\
-- \\
47 \\
49\end{array}$ & $\begin{array}{l}-- \\
\overline{62} \\
\overline{60}\end{array}$ & $\begin{array}{l}70 \\
68 \\
66 \\
64 \\
--\end{array}$ & $\begin{array}{l}82 \\
82 \\
-- \\
-- \\
--\end{array}$ & $\begin{array}{l}-- \\
80 \\
81 \\
81 \\
80\end{array}$ & $\begin{array}{l}-2 \\
79 \\
79 \\
-- \\
--\end{array}$ \\
\hline $\begin{array}{r}6 \\
7 \\
8 \\
9 \\
10\end{array}$ & $\begin{array}{l}64 \\
63 \\
63 \\
64 \\
63\end{array}$ & $\begin{array}{l}51 \\
48 \\
-- \\
48 \\
46\end{array}$ & $\begin{array}{l}-- \\
44 \\
45 \\
-- \\
40\end{array}$ & $\begin{array}{l}36 \\
38 \\
37 \\
-- \\
33\end{array}$ & $\begin{array}{l}35 \\
-- \\
36 \\
38 \\
38\end{array}$ & $\begin{array}{l}-2 \\
37 \\
39 \\
44 \\
41\end{array}$ & $\begin{array}{l}50 \\
53 \\
52 \\
52 \\
--\end{array}$ & $\begin{array}{l}58 \\
57 \\
-- \\
-- \\
56\end{array}$ & $\begin{array}{l}-- \\
67 \\
68 \\
-- \\
69\end{array}$ & $\begin{array}{l}83 \\
83 \\
82 \\
80 \\
--\end{array}$ & $\begin{array}{l}80 \\
-- \\
-- \\
78 \\
78\end{array}$ & $\begin{array}{l}-- \\
79 \\
78 \\
77 \\
75\end{array}$ \\
\hline $\begin{array}{l}11 \\
12 \\
13 \\
14 \\
15\end{array}$ & $\begin{array}{l}-- \\
62 \\
63 \\
63 \\
63\end{array}$ & $\begin{array}{l}47 \\
47 \\
47 \\
48 \\
--\end{array}$ & $\begin{array}{l}38 \\
41 \\
-- \\
37 \\
38\end{array}$ & $\begin{array}{l}33 \\
-- \\
32 \\
33 \\
32\end{array}$ & $\begin{array}{l}38 \\
36 \\
- \\
- \\
43\end{array}$ & $\begin{array}{l}41 \\
45 \\
-- \\
41 \\
40\end{array}$ & $\begin{array}{l}-- \\
55 \\
58 \\
58 \\
60\end{array}$ & $\begin{array}{l}57 \\
57 \\
58 \\
59 \\
--\end{array}$ & $\begin{array}{l}72 \\
-- \\
-- \\
78 \\
79\end{array}$ & $\begin{array}{l}-- \\
81 \\
82 \\
83 \\
82\end{array}$ & $\begin{array}{l}75 \\
74 \\
-- \\
--\end{array}$ & $\begin{array}{l}-- \\
-- \\
73 \\
73 \\
73\end{array}$ \\
\hline $\begin{array}{l}16 \\
17 \\
18 \\
19 \\
20\end{array}$ & $\begin{array}{l}63 \\
-- \\
64 \\
63 \\
65\end{array}$ & $\begin{array}{l}\mathbf{5 2} \\
51 \\
50 \\
52 \\
52\end{array}$ & $\begin{array}{l}37 \\
34 \\
32 \\
-- \\
36\end{array}$ & $\begin{array}{l}-- \\
32 \\
32 \\
34 \\
38\end{array}$ & $\begin{array}{l}44 \\
41 \\
43 \\
43 \\
--\end{array}$ & $\begin{array}{l}41 \\
41 \\
42 \\
44 \\
--\end{array}$ & $\begin{array}{l}58 \\
-- \\
-- \\
60 \\
61\end{array}$ & $\begin{array}{l}-5 \\
64 \\
61 \\
60 \\
64\end{array}$ & $\begin{array}{l}79 \\
80 \\
80 \\
-- \\
--\end{array}$ & $\begin{array}{l}81 \\
-- \\
-2 \\
83 \\
83\end{array}$ & \begin{tabular}{l}
81 \\
79 \\
\hdashline- \\
78 \\
80
\end{tabular} & $\begin{array}{l}\ddot{75} \\
-- \\
75\end{array}$ \\
\hline $\begin{array}{l}21 \\
22 \\
23 \\
24 \\
25\end{array}$ & $\begin{array}{l}65 \\
65 \\
64 \\
-- \\
60\end{array}$ & $\begin{array}{l}-- \\
50 \\
48 \\
48 \\
45\end{array}$ & $\begin{array}{l}36 \\
-- \\
32 \\
32 \\
--\end{array}$ & $\begin{array}{c}32 \\
32 \\
-- \\
-- \\
34\end{array}$ & $\begin{array}{l}44 \\
43 \\
44 \\
42 \\
44\end{array}$ & $\begin{array}{l}41 \\
42 \\
42 \\
44 \\
47\end{array}$ & $\begin{array}{l}62 \\
61 \\
60 \\
-- \\
--\end{array}$ & $\begin{array}{l}61 \\
-- \\
-\overline{65} \\
65\end{array}$ & $\begin{array}{l}82 \\
81 \\
82 \\
81 \\
81\end{array}$ & $\begin{array}{l}84 \\
84 \\
83 \\
\ldots \\
\ldots\end{array}$ & $\begin{array}{l}-- \\
82 \\
80 \\
--\end{array}$ & $\begin{array}{l}70 \\
-\therefore \\
70 \\
69 \\
\cdots\end{array}$ \\
\hline $\begin{array}{l}26 \\
27 \\
28 \\
29 \\
30 \\
31\end{array}$ & $\begin{array}{l}60 \\
59 \\
57 \\
56 \\
57 \\
55\end{array}$ & $\begin{array}{l}43 \\
43 \\
41 \\
-- \\
43 \\
-.\end{array}$ & $\begin{array}{l}33 \\
34 \\
32 \\
34 \\
33 \\
34\end{array}$ & $\begin{array}{l}33 \\
32 \\
32 \\
34 \\
-- \\
34\end{array}$ & $\begin{array}{l}43 \\
-- \\
41 \\
-- \\
-- \\
--\end{array}$ & $\begin{array}{l}47 \\
-2 \\
49 \\
45 \\
45 \\
44\end{array}$ & $\begin{array}{l}-- \\
65 \\
64 \\
64 \\
65 \\
--\end{array}$ & $\begin{array}{l}66 \\
67 \\
69 \\
-- \\
-- \\
--\end{array}$ & $\begin{array}{l}-. \\
- \\
82 \\
81 \\
80 \\
--\end{array}$ & $\begin{array}{l}80 \\
80 \\
81 \\
-- \\
82 \\
--\end{array}$ & $\begin{array}{l}82 \\
82 \\
-- \\
- \\
81 \\
78\end{array}$ & $\begin{array}{l}-. \\
70 \\
71 \\
-\therefore \\
70 \\
--\end{array}$ \\
\hline $\begin{array}{c}\text { Aver- } \\
\text { age }\end{array}$ & 63 & 48 & 37 & - & 40 & 42 & -- & -- & -- & -- & -- & - \\
\hline
\end{tabular}

$4888170-59-3$ 
MISSISSIPPI RIVER MAIN STEM--Continued

MISSISSIPPI RIVER AT ST. LOUIS, MO.--Continued

Suspended sediment, water year October 1953 to September 1954

\begin{tabular}{|c|c|c|c|c|c|c|c|c|c|}
\hline \multirow[b]{3}{*}{ Day } & \multicolumn{3}{|c|}{ October } & \multicolumn{3}{|c|}{ November } & \multicolumn{3}{|c|}{ December } \\
\hline & \multirow[b]{2}{*}{$\begin{array}{l}\text { Mean } \\
\text { dis - } \\
\text { charge } \\
\text { (cfs) }\end{array}$} & \multicolumn{2}{|c|}{ Suspended sediment } & \multirow[b]{2}{*}{$\begin{array}{c}\text { Mean } \\
\text { dis- } \\
\text { charge } \\
\text { (cfs) }\end{array}$} & \multicolumn{2}{|c|}{ Suspended sediment } & \multirow[b]{2}{*}{$\begin{array}{l}\text { Mean } \\
\text { dis- } \\
\text { charge } \\
\text { (cfs) }\end{array}$} & \multicolumn{2}{|c|}{ Suspended sediment } \\
\hline & & $\begin{array}{l}\text { Mean } \\
\text { concen- } \\
\text { tration } \\
\text { (ppm) }\end{array}$ & $\begin{array}{l}\text { Tons } \\
\text { per } \\
\text { day }\end{array}$ & & $\begin{array}{l}\text { Mean } \\
\text { concen- } \\
\text { tration } \\
\text { (ppm) }\end{array}$ & $\begin{array}{l}\text { Tons } \\
\text { per } \\
\text { day }\end{array}$ & & $\begin{array}{l}\text { Mean } \\
\text { concen- } \\
\text { tration } \\
\text { (ppm) }\end{array}$ & $\begin{array}{l}\text { Tons } \\
\text { per } \\
\text { day }\end{array}$ \\
\hline $\begin{array}{l}1 . \ldots \ldots \\
2 \ldots \ldots \\
3 . \ldots \ldots \\
4 \ldots \ldots \\
5 \ldots \ldots\end{array}$ & $\begin{array}{l}71,500 \\
71,500 \\
70,800 \\
70,100 \\
74,300\end{array}$ & $\begin{array}{l}194 \\
198 \\
224 \\
180 \\
182\end{array}$ & $\begin{array}{r}37,500 \\
38,200 \\
42,800 \\
\mathrm{a} 34,100 \\
36,500\end{array}$ & $\begin{array}{l}68,000 \\
68,700 \\
70,100 \\
69,400 \\
68,700\end{array}$ & $\begin{array}{l}224 \\
220 \\
220 \\
222 \\
234\end{array}$ & $\begin{array}{r}41,100 \\
\mathrm{a} 40,800 \\
\mathrm{a} 41,600 \\
41,600 \\
43,400\end{array}$ & $\begin{array}{l}66,600 \\
61,000 \\
61,000 \\
61,700 \\
62,400\end{array}$ & $\begin{array}{l}150 \\
189 \\
133 \\
132 \\
133\end{array}$ & $\begin{array}{l}27,000 \\
31,100 \\
21,900 \\
22,000 \\
22,400\end{array}$ \\
\hline $\begin{array}{r}6 \ldots \ldots \\
7 \ldots \ldots \\
8 \ldots \ldots \\
9 \ldots \ldots \\
10 \ldots \ldots\end{array}$ & $\begin{array}{l}72,200 \\
73,600 \\
71,500 \\
72,900 \\
71,500\end{array}$ & $\begin{array}{l}196 \\
199 \\
194 \\
188 \\
156\end{array}$ & $\begin{array}{l}38,200 \\
39,500 \\
37,500 \\
37,000 \\
30,100\end{array}$ & $\begin{array}{l}68,000 \\
68,000 \\
68,000 \\
68,000 \\
68,000\end{array}$ & $\begin{array}{l}221 \\
210 \\
207 \\
206 \\
199\end{array}$ & $\begin{array}{r}40,600 \\
38,600 \\
\text { a } 38,000 \\
37,800 \\
36,500\end{array}$ & $\begin{array}{l}65,900 \\
68,000 \\
66,600 \\
70,800 \\
73,600\end{array}$ & $\begin{array}{l}136 \\
150 \\
163 \\
175 \\
184\end{array}$ & $\begin{array}{r}\text { a } 24,200 \\
27,500 \\
29,300 \\
\text { a } 33,500 \\
36,600\end{array}$ \\
\hline $\begin{array}{l}11 \ldots \ldots \\
12 \ldots \ldots \\
13 \ldots \ldots \\
14 \ldots \ldots \\
15 \ldots \ldots\end{array}$ & $\begin{array}{l}67,300 \\
65,900 \\
66,600 \\
68,000 \\
69,400\end{array}$ & $\begin{array}{l}160 \\
192 \\
212 \\
210 \\
199\end{array}$ & $\begin{array}{r}\text { a } 29,100 \\
34,200 \\
38,100 \\
38,600 \\
37,300\end{array}$ & $\begin{array}{l}68,000 \\
67,300 \\
67,300 \\
67,300 \\
67,300\end{array}$ & $\begin{array}{l}212 \\
218 \\
206 \\
192 \\
189\end{array}$ & $\begin{array}{r}38,900 \\
39,600 \\
37,400 \\
34,900 \\
\text { a } 34,300\end{array}$ & $\begin{array}{l}70,800 \\
81,400 \\
70,800 \\
66,600 \\
66,600\end{array}$ & $\begin{array}{l}186 \\
168 \\
186 \\
183 \\
182\end{array}$ & $\begin{array}{r}35,600 \\
36,900 \\
\mathrm{a} 35,600 \\
32,900 \\
32,700\end{array}$ \\
\hline $\begin{array}{l}16 \ldots \ldots \\
17 . \ldots \ldots \\
18 \ldots \ldots \\
19 . \ldots \ldots \\
20 \ldots \ldots\end{array}$ & $\begin{array}{l}69,400 \\
68,000 \\
67,300 \\
66,600 \\
66,600\end{array}$ & $\begin{array}{l}200 \\
216 \\
245 \\
202 \\
185\end{array}$ & $\begin{array}{r}37,500 \\
\mathrm{a} 39,700 \\
44,500 \\
36,300 \\
33,300\end{array}$ & $\begin{array}{l}66,600 \\
66,600 \\
66,600 \\
65,900 \\
66,600\end{array}$ & $\begin{array}{l}201 \\
206 \\
176 \\
176 \\
163\end{array}$ & $\begin{array}{l}36,100 \\
37,000 \\
31,600 \\
31,300 \\
29,300\end{array}$ & $\begin{array}{l}67,300 \\
70,100 \\
66,600 \\
67,300 \\
72,200\end{array}$ & $\begin{array}{l}201 \\
187 \\
182 \\
173 \\
161\end{array}$ & $\begin{array}{r}36,500 \\
35,400 \\
32,700 \\
\text { a } 31,400 \\
31,400\end{array}$ \\
\hline $\begin{array}{l}21 . \ldots \ldots \\
22 . \ldots \ldots \\
23 . \ldots \ldots \\
24 \ldots \ldots \\
25 . \ldots \ldots\end{array}$ & $\begin{array}{l}65,900 \\
66,600 \\
68,000 \\
70,100 \\
68,000\end{array}$ & $\begin{array}{l}195 \\
198 \\
182 \\
180 \\
194\end{array}$ & $\begin{array}{r}\mathrm{a} 34,700 \\
35,600 \\
33,400 \\
\mathrm{a} 34,100 \\
35,600\end{array}$ & $\begin{array}{l}70,800 \\
67,300 \\
67,300 \\
65,900 \\
65,900\end{array}$ & $\begin{array}{l}146 \\
147 \\
158 \\
213 \\
181\end{array}$ & $\begin{array}{r}\text { a } 27,900 \\
26700 \\
28,700 \\
37,900 \\
32,200\end{array}$ & $\begin{array}{l}75,800 \\
79,800 \\
78,200 \\
65,900 \\
62,400\end{array}$ & $\begin{array}{l}161 \\
144 \\
136 \\
132 \\
127\end{array}$ & $\begin{array}{r}33,000 \\
\text { a } 31,000 \\
28,700 \\
23,500 \\
\text { a } 21,400\end{array}$ \\
\hline $\begin{array}{l}26 \ldots \ldots \\
27 \ldots \ldots \\
28 . \ldots \ldots \\
29 . \ldots \ldots \\
30 \ldots \ldots \\
31 \ldots \ldots\end{array}$ & $\begin{array}{l}69,400 \\
75,800 \\
72,900 \\
69,400 \\
71,500 \\
69,400 \\
\end{array}$ & $\begin{array}{l}212 \\
233 \\
227 \\
237 \\
223 \\
232 \\
\end{array}$ & $\begin{array}{l}39,700 \\
47,700 \\
44,700 \\
44,400 \\
43,100 \\
43,500 \\
\end{array}$ & $\begin{array}{r}65,200 \\
65,200 \\
65,200 \\
63,100 \\
64,500 \\
-- \\
\end{array}$ & $\begin{array}{r}166 \\
155 \\
161 \\
176 \\
215 \\
-- \\
\end{array}$ & $\begin{array}{r}29,200 \\
27,300 \\
28,300 \\
\mathrm{a} 30,000 \\
37,400 \\
-- \\
\end{array}$ & $\begin{array}{l}63,800 \\
63,100 \\
62,400 \\
61,700 \\
61,700 \\
60,400 \\
\end{array}$ & $\begin{array}{r}113 \\
98 \\
83 \\
57 \\
64 \\
78 \\
\end{array}$ & $\begin{array}{r}19,500 \\
16,700 \\
14,000 \\
9,500 \\
10,700 \\
12,700 \\
\end{array}$ \\
\hline \multirow[t]{2}{*}{ Total. } & $2,162,000$ & -- & $1,176,500$ & $2,014,800$ & -- & $1,056,000$ & $2,092,500$ & -- & 837,300 \\
\hline & \multicolumn{3}{|c|}{ January } & \multicolumn{3}{|c|}{ February } & \multicolumn{3}{|c|}{ March } \\
\hline $\begin{array}{l}1 \ldots \ldots \\
2 \ldots \ldots \\
3 \ldots \ldots \\
4 \ldots \ldots \\
5 \ldots \ldots\end{array}$ & $\begin{array}{l}59,000 \\
57,000 \\
57,000 \\
52,200 \\
58,300\end{array}$ & $\begin{array}{l}71 \\
57 \\
54 \\
81 \\
76\end{array}$ & $\begin{array}{r}a 11,300 \\
8,770 \\
8,310 \\
11,400 \\
12,000\end{array}$ & $\begin{array}{l}49,900 \\
50,400 \\
50,400 \\
51,000 \\
52,200\end{array}$ & $\begin{array}{l}64 \\
53 \\
56 \\
58 \\
74\end{array}$ & $\begin{array}{r}8,620 \\
7,210 \\
7,620 \\
7,990 \\
10,400\end{array}$ & $\begin{array}{l}82,200 \\
78,400 \\
79,900 \\
82,200 \\
80,600\end{array}$ & $\begin{array}{l}305 \\
313 \\
329 \\
362 \\
378\end{array}$ & $\begin{array}{l}67,700 \\
66,300 \\
71,000 \\
80,300 \\
82,300\end{array}$ \\
\hline $\begin{array}{r}6 \ldots \ldots \\
7 \ldots \ldots \\
8 \ldots \ldots \\
9 \ldots \ldots \\
10 . \ldots \ldots\end{array}$ & $\begin{array}{l}58,300 \\
58,300 \\
58,300 \\
60,200 \\
60,200\end{array}$ & $\begin{array}{l}70 \\
68 \\
64 \\
62 \\
67\end{array}$ & $\begin{array}{r}11,000 \\
10,700 \\
10,100 \\
\mathrm{a} 10,100 \\
10,900\end{array}$ & $\begin{array}{l}52,200 \\
52,200 \\
52,200 \\
52,200 \\
53,400\end{array}$ & $\begin{array}{l}74 \\
64 \\
64 \\
79 \\
93\end{array}$ & $\begin{array}{r}10,400 \\
\mathrm{a} 9,020 \\
9,020 \\
11,100 \\
13,400\end{array}$ & $\begin{array}{l}78,400 \\
76,200 \\
77,600 \\
77,600 \\
80,600\end{array}$ & $\begin{array}{l}349 \\
341 \\
392 \\
614 \\
482\end{array}$ & $\begin{array}{r}\text { a } 73,900 \\
70,200 \\
82,100 \\
129,000 \\
105,000\end{array}$ \\
\hline $\begin{array}{l}11 . \ldots \ldots \\
12 \ldots \ldots \ldots \\
13 \ldots \ldots \\
14 \ldots \ldots \\
15 . \ldots \ldots\end{array}$ & $\begin{array}{l}60,900 \\
59,000 \\
54,600 \\
53,400 \\
55,800\end{array}$ & $\begin{array}{r}89 \\
103 \\
90 \\
90 \\
90\end{array}$ & $\begin{array}{r}14,600 \\
\mathrm{a} 16,400 \\
13,300 \\
13,000 \\
13,600\end{array}$ & $\begin{array}{l}54,600 \\
55,200 \\
54,600 \\
54,600 \\
55,200\end{array}$ & $\begin{array}{r}114 \\
123 \\
98 \\
81 \\
84\end{array}$ & $\begin{array}{r}16,800 \\
18,300 \\
\text { a } 14,400 \\
\text { a } 11,900 \\
12,500\end{array}$ & $\begin{array}{l}83,600 \\
82,200 \\
77,600 \\
76,200 \\
68,300\end{array}$ & $\begin{array}{l}380 \\
286 \\
232 \\
217 \\
185\end{array}$ & $\begin{array}{r}85,800 \\
63,500 \\
\mathrm{a} 48,600 \\
44,600 \\
34,100\end{array}$ \\
\hline $\begin{array}{l}16 \ldots \ldots \\
17 . \ldots \ldots \\
18 . \ldots \ldots \\
19 \ldots \ldots \\
20 . \ldots \ldots\end{array}$ & $\begin{array}{l}56,400 \\
57,000 \\
55,800 \\
54,600 \\
54,600\end{array}$ & $\begin{array}{r}90 \\
92 \\
96 \\
102 \\
105\end{array}$ & $\begin{array}{r}\mathrm{a} 13,700 \\
14,200 \\
14,500 \\
15,000 \\
15,500\end{array}$ & $\begin{array}{l}56,400 \\
57,000 \\
56,400 \\
5 e, 800 \\
57,000\end{array}$ & $\begin{array}{l}105 \\
193 \\
231 \\
216 \\
211\end{array}$ & $\begin{array}{r}16,000 \\
29,700 \\
35,200 \\
32,700 \\
\text { a } 32,500\end{array}$ & $\begin{array}{l}66,200 \\
65,500 \\
64,800 \\
67,600 \\
76,900\end{array}$ & $\begin{array}{l}175 \\
150 \\
162 \\
194 \\
237\end{array}$ & $\begin{array}{r}31,300 \\
26,500 \\
28,300 \\
35,400 \\
\text { a } 49,300\end{array}$ \\
\hline $\begin{array}{l}21 . \ldots \ldots \\
22 . \ldots \ldots \\
23 . \ldots \ldots \\
24 \ldots \ldots \\
25 . \ldots \ldots\end{array}$ & $\begin{array}{l}54,000 \\
52,800 \\
52,800 \\
52,200 \\
52,200\end{array}$ & $\begin{array}{l}90 \\
77 \\
62 \\
50 \\
70\end{array}$ & $\begin{array}{r}13,100 \\
11,000 \\
8,840 \\
7,050 \\
9,870\end{array}$ & $\begin{array}{l}59,600 \\
67,600 \\
69,000 \\
71,800 \\
76,200\end{array}$ & $\begin{array}{l}207 \\
180 \\
175 \\
130 \\
145\end{array}$ & $\begin{array}{l}33,300 \\
32,900 \\
32,600 \\
25,200 \\
29,800\end{array}$ & $\begin{array}{l}82,200 \\
79,900 \\
78,400 \\
81,400 \\
91,500\end{array}$ & $\begin{array}{l}319 \\
313 \\
271 \\
240 \\
234\end{array}$ & $\begin{array}{l}70,800 \\
67,500 \\
57,400 \\
52,700 \\
57,800\end{array}$ \\
\hline $\begin{array}{l}26 \ldots \ldots \\
27 . \ldots \ldots \\
28 . \ldots \ldots \\
29 . \ldots \ldots \\
30 \ldots \ldots \\
31 . \ldots \ldots\end{array}$ & $\begin{array}{l}53,400 \\
48,800 \\
45,500 \\
49,400 \\
49,900 \\
48,800 \\
\end{array}$ & $\begin{array}{l}68 \\
68 \\
55 \\
68 \\
71 \\
71 \\
\end{array}$ & $\begin{array}{r}9,800 \\
8,960 \\
6,760 \\
9,070 \\
\mathrm{a} 9,570 \\
9,350 \\
\end{array}$ & $\begin{array}{r}83,600 \\
85,900 \\
87,500 \\
-- \\
-- \\
--\end{array}$ & $\begin{array}{r}234 \\
321 \\
403 \\
-- \\
-- \\
-- \\
\end{array}$ & $\begin{array}{r}52,800 \\
\text { a } 74,400 \\
95,200 \\
-- \\
-- \\
\end{array}$ & $\begin{array}{l}110,000 \\
131,000 \\
140,000 \\
147,000 \\
147.000 \\
138,000 \\
\end{array}$ & $\begin{array}{r}312 \\
340 \\
396 \\
827 \\
1,290 \\
996 \\
\end{array}$ & $\begin{array}{r}92,700 \\
\mathrm{a} 120,000 \\
150,000 \\
328,000 \\
512,000 \\
371,000 \\
\end{array}$ \\
\hline Total. & $1,700,700$ & -- & 351,750 & $1,674,100$ & -- & 690,980 & $2,749,000$ & -- & $3,155,100$ \\
\hline
\end{tabular}

a Computed from estimated concentration graph. 
MISSISSIPPI RIVER MAIN STEM--Continued

MISSISSIPPI RIVER AT ST. LOUIS, MO .--Continued

Suspended sediment, water year October 1953 to September 1954--Continued

\begin{tabular}{|c|c|c|c|c|c|c|c|c|c|}
\hline \multirow[b]{3}{*}{ Day } & \multicolumn{3}{|c|}{ April } & \multicolumn{3}{|c|}{ May } & \multicolumn{3}{|c|}{ June } \\
\hline & \multirow[b]{2}{*}{$\begin{array}{l}\text { Mean } \\
\text { dis- } \\
\text { charge } \\
\text { (cfs) }\end{array}$} & \multicolumn{2}{|c|}{ Suspended sediment } & \multirow[b]{2}{*}{$\begin{array}{c}\text { Mean } \\
\text { dis- } \\
\text { charge } \\
\text { (cfs) }\end{array}$} & \multicolumn{2}{|c|}{ Suspended sediment } & \multirow[b]{2}{*}{$\begin{array}{l}\text { Mean } \\
\text { dis- } \\
\text { charge } \\
\text { (cfs) }\end{array}$} & \multicolumn{2}{|c|}{ Suspended sediment } \\
\hline & & $\begin{array}{c}\text { Mean } \\
\text { concen- } \\
\text { tration } \\
\text { (ppm) }\end{array}$ & $\begin{array}{l}\text { Tons } \\
\text { per } \\
\text { day }\end{array}$ & & $\begin{array}{l}\text { Mean } \\
\text { concen- } \\
\text { tration } \\
\text { (ppm) }\end{array}$ & $\begin{array}{l}\text { Tons } \\
\text { per } \\
\text { day }\end{array}$ & & $\begin{array}{c}\text { Mean } \\
\text { concen- } \\
\text { tration } \\
\text { (ppm) }\end{array}$ & $\begin{array}{l}\text { Tons } \\
\text { per } \\
\text { day }\end{array}$ \\
\hline $\begin{array}{l}1 \ldots \ldots \\
2 \ldots \ldots \\
3 \ldots \ldots \\
4 \ldots \ldots \\
5 \ldots \ldots\end{array}$ & $\begin{array}{l}133,000 \\
128,000 \\
126,000 \\
127,000 \\
131,000\end{array}$ & $\begin{array}{l}688 \\
570 \\
521 \\
471 \\
432\end{array}$ & $\begin{array}{r}247,000 \\
197,000 \\
2177,000 \\
162,000 \\
153,000\end{array}$ & $\begin{array}{l}180,000 \\
188,000 \\
198,000 \\
202,000 \\
216,000\end{array}$ & $\begin{array}{r}343 \\
666 \\
1,190 \\
1,030 \\
1,370\end{array}$ & $\begin{array}{r}\text { a } 167,000 \\
\text { a } 338,000 \\
636,000 \\
562,000 \\
799,000\end{array}$ & $\begin{array}{l}157,000 \\
187,000 \\
215,000 \\
222,000 \\
262,000\end{array}$ & \begin{tabular}{r|}
326 \\
331 \\
485 \\
854 \\
1,650
\end{tabular} & $\begin{array}{r}138,000 \\
167,000 \\
282,000 \\
512,000 \\
\mathrm{a} 1,170,000\end{array}$ \\
\hline $\begin{array}{r}6 . \ldots \ldots \\
7 \ldots \ldots \\
8 \ldots \ldots \\
9 \ldots \ldots \\
10 \ldots \ldots\end{array}$ & $\begin{array}{l}132,000 \\
137,000 \\
160,000 \\
145,000 \\
128,000\end{array}$ & $\begin{array}{l}404 \\
385 \\
428 \\
383 \\
387\end{array}$ & $\begin{array}{r}144,000 \\
142,000 \\
185,000 \\
150,000 \\
\text { a } 134,000\end{array}$ & $\begin{array}{l}240,000 \\
246,000 \\
240,000 \\
232,000 \\
225,000\end{array}$ & $\begin{array}{l}1,430 \\
1,650 \\
1,200 \\
1,100 \\
1,070\end{array}$ & $\begin{array}{r}927,000 \\
1,100,000 \\
\text { a } 778,000 \\
\text { a } 689,000 \\
650,000\end{array}$ & $\begin{array}{l}289,000 \\
281,000 \\
262,000 \\
250,000 \\
240,000\end{array}$ & $\begin{array}{l}2,330 \\
2,450 \\
2,180 \\
1,770 \\
1,530\end{array}$ & $\begin{array}{r}\text { 1 }, 820,000 \\
1,860,000 \\
1,540,000 \\
\text { a } 1,190,000 \\
991,000\end{array}$ \\
\hline $\begin{array}{l}11 . \ldots \ldots \\
12 . \ldots \ldots \\
13 . \ldots \ldots \\
14 . \ldots \ldots \\
15 . \ldots \ldots\end{array}$ & $\begin{array}{l}126,000 \\
133,000 \\
133,000 \\
132,000 \\
133,000\end{array}$ & $\begin{array}{l}504 \\
493 \\
450 \\
438 \\
461\end{array}$ & $\begin{array}{r}\text { 171, 000 } \\
177,000 \\
162,000 \\
156,000 \\
166,000\end{array}$ & $\begin{array}{l}222,000 \\
220,000 \\
225,000 \\
228,000 \\
228000\end{array}$ & $\begin{array}{l}970 \\
858 \\
770 \\
710 \\
663\end{array}$ & $\begin{array}{r}581,000 \\
510,000 \\
468,000 \\
437,000 \\
\text { a } 408,000\end{array}$ & $\begin{array}{l}222,000 \\
208,000 \\
195,000 \\
192,000 \\
185,000\end{array}$ & $\begin{array}{r}1,380 \\
1,230 \\
1,060 \\
940 \\
828\end{array}$ & $\begin{array}{r}827,000 \\
\text { a } 691,000 \\
\text { a } 558,000 \\
487,000 \\
414,000\end{array}$ \\
\hline $\begin{array}{l}16 \ldots \ldots \\
17 . \ldots \ldots \\
18 . \ldots \ldots \\
19 . \ldots \ldots \\
20 . \ldots \ldots\end{array}$ & $\begin{array}{l}132,000 \\
130,000 \\
136,000 \\
137,000 \\
130,000\end{array}$ & $\begin{array}{l}588 \\
502 \\
443 \\
428 \\
359\end{array}$ & $\begin{array}{r}210,000 \\
\text { a } 176,000 \\
\text { a } 163,000 \\
158,000 \\
126,000\end{array}$ & $\begin{array}{l}230,000 \\
235,000 \\
235,000 \\
235,000 \\
238,000\end{array}$ & $\begin{array}{l}639 \\
617 \\
622 \\
737 \\
795\end{array}$ & $\begin{array}{r}\text { a } 397,000 \\
391,000 \\
395,000 \\
468,000 \\
511,000\end{array}$ & $\begin{array}{l}190,000 \\
208,000 \\
205,000 \\
194,000 \\
188,000\end{array}$ & $\begin{array}{r}727 \\
1,630 \\
1,550 \\
1,140 \\
1,020\end{array}$ & $\begin{array}{r}373,000 \\
.915,000 \\
858,000 \\
\text { a } 597,000 \\
\text { a } 518,000\end{array}$ \\
\hline $\begin{array}{l}21 . \ldots \ldots \\
22 \ldots \ldots \ldots \\
23 . \ldots \ldots \\
24 \ldots \ldots \\
25 . \ldots \ldots\end{array}$ & $\begin{array}{l}134,000 \\
167,000 \\
185,000 \\
173,000 \\
164,000\end{array}$ & $\begin{array}{l}313 \\
385 \\
428 \\
430 \\
464\end{array}$ & $\begin{array}{r}113,000 \\
174,000 \\
214,000 \\
\text { a201, 000 } \\
\text { a205, 000 }\end{array}$ & $\begin{array}{l}238,000 \\
232,000 \\
226,000 \\
226,000 \\
218,000\end{array}$ & $\begin{array}{l}563 \\
456 \\
412 \\
495 \\
730\end{array}$ & $\begin{array}{r}362,000 \\
\text { a } 286,000 \\
\text { a } 251,000 \\
302,000 \\
430,000\end{array}$ & $\begin{array}{l}184,000 \\
187,000 \\
185,000 \\
183,000 \\
192,000\end{array}$ & $\begin{array}{l}1,020 \\
1,390 \\
1,500 \\
2,050 \\
1,950\end{array}$ & $\begin{array}{r}507,000 \\
702,000 \\
749,000 \\
1,010,000 \\
1,010,000\end{array}$ \\
\hline $\begin{array}{l}26 . \ldots \ldots \\
27 . \ldots . \\
28 . \ldots \ldots \\
29 . \ldots \ldots \\
30 . \ldots \ldots \\
31 . \ldots .\end{array}$ & $\begin{array}{r}162,000 \\
164,000 \\
173,000 \\
188,000 \\
181,000 \\
--\end{array}$ & $\begin{array}{r}570 \\
546 \\
438 \\
468 \\
356 \\
-- \\
\end{array}$ & $\begin{array}{r}a 249,000 \\
242,000 \\
205,000 \\
238,000 \\
174,000 \\
\ldots\end{array}$ & $\begin{array}{l}197,000 \\
176,000 \\
156,000 \\
137,000 \\
131,000 \\
138,000 \\
\end{array}$ & $\begin{array}{l}662 \\
490 \\
398 \\
336 \\
288 \\
288 \\
\end{array}$ & $\begin{array}{r}352,000 \\
233,000 \\
168,000 \\
\text { a124, 000 } \\
\text { a102,000 } \\
\text { a107,000 } \\
\end{array}$ & $\begin{array}{r}229,000 \\
256,000 \\
260,000 \\
254,000 \\
250,000 \\
-- \\
\end{array}$ & $\begin{array}{r}1,580 \\
1,730 \\
2,170 \\
2,180 \\
1,960 \\
-- \\
\end{array}$ & $\begin{array}{r}\text { a } 977,000 \\
\text { a 1, 200 } 000 \\
1,520,000 \\
1,500,000 \\
1,320,000 \\
- \\
\end{array}$ \\
\hline \multirow[t]{2}{*}{ Total. } & $4,360,000$ & -- & $5,371,000$ & $6,538,000$ & - & $13,929 \rho 00$ & $6,532,000$ & - & $26,403,000$ \\
\hline & \multicolumn{3}{|c|}{ July } & \multicolumn{3}{|c|}{ August } & \multicolumn{3}{|c|}{ September } \\
\hline $\begin{array}{l}1 \ldots \ldots \\
2 \ldots \ldots \\
3 \ldots \ldots \\
4 \ldots \ldots \\
5 \ldots \ldots\end{array}$ & $\begin{array}{l}247,000 \\
254,000 \\
259,000 \\
254,000 \\
244,000\end{array}$ & $\begin{array}{r}1,660 \\
1,380 \\
1,160 \\
966 \\
788\end{array}$ & $\begin{array}{r}1,110,000 \\
946,000 \\
a 811,000 \\
a 662,000 \\
\text { a519, 000 }\end{array}$ & $\begin{array}{l}84,400 \\
83,600 \\
83,600 \\
85,200 \\
87,500\end{array}$ & $\begin{array}{l}193 \\
176 \\
181 \\
218 \\
207\end{array}$ & $\begin{array}{r}\mathrm{a} 44,000 \\
39,700 \\
40,900 \\
50,100 \\
48,900\end{array}$ & $\begin{array}{l}159,000 \\
147,000 \\
135,000 \\
130,000 \\
126,000\end{array}$ & $\begin{array}{r}1,520 \\
1,310 \\
1,110 \\
779 \\
533\end{array}$ & $\begin{array}{r}\text { a } 653,000 \\
520,000 \\
405,000 \\
\text { a } 273,000 \\
\text { a } 181,000\end{array}$ \\
\hline $\begin{array}{r}6 . \ldots \ldots \\
7 \ldots \ldots \\
8 \ldots \ldots \\
9 . \ldots \ldots \\
10 . \ldots \ldots\end{array}$ & $\begin{array}{l}228,000 \\
212,000 \\
192,000 \\
180,000 \\
177,000\end{array}$ & $\begin{array}{l}678 \\
590 \\
572 \\
505 \\
440\end{array}$ & $\begin{array}{r}417,000 \\
338,000 \\
297,000 \\
245,000 \\
\mathrm{a} 210,000\end{array}$ & $\begin{array}{r}96,300 \\
104,000 \\
108,000 \\
115,000 \\
111,000\end{array}$ & $\begin{array}{l}258 \\
235 \\
232 \\
446 \\
714\end{array}$ & $\begin{array}{r}67,100 \\
\text { a } 66,000 \\
\text { a } 67,700 \\
138,000 \\
214,000\end{array}$ & $\begin{array}{r}113,000 \\
108,000 \\
97,100 \\
86,700 \\
89,900\end{array}$ & $\begin{array}{l}441 \\
477 \\
449 \\
391 \\
323\end{array}$ & $\begin{array}{r}135,000 \\
139,000 \\
118,000 \\
91,500 \\
78,400\end{array}$ \\
\hline $\begin{array}{l}11 . \ldots \ldots \\
12 \ldots \ldots \\
13 . \ldots \ldots \\
14 \ldots \ldots \\
15 . \ldots \ldots\end{array}$ & $\begin{array}{l}176,000 \\
173,000 \\
173,000 \\
172,000 \\
168,000\end{array}$ & $\begin{array}{l}397 \\
387 \\
394 \\
380 \\
342\end{array}$ & $\begin{array}{r}\mathrm{a} 189,000 \\
181,000 \\
184,000 \\
176,000 \\
155,000\end{array}$ & $\begin{array}{l}103,000 \\
105,000 \\
114,000 \\
110,000 \\
106,000\end{array}$ & $\begin{array}{r}654 \\
697 \\
834 \\
779 \\
1,230\end{array}$ & $\begin{array}{r}\text { a182, } 000 \\
198,000 \\
257,000 \\
\text { a231, 000 } \\
\text { a352, 000 }\end{array}$ & $\begin{array}{l}79,200 \\
74600 \\
76,200 \\
79,900 \\
83,600\end{array}$ & $\begin{array}{l}293 \\
343 \\
320 \\
273 \\
236\end{array}$ & $\begin{array}{r}\text { a } 62,700 \\
\text { a } 69,100 \\
65,800 \\
58,900 \\
53,300\end{array}$ \\
\hline $\begin{array}{l}16 \ldots \ldots \\
17 . \ldots \ldots \\
18 . \ldots \ldots \\
19 . \ldots \ldots \\
20 \ldots \ldots\end{array}$ & $\begin{array}{l}164,000 \\
159,000 \\
154,000 \\
151,000 \\
147,000\end{array}$ & $\begin{array}{l}287 \\
251 \\
239 \\
235 \\
239\end{array}$ & $\begin{array}{r}127,000 \\
\text { a108,000 } \\
\text { a } 99,400 \\
95,800 \\
94,900\end{array}$ & $\begin{array}{r}102,000 \\
96,300 \\
96,300 \\
96,300 \\
104,000\end{array}$ & $\begin{array}{r}1,800 \\
1,900 \\
1,330 \\
871 \\
560\end{array}$ & $\begin{array}{r}496,000 \\
494,000 \\
\mathrm{a346}, 000 \\
226,000 \\
157,000\end{array}$ & $\begin{array}{r}85,200 \\
88,300 \\
91,500 \\
91,500 \\
103,000\end{array}$ & $\begin{array}{l}210 \\
205 \\
210 \\
222 \\
307\end{array}$ & $\begin{array}{r}\text { a } 48,300 \\
48,900 \\
\text { a } 51,900 \\
\text { a } 54,800 \\
85,400\end{array}$ \\
\hline $\begin{array}{l}21 . \ldots \ldots \\
22 . \ldots \ldots \\
23 . \ldots \ldots \\
24 \ldots \ldots \\
25 . \ldots \ldots\end{array}$ & $\begin{array}{l}143,000 \\
138,000 \\
142,000 \\
136,000 \\
128,000\end{array}$ & $\begin{array}{l}230 \\
220 \\
214 \\
207 \\
196\end{array}$ & $\begin{array}{r}88,800 \\
82,000 \\
82,000 \\
\text { a } 76,000 \\
\text { a } 67,700\end{array}$ & $\begin{array}{r}106,000 \\
114,000 \\
103,000 \\
89,100 \\
94,700\end{array}$ & $\begin{array}{l}389 \\
376 \\
328 \\
291 \\
270\end{array}$ & $\begin{array}{r}\text { a } 111,000 \\
\text { a } 116,000 \\
91,200 \\
70,000 \\
\text { a } 69,000\end{array}$ & $\begin{array}{r}107,000 \\
99,500 \\
99,500 \\
103,000 \\
103,000\end{array}$ & $\begin{array}{l}363 \\
337 \\
278 \\
243 \\
227\end{array}$ & $\begin{array}{r}105,000 \\
\text { a } 90,500 \\
74,700 \\
67,600 \\
\text { a } 63,100\end{array}$ \\
\hline $\begin{array}{l}26 . \ldots \ldots \\
27 . \ldots \ldots \\
28 . \ldots \ldots \\
29 \ldots \ldots \\
30 \ldots \ldots \\
31 . \ldots \ldots\end{array}$ & $\begin{array}{r}116,000 \\
104,000 \\
96,300 \\
95,500 \\
87,500 \\
77,600\end{array}$ & $\begin{array}{l}203 \\
258 \\
272 \\
261 \\
252 \\
225\end{array}$ & $\begin{array}{r}63,600 \\
72,400 \\
70,700 \\
267,300 \\
59,500 \\
247,100\end{array}$ & $\begin{array}{r}98,700 \\
118,000 \\
166,000 \\
190,000 \\
180,000 \\
169,000\end{array}$ & $\begin{array}{r}265 \\
302 \\
433 \\
711 \\
1,060 \\
1,410 \\
\end{array}$ & $\begin{array}{r}70,600 \\
96,200 \\
\text { a } 194,000 \\
\text { a } 365,000 \\
515,000 \\
643,000 \\
\end{array}$ & $\begin{array}{r}102,000 \\
96,300 \\
94,700 \\
94,700 \\
97,900\end{array}$ & $\begin{array}{l}221 \\
222 \\
220 \\
212 \\
206\end{array}$ & $\begin{array}{r}\text { a } 60,900 \\
57,700 \\
56,300 \\
\text { a } 54,200 \\
54,500\end{array}$ \\
\hline Total & $5,147,900$ & -- & $7,742,200$ & $3,420,000$ & - & $6,056,400$ & $3,042,300$ & - & $3,877,500$ \\
\hline
\end{tabular}

Total discharge for year (cfs-days) $\ldots \ldots \ldots \ldots \ldots \ldots \ldots \ldots \ldots \ldots \ldots \ldots \ldots \ldots \ldots \ldots \ldots \ldots \ldots \ldots \ldots \ldots, 41,433,300$

Total load for year (tons) $\ldots \ldots \ldots \ldots \ldots \ldots \ldots \ldots \ldots \ldots \ldots \ldots \ldots \ldots \ldots \ldots \ldots \ldots \ldots \ldots \ldots \ldots \ldots \ldots \ldots, 70,646,730$

a Computed from estimated concentration graph. 

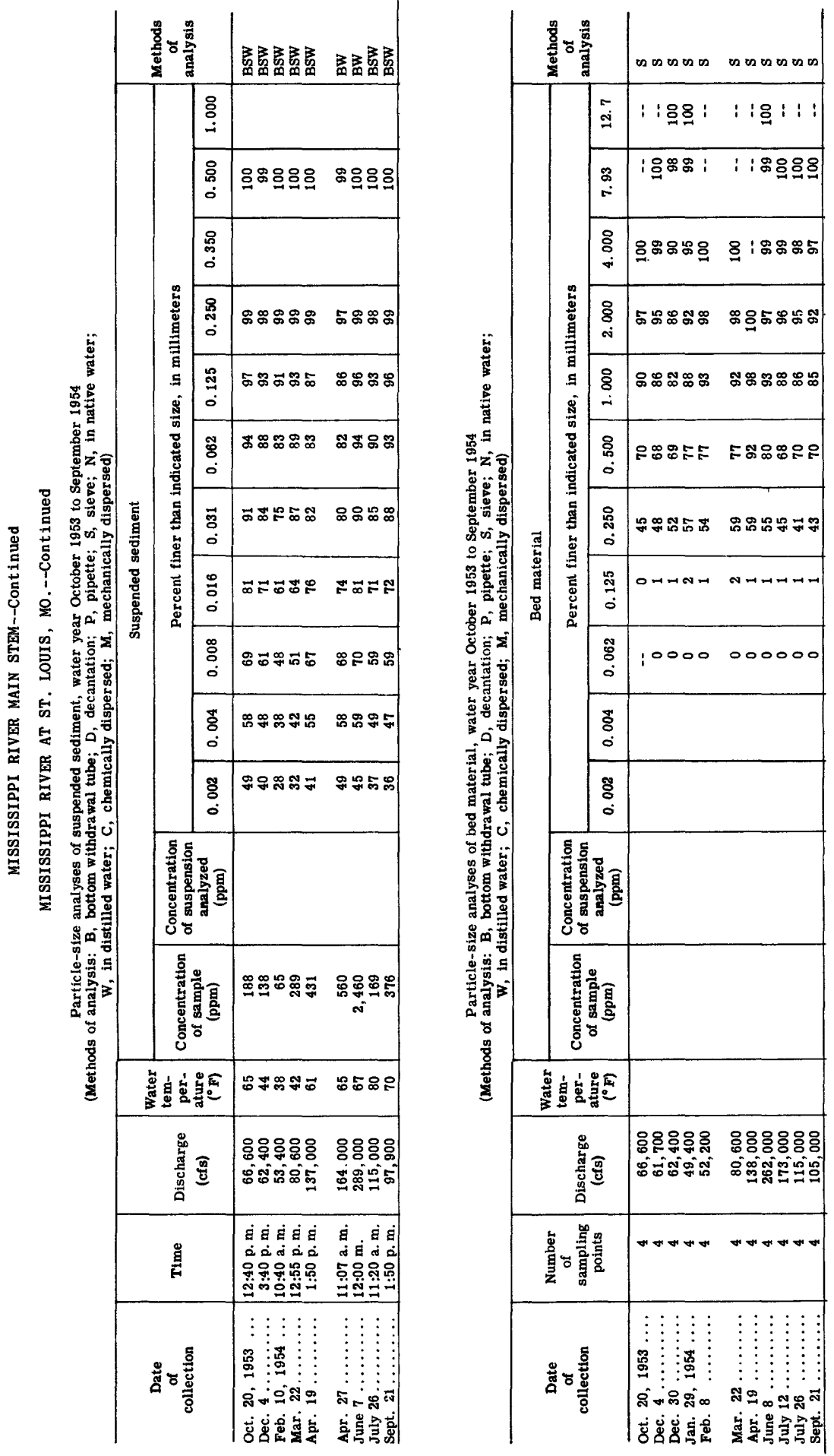


\begin{tabular}{|c|c|c|c|c|c|}
\hline ชัँ & $-\infty \infty$ & $=$ & ธ็ริส & 요요 & ิㅗㄱㅗ \\
\hline 몀 & $\begin{array}{c}\forall+\infty \\
\infty \infty \infty \infty\end{array}$ & $\stackrel{+}{\infty}$ & $\begin{array}{l}0+\infty \\
\infty \\
\infty\end{array}$ & $\begin{array}{l}0 \infty 10 \infty \\
\infty \infty_{\infty}^{\infty} \infty \infty_{\infty}^{\infty} \\
\end{array}$ & $\begin{array}{l}r+10 \\
\infty \infty \infty \infty \infty \\
\infty\end{array}$ \\
\hline 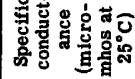 & 与考萦 & స్ల్ల & 过总总 & 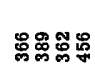 & 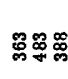 \\
\hline कृ & $\sim \pm \infty$ & 0 & $\approx r=$ & $\operatorname{man}^{\infty}$ & $\infty \infty \infty$ \\
\hline 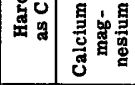 & 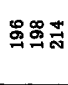 & $\stackrel{\mathscr{2}}{\Xi}$ & $\stackrel{9}{9}$ & 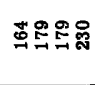 & 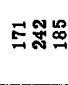 \\
\hline 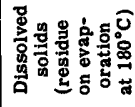 & 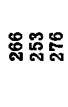 & जี้ & Е્木 & ఇ్ఞి స్రి సేర్లి & 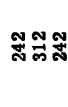 \\
\hline$\stackrel{8}{2}$ & & & & & \\
\hline
\end{tabular}

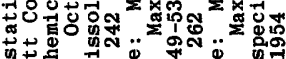
㻤范

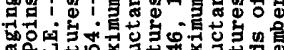
我约 ڤ4

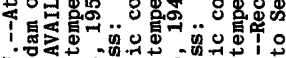
은

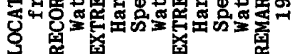

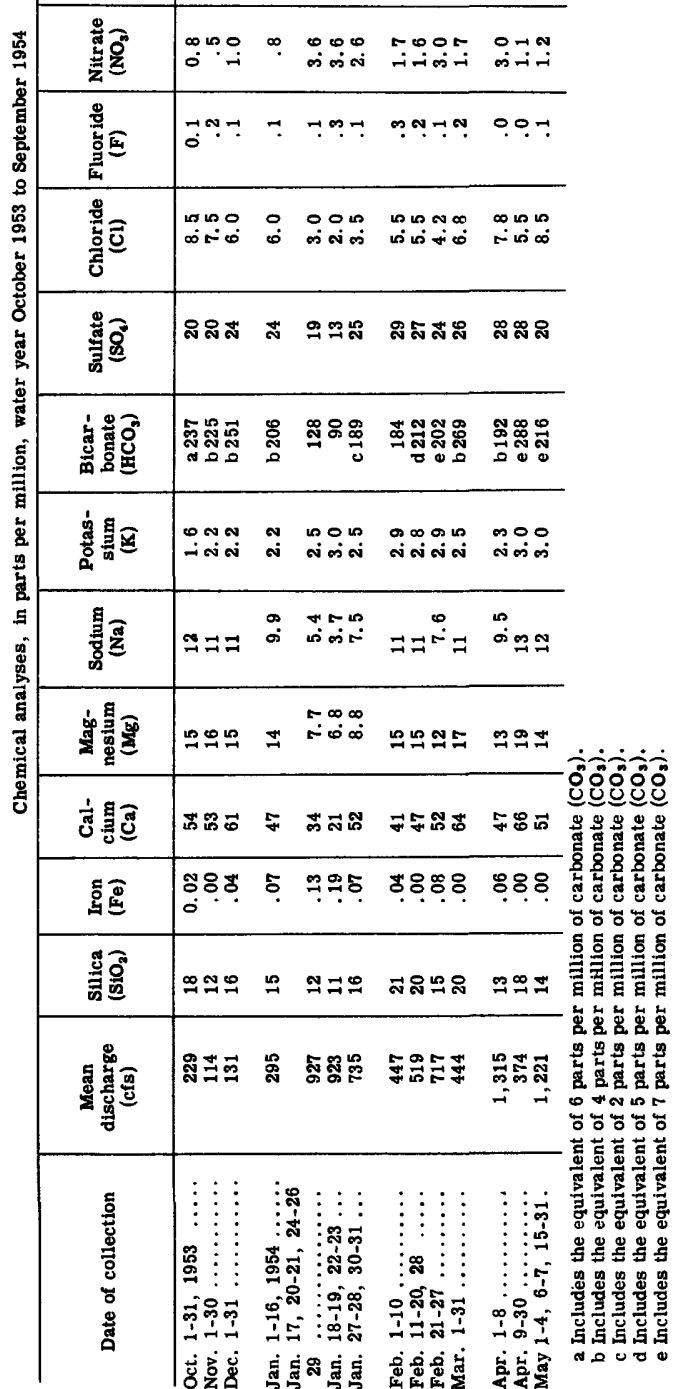




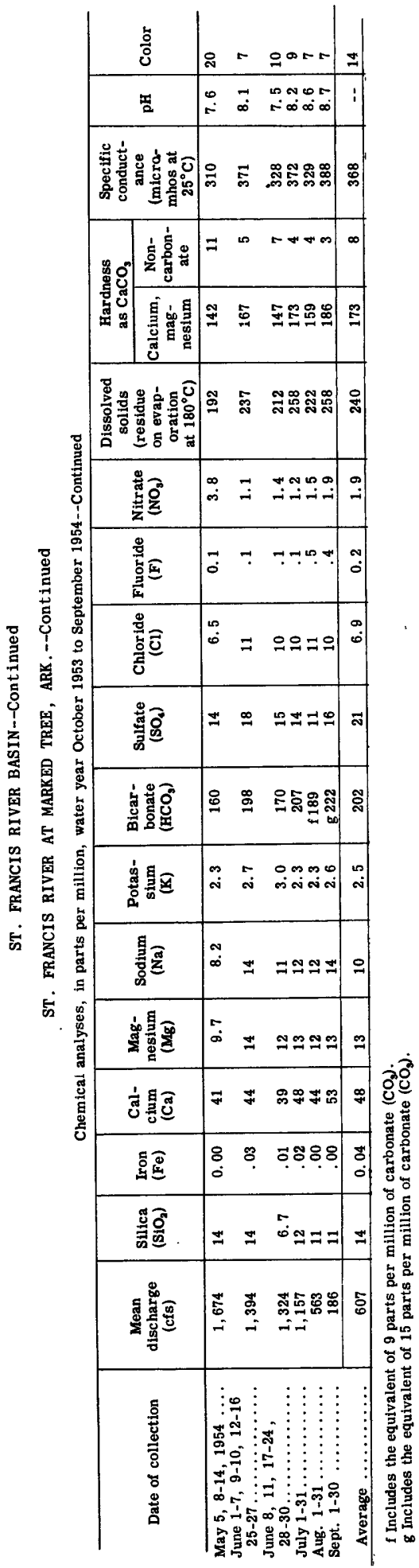


ST. FRANCIS RIVER BASIN--Continued

ST. FRANCIS RIVER AT MARKED TREE, ARK.--Continued

Temperature ( ${ }^{\circ} \mathrm{F}$ ) of water, water year October 1953 to September 1954

\begin{tabular}{|c|c|c|c|c|c|c|c|c|c|c|c|c|}
\hline Day & Oct. & Nov. & Dec. & Jan. & Feb. & Mar. & Apr. & May & June & July & Aug. & Sept. \\
\hline $\begin{array}{l}1 \\
2 \\
3 \\
4 \\
5\end{array}$ & $\begin{array}{l}80 \\
80 \\
80 \\
80 \\
80\end{array}$ & $\begin{array}{l}58 \\
63 \\
67 \\
68 \\
60\end{array}$ & $\begin{array}{l}48 \\
48 \\
-2 \\
48 \\
50\end{array}$ & $\begin{array}{l}40 \\
40 \\
40 \\
40 \\
40\end{array}$ & $\begin{array}{l}45 \\
46 \\
44 \\
46 \\
48\end{array}$ & $\begin{array}{l}50 \\
48 \\
48 \\
48 \\
48\end{array}$ & $\begin{array}{l}54 \\
54 \\
50 \\
50 \\
50\end{array}$ & $\begin{array}{l}70 \\
70 \\
70 \\
68 \\
68\end{array}$ & $\begin{array}{l}72 \\
72 \\
74 \\
72 \\
72\end{array}$ & $\begin{array}{l}81 \\
84 \\
84 \\
82 \\
82\end{array}$ & $\begin{array}{l}86 \\
85 \\
86 \\
86 \\
86\end{array}$ & $\begin{array}{l}84 \\
80 \\
80 \\
80 \\
80\end{array}$ \\
\hline $\begin{array}{r}6 \\
7 \\
8 \\
9 \\
10\end{array}$ & $\begin{array}{l}78 \\
74 \\
72 \\
68 \\
68\end{array}$ & $\begin{array}{l}48 \\
48 \\
48 \\
50 \\
50\end{array}$ & $\begin{array}{l}50 \\
50 \\
48 \\
48 \\
48\end{array}$ & $\begin{array}{l}38 \\
38 \\
38 \\
40 \\
38\end{array}$ & $\begin{array}{l}48 \\
46 \\
46 \\
49 \\
48\end{array}$ & $\begin{array}{l}48 \\
48 \\
48 \\
50 \\
48\end{array}$ & $\begin{array}{l}50 \\
54 \\
50 \\
52 \\
52\end{array}$ & $\begin{array}{l}68 \\
68 \\
69 \\
69 \\
68\end{array}$ & $\begin{array}{l}72 \\
72 \\
75 \\
77 \\
76\end{array}$ & $\begin{array}{l}81 \\
82 \\
82 \\
82 \\
82\end{array}$ & $\begin{array}{l}86 \\
86 \\
86 \\
86 \\
--\end{array}$ & $\begin{array}{l}80 \\
78 \\
78 \\
78 \\
76\end{array}$ \\
\hline $\begin{array}{l}11 \\
12 \\
13 \\
14 \\
15\end{array}$ & $\begin{array}{l}68 \\
70 \\
68 \\
67 \\
68\end{array}$ & $\begin{array}{l}48 \\
46 \\
48 \\
48 \\
48\end{array}$ & $\begin{array}{l}45 \\
47 \\
48 \\
48 \\
46\end{array}$ & $\begin{array}{l}36 \\
36 \\
36 \\
36 \\
37\end{array}$ & $\begin{array}{l}46 \\
46 \\
47 \\
48 \\
48\end{array}$ & $\begin{array}{l}49 \\
50 \\
52 \\
52 \\
52\end{array}$ & $\begin{array}{l}\mathbf{5 2} \\
\mathbf{5 4} \\
\mathbf{5 6} \\
\mathbf{5 8} \\
\mathbf{6 0}\end{array}$ & $\begin{array}{l}68 \\
67 \\
-- \\
68 \\
68\end{array}$ & $\begin{array}{l}76 \\
78 \\
78 \\
78 \\
78\end{array}$ & $\begin{array}{l}82 \\
82 \\
82 \\
82 \\
83\end{array}$ & $\begin{array}{l}86 \\
84 \\
84 \\
86 \\
86\end{array}$ & $\begin{array}{l}76 \\
76 \\
77 \\
76 \\
75\end{array}$ \\
\hline $\begin{array}{l}16 \\
17 \\
18 \\
19 \\
20\end{array}$ & $\begin{array}{l}68 \\
68 \\
68 \\
67 \\
68\end{array}$ & $\begin{array}{l}52 \\
52 \\
50 \\
54 \\
54\end{array}$ & $\begin{array}{l}46 \\
44 \\
40 \\
38 \\
38\end{array}$ & $\begin{array}{l}38 \\
38 \\
39 \\
40 \\
38\end{array}$ & $\begin{array}{l}48 \\
48 \\
48 \\
48 \\
48\end{array}$ & $\begin{array}{l}48 \\
50 \\
50 \\
52 \\
52\end{array}$ & $\begin{array}{l}62 \\
64 \\
65 \\
67 \\
69\end{array}$ & $\begin{array}{l}68 \\
68 \\
68 \\
69 \\
69\end{array}$ & $\begin{array}{l}79 \\
79 \\
80 \\
80 \\
80\end{array}$ & $\begin{array}{l}82 \\
82 \\
82 \\
82 \\
85\end{array}$ & $\begin{array}{l}86 \\
86 \\
86 \\
88 \\
84\end{array}$ & $\begin{array}{l}74 \\
74 \\
74 \\
74 \\
74\end{array}$ \\
\hline $\begin{array}{l}21 \\
22 \\
23 \\
24 \\
25\end{array}$ & $\begin{array}{l}68 \\
68 \\
68 \\
70 \\
68\end{array}$ & $\begin{array}{l}55 \\
54 \\
52 \\
50 \\
48\end{array}$ & $\begin{array}{l}40 \\
40 \\
40 \\
38 \\
38\end{array}$ & $\begin{array}{l}43 \\
40 \\
38 \\
40 \\
38\end{array}$ & $\begin{array}{l}48 \\
50 \\
50 \\
50 \\
50\end{array}$ & $\begin{array}{l}52 \\
52 \\
52 \\
52 \\
54\end{array}$ & $\begin{array}{l}69 \\
69 \\
69 \\
69 \\
69\end{array}$ & $\begin{array}{l}68 \\
68 \\
66 \\
70 \\
70\end{array}$ & $\begin{array}{l}80 \\
80 \\
81 \\
81 \\
80\end{array}$ & $\begin{array}{l}86 \\
86 \\
86 \\
85 \\
84\end{array}$ & $\begin{array}{l}86 \\
86 \\
86 \\
86 \\
86\end{array}$ & $\begin{array}{l}72 \\
70 \\
69 \\
70 \\
76\end{array}$ \\
\hline $\begin{array}{l}26 \\
27 \\
28 \\
29 \\
30 \\
31\end{array}$ & $\begin{array}{l}68 \\
68 \\
67 \\
65 \\
64 \\
60\end{array}$ & $\begin{array}{l}48 \\
48 \\
50 \\
48 \\
48 \\
--\end{array}$ & $\begin{array}{l}38 \\
40 \\
40 \\
40 \\
40 \\
40\end{array}$ & $\begin{array}{l}40 \\
40 \\
42 \\
38 \\
40 \\
43\end{array}$ & $\begin{array}{l}50 \\
50 \\
54 \\
-- \\
-- \\
--\end{array}$ & $\begin{array}{l}54 \\
54 \\
56 \\
58 \\
56 \\
56\end{array}$ & $\begin{array}{l}69 \\
70 \\
69 \\
70 \\
70 \\
--\end{array}$ & $\begin{array}{l}70 \\
70 \\
70 \\
- \\
76 \\
70\end{array}$ & $\begin{array}{l}80 \\
81 \\
82 \\
82 \\
80 \\
--\end{array}$ & $\begin{array}{l}84 \\
84 \\
83 \\
82 \\
84 \\
86\end{array}$ & $\begin{array}{l}86 \\
86 \\
87 \\
87 \\
86 \\
86\end{array}$ & $\begin{array}{c}76 \\
76 \\
76 \\
76 \\
76 \\
--\end{array}$ \\
\hline $\begin{array}{c}\text { Aver- } \\
\text { age }\end{array}$ & 70 & 52 & 44 & 39 & 48 & 50 & 61 & 69 & 78 & 83 & 86 & 76 \\
\hline
\end{tabular}




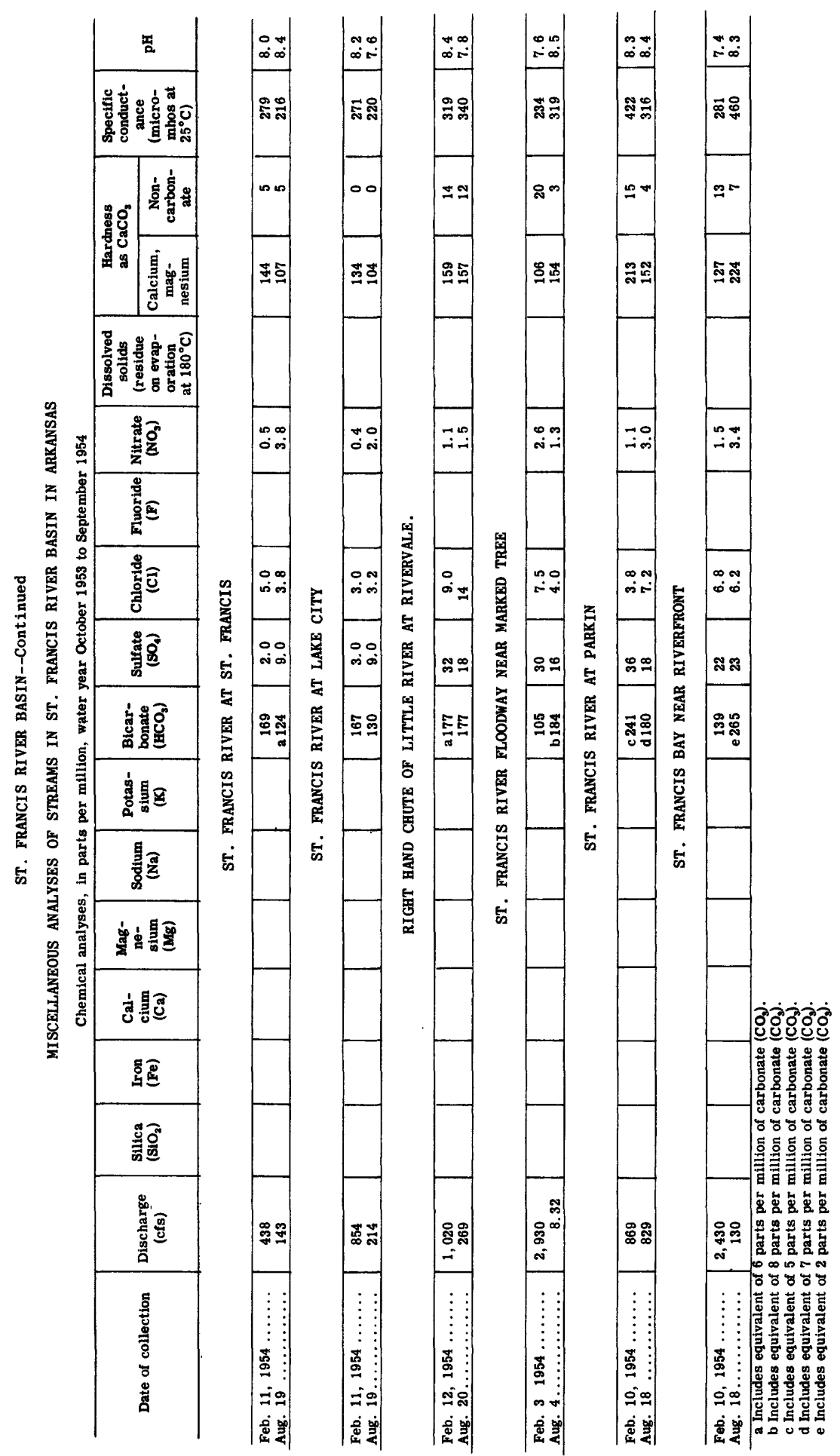




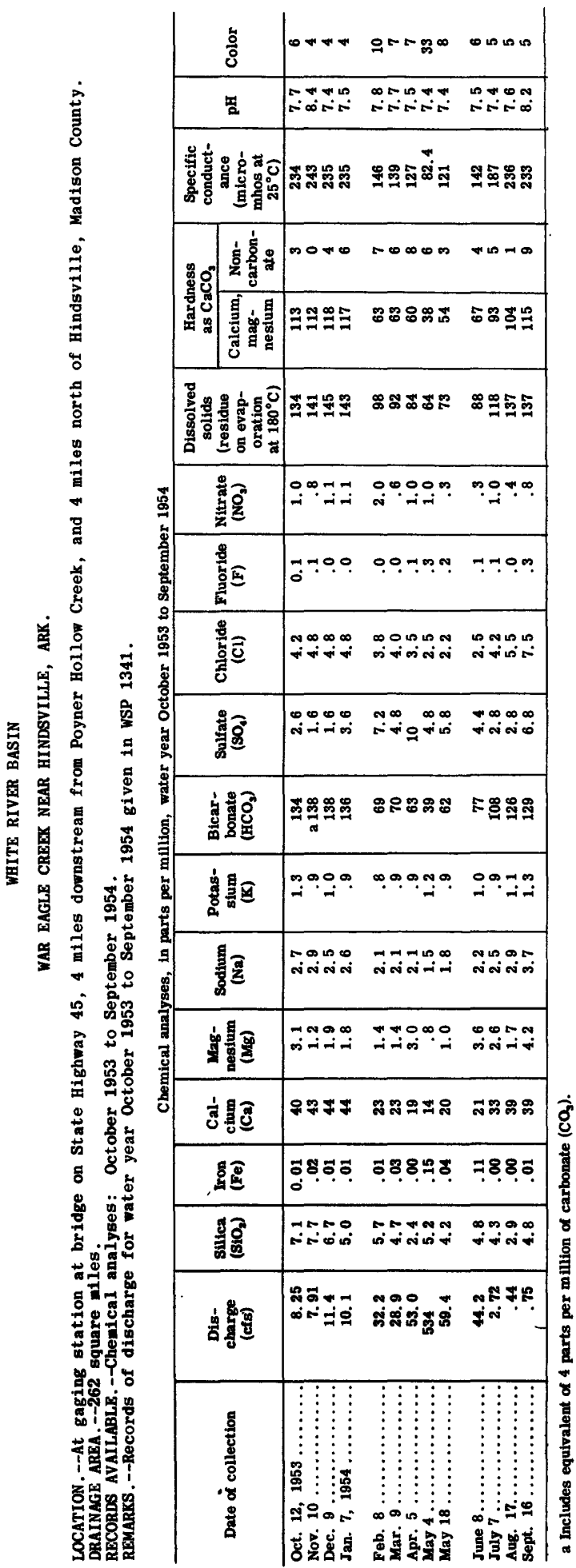




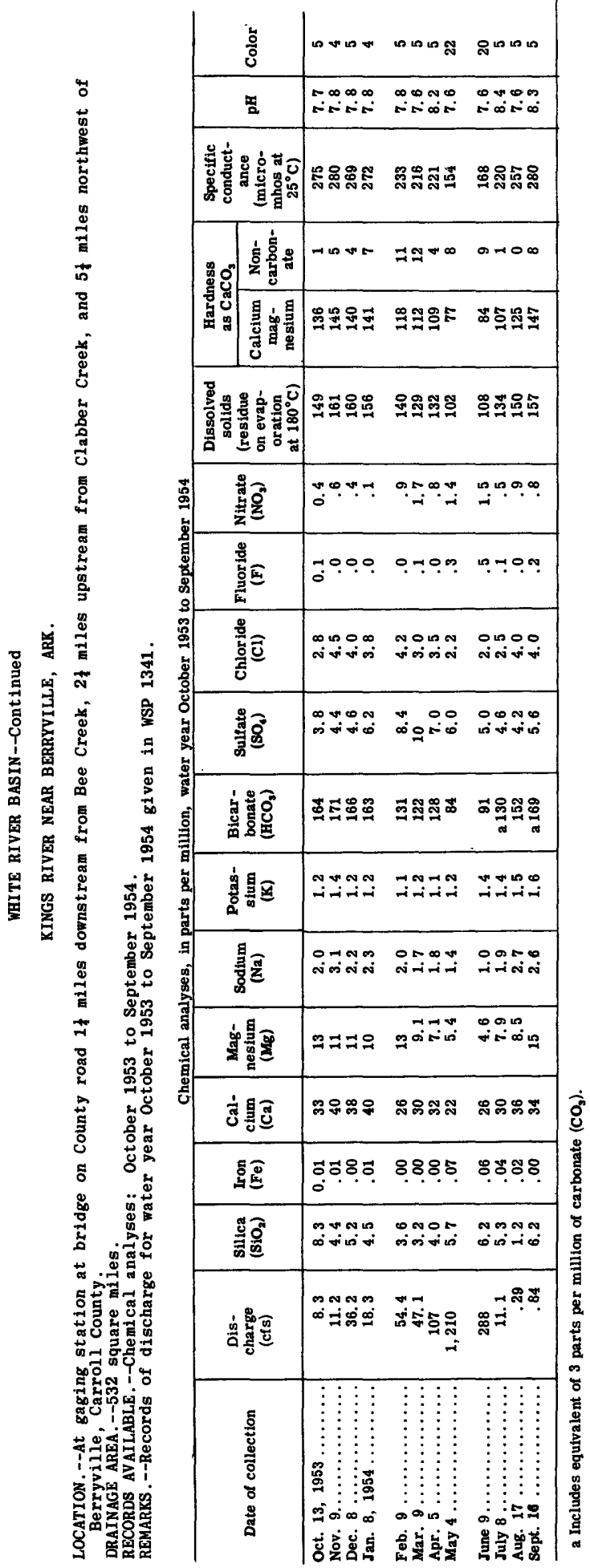




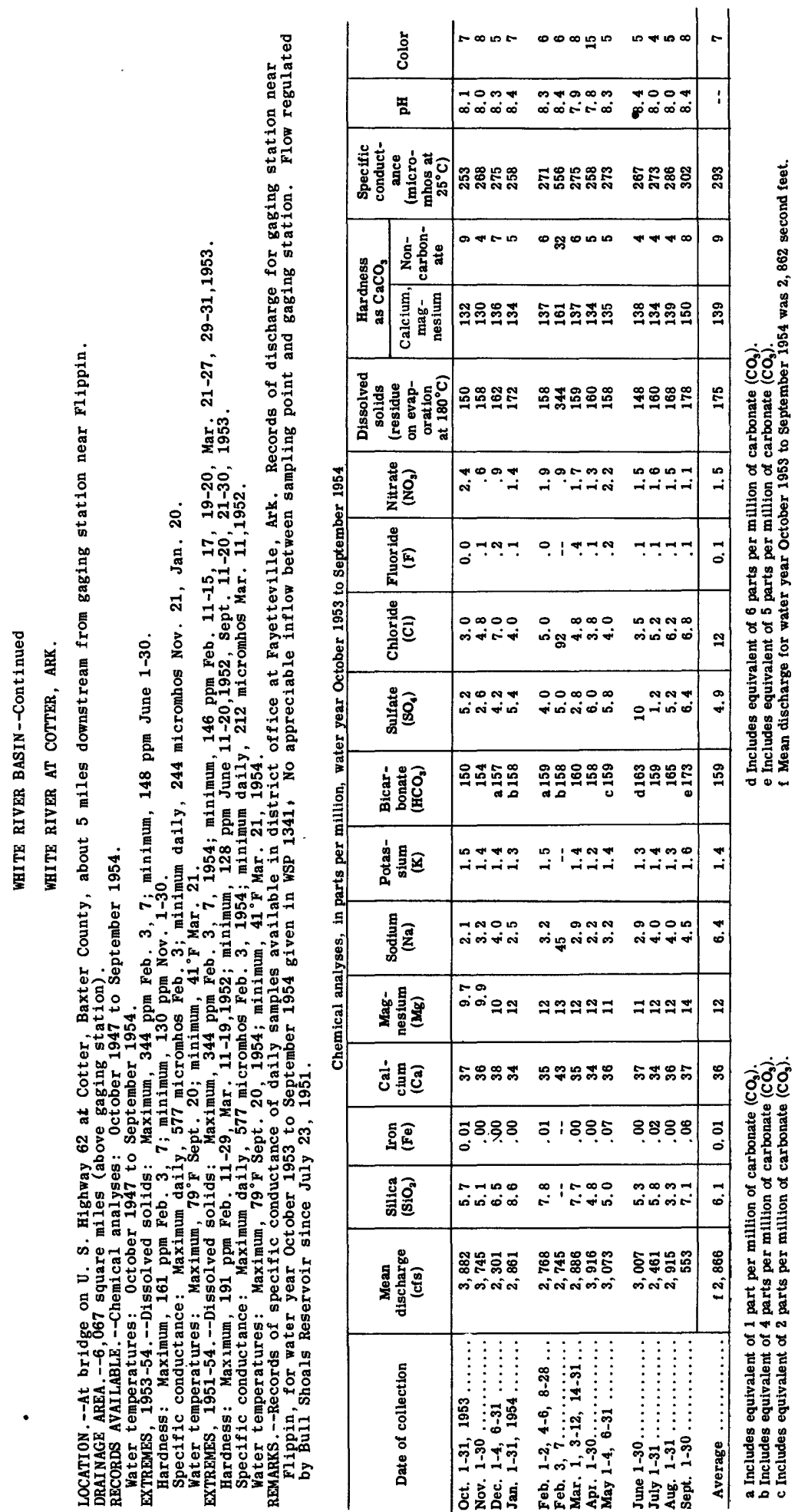


WHITE RIVER BASIN--Continued

WHITE RIVER AT COTTER, ARK.--Continued

Temperature $\left({ }^{\circ} \mathrm{F}\right)$ of water, water year October 1953 to September 1954

\begin{tabular}{|c|c|c|c|c|c|c|c|c|c|c|c|c|}
\hline Day & Oct. & Nov. & Bec. & Jan. & Feb. & Mar. & Apr. & May & June & July & Aug. & Sept. \\
\hline $\begin{array}{l}1 \\
2 \\
3 \\
4 \\
5\end{array}$ & $\begin{array}{l}56 \\
56 \\
58 \\
-\because \\
58\end{array}$ & $\begin{array}{l}54 \\
54 \\
56 \\
56 \\
56\end{array}$ & $\begin{array}{l}51 \\
51 \\
51 \\
51 \\
51\end{array}$ & $\begin{array}{l}48 \\
48 \\
48 \\
46 \\
46\end{array}$ & $\begin{array}{l}46 \\
46 \\
46 \\
46 \\
46\end{array}$ & $\begin{array}{l}45 \\
46 \\
44 \\
44 \\
44\end{array}$ & $\begin{array}{l}46 \\
46 \\
48 \\
50 \\
54\end{array}$ & $\begin{array}{l}52 \\
55 \\
49 \\
52 \\
52\end{array}$ & $\begin{array}{l}58 \\
59 \\
56 \\
59 \\
58\end{array}$ & $\begin{array}{l}61 \\
63 \\
-2 \\
66 \\
72\end{array}$ & $\begin{array}{l}65 \\
69 \\
65 \\
65 \\
65\end{array}$ & $\begin{array}{l}-2 \\
65 \\
68 \\
67 \\
71\end{array}$ \\
\hline $\begin{array}{r}6 \\
7 \\
8 \\
9 \\
10\end{array}$ & $\begin{array}{l}57 \\
56 \\
56 \\
56 \\
54\end{array}$ & $\begin{array}{l}54 \\
54 \\
54 \\
51 \\
49\end{array}$ & $\begin{array}{l}\mathbf{5 1} \\
\mathbf{5 0} \\
\mathbf{5 1} \\
\mathbf{5 1} \\
\mathbf{5 1}\end{array}$ & $\begin{array}{l}46 \\
46 \\
47 \\
47 \\
46\end{array}$ & $\begin{array}{l}46 \\
46 \\
46 \\
44 \\
44\end{array}$ & $\begin{array}{l}44 \\
44 \\
44 \\
44 \\
45\end{array}$ & $\begin{array}{l}54 \\
54 \\
50 \\
51\end{array}$ & $\begin{array}{l}54 \\
54 \\
53 \\
54 \\
55\end{array}$ & $\begin{array}{l}58 \\
69 \\
61 \\
59 \\
65\end{array}$ & $\begin{array}{l}74 \\
64 \\
64 \\
63 \\
63\end{array}$ & $\begin{array}{l}65 \\
65 \\
65 \\
70 \\
65\end{array}$ & $\begin{array}{l}73 \\
75 \\
70 \\
67 \\
--\end{array}$ \\
\hline $\begin{array}{l}11 \\
12 \\
13 \\
14 \\
15\end{array}$ & $\begin{array}{l}54 \\
56 \\
56 \\
56 \\
56\end{array}$ & $\begin{array}{l}51 \\
52 \\
51 \\
51 \\
51\end{array}$ & $\begin{array}{l}51 \\
51 \\
51 \\
51 \\
51\end{array}$ & $\begin{array}{l}46 \\
46 \\
46 \\
46 \\
46\end{array}$ & $\begin{array}{l}44 \\
44 \\
44 \\
46 \\
46\end{array}$ & $\begin{array}{l}45 \\
46 \\
45 \\
44 \\
44\end{array}$ & $\begin{array}{l}\mathbf{5 5} \\
53 \\
51 \\
54 \\
55\end{array}$ & $\begin{array}{l}53 \\
53 \\
52 \\
53 \\
55\end{array}$ & $\begin{array}{l}64 \\
61 \\
60 \\
70 \\
61\end{array}$ & $\begin{array}{l}64 \\
70 \\
64 \\
64 \\
64\end{array}$ & $\begin{array}{l}64 \\
64 \\
64 \\
64 \\
68\end{array}$ & $\begin{array}{l}66 \\
66 \\
68 \\
67 \\
72\end{array}$ \\
\hline $\begin{array}{l}16 \\
17 \\
18 \\
19 \\
20\end{array}$ & $\begin{array}{l}56 \\
56 \\
56 \\
56 \\
56\end{array}$ & $\begin{array}{l}52 \\
52 \\
54 \\
58 \\
54\end{array}$ & $\begin{array}{l}50 \\
50 \\
50 \\
50 \\
50\end{array}$ & $\begin{array}{l}46 \\
46 \\
44 \\
44 \\
44\end{array}$ & $\begin{array}{l}46 \\
46 \\
46 \\
46 \\
46\end{array}$ & $\begin{array}{l}45 \\
46 \\
46 \\
46 \\
46\end{array}$ & $\begin{array}{l}49 \\
50 \\
52 \\
55 \\
52\end{array}$ & $\begin{array}{l}54 \\
64 \\
54 \\
55 \\
54\end{array}$ & $\begin{array}{l}61 \\
62 \\
62 \\
63 \\
63\end{array}$ & $\begin{array}{l}63 \\
64 \\
65 \\
\ldots- \\
64\end{array}$ & $\begin{array}{l}73 \\
67 \\
66 \\
68 \\
66\end{array}$ & $\begin{array}{l}73 \\
74 \\
73 \\
77 \\
79\end{array}$ \\
\hline $\begin{array}{l}21 \\
22 \\
23 \\
24 \\
25\end{array}$ & $\begin{array}{l}56 \\
56 \\
58 \\
58 \\
56\end{array}$ & $\begin{array}{l}53 \\
54 \\
52 \\
52 \\
52\end{array}$ & $\begin{array}{l}50 \\
50 \\
48 \\
48 \\
48\end{array}$ & $\begin{array}{l}44 \\
44 \\
44 \\
44 \\
46\end{array}$ & $\begin{array}{l}46 \\
46 \\
48 \\
46 \\
47\end{array}$ & $\begin{array}{l}41 \\
46 \\
46 \\
46 \\
48\end{array}$ & $\begin{array}{l}53 \\
51 \\
52 \\
52 \\
53\end{array}$ & $\begin{array}{l}54 \\
54 \\
57 \\
63 \\
57\end{array}$ & $\begin{array}{l}71 \\
63 \\
63 \\
62 \\
61\end{array}$ & $\begin{array}{l}65 \\
64 \\
63 \\
66 \\
66\end{array}$ & $\begin{array}{l}65 \\
66 \\
70 \\
65 \\
66\end{array}$ & $\begin{array}{l}74 \\
68 \\
67 \\
66 \\
67\end{array}$ \\
\hline $\begin{array}{l}26 \\
27\end{array}$ & $\begin{array}{l}56 \\
56\end{array}$ & $\begin{array}{l}52 \\
53\end{array}$ & $\begin{array}{l}48 \\
48\end{array}$ & $\begin{array}{l}46 \\
46\end{array}$ & $\begin{array}{l}46 \\
46\end{array}$ & $\begin{array}{l}48 \\
48\end{array}$ & $\begin{array}{l}53 \\
54\end{array}$ & $\begin{array}{l}57 \\
56\end{array}$ & $\begin{array}{l}64 \\
65\end{array}$ & $\begin{array}{l}70 \\
63\end{array}$ & $\begin{array}{l}66 \\
67\end{array}$ & $\begin{array}{l}69 \\
69\end{array}$ \\
\hline $\begin{array}{l}28 \\
29 \\
30 \\
31\end{array}$ & $\begin{array}{l}56 \\
54 \\
54 \\
54 \\
\end{array}$ & $\begin{array}{l}51 \\
51 \\
51 \\
-- \\
\end{array}$ & $\begin{array}{l}48 \\
48 \\
48 \\
48\end{array}$ & $\begin{array}{l}46 \\
46 \\
46 \\
46\end{array}$ & $\begin{array}{l}46 \\
-- \\
-- \\
--\end{array}$ & $\begin{array}{l}48 \\
50 \\
48 \\
48\end{array}$ & $\begin{array}{l}55 \\
53 \\
54 \\
--\end{array}$ & $\begin{array}{l}56 \\
58 \\
57 \\
65 \\
\end{array}$ & $\begin{array}{l}72 \\
63 \\
62 \\
-- \\
\end{array}$ & $\begin{array}{l}64 \\
64 \\
-65 \\
\end{array}$ & $\begin{array}{l}69 \\
70 \\
77 \\
68 \\
\end{array}$ & $\begin{array}{l}72 \\
70 \\
72 \\
-- \\
\end{array}$ \\
\hline $\begin{array}{c}\text { Aver- } \\
\text { age }\end{array}$ & 56 & 53 & 50 & 46 & 46 & 46 & 52 & 55 & 62 & 65 & 67 & 70 \\
\hline
\end{tabular}


WHITE RIVER BASIN

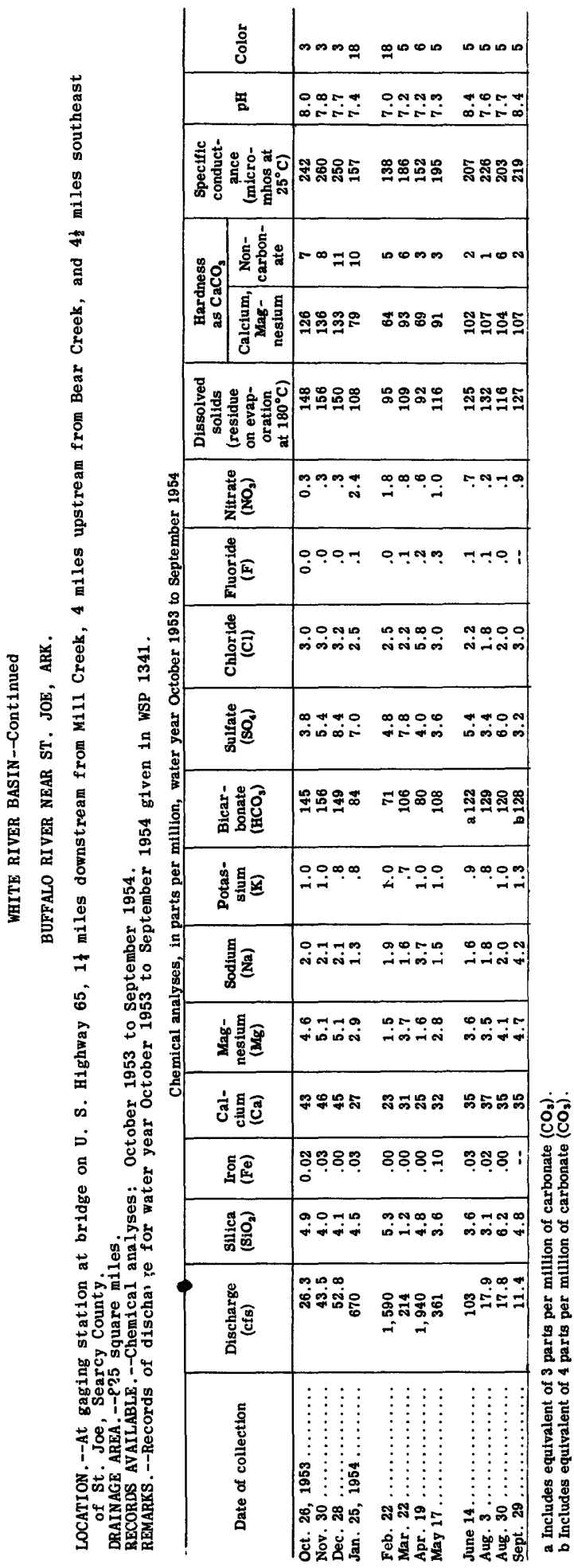




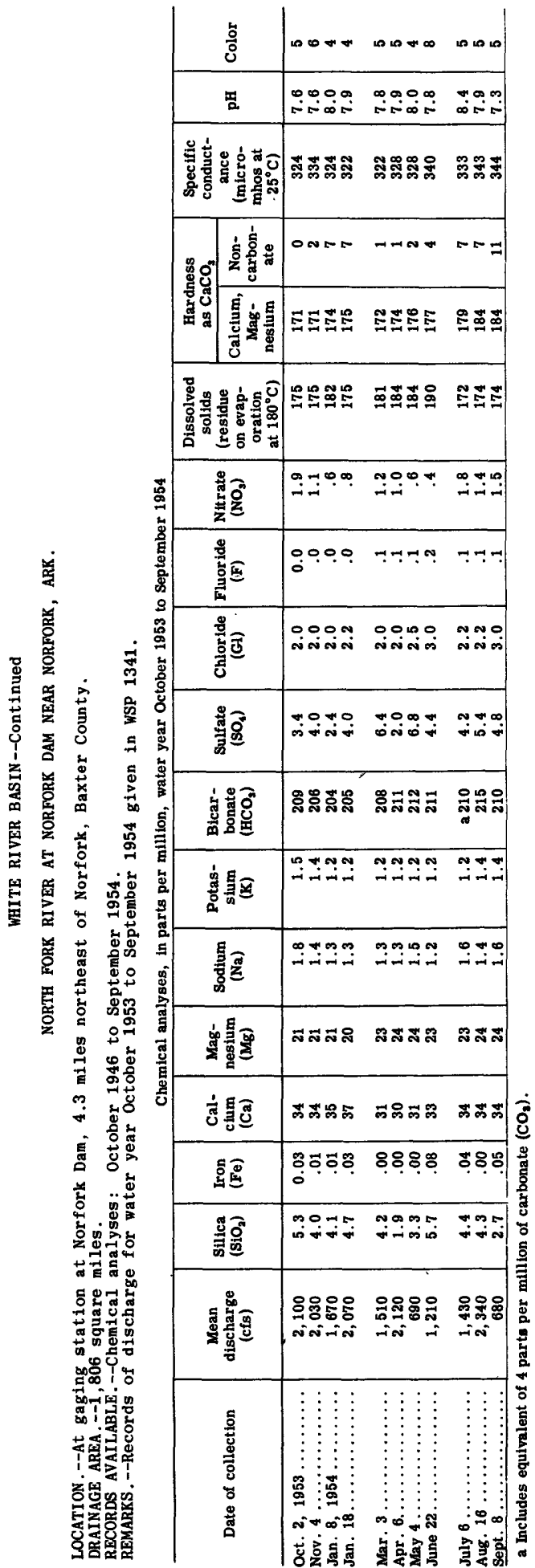




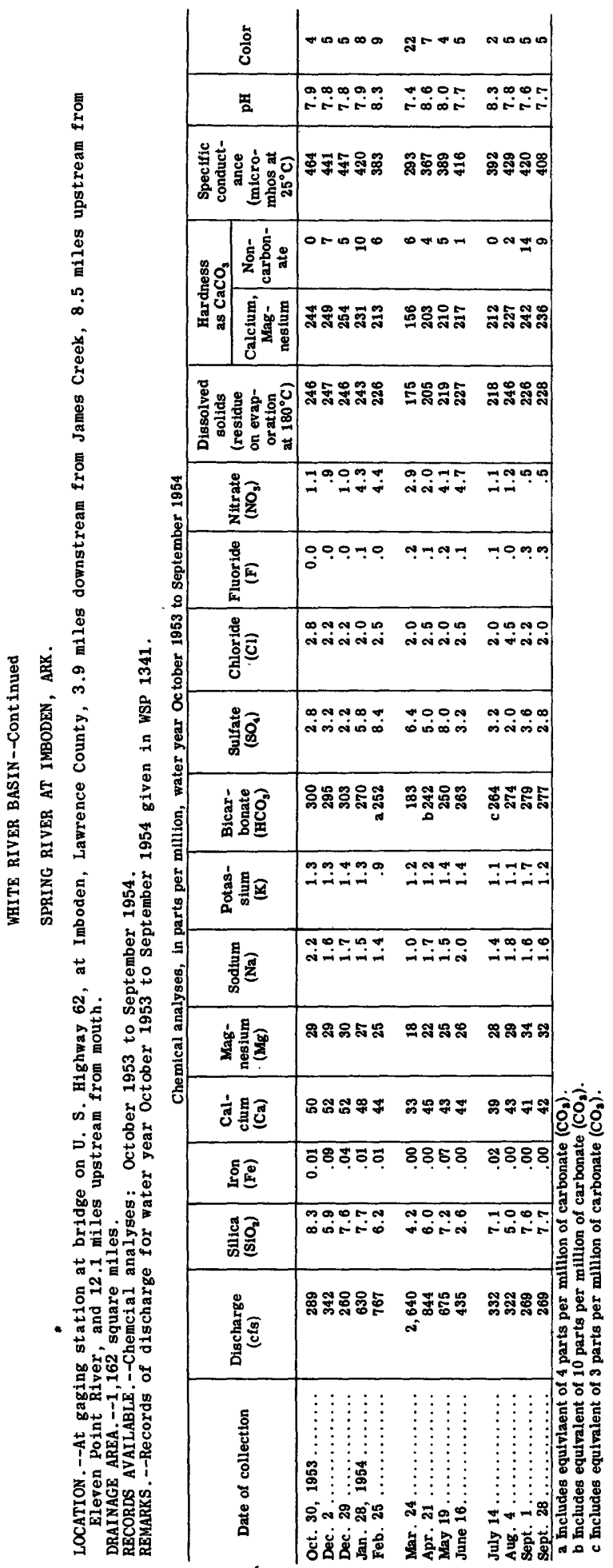




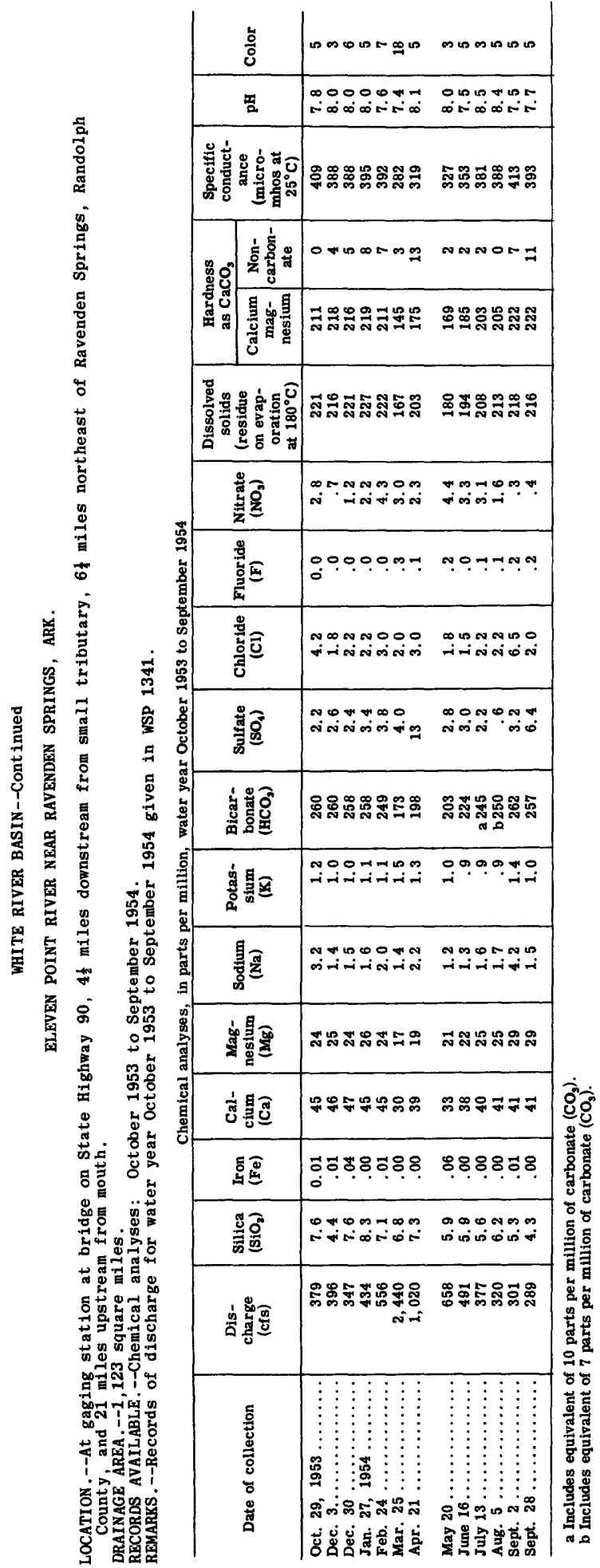




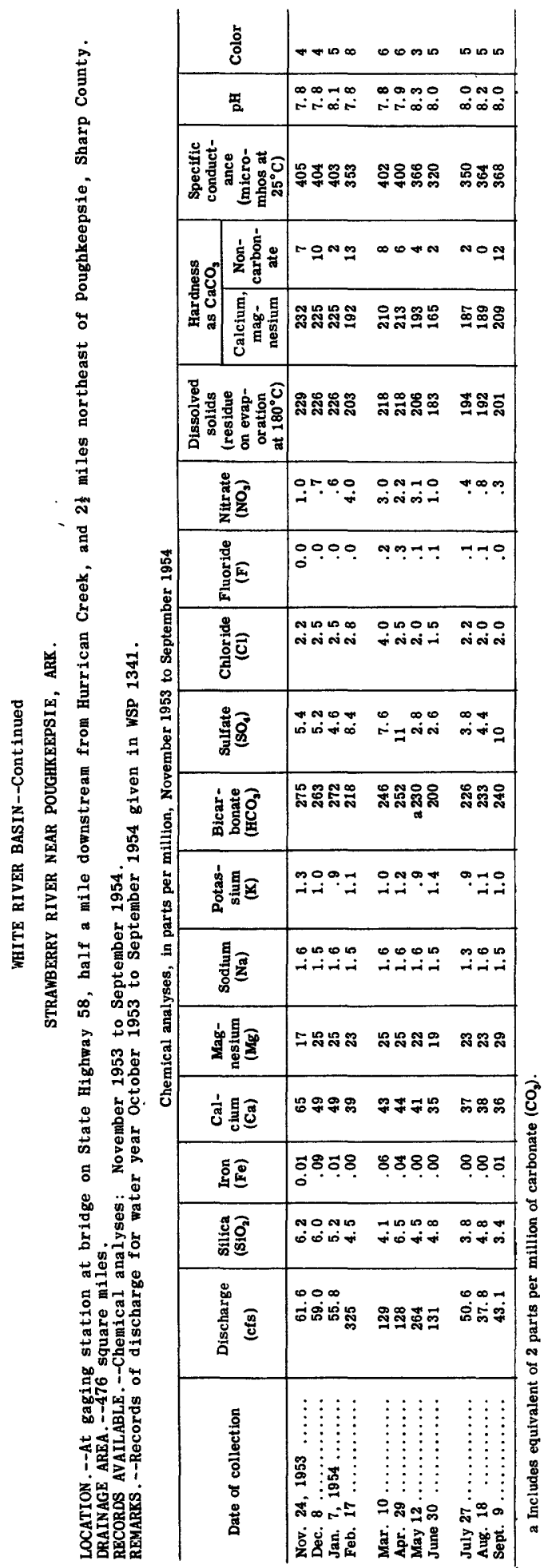




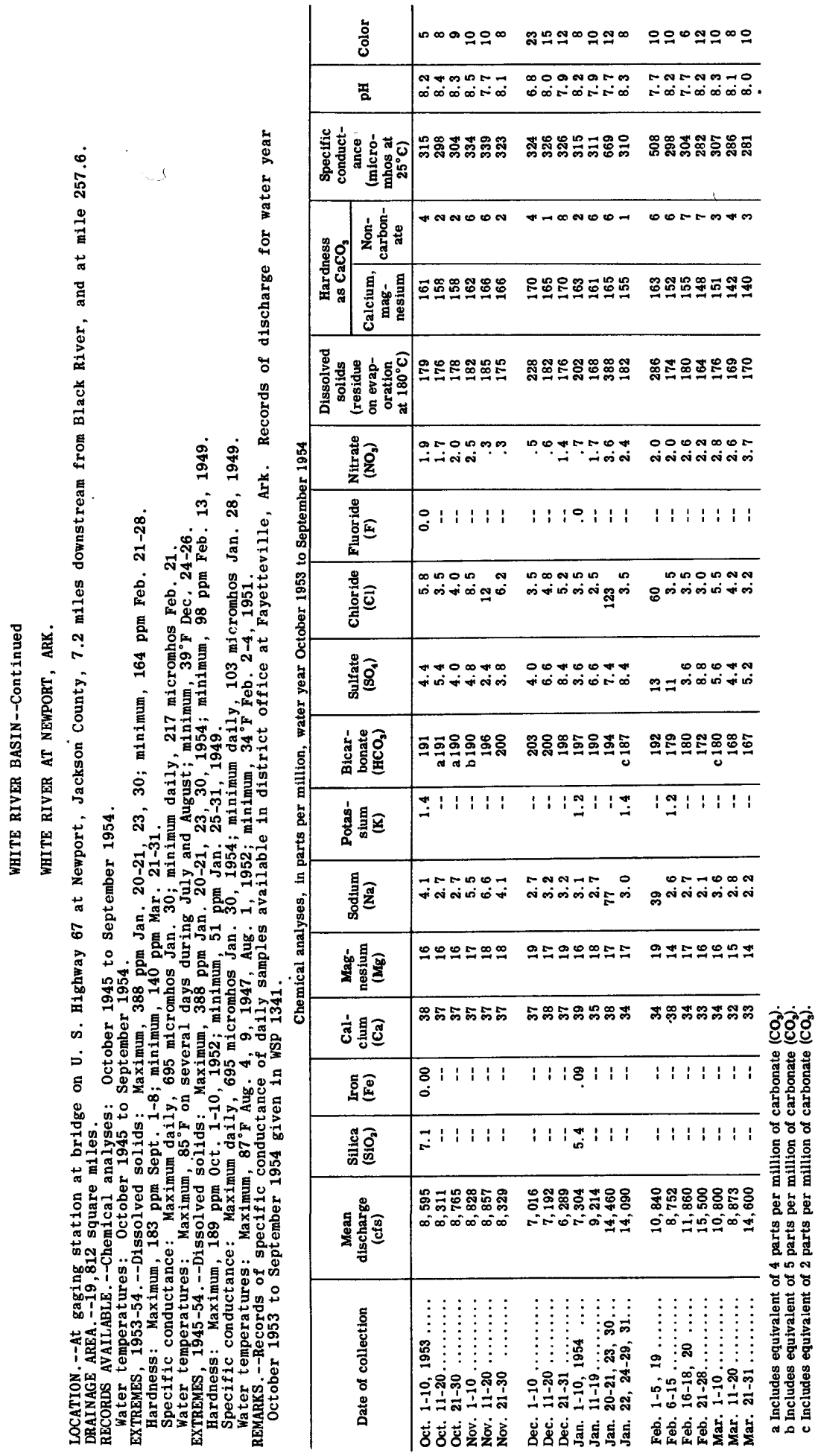




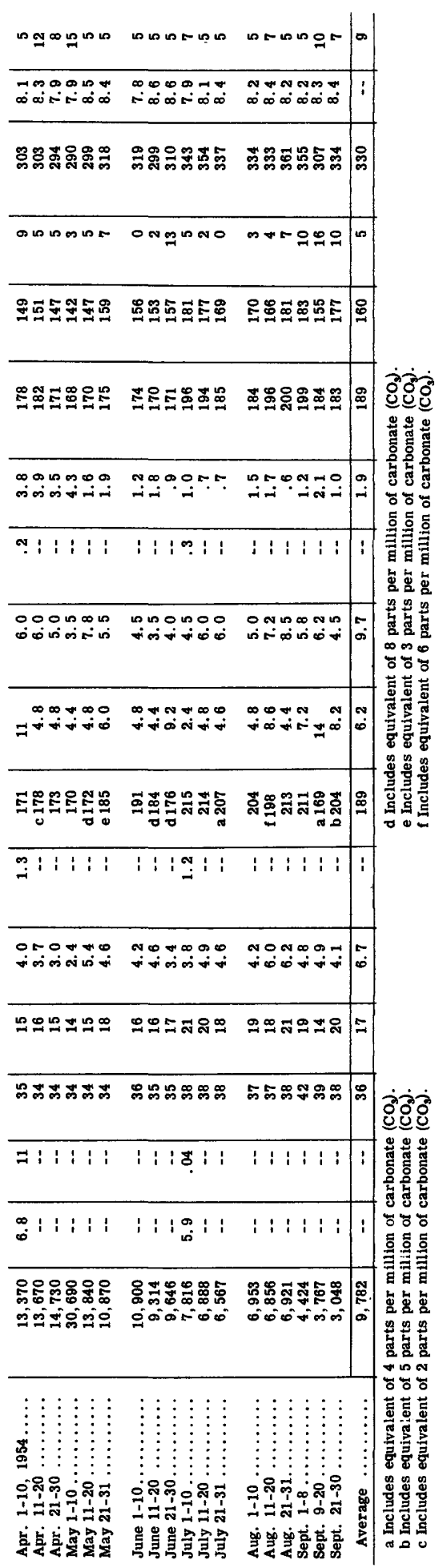


WHITE RIVER BASIN--Continued

WHITE RIVER AT NEWPORT, ARK.--Continued

Temperature $\left({ }^{\circ} \mathrm{F}\right)$ of water, water year October 1953 to September 1954

\begin{tabular}{|c|c|c|c|c|c|c|c|c|c|c|c|c|}
\hline Day & Oct. & Nov. & Dec. & Jan. & Feb. & Mar. & Apr. & May & June & July & Aug. & Sept. \\
\hline $\begin{array}{l}1 \\
2 \\
3 \\
4 \\
5\end{array}$ & $\begin{array}{l}71 \\
72 \\
72 \\
72 \\
72\end{array}$ & $\begin{array}{l}55 \\
56 \\
56 \\
56 \\
53\end{array}$ & $\begin{array}{l}48 \\
48 \\
48 \\
48 \\
48\end{array}$ & $\begin{array}{l}45 \\
45 \\
45 \\
45 \\
45\end{array}$ & $\begin{array}{l}46 \\
45 \\
45 \\
46 \\
44\end{array}$ & $\begin{array}{l}51 \\
51 \\
51 \\
57 \\
52\end{array}$ & $\begin{array}{l}57 \\
57 \\
57 \\
57 \\
57\end{array}$ & $\begin{array}{l}63 \\
64 \\
63 \\
63 \\
63\end{array}$ & $\begin{array}{l}72 \\
73 \\
73 \\
73 \\
74\end{array}$ & $\begin{array}{l}80 \\
80 \\
82 \\
82 \\
82\end{array}$ & $\begin{array}{l}83 \\
83 \\
83 \\
82 \\
82\end{array}$ & $\begin{array}{l}84 \\
84 \\
84 \\
84 \\
84\end{array}$ \\
\hline $\begin{array}{r}6 \\
7 \\
8 \\
9 \\
10\end{array}$ & $\begin{array}{l}72 \\
72 \\
69 \\
68 \\
67\end{array}$ & $\begin{array}{l}53 \\
53 \\
53 \\
53 \\
54\end{array}$ & $\begin{array}{l}47 \\
47 \\
46 \\
46 \\
46\end{array}$ & $\begin{array}{l}45 \\
45 \\
45 \\
45 \\
45\end{array}$ & $\begin{array}{l}44 \\
45 \\
45 \\
45 \\
45\end{array}$ & $\begin{array}{l}59 \\
54 \\
54 \\
55 \\
55\end{array}$ & $\begin{array}{l}\mathbf{5 9} \\
\mathbf{5 9} \\
\mathbf{5 8} \\
\mathbf{5 9} \\
\mathbf{5 8}\end{array}$ & $\begin{array}{l}64 \\
65 \\
64 \\
65 \\
65\end{array}$ & $\begin{array}{l}74 \\
74 \\
75 \\
75 \\
75\end{array}$ & $\begin{array}{l}82 \\
82 \\
82 \\
82 \\
82\end{array}$ & $\begin{array}{l}83 \\
83 \\
82 \\
82 \\
83\end{array}$ & $\begin{array}{l}84 \\
84 \\
83 \\
83 \\
80\end{array}$ \\
\hline $\begin{array}{l}11 \\
12 \\
13 \\
14 \\
15\end{array}$ & $\begin{array}{l}67 \\
67 \\
67 \\
67 \\
69\end{array}$ & $\begin{array}{l}52 \\
52 \\
52 \\
51 \\
50\end{array}$ & $\begin{array}{l}46 \\
45 \\
44 \\
44 \\
43\end{array}$ & $\begin{array}{l}44 \\
44 \\
44 \\
-- \\
44\end{array}$ & $\begin{array}{l}45 \\
46 \\
48 \\
50 \\
50\end{array}$ & $\begin{array}{l}64 \\
58 \\
55 \\
53 \\
52\end{array}$ & $\begin{array}{l}61 \\
61 \\
61 \\
61 \\
60\end{array}$ & $\begin{array}{l}62 \\
65 \\
65 \\
69 \\
69\end{array}$ & $\begin{array}{l}75 \\
75 \\
76 \\
77 \\
77\end{array}$ & $\begin{array}{l}82 \\
83 \\
83 \\
85 \\
85\end{array}$ & $\begin{array}{l}83 \\
82 \\
82 \\
82 \\
84\end{array}$ & $\begin{array}{l}79 \\
79 \\
79 \\
78 \\
76\end{array}$ \\
\hline $\begin{array}{l}16 \\
17 \\
18 \\
19 \\
20\end{array}$ & $\begin{array}{l}66 \\
65 \\
65 \\
65 \\
64\end{array}$ & $\begin{array}{l}\mathbf{5 1} \\
\mathbf{5 1} \\
\mathbf{5 1} \\
\mathbf{5 2} \\
\mathbf{5 2}\end{array}$ & $\begin{array}{l}42 \\
45 \\
44 \\
44 \\
44\end{array}$ & $\begin{array}{l}44 \\
44 \\
41 \\
42 \\
42\end{array}$ & $\begin{array}{l}50 \\
50 \\
50 \\
51 \\
51\end{array}$ & $\begin{array}{l}53 \\
53 \\
63 \\
54 \\
54\end{array}$ & $\begin{array}{l}61 \\
60 \\
59 \\
60 \\
60\end{array}$ & $\begin{array}{l}69 \\
70 \\
70 \\
70 \\
70\end{array}$ & $\begin{array}{l}77 \\
77 \\
77 \\
78 \\
78\end{array}$ & $\begin{array}{l}85 \\
85 \\
85 \\
85 \\
85\end{array}$ & $\begin{array}{l}83 \\
84 \\
83 \\
84 \\
84\end{array}$ & $\begin{array}{l}76 \\
76 \\
75 \\
76 \\
76\end{array}$ \\
\hline $\begin{array}{l}21 \\
22 \\
23 \\
24 \\
25\end{array}$ & $\begin{array}{l}64 \\
63 \\
62 \\
61 \\
60\end{array}$ & $\begin{array}{l}\mathbf{5 4} \\
\mathbf{5 5} \\
\mathbf{5 2} \\
\mathbf{5 1} \\
\mathbf{5 0}\end{array}$ & $\begin{array}{l}43 \\
43 \\
40 \\
39 \\
39\end{array}$ & $\begin{array}{l}42 \\
40 \\
41 \\
41 \\
41\end{array}$ & $\begin{array}{l}\mathbf{5 0} \\
\mathbf{5 1} \\
\mathbf{5 1} \\
\mathbf{5 1} \\
\mathbf{5 1}\end{array}$ & $\begin{array}{l}\mathbf{5 4} \\
\mathbf{5 4} \\
\mathbf{5 2} \\
\mathbf{5 4} \\
\mathbf{5 4}\end{array}$ & $\begin{array}{l}61 \\
61 \\
61 \\
62 \\
62\end{array}$ & $\begin{array}{l}70 \\
70 \\
70 \\
70 \\
71\end{array}$ & $\begin{array}{l}75 \\
79 \\
79 \\
79 \\
80\end{array}$ & $\begin{array}{l}85 \\
85 \\
85 \\
85 \\
85\end{array}$ & $\begin{array}{l}84 \\
84 \\
84 \\
84 \\
84\end{array}$ & $\begin{array}{l}75 \\
70 \\
69 \\
74 \\
72\end{array}$ \\
\hline $\begin{array}{l}26 \\
27 \\
28 \\
29 \\
30 \\
31\end{array}$ & $\begin{array}{l}60 \\
60 \\
60 \\
59 \\
59 \\
57\end{array}$ & $\begin{array}{l}56 \\
50 \\
49 \\
49 \\
47 \\
-- \\
\end{array}$ & $\begin{array}{l}39 \\
40 \\
40 \\
40 \\
42 \\
42 \\
\end{array}$ & $\begin{array}{l}41 \\
42 \\
42 \\
41 \\
41 \\
47 \\
\end{array}$ & $\begin{array}{l}51 \\
51 \\
51 \\
-- \\
-- \\
-- \\
\end{array}$ & $\begin{array}{l}\mathbf{5 3} \\
\mathbf{5 3} \\
\mathbf{5 8} \\
\mathbf{5 8} \\
\mathbf{5 7} \\
\mathbf{5 7}\end{array}$ & $\begin{array}{l}63 \\
63 \\
63 \\
63 \\
63 \\
-- \\
\end{array}$ & $\begin{array}{l}\mathbf{7 1} \\
\mathbf{7 1} \\
\mathbf{7 2} \\
\mathbf{7 1} \\
\mathbf{7 2} \\
\mathbf{7 2} \\
\end{array}$ & $\begin{array}{l}80 \\
80 \\
-- \\
80 \\
80 \\
-- \\
\end{array}$ & $\begin{array}{l}84 \\
84 \\
84 \\
84 \\
84 \\
83 \\
\end{array}$ & $\begin{array}{l}85 \\
85 \\
85 \\
85 \\
85 \\
84 \\
\end{array}$ & $\begin{array}{l}74 \\
74 \\
74 \\
74 \\
72 \\
-- \\
\end{array}$ \\
\hline $\begin{array}{c}\text { Aver- } \\
\text { age }\end{array}$ & 66 & 52 & 44 & 43 & 48 & 55 & 60 & 68 & 76 & 83 & 83 & 78 \\
\hline
\end{tabular}




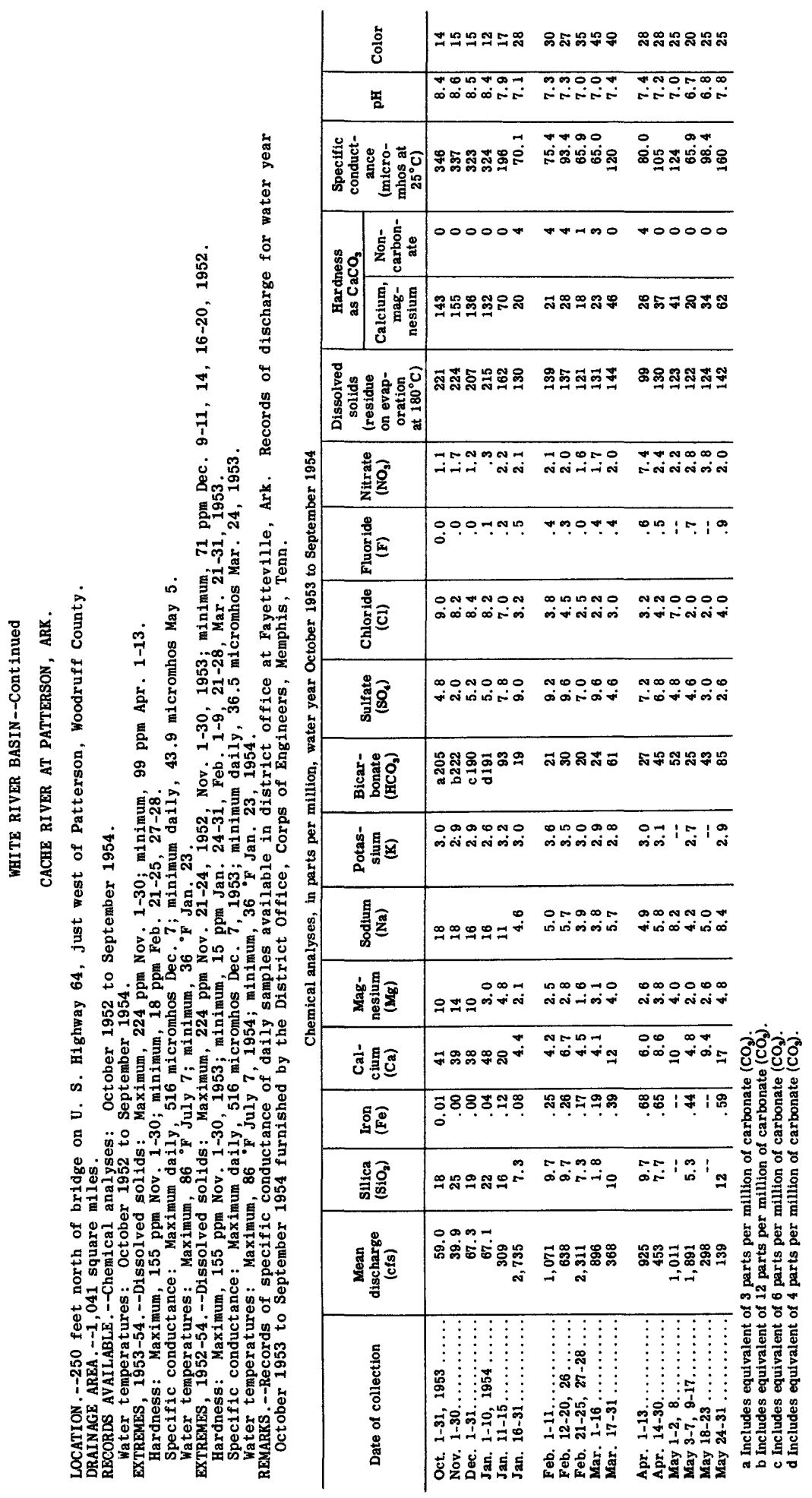




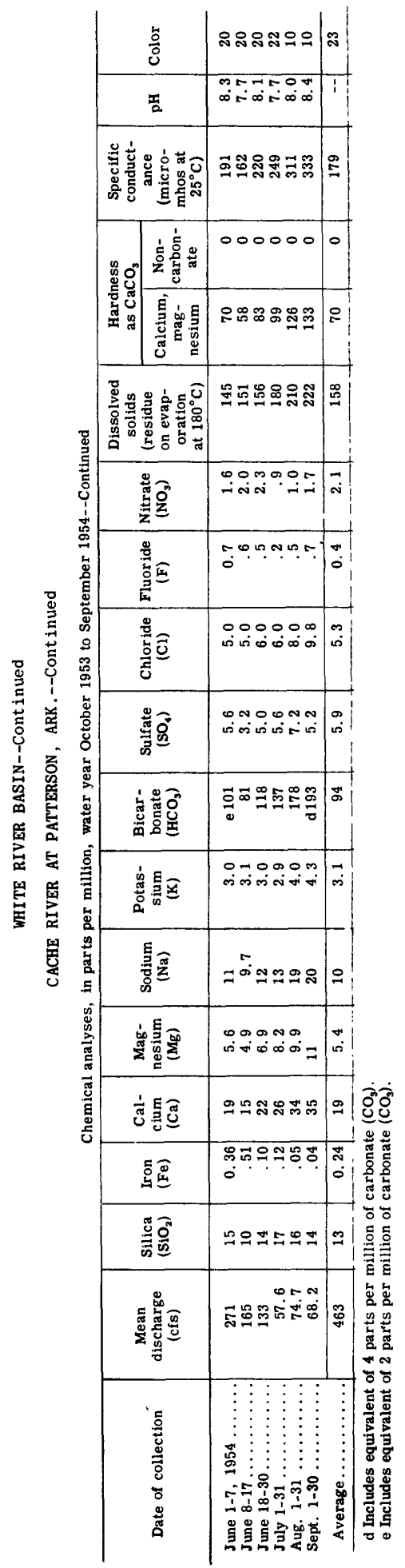


WHITE RIVER BASIN--Continued

CACHE RIVER AT PATTERSON, ARK.--Continued

Temperature $\left({ }^{\circ} \mathrm{F}\right)$ of water, water year October 1953 to September 1954

\begin{tabular}{|c|c|c|c|c|c|c|c|c|c|c|c|c|}
\hline Day & Oct. & Nov. & Dec. & Jan. & Feb. & Mar. & Apr. & May & June & July & Aug. & Sept. \\
\hline $\begin{array}{l}1 \\
2 \\
3 \\
4 \\
5\end{array}$ & $\begin{array}{l}72 \\
73 \\
74 \\
74 \\
74\end{array}$ & $\begin{array}{l}56 \\
55 \\
56 \\
57 \\
56\end{array}$ & $\begin{array}{l}48 \\
50 \\
50 \\
51 \\
52\end{array}$ & $\begin{array}{l}44 \\
45 \\
44 \\
44 \\
45\end{array}$ & $\begin{array}{l}44 \\
46 \\
48 \\
46 \\
47\end{array}$ & $\begin{array}{l}50 \\
50 \\
47 \\
45 \\
46\end{array}$ & $\begin{array}{l}54 \\
53 \\
55 \\
58 \\
61\end{array}$ & $\begin{array}{l}70 \\
69 \\
65 \\
61 \\
59\end{array}$ & $\begin{array}{c}76 \\
76 \\
75 \\
-\therefore \\
72\end{array}$ & $\begin{array}{l}84 \\
83 \\
84 \\
84 \\
85\end{array}$ & $\begin{array}{l}82 \\
81 \\
80 \\
81 \\
82\end{array}$ & $\begin{array}{l}78 \\
77 \\
77 \\
76 \\
77\end{array}$ \\
\hline $\begin{array}{r}6 \\
7 \\
8 \\
9 \\
10\end{array}$ & $\begin{array}{l}70 \\
66 \\
65 \\
64 \\
64\end{array}$ & $\begin{array}{l}52 \\
52 \\
52 \\
50 \\
48\end{array}$ & $\begin{array}{l}53 \\
52 \\
51 \\
53 \\
50\end{array}$ & $\begin{array}{l}45 \\
44 \\
45 \\
48 \\
47\end{array}$ & $\begin{array}{l}48 \\
46 \\
43 \\
45 \\
45\end{array}$ & $\begin{array}{l}46 \\
47 \\
48 \\
50 \\
52\end{array}$ & $\begin{array}{l}65 \\
66 \\
67 \\
65 \\
65\end{array}$ & $\begin{array}{l}60 \\
63 \\
63 \\
62 \\
63\end{array}$ & $\begin{array}{l}72 \\
74 \\
75 \\
76 \\
77\end{array}$ & $\begin{array}{l}85 \\
86 \\
85 \\
84 \\
83\end{array}$ & $\begin{array}{l}82 \\
83 \\
84 \\
83 \\
82\end{array}$ & $\begin{array}{l}77 \\
75 \\
78 \\
78 \\
79\end{array}$ \\
\hline $\begin{array}{l}11 \\
12 \\
13 \\
14 \\
15\end{array}$ & $\begin{array}{l}66 \\
65 \\
65 \\
64 \\
63\end{array}$ & $\begin{array}{l}48 \\
49 \\
50 \\
51 \\
51\end{array}$ & $\begin{array}{l}50 \\
49 \\
48 \\
47 \\
45\end{array}$ & $\begin{array}{l}42 \\
38 \\
37 \\
40 \\
40\end{array}$ & $\begin{array}{l}47 \\
47 \\
46 \\
48 \\
51\end{array}$ & $\begin{array}{l}55 \\
57 \\
59 \\
56 \\
53\end{array}$ & $\begin{array}{l}65 \\
64 \\
64 \\
64 \\
66\end{array}$ & $\begin{array}{l}63 \\
64 \\
62 \\
62 \\
64\end{array}$ & $\begin{array}{l}77 \\
78 \\
78 \\
79 \\
80\end{array}$ & $\begin{array}{l}81 \\
81 \\
82 \\
84 \\
84\end{array}$ & $\begin{array}{l}82 \\
82 \\
82 \\
82 \\
--\end{array}$ & $\begin{array}{l}72 \\
75 \\
74 \\
75 \\
74\end{array}$ \\
\hline $\begin{array}{l}16 \\
17 \\
18 \\
19 \\
20\end{array}$ & $\begin{array}{l}64 \\
63 \\
64 \\
64 \\
64\end{array}$ & $\begin{array}{l}52 \\
51 \\
54 \\
56 \\
56\end{array}$ & $\begin{array}{l}46 \\
44 \\
42 \\
41 \\
42\end{array}$ & $\begin{array}{l}40 \\
41 \\
39 \\
41 \\
45\end{array}$ & $\begin{array}{l}54 \\
54 \\
52 \\
52 \\
53\end{array}$ & $\begin{array}{l}54 \\
52 \\
52 \\
55 \\
56\end{array}$ & $\begin{array}{l}67 \\
65 \\
65 \\
65 \\
66\end{array}$ & $\begin{array}{l}65 \\
67 \\
67 \\
68 \\
68\end{array}$ & $\begin{array}{l}80 \\
80 \\
80 \\
82 \\
81\end{array}$ & $\begin{array}{l}84 \\
83 \\
82 \\
82 \\
81\end{array}$ & $\begin{array}{l}82 \\
83 \\
84 \\
84 \\
83\end{array}$ & $\begin{array}{l}74 \\
75 \\
76 \\
77 \\
78\end{array}$ \\
\hline $\begin{array}{l}21 \\
22 \\
23 \\
24 \\
25\end{array}$ & $\begin{array}{l}64 \\
64 \\
65 \\
65 \\
63\end{array}$ & $\begin{array}{l}\mathbf{5 5} \\
\mathbf{5 5} \\
\mathbf{5 4} \\
54 \\
\mathbf{5 1}\end{array}$ & $\begin{array}{l}45 \\
45 \\
40 \\
38 \\
38\end{array}$ & $\begin{array}{l}44 \\
38 \\
36 \\
39 \\
40\end{array}$ & $\begin{array}{l}52 \\
51 \\
53 \\
53 \\
53\end{array}$ & $\begin{array}{l}55 \\
54 \\
55 \\
55 \\
58\end{array}$ & $\begin{array}{l}68 \\
69 \\
69 \\
70 \\
69\end{array}$ & $\begin{array}{l}66 \\
-- \\
67 \\
68 \\
70\end{array}$ & $\begin{array}{l}81 \\
81 \\
82 \\
81 \\
81\end{array}$ & $\begin{array}{l}82 \\
82 \\
83 \\
83 \\
81\end{array}$ & $\begin{array}{l}83 \\
82 \\
81 \\
81 \\
82\end{array}$ & $\begin{array}{l}77 \\
75 \\
72 \\
71 \\
69\end{array}$ \\
\hline $\begin{array}{l}26 \\
27 \\
28 \\
29 \\
30 \\
31\end{array}$ & $\begin{array}{l}63 \\
62 \\
59 \\
57 \\
55 \\
56\end{array}$ & $\begin{array}{l}50 \\
50 \\
48 \\
49 \\
49 \\
--\end{array}$ & $\begin{array}{l}40 \\
41 \\
45 \\
45 \\
44 \\
43\end{array}$ & $\begin{array}{l}44 \\
43 \\
44 \\
45 \\
46 \\
45\end{array}$ & $\begin{array}{l}53 \\
54 \\
53 \\
-- \\
-- \\
--\end{array}$ & $\begin{array}{l}58 \\
59 \\
-- \\
62 \\
62 \\
59\end{array}$ & $\begin{array}{r}70 \\
72 \\
71 \\
+70 \\
70 \\
--\end{array}$ & $\begin{array}{l}71 \\
70 \\
70 \\
72 \\
73 \\
75\end{array}$ & $\begin{array}{l}82 \\
82 \\
83 \\
84 \\
83 \\
--\end{array}$ & $\begin{array}{l}80 \\
80 \\
82 \\
81 \\
82 \\
81\end{array}$ & $\begin{array}{l}81 \\
82 \\
82 \\
82 \\
83 \\
80\end{array}$ & $\begin{array}{l}70 \\
71 \\
72 \\
73 \\
74 \\
--\end{array}$ \\
\hline $\begin{array}{c}\text { Aver - } \\
\text { age }\end{array}$ & 65 & 52 & 46 & 43 & 49 & 54 & 65 & 66 & 79 & 83 & 82 & 75 \\
\hline
\end{tabular}




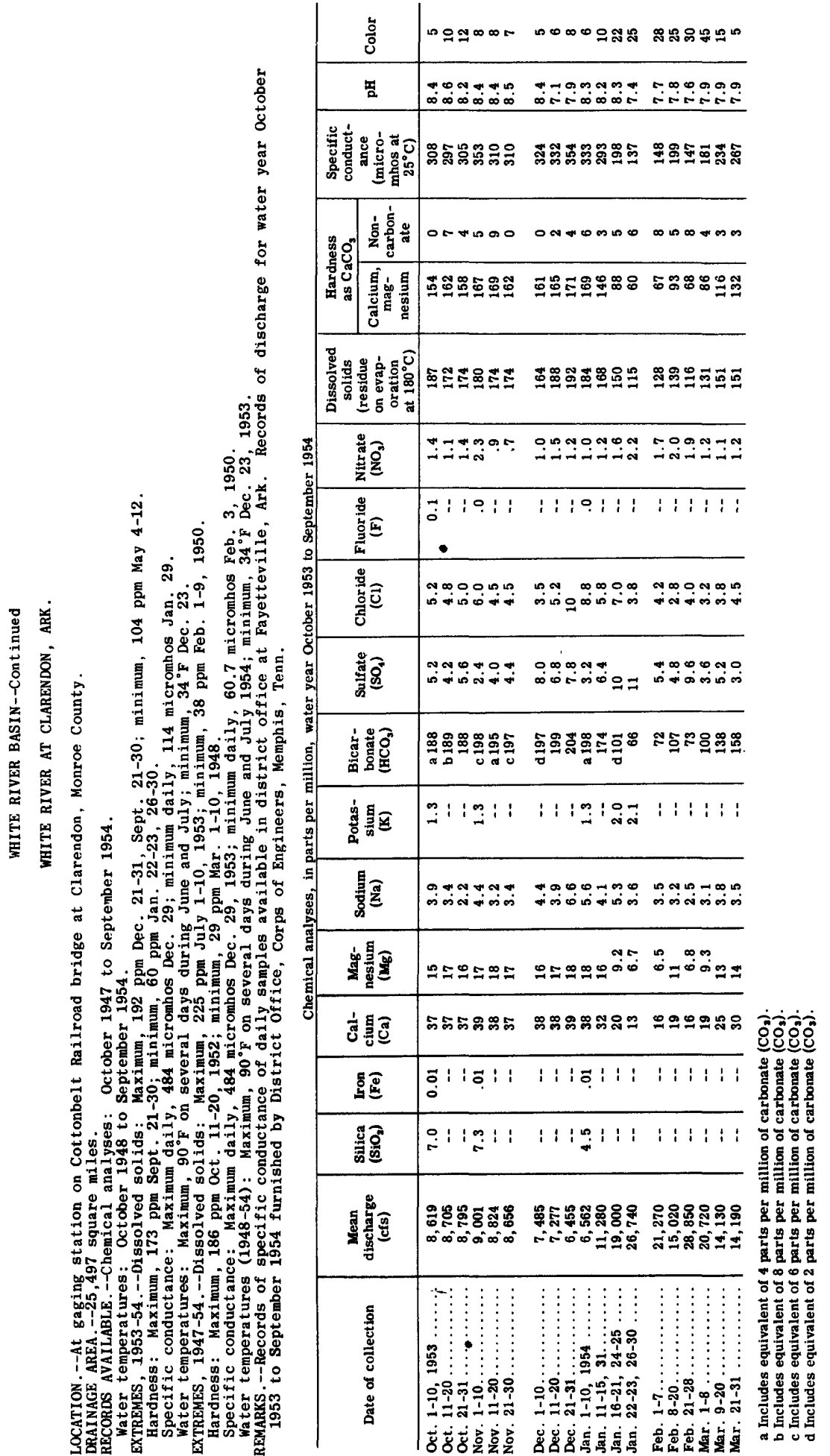




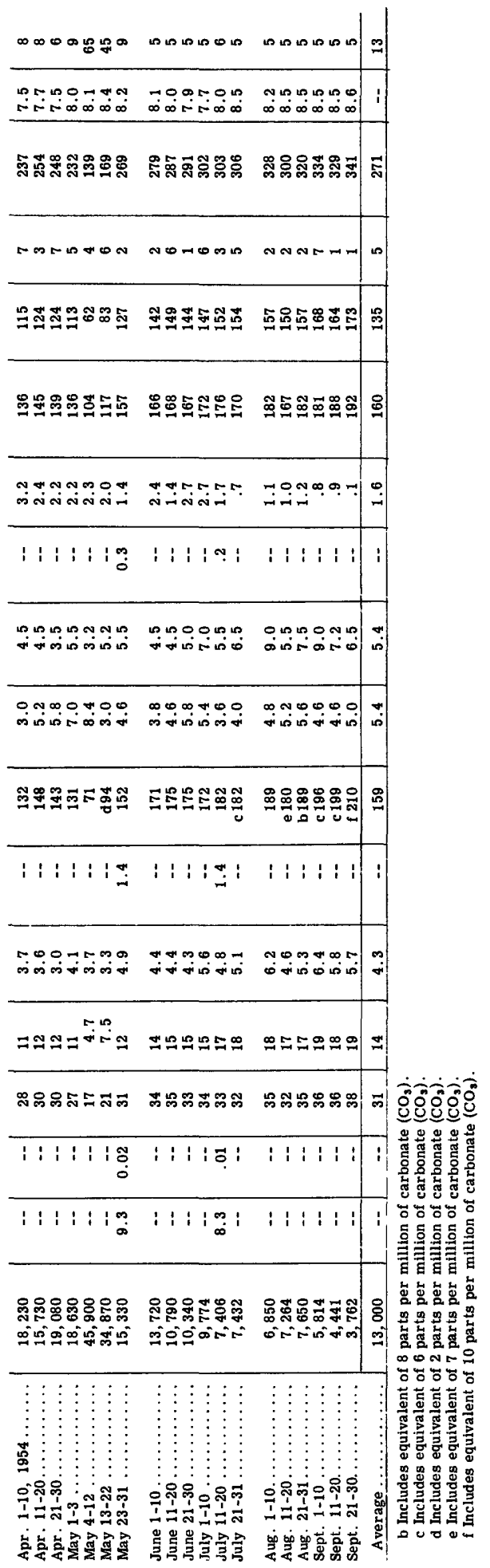


WHITE RIVER BASIN--Continued

WHITE RIVER AT CLARENDON, ARK.--Continued

Temperature $\left({ }^{\circ} \mathrm{F}\right)$ of water, water year October 1953 to September 1954

\begin{tabular}{|c|c|c|c|c|c|c|c|c|c|c|c|c|}
\hline Day & Oct. & Nov. & Dec. & Jan. & Feb. & Mar. & Apr. & May & June & July & Aug. & Sept. \\
\hline $\begin{array}{l}1 \\
2 \\
3 \\
4 \\
5\end{array}$ & $\begin{array}{l}76 \\
76 \\
75 \\
73 \\
71\end{array}$ & $\begin{array}{l}61 \\
61 \\
61 \\
58 \\
56\end{array}$ & $\begin{array}{l}51 \\
51 \\
51 \\
53 \\
55\end{array}$ & $\begin{array}{l}43 \\
44 \\
44 \\
49 \\
44\end{array}$ & $\begin{array}{l}46 \\
49 \\
47 \\
50 \\
49\end{array}$ & $\begin{array}{l}-- \\
-- \\
48 \\
49 \\
--\end{array}$ & $\begin{array}{l}56 \\
60 \\
66 \\
65 \\
65\end{array}$ & $\begin{array}{l}70 \\
68 \\
66 \\
66 \\
64\end{array}$ & $\begin{array}{l}-- \\
-- \\
-- \\
-- \\
--\end{array}$ & $\begin{array}{l}89 \\
88 \\
88 \\
89 \\
90\end{array}$ & $\begin{array}{l}84 \\
85 \\
86 \\
87 \\
87\end{array}$ & $\begin{array}{l}82 \\
84 \\
84 \\
85 \\
85\end{array}$ \\
\hline $\begin{array}{r}6 \\
7 \\
8 \\
9 \\
10\end{array}$ & $\begin{array}{l}71 \\
64 \\
69 \\
70 \\
71\end{array}$ & $\begin{array}{l}53 \\
54 \\
53 \\
52 \\
52\end{array}$ & $\begin{array}{l}51 \\
51 \\
52 \\
49 \\
50\end{array}$ & $\begin{array}{l}44 \\
50 \\
49 \\
49 \\
45\end{array}$ & $\begin{array}{l}49 \\
45 \\
46 \\
50 \\
54\end{array}$ & $\begin{array}{l}50 \\
53 \\
55 \\
54 \\
46\end{array}$ & $\begin{array}{l}65 \\
67 \\
64 \\
65 \\
65\end{array}$ & $\begin{array}{l}64 \\
63 \\
65 \\
63 \\
63\end{array}$ & $\begin{array}{l}-- \\
-- \\
--\end{array}$ & $\begin{array}{l}90 \\
-- \\
89 \\
87 \\
87\end{array}$ & $\begin{array}{l}88 \\
87 \\
89 \\
86 \\
87\end{array}$ & $\begin{array}{l}85 \\
82 \\
83 \\
86 \\
82\end{array}$ \\
\hline $\begin{array}{l}11 \\
12 \\
13 \\
14 \\
15\end{array}$ & $\begin{array}{l}72 \\
71 \\
68 \\
70 \\
70\end{array}$ & $\begin{array}{l}54 \\
53 \\
55 \\
53 \\
54\end{array}$ & $\begin{array}{l}49 \\
50 \\
49 \\
47 \\
50\end{array}$ & $\begin{array}{l}42 \\
38 \\
39 \\
42 \\
44\end{array}$ & $\begin{array}{l}50 \\
46 \\
47 \\
-- \\
--\end{array}$ & $\begin{array}{l}60 \\
62 \\
58 \\
52 \\
52\end{array}$ & $\begin{array}{l}64 \\
63 \\
66 \\
69 \\
--\end{array}$ & $\begin{array}{l}64 \\
63 \\
64 \\
65 \\
67\end{array}$ & $\begin{array}{l}-- \\
-- \\
-- \\
-- \\
--\end{array}$ & $\begin{array}{l}87 \\
90 \\
90 \\
89 \\
88\end{array}$ & $\begin{array}{l}88 \\
88 \\
87 \\
88 \\
88\end{array}$ & $\begin{array}{r}80 \\
80 \\
81 \\
.81 \\
81\end{array}$ \\
\hline $\begin{array}{l}16 \\
17 \\
18 \\
19 \\
20\end{array}$ & $\begin{array}{l}70 \\
70 \\
69 \\
69 \\
69\end{array}$ & $\begin{array}{l}54 \\
56 \\
56 \\
60 \\
56\end{array}$ & $\begin{array}{l}46 \\
44 \\
43 \\
41 \\
45\end{array}$ & $\begin{array}{l}43 \\
45 \\
42 \\
44 \\
47\end{array}$ & $\begin{array}{l}54 \\
-- \\
-- \\
55 \\
55\end{array}$ & $\begin{array}{l}53 \\
54 \\
55 \\
57 \\
--\end{array}$ & $\begin{array}{l}64 \\
67 \\
68 \\
68 \\
70\end{array}$ & $\begin{array}{l}69 \\
69 \\
68 \\
69 \\
67\end{array}$ & $\begin{array}{l}-- \\
-- \\
-- \\
-- \\
--\end{array}$ & $\begin{array}{l}90 \\
89 \\
88 \\
85 \\
85\end{array}$ & $\begin{array}{l}88 \\
88 \\
80 \\
87 \\
84\end{array}$ & $\begin{array}{l}83 \\
80 \\
81 \\
88 \\
83\end{array}$ \\
\hline $\begin{array}{l}21 \\
22 \\
23 \\
24 \\
25\end{array}$ & $\begin{array}{l}69 \\
69 \\
68 \\
65 \\
65\end{array}$ & $\begin{array}{l}57 \\
55 \\
54 \\
54 \\
52\end{array}$ & $\begin{array}{l}41 \\
41 \\
34 \\
39 \\
43\end{array}$ & $\begin{array}{l}40 \\
49 \\
48 \\
44 \\
47\end{array}$ & $\begin{array}{l}56 \\
-- \\
55 \\
54 \\
58\end{array}$ & $\begin{array}{l}55 \\
57 \\
57 \\
57 \\
59\end{array}$ & $\begin{array}{l}70 \\
70 \\
70 \\
72 \\
75\end{array}$ & $\begin{array}{l}68 \\
71 \\
72 \\
75 \\
74\end{array}$ & $\begin{array}{l}-- \\
-- \\
-- \\
89\end{array}$ & $\begin{array}{l}86 \\
87 \\
87 \\
87 \\
86\end{array}$ & $\begin{array}{l}86 \\
86 \\
87 \\
86 \\
87\end{array}$ & $\begin{array}{l}79 \\
75 \\
76 \\
78 \\
79\end{array}$ \\
\hline $\begin{array}{l}26 \\
27 \\
28 \\
29 \\
30 \\
31\end{array}$ & $\begin{array}{l}63 \\
62 \\
61 \\
60 \\
62 \\
62 \\
\end{array}$ & $\begin{array}{l}51 \\
52 \\
57 \\
53 \\
53 \\
-- \\
\end{array}$ & $\begin{array}{l}41 \\
42 \\
43 \\
45 \\
42 \\
42\end{array}$ & $\begin{array}{l}46 \\
44 \\
45 \\
45 \\
45 \\
46\end{array}$ & $\begin{array}{l}54 \\
-- \\
51 \\
-- \\
-- \\
--\end{array}$ & $\begin{array}{l}57 \\
62 \\
-- \\
64 \\
55 \\
55\end{array}$ & $\begin{array}{l}75 \\
75 \\
70 \\
74 \\
70 \\
--\end{array}$ & $\begin{array}{l}74 \\
72 \\
75 \\
76 \\
-- \\
--\end{array}$ & $\begin{array}{l}89 \\
-- \\
90 \\
84 \\
88 \\
--\end{array}$ & $\begin{array}{l}86 \\
86 \\
86 \\
86 \\
86 \\
87\end{array}$ & $\begin{array}{l}86 \\
87 \\
86 \\
87 \\
87 \\
82 \\
\end{array}$ & $\begin{array}{l}80 \\
74 \\
82 \\
77 \\
88 \\
-- \\
\end{array}$ \\
\hline $\begin{array}{c}\text { Aver- } \\
\text { age }\end{array}$ & 68 & 55 & 46 & 45 & -- & 55 & 68 & 68 & -- & 88 & 86 & 81 \\
\hline
\end{tabular}


WHITE RIVER BASIN

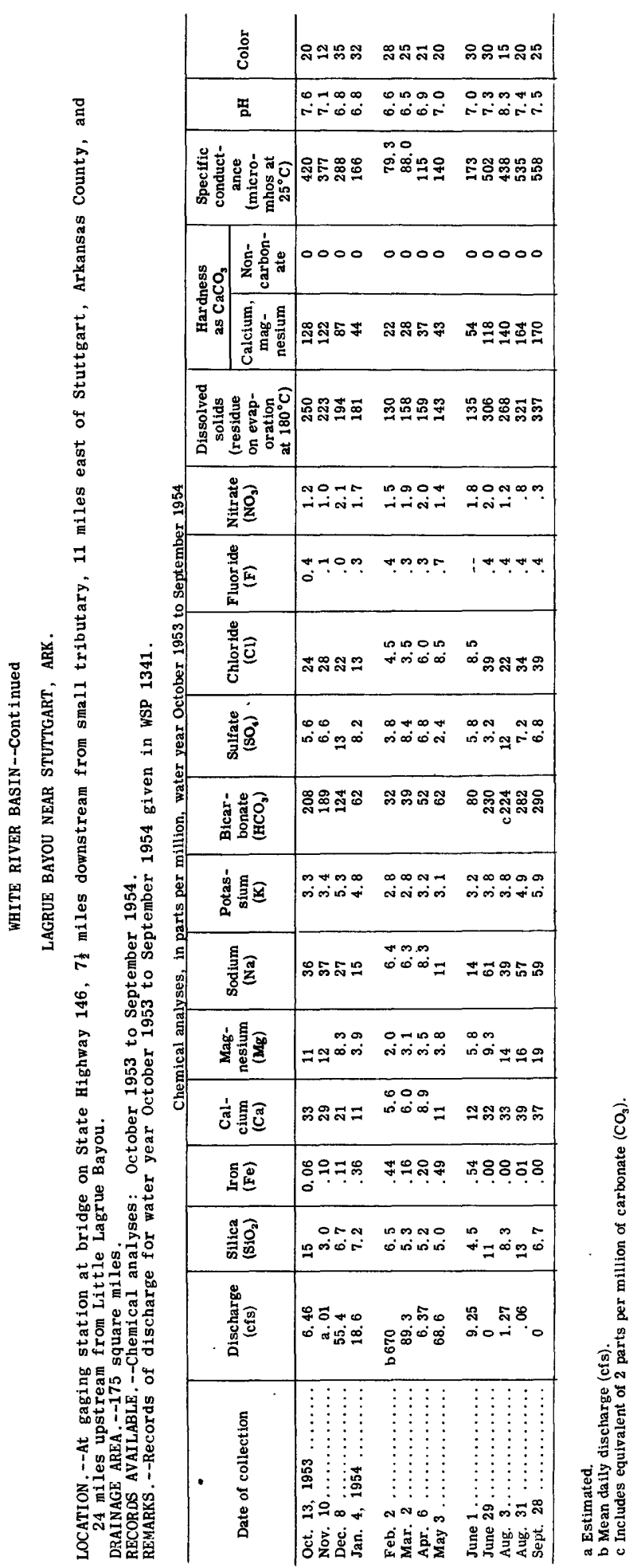




\begin{tabular}{|c|c|c|c|c|c|c|}
\hline 芦 & 요츄유 정 & 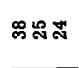 & 고ล요 & 오옹ㅇㅁㅇ & | & 우용우욤 \\
\hline 贸 & 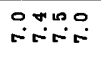 & 웅웅 & 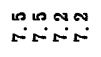 & $\stackrel{\forall}{* \infty \infty}$ & $\begin{array}{l}1000 \\
1000 \\
100\end{array}$ & 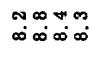 \\
\hline 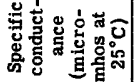 & 赵 & 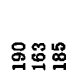 & 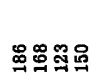 & 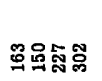 & 总品点 & 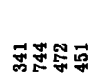 \\
\hline
\end{tabular}

\begin{tabular}{|c|c|c|c|c|c|c|c|}
\hline no & 宕客总 & 0000 & 000 & 0000 & 0000 & 000 & 0000 \\
\hline 莺 & 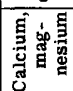 & - & 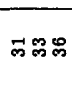 & దొ్ల & 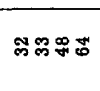 & ธํำ & కొ \\
\hline
\end{tabular}

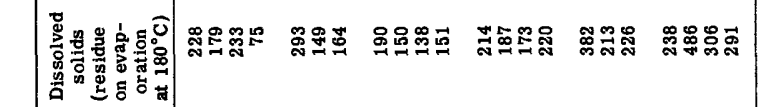
\%

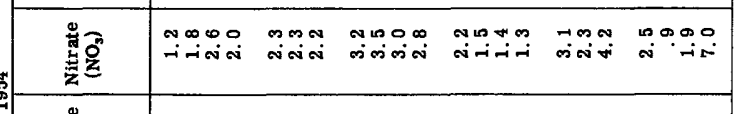

\begin{tabular}{|c|c|c|c|c|}
\hline 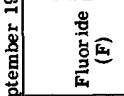 & in: & $\because \pi$ & ब⿻日禸. & $\because 19.1$ \\
\hline 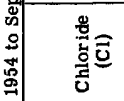 & 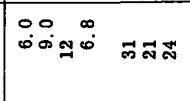 & 웅요영 & 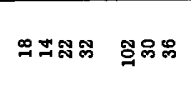 & 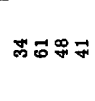 \\
\hline 密总 & 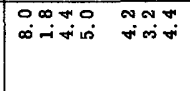 & 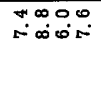 & 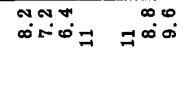 & $\infty_{\infty}=9$ \\
\hline
\end{tabular}

\begin{tabular}{|c|c|c|c|c|c|c|}
\hline 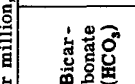 & ザロらீ & 국음윰 & ட유 & $\mathcal{W} \infty \mathbb{\sim}$ & 只 $ळ \infty$ & פ్య \\
\hline
\end{tabular}

尊


WHITE RIVER BASIN--Continued

LITTLE , LAGRUE BAYOU NEAR STUTTGART, ARK, --Cont inued

Temperature $\left({ }^{\circ} \mathrm{F}\right)$ of water, February 1954 to September 1954

\begin{tabular}{|c|c|c|c|c|c|c|c|c|c|c|c|c|}
\hline Day & Oct. & Nov. & Dec. & Jan. & Feb. & Mar. & Apr. & May & June & July & Aug. & Sept. \\
\hline $\begin{array}{l}1 \\
2 \\
3 \\
4 \\
5\end{array}$ & & & & & $\begin{array}{l}-- \\
53 \\
51 \\
50 \\
50\end{array}$ & $\begin{array}{l}50 \\
50 \\
47 \\
42 \\
--\end{array}$ & $\begin{array}{l}47 \\
51 \\
55 \\
63 \\
56\end{array}$ & $\begin{array}{l}71 \\
-- \\
61 \\
66 \\
64\end{array}$ & $\begin{array}{l}84 \\
-- \\
-- \\
-- \\
--\end{array}$ & $\begin{array}{l}92 \\
90 \\
88 \\
-- \\
--\end{array}$ & $\begin{array}{l}-- \\
85 \\
-- \\
--\end{array}$ & $\begin{array}{l}79 \\
83 \\
84 \\
80 \\
--\end{array}$ \\
\hline $\begin{array}{r}6 \\
7 \\
8 \\
9 \\
10\end{array}$ & & & & & $\begin{array}{l}50 \\
45 \\
39 \\
42 \\
47\end{array}$ & $\begin{array}{l}-- \\
47 \\
-- \\
-- \\
--\end{array}$ & $\begin{array}{l}75 \\
69 \\
67 \\
65 \\
65\end{array}$ & $\begin{array}{l}62 \\
69 \\
69 \\
-- \\
--\end{array}$ & $\begin{array}{l}-- \\
=- \\
-- \\
--\end{array}$ & $\begin{array}{l}-- \\
-- \\
85 \\
-- \\
--\end{array}$ & $\begin{array}{l}-- \\
-- \\
-- \\
--\end{array}$ & $\begin{array}{l}-- \\
82 \\
82 \\
83 \\
--\end{array}$ \\
\hline $\begin{array}{l}11 \\
12 \\
13 \\
14 \\
15\end{array}$ & & & & & $\begin{array}{l}51 \\
41 \\
41 \\
50 \\
52\end{array}$ & $\begin{array}{l}57 \\
62 \\
50 \\
-\overline{48}\end{array}$ & $\begin{array}{l}72 \\
65 \\
69 \\
73 \\
70\end{array}$ & $\begin{array}{l}67 \\
64 \\
60 \\
64 \\
67\end{array}$ & $\begin{array}{l}- \\
- \\
-- \\
--\end{array}$ & $\begin{array}{l}-- \\
-- \\
-- \\
--\end{array}$ & $\begin{array}{l}-- \\
-- \\
-- \\
-- \\
--\end{array}$ & $\begin{array}{l}77 \\
-- \\
-- \\
79 \\
--\end{array}$ \\
\hline $\begin{array}{l}16 \\
17 \\
18 \\
19 \\
20\end{array}$ & & & & & $\begin{array}{l}51 \\
55 \\
52 \\
54 \\
52\end{array}$ & $\begin{array}{l}47 \\
49 \\
56 \\
55 \\
51\end{array}$ & $\begin{array}{l}64 \\
59 \\
72 \\
64 \\
67\end{array}$ & $\begin{array}{l}-- \\
70 \\
82 \\
79 \\
74\end{array}$ & $\begin{array}{l}85 \\
89 \\
87 \\
87 \\
-2\end{array}$ & $\begin{array}{l}-- \\
-- \\
-- \\
83 \\
--\end{array}$ & $\begin{array}{l}- \\
-- \\
-- \\
--\end{array}$ & $\begin{array}{l}80 \\
-- \\
80 \\
\overline{82}\end{array}$ \\
\hline $\begin{array}{l}21 \\
22 \\
23 \\
24 \\
25\end{array}$ & & & & & $\begin{array}{l}-- \\
50 \\
54 \\
51 \\
53\end{array}$ & $\begin{array}{l}57 \\
57 \\
58 \\
63\end{array}$ & $\begin{array}{l}77 \\
77 \\
80 \\
75 \\
79\end{array}$ & $\begin{array}{l}78 \\
-- \\
-- \\
81 \\
77\end{array}$ & $\begin{array}{l}-- \\
82 \\
88 \\
-- \\
92\end{array}$ & $\begin{array}{l}-- \\
-- \\
-- \\
-- \\
--\end{array}$ & $\begin{array}{l}-- \\
-- \\
-- \\
--\end{array}$ & $\begin{array}{l}78 \\
75 \\
72 \\
-- \\
--\end{array}$ \\
\hline $\begin{array}{l}26 \\
27 \\
28 \\
29 \\
30 \\
31\end{array}$ & & & & & $\begin{array}{l}57 \\
56 \\
55 \\
-- \\
-- \\
-- \\
\end{array}$ & $\begin{array}{l}62 \\
59 \\
60 \\
-- \\
67 \\
50 \\
\end{array}$ & $\begin{array}{l}78 \\
78 \\
75 \\
75 \\
75 \\
-- \\
\end{array}$ & $\begin{array}{l}77 \\
75 \\
81 \\
78 \\
-- \\
85 \\
\end{array}$ & $\begin{array}{l}81 \\
-21 \\
81 \\
82 \\
\therefore \\
\end{array}$ & $\begin{array}{l}-- \\
-- \\
-- \\
-- \\
-- \\
\end{array}$ & $\begin{array}{l}-- \\
-- \\
-- \\
-- \\
--\end{array}$ & $\begin{array}{l}-- \\
-- \\
77 \\
77 \\
-- \\
-- \\
\end{array}$ \\
\hline $\begin{array}{c}\text { Aver- } \\
\text { age }\end{array}$ & & & & & 50 & $\cdots$ & 69 & -- & $\cdots$ & $=-$ & $\cdots$ & -- \\
\hline
\end{tabular}




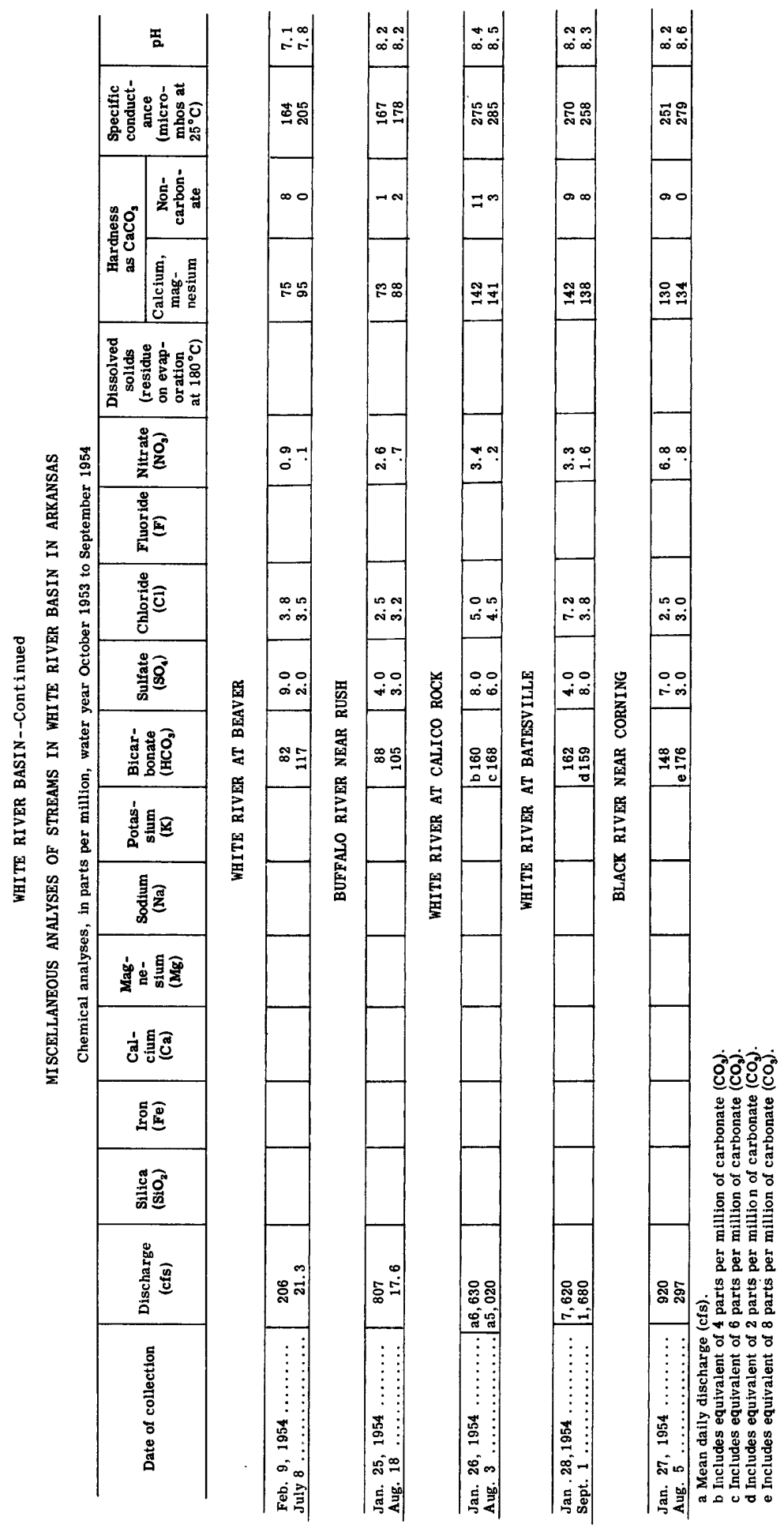




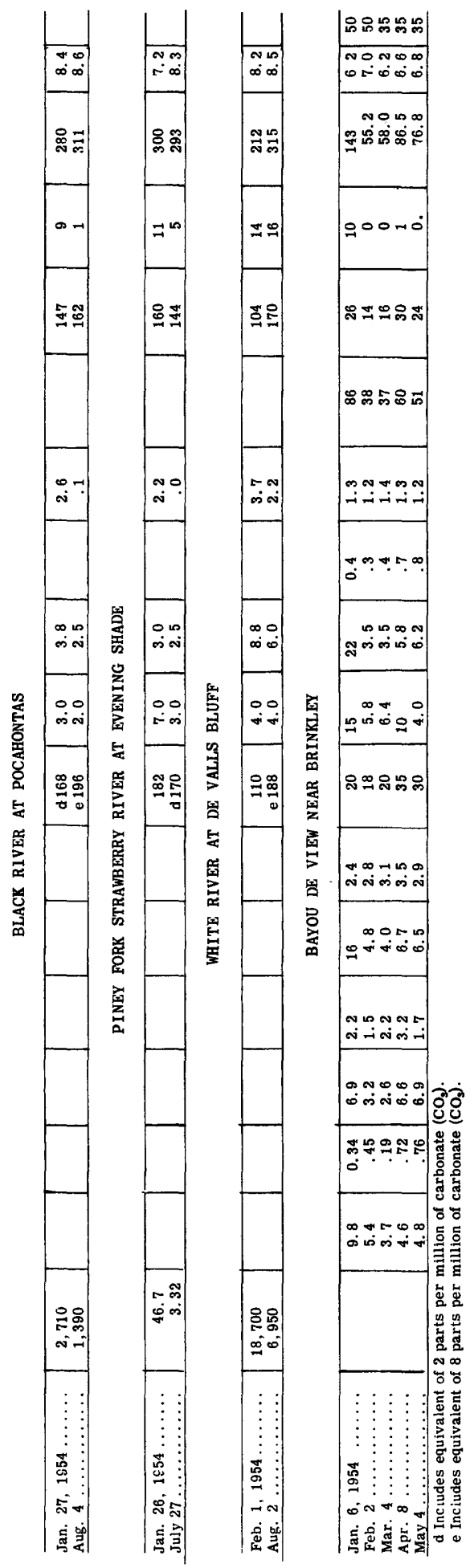




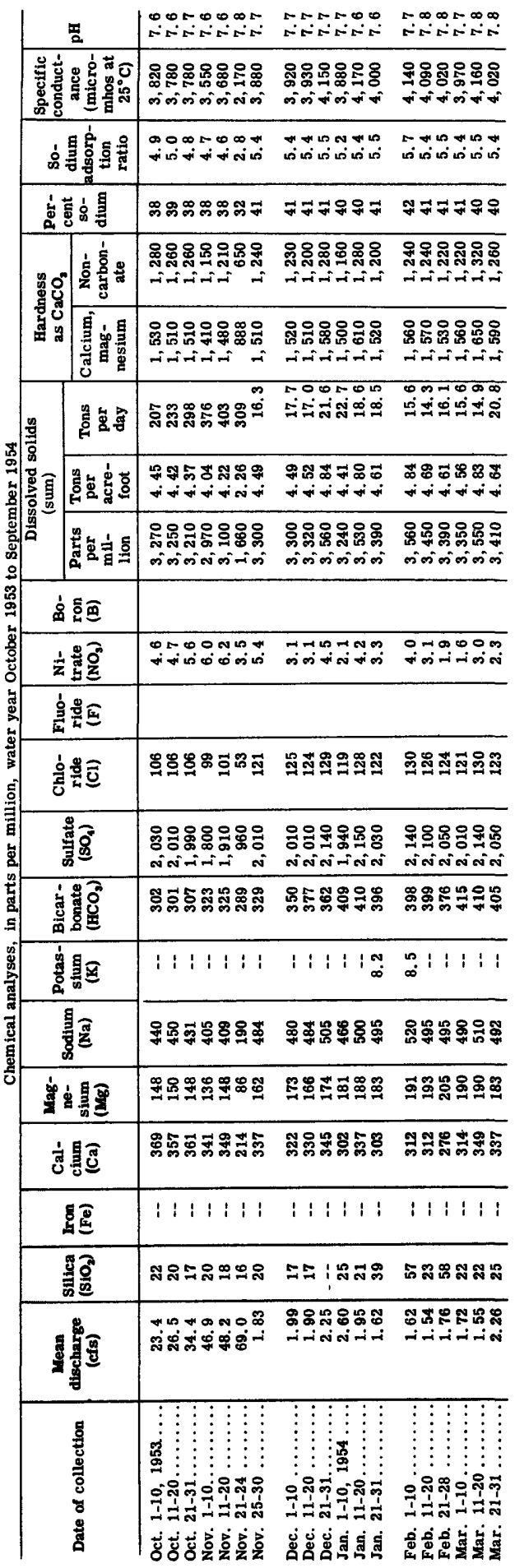




\begin{tabular}{|c|c|c|c|c|}
\hline 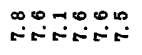 & 象 & 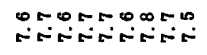 & 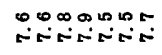 & ! \\
\hline 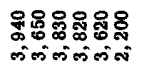 & 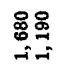 & 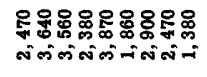 & 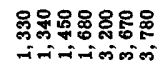 & $\stackrel{8}{8}$ \\
\hline 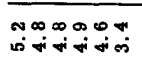 & Fin & 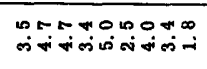 & 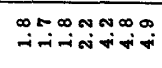 & $\stackrel{\infty}{\infty}$ \\
\hline 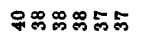 & 늉유 & 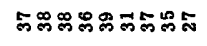 & 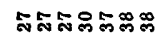 & $\infty$ \\
\hline 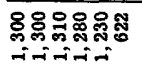 & $\frac{\infty}{2} \div$ & 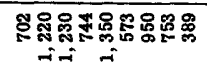 & 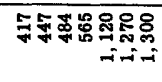 & 8 \\
\hline 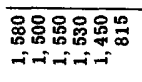 & 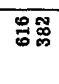 & 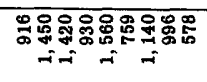 & 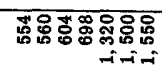 & $\stackrel{\infty}{\$}$ \\
\hline 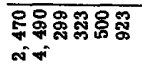 & 兽: & 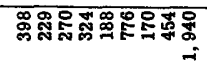 & 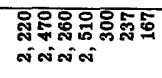 & 5 \\
\hline 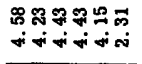 & $\stackrel{8}{8} \underset{-}{2}$ & 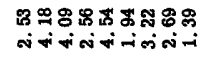 & 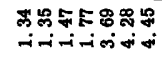 & $\Rightarrow$ \\
\hline 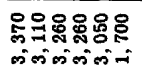 & స్ㅠㅀ & 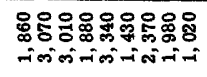 & 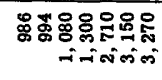 & 总 \\
\hline 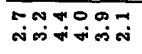 & $\infty_{\infty}^{\infty}$ & 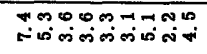 & 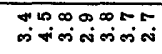 & $\vec{m}$ \\
\hline 용్ㅀㅇㅛ & $5 \pi$ & 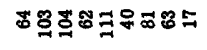 & 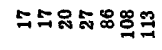 & $F$ \\
\hline 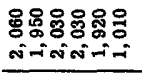 & 류요 & 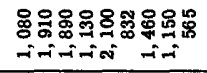 & 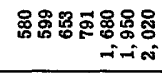 & ह \\
\hline 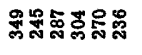 & 융류 & 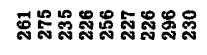 & 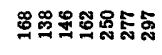 & $\stackrel{\infty}{\stackrel{్}{二}}$ \\
\hline :1:1:1: & 11 & $1: 1: 1:$ & 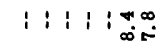 & i \\
\hline 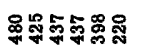 & 泀里 & 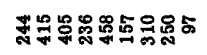 & 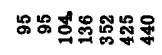 & 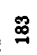 \\
\hline 운 & $\overrightarrow{\text { ธ่ }}$ & 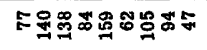 & 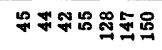 & $=$ \\
\hline 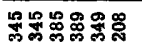 & 옹 & 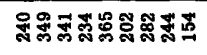 & 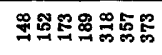 & ๙ั \\
\hline $1: 1: 11$ & 11 & i $1: 1$ & | 1 : & $i$ \\
\hline 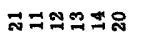 & 90 & 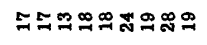 & 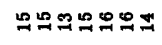 & $\cong$ \\
\hline 蛋品 & 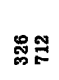 & 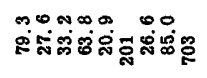 & 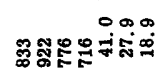 & $\vec{\oplus}$ \\
\hline 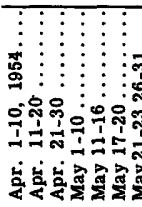 & 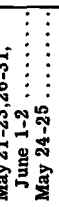 & 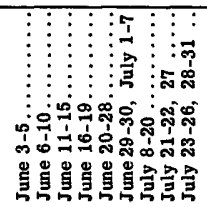 & 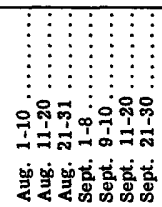 & 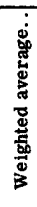 \\
\hline
\end{tabular}


ARKANSAS RIVER BASIN--Continued

ARKANSAS RIVER BELOW JOHN MARTIN RESERVOIR, COLO.--Continued

Temperature $\left({ }^{\circ} \mathrm{F}\right)$ of water, water year October 1953 to September 1954

\begin{tabular}{|c|c|c|c|c|c|c|c|c|c|c|c|c|}
\hline Day & Oct. & Nov. & Dec. & Jan. & Feb. & Mar. & Apr. & . May & June & July & Aug. & Sept. \\
\hline $\begin{array}{l}1 \\
2 \\
3 \\
4 \\
5\end{array}$ & $\begin{array}{l}56 \\
68 \\
64 \\
63 \\
54\end{array}$ & $\begin{array}{l}48 \\
54 \\
52 \\
48 \\
50\end{array}$ & $\begin{array}{l}45 \\
40 \\
38 \\
36 \\
41\end{array}$ & $\begin{array}{l}38 \\
40 \\
40 \\
38 \\
36\end{array}$ & $\begin{array}{l}40 \\
46 \\
44 \\
48 \\
46\end{array}$ & $\begin{array}{l}46 \\
32 \\
32 \\
32 \\
42\end{array}$ & $\begin{array}{l}45 \\
48 \\
45 \\
50 \\
48\end{array}$ & $\begin{array}{l}46 \\
41 \\
46 \\
48 \\
52\end{array}$ & $\begin{array}{l}60 \\
56 \\
55 \\
55 \\
55\end{array}$ & $\begin{array}{l}66 \\
68 \\
72 \\
72 \\
73\end{array}$ & $\begin{array}{l}76 \\
76 \\
76 \\
77 \\
75\end{array}$ & $\begin{array}{l}75 \\
75 \\
75 \\
76 \\
78\end{array}$ \\
\hline $\begin{array}{l}6 \\
7\end{array}$ & $\begin{array}{l}53 \\
50\end{array}$ & $\begin{array}{l}50 \\
45\end{array}$ & $\begin{array}{l}38 \\
36\end{array}$ & $\begin{array}{l}37 \\
36\end{array}$ & $\begin{array}{l}45 \\
45\end{array}$ & $\begin{array}{l}42 \\
41\end{array}$ & $\begin{array}{l}52 \\
52\end{array}$ & $\begin{array}{l}56 \\
54\end{array}$ & $\begin{array}{l}66 \\
58\end{array}$ & $\begin{array}{l}74 \\
72\end{array}$ & $\begin{array}{l}77 \\
76\end{array}$ & $\begin{array}{l}73 \\
73\end{array}$ \\
\hline $\begin{array}{r}8 \\
9 \\
10\end{array}$ & $\begin{array}{l}52 \\
55 \\
56\end{array}$ & $\begin{array}{l}42 \\
44 \\
44\end{array}$ & $\begin{array}{l}41 \\
37 \\
37\end{array}$ & $\begin{array}{l}38 \\
41 \\
36\end{array}$ & $\begin{array}{l}52 \\
50 \\
46\end{array}$ & $\begin{array}{l}45 \\
47 \\
50\end{array}$ & $\begin{array}{l}50 \\
54 \\
51\end{array}$ & $\begin{array}{l}54 \\
56 \\
52\end{array}$ & $\begin{array}{l}60 \\
65 \\
64\end{array}$ & $\begin{array}{l}74 \\
74 \\
74\end{array}$ & $\begin{array}{l}74 \\
74 \\
74\end{array}$ & $\begin{array}{l}70 \\
72 \\
67\end{array}$ \\
\hline $\begin{array}{l}11 \\
12 \\
13 \\
14 \\
15\end{array}$ & $\begin{array}{l}56 \\
52 \\
54 \\
52 \\
54\end{array}$ & $\begin{array}{l}42 \\
44 \\
42 \\
39 \\
41\end{array}$ & $\begin{array}{l}35 \\
35 \\
40 \\
38 \\
42\end{array}$ & $\begin{array}{l}32 \\
32 \\
-- \\
35 \\
34\end{array}$ & $\begin{array}{l}41 \\
42 \\
44 \\
44 \\
46\end{array}$ & $\begin{array}{l}51 \\
44 \\
34 \\
44 \\
42\end{array}$ & $\begin{array}{l}53 \\
49 \\
55 \\
-- \\
52\end{array}$ & $\begin{array}{l}50 \\
53 \\
56 \\
56 \\
58\end{array}$ & $\begin{array}{l}65 \\
66 \\
70 \\
63 \\
62\end{array}$ & $\begin{array}{l}71 \\
75 \\
71 \\
74 \\
74\end{array}$ & $\begin{array}{l}74 \\
75 \\
74 \\
74 \\
74\end{array}$ & $\begin{array}{l}67 \\
70 \\
68 \\
69 \\
68\end{array}$ \\
\hline $\begin{array}{l}16 \\
17 \\
18 \\
19 \\
20\end{array}$ & $\begin{array}{l}56 \\
58 \\
58 \\
52 \\
56\end{array}$ & $\begin{array}{l}48 \\
47 \\
52 \\
35 \\
32\end{array}$ & $\begin{array}{l}44 \\
43 \\
-2 \\
42 \\
42\end{array}$ & $\begin{array}{l}38 \\
36 \\
36 \\
40 \\
32\end{array}$ & $\begin{array}{l}48 \\
50 \\
52 \\
50 \\
40\end{array}$ & $\begin{array}{l}45 \\
45 \\
46 \\
44 \\
43\end{array}$ & $\begin{array}{l}54 \\
53 \\
53 \\
50 \\
57\end{array}$ & $\begin{array}{l}54 \\
54 \\
63 \\
61 \\
56\end{array}$ & $\begin{array}{l}67 \\
71 \\
69 \\
73 \\
71\end{array}$ & $\begin{array}{l}75 \\
73 \\
74 \\
75 \\
74\end{array}$ & $\begin{array}{l}75 \\
75 \\
75 \\
75 \\
71\end{array}$ & $\begin{array}{l}68 \\
68 \\
63 \\
65 \\
64\end{array}$ \\
\hline $\begin{array}{l}21 \\
22 \\
23 \\
24 \\
25\end{array}$ & $\begin{array}{l}49 \\
49 \\
49 \\
48 \\
48\end{array}$ & $\begin{array}{l}36 \\
36 \\
38 \\
42 \\
46\end{array}$ & $\begin{array}{l}43 \\
35 \\
32 \\
34 \\
42\end{array}$ & $\begin{array}{l}32 \\
32 \\
40 \\
39 \\
35\end{array}$ & $\begin{array}{l}43 \\
41 \\
42 \\
48 \\
47\end{array}$ & $\begin{array}{l}45 \\
44 \\
44 \\
49 \\
46\end{array}$ & $\begin{array}{l}50 \\
49 \\
55 \\
58 \\
50\end{array}$ & $\begin{array}{l}58 \\
60 \\
62 \\
58 \\
57\end{array}$ & $\begin{array}{l}70 \\
74 \\
72 \\
70 \\
75\end{array}$ & $\begin{array}{l}76 \\
76 \\
74 \\
72 \\
72\end{array}$ & $\begin{array}{l}73 \\
74 \\
73 \\
74 \\
72\end{array}$ & $\begin{array}{l}58 \\
58 \\
56 \\
55 \\
62\end{array}$ \\
\hline $\begin{array}{l}26 \\
27 \\
28 \\
29 \\
30 \\
31\end{array}$ & $\begin{array}{l}48 \\
50 \\
49 \\
48 \\
48 \\
47 \\
\end{array}$ & $\begin{array}{l}45 \\
45 \\
46 \\
46 \\
42 \\
-- \\
\end{array}$ & $\begin{array}{l}41 \\
46 \\
35 \\
35 \\
35 \\
34 \\
\end{array}$ & $\begin{array}{l}32 \\
32 \\
32 \\
38 \\
44 \\
42 \\
\end{array}$ & $\begin{array}{l}48 \\
41 \\
39 \\
-- \\
-- \\
-- \\
\end{array}$ & $\begin{array}{l}46 \\
46 \\
51 \\
40 \\
40 \\
45 \\
\end{array}$ & $\begin{array}{l}58 \\
55 \\
54 \\
48 \\
45 \\
-- \\
\end{array}$ & $\begin{array}{l}58 \\
58 \\
58 \\
60 \\
63 \\
61 \\
\end{array}$ & $\begin{array}{l}69 \\
70 \\
68 \\
65 \\
68 \\
-- \\
\end{array}$ & $\begin{array}{l}74 \\
74 \\
73 \\
74 \\
74 \\
75 \\
\end{array}$ & $\begin{array}{l}72 \\
74 \\
72 \\
73 \\
71 \\
75 \\
\end{array}$ & $\begin{array}{l}62 \\
64 \\
60 \\
62 \\
58 \\
- \\
\end{array}$ \\
\hline $\begin{array}{c}\text { Aver - } \\
\text { age }\end{array}$ & 53 & 44 & 39 & 36 & 45 & 43 & 51 & 55 & 66 & 73 & 74 & 67. \\
\hline
\end{tabular}




\begin{tabular}{|c|c|c|c|}
\hline 풍 & 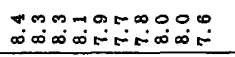 & 年 & $\begin{array}{l}-000 \\
\infty \\
\infty\end{array}$ \\
\hline 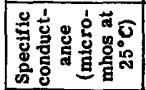 & 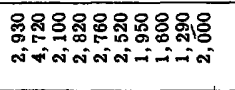 & 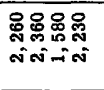 & 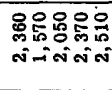 \\
\hline 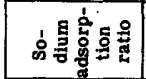 & 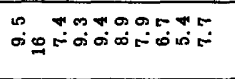 & 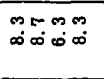 & \\
\hline 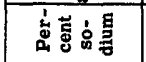 & 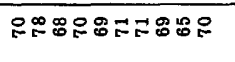 & $8 \approx 50$ & 웅요용 \\
\hline 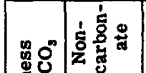 & 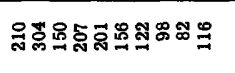 & 题品욤요 & 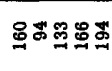 \\
\hline 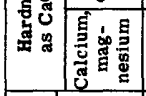 & 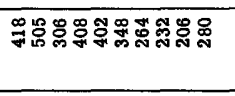 & 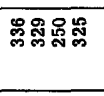 & 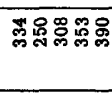 \\
\hline 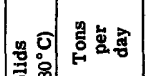 & 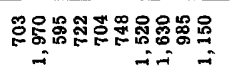 & 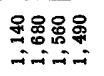 & 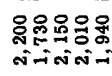 \\
\hline 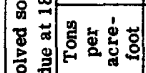 & 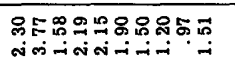 & 年 & 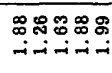 \\
\hline 政 & 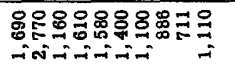 & 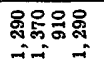 & 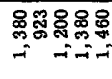 \\
\hline 宮部鱼 & 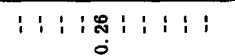 & $\stackrel{\infty}{*}: 1:$ : & $::$ \\
\hline 安造是 & $\cong \Xi=\cong \sigma^{\infty} \cong \cong \infty \sigma^{\circ} \Omega$ & $==\begin{array}{c}\infty N \\
\infty\end{array}$ & $\infty 0$ \\
\hline 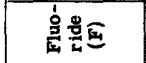 & $: 1: 1: \begin{array}{l}n \\
0\end{array}$ & ๑:: : : & $: i^{2}$ \\
\hline 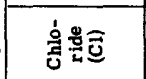 & 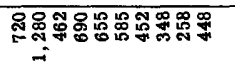 & 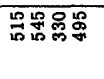 & $\mathscr{0}$ \\
\hline 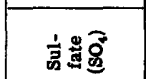 & వ్తి & 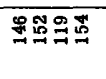 & 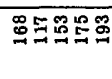 \\
\hline 赔 & 100 & 0000 & 00 \\
\hline 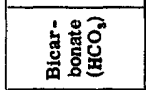 & 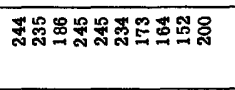 & สిส & 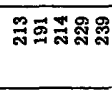 \\
\hline 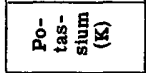 & : $: 1::_{\infty}^{\infty}: 1: 1: 1:$ & $\stackrel{0}{2}: 1: 1$ & i i : \\
\hline 官害孚 & 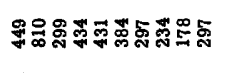 & 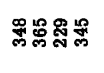 & $\mathscr{\mathscr { E }} \overrightarrow{\tilde{\pi}}$ \\
\hline 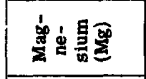 & 묨요 & สูก๊ & 誌 \\
\hline 皇量可 & $\stackrel{\infty}{=}$ & 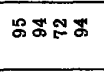 & $\mathscr{\&}$ \\
\hline ธ્口 & :1:1:80:1:1:1 & $8: 1:$ & : : \\
\hline 产高 & $1: 11011: 11$ & $=11:$ & $1: 1: \pm$ \\
\hline 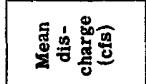 & 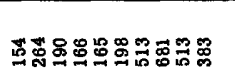 & స్ల్లో\% & 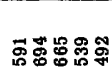 \\
\hline 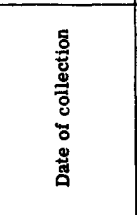 & 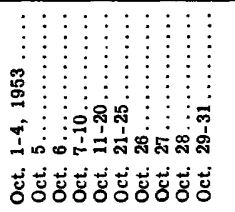 & 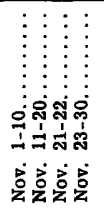 & 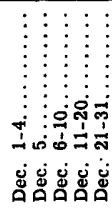 \\
\hline
\end{tabular}




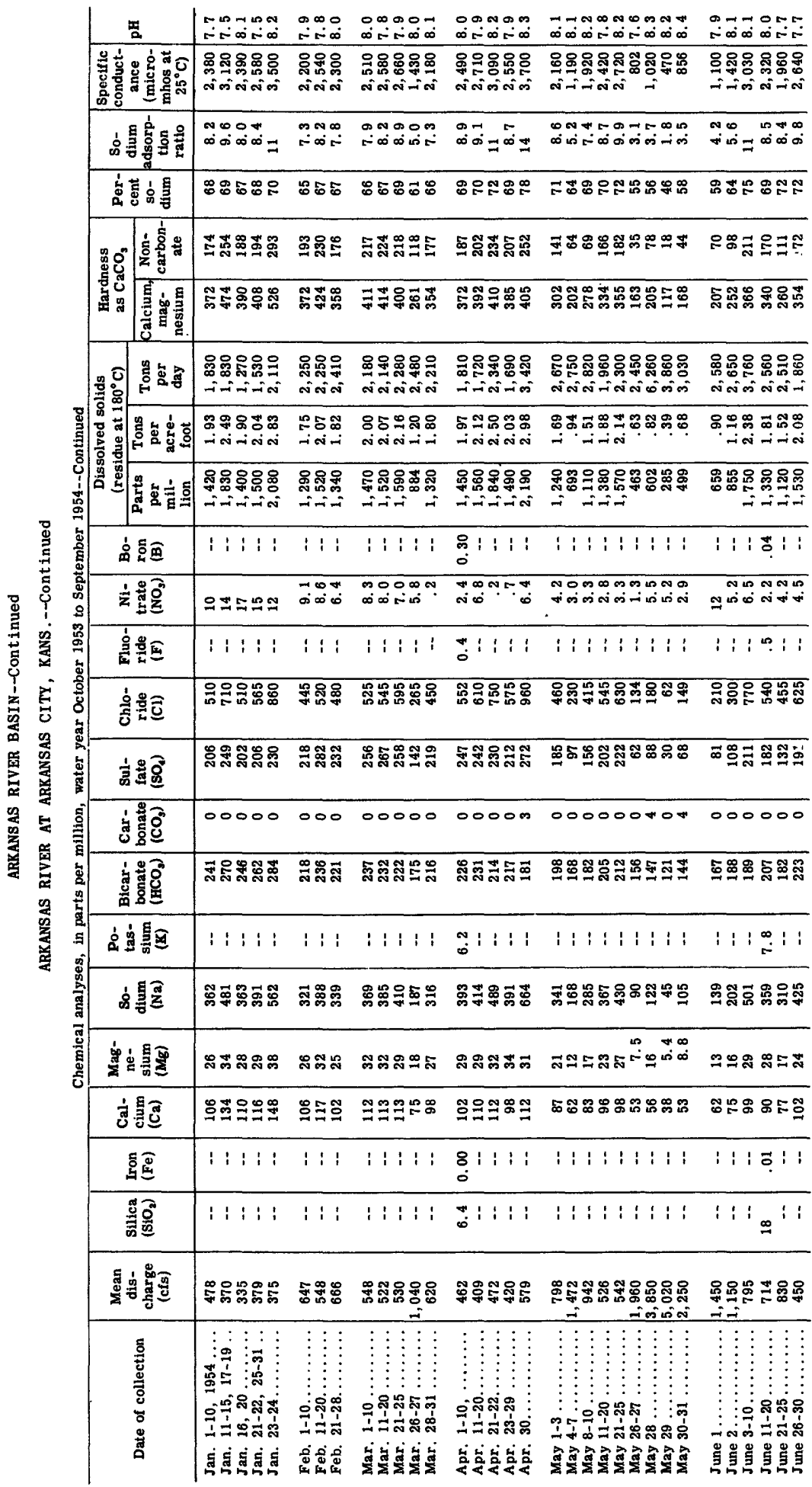




\begin{tabular}{|c|c|c|c|}
\hline 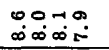 & om & $\begin{array}{l}0 \infty ⿻ 0 \\
\infty \infty \infty \infty \infty \\
\infty\end{array}$ & $i$ \\
\hline 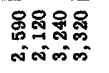 & 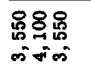 & 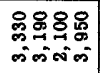 & 离 \\
\hline 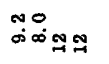 & Ж્ન ్ㅗㄱ & 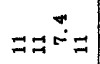 & $\ddot{\infty}$ \\
\hline 유ㅇㅠㅛ & คำ & 꽁유 & 8 \\
\hline 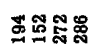 & 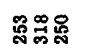 & สี & 里 \\
\hline 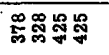 & 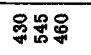 & ఫㄱํㄱㅇㅠ & 㞼 \\
\hline 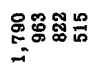 & 욤욤요 & 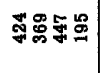 & $\begin{array}{c}8 \\
8 \\
-1\end{array}$ \\
\hline 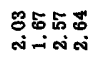 & 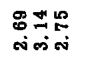 & 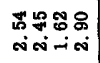 & $=$ \\
\hline 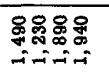 & $\begin{array}{l}\text { 융유용 } \\
\text {-in }\end{array}$ & 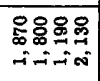 & 点 \\
\hline 1: : : & : : : & : : : : & $i$ \\
\hline 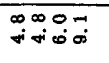 & $\begin{array}{l}\text { Oof } \\
\text { risit }\end{array}$ & 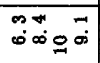 & 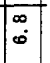 \\
\hline i : i & : : : & $\begin{array}{llll}1 & 1 & 1 & 0 \\
0\end{array}$ & 1 \\
\hline 용융용으 & 영요 & 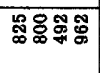 & 5 \\
\hline 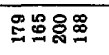 & 䙵吕吕 & : ్ㅠ్ㅀㅇ & $\underset{\sim}{\stackrel{9}{*}}$ \\
\hline$\infty 000$ & ono & $0 \times 00$ & $i$ \\
\hline 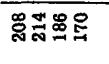 & ํㅠำ品 & 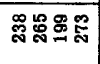 & 胥 \\
\hline 1 1 i i & 1：： & i i : & 1 \\
\hline ‡品品品 & 吕䍐莒品 & 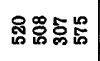 & 융 \\
\hline 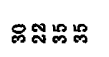 & 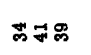 & 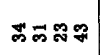 & ম \\
\hline 워워 & 역욤워 & 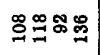 & $\approx$ \\
\hline : : : : & 1：1 & $\begin{array}{rrrr}1 & 1 & 1 & 0 \\
& & 0 \\
0\end{array}$ & i \\
\hline . : : : : & i : i & 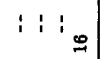 & i \\
\hline 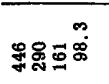 & 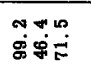 & 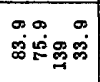 & 5 \\
\hline 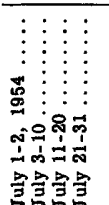 & 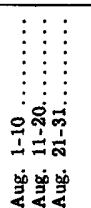 & 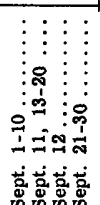 & 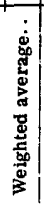 \\
\hline
\end{tabular}


ARKANSAS RIVER BASIN--Continued

ARKANSAS RIVER AT ARKANSAS CITY, KANS,--Continued

Temperature $\left({ }^{\circ} \mathrm{F}\right.$ ) of water, water year October 1953 to September 1954

\begin{tabular}{|c|c|c|c|c|c|c|c|c|c|c|c|c|}
\hline Day & Oct. & Nov. & Dec. & Jan. & Feb. & Mar. & Apr. & May & June & July & Aug. & Sept. \\
\hline $\begin{array}{l}1 \\
2 \\
3 \\
4 \\
5\end{array}$ & $\begin{array}{l}62 \\
67 \\
70 \\
61 \\
55\end{array}$ & $\begin{array}{l}54 \\
55 \\
54 \\
54 \\
49\end{array}$ & $\begin{array}{l}44 \\
55 \\
52 \\
41 \\
45\end{array}$ & $\begin{array}{l}36 \\
37 \\
36 \\
37 \\
38\end{array}$ & $\begin{array}{l}36 \\
38 \\
41 \\
42 \\
42\end{array}$ & $\begin{array}{l}40 \\
38 \\
35 \\
34 \\
37\end{array}$ & $\begin{array}{l}42 \\
42 \\
51 \\
53 \\
63\end{array}$ & $\begin{array}{l}56 \\
55 \\
46 \\
56 \\
55\end{array}$ & $\begin{array}{l}68 \\
70 \\
60 \\
69 \\
65\end{array}$ & $\begin{array}{l}77 \\
76 \\
76 \\
76 \\
79\end{array}$ & $\begin{array}{l}76 \\
73 \\
79 \\
75 \\
75\end{array}$ & $\begin{array}{l}72 \\
72 \\
71 \\
70 \\
70\end{array}$ \\
\hline $\begin{array}{r}6 \\
7 \\
8 \\
9 \\
10\end{array}$ & $\begin{array}{l}55 \\
53 \\
54 \\
57 \\
58\end{array}$ & $\begin{array}{l}42 \\
40 \\
42 \\
40 \\
43\end{array}$ & $\begin{array}{l}40 \\
39 \\
42 \\
37 \\
37\end{array}$ & $\begin{array}{l}37 \\
39 \\
44 \\
39 \\
32\end{array}$ & $\begin{array}{l}43 \\
36 \\
39 \\
44 \\
46\end{array}$ & $\begin{array}{l}37 \\
36 \\
42 \\
45 \\
51\end{array}$ & $\begin{array}{l}65 \\
63 \\
53 \\
54 \\
62\end{array}$ & $\begin{array}{l}61 \\
60 \\
62 \\
59 \\
58\end{array}$ & $\begin{array}{l}68 \\
69 \\
72 \\
72 \\
73\end{array}$ & $\begin{array}{l}78 \\
76 \\
77 \\
76 \\
79\end{array}$ & $\begin{array}{l}76 \\
76 \\
72 \\
73 \\
74\end{array}$ & $\begin{array}{l}70 \\
73 \\
72 \\
-- \\
68\end{array}$ \\
\hline $\begin{array}{l}11 \\
12 \\
13 \\
14 \\
15\end{array}$ & $\begin{array}{l}59 \\
61 \\
60 \\
65 \\
64\end{array}$ & $\begin{array}{l}46 \\
47 \\
47 \\
49 \\
49\end{array}$ & $\begin{array}{l}38 \\
34 \\
37 \\
35 \\
36\end{array}$ & $\begin{array}{l}32 \\
32 \\
32 \\
33 \\
34\end{array}$ & $\begin{array}{l}40 \\
36 \\
38 \\
47 \\
56\end{array}$ & $\begin{array}{l}54 \\
54 \\
37 \\
33 \\
38\end{array}$ & $\begin{array}{l}59 \\
58 \\
57 \\
66 \\
63\end{array}$ & $\begin{array}{l}59 \\
59 \\
62 \\
64 \\
66\end{array}$ & $\begin{array}{l}73 \\
75 \\
71 \\
71 \\
70\end{array}$ & $\begin{array}{l}76 \\
77 \\
80 \\
80 \\
76\end{array}$ & $\begin{array}{l}74 \\
74 \\
73 \\
73 \\
74\end{array}$ & $\begin{array}{l}66 \\
66 \\
63 \\
67 \\
70\end{array}$ \\
\hline $\begin{array}{l}16 \\
17 \\
18 \\
19 \\
20\end{array}$ & $\begin{array}{l}63 \\
62 \\
60 \\
62 \\
62\end{array}$ & $\begin{array}{l}51 \\
53 \\
54 \\
60 \\
48\end{array}$ & \begin{tabular}{l|}
38 \\
36 \\
32 \\
36 \\
42
\end{tabular} & $\begin{array}{l}34 \\
32 \\
33 \\
39 \\
38\end{array}$ & $\begin{array}{l}45 \\
44 \\
44 \\
51 \\
42\end{array}$ & $\begin{array}{l}43 \\
43 \\
49 \\
44 \\
47\end{array}$ & $\begin{array}{l}52 \\
54 \\
58 \\
63 \\
64\end{array}$ & $\begin{array}{l}68 \\
67 \\
65 \\
67 \\
62\end{array}$ & $\begin{array}{l}72 \\
76 \\
77 \\
79 \\
78\end{array}$ & $\begin{array}{l}82 \\
79 \\
78 \\
79 \\
76\end{array}$ & $\begin{array}{l}75 \\
74 \\
73 \\
72 \\
71\end{array}$ & $\begin{array}{l}69 \\
69 \\
71 \\
71 \\
73\end{array}$ \\
\hline $\begin{array}{l}21 \\
22 \\
23 \\
24 \\
25\end{array}$ & $\begin{array}{l}62 \\
65 \\
60 \\
53 \\
58\end{array}$ & $\begin{array}{l}43 \\
41 \\
41 \\
45 \\
43\end{array}$ & $\begin{array}{l}45 \\
32 \\
32 \\
32 \\
33\end{array}$ & $\begin{array}{l}32 \\
32 \\
32 \\
35 \\
32\end{array}$ & $\begin{array}{l}43 \\
45 \\
45 \\
45 \\
50\end{array}$ & $\begin{array}{l}44 \\
48 \\
49 \\
50 \\
51\end{array}$ & $\begin{array}{l}64 \\
55 \\
59 \\
63 \\
67\end{array}$ & $\begin{array}{l}62 \\
66 \\
69 \\
67 \\
64\end{array}$ & $\begin{array}{l}77 \\
79 \\
77 \\
79 \\
77\end{array}$ & $\begin{array}{l}-- \\
76 \\
-- \\
78 \\
79\end{array}$ & $\begin{array}{l}72 \\
74 \\
73 \\
74 \\
74\end{array}$ & $\begin{array}{l}61 \\
56 \\
58 \\
59 \\
63\end{array}$ \\
\hline $\begin{array}{l}26 \\
27 \\
28 \\
29 \\
30 \\
31\end{array}$ & $\begin{array}{l}53 \\
46 \\
43 \\
51 \\
53 \\
55 \\
\end{array}$ & $\begin{array}{l}40 \\
44 \\
41 \\
41 \\
42 \\
-- \\
\end{array}$ & $\begin{array}{l}35 \\
34 \\
34 \\
33 \\
34 \\
34\end{array}$ & $\begin{array}{l}32 \\
33 \\
33 \\
33 \\
33 \\
33\end{array}$ & $\begin{array}{l}45 \\
46 \\
44 \\
-- \\
-- \\
-- \\
\end{array}$ & $\begin{array}{l}50 \\
50 \\
55 \\
47 \\
41 \\
40\end{array}$ & $\begin{array}{l}67 \\
65 \\
65 \\
66 \\
65 \\
-- \\
\end{array}$ & $\begin{array}{l}65 \\
68 \\
72 \\
69 \\
70 \\
72 \\
\end{array}$ & $\begin{array}{l}77 \\
77 \\
76 \\
76 \\
79 \\
--\end{array}$ & $\begin{array}{l}75 \\
73 \\
76 \\
80 \\
76 \\
76 \\
\end{array}$ & $\begin{array}{l}75 \\
74 \\
76 \\
77 \\
77 \\
74 \\
\end{array}$ & $\begin{array}{l}67 \\
69 \\
67 \\
70 \\
66 \\
-- \\
\end{array}$ \\
\hline $\begin{array}{c}\text { Aver- } \\
\text { age }\end{array}$ & 58 & 47 & 38 & 35 & 43 & 44 & 59 & 63 & 73 & 77 & 74 & 68 \\
\hline
\end{tabular}




\begin{tabular}{|c|c|c|c|c|}
\hline 평 & 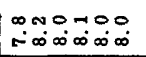 & 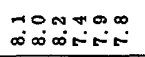 & 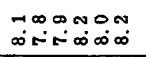 & 要 \\
\hline 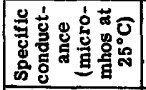 & 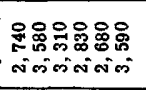 & 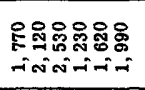 & 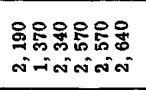 & 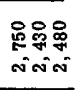 \\
\hline 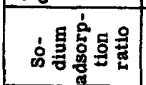 & 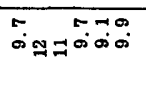 & 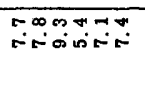 & 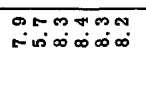 & No. \\
\hline 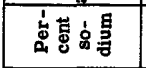 & テミ゚ニ゚ロ & テタテらニ & 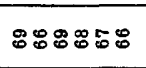 & 855 \\
\hline 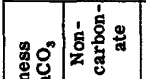 & 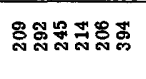 & 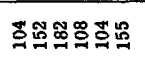 & 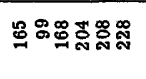 & 융్ㅀ \\
\hline 密它 & 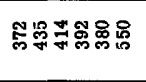 & 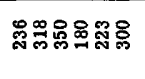 & 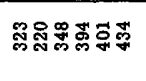 & 尔哭苛 \\
\hline 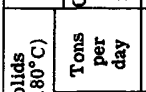 & 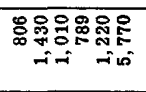 & 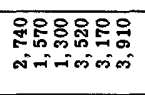 & 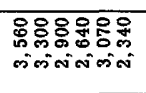 & 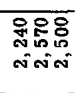 \\
\hline 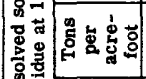 & 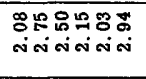 & 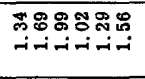 & 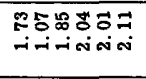 & 舟员: \\
\hline 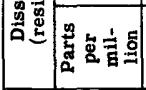 & 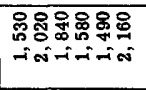 & 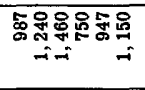 & 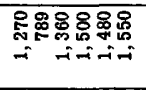 & 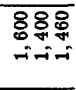 \\
\hline 高总画 & 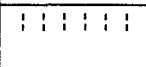 & 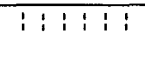 & $1: 1: 11$ & $\overline{1: 1}$ \\
\hline 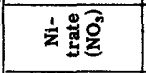 & $\begin{array}{c}n \infty \\
-\infty \\
-\infty\end{array}$ & 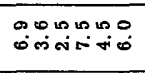 & 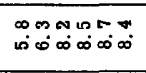 & 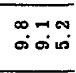 \\
\hline 高量匡 & $1: 1: 1: 1$ & $1: 1: 1: 11$ & $\begin{array}{lllllll} & 1 & 1 & 1 & 1 & 1 & 1\end{array}$ & $\overline{1: i}$ \\
\hline 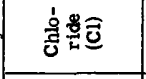 & 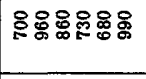 & 국우응응유유 & 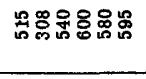 & 品品需 \\
\hline 方重总 & 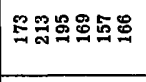 & 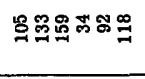 & 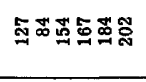 & 声金品 \\
\hline मู & 000000 & 000000 & Do & \\
\hline 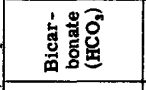 & 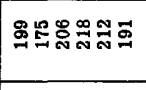 & 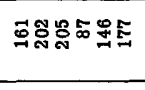 & 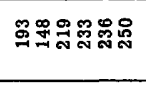 & 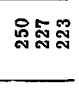 \\
\hline 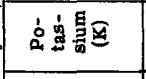 & 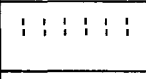 & $1: 1: 1: 1$ & $1: 1: 1:$ & i:i \\
\hline 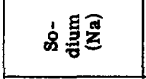 & 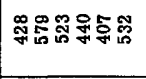 & 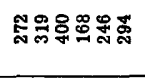 & 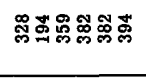 & 怘品䓛 \\
\hline 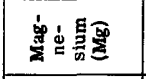 & రํำ & ๑ సే心 & 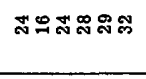 & ๓ळळ \\
\hline डิ & 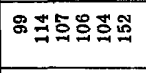 & ロロすら゙ロむ゙ & 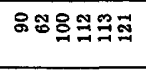 & 赵氙 \\
\hline 窇豎 & i : $: 1: 1: 1:$ & : $: 1: 1: 1$ & : $1: 1: 11:$ & 1: 1 \\
\hline 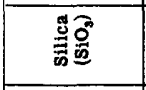 & $1: 1: 1: 1:$ & 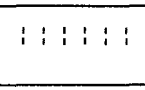 & ：：：：：：：： & $1: 1$ \\
\hline 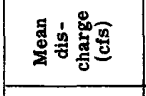 & 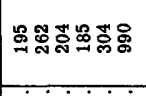 & 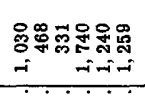 & 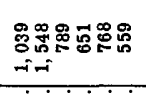 & 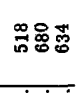 \\
\hline 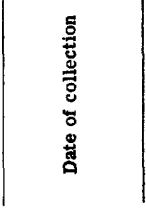 & 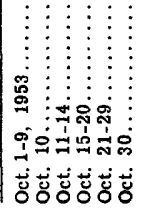 & 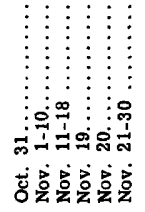 & 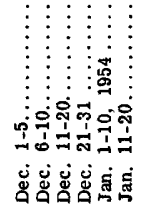 & 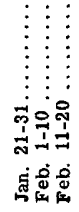 \\
\hline
\end{tabular}




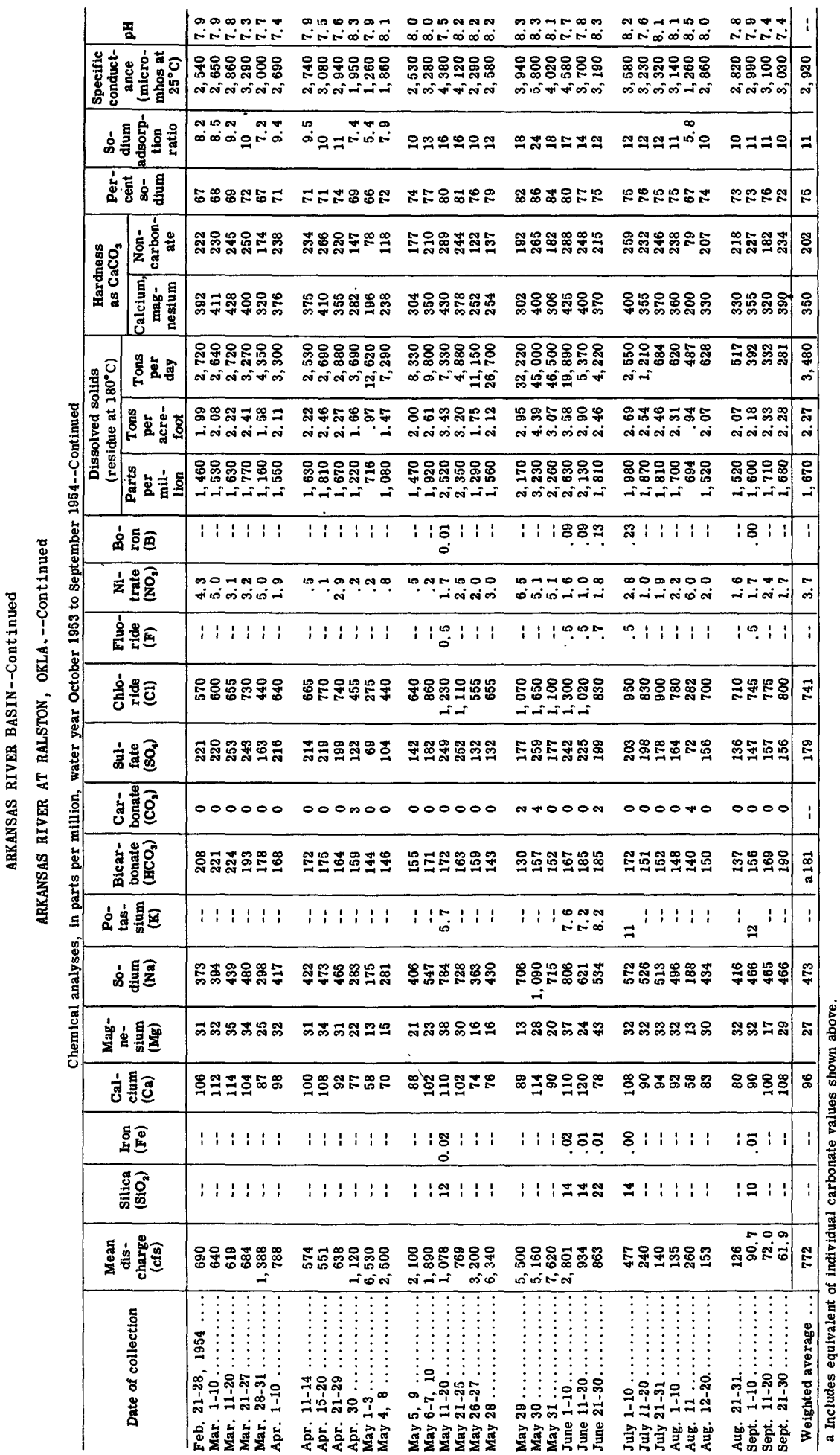


ARKANSAS RIVER BASIN--Continued

ARKANSAS RIVER AT RALSTON, OKLA,--Continued

Temperature $\left({ }^{\circ} \mathrm{F}\right)$ of water, water year October 1953 to September 1954

\begin{tabular}{|c|c|c|c|c|c|c|c|c|c|c|c|c|}
\hline Day & Oct. & Nov. & Dec. & Jan. & Feb. & Mar. & Apr. & May & June & July & Aug. & Sept. \\
\hline $\begin{array}{l}1 \\
2 \\
3 \\
4 \\
5\end{array}$ & $\begin{array}{l}80 \\
80 \\
75 \\
63 \\
68\end{array}$ & $\begin{array}{l}64 \\
64 \\
65 \\
57 \\
54\end{array}$ & $\begin{array}{l}52 \\
56 \\
50 \\
48 \\
50\end{array}$ & $\begin{array}{l}43 \\
45 \\
43 \\
45 \\
43\end{array}$ & $\begin{array}{l}\mathbf{5 0} \\
\mathbf{5 2} \\
\mathbf{5 1} \\
\mathbf{5 4} \\
\mathbf{5 3}\end{array}$ & $\begin{array}{l}52 \\
42 \\
42 \\
45 \\
43\end{array}$ & \begin{tabular}{c}
56 \\
65 \\
68 \\
$-\square$ \\
\hdashline
\end{tabular} & $\begin{array}{l}64 \\
58 \\
58 \\
63 \\
71\end{array}$ & $\begin{array}{l}79 \\
77 \\
71 \\
75 \\
75\end{array}$ & $\begin{array}{l}90 \\
89 \\
89 \\
92 \\
93\end{array}$ & $\begin{array}{l}89 \\
95 \\
90 \\
88 \\
88\end{array}$ & $\begin{array}{l}90 \\
90 \\
85 \\
88 \\
89\end{array}$ \\
\hline $\begin{array}{r}6 \\
7 \\
8 \\
9 \\
10\end{array}$ & $\begin{array}{l}66 \\
66 \\
70 \\
72 \\
71\end{array}$ & $\begin{array}{l}43 \\
44 \\
43 \\
51 \\
54\end{array}$ & $\begin{array}{l}55 \\
48 \\
45 \\
-- \\
--\end{array}$ & $\begin{array}{l}45 \\
49 \\
53 \\
41 \\
33\end{array}$ & $\begin{array}{l}48 \\
46 \\
50 \\
50 \\
57\end{array}$ & $\begin{array}{l}50 \\
57 \\
55 \\
61 \\
67\end{array}$ & $\begin{array}{l}80 \\
70 \\
65 \\
68 \\
75\end{array}$ & $\begin{array}{l}73 \\
70 \\
65 \\
62 \\
60\end{array}$ & $\begin{array}{l}76 \\
80 \\
85 \\
85 \\
85\end{array}$ & $\begin{array}{l}90 \\
89 \\
93 \\
95 \\
93\end{array}$ & $\begin{array}{l}88 \\
89 \\
61 \\
87 \\
88\end{array}$ & $\begin{array}{l}86 \\
84 \\
87 \\
83 \\
80\end{array}$ \\
\hline $\begin{array}{l}11 \\
12 \\
13 \\
14 \\
15\end{array}$ & $\begin{array}{l}75 \\
74 \\
74 \\
73 \\
68\end{array}$ & $\begin{array}{l}57 \\
58 \\
58 \\
60 \\
62\end{array}$ & $\begin{array}{l}-- \\
-- \\
-- \\
-- \\
40\end{array}$ & $\begin{array}{l}35 \\
33 \\
33 \\
37 \\
43\end{array}$ & $\begin{array}{l}47 \\
45 \\
59 \\
62 \\
64\end{array}$ & $\begin{array}{l}65 \\
55 \\
43 \\
42 \\
52\end{array}$ & $\begin{array}{l}60 \\
60 \\
66 \\
68 \\
69\end{array}$ & $\begin{array}{l}61 \\
70 \\
75 \\
77 \\
79\end{array}$ & $\begin{array}{l}86 \\
77 \\
82 \\
80 \\
83\end{array}$ & $\begin{array}{l}92 \\
95 \\
96 \\
97 \\
96\end{array}$ & $\begin{array}{l}88 \\
88 \\
87 \\
89 \\
88\end{array}$ & $\begin{array}{l}80 \\
87 \\
78 \\
76 \\
83\end{array}$ \\
\hline $\begin{array}{l}16 \\
17 \\
18 \\
19 \\
20\end{array}$ & $\begin{array}{l}80 \\
70 \\
71 \\
72 \\
72\end{array}$ & $\begin{array}{l}60 \\
62 \\
61 \\
59 \\
46\end{array}$ & $\begin{array}{l}43 \\
38 \\
40 \\
41 \\
41\end{array}$ & $\begin{array}{l}39 \\
33 \\
35 \\
48 \\
33\end{array}$ & $\begin{array}{l}\mathbf{5 8} \\
55 \\
\mathbf{5 3} \\
\mathbf{5 5} \\
\mathbf{4 8}\end{array}$ & $\begin{array}{l}\mathbf{5 2} \\
\mathbf{5 5} \\
\mathbf{5 7} \\
\mathbf{5 6} \\
\mathbf{4 9}\end{array}$ & $\begin{array}{l}66 \\
72 \\
76 \\
75 \\
75\end{array}$ & $\begin{array}{l}74 \\
70 \\
77 \\
75 \\
73\end{array}$ & $\begin{array}{l}88 \\
90 \\
85 \\
91 \\
89\end{array}$ & $\begin{array}{l}95 \\
94 \\
96 \\
97 \\
92\end{array}$ & $\begin{array}{l}88 \\
89 \\
86 \\
85 \\
85\end{array}$ & $\begin{array}{l}86 \\
84 \\
87 \\
87 \\
87\end{array}$ \\
\hline $\begin{array}{l}21 \\
22 \\
23 \\
24 \\
25\end{array}$ & $\begin{array}{l}70 \\
70 \\
64 \\
65 \\
60\end{array}$ & $\begin{array}{l}47 \\
48 \\
44 \\
50 \\
47\end{array}$ & $\begin{array}{l}43 \\
33 \\
33 \\
33 \\
35\end{array}$ & $\begin{array}{l}33 \\
33 \\
33 \\
33 \\
49\end{array}$ & $\begin{array}{l}55 \\
57 \\
55 \\
59 \\
56\end{array}$ & $\begin{array}{l}57 \\
55 \\
60 \\
64 \\
65\end{array}$ & $\begin{array}{l}70 \\
60 \\
75 \\
79 \\
--\end{array}$ & $\begin{array}{l}75 \\
80 \\
- \\
80 \\
72\end{array}$ & $\begin{array}{l}89 \\
93 \\
94 \\
90 \\
90\end{array}$ & $\begin{array}{l}85 \\
92 \\
95 \\
95 \\
94\end{array}$ & $\begin{array}{l}-2 \\
89 \\
85 \\
88 \\
88\end{array}$ & $\begin{array}{l}70 \\
75 \\
75 \\
76 \\
77\end{array}$ \\
\hline $\begin{array}{l}26 \\
27 \\
28 \\
29 \\
30 \\
31\end{array}$ & $\begin{array}{l}52 \\
53 \\
60 \\
63 \\
61 \\
63\end{array}$ & $\begin{array}{l}48 \\
50 \\
49 \\
50 \\
50 \\
--\end{array}$ & $\begin{array}{l}39 \\
40 \\
40 \\
41 \\
39 \\
42\end{array}$ & $\begin{array}{l}35 \\
37 \\
39 \\
40 \\
45 \\
--\end{array}$ & $\begin{array}{l}58 \\
41 \\
50 \\
-- \\
-- \\
--\end{array}$ & $\begin{array}{l}54 \\
64 \\
68 \\
50 \\
43 \\
51\end{array}$ & $\begin{array}{l}78 \\
73 \\
78 \\
80 \\
66 \\
--\end{array}$ & $\begin{array}{l}77 \\
78 \\
75 \\
77 \\
78 \\
78 \\
\end{array}$ & $\begin{array}{l}90 \\
91 \\
90 \\
92 \\
85 \\
--\end{array}$ & $\begin{array}{l}89 \\
91 \\
92 \\
95 \\
90 \\
85\end{array}$ & $\begin{array}{l}87 \\
90 \\
93 \\
94 \\
91 \\
89\end{array}$ & $\begin{array}{l}77 \\
78 \\
80 \\
76 \\
74 \\
--\end{array}$ \\
\hline $\begin{array}{c}\text { Aver- } \\
\text { age }\end{array}$ & 68 & 54 & 43 & 40 & 53 & 54 & 70 & 72 & 85 & 92 & 88 & 82 \\
\hline
\end{tabular}




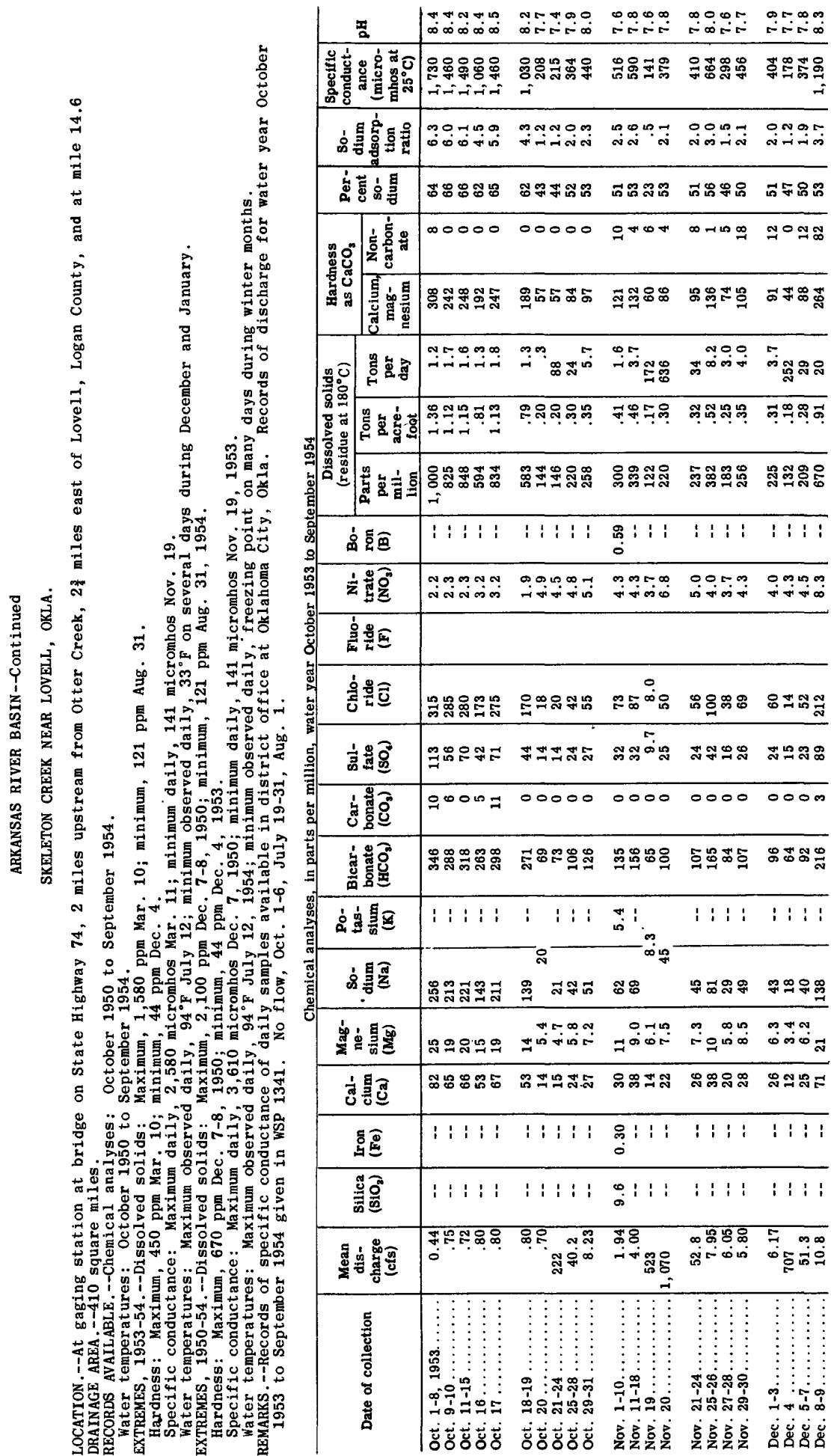




\begin{tabular}{|c|c|c|c|c|c|}
\hline $\begin{array}{l}\text { NO⿻ } \\
\infty \infty \infty \infty \\
\infty\end{array}$ & 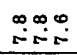 & 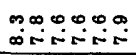 & 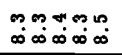 & 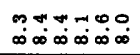 & 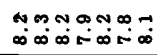 \\
\hline 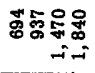 & $\begin{array}{l}\text { 융융유 } \\
\text { Nंतi }\end{array}$ & 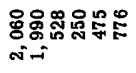 & 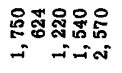 & 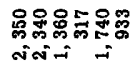 & 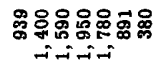 \\
\hline 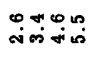 & $\begin{array}{lll}4 & 0 & 0 \\
0 & 0 & 0 \\
0 & 0\end{array}$ & $\infty$ & مَّ & 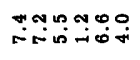 & ris \\
\hline 郧藏的品 & 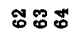 & 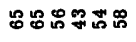 & 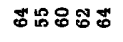 & ઇేઇ & ㅇํำ \\
\hline 유묘용 & 누요 & 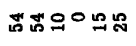 & ๑ & ஐ윹요요 & $\infty 0$ \\
\hline 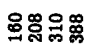 & 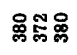 & 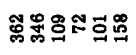 & 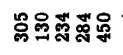 & 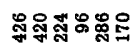 & 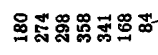 \\
\hline$\because 0$ & $\stackrel{0}{\infty}$ & 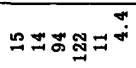 & 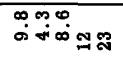 & 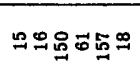 & 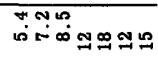 \\
\hline 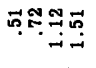 & 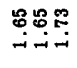 & 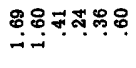 & 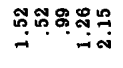 & 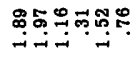 & 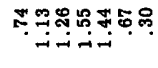 \\
\hline 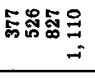 & 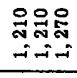 & 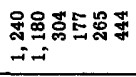 & 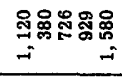 & 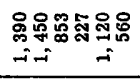 & 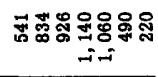 \\
\hline $\left.\begin{array}{r}1 \\
1\end{array}\right): \begin{array}{l}: \\
0\end{array}$ & i i i & $1: 1: 1: 1$ & : $1: 1: 1:$ & $1: 1: 1: 11$ & $: 1: 1: 1: 1: 1: 1$ \\
\hline & & 유 & 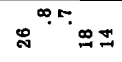 & $=\stackrel{0}{=}$ & क⿻ \\
\hline
\end{tabular}

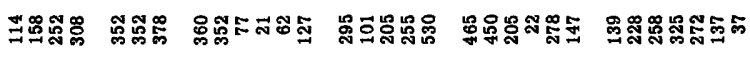

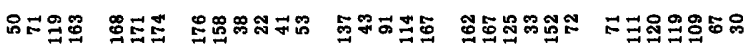

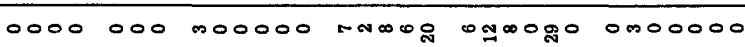

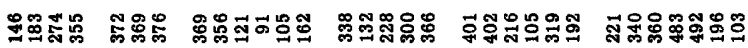

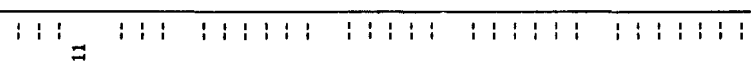

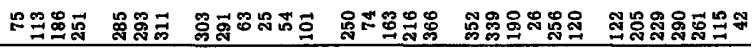

\begin{tabular}{|c|c|c|c|c|c|}
\hline 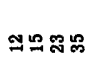 & దేస్లే స్లే & ส요 & ஜேニลスั & ๓ & ๑ホ๙ \\
\hline 요요용 & 55 & 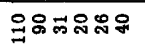 & 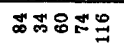 & 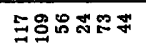 & 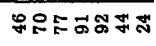 \\
\hline
\end{tabular}

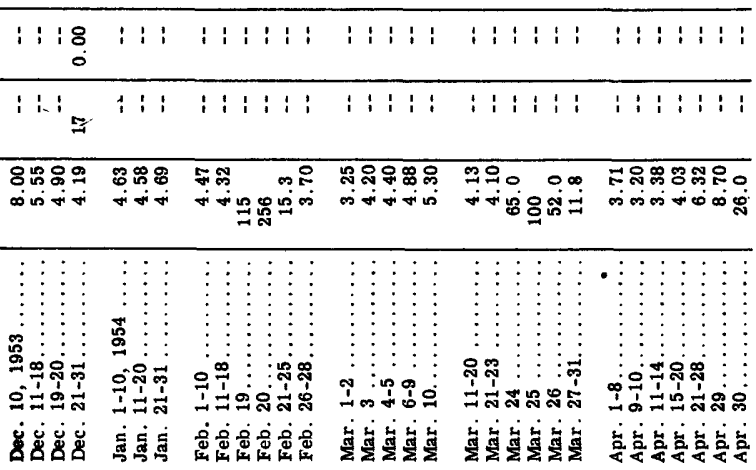




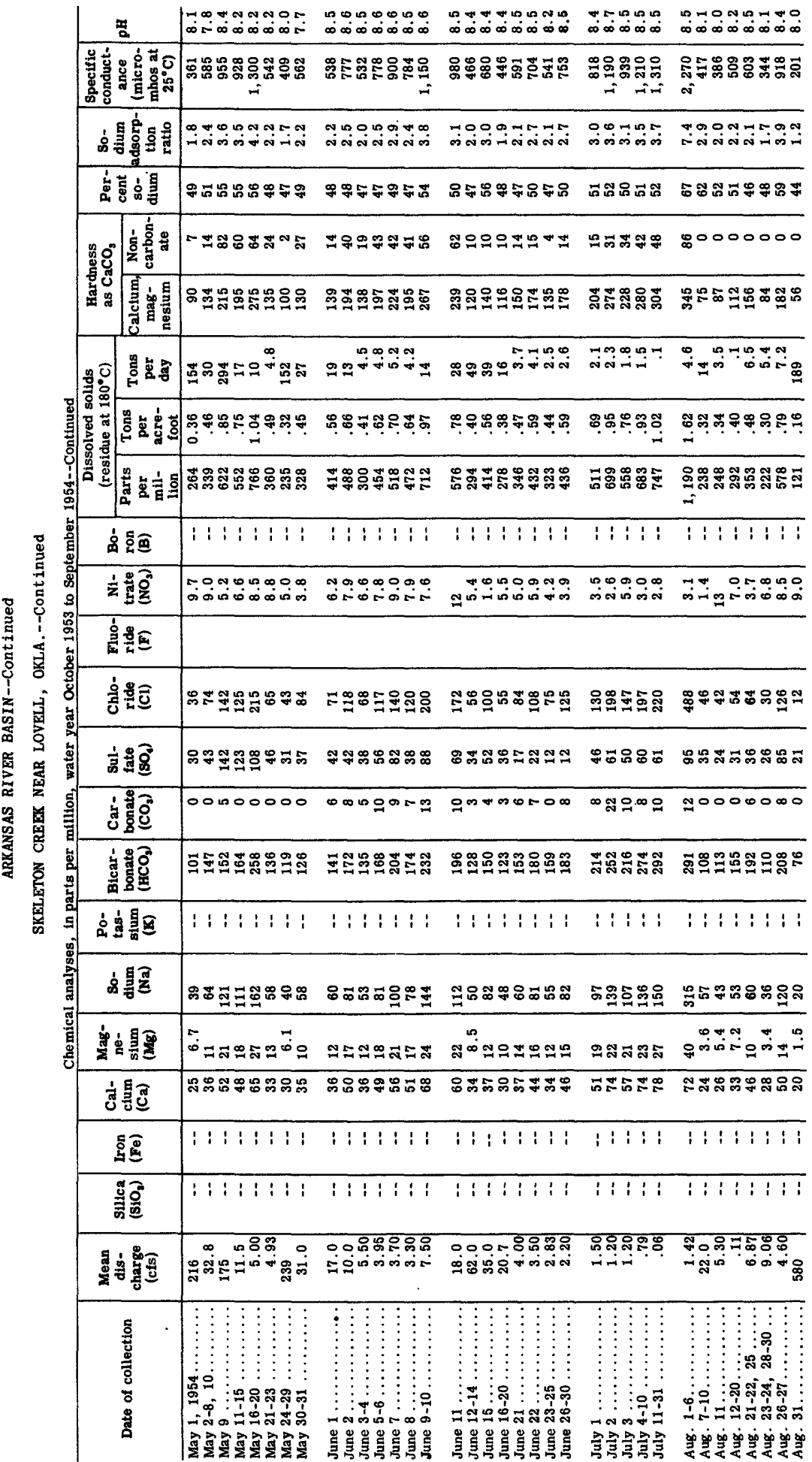




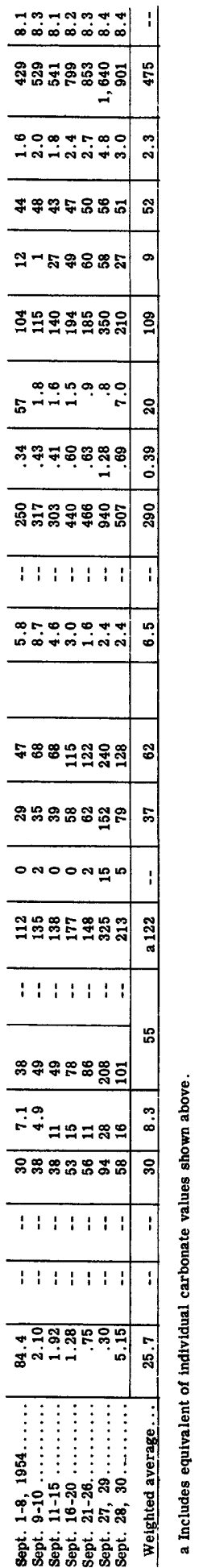


ARKANSAS RIVER BASIN--Cont inued

SKELETON CREEK NEAR LOVELL, OKLA.--Continued

Temperature $\left({ }^{\circ} \mathrm{F}\right)$ of water, water year October 1953 to September 1954

\begin{tabular}{|c|c|c|c|c|c|c|c|c|c|c|c|c|}
\hline Day & Oct. & Nov. & Dec. & Jan. & Feb. & Mar. & Apr. & May & June & July & Aug. & Sept. \\
\hline $\begin{array}{l}1 \\
2 \\
3 \\
4 \\
5\end{array}$ & $\begin{array}{l}-- \\
-- \\
-- \\
-- \\
--\end{array}$ & $\begin{array}{l}54 \\
62 \\
62 \\
39 \\
58\end{array}$ & $\begin{array}{l}44 \\
44 \\
44 \\
42 \\
42\end{array}$ & $\begin{array}{l}37 \\
36 \\
37 \\
38 \\
38\end{array}$ & $\begin{array}{l}37 \\
37 \\
37 \\
37 \\
37\end{array}$ & $\begin{array}{l}55 \\
49 \\
42 \\
42 \\
43\end{array}$ & $\begin{array}{l}\mathbf{5 2} \\
53 \\
55 \\
56 \\
58\end{array}$ & $\begin{array}{l}\mathbf{5 3} \\
\mathbf{5 2} \\
\mathbf{5 2} \\
\mathbf{5 4} \\
\mathbf{5 5}\end{array}$ & $\begin{array}{l}77 \\
75 \\
77 \\
73 \\
75\end{array}$ & $\begin{array}{l}86 \\
83 \\
85 \\
86 \\
84\end{array}$ & $\begin{array}{l}-- \\
86 \\
83 \\
85 \\
85\end{array}$ & $\begin{array}{l}85 \\
86 \\
86 \\
86 \\
86\end{array}$ \\
\hline $\begin{array}{r}6 \\
7 \\
8 \\
9 \\
10\end{array}$ & $\begin{array}{l}-- \\
63 \\
60 \\
61 \\
61\end{array}$ & $\begin{array}{l}48 \\
45 \\
47 \\
48 \\
50\end{array}$ & $\begin{array}{l}45 \\
50 \\
45 \\
45 \\
45\end{array}$ & $\begin{array}{l}38 \\
37 \\
36 \\
35 \\
36\end{array}$ & $\begin{array}{l}37 \\
38 \\
\ldots- \\
- \\
40\end{array}$ & $\begin{array}{l}43 \\
44 \\
45 \\
46 \\
46\end{array}$ & $\begin{array}{l}59 \\
61 \\
61 \\
62 \\
62\end{array}$ & $\begin{array}{l}58 \\
58 \\
61 \\
61 \\
64\end{array}$ & $\begin{array}{l}79 \\
78 \\
79 \\
79 \\
80\end{array}$ & $\begin{array}{l}89 \\
84 \\
88 \\
87 \\
93\end{array}$ & $\begin{array}{l}-- \\
86 \\
85 \\
85 \\
85\end{array}$ & $\begin{array}{l}86 \\
86 \\
85 \\
85 \\
84\end{array}$ \\
\hline $\begin{array}{l}11 \\
12 \\
13 \\
14 \\
15\end{array}$ & $\begin{array}{l}61 \\
62 \\
63 \\
62 \\
63\end{array}$ & $\begin{array}{l}50 \\
50 \\
50 \\
53 \\
55\end{array}$ & $\begin{array}{l}45 \\
45 \\
45 \\
46 \\
46\end{array}$ & $\begin{array}{l}35 \\
34 \\
34 \\
37 \\
38\end{array}$ & $\begin{array}{l}42 \\
44 \\
46 \\
52 \\
50\end{array}$ & $\begin{array}{l}47 \\
47 \\
48 \\
48 \\
46\end{array}$ & $\begin{array}{l}62 \\
62 \\
62 \\
63 \\
63\end{array}$ & $\begin{array}{l}70 \\
70 \\
70 \\
72 \\
72\end{array}$ & $\begin{array}{l}79 \\
80 \\
78 \\
83 \\
75\end{array}$ & $\begin{array}{l}93 \\
94 \\
85 \\
92 \\
84\end{array}$ & $\begin{array}{l}85 \\
86 \\
85 \\
85 \\
86\end{array}$ & $\begin{array}{l}82 \\
83 \\
82 \\
83 \\
82\end{array}$ \\
\hline $\begin{array}{l}16 \\
17 \\
18 \\
19 \\
20\end{array}$ & $\begin{array}{l}68 \\
68 \\
70 \\
70 \\
68\end{array}$ & $\begin{array}{l}55 \\
57 \\
55 \\
58 \\
45\end{array}$ & $\begin{array}{l}45 \\
46 \\
45 \\
45 \\
45\end{array}$ & $\begin{array}{l}34 \\
40 \\
34 \\
34 \\
35\end{array}$ & $\begin{array}{l}51 \\
52 \\
52 \\
52 \\
48\end{array}$ & $\begin{array}{l}46 \\
49 \\
49 \\
50 \\
51\end{array}$ & $\begin{array}{l}63 \\
64 \\
64 \\
64 \\
53\end{array}$ & $\begin{array}{l}73 \\
74 \\
74 \\
73 \\
70\end{array}$ & $\begin{array}{l}79 \\
80 \\
80 \\
81 \\
84\end{array}$ & $\begin{array}{l}85 \\
85 \\
86 \\
-- \\
--\end{array}$ & $\begin{array}{l}86 \\
86 \\
86 \\
86 \\
86\end{array}$ & $\begin{array}{l}82 \\
82 \\
80 \\
80 \\
81\end{array}$ \\
\hline $\begin{array}{l}21 \\
22 \\
23 \\
24 \\
25\end{array}$ & $\begin{array}{l}65 \\
63 \\
62 \\
62 \\
62\end{array}$ & $\begin{array}{l}44 \\
44 \\
45 \\
45 \\
45\end{array}$ & $\begin{array}{l}33 \\
\mathbf{3 3} \\
\mathbf{3 3} \\
\mathbf{3 3} \\
\mathbf{3 3}\end{array}$ & $\begin{array}{l}34 \\
33 \\
34 \\
35 \\
35\end{array}$ & $\begin{array}{l}45 \\
48 \\
49 \\
49 \\
51\end{array}$ & $\begin{array}{l}\mathbf{5 1} \\
\mathbf{5 1} \\
\mathbf{5 1} \\
\mathbf{5 1} \\
\mathbf{5 3}\end{array}$ & $\begin{array}{l}\mathbf{5 4} \\
\mathbf{5 4} \\
\mathbf{5 5} \\
\mathbf{5 5} \\
\mathbf{5 5}\end{array}$ & $\begin{array}{l}-- \\
65 \\
65 \\
69 \\
73\end{array}$ & $\begin{array}{l}82 \\
84 \\
84 \\
83 \\
85\end{array}$ & $\begin{array}{l}-- \\
-- \\
-- \\
-- \\
--\end{array}$ & $\begin{array}{l}87 \\
86 \\
87 \\
89 \\
85\end{array}$ & $\begin{array}{l}82 \\
-- \\
80 \\
78 \\
76\end{array}$ \\
\hline $\begin{array}{l}26 \\
27 \\
28 \\
29 \\
30 \\
31\end{array}$ & $\begin{array}{l}59 \\
58 \\
57 \\
57 \\
55 \\
55 \\
\end{array}$ & $\begin{array}{l}45 \\
45 \\
45 \\
45 \\
45 \\
-- \\
\end{array}$ & $\begin{array}{l}33 \\
34 \\
34 \\
35 \\
35 \\
36 \\
\end{array}$ & $\begin{array}{l}35 \\
35 \\
36 \\
36 \\
38 \\
-- \\
\end{array}$ & $\begin{array}{l}55 \\
55 \\
51 \\
-- \\
-- \\
-- \\
\end{array}$ & $\begin{array}{l}\mathbf{5 4} \\
54 \\
55 \\
54 \\
54 \\
53 \\
\end{array}$ & $\begin{array}{l}56 \\
53 \\
-- \\
53 \\
54 \\
-- \\
\end{array}$ & $\begin{array}{l}68 \\
73 \\
-- \\
73 \\
74 \\
77 \\
\end{array}$ & $\begin{array}{l}86 \\
85 \\
81 \\
83 \\
85 \\
-- \\
\end{array}$ & $\begin{array}{l}-- \\
-- \\
-- \\
-- \\
-- \\
-\end{array}$ & $\begin{array}{l}87 \\
87 \\
87 \\
87 \\
86 \\
87 \\
\end{array}$ & $\begin{array}{l}77 \\
77 \\
78 \\
78 \\
80 \\
-- \\
\end{array}$ \\
\hline $\begin{array}{c}\text { Aver- } \\
\text { age }\end{array}$ & 62 & 50 & 41 & 36 & 46 & 49 & 58 & 66 & 80 & -- & 86 & 82 \\
\hline
\end{tabular}




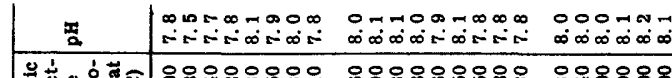

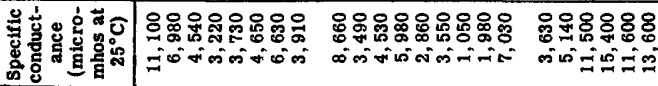

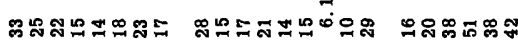

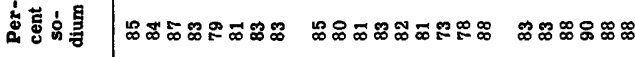

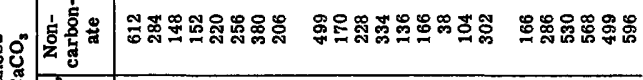

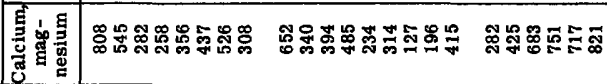

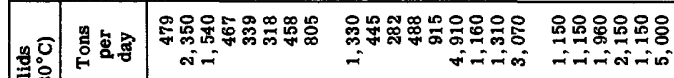

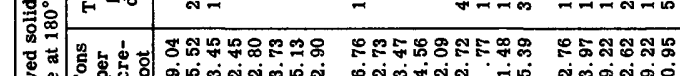

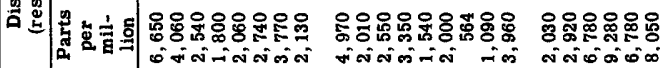

\begin{tabular}{|c|c|}
\hline 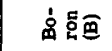 & \\
\hline 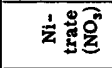 & i 1 ion \\
\hline
\end{tabular}

\begin{tabular}{|c|c|}
\hline 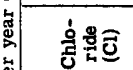 & 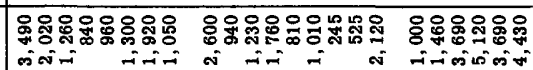 \\
\hline & $0 . \overline{0}$ \\
\hline
\end{tabular}

\begin{tabular}{l|l}
\hline | & \\
\hline i & 00000000000000000000000
\end{tabular}

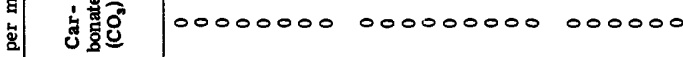

\begin{tabular}{|c|c|}
\hline 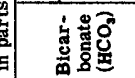 & 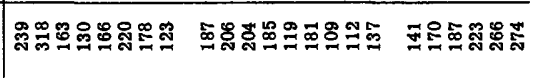 \\
\hline
\end{tabular}

\begin{tabular}{|c|c|c|c|c|}
\hline 家高重 & \multirow{2}{*}{ 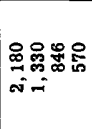 } & & & \\
\hline 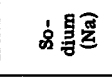 & & 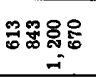 & 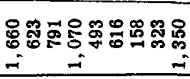 & 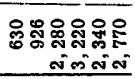 \\
\hline
\end{tabular}

\begin{tabular}{|c|c|c|c|}
\hline 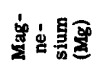 & 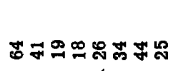 & 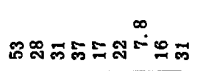 & 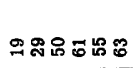 \\
\hline ฮู่ & 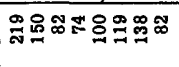 & 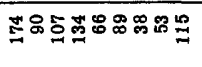 & 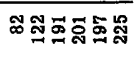 \\
\hline 害递 & & & \\
\hline 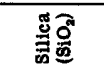 & & & \\
\hline 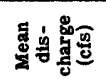 & 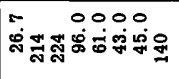 & 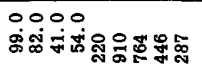 & 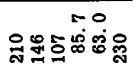 \\
\hline 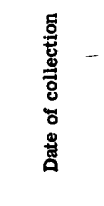 & 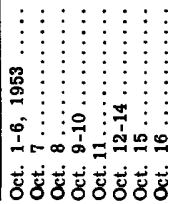 & 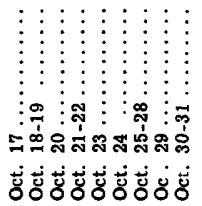 & 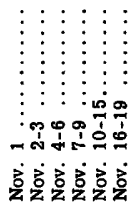 \\
\hline
\end{tabular}




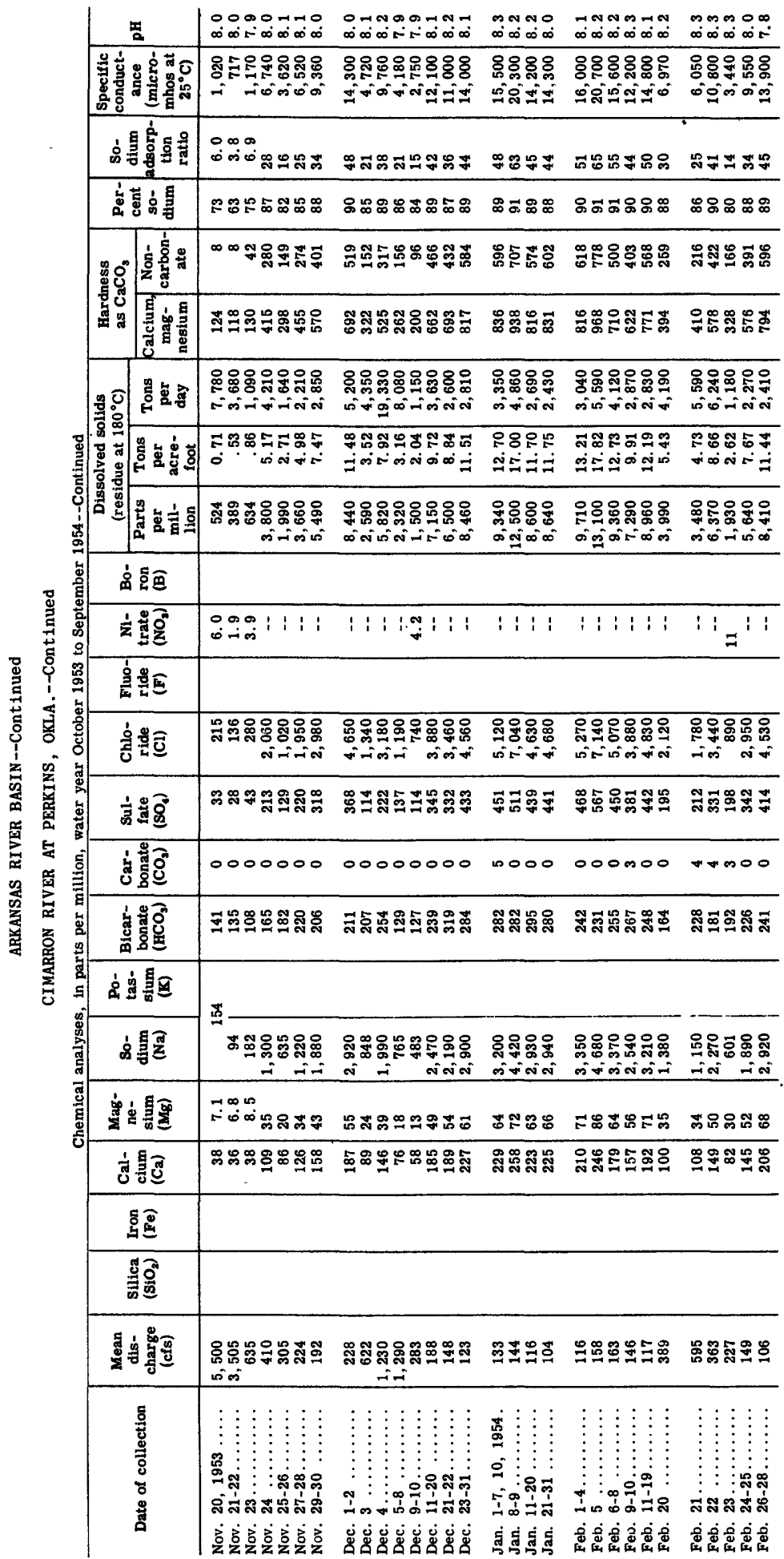




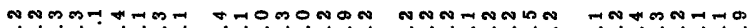

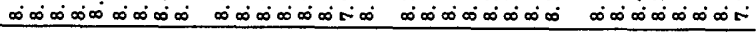

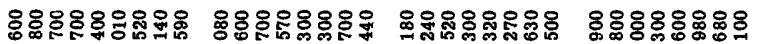

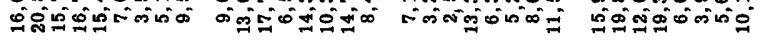

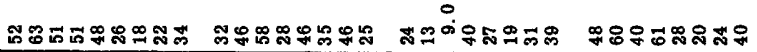

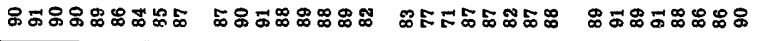

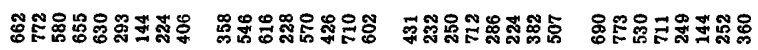

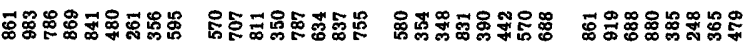

\begin{tabular}{|c|c|c|c|}
\hline 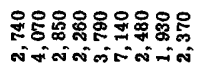 & 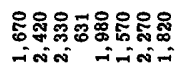 & 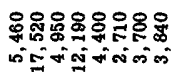 & 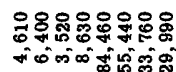 \\
\hline 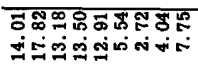 & 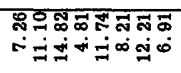 & 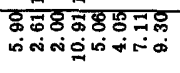 & 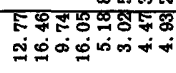 \\
\hline 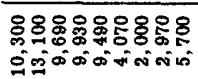 & 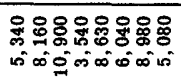 & 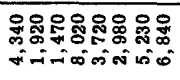 & 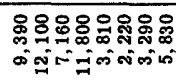 \\
\hline
\end{tabular}

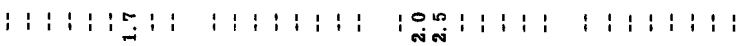

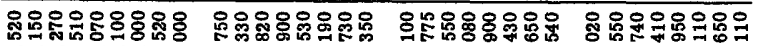

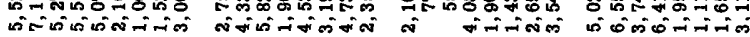

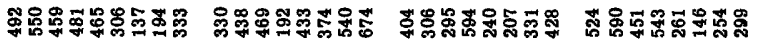

OOHONOWO 00000000 00000000 00R

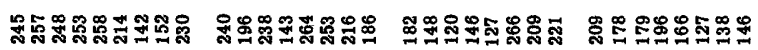

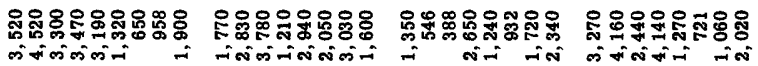

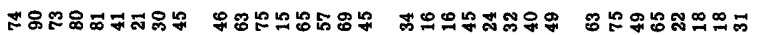

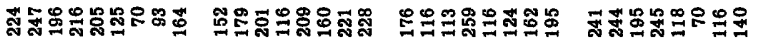

\begin{tabular}{|c|c|c|c|}
\hline $\begin{array}{l}\infty \\
\infty \\
\infty\end{array}$ & 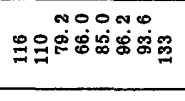 & 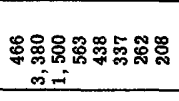 & 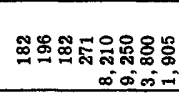 \\
\hline 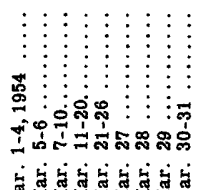 & 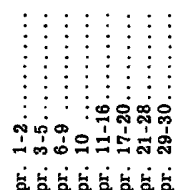 & 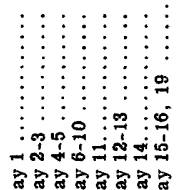 & 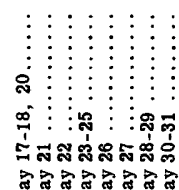 \\
\hline 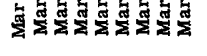 & & 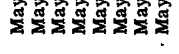 & 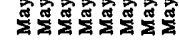 \\
\hline
\end{tabular}




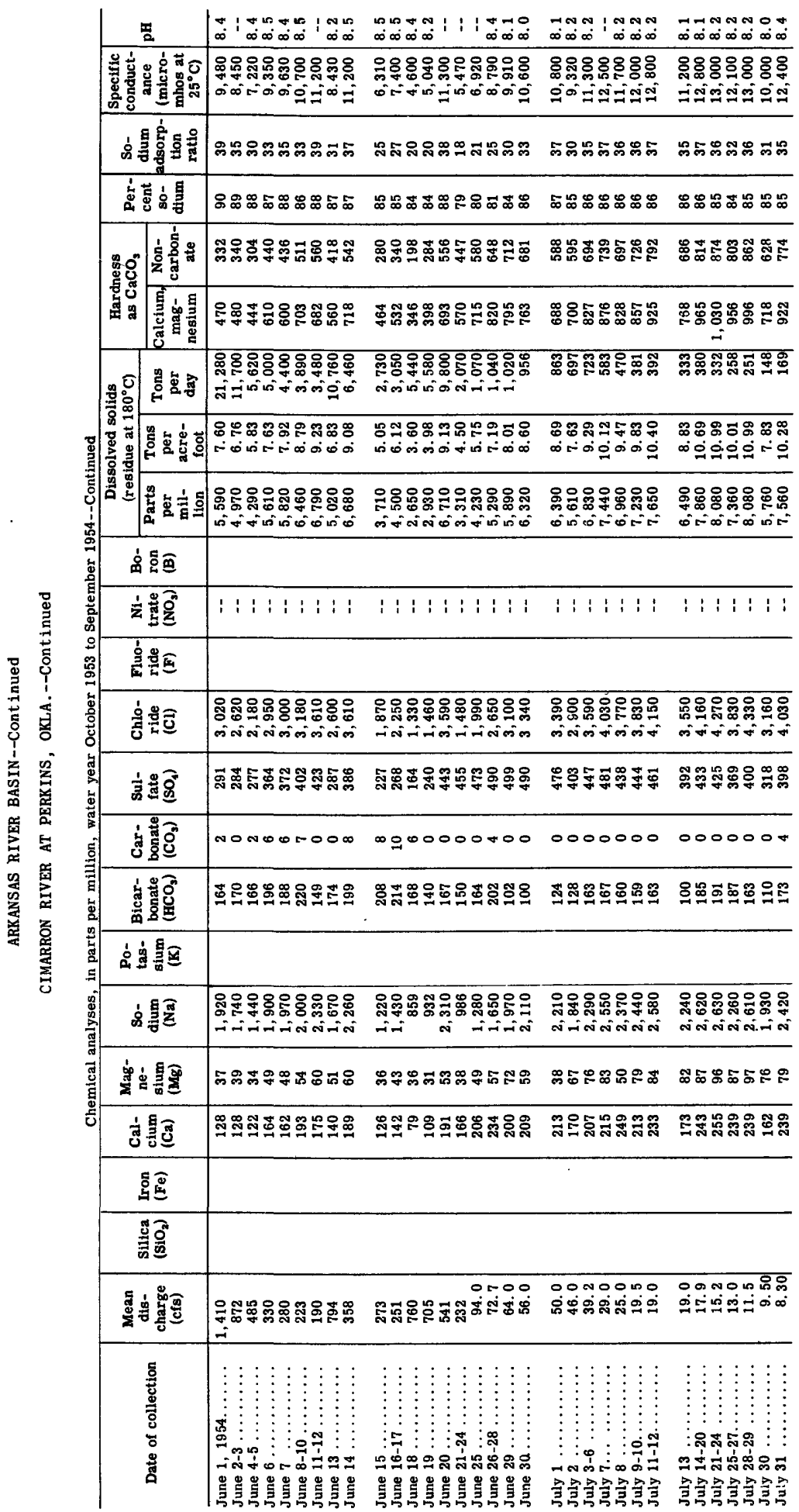




\begin{tabular}{|c|c|c|c|}
\hline 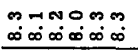 & 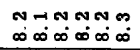 & 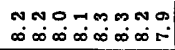 & i) \\
\hline 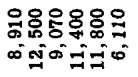 & 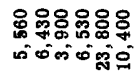 & 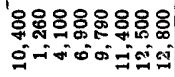 & $\begin{array}{c}\text { 영 } \\
\infty \\
\infty\end{array}$ \\
\hline 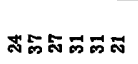 & 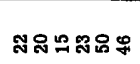 & 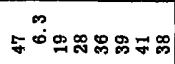 & $\stackrel{\sim}{\sim}$ \\
\hline 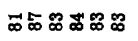 & 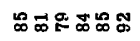 & אేテロ & ธ \\
\hline 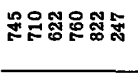 & 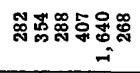 & 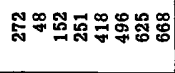 & జ \\
\hline 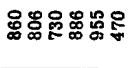 & 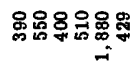 & 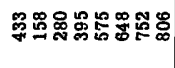 & 苟 \\
\hline あ & 융ㅎํ क영 & 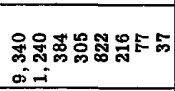 & 윰. \\
\hline 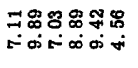 & 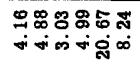 & 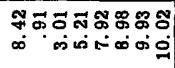 & $\begin{array}{c}\text { : } \\
\text { is }\end{array}$ \\
\hline 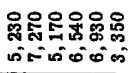 & 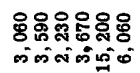 & 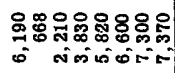 & षे \\
\hline & & $\stackrel{2}{0}$ & $i$ \\
\hline : : : : : i & $1: 11: 1$ & $15: 1: 1:$ 宓 & i) \\
\hline & & m. & i. \\
\hline 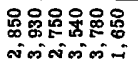 & 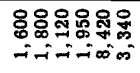 & 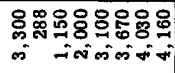 & $\begin{array}{l}8 \\
6 \\
\infty\end{array}$ \\
\hline พัง & 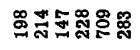 & 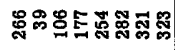 & 矛 \\
\hline NoOON & $00000 \%$ & 0000 Nmo & $i$ \\
\hline 怘恕总怘怘 & 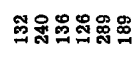 & 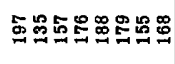 & 웜 \\
\hline & & 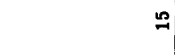 & : \\
\hline 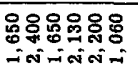 & 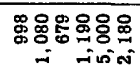 & 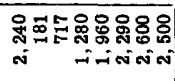 & $\Rightarrow$ \\
\hline ஃஃஃீஃே & 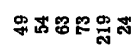 & 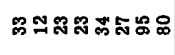 & का \\
\hline 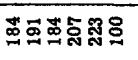 & உ ్⿹\zh26్ & 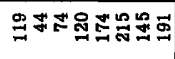 & $\underset{\sim}{2}$ \\
\hline & & 5 & : \\
\hline & & 윽 & ; \\
\hline 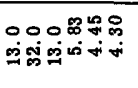 & 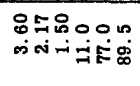 & 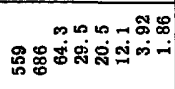 & 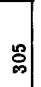 \\
\hline 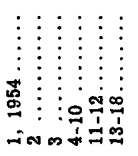 & 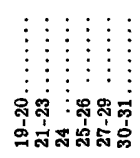 & 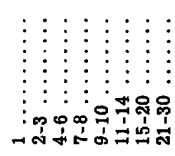 & 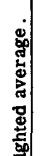 \\
\hline 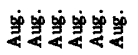 & 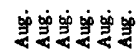 & 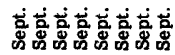 & 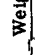 \\
\hline
\end{tabular}


ARKANSAS RIVER BASIN--Continued

CIMARRON RIVER AT PERKINS, OKLA.--Continued

Temperature $\left({ }^{\circ} \mathrm{F}\right)$ of water, water year October 1953 to September 1954

\begin{tabular}{|c|c|c|c|c|c|c|c|c|c|c|c|c|}
\hline Day & Oct. & Nov. & Dec. & Jan. & Feb. & Mar. & Apr. & May & June & July & Aug. & Sept. \\
\hline $\begin{array}{l}1 \\
2 \\
3 \\
4 \\
5\end{array}$ & $\begin{array}{l}66 \\
66 \\
65 \\
65 \\
63\end{array}$ & $\begin{array}{l}57 \\
58 \\
59 \\
60 \\
57\end{array}$ & $\begin{array}{l}46 \\
54 \\
50 \\
52 \\
54\end{array}$ & $\begin{array}{l}40 \\
41 \\
39 \\
43 \\
42\end{array}$ & $\begin{array}{l}47 \\
48 \\
47 \\
48 \\
47\end{array}$ & $\begin{array}{l}43 \\
35 \\
35 \\
34 \\
48\end{array}$ & $\begin{array}{l}43 \\
50 \\
56 \\
58 \\
60\end{array}$ & $\begin{array}{l}71 \\
56 \\
54 \\
52 \\
56\end{array}$ & $\begin{array}{l}70 \\
69 \\
70 \\
71 \\
72\end{array}$ & $\begin{array}{l}83 \\
84 \\
82 \\
84 \\
84\end{array}$ & $\begin{array}{l}81 \\
82 \\
82 \\
80 \\
80\end{array}$ & $\begin{array}{l}81 \\
79 \\
79 \\
77 \\
77\end{array}$ \\
\hline $\begin{array}{r}6 \\
7 \\
8 \\
9 \\
10\end{array}$ & $\begin{array}{l}60 \\
59 \\
60 \\
60 \\
59\end{array}$ & $\begin{array}{l}54 \\
48 \\
49 \\
45 \\
46\end{array}$ & $\begin{array}{l}54 \\
49 \\
46 \\
48 \\
--\end{array}$ & $\begin{array}{l}42 \\
-- \\
42 \\
38 \\
32\end{array}$ & $\begin{array}{l}46 \\
45 \\
45 \\
45 \\
46\end{array}$ & $\begin{array}{l}49 \\
43 \\
45 \\
50 \\
55\end{array}$ & $\begin{array}{l}65 \\
67 \\
58 \\
58 \\
68\end{array}$ & $\begin{array}{l}60 \\
62 \\
66 \\
65 \\
66\end{array}$ & $\begin{array}{l}74 \\
74 \\
76 \\
76 \\
76\end{array}$ & $\begin{array}{l}85 \\
84 \\
83 \\
84 \\
83\end{array}$ & $\begin{array}{l}81 \\
82 \\
80 \\
87 \\
81\end{array}$ & $\begin{array}{l}77 \\
76 \\
77 \\
76 \\
--\end{array}$ \\
\hline $\begin{array}{l}11 \\
12 \\
13 \\
14 \\
15\end{array}$ & $\begin{array}{l}62 \\
63 \\
65 \\
65 \\
65\end{array}$ & $\begin{array}{l}48 \\
48 \\
48 \\
51 \\
51\end{array}$ & $\begin{array}{l}50 \\
45 \\
44 \\
42 \\
43\end{array}$ & $\begin{array}{l}32 \\
32 \\
34 \\
36 \\
36\end{array}$ & $\begin{array}{r}45 \\
-46 \\
46 \\
44 \\
45\end{array}$ & $\begin{array}{l}49 \\
48 \\
34 \\
33 \\
38\end{array}$ & $\begin{array}{l}66 \\
58 \\
60 \\
64 \\
66\end{array}$ & $\begin{array}{l}64 \\
63 \\
67 \\
71 \\
78\end{array}$ & $\begin{array}{l}77 \\
78 \\
78 \\
78 \\
79\end{array}$ & $\begin{array}{l}85 \\
85 \\
84 \\
84 \\
84\end{array}$ & $\begin{array}{l}82 \\
82 \\
82 \\
82 \\
83\end{array}$ & $\begin{array}{l}69 \\
69 \\
68 \\
70 \\
69\end{array}$ \\
\hline $\begin{array}{l}16 \\
17 \\
18 \\
19 \\
20\end{array}$ & $\begin{array}{l}66 \\
64 \\
65 \\
65 \\
66\end{array}$ & $\begin{array}{l}51 \\
56 \\
59 \\
69 \\
48\end{array}$ & $\begin{array}{l}42 \\
40 \\
38 \\
36 \\
36\end{array}$ & $\begin{array}{l}36 \\
32 \\
37 \\
39 \\
38\end{array}$ & $\begin{array}{l}44 \\
47 \\
48 \\
48 \\
48\end{array}$ & $\begin{array}{l}42 \\
49 \\
50 \\
48 \\
49\end{array}$ & $\begin{array}{l}67 \\
66 \\
68 \\
68 \\
69\end{array}$ & $\begin{array}{l}68 \\
67 \\
68 \\
69 \\
70\end{array}$ & $\begin{array}{l}80 \\
82 \\
82 \\
84 \\
85\end{array}$ & $\begin{array}{l}85 \\
84 \\
85 \\
851 \\
84\end{array}$ & $\begin{array}{l}83 \\
83 \\
85 \\
85 \\
86\end{array}$ & $\begin{array}{l}69 \\
67 \\
68 \\
57 \\
-\end{array}$ \\
\hline $\begin{array}{l}21 \\
22 \\
23 \\
24 \\
25\end{array}$ & $\begin{array}{l}65 \\
66 \\
64 \\
62 \\
62\end{array}$ & $\begin{array}{l}46 \\
44 \\
45 \\
44 \\
45\end{array}$ & $\begin{array}{l}37 \\
32 \\
32 \\
32 \\
32\end{array}$ & $\begin{array}{l}32 \\
32 \\
32 \\
38 \\
32\end{array}$ & $\begin{array}{l}52 \\
53 \\
53 \\
54 \\
53\end{array}$ & $\begin{array}{l}50 \\
53 \\
51 \\
54 \\
56\end{array}$ & $\begin{array}{l}69 \\
66 \\
67 \\
68 \\
70\end{array}$ & $\begin{array}{l}71 \\
72 \\
74 \\
71 \\
71\end{array}$ & $\begin{array}{l}85 \\
84 \\
84 \\
85 \\
85\end{array}$ & $\begin{array}{l}85 \\
85 \\
85 \\
85 \\
83\end{array}$ & $\begin{array}{l}83 \\
84 \\
84 \\
84 \\
84\end{array}$ & $\begin{array}{l}70 \\
64 \\
65 \\
65 \\
--\end{array}$ \\
\hline $\begin{array}{l}26 \\
27 \\
28 \\
29 \\
30 \\
31\end{array}$ & $\begin{array}{l}60 \\
57 \\
58 \\
60 \\
57 \\
57\end{array}$ & $\begin{array}{l}45 \\
46 \\
46 \\
45 \\
46 \\
--\end{array}$ & $\begin{array}{l}32 \\
32 \\
32 \\
32 \\
32 \\
32\end{array}$ & $\begin{array}{l}35 \\
36 \\
38 \\
40 \\
41 \\
48\end{array}$ & $\begin{array}{l}49 \\
47 \\
44 \\
-- \\
-- \\
--\end{array}$ & $\begin{array}{l}52 \\
56 \\
56 \\
48 \\
48 \\
46\end{array}$ & $\begin{array}{l}70 \\
74 \\
73 \\
69 \\
70 \\
--\end{array}$ & $\begin{array}{l}70 \\
71 \\
73 \\
74 \\
71 \\
73\end{array}$ & $\begin{array}{l}85 \\
85 \\
84 \\
85 \\
84 \\
--\end{array}$ & $\begin{array}{l}82 \\
82 \\
81 \\
81 \\
81 \\
81\end{array}$ & $\begin{array}{l}84 \\
84 \\
83 \\
84 \\
81 \\
79\end{array}$ & $\begin{array}{l}67 \\
68 \\
71 \\
72 \\
73 \\
--\end{array}$ \\
\hline $\begin{array}{c}\text { Aver- } \\
\text { age }\end{array}$ & 62 & 50 & 41 & 37 & 48 & 47 & 64 & 67 & 79 & 84 & 83 & 72 \\
\hline
\end{tabular}




\begin{tabular}{|c|c|c|c|c|}
\hline 四 & 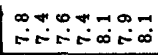 & 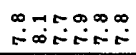 & 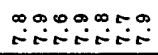 & 車品 \\
\hline 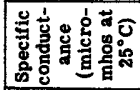 & 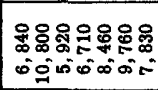 & 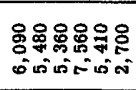 & 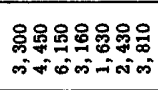 & 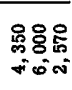 \\
\hline
\end{tabular}

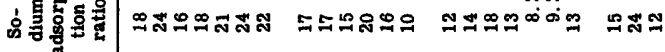

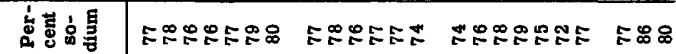

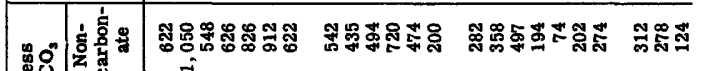

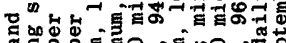

क็

$\leq \approx 0$ 국

ณ

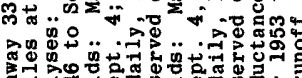

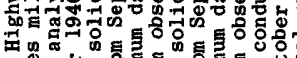
4 क

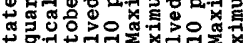

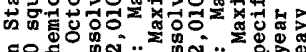

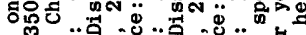

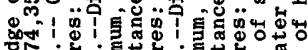

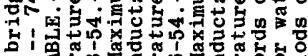

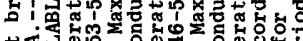

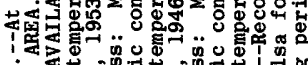

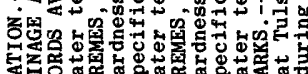

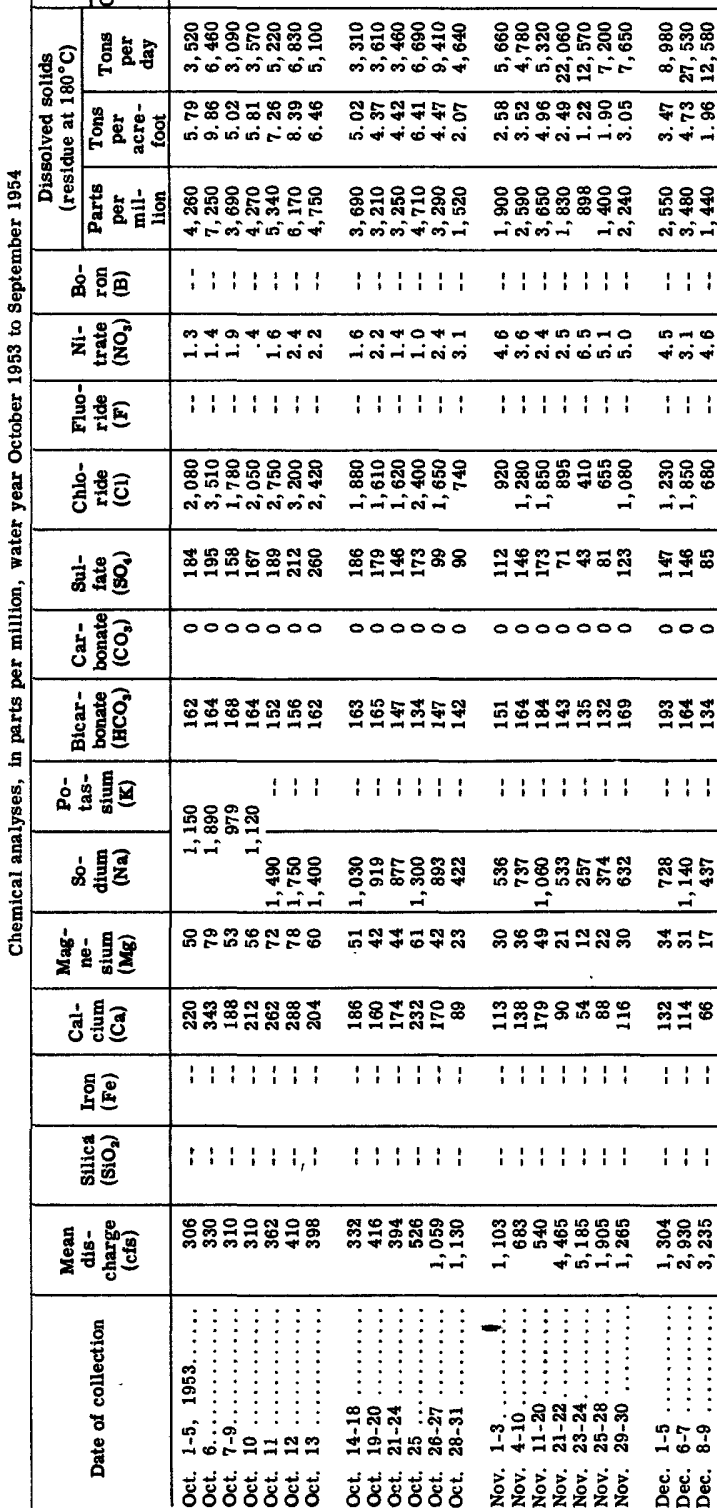




\begin{tabular}{|c|c|c|c|c|c|c|c|c|}
\hline & 명 & 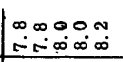 & 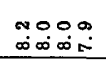 & $\begin{array}{l}\infty \infty+\infty \\
\infty \\
\therefore-\infty\end{array}$ & 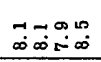 & 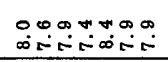 & 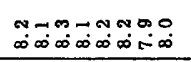 & $\stackrel{\infty}{\infty}$ \\
\hline & 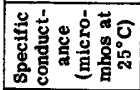 & 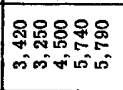 & 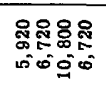 & 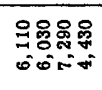 & 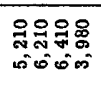 & 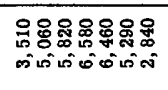 & 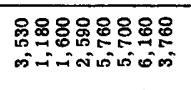 & 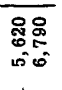 \\
\hline & 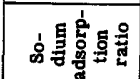 & 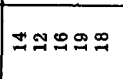 & 오옳ㅇ & 무ำสำ & 9 & $\approx 9$ & $\pm \infty$ & $\pi \stackrel{乛}{\pi}$ \\
\hline & 离蒿方最 & 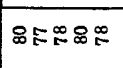 & ๑̊ロ & $\mathscr{\infty} \boldsymbol{\infty} \tilde{\infty}$ & 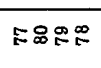 & 舟足 & 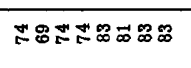 & 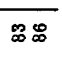 \\
\hline & 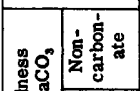 & 오สำ & 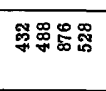 & 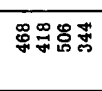 & 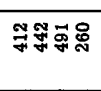 & 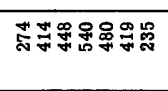 & 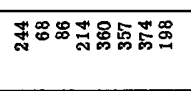 & 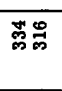 \\
\hline & 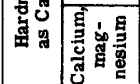 & 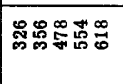 & 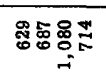 & 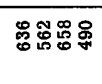 & 营思居。 & 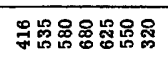 & 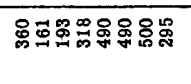 & \$ \\
\hline & 명영 & $\begin{array}{l}8.2 \\
\infty: 0 \\
0.0 \\
0.0\end{array}$ & 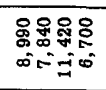 & 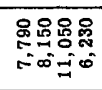 & 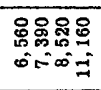 & 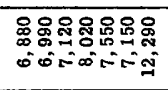 & 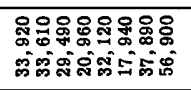 & 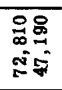 \\
\hline & 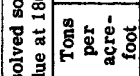 & 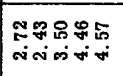 & 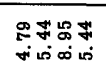 & & & & 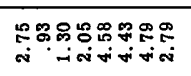 & 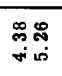 \\
\hline 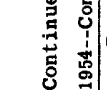 & 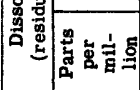 & 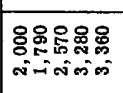 & 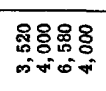 & 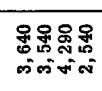 & 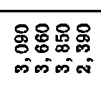 & 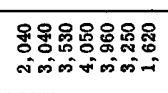 & 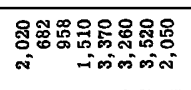 & $\begin{array}{l}\text { 裉怘 } \\
\text { sion }\end{array}$ \\
\hline & 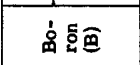 & $::$ & i $: 1:$ : & 1:：：： & i i & : : & 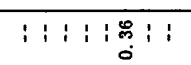 & i \\
\hline . & 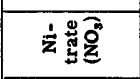 & $\begin{array}{l}\infty \\
\infty \\
\infty\end{array}$ & & 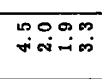 & कמ⿻上丨 & $\infty$ & 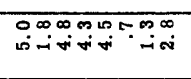 & $!$ \\
\hline 至 & 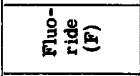 & $1: 1: 1$ & $1: 1:$ & $\overline{1: 1}$ & $\begin{array}{l}1: 1 \\
1\end{array}$ & $1: 1$ & : : $1: 1: \begin{array}{c}N \\
0\end{array}: !$ & $\overline{i !}$ \\
\hline 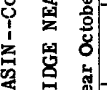 & 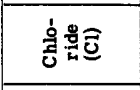 & 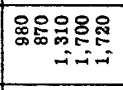 & 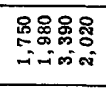 & 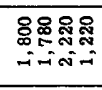 & 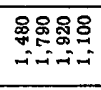 & $\stackrel{\circ}{\circ \% 5}$ & 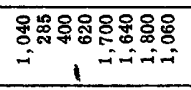 & 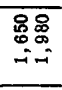 \\
\hline 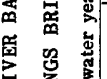 & 官芯高 & జ & 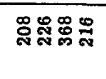 & 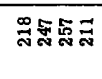 & 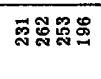 & 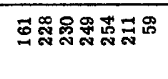 & 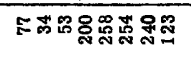 & 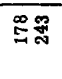 \\
\hline . & ปี่ & & 00 & 100 & 0009 & $\infty 00$ & 000 & 10 \\
\hline 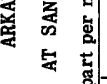 & 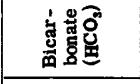 & 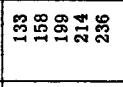 & 코웣 & 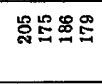 & 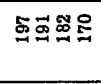 & 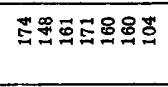 & 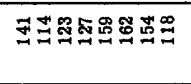 & 总司 \\
\hline 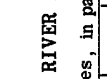 & 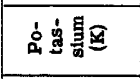 & : : & $1: 1:$ & 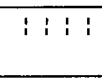 & 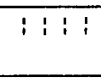 & $: 1$ & : $1: 1: l_{\infty}^{0}: 1 !$ & $\overline{1 !}$ \\
\hline 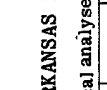 & 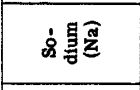 & 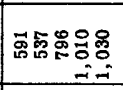 & 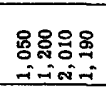 & 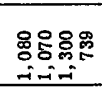 & 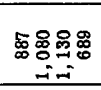 & 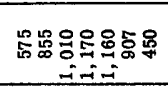 & 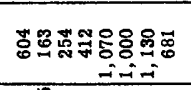 & 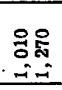 \\
\hline 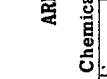 & 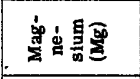 & 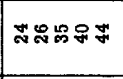 & 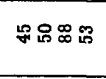 & భ & 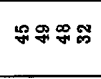 & 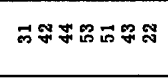 & 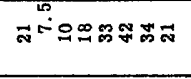 & $=0$ \\
\hline & 光皇 & 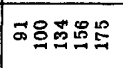 & 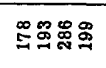 & 节㤩总芯 & 总品点: & 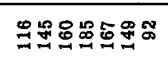 & 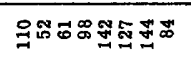 & 品芯 \\
\hline & 高棉 & $11: 1 !$ & $1: 1:$ & $1: 11$ & $1: 1 !$ & 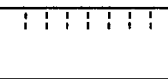 & 1:11:81! & : ! \\
\hline & 氙 & : : & : : : : : & $:: 1:$ & : : : : : & i: : & 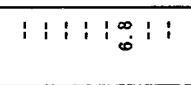 & : ! \\
\hline & 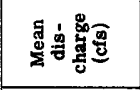 & 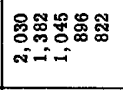 & 赵華 & 8 & 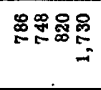 & 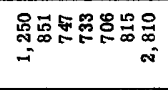 & 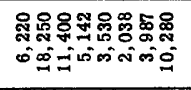 & 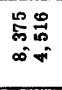 \\
\hline & 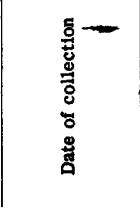 & 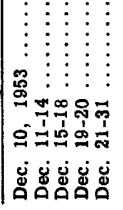 & 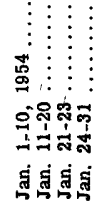 & 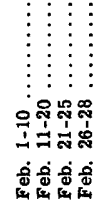 & 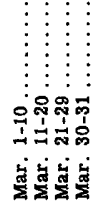 & 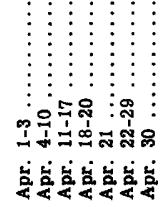 & 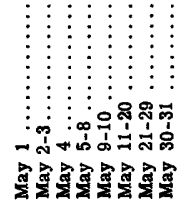 & 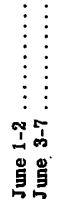 \\
\hline
\end{tabular}




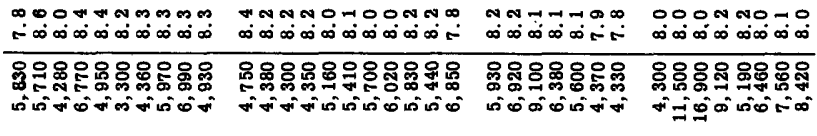

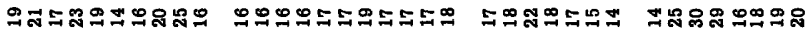

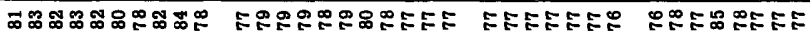

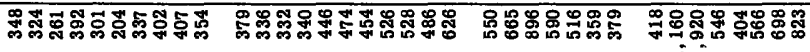
in

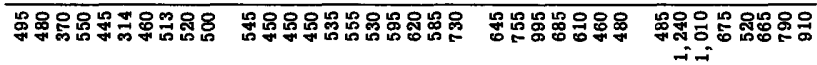

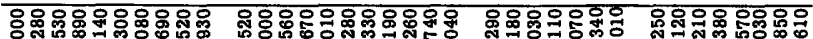

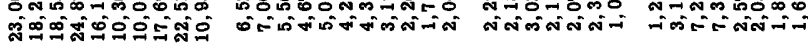

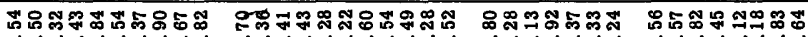

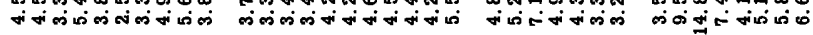

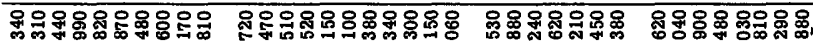

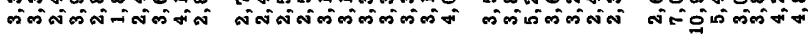

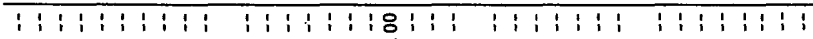

¿

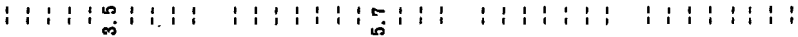

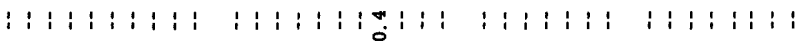

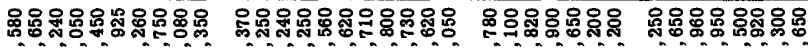

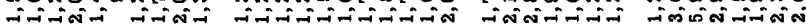

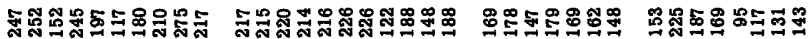

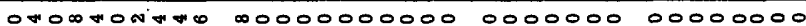

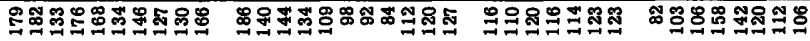

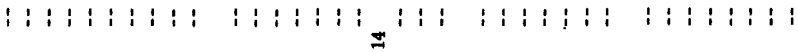

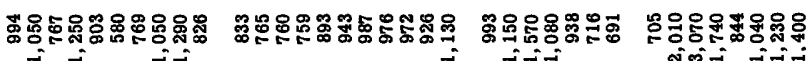

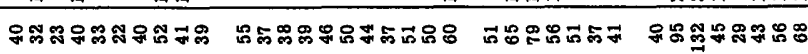

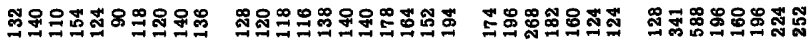

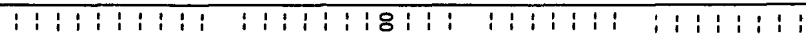

$\dot{0}$

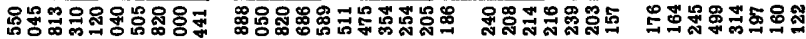
4⿻

窇

ำ

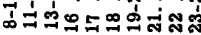

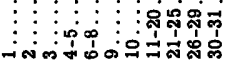

: 


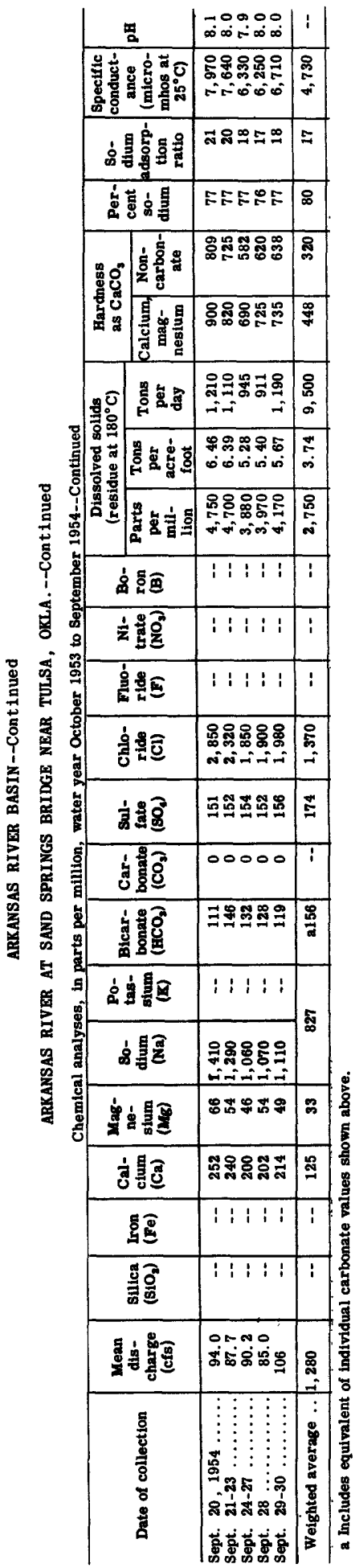


ARKANSAS RIVER BASIN--Cont inued

ARKANSAS RIVER AT SAND SPRINGS BRIDGE NEAR TULSA, OKLA.--Continued

Temperature $\left({ }^{\circ} \mathrm{F}\right.$ ) of water, water year October 1953 to September 1954

\begin{tabular}{|c|c|c|c|c|c|c|c|c|c|c|c|c|}
\hline Day & Oct. & Nov. & Dec. & Jan. & Feb. & Mar. & Apr. & May & June & July & Aug. & Sept. \\
\hline $\begin{array}{l}1 \\
2 \\
3 \\
4 \\
5\end{array}$ & $\begin{array}{l}83 \\
72 \\
73 \\
71 \\
61\end{array}$ & $\begin{array}{l}55 \\
57 \\
57 \\
59 \\
53\end{array}$ & $\begin{array}{l}45 \\
53 \\
53 \\
46 \\
--\end{array}$ & $\begin{array}{l}47 \\
48 \\
44 \\
47 \\
45\end{array}$ & $\begin{array}{l}41 \\
42 \\
44 \\
46 \\
45\end{array}$ & $\begin{array}{l}41 \\
42 \\
44 \\
45 \\
45\end{array}$ & $\begin{array}{l}55 \\
53 \\
58 \\
63 \\
66\end{array}$ & $\begin{array}{l}64 \\
62 \\
57 \\
56 \\
60\end{array}$ & $\begin{array}{l}75 \\
75 \\
70 \\
69 \\
71\end{array}$ & $\begin{array}{l}84 \\
93 \\
92 \\
79 \\
82\end{array}$ & $\begin{array}{l}80 \\
75 \\
82 \\
80 \\
81\end{array}$ & $\begin{array}{l}74 \\
75 \\
75 \\
77 \\
77\end{array}$ \\
\hline $\begin{array}{r}6 \\
7 \\
8 \\
9 \\
10\end{array}$ & $\begin{array}{l}58 \\
56 \\
70 \\
59 \\
59\end{array}$ & $\begin{array}{l}40 \\
41 \\
38 \\
40 \\
43\end{array}$ & $\begin{array}{l}46 \\
45 \\
45 \\
42 \\
42\end{array}$ & $\begin{array}{l}38 \\
41 \\
52 \\
45 \\
33\end{array}$ & $\begin{array}{l}48 \\
47 \\
39 \\
45 \\
47\end{array}$ & $\begin{array}{l}43 \\
46 \\
47 \\
49 \\
54\end{array}$ & $\begin{array}{l}67 \\
75 \\
64 \\
65 \\
64\end{array}$ & $\begin{array}{l}65 \\
70 \\
60 \\
60 \\
63\end{array}$ & $\begin{array}{l}71 \\
74 \\
70 \\
84 \\
85\end{array}$ & $\begin{array}{l}81 \\
81 \\
86 \\
87 \\
84\end{array}$ & $\begin{array}{l}82 \\
83 \\
76 \\
75 \\
77\end{array}$ & $\begin{array}{l}76 \\
76 \\
75 \\
83 \\
80\end{array}$ \\
\hline $\begin{array}{l}11 \\
12 \\
13 \\
14 \\
15\end{array}$ & $\begin{array}{l}61 \\
64 \\
64 \\
66 \\
72\end{array}$ & $\begin{array}{l}46 \\
48 \\
59 \\
51 \\
52\end{array}$ & $\begin{array}{l}42 \\
41 \\
40 \\
37 \\
--\end{array}$ & $\begin{array}{l}33 \\
32 \\
32 \\
33 \\
40\end{array}$ & $\begin{array}{l}42 \\
39 \\
41 \\
65 \\
59\end{array}$ & $\begin{array}{l}65 \\
64 \\
43 \\
38 \\
40\end{array}$ & $\begin{array}{l}66 \\
58 \\
58 \\
62 \\
64\end{array}$ & $\begin{array}{l}62 \\
64 \\
65 \\
66 \\
71\end{array}$ & $\begin{array}{l}87 \\
78 \\
84 \\
77 \\
74\end{array}$ & $\begin{array}{l}84 \\
83 \\
85 \\
86 \\
90\end{array}$ & $\begin{array}{l}76 \\
77 \\
80 \\
80 \\
79\end{array}$ & $\begin{array}{l}70 \\
69 \\
69 \\
71 \\
73\end{array}$ \\
\hline $\begin{array}{l}16 \\
17 \\
18 \\
19 \\
20\end{array}$ & $\begin{array}{l}65 \\
64 \\
64 \\
-5 \\
65\end{array}$ & $\begin{array}{l}53 \\
54 \\
60 \\
57 \\
47\end{array}$ & $\begin{array}{l}37 \\
36 \\
35 \\
37 \\
44\end{array}$ & $\begin{array}{l}35 \\
32 \\
33 \\
41 \\
40\end{array}$ & $\begin{array}{l}52 \\
46 \\
50 \\
52 \\
52\end{array}$ & $\begin{array}{l}48 \\
47 \\
49 \\
50 \\
50\end{array}$ & $\begin{array}{l}-5 \\
62 \\
62 \\
65 \\
66\end{array}$ & $\begin{array}{l}70 \\
70 \\
66 \\
74 \\
69\end{array}$ & $\begin{array}{l}85 \\
88 \\
81 \\
86 \\
84\end{array}$ & $\begin{array}{l}82 \\
87 \\
86 \\
83 \\
80\end{array}$ & $\begin{array}{l}82 \\
80 \\
79 \\
85 \\
77\end{array}$ & $\begin{array}{l}75 \\
78 \\
77 \\
77 \\
76\end{array}$ \\
\hline $\begin{array}{l}21 \\
22 \\
23 \\
24 \\
25\end{array}$ & $\begin{array}{l}64 \\
63 \\
63 \\
60 \\
61\end{array}$ & $\begin{array}{l}46 \\
46 \\
45 \\
46 \\
45\end{array}$ & $\begin{array}{l}46 \\
32 \\
32 \\
32 \\
34\end{array}$ & $\begin{array}{l}32 \\
32 \\
32 \\
40 \\
52\end{array}$ & $\begin{array}{l}55 \\
47 \\
47 \\
47 \\
51\end{array}$ & $\begin{array}{l}57 \\
50 \\
50 \\
54 \\
57\end{array}$ & $\begin{array}{l}70 \\
67 \\
62 \\
72 \\
68\end{array}$ & $\begin{array}{l}66 \\
74 \\
72 \\
72 \\
70\end{array}$ & $\begin{array}{l}82 \\
82 \\
84 \\
87 \\
88\end{array}$ & $\begin{array}{l}80 \\
81 \\
82 \\
86 \\
86\end{array}$ & $\begin{array}{l}77 \\
77 \\
77 \\
78 \\
79\end{array}$ & $\begin{array}{l}67 \\
62 \\
66 \\
66 \\
69\end{array}$ \\
\hline $\begin{array}{l}26 \\
27 \\
28 \\
29 \\
30 \\
31\end{array}$ & $\begin{array}{l}56 \\
50 \\
58 \\
51 \\
55 \\
56 \\
\end{array}$ & $\begin{array}{l}42 \\
43 \\
43 \\
42 \\
42 \\
-- \\
\end{array}$ & $\begin{array}{l}37 \\
38 \\
33 \\
35 \\
34 \\
35 \\
\end{array}$ & $\begin{array}{l}33 \\
38 \\
36 \\
41 \\
39 \\
39 \\
\end{array}$ & $\begin{array}{l}50 \\
47 \\
44 \\
-- \\
-- \\
--\end{array}$ & $\begin{array}{l}54 \\
56 \\
58 \\
56 \\
45 \\
50\end{array}$ & $\begin{array}{l}-- \\
69 \\
70 \\
72 \\
67 \\
--\end{array}$ & $\begin{array}{l}81 \\
82 \\
75 \\
71 \\
74 \\
75 \\
\end{array}$ & $\begin{array}{l}88 \\
90 \\
89 \\
88 \\
88 \\
-- \\
\end{array}$ & $\begin{array}{l}82 \\
79 \\
80 \\
94 \\
81 \\
82 \\
\end{array}$ & $\begin{array}{l}78 \\
80 \\
84 \\
84 \\
81 \\
75 \\
\end{array}$ & $\begin{array}{l}69 \\
74 \\
72 \\
75 \\
74 \\
-- \\
\end{array}$ \\
\hline $\begin{array}{c}\text { Aver- } \\
\text { age }\end{array}$ & 63 & 48 & 40 & 39 & 48 & 50 & 65 & 68 & 81 & 84 & 79 & 73 \\
\hline
\end{tabular}




\begin{tabular}{|c|c|c|c|c|}
\hline 폄 & : & 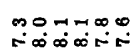 & 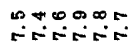 & 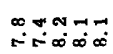 \\
\hline 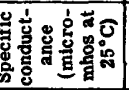 & 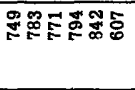 & 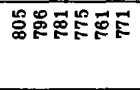 & 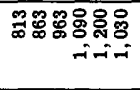 & 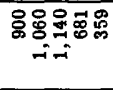 \\
\hline 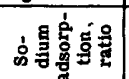 & 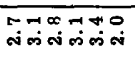 & 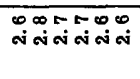 & 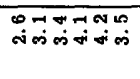 & 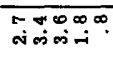 \\
\hline 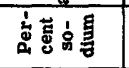 & 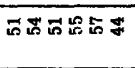 & 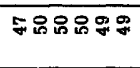 & 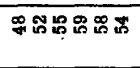 & 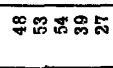 \\
\hline 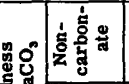 & 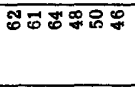 & 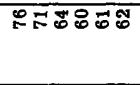 & 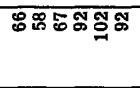 & 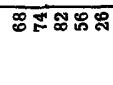 \\
\hline 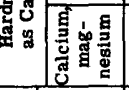 & 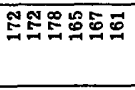 & 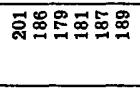 & 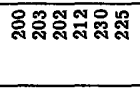 & 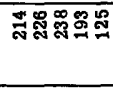 \\
\hline ठ & 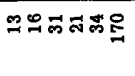 & 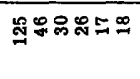 & 무우ㅇㅠㅜㅇㅛ & \%요요요 \\
\hline 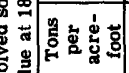 & ద유유. & 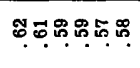 & 윰요요 & 웅ㅎ․ \\
\hline 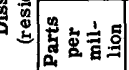 & 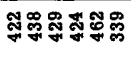 & 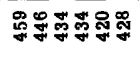 & 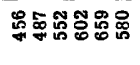 & 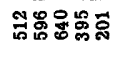 \\
\hline 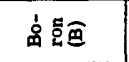 & 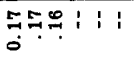 & 윰：：： & : : : : : : & $1: 1: 1:$ \\
\hline 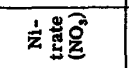 & $\exists$ & 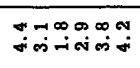 & 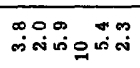 & 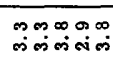 \\
\hline 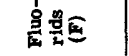 & $\overbrace{0}^{\infty}$ & no: : i i i & $1: 1: 1:$ & $1: 1: 1$ \\
\hline 웒 휼르 & 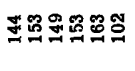 & 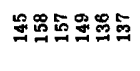 & 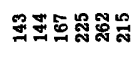 & ฮ్ర \\
\hline 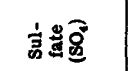 & 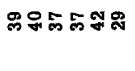 & 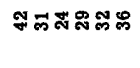 & 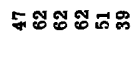 & 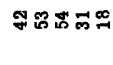 \\
\hline 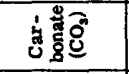 & 000000 & 000000 & 000000 & 00000 \\
\hline 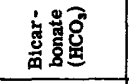 & 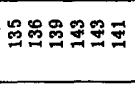 & 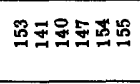 & 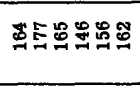 & 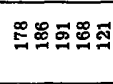 \\
\hline 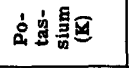 & 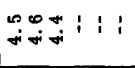 & 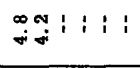 & : $: 1:: 1:$ & $1: 1: 1$ \\
\hline 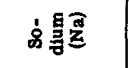 & ธూ & 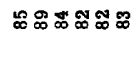 & 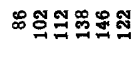 & న \\
\hline 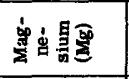 & 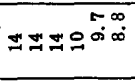 & ตำ & 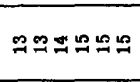 & 거욤ㅇㅇ \\
\hline 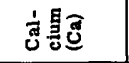 & 우원 & 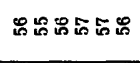 & 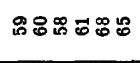 & ஜேேேす \\
\hline 菓函 & $888: 1: 1$ & 8 & 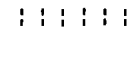 & $: 1:: 1:$ \\
\hline 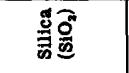 & 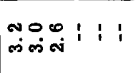 & 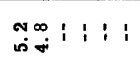 & $1: 1: 1: 1$ & : $1: 1: 1$ \\
\hline รี & 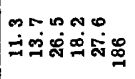 & 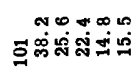 & 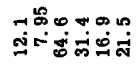 & 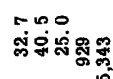 \\
\hline 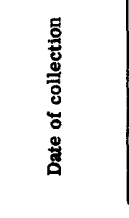 & 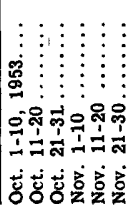 & 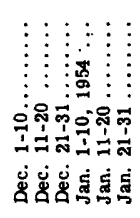 & 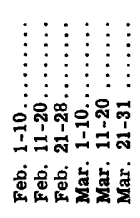 & 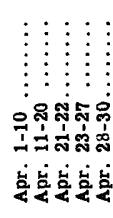 \\
\hline
\end{tabular}




\begin{tabular}{|c|c|c|c|c|}
\hline 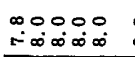 & 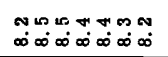 & 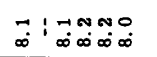 & 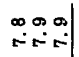 & : \\
\hline 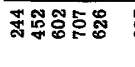 & 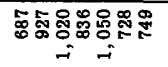 & 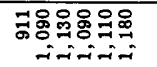 & 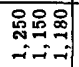 & : \\
\hline 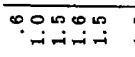 & $\begin{array}{l}m \infty n-100 \\
-1 \text { - }\end{array}$ & 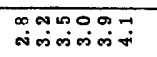 & 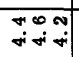 & 암 \\
\hline 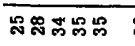 & 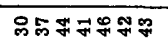 & 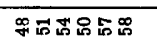 & 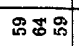 & 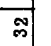 \\
\hline 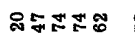 & 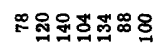 & 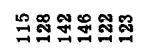 & $\stackrel{\infty}{\infty} \times \nsubseteq$ & ఱ్ల \\
\hline 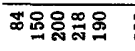 & 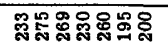 & 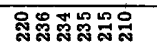 & స్టి유유 & $\exists$ \\
\hline 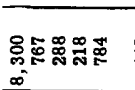 & 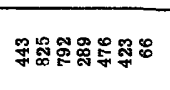 & 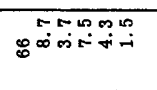 & - & ఊั \\
\hline 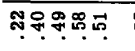 & 员 & 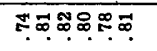 & 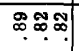 & 周 \\
\hline 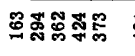 & 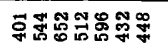 & 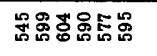 & 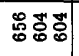 & สู่ \\
\hline $\begin{array}{c}15: 1 \\
1 \\
0\end{array}$ & : : : $1: 1: 1$ 年 & $\exists: 1: 1:$ & s: : & $i$ \\
\hline 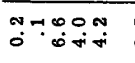 & 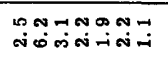 & " & 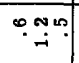 & $\stackrel{-1}{=}$ \\
\hline $1: \begin{array}{l}\infty \\
0\end{array} 1$ & $1: 1: 11: 9$ & $9: 1: 1:$ : & ?.: & $i$ \\
\hline 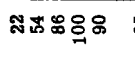 & 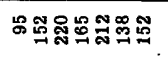 & 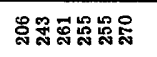 & : & 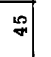 \\
\hline 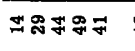 & 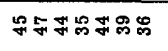 & 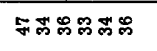 & 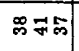 & 8 \\
\hline 00000 & $00004 \pi, n 0$ & 000000 & 000 & $i$ \\
\hline 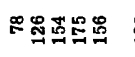 & 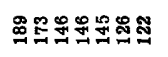 & 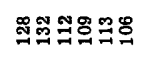 & ৪্রळ\% & 8 \\
\hline$i: \infty$ & $: 1: 1: 1: \%$ & $5: 1: 1: 1$ & $\begin{array}{c:cc}0 & 0 \\
\text { is } & \text { is }\end{array}$ & $:$ \\
\hline のลかロ & 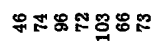 & 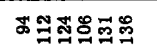 & $\overrightarrow{b \infty}$ & 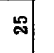 \\
\hline 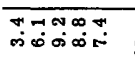 & のニののののの & ๑ㅗสำำ & $\stackrel{-\infty}{=\infty}$ & ஸे \\
\hline ஸ̊ำ: & 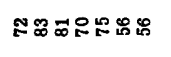 & 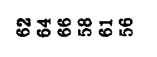 & 옹용 & 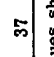 \\
\hline i io : & $1: 1: 1: 1: 0$ & $5: 1: 1: 1$ & 우: $: 5$ & $\mathrm{i}$ \\
\hline $11 \pm 11$ & $1: 1: 1: 9$ & $\begin{array}{l}0 \\
\infty\end{array}: 1: 1: 1:$ & $\begin{array}{llll}0 & 1 & 0 \\
\text { in } & \text { is }\end{array}$ & 1 \\
\hline 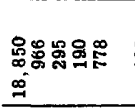 & 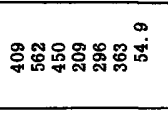 & 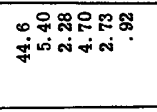 & 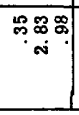 & 怘 \\
\hline 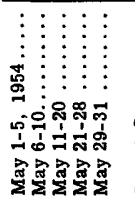 & 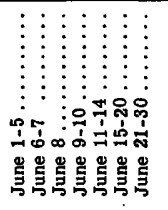 & 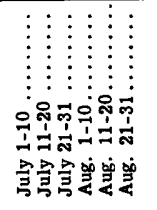 & 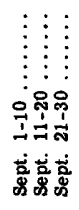 & 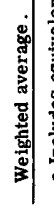 \\
\hline
\end{tabular}


ARKANSAS RIVER BASIN--Continued

VERDIGRIS RIVER NEAR LENAPAH, OKLA.--Cont inued

Temperature $\left({ }^{\circ} \mathrm{F}\right)$ of water, water year October 1953 to September 1954

\begin{tabular}{|c|c|c|c|c|c|c|c|c|c|c|c|c|}
\hline Das & Oct. & Nov. & Dec. & Jan. & Feb. & Mar. & Apr. & May & June & July & Aug. & Sept. \\
\hline $\begin{array}{l}1 \\
2 \\
3 \\
4 \\
5\end{array}$ & $\begin{array}{l}75 \\
75 \\
75 \\
72 \\
68\end{array}$ & $\begin{array}{l}62 \\
63 \\
58 \\
56 \\
57\end{array}$ & $\begin{array}{l}49 \\
51 \\
51 \\
52 \\
52\end{array}$ & $\begin{array}{l}44 \\
45 \\
45 \\
45 \\
47\end{array}$ & $\begin{array}{l}45 \\
-- \\
46 \\
47 \\
49\end{array}$ & $\begin{array}{l}52 \\
47 \\
45 \\
46 \\
47\end{array}$ & $\begin{array}{l}56 \\
65 \\
65 \\
66 \\
68\end{array}$ & $\begin{array}{l}64 \\
64 \\
61 \\
59 \\
60\end{array}$ & $\begin{array}{l}75 \\
74 \\
74 \\
71 \\
72\end{array}$ & & $\begin{array}{l}-- \\
-- \\
-- \\
--\end{array}$ & $\begin{array}{l}83 \\
82 \\
85 \\
84 \\
86\end{array}$ \\
\hline $\begin{array}{r}6 \\
7 \\
8 \\
9 \\
10\end{array}$ & $\begin{array}{l}65 \\
63 \\
63 \\
65 \\
66\end{array}$ & $\begin{array}{l}50 \\
48 \\
50 \\
50 \\
50\end{array}$ & $\begin{array}{l}\mathbf{5 1} \\
50 \\
50 \\
\mathbf{4 7} \\
\mathbf{4 8}\end{array}$ & $\begin{array}{l}47 \\
50 \\
53 \\
40 \\
38\end{array}$ & $\begin{array}{l}48 \\
47 \\
47 \\
53 \\
51\end{array}$ & $\begin{array}{l}49 \\
51 \\
52 \\
56 \\
55\end{array}$ & $\begin{array}{l}70 \\
72 \\
70 \\
68 \\
65\end{array}$ & $\begin{array}{l}60 \\
62 \\
63 \\
65 \\
66\end{array}$ & $\begin{array}{l}75 \\
75 \\
78 \\
80 \\
83\end{array}$ & & $\begin{array}{l}-- \\
=- \\
-- \\
--\end{array}$ & $\begin{array}{l}83 \\
80 \\
83 \\
82 \\
80\end{array}$ \\
\hline $\begin{array}{l}11 \\
12 \\
13 \\
14 \\
15\end{array}$ & $\begin{array}{l}65 \\
68 \\
67 \\
68 \\
70\end{array}$ & $\begin{array}{l}\mathbf{5 1} \\
55 \\
55 \\
55 \\
57\end{array}$ & $\begin{array}{l}45 \\
-- \\
-- \\
42 \\
41\end{array}$ & $\begin{array}{l}37 \\
36 \\
37 \\
38 \\
40\end{array}$ & $\begin{array}{l}46 \\
-- \\
53 \\
55 \\
57\end{array}$ & $\begin{array}{l}58 \\
60 \\
54 \\
52 \\
50\end{array}$ & $\begin{array}{l}64 \\
65 \\
70 \\
71 \\
70\end{array}$ & $\begin{array}{l}67 \\
66 \\
67 \\
68 \\
70\end{array}$ & $\begin{array}{l}80 \\
82 \\
73 \\
72 \\
73\end{array}$ & & $\begin{array}{l}-- \\
-- \\
-- \\
--\end{array}$ & $\begin{array}{l}80 \\
77 \\
75 \\
80 \\
81\end{array}$ \\
\hline $\begin{array}{l}16 \\
17 \\
18 \\
19 \\
20\end{array}$ & $\begin{array}{l}70 \\
70 \\
69 \\
68 \\
68\end{array}$ & $\begin{array}{r}54 \\
58 \\
60 \\
-5 \\
153\end{array}$ & $\begin{array}{l}41 \\
40 \\
40 \\
42 \\
43\end{array}$ & $\begin{array}{l}37 \\
37 \\
44 \\
45 \\
42\end{array}$ & $\begin{array}{l}58 \\
54 \\
53 \\
53 \\
54\end{array}$ & $\begin{array}{l}52 \\
54 \\
56 \\
56 \\
51\end{array}$ & $\begin{array}{l}67 \\
72 \\
74 \\
70 \\
70\end{array}$ & $\begin{array}{l}71 \\
70 \\
70 \\
70 \\
72\end{array}$ & $\begin{array}{l}- \\
-- \\
-- \\
--\end{array}$ & & $\begin{array}{l}-- \\
-- \\
85 \\
87 \\
86\end{array}$ & $\begin{array}{l}80 \\
81 \\
84 \\
83 \\
85\end{array}$ \\
\hline $\begin{array}{l}21 \\
22 \\
23 \\
24 \\
25\end{array}$ & $\begin{array}{l}68 \\
66 \\
65 \\
-- \\
62\end{array}$ & $\begin{array}{l}52 \\
-2 \\
51 \\
49 \\
50\end{array}$ & $\begin{array}{l}44 \\
35 \\
36 \\
37 \\
37\end{array}$ & $\begin{array}{l}36 \\
35 \\
38 \\
39 \\
47\end{array}$ & $\begin{array}{l}54 \\
54 \\
55 \\
50 \\
50\end{array}$ & $\begin{array}{l}50 \\
49 \\
55 \\
60 \\
60\end{array}$ & $\begin{array}{l}68 \\
64 \\
70 \\
70 \\
72\end{array}$ & $\begin{array}{l}75 \\
72 \\
72 \\
76 \\
72\end{array}$ & $\begin{array}{l}-- \\
-- \\
-- \\
--\end{array}$ & & $\begin{array}{l}86 \\
84 \\
82 \\
84 \\
84\end{array}$ & $\begin{array}{l}84 \\
77 \\
75 \\
74 \\
74\end{array}$ \\
\hline $\begin{array}{l}26 \\
27 \\
28 \\
29 \\
30 \\
31\end{array}$ & $\begin{array}{l}58 \\
55 \\
60 \\
63 \\
58 \\
59 \\
\end{array}$ & $\begin{array}{l}50 \\
48 \\
47 \\
47 \\
47 \\
-- \\
\end{array}$ & $\begin{array}{l}39 \\
40 \\
41 \\
40 \\
42 \\
42 \\
\end{array}$ & $\begin{array}{l}38 \\
38 \\
40 \\
42 \\
42 \\
45 \\
\end{array}$ & $\begin{array}{l}50 \\
51 \\
51 \\
-- \\
-- \\
-- \\
\end{array}$ & $\begin{array}{l}60 \\
60 \\
66 \\
55 \\
50 \\
55 \\
\end{array}$ & $\begin{array}{l}73 \\
73 \\
69 \\
68 \\
64 \\
-- \\
\end{array}$ & $\begin{array}{l}73 \\
75 \\
75 \\
75 \\
76 \\
77 \\
\end{array}$ & $\begin{array}{l}-- \\
-- \\
-- \\
-- \\
-- \\
-- \\
\end{array}$ & & $\begin{array}{l}83 \\
87 \\
88 \\
90 \\
87 \\
85 \\
\end{array}$ & $\begin{array}{l}76 \\
77 \\
78 \\
79 \\
75 \\
-- \\
\end{array}$ \\
\hline $\begin{array}{c}\text { Aver- } \\
\text { age }\end{array}$ & 66 & 53 & 44 & 42 & 51 & 54 & 68 & 69 & -- & & -- & 80 \\
\hline
\end{tabular}




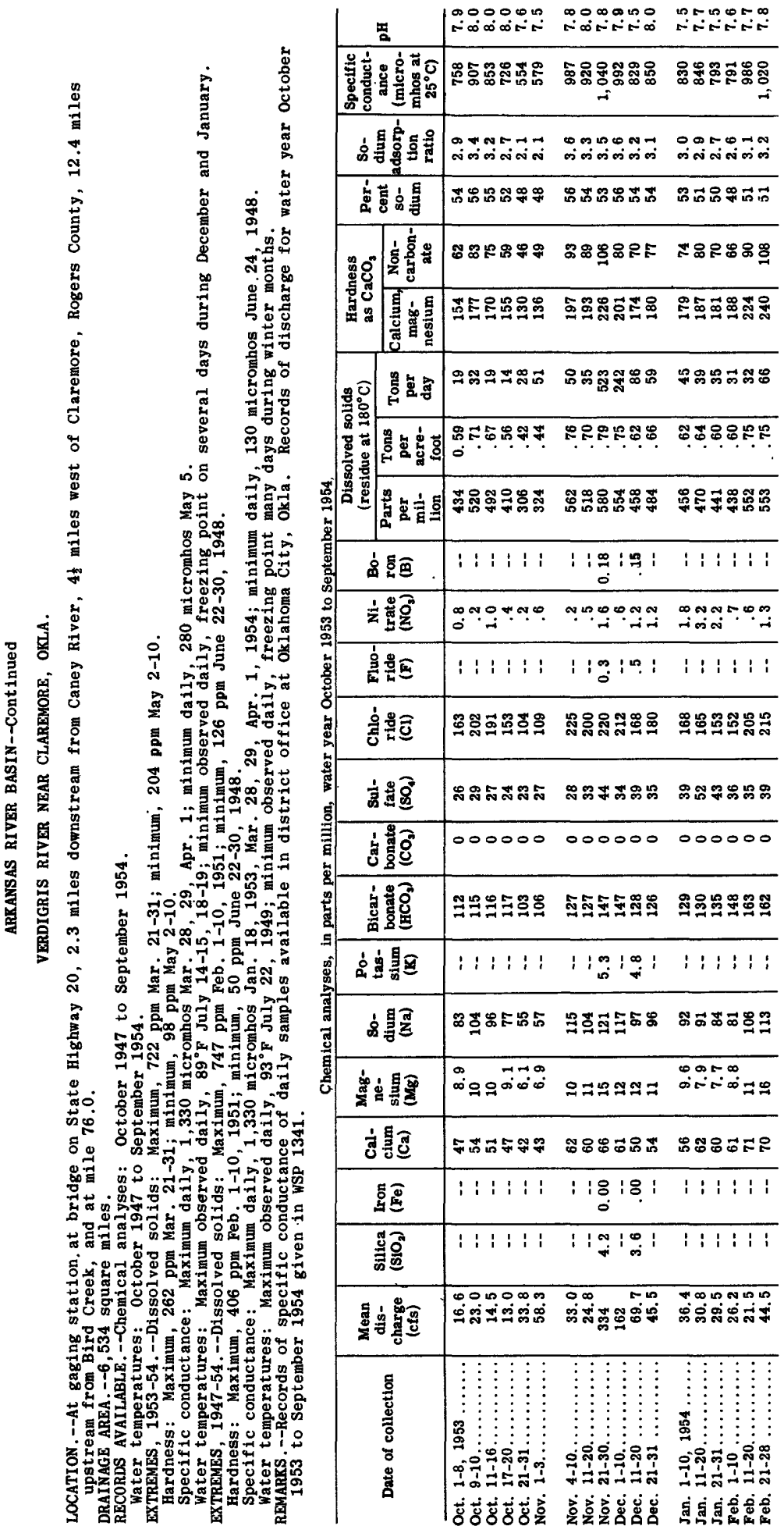




\begin{tabular}{|c|c|c|c|c|c|c|c|}
\hline & 평 & 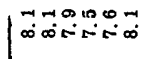 & 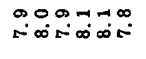 & \multicolumn{3}{|c|}{ 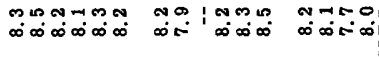 } & 1 \\
\hline & 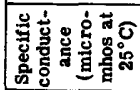 & 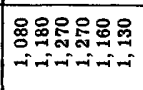 & 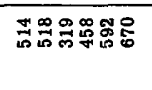 & 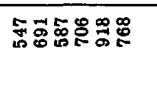 & 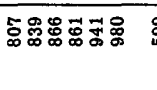 & 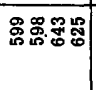 & 产 \\
\hline & 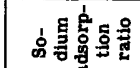 & 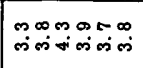 & Wiogomo & 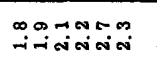 & 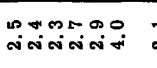 & 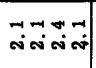 & $=$ \\
\hline & 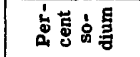 & ธี่ & 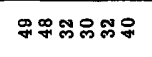 & 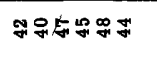 & 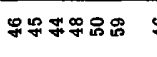 & 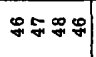 & 8 \\
\hline & 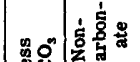 & 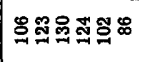 & サが & 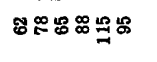 & ๓ & ำำ 8 的 & o \\
\hline & 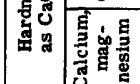 & 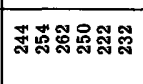 & 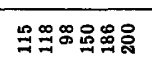 & 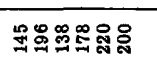 & 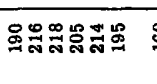 & 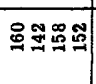 & $\nexists$ \\
\hline & 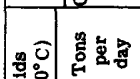 & 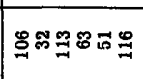 & 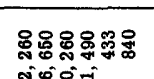 & 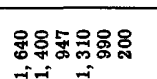 & 윰ำ & 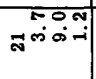 & 电 \\
\hline & 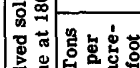 & ০ळळळळ & 암 & \%क्ष & 5. & 둥워 & ज्ञ \\
\hline & & 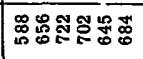 & 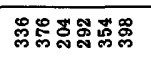 & 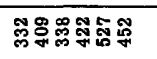 & 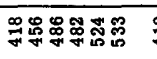 & 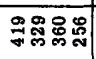 & 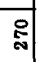 \\
\hline I & 850 & 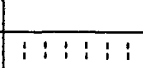 & & i: $1: 1 \vec{m}$ & $81: i 1 i$ & & \\
\hline & $\frac{102}{02}$ & & $\begin{array}{r}\cdot 0 \\
0 \times 000\end{array}$ & & & & \\
\hline \begin{tabular}{ll|l}
$\overrightarrow{1}$ & $\overline{0}$ \\
0 & 8 \\
0 & 8
\end{tabular} & 云藏是 & $\underbrace{\infty}_{i-i}$ & Tinisina & $-i$ & i & & oi \\
\hline & 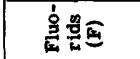 & $1: 1: 1: 1:$ & : $1: 1:$ is. & i: : : i & ๑:: : : : : : & $1: 00: 1$ & 1 \\
\hline 吾 & ㅎㅝㅎㅀ. & 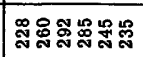 & 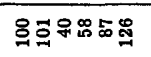 & 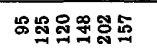 & 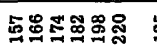 & ํㅕㅋㅋㄱ & 8 \\
\hline 亩 & & & & & & & \\
\hline 产 & 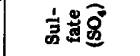 & 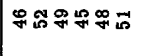 & สี జూన జ & 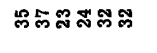 & 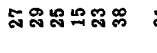 & ตีสเ์ สุ & 이 \\
\hline 悉客 & 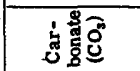 & 000000 & 000000 & moono & $0080 N \infty$ & 0000 & i \\
\hline 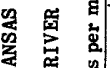 & 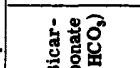 & 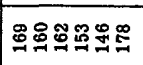 & 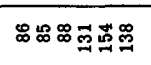 & 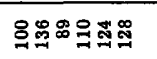 & 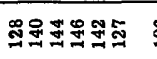 & 엄웍్ㅀ월 & 5. \\
\hline 空 & $\frac{\infty}{1+6}$ & : : : : : : & $1^{\infty}$ & ; & a:1:1: & {$[\infty .1]$} & i) \\
\hline 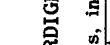 & 过 & 1 & & ' 1 ' ' ' & $\nabla^{1} 1111$ & ' & \\
\hline 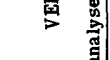 & 的昗会 & 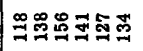 & 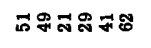 & 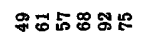 & 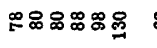 & 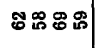 & $\mathscr{m}$ \\
\hline : & 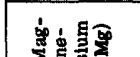 & 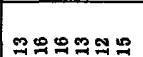 & 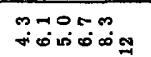 & $\operatorname{lom}_{\infty}^{\infty}$ & 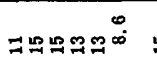 & 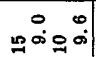 & $\ddot{\circ}$ \\
\hline & $\therefore E \pi$ & $\infty \circ \infty \infty 8 \infty$ & の゚ーロのコー & $\exists \infty=750$ & 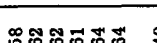 & 아모요요 요 & $=$ \\
\hline & 로를 & & & & & & \\
\hline & 总通 & $\begin{array}{llllll:}1 & 1 & 1 & 1 & 1 & 1\end{array}$ & 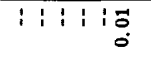 & 1: : : : : & $\overrightarrow{5}: 1: 1: 1$ & $1: 8: 1$ & 1 \\
\hline & 㛚产 & $1: 1: 1: 1$ & 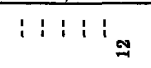 & $1: 1: i_{9}$ & $\approx:: 1::$ & 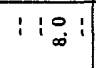 & 1 \\
\hline & 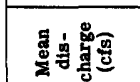 & 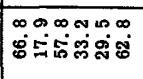 & S뭉 & 总昰 & 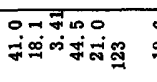 & 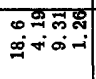 & $:$ \\
\hline & 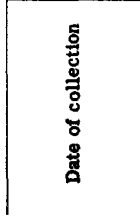 & 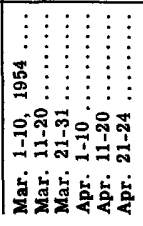 & 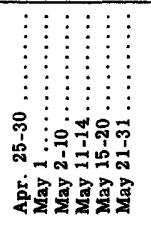 & 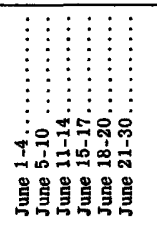 & 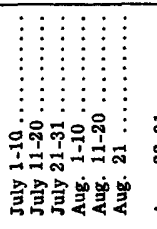 & 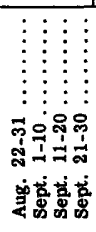 & 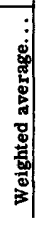 \\
\hline
\end{tabular}


ARKANSAS RIVER BASIN--Continued

VERDIGRIS RIVER NEAR CLAREMORE, OKLA.--Continued

Temperature $\left({ }^{\circ} \mathrm{F}\right)$ of water, water year October 1953 to September 1954

\begin{tabular}{|c|c|c|c|c|c|c|c|c|c|c|c|c|}
\hline Day & Oct. & Nov. & Dec. & Jan. & Feb. & Mar. & Apr. & May & June & July & Aug. & Sept. \\
\hline $\begin{array}{l}1 \\
2 \\
3 \\
4 \\
5\end{array}$ & $\begin{array}{l}70 \\
69 \\
69 \\
64 \\
63\end{array}$ & $\begin{array}{l}\mathbf{5 5} \\
56 \\
57 \\
55 \\
53\end{array}$ & $\begin{array}{l}47 \\
48 \\
50 \\
45 \\
44\end{array}$ & $\begin{array}{l}35 \\
40 \\
38 \\
38 \\
36\end{array}$ & $\begin{array}{l}40 \\
41 \\
45 \\
43 \\
43\end{array}$ & $\begin{array}{l}47 \\
45 \\
43 \\
42 \\
44\end{array}$ & $\begin{array}{l}52 \\
55 \\
58 \\
-- \\
62\end{array}$ & $\begin{array}{l}63 \\
61 \\
60 \\
56 \\
54\end{array}$ & $\begin{array}{l}73 \\
71 \\
69 \\
68 \\
73\end{array}$ & $\begin{array}{l}84 \\
84 \\
85 \\
85 \\
86\end{array}$ & $\begin{array}{l}79 \\
78 \\
80 \\
83 \\
84\end{array}$ & $\begin{array}{l}80 \\
78 \\
76 \\
77 \\
78\end{array}$ \\
\hline $\begin{array}{r}6 \\
7 \\
8 \\
9 \\
10\end{array}$ & $\begin{array}{l}62 \\
60 \\
59 \\
58 \\
59\end{array}$ & $\begin{array}{l}49 \\
48 \\
47 \\
45 \\
44\end{array}$ & $\begin{array}{l}40 \\
39 \\
40 \\
41 \\
41\end{array}$ & $\begin{array}{l}38 \\
40 \\
41 \\
- \\
36\end{array}$ & $\begin{array}{l}45 \\
45 \\
39 \\
38 \\
40\end{array}$ & $\begin{array}{l}44 \\
47 \\
48 \\
50 \\
54\end{array}$ & $\begin{array}{l}65 \\
67 \\
66 \\
65 \\
66\end{array}$ & $\begin{array}{l}58 \\
60 \\
60 \\
61 \\
62\end{array}$ & $\begin{array}{l}71 \\
70 \\
74 \\
78 \\
76\end{array}$ & $\begin{array}{l}86 \\
87 \\
87 \\
86 \\
87\end{array}$ & $\begin{array}{l}83 \\
82 \\
80 \\
79 \\
80\end{array}$ & $\begin{array}{l}79 \\
79 \\
78 \\
76 \\
75\end{array}$ \\
\hline $\begin{array}{l}11 \\
12 \\
13 \\
14 \\
15\end{array}$ & $\begin{array}{l}63 \\
68 \\
66 \\
67 \\
66\end{array}$ & $\begin{array}{l}46 \\
48 \\
49 \\
49 \\
52\end{array}$ & $\begin{array}{l}43 \\
41 \\
40 \\
39 \\
39\end{array}$ & $\begin{array}{l}32 \\
32 \\
32 \\
33 \\
35\end{array}$ & $\begin{array}{l}43 \\
43 \\
46 \\
50 \\
53\end{array}$ & $\begin{array}{l}56 \\
59 \\
52 \\
49 \\
47\end{array}$ & $\begin{array}{l}65 \\
64 \\
62 \\
63 \\
64\end{array}$ & $\begin{array}{l}63 \\
64 \\
65 \\
65 \\
66\end{array}$ & $\begin{array}{l}79 \\
79 \\
78 \\
77 \\
77\end{array}$ & $\begin{array}{l}88 \\
88 \\
88 \\
89 \\
89\end{array}$ & $\begin{array}{l}81 \\
82 \\
82 \\
84 \\
85\end{array}$ & $\begin{array}{l}74 \\
74 \\
73 \\
74 \\
75\end{array}$ \\
\hline $\begin{array}{l}16 \\
17 \\
18 \\
19 \\
20\end{array}$ & $\begin{array}{l}65 \\
64 \\
63 \\
63 \\
64\end{array}$ & $\begin{array}{l}54 \\
56 \\
58 \\
59 \\
52\end{array}$ & $\begin{array}{l}38 \\
37 \\
35 \\
35 \\
--\end{array}$ & $\begin{array}{l}35 \\
37 \\
38 \\
40 \\
43\end{array}$ & $\begin{array}{l}53 \\
51 \\
50 \\
49 \\
48\end{array}$ & $\begin{array}{l}\mathbf{5 0} \\
\mathbf{5 1} \\
\mathbf{5 4} \\
\mathbf{5 2} \\
\mathbf{5 2}\end{array}$ & $\begin{array}{c}64 \\
65 \\
66 \\
-- \\
67\end{array}$ & $\begin{array}{l}67 \\
69 \\
68 \\
67 \\
67\end{array}$ & $\begin{array}{l}78 \\
80 \\
81 \\
82 \\
73\end{array}$ & $\begin{array}{l}87 \\
87 \\
89 \\
89 \\
85\end{array}$ & $\begin{array}{l}87 \\
88 \\
88 \\
85 \\
82\end{array}$ & $\begin{array}{l}76 \\
76 \\
76 \\
77 \\
78\end{array}$ \\
\hline $\begin{array}{l}21 \\
22 \\
23 \\
24 \\
25\end{array}$ & $\begin{array}{l}64 \\
63 \\
60 \\
59 \\
58\end{array}$ & $\begin{array}{l}49 \\
48 \\
46 \\
45 \\
45\end{array}$ & $\begin{array}{l}36 \\
32 \\
32 \\
32 \\
32\end{array}$ & $\begin{array}{l}40 \\
34 \\
32 \\
33 \\
35\end{array}$ & $\begin{array}{l}\mathbf{5 9} \\
\mathbf{5 1} \\
\mathbf{5 0} \\
\mathbf{5 2} \\
\mathbf{5 2}\end{array}$ & $\begin{array}{l}53 \\
54 \\
54 \\
55 \\
57\end{array}$ & $\begin{array}{l}68 \\
69 \\
69 \\
70 \\
72\end{array}$ & $\begin{array}{l}66 \\
68 \\
70 \\
73 \\
70\end{array}$ & $\begin{array}{l}74 \\
84 \\
85 \\
85 \\
86\end{array}$ & $\begin{array}{l}88 \\
87 \\
86 \\
86 \\
85\end{array}$ & $\begin{array}{l}80 \\
83 \\
84 \\
85 \\
87\end{array}$ & $\begin{array}{l}75 \\
73 \\
70 \\
68 \\
70\end{array}$ \\
\hline $\begin{array}{l}26 \\
27 \\
28 \\
29 \\
30 \\
31\end{array}$ & $\begin{array}{l}58 \\
55 \\
53 \\
54 \\
54 \\
56 \\
\end{array}$ & $\begin{array}{l}44 \\
44 \\
46 \\
46 \\
46 \\
--\end{array}$ & $\begin{array}{l}35 \\
36 \\
37 \\
38 \\
32 \\
32\end{array}$ & $\begin{array}{l}36 \\
33 \\
33 \\
34 \\
37 \\
41\end{array}$ & $\begin{array}{l}50 \\
50 \\
48 \\
-- \\
-- \\
--\end{array}$ & $\begin{array}{l}\mathbf{5 7} \\
\mathbf{5 8} \\
\mathbf{5 9} \\
\mathbf{5 7} \\
\mathbf{5 5} \\
\mathbf{5 3}\end{array}$ & $\begin{array}{l}73 \\
72 \\
70 \\
68 \\
65 \\
--\end{array}$ & $\begin{array}{l}69 \\
69 \\
70 \\
72 \\
73 \\
75\end{array}$ & $\begin{array}{l}86 \\
86 \\
87 \\
87 \\
85 \\
--\end{array}$ & $\begin{array}{l}84 \\
84 \\
83 \\
82 \\
80 \\
80\end{array}$ & $\begin{array}{l}88 \\
87 \\
87 \\
86 \\
85 \\
82\end{array}$ & $\begin{array}{l}72 \\
74 \\
75 \\
77 \\
78 \\
-- \\
\end{array}$ \\
\hline $\begin{array}{l}\text { Aver- } \\
\text { age }\end{array}$ & 62 & 50 & 39 & 36 & 47 & 52 & 65 & 66 & 78 & 86 & 83 & 75 \\
\hline
\end{tabular}




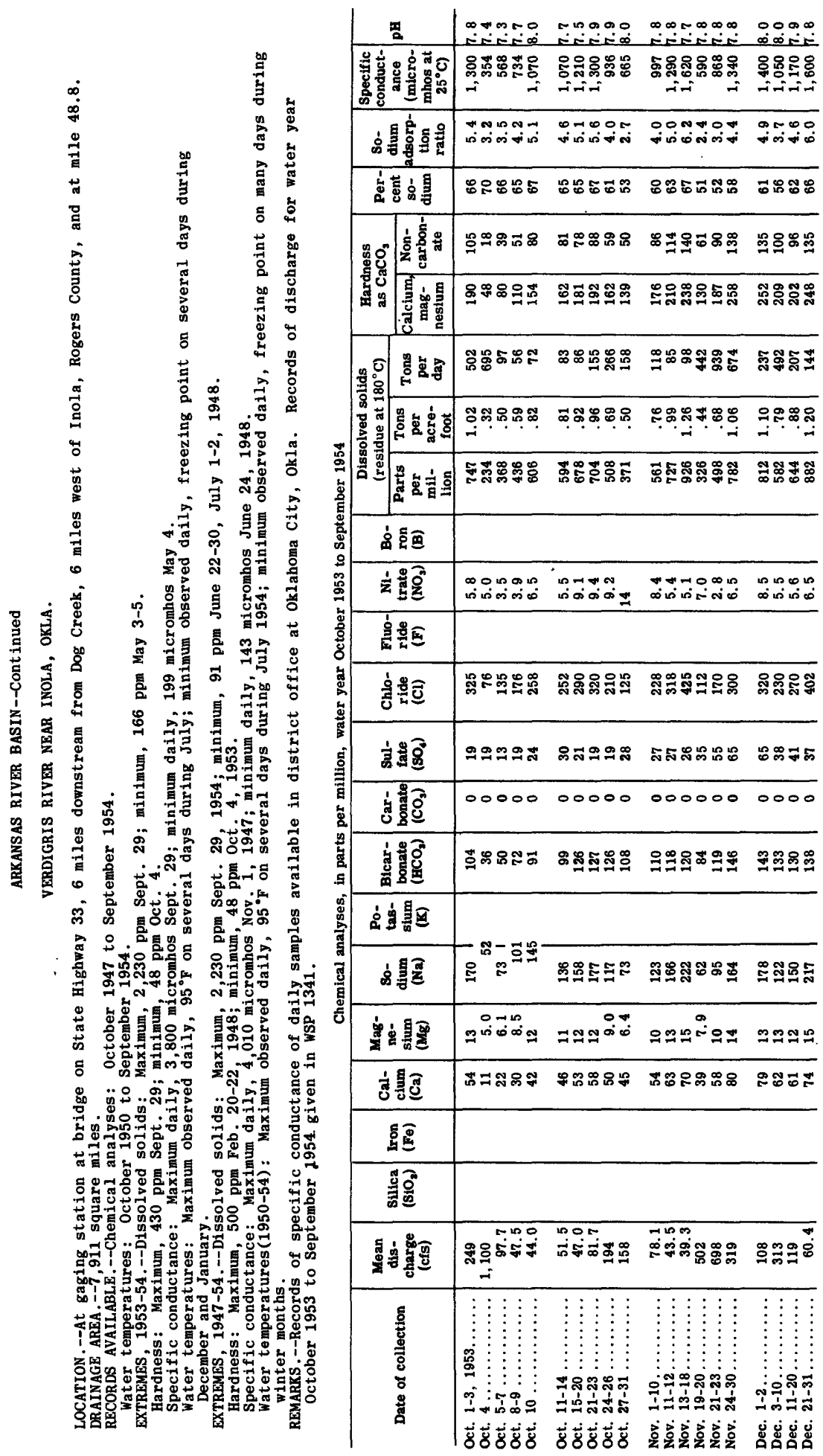




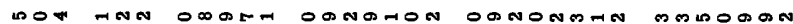

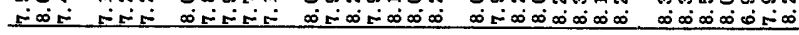

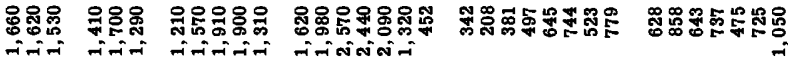

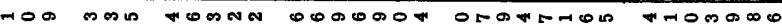

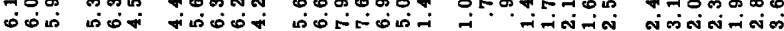

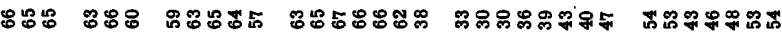

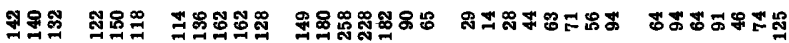

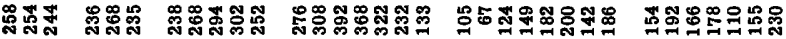

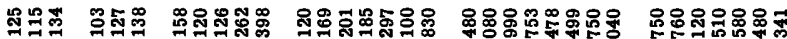

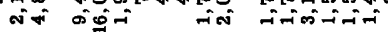

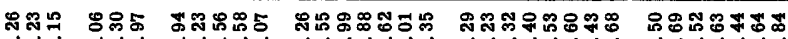
-i-i $-i$.

๙

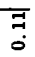

\begin{tabular}{|c|c|c|c|c|c|}
\hline$\ddot{\infty}$ & 에굠어 & 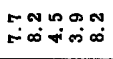 & ه⿴囗十 & 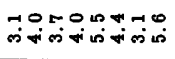 & ن \\
\hline
\end{tabular}

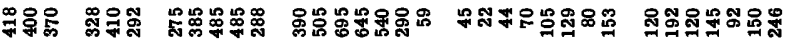

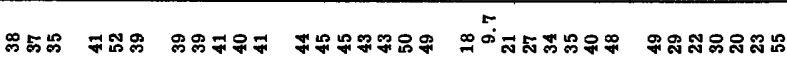

000000000000000000 00000N00 nNm0000

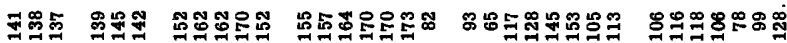

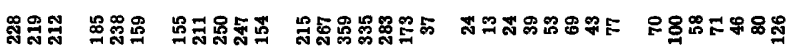

\begin{tabular}{|c|c|c|c|c|c|}
\hline உ્ల & $\stackrel{9}{90}$ & 뮤오도요 & 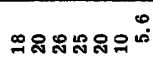 & 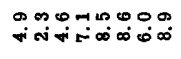 & $\because=\infty \infty^{\infty}$ \\
\hline 도오 & :゚̊: & テッタ゚ジ & 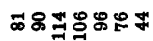 & 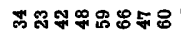 & 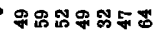 \\
\hline
\end{tabular}

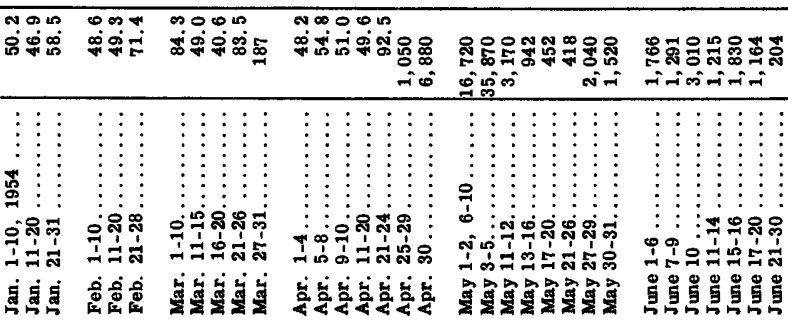




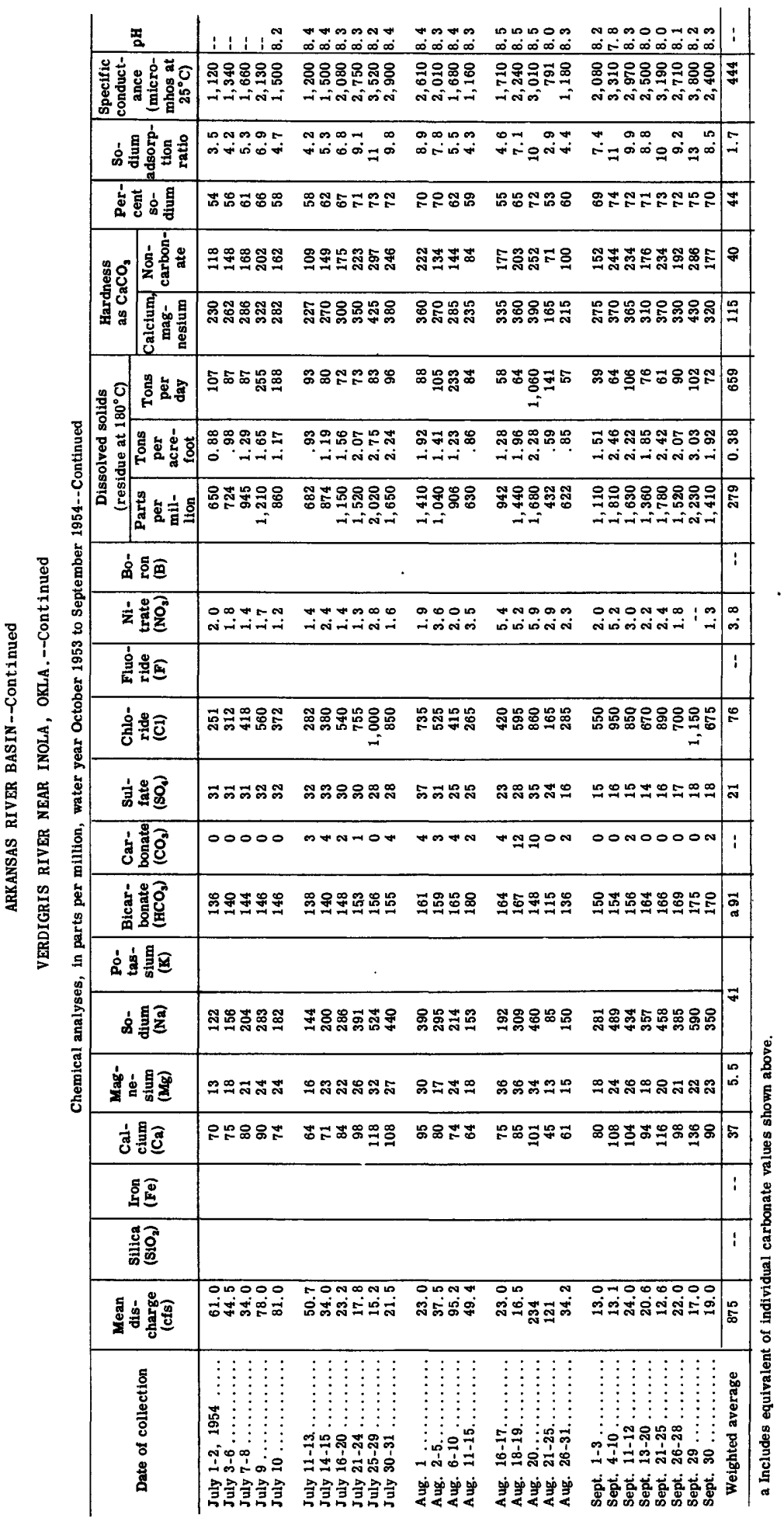


ARKANSAS RIVER BASIN--Cont inued

VERDIGRIS RIVER NEAR INOLA, OKLA.--Continued

Temperature $\left({ }^{\circ} \mathrm{F}\right)$ of water, water year October 1953 to September 1954

\begin{tabular}{|c|c|c|c|c|c|c|c|c|c|c|c|c|}
\hline Day & Oct. & Nov. & Dec. & Jan. & Feb. & Mar. & Apr. & May & June & July & Aug. & Sept. \\
\hline $\begin{array}{l}1 \\
2 \\
3 \\
4 \\
5\end{array}$ & $\begin{array}{l}86 \\
84 \\
84 \\
71 \\
76\end{array}$ & $\begin{array}{l}60 \\
60 \\
60 \\
59 \\
59\end{array}$ & $\begin{array}{l}51 \\
53 \\
53 \\
53 \\
52\end{array}$ & $\begin{array}{l}34 \\
37 \\
35 \\
36 \\
36\end{array}$ & $\begin{array}{l}44 \\
48 \\
48 \\
48 \\
48\end{array}$ & $\begin{array}{l}50 \\
49 \\
48 \\
48 \\
47\end{array}$ & $\begin{array}{l}54 \\
54 \\
56 \\
58 \\
57\end{array}$ & $\begin{array}{l}68 \\
67 \\
67 \\
67 \\
64\end{array}$ & $\begin{array}{l}75 \\
76 \\
74 \\
88 \\
76\end{array}$ & $\begin{array}{l}92 \\
93 \\
94 \\
94 \\
94\end{array}$ & $\begin{array}{l}81 \\
81 \\
81 \\
81 \\
80\end{array}$ & $\begin{array}{l}80 \\
80 \\
80 \\
80 \\
80\end{array}$ \\
\hline $\begin{array}{l}6 \\
7 \\
8\end{array}$ & $\begin{array}{l}75 \\
69 \\
68\end{array}$ & $\begin{array}{l}56 \\
-2 \\
55\end{array}$ & $\begin{array}{l}50 \\
50 \\
50\end{array}$ & $\begin{array}{l}36 \\
37 \\
37\end{array}$ & $\begin{array}{l}48 \\
48 \\
49\end{array}$ & $\begin{array}{l}49 \\
51 \\
52\end{array}$ & $\begin{array}{l}59 \\
60 \\
62\end{array}$ & $\begin{array}{l}62 \\
61 \\
62\end{array}$ & $\begin{array}{l}76 \\
76 \\
76\end{array}$ & $\begin{array}{l}94 \\
94 \\
94\end{array}$ & $\begin{array}{l}80 \\
80 \\
80\end{array}$ & $\begin{array}{l}80 \\
71 \\
80\end{array}$ \\
\hline $\begin{array}{r}9 \\
10\end{array}$ & $\begin{array}{l}76 \\
76\end{array}$ & $\begin{array}{l}52 \\
52\end{array}$ & $\begin{array}{l}49 \\
44\end{array}$ & 34 & $\begin{array}{l}49 \\
59\end{array}$ & $\begin{array}{l}54 \\
55\end{array}$ & $\begin{array}{l}65 \\
64\end{array}$ & $\begin{array}{l}60 \\
60\end{array}$ & $\begin{array}{l}76 \\
77\end{array}$ & $\begin{array}{l}94 \\
89\end{array}$ & $\begin{array}{l}80 \\
80\end{array}$ & $\begin{array}{l}71 \\
80\end{array}$ \\
\hline $\begin{array}{l}11 \\
12 \\
13 \\
14 \\
15\end{array}$ & $\begin{array}{l}76 \\
76 \\
76 \\
-- \\
74\end{array}$ & $\begin{array}{l}51 \\
51 \\
52 \\
54 \\
54\end{array}$ & $\begin{array}{l}49 \\
48 \\
46 \\
45 \\
46\end{array}$ & $\begin{array}{r}33 \\
32 \\
32 \\
133 \\
33\end{array}$ & $\begin{array}{l}48 \\
48 \\
49 \\
50 \\
51\end{array}$ & $\begin{array}{l}55 \\
54 \\
54 \\
51 \\
51\end{array}$ & $\begin{array}{l}64 \\
64 \\
66 \\
66 \\
66\end{array}$ & $\begin{array}{l}63 \\
60 \\
64 \\
64 \\
66\end{array}$ & $\begin{array}{l}71 \\
71 \\
80 \\
80 \\
80\end{array}$ & $\begin{array}{l}94 \\
95 \\
95 \\
94 \\
95\end{array}$ & $\begin{array}{l}80 \\
80 \\
80 \\
80 \\
80\end{array}$ & $\begin{array}{l}71 \\
71 \\
71 \\
71 \\
71\end{array}$ \\
\hline $\begin{array}{l}16 \\
17 \\
18 \\
19 \\
20\end{array}$ & $\begin{array}{l}75 \\
74 \\
74 \\
72 \\
70\end{array}$ & $\begin{array}{l}\mathbf{5 5} \\
\mathbf{5 5} \\
\mathbf{5 6} \\
\mathbf{5 2} \\
\mathbf{5 6}\end{array}$ & $\begin{array}{l}46 \\
44 \\
42 \\
46 \\
41\end{array}$ & $\begin{array}{l}33 \\
32 \\
34 \\
34 \\
34\end{array}$ & $\begin{array}{l}51 \\
49 \\
51 \\
49 \\
49\end{array}$ & $\begin{array}{l}51 \\
5 \overline{3} \\
54 \\
54 \\
54\end{array}$ & $\begin{array}{l}69 \\
70 \\
71 \\
72 \\
72\end{array}$ & $\begin{array}{l}67 \\
68 \\
68 \\
68 \\
68\end{array}$ & $\begin{array}{l}80 \\
80 \\
80 \\
80 \\
80\end{array}$ & $\begin{array}{l}94 \\
95 \\
95 \\
95 \\
95\end{array}$ & $\begin{array}{l}80 \\
80 \\
80 \\
80 \\
80\end{array}$ & $\begin{array}{l}71 \\
71 \\
71 \\
80 \\
80\end{array}$ \\
\hline $\begin{array}{l}21 \\
22 \\
23 \\
24 \\
25\end{array}$ & $\begin{array}{l}72 \\
69 \\
67 \\
66 \\
66\end{array}$ & $\begin{array}{l}\mathbf{5 2} \\
\mathbf{5 2} \\
\mathbf{5 2} \\
\mathbf{5 2} \\
\mathbf{5 2}\end{array}$ & $\begin{array}{l}41 \\
36 \\
32 \\
32 \\
34\end{array}$ & $\begin{array}{l}32 \\
32 \\
32 \\
33 \\
35\end{array}$ & $\begin{array}{l}51 \\
52 \\
51 \\
52 \\
52\end{array}$ & $\begin{array}{l}\mathbf{5 5} \\
55 \\
54 \\
57 \\
55\end{array}$ & $\begin{array}{l}73 \\
71 \\
73 \\
73 \\
74\end{array}$ & $\begin{array}{l}70 \\
61 \\
70 \\
70 \\
71\end{array}$ & $\begin{array}{l}84 \\
87 \\
88 \\
88 \\
88\end{array}$ & $\begin{array}{l}91 \\
91 \\
90 \\
91 \\
90\end{array}$ & $\begin{array}{l}71 \\
71 \\
71 \\
71 \\
71\end{array}$ & $\begin{array}{l}80 \\
71 \\
79 \\
71 \\
71\end{array}$ \\
\hline $\begin{array}{l}26 \\
27 \\
28 \\
29 \\
30 \\
31\end{array}$ & $\begin{array}{l}62 \\
64 \\
64 \\
61 \\
60 \\
60\end{array}$ & $\begin{array}{l}52 \\
52 \\
52 \\
50 \\
50 \\
--\end{array}$ & $\begin{array}{l}35 \\
35 \\
34 \\
35 \\
34 \\
34\end{array}$ & $\begin{array}{l}32 \\
36 \\
38 \\
39 \\
-- \\
45\end{array}$ & $\begin{array}{l}52 \\
50 \\
49 \\
-- \\
-- \\
--\end{array}$ & $\begin{array}{l}55 \\
57 \\
58 \\
54 \\
51 . \\
51\end{array}$ & $\begin{array}{l}74 \\
73 \\
74 \\
73 \\
73 \\
--\end{array}$ & $\begin{array}{l}70 \\
70 \\
70 \\
70 \\
70 \\
70\end{array}$ & $\begin{array}{l}89 \\
90 \\
91 \\
92 \\
92 \\
--\end{array}$ & $\begin{array}{l}-- \\
90 \\
90 \\
90 \\
81 \\
81\end{array}$ & $\begin{array}{l}80 \\
80 \\
80 \\
81 \\
80 \\
80\end{array}$ & $\begin{array}{l}71 \\
71 \\
71 \\
71 \\
71 \\
-\end{array}$ \\
\hline $\begin{array}{c}\text { Aver- } \\
\text { age }\end{array}$ & 71 & 54 & 43 & 35 & 50 & 53 & 67 & 66 & 81 & 92 & 79 & 75 \\
\hline
\end{tabular}




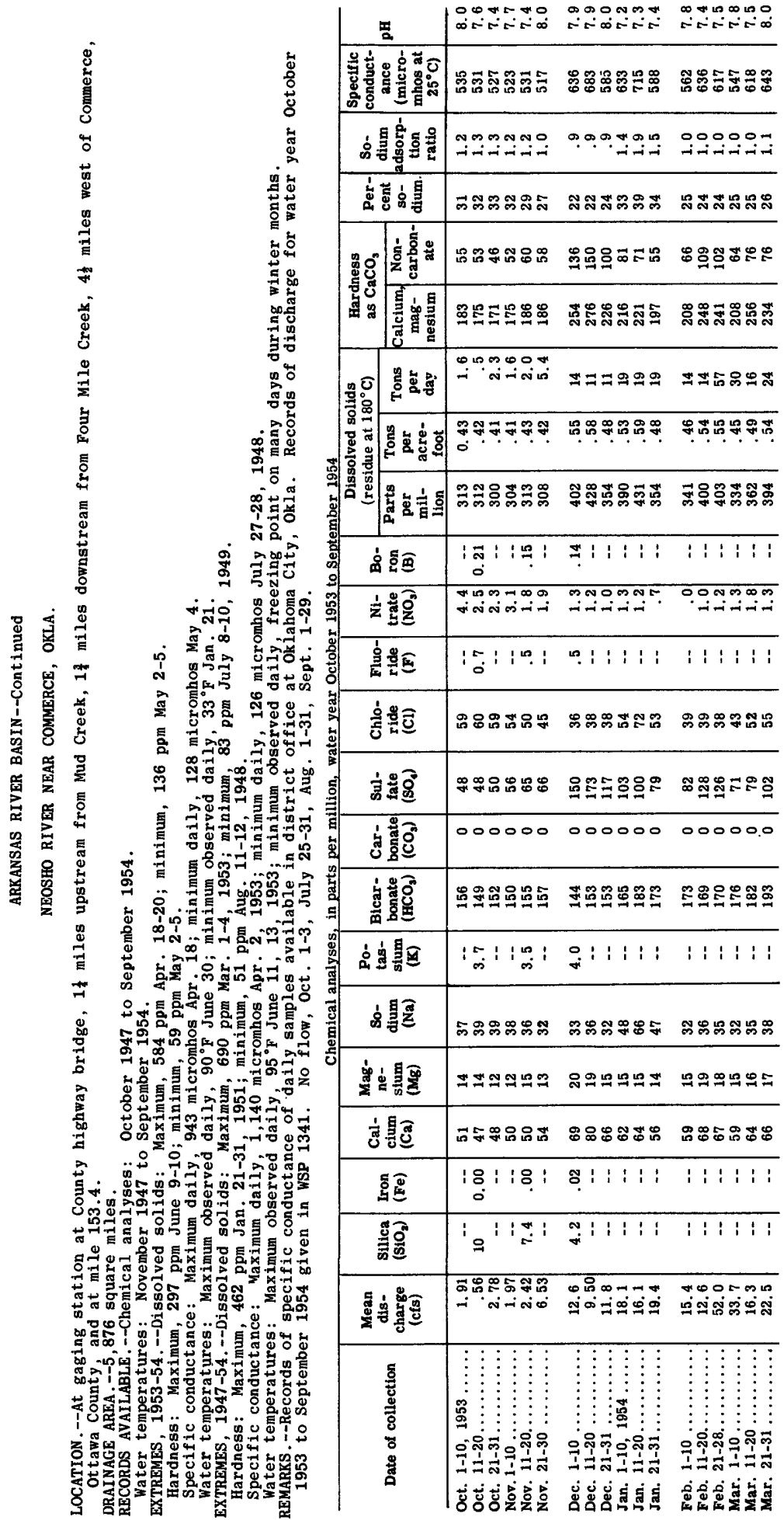




\begin{tabular}{|c|c|c|c|c|c|c|}
\hline 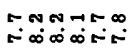 & 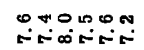 & 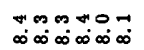 & 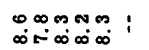 & $1_{\infty}^{0}$ & 1 & \\
\hline 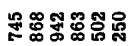 & 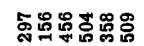 & 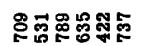 & 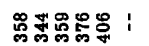 & i & $\left|\begin{array}{l}\infty \\
\mathbf{N}\end{array}\right|$ & \\
\hline 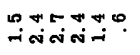 & $\because \div$ & 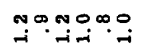 & $\varphi$ & 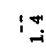 & $\because$ & \\
\hline 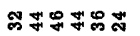 & 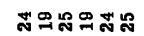 & 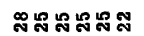 & 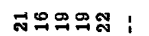 & ! ம & $\Phi$ & \\
\hline 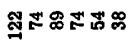 & 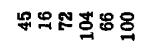 & 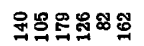 & 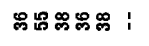 & ! 多 & 웨 & \\
\hline 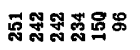 & 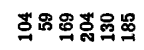 & 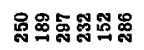 & 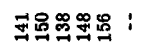 & 옥 & : & \\
\hline 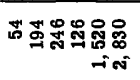 & 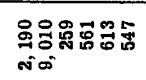 & 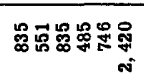 & 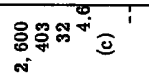 & '̊ & : & \\
\hline 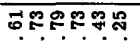 & 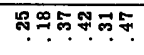 & 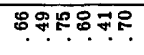 & 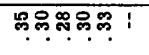 & 17 & \begin{tabular}{l}
\multirow{2}{*}{} \\
0 \\
0
\end{tabular} & \\
\hline 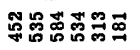 & 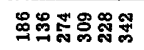 & 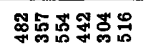 & 号点怘哭导！ & i & ผู่ & \\
\hline $1: 11: 1$ & $1: 190 ;$ & i : $1: 11: 1$ & 1888: 1: & $1 \mathrm{i}$ & 1 & \\
\hline Normo & 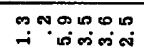 & 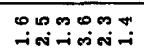 & 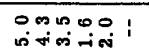 & $i_{\infty}^{\infty}$ & $\begin{array}{l}0 \\
\text { i. }\end{array}$ & \\
\hline : $1: 11: 1 \quad 1:$ & i $1: 1001$ & i : & 111 & $1:$ & $i$ & \\
\hline 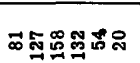 & 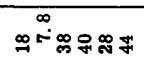 & 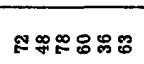 & 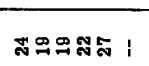 & 1 ชั & $\overline{\mathbf{n}}$ & \\
\hline ஓ゚に゚ロ & 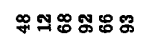 & ஜ్ㅇ్ㅀ & 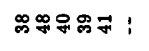 & $1 ㅇ$ & $\infty$ & \\
\hline 000000 & 00 & TNONOO & DONON: & 10 & 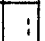 & \\
\hline 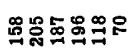 & ヘ & 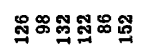 & 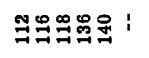 & ! 号 & $\begin{array}{l}2 \\
2 \\
2\end{array}$ & \\
\hline$: 1: 1::$ & : $: \mid \begin{array}{c}\infty \\
\infty\end{array}$ & i i & 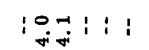 & 11 & $i$ & \\
\hline แ゙ッ§ロ & 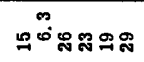 & 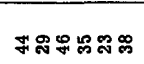 & ニッッッ： & $i=$ & $\stackrel{0}{2}$ & \\
\hline 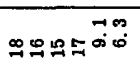 & 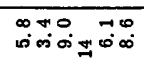 & $\Rightarrow \stackrel{\infty}{\Rightarrow}$ ڤ & 읭ํㅇㅇㅢ & $1_{\infty}^{\infty}$ & $\overrightarrow{0}$ & $\frac{8}{8}$ \\
\hline モミッロ早界 & 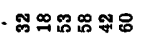 & 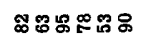 & 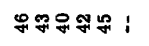 & : ชั & ఖ్ & 8 \\
\hline$\overline{1: 1: 1: 1}$ & ' 1 i & $1 !$ & 18 & : : & i & \\
\hline & 1 i io i i & & ! & 1 & i & हु \\
\hline 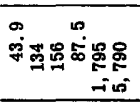 & 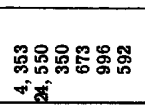 & 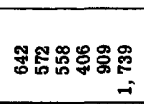 & 융ㅎํ & 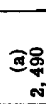 & 㽞 & 㟒密 \\
\hline 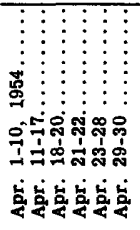 & 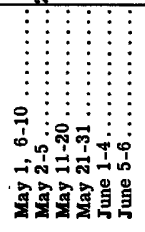 & 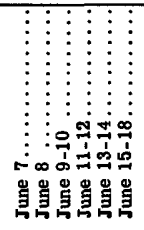 & 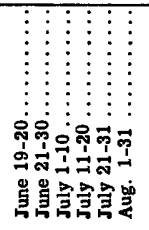 & 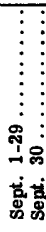 & \begin{tabular}{|c|} 
\\
\\
\end{tabular} & 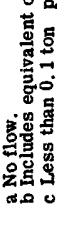 \\
\hline
\end{tabular}


ARKANSAS RIVER BASIN--Continued

NEOSHO RIVER NEAR COMMERCE, OKLA. --Continued

Temperature $\left({ }^{\circ} \mathrm{F}\right)$ of water, water year October 1953 to September 1954

\begin{tabular}{|c|c|c|c|c|c|c|c|c|c|c|c|c|}
\hline Day & Oct. & Nov. & Dec. & Jan. & Feb. & Mar. & Apr. & May & June & July & Aug. & Sept. \\
\hline $\begin{array}{l}1 \\
2 \\
3 \\
4 \\
5\end{array}$ & $\begin{array}{l}-- \\
- \\
70 \\
70\end{array}$ & $\begin{array}{l}61 \\
62 \\
-- \\
-- \\
57\end{array}$ & $\begin{array}{l}48 \\
54 \\
53 \\
51 \\
51\end{array}$ & $\begin{array}{l}47 \\
47 \\
45 \\
41 \\
43\end{array}$ & $\begin{array}{l}46 \\
48 \\
48 \\
49 \\
48\end{array}$ & $\begin{array}{l}48 \\
47 \\
43 \\
45 \\
47\end{array}$ & $\begin{array}{l}53 \\
50 \\
65 \\
65 \\
69\end{array}$ & $\begin{array}{l}67 \\
64 \\
62 \\
60 \\
63\end{array}$ & $\begin{array}{l}75 \\
73 \\
71 \\
71 \\
75\end{array}$ & $\begin{array}{l}86 \\
87 \\
86 \\
85 \\
86\end{array}$ & $\begin{array}{l}=- \\
-- \\
-- \\
--\end{array}$ & $\begin{array}{l}-- \\
-- \\
-- \\
--\end{array}$ \\
\hline $\begin{array}{r}6 \\
7 \\
8 \\
9 \\
10\end{array}$ & $\begin{array}{l}67 \\
67 \\
67 \\
63 \\
70\end{array}$ & $\begin{array}{l}50 \\
49 \\
51 \\
-- \\
49\end{array}$ & $\begin{array}{l}49 \\
49 \\
48 \\
46 \\
45\end{array}$ & $\begin{array}{l}44 \\
46 \\
51 \\
44 \\
38\end{array}$ & $\begin{array}{l}48 \\
46 \\
47 \\
49 \\
53\end{array}$ & $\begin{array}{l}51 \\
54 \\
56 \\
54 \\
60\end{array}$ & $\begin{array}{l}74 \\
72 \\
69 \\
64 \\
60\end{array}$ & $\begin{array}{l}63 \\
63 \\
63 \\
63 \\
65\end{array}$ & $\begin{array}{l}75 \\
78 \\
77 \\
79 \\
82\end{array}$ & $\begin{array}{l}86 \\
86 \\
85 \\
84 \\
83\end{array}$ & $\begin{array}{l}-- \\
-- \\
-- \\
--\end{array}$ & $\begin{array}{l}-- \\
-- \\
-- \\
--\end{array}$ \\
\hline $\begin{array}{l}11 \\
12 \\
13 \\
14 \\
15\end{array}$ & $\begin{array}{l}68 \\
71 \\
71 \\
72 \\
73\end{array}$ & $\begin{array}{l}48 \\
-- \\
55 \\
55 \\
56\end{array}$ & $\begin{array}{l}43 \\
45 \\
43 \\
41 \\
38\end{array}$ & $\begin{array}{l}39 \\
39 \\
37 \\
38 \\
37\end{array}$ & $\begin{array}{l}48 \\
47 \\
48 \\
58 \\
59\end{array}$ & $\begin{array}{l}62 \\
62 \\
50 \\
48 \\
45\end{array}$ & $\begin{array}{l}66 \\
65 \\
66 \\
72 \\
72\end{array}$ & $\begin{array}{l}64 \\
66 \\
71 \\
73 \\
74\end{array}$ & $\begin{array}{l}81 \\
81 \\
78 \\
82 \\
79\end{array}$ & $\begin{array}{l}83 \\
86 \\
87 \\
88 \\
87\end{array}$ & $\begin{array}{l}-- \\
-- \\
-- \\
--\end{array}$ & $\begin{array}{l}-- \\
-- \\
--\end{array}$ \\
\hline $\begin{array}{l}16 \\
17 \\
18 \\
19 \\
20\end{array}$ & $\begin{array}{l}73 \\
73 \\
72 \\
72 \\
72\end{array}$ & $\begin{array}{l}\mathbf{5 6} \\
\mathbf{5 7} \\
\mathbf{5 8} \\
\mathbf{5 9} \\
\mathbf{5 4}\end{array}$ & $\begin{array}{l}42 \\
40 \\
42 \\
44 \\
43\end{array}$ & $\begin{array}{l}39 \\
39 \\
38 \\
44 \\
39\end{array}$ & $\begin{array}{l}57 \\
56 \\
57 \\
55 \\
47\end{array}$ & $\begin{array}{l}\mathbf{5 2} \\
\mathbf{5 2} \\
\mathbf{5 5} \\
\mathbf{5 6} \\
\mathbf{5 1}\end{array}$ & $\begin{array}{l}63 \\
69 \\
69 \\
70 \\
73\end{array}$ & $\begin{array}{l}71 \\
73 \\
75 \\
74 \\
76\end{array}$ & $\begin{array}{l}80 \\
82 \\
85 \\
82 \\
82\end{array}$ & $\begin{array}{l}87 \\
88 \\
88 \\
87 \\
85\end{array}$ & $\begin{array}{l}-- \\
-- \\
-- \\
--\end{array}$ & $\begin{array}{l}- \\
-- \\
-- \\
--\end{array}$ \\
\hline $\begin{array}{l}21 \\
22 \\
23 \\
24 \\
25\end{array}$ & $\begin{array}{l}70 \\
68 \\
66 \\
65 \\
63\end{array}$ & $\begin{array}{l}52 \\
51 \\
51 \\
51 \\
48\end{array}$ & $\begin{array}{l}47 \\
35 \\
37 \\
40 \\
40\end{array}$ & $\begin{array}{l}33 \\
35 \\
34 \\
38 \\
43\end{array}$ & $\begin{array}{l}\mathbf{5 1} \\
\mathbf{5 7} \\
\mathbf{5 3} \\
\mathbf{5 3} \\
\mathbf{5 4}\end{array}$ & $\begin{array}{l}54 \\
52 \\
52 \\
60 \\
62\end{array}$ & $\begin{array}{l}71 \\
67 \\
73 \\
70 \\
73\end{array}$ & $\begin{array}{l}71 \\
77 \\
77 \\
79 \\
76\end{array}$ & $\begin{array}{l}81 \\
82 \\
81 \\
88 \\
85\end{array}$ & $\begin{array}{l}85 \\
84 \\
85 \\
85 \\
--\end{array}$ & $\begin{array}{l}-- \\
-- \\
-- \\
--\end{array}$ & $\begin{array}{l}-- \\
-- \\
-- \\
--\end{array}$ \\
\hline $\begin{array}{l}26 \\
27 \\
28 \\
29 \\
30 \\
31\end{array}$ & $\begin{array}{l}58 \\
58 \\
60 \\
58 \\
58 \\
60\end{array}$ & $\begin{array}{l}48 \\
47 \\
47 \\
46 \\
46 \\
\ldots\end{array}$ & $\begin{array}{l}44 \\
42 \\
44 \\
42 \\
43 \\
43 \\
\end{array}$ & $\begin{array}{l}36 \\
38 \\
38 \\
43 \\
43 \\
39 \\
\end{array}$ & $\begin{array}{l}55 \\
48 \\
48 \\
-- \\
-- \\
--\end{array}$ & $\begin{array}{l}60 \\
62 \\
\mathbf{6 7} \\
\mathbf{5 6} \\
48 \\
49\end{array}$ & $\begin{array}{l}72 \\
75 \\
71 \\
70 \\
66 \\
-- \\
\end{array}$ & $\begin{array}{l}75 \\
78 \\
79 \\
73 \\
69 \\
75\end{array}$ & $\begin{array}{l}83 \\
85 \\
86 \\
86 \\
90 \\
-- \\
\end{array}$ & $\begin{array}{l}-- \\
-- \\
-- \\
-- \\
\end{array}$ & $\begin{array}{l}-- \\
-- \\
-- \\
-- \\
-\end{array}$ & $\begin{array}{l}-- \\
-- \\
-- \\
77\end{array}$ \\
\hline $\begin{array}{c}\text { Aver - } \\
\text { age }\end{array}$ & 67 & 52 & 44 & 40 & 51 & 54 & 68 & 70 & 81 & -- & - & \\
\hline
\end{tabular}




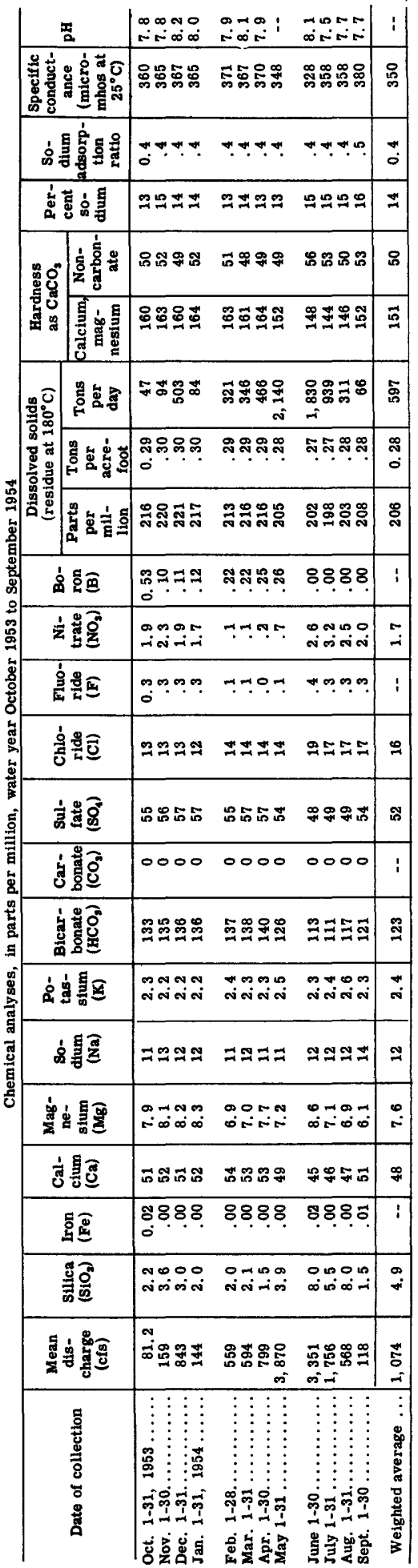


ARKANSAS RIVER BASIN--Continued

NEOSHO (GRAND) RIVER AT PENSACOLA RESERVOIR AT LANGLEY, OKLA.--Continued (Lake $0^{\circ}$ the Cherokees)

Temperature $\left({ }^{\circ} \mathrm{F}\right)$ of water, water year October 1953 to September 1954

\begin{tabular}{|c|c|c|c|c|c|c|c|c|c|c|c|c|}
\hline Day & Oct. & Nov. & Dec. & Jan. & Feb. & Mar. & Apr. & May & June & July & Aug. & Sept. \\
\hline $\begin{array}{l}1 \\
2 \\
3 \\
4 \\
5\end{array}$ & $\begin{array}{l}75 \\
74 \\
74 \\
73 \\
73\end{array}$ & $\begin{array}{l}66 \\
66 \\
66 \\
65 \\
65\end{array}$ & $\begin{array}{l}\mathbf{5 6} \\
\mathbf{5 5} \\
\mathbf{5 5} \\
\mathbf{5 4} \\
\mathbf{5 4}\end{array}$ & $\begin{array}{l}45 \\
44 \\
45 \\
45 \\
44\end{array}$ & $\begin{array}{l}40 \\
40 \\
40 \\
40 \\
40\end{array}$ & $\begin{array}{l}45 \\
44 \\
44 \\
44 \\
44\end{array}$ & $\begin{array}{l}48 \\
48 \\
49 \\
49 \\
49\end{array}$ & $\begin{array}{l}59 \\
59 \\
59 \\
62 \\
65\end{array}$ & $\begin{array}{l}64 \\
64 \\
65 \\
65 \\
66\end{array}$ & $\begin{array}{l}74 \\
74 \\
75 \\
75 \\
74\end{array}$ & $\begin{array}{l}\mathbf{7 5} \\
\mathbf{7 5} \\
\mathbf{7 5} \\
\mathbf{7 5} \\
\mathbf{7 5}\end{array}$ & $\begin{array}{l}81 \\
81 \\
80 \\
80 \\
79\end{array}$ \\
\hline $\begin{array}{r}6 \\
7 \\
8 \\
9 \\
10\end{array}$ & $\begin{array}{l}73 \\
72 \\
72 \\
72 \\
71\end{array}$ & $\begin{array}{l}65 \\
65 \\
64 \\
64 \\
64\end{array}$ & $\begin{array}{l}\mathbf{5 3} \\
\mathbf{5 3} \\
\mathbf{5 2} \\
\mathbf{5 2} \\
\mathbf{5 2}\end{array}$ & $\begin{array}{l}44 \\
44 \\
44 \\
44 \\
44\end{array}$ & $\begin{array}{l}41 \\
41 \\
41 \\
41 \\
41\end{array}$ & $\begin{array}{l}44 \\
45 \\
44 \\
44 \\
45\end{array}$ & $\begin{array}{l}50 \\
50 \\
49 \\
50 \\
50\end{array}$ & $\begin{array}{l}64 \\
64 \\
64 \\
65 \\
64\end{array}$ & $\begin{array}{l}66 \\
66 \\
66 \\
67 \\
67\end{array}$ & $\begin{array}{l}75 \\
76 \\
75 \\
75 \\
74\end{array}$ & $\begin{array}{l}74 \\
74 \\
74 \\
74 \\
--\end{array}$ & $\begin{array}{l}79 \\
78 \\
78 \\
78 \\
77\end{array}$ \\
\hline $\begin{array}{l}11 \\
12 \\
13 \\
14 \\
15\end{array}$ & $\begin{array}{l}71 \\
70 \\
70 \\
70 \\
70\end{array}$ & $\begin{array}{l}64 \\
64 \\
64 \\
64 \\
64\end{array}$ & $\begin{array}{l}51 \\
51 \\
51 \\
51 \\
51\end{array}$ & $\begin{array}{l}44 \\
44 \\
43 \\
43 \\
42\end{array}$ & $\begin{array}{l}42 \\
42 \\
42 \\
42 \\
42\end{array}$ & $\begin{array}{l}45 \\
45 \\
45 \\
45 \\
45\end{array}$ & $\begin{array}{l}\mathbf{5 1} \\
\mathbf{5 1} \\
\mathbf{5 2} \\
\mathbf{5 3} \\
\mathbf{5 4}\end{array}$ & $\begin{array}{l}64 \\
65 \\
65 \\
65 \\
64\end{array}$ & $\begin{array}{l}68 \\
68 \\
69 \\
69 \\
70\end{array}$ & $\begin{array}{l}75 \\
75 \\
75 \\
76 \\
75\end{array}$ & $\begin{array}{l}74 \\
74 \\
74 \\
74 \\
74\end{array}$ & $\begin{array}{l}77 \\
77 \\
77 \\
77 \\
78\end{array}$ \\
\hline $\begin{array}{l}16 \\
17 \\
18 \\
19 \\
20\end{array}$ & $\begin{array}{l}69 \\
68 \\
68 \\
67 \\
68\end{array}$ & $\begin{array}{l}63 \\
63 \\
62 \\
62 \\
62\end{array}$ & $\begin{array}{l}\mathbf{5 1} \\
50 \\
50 \\
49 \\
\mathbf{4 9}\end{array}$ & $\begin{array}{l}41 \\
41 \\
41 \\
41 \\
41\end{array}$ & $\begin{array}{l}42 \\
42 \\
43 \\
43 \\
43\end{array}$ & $\begin{array}{l}-- \\
45 \\
46 \\
46 \\
46\end{array}$ & $\begin{array}{l}54 \\
55 \\
55 \\
56 \\
56\end{array}$ & $\begin{array}{l}64 \\
65 \\
64 \\
65 \\
64\end{array}$ & $\begin{array}{l}70 \\
70 \\
71 \\
71 \\
72\end{array}$ & $\begin{array}{l}75 \\
75 \\
75 \\
75 \\
75\end{array}$ & $\begin{array}{l}74 \\
75 \\
75 \\
76 \\
76\end{array}$ & $\begin{array}{l}78 \\
76 \\
76 \\
76 \\
76\end{array}$ \\
\hline $\begin{array}{l}21 \\
22 \\
23 \\
24 \\
25\end{array}$ & $\begin{array}{l}67 \\
67 \\
67 \\
67 \\
67\end{array}$ & $\begin{array}{l}61 \\
61 \\
60 \\
60 \\
60\end{array}$ & $\begin{array}{l}49 \\
48 \\
48 \\
47 \\
48\end{array}$ & $\begin{array}{l}41 \\
41 \\
41 \\
41 \\
41\end{array}$ & $\begin{array}{l}43 \\
43 \\
44 \\
44 \\
44\end{array}$ & $\begin{array}{l}46 \\
46 \\
47 \\
47 \\
47\end{array}$ & $\begin{array}{l}56 \\
57 \\
57 \\
58 \\
58\end{array}$ & $\begin{array}{l}64 \\
64 \\
64 \\
64 \\
65\end{array}$ & $\begin{array}{l}72 \\
72 \\
72 \\
72 \\
72\end{array}$ & $\begin{array}{l}75 \\
74 \\
75 \\
74 \\
75\end{array}$ & $\begin{array}{l}76 \\
76 \\
77 \\
77 \\
77\end{array}$ & $\begin{array}{l}75 \\
-- \\
75 \\
-- \\
--\end{array}$ \\
\hline $\begin{array}{l}26 \\
27 \\
28 \\
29 \\
30 \\
31\end{array}$ & $\begin{array}{l}67 \\
66 \\
66 \\
66 \\
66 \\
66 \\
\end{array}$ & $\begin{array}{l}59 \\
58 \\
58 \\
57 \\
57 \\
-- \\
\end{array}$ & $\begin{array}{l}48 \\
47 \\
47 \\
46 \\
46 \\
45\end{array}$ & $\begin{array}{l}40 \\
40 \\
40 \\
40 \\
40 \\
40\end{array}$ & $\begin{array}{l}44 \\
45 \\
45 \\
-- \\
-- \\
--\end{array}$ & $\begin{array}{l}47 \\
47 \\
47 \\
47 \\
47 \\
47\end{array}$ & $\begin{array}{l}59 \\
59 \\
59 \\
59 \\
59 \\
--\end{array}$ & $\begin{array}{l}65 \\
65 \\
64 \\
64 \\
64 \\
64\end{array}$ & $\begin{array}{l}72 \\
72 \\
73 \\
74 \\
74 \\
-- \\
\end{array}$ & $\begin{array}{l}76 \\
76 \\
74 \\
75 \\
75 \\
75 \\
\end{array}$ & $\begin{array}{l}78 \\
79 \\
79 \\
80 \\
80 \\
-- \\
\end{array}$ & $\begin{array}{l}-- \\
-74 \\
74 \\
--\end{array}$ \\
\hline $\begin{array}{c}\text { Aver- } \\
\text { age }\end{array}$ & 69 & 62 & 50 & 42 & 42 & 46 & 54 & 64 & 69 & 75 & 76 & 74 \\
\hline
\end{tabular}


1000

(1)

1

\begin{tabular}{|c|c|c|c|c|}
\hline 명 & $\mid \begin{array}{lll}\infty & \infty & \infty \\
-\infty & -\infty & -\infty \\
-\pi & -\infty\end{array}$ & :- & 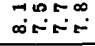 & \\
\hline 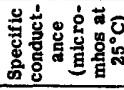 & 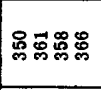 & 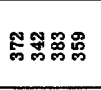 & 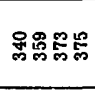 & 呇 \\
\hline 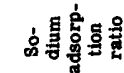 & 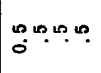 & . p. p. p. & . & : \\
\hline 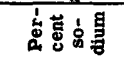 & 무웜요 & ำニニ & 옥 & 9 \\
\hline
\end{tabular}

政

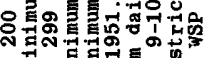
DE है

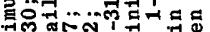

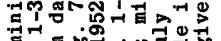
है है

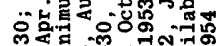

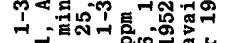

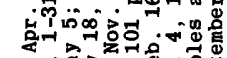

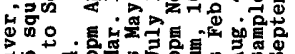

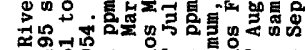

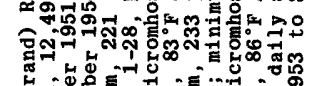

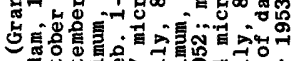

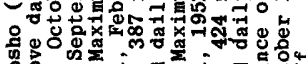

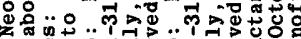

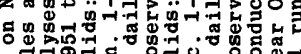

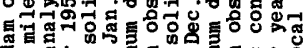
का

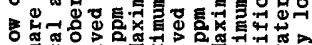

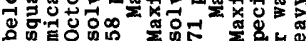
\&

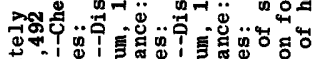

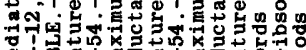

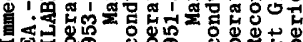

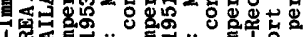

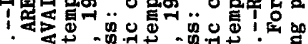

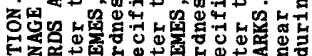

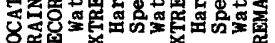

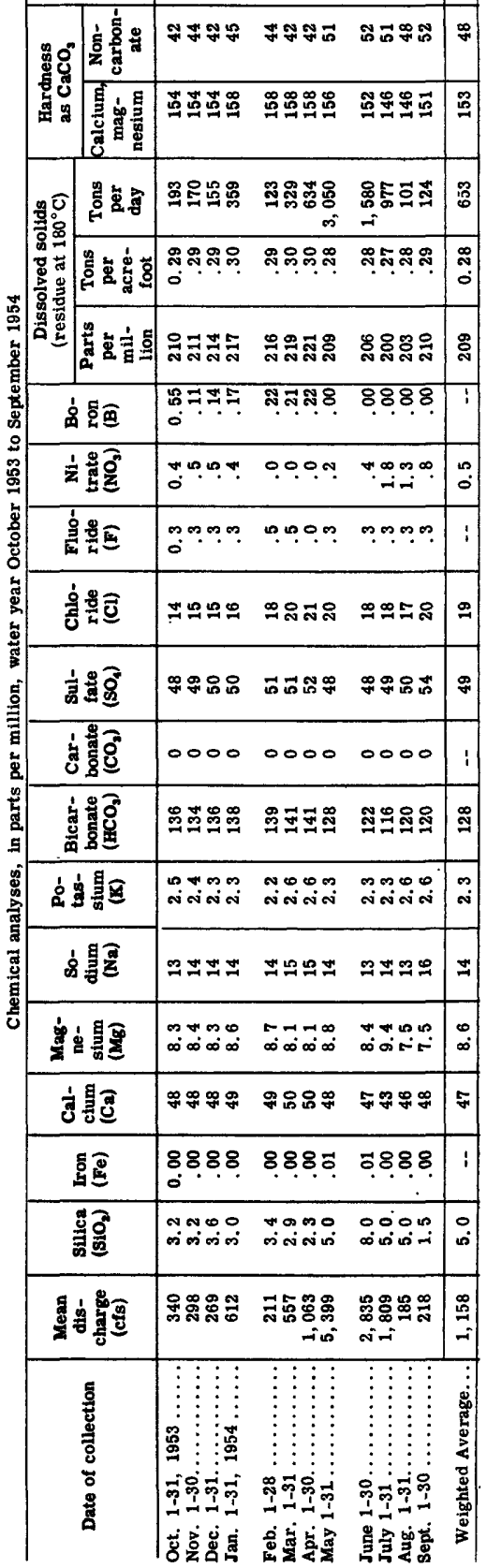


ARKANSAS RIVER BASIN--Continued NEOSHO (GRAND) RIVER AT FORT GIBSON RESERVOIR NEAR FORT GIBSON, OKLA.--Continued

Temperature ( $\left.{ }^{\circ} \mathrm{F}\right)$ of water, water year October 1953 to September 1954

\begin{tabular}{|c|c|c|c|c|c|c|c|c|c|c|c|c|}
\hline Day & Oct. & Nov. & Dec. & Jan. & Feb. & Mar. & Apr. & May & June & July & Aug. & Sept. \\
\hline $\begin{array}{l}1 \\
2 \\
3 \\
4 \\
5\end{array}$ & $\begin{array}{l}74 \\
74 \\
72 \\
70 \\
71\end{array}$ & $\begin{array}{l}60 \\
64 \\
64 \\
64 \\
63\end{array}$ & $\begin{array}{l}54 \\
54 \\
55 \\
59 \\
52\end{array}$ & $\begin{array}{l}42 \\
41 \\
41 \\
42 \\
42\end{array}$ & $\begin{array}{l}43 \\
43 \\
43 \\
44 \\
44\end{array}$ & $\begin{array}{l}49 \\
50 \\
48 \\
47 \\
47\end{array}$ & $\begin{array}{l}\mathbf{5 1} \\
\mathbf{5 3} \\
\mathbf{5 5} \\
\mathbf{5 5} \\
\mathbf{5 6}\end{array}$ & $\begin{array}{l}68 \\
66 \\
65 \\
64 \\
64\end{array}$ & $\begin{array}{l}71 \\
70 \\
71 \\
71 \\
70\end{array}$ & $\begin{array}{l}79 \\
78 \\
80 \\
79 \\
80\end{array}$ & $\begin{array}{l}81 \\
78 \\
79 \\
80 \\
79\end{array}$ & $\begin{array}{l}81 \\
80 \\
80 \\
79 \\
79\end{array}$ \\
\hline $\begin{array}{r}6 \\
7 \\
8 \\
9 \\
10\end{array}$ & $\begin{array}{l}69 \\
69 \\
68 \\
68 \\
68\end{array}$ & $\begin{array}{l}63 \\
58 \\
57 \\
58 \\
58\end{array}$ & $\begin{array}{l}50 \\
53 \\
55 \\
52 \\
52\end{array}$ & $\begin{array}{l}42 \\
42 \\
44 \\
-- \\
41\end{array}$ & $\begin{array}{l}48 \\
50 \\
43 \\
45 \\
45\end{array}$ & $\begin{array}{l}47 \\
43 \\
-- \\
50 \\
50\end{array}$ & $\begin{array}{l}57 \\
57 \\
57 \\
58 \\
59\end{array}$ & $\begin{array}{l}64 \\
65 \\
67 \\
65 \\
64\end{array}$ & $\begin{array}{l}72 \\
72 \\
71 \\
72 \\
73\end{array}$ & $\begin{array}{l}79 \\
79 \\
79 \\
79 \\
80\end{array}$ & $\begin{array}{l}80 \\
83 \\
80 \\
80 \\
80\end{array}$ & $\begin{array}{l}79 \\
79 \\
79 \\
80 \\
79\end{array}$ \\
\hline $\begin{array}{l}11 \\
12 \\
13 \\
14 \\
15\end{array}$ & $\begin{array}{l}70 \\
68 \\
68 \\
68 \\
69\end{array}$ & $\begin{array}{l}\mathbf{5 8} \\
\mathbf{5 7} \\
\mathbf{5 8} \\
\mathbf{5 7} \\
\mathbf{5 6}\end{array}$ & $\begin{array}{l}52 \\
49 \\
48 \\
48 \\
48\end{array}$ & $\begin{array}{l}42 \\
44 \\
42 \\
42 \\
43\end{array}$ & $\begin{array}{l}44 \\
45 \\
48 \\
42 \\
50\end{array}$ & $\begin{array}{l}51 \\
51 \\
40 \\
45 \\
49\end{array}$ & $\begin{array}{l}59 \\
59 \\
59 \\
60 \\
61\end{array}$ & $\begin{array}{l}65 \\
64 \\
64 \\
64 \\
67\end{array}$ & $\begin{array}{l}73 \\
74 \\
76 \\
74 \\
73\end{array}$ & $\begin{array}{l}79 \\
79 \\
80 \\
80 \\
80\end{array}$ & $\begin{array}{l}80 \\
80 \\
79 \\
80 \\
82\end{array}$ & $\begin{array}{l}77 \\
77 \\
77 \\
77 \\
77\end{array}$ \\
\hline $\begin{array}{l}16 \\
17 \\
18 \\
19 \\
20\end{array}$ & $\begin{array}{l}69 \\
70 \\
68 \\
69 \\
69\end{array}$ & $\begin{array}{l}\mathbf{5 8} \\
\mathbf{5 8} \\
\mathbf{5 9} \\
60 \\
\mathbf{5 8}\end{array}$ & $\begin{array}{l}48 \\
48 \\
47 \\
48 \\
50\end{array}$ & $\begin{array}{l}50 \\
42 \\
41 \\
43 \\
44\end{array}$ & $\begin{array}{l}-- \\
48 \\
49 \\
50 \\
50\end{array}$ & $\begin{array}{l}49 \\
49 \\
50 \\
50 \\
50\end{array}$ & $\begin{array}{l}61 \\
60 \\
61 \\
62 \\
62\end{array}$ & $\begin{array}{r}65 \\
65 \\
65 \\
66 \\
66\end{array}$ & $\begin{array}{l}74 \\
74 \\
75 \\
78 \\
78\end{array}$ & $\begin{array}{l}79 \\
82 \\
83 \\
79 \\
78\end{array}$ & $\begin{array}{l}79 \\
80 \\
80 \\
80 \\
79\end{array}$ & $\begin{array}{l}77 \\
77 \\
78 \\
78 \\
80\end{array}$ \\
\hline $\begin{array}{l}21 \\
22 \\
23 \\
24 \\
25\end{array}$ & $\begin{array}{l}68 \\
69 \\
68 \\
64 \\
66\end{array}$ & $\begin{array}{l}\mathbf{5 2} \\
\mathbf{5 2} \\
\mathbf{5 4} \\
\mathbf{5 6} \\
\mathbf{5 6}\end{array}$ & $\begin{array}{l}48 \\
43 \\
42 \\
42 \\
42\end{array}$ & $\begin{array}{l}41 \\
39 \\
42 \\
43 \\
43\end{array}$ & $\begin{array}{l}52 \\
50 \\
50 \\
49 \\
51\end{array}$ & $\begin{array}{l}\mathbf{5 2} \\
50 \\
\mathbf{5 1} \\
\mathbf{5 3} \\
\mathbf{5 2}\end{array}$ & $\begin{array}{l}63 \\
63 \\
63 \\
65 \\
64\end{array}$ & $\begin{array}{l}65 \\
67 \\
68 \\
68 \\
68\end{array}$ & $\begin{array}{l}75 \\
76 \\
77 \\
77 \\
77\end{array}$ & $\begin{array}{l}79 \\
81 \\
80 \\
82 \\
83\end{array}$ & $\begin{array}{l}80 \\
79 \\
79 \\
80 \\
80\end{array}$ & $\begin{array}{l}76 \\
74 \\
74 \\
74 \\
75\end{array}$ \\
\hline $\begin{array}{l}26 \\
27 \\
28 \\
29 \\
30 \\
31\end{array}$ & $\begin{array}{l}66 \\
64 \\
64 \\
64 \\
60 \\
60\end{array}$ & $\begin{array}{l}52 \\
53 \\
54 \\
54 \\
52 \\
--\end{array}$ & $\begin{array}{l}43 \\
39 \\
42 \\
42 \\
42 \\
42\end{array}$ & $\begin{array}{l}42 \\
40 \\
40 \\
41 \\
40 \\
45\end{array}$ & $\begin{array}{l}50 \\
50 \\
49 \\
-- \\
-- \\
--\end{array}$ & $\begin{array}{l}\mathbf{5 3} \\
\mathbf{5 5} \\
\mathbf{5 8} \\
\mathbf{5 4} \\
\mathbf{5 3} \\
\mathbf{5 2}\end{array}$ & $\begin{array}{l}64 \\
64 \\
65 \\
66 \\
65 \\
-\end{array}$ & $\begin{array}{l}67 \\
68 \\
69 \\
69 \\
68 \\
70\end{array}$ & $\begin{array}{l}79 \\
78 \\
79 \\
78 \\
78 \\
--\end{array}$ & $\begin{array}{l}80 \\
80 \\
80 \\
79 \\
80 \\
81\end{array}$ & $\begin{array}{l}80 \\
80 \\
81 \\
81 \\
81 \\
81\end{array}$ & $\begin{array}{l}75 \\
75 \\
75 \\
74 \\
75 \\
--\end{array}$ \\
\hline $\begin{array}{c}\text { Aver- } \\
\text { age }\end{array}$ & 68 & 57 & 48 & 42 & 47 & 50 & 60 & 66 & 75 & 80 & 80 & 77 \\
\hline
\end{tabular}




\section{ARKANSAS RIVER BASIN--Continued}

UTE CREEK NEAR BUEYEROS, N. MEX.

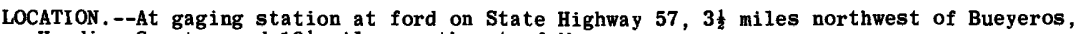
Harding County, and $19 \frac{1}{2}$ miles northeast of Mosquero.

DRAINAGE AREA. - -620 square miles, of which 162 square miles is probably noncontributing RECORDS AVAILABLE, --Chemical analyses: February 1950 to September 1953 (discontinued)

Water temperatures: March 1949 to September 1954 (discontinued).

Sediment records: March 1949 to September 1954 (discontinued).

EXTREMES, 1953-54.--Water temperatures: Maximum observed, $91{ }^{\circ} \mathrm{F}$ Aug. 5 ; minimum observed, freezing point Dec. 6,22 .

Sediment concentrations: Maximum daily, 8,440 ppm May 17; ppm minimum daily, no flow on many days.

Sediment loads: Maximum daily, 6,830 tons May 16; minimum daily, 0 tons on many days. EXTREMES, 1949-54.--Water temperátures: Maximum observed, $94^{\circ} \mathrm{F}$ June 16, 1950; minimum observed, freezing point on many days.

Sediment concentrations: Maximum daily, 21,700 ppm Aug. 23, 1952; minimum daily, no flow on many days.

Sediment loads: Maximum daily, 840,000 tons Aug. 16, 1953; minimum daily, 0 tons on many days.

REMARKS, --Records of discharge for water year October 1953 to September $1954 \mathrm{given}$ in WSP 1341. No flow on days where temperature not shown. Stage relation affected by ice Dec. 6-18, 23-31, Jan. 1-5, Jan. 9-17, 21-24, Feb. 17-18, 28, Mar. 1-6, 13-14.

Temperature $\left({ }^{\circ} \mathrm{F}\right)$ of water, water year October 1953 to September 1954 Once-daily measurement, generally between $11 \mathrm{a} . \mathrm{m}$. and $6 \mathrm{p.m} .7$

\begin{tabular}{|c|c|c|c|c|c|c|c|c|c|c|c|c|}
\hline Day & Oct. & Nov. & Dec. & Jan. & Feb. & Mar. & Apr. & May & June & July & Aug. & Sept. \\
\hline $\begin{array}{l}1 \\
2 \\
3 \\
4 \\
5\end{array}$ & $\begin{array}{l}65 \\
65 \\
67 \\
66 \\
64\end{array}$ & $\begin{array}{l}65 \\
63 \\
52 \\
52 \\
43\end{array}$ & $\begin{array}{r}49 \\
39 \\
42 \\
42 \\
\mathrm{a} 34\end{array}$ & $\begin{array}{l}39 \\
35 \\
42 \\
42 \\
46\end{array}$ & $\begin{array}{l}49 \\
56 \\
57 \\
57 \\
56\end{array}$ & $\begin{array}{l}46 \\
38 \\
45 \\
48 \\
47\end{array}$ & $\begin{array}{r}60 \\
72 \\
\text { b } 52 \\
63 \\
66\end{array}$ & $\begin{array}{l}51 \\
58 \\
65 \\
70 \\
70\end{array}$ & $\begin{array}{r}72 \\
71 \\
71 \\
77 \\
\text { b70 }\end{array}$ & $\begin{array}{l}\overrightarrow{65} \\
-- \\
--\end{array}$ & $\begin{array}{r}76 \\
\text { b74 } \\
\text { a } 80 \\
81 \\
91\end{array}$ & $\begin{array}{l}80 \\
80 \\
-- \\
-- \\
--\end{array}$ \\
\hline $\begin{array}{r}6 \\
7 \\
8 \\
9 \\
10\end{array}$ & $\begin{array}{l}63 \\
66 \\
67 \\
65 \\
68\end{array}$ & $\begin{array}{l}49 \\
50 \\
55 \\
50 \\
60\end{array}$ & $\begin{array}{l}31 \\
43 \\
38 \\
36 \\
43\end{array}$ & $\begin{array}{l}49 \\
46 \\
46 \\
42 \\
40\end{array}$ & $\begin{array}{l}49 \\
55 \\
60 \\
55 \\
52\end{array}$ & $\begin{array}{l}46 \\
46 \\
55 \\
58 \\
60\end{array}$ & $\begin{array}{l}65 \\
62 \\
61 \\
66 \\
63\end{array}$ & $\begin{array}{l}\mathbf{7 5} \\
\mathbf{7 0} \\
\mathbf{6 5} \\
\mathbf{5 8} \\
\mathbf{5 5}\end{array}$ & $\begin{array}{l}79 \\
-- \\
-- \\
--\end{array}$ & $\begin{array}{l}-- \\
-- \\
-- \\
75 \\
78\end{array}$ & $\begin{array}{r}82 \\
\text { b } 69 \\
83 \\
76 \\
\text { b72 }\end{array}$ & $\begin{array}{l}-- \\
-- \\
73 \\
65\end{array}$ \\
\hline $\begin{array}{l}11 \\
12 \\
13 \\
14 \\
15\end{array}$ & $\begin{array}{l}-- \\
-- \\
-- \\
=-\end{array}$ & $\begin{array}{l}57 \\
57 \\
60 \\
62 \\
60\end{array}$ & $\begin{array}{l}34 \\
37 \\
38 \\
38 \\
46\end{array}$ & $\begin{array}{l}37 \\
33 \\
36 \\
38 \\
41\end{array}$ & $\begin{array}{l}48 \\
54 \\
55 \\
55 \\
45\end{array}$ & $\begin{array}{l}45 \\
48 \\
41 \\
51 \\
46\end{array}$ & $\begin{array}{l}49 \\
62 \\
68 \\
65 \\
57\end{array}$ & $\begin{array}{r}56 \\
68 \\
71 \\
74 \\
\mathrm{a} 71\end{array}$ & $\begin{array}{l}-- \\
=- \\
- \\
\text { b70 }\end{array}$ & $\begin{array}{l}84 \\
-- \\
-- \\
-- \\
--\end{array}$ & $\begin{array}{r}81 \\
74 \\
\text { b75 } \\
-- \\
--\end{array}$ & $\begin{array}{l}82 \\
70 \\
72 \\
70 \\
--\end{array}$ \\
\hline $\begin{array}{l}16 \\
17 \\
18 \\
19 \\
20\end{array}$ & $\begin{array}{l}-- \\
-- \\
-- \\
58\end{array}$ & $\begin{array}{l}58 \\
53 \\
52 \\
40 \\
45\end{array}$ & $\begin{array}{l}39 \\
47 \\
46 \\
47 \\
45\end{array}$ & $\begin{array}{l}48 \\
46 \\
57 \\
45 \\
35\end{array}$ & $\begin{array}{l}50 \\
58 \\
54 \\
43 \\
47\end{array}$ & $\begin{array}{l}46 \\
52 \\
49 \\
49 \\
55\end{array}$ & $\begin{array}{l}-- \\
72 \\
70 \\
68 \\
63\end{array}$ & $\begin{array}{r}59 \\
\text { a } 58 \\
\text { b 72 } \\
79 \\
81\end{array}$ & $\begin{array}{l}75 \\
82 \\
-- \\
81 \\
80\end{array}$ & $\begin{array}{r}-- \\
\text { b70 } \\
78\end{array}$ & $\begin{array}{r}-- \\
\text { b 79 } \\
\text { b75 } \\
72\end{array}$ & $\begin{array}{l}-- \\
-- \\
-- \\
-- \\
--\end{array}$ \\
\hline $\begin{array}{l}21 \\
22 \\
23 \\
24 \\
25\end{array}$ & $\begin{array}{l}65 \\
50 \\
49 \\
60 \\
52\end{array}$ & $\begin{array}{l}37 \\
43 \\
51 \\
51 \\
49\end{array}$ & $\begin{array}{l}41 \\
32 \\
33 \\
36 \\
36\end{array}$ & $\begin{array}{l}35 \\
36 \\
47 \\
48 \\
50\end{array}$ & $\begin{array}{l}47 \\
48 \\
52 \\
57 \\
58\end{array}$ & $\begin{array}{l}66 \\
51 \\
60 \\
54 \\
56\end{array}$ & $\begin{array}{l}65 \\
65 \\
66 \\
74 \\
75\end{array}$ & $\begin{array}{r}62 \\
\mathrm{a} 66 \\
60 \\
62 \\
72\end{array}$ & $\begin{array}{l}81 \\
87 \\
90 \\
85 \\
--\end{array}$ & $\begin{array}{l}79 \\
73 \\
78 \\
87 \\
83\end{array}$ & $\begin{array}{r}-- \\
\text { b 71 } \\
\text { b71 } \\
70 \\
74\end{array}$ & $\begin{array}{l}-- \\
-- \\
-- \\
62 \\
62\end{array}$ \\
\hline $\begin{array}{l}26 \\
27 \\
28 \\
29 \\
30 \\
31\end{array}$ & $\begin{array}{r}55 \\
62 \\
65 \\
58 \\
61 \\
\text { b } 43 \\
\end{array}$ & $\begin{array}{l}45 \\
55 \\
50 \\
52 \\
50 \\
-- \\
\end{array}$ & $\begin{array}{l}36 \\
35 \\
33 \\
35 \\
38 \\
41 \\
\end{array}$ & $\begin{array}{r}\mathbf{4 7} \\
\mathbf{4 8} \\
\mathbf{4 9} \\
57 \\
\text { a } 40 \\
\text { b } 46 \\
\end{array}$ & $\begin{array}{l}54 \\
46 \\
57 \\
-- \\
-- \\
-- \\
\end{array}$ & $\begin{array}{l}53 \\
60 \\
61 \\
58 \\
55 \\
55 \\
\end{array}$ & $\begin{array}{l}69 \\
71 \\
68 \\
61 \\
41 \\
--\end{array}$ & $\begin{array}{l}76 \\
73 \\
66 \\
75 \\
69 \\
75 \\
\end{array}$ & $\begin{array}{l}-- \\
-- \\
-- \\
85 \\
--\end{array}$ & $\begin{array}{l}85 \\
69 \\
85 \\
80 \\
82 \\
86\end{array}$ & $\begin{array}{r}\text { b 72 } \\
82 \\
80 \\
78 \\
71 \\
82 \\
\end{array}$ & $\begin{array}{l}66 \\
65 \\
62 \\
-- \\
-- \\
-- \\
\end{array}$ \\
\hline $\begin{array}{c}\text { Aver- } \\
\text { age }\end{array}$ & -- & 52 & 39 & 43 & 53 & 52 & 64 & 67 & -- & -- & - & - \\
\hline
\end{tabular}

a Measurement before $11 \mathrm{a} . \mathrm{m}$

b Measurement after $6 \mathrm{p} . \mathrm{m}$. 
ARKANSAS RIVER BASIN--Continued

UTE CREEK NEAR BUEYEROS, N. MEX.--Continued

Suspended sediment, water year October 1953 to September 1954

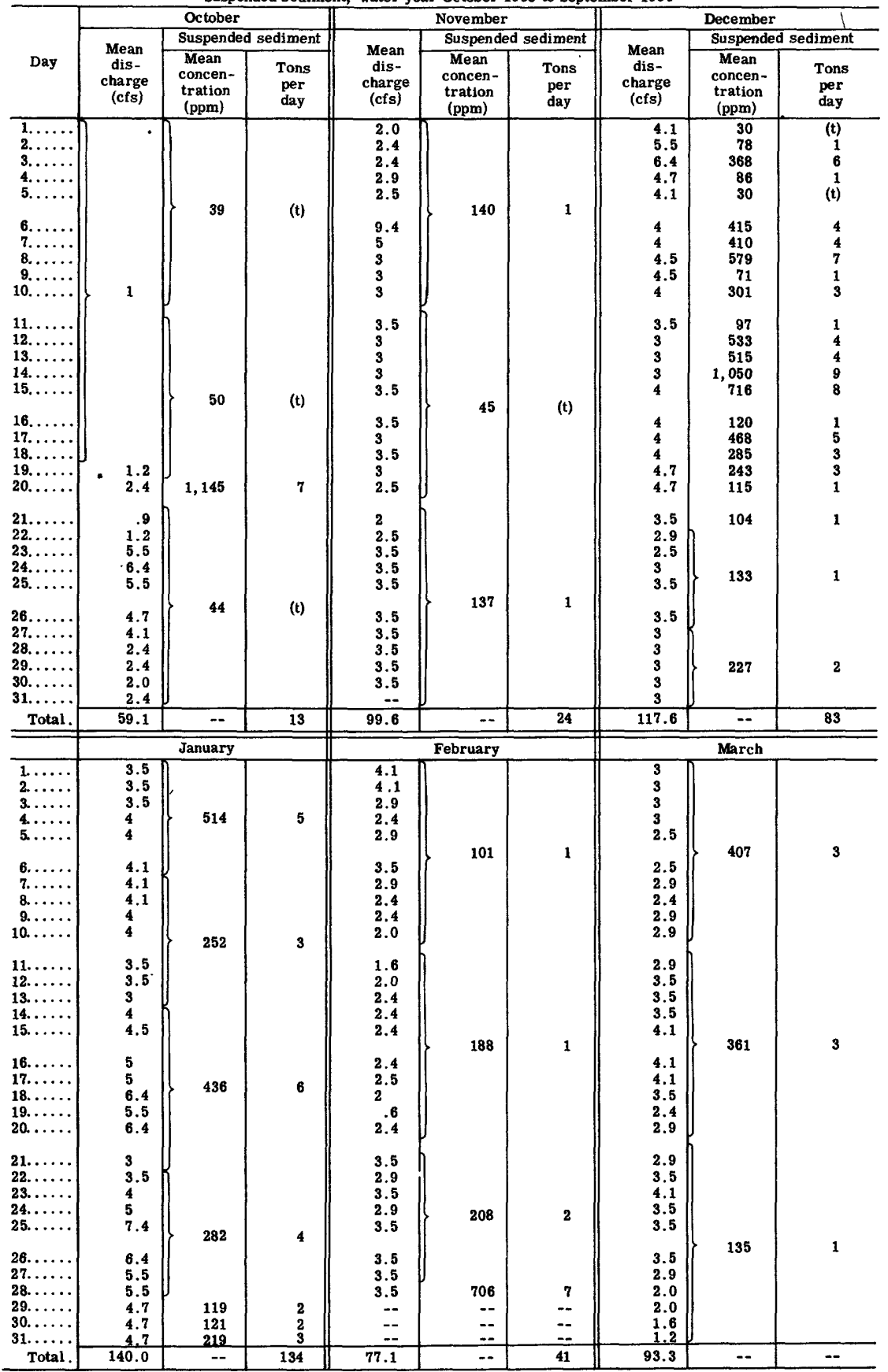

$t$ Less than 0.50 ton. 
ARKANSAS RIVER BASIN--Cont inued

UTE CREEK NEAR BUEYEROS, N. MEX.--Continued

Suspended sediment, water year October 1953 to September 1954 --Continued

\begin{tabular}{|c|c|c|c|c|c|c|c|c|c|}
\hline \multirow[b]{3}{*}{ Day } & \multicolumn{3}{|c|}{ April } & \multicolumn{3}{|c|}{ May } & \multicolumn{3}{|c|}{ June } \\
\hline & \multirow[b]{2}{*}{$\begin{array}{c}\text { Mean } \\
\text { dis - } \\
\text { charge } \\
\text { (cfs) }\end{array}$} & \multicolumn{2}{|c|}{ Suspended sediment } & \multirow[b]{2}{*}{$\begin{array}{l}\text { Mean } \\
\text { dis- } \\
\text { charge } \\
\text { (cfs) }\end{array}$} & \multicolumn{2}{|c|}{ Suspended sediment } & \multirow[b]{2}{*}{$\begin{array}{l}\text { Mean } \\
\text { dis- } \\
\text { charge } \\
\text { (cfs) }\end{array}$} & \multicolumn{2}{|c|}{ Suspended sediment } \\
\hline & & $\begin{array}{l}\text { Mean } \\
\text { concen- } \\
\text { tration } \\
\text { (ppm) }\end{array}$ & $\begin{array}{l}\text { Tons } \\
\text { per } \\
\text { day }\end{array}$ & & $\begin{array}{c}\text { Mean } \\
\text { concen- } \\
\text { tration } \\
\text { (ppm) }\end{array}$ & $\begin{array}{l}\text { Tons } \\
\text { per } \\
\text { day }\end{array}$ & & $\begin{array}{l}\text { Mean } \\
\text { concen- } \\
\text { tration } \\
\text { (ppm) }\end{array}$ & $\begin{array}{l}\text { Tons } \\
\text { per } \\
\text { day }\end{array}$ \\
\hline $\begin{array}{l}1 \ldots \ldots \\
2 . \ldots \ldots \\
3 . \ldots \ldots \\
4 . \ldots \ldots \\
5 . \ldots \ldots\end{array}$ & $\begin{array}{r}1.6 \\
.6 \\
.6 \\
.4 \\
.6\end{array}$ & 243 & 1 & $\begin{array}{l}6.4 \\
3.5 \\
3.5 \\
2.9 \\
2.0\end{array}$ & $\begin{array}{r}2,100 \\
168 \\
122 \\
137 \\
75\end{array}$ & $\begin{array}{r}36 \\
2 \\
1 \\
1 \\
\text { (t) }\end{array}$ & $\begin{array}{r}0.4 \\
.6 \\
.9 \\
1.2 \\
.4\end{array}$ & 23 & (t) \\
\hline $\begin{array}{r}6 \ldots \ldots \\
7 \ldots \ldots \ldots \\
8 . \ldots \ldots \\
9 \ldots \ldots \\
10 \ldots \ldots\end{array}$ & $\begin{array}{l}.2 \\
.2 \\
.4 \\
.9 \\
.6\end{array}$ & 75 & (t) & $\begin{array}{l}1.6 \\
1.2 \\
1.2 \\
3.5 \\
2.4\end{array}$ & $\begin{array}{r}103 \\
72 \\
64 \\
125 \\
126\end{array}$ & $\begin{array}{ll}(t) & \\
(t) & \\
(t) & \\
& 1 \\
& 1\end{array}$ & $\begin{array}{l}.1 \\
0 \\
0 \\
0 \\
0\end{array}$ & $\begin{array}{l}13 \\
-- \\
-- \\
-- \\
--\end{array}$ & (t) $\begin{array}{l}0 \\
0 \\
0 \\
0\end{array}$ \\
\hline $\begin{array}{l}11 \ldots \ldots \\
12 . \ldots \ldots \\
13 . \ldots \ldots \\
14 \ldots \ldots \\
15 \ldots \ldots\end{array}$ & $\begin{array}{l}1.6 \\
3.5 \\
3.5 \\
2.9 \\
2.9\end{array}$ & & & $\begin{array}{l}4.1 \\
2.9 \\
4.1 \\
6.4 \\
34\end{array}$ & $\begin{array}{r}635 \\
500 \\
300 \\
500 \\
4,840\end{array}$ & $\begin{array}{r}7 \\
4 \\
3 \\
9 \\
444\end{array}$ & $\begin{array}{l}0 \\
0 \\
0 \\
0 \\
1.4\end{array}$ & $\begin{array}{l}-- \\
\overline{--} \\
\overline{\mathbf{3 5}}\end{array}$ & (t) $\begin{array}{r}0 \\
0 \\
0 \\
0\end{array}$ \\
\hline $\begin{array}{l}16 \ldots \ldots \\
17 \ldots \ldots \\
18 \ldots \ldots \\
19 \ldots \ldots \\
20 \ldots \ldots\end{array}$ & $\begin{array}{l}1.6 \\
2.4 \\
2.4 \\
2.0 \\
1.6\end{array}$ & 42 & $(t)$ & $\begin{array}{c}138 \\
155 \\
29 \\
14 \\
8.4\end{array}$ & $\begin{array}{r}7,310 \\
8,440 \\
\\
119\end{array}$ & $\begin{array}{r}\text { s } 6,830 \\
3,530\end{array}$ & $\begin{array}{r}2.9 \\
0^{0} \\
34 \\
34\end{array}$ & $\begin{array}{r}443 \\
2,660 \\
3,200\end{array}$ & $\begin{array}{r}1 \\
\mathrm{~s} 647 \\
293\end{array}$ \\
\hline $\begin{array}{l}21 \ldots \ldots \ldots \\
22 . \ldots \ldots \\
23 . \ldots \ldots \\
24 \ldots \ldots \\
25 . \ldots \ldots\end{array}$ & $\begin{array}{r}.9 \\
1.2 \\
1.6 \\
1.2 \\
.9\end{array}$ & & & $\begin{array}{l}7.4 \\
7.4 \\
5.5 \\
6.4 \\
8.4\end{array}$ & 164 & 3 & $\begin{array}{l}{ }^{8} \\
3 \\
.5 \\
. .4\end{array}$ & $\begin{array}{r}1,700 \\
800 \\
300 \\
100 \\
--\end{array}$ & $\begin{array}{r}a 37 \\
a 6 \\
(a)(t) \\
(a)(t)\end{array}$ \\
\hline $\begin{array}{l}26 \ldots \ldots \\
27 \ldots \ldots \ldots \\
28 \ldots \ldots \\
29 \ldots \ldots \\
30 \ldots \ldots \\
31 \ldots \ldots \\
\end{array}$ & $\begin{array}{r}.9 \\
.6 \\
.9 \\
.9 \\
1.2 \\
-- \\
\end{array}$ & 65 & (t) & $\begin{array}{r}6.4 \\
4.7 \\
3.5 \\
3.5 \\
1.2 \\
.6 \\
\end{array}$ & 197 & 1 & $\begin{array}{l}0 \\
0 \\
0 \\
0 \\
.7 \\
. \\
\end{array}$ & $\begin{array}{l}-- \\
-- \\
-- \\
32 \\
--\end{array}$ & $\begin{array}{r}0 \\
0 \\
0 \\
0 \\
\end{array}$ \\
\hline \multirow[t]{2}{*}{ Total } & 40.8 & -- & 10 & 479.1 & -- & 10,910 & 88.6 & -- & 987 \\
\hline & \multicolumn{3}{|c|}{ July } & \multicolumn{3}{|c|}{ August } & \multicolumn{3}{|c|}{ September } \\
\hline $\begin{array}{l}1 . \ldots \ldots \\
2 \ldots \ldots \\
3 . \ldots \ldots \\
4 \ldots \ldots \\
5 \ldots \ldots\end{array}$ & $\begin{array}{l}0 \\
1.0 \\
0 \\
0 \\
0\end{array}$ & $\begin{array}{r}1,290 \\
-- \\
-- \\
--\end{array}$ & $\begin{array}{r}0 \\
\mathbf{s} 16 \\
0 \\
0 \\
0\end{array}$ & $\begin{array}{r}0.1 \\
.1 \\
1.2 \\
1.2 \\
.4\end{array}$ & 250 & $(t)$ & $\begin{array}{l}0.3 \\
.2 \\
0 \\
0 \\
0\end{array}$ & $\begin{array}{r}100 \\
150 \\
-- \\
-- \\
--\end{array}$ & $\begin{array}{l}\text { (t) } \\
(\mathrm{t}) \\
\\
0 \\
0 \\
0\end{array}$ \\
\hline $\begin{array}{c}6 \ldots \ldots \\
7 . \ldots \ldots \\
8 \ldots \ldots \\
9 \ldots \ldots \\
10 \ldots \ldots\end{array}$ & $\begin{array}{c}0 \\
0 \\
0 \\
22 \\
6.4\end{array}$ & 2,170 & $\begin{array}{r}0 \\
0 \\
0 \\
\mathbf{s} 181\end{array}$ & $\begin{array}{c}1.2 \\
8.4 \\
32 \\
5.5 \\
6.4\end{array}$ & $\begin{array}{r}3,500 \\
1,800 \\
500 \\
2,750\end{array}$ & $\begin{array}{r}79 \\
156 \\
7 \\
48\end{array}$ & $\begin{array}{l}0 \\
0 \\
8.4 \\
4.1 \\
4.1\end{array}$ & $\begin{array}{r}-- \\
250 \\
800 \\
85\end{array}$ & $\begin{array}{r}0 \\
0 \\
51 \\
9 \\
1\end{array}$ \\
\hline $\begin{array}{l}11 \ldots \ldots \\
12 \ldots \ldots \\
13 \ldots \ldots \\
14 \ldots \ldots \\
15 \ldots \ldots\end{array}$ & $\begin{array}{l}.1 \\
0 \\
0 \\
0\end{array}$ & $\begin{array}{l}2 \\
-- \\
-- \\
--\end{array}$ & $\begin{array}{l}1 \\
0 \\
0 \\
0 \\
0\end{array}$ & $\begin{array}{l}.9 \\
.4 \\
1.2 \\
0 \\
0\end{array}$ & $\begin{array}{r}980 \\
240 \\
200 \\
-- \\
--\end{array}$ & (t) $\begin{array}{l}2 \\
1 \\
0 \\
0\end{array}$ & $\begin{array}{l}1.6 \\
.1 \\
.2 \\
.2 \\
0\end{array}$ & $\begin{array}{r}70 \\
100 \\
90 \\
85 \\
--\end{array}$ & $\begin{array}{l}(t) \\
(t) \\
(t) \\
(t) \\
\\
\end{array}$ \\
\hline $\begin{array}{l}16 \ldots \ldots \\
17 \ldots \ldots \\
18 \ldots \ldots \\
19 \ldots \ldots \\
20 \ldots \ldots\end{array}$ & $\begin{array}{c}0 \\
0 \\
0 \\
7.0 \\
94\end{array}$ & $\begin{array}{r}-- \\
-- \\
2,040 \\
5,340\end{array}$ & $\begin{array}{r}0 \\
0 \\
0 \\
\mathbf{s} 132 \\
\mathbf{s} \mathbf{1 , 5 0 0}\end{array}$ & $\begin{array}{c}0 \\
0 \\
20 \\
12 \\
1.2\end{array}$ & $\begin{array}{r}-- \\
-- \\
1,850 \\
930 \\
350\end{array}$ & $\begin{array}{r}0 \\
0 \\
8205 \\
30 \\
1\end{array}$ & $\begin{array}{l}0 \\
0 \\
0 \\
0 \\
0\end{array}$ & $\begin{array}{l}-- \\
-- \\
-- \\
--\end{array}$ & $\begin{array}{l}0 \\
0 \\
0 \\
0 \\
0\end{array}$ \\
\hline $\begin{array}{l}21 \ldots \ldots \\
22 \ldots \ldots \ldots \\
23 . \ldots \ldots \\
24 \ldots \ldots \\
25 \ldots \ldots\end{array}$ & $\begin{array}{l}24 \\
13 \\
80 \\
41 \\
20\end{array}$ & $\begin{array}{r}1,800 \\
3,180 \\
4,900 \\
1,000 \\
400\end{array}$ & $\begin{array}{r}117 \\
112 \\
1,060 \\
\mathrm{a} 110 \\
\mathrm{a22}\end{array}$ & $\begin{array}{c}0 \\
7.4 \\
22 \\
8.4 \\
4.1\end{array}$ & $\begin{array}{l}-- \\
800 \\
530 \\
200 \\
480\end{array}$ & $\begin{array}{r}0 \\
16 \\
31 \\
5 \\
5\end{array}$ & $\begin{array}{c}0 \\
0 \\
0 \\
2.4 \\
29\end{array}$ & $\begin{array}{r}-\overline{-} \\
2,500 \\
2,700\end{array}$ & $\begin{array}{r}0 \\
0 \\
0 \\
16 \\
211\end{array}$ \\
\hline $\begin{array}{l}26 \ldots \ldots \\
27 . \ldots \ldots \\
28 . \ldots \ldots \\
29 . \ldots \ldots \\
30 \ldots \ldots \\
31 \ldots \ldots\end{array}$ & $\begin{array}{l}6.4 \\
26 \\
41 \\
27 \\
3.5 \\
.6 \\
\end{array}$ & $\begin{array}{r}300 \\
2,980 \\
4,250 \\
2,900 \\
600 \\
300 \\
\end{array}$ & $\begin{array}{rr}\text { a } 5 \\
s 1,020 \\
470 \\
211 \\
\text { (t) } \quad 6 \\
\end{array}$ & $\begin{array}{r}5.5 \\
8.4 \\
2.4 \\
.4 \\
33^{.4} \\
\end{array}$ & $\begin{array}{r}790 \\
200 \\
200 \\
110 \\
4,710 \\
1,400 \\
\end{array}$ & $\begin{array}{r}12 \\
5 \\
1 \\
\text { (t) } \\
s 1,760 \\
\end{array}$ & $\begin{array}{l}2.4 \\
1.2 \\
.2 \\
0 \\
0 \\
. .\end{array}$ & $\begin{array}{r}300 \\
300 \\
320 \\
-- \\
-- \\
-- \\
\end{array}$ & (t) $\begin{array}{r}2 \\
1 \\
0 \\
0 \\
-\end{array}$ \\
\hline Total. & 413.0 & -- & 4,964 & 184.2 & -- & 2,367 & 54.4 & -- & 292 \\
\hline
\end{tabular}

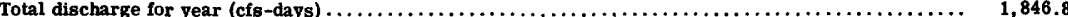

Total load for year (tons)

s Computed by subdividing day.

$t$ Less than 0.50 ton. 


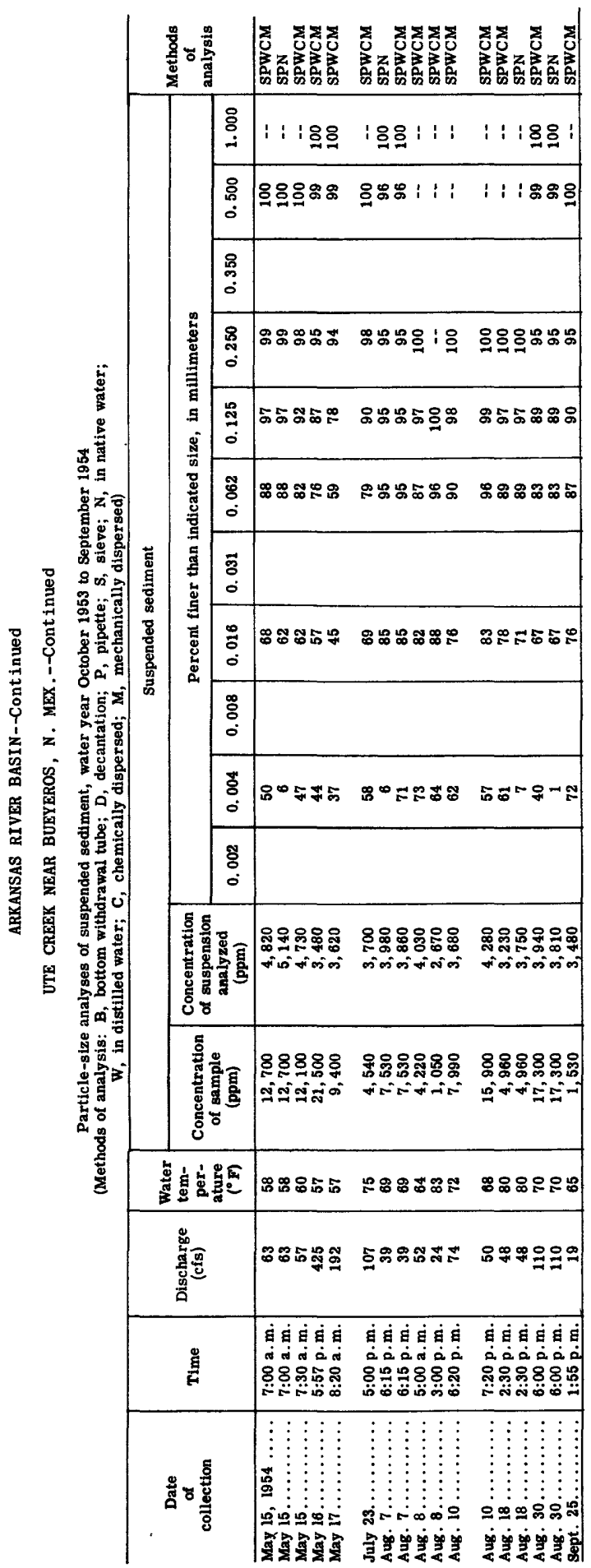




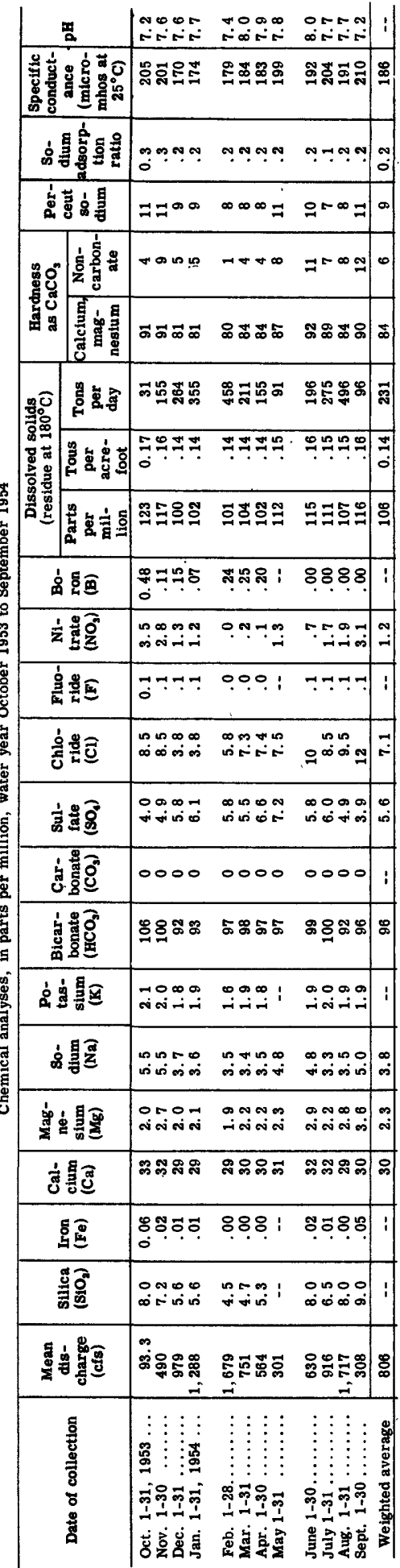


ARKANSAS RIVER BASIN--Continued

ILLINOIS RIVER AT TENKILLER RESERVOIR NEAR GORE, OKLA.--Continued

Temperature $\left({ }^{\circ} \mathrm{F}\right)$ of water, water year October 1953 to September 1954

\begin{tabular}{|c|c|c|c|c|c|c|c|c|c|c|c|c|}
\hline Day & Oct. & Nov. & Dec. & Jan. & Feb. & Mar. & Apr. & May & June & July & Aug. & Sept. \\
\hline $\begin{array}{l}1 \\
2 \\
3 \\
4 \\
5\end{array}$ & $\begin{array}{l}57 \\
59 \\
57 \\
57 \\
56\end{array}$ & $\begin{array}{l}57 \\
56 \\
56 \\
56 \\
56\end{array}$ & $\begin{array}{l}57 \\
56 \\
56 \\
56 \\
58\end{array}$ & $\begin{array}{l}51 \\
52 \\
50 \\
49 \\
48\end{array}$ & $\begin{array}{l}44 \\
44 \\
44 \\
44 \\
44\end{array}$ & $\begin{array}{l}46 \\
46 \\
46 \\
45 \\
46\end{array}$ & $\begin{array}{l}47 \\
49 \\
49 \\
49 \\
49\end{array}$ & $\begin{array}{l}52 \\
54 \\
53 \\
52 \\
51\end{array}$ & $\begin{array}{l}50 \\
50 \\
52 \\
52 \\
--\end{array}$ & $\begin{array}{l}53 \\
52 \\
54 \\
54 \\
54\end{array}$ & $\begin{array}{l}\mathbf{5 5} \\
\mathbf{5 6} \\
\mathbf{5 8} \\
\mathbf{5 8} \\
\mathbf{5 8}\end{array}$ & $\begin{array}{l}58 \\
58 \\
58 \\
58 \\
58\end{array}$ \\
\hline $\begin{array}{r}6 \\
7 \\
8 \\
9 \\
10\end{array}$ & $\begin{array}{l}56 \\
56 \\
56 \\
60 \\
56\end{array}$ & $\begin{array}{l}56 \\
58 \\
55 \\
56 \\
55\end{array}$ & $\begin{array}{l}57 \\
56 \\
55 \\
55 \\
54\end{array}$ & $\begin{array}{l}48 \\
47 \\
48 \\
52 \\
46\end{array}$ & $\begin{array}{l}44 \\
44 \\
44 \\
44 \\
44\end{array}$ & $\begin{array}{l}47 \\
46 \\
46 \\
47 \\
47\end{array}$ & $\begin{array}{l}50 \\
50 \\
50 \\
49 \\
49\end{array}$ & $\begin{array}{l}51 \\
51 \\
51 \\
51 \\
51\end{array}$ & $\begin{array}{l}-2 \\
54 \\
-- \\
53 \\
53\end{array}$ & $\begin{array}{l}54 \\
54 \\
54 \\
52 \\
54\end{array}$ & $\begin{array}{l}60 \\
59 \\
58 \\
59 \\
60\end{array}$ & $\begin{array}{l}59 \\
59 \\
59 \\
59 \\
59\end{array}$ \\
\hline $\begin{array}{l}11 \\
12 \\
13 \\
14 \\
15\end{array}$ & $\begin{array}{l}\mathbf{5 7} \\
57 \\
\mathbf{5 7} \\
\mathbf{5 7} \\
\mathbf{5 4}\end{array}$ & $\begin{array}{l}\mathbf{5 5} \\
\mathbf{5 5} \\
\mathbf{5 5} \\
\mathbf{5 7} \\
\mathbf{5 7}\end{array}$ & $\begin{array}{l}54 \\
54 \\
54 \\
55 \\
52\end{array}$ & $\begin{array}{l}46 \\
46 \\
46 \\
46 \\
46\end{array}$ & $\begin{array}{l}44 \\
44 \\
44 \\
44 \\
45\end{array}$ & $\begin{array}{l}47 \\
48 \\
45 \\
45 \\
47\end{array}$ & $\begin{array}{l}49 \\
54 \\
50 \\
50 \\
50\end{array}$ & $\begin{array}{l}51 \\
52 \\
52 \\
48 \\
48\end{array}$ & $\begin{array}{l}52 \\
51 \\
51 \\
52 \\
53\end{array}$ & $\begin{array}{l}54 \\
54 \\
54 \\
54 \\
54\end{array}$ & $\begin{array}{l}60 \\
60 \\
60 \\
61 \\
61\end{array}$ & $\begin{array}{l}58 \\
59 \\
59 \\
59 \\
58\end{array}$ \\
\hline $\begin{array}{l}16 \\
17 \\
18 \\
19 \\
20\end{array}$ & $\begin{array}{l}54 \\
-- \\
56 \\
54 \\
56\end{array}$ & $\begin{array}{l}\mathbf{5 7} \\
\mathbf{5 7} \\
\mathbf{5 7} \\
\mathbf{5 7} \\
\mathbf{5 7}\end{array}$ & $\begin{array}{l}52 \\
52 \\
52 \\
52 \\
53\end{array}$ & $\begin{array}{l}46 \\
46 \\
46 \\
46 \\
46\end{array}$ & $\begin{array}{l}45 \\
45 \\
45 \\
45 \\
45\end{array}$ & $\begin{array}{l}47 \\
47 \\
47 \\
47 \\
45\end{array}$ & $\begin{array}{l}50 \\
51 \\
54 \\
50 \\
50\end{array}$ & $\begin{array}{l}50 \\
50 \\
50 \\
50 \\
50\end{array}$ & $\begin{array}{l}50 \\
52 \\
53 \\
61 \\
61\end{array}$ & $\begin{array}{l}54 \\
54 \\
54 \\
54 \\
54\end{array}$ & $\begin{array}{l}60 \\
60 \\
62 \\
61 \\
63\end{array}$ & $\begin{array}{l}58 \\
59 \\
62 \\
58 \\
58\end{array}$ \\
\hline $\begin{array}{l}21 \\
22 \\
23 \\
24 \\
25\end{array}$ & $\begin{array}{l}56 \\
56 \\
56 \\
56 \\
55\end{array}$ & $\begin{array}{l}58 \\
60 \\
57 \\
57 \\
57\end{array}$ & $\begin{array}{l}\mathbf{5 1} \\
\mathbf{5 1} \\
\mathbf{5 0} \\
\mathbf{5 0} \\
\mathbf{5 2}\end{array}$ & $\begin{array}{l}45 \\
44 \\
44 \\
46 \\
44\end{array}$ & $\begin{array}{l}47 \\
45 \\
45 \\
-- \\
46\end{array}$ & $\begin{array}{l}44 \\
44 \\
44 \\
44 \\
44\end{array}$ & $\begin{array}{l}47 \\
49 \\
49 \\
49 \\
49\end{array}$ & $\begin{array}{l}50 \\
50 \\
50 \\
50 \\
50\end{array}$ & $\begin{array}{l}\mathbf{5 2} \\
\mathbf{5 2} \\
\mathbf{5 3} \\
\mathbf{5 2} \\
\mathbf{5 3}\end{array}$ & $\begin{array}{l}\mathbf{5 5} \\
\mathbf{5 5} \\
\mathbf{5 5} \\
\mathbf{5 5} \\
\mathbf{5 5}\end{array}$ & $\begin{array}{l}62 \\
60 \\
-- \\
64 \\
63\end{array}$ & $\begin{array}{l}58 \\
57 \\
57 \\
57 \\
58\end{array}$ \\
\hline $\begin{array}{l}26 \\
27 \\
28 \\
29 \\
30 \\
31\end{array}$ & $\begin{array}{l}- \\
56 \\
55 \\
56 \\
56 \\
58 \\
\end{array}$ & $\begin{array}{l}\mathbf{5 5} \\
\mathbf{5 7} \\
59 \\
56 \\
55 \\
-- \\
\end{array}$ & $\begin{array}{l}52 \\
52 \\
49 \\
49 \\
48 \\
49 \\
\end{array}$ & $\begin{array}{l}44 \\
44 \\
44 \\
44 \\
44 \\
46\end{array}$ & $\begin{array}{l}46 \\
45 \\
41 \\
-- \\
-- \\
-- \\
\end{array}$ & $\begin{array}{l}44 \\
44 \\
44 \\
44 \\
44 \\
44 \\
\end{array}$ & $\begin{array}{l}50 \\
53 \\
50 \\
52 \\
52 \\
-- \\
\end{array}$ & $\begin{array}{l}\mathbf{5 0} \\
\mathbf{5 0} \\
\mathbf{5 0} \\
\mathbf{5 0} \\
\mathbf{5 0} \\
\mathbf{5 0} \\
\end{array}$ & $\begin{array}{l}61 \\
54 \\
54 \\
54 \\
53 \\
-- \\
\end{array}$ & $\begin{array}{l}\mathbf{5 5} \\
55 \\
55 \\
55 \\
55 \\
55 \\
\end{array}$ & $\begin{array}{l}60 \\
62 \\
59 \\
60 \\
62 \\
62 \\
\end{array}$ & $\begin{array}{l}58 \\
58 \\
58 \\
58 \\
58 \\
-- \\
\end{array}$ \\
\hline $\begin{array}{c}\text { Aver- } \\
\text { age }\end{array}$ & 56 & 57 & 53 & 46 & 44 & 46 & 50 & 51 & 53 & 54 & 58 & 58 \\
\hline
\end{tabular}




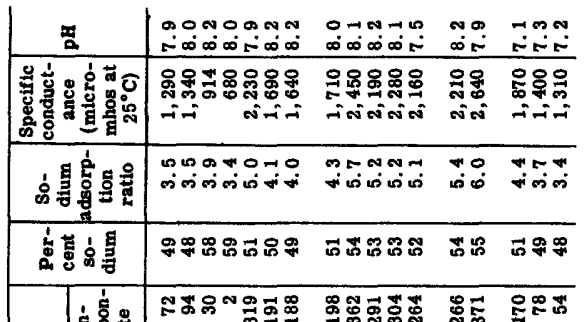

i

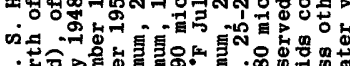

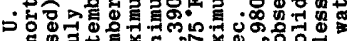
5

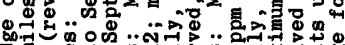

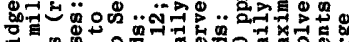
車。

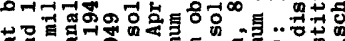

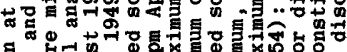

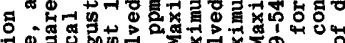

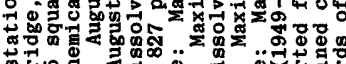

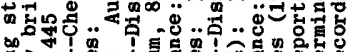

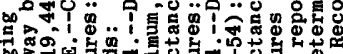

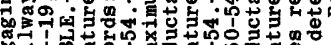

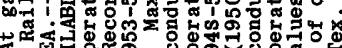

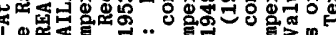

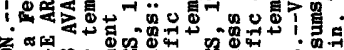

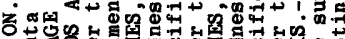

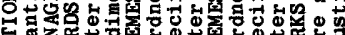

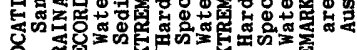

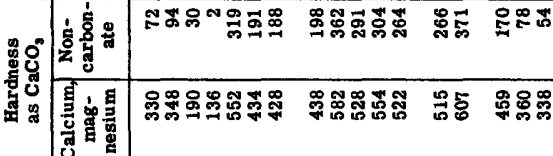

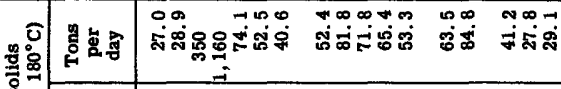

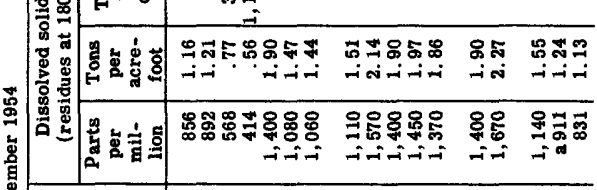

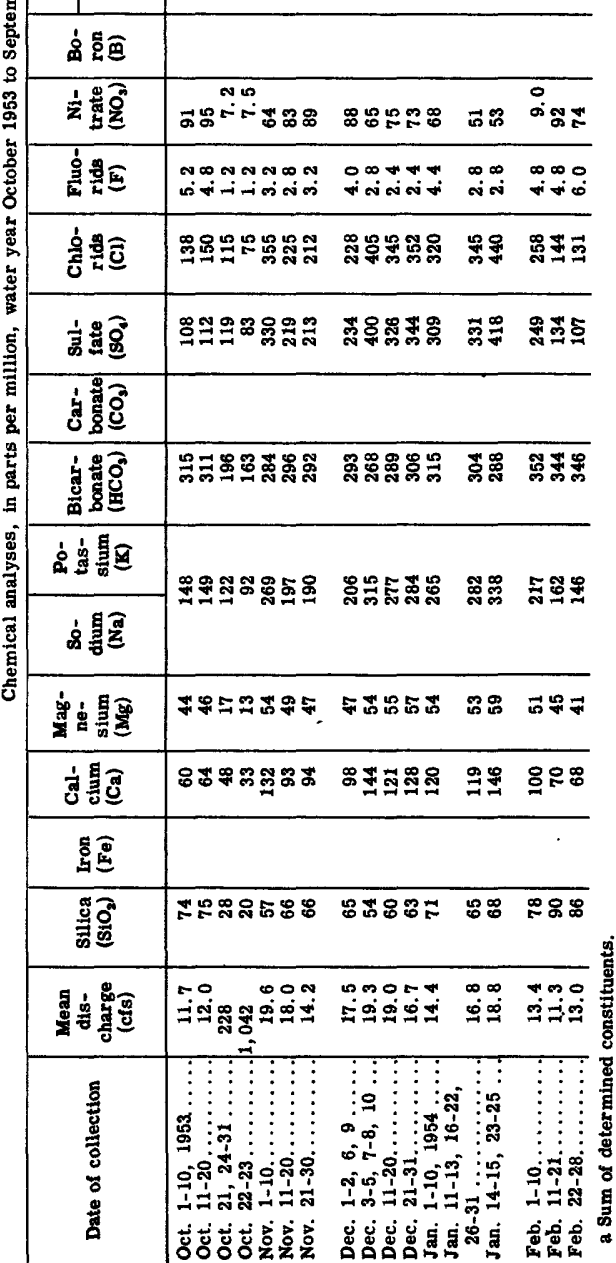




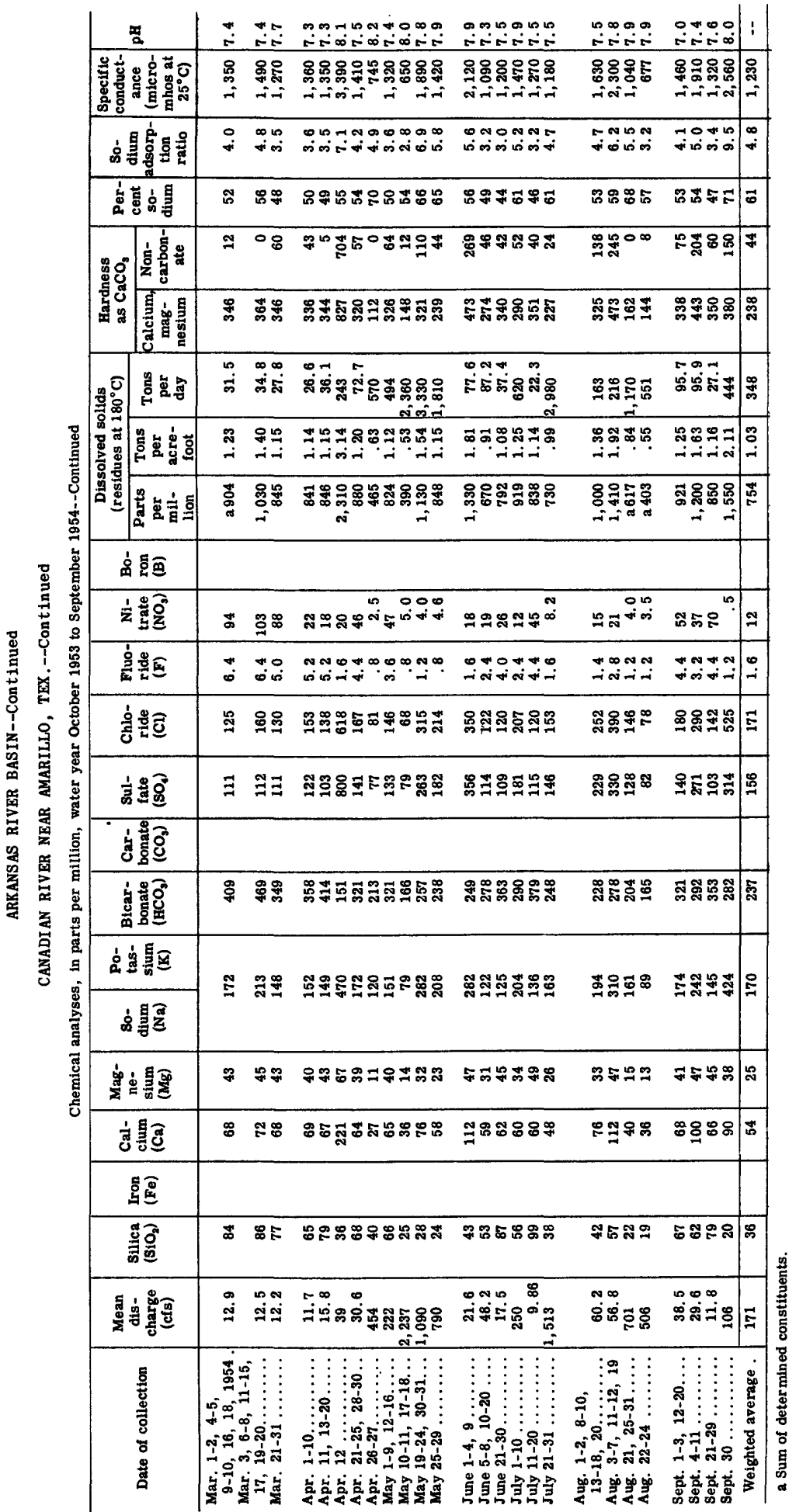


ARKANSAS RIVER BASIN--Continued

CANADI AN RIVER NEAR AMARILLO, TEX.--Continued

Temperature $\left({ }^{\circ} \mathrm{F}\right)$ of water, water year October 1953 to September 1954

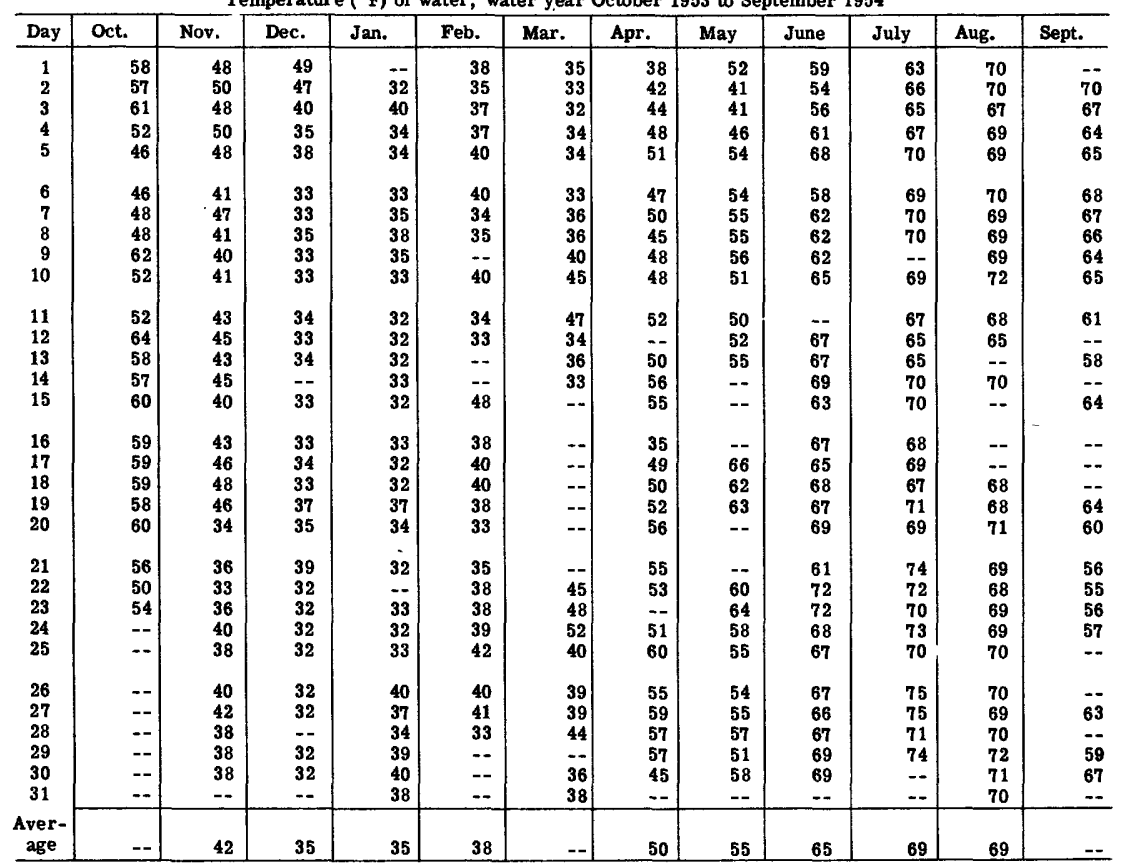




$$
\text { 亶 }
$$
ลं.

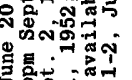

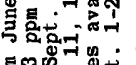

铅尔
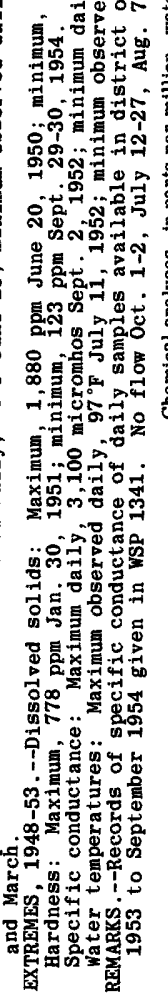

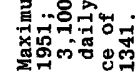

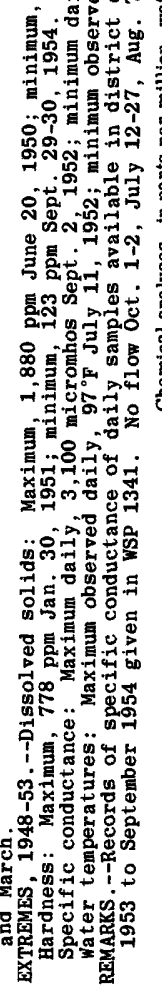

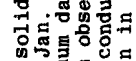
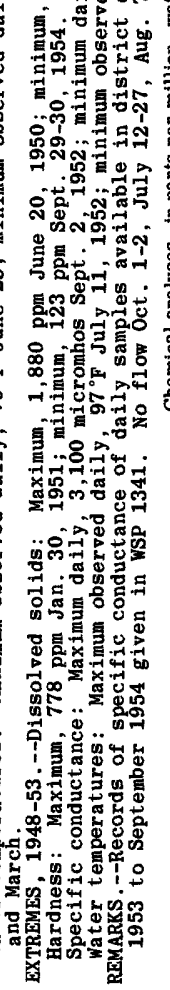

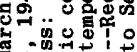

\begin{tabular}{|c|c|}
\hline & T \\
\hline 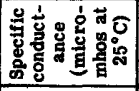 & 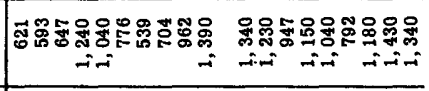 \\
\hline 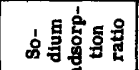 & 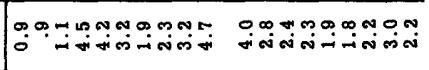 \\
\hline 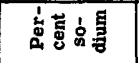 & 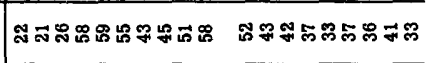 \\
\hline 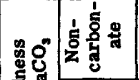 & 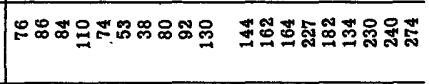 \\
\hline 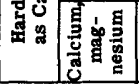 & 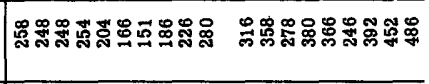 \\
\hline : & 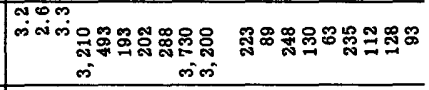 \\
\hline 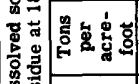 & 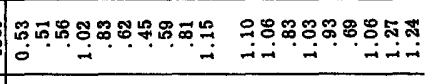 \\
\hline & 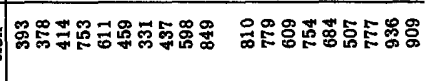 \\
\hline 富宫重 & 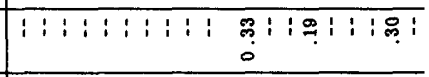 \\
\hline$\frac{1}{\overline{2}} \frac{8}{g}$ & 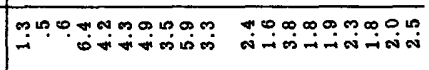 \\
\hline 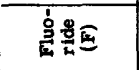 & $: 1: 1: 1: 1: 1:: \stackrel{\infty}{=}$ \\
\hline 옹몬? & 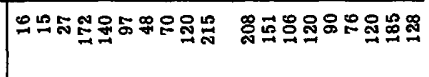 \\
\hline 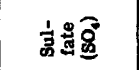 & 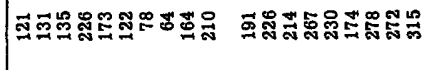 \\
\hline 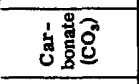 & 000000000000 \\
\hline 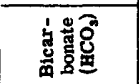 & 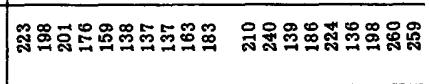 \\
\hline 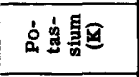 & 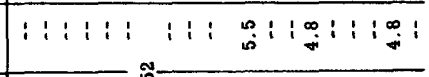 \\
\hline 官婰 & 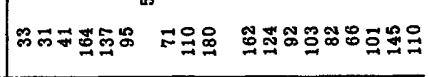 \\
\hline 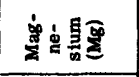 & 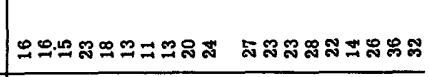 \\
\hline 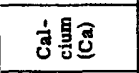 & 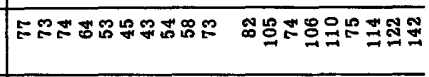 \\
\hline 跑焉 & $1: 1: 11: 11: 11: 80: 18: 1118$ \\
\hline 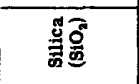 & 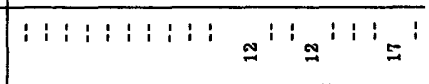 \\
\hline 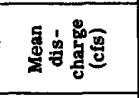 & 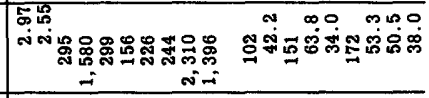 \\
\hline 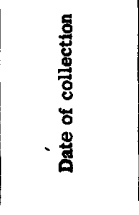 & 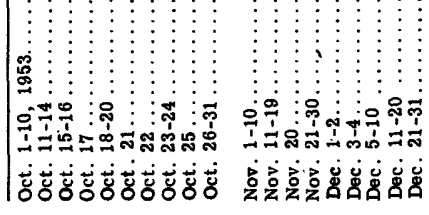 \\
\hline
\end{tabular}

(1)

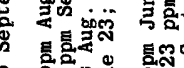

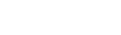

我




\begin{tabular}{|c|c|c|c|c|}
\hline 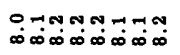 & فㅁ & 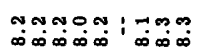 & 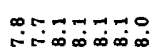 & ف \\
\hline 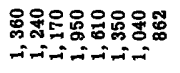 & 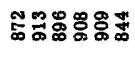 & 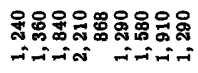 & 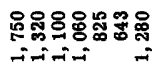 & 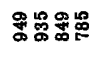 \\
\hline 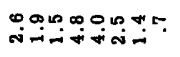 & 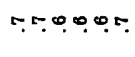 & 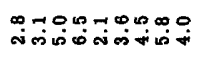 & ن & تִ \\
\hline 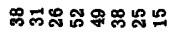 & 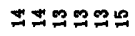 & 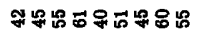 & 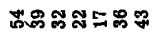 & 速勉品 \\
\hline 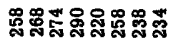 & 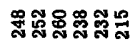 & 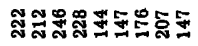 & 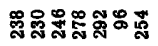 & 터윰유 \\
\hline
\end{tabular}

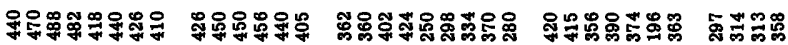

\begin{tabular}{|c|c|c|c|c|}
\hline 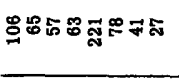 & 蛋 & 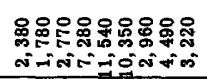 & 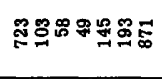 & \\
\hline జ̛̃ & 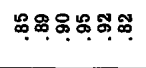 & 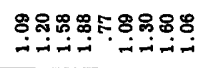 & 蓆 & \\
\hline 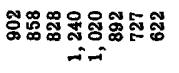 & สิธ్์ & 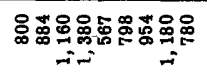 & 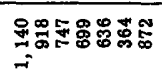 & 䒿芯: \\
\hline 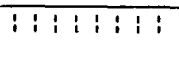 & : $1: 1: \begin{array}{l}5 \\
0\end{array}$ & Æै: : : : : : : & $1: 1$ & \\
\hline 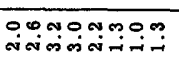 & 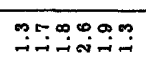 & 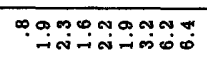 & 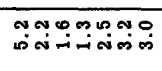 & $\stackrel{9}{+40}$ \\
\hline & & & & \\
\hline
\end{tabular}

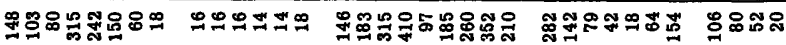

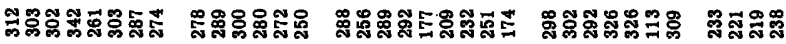

000000000000000000000 W 0000000 19유

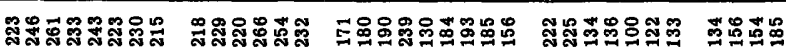

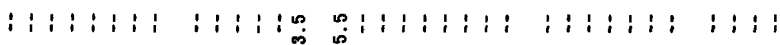

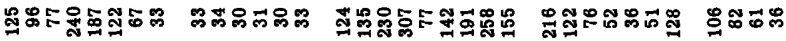

\begin{tabular}{|c|c|c|c|c|}
\hline \% & $\stackrel{2}{2}$ & 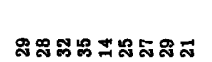 & ็ีส สลส & 电 \\
\hline ชูสำสำส & 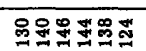 & :̊ロ & 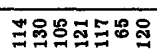 & $\overline{8: \%}$ \\
\hline
\end{tabular}

\begin{tabular}{|c|c|c|c|c|}
\hline $1: 1: 1: 1 !$ & $1: 1: 1: 8$ & $8: 11: 1111$ & $1: 1: 1: 1$ & i: \\
\hline$:: i: 1: i$ & $1: 1: 1: 1:$ & $: 1: 1: 1$ & : : & $: 1$ \\
\hline 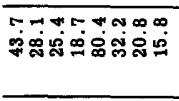 & 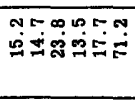 & 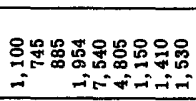 & 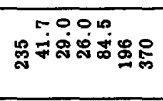 & $\begin{array}{l}0.0 \% \\
j 0^{\circ} 0^{\circ}\end{array}$ \\
\hline 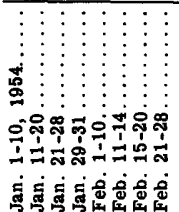 & 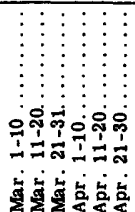 & 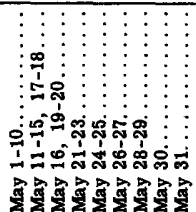 & 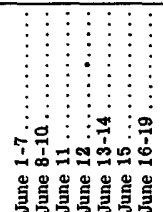 & 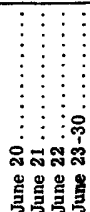 \\
\hline
\end{tabular}




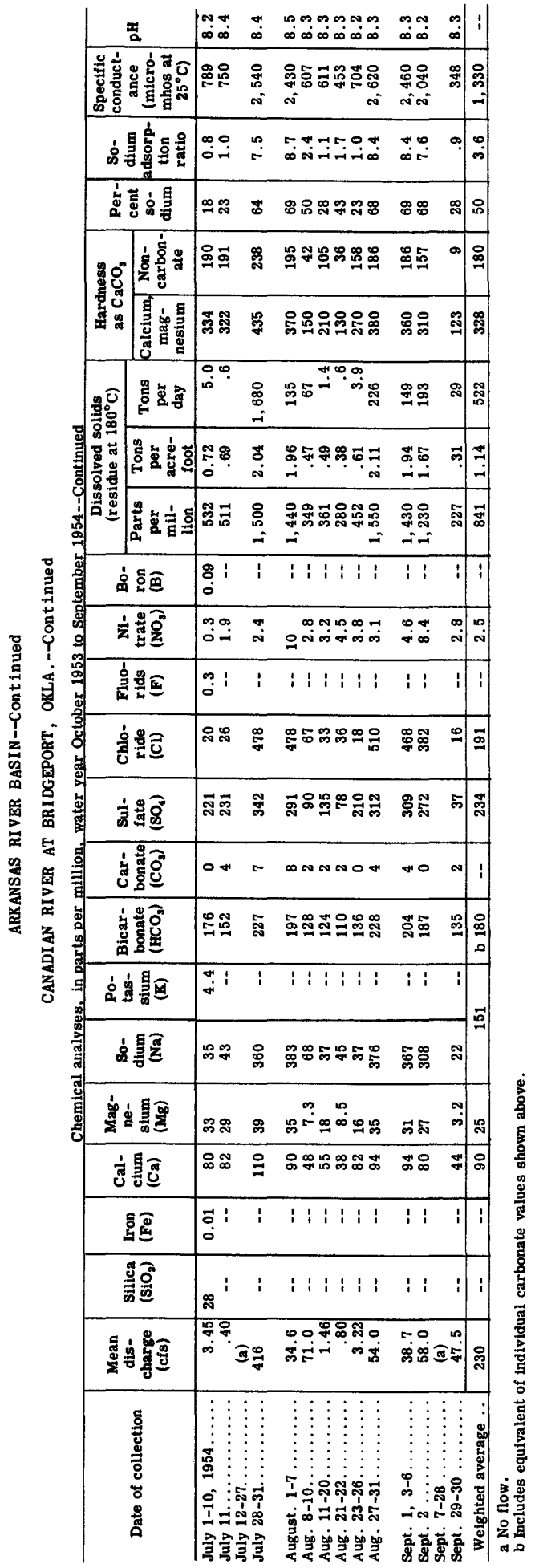


ARKANSAS RIVER BASIN--Continued

CANADIAŃ RIVER AT BRIDGEPORT, OKLA.--Continued

Temperature $\left({ }^{\circ} \mathrm{F}\right)$ of water, water year October 1953 to September 1954

\begin{tabular}{|c|c|c|c|c|c|c|c|c|c|c|c|c|}
\hline Day & Oct. & Nov. & Dec. & Jan. & Feb. & Mar. & Apr. & May & June & July & Aug. & Sept. \\
\hline $\begin{array}{l}1 \\
2 \\
3 \\
4 \\
5\end{array}$ & $\begin{array}{l}-- \\
-- \\
-- \\
--\end{array}$ & $\begin{array}{l}54 \\
54 \\
53 \\
55 \\
49\end{array}$ & $\begin{array}{l}52 \\
57 \\
56 \\
41 \\
45\end{array}$ & $\begin{array}{l}33 \\
34 \\
32 \\
40 \\
35\end{array}$ & $\begin{array}{l}40 \\
37 \\
40 \\
42 \\
40\end{array}$ & $\begin{array}{l}36 \\
34 \\
32 \\
32 \\
42\end{array}$ & $\begin{array}{l}39 \\
46 \\
47 \\
60 \\
65\end{array}$ & $\begin{array}{l}55 \\
50 \\
45 \\
49 \\
56\end{array}$ & $\begin{array}{l}63 \\
68 \\
59 \\
62 \\
63\end{array}$ & $\begin{array}{l}75 \\
73 \\
73 \\
77 \\
75\end{array}$ & $\begin{array}{l}75 \\
73 \\
77 \\
73 \\
73\end{array}$ & $\begin{array}{l}-- \\
74 \\
70 \\
69 \\
68\end{array}$ \\
\hline $\begin{array}{r}6 \\
7 \\
8 \\
9 \\
10\end{array}$ & $\begin{array}{l}51 \\
47 \\
52 \\
55 \\
--\end{array}$ & $\begin{array}{l}44 \\
41 \\
41 \\
35 \\
42\end{array}$ & $\begin{array}{l}37 \\
38 \\
39 \\
34 \\
35\end{array}$ & $\begin{array}{l}35 \\
40 \\
45 \\
35 \\
--\end{array}$ & $\begin{array}{l}45 \\
36 \\
37 \\
42 \\
43\end{array}$ & $\begin{array}{l}41 \\
40 \\
36 \\
46 \\
46\end{array}$ & $\begin{array}{l}62 \\
58 \\
47 \\
54 \\
63\end{array}$ & $\begin{array}{l}59 \\
54 \\
58 \\
55 \\
51\end{array}$ & $\begin{array}{l}68 \\
-- \\
69 \\
70 \\
69\end{array}$ & $\begin{array}{l}75 \\
75 \\
74 \\
77 \\
74\end{array}$ & $\begin{array}{l}75 \\
\therefore-5 \\
73 \\
74\end{array}$ & $\begin{array}{l}69 \\
-- \\
-- \\
--\end{array}$ \\
\hline $\begin{array}{l}11 \\
12 \\
13 \\
14 \\
15\end{array}$ & $\begin{array}{l}54 \\
55 \\
57 \\
62 \\
61\end{array}$ & $\begin{array}{l}45 \\
44 \\
45 \\
48 \\
48\end{array}$ & $\begin{array}{l}37 \\
33 \\
36 \\
33 \\
33\end{array}$ & $\begin{array}{l}33 \\
32 \\
32 \\
33 \\
--\end{array}$ & $\begin{array}{l}36 \\
34 \\
40 \\
48 \\
57\end{array}$ & $\begin{array}{l}54 \\
50 \\
34 \\
34 \\
34\end{array}$ & $\begin{array}{l}60 \\
54 \\
55 \\
61 \\
63\end{array}$ & $\begin{array}{l}54 \\
55 \\
57 \\
62 \\
64\end{array}$ & $\begin{array}{l}72 \\
72 \\
70 \\
69 \\
70\end{array}$ & $\begin{array}{l}72 \\
-- \\
-- \\
-- \\
--\end{array}$ & $\begin{array}{l}76 \\
71 \\
75 \\
-\therefore \\
--\end{array}$ & $\begin{array}{l}-- \\
-- \\
-- \\
--\end{array}$ \\
\hline $\begin{array}{l}16 \\
17 \\
18 \\
19 \\
20\end{array}$ & $\begin{array}{l}60 \\
62 \\
62 \\
61 \\
--\end{array}$ & $\begin{array}{l}49 \\
51 \\
56 \\
58 \\
40\end{array}$ & $\begin{array}{l}34 \\
37 \\
39 \\
40 \\
43\end{array}$ & $\begin{array}{l}32 \\
32 \\
34 \\
37 \\
34\end{array}$ & $\begin{array}{l}39 \\
40 \\
44 \\
54 \\
37\end{array}$ & $\begin{array}{l}42 \\
39 \\
53 \\
43 \\
45\end{array}$ & $\begin{array}{l}50 \\
53 \\
57 \\
60 \\
63\end{array}$ & $\begin{array}{l}65 \\
70 \\
75 \\
67 \\
61\end{array}$ & $\begin{array}{l}71 \\
75 \\
74 \\
74 \\
76\end{array}$ & $\begin{array}{l}-- \\
-- \\
-- \\
--\end{array}$ & $\begin{array}{l}-- \\
-- \\
-- \\
-- \\
--\end{array}$ & 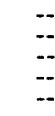 \\
\hline $\begin{array}{l}21 \\
22 \\
23 \\
24 \\
25\end{array}$ & $\begin{array}{l}73 \\
66 \\
58 \\
53 \\
58\end{array}$ & $\begin{array}{l}38 \\
32 \\
38 \\
43 \\
43\end{array}$ & $\begin{array}{l}32 \\
32 \\
32 \\
32 \\
35\end{array}$ & $\begin{array}{l}33 \\
33 \\
34 \\
35 \\
37\end{array}$ & $\begin{array}{l}44 \\
-- \\
-- \\
--\end{array}$ & $\begin{array}{l}42 \\
50 \\
49 \\
59 \\
52\end{array}$ & $\begin{array}{l}64 \\
57 \\
60 \\
63 \\
65\end{array}$ & $\begin{array}{l}60 \\
70 \\
69 \\
62 \\
64\end{array}$ & $\begin{array}{l}75 \\
75 \\
79 \\
75 \\
73\end{array}$ & $\begin{array}{l}-- \\
-- \\
-- \\
\ldots\end{array}$ & $\begin{array}{l}- \\
73 \\
74 \\
73 \\
74\end{array}$ & $\begin{array}{l}-- \\
-- \\
--\end{array}$ \\
\hline $\begin{array}{l}26 \\
27 \\
28 \\
29 \\
30 \\
31\end{array}$ & $\begin{array}{l}53 \\
45 \\
53 \\
51 \\
53 \\
55\end{array}$ & $\begin{array}{l}38 \\
43 \\
42 \\
40 \\
40 \\
--\end{array}$ & $\begin{array}{l}33 \\
32 \\
33 \\
33 \\
32 \\
32\end{array}$ & $\begin{array}{l}32 \\
33 \\
45 \\
38 \\
34 \\
36\end{array}$ & $\begin{array}{l}44 \\
47 \\
34 \\
-- \\
-- \\
--\end{array}$ & $\begin{array}{l}44 \\
44 \\
50 \\
39 \\
35 \\
37\end{array}$ & $\begin{array}{l}66 \\
65 \\
64 \\
70 \\
58 \\
--\end{array}$ & $\begin{array}{l}64 \\
67 \\
70 \\
63 \\
79 \\
70\end{array}$ & $\begin{array}{l}74 \\
77 \\
73 \\
73 \\
77 \\
--\end{array}$ & $\begin{array}{l}-- \\
-- \\
-- \\
77 \\
78 \\
76\end{array}$ & $\begin{array}{l}-7 \\
74 \\
75 \\
75 \\
74 \\
71\end{array}$ & $\begin{array}{l}-- \\
-- \\
- \\
-\end{array}$ \\
\hline $\begin{array}{c}\text { Aver- } \\
\text { age }\end{array}$ & -- & 45 & 37 & 35 & 42 & 42 & 58 & 61 & 71 & -- & $=$ & $\cdots$ \\
\hline
\end{tabular}




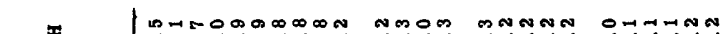

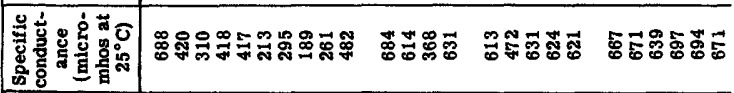

00000000000000 N0000 0nN0N0

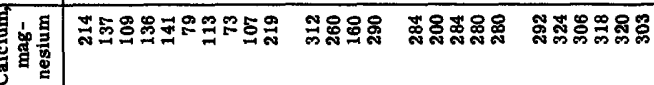

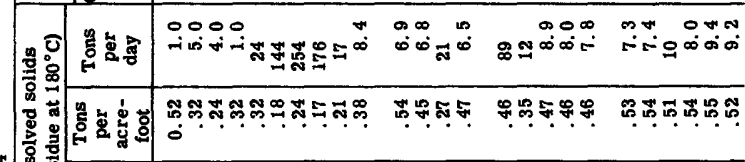

起战言

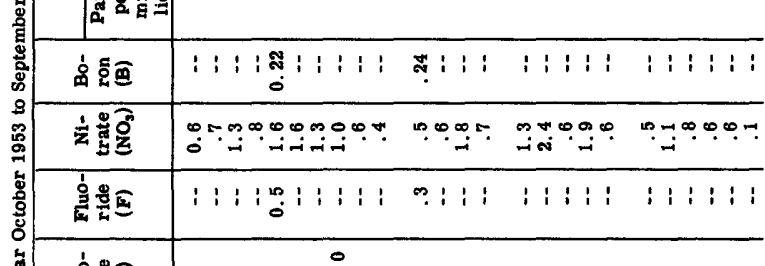

8 要

틍

สี

\begin{tabular}{|c|c|c|c|c|}
\hline 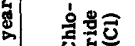 & 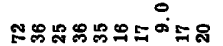 & 토요 & 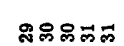 & 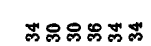 \\
\hline
\end{tabular}

\begin{tabular}{|c|c|c|c|c|}
\hline 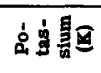 & \multirow{2}{*}{\multicolumn{4}{|c|}{ 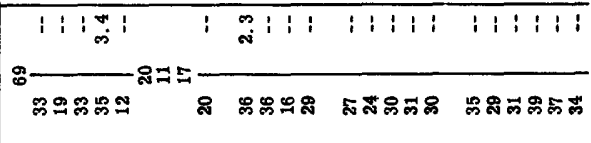 }} \\
\hline ฌ่ & & & & \\
\hline 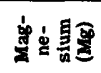 & 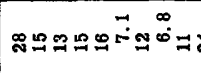 & 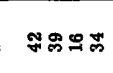 & $; \infty$ & 광ㅇ \\
\hline ปี่ & 8 & 品8 & & \\
\hline ธ్ & 1: 1: & 8 & & \\
\hline 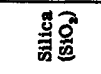 & $\overline{1} 1: 10_{\infty}^{0} 1: 11:$ & $m: 1:$ & & \\
\hline 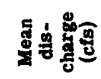 & 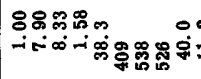 & $\begin{array}{ll}\infty \\
\infty \\
0 \\
0\end{array}$ & is & \\
\hline 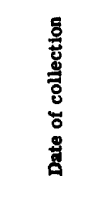 & 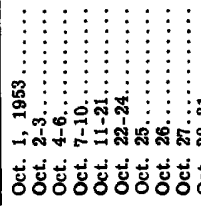 & 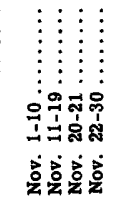 & 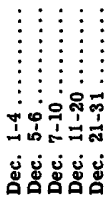 & 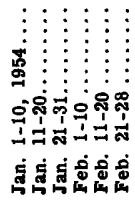 \\
\hline
\end{tabular}




\begin{tabular}{|c|c|c|c|c|c|}
\hline 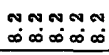 & 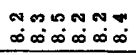 & 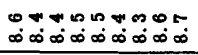 & 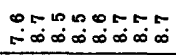 & $\begin{array}{l}\infty \\
\infty \infty \infty \infty\end{array}$ & 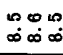 \\
\hline 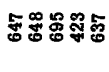 & : & 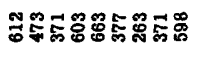 & 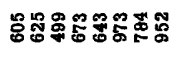 & 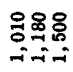 & 형용요 \\
\hline 구유. & 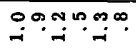 & 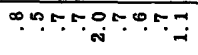 & 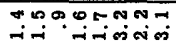 & $\begin{array}{l}\text { NकO } \\
\text { intio }\end{array}$ & $\begin{array}{l}\text { nato } \\
\text { nation }\end{array}$ \\
\hline
\end{tabular}

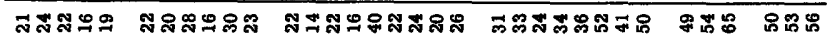

00000 00000N N000010000 00007000 0N900\%

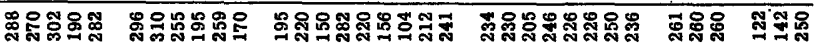

\begin{tabular}{|c|c|c|c|c|c|}
\hline 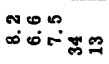 & 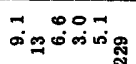 & 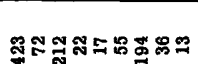 & 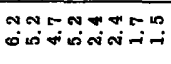 & $\infty 0.9$. & 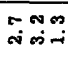 \\
\hline 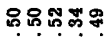 & 5 & 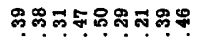 & 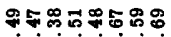 & $5 \mathbf{D}$ & 85 \\
\hline
\end{tabular}

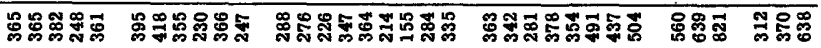

\begin{tabular}{|c|c|c|c|c|c|}
\hline $1: 1: 1$ & $911: 11$ & $1: 1: 1: 1: 1$ & 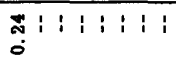 & $\neq: 1$ & $1 i$ \\
\hline טִ & 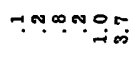 & 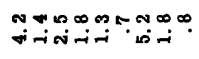 & 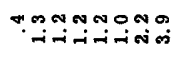 & 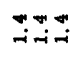 & किज्ञ \\
\hline i : i : i & 1: $1: 1: 1:$ & $1: 1: 1:$ & 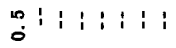 & ?: : & $1:$ i \\
\hline
\end{tabular}

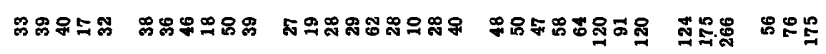

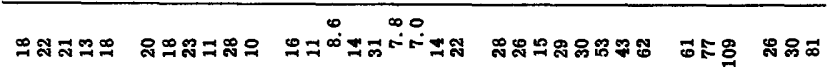

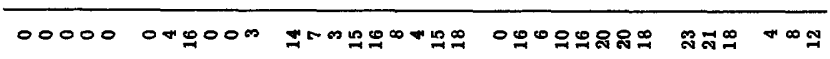

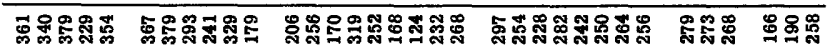

\begin{tabular}{|c|c|c|c|c|c|}
\hline 19 & $1: 1.11:$ & $1: 191: 111$ & $\overrightarrow{\mathbf{j}}: 1: 1: 1: 11$ & is: & $\overline{111}$ \\
\hline 乎 क & ํํำะロ & 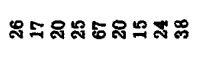 & कธ & 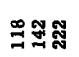 & $5:$ \\
\hline ำ ำ & 욖주요옹 & 吅 & : & $\$ 5$ & 9 \\
\hline 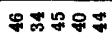 & 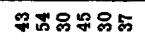 & 疍吊 & สละ & จุล & รี \\
\hline $1: 1: 1:$ & : $1: 1: 1:$ : & i : & & $i$ & \\
\hline$: 1$ & & & & $:$ & \\
\hline 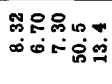 & 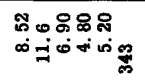 & 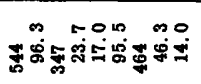 & 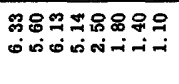 & 웅유 & 乐里下 \\
\hline & & & & & \\
\hline 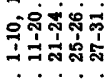 & 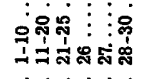 & 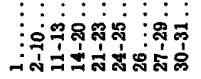 & 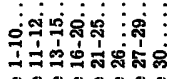 & 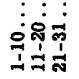 & $\begin{array}{c}\vdots \\
\vdots \\
1 \\
-1 \\
\vdots\end{array}$ \\
\hline$\dot{4} \dot{a} \dot{a}$ & 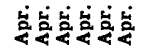 & 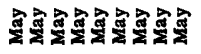 & 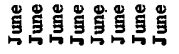 & 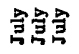 & 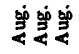 \\
\hline
\end{tabular}




\begin{tabular}{|c|c|c|c|}
\hline & & 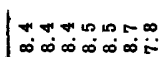 & : \\
\hline & 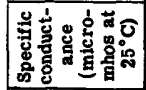 & 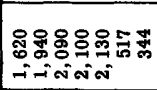 & 疋 \\
\hline & 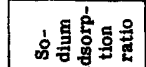 & 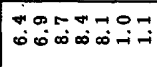 & $\infty$ \\
\hline & 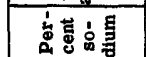 & ธะฐะสำ & $\approx$ \\
\hline & 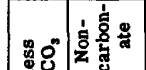 & ○品ずに゚ & 10 \\
\hline & 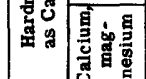 & 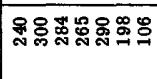 & $\underline{\Sigma}$ \\
\hline & m & $\stackrel{0}{-\infty m \infty}$ & $=$ \\
\hline & 要 & 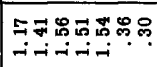 & कृ \\
\hline 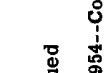 & 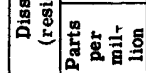 & 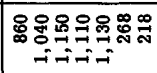 & I: \\
\hline & 官点可 & 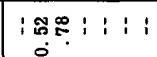 & $:$ \\
\hline 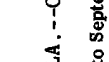 & 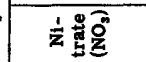 & هั & $\mid \stackrel{i}{i}$ \\
\hline 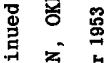 & 产密医 & $\left.\mid \begin{array}{lllll}1 & 0 \\
0 & 0\end{array}\right]$ & i \\
\hline 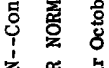 & 형혛으 & 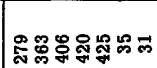 & 2 \\
\hline 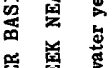 & 富 㤩总 & 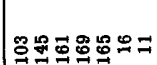 & $\approx$ \\
\hline $\begin{array}{ll}0 \\
8\end{array}$ & : & 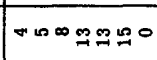 & $i$ \\
\hline 焉 & 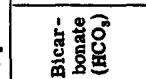 & ర్లై & มุ \\
\hline & 就悬区 & 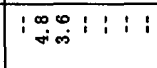 & \\
\hline & 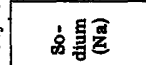 & జูำ & \\
\hline 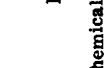 & 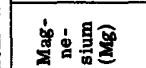 & 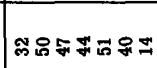 & $\vec{N}$ \\
\hline & 造贯饲 & 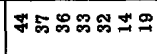 & $\infty$ \\
\hline & ๕્વَ & $188: 1: 1:$ & $:$ \\
\hline & 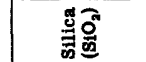 & $\pm 0: 1: 1$ & $i$ \\
\hline & 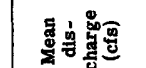 & 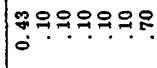 & 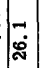 \\
\hline & 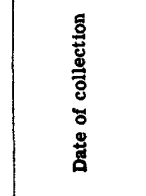 & 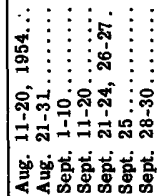 & 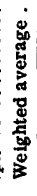 \\
\hline
\end{tabular}


ARKANSAS RIVER BASIN--Continued

LITTLE RIVER BELOW HOG CREEK NEAR NORMAN, OKLA.--Continued

Temperature $\left({ }^{\circ} \mathrm{F}\right)$ of water, water year October 1953 to September 1954

\begin{tabular}{|c|c|c|c|c|c|c|c|c|c|c|c|c|}
\hline Day & Oct. & Nov. & Dec. & Jan. & Feb. & Mar. & Apr. & May & June & July & Aug. & Sept. \\
\hline $\begin{array}{l}1 \\
2 \\
3 \\
4 \\
5\end{array}$ & $\begin{array}{l}75 \\
75 \\
70 \\
65 \\
66\end{array}$ & $\begin{array}{l}\mathbf{5 3} \\
\mathbf{5 2} \\
\mathbf{5 3} \\
\mathbf{5 3} \\
\mathbf{5 2}\end{array}$ & $\begin{array}{l}50 \\
50 \\
52 \\
52 \\
52\end{array}$ & $\begin{array}{l}39 \\
39 \\
40 \\
45 \\
47\end{array}$ & $\begin{array}{l}-- \\
-- \\
-- \\
-- \\
52\end{array}$ & $\begin{array}{l}56 \\
48 \\
44 \\
44 \\
42\end{array}$ & $\begin{array}{l}55 \\
57 \\
67 \\
68 \\
72\end{array}$ & $\begin{array}{c}79 \\
-- \\
63 \\
- \\
69\end{array}$ & $\begin{array}{l}79 \\
-- \\
76 \\
80 \\
80\end{array}$ & $\begin{array}{l}90 \\
90 \\
92 \\
91 \\
91\end{array}$ & $\begin{array}{l}-- \\
88 \\
89 \\
89 \\
92\end{array}$ & $\begin{array}{l}88 \\
87 \\
86 \\
90 \\
90\end{array}$ \\
\hline $\begin{array}{r}6 \\
7 \\
8 \\
9 \\
10\end{array}$ & $\begin{array}{l}65 \\
65 \\
66 \\
67 \\
68\end{array}$ & $\begin{array}{l}53 \\
53 \\
45 \\
-- \\
--\end{array}$ & $\begin{array}{l}52 \\
48 \\
48 \\
47 \\
46\end{array}$ & $\begin{array}{l}48 \\
52 \\
50 \\
45 \\
54\end{array}$ & $\begin{array}{l}54 \\
52 \\
53 \\
52 \\
50\end{array}$ & $\begin{array}{l}50 \\
52 \\
54 \\
63 \\
64\end{array}$ & $\begin{array}{l}76 \\
70 \\
64 \\
64 \\
73\end{array}$ & $\begin{array}{l}70 \\
-- \\
-- \\
59 \\
60\end{array}$ & $\begin{array}{l}81 \\
77 \\
81 \\
79 \\
81\end{array}$ & $\begin{array}{l}93 \\
94 \\
93 \\
92 \\
97\end{array}$ & $\begin{array}{l}92 \\
89 \\
89 \\
89 \\
88\end{array}$ & $\begin{array}{l}90 \\
89 \\
88 \\
88 \\
87\end{array}$ \\
\hline $\begin{array}{l}11 \\
12 \\
13 \\
14 \\
15\end{array}$ & $\begin{array}{l}67 \\
75 \\
75 \\
63 \\
66\end{array}$ & $\begin{array}{l}56 \\
57 \\
56 \\
56 \\
57\end{array}$ & $\begin{array}{l}48 \\
46 \\
50 \\
46 \\
48\end{array}$ & $\begin{array}{l}42 \\
38 \\
39 \\
40 \\
40\end{array}$ & $\begin{array}{l}50 \\
49 \\
52 \\
52 \\
52\end{array}$ & $\begin{array}{l}62 \\
61 \\
59 \\
50 \\
51\end{array}$ & $\begin{array}{l}63 \\
57 \\
64 \\
70 \\
68\end{array}$ & $\begin{array}{l}59 \\
65 \\
69 \\
74 \\
79\end{array}$ & $\begin{array}{l}82 \\
83 \\
81 \\
86 \\
84\end{array}$ & $\begin{array}{l}98 \\
98 \\
94 \\
95 \\
--\end{array}$ & $\begin{array}{l}89 \\
89 \\
89 \\
89 \\
89\end{array}$ & $\begin{array}{l}87 \\
86 \\
86 \\
84 \\
82\end{array}$ \\
\hline $\begin{array}{l}16 \\
17 \\
18 \\
19 \\
20\end{array}$ & $\begin{array}{l}67 \\
68 \\
69 \\
73 \\
72\end{array}$ & $\begin{array}{l}57 \\
57 \\
57 \\
57 \\
52\end{array}$ & $\begin{array}{l}45 \\
44 \\
40 \\
39 \\
--\end{array}$ & $\begin{array}{l}39 \\
39 \\
44 \\
42 \\
40\end{array}$ & $\begin{array}{l}53 \\
51 \\
53 \\
57 \\
51\end{array}$ & $\begin{array}{l}49 \\
52 \\
55 \\
57 \\
55\end{array}$ & $\begin{array}{l}64 \\
58 \\
69 \\
72 \\
70\end{array}$ & $\begin{array}{l}79 \\
69 \\
79 \\
-- \\
79\end{array}$ & $\begin{array}{l}85 \\
84 \\
84 \\
86 \\
86\end{array}$ & $\begin{array}{l}92 \\
90 \\
90 \\
89 \\
89\end{array}$ & $\begin{array}{l}89 \\
88 \\
87 \\
89 \\
89\end{array}$ & $\begin{array}{l}86 \\
86 \\
87 \\
88 \\
82\end{array}$ \\
\hline $\begin{array}{l}21 \\
22 \\
23 \\
24 \\
25\end{array}$ & $\begin{array}{l}-- \\
69 \\
61 \\
60\end{array}$ & $\begin{array}{l}48 \\
46 \\
46 \\
-- \\
52\end{array}$ & $\begin{array}{l}-2 \\
38 \\
-- \\
38 \\
39\end{array}$ & $\begin{array}{l}38 \\
36 \\
36 \\
48 \\
52\end{array}$ & $\begin{array}{l}53 \\
56 \\
55 \\
56 \\
54\end{array}$ & $\begin{array}{l}60 \\
57 \\
-- \\
-57 \\
67\end{array}$ & $\begin{array}{l}70 \\
68 \\
75 \\
76 \\
73\end{array}$ & $\begin{array}{l}87 \\
89 \\
-7 \\
79 \\
80\end{array}$ & $\begin{array}{l}-- \\
-- \\
90 \\
89 \\
89\end{array}$ & $\begin{array}{l}-- \\
-- \\
92 \\
-- \\
94\end{array}$ & $\begin{array}{l}89 \\
89 \\
88 \\
88 \\
88\end{array}$ & $\begin{array}{l}76 \\
76 \\
79 \\
-- \\
80\end{array}$ \\
\hline $\begin{array}{l}26 \\
27 \\
28 \\
29 \\
30 \\
31\end{array}$ & $\begin{array}{l}57 \\
58 \\
58 \\
57 \\
56 \\
56 \\
\end{array}$ & $\begin{array}{l}51 \\
52 \\
52 \\
52 \\
51 \\
-- \\
\end{array}$ & $\begin{array}{l}39 \\
39 \\
38 \\
39 \\
39 \\
41\end{array}$ & $\begin{array}{l}50 \\
50 \\
51 \\
-- \\
-- \\
--\end{array}$ & $\begin{array}{l}54 \\
54 \\
51 \\
-- \\
-- \\
--\end{array}$ & $\begin{array}{l}57 \\
-- \\
65 \\
53 \\
46 \\
51\end{array}$ & $\begin{array}{l}76 \\
76 \\
73 \\
77 \\
67 \\
--\end{array}$ & $\begin{array}{l}80 \\
80 \\
80 \\
81 \\
80 \\
79\end{array}$ & $\begin{array}{l}90 \\
90 \\
89 \\
89 \\
90 \\
--\end{array}$ & $\begin{array}{l}90 \\
90 \\
90 \\
89 \\
86 \\
--\end{array}$ & $\begin{array}{l}90 \\
92 \\
92 \\
89 \\
89 \\
88\end{array}$ & $\begin{array}{l}80 \\
81 \\
-- \\
-- \\
74 \\
-.\end{array}$ \\
\hline $\begin{array}{c}\text { Aver- } \\
\text { age }\end{array}$ & 66 & 53 & 45 & 44 & 53 & 54 & 68 & 75 & 84 & 92 & 89 & 85 \\
\hline
\end{tabular}


ARKANSAS RIVER BASIN--Continued

NORTH CANADIAN RIVER AT CANTON RESERVOIR NEAR CANTON, OKLA.--Continued

\begin{tabular}{|c|c|c|c|c|c|c|c|c|c|c|c|c|}
\hline Day & Oct. & Nov. & Dec. & Jan. & Feb. & Mar. & Apr. & May & June & July & Aug. & Sept. \\
\hline $\begin{array}{l}1 \\
\mathbf{2} \\
\mathbf{3} \\
4 \\
\mathbf{5}\end{array}$ & & & & & & $\begin{array}{l}-- \\
-- \\
-- \\
--\end{array}$ & $\begin{array}{l}46 \\
48 \\
53 \\
55 \\
58\end{array}$ & $\begin{array}{l}57 \\
63 \\
51 \\
\ldots- \\
57\end{array}$ & $\begin{array}{l}73 \\
72 \\
70 \\
69 \\
71\end{array}$ & $\begin{array}{l}81 \\
82 \\
84 \\
83 \\
--\end{array}$ & & \\
\hline $\begin{array}{r}6 \\
7 \\
8 \\
9 \\
10\end{array}$ & & & & & & $\begin{array}{l}-- \\
=- \\
=- \\
--\end{array}$ & $\begin{array}{l}61 \\
61 \\
60 \\
63 \\
--\end{array}$ & $\begin{array}{l}60 \\
63 \\
61 \\
60 \\
58\end{array}$ & $\begin{array}{l}75 \\
-- \\
75 \\
76 \\
76\end{array}$ & $\begin{array}{l}84 \\
83 \\
-- \\
-- \\
--\end{array}$ & & \\
\hline $\begin{array}{l}11 \\
12 \\
13 \\
14 \\
15\end{array}$ & & & & & & $\begin{array}{l}=- \\
=- \\
=- \\
=-\end{array}$ & $\begin{array}{l}\mathbf{5 9} \\
\mathbf{5 7} \\
\mathbf{5 8} \\
\mathbf{6 0} \\
\mathbf{5 9}\end{array}$ & $\begin{array}{l}57 \\
57 \\
59 \\
61 \\
65\end{array}$ & $\begin{array}{c}78 \\
-- \\
77 \\
-\overline{76}\end{array}$ & $\begin{array}{l}-- \\
-- \\
-- \\
--\end{array}$ & & \\
\hline $\begin{array}{l}16 \\
17 \\
18 \\
19 \\
20\end{array}$ & & & & & & $\begin{array}{l}-- \\
-- \\
46 \\
47 \\
47\end{array}$ & $\begin{array}{l}60 \\
62 \\
62 \\
63 \\
66\end{array}$ & $\begin{array}{l}-- \\
68 \\
71 \\
69 \\
68\end{array}$ & $\begin{array}{l}77 \\
79 \\
79 \\
81 \\
81\end{array}$ & $\begin{array}{l}-- \\
-- \\
-- \\
--\end{array}$ & & \\
\hline $\begin{array}{l}21 \\
22 \\
23 \\
24 \\
25\end{array}$ & & & & & & $\begin{array}{l}49 \\
50 \\
48 \\
55 \\
52\end{array}$ & $\begin{array}{l}62 \\
61 \\
-2 \\
66 \\
67\end{array}$ & $\begin{array}{l}68 \\
71 \\
70 \\
68 \\
65\end{array}$ & $\begin{array}{l}82 \\
84 \\
84 \\
82 \\
82\end{array}$ & $\begin{array}{l}-- \\
-- \\
-- \\
--\end{array}$ & & \\
\hline $\begin{array}{l}26 \\
27 \\
28 \\
29 \\
30 \\
31\end{array}$ & & & & & & $\begin{array}{l}52 \\
55 \\
-- \\
54 \\
51 \\
46\end{array}$ & $\begin{array}{l}67 \\
70 \\
72 \\
72 \\
65 \\
--\end{array}$ & $\begin{array}{l}66 \\
68 \\
71 \\
71 \\
72 \\
73\end{array}$ & $\begin{array}{l}81 \\
82 \\
81 \\
80 \\
83 \\
--\end{array}$ & $\begin{array}{l}-- \\
-- \\
-- \\
-- \\
--\end{array}$ & & \\
\hline $\begin{array}{c}\text { Aver- } \\
\text { age }\end{array}$ & & & & & & - & 61 & 64 & 78 & $=-$ & & \\
\hline
\end{tabular}




\begin{tabular}{|c|c|c|c|}
\hline 펼 & 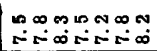 & 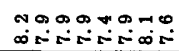 & 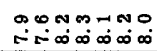 \\
\hline 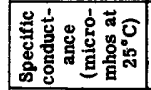 & 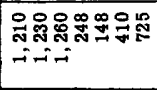 & 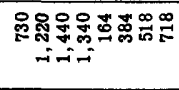 & 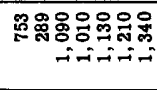 \\
\hline 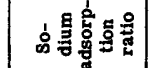 & 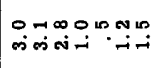 & نำ & 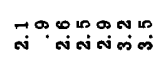 \\
\hline 安嘻 & 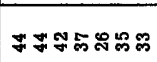 & 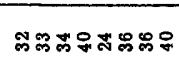 & 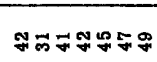 \\
\hline : & 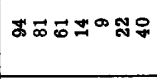 & 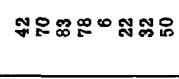 & 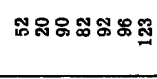 \\
\hline 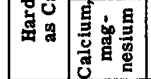 & 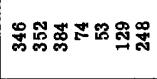 & 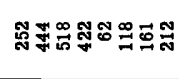 & 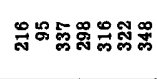 \\
\hline 몸잉 & ن & 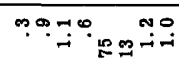 & 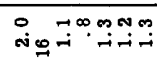 \\
\hline 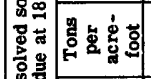 & 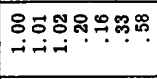 & 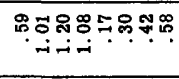 & 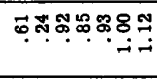 \\
\hline 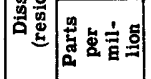 & 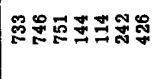 & 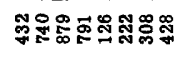 & 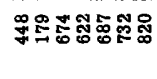 \\
\hline 㝘哭鱼 & 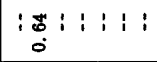 & $1: 1$ & 1:오: : : : : \\
\hline 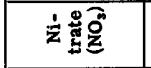 & 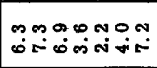 & ஸ。 & 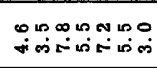 \\
\hline 高哭画 & 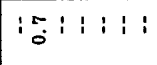 & : : : : : : $1: 1: 1$ & : : \\
\hline 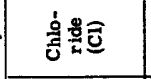 & 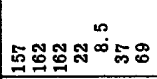 & : & 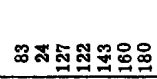 \\
\hline 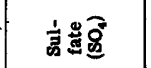 & 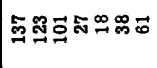 & 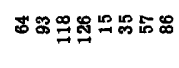 & 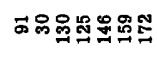 \\
\hline : & 0000000 & 00000000 & $000-1000$ \\
\hline 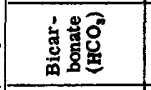 & 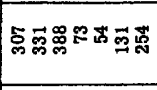 & 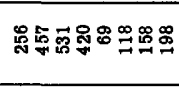 & 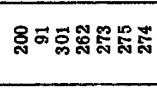 \\
\hline 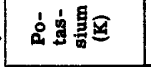 & 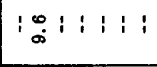 & 1:1:1:1:1: & $1: 091: 11$ \\
\hline 字息委 & 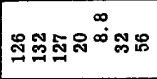 & 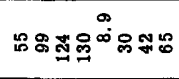 & 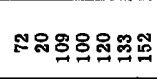 \\
\hline 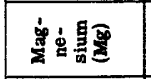 & 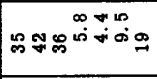 & 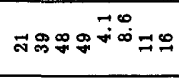 & 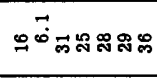 \\
\hline 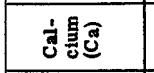 & 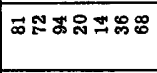 & ూ & 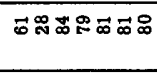 \\
\hline : & 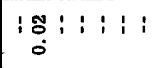 & $1: 1: 1: 1:$ & $: 18: 1: 1$ \\
\hline 戀方 & $: 5::: 1:$ & : : : : : : : : : & $: 15:: 1:$ \\
\hline 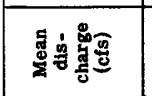 & 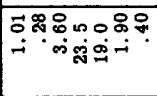 & 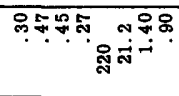 & 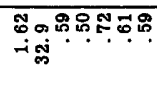 \\
\hline 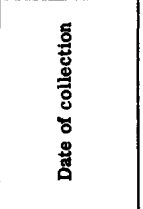 & 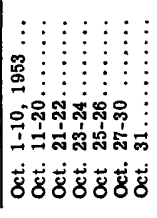 & 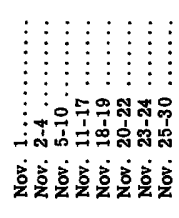 & 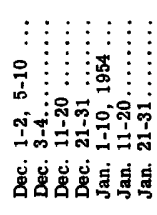 \\
\hline
\end{tabular}




\begin{tabular}{|c|c|c|c|c|}
\hline 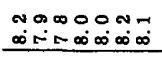 & 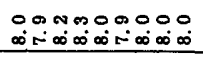 & $\begin{array}{l}N \sim N \infty \infty 0 \\
\infty \infty \infty \infty \infty \infty \infty \\
\end{array}$ & 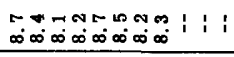 & i) \\
\hline 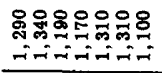 & 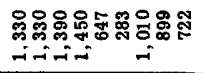 & 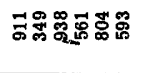 & 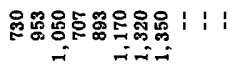 & జ \\
\hline 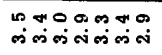 & 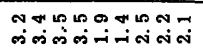 & 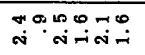 & 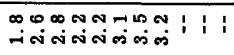 & sं \\
\hline 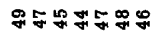 & 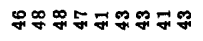 & 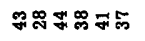 & 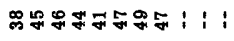 & $\mathscr{F}$ \\
\hline 잉 & 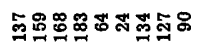 & ‡ & 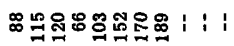 & 家 \\
\hline 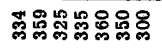 & 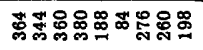 & 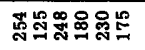 & 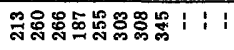 & :ึ| \\
\hline 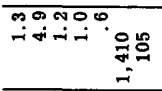 & 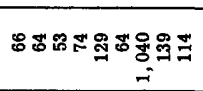 & 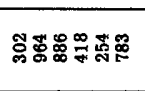 & 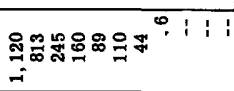 & ס्ञ \\
\hline ஜБ요. & 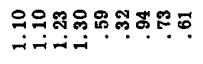 & 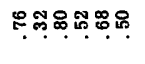 & 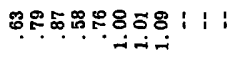 & $\stackrel{\infty}{:}$ \\
\hline 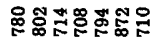 & 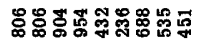 & 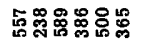 & 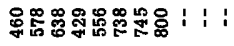 & 윤 \\
\hline $1 \quad 1 \quad 1 \quad 1 ; 1$ & : : : & 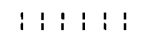 & 1 1:1:18: 1 1 1 & $i$ \\
\hline 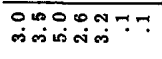 & 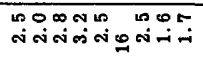 & 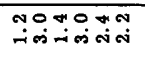 & 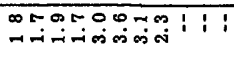 & $\stackrel{\infty}{-\infty}$ \\
\hline : 1:1: 1: & : : : : & 1: i : i i & １：：：：：：：：⿱ & i) \\
\hline 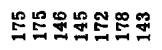 & 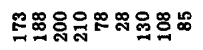 & 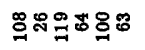 & 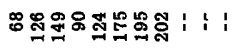 & $\exists$ \\
\hline 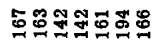 & 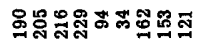 & 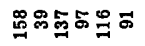 & 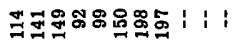 & 虫 \\
\hline 0000000 & $000 N 00000$ & 009070 & nROONOON I i i & $i$ \\
\hline 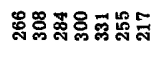 & 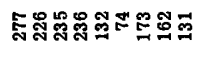 & 怘す必 & 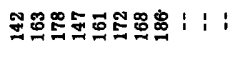 & $\underset{5}{5}$ \\
\hline 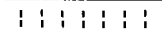 & $1: 1: 1: 1: 1$ & $1: 1: 1:$ & 1:1:1:ㅇ:1: & \\
\hline 疋栗 & 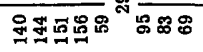 & 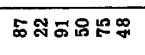 & 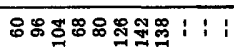 & 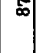 \\
\hline 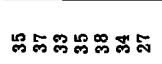 & 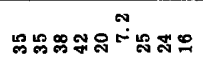 & 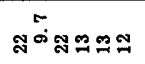 & 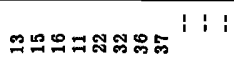 & ลี \\
\hline ゚゚ロ゚ロす゚ & 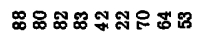 & 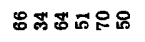 & 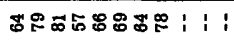 & 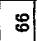 \\
\hline $1: 1: 1: 1: 1$ & i : i & $1: 1111$ & 1:1: 1:8: & $i$ \\
\hline $1: 1: 1: 1$ & $1: 1: 1: 1: 11$ & 1:1:1: & 1:1:1:91:1: & i) \\
\hline ஜำ & 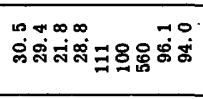 & 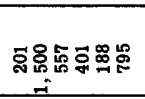 & 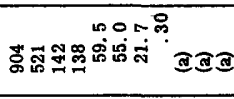 & \begin{tabular}{|l|}
0 \\
$\vdots$ \\
0
\end{tabular} \\
\hline 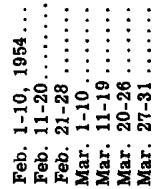 & 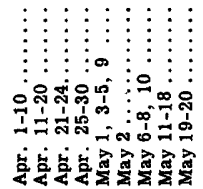 & 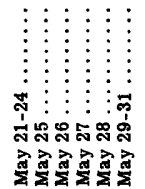 & 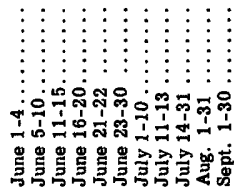 & 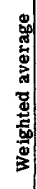 \\
\hline
\end{tabular}


ARKANSAS RIVER BASIN--Cont inued

NORTH CANADIAN RIVER NEAR YUKON, OKLA.--Continued

Temperature $\left({ }^{\circ} \mathrm{F}\right)$ of water, water year October 1953 to September 1954

\begin{tabular}{|c|c|c|c|c|c|c|c|c|c|c|c|c|}
\hline Day & Oct. & Nov. & Dec. & Jan. & Feb. & Mar. & Apr. & May & June & July & Aug. & Sept. \\
\hline $\begin{array}{l}1 \\
2 \\
3 \\
4 \\
5\end{array}$ & $\begin{array}{l}74 \\
-7 \\
76 \\
61 \\
60\end{array}$ & $\begin{array}{l}61 \\
75 \\
67 \\
63 \\
57\end{array}$ & $\begin{array}{l}\mathbf{5 2} \\
\mathbf{5 3} \\
\mathbf{5 0} \\
\mathbf{5 0} \\
--\end{array}$ & $\begin{array}{l}39 \\
41 \\
40 \\
43 \\
42\end{array}$ & $\begin{array}{l}45 \\
46 \\
47 \\
45 \\
46\end{array}$ & $\begin{array}{l}44 \\
46 \\
48 \\
40 \\
40\end{array}$ & $\begin{array}{l}51 \\
55 \\
59 \\
64 \\
69\end{array}$ & $\begin{array}{l}65 \\
57 \\
58 \\
62 \\
69\end{array}$ & $\begin{array}{l}75 \\
72 \\
70 \\
74 \\
75\end{array}$ & $\begin{array}{l}88 \\
83 \\
84 \\
85 \\
87\end{array}$ & & \\
\hline $\begin{array}{r}6 \\
7 \\
8 \\
9 \\
10\end{array}$ & $\begin{array}{l}75 \\
-- \\
-- \\
-- \\
--\end{array}$ & $\begin{array}{l}56 \\
45 \\
45 \\
53 \\
54\end{array}$ & $\begin{array}{l}-- \\
-- \\
-- \\
--\end{array}$ & $\begin{array}{l}42 \\
44 \\
44 \\
43 \\
39\end{array}$ & $\begin{array}{l}41 \\
45 \\
44 \\
48 \\
50\end{array}$ & $\begin{array}{l}44 \\
47 \\
45 \\
48 \\
53\end{array}$ & $\begin{array}{l}69 \\
69 \\
66 \\
62 \\
65\end{array}$ & $\begin{array}{l}69 \\
65 \\
65 \\
60 \\
57\end{array}$ & $\begin{array}{l}77 \\
77 \\
81 \\
81 \\
82\end{array}$ & $\begin{array}{l}88 \\
89 \\
88 . \\
88 \\
89\end{array}$ & & \\
\hline $\begin{array}{l}11 \\
12 \\
13 \\
14 \\
15\end{array}$ & $\begin{array}{l}-- \\
-- \\
-- \\
-- \\
68\end{array}$ & $\begin{array}{l}53 \\
53 \\
54 \\
=- \\
66\end{array}$ & $\begin{array}{l}-- \\
-- \\
\overline{50} \\
39\end{array}$ & $\begin{array}{l}37 \\
38 \\
38 \\
39 \\
38\end{array}$ & $\begin{array}{l}45 \\
41 \\
45 \\
51 \\
57\end{array}$ & $\begin{array}{l}58 \\
40 \\
32 \\
35 \\
37\end{array}$ & $\begin{array}{l}64 \\
60 \\
67 \\
63 \\
64\end{array}$ & $\begin{array}{l}57 \\
62 \\
71 \\
72 \\
75\end{array}$ & $\begin{array}{l}81 \\
80 \\
79 \\
81 \\
81\end{array}$ & $\begin{array}{l}90 \\
89 \\
91 \\
-- \\
--\end{array}$ & & \\
\hline $\begin{array}{l}16 \\
17 \\
18 \\
19 \\
20\end{array}$ & $\begin{array}{l}70 \\
70 \\
-- \\
-- \\
--\end{array}$ & $\begin{array}{l}- \\
54 \\
60 \\
58 \\
53\end{array}$ & $\begin{array}{l}41 \\
40 \\
40 \\
41 \\
42\end{array}$ & $\begin{array}{l}37 \\
36 \\
39 \\
40 \\
40\end{array}$ & $\begin{array}{l}51 \\
49 \\
50 \\
50 \\
48\end{array}$ & $\begin{array}{l}34 \\
35 \\
39 \\
42 \\
45\end{array}$ & $\begin{array}{l}61 \\
64 \\
69 \\
70 \\
67\end{array}$ & $\begin{array}{l}72 \\
74 \\
72 \\
69 \\
67\end{array}$ & $\begin{array}{l}83 \\
84 \\
86 \\
86 \\
85\end{array}$ & $\begin{array}{l}-- \\
-- \\
-- \\
-- \\
--\end{array}$ & & \\
\hline $\begin{array}{l}21 \\
22 \\
23 \\
24 \\
25\end{array}$ & $\begin{array}{l}-- \\
69 \\
60 \\
61 \\
59\end{array}$ & $\begin{array}{l}54 \\
52 \\
50 \\
49 \\
--\end{array}$ & $\begin{array}{l}45 \\
37 \\
35 \\
38 \\
41\end{array}$ & $\begin{array}{l}32 \\
32 \\
33 \\
37 \\
41\end{array}$ & $\begin{array}{l}49 \\
51 \\
52 \\
51 \\
52\end{array}$ & $\begin{array}{l}48 \\
52 \\
52 \\
53 \\
55\end{array}$ & $\begin{array}{l}68 \\
68 \\
71 \\
72 \\
73\end{array}$ & $\begin{array}{l}70 \\
72 \\
71 \\
73 \\
67\end{array}$ & $\begin{array}{l}84 \\
89 \\
90 \\
89 \\
88\end{array}$ & $\begin{array}{l}-- \\
-- \\
-- \\
-- \\
--\end{array}$ & & \\
\hline $\begin{array}{l}26 \\
27 \\
28 \\
29 \\
30 \\
31\end{array}$ & $\begin{array}{l}57 \\
61 \\
59 \\
58 \\
59 \\
60\end{array}$ & $\begin{array}{l}-- \\
50 \\
50 \\
51 \\
53 \\
--\end{array}$ & $\begin{array}{l}42 \\
43 \\
39 \\
40 \\
39 \\
40\end{array}$ & $\begin{array}{l}38 \\
40 \\
40 \\
41 \\
41 \\
43\end{array}$ & $\begin{array}{l}52 \\
51 \\
48 \\
-- \\
-- \\
--\end{array}$ & $\begin{array}{l}52 \\
53 \\
60 \\
57 \\
47 \\
44\end{array}$ & $\begin{array}{l}75 \\
75 \\
76 \\
76 \\
68 \\
--\end{array}$ & $\begin{array}{l}70 \\
72 \\
75 \\
75 \\
74 \\
-.\end{array}$ & $\begin{array}{l}86 \\
85 \\
87 \\
87 \\
87 \\
--\end{array}$ & $\begin{array}{l}-- \\
-- \\
-- \\
-- \\
--\end{array}$ & & \\
\hline $\begin{array}{c}\text { Aver- } \\
\text { age }\end{array}$ & - & 55 & -- & 39 & 48 & 46 & 67 & 68 & 82 & $\rightarrow$ & & \\
\hline
\end{tabular}




\begin{tabular}{|c|c|c|c|c|}
\hline 圆 & | & 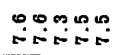 & 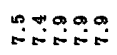 & ف \\
\hline 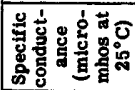 & 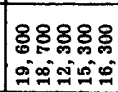 & 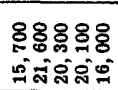 & 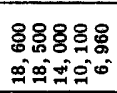 & 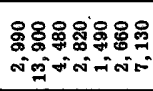 \\
\hline
\end{tabular}

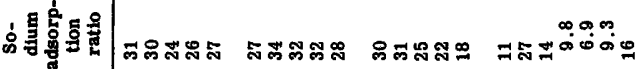

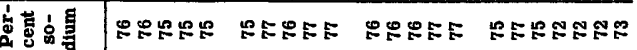

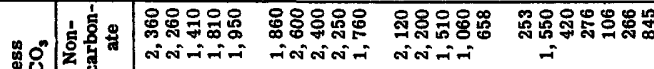

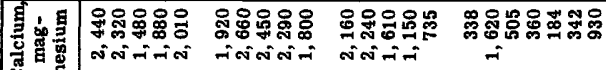

\begin{tabular}{|c|c|c|c|c|c|}
\hline \multirow{2}{*}{ 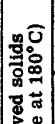 } & 总草害 & 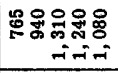 & 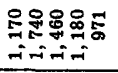 & 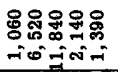 & 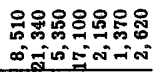 \\
\hline & & 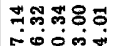 & & 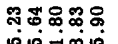 & 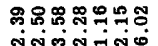 \\
\hline
\end{tabular}

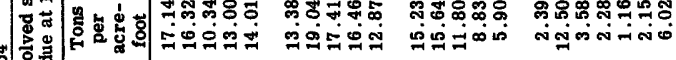

눈

\begin{tabular}{|c|c|c|c|}
\hline & 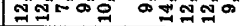 & & \\
\hline 宫点鱼 & $:: 1: 1: 1: 1: 1:$ & $1:: 1:$ & $1: 1: 1: 11$ \\
\hline 公最总 & $1: 11: 11: 11$ & $1: 11 i$ & $=1 \mid$\begin{tabular}{l|l}
$\infty$ \\
$\infty$
\end{tabular} \\
\hline 变部正 & $1: 11: 19111$ & $1: 1: 1$ & $\overline{1}: 1: 1: 1:$ \\
\hline ํํํ류를 & 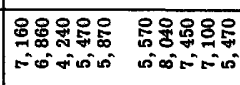 & 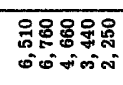 & 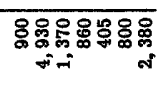 \\
\hline 容题 & 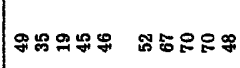 & 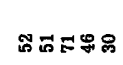 & 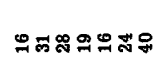 \\
\hline म & 0000000000 & 00000 & 0000000 \\
\hline 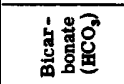 & 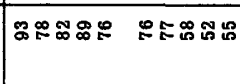 & 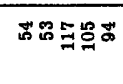 & 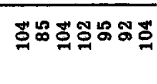 \\
\hline 旅焉区 & $1: 11111191$ & $1: 1: 1$ & $1: 1: 1: 1$ \\
\hline 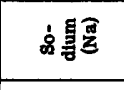 & 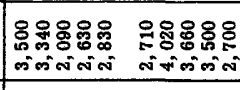 & 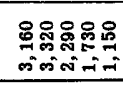 & 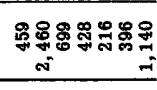 \\
\hline 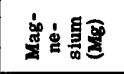 & 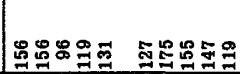 & 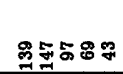 & 䑻瓦 \\
\hline 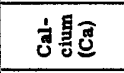 & 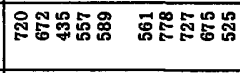 & : & 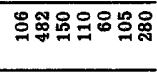 \\
\hline 호ㅇㅛㅛ & $1: 111: 11: 11$ & $1: 1: 1$ & $1: 1: 1: 1$ \\
\hline 总产 & $1: 11: 11: 1: 1$ & $1: 11:$ & $1: 1: 1: 1:$ \\
\hline 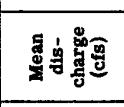 & 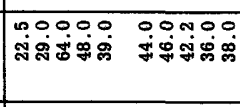 & 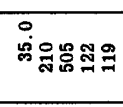 & 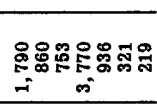 \\
\hline 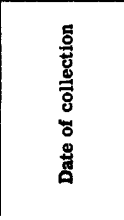 & 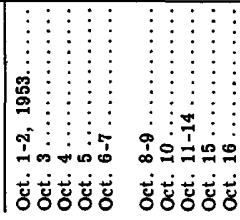 & 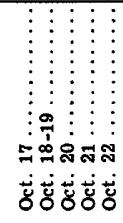 & 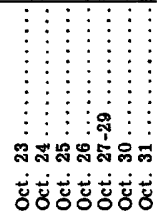 \\
\hline
\end{tabular}




\begin{tabular}{|c|c|c|c|c|c|}
\hline & 䆞 & 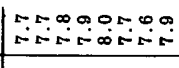 & 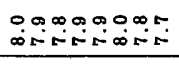 & 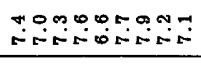 & 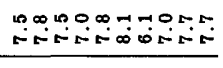 \\
\hline & 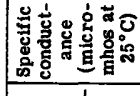 & 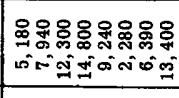 & 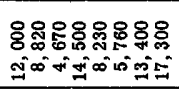 & 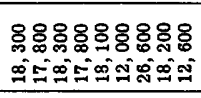 & 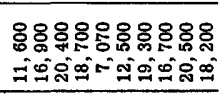 \\
\hline & 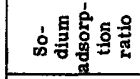 & サか心 & 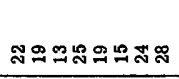 & 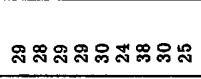 & 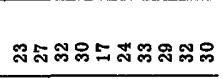 \\
\hline & 离虽宫韵 & 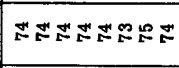 & 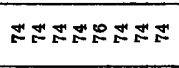 & 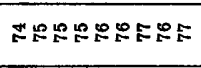 & 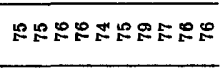 \\
\hline & 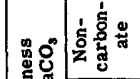 & 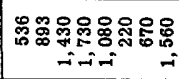 & 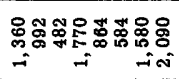 & 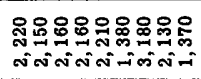 & 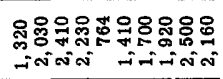 \\
\hline & 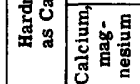 & 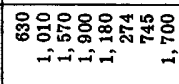 & 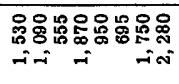 & 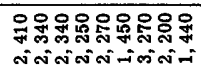 & 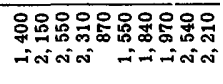 \\
\hline & 뭉윰 & 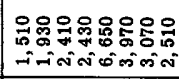 & 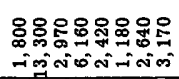 & 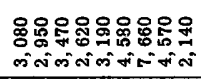 & 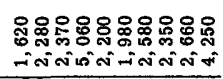 \\
\hline & 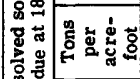 & 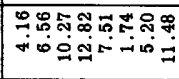 & 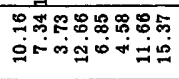 & 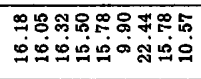 & 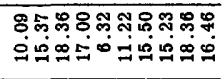 \\
\hline . & $\underbrace{2}$ & 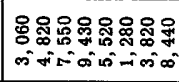 & 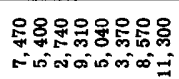 & 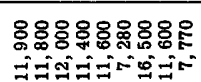 & 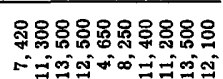 \\
\hline & 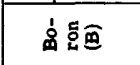 & 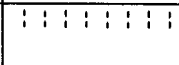 & $1: 1: i: 1:$ & $1: 1: 1$ & $1: 1: 1: 1: 1:$ \\
\hline & 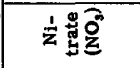 & 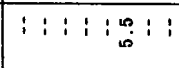 & $1: 1: 1: 1: 1:$ & i i : & $1: 1: 1:$ \\
\hline & 变害国 & 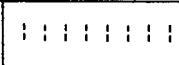 & $i: i:$ & $:: 1: 1: 1$ & $1: 1: 1$ \\
\hline $\begin{array}{ll}0 \\
0 \\
0\end{array}$ & 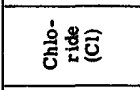 & 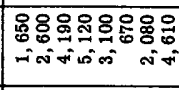 & 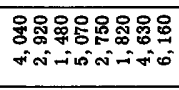 & 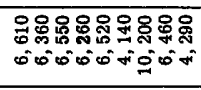 & 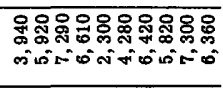 \\
\hline 至 & 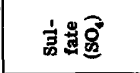 & 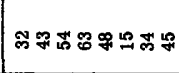 & ร: & E\& & ๘ \\
\hline 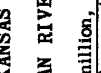 & 究 & 0 & 00000000 & 00000 & 200000 \\
\hline 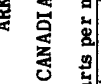 & 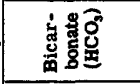 & 热点点 & 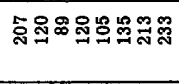 & 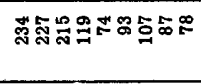 & 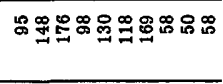 \\
\hline 这 & 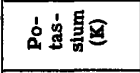 & $: 1: 1: 1:$ & $1: 1: 1: 11$ & $1: 1: 1: 1: 1: 1: 1$ & $1: 1: 11: 1: 1:$ \\
\hline 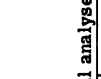 & 字贯要 & 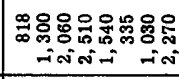 & 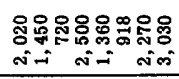 & 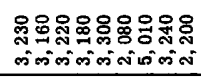 & 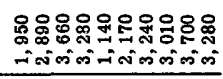 \\
\hline : & 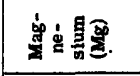 & $F$ & 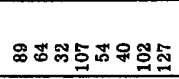 & 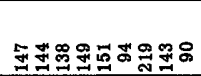 & 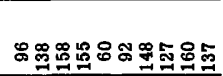 \\
\hline & 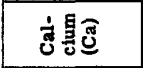 & 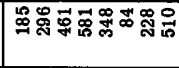 & 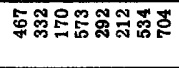 & 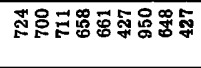 & 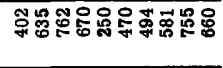 \\
\hline & 氞 & i : & $:: 1:$ & $::$ & : : \\
\hline & 赎 & i i & $1: 1:$ & $1: 1: 1: 1: 1: 1$ & i : : \\
\hline & 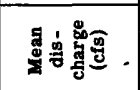 & 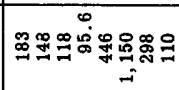 & 芩 & 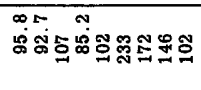 & 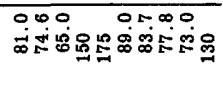 \\
\hline & 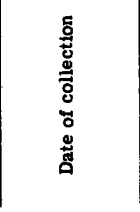 & 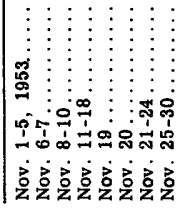 & 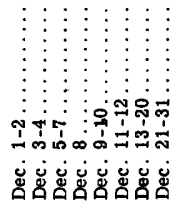 & 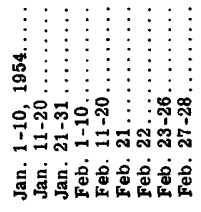 & 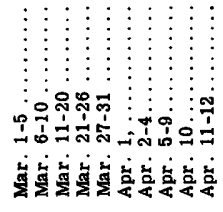 \\
\hline
\end{tabular}




\begin{tabular}{|c|c|c|c|c|c|}
\hline 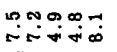 & 吊 & ஸ் & ח & مص & م \\
\hline 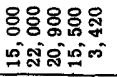 & 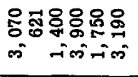 & 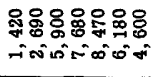 & 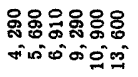 & 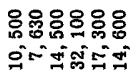 & 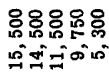 \\
\hline 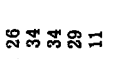 & क्ष & 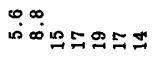 & 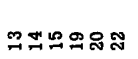 & 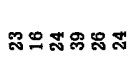 & 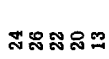 \\
\hline 电た象象昰 & 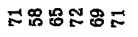 & ロேッェッ゚ロ & ホッロッロニ & ゚ミ゙トッ゚ & パドー \\
\hline 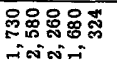 & 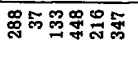 & 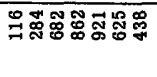 & 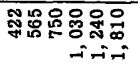 & 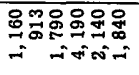 & 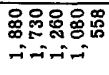 \\
\hline 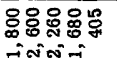 & 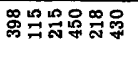 & 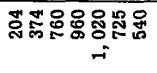 & 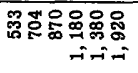 & 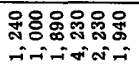 & 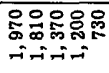 \\
\hline 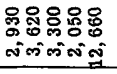 & 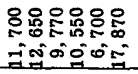 & 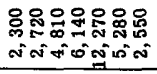 & 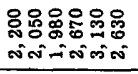 & 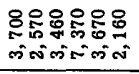 & 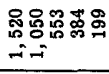 \\
\hline 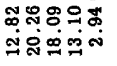 & 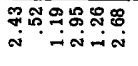 & 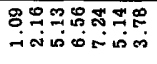 & 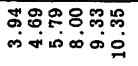 & 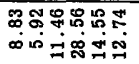 & 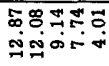 \\
\hline
\end{tabular}

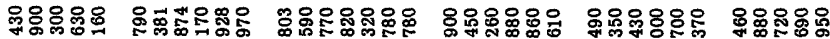

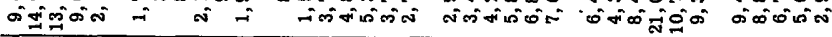

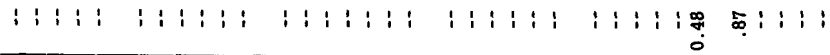

i 1 i i:

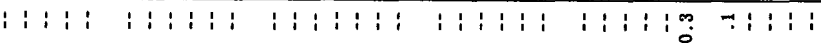

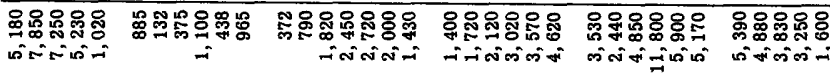

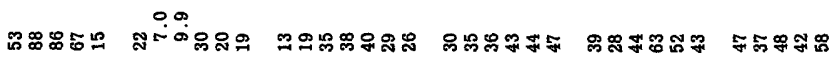

00000000000000000 m00000000000 0000J

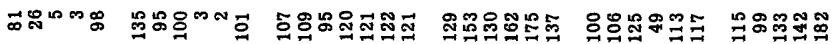

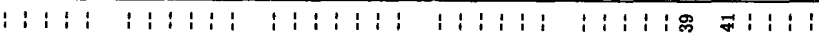

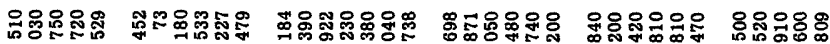

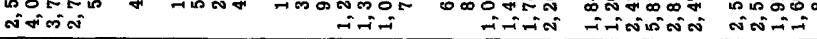

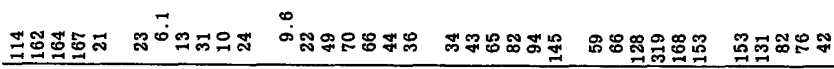

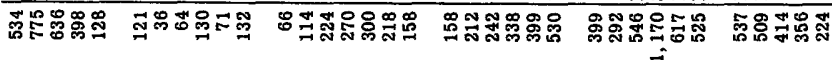

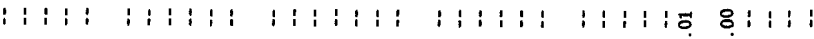

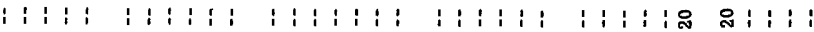

\begin{tabular}{|c|c|c|c|c|c|}
\hline 영ํ유 & 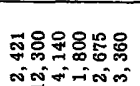 & 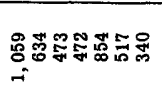 & 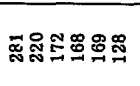 & 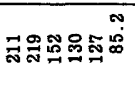 & 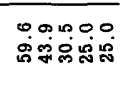 \\
\hline
\end{tabular}

范

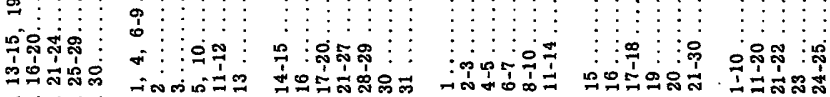

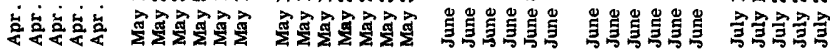




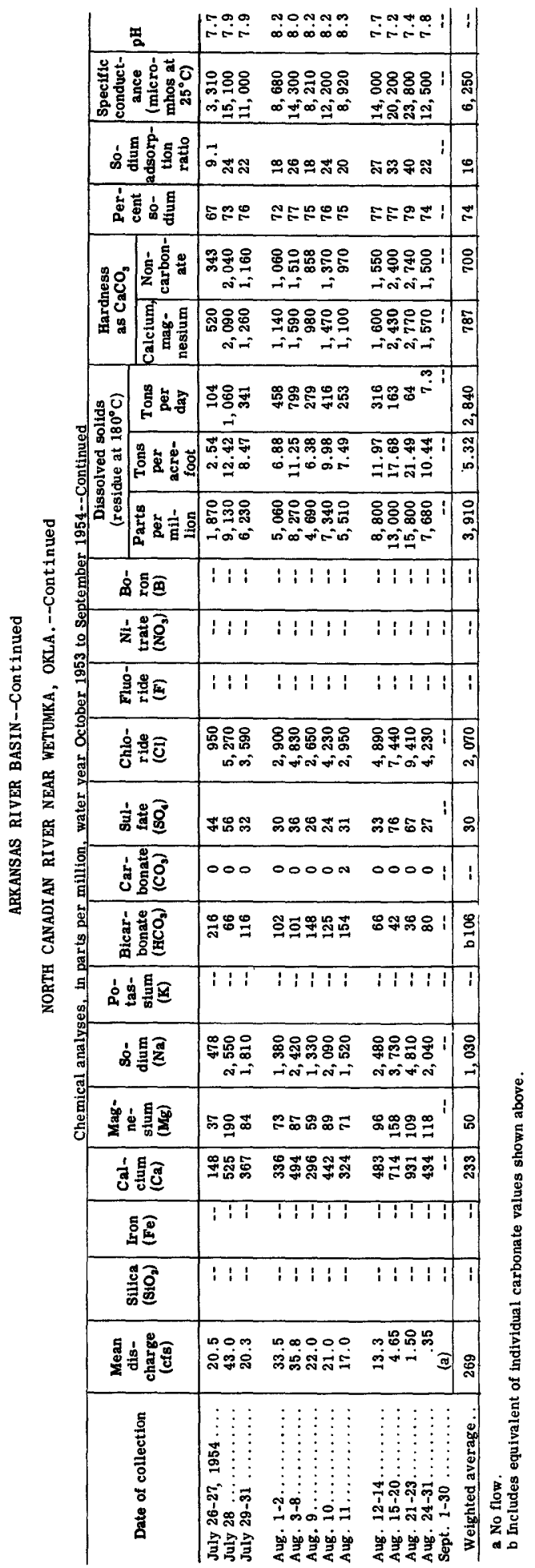


ARKANSAS RIVER BASIN--Continued

NORTH CANADIAN RIVER NEAR WETUMKA, OKLA.--Continued

Temperature $\left({ }^{\circ} \mathrm{F}\right)$ of water, water year October 1953 to September 1954

\begin{tabular}{|c|c|c|c|c|c|c|c|c|c|c|c|c|}
\hline Day & Oct. & Nov. & Dec. & Jan. & Feb. & Mar. & Apr. & May & June & July & Aug. & Sept. \\
\hline $\begin{array}{l}1 \\
2 \\
3 \\
4 \\
5\end{array}$ & $\begin{array}{l}80 \\
-- \\
85 \\
67 \\
60\end{array}$ & $\begin{array}{l}\mathbf{5 6} \\
\mathbf{5 4} \\
\mathbf{5 4} \\
\mathbf{5 2} \\
\mathbf{5 2}\end{array}$ & $\begin{array}{l}45 \\
56 \\
50 \\
46 \\
47\end{array}$ & $\begin{array}{l}35 \\
41 \\
36 \\
46 \\
39\end{array}$ & $\begin{array}{l}42 \\
41 \\
42 \\
43 \\
41\end{array}$ & $\begin{array}{l}40 \\
42 \\
35 \\
34 \\
40\end{array}$ & $\begin{array}{l}44 \\
50 \\
54 \\
65 \\
65\end{array}$ & $\begin{array}{l}61 \\
60 \\
55 \\
56 \\
58\end{array}$ & $\begin{array}{l}70 \\
72 \\
65 \\
65 \\
67\end{array}$ & $\begin{array}{l}78 \\
80 \\
80 \\
90 \\
80\end{array}$ & $\begin{array}{l}85 \\
73 \\
78 \\
81 \\
78\end{array}$ & \\
\hline $\begin{array}{r}6 \\
7 \\
8 \\
9 \\
10\end{array}$ & $\begin{array}{l}57 \\
54 \\
55 \\
57 \\
65\end{array}$ & $\begin{array}{l}47 \\
44 \\
45 \\
42 \\
52\end{array}$ & $\begin{array}{l}51 \\
42 \\
45 \\
41 \\
38\end{array}$ & $\begin{array}{l}38 \\
39 \\
47 \\
47 \\
37\end{array}$ & $\begin{array}{l}43 \\
38 \\
41 \\
42 \\
48\end{array}$ & $\begin{array}{l}36 \\
42 \\
46 \\
47 \\
52\end{array}$ & $\begin{array}{l}65 \\
66 \\
54 \\
58 \\
60\end{array}$ & $\begin{array}{l}60 \\
62 \\
60 \\
62 \\
58\end{array}$ & $\begin{array}{l}67 \\
71 \\
71 \\
76 \\
75\end{array}$ & $\begin{array}{l}79 \\
80 \\
80 \\
80 \\
81\end{array}$ & $\begin{array}{l}77 \\
76 \\
77 \\
78 \\
75\end{array}$ & \\
\hline $\begin{array}{l}11 \\
12 \\
13 \\
14 \\
15\end{array}$ & $\begin{array}{l}75 \\
67 \\
65 \\
67 \\
67\end{array}$ & $\begin{array}{l}51 \\
50 \\
54 \\
51 \\
62\end{array}$ & $\begin{array}{l}42 \\
40 \\
-- \\
- \\
40\end{array}$ & $\begin{array}{l}37 \\
32 \\
32 \\
35 \\
39\end{array}$ & $\begin{array}{l}42 \\
38 \\
41 \\
52 \\
58\end{array}$ & $\begin{array}{l}56 \\
56 \\
42 \\
35 \\
37\end{array}$ & $\begin{array}{l}68 \\
58 \\
56 \\
62 \\
68\end{array}$ & $\begin{array}{l}56 \\
57 \\
58 \\
58 \\
62\end{array}$ & $\begin{array}{l}75 \\
76 \\
76 \\
75 \\
79\end{array}$ & $\begin{array}{l}78 \\
85 \\
83 \\
81 \\
80\end{array}$ & $\begin{array}{l}72 \\
78 \\
72 \\
77 \\
80\end{array}$ & \\
\hline $\begin{array}{l}16 \\
17 \\
18 \\
19 \\
20\end{array}$ & $\begin{array}{l}64 \\
64 \\
64 \\
63 \\
64\end{array}$ & $\begin{array}{l}49 \\
55 \\
65 \\
65 \\
50\end{array}$ & $\begin{array}{l}45 \\
41 \\
37 \\
39 \\
41\end{array}$ & $\begin{array}{l}36 \\
32 \\
34 \\
47 \\
55\end{array}$ & $\begin{array}{l}50 \\
46 \\
48 \\
54 \\
42\end{array}$ & $\begin{array}{l}42 \\
45 \\
52 \\
-- \\
50\end{array}$ & $\begin{array}{l}55 \\
55 \\
58 \\
59 \\
61\end{array}$ & $\begin{array}{l}65 \\
69 \\
65 \\
67 \\
64\end{array}$ & $\begin{array}{l}75 \\
76 \\
79 \\
82 \\
81\end{array}$ & $\begin{array}{l}79 \\
80 \\
79 \\
80 \\
78\end{array}$ & $\begin{array}{l}76 \\
80 \\
80 \\
79 \\
79\end{array}$ & \\
\hline $\begin{array}{l}21 \\
22 \\
23 \\
24 \\
25\end{array}$ & $\begin{array}{l}68 \\
70 \\
68 \\
60 \\
62\end{array}$ & $\begin{array}{l}46 \\
48 \\
41 \\
45 \\
43\end{array}$ & $\begin{array}{l}45 \\
33 \\
32 \\
32 \\
32\end{array}$ & $\begin{array}{l}32 \\
32 \\
32 \\
36 \\
49\end{array}$ & $\begin{array}{l}48 \\
49 \\
50 \\
45 \\
48\end{array}$ & $\begin{array}{l}48 \\
52 \\
54 \\
52 \\
55\end{array}$ & $\begin{array}{l}64 \\
65 \\
62 \\
65 \\
68\end{array}$ & $\begin{array}{l}63 \\
66 \\
-- \\
70 \\
70\end{array}$ & $\begin{array}{l}78 \\
80 \\
81 \\
82 \\
80\end{array}$ & $\begin{array}{l}79 \\
79 \\
81 \\
88 \\
84\end{array}$ & $\begin{array}{l}78 \\
78 \\
80 \\
92 \\
92\end{array}$ & \\
\hline $\begin{array}{l}26 \\
27 \\
28 \\
29 \\
30 \\
31\end{array}$ & $\begin{array}{l}56 \\
55 \\
55 \\
55 \\
54 \\
53 \\
\end{array}$ & $\begin{array}{l}45 \\
45 \\
42 \\
43 \\
41 \\
-- \\
\end{array}$ & $\begin{array}{l}35 \\
40 \\
40 \\
45 \\
33 \\
33 \\
\end{array}$ & $\begin{array}{l}44 \\
33 \\
38 \\
39 \\
42 \\
41 \\
\end{array}$ & $\begin{array}{l}47 \\
52 \\
40 \\
-- \\
-- \\
-- \\
\end{array}$ & $\begin{array}{l}54 \\
53 \\
58 \\
56 \\
44 \\
41\end{array}$ & $\begin{array}{l}68 \\
69 \\
66 \\
68 \\
65 \\
--\end{array}$ & $\begin{array}{l}69 \\
70 \\
72 \\
70 \\
73 \\
75\end{array}$ & $\begin{array}{l}80 \\
82 \\
77 \\
79 \\
80 \\
--\end{array}$ & $\begin{array}{l}79 \\
87 \\
82 \\
80 \\
80 \\
79\end{array}$ & $\begin{array}{l}78 \\
-- \\
-- \\
-- \\
--\end{array}$ & \\
\hline $\begin{array}{c}\text { Aver- } \\
\text { age }\end{array}$ & 63 & 50 & 41 & 39 & 45 & 47 & 61 & 64 & 76 & 81 & 79 & \\
\hline
\end{tabular}




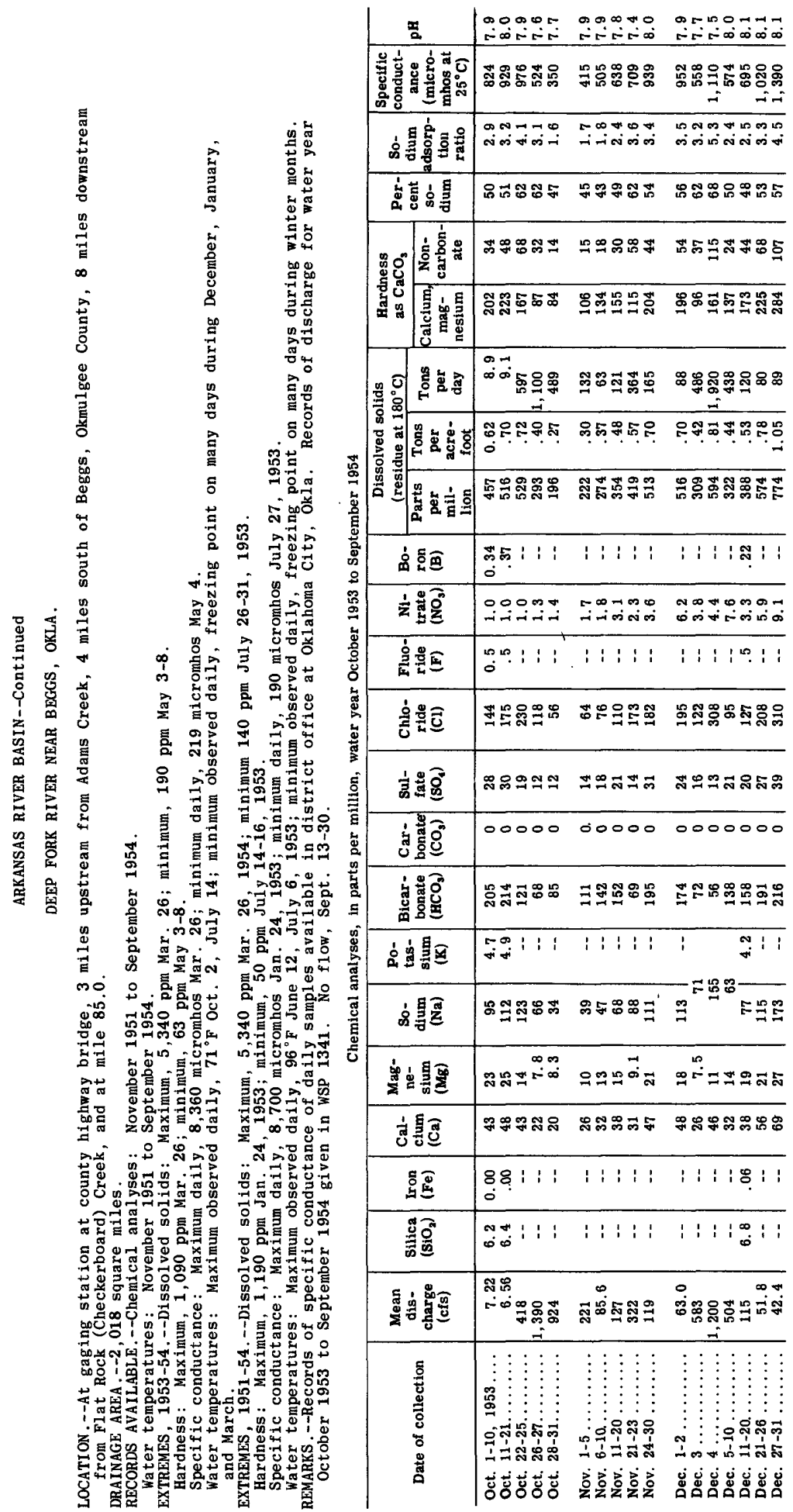




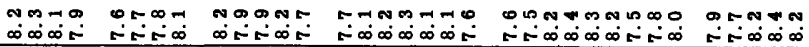

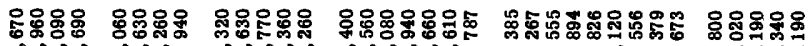

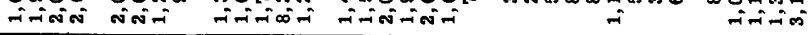

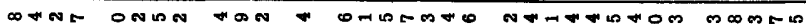

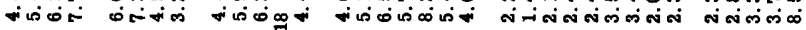

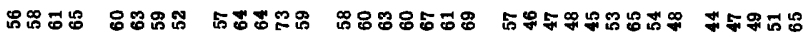

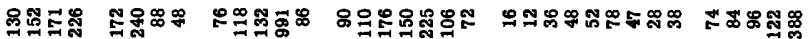

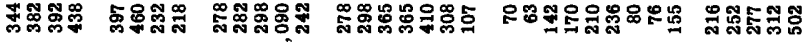

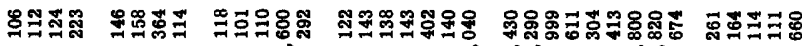

洛范 :

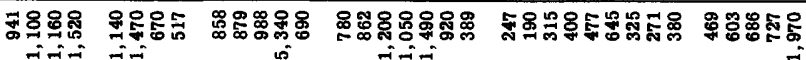

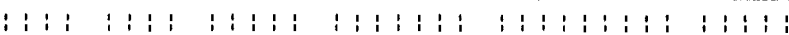

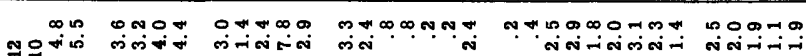

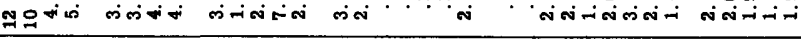

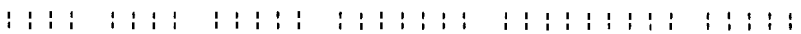

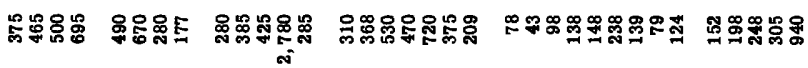

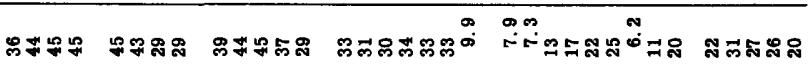

$0 m 00000000000000+000000 m 0000000+10$

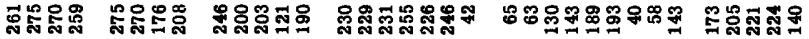

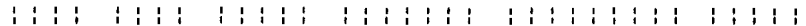

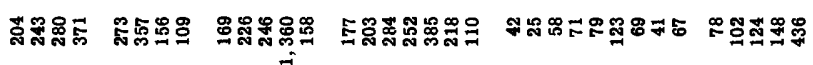

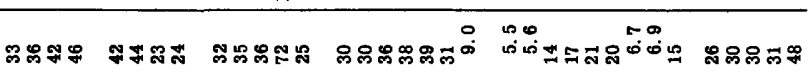

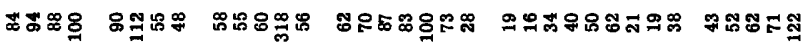

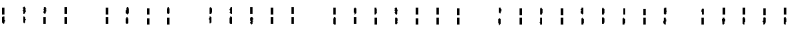

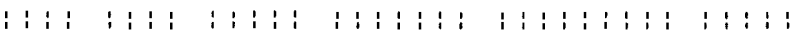

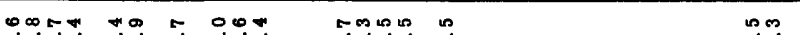

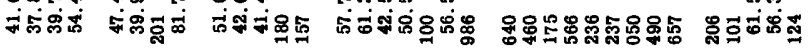
n+i-1 กิ่

葛

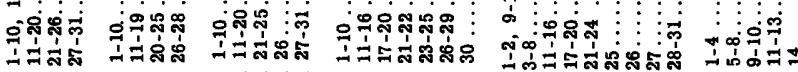

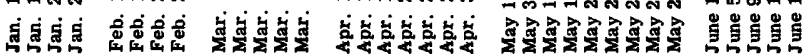




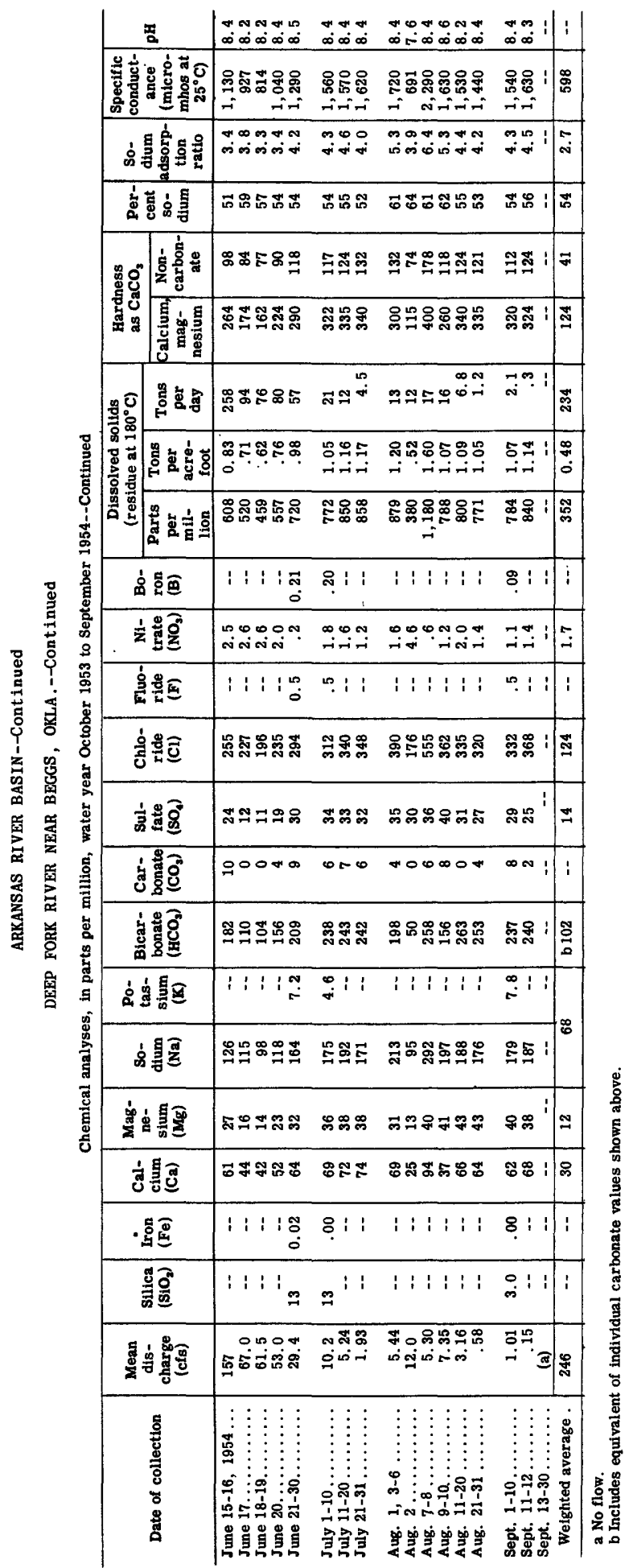


ARKANSAS RIVER BASIN--Continued

DEEP FORK RIVER NEAR BEGGS, OKLA.--Continued

Temperature $\left({ }^{\circ} \mathrm{F}\right)$ of water, water year October 1953 to September 1954

\begin{tabular}{|c|c|c|c|c|c|c|c|c|c|c|c|c|}
\hline Day & Oct. & Nov. & Dec. & Jan. & Feb. & Mar. & Apr. & May & June & July & Aug. & Sept. \\
\hline $\begin{array}{l}1 \\
2 \\
3 \\
4 \\
5\end{array}$ & $\begin{array}{l}70 \\
71 \\
69 \\
56 \\
57\end{array}$ & $\begin{array}{l}50 \\
53 \\
53 \\
48 \\
42\end{array}$ & $\begin{array}{l}41 \\
40 \\
40 \\
42 \\
40\end{array}$ & $\begin{array}{l}32 \\
32 \\
35 \\
34 \\
39\end{array}$ & $\begin{array}{l}36 \\
38 \\
39 \\
40 \\
41\end{array}$ & $\begin{array}{l}43 \\
37 \\
33 \\
32 \\
32\end{array}$ & $\begin{array}{l}40 \\
45 \\
47 \\
50 \\
51\end{array}$ & $\begin{array}{l}41 \\
39 \\
41 \\
43 \\
45\end{array}$ & $\begin{array}{l}\mathbf{5 7} \\
\mathbf{5 3} \\
\mathbf{5 1} \\
\mathbf{5 4} \\
\mathbf{5 7}\end{array}$ & $\begin{array}{l}66 \\
65 \\
67 \\
66 \\
67\end{array}$ & $\begin{array}{l}55 \\
52 \\
58 \\
60 \\
57\end{array}$ & $\begin{array}{l}\mathbf{5 1} \\
\mathbf{5 2} \\
\mathbf{5 3} \\
\mathbf{5 2} \\
\mathbf{5 0}\end{array}$ \\
\hline 6 & 56 & 41 & 43 & 38 & 41 & 37 & 51 & 45 & 57 & 67 & 56 & 49 \\
\hline $\begin{array}{r}7 \\
8 \\
9 \\
10\end{array}$ & $\begin{array}{l}57 \\
58 \\
58 \\
60\end{array}$ & $\begin{array}{l}39 \\
41 \\
39 \\
49\end{array}$ & $\begin{array}{l}-- \\
-- \\
--\end{array}$ & $\begin{array}{l}34 \\
37 \\
32 \\
32\end{array}$ & $\begin{array}{l}42 \\
40 \\
44 \\
41\end{array}$ & $\begin{array}{l}39 \\
40 \\
41 \\
41\end{array}$ & $\begin{array}{l}\mathbf{5 3} \\
\mathbf{5 3} \\
\mathbf{5 5} \\
\mathbf{5 1}\end{array}$ & $\begin{array}{l}46 \\
44 \\
46 \\
41\end{array}$ & $\begin{array}{l}59 \\
61 \\
63 \\
60\end{array}$ & $\begin{array}{l}65 \\
67 \\
66 \\
68\end{array}$ & $\begin{array}{l}56 \\
47 \\
51 \\
54\end{array}$ & $\begin{array}{l}46 \\
49 \\
42 \\
49\end{array}$ \\
\hline $\begin{array}{l}11 \\
12 \\
13 \\
14 \\
15\end{array}$ & $\begin{array}{l}60 \\
64 \\
62 \\
63 \\
64\end{array}$ & $\begin{array}{l}47 \\
45 \\
45 \\
44 \\
50\end{array}$ & $\begin{array}{l}-- \\
-- \\
-- \\
33 \\
39\end{array}$ & $\begin{array}{l}36 \\
32 \\
32 \\
34 \\
32\end{array}$ & $\begin{array}{l}39 \\
41 \\
36 \\
46 \\
47\end{array}$ & $\begin{array}{l}49 \\
41 \\
37 \\
35 \\
36\end{array}$ & $\begin{array}{l}47 \\
44 \\
51 \\
52 \\
51\end{array}$ & $\begin{array}{l}42 \\
39 \\
39 \\
49 \\
47\end{array}$ & $\begin{array}{l}63 \\
63 \\
61 \\
64 \\
56\end{array}$ & $\begin{array}{l}67 \\
67 \\
69 \\
71 \\
63\end{array}$ & $\begin{array}{l}\mathbf{5 5} \\
\mathbf{5 5} \\
\mathbf{5 3} \\
\mathbf{6 0} \\
\mathbf{5 5}\end{array}$ & $\begin{array}{l}51 \\
47 \\
-- \\
-- \\
--\end{array}$ \\
\hline $\begin{array}{l}16 \\
17 \\
18 \\
19 \\
20\end{array}$ & $\begin{array}{l}65 \\
64 \\
65 \\
62 \\
64\end{array}$ & $\begin{array}{l}\mathbf{5 2} \\
\mathbf{5 2} \\
\mathbf{5 3} \\
\mathbf{4 9} \\
\mathbf{4 1}\end{array}$ & $\begin{array}{l}37 \\
36 \\
34 \\
39 \\
40\end{array}$ & $\begin{array}{l}34 \\
32 \\
32 \\
35 \\
32\end{array}$ & $\begin{array}{l}49 \\
39 \\
43 \\
41 \\
39\end{array}$ & $\begin{array}{l}39 \\
39 \\
41 \\
47 \\
47\end{array}$ & $\begin{array}{l}49 \\
51 \\
55 \\
57 \\
55\end{array}$ & $\begin{array}{l}49 \\
51 \\
55 \\
49 \\
49\end{array}$ & $\begin{array}{l}64 \\
66 \\
65 \\
68 \\
64\end{array}$ & $\begin{array}{l}69 \\
68 \\
69 \\
68 \\
64\end{array}$ & $\begin{array}{l}56 \\
55 \\
58 \\
57 \\
53\end{array}$ & $\begin{array}{l}-- \\
-- \\
-- \\
--\end{array}$ \\
\hline $\begin{array}{l}21 \\
22 \\
23 \\
24 \\
25\end{array}$ & $\begin{array}{l}60 \\
58 \\
54 \\
54 \\
52\end{array}$ & $\begin{array}{l}43 \\
42 \\
45 \\
41 \\
41\end{array}$ & $\begin{array}{l}32 \\
32 \\
32 \\
32 \\
32\end{array}$ & $\begin{array}{l}32 \\
32 \\
32 \\
34 \\
32\end{array}$ & $\begin{array}{l}47 \\
42 \\
47 \\
43 \\
43\end{array}$ & $\begin{array}{l}42 \\
40 \\
40 \\
39 \\
41\end{array}$ & $\begin{array}{l}\mathbf{5 3} \\
\mathbf{5 3} \\
\mathbf{5 4} \\
\mathbf{5 7} \\
\mathbf{5 8}\end{array}$ & $\begin{array}{l}\mathbf{5 1} \\
\mathbf{5 3} \\
\mathbf{5 7} \\
\mathbf{5 5} \\
\mathbf{5 3}\end{array}$ & $\begin{array}{l}66 \\
64 \\
67 \\
66 \\
67\end{array}$ & $\begin{array}{l}59 \\
63 \\
61 \\
63 \\
67\end{array}$ & $\begin{array}{l}\mathbf{5 0} \\
55 \\
54 \\
52 \\
57\end{array}$ & $\begin{array}{l}-- \\
-- \\
-- \\
--\end{array}$ \\
\hline $\begin{array}{l}26 \\
27 \\
28 \\
29 \\
30 \\
31\end{array}$ & $\begin{array}{l}47 \\
48 \\
52 \\
48 \\
52 \\
55\end{array}$ & $\begin{array}{l}43 \\
41 \\
41 \\
44 \\
46 \\
--\end{array}$ & $\begin{array}{l}32 \\
35 \\
32 \\
32 \\
32 \\
33 \\
\end{array}$ & $\begin{array}{l}32 \\
41 \\
38 \\
32 \\
32 \\
32 \\
\end{array}$ & $\begin{array}{l}42 \\
34 \\
34 \\
-- \\
-- \\
--\end{array}$ & $\begin{array}{l}45 \\
46 \\
51 \\
41 \\
35 \\
35 \\
\end{array}$ & $\begin{array}{l}59 \\
59 \\
57 \\
59 \\
48 \\
- \\
\end{array}$ & $\begin{array}{l}\mathbf{5 0} \\
\mathbf{5 3} \\
\mathbf{5 5} \\
\mathbf{5 6} \\
\mathbf{5 7} \\
\mathbf{5 8} \\
\end{array}$ & $\begin{array}{l}67 \\
68 \\
67 \\
70 \\
70 \\
-- \\
\end{array}$ & $\begin{array}{l}67 \\
63 \\
64 \\
67 \\
62 \\
62 \\
\end{array}$ & $\begin{array}{l}56 \\
53 \\
54 \\
53 \\
52 \\
50 \\
\end{array}$ & $\begin{array}{l}-- \\
-- \\
-- \\
--\end{array}$ \\
\hline $\begin{array}{l}\text { Aver- } \\
\text { age }\end{array}$ & 59 & 45 & $=$ & 34 & 41 & 40 & 52 & 48 & 63 & 66 & 54 & $=$ \\
\hline
\end{tabular}




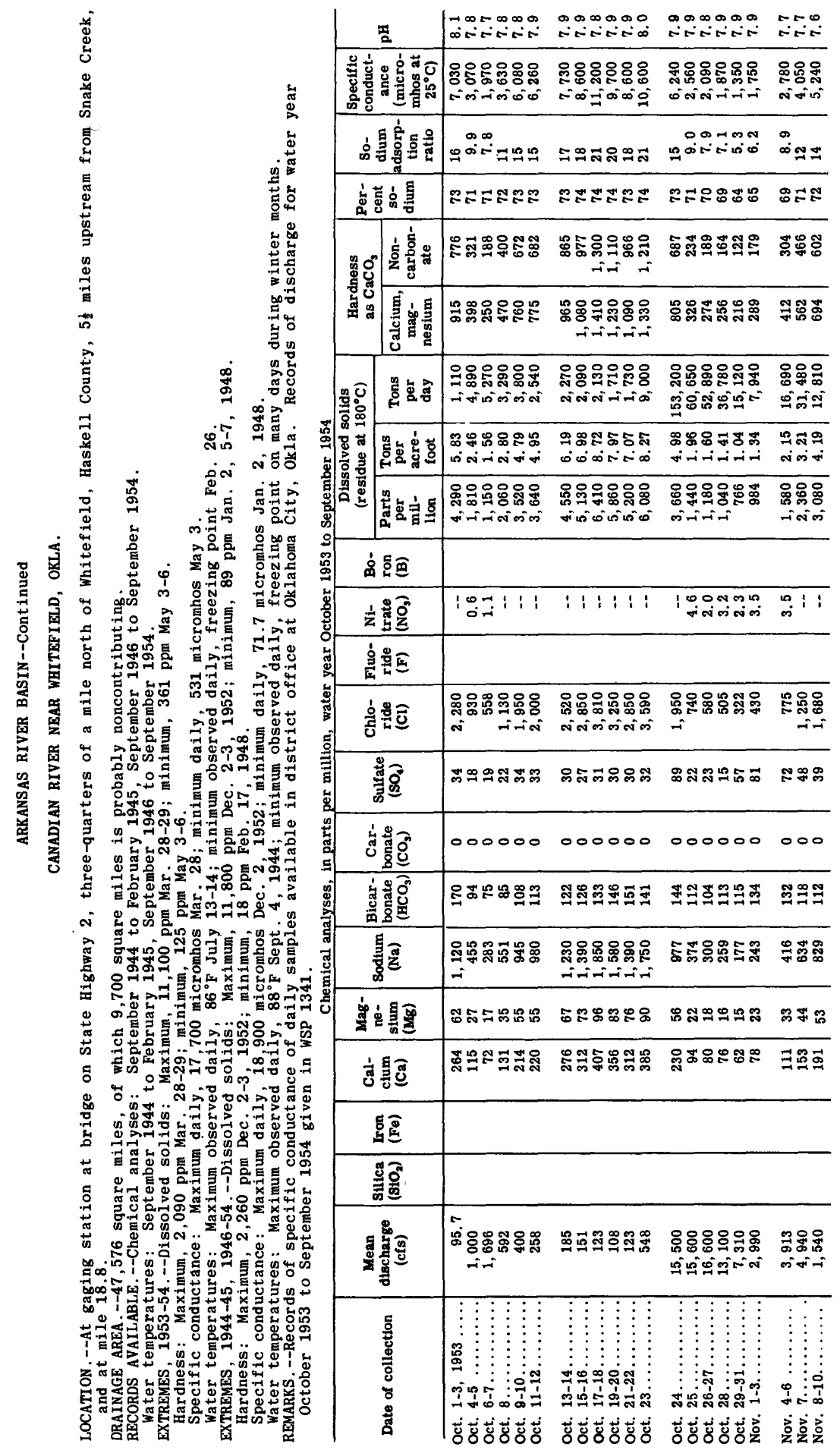




\begin{tabular}{|c|c|c|c|c|c|}
\hline 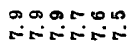 & 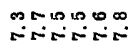 & 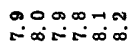 & 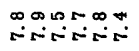 & 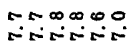 & $\begin{array}{l}005 \infty \\
\infty \leftarrow 5\end{array}$ \\
\hline 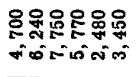 & 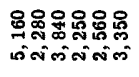 & 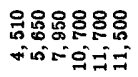 & 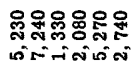 & 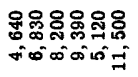 & 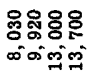 \\
\hline 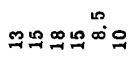 & $\underset{\sim}{\infty} \stackrel{\infty}{\infty} \underset{\sim}{\infty}$ & 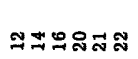 & 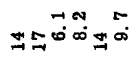 & $\ddot{\sim} ニ の$ & 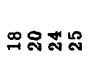 \\
\hline ミミッッロに & 토용웅유 & モ゙ニッッホ & ゚ポ゚゙゚ & 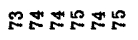 & ポ卡是 \\
\hline 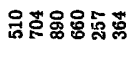 & 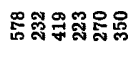 & 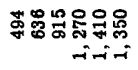 & 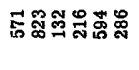 & 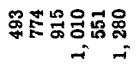 & 응유유용 \\
\hline 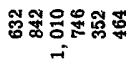 & 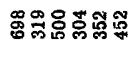 & 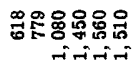 & 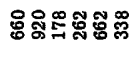 & 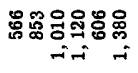 & 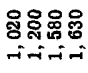 \\
\hline 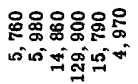 & 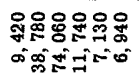 & 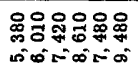 & 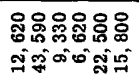 & 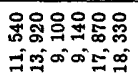 & 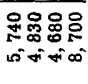 \\
\hline 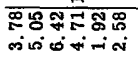 & 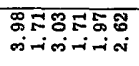 & 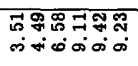 & 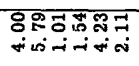 & 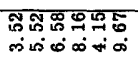 & 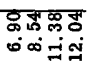 \\
\hline 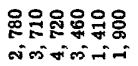 & 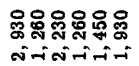 & 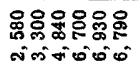 & 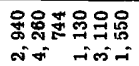 & 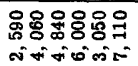 & 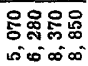 \\
\hline
\end{tabular}

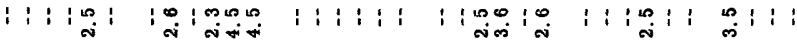

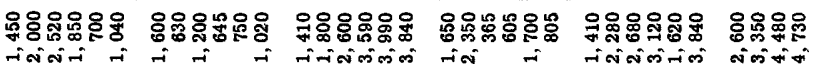

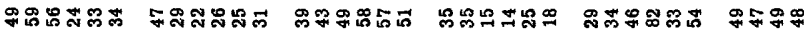

0000000000000000000000000000000000

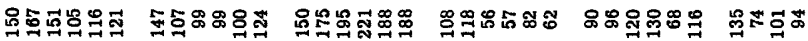

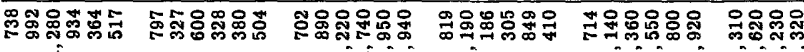

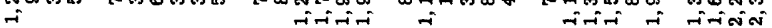

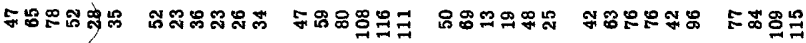

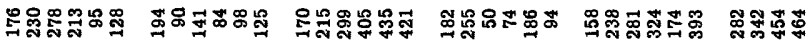

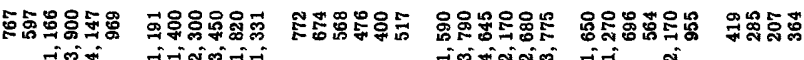

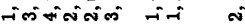

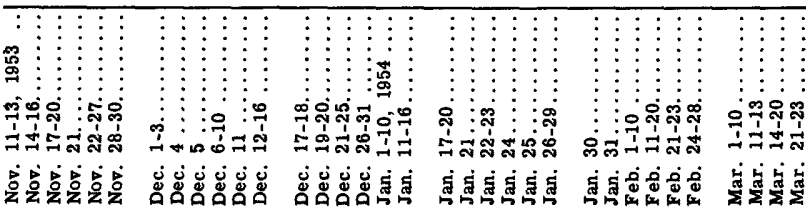




\begin{tabular}{|c|c|c|c|c|c|c|c|}
\hline & 펼 & 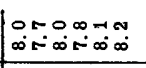 & 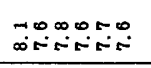 & 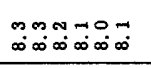 & 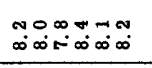 & 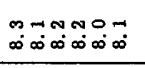 & 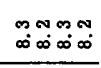 \\
\hline & 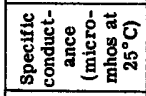 & 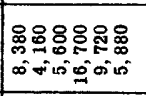 & 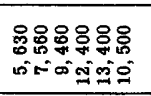 & 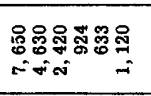 & 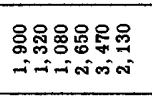 & 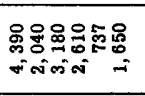 & 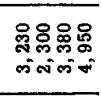 \\
\hline & 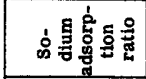 & 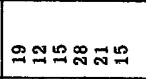 & 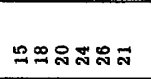 & $\begin{array}{r}n \infty 0 \infty \\
\infty \\
\infty \\
\infty\end{array}$ & 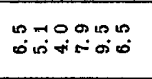 & 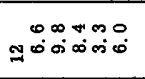 & $\stackrel{\circ}{\circ}=m$ \\
\hline & 岕葶字息 & 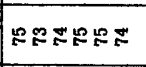 & ๓ำำำ & 초오요 & 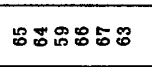 & 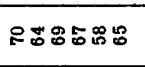 & ำสำ \\
\hline & 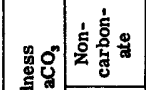 & 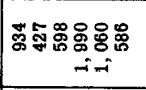 & 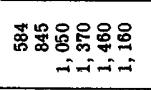 & 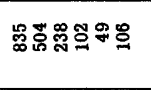 & 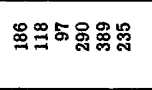 & 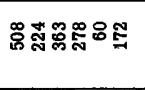 & 节蛋芯品 \\
\hline & 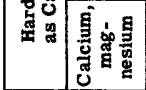 & 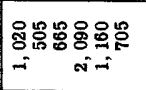 & 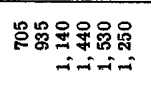 & 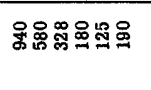 & 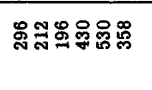 & 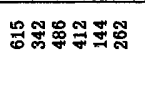 & 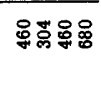 \\
\hline : & 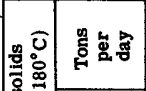 & 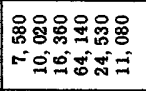 & 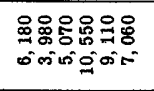 & 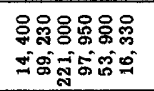 & 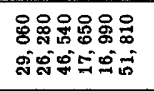 & 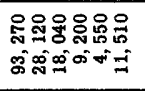 & 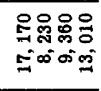 \\
\hline . & 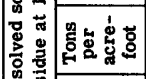 & 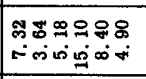 & 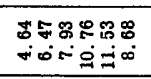 & 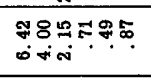 & 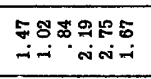 & 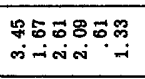 & 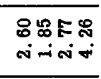 \\
\hline 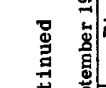 & 兽总 & 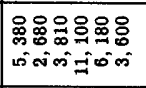 & 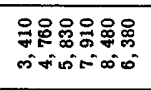 & 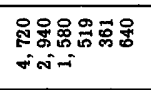 & 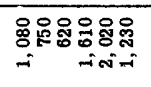 & 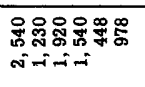 & 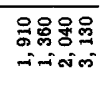 \\
\hline $\begin{array}{ll} & 0 \\
0 & 0 \\
& 0 \\
1 & 0\end{array}$ & 容宫重 & & & & & & \\
\hline 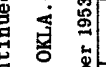 & 完焉客 & $1: 1: 1: 1$ & $1: 1: 111$ & 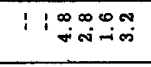 & 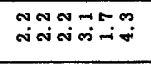 & 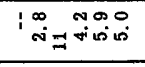 & 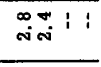 \\
\hline 空 & 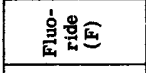 & & & & & & \\
\hline 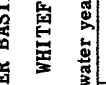 & 옳흅으 & 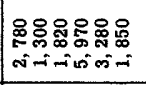 & 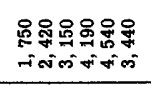 & 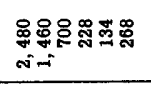 & 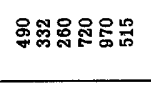 & 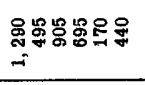 & 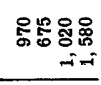 \\
\hline 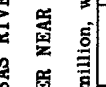 & 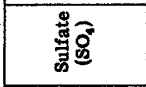 & ஜํㅛ & 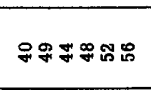 & 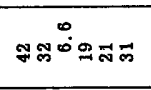 & 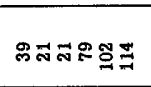 & 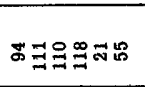 & ず距占品 \\
\hline 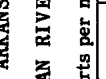 & 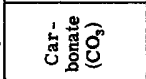 & 000000 & 000000 & NNo000 & 000000 & 000000 & Nono \\
\hline 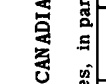 & 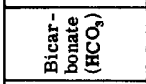 & 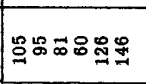 & 承워ㅋㅝㅀㅀ & ్ㅀㅇㅠఃミః & 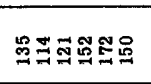 & 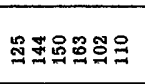 & 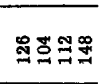 \\
\hline 离 & 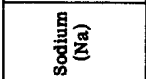 & 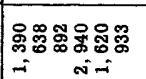 & 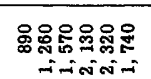 & 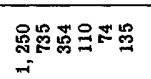 & 䓀토 & §゚心 & 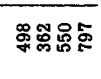 \\
\hline : & 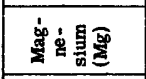 & 두유요 역 & 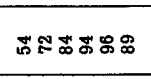 & 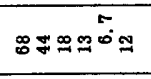 & 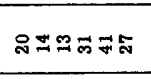 & 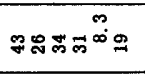 & 밌오ㅇㅛㅛ \\
\hline & 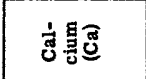 & 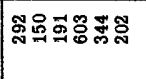 & 苂品圌染品品 & 总吕 & 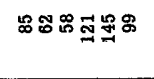 & 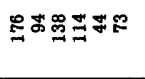 & 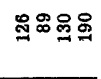 \\
\hline & 施通 & & & & & & \\
\hline & 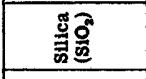 & & & & & & \\
\hline & 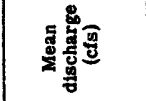 & 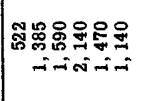 & 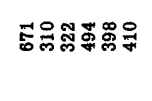 & 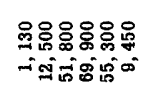 & 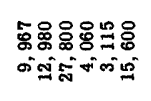 & 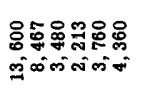 & 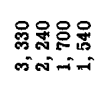 \\
\hline & 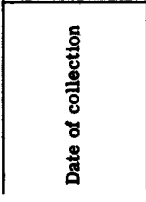 & 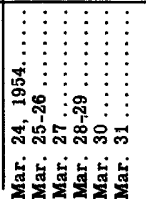 & 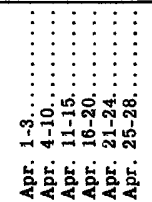 & 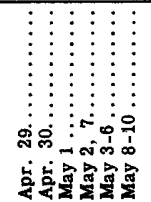 & 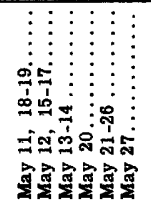 & 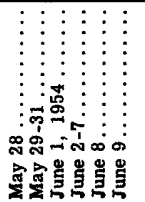 & 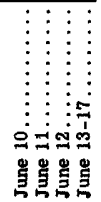 \\
\hline
\end{tabular}




\begin{tabular}{|c|c|c|c|c|}
\hline $\begin{array}{l}\overrightarrow{1}=\infty \\
\infty \\
\infty \\
\infty\end{array}$ & 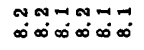 & 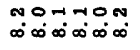 & 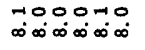 & 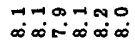 \\
\hline 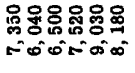 & 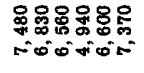 & 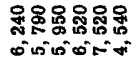 & 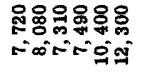 & 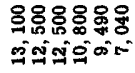 \\
\hline 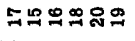 & 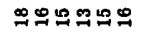 & 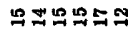 & 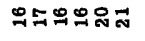 & สิฐ \\
\hline ゚゚ジミ゙ッ゚ & に゚ポテニ & ニホッニポ & テ゚゙ェ゚゚ & 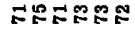 \\
\hline 怘 & స్心 & 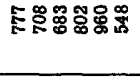 & 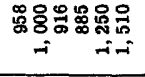 & 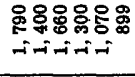 \\
\hline 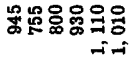 & ్ㅐ욣윯융ㅇㅀㅇ & 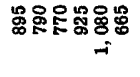 & 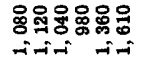 & 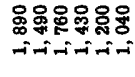 \\
\hline 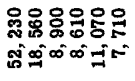 & 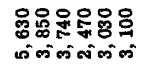 & 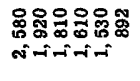 & 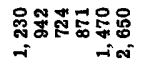 & 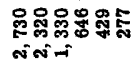 \\
\hline 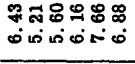 & 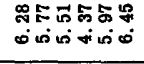 & 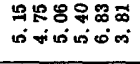 & 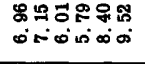 & 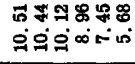 \\
\hline 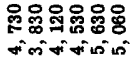 & 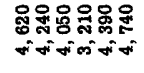 & 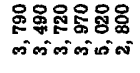 & 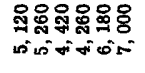 & 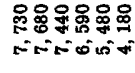 \\
\hline
\end{tabular}

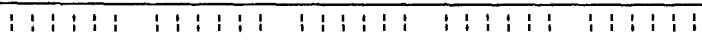

\begin{tabular}{|c|c|c|c|c|}
\hline 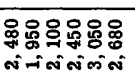 & 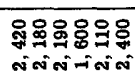 & 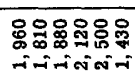 & 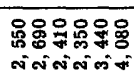 & 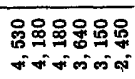 \\
\hline 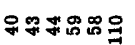 & 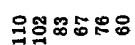 & స్లాఃఖ & $\because 0$ & 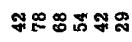 \\
\hline
\end{tabular}

$00 \forall+1000000000000000000000000$

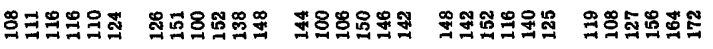

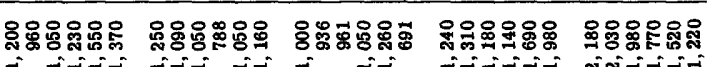

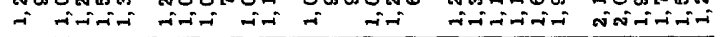

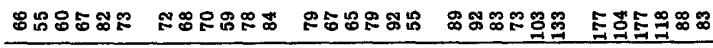

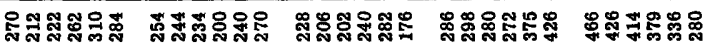

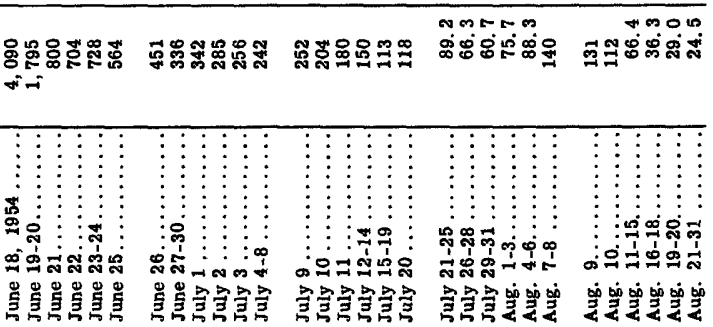




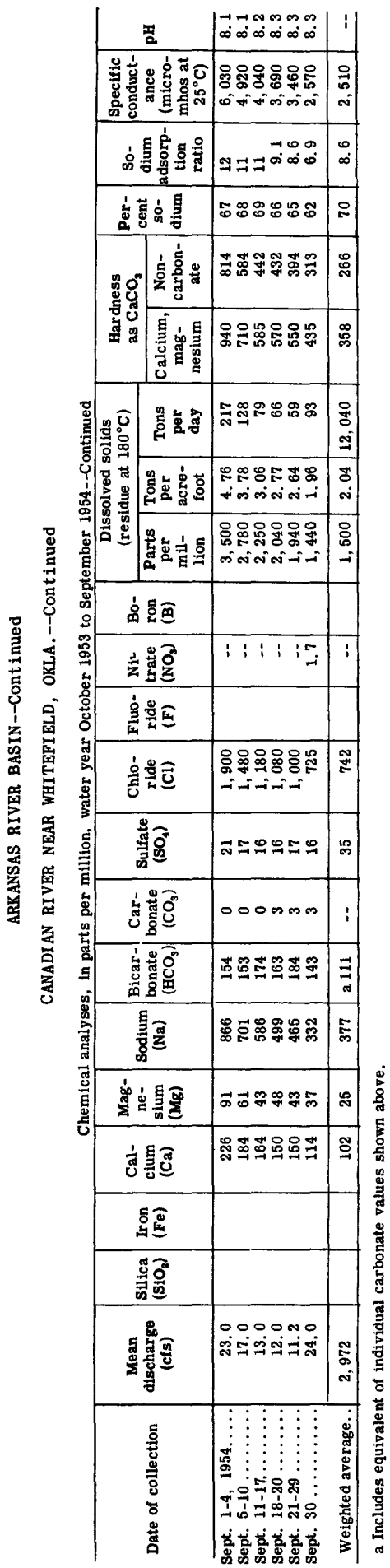


ARKANSAS RIVER BASIN--Cont inued

CANADIAN RIVER NEAR WHITEFIELD, OKLA,--Cont inued

Temperature $\left({ }^{\circ} \mathrm{F}\right)$ of water, water year October 1953 to September 1954

\begin{tabular}{|c|c|c|c|c|c|c|c|c|c|c|c|c|}
\hline Day & Oct. & Nov. & Dec. & Jan. & Feb. & Mar. & Apr. & May & June & July & Aug. & Sept. \\
\hline $\begin{array}{l}1 \\
2 \\
3 \\
4 \\
5\end{array}$ & $\begin{array}{l}70 \\
72 \\
75 \\
70 \\
64\end{array}$ & $\begin{array}{l}55 \\
55 \\
55 \\
60 \\
50\end{array}$ & $\begin{array}{l}45 \\
55 \\
54 \\
47 \\
50\end{array}$ & $\begin{array}{l}40 \\
48 \\
39 \\
45 \\
42\end{array}$ & $\begin{array}{l}44 \\
45 \\
46 \\
46 \\
45\end{array}$ & $\begin{array}{l}43 \\
46 \\
36 \\
37 \\
41\end{array}$ & $\begin{array}{l}46 \\
50 \\
57 \\
65 \\
67\end{array}$ & $\begin{array}{l}65 \\
66 \\
56 \\
57 \\
59\end{array}$ & $\begin{array}{l}71 \\
72 \\
67 \\
65 \\
70\end{array}$ & $\begin{array}{l}77 \\
82 \\
83 \\
82 \\
82\end{array}$ & $\begin{array}{l}78 \\
77 \\
78 \\
80 \\
78\end{array}$ & $\begin{array}{l}72 \\
71 \\
71 \\
76 \\
77\end{array}$ \\
\hline $\begin{array}{r}6 \\
7 \\
8 \\
9 \\
10\end{array}$ & $\begin{array}{l}60 \\
56 \\
58 \\
59 \\
61\end{array}$ & $\begin{array}{l}46 \\
45 \\
45 \\
42 \\
43\end{array}$ & $\begin{array}{l}46 \\
45 \\
48 \\
44 \\
40\end{array}$ & $\begin{array}{l}40 \\
41 \\
50 \\
52 \\
39\end{array}$ & $\begin{array}{l}47 \\
40 \\
40 \\
46 \\
47\end{array}$ & $\begin{array}{l}40 \\
46 \\
48 \\
47 \\
54\end{array}$ & $\begin{array}{l}67 \\
68 \\
60 \\
58 \\
64\end{array}$ & $\begin{array}{l}61 \\
63 \\
60 \\
60 \\
58\end{array}$ & $\begin{array}{l}70 \\
74 \\
70 \\
76 \\
75\end{array}$ & $\begin{array}{l}80 \\
80 \\
81 \\
82 \\
81\end{array}$ & $\begin{array}{l}78 \\
80 \\
80 \\
77 \\
76\end{array}$ & $\begin{array}{l}74 \\
72 \\
75 \\
74 \\
72\end{array}$ \\
\hline $\begin{array}{l}11 \\
12 \\
13 \\
14 \\
15\end{array}$ & $\begin{array}{l}62 \\
64 \\
64 \\
66 \\
65\end{array}$ & $\begin{array}{l}45 \\
47 \\
48 \\
49 \\
50\end{array}$ & $\begin{array}{l}45 \\
43 \\
39 \\
39 \\
39\end{array}$ & $\begin{array}{l}33 \\
33 \\
33 \\
35 \\
40\end{array}$ & $\begin{array}{l}47 \\
41 \\
44 \\
55 \\
60\end{array}$ & $\begin{array}{l}58 \\
64 \\
46 \\
38 \\
38\end{array}$ & $\begin{array}{l}68 \\
61 \\
54 \\
64 \\
69\end{array}$ & $\begin{array}{l}58 \\
58 \\
58 \\
60 \\
62\end{array}$ & $\begin{array}{l}76 \\
76 \\
75 \\
76 \\
77\end{array}$ & $\begin{array}{l}81 \\
83 \\
86 \\
86 \\
84\end{array}$ & $\begin{array}{l}78 \\
77 \\
75 \\
78 \\
78\end{array}$ & $\begin{array}{l}63 \\
60 \\
60 \\
67 \\
71\end{array}$ \\
\hline $\begin{array}{l}16 \\
17 \\
18 \\
19 \\
20\end{array}$ & $\begin{array}{l}66 \\
65 \\
63 \\
65 \\
63\end{array}$ & $\begin{array}{l}50 \\
54 \\
60 \\
63 \\
50\end{array}$ & $\begin{array}{l}40 \\
40 \\
35 \\
41 \\
45\end{array}$ & $\begin{array}{l}39 \\
35 \\
38 \\
47 \\
59\end{array}$ & $\begin{array}{l}55 \\
49 \\
48 \\
55 \\
48\end{array}$ & $\begin{array}{l}43 \\
48 \\
52 \\
50 \\
50\end{array}$ & $\begin{array}{l}58 \\
57 \\
62 \\
63 \\
66\end{array}$ & $\begin{array}{l}65 \\
67 \\
66 \\
67 \\
64\end{array}$ & $\begin{array}{l}76 \\
80 \\
80 \\
80 \\
82\end{array}$ & $\begin{array}{l}82 \\
83 \\
85 \\
82 \\
79\end{array}$ & $\begin{array}{l}79 \\
79 \\
78 \\
78 \\
76\end{array}$ & $\begin{array}{l}70 \\
73 \\
76 \\
76 \\
76\end{array}$ \\
\hline $\begin{array}{l}21 \\
22 \\
23 \\
24 \\
25\end{array}$ & $\begin{array}{l}65 \\
67 \\
65 \\
59 \\
59\end{array}$ & $\begin{array}{l}46 \\
46 \\
46 \\
48 \\
45\end{array}$ & $\begin{array}{l}50 \\
37 \\
34 \\
33 \\
33\end{array}$ & $\begin{array}{l}35 \\
33 \\
37 \\
42 \\
50\end{array}$ & $\begin{array}{l}48 \\
38 \\
50 \\
47 \\
53\end{array}$ & $\begin{array}{l}48 \\
50 \\
55 \\
55 \\
56\end{array}$ & $\begin{array}{l}67 \\
67 \\
64 \\
67 \\
70\end{array}$ & $\begin{array}{l}65 \\
66 \\
67 \\
70 \\
70\end{array}$ & $\begin{array}{l}81 \\
82 \\
85 \\
84 \\
84\end{array}$ & $\begin{array}{l}80 \\
80 \\
-- \\
80 \\
80\end{array}$ & $\begin{array}{l}76 \\
77 \\
76 \\
76 \\
76\end{array}$ & $\begin{array}{l}67 \\
57 \\
59 \\
61 \\
--\end{array}$ \\
\hline $\begin{array}{l}26 \\
27 \\
28 \\
29 \\
30 \\
31\end{array}$ & $\begin{array}{l}60 \\
53 \\
54 \\
53 \\
54 \\
54 \\
\end{array}$ & $\begin{array}{l}41 \\
45 \\
44 \\
43 \\
44 \\
-- \\
\end{array}$ & $\begin{array}{l}33 \\
40 \\
37 \\
35 \\
33 \\
35 \\
\end{array}$ & $\begin{array}{l}48 \\
37 \\
40 \\
43 \\
45 \\
44\end{array}$ & $\begin{array}{l}32 \\
55 \\
44 \\
-- \\
-- \\
--\end{array}$ & $\begin{array}{l}56 \\
53 \\
60 \\
63 \\
50 \\
46 \\
\end{array}$ & $\begin{array}{l}70 \\
71 \\
69 \\
68 \\
70 \\
--\end{array}$ & $\begin{array}{l}71 \\
72 \\
72 \\
73 \\
74 \\
75 \\
\end{array}$ & $\begin{array}{l}83 \\
83 \\
83 \\
84 \\
80 \\
-- \\
\end{array}$ & $\begin{array}{l}80 \\
79 \\
79 \\
80 \\
78 \\
78 \\
\end{array}$ & $\begin{array}{l}77 \\
78 \\
80 \\
77 \\
78 \\
76 \\
\end{array}$ & $\begin{array}{l}67 \\
68 \\
72 \\
78 \\
75 \\
--\end{array}$ \\
\hline $\begin{array}{c}\text { Aver- } \\
\text { age }\end{array}$ & 62 & 49 & 41 & 41 & 47 & 49 & 64 & 65 & 77 & 81 & 78 & 70 \\
\hline
\end{tabular}




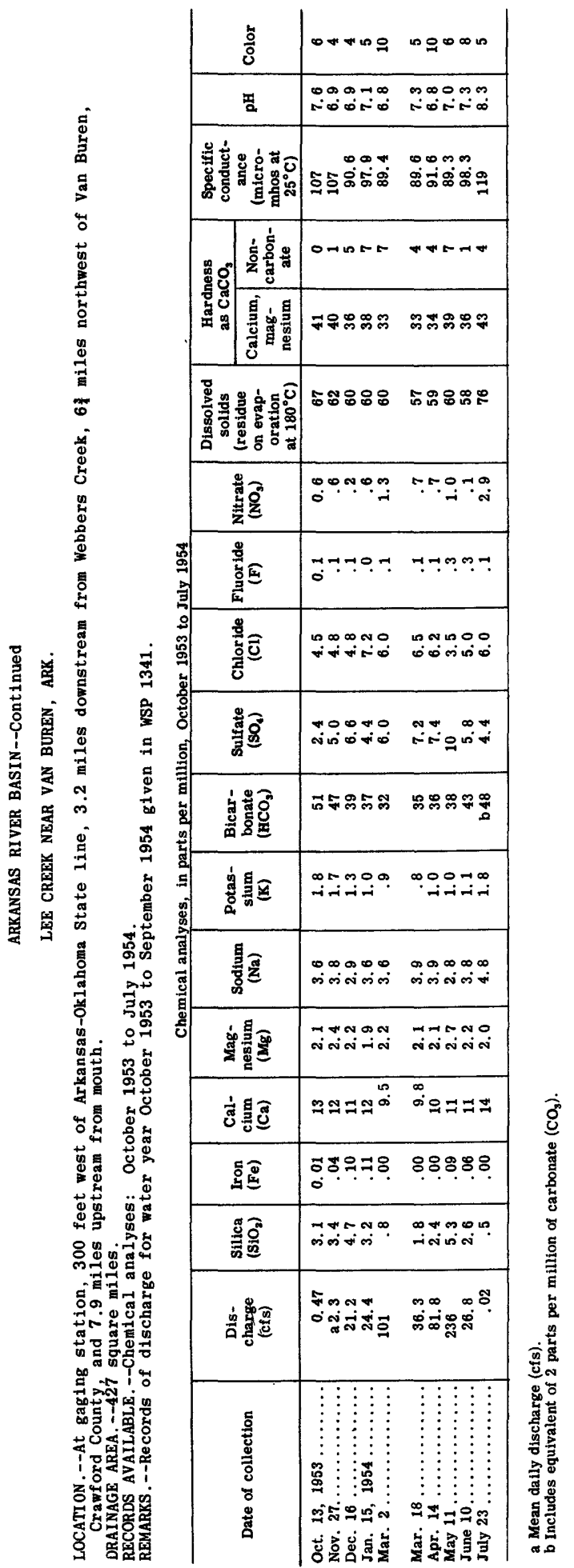




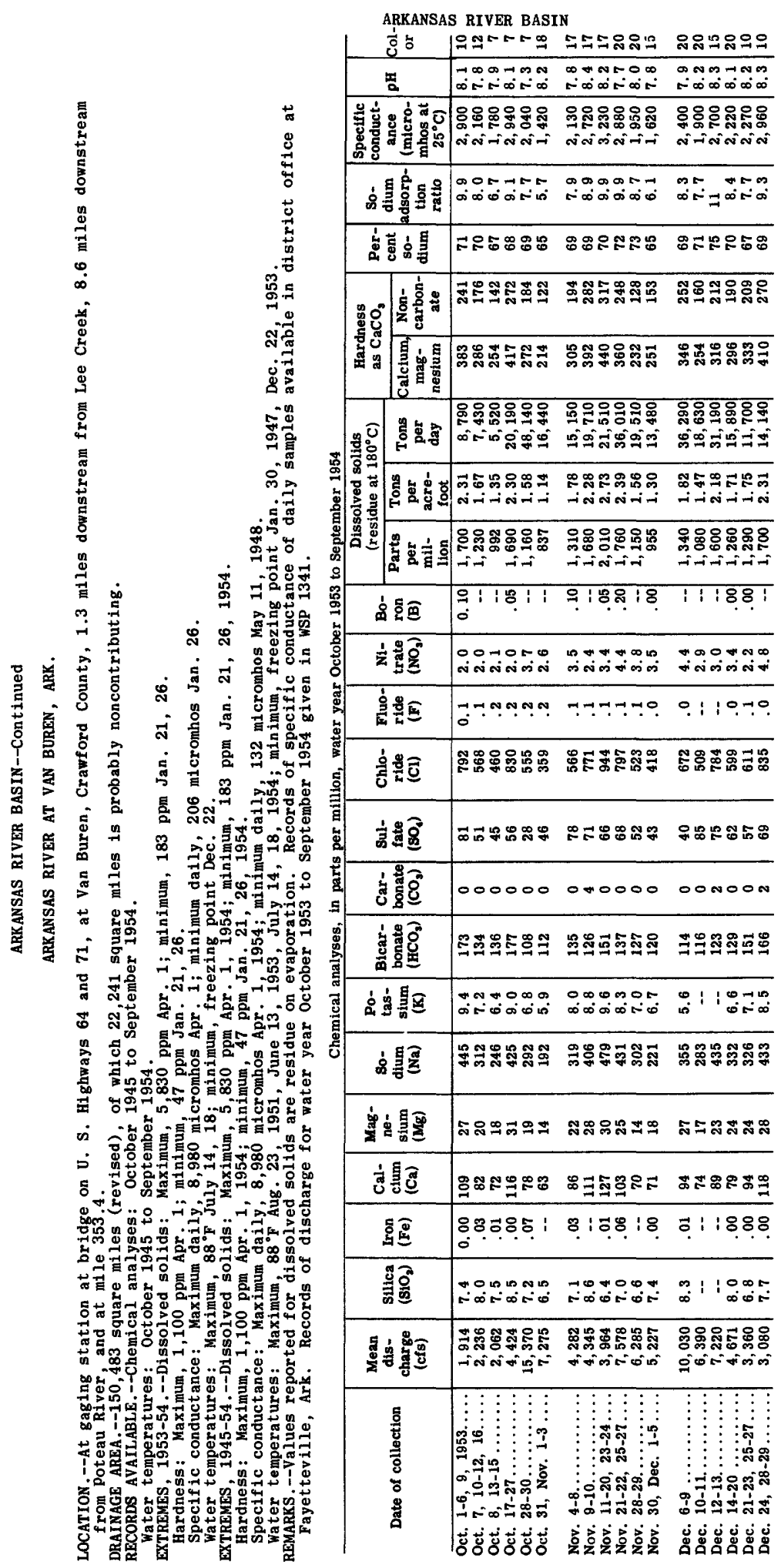


LOWER MISSISSIPPI RIVER BASIN

\begin{tabular}{|c|c|c|c|c|c|c|}
\hline 完务 & 900ڤ & 89 & & $0 \infty$ & $\infty$ 舟 & \\
\hline 평 & 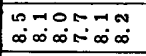 & 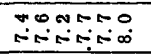 & 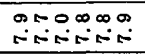 & 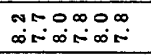 & 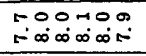 & 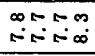 \\
\hline 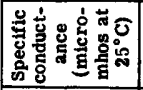 & 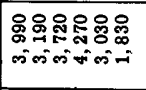 & 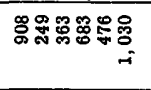 & 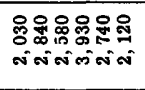 & 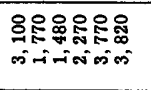 & 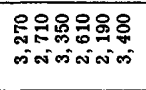 & 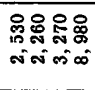 \\
\hline 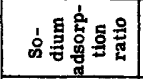 & 조워 & 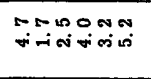 & $\infty \infty_{\infty}^{\infty} \underset{\infty}{\infty}$ & 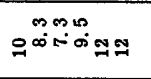 & $\approx \sigma^{\infty}=\ddot{0}=$ & 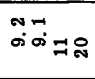 \\
\hline 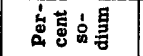 & จะลงจะะ & 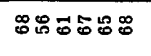 & 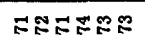 & 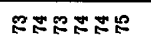 & ゙ㅠㅇㅛ & 옹ำ \\
\hline 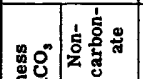 & 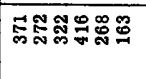 & 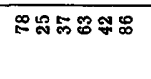 & 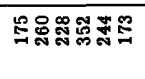 & 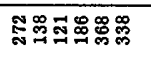 & 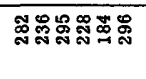 & 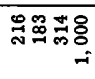 \\
\hline 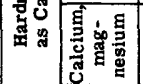 & 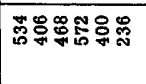 & 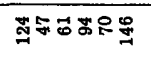 & 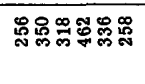 & 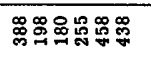 & 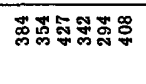 & 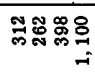 \\
\hline 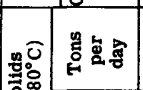 & 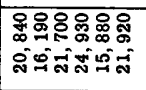 & 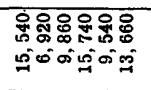 & 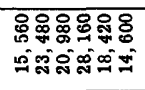 & 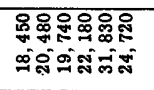 & 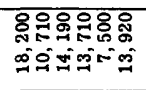 & 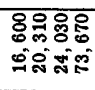 \\
\hline 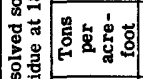 & 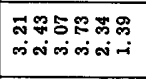 & 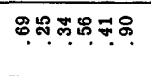 & 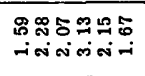 & 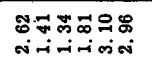 & 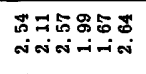 & 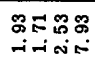 \\
\hline 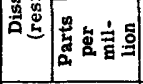 & 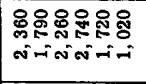 & 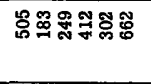 & 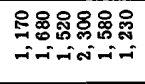 & 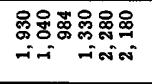 & 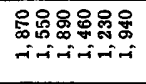 & 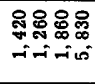 \\
\hline 㝘总鱼 & $\begin{array}{r}18: 18: \\
0\end{array}$ & : : : & 1: $1: 19 !$ & : : : : : : : & 881480 & $8: 1:$ \\
\hline 芸农泀 & 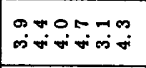 & 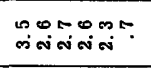 & $\begin{array}{l}\text { Nondrod } \\
\text { rifi-i }\end{array}$ & 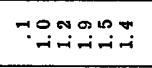 & 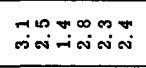 & 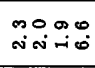 \\
\hline 高要国 & : & : $: 1: 1: 1: 1:$ & $\because \because ロ: \because:$ & $1 \because: \because: 1$ & $\because \because: \because \because$ & $\because: 1: 1:$ \\
\hline 형흄흐 & 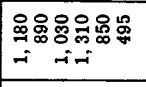 & & 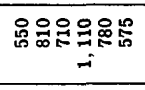 & 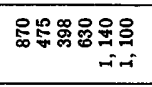 & 영역영옹용요 & 옹웅형용 \\
\hline 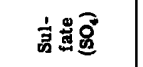 & పేஃ̊ఃః & 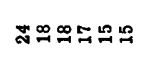 & 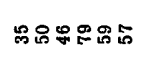 & ஃ5ஃั & $\mathscr{2}$ & 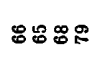 \\
\hline 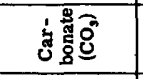 & 0000000 & 000000 & 000000 & 000000 & 000000 & $000 \mathrm{~m}$ \\
\hline 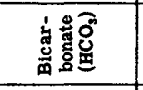 & 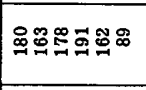 & 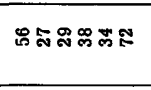 & 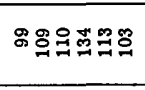 & 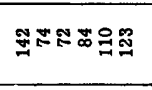 & 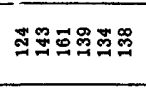 & 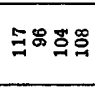 \\
\hline 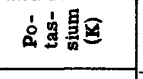 & 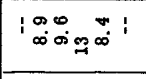 & i: & 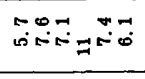 & 151001 & 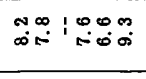 & $\stackrel{N}{\approx}: 111$ \\
\hline ่ं & 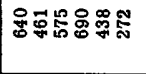 & 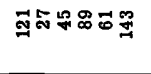 & 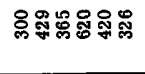 & 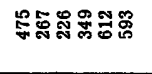 & 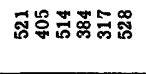 & 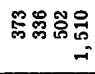 \\
\hline 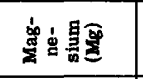 & 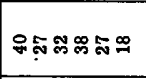 & 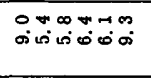 & 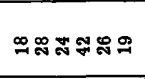 & ஜீエのの゚ & 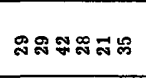 & ニ \\
\hline 远旡可 & 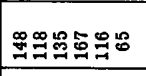 & 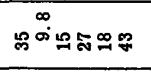 & 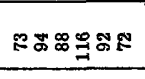 & 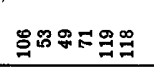 & 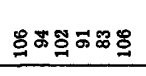 & ธธす్తి \\
\hline ธ્ક์ & : $08 \% 50$ & $1:$ : & 088878 & $: 0$ & 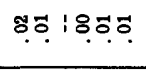 & $8: 1:$ \\
\hline 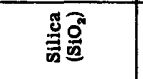 & $\mid \begin{array}{l}\infty \\
\mid\end{array}$ & : : : $1:$ : $: 1$ & 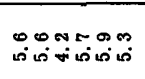 & $\mid \begin{array}{l}\infty \\
\text { in } \\
\text { in }\end{array}$ & 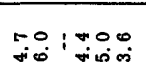 & $\stackrel{0}{\circ}: 1: 1$ \\
\hline 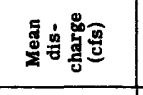 & 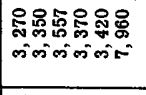 & 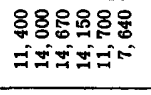 & 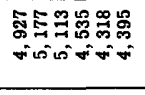 & 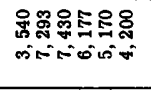 & 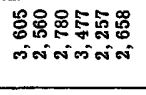 & 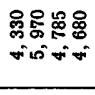 \\
\hline 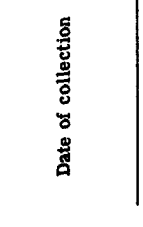 & 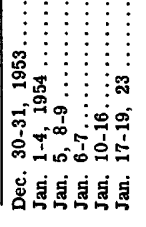 & 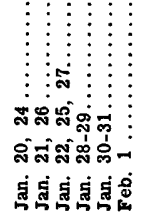 & 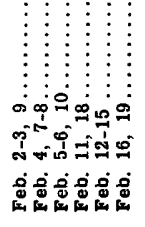 & 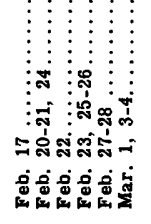 & 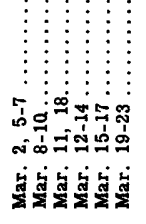 & 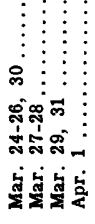 \\
\hline
\end{tabular}




\begin{tabular}{|c|c|c|c|c|c|}
\hline 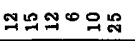 & 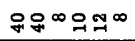 & 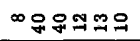 & ○コゴ9유 & Nogun in & 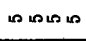 \\
\hline 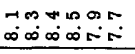 & 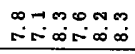 & 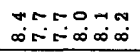 & $\begin{array}{l}\Rightarrow \rightarrow 0 \\
\infty \infty \infty \infty\end{array}$ & 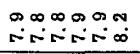 & $\begin{array}{c}\infty \rightarrow \infty \rightarrow \infty \\
\infty \rightarrow \infty \infty \infty \\
\infty+\infty\end{array}$ \\
\hline 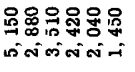 & 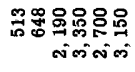 & 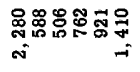 & 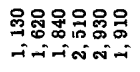 & 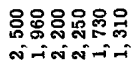 & 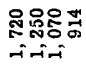 \\
\hline 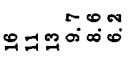 & $\begin{array}{l}0 \infty \\
m+\infty \\
\infty\end{array}$ & 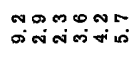 & $\stackrel{\sim}{\sim}$ & 它 & $\begin{array}{l}\text { F⿻m } \\
\text { rivition }\end{array}$ \\
\hline パ゙゚ボ゚゚ & ภ゚ミ゙ッฐッ & 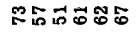 & ธロロ오용 & ゚ホミボミ゚ & న ஜ8: \\
\hline 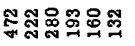 & 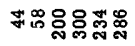 & 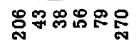 & 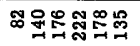 & 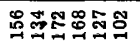 & gq \\
\hline
\end{tabular}

\begin{tabular}{|c|c|c|c|c|c|}
\hline 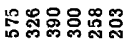 & 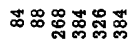 & 怘 & 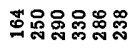 & 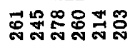 & 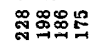 \\
\hline 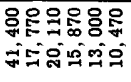 & 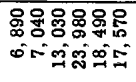 & 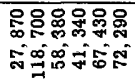 & 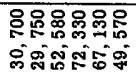 & 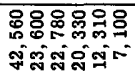 & 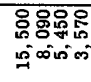 \\
\hline 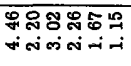 & 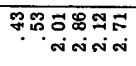 & 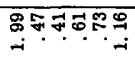 & 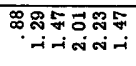 & $\begin{array}{l}\text { कश्ष } \\
\text { iनi-i }\end{array}$ & 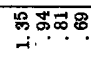 \\
\hline 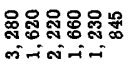 & 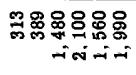 & 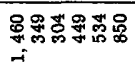 & 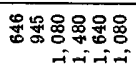 & 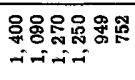 & 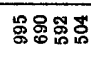 \\
\hline 8 & $1: 1$ & $1:$ & $1:$ & $8: 11$ & $18:$ \\
\hline 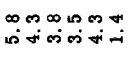 & 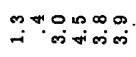 & 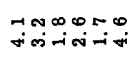 & 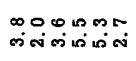 & 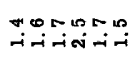 & $\stackrel{\infty}{\infty}$ \\
\hline ?ח: & i & : & $\because \because$ & $\because:$ & : \\
\hline 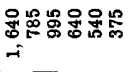 & 콩ㅇㅀㅇ요용으. & 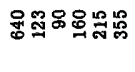 & 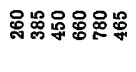 & 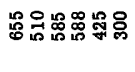 & బొఖ్జ \\
\hline 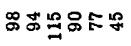 & 유묘ㅇㅛㅛ & 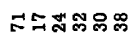 & 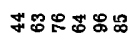 & ஐミ゙ஐロ & ๓๕ฐี \\
\hline 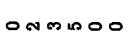 & 00 NOOH & N00000 & 000000 & 000 & \\
\hline శ్త్సిత్తి & 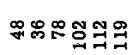 & 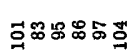 & 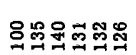 & 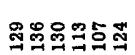 & d \\
\hline
\end{tabular}

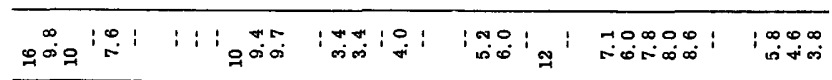

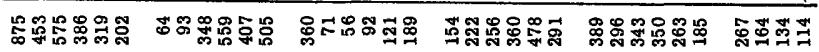

\begin{tabular}{|c|c|c|c|c|c|}
\hline 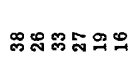 & 유デ & 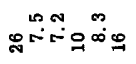 & 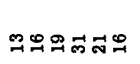 & 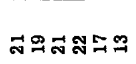 & $\stackrel{9}{9}$ \\
\hline 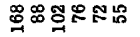 & こニ昂号品 & 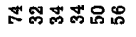 & オ゙ボゅのஃ & ค๖ミロ & ํํำ吕员 \\
\hline 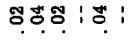 & 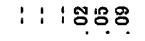 & $\pi$ & & & \\
\hline
\end{tabular}

\begin{tabular}{|c|c|c|c|c|c|}
\hline $\begin{array}{ll}\operatorname{lom}: \infty \\
\sin :\end{array}$ & : : : : : & 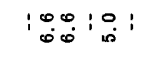 & : & 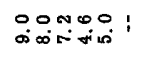 & 10.0 \\
\hline 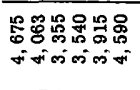 & 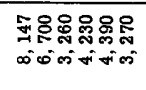 & 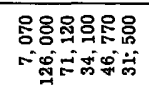 & 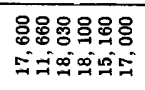 & 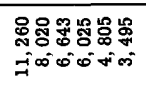 & 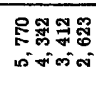 \\
\hline 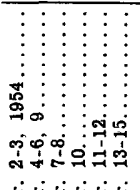 & 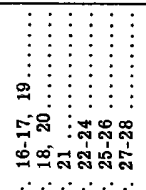 & 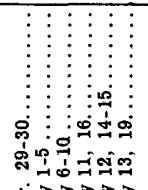 & 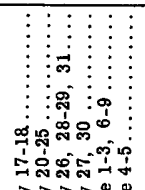 & 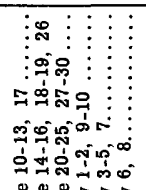 & 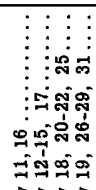 \\
\hline & $\therefore$ & 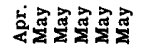 & $\Leftrightarrow \Rightarrow$ & 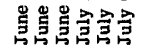 & 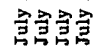 \\
\hline
\end{tabular}




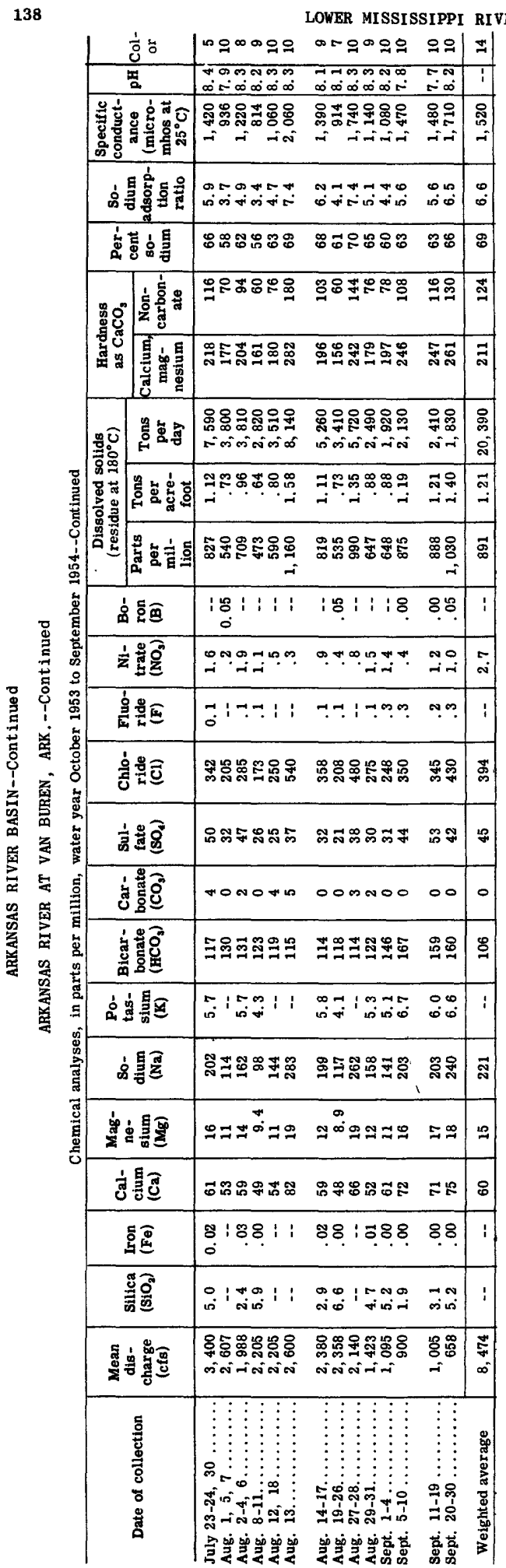


ARKANSAS RIVER BASIN--Cont inued

ARKANSAS RIVER AT VAN BUREN, ARK.--Continued

Temperature $\left({ }^{\circ} \mathrm{F}\right)$ of water, water year October 1953 to September 1954

\begin{tabular}{|c|c|c|c|c|c|c|c|c|c|c|c|c|}
\hline Day & Oct. & Nov. & Dec. & Jan. & Feb. & Mar. & Apr. & May & June & July & Aug. & Sept. \\
\hline $\begin{array}{l}1 \\
2 \\
3 \\
4 \\
5\end{array}$ & $\begin{array}{l}73 \\
73 \\
76 \\
74 \\
72\end{array}$ & $\begin{array}{l}55 \\
56 \\
56 \\
60 \\
55\end{array}$ & $\begin{array}{l}46 \\
51 \\
52 \\
47 \\
49\end{array}$ & $\begin{array}{l}39 \\
42 \\
41 \\
41 \\
43\end{array}$ & $\begin{array}{l}43 \\
44 \\
46 \\
45 \\
45\end{array}$ & $\begin{array}{l}44 \\
47 \\
39 \\
46 \\
44\end{array}$ & $\begin{array}{l}50 \\
52 \\
56 \\
60 \\
65\end{array}$ & $\begin{array}{l}68 \\
67 \\
57 \\
60 \\
61\end{array}$ & $\begin{array}{l}74 \\
72 \\
67 \\
67 \\
69\end{array}$ & $\begin{array}{l}82 \\
83 \\
83 \\
85 \\
85\end{array}$ & $\begin{array}{l}81 \\
76 \\
81 \\
83 \\
84\end{array}$ & $\begin{array}{l}76 \\
76 \\
78 \\
79 \\
79\end{array}$ \\
\hline $\begin{array}{r}6 \\
7 \\
8 \\
9 \\
10\end{array}$ & $\begin{array}{l}65 \\
62 \\
61 \\
64 \\
63\end{array}$ & $\begin{array}{l}48 \\
47 \\
48 \\
43 \\
45\end{array}$ & $\begin{array}{l}46 \\
46 \\
47 \\
45 \\
41\end{array}$ & $\begin{array}{l}42 \\
42 \\
45 \\
41 \\
41\end{array}$ & $\begin{array}{l}47 \\
43 \\
47 \\
45 \\
48\end{array}$ & $\begin{array}{l}47 \\
45 \\
48 \\
49 \\
54\end{array}$ & $\begin{array}{l}68 \\
70 \\
65 \\
61 \\
65\end{array}$ & $\begin{array}{l}63 \\
63 \\
63 \\
63 \\
61\end{array}$ & $\begin{array}{l}71 \\
75 \\
73 \\
78 \\
78\end{array}$ & $\begin{array}{l}83 \\
82 \\
84 \\
-- \\
82\end{array}$ & $\begin{array}{l}83 \\
81 \\
83 \\
81 \\
81\end{array}$ & $\begin{array}{l}80 \\
78 \\
79 \\
79 \\
76\end{array}$ \\
\hline $\begin{array}{l}11 \\
12 \\
13 \\
14 \\
15\end{array}$ & $\begin{array}{l}65 \\
65 \\
65 \\
66 \\
67\end{array}$ & $\begin{array}{l}46 \\
48 \\
48 \\
50 \\
50\end{array}$ & $\begin{array}{l}44 \\
44 \\
42 \\
42 \\
39\end{array}$ & $\begin{array}{l}35 \\
35 \\
34 \\
34 \\
38\end{array}$ & $\begin{array}{l}48 \\
43 \\
44 \\
52 \\
56\end{array}$ & $\begin{array}{l}57 \\
61 \\
50 \\
44 \\
46\end{array}$ & $\begin{array}{l}66 \\
62 \\
61 \\
64 \\
69\end{array}$ & $\begin{array}{l}62 \\
61 \\
60 \\
62 \\
64\end{array}$ & $\begin{array}{l}79 \\
79 \\
79 \\
79 \\
80\end{array}$ & $\begin{array}{l}81 \\
82 \\
87 \\
88 \\
86\end{array}$ & $\begin{array}{l}82 \\
82 \\
81 \\
80 \\
82\end{array}$ & $\begin{array}{l}73 \\
74 \\
71 \\
73 \\
75\end{array}$ \\
\hline $\begin{array}{l}16 \\
17 \\
18 \\
19 \\
20\end{array}$ & $\begin{array}{l}67 \\
66 \\
67 \\
68 \\
66\end{array}$ & $\begin{array}{l}51 \\
53 \\
57 \\
59 \\
54\end{array}$ & $\begin{array}{l}40 \\
39 \\
37 \\
41 \\
43\end{array}$ & $\begin{array}{l}37 \\
39 \\
35 \\
41 \\
49\end{array}$ & $\begin{array}{l}53 \\
49 \\
51 \\
53 \\
48\end{array}$ & $\begin{array}{l}48 \\
48 \\
52 \\
51 \\
52\end{array}$ & $\begin{array}{l}61 \\
61 \\
64 \\
65 \\
66\end{array}$ & $\begin{array}{l}66 \\
68 \\
70 \\
70 \\
68\end{array}$ & $\begin{array}{l}78 \\
80 \\
81 \\
82 \\
82\end{array}$ & $\begin{array}{l}85 \\
86 \\
88 \\
84 \\
81\end{array}$ & $\begin{array}{l}83 \\
83 \\
84 \\
83 \\
81\end{array}$ & $\begin{array}{l}76 \\
77 \\
78 \\
81 \\
82\end{array}$ \\
\hline $\begin{array}{l}21 \\
22 \\
23 \\
24 \\
25\end{array}$ & $\begin{array}{l}67 \\
68 \\
68 \\
66 \\
62\end{array}$ & $\begin{array}{l}50 \\
48 \\
45 \\
48 \\
45\end{array}$ & $\begin{array}{l}47 \\
32 \\
33 \\
33 \\
34\end{array}$ & $\begin{array}{l}43 \\
36 \\
41 \\
38 \\
44\end{array}$ & $\begin{array}{l}46 \\
46 \\
51 \\
48 \\
51\end{array}$ & $\begin{array}{l}\mathbf{5 1} \\
\mathbf{5 0} \\
\mathbf{5 2} \\
\mathbf{5 2} \\
\mathbf{5 3}\end{array}$ & $\begin{array}{l}68 \\
70 \\
68 \\
69 \\
71\end{array}$ & $\begin{array}{l}66 \\
69 \\
71 \\
72 \\
72\end{array}$ & $\begin{array}{l}82 \\
83 \\
86 \\
83 \\
85\end{array}$ & $\begin{array}{l}85 \\
84 \\
84 \\
84 \\
81\end{array}$ & $\begin{array}{l}80 \\
80 \\
80 \\
80 \\
82\end{array}$ & $\begin{array}{l}75 \\
65 \\
69 \\
73 \\
69\end{array}$ \\
\hline $\begin{array}{l}26 \\
27 \\
28 \\
29 \\
30 \\
31\end{array}$ & $\begin{array}{l}62 \\
57 \\
56 \\
54 \\
54 \\
55\end{array}$ & $\begin{array}{l}44 \\
46 \\
45 \\
45 \\
45 \\
--\end{array}$ & $\begin{array}{l}\mathbf{3 6} \\
\mathbf{3 8} \\
\mathbf{3 9} \\
\mathbf{3 7} \\
\mathbf{3 8} \\
\mathbf{3 7}\end{array}$ & $\begin{array}{l}47 \\
40 \\
41 \\
42 \\
44 \\
45\end{array}$ & $\begin{array}{l}48 \\
53 \\
46 \\
-- \\
-- \\
--\end{array}$ & $\begin{array}{l}55 \\
55 \\
59 \\
61 \\
54 \\
52\end{array}$ & $\begin{array}{l}73 \\
75 \\
74 \\
70 \\
70 \\
--\end{array}$ & $\begin{array}{l}71 \\
74 \\
74 \\
73 \\
74 \\
77\end{array}$ & $\begin{array}{l}85 \\
85 \\
85 \\
86 \\
80 \\
--\end{array}$ & $\begin{array}{l}82 \\
80 \\
81 \\
-2 \\
80 \\
81\end{array}$ & $\begin{array}{l}83 \\
82 \\
84 \\
83 \\
83 \\
81\end{array}$ & $\begin{array}{l}71 \\
72 \\
74 \\
76 \\
75 \\
--\end{array}$ \\
\hline $\begin{array}{l}\text { Aver- } \\
\text { age }\end{array}$ & 65 & 50 & 41 & 40 & 48 & 51 & 65 & 67 & 79 & 83 & 82 & 75 \\
\hline
\end{tabular}




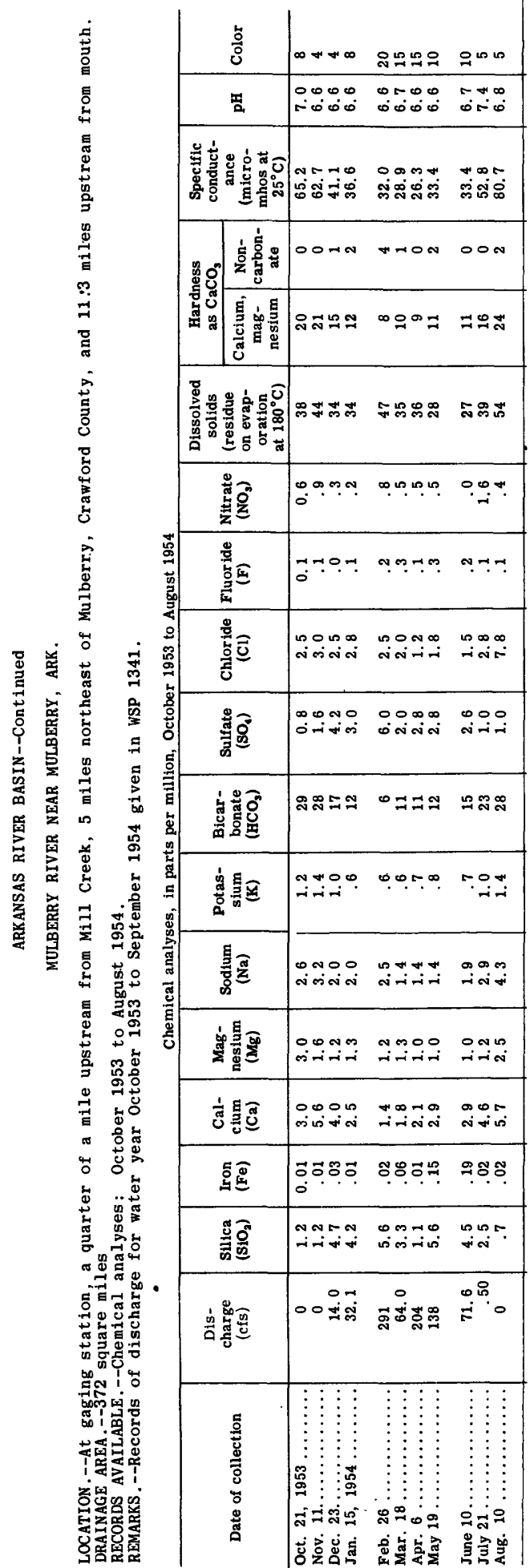




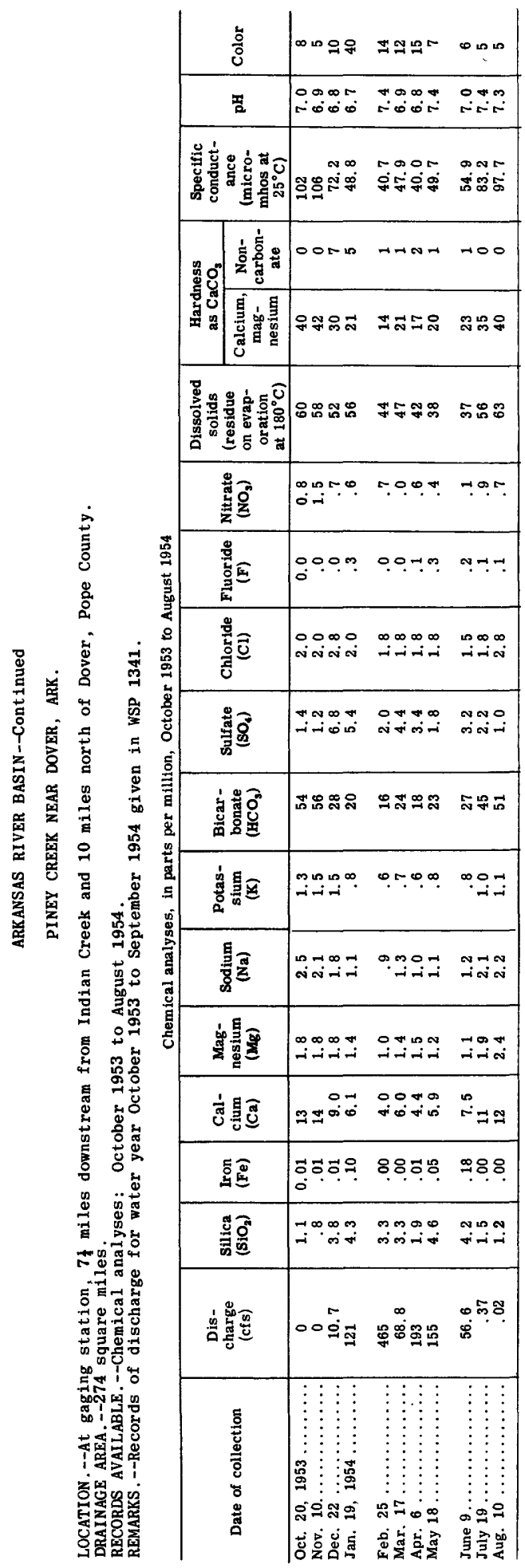




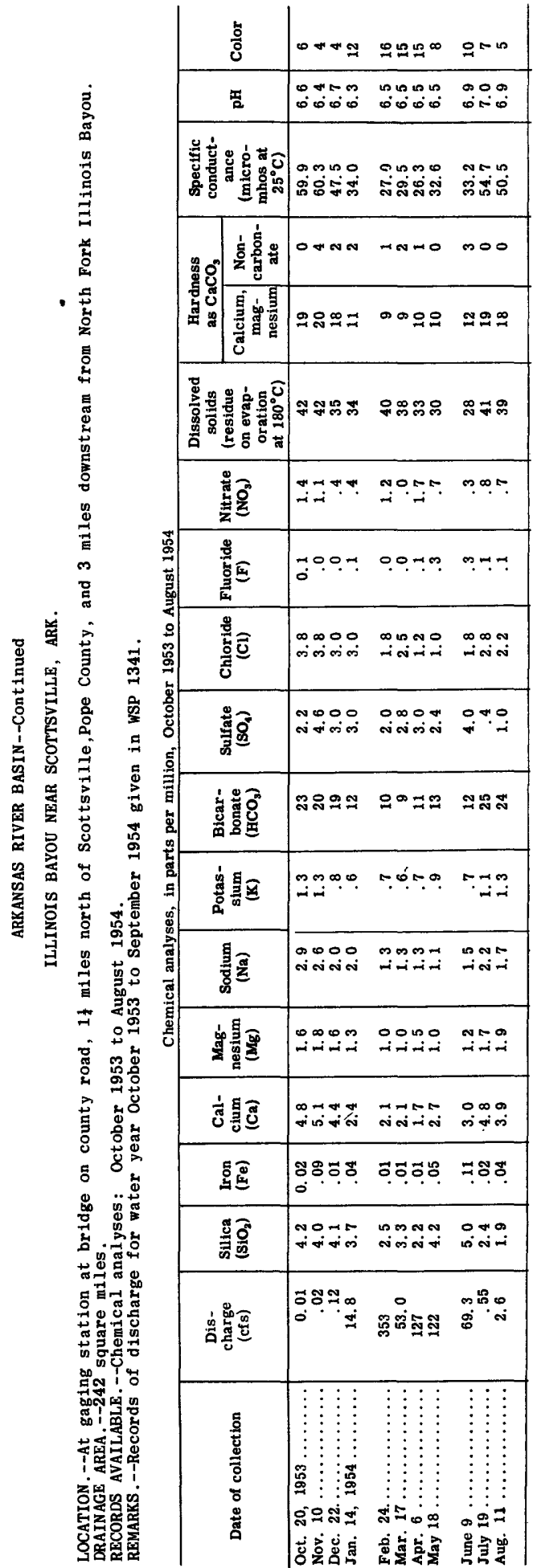




\begin{tabular}{|c|c|c|c|c|}
\hline 宫 & 요요요 & $\stackrel{-\infty}{-\infty}$ & & \\
\hline$x$ & & $=\infty \begin{array}{c}\infty \\
-\infty\end{array}$ & & $\infty$ \\
\hline 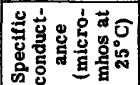 & : & की & 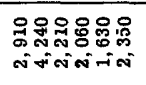 & 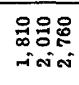 \\
\hline 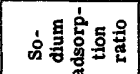 & 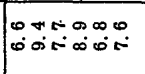 & $\infty$ & $\begin{array}{c}\infty \\
\infty \infty \infty\end{array}$ & $\therefore \div$ \\
\hline 宫莣 & テニロ:요 & : & 288 & 요도 \\
\hline 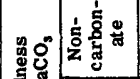 & 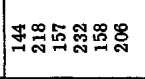 & 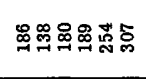 & 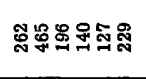 & 需: \\
\hline 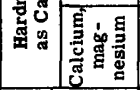 & 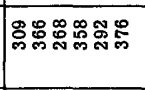 & ㅇㅠㅀㅛㅛ & 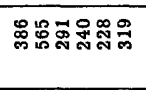 & హ్హొ ప్రి \\
\hline 言岁总 & 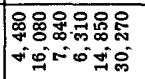 & 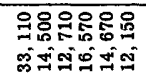 & 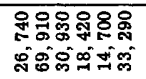 & 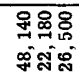 \\
\hline 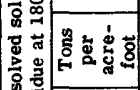 & 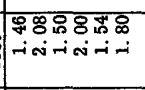 & 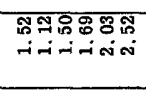 & $\begin{array}{l}\text { तुक्ष } \\
\text { ifi-i }\end{array}$ & 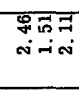 \\
\hline 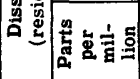 & 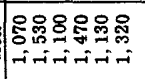 & 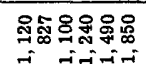 & 赵总品 & 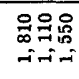 \\
\hline 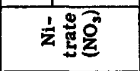 & 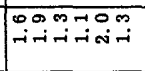 & N.M & & 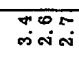 \\
\hline 产害国 & $:: 1: 0:$ & & & $1:$ \\
\hline 월휼 & 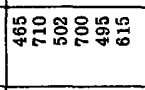 & & 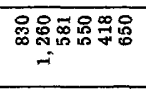 & נָ: \\
\hline 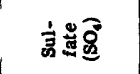 & พำ ํํㅁ & & 必思 & $7 \%$ \\
\hline 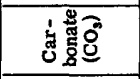 & Doo & 00 & 00 & 000 \\
\hline 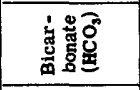 & : & F。 & 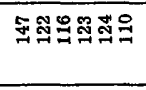 & 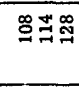 \\
\hline 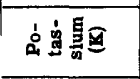 & $i$ & 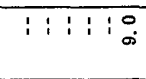 & $1: 0$ & $i$ \\
\hline ぬ & 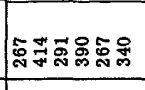 & 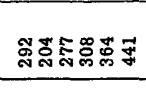 & 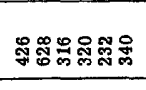 & ఫ్రా \\
\hline 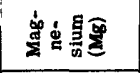 & จลล & 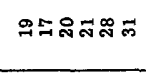 & ลデテッロ & 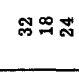 \\
\hline ฮี่ & 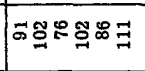 & $5 \square$ & 58 & 유ㅁㅛㅛ \\
\hline 总氮 & 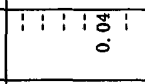 & 종 & $1: 11:=$ & 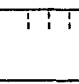 \\
\hline 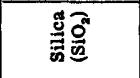 & $1: 1: 10_{\infty}^{0}:$ & 19 & $1: 1: \begin{array}{c}0 \\
0\end{array}$ & : \\
\hline 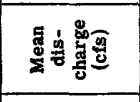 & 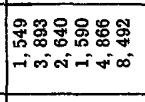 & $\begin{array}{l}\text { 용여 } \\
\text { s. }\end{array}$ & 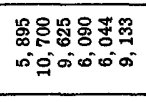 & 㾸骂器 \\
\hline 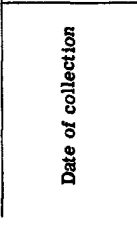 & 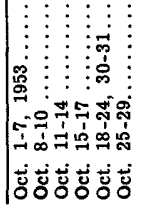 & 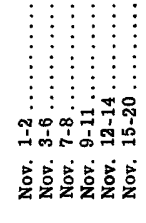 & 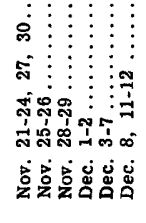 & 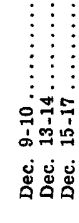 \\
\hline
\end{tabular}




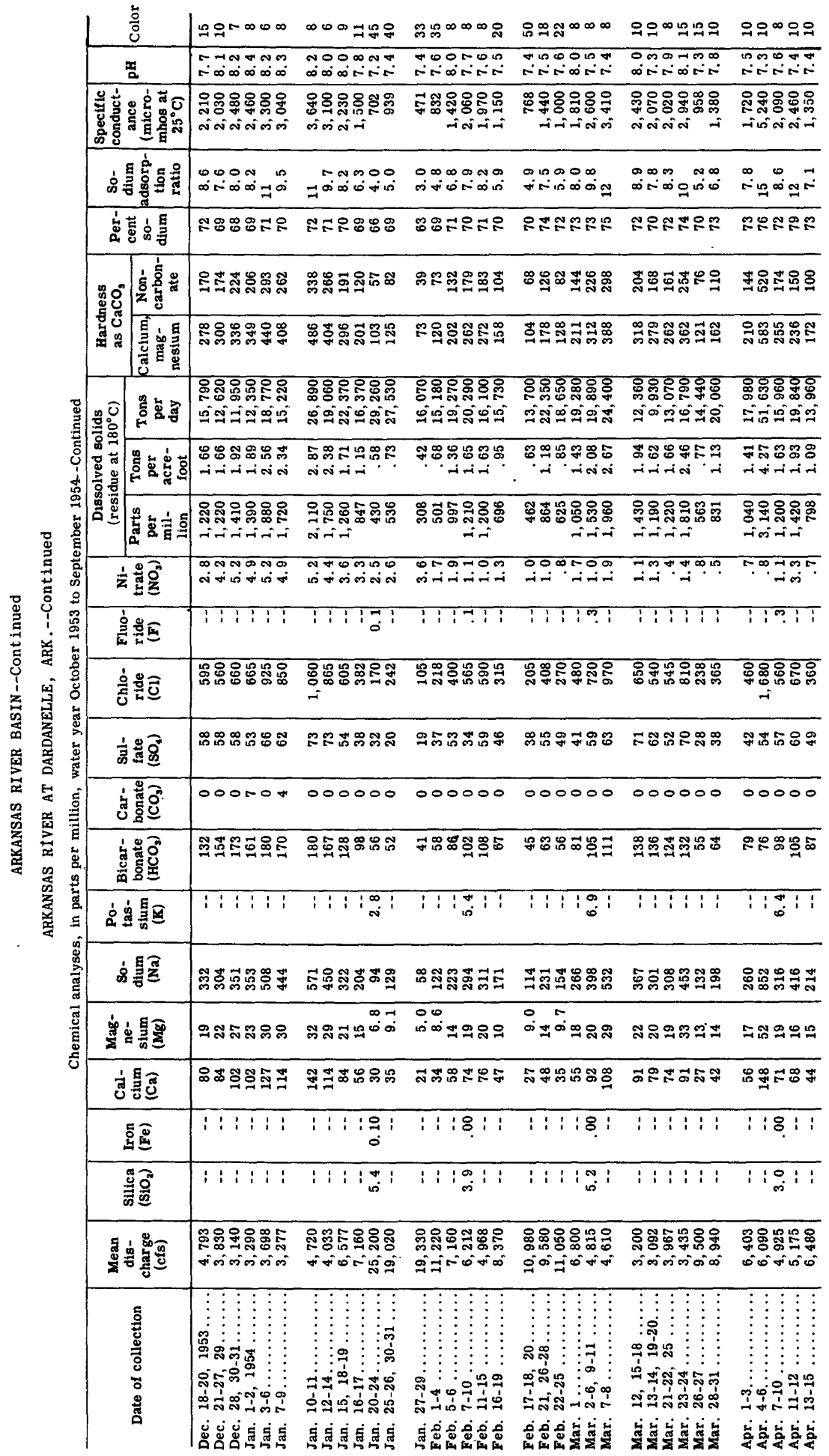




\begin{tabular}{|c|c|c|c|c|c|}
\hline 유요 & 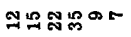 & $\infty \pi r-\infty 9$ & ORー & man & a \\
\hline 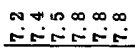 & 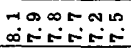 & 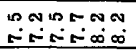 & 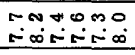 & 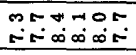 & $\begin{array}{l}00 \infty m \infty \\
\sim 2-\infty \infty \infty \\
\end{array}$ \\
\hline 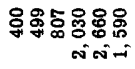 & 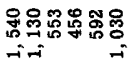 & 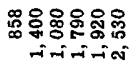 & & 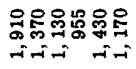 & 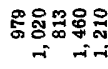 \\
\hline 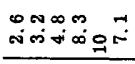 & 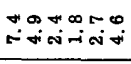 & จ & $\Rightarrow 0^{\circ}=0^{\circ}$ & 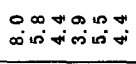 & 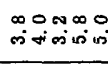 \\
\hline 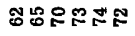 & 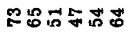 & 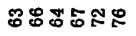 & 윰유용 & 룽요 & 눙요요요 \\
\hline ฟูษ๋ & 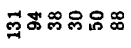 & 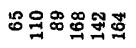 & 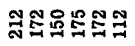 & 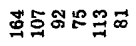 & 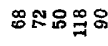 \\
\hline
\end{tabular}

:

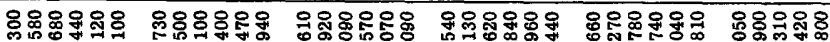

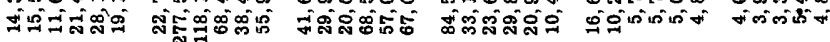

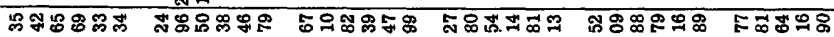

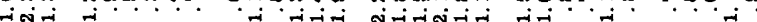

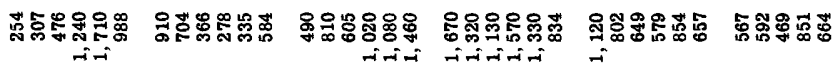

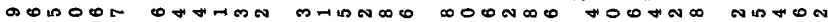

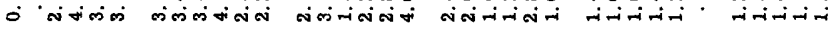

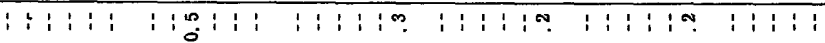

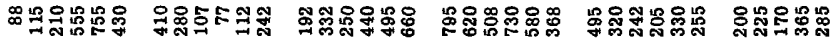

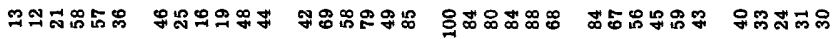

$0000000000000000000000000010000000 N 0$

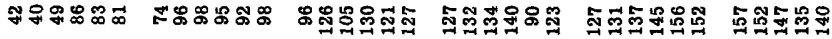

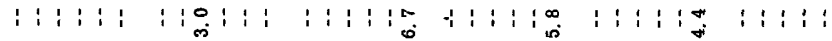

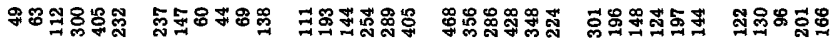

\begin{tabular}{|c|c|c|c|c|c|}
\hline 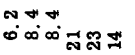 & 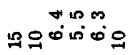 & $\stackrel{\sim}{\infty} \approx \cong 99$ & 只 & 吕 & 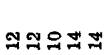 \\
\hline $\mathscr{7}$ & 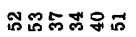 & 포ㅇㅛㅛ용요 & 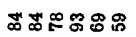 & 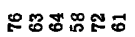 & 몽맴ㅇㅇㅇㅛ \\
\hline
\end{tabular}

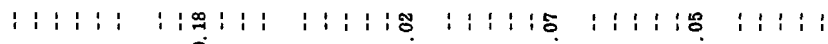
$\circ$

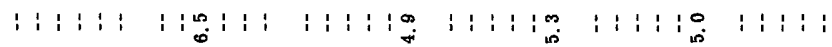

\begin{tabular}{|c|c|c|c|c|c|}
\hline 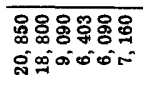 & 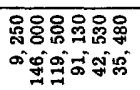 & 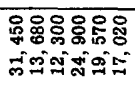 & 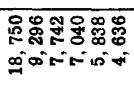 & 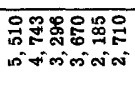 & 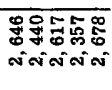 \\
\hline 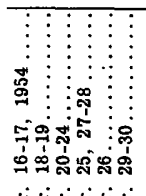 & 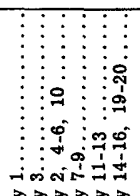 & 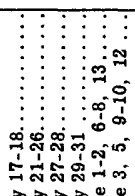 & 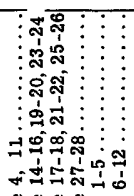 & 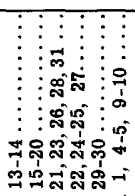 & 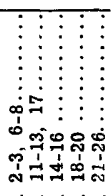 \\
\hline & 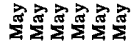 & 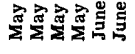 & 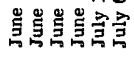 & 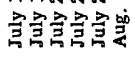 & 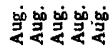 \\
\hline
\end{tabular}




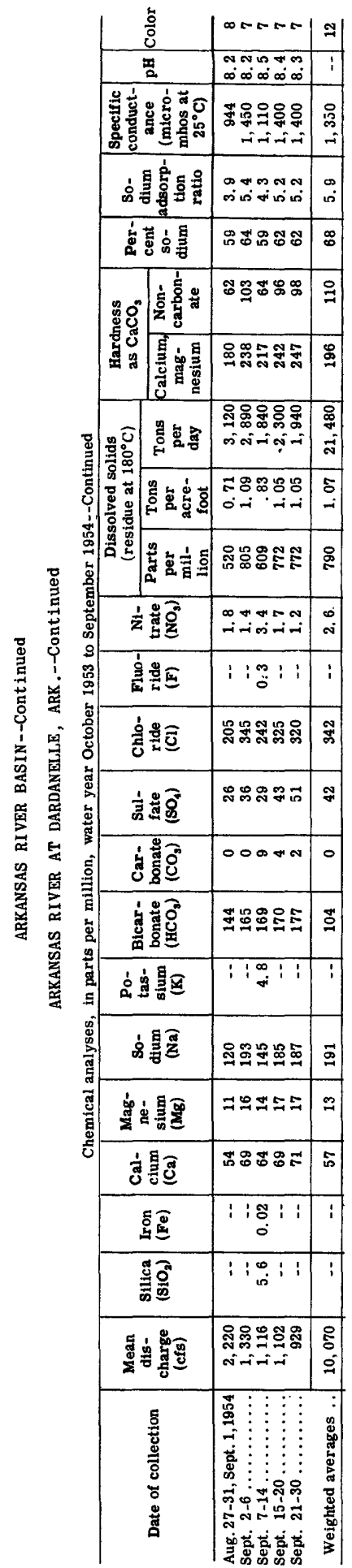


ARKANSAS RIVER BASIN--Continued

ARKANSAS RIVER AT DARDANELLE, ARK.--Continued

Temperature $\left({ }^{\circ} \mathrm{F}\right)$ of water, water year October 1953 to September 1954

\begin{tabular}{|c|c|c|c|c|c|c|c|c|c|c|c|c|}
\hline Day & Oct. & Nov. & Dec. & Jan. & Feb. & Mar. & Apr. & May & June & July & Aug. & Sept. \\
\hline $\begin{array}{l}1 \\
2\end{array}$ & $\begin{array}{l}79 \\
79\end{array}$ & $\begin{array}{l}60 \\
60\end{array}$ & $\begin{array}{l}48 \\
49\end{array}$ & $\begin{array}{l}41 \\
44\end{array}$ & $\begin{array}{l}48 \\
49\end{array}$ & $\begin{array}{l}50 \\
47\end{array}$ & $\begin{array}{l}55 \\
58\end{array}$ & $\begin{array}{l}70 \\
65\end{array}$ & $\begin{array}{l}80 \\
80\end{array}$ & $\begin{array}{l}90 \\
89\end{array}$ & $\begin{array}{l}84 \\
86\end{array}$ & $\begin{array}{l}85 \\
89\end{array}$ \\
\hline $\begin{array}{l}3 \\
4 \\
5\end{array}$ & $\begin{array}{l}78 \\
78 \\
74\end{array}$ & $\begin{array}{l}60 \\
59 \\
58\end{array}$ & $\begin{array}{l}48 \\
50 \\
50\end{array}$ & $\begin{array}{l}44 \\
43 \\
44\end{array}$ & $\begin{array}{l}50 \\
50 \\
50\end{array}$ & $\begin{array}{l}45 \\
45 \\
46\end{array}$ & $\begin{array}{l}60 \\
65 \\
68\end{array}$ & $\begin{array}{l}64 \\
63 \\
64\end{array}$ & $\begin{array}{l}75 \\
75 \\
71\end{array}$ & $\begin{array}{l}90 \\
91 \\
92\end{array}$ & $\begin{array}{l}90 \\
90 \\
92\end{array}$ & $\begin{array}{l}89 \\
86 \\
88\end{array}$ \\
\hline $\begin{array}{r}6 \\
7 \\
8 \\
9 \\
10\end{array}$ & $\begin{array}{l}70 \\
68 \\
68 \\
68 \\
69\end{array}$ & $\begin{array}{l}52 \\
49 \\
50 \\
49 \\
50\end{array}$ & $\begin{array}{l}49 \\
49 \\
48 \\
46 \\
45\end{array}$ & $\begin{array}{l}45 \\
45 \\
46 \\
47 \\
--\end{array}$ & $\begin{array}{l}48 \\
46 \\
48 \\
50 \\
51\end{array}$ & $\begin{array}{l}48 \\
50 \\
53 \\
55 \\
56\end{array}$ & $\begin{array}{l}70 \\
72 \\
70 \\
67 \\
65\end{array}$ & $\begin{array}{l}65 \\
65 \\
65 \\
66 \\
65\end{array}$ & $\begin{array}{l}77 \\
71 \\
80 \\
82 \\
84\end{array}$ & $\begin{array}{l}89 \\
90 \\
90 \\
89 \\
87\end{array}$ & $\begin{array}{l}92 \\
90 \\
87 \\
90 \\
90\end{array}$ & $\begin{array}{l}85 \\
84 \\
88 \\
85 \\
90\end{array}$ \\
\hline $\begin{array}{l}11 \\
12 \\
13 \\
14 \\
15\end{array}$ & $\begin{array}{l}70 \\
70 \\
70 \\
70 \\
71\end{array}$ & $\begin{array}{l}\mathbf{5 0} \\
50 \\
50 \\
\mathbf{5 2} \\
\mathbf{5 3}\end{array}$ & $\begin{array}{l}45 \\
46 \\
46 \\
42 \\
41\end{array}$ & $\begin{array}{l}39 \\
37 \\
35 \\
46 \\
39\end{array}$ & $\begin{array}{l}51 \\
48 \\
47 \\
50 \\
55\end{array}$ & $\begin{array}{l}59 \\
62 \\
54 \\
50 \\
51\end{array}$ & $\begin{array}{l}66 \\
64 \\
64 \\
68 \\
68\end{array}$ & $\begin{array}{l}64 \\
63 \\
65 \\
66 \\
68\end{array}$ & $\begin{array}{l}85 \\
87 \\
86 \\
87 \\
84\end{array}$ & $\begin{array}{l}88 \\
90 \\
92 \\
92 \\
91\end{array}$ & $\begin{array}{l}89 \\
90 \\
86 \\
88 \\
88\end{array}$ & $\begin{array}{l}83 \\
80 \\
82 \\
80 \\
84\end{array}$ \\
\hline $\begin{array}{l}16 \\
17 \\
18 \\
19 \\
20\end{array}$ & $\begin{array}{l}71 \\
72 \\
72 \\
70 \\
70\end{array}$ & $\begin{array}{l}54 \\
54 \\
55 \\
58 \\
56\end{array}$ & $\begin{array}{l}42 \\
40 \\
40 \\
40 \\
40\end{array}$ & $\begin{array}{l}41 \\
39 \\
38 \\
37 \\
48\end{array}$ & $\begin{array}{l}55 \\
54 \\
53 \\
52 \\
49\end{array}$ & $\begin{array}{l}\mathbf{5 2} \\
\mathbf{5 4} \\
\mathbf{5 2} \\
\mathbf{5 5} \\
\mathbf{5 3}\end{array}$ & $\begin{array}{l}64 \\
65 \\
66 \\
68 \\
71\end{array}$ & $\begin{array}{l}69 \\
70 \\
73 \\
74 \\
72\end{array}$ & $\begin{array}{l}84 \\
85 \\
88 \\
88 \\
89\end{array}$ & $\begin{array}{l}89 \\
92 \\
90 \\
86 \\
87\end{array}$ & $\begin{array}{l}89 \\
86 \\
90 \\
90 \\
86\end{array}$ & $\begin{array}{l}84 \\
81 \\
84 \\
84 \\
85\end{array}$ \\
\hline $\begin{array}{l}21 \\
22 \\
23 \\
24 \\
25\end{array}$ & $\begin{array}{l}70 \\
70 \\
69 \\
68 \\
66\end{array}$ & $\begin{array}{l}53 \\
51 \\
50 \\
50 \\
49\end{array}$ & $\begin{array}{l}42 \\
40 \\
38 \\
38 \\
38\end{array}$ & $\begin{array}{l}44 \\
42 \\
39 \\
40 \\
43\end{array}$ & $\begin{array}{l}50 \\
51 \\
52 \\
54 \\
54\end{array}$ & $\begin{array}{l}\mathbf{5 2} \\
\mathbf{5 2} \\
\mathbf{5 2} \\
\mathbf{5 5} \\
\mathbf{6 0}\end{array}$ & $\begin{array}{l}72 \\
73 \\
75 \\
75 \\
77\end{array}$ & $\begin{array}{l}73 \\
75 \\
76 \\
78 \\
75\end{array}$ & $\begin{array}{l}89 \\
90 \\
90 \\
90 \\
90\end{array}$ & $\begin{array}{l}87 \\
89 \\
88 \\
91 \\
88\end{array}$ & $\begin{array}{l}82 \\
84 \\
87 \\
87 \\
87\end{array}$ & $\begin{array}{l}79 \\
77 \\
77 \\
77 \\
78\end{array}$ \\
\hline $\begin{array}{l}26 \\
27 \\
28 \\
29 \\
30 \\
31\end{array}$ & $\begin{array}{l}65 \\
60 \\
60 \\
60 \\
59 \\
59 \\
\end{array}$ & $\begin{array}{l}47 \\
47 \\
45 \\
47 \\
48 \\
-- \\
\end{array}$ & $\begin{array}{l}48 \\
38 \\
39 \\
41 \\
40 \\
41 \\
\end{array}$ & $\begin{array}{l}44 \\
42 \\
42 \\
46 \\
45 \\
41 \\
\end{array}$ & $\begin{array}{l}53 \\
54 \\
50 \\
-- \\
-- \\
-- \\
\end{array}$ & $\begin{array}{l}58 \\
60 \\
62 \\
62 \\
56 \\
55 \\
\end{array}$ & $\begin{array}{l}76 \\
78 \\
74 \\
73 \\
72 \\
-- \\
\end{array}$ & $\begin{array}{l}74 \\
75 \\
77 \\
79 \\
-- \\
80 \\
\end{array}$ & $\begin{array}{l}91 \\
92 \\
93 \\
88 \\
88 \\
-- \\
\end{array}$ & $\begin{array}{l}85 \\
88 \\
88 \\
88 \\
82 \\
86 \\
\end{array}$ & $\begin{array}{l}89 \\
87 \\
88 \\
88 \\
87 \\
87 \\
\end{array}$ & $\begin{array}{l}78 \\
79 \\
78 \\
80 \\
75 \\
- \\
\end{array}$ \\
\hline $\begin{array}{c}\text { Aver- } \\
\text { age }\end{array}$ & 69 & 52 & 43 & 42 & 51 & 54 & 69 & 70 & 85 & 89 & 88 & 82 \\
\hline
\end{tabular}




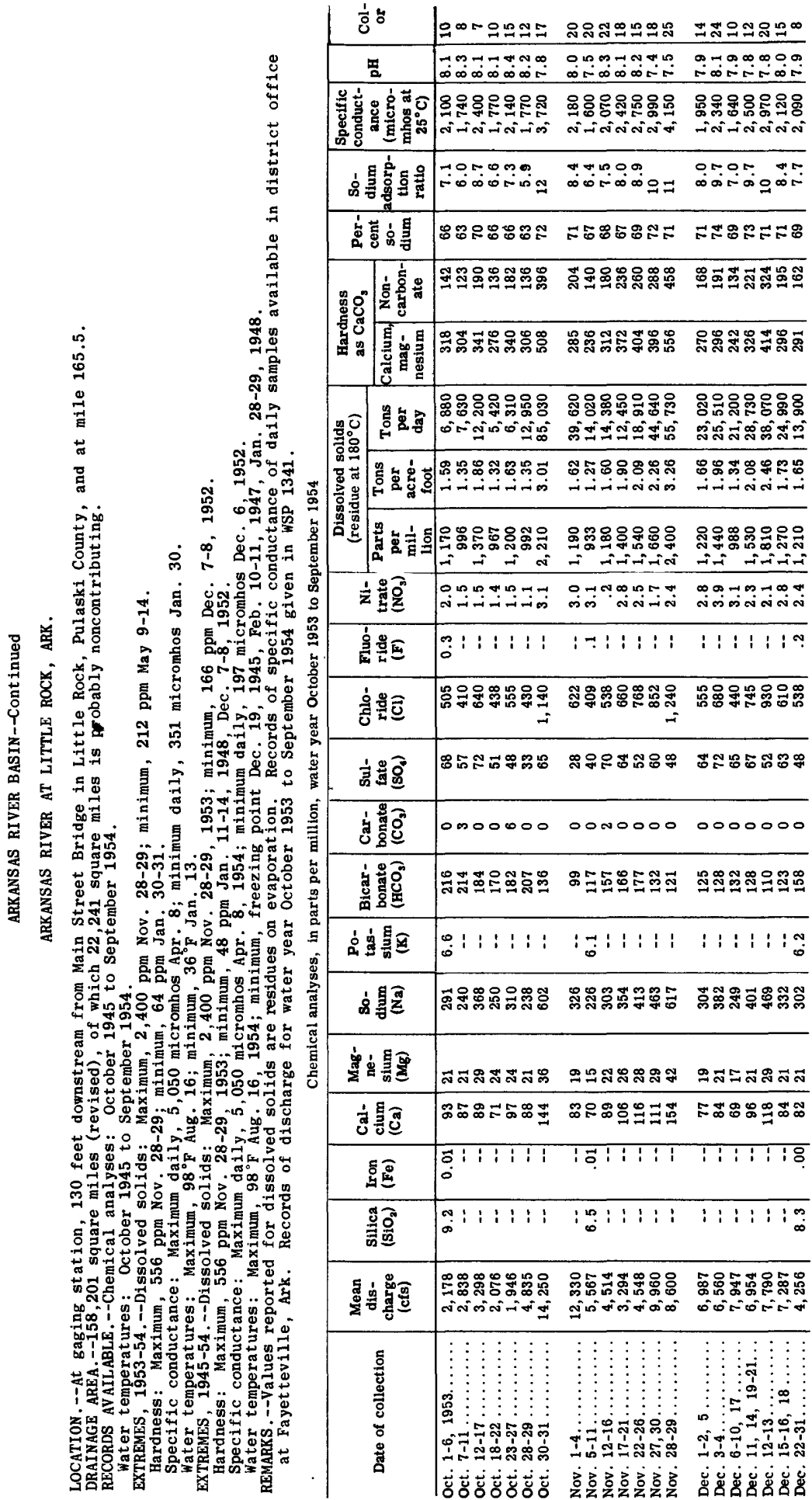




\begin{tabular}{|c|c|c|c|c|c|}
\hline$\infty \infty \infty \infty \mathbb{N}$ & ๓웡용 ! & 옹워 & $\infty \varnothing=\infty$ & $\infty \infty \bigcirc$ & 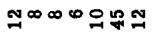 \\
\hline $\begin{array}{l}\sim \\
\infty \infty \infty \infty \infty \infty \\
\infty\end{array}$ & $\begin{array}{l}00500 \\
\infty \infty 5=\infty\end{array}$ & 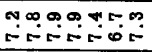 & 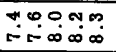 & ஸ & 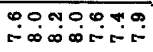 \\
\hline 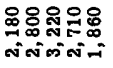 & 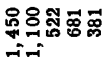 & 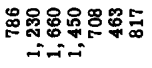 & 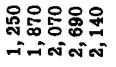 & 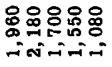 & 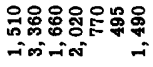 \\
\hline 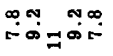 & 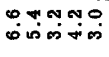 & 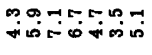 & 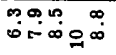 & " & 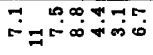 \\
\hline
\end{tabular}

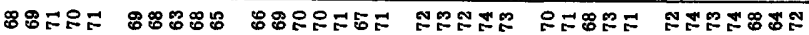

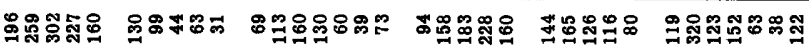

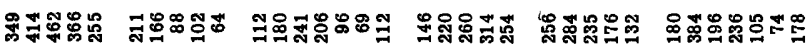

\begin{tabular}{|c|c|c|c|c|c|}
\hline 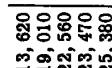 & 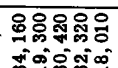 & 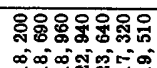 & 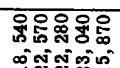 & 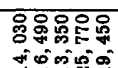 & 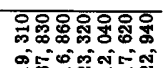 \\
\hline & & $68 \%:$ & 5858 & $\left(\begin{array}{lll}0 \\
0\end{array}\right.$ & 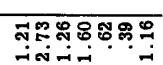 \\
\hline
\end{tabular}

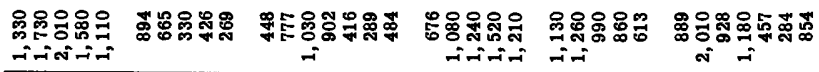

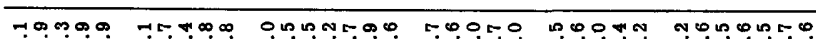

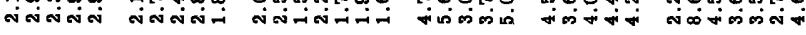

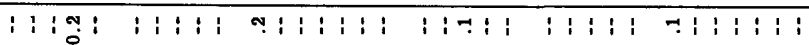

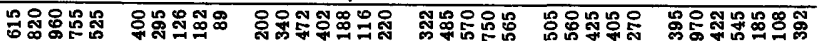

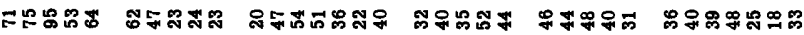

0000000000000000000001000000000000

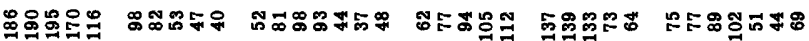

: : :

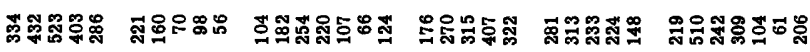

\begin{tabular}{|c|c|c|c|c|c|}
\hline & 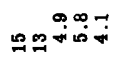 & 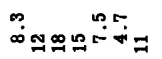 & 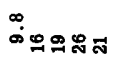 & 오요묙 & 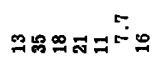 \\
\hline 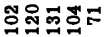 & 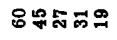 & "ై & 꾸요 & 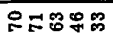 & $\overline{61}$ \\
\hline
\end{tabular}

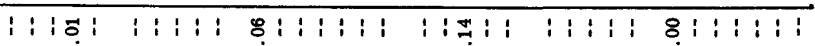

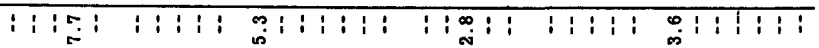

\begin{tabular}{|c|c|c|c|c|c|}
\hline 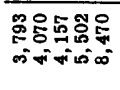 & 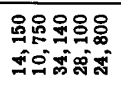 & 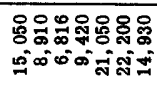 & 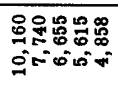 & 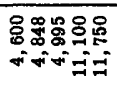 & 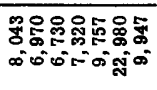 \\
\hline & 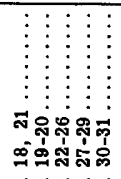 & 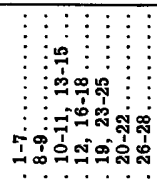 & บํํำ & 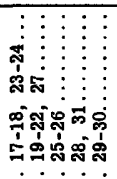 & 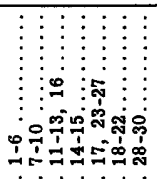 \\
\hline 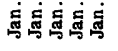 & 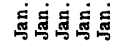 & 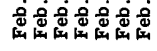 & 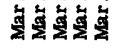 & 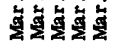 & 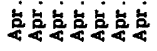 \\
\hline
\end{tabular}




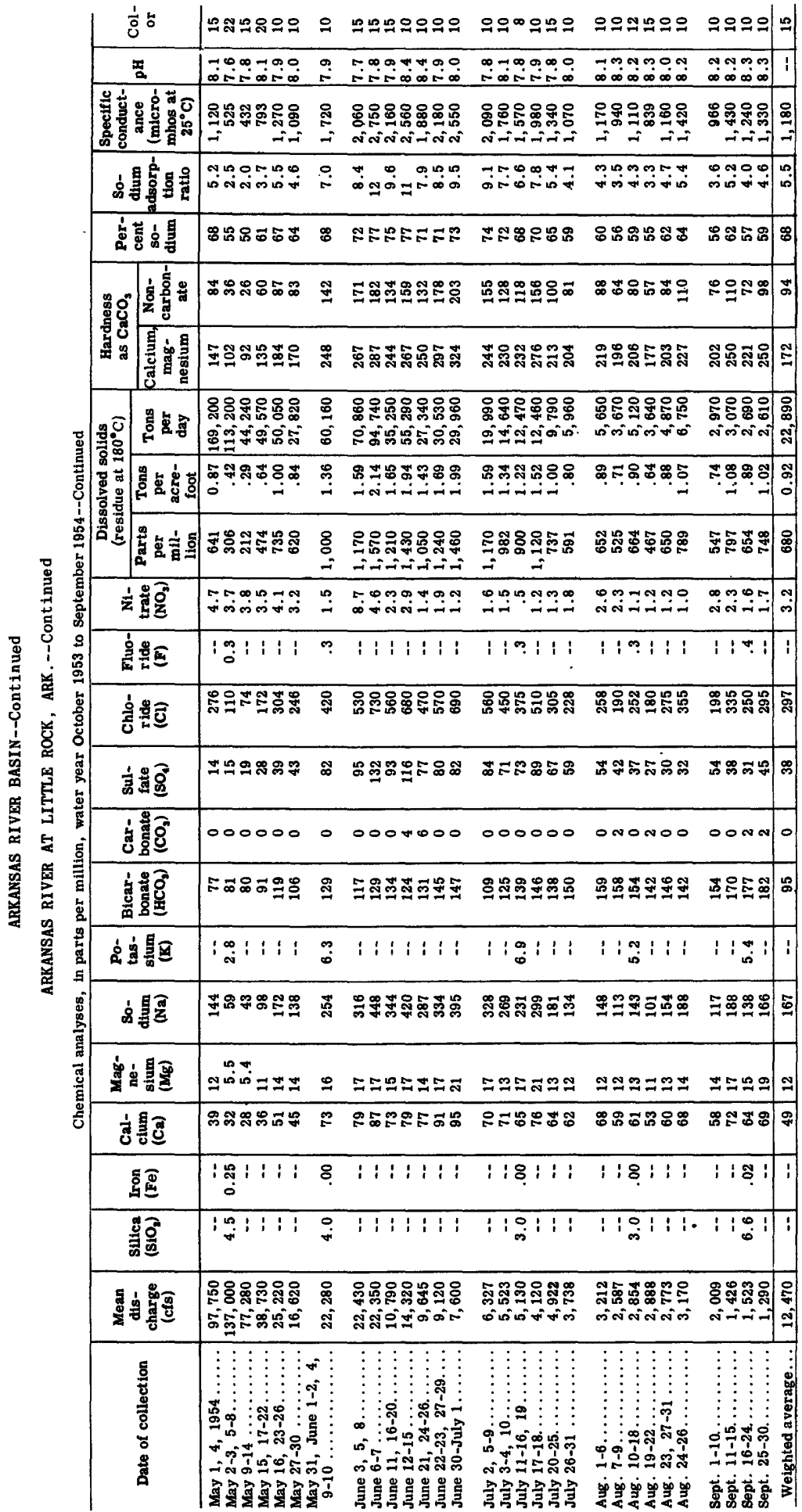


ARKANSAS RIVER BASIN--Continued

ARKANSAS RIVER AT LITTLE ROCK, ARK.--Continued

Temperature $\left({ }^{\circ} \mathrm{F}\right)$ of water, water year October 1953 to September 1954

\begin{tabular}{|c|c|c|c|c|c|c|c|c|c|c|c|c|}
\hline Day & Oct. & Nov. & Dec. & Jan. & Feb. & Mar. & Apr. & May & June & July & Aug. & Sept. \\
\hline $\begin{array}{l}1 \\
2 \\
3 \\
4 \\
5\end{array}$ & $\begin{array}{l}80 \\
79 \\
80 \\
78 \\
73\end{array}$ & $\begin{array}{l}60 \\
60 \\
60 \\
59 \\
58\end{array}$ & $\begin{array}{l}51 \\
50 \\
54 \\
53 \\
53\end{array}$ & $\begin{array}{l}43 \\
41 \\
45 \\
45 \\
46\end{array}$ & $\begin{array}{l}48 \\
49 \\
49 \\
50 \\
50\end{array}$ & $\begin{array}{l}52 \\
48 \\
46 \\
46 \\
46\end{array}$ & $\begin{array}{l}56 \\
58 \\
62 \\
62 \\
69\end{array}$ & $\begin{array}{l}70 \\
66 \\
65 \\
64 \\
66\end{array}$ & $\begin{array}{l}80 \\
80 \\
75 \\
76 \\
76\end{array}$ & $\begin{array}{l}91 \\
91 \\
90 \\
91 \\
91\end{array}$ & $\begin{array}{l}83 \\
84 \\
83 \\
84 \\
88\end{array}$ & $\begin{array}{l}85 \\
83 \\
84 \\
84 \\
83\end{array}$ \\
\hline $\begin{array}{r}6 \\
7 \\
8 \\
9 \\
10\end{array}$ & $\begin{array}{l}76 \\
68 \\
68 \\
-- \\
70\end{array}$ & $\begin{array}{l}\mathbf{5 2} \\
\mathbf{5 2} \\
\mathbf{5 1} \\
\mathbf{5 0} \\
\mathbf{5 2}\end{array}$ & $\begin{array}{l}50 \\
50 \\
50 \\
48 \\
48\end{array}$ & $\begin{array}{l}46 \\
46 \\
49 \\
50 \\
42\end{array}$ & $\begin{array}{l}48 \\
45 \\
48 \\
50 \\
53\end{array}$ & $\begin{array}{l}\mathbf{5 1} \\
\mathbf{5 2} \\
\mathbf{5 4} \\
\mathbf{5 6} \\
\mathbf{5 8}\end{array}$ & $\begin{array}{l}70 \\
72 \\
69 \\
69 \\
69\end{array}$ & $\begin{array}{l}66 \\
65 \\
66 \\
66 \\
65\end{array}$ & $\begin{array}{l}77 \\
78 \\
80 \\
82 \\
83\end{array}$ & $\begin{array}{l}92 \\
91 \\
89 \\
89 \\
88\end{array}$ & $\begin{array}{l}87 \\
89 \\
89 \\
89 \\
89\end{array}$ & $\begin{array}{l}83 \\
83 \\
83 \\
84 \\
83\end{array}$ \\
\hline $\begin{array}{l}11 \\
12 \\
13 \\
14 \\
15\end{array}$ & $\begin{array}{l}71 \\
71 \\
71 \\
71 \\
71\end{array}$ & $\begin{array}{l}\mathbf{5 3} \\
54 \\
54 \\
54 \\
55\end{array}$ & $\begin{array}{l}45 \\
48 \\
46 \\
43 \\
43\end{array}$ & $\begin{array}{l}41 \\
37 \\
36 \\
38 \\
41\end{array}$ & $\begin{array}{l}52 \\
-79 \\
- \\
57\end{array}$ & $\begin{array}{l}\mathbf{6 1} \\
64 \\
55 \\
51 \\
52\end{array}$ & $\begin{array}{l}68 \\
67 \\
68 \\
71 \\
70\end{array}$ & $\begin{array}{l}65 \\
64 \\
67 \\
67 \\
68\end{array}$ & $\begin{array}{l}85 \\
86 \\
86 \\
86 \\
85\end{array}$ & $\begin{array}{l}88 \\
89 \\
91 \\
91 \\
90\end{array}$ & $\begin{array}{l}88 \\
88 \\
87 \\
97 \\
87\end{array}$ & $\begin{array}{l}82 \\
79 \\
80 \\
80 \\
80\end{array}$ \\
\hline $\begin{array}{l}16 \\
17 \\
18 \\
19 \\
20\end{array}$ & $\begin{array}{l}71 \\
70 \\
70 \\
70 \\
70\end{array}$ & $\begin{array}{l}55 \\
55 \\
57 \\
59 \\
58\end{array}$ & $\begin{array}{l}44 \\
41 \\
41 \\
42 \\
42\end{array}$ & $\begin{array}{l}42 \\
39 \\
41 \\
43 \\
49\end{array}$ & $\begin{array}{l}58 \\
55 \\
47 \\
54 \\
52\end{array}$ & $\begin{array}{l}51 \\
54 \\
54 \\
57 \\
56\end{array}$ & $\begin{array}{l}66 \\
68 \\
69 \\
69 \\
71\end{array}$ & $\begin{array}{l}70 \\
70 \\
71 \\
72 \\
72\end{array}$ & $\begin{array}{l}84 \\
85 \\
87 \\
88 \\
88\end{array}$ & $\begin{array}{l}91 \\
90 \\
88 \\
83 \\
84\end{array}$ & $\begin{array}{l}98 \\
88 \\
88 \\
88 \\
86\end{array}$ & $\begin{array}{l}82 \\
79 \\
80 \\
83 \\
84\end{array}$ \\
\hline $\begin{array}{l}21 \\
22 \\
23 \\
24 \\
25\end{array}$ & $\begin{array}{l}71 \\
70 \\
70 \\
69 \\
66\end{array}$ & $\begin{array}{l}55 \\
54 \\
53 \\
51 \\
50\end{array}$ & $\begin{array}{l}44 \\
40 \\
37 \\
37 \\
38\end{array}$ & $\begin{array}{l}43 \\
43 \\
41 \\
42 \\
45\end{array}$ & $\begin{array}{l}52 \\
53 \\
53 \\
55 \\
56\end{array}$ & $\begin{array}{l}54 \\
.56 \\
54 \\
59 \\
62\end{array}$ & $\begin{array}{l}73 \\
72 \\
74 \\
76 \\
76\end{array}$ & $\begin{array}{l}72 \\
73 \\
74 \\
76 \\
76\end{array}$ & $\begin{array}{l}88 \\
88 \\
89 \\
89 \\
91\end{array}$ & $\begin{array}{l}87 \\
88 \\
89 \\
89 \\
88\end{array}$ & $\begin{array}{l}83 \\
85 \\
86 \\
85 \\
87\end{array}$ & $\begin{array}{l}79 \\
77 \\
75 \\
76 \\
77\end{array}$ \\
\hline $\begin{array}{l}26 \\
27 \\
28 \\
29 \\
30 \\
31\end{array}$ & $\begin{array}{l}64 \\
60 \\
60 \\
59 \\
59 \\
59\end{array}$ & $\begin{array}{l}50 \\
47 \\
46 \\
49 \\
49 \\
--\end{array}$ & $\begin{array}{l}40 \\
40 \\
41 \\
43 \\
42 \\
42\end{array}$ & $\begin{array}{l}48 \\
44 \\
44 \\
45 \\
45 \\
46\end{array}$ & $\begin{array}{l}54 \\
56 \\
50 \\
-- \\
-- \\
--\end{array}$ & $\begin{array}{l}60 \\
62 \\
64 \\
66 \\
58 \\
55\end{array}$ & $\begin{array}{l}78 \\
79 \\
72 \\
70 \\
71 \\
-\end{array}$ & $\begin{array}{l}76 \\
76 \\
78 \\
78 \\
80 \\
80\end{array}$ & $\begin{array}{l}91 \\
92 \\
93 \\
88 \\
90 \\
--\end{array}$ & $\begin{array}{l}88 \\
83 \\
86 \\
86 \\
85 \\
86\end{array}$ & $\begin{array}{l}87 \\
89 \\
86 \\
88 \\
88 \\
85\end{array}$ & $\begin{array}{l}79 \\
79 \\
79 \\
79 \\
77 \\
--\end{array}$ \\
\hline $\begin{array}{c}\text { Aver- } \\
\text { age }\end{array}$ & 70 & 54 & 45 & 43 & 52 & 55 & 69 & 70 & 85 & 88 & 87 & 81 \\
\hline
\end{tabular}

$4888170-59-11$ 


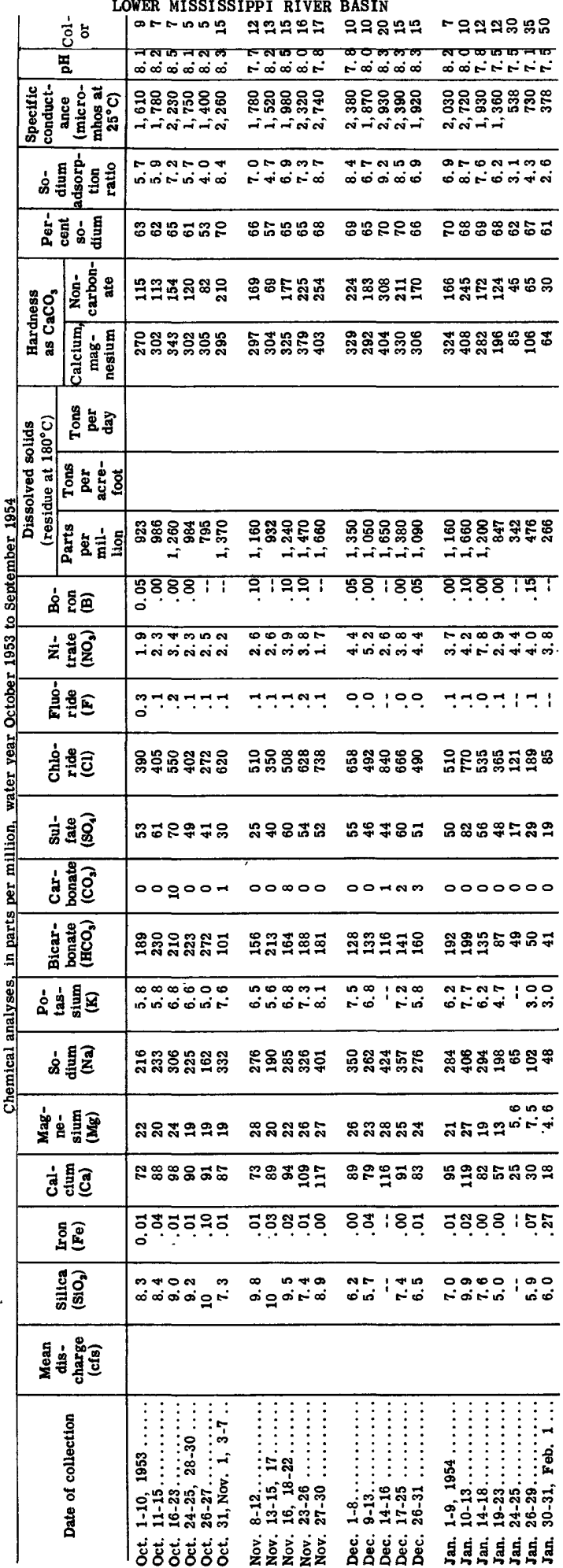




\begin{tabular}{|c|c|c|c|c|}
\hline 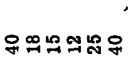 & $=-\infty$ ㄴom & 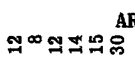 & 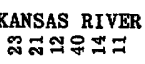 & 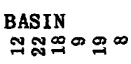 \\
\hline 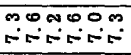 & 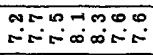 & 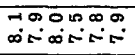 & 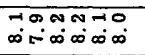 & 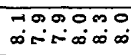 \\
\hline 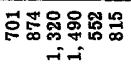 & 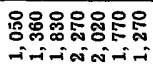 & 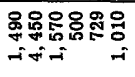 & 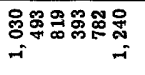 & 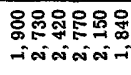 \\
\hline 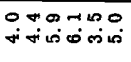 & DN & $\overrightarrow{5} \vec{\Xi}$ & 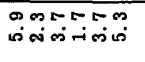 & $\stackrel{\infty}{\sim}=9$ 워 \\
\hline 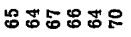 & 옹오유た드 & 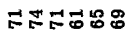 & ํㅗำ & ロト゚ロッ゙ロ \\
\hline 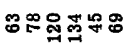 & 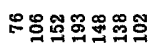 & 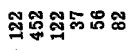 & 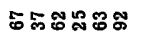 & 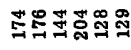 \\
\hline 웍켜요 & 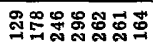 & 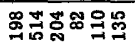 & 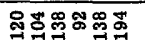 & \\
\hline
\end{tabular}

\begin{tabular}{|c|c|c|c|c|}
\hline 우윯윯 & 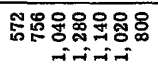 & 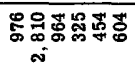 & 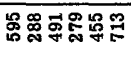 & 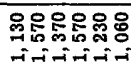 \\
\hline $1: 8: 48$. & 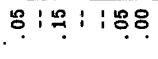 & $: 1: 1: 1:$ & 1음 1 1농옥 & $8 \%$ \\
\hline 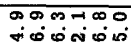 & 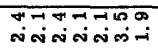 & 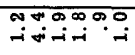 & 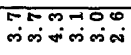 & 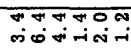 \\
\hline$\because: \because: \because:$ & $\because: \because: \because \because$ & 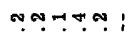 & $\because \div: \because: \because$ & $\because \because \because !$ \\
\hline 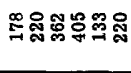 & : & 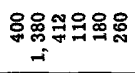 & 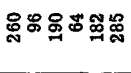 & $\infty$ \\
\hline
\end{tabular}

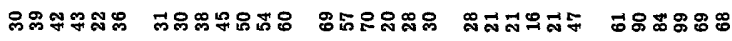

000000 0000N00000000000000 0000m0

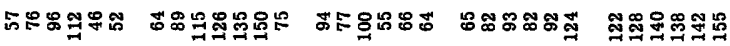

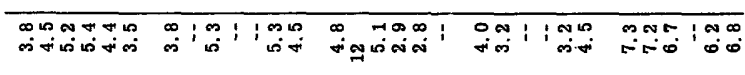

\&

\begin{tabular}{|c|c|c|c|c|}
\hline 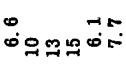 & 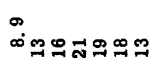 & 녹 용 & 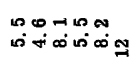 & આ옳 \\
\hline ణ유ㅇㅠㅀㅀㅛ & 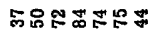 & 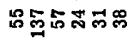 & 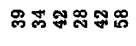 & 品品の5 \\
\hline 1 : & 웅 : & 용요용 & 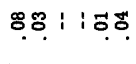 & 885188 \\
\hline 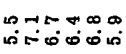 & 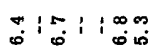 & 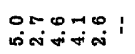 & 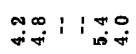 & 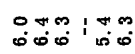 \\
\hline
\end{tabular}

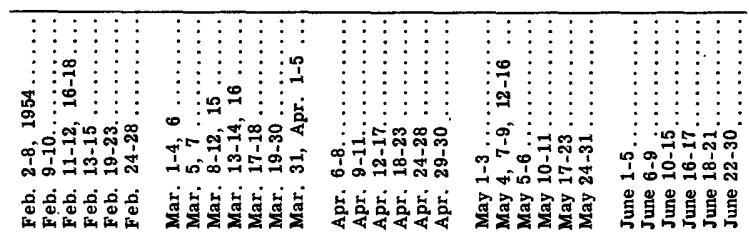




\begin{tabular}{|c|c|c|c|c|}
\hline 完台 & 이엄융요 & $\begin{array}{l}\text { LOWER MIS } \\
\infty \infty \infty \infty \infty 0\end{array}$ & | & RI \\
\hline 평 & 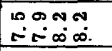 & 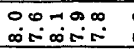 & 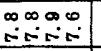 & $i$ \\
\hline 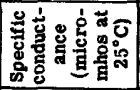 & 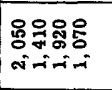 & 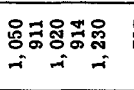 & 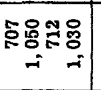 & 䰚 \\
\hline 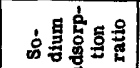 & कामिए & 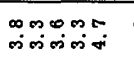 & 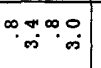 & $\overrightarrow{0}$ \\
\hline 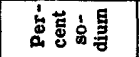 & ํㅜㅇำ & เค็ณำ & 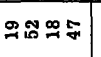 & 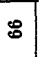 \\
\hline 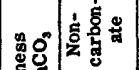 & 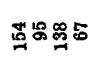 & 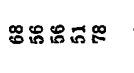 & $\circ$ 정요 & $\mathbb{J}$ \\
\hline 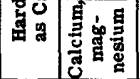 & 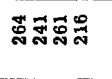 & สีฐฐస్ & 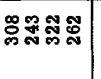 & 욕 \\
\hline 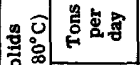 & & & & \\
\hline 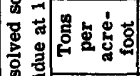 & & & & \\
\hline 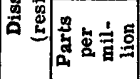 & 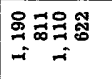 & 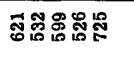 & 궁영영 & है \\
\hline 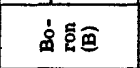 & 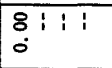 & 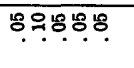 & 유: & $i$ \\
\hline 㐫至要 & 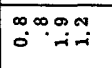 & 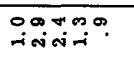 & 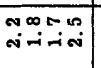 & $\begin{array}{l}0 \\
i\end{array}$ \\
\hline 高密至 & ปั่งก & 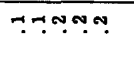 & ๓๓m & $\stackrel{0}{0}$ \\
\hline 호ㅇㅝㅠ & 윰음 \% \% & 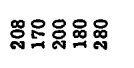 & 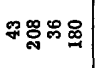 & $\stackrel{\infty}{\infty}$ \\
\hline 它恳 & ฉซำ & 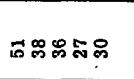 & 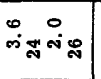 & 8 \\
\hline 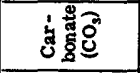 & 0000 & 00000 & 0000 & 0 \\
\hline 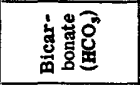 & 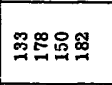 & 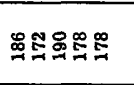 & 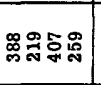 & I \\
\hline 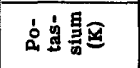 & 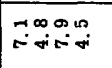 & 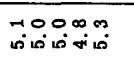 & $\begin{array}{l}\text { roost } \\
\text { visionis }\end{array}$ & is \\
\hline 安䡒要 & 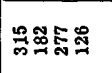 & 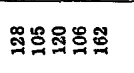 & $\bar{m} \Phi \equiv$ & $\sqrt{\mathrm{N}}$ \\
\hline 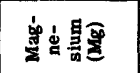 & 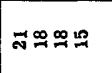 & 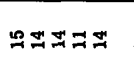 & 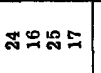 & $=$ \\
\hline 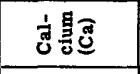 & โธะ์ & 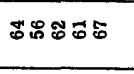 & $\Phi \approx \infty 5$ & 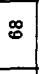 \\
\hline 害总 & $\begin{array}{l}8 \% 50 \\
0 \\
\end{array}$ & 훙ํํㅇํㅇㅇㅗ & $88: 15$ & $\begin{array}{l}8 \\
: \\
\end{array}$ \\
\hline 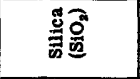 & 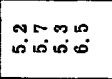 & 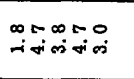 & 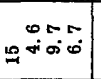 & 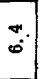 \\
\hline 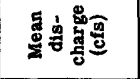 & & & & \\
\hline 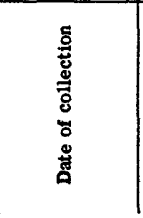 & 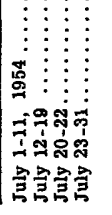 & 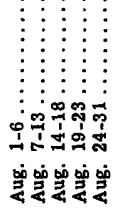 & 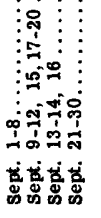 & 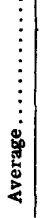 \\
\hline
\end{tabular}


ARKANSAS RIVER BASIN--Continued

ARIKANSAS RIVER NEAR ALTHEIMER, ARK.--Continued

Temperature $\left({ }^{\circ} \mathrm{F}\right)$ of water, October 1953 to August 1954

\begin{tabular}{|c|c|c|c|c|c|c|c|c|c|c|c|c|}
\hline Das & Oct. & Nov. & Dec. & Jan. & Feb. & Mar. & Apr. & May & June & July & Aug. & Sept. \\
\hline $\begin{array}{l}1 \\
2 \\
3 \\
4 \\
5\end{array}$ & $\begin{array}{l}82 \\
80 \\
80 \\
79 \\
70\end{array}$ & $\begin{array}{l}62 \\
61 \\
64 \\
60 \\
59\end{array}$ & $\begin{array}{l}52 \\
51 \\
50 \\
52 \\
52\end{array}$ & $\begin{array}{l}45 \\
45 \\
44 \\
45 \\
46\end{array}$ & $\begin{array}{l}52 \\
-- \\
54 \\
54 \\
58\end{array}$ & $\begin{array}{l}60 \\
59 \\
58 \\
56 \\
60\end{array}$ & $\begin{array}{l}65 \\
66 \\
67 \\
68 \\
70\end{array}$ & $\begin{array}{l}75 \\
73 \\
69 \\
70 \\
65\end{array}$ & $\begin{array}{l}75 \\
80 \\
83 \\
79 \\
81\end{array}$ & $\begin{array}{l}92 \\
93 \\
92 \\
90 \\
91\end{array}$ & $\begin{array}{l}90 \\
87 \\
88 \\
85 \\
84\end{array}$ & \\
\hline $\begin{array}{r}6 \\
7 \\
8 \\
9 \\
10\end{array}$ & $\begin{array}{l}68 \\
-\overline{68} \\
72 \\
66\end{array}$ & $\begin{array}{l}\mathbf{5 5} \\
\mathbf{5 1} \\
\mathbf{5 1} \\
\mathbf{5 2} \\
\mathbf{5 1}\end{array}$ & $\begin{array}{l}53 \\
53 \\
-- \\
50 \\
49\end{array}$ & $\begin{array}{l}46 \\
47 \\
46 \\
45 \\
44\end{array}$ & $\begin{array}{l}55 \\
56 \\
56 \\
56 \\
55 .\end{array}$ & $\begin{array}{l}59 \\
58 \\
60 \\
61 \\
63\end{array}$ & $\begin{array}{l}70 \\
71 \\
72 \\
70 \\
71\end{array}$ & $\begin{array}{l}69 \\
66 \\
68 \\
69 \\
65\end{array}$ & $\begin{array}{l}82 \\
81 \\
82 \\
83 \\
83\end{array}$ & $\begin{array}{l}88 \\
89 \\
90 \\
92 \\
90\end{array}$ & $\begin{array}{l}86 \\
89 \\
-- \\
84 \\
86\end{array}$ & \\
\hline $\begin{array}{l}11 \\
12 \\
13 \\
14 \\
15\end{array}$ & $\begin{array}{l}65 \\
76 \\
76 \\
73 \\
74\end{array}$ & $\begin{array}{l}56 \\
59 \\
60 \\
53 \\
52\end{array}$ & $\begin{array}{l}50 \\
52 \\
-- \\
48 \\
46\end{array}$ & $\begin{array}{l}45 \\
46 \\
44 \\
43 \\
44\end{array}$ & $\begin{array}{l}54 \\
53 \\
54 \\
55 \\
56\end{array}$ & $\begin{array}{l}65 \\
70 \\
66 \\
61 \\
58\end{array}$ & $\begin{array}{l}70 \\
69 \\
68 \\
72 \\
71\end{array}$ & $\begin{array}{l}67 \\
68 \\
70 \\
65 \\
70\end{array}$ & $\begin{array}{l}82 \\
84 \\
81 \\
82 \\
83\end{array}$ & $\begin{array}{l}89 \\
90 \\
88 \\
89 \\
87\end{array}$ & $\begin{array}{l}87 \\
87 \\
86 \\
87 \\
85\end{array}$ & \\
\hline $\begin{array}{l}16 \\
17 \\
18 \\
19 \\
20\end{array}$ & $\begin{array}{l}67 \\
65 \\
71 \\
72 \\
72\end{array}$ & $\begin{array}{l}55 \\
68 \\
60 \\
60 \\
54\end{array}$ & $\begin{array}{l}-\overline{44} \\
-\overline{44} \\
--\end{array}$ & $\begin{array}{l}44 \\
45 \\
44 \\
48 \\
54\end{array}$ & $\begin{array}{l}57 \\
59 \\
61 \\
60 \\
59\end{array}$ & $\begin{array}{l}57 \\
56 \\
59 \\
59 \\
60\end{array}$ & $\begin{array}{l}70 \\
72 \\
73 \\
75 \\
76\end{array}$ & $\begin{array}{l}71 \\
70 \\
72 \\
74 \\
70\end{array}$ & $\begin{array}{l}84 \\
84 \\
85 \\
86 \\
86\end{array}$ & $\begin{array}{l}-- \\
86 \\
87 \\
85 \\
84\end{array}$ & $\begin{array}{l}86 \\
88 \\
86 \\
87 \\
84\end{array}$ & \\
\hline $\begin{array}{l}21 \\
22 \\
23 \\
24 \\
25\end{array}$ & $\begin{array}{l}72 \\
71 \\
70 \\
68 \\
64\end{array}$ & $\begin{array}{l}\mathbf{5 4} \\
55 \\
54 \\
53 \\
51\end{array}$ & $\begin{array}{l}42 \\
43 \\
43 \\
42 \\
41\end{array}$ & $\begin{array}{l}50 \\
46 \\
41 \\
44 \\
46\end{array}$ & $\begin{array}{l}58 \\
61 \\
58 \\
59 \\
60\end{array}$ & $\begin{array}{l}60 \\
61 \\
61 \\
62 \\
63\end{array}$ & $\begin{array}{l}77 \\
74 \\
75 \\
78 \\
--\end{array}$ & $\begin{array}{l}71 \\
75 \\
78 \\
71 \\
79\end{array}$ & $\begin{array}{l}87 \\
88 \\
85 \\
86 \\
90\end{array}$ & $\begin{array}{l}86 \\
86 \\
85 \\
83 \\
84\end{array}$ & $\begin{array}{l}85 \\
88 \\
83 \\
82 \\
80\end{array}$ & \\
\hline $\begin{array}{l}26 \\
27 \\
28 \\
29 \\
30 \\
31\end{array}$ & $\begin{array}{l}60 \\
55 \\
58 \\
60 \\
61 \\
60\end{array}$ & $\begin{array}{l}50 \\
49 \\
48 \\
52 \\
51 \\
--\end{array}$ & $\begin{array}{l}40 \\
40 \\
40 \\
40 \\
42 \\
44\end{array}$ & $\begin{array}{l}45 \\
46 \\
47 \\
48 \\
50 \\
53\end{array}$ & $\begin{array}{l}60 \\
60 \\
61 \\
-- \\
-- \\
--\end{array}$ & $\begin{array}{l}64 \\
65 \\
72 \\
69 \\
65 \\
61\end{array}$ & $\begin{array}{l}79 \\
-- \\
76 \\
75 \\
74 \\
--\end{array}$ & $\begin{array}{l}75 \\
79 \\
80 \\
78 \\
80 \\
83\end{array}$ & $\begin{array}{l}91 \\
-- \\
92 \\
88 \\
91 \\
--\end{array}$ & $\begin{array}{l}86 \\
87 \\
89 \\
85 \\
83 \\
80\end{array}$ & $\begin{array}{l}78 \\
76 \\
74 \\
73 \\
71 \\
--\end{array}$ & \\
\hline $\begin{array}{c}\text { Aver- } \\
\text { age }\end{array}$ & 69 & 55 & 46 & 46 & 57 & 62 & 72 & 72 & 84 & 88 & 84 & \\
\hline
\end{tabular}




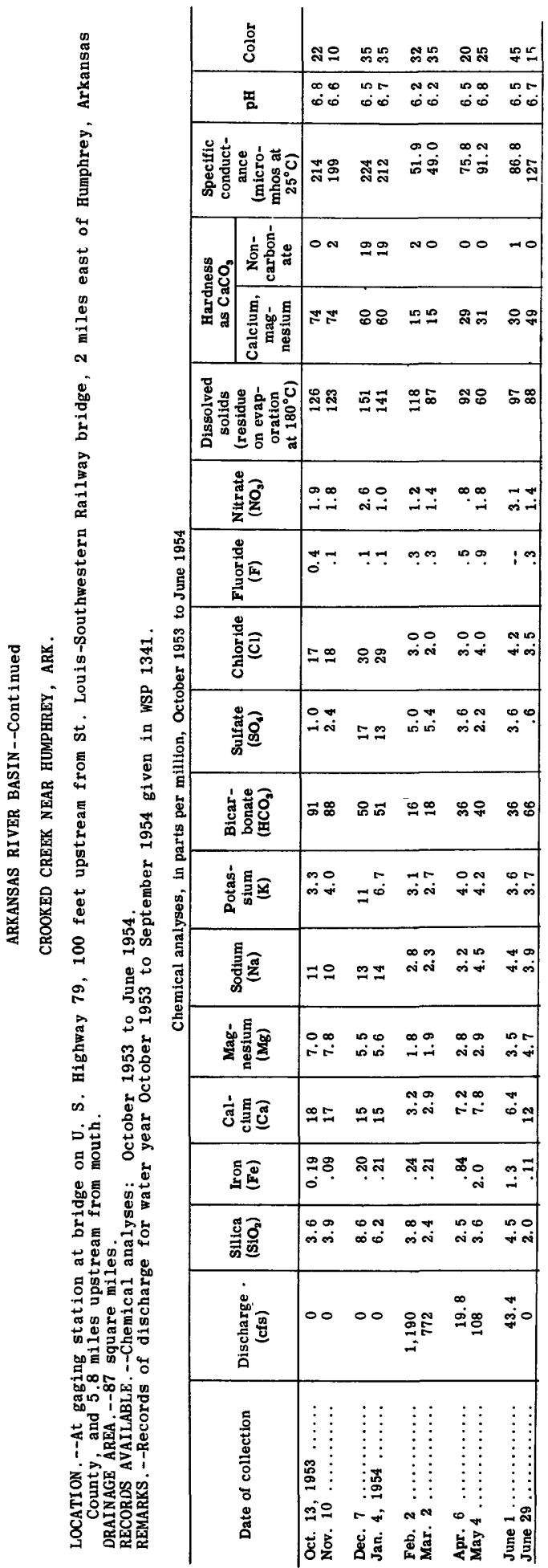



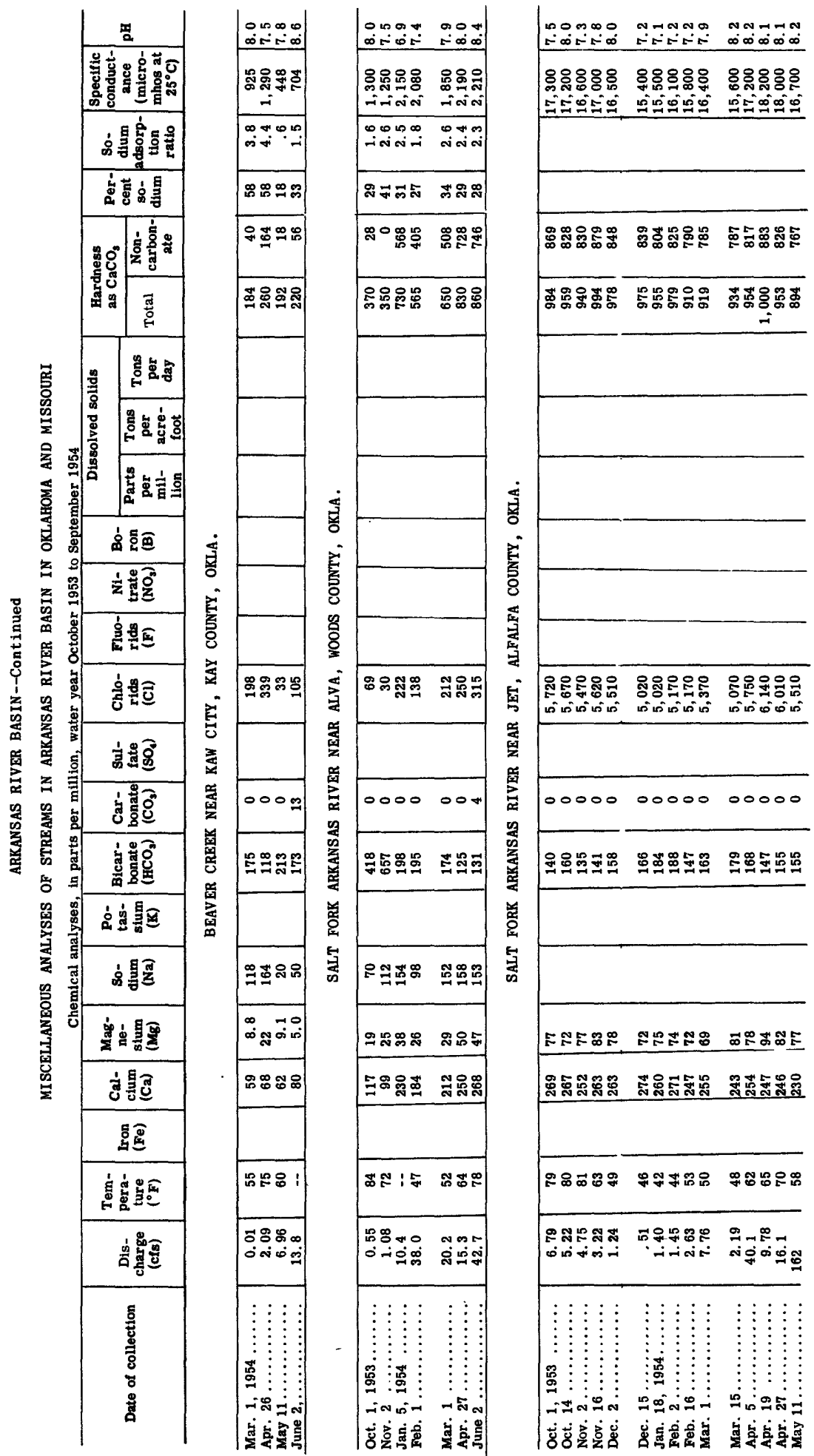

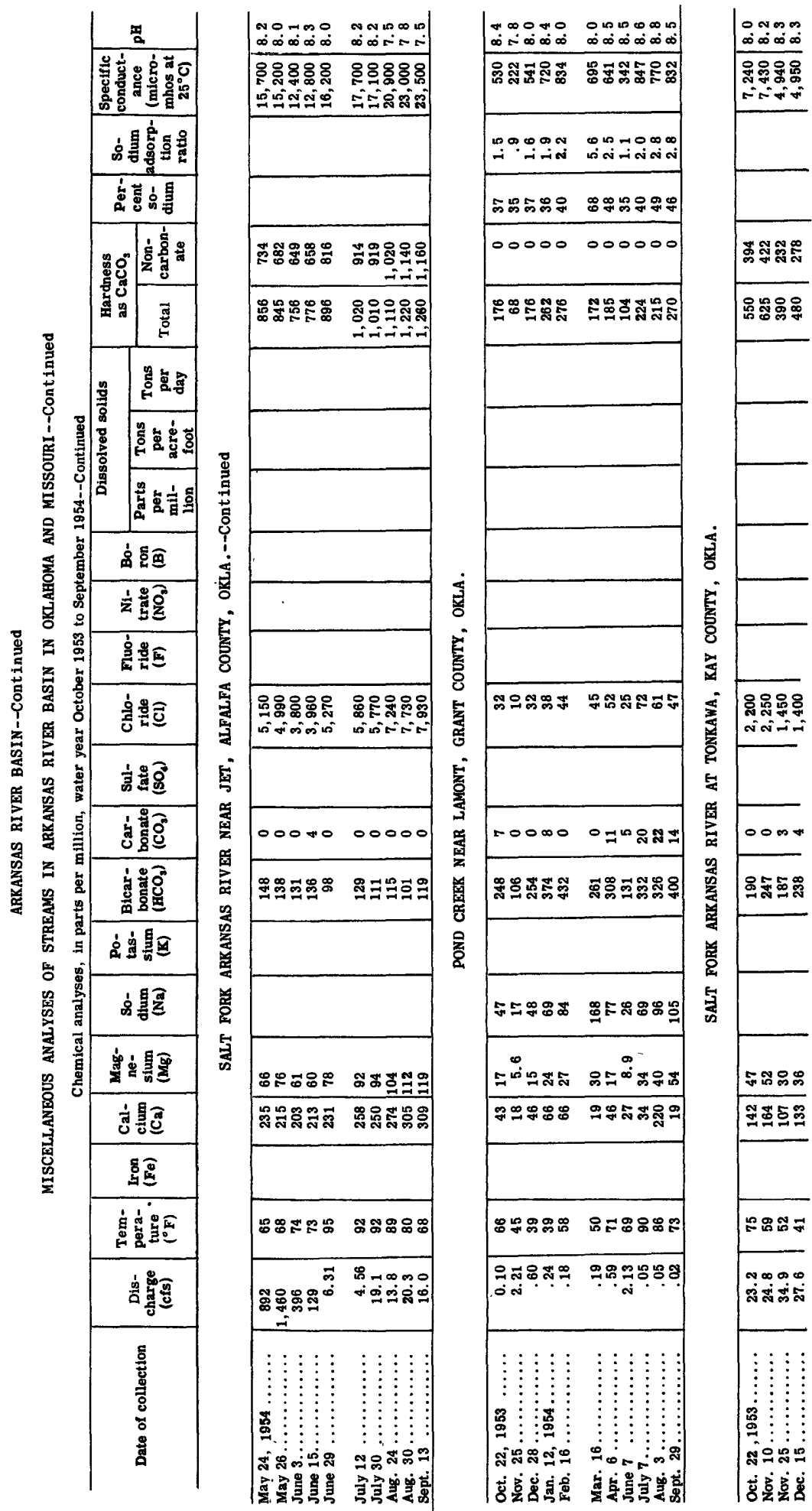


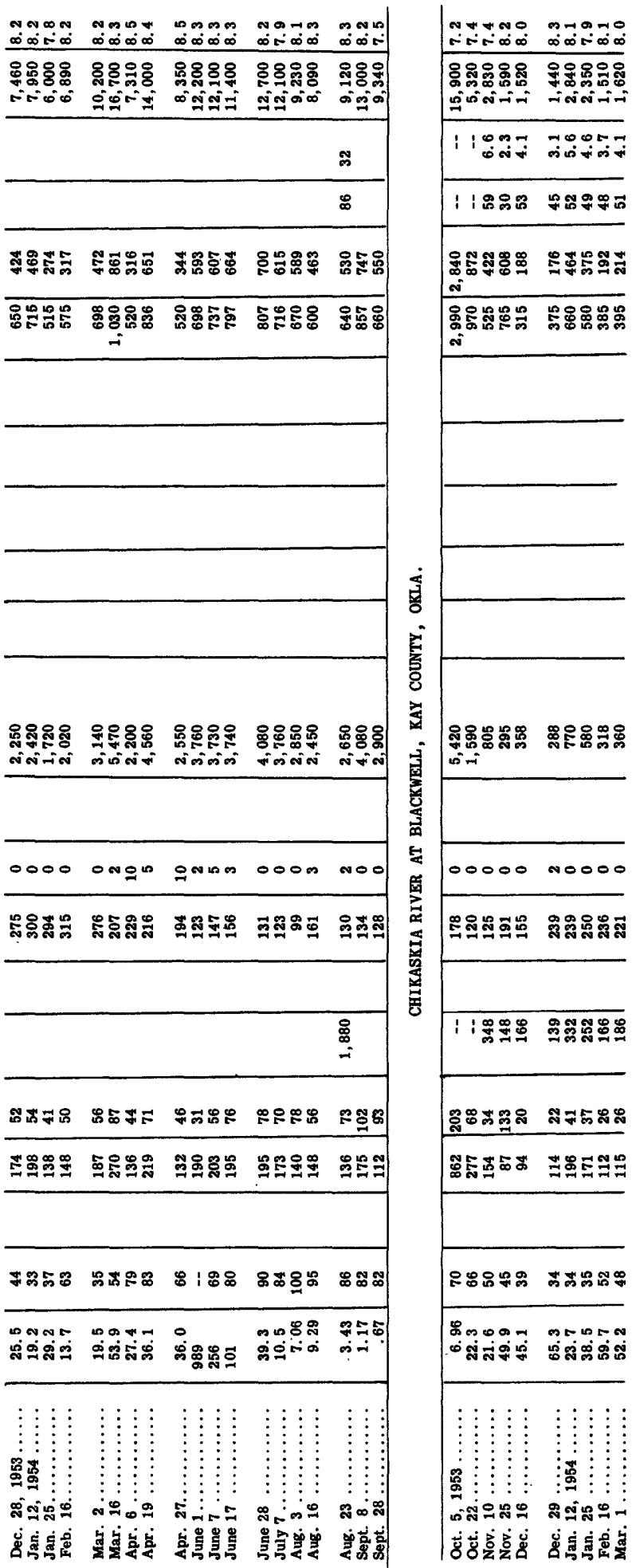




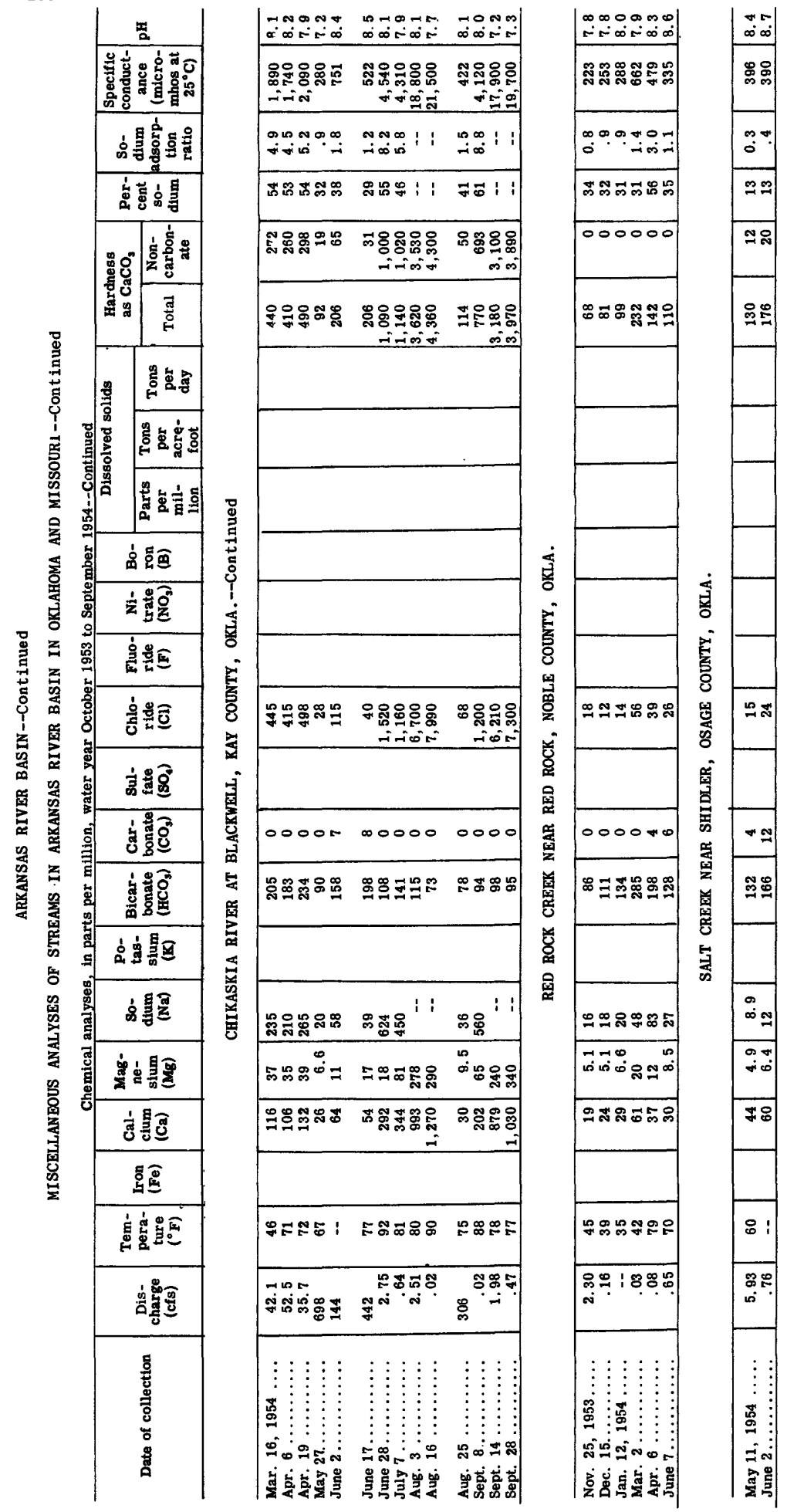




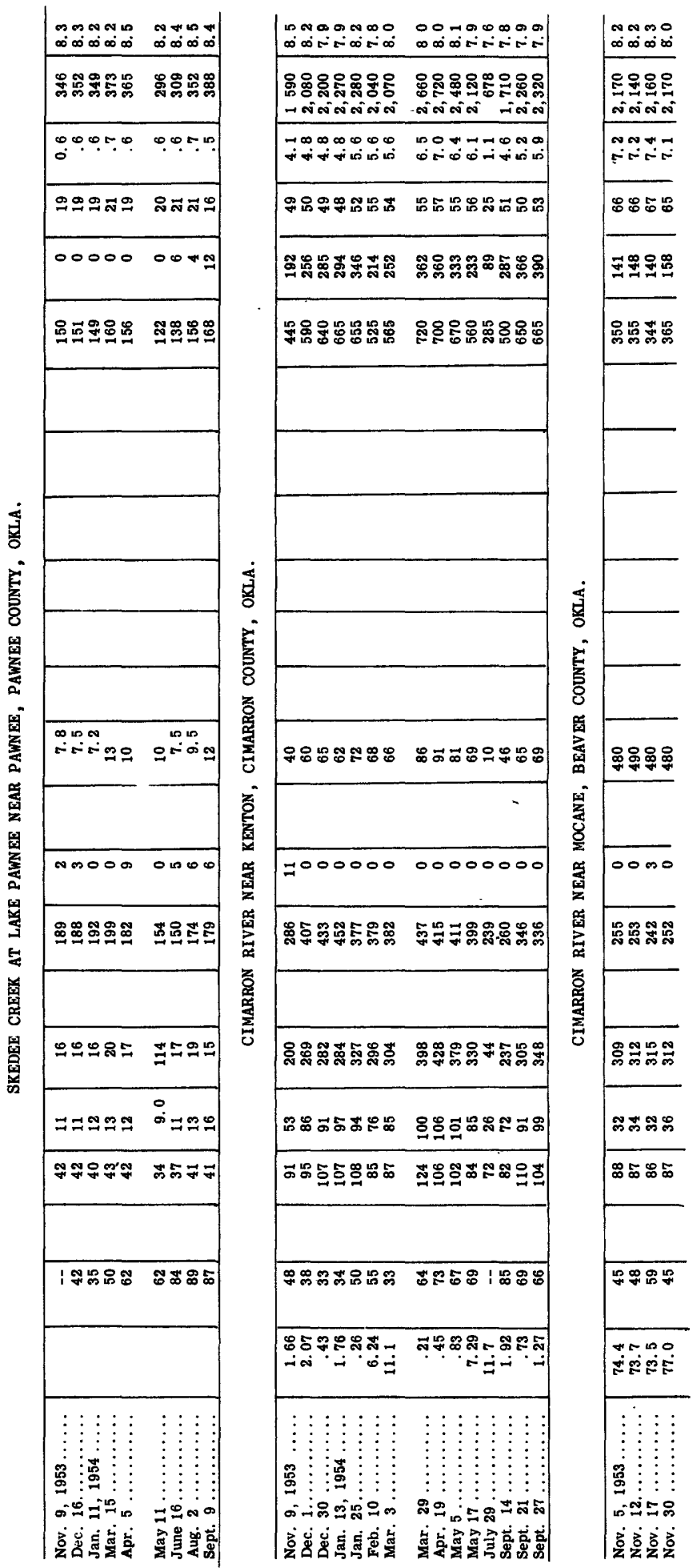




\begin{tabular}{|c|c|c|c|c|c|c|c|}
\hline & 폄 & & 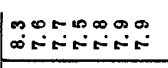 & 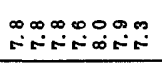 & 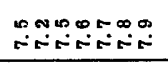 & 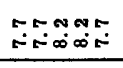 & mó5 \\
\hline & 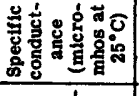 & & 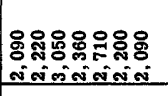 & 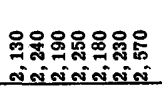 & 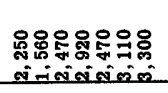 & 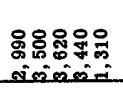 & 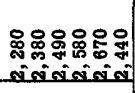 \\
\hline & 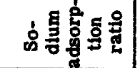 & & 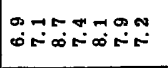 & 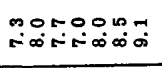 & 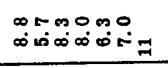 & 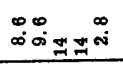 & 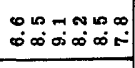 \\
\hline & 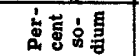 & & 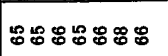 & 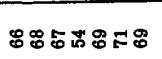 & 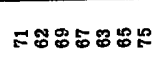 & 유퐁ㅇㅇ & 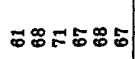 \\
\hline & 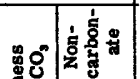 & & 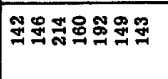 & 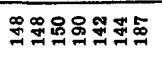 & 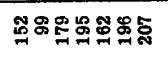 & 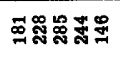 & 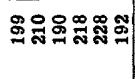 \\
\hline & 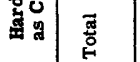 & & 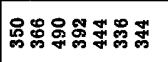 & 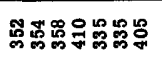 & 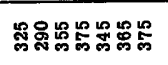 & 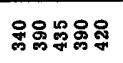 & 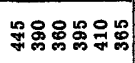 \\
\hline 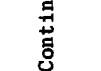 & 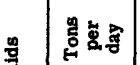 & & & & & & \\
\hline & 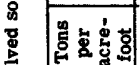 & & & & & & \\
\hline 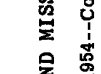 & 总 & $\underset{g}{g}$ & & & & & \\
\hline & 宮点畺 & है & & & & & \\
\hline & 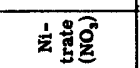 & 8 & & & & & \\
\hline & 官要要 & 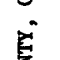 & & & & & \\
\hline $\begin{array}{ll}0 \\
0 \\
5\end{array}$ & ㅎํํ류 & $\begin{array}{l}8 \\
8 \\
\times 19\end{array}$ & 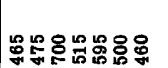 & 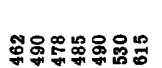 & ్ㅐำ & 옹잉동요유 & 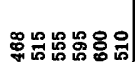 \\
\hline 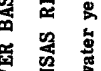 & 实番高 & 商 & & & & & \\
\hline 20 & : & 摡 & 0000000 & 0000000 & 0000000 & 00000 & 000000 \\
\hline 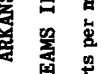 & 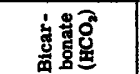 & 愛 & సే: & 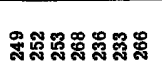 & 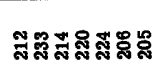 & 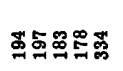 & 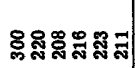 \\
\hline & 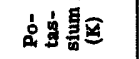 & 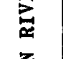 & & & & & \\
\hline & 宫息要 & 㱐 & 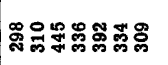 & 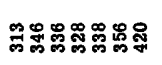 & 吅ส̃ & 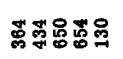 & 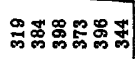 \\
\hline & 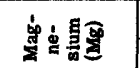 & & 凩的 & 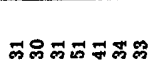 & 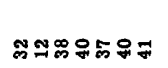 & 焗毞品尔 & $\$$ \\
\hline 悉 & 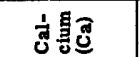 & & 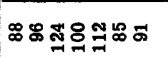 & 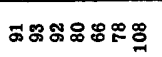 & 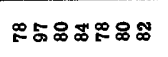 & 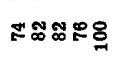 & 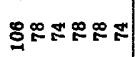 \\
\hline . & 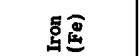 & & & & & & \\
\hline & 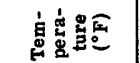 & & パ요 & 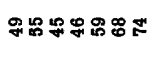 & 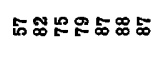 & ৪ゅஃ® & ボミ: \\
\hline & 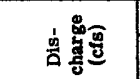 & & 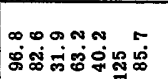 & 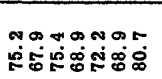 & 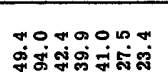 & 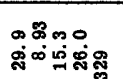 & 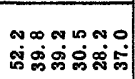 \\
\hline & 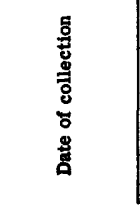 & & 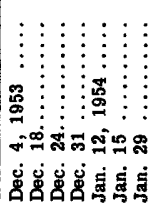 & 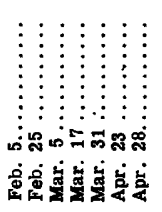 & 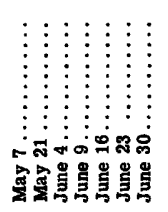 & 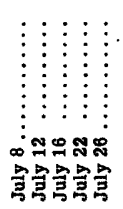 & 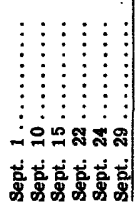 \\
\hline
\end{tabular}




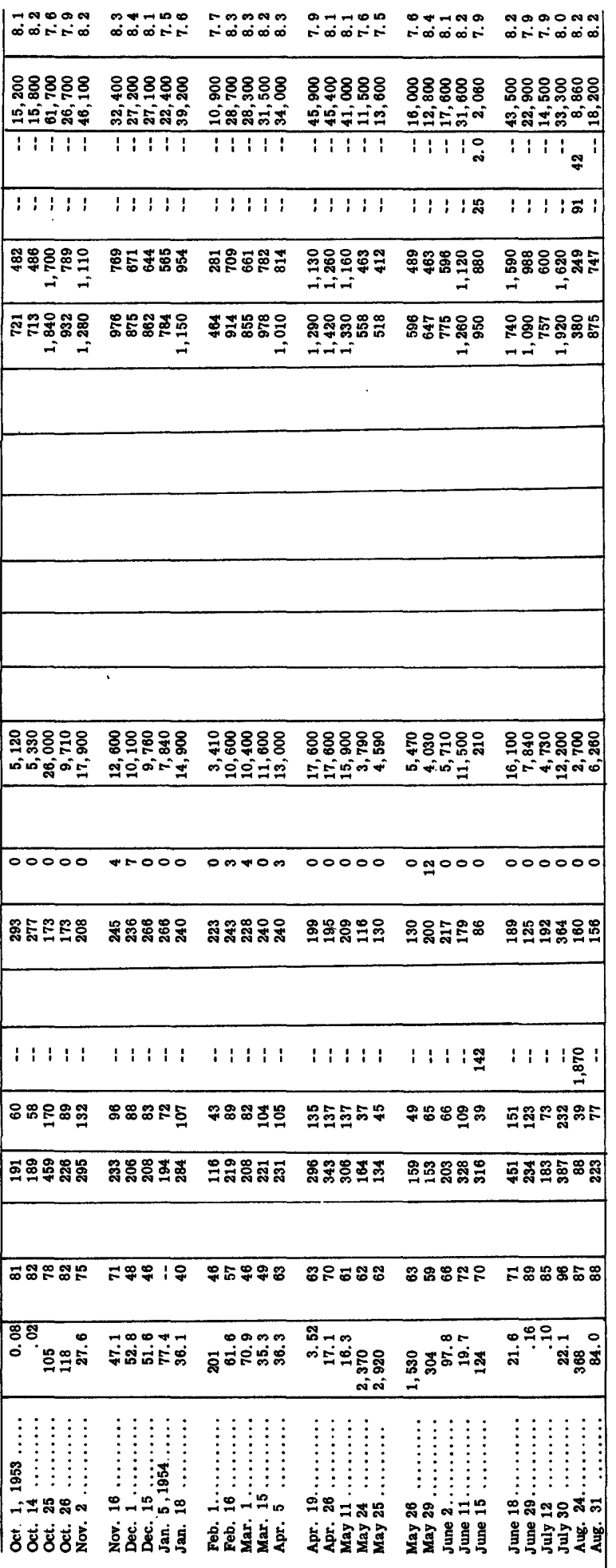




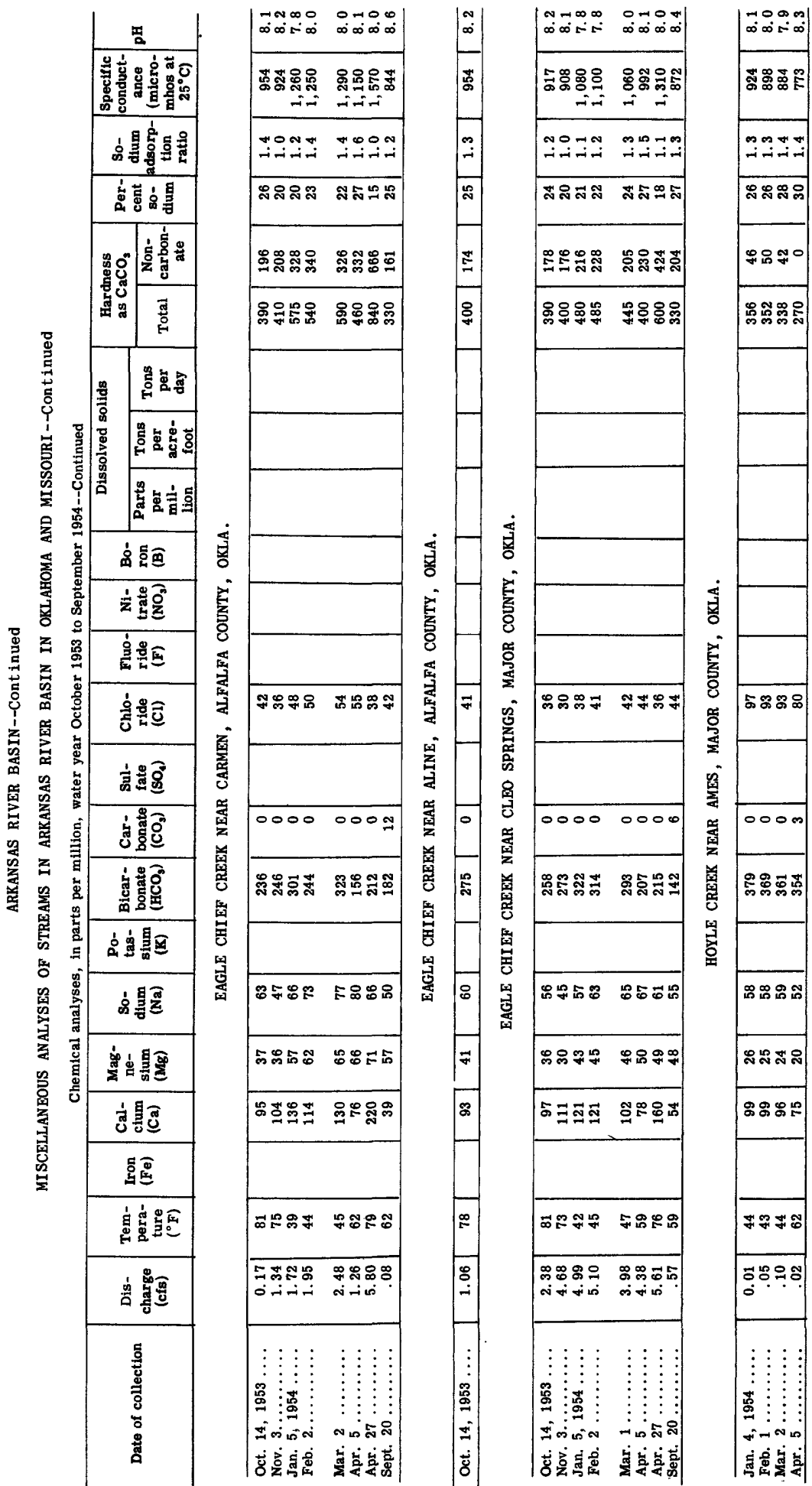




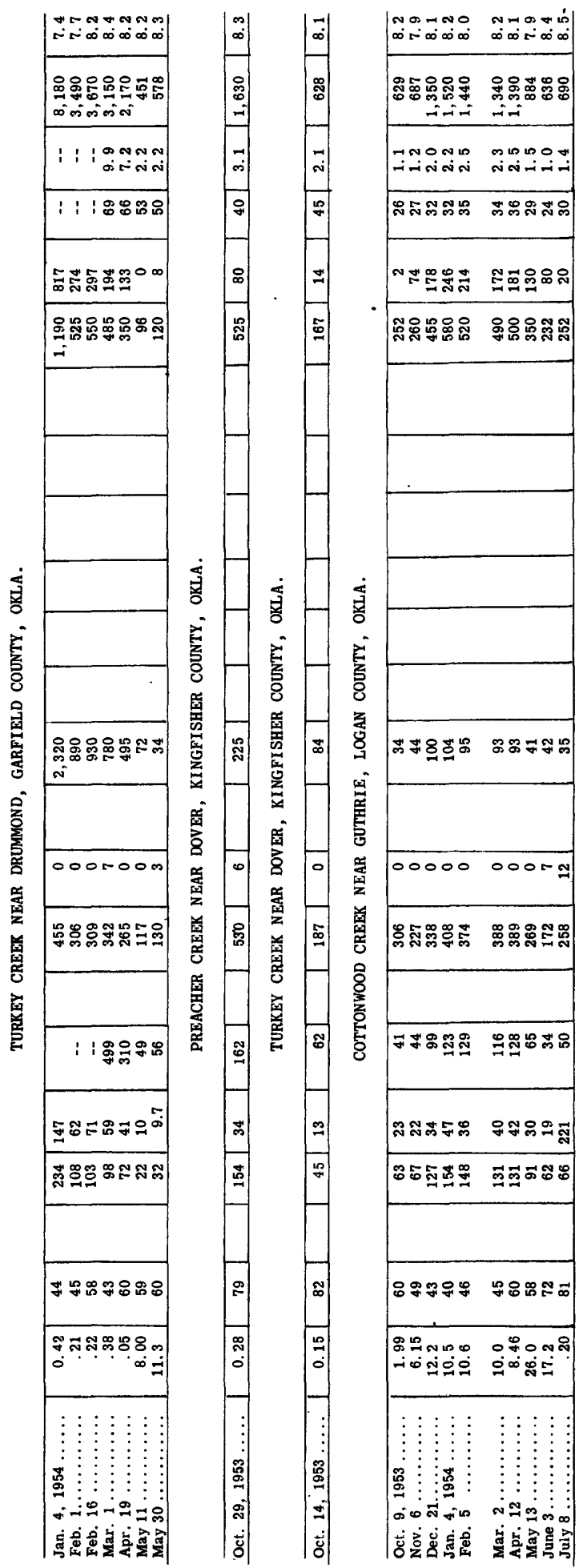




\begin{tabular}{|c|c|c|c|c|c|c|c|}
\hline & 폄 & & 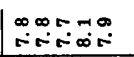 & $\begin{array}{l}0=0 \rightarrow 0 \\
\infty \infty \infty \infty+\infty) \infty\end{array}$ & 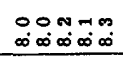 & 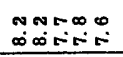 & 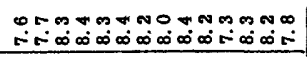 \\
\hline & 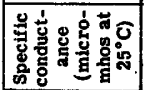 & & 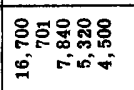 & 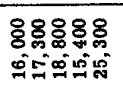 & 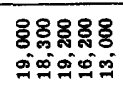 & 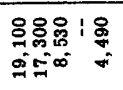 & 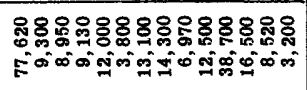 \\
\hline & 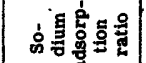 & & is & $: 1: 1:$ & $1: 1: 1$ & $::: 1:$ & : : : 1:19:1:1: : \\
\hline & 离莣富皇 & & $1=: ： 1$ & : : 1: : & : : : : i & : : : : : : & 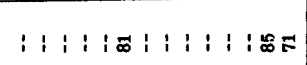 \\
\hline & 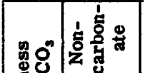 & & 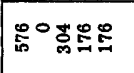 & 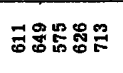 & 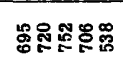 & 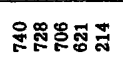 & 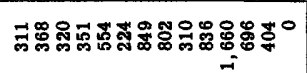 \\
\hline & 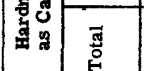 & & 동 & 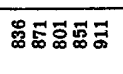 & 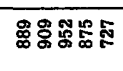 & 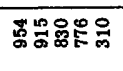 & 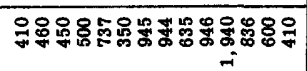 \\
\hline 营 & 善高要 & & & & & & \\
\hline & 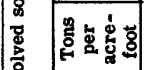 & & & & & & \\
\hline 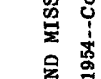 & 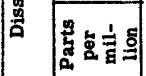 & & & & & & \\
\hline & 宮莒鱼 & 送 & & & & & \\
\hline 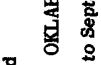 & 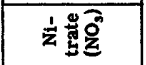 & 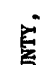 & & & & & \\
\hline & 富带国 & 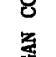 & & & & & \\
\hline 要 & 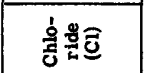 & 8 & 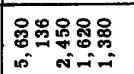 & 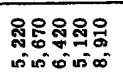 & 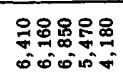 & 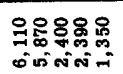 & 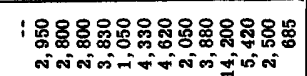 \\
\hline 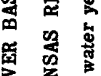 & 实带曼 & 密 & & & & & \\
\hline 这 & มื่ & 㓙 & 00000 & 00000 & $0000 \mathrm{~m}$ & 00000 & $00 N 00+00 \$ 00000$ \\
\hline 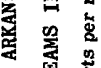 & 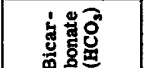 & $\sum_{\infty}$ & 号年吅只馬 & 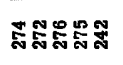 & 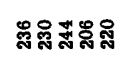 & 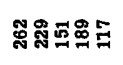 & 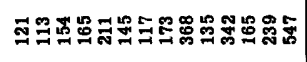 \\
\hline 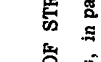 & 旅悬受 & 新 & & & & & \\
\hline 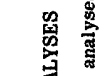 & 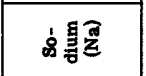 & & 1: $: 1\}$ & : : i : i & $: 1: 1:$ & $:: 1: 1:$ & ：：：：：：届：：：：：：：： \\
\hline 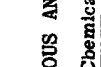 & 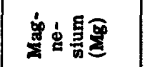 & & 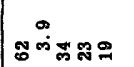 & ๕๕ロำ & 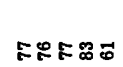 & 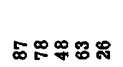 & 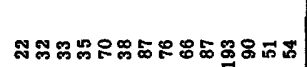 \\
\hline$\frac{9}{3}$ & 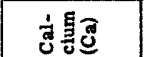 & & פ్తి & สำรสำ & 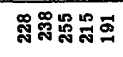 & 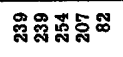 & 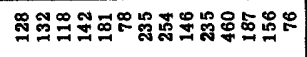 \\
\hline 岶 & 密跑 & & & & & & \\
\hline & 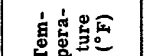 & & 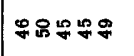 & 平积品 & 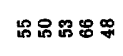 & 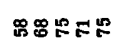 & 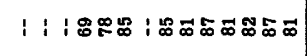 \\
\hline & 总总 & & 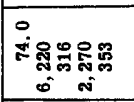 & 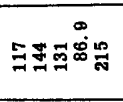 & 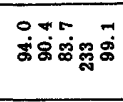 & 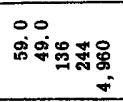 & 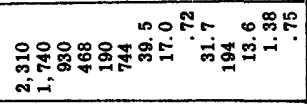 \\
\hline & 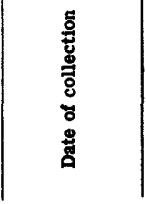 & & 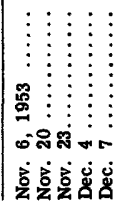 & 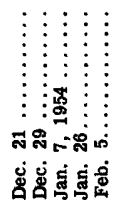 & 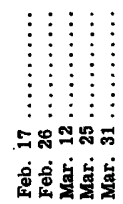 & 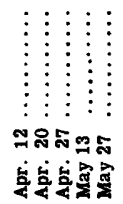 & 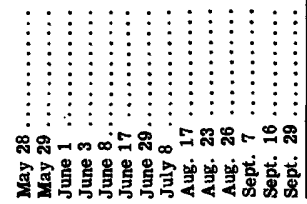 \\
\hline
\end{tabular}




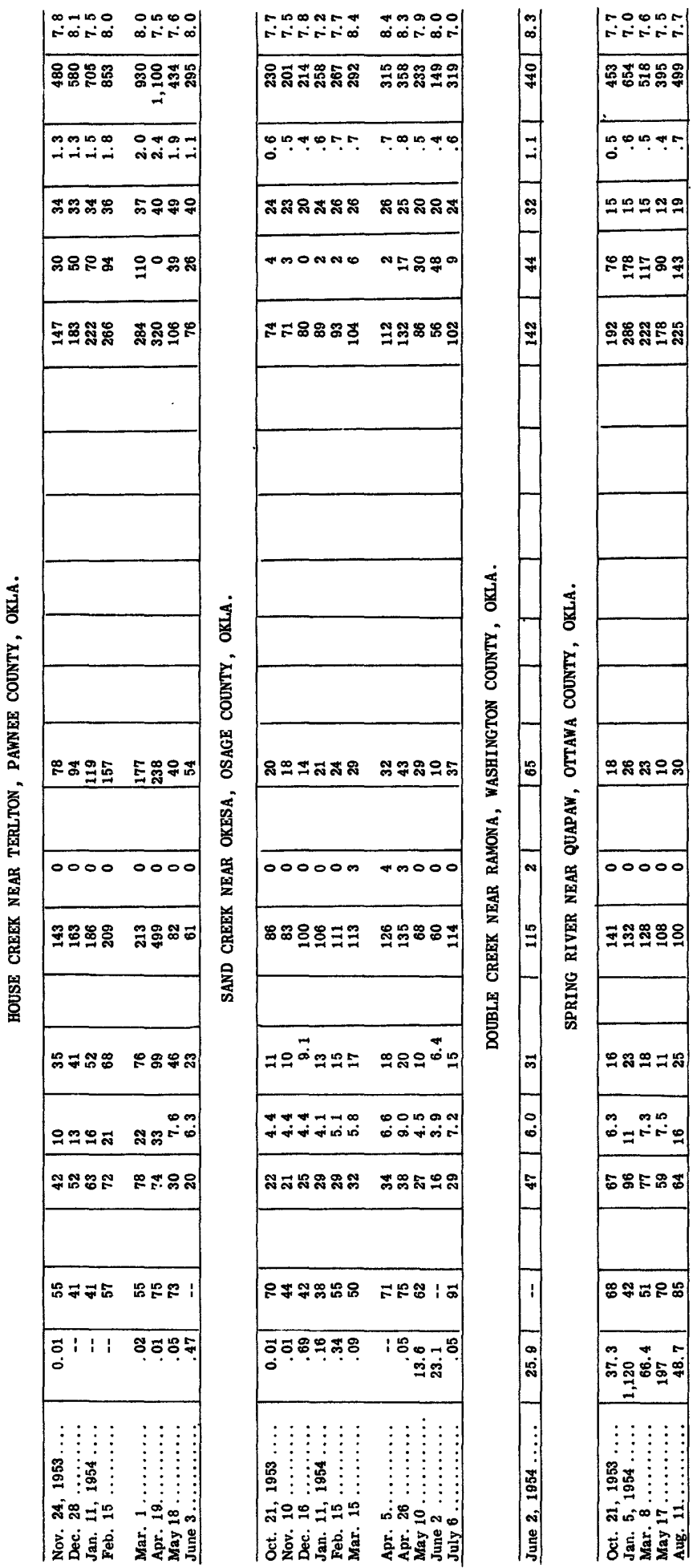




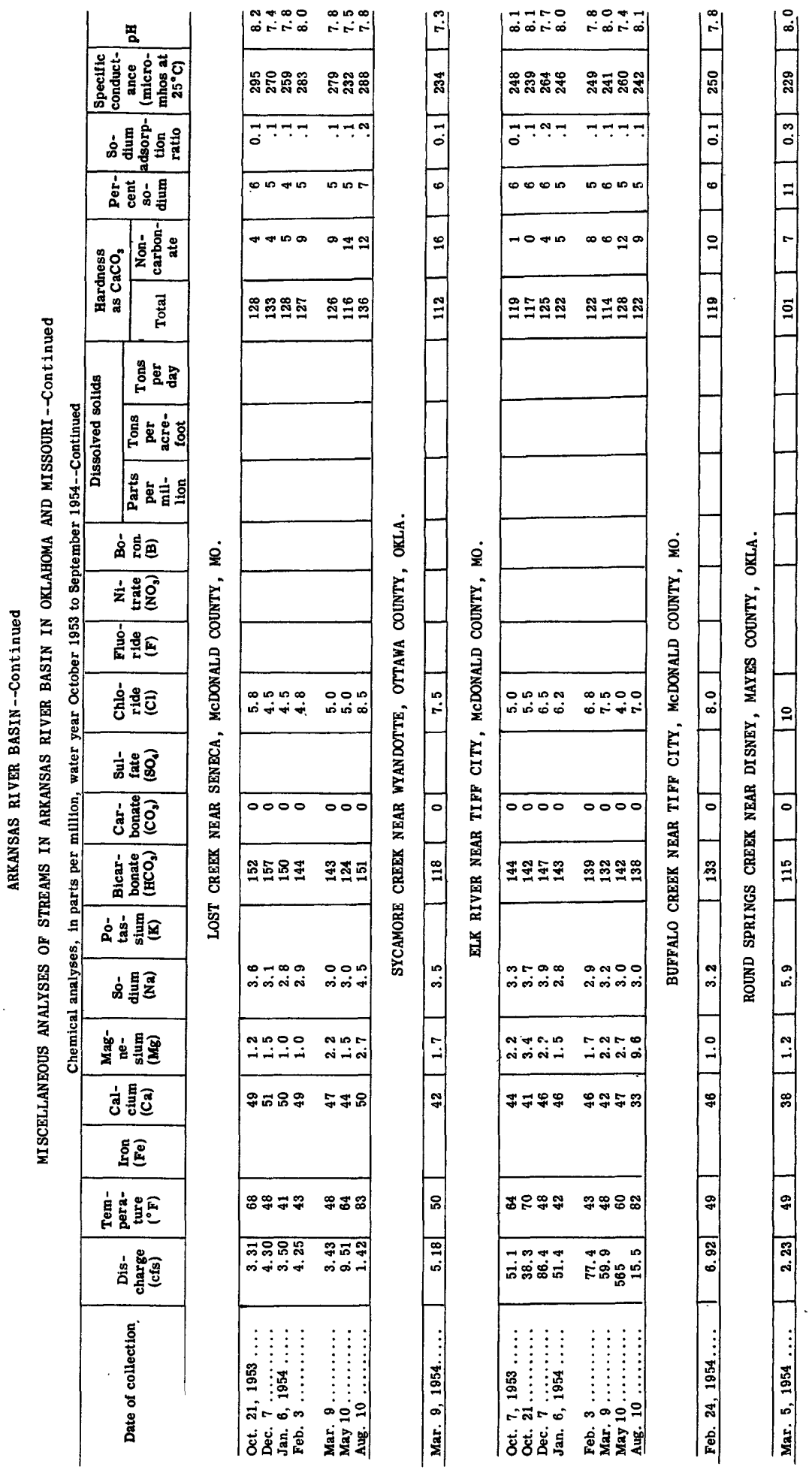




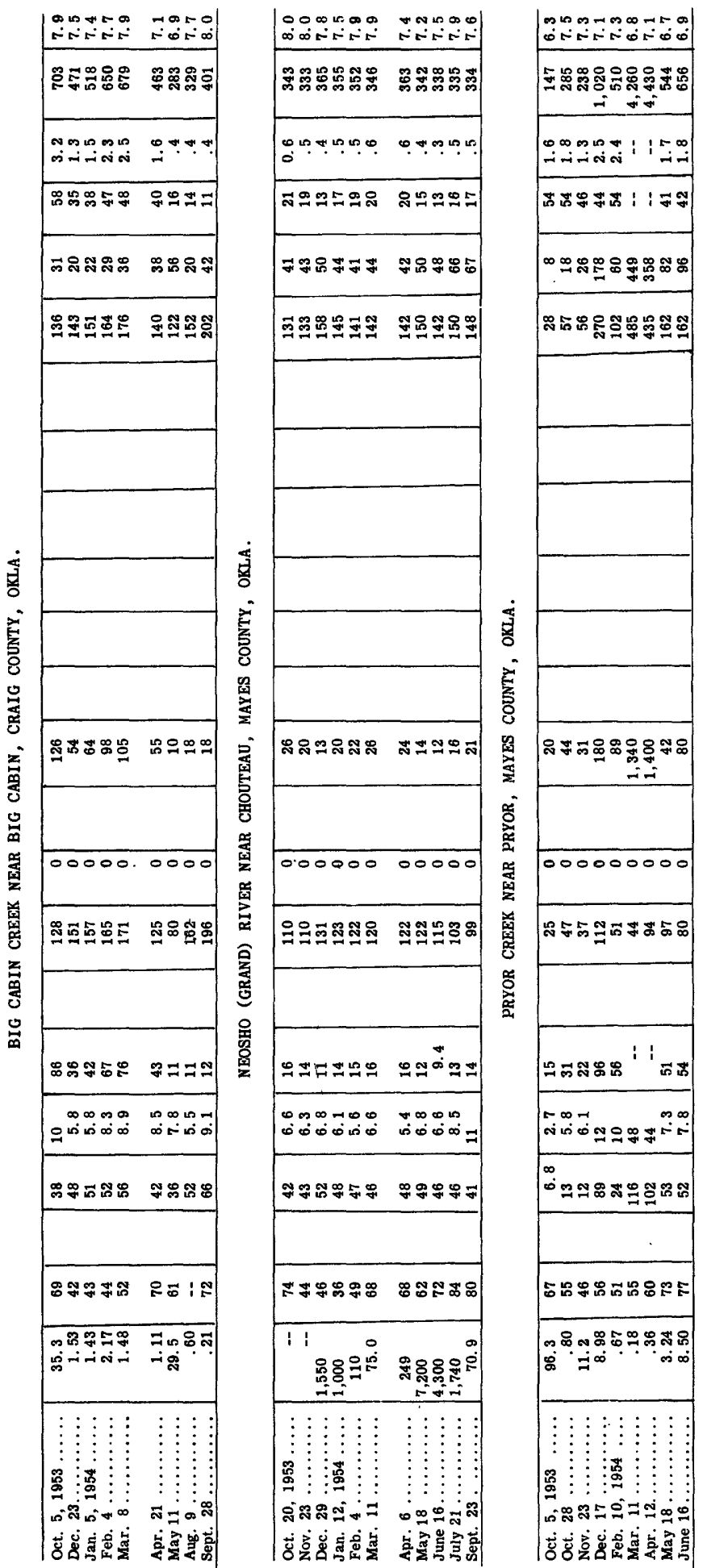




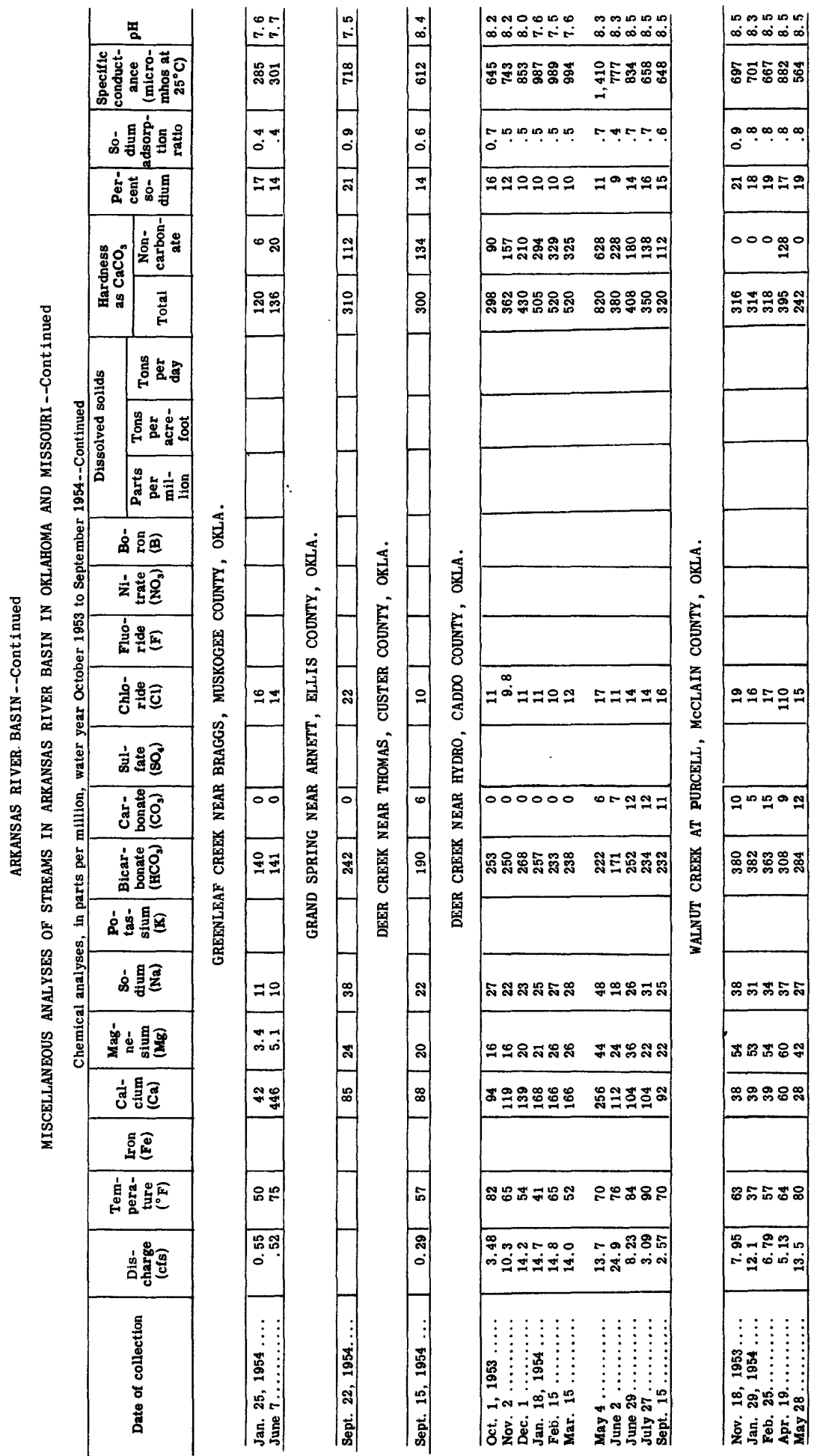




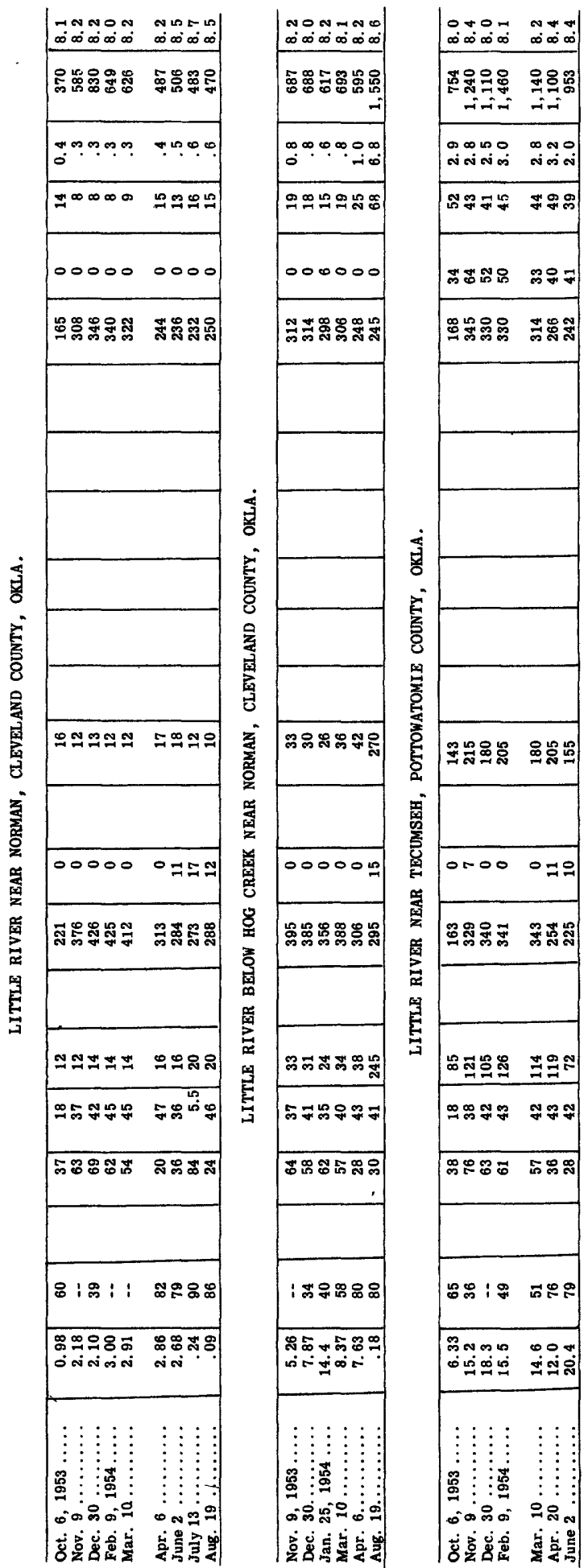




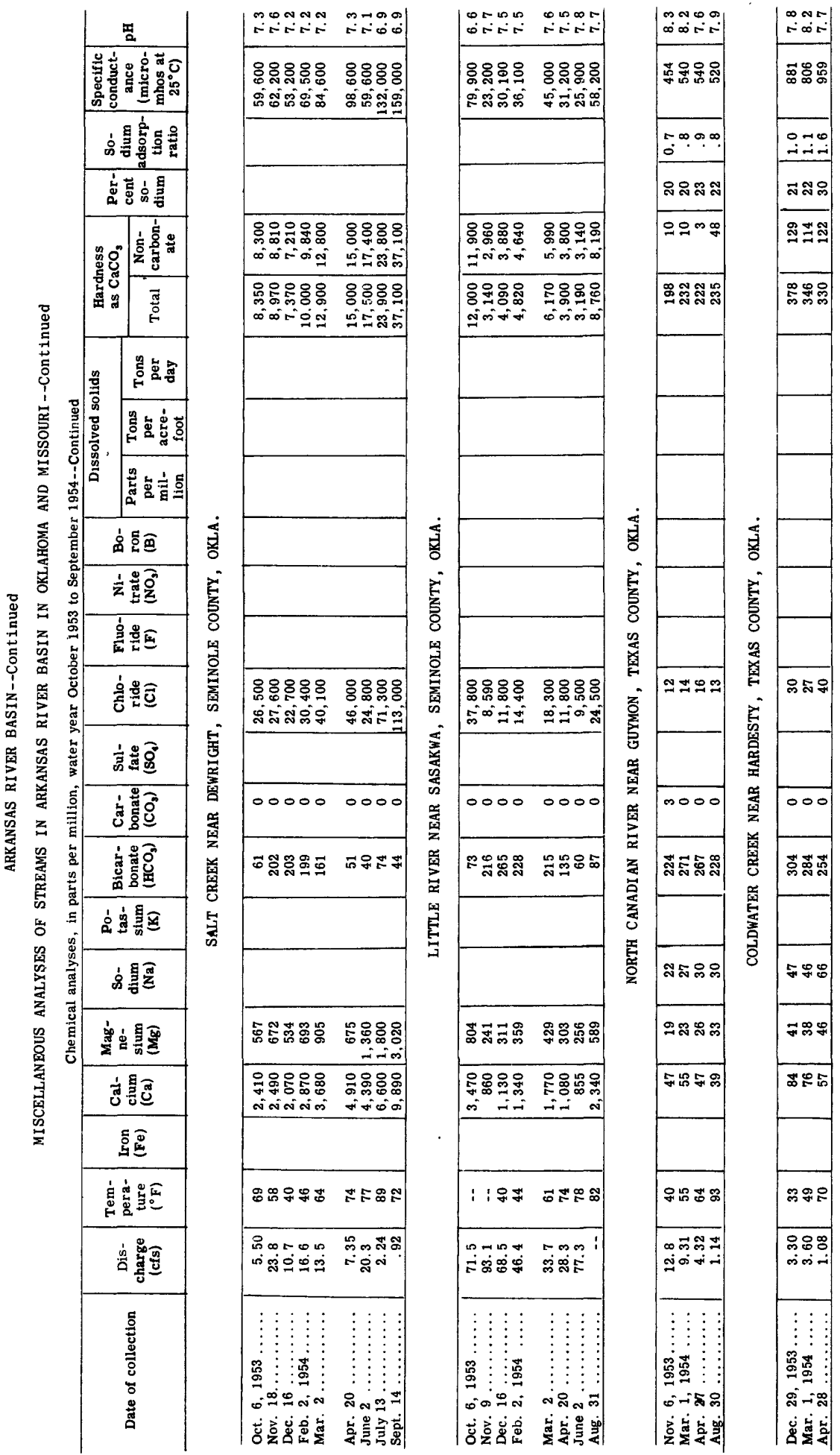




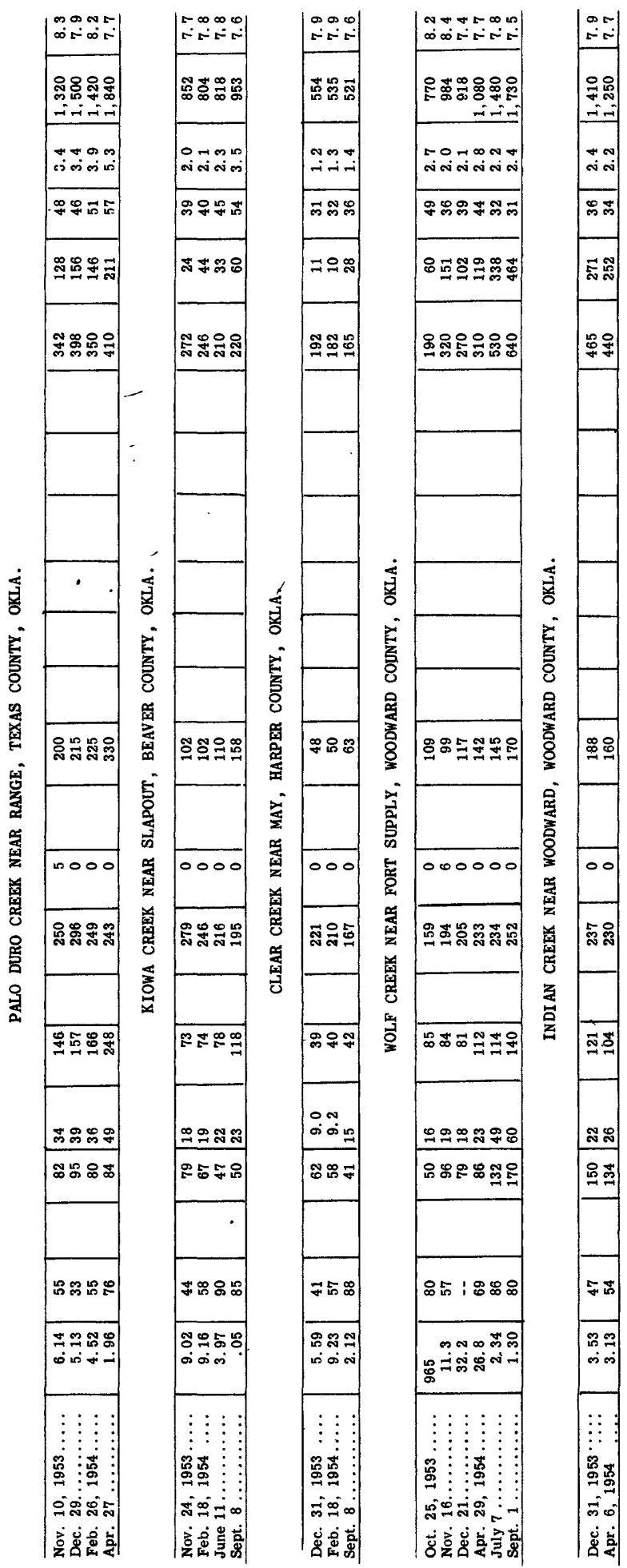




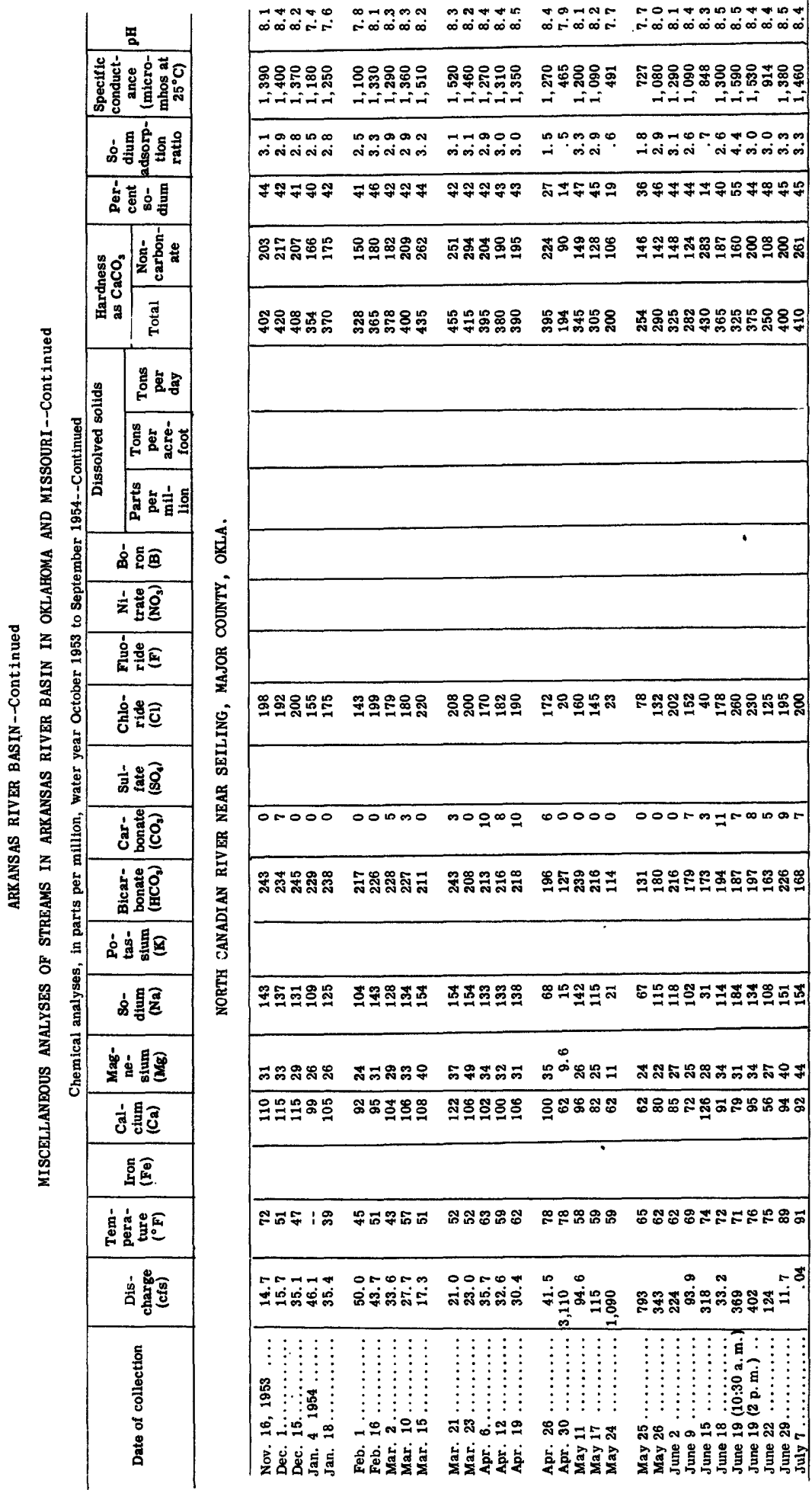




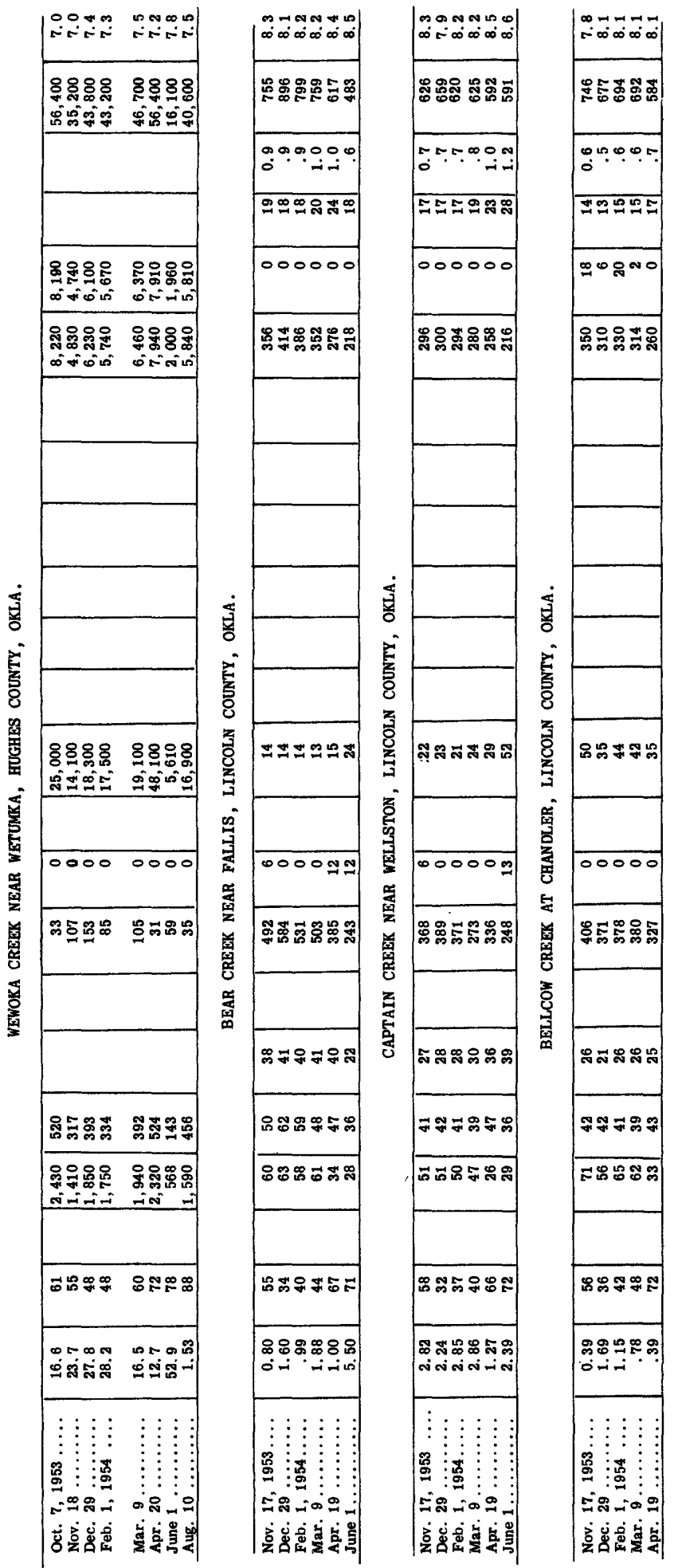




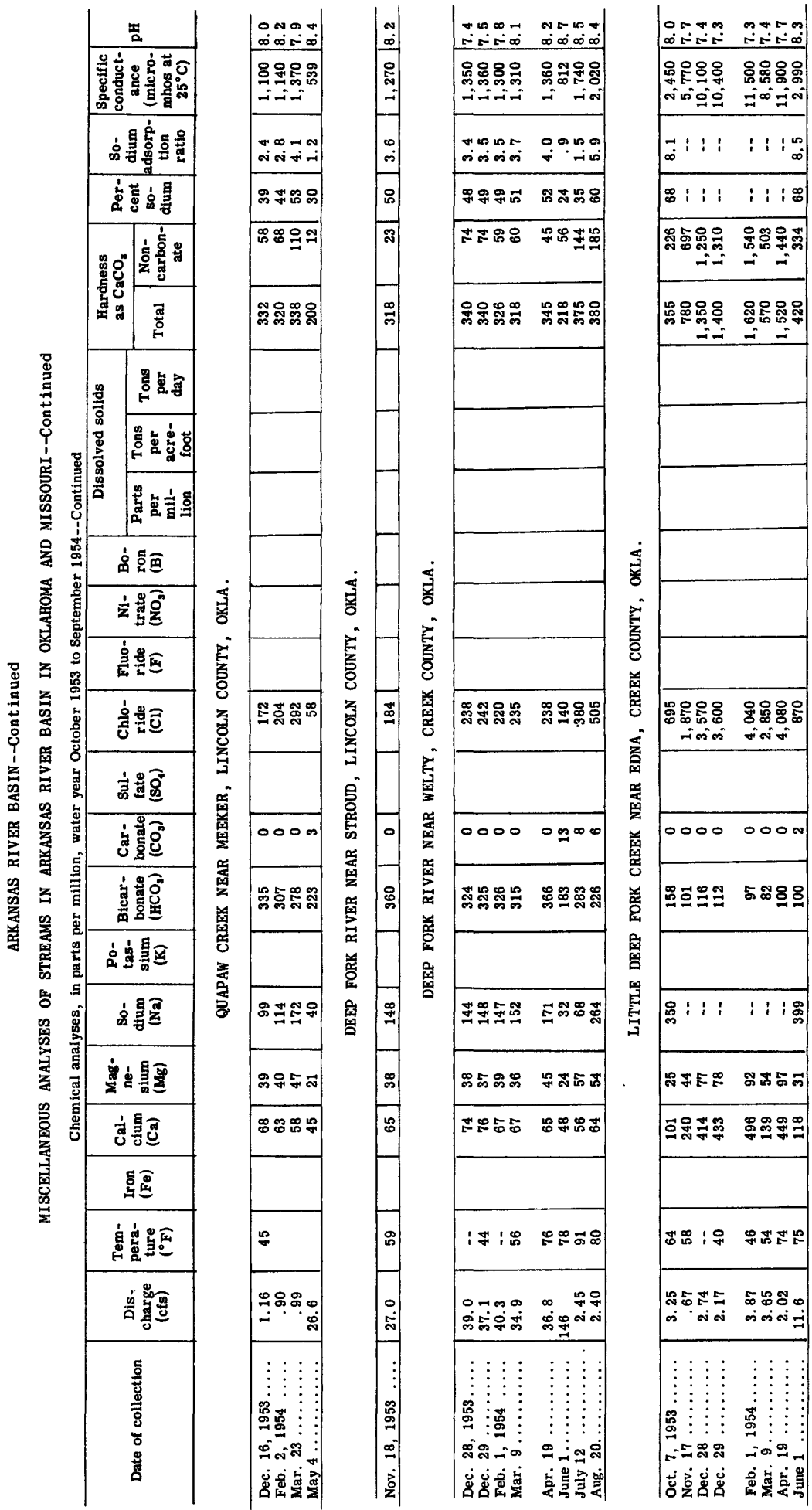




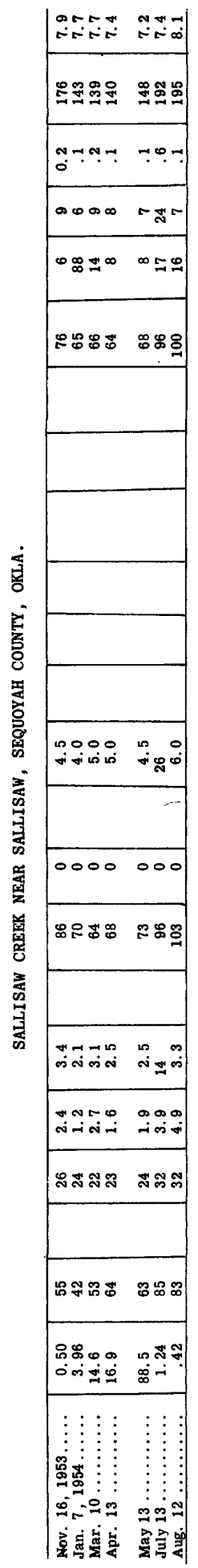




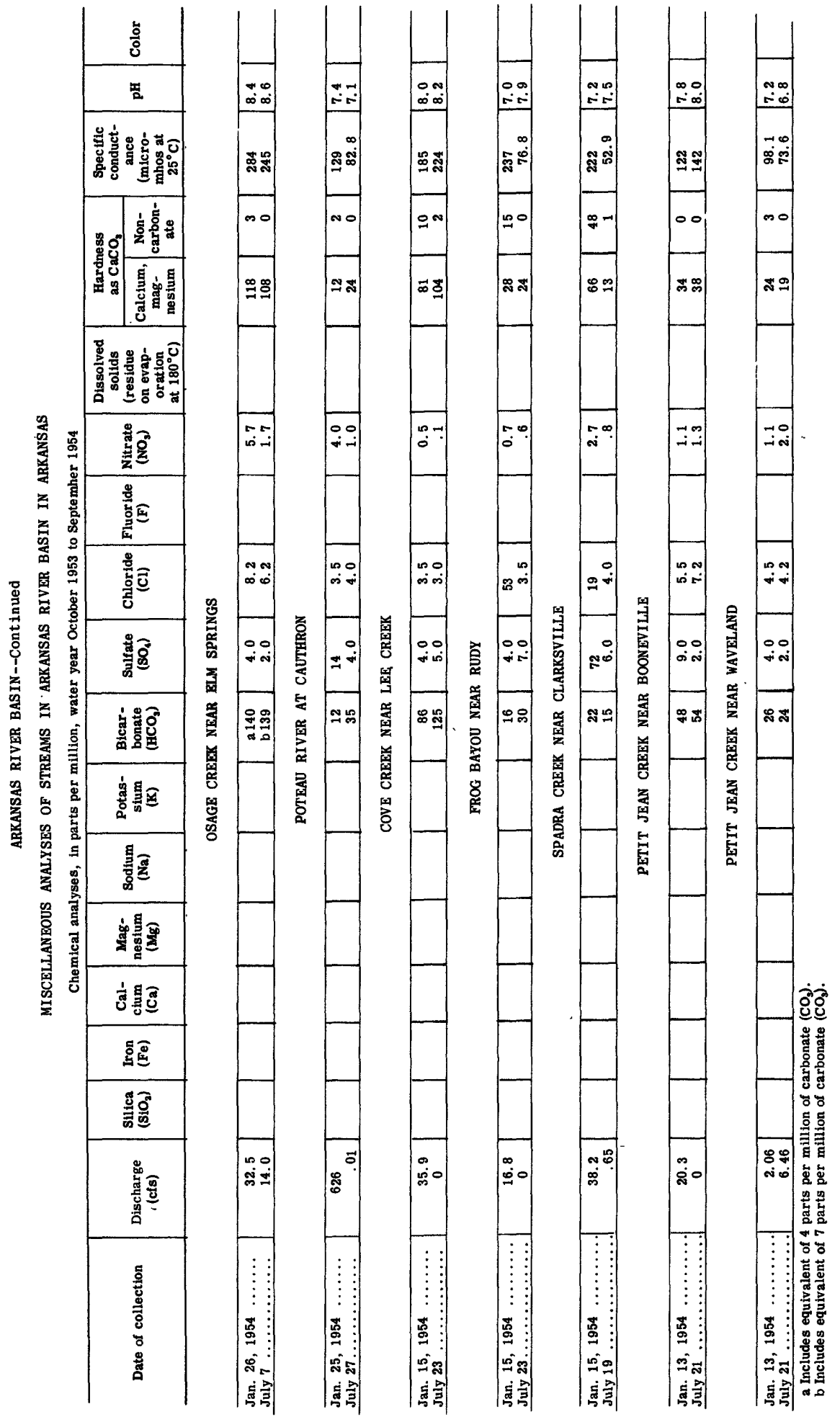




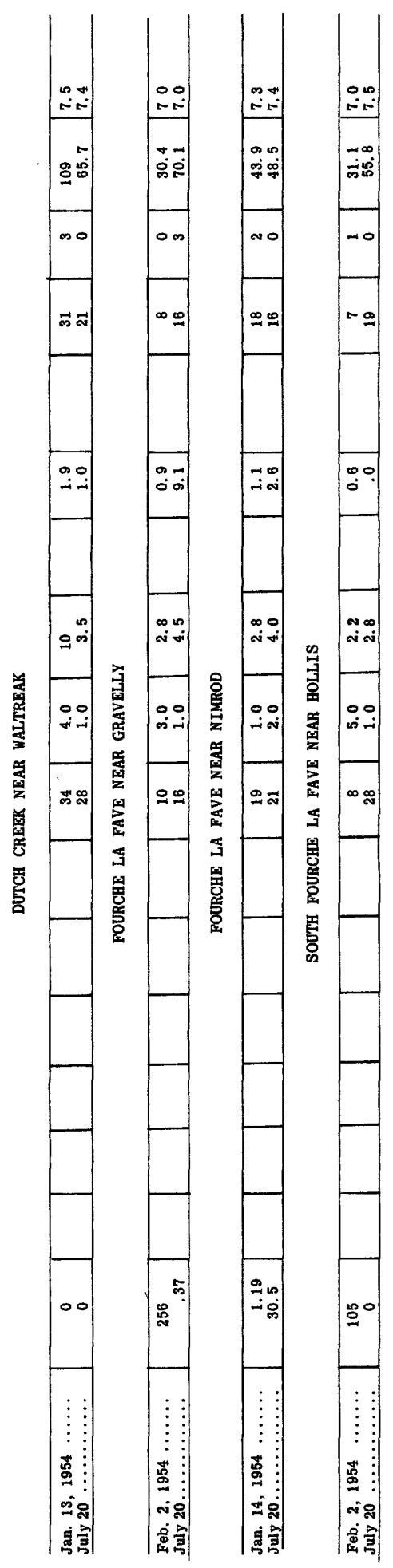




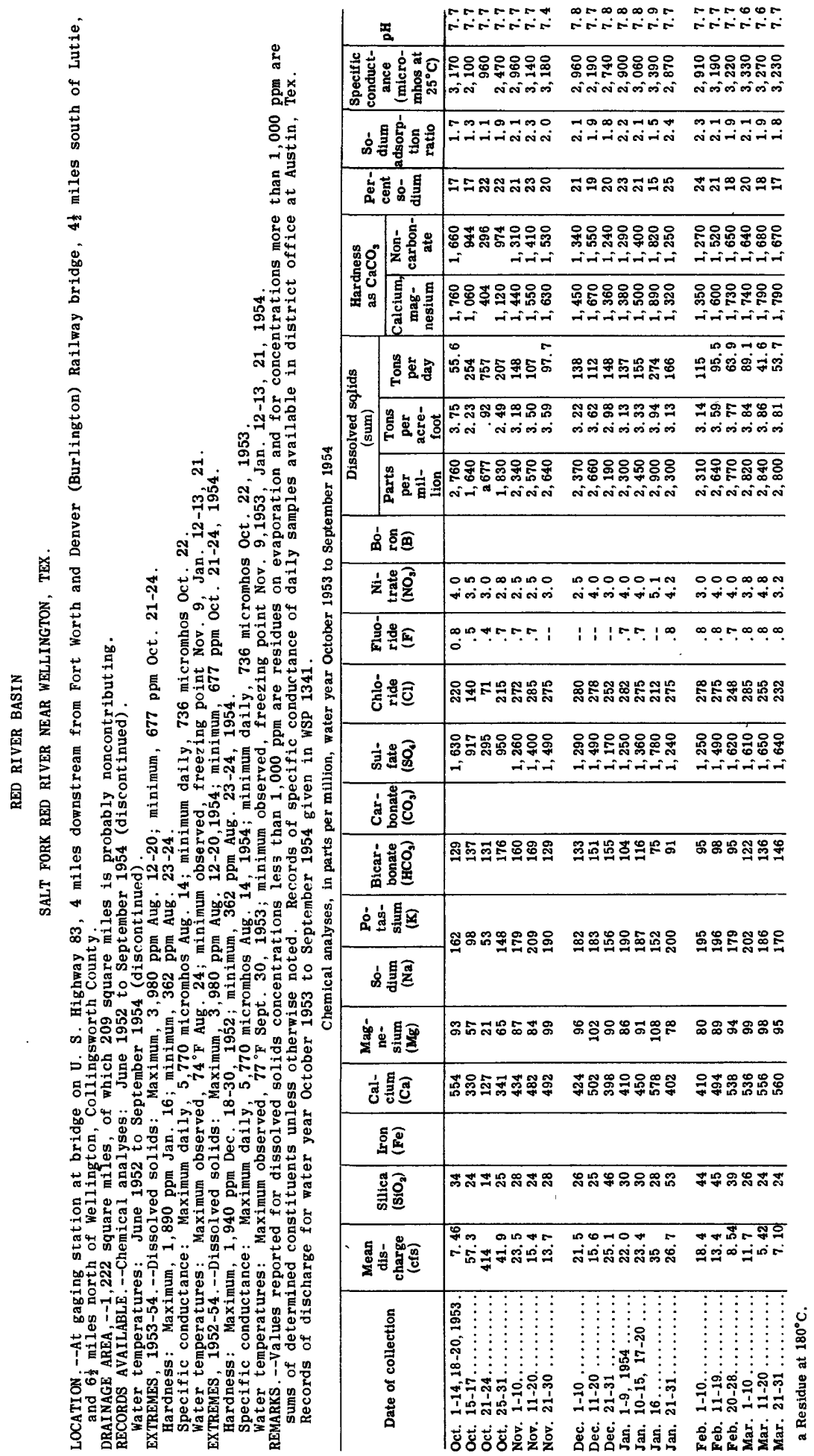




\begin{tabular}{|c|c|c|c|c|c|}
\hline$\sum_{\infty}^{\infty}$ & $\stackrel{\infty}{i}$ & 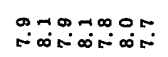 & 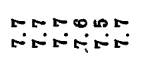 & 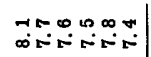 & \\
\hline 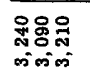 & 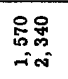 & 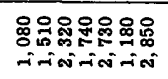 & 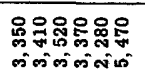 & 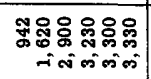 & 象 \\
\hline in & oim & Fio & mod & 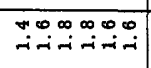 & $\stackrel{\infty}{-}$ \\
\hline 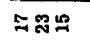 & 요 & 요ำลำสำ & สุฒ สิ สีฐั & ลฒ & 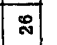 \\
\hline 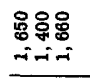 & 沛 & 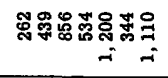 & 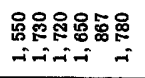 & 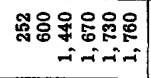 & 文 \\
\hline $\begin{array}{l}\text { 웅유 } \\
\text { ini-i }\end{array}$ & 怘惉 & 品品 ⿻ㅗ⿱ & 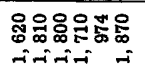 & 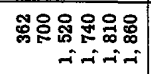 & 范 \\
\hline ஹֻ & 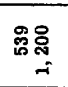 & 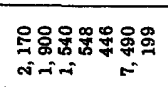 & 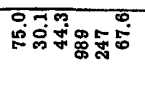 & 哭 & 呫 \\
\hline 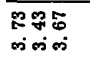 & $\begin{array}{l}F \vec{m} \\
-i \dot{i n}\end{array}$ & 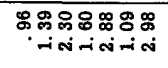 & 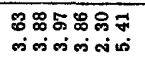 & 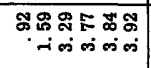 & $\begin{array}{l}\text { in } \\
-i\end{array}$ \\
\hline $\begin{array}{l}\text { iㅛ유요 } \\
\text { जiñ }\end{array}$ & 융원 & 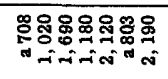 & 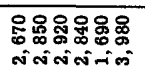 & 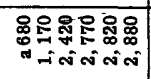 & $\begin{array}{l} \\
- \\
-\end{array}$ \\
\hline $\begin{array}{l}0.00 \\
\text { insios }\end{array}$ & 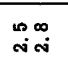 & 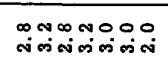 & $\begin{array}{l}\text { Yous } \\
\text { Sinion }\end{array}$ & 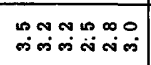 & : \\
\hline$\infty_{0}^{\infty} . \infty$. & $\because$ & 6.? & $\because \sqcap \infty \infty$ & $\because \div \infty .90$ & $\because$ \\
\hline స్ูำ & 荨喿 & ธธ్ โสำ & 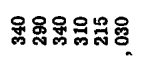 & 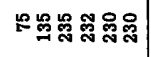 & $\Xi$ \\
\hline 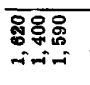 & 葛品 & 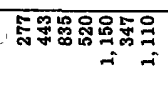 & 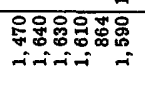 & 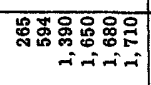 & 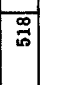 \\
\hline 嗎 & $\Phi$ & 串: & ஜ\$: & 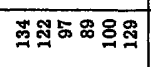 & I \\
\hline : & $\cong$ & $F \Xi \Xi$ & 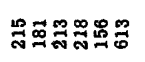 & ๙ & s \\
\hline ஓேே & 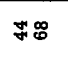 & $: F$ & 8 & 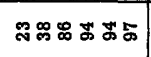 & o \\
\hline 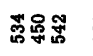 & 。్త & $\exists:$ & 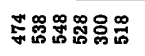 & 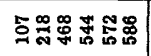 & $\begin{array}{c}\infty \\
\pm \\
=\end{array}$ \\
\hline 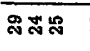 & 怘 & สิธี & 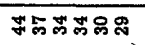 & 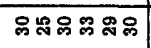 & 䑰 \\
\hline 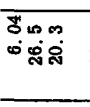 & 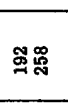 & 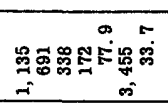 & 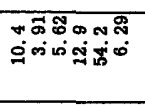 & 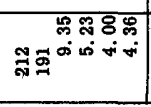 & @ \\
\hline 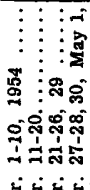 & 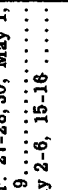 & 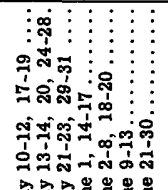 & 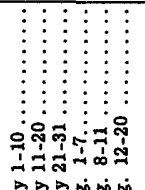 & 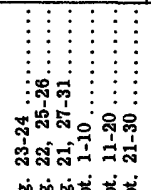 & : \\
\hline & & & 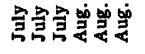 & 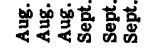 & \\
\hline
\end{tabular}


RED RIVER BASIN--Cont inued

SALT FORK RED RIVER NEAR WELLINGTON, TEX.--Cont inued

Temperature ( ${ }^{\circ} \mathrm{F}$ ) of water, water year October 1953 to September 1954

\begin{tabular}{|c|c|c|c|c|c|c|c|c|c|c|c|c|}
\hline Day & Oct. & Nov. & Dec. & Jan. & Feb. & Mar. & Apr. & May & June & July & Aug. & Sept \\
\hline $\begin{array}{l}1 \\
2 \\
3 \\
4 \\
5\end{array}$ & $\begin{array}{l}\mathbf{5 9} \\
\mathbf{5 7} \\
\mathbf{6 0} \\
\mathbf{5 5} \\
\mathbf{5 5}\end{array}$ & $\begin{array}{l}\mathbf{5 4} \\
\mathbf{5 5} \\
\mathbf{5 1} \\
\mathbf{5 5} \\
\mathbf{5 0}\end{array}$ & $\begin{array}{l}48 \\
50 \\
45 \\
40 \\
42\end{array}$ & $\begin{array}{l}36 \\
38 \\
41 \\
45 \\
38\end{array}$ & $\begin{array}{l}38 \\
39 \\
41 \\
43 \\
45\end{array}$ & $\begin{array}{l}40 \\
36 \\
33 \\
35 \\
38\end{array}$ & $\begin{array}{l}40 \\
50 \\
51 \\
48 \\
50\end{array}$ & $\begin{array}{l}55 \\
43 \\
45 \\
44 \\
48\end{array}$ & $\begin{array}{l}68 \\
60 \\
57 \\
57 \\
62\end{array}$ & $\begin{array}{l}68 \\
67 \\
-- \\
68 \\
69\end{array}$ & $\begin{array}{l}72 \\
73 \\
70 \\
73 \\
73\end{array}$ & $\begin{array}{l}70 \\
70 \\
70 \\
69 \\
68\end{array}$ \\
\hline $\begin{array}{r}6 \\
7 \\
8 \\
9 \\
10\end{array}$ & $\begin{array}{l}49 \\
50 \\
47 \\
51 \\
55\end{array}$ & $\begin{array}{l}44 \\
41 \\
43 \\
31 \\
44\end{array}$ & $\begin{array}{l}41 \\
39 \\
38 \\
-38\end{array}$ & $\begin{array}{l}39 \\
46 \\
38 \\
35 \\
35\end{array}$ & $\begin{array}{l}42 \\
44 \\
44 \\
45 \\
44\end{array}$ & $\begin{array}{l}36 \\
38 \\
36 \\
40 \\
42\end{array}$ & $\begin{array}{l}47 \\
53 \\
55 \\
52 \\
55\end{array}$ & $\begin{array}{l}53 \\
65 \\
55 \\
55 \\
60\end{array}$ & $\begin{array}{l}64 \\
62 \\
62 \\
70 \\
65\end{array}$ & $\begin{array}{l}71 \\
71 \\
72 \\
70 \\
70\end{array}$ & $\begin{array}{l}72 \\
72 \\
72 \\
72 \\
70\end{array}$ & $\begin{array}{l}67 \\
70 \\
69 \\
69 \\
62\end{array}$ \\
\hline $\begin{array}{l}11 \\
12 \\
13 \\
14 \\
15\end{array}$ & $\begin{array}{l}\mathbf{5 5} \\
52 \\
58 \\
60 \\
61\end{array}$ & $\begin{array}{l}47 \\
44 \\
45 \\
44 \\
45\end{array}$ & $\begin{array}{l}36 \\
\mathbf{3 6} \\
\mathbf{3 5} \\
\mathbf{3 4} \\
\mathbf{3 6}\end{array}$ & $\begin{array}{l}34 \\
32 \\
32 \\
45 \\
44\end{array}$ & $\begin{array}{l}41 \\
38 \\
43 \\
45 \\
48\end{array}$ & $\begin{array}{l}50 \\
40 \\
45 \\
40 \\
40\end{array}$ & $\begin{array}{r}50 \\
45 \\
.53 \\
58 \\
55\end{array}$ & $\begin{array}{l}\mathbf{5 6} \\
53 \\
\mathbf{5 5} \\
\mathbf{5 5} \\
\mathbf{5 8}\end{array}$ & $\begin{array}{l}65 \\
69 \\
69 \\
68 \\
65\end{array}$ & $\begin{array}{l}69 \\
68 \\
70 \\
71 \\
72\end{array}$ & $\begin{array}{l}70 \\
69 \\
69 \\
69 \\
69\end{array}$ & $\begin{array}{l}59 \\
60 \\
60 \\
64 \\
70\end{array}$ \\
\hline $\begin{array}{l}16 \\
17 \\
18 \\
19 \\
20\end{array}$ & $\begin{array}{l}61 \\
60 \\
60 \\
61 \\
62\end{array}$ & $\begin{array}{l}43 \\
45 \\
55 \\
41 \\
57\end{array}$ & $\begin{array}{l}36 \\
-5 \\
40 \\
45 \\
45\end{array}$ & $\begin{array}{l}41 \\
35 \\
41 \\
38 \\
44\end{array}$ & $\begin{array}{l}50 \\
41 \\
45 \\
45 \\
45\end{array}$ & $\begin{array}{l}40 \\
42 \\
43 \\
42 \\
40\end{array}$ & $\begin{array}{l}46 \\
50 \\
55 \\
56 \\
58\end{array}$ & $\begin{array}{l}62 \\
62 \\
64 \\
61 \\
60\end{array}$ & $\begin{array}{l}69 \\
68 \\
70 \\
69 \\
69\end{array}$ & $\begin{array}{l}70 \\
71 \\
72 \\
72 \\
72\end{array}$ & $\begin{array}{l}72 \\
71 \\
69 \\
72 \\
71\end{array}$ & $\begin{array}{l}-- \\
69 \\
70 \\
73 \\
72\end{array}$ \\
\hline $\begin{array}{l}21 \\
22 \\
23 \\
24 \\
25\end{array}$ & $\begin{array}{l}58 \\
60 \\
55 \\
57 \\
55\end{array}$ & $\begin{array}{l}40 \\
42 \\
40 \\
-- \\
48\end{array}$ & $\begin{array}{l}45 \\
41 \\
35 \\
34 \\
36\end{array}$ & $\begin{array}{l}32 \\
33 \\
-- \\
-- \\
--\end{array}$ & $\begin{array}{l}44 \\
42 \\
46 \\
45 \\
58\end{array}$ & $\begin{array}{l}44 \\
46 \\
47 \\
-- \\
--\end{array}$ & $\begin{array}{l}60 \\
55 \\
55 \\
58 \\
60\end{array}$ & $\begin{array}{l}59 \\
60 \\
60 \\
-- \\
58\end{array}$ & $\begin{array}{l}68 \\
71 \\
70 \\
72 \\
69\end{array}$ & $\begin{array}{l}72 \\
73 \\
70 \\
70 \\
69\end{array}$ & $\begin{array}{l}72 \\
-- \\
73 \\
74 \\
72\end{array}$ & $\begin{array}{l}\mathbf{5 7} \\
\mathbf{5 9} \\
\mathbf{5 7} \\
\mathbf{5 5} \\
\mathbf{6 2}\end{array}$ \\
\hline $\begin{array}{l}26 \\
27 \\
28 \\
29 \\
30 \\
31\end{array}$ & $\begin{array}{l}52 \\
47 \\
50 \\
55 \\
56 \\
57 \\
\end{array}$ & $\begin{array}{l}46 \\
46 \\
44 \\
41 \\
40 \\
--\end{array}$ & $\begin{array}{l}38 \\
37 \\
35 \\
37 \\
38 \\
34\end{array}$ & $\begin{array}{l}-- \\
35 \\
45 \\
45 \\
44 \\
40\end{array}$ & $\begin{array}{l}-- \\
46 \\
-- \\
-- \\
-- \\
--\end{array}$ & $\begin{array}{l}43 \\
46 \\
50 \\
36 \\
38 \\
39 \\
\end{array}$ & $\begin{array}{l}64 \\
60 \\
62 \\
59 \\
50 \\
-- \\
\end{array}$ & $\begin{array}{l}\mathbf{5 6} \\
\mathbf{5 8} \\
\mathbf{6 0} \\
\mathbf{5 7} \\
60 \\
61 \\
\end{array}$ & $\begin{array}{l}69 \\
70 \\
69 \\
69 \\
68 \\
-- \\
\end{array}$ & $\begin{array}{l}69 \\
69 \\
70 \\
71 \\
71 \\
70 \\
\end{array}$ & $\begin{array}{l}72 \\
71 \\
72 \\
71 \\
72 \\
71 \\
\end{array}$ & $\begin{array}{l}63 \\
68 \\
65 \\
66 \\
62 \\
-- \\
\end{array}$ \\
\hline $\begin{array}{c}\text { Aver- } \\
\text { age }\end{array}$ & 56 & 46 & 39 & 39 & 44 & 41 & 54 & 57 & 67 & 70 & 71 & 66 \\
\hline
\end{tabular}


RED RIVER BASIN--Continued

NORTH FORK RED RIVER NEAR CARTER, OKLA.

LOCATION.--At gaging station at bridge on State Highway 34, 3 miles south of Carter, Beckham County, 10.8 miles downstream from Timber Creek, and at mile 110.5.

DRAINAGE AREA. --2,337 square miles (revised), of which 399 square miles is probably

noncontributing.

RECORDS AVAILABLE.--Sediment records: March 1948 to September 1954.

EXTREMES, 1953-54.--Sediment concentrations: Maximum, 12,000 ppm Oct. 27; minimum, no

flow oct. 1-2, 6-20, Dec. 16-17, June 26-30, July 1-31, Aug. 1-6, 8-9, 11-31, Sept. 1-30. Sediment loads: Maximum daily, 287,000 tons May 24; minimum, no flow 0ct. 1-2, 6-20,

Dec. 16-17, June 26-30, July 1-31, Aug. 1-6, 8-9, 11-31, Sept. 1-30.

EXTREMES, 1948-54.--Sediment concentrations: Maximum, 19,600 ppm Sept. 26, 1950; minimum, no flow at times each year.

Sediment loads: Maximum daily, 633,000 tons May 18, 1951; minimum, no flow at times each year.

REMARKS.--Records of discharge for water year October 1953 to September $1954 \mathrm{given}$ in WSP 1341 .

Suspended sediment, water year October 1953 to September 1954

\begin{tabular}{|c|c|c|c|c|c|c|c|c|c|}
\hline \multirow[b]{3}{*}{ Day } & \multicolumn{3}{|c|}{ October } & \multicolumn{3}{|c|}{ November } & \multicolumn{3}{|c|}{ December } \\
\hline & \multirow[b]{2}{*}{$\begin{array}{l}\text { Mean } \\
\text { dis- } \\
\text { charge } \\
\text { (cfs) }\end{array}$} & \multicolumn{2}{|c|}{ Suspended sediment } & \multirow[b]{2}{*}{$\begin{array}{c}\text { Mean } \\
\text { dis- } \\
\text { charge } \\
\text { (cfs) }\end{array}$} & \multicolumn{2}{|c|}{ Suspended sediment } & \multirow[b]{2}{*}{$\begin{array}{l}\text { Mean } \\
\text { dis- } \\
\text { charge } \\
\text { (cfs) }\end{array}$} & \multicolumn{2}{|c|}{ Suspended sediment } \\
\hline & & $\begin{array}{l}\text { Mean } \\
\text { concen- } \\
\text { tration } \\
\text { (ppm) }\end{array}$ & $\begin{array}{l}\text { Tons } \\
\text { per } \\
\text { day }\end{array}$ & & $\begin{array}{c}\text { Mean } \\
\text { concen- } \\
\text { tration } \\
\text { (ppm) }\end{array}$ & $\begin{array}{l}\text { Tons } \\
\text { per } \\
\text { day }\end{array}$ & & $\begin{array}{c}\text { Mean } \\
\text { concen- } \\
\text { tration } \\
\text { (ppm) }\end{array}$ & $\begin{array}{l}\text { Tons } \\
\text { per } \\
\text { day }\end{array}$ \\
\hline $\begin{array}{l}1 \ldots \ldots \\
2 \ldots \ldots \\
3 . \ldots \ldots \\
4 \ldots \ldots \\
5 \ldots \ldots\end{array}$ & $\begin{array}{c}0 \\
0 \\
301 \\
99 \\
1.0\end{array}$ & $\begin{array}{r}0 \\
0 \\
3,990 \\
4,050 \\
737\end{array}$ & $\begin{array}{r}0 \\
0 \\
\mathrm{~s} 10,700 \\
\mathrm{~s} 1,870 \\
2.0\end{array}$ & $\begin{array}{l}11 \\
10 \\
9.1 \\
8.4 \\
8.1\end{array}$ & $\begin{array}{r}1,080 \\
899 \\
294 \\
807 \\
323\end{array}$ & $\begin{array}{c}32 \\
24 \\
7.2 \\
18 \\
7.1\end{array}$ & $\begin{array}{l}2.2 \\
1.4 \\
1.7 \\
1.2 \\
1.0\end{array}$ & $\begin{array}{l}619 \\
476 \\
442 \\
478 \\
652\end{array}$ & $\begin{array}{l}3.7 \\
1.8 \\
2.0 \\
1.5 \\
1.8\end{array}$ \\
\hline $\begin{array}{r}6 \ldots \ldots \\
7 \ldots \ldots \\
8 \ldots \ldots \\
9 \ldots \ldots \\
10 \ldots \ldots\end{array}$ & & & & $\begin{array}{l}7.8 \\
6.6 \\
5.7 \\
5.4 \\
5.7\end{array}$ & $\begin{array}{l}510 \\
200 \\
290 \\
376 \\
306\end{array}$ & $\begin{array}{r}11 \\
3.6 \\
4.5 \\
5.5 \\
4.7\end{array}$ & $\begin{array}{l}1.0 \\
2.0 \\
2.6 \\
2.2 \\
2.0\end{array}$ & $\begin{array}{l}451 \\
386 \\
364 \\
526 \\
422\end{array}$ & $\begin{array}{l}1.2 \\
2.1 \\
2.6 \\
3.1 \\
2.5\end{array}$ \\
\hline $\begin{array}{l}11 . \ldots \ldots \\
12 \ldots \ldots \\
13 . \ldots \ldots \\
14 \ldots \ldots \\
15 \ldots \ldots\end{array}$ & $\mathbf{0}$ & 0 & $\mathbf{0}$ & $\begin{array}{l}4.9 \\
4.2 \\
2.4 \\
1.7 \\
1.0\end{array}$ & \begin{tabular}{r|r}
114 \\
68 \\
-58 \\
110 \\
205
\end{tabular} & $\begin{array}{r}1.5 \\
.8 \\
.4 \\
.5 \\
.6\end{array}$ & $\begin{array}{r}2.2 \\
3.9 \\
1.5 \\
1.0 \\
.2\end{array}$ & $\begin{array}{l}131 \\
188 \\
218 \\
146 \\
126\end{array}$ & $\begin{array}{r}.8 \\
2.0 \\
.9 \\
.4 \\
.1\end{array}$ \\
\hline $\begin{array}{l}16 \ldots \ldots \\
17 . \ldots \ldots \\
18 . \ldots \ldots \\
19 \ldots \ldots \\
20 \ldots \ldots\end{array}$ & & & & $\begin{array}{c}1.2 \\
1.2 \\
1.5 \\
108 \\
37\end{array}$ & $\begin{array}{r}202 \\
220 \\
212 \\
6,320 \\
4,370\end{array}$ & $\begin{array}{r}.7 \\
.7 \\
.93,860 \\
\text { s 481 }\end{array}$ & $\begin{array}{l}0 \\
0 \\
.2 \\
.9 \\
2.2\end{array}$ & $\begin{array}{r}0 \\
0 \\
122 \\
124 \\
166\end{array}$ & $\begin{array}{l}0 \\
0 \\
.1 \\
.3 \\
1.0\end{array}$ \\
\hline $\begin{array}{l}21 \ldots \ldots \\
22 . \ldots \ldots \\
23 . \ldots \ldots \\
24 \ldots \ldots \\
25 . \ldots \ldots\end{array}$ & $\begin{array}{r}6.1 \\
934 \\
2,490 \\
333 \\
118\end{array}$ & $\begin{array}{r}994 \\
11,300 \\
10,500 \\
5,000 \\
5,740\end{array}$ & $\begin{array}{r}s 51 \\
s 49,200 \\
s 81,700 \\
s 5,040 \\
s 2,220\end{array}$ & $\begin{array}{c}16 \\
6.3 \\
3.7 \\
28 \\
20\end{array}$ & $\begin{array}{l}\mathbf{7 0 0} \\
\mathbf{5 8 6} \\
\mathbf{6 1 0} \\
\mathbf{5 2 2} \\
\mathbf{5 3 2}\end{array}$ & $\begin{array}{l}30 \\
10 \\
6.1 \\
3.9 \\
2.9\end{array}$ & $\begin{array}{r}2.4 \\
2.2 \\
1.4 \\
.6 \\
.9\end{array}$ & $\begin{array}{l}349 \\
346 \\
382 \\
303 \\
480\end{array}$ & $\begin{array}{r}2.3 \\
2.1 \\
1.4 \\
.5 \\
1.2\end{array}$ \\
\hline $\begin{array}{l}26 . \ldots \ldots \\
27 . \ldots \ldots \\
28 . \ldots \ldots \\
29 . \ldots \ldots \\
30 \ldots \ldots \\
31 . \ldots \ldots\end{array}$ & $\begin{array}{r}182 \\
279 \\
80 \\
38 \\
22 \\
15\end{array}$ & $\begin{array}{r}7,000 \\
12,000 \\
6,400 \\
3,400 \\
2,400 \\
1,350\end{array}$ & $\begin{array}{r}\mathrm{s} 3,620 \\
\mathrm{~s} 10,100 \\
\mathrm{~s} 1,430 \\
348 \\
142 \\
55\end{array}$ & $\begin{array}{r}1.2 \\
1.5 \\
1.4 \\
1.5 \\
1.0 \\
--\end{array}$ & $\begin{array}{r}1,010 \\
871 \\
971 \\
856 \\
984 \\
--\end{array}$ & $\begin{array}{r}3.3 \\
3.5 \\
3.7 \\
3.5 \\
2.7 \\
--\end{array}$ & $\begin{array}{l}1.4 \\
2.0 \\
3.7 \\
3.0 \\
5.2 \\
4.7\end{array}$ & $\begin{array}{l}194 \\
286 \\
224 \\
260 \\
248 \\
258 \\
\end{array}$ & $\begin{array}{l}.7 \\
1.5 \\
2.2 \\
2.1 . \\
3.5 \\
3.3\end{array}$ \\
\hline Total. & $4,898.1$ & - & 166,478 & 278.3 & -- & $4,534.3$ & 56.9 & -- & 48.7 \\
\hline
\end{tabular}

s Computed by subdividing day.

$4888170-59-13$ 
RED RIVER BASIN--Continued

NORTH FORK RED RIVER NEAR CARTER, OKLA.--Continued

Suspended sediment, water year October 1953 to September 1954--Continued

\begin{tabular}{|c|c|c|c|c|c|c|c|c|c|}
\hline \multirow[b]{3}{*}{ Day } & \multicolumn{3}{|c|}{ January } & \multicolumn{3}{|c|}{ February } & \multicolumn{3}{|c|}{ March } \\
\hline & \multirow[b]{2}{*}{$\begin{array}{c}\text { Mean } \\
\text { dis- } \\
\text { charge } \\
\text { (cfs) }\end{array}$} & \multicolumn{2}{|c|}{ Suspended sediment } & \multirow[b]{2}{*}{$\begin{array}{l}\text { Mean } \\
\text { dis- } \\
\text { charge } \\
\text { (cfs) }\end{array}$} & \multicolumn{2}{|c|}{ Suspended sediment } & \multirow[b]{2}{*}{$\begin{array}{l}\text { Mean } \\
\text { dis- } \\
\text { charge } \\
\text { (cfs) }\end{array}$} & \multicolumn{2}{|c|}{ Suspended sediment } \\
\hline & & $\begin{array}{l}\text { Mean } \\
\text { concen- } \\
\text { tration } \\
\text { (ppm) }\end{array}$ & $\begin{array}{l}\text { Tons } \\
\text { per } \\
\text { day }\end{array}$ & & $\begin{array}{c}\text { Mean } \\
\text { concen- } \\
\text { tration } \\
(\mathrm{ppm})\end{array}$ & $\begin{array}{l}\text { Tons } \\
\text { per } \\
\text { day }\end{array}$ & & $\begin{array}{c}\text { Mean } \\
\text { concen- } \\
\text { tration } \\
\text { (ppm) }\end{array}$ & $\begin{array}{l}\text { Tons } \\
\text { per } \\
\text { day }\end{array}$ \\
\hline $\begin{array}{l}1 . \ldots \ldots \\
2 . \ldots \ldots \\
3 . \ldots \ldots \\
4 . \ldots \ldots \\
5 . \ldots \ldots\end{array}$ & $\begin{array}{l}4.4 \\
5.7 \\
6.3 \\
6.0 \\
5.7\end{array}$ & $\begin{array}{l}128 \\
112 \\
138 \\
111 \\
120\end{array}$ & $\begin{array}{r}1.5 \\
1.7 \\
2.3 \\
1.8 \\
\mathrm{a} 1.8\end{array}$ & $\begin{array}{l}14 \\
14 \\
13 \\
11 \\
10\end{array}$ & $\begin{array}{l}723 \\
740 \\
740 \\
752 \\
700\end{array}$ & $\begin{array}{r}27 \\
\text { a } 28 \\
\text { a } 26 \\
22 \\
19\end{array}$ & $\begin{array}{l}4.7 \\
4.2 \\
4.4 \\
4.4 \\
5.7\end{array}$ & $\begin{array}{l}78 \\
92 \\
90 \\
86 \\
83\end{array}$ & $\begin{array}{r}1.0 \\
1.0 \\
\text { a } 1.1 \\
1.0 \\
1.3\end{array}$ \\
\hline $\begin{array}{r}6 \ldots \ldots \\
7 \ldots \ldots \\
8 \ldots \ldots \\
9 \ldots \ldots \\
10 \ldots \ldots\end{array}$ & $\begin{array}{l}6.0 \\
5.7 \\
5.7 \\
5.7 \\
5.4\end{array}$ & $\begin{array}{l}437 \\
424 \\
516 \\
362 \\
467\end{array}$ & $\begin{array}{l}7.1 \\
6.5 \\
7.9 \\
5.6 \\
6.8\end{array}$ & $\begin{array}{l}9.4 \\
8.4 \\
8.1 \\
8.1 \\
7.8\end{array}$ & $\begin{array}{l}846 \\
226 \\
276 \\
263 \\
219\end{array}$ & $\begin{array}{r}21 \\
5.1 \\
6.0 \\
5.8 \\
4.6\end{array}$ & $\begin{array}{l}7.5 \\
9.1 \\
8.4 \\
8.1 \\
7.5\end{array}$ & $\begin{array}{l}189 \\
199 \\
186 \\
193 \\
174\end{array}$ & $\begin{array}{l}3.8 \\
4.9 \\
4.2 \\
4.2 \\
3.5\end{array}$ \\
\hline $\begin{array}{l}11 \ldots \ldots \\
12 \ldots \ldots \\
13 \ldots \ldots \\
14 \ldots \ldots \\
15 . \ldots \ldots\end{array}$ & $\begin{array}{l}5.4 \\
5.4 \\
5.7 \\
6.0 \\
6.9\end{array}$ & $\begin{array}{l}390 \\
346 \\
492 \\
386 \\
442\end{array}$ & $\begin{array}{l}5.7 \\
5.0 \\
7.6 \\
6.2 \\
8.2\end{array}$ & $\begin{array}{l}6.9 \\
5.7 \\
5.2 \\
4.9 \\
5.4\end{array}$ & $\begin{array}{l}271 \\
290 \\
258 \\
291 \\
244\end{array}$ & $\begin{array}{l}5.0 \\
4.5 \\
3.6 \\
3.8 \\
3.6\end{array}$ & $\begin{array}{l}7.2 \\
5.2 \\
3.7 \\
3.0 \\
3.2\end{array}$ & $\begin{array}{l}91 \\
89 \\
94 \\
81 \\
84\end{array}$ & $\begin{array}{r}1.8 \\
1.2 \\
.9 \\
.7 \\
.7\end{array}$ \\
\hline $\begin{array}{l}16 \ldots \ldots \\
17 . \ldots \ldots \\
18 . \ldots \ldots \\
19 . \ldots \ldots \\
20 . \ldots \ldots\end{array}$ & $\begin{array}{l}7.2 \\
7.2 \\
10 \\
16 \\
11\end{array}$ & $\begin{array}{l}251 \\
280 \\
292 \\
294 \\
233\end{array}$ & $\begin{array}{c}4.9 \\
5.4 \\
7.9 \\
13 \\
9.9\end{array}$ & $\begin{array}{l}4.9 \\
4.7 \\
4.9 \\
5.7 \\
5.2\end{array}$ & $\begin{array}{l}245 \\
231 \\
214 \\
295 \\
245\end{array}$ & $\begin{array}{l}3.2 \\
2.9 \\
2.8 \\
4.5 \\
3.4\end{array}$ & $\begin{array}{r}1.5 \\
-2.4 \\
3.4 \\
3.2 \\
3.4\end{array}$ & $\begin{array}{r}103 \\
112 \\
99 \\
114 \\
97\end{array}$ & $\begin{array}{r}.4 \\
.7 \\
.9 \\
1.0 \\
.9\end{array}$ \\
\hline $\begin{array}{l}21 . \ldots \ldots \\
22 . \ldots \ldots \\
23 . \ldots \ldots \\
24 \ldots \ldots \\
25 . \ldots \ldots\end{array}$ & $\begin{array}{r}8 \\
7 \\
9 \\
10 \\
11\end{array}$ & $\begin{array}{l}140 \\
144 \\
132 \\
136 \\
132\end{array}$ & $\begin{array}{l}3.0 \\
2.7 \\
3.2 \\
3.7 \\
3.9\end{array}$ & $\begin{array}{l}4.7 \\
3.7 \\
1.4 \\
1.5 \\
3.7\end{array}$ & $\begin{array}{l}135 \\
126 \\
132 \\
148 \\
120\end{array}$ & $\begin{array}{r}1.7 \\
1.3 \\
.5 \\
.6 \\
1.2\end{array}$ & $\begin{array}{l}3.4 \\
3.4 \\
4.4 \\
4.9 \\
3.9\end{array}$ & $\begin{array}{l}55 \\
60 \\
58 \\
56 \\
65\end{array}$ & $\begin{array}{l}.5 \\
.6 \\
.7 \\
.7 \\
.7\end{array}$ \\
\hline $\begin{array}{l}26 \ldots \ldots \\
27 \ldots \ldots \\
28 \ldots \ldots \\
29 . \ldots \ldots \\
30 \ldots \ldots \\
31 \ldots \ldots\end{array}$ & $\begin{array}{l}12 \\
17 \\
22 \\
19 \\
16 \\
13 \\
\end{array}$ & $\begin{array}{l}460 \\
404 \\
387 \\
458 \\
448 \\
419 \\
\end{array}$ & $\begin{array}{l}15 \\
19 \\
23 \\
23 \\
19 \\
15 \\
\end{array}$ & $\begin{array}{r}2.8 \\
4.7 \\
4.4 \\
-- \\
-. \\
-- \\
\end{array}$ & $\begin{array}{r}106 \\
106 \\
117 \\
-- \\
-- \\
-- \\
\end{array}$ & $\begin{array}{r}.8 \\
1.3 \\
1.4 \\
-- \\
-. \\
-- \\
\end{array}$ & $\begin{array}{l}3.7 \\
3.7 \\
3.7 \\
4.2 \\
4.4 \\
3.9 \\
\end{array}$ & $\begin{array}{l}34 \\
36 \\
36 \\
38 \\
34 \\
40 \\
\end{array}$ & $\begin{array}{l}.3 \\
.4 \\
.4 \\
.4 \\
.4 \\
.4 \\
\end{array}$ \\
\hline \multirow[t]{2}{*}{ Total } & 281.4 & $\cdots$ & 247,3 & 184.2 &.- & 210.6 & 143.8 & -- & 40.7 \\
\hline & \multicolumn{3}{|c|}{ April } & \multicolumn{3}{|c|}{ May } & \multicolumn{3}{|c|}{ June } \\
\hline $\begin{array}{l}1 \ldots \ldots \\
2 \ldots \ldots \\
3 \ldots \ldots \\
4 \ldots \ldots \\
5 \ldots \ldots\end{array}$ & $\begin{array}{l}4.2 \\
2.8 \\
2.6 \\
3.0 \\
3.0\end{array}$ & $\begin{array}{l}28 \\
36 \\
29 \\
30 \\
28\end{array}$ & \begin{tabular}{r|}
0.3 \\
.3 \\
.2 \\
.2 \\
.2
\end{tabular} & $\begin{array}{r}1,860 \\
836 \\
382 \\
285 \\
268\end{array}$ & $\begin{array}{l}8,790 \\
7,220 \\
3,600 \\
2,200 \\
2,100\end{array}$ & $\begin{array}{r}s 47,100 \\
s 17,800 \\
3,710 \\
1,690 \\
1,520\end{array}$ & $\begin{array}{l}376 \\
342 \\
313 \\
260 \\
239\end{array}$ & $\begin{array}{r}2,800 \\
2,500 \\
1,400 \\
622 \\
764\end{array}$ & $\begin{array}{r}2,840 \\
2,310 \\
1,180 \\
436 \\
493\end{array}$ \\
\hline $\begin{array}{r}6 \ldots \ldots \\
7 \ldots \ldots \\
8 \ldots \ldots \\
9 \ldots \ldots \\
10 \ldots \ldots\end{array}$ & $\begin{array}{r}2.8 \\
2.6 \\
1.4 \\
1.0 \\
.4\end{array}$ & $\begin{array}{l}52 \\
60 \\
55 \\
57 \\
58\end{array}$ & $\begin{array}{l}.4 \\
.4 \\
.2 \\
.2 \\
.1\end{array}$ & $\begin{array}{l}247 \\
272 \\
224 \\
849 \\
348\end{array}$ & $\begin{array}{r}1,500 \\
1,000 \\
700 \\
6,970 \\
2,600\end{array}$ & $\begin{array}{r}1,000 \\
734 \\
423 \\
\mathrm{~s} 20,400 \\
2,440\end{array}$ & $\begin{array}{l}212 \\
194 \\
180 \\
420 \\
438\end{array}$ & $\begin{array}{r}634 \\
529 \\
310 \\
3,480 \\
2,990\end{array}$ & $\begin{array}{r}363 \\
277 \\
151 \\
\mathrm{~s} 5,560 \\
\mathrm{~s} 4,030\end{array}$ \\
\hline $\begin{array}{l}11 \ldots \ldots \\
12 \ldots \ldots \\
13 \ldots \ldots \\
14 \ldots \ldots \\
15 \ldots \ldots\end{array}$ & $\begin{array}{l}2.8 \\
6.0 \\
8.1 \\
9.1 \\
9.4\end{array}$ & $\begin{array}{r}70 \\
101 \\
78 \\
64 \\
70\end{array}$ & $\begin{array}{l}.5 \\
1.6 \\
1.7 \\
1.6 \\
1.8\end{array}$ & $\begin{array}{r}2,100 \\
2,220 \\
833 \\
653 \\
451\end{array}$ & $\begin{array}{l}8,900 \\
9,370 \\
4,600 \\
4,000 \\
2,900\end{array}$ & $\begin{array}{r}s 66,500 \\
s 60,800 \\
10,300 \\
7,060 \\
3,530\end{array}$ & $\begin{array}{r}1,110 \\
654 \\
485 \\
277 \\
139\end{array}$ & $\begin{array}{l}7,860 \\
8,720 \\
7,400 \\
5,200 \\
2,800\end{array}$ & $\begin{array}{r}\mathrm{s} 34,300 \\
15,400 \\
9,690 \\
3,890 \\
1,050\end{array}$ \\
\hline $\begin{array}{l}16 \ldots \ldots \\
17 \ldots \ldots \\
18 \ldots \ldots \\
19 \ldots \ldots \\
20 \ldots \ldots\end{array}$ & $\begin{array}{l}8.7 \\
8.1 \\
4.7 \\
5.7 \\
3.9\end{array}$ & \begin{tabular}{r|r|}
167 \\
195 \\
176 \\
76 \\
82
\end{tabular} & \begin{tabular}{r|}
3.9 \\
4.3 \\
2.2 \\
1.2 \\
.9
\end{tabular} & $\begin{array}{l}276 \\
383 \\
563 \\
634 \\
588\end{array}$ & $\begin{array}{l}1,900 \\
3,230 \\
4,000 \\
3,100 \\
2,600\end{array}$ & $\begin{array}{r}1,410 \\
\mathrm{~s} 4,880 \\
6,080 \\
5,310 \\
4,130\end{array}$ & $\begin{array}{c}165 \\
71 \\
20 \\
8.1 \\
4.7\end{array}$ & $\begin{array}{r}1,800 \\
1,300 \\
1,150 \\
476 \\
344\end{array}$ & $\begin{array}{r}802 \\
249 \\
62 \\
10 \\
4.4\end{array}$ \\
\hline $\begin{array}{l}21 \ldots \ldots \\
22 \ldots \ldots \ldots \\
23 . \ldots \ldots \\
24 \ldots \ldots \\
25 \ldots \ldots\end{array}$ & $\begin{array}{l}2.0 \\
1.0 \\
1.5 \\
1.5 \\
1.1\end{array}$ & \begin{tabular}{r|r|}
144 \\
73 \\
94 \\
173 \\
212
\end{tabular} & $\begin{array}{l}.8 \\
.2 \\
.4 \\
.7 \\
.6\end{array}$ & $\begin{array}{r}387 \\
316 \\
1,050 \\
9,290 \\
2,800\end{array}$ & $\begin{array}{r}2,300 \\
2,000 \\
8,160 \\
11,900 \\
8,050\end{array}$ & $\begin{array}{r}2,400 \\
1,700 \\
s 32,100 \\
s 287,000 \\
60,800\end{array}$ & $\begin{array}{r}2.4 \\
1.7 \\
1.7 \\
1.7 \\
.6\end{array}$ & $\begin{array}{r}100 \\
40 \\
70 \\
146 \\
80\end{array}$ & $\begin{array}{l}.6 \\
.2 \\
.3 \\
.7 \\
.1\end{array}$ \\
\hline $\begin{array}{l}26 \ldots \ldots \\
27 \ldots \ldots \\
28 \ldots \ldots \\
29 \ldots \ldots \\
30 \ldots \ldots \\
31 \ldots \ldots\end{array}$ & $\begin{array}{r}82^{.2} \\
567 \\
190 \\
4,890 \\
\end{array}$ & $\begin{array}{r}136 \\
1,550 \\
11,300 \\
4,400 \\
11,000 \\
\end{array}$ & $\begin{array}{r}\mathrm{s} 396^{.1} \\
\mathrm{~s} 21,900 \\
\mathrm{~s} 2,420 \\
\mathrm{~s} 192,000\end{array}$ & $\begin{array}{r}1,640 \\
938 \\
403 \\
353 \\
363 \\
830 \\
\end{array}$ & $\begin{array}{l}7,700 \\
5,600 \\
3,500 \\
2,200 \\
1,800 \\
7,980\end{array}$ & $\begin{array}{r}34,100 \\
14,200 \\
3,810 \\
2,100 \\
1,760 \\
\times 22,800 \\
\end{array}$ & $\ldots$ & $\ldots$ & 0 \\
\hline Total & $5,826,6$ & -- & 216,741 & 32,642 & - & 729,587 & $5,915.9$ & -- & $83,099.3$ \\
\hline
\end{tabular}

s Computed by subdividing day.

a Computed from estimated concentration graph. 
RED RI VER BASIN- Cont inued

NORTH FORK RED RIVER NEAR CARTER, OKLA.--COntinued

Suspended sediment, water year October 1953 to September 1954 --Continued

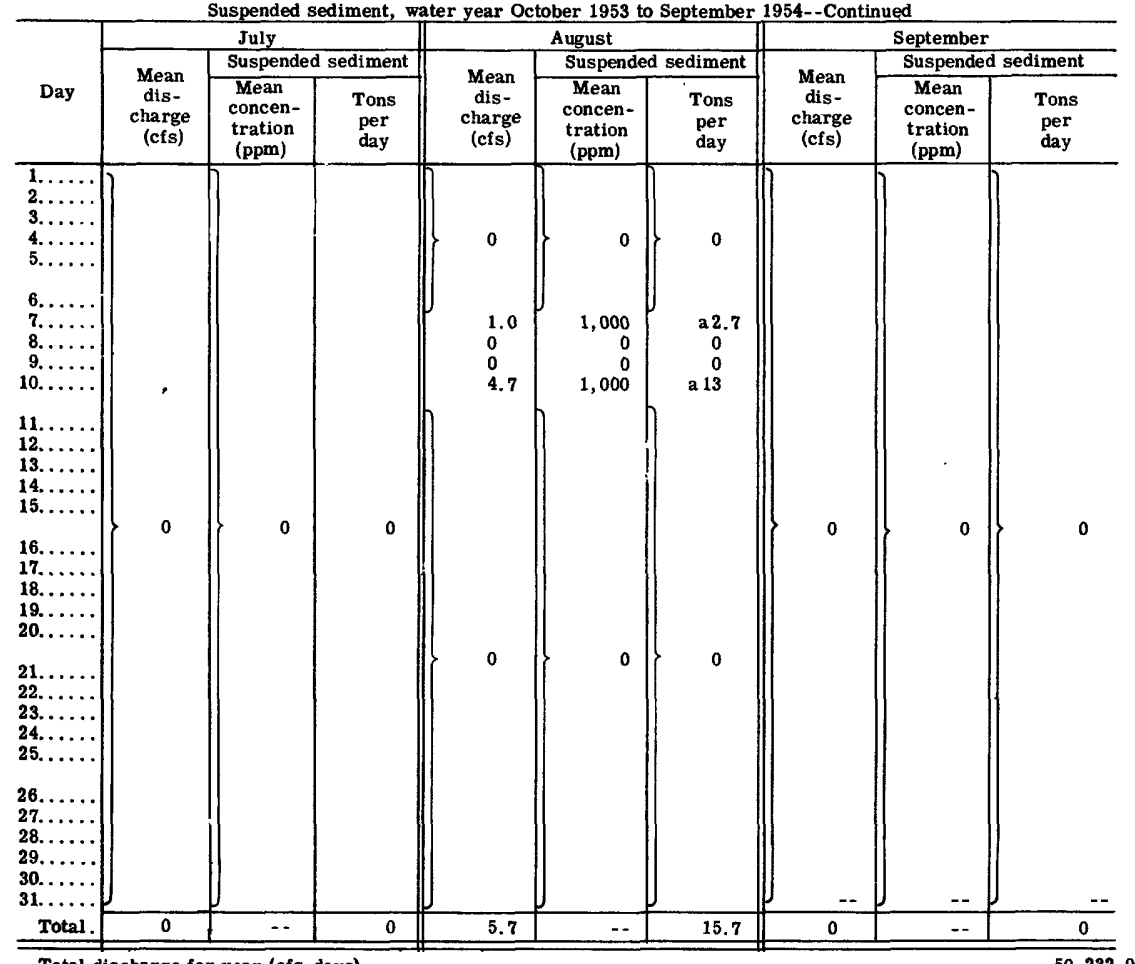

Total discharge for year (cfs-days) $\ldots \ldots \ldots \ldots \ldots \ldots \ldots \ldots \ldots \ldots \ldots \ldots \ldots \ldots \ldots \ldots \ldots \ldots \ldots \ldots \ldots \ldots, \mathbf{5 3 2}, 9$

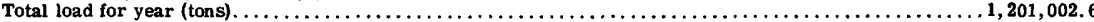

a Computed from estimated concentration graph. 


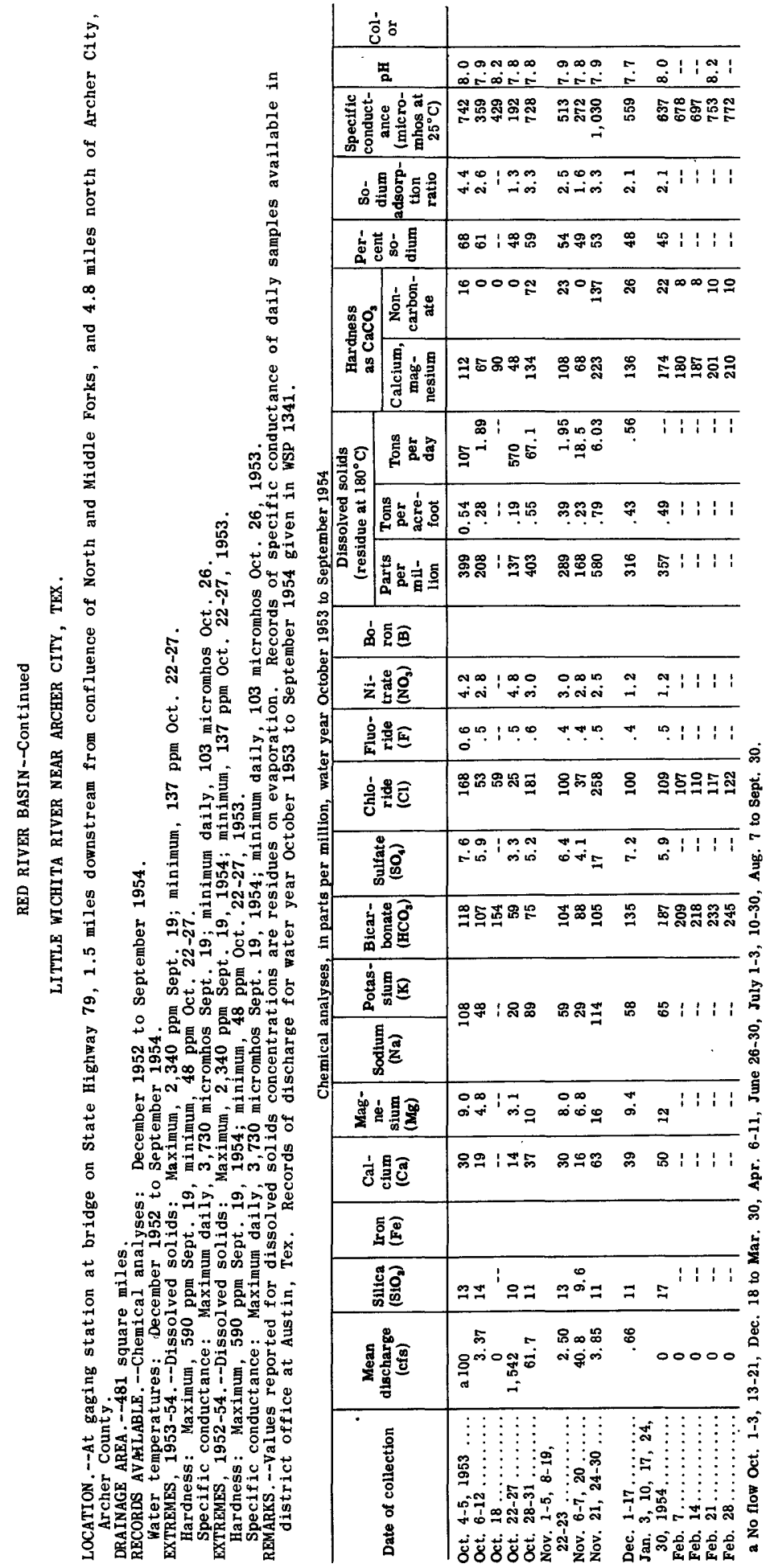




\begin{tabular}{|c|c|c|c|c|c|c|}
\hline $1: 1: 1:=$ & $\stackrel{\square}{\Sigma}$ & 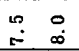 & 5 & $\stackrel{\circ}{\infty}$ & $\stackrel{2}{2}$ & $\stackrel{\infty}{=}$ \\
\hline 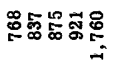 & : & 今ึ คํำ & $\$$ & 总 & :్ఠి & 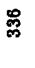 \\
\hline i: $1: 1: \begin{array}{l}0 \\
0\end{array}$ & $\stackrel{\circ}{*}$ & $\bar{\square}$ & $\stackrel{\square}{-i}$ & ì & $\stackrel{\infty}{\infty}$ & $\stackrel{\infty}{-}$ \\
\hline ：：：：哭 & ฮ & is 6 & $\mathscr{9}$ & เ7 & 욤 & 品 \\
\hline ฆง ๑๐ & I & 10 & $*$ & \% & $\$$ & 녹 \\
\hline 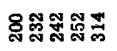 & $\stackrel{\circ}{\circ}$ & 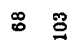 & 8 & $\stackrel{8}{\circ}$ & $\stackrel{9}{\exists}$ & ळ \\
\hline 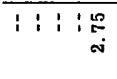 & 혀 & में & 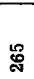 & $\stackrel{\circ}{\stackrel{\circ}{*}}$ & $\stackrel{\varpi}{\varpi}$ & 5 \\
\hline 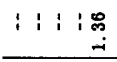 & 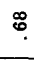 & 范 & สุ & $\mathscr{\infty}$ & เี. & ڤ్. \\
\hline 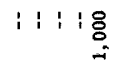 & $\stackrel{\infty}{\stackrel{一}{\$}}$ & $\stackrel{\infty}{\longleftarrow}$ & 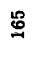 & 岕 & $\stackrel{\circ}{\circ}$ & ลิ \\
\hline
\end{tabular}

\begin{tabular}{|c|c|c|c|c|c|c|c|}
\hline$i: 1: i_{\infty}^{0}$ & $\stackrel{\circ}{i}$ & $\stackrel{\infty}{\infty}$ & 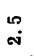 & $\ddot{0}$ & $\stackrel{\sim}{i}$ & $\stackrel{\infty}{\infty}$ & $\stackrel{8}{i}$ \\
\hline$:: 1:: \begin{array}{l}4 \\
0\end{array}$ & $\because$ & เ. & ? & $=$ & $\varphi$ & เ & $\stackrel{0}{.}$ \\
\hline 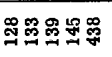 & $\overline{\text { สี }}$ & q & $\underset{\Xi}{*}$ & 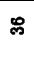 & 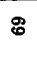 & 5 & న్ \\
\hline
\end{tabular}

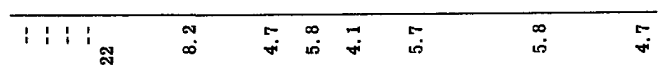

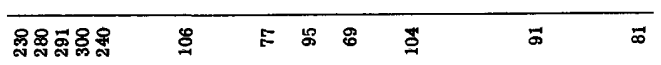

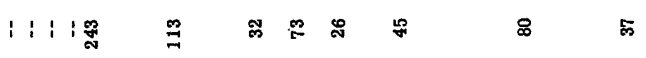

\begin{tabular}{|c|c|c|c|c|c|c|c|}
\hline 1: : : & $\approx$ & $\vec{n}$ & o & i & $\stackrel{\infty}{=}$ & $\stackrel{\circ}{\circ}$ & $\overrightarrow{-1}$ \\
\hline ：：：：足 & 암 & 9 & $\stackrel{\infty}{\sim}$ & 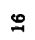 & $\stackrel{\infty}{\circ}$ & ભ & $\overrightarrow{\text { ม }}$ \\
\hline
\end{tabular}

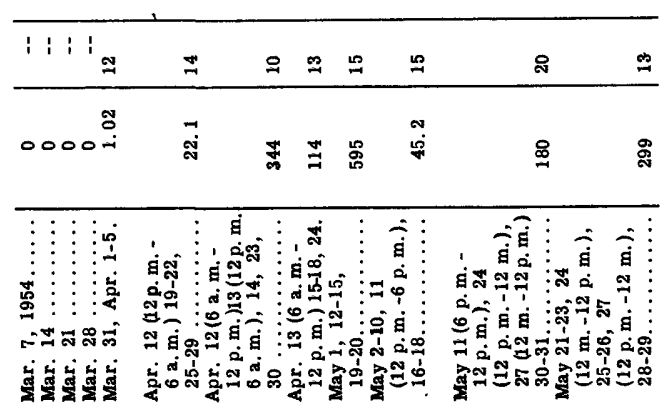




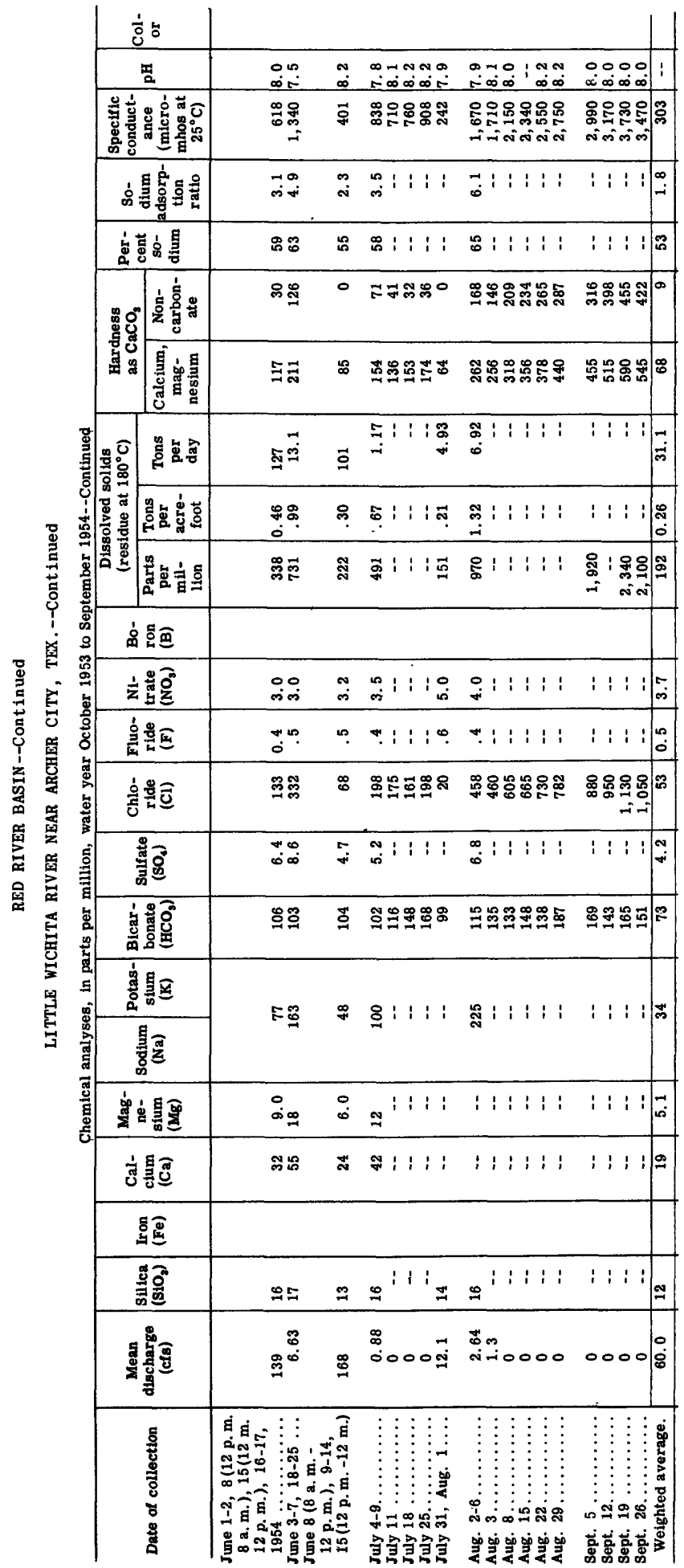


RED RIVER BASIN--Continued

LITTLE WICHITA RIVER NEAR ARCHER CITY, TEX.--Continued

Temperature $\left({ }^{\circ} \mathrm{F}\right)$ of water, water year October 1953 to September 1954

\begin{tabular}{|c|c|c|c|c|c|c|c|c|c|c|c|c|}
\hline Day & Oct. & Nov. & Dec. & Jan. & Feb. & Mar. & Apr. & May & June & July & Aug. & Sept. \\
\hline $\begin{array}{l}1 \\
2 \\
3 \\
4 \\
5\end{array}$ & $\begin{array}{l}-- \\
-- \\
-- \\
68 \\
65\end{array}$ & $\begin{array}{l}56 \\
56 \\
58 \\
60 \\
56\end{array}$ & $\begin{array}{l}-- \\
54 \\
51 \\
49\end{array}$ & $\begin{array}{l}-- \\
-- \\
42 \\
-- \\
--\end{array}$ & $\begin{array}{l}- \\
-- \\
-- \\
--\end{array}$ & $\begin{array}{l}-- \\
-- \\
-- \\
--\end{array}$ & $\begin{array}{l}57 \\
51 \\
55 \\
65 \\
65\end{array}$ & $\begin{array}{l}62 \\
64 \\
55 \\
51 \\
61\end{array}$ & $\begin{array}{l}65 \\
69 \\
70 \\
66 \\
70\end{array}$ & $\begin{array}{l}-- \\
-- \\
-- \\
84 \\
86\end{array}$ & $\begin{array}{l}76 \\
79 \\
-- \\
-- \\
--\end{array}$ & \\
\hline $\begin{array}{r}6 \\
7 \\
8 \\
9 \\
10\end{array}$ & $\begin{array}{l}60 \\
58 \\
59 \\
60 \\
61\end{array}$ & $\begin{array}{l}52 \\
50 \\
48 \\
44 \\
46\end{array}$ & $\begin{array}{l}46 \\
45 \\
42 \\
42 \\
--\end{array}$ & $\begin{array}{l}-- \\
-- \\
-- \\
-- \\
33\end{array}$ & $\begin{array}{l}-- \\
40 \\
-- \\
--\end{array}$ & $\begin{array}{l}-- \\
57 \\
-- \\
-- \\
--\end{array}$ & $\begin{array}{l}-- \\
-- \\
-- \\
-- \\
--\end{array}$ & $\begin{array}{l}64 \\
64 \\
64 \\
65 \\
60\end{array}$ & $\begin{array}{l}75 \\
75 \\
67 \\
74 \\
73\end{array}$ & $\begin{array}{l}82 \\
80 \\
-- \\
-- \\
--\end{array}$ & $\begin{array}{l}-- \\
-- \\
-- \\
--\end{array}$ & . \\
\hline $\begin{array}{l}11 \\
12 \\
13 \\
14 \\
15\end{array}$ & $\begin{array}{l}62 \\
62 \\
-- \\
-- \\
--\end{array}$ & $\begin{array}{l}48 \\
49 \\
50 \\
50 \\
50\end{array}$ & $\begin{array}{l}-- \\
-- \\
40 \\
--\end{array}$ & $\begin{array}{l}-- \\
-- \\
-- \\
--\end{array}$ & $\begin{array}{l}-- \\
\cdots \\
51 \\
--\end{array}$ & $\begin{array}{l}-- \\
-- \\
-- \\
38 \\
--\end{array}$ & $\begin{array}{l}70 \\
60 \\
57 \\
60 \\
68\end{array}$ & $\begin{array}{l}55 \\
56 \\
55 \\
60 \\
65\end{array}$ & $\begin{array}{l}76 \\
81 \\
79 \\
79 \\
72\end{array}$ & $\begin{array}{l}-- \\
-- \\
-- \\
--\end{array}$ & $\begin{array}{l}-- \\
-- \\
-- \\
--\end{array}$ & \\
\hline $\begin{array}{l}16 \\
17 \\
18 \\
19 \\
20\end{array}$ & $\begin{array}{l}-- \\
-- \\
-- \\
-- \\
--\end{array}$ & $\begin{array}{l}-- \\
-- \\
-\overline{61} \\
54\end{array}$ & $\begin{array}{l}- \\
- \\
-- \\
46\end{array}$ & $\begin{array}{l}-- \\
40 \\
-- \\
-- \\
--\end{array}$ & $\begin{array}{l}-- \\
-- \\
-- \\
--\end{array}$ & $\begin{array}{l}-- \\
-- \\
-- \\
-- \\
--\end{array}$ & $\begin{array}{l}58 \\
58 \\
63 \\
66 \\
68\end{array}$ & $\begin{array}{l}70 \\
70 \\
70 \\
65 \\
68\end{array}$ & $\begin{array}{l}74 \\
77 \\
78 \\
81 \\
82\end{array}$ & $\begin{array}{l}-- \\
-- \\
-- \\
--\end{array}$ & $\begin{array}{l}-- \\
-- \\
-- \\
--\end{array}$ & \\
\hline $\begin{array}{l}21 \\
22 \\
23 \\
24 \\
25\end{array}$ & $\begin{array}{l}-- \\
-- \\
65 \\
59 \\
64\end{array}$ & \begin{tabular}{l}
48 \\
\hdashline 45 \\
47 \\
48
\end{tabular} & $\begin{array}{l}- \\
-- \\
-- \\
--\end{array}$ & $\begin{array}{l}-- \\
-- \\
-- \\
39 \\
--\end{array}$ & $\begin{array}{l}56 \\
-- \\
-- \\
-- \\
--\end{array}$ & $\begin{array}{l}59 \\
-- \\
-- \\
-- \\
--\end{array}$ & $\begin{array}{l}68 \\
70 \\
63 \\
66 \\
67\end{array}$ & $\begin{array}{l}67 \\
73 \\
75 \\
65 \\
64\end{array}$ & $\begin{array}{l}81 \\
81 \\
-- \\
-- \\
--\end{array}$ & $\begin{array}{l}-- \\
-- \\
-- \\
--\end{array}$ & $\begin{array}{l}-- \\
-- \\
-- \\
--\end{array}$ & \\
\hline $\begin{array}{l}26 \\
27 \\
28 \\
29 \\
30 \\
31\end{array}$ & $\begin{array}{l}61 \\
54 \\
55 \\
55 \\
58 \\
59\end{array}$ & $\begin{array}{l}46 \\
47 \\
48 \\
-- \\
-- \\
--\end{array}$ & $\begin{array}{l}-- \\
35 \\
-- \\
-- \\
-- \\
--\end{array}$ & $\begin{array}{l}-- \\
-- \\
-- \\
40 \\
--\end{array}$ & $\begin{array}{l}-- \\
-- \\
52 \\
-- \\
--\end{array}$ & $\begin{array}{l}-- \\
-- \\
60 \\
-- \\
--\end{array}$ & $\begin{array}{l}71 \\
71 \\
70 \\
70 \\
63 \\
--\end{array}$ & $\begin{array}{l}66 \\
65 \\
70 \\
68 \\
73 \\
73\end{array}$ & $\begin{array}{l}-- \\
85 \\
-- \\
-- \\
--\end{array}$ & $\begin{array}{l}-- \\
-- \\
-- \\
--\end{array}$ & $\begin{array}{l}-- \\
-- \\
-- \\
-- \\
--\end{array}$ & \\
\hline $\begin{array}{c}\text { Aver- } \\
\text { age }\end{array}$ & -- & -- & -- & -- & - & -- & -- & 62 & - & -- & -. & \\
\hline
\end{tabular}




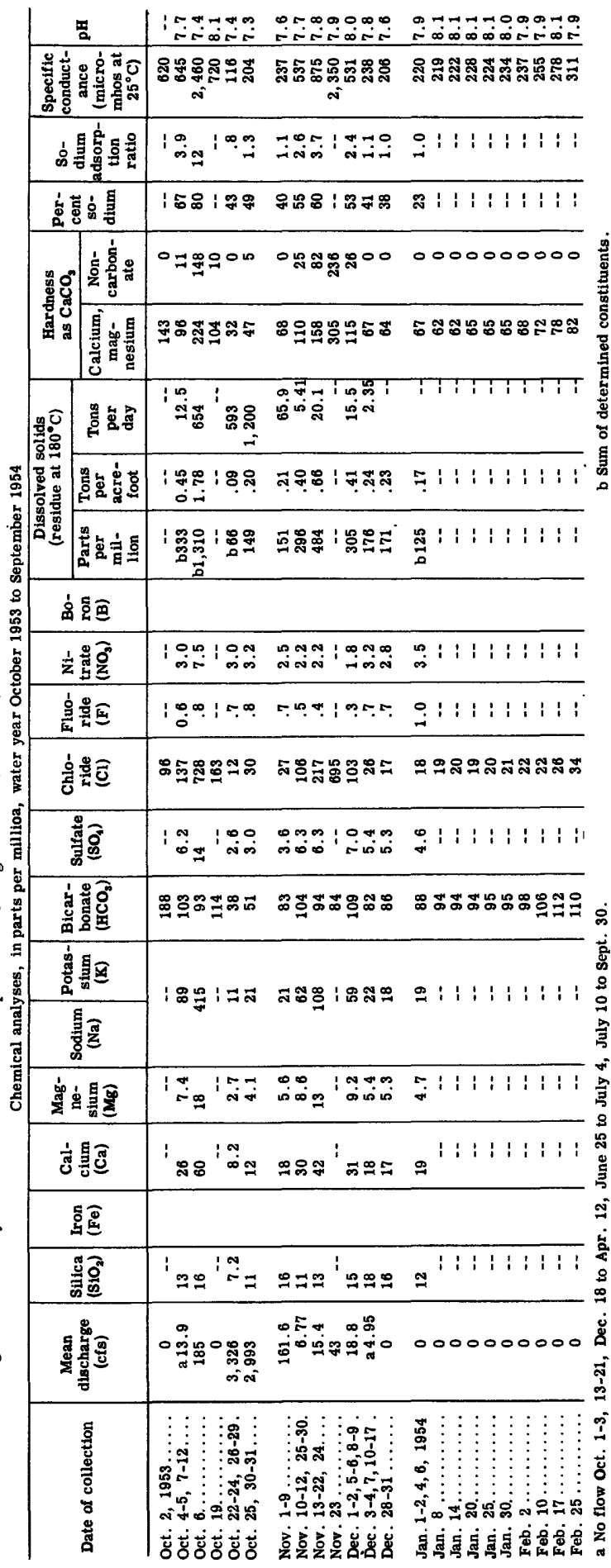


ดำ

\begin{tabular}{|c|}
\hline 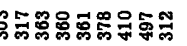 \\
\hline
\end{tabular}

\begin{tabular}{|c|c|c|c|c|c|c|c|c|}
\hline : & $\underbrace{\infty}_{-\infty}$ & $\stackrel{\infty}{i}$ & $\stackrel{\dot{i}}{i}$ & is & $\stackrel{9}{-}$ & 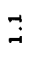 & min & 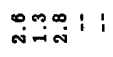 \\
\hline $1: 1: 1: 18 \%$ & 5 & 9 & 品 & $\overline{8}$ & 品 & $\$$ & 망 & 品尔嚾: \\
\hline 000000090 & $\infty$ 요 & $\infty$ & g & ๙ & 웅 & - & స్రిః & สูㅇำ \\
\hline 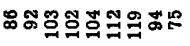 & ๓ึะ & $\approx$ & \& & $\cong$ & 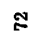 & 吕 & 氶 & 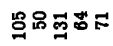 \\
\hline 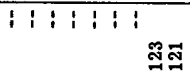 & 孚 & 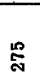 & ले & สิ & $\stackrel{\circ}{\circ}$ & \&్ & 吕 స్ & 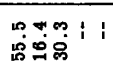 \\
\hline : : : : 1 : 1 : & ザّ & $\stackrel{\circ}{9}$ & ษ & $\stackrel{0}{\infty}$ & สุ & $?$ & సุำ & 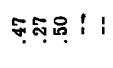 \\
\hline ：：：：：：：㤂怘 & 起点 & 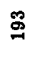 & 罵 & 莒 & ప్ & 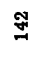 & 占昂 & 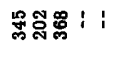 \\
\hline
\end{tabular}

\begin{tabular}{|c|c|c|c|c|c|c|c|c|}
\hline $1: 1: 1: 1: \min _{0}$ & 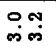 & $\stackrel{i}{i}$ & in & is & $\stackrel{\circ}{\infty}$ & $\stackrel{\leftrightarrow}{\stackrel{\sim}{*}}$ & 宓吕 & | \\
\hline $1: 11: 1: 0000$ & :T: & $?$ & 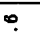 & $i$ & 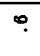 & $\because$ & 00 & | \\
\hline 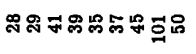 & สูฐ & $\$$ & $\stackrel{0}{\Perp}$ & 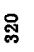 & ๓̊ & $\mathscr{్}$ & 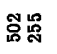 & 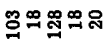 \\
\hline : : $1: 1: 1:$ : & $\infty \underset{\infty}{\infty}$ & $\stackrel{\infty}{+\infty}$ & $\ddot{0}$ & $\stackrel{\infty}{\infty}$ & $\stackrel{4}{4}$ & $\dot{m}$ & $\cong \vec{\infty}$ & | \\
\hline 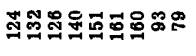 & 吕: & $\vec{\infty}$ & $\stackrel{\infty}{\infty}$ & 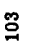 & $\stackrel{\leftrightarrow}{\sim}$ & 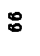 & 55 & 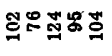 \\
\hline : : : : : : : జ్ల & คำ & $\mathscr{\infty}$ & 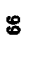 & $\Phi$ & ల్ & $\Phi$ & స్ㅍㅛㅛ & อสะ์: \\
\hline : $1: 11: 11: \underset{: 0}{\infty}$ & कि: & के & 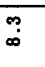 & $i$ & $\underset{m}{m}$ & $\stackrel{4}{+\infty}$ & 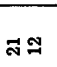 & 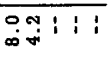 \\
\hline : : : : : : & $\simeq \mathscr{7}$ & ฐ & : & $:$ & శి & \pm & $9 \%$ & 赵赵 \\
\hline $\begin{array}{l:l:l:l}1 & 1 & 1 & 1\end{array}$ & $=$ & $x$ & 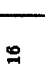 & స & $=$ & 9 & สีสิ & $\mathscr{\Xi} \mathscr{\Phi}^{\prime}$ \\
\hline
\end{tabular}

\section{高}

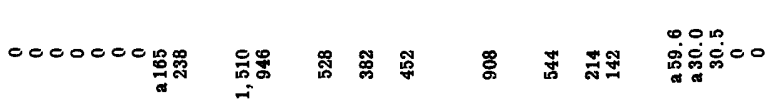

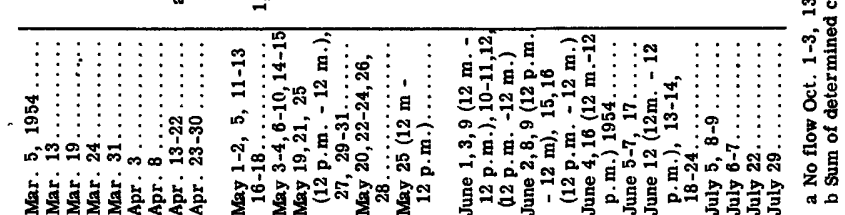




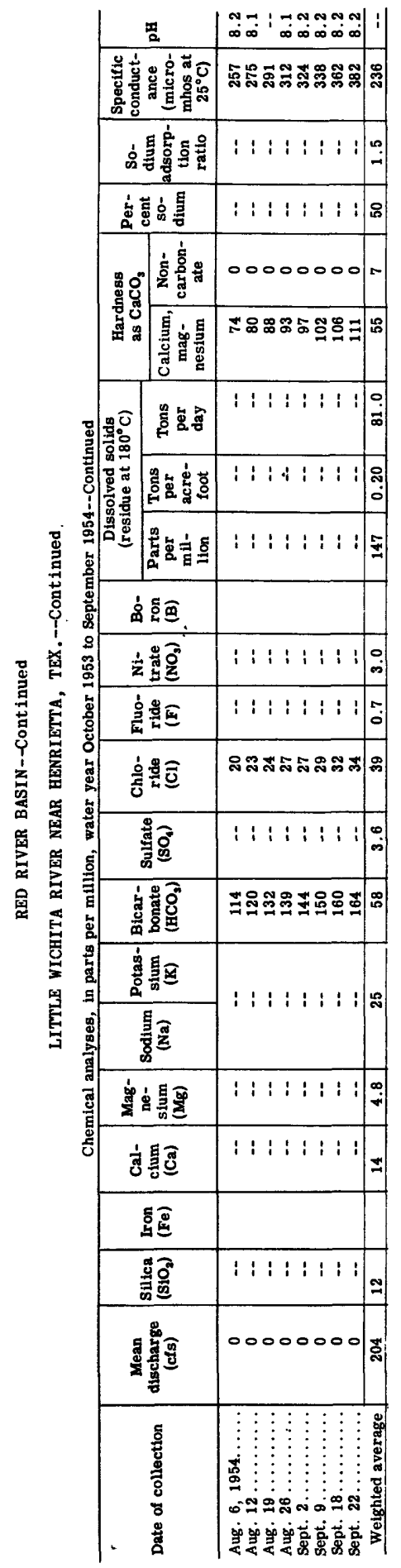


RED RIVER BASIN--Continued

LITTLE WICHITA RIVER NEAR HENRI ETTA, ; TEX. --Cont inued

Temperature $\left({ }^{\circ} \mathrm{F}\right)$ of water, water year October 1953 to September 1954 於o flow Oct. 1-3, 13-21, Dec. 18 to Apr. 12, June 25 to July 4, July 10 to Sept. 30.7

\begin{tabular}{|c|c|c|c|c|c|c|c|c|c|c|c|c|}
\hline Day & Oct. & Nov. & Dec. & Jan. & Feb. & Mar. & Apr. & May & June & July & Aug. & Sept. \\
\hline $\begin{array}{l}1 \\
2 \\
3 \\
4 \\
5\end{array}$ & $\begin{array}{l}-- \\
-- \\
-- \\
70\end{array}$ & $\begin{array}{l}65 \\
59 \\
63 \\
62 \\
58\end{array}$ & $\begin{array}{l}55 \\
58 \\
58 \\
56 \\
55\end{array}$ & $\begin{array}{l}46 \\
51 \\
-- \\
49 \\
=-\end{array}$ & $\begin{array}{l}-- \\
51 \\
-- \\
-- \\
--\end{array}$ & $\begin{array}{l}-- \\
-- \\
-- \\
-- \\
48\end{array}$ & $\begin{array}{l}-- \\
-- \\
67 \\
--\end{array}$ & $\begin{array}{l}71 \\
69 \\
68 \\
63 \\
67\end{array}$ & $\begin{array}{l}76 \\
77 \\
78 \\
76\end{array}$ & $\begin{array}{l}95 \\
=- \\
-- \\
-- \\
--\end{array}$ & & \\
\hline $\begin{array}{r}6 \\
7 \\
8 \\
9 \\
10\end{array}$ & $\begin{array}{l}71 \\
68 \\
68 \\
78 \\
79\end{array}$ & $\begin{array}{l}\mathbf{5 5} \\
\mathbf{5 2} \\
\mathbf{5 1} \\
\mathbf{5 3} \\
\mathbf{5 4}\end{array}$ & $\begin{array}{l}-7 \\
57 \\
50 \\
-2 \\
48\end{array}$ & $\begin{array}{l}48 \\
-- \\
-- \\
-- \\
--\end{array}$ & $\begin{array}{l}-- \\
-- \\
-- \\
-- \\
57\end{array}$ & $\begin{array}{l}-- \\
=- \\
-- \\
-- \\
--\end{array}$ & $\begin{array}{l}-- \\
-- \\
68 \\
--\end{array}$ & $\begin{array}{l}70 \\
73 \\
73 \\
-- \\
58\end{array}$ & $\begin{array}{l}-- \\
85 \\
77 \\
74 \\
82\end{array}$ & $\begin{array}{l}-\overline{93} \\
89 \\
93 \\
--\end{array}$ & & \\
\hline $\begin{array}{l}11 \\
12 \\
13 \\
14 \\
15\end{array}$ & $\begin{array}{l}-- \\
79 \\
69 \\
70 \\
74\end{array}$ & $\begin{array}{l}59 \\
61 \\
59 \\
60 \\
--\end{array}$ & $\begin{array}{l}48 \\
50 \\
-2 \\
45 \\
48\end{array}$ & $\begin{array}{l}-- \\
-- \\
-- \\
--\end{array}$ & $\begin{array}{l}-- \\
-- \\
-- \\
-- \\
--\end{array}$ & $\begin{array}{l}-- \\
-- \\
-- \\
--\end{array}$ & $\begin{array}{l}-- \\
-- \\
63 \\
62 \\
66\end{array}$ & $\begin{array}{l}56 \\
52 \\
61 \\
67 \\
72\end{array}$ & $\begin{array}{l}85 \\
80 \\
87 \\
86 \\
77\end{array}$ & $\begin{array}{l}-- \\
-- \\
-- \\
93\end{array}$ & & \\
\hline $\begin{array}{l}16 \\
17 \\
18 \\
19 \\
20\end{array}$ & $\begin{array}{l}-- \\
-- \\
-- \\
--\end{array}$ & $\begin{array}{l}58 \\
59 \\
61 \\
-- \\
57\end{array}$ & $\begin{array}{l}48 \\
45 \\
44 \\
48 \\
46\end{array}$ & $\begin{array}{l}-- \\
-- \\
-- \\
--\end{array}$ & $\begin{array}{l}-- \\
58 \\
-- \\
-- \\
--\end{array}$ & $\begin{array}{l}-- \\
-- \\
-- \\
--\end{array}$ & $\begin{array}{l}66 \\
70 \\
-- \\
80 \\
73\end{array}$ & $\begin{array}{l}73 \\
73 \\
67 \\
65 \\
72\end{array}$ & $\begin{array}{l}83 \\
80 \\
80 \\
82 \\
--\end{array}$ & $\begin{array}{l}-- \\
-- \\
-- \\
=-\end{array}$ & & \\
\hline $\begin{array}{l}21 \\
22 \\
23 \\
24 \\
25\end{array}$ & $\begin{array}{l}-- \\
-- \\
63 \\
65 \\
65\end{array}$ & $\begin{array}{l}56 \\
-- \\
-- \\
57 \\
52\end{array}$ & $\begin{array}{l}45 \\
\therefore- \\
=- \\
-\end{array}$ & $\begin{array}{l}-- \\
-- \\
-- \\
--\end{array}$ & $\begin{array}{l}-- \\
-- \\
-- \\
-- \\
62\end{array}$ & $\begin{array}{l}-- \\
-- \\
67 \\
--\end{array}$ & $\begin{array}{l}-- \\
-- \\
72 \\
73 \\
78\end{array}$ & $\begin{array}{l}76 \\
73 \\
-- \\
68 \\
71\end{array}$ & $\begin{array}{l}95 \\
91 \\
87 \\
89 \\
88\end{array}$ & $\begin{array}{l}-- \\
-- \\
-- \\
-- \\
--\end{array}$ & & \\
\hline $\begin{array}{l}26 \\
27 \\
28 \\
29 \\
30 \\
31\end{array}$ & $\begin{array}{l}60 \\
60 \\
62 \\
63 \\
62 \\
62 \\
\end{array}$ & $\begin{array}{l}-- \\
54 \\
52 \\
51 \\
55 \\
-- \\
\end{array}$ & $\begin{array}{l}-- \\
-- \\
46 \\
44 \\
44\end{array}$ & $\begin{array}{l}-- \\
-- \\
-- \\
-- \\
-- \\
\end{array}$ & $\begin{array}{l}-- \\
-- \\
-- \\
-- \\
--\end{array}$ & $\begin{array}{l}-- \\
-- \\
-- \\
-- \\
-57 \\
\end{array}$ & $\begin{array}{l}76 \\
78 \\
79 \\
76 \\
68 \\
-- \\
\end{array}$ & $\begin{array}{l}72 \\
75 \\
79 \\
76 \\
81 \\
83 \\
\end{array}$ & $\begin{array}{l}-- \\
-- \\
-- \\
-- \\
-- \\
\end{array}$ & $\begin{array}{l}-- \\
-- \\
-- \\
-- \\
-- \\
--\end{array}$ & & \\
\hline $\begin{array}{c}\text { Aver- } \\
\text { age }\end{array}$ & -- & -- & 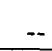 & -- & - & -- & -- & 70 & $=$ & - & & \\
\hline
\end{tabular}



ช

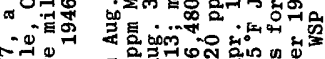

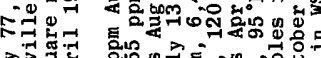

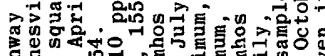

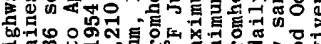

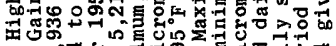

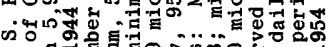

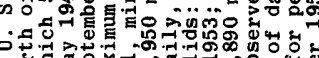
a 范. 年

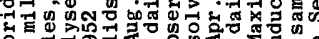

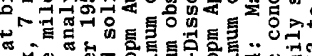
" के

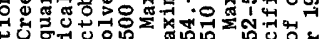

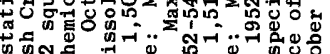

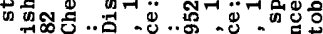

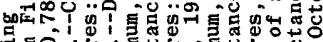

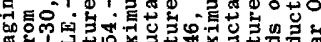

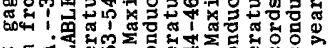

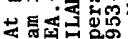

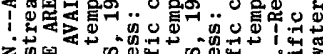
z

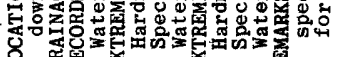

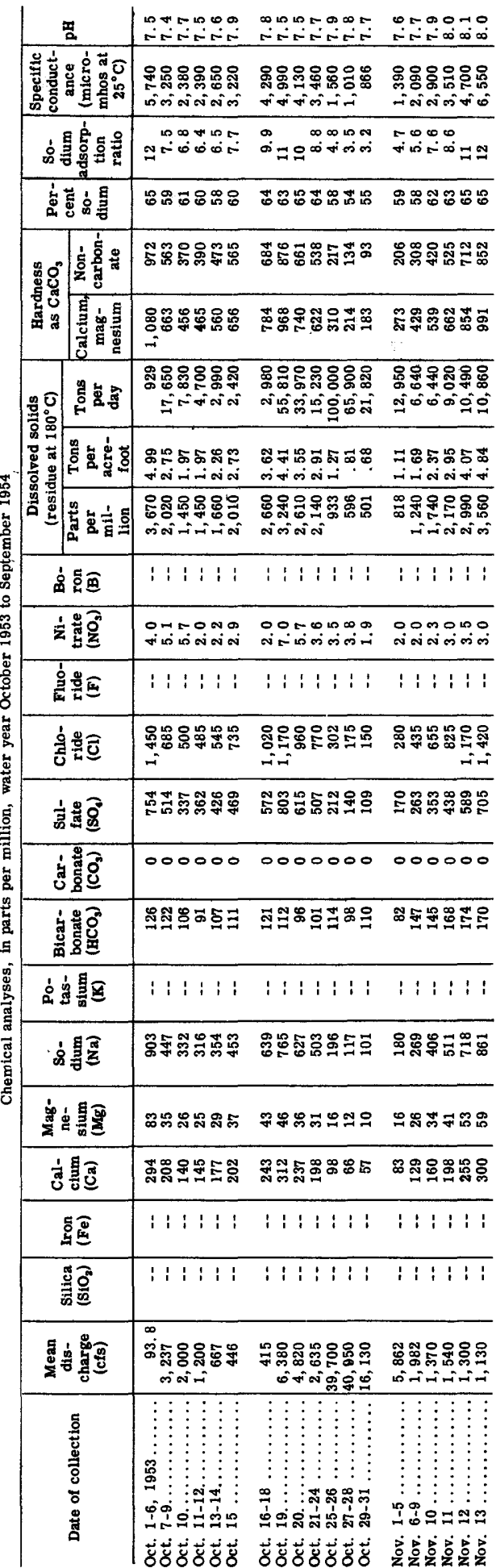




\begin{tabular}{|c|c|c|c|c|}
\hline 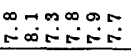 & 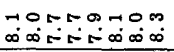 & 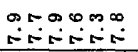 & 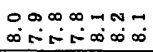 & $\begin{array}{l}N \infty 0^{\circ} \infty \\
\infty \infty \infty \infty \infty\end{array}$ \\
\hline 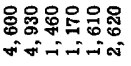 & 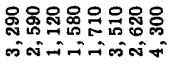 & 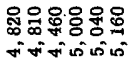 & 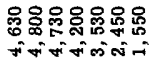 & 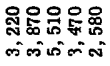 \\
\hline 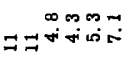 & 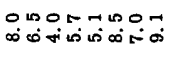 & $\because \sigma^{\infty} \infty 0=0$ & 5 कळ & 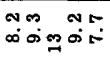 \\
\hline
\end{tabular}

๒ํํำ

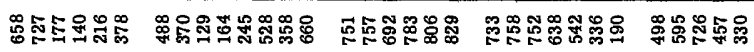

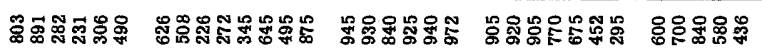

\begin{tabular}{|c|c|c|c|c|}
\hline 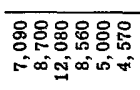 & 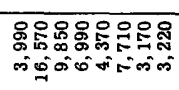 & 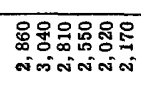 & 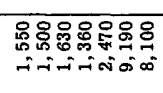 & 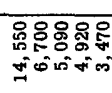 \\
\hline 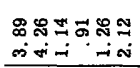 & 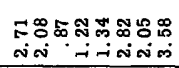 & & & \\
\hline 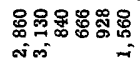 & 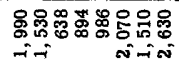 & 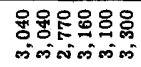 & 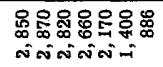 & 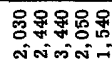 \\
\hline
\end{tabular}

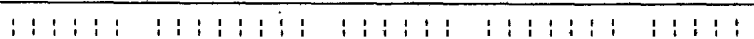

\begin{tabular}{|c|c|c|c|c|}
\hline 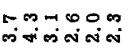 & 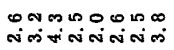 & 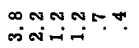 & 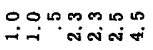 & 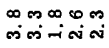 \\
\hline
\end{tabular}

1:1:1: 1: 1:1:1: 1:1:1: 1:1:1:1:1:1:

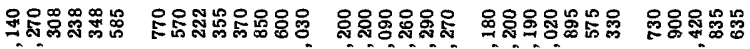
تन

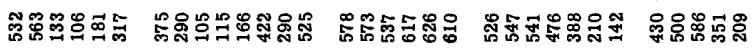

$0000000000000 N 000000000000000000$

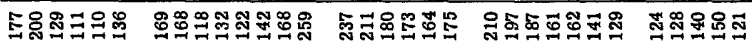

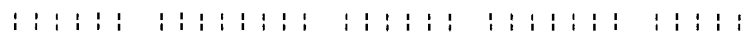

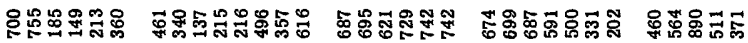

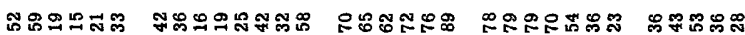

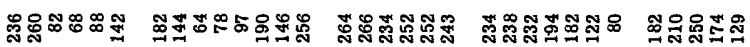

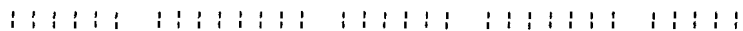

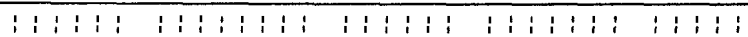

\begin{tabular}{|c|c|c|c|c|}
\hline 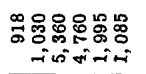 & 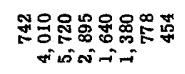 & 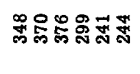 & 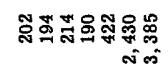 & 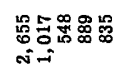 \\
\hline & & & & \\
\hline & & & & \\
\hline 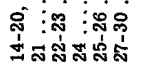 & 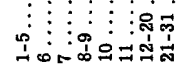 & 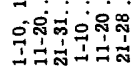 & 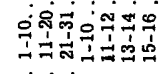 & 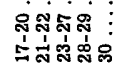 \\
\hline 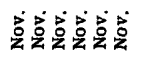 & 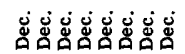 & สำำ & 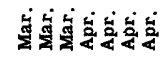 & 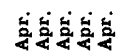 \\
\hline
\end{tabular}




\begin{tabular}{|c|c|c|c|c|c|c|c|}
\hline & 国 & 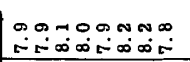 & 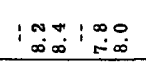 & 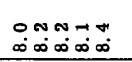 & 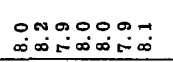 & 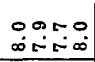 & $:$ \\
\hline & 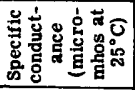 & 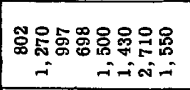 & 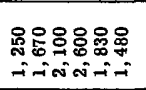 & 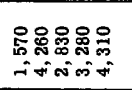 & 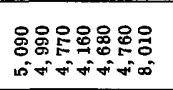 & 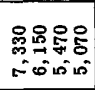 & $\mid \begin{array}{c}8 \\
\$ \\
-1\end{array}$ \\
\hline & 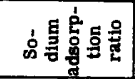 & 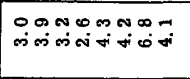 & 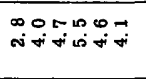 & 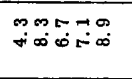 & 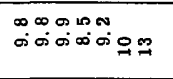 & $\cong=\Xi 0$ & \begin{tabular}{|c|}
5 \\
is
\end{tabular} \\
\hline & 离葶宫䅧 & 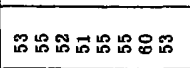 & 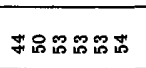 & 鿒品品的。 & 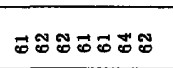 & ๓๐ஜஜ & 舟 \\
\hline & 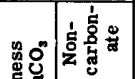 & 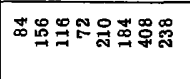 & 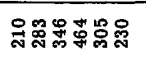 & 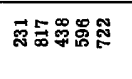 & 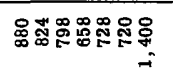 & $\begin{array}{l}\text { 영휴: } \\
\text { †- }\end{array}$ & 怘 \\
\hline & 氕 & 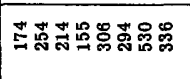 & స్ల్ల & 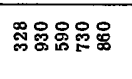 & 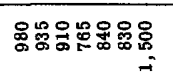 & 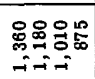 & 吅 \\
\hline & 类它 & 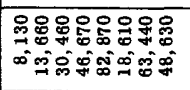 & 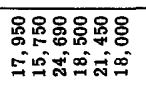 & 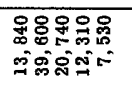 & 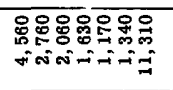 & 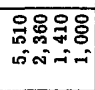 & \begin{tabular}{|c|}
0 \\
6 \\
0 \\
$\infty$
\end{tabular} \\
\hline & 足 & 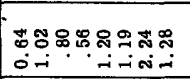 & 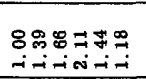 & 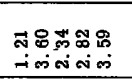 & 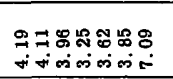 & 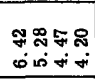 & 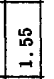 \\
\hline 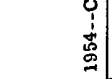 & 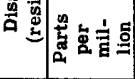 & 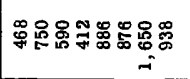 & 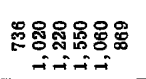 & 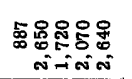 & 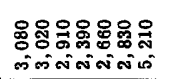 & 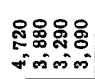 & $\mid$ \\
\hline 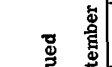 & 嵩点鳥 & $1: 1: 11: 11$ & $1: 1: 1: 1$ & $: 1: 1:$ & $\begin{array}{lllllll}5 & 5 & 1 & 1 & 1 & 1 & 1 \\
0 & & & & & \end{array}$ & $1: 19$ & $i$ \\
\hline 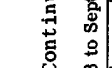 & 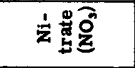 & 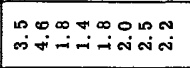 & 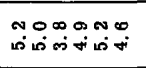 & 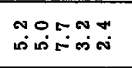 & 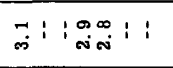 & $\stackrel{\infty}{1}:$ & $i$ \\
\hline 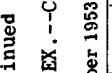 & 产荌国 & $:: 1: 1: 1: 1:$ & : : : : : : & : : : : : & 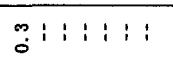 & $i \infty: 1$ & i \\
\hline 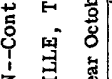 & 형흃 & 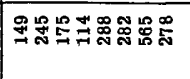 & 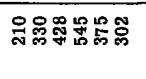 & 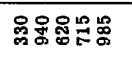 & 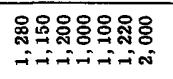 & 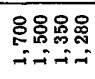 & 芯 \\
\hline 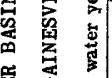 & 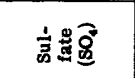 & 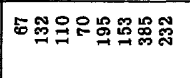 & 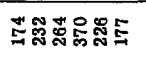 & 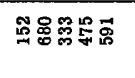 & 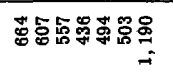 & 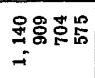 & 串 \\
\hline 芴 & is & 00000000 & 000000 & $0000 N$ & 0000000 & 0000 & : \\
\hline 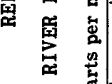 & 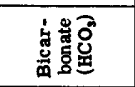 & 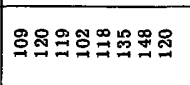 & 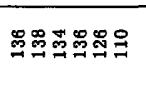 & 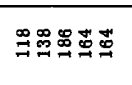 & స్తి & 욣푬워 & $\underset{\pi}{\pi}$ \\
\hline 㑹 & 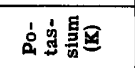 & : $: 1: 1: 15: 1: 1:$ & $1:$ & : : : : & : : & & $!$ \\
\hline 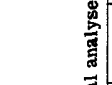 & 字臱元 & 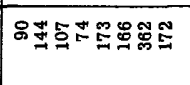 & 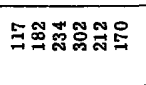 & 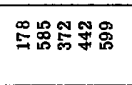 & 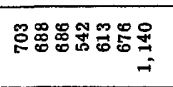 & 융유용 & $\nexists$ \\
\hline . & 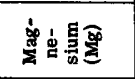 & 范 & 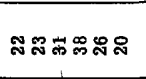 & 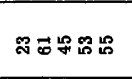 & 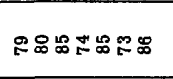 & 웅 & 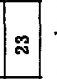 \\
\hline & 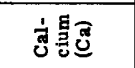 & 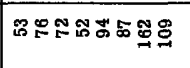 & 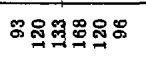 & 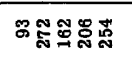 & 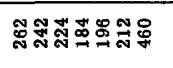 & 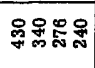 & $\cong$ \\
\hline & 浛 & $1: 1: 1: 11$ & $1: 11:$ & $11 ! 11$ & $\begin{array}{l}0 \\
0 \\
0\end{array}$ & $1 \dot{0} 1$ & $!$ \\
\hline & 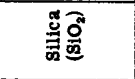 & $: 1: 1: 1: 1:$ & $1: 1: 1: 1:$ & $1: 1: 1$ & \&: $1: 1: 1: 1:$ & $1: 51$ & $i$ \\
\hline & 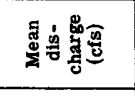 & 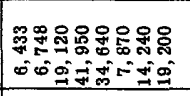 & 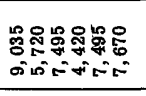 & 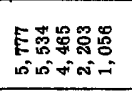 & 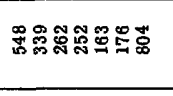 & 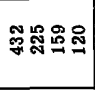 & $\begin{array}{l}0 \\
0 \\
0 \\
-5\end{array}$ \\
\hline & 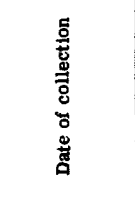 & 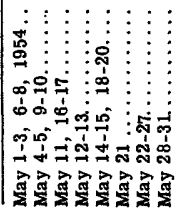 & 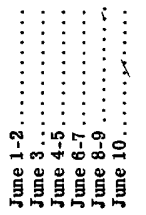 & 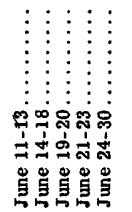 & 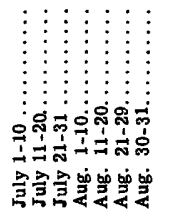 & 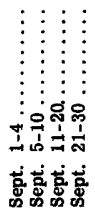 & 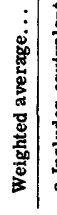 \\
\hline
\end{tabular}


RED RIVER BASIN--Continued

RED RIVER NEAR GAINESVILLE, TEX.--Continued

Temperature $\left({ }^{\circ} \mathrm{F}\right)$ of water, water year October 1953 to September 1954

\begin{tabular}{|c|c|c|c|c|c|c|c|c|c|c|c|c|}
\hline Day & Oct. & Nov. & Dec. & Jan. & Feb. & Mar. & Apr. & May & June & July & Aug. & Sept. \\
\hline $\begin{array}{l}1 \\
2 \\
3 \\
4 \\
5\end{array}$ & $\begin{array}{l}-- \\
-- \\
-- \\
-- \\
--\end{array}$ & $\begin{array}{l}62 \\
64 \\
64 \\
60 \\
58\end{array}$ & $\begin{array}{l}56 \\
58 \\
58 \\
56 \\
59\end{array}$ & $\begin{array}{l}\mathbf{5 2} \\
52 \\
52 \\
55 \\
50\end{array}$ & $\begin{array}{l}57 \\
58 \\
62 \\
58 \\
57\end{array}$ & $\begin{array}{l}53 \\
49 \\
44 \\
45 \\
44\end{array}$ & $\begin{array}{l}57 \\
64 \\
66 \\
68 \\
66\end{array}$ & $\begin{array}{l}77 \\
56 \\
60 \\
59 \\
67\end{array}$ & $\begin{array}{l}80 \\
77 \\
71 \\
72 \\
77\end{array}$ & $\begin{array}{l}92 \\
87 \\
88 \\
80 \\
88\end{array}$ & $\begin{array}{l}82 \\
87 \\
89 \\
86 \\
88\end{array}$ & $\begin{array}{l}92 \\
87 \\
86 \\
84 \\
86\end{array}$ \\
\hline $\begin{array}{r}6 \\
7 \\
8 \\
9 \\
10\end{array}$ & $\begin{array}{l}-- \\
-- \\
66 \\
72 \\
67\end{array}$ & $\begin{array}{l}54 \\
56 \\
48 \\
56 \\
56\end{array}$ & $\begin{array}{l}54 \\
50 \\
55 \\
48 \\
54\end{array}$ & $\begin{array}{l}59 \\
56 \\
58 \\
48 \\
38\end{array}$ & $\begin{array}{l}51 \\
50 \\
54 \\
57 \\
60\end{array}$ & $\begin{array}{l}54 \\
56 \\
57 \\
61 \\
64\end{array}$ & $\begin{array}{l}76 \\
75 \\
64 \\
68 \\
66\end{array}$ & $\begin{array}{l}69 \\
66 \\
71 \\
68 \\
60\end{array}$ & $\begin{array}{l}75 \\
79 \\
81 \\
81 \\
83\end{array}$ & $\begin{array}{l}86 \\
89 \\
87 \\
89 \\
90\end{array}$ & $\begin{array}{l}90 \\
94 \\
88 \\
92 \\
91\end{array}$ & $\begin{array}{l}89 \\
82 \\
85 \\
88 \\
82\end{array}$ \\
\hline $\begin{array}{l}11 \\
12 \\
13 \\
14 \\
15\end{array}$ & $\begin{array}{l}70 \\
76 \\
78 \\
76 \\
78\end{array}$ & $\begin{array}{l}60 \\
56 \\
60 \\
62 \\
64\end{array}$ & $\begin{array}{l}48 \\
48 \\
50 \\
44 \\
54\end{array}$ & $\begin{array}{l}44 \\
34 \\
36 \\
42 \\
48\end{array}$ & $\begin{array}{l}49 \\
51 \\
54 \\
64 \\
67\end{array}$ & $\begin{array}{l}66 \\
63 \\
47 \\
49 \\
50\end{array}$ & $\begin{array}{l}65 \\
64 \\
65 \\
68 \\
69\end{array}$ & $\begin{array}{l}56 \\
58 \\
58 \\
67 \\
70\end{array}$ & $\begin{array}{l}86 \\
84 \\
83 \\
82 \\
78\end{array}$ & $\begin{array}{l}88 \\
94 \\
95 \\
91 \\
90\end{array}$ & $\begin{array}{l}94 \\
89 \\
89 \\
92 \\
87\end{array}$ & $\begin{array}{l}79 \\
79 \\
84 \\
87 \\
87\end{array}$ \\
\hline $\begin{array}{l}16 \\
17 \\
18 \\
19 \\
20\end{array}$ & $\begin{array}{l}75 \\
74 \\
73 \\
71 \\
72\end{array}$ & $\begin{array}{l}64 \\
64 \\
66 \\
64 \\
54\end{array}$ & $\begin{array}{l}46 \\
45 \\
44 \\
45 \\
47\end{array}$ & $\begin{array}{l}44 \\
40 \\
51 \\
59 \\
48\end{array}$ & $\begin{array}{r}58 \\
63 \\
60 \\
51 \\
54\end{array}$ & $\begin{array}{l}\mathbf{5 1} \\
53 \\
52 \\
62 \\
58\end{array}$ & $\begin{array}{l}64 \\
68 \\
-- \\
79 \\
74\end{array}$ & $\begin{array}{l}71 \\
74 \\
73 \\
76 \\
70\end{array}$ & $\begin{array}{l}91 \\
94 \\
88 \\
93 \\
88\end{array}$ & $\begin{array}{l}92 \\
93 \\
91 \\
92 \\
89\end{array}$ & $\begin{array}{l}90 \\
94 \\
91 \\
89 \\
82\end{array}$ & $\begin{array}{l}86 \\
84 \\
88 \\
89 \\
88\end{array}$ \\
\hline $\begin{array}{l}21 \\
22 \\
23 \\
24 \\
25\end{array}$ & $\begin{array}{l}70 \\
74 \\
68 \\
66 \\
64\end{array}$ & $\begin{array}{l}56 \\
48 \\
52 \\
52 \\
52\end{array}$ & $\begin{array}{l}48 \\
38 \\
32 \\
34 \\
38\end{array}$ & $\begin{array}{l}32 \\
36 \\
42 \\
48 \\
60\end{array}$ & $\begin{array}{l}58 \\
64 \\
58 \\
57 \\
59\end{array}$ & $\begin{array}{l}61 \\
67 \\
69 \\
74 \\
64\end{array}$ & $\begin{array}{l}73 \\
72 \\
76 \\
80 \\
78\end{array}$ & $\begin{array}{l}76 \\
75 \\
74 \\
76 \\
72\end{array}$ & $\begin{array}{l}89 \\
89 \\
91 \\
89 \\
88\end{array}$ & $\begin{array}{l}90 \\
91 \\
93 \\
94 \\
93\end{array}$ & $\begin{array}{l}91 \\
84 \\
87 \\
89 \\
87\end{array}$ & $\begin{array}{l}77 \\
76 \\
73 \\
77 \\
78\end{array}$ \\
\hline $\begin{array}{l}26 \\
27 \\
28 \\
29 \\
30 \\
31\end{array}$ & $\begin{array}{l}64 \\
60 \\
60 \\
58 \\
59 \\
60\end{array}$ & $\begin{array}{l}54 \\
58 \\
54 \\
55 \\
58 \\
--\end{array}$ & $\begin{array}{l}40 \\
44 \\
42 \\
48 \\
44 \\
46\end{array}$ & $\begin{array}{l}46 \\
44 \\
50 \\
55 \\
54 \\
58\end{array}$ & $\begin{array}{l}63 \\
49 \\
52 \\
-- \\
-- \\
--\end{array}$ & $\begin{array}{l}64 \\
73 \\
\mathbf{7 0} \\
\mathbf{5 7} \\
\mathbf{5 2} \\
\mathbf{5 3}\end{array}$ & $\begin{array}{l}76 \\
79 \\
74 \\
77 \\
78 \\
--\end{array}$ & $\begin{array}{l}72 \\
76 \\
79 \\
77 \\
80 \\
82 \\
\end{array}$ & $\begin{array}{l}87 \\
86 \\
87 \\
89 \\
96 \\
--\end{array}$ & $\begin{array}{l}90 \\
93 \\
91 \\
88 \\
81 \\
86\end{array}$ & $\begin{array}{l}88 \\
91 \\
90 \\
91 \\
91 \\
86\end{array}$ & $\begin{array}{l}83 \\
84 \\
81 \\
79 \\
77 \\
--\end{array}$ \\
\hline $\begin{array}{c}\text { Aver- } \\
\text { age }\end{array}$ & -- & 58 & 48 & 48 & 57 & 57 & 71 & 70 & 84 & 90 & 89 & 83 \\
\hline
\end{tabular}




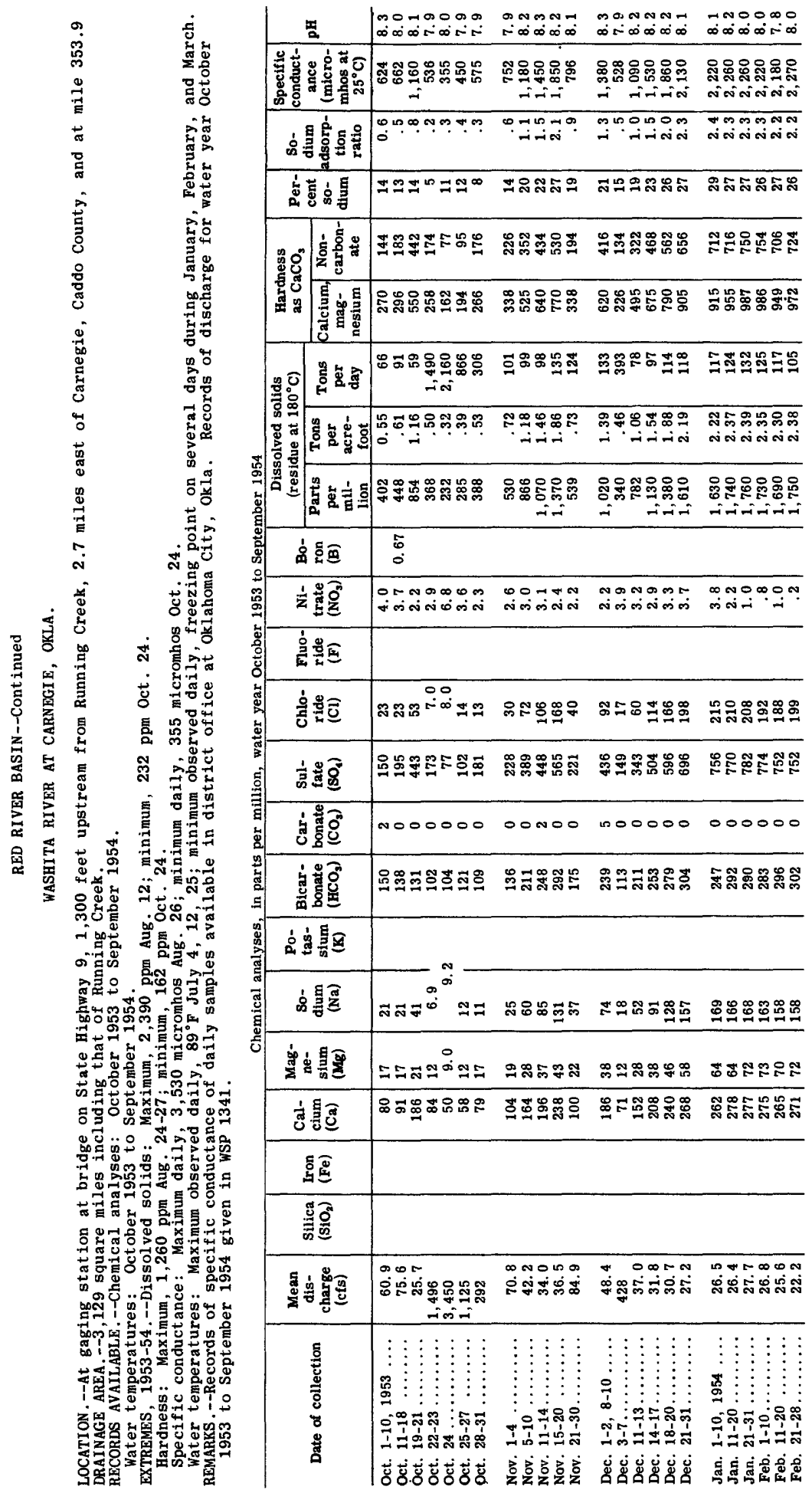




\begin{tabular}{|c|c|c|c|c|}
\hline $\begin{array}{l}0-0 \infty \infty \\
\infty \infty \infty \pi \infty\end{array}$ & $\begin{array}{l}\infty \infty 0 \infty \\
\infty \leftarrow \infty\end{array}$ & 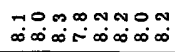 & 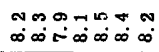 & $\stackrel{0}{\infty \infty}$ \\
\hline 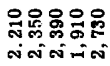 & 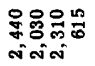 & 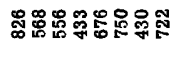 & 退윰유: & 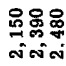 \\
\hline 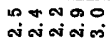 & 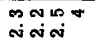 & 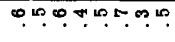 & 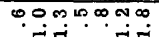 & 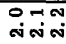 \\
\hline
\end{tabular}

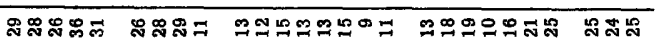

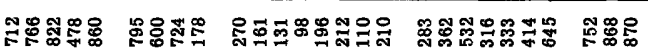

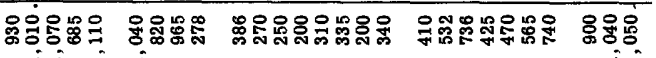

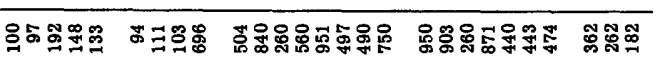
जiनi का

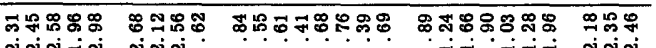

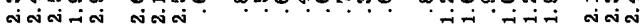

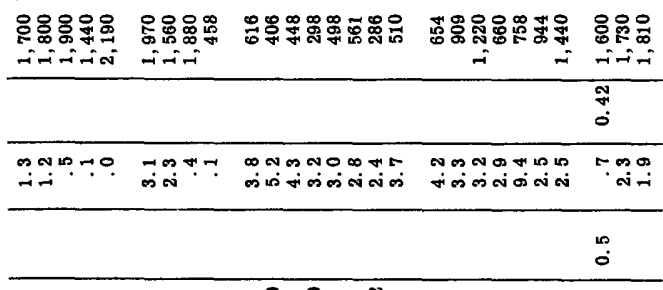

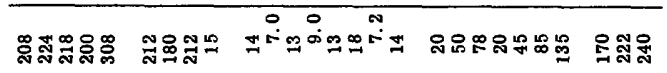

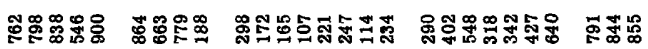

00000000000000000100000000

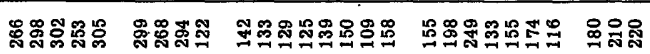

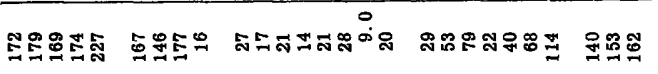

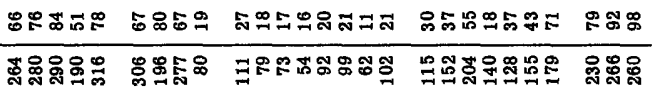

\begin{tabular}{c}
\hline$\vdots$ \\
0 \\
\hline
\end{tabular}

\begin{tabular}{|c|c|c|c|c|}
\hline 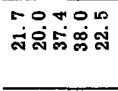 & 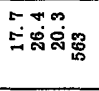 & 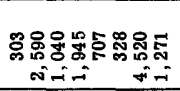 & 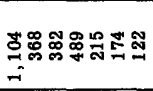 & $\begin{array}{l}\infty=\infty \\
\dot{\infty} \infty \\
\infty\end{array}$ \\
\hline
\end{tabular}

要

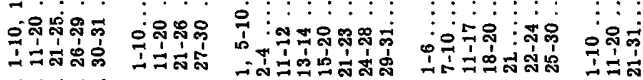

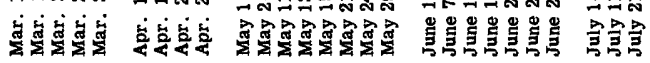

488817 O $-59-14$ 


\begin{tabular}{|c|c|c|c|c|}
\hline & 폄 & 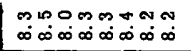 & 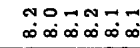 & : \\
\hline & 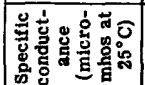 & 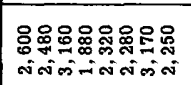 & 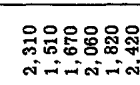 & 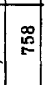 \\
\hline & 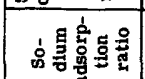 & 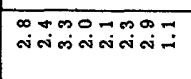 & 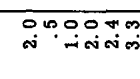 & 당. \\
\hline & 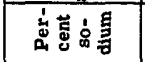 & 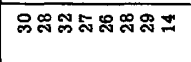 & 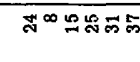 & 9 \\
\hline & 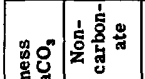 & 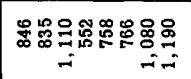 & 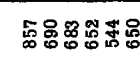 & $\stackrel{\infty}{\sim}$ \\
\hline & 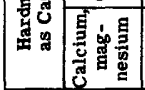 & 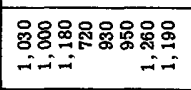 & 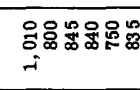 & 声 \\
\hline & 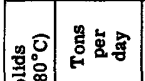 & 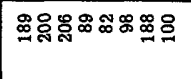 & 台和等历曲 & 隽 \\
\hline & 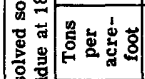 & 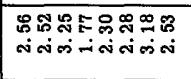 & 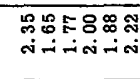 & $\begin{array}{l}0 \\
0 \\
0\end{array}$ \\
\hline & 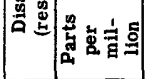 & 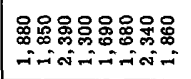 & 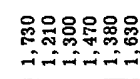 & $\overline{6}$ \\
\hline & 高哭鱼 & & & \\
\hline 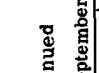 & 云苞产 & 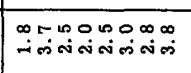 & बis & $\infty$ \\
\hline $\begin{array}{ll} & : \\
5 & 0 \\
0 & 8 \\
0 & 0 \\
0\end{array}$ & 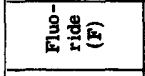 & & & \\
\hline 竞 & 웡 흠흐 & 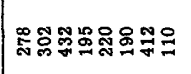 & 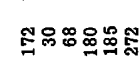 & $\approx$ \\
\hline 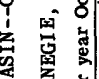 & 寈造总 & 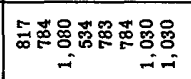 & 놇. & : \\
\hline $\begin{array}{ll}0 \\
0 \\
0\end{array}$ & 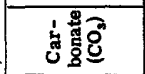 & NOON00000 & 000000 & : \\
\hline 葛 & 它荾宽 & 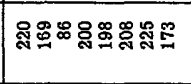 & 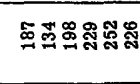 & ज्ञ \\
\hline 态悹 & 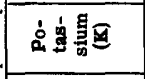 & & & \\
\hline & 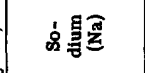 & 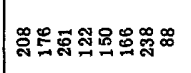 & 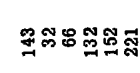 & \\
\hline ]్ & 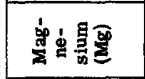 & 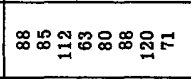 & 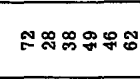 & $\approx$ \\
\hline . & 宅产要 & 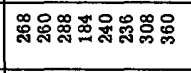 & 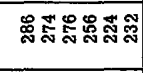 & 욤 \\
\hline & 哭跑 & & & \\
\hline & 氕 & & & \\
\hline & 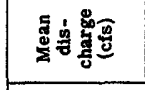 & 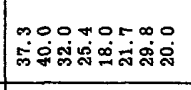 & 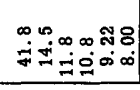 & $=$ \\
\hline & 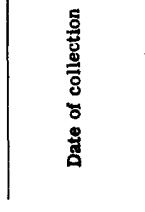 & 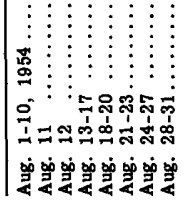 & 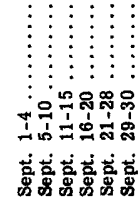 & 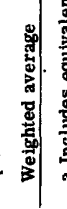 \\
\hline
\end{tabular}


RED RIVER BASIN--Continued

WASHITA RIVER AT CARNEGIE, OKLA.--Continued

Temperature $\left({ }^{\circ} \mathrm{F}\right.$ ) of water, water year October 1953 to September 1954

\begin{tabular}{|c|c|c|c|c|c|c|c|c|c|c|c|c|}
\hline Day & Oct. & Nov. & Dec. & Jan. & Feb. & Mar. & Apr. & May & June & July & Aug. & Sept. \\
\hline $\begin{array}{l}1 \\
2 \\
3 \\
4 \\
5\end{array}$ & $\begin{array}{l}-- \\
-- \\
-- \\
--\end{array}$ & $\begin{array}{c}56 \\
57 \\
57 \\
-- \\
53\end{array}$ & $\begin{array}{l}48 \\
-- \\
52 \\
-- \\
--\end{array}$ & $\begin{array}{l}38 \\
38 \\
43 \\
-- \\
--\end{array}$ & $\begin{array}{l}46 \\
45 \\
46 \\
48 \\
46\end{array}$ & $\begin{array}{l}32 \\
32 \\
32 \\
32 \\
--\end{array}$ & $\begin{array}{l}-- \\
=- \\
=- \\
--\end{array}$ & \begin{tabular}{l|}
63 \\
59 \\
54 \\
56 \\
60
\end{tabular} & $\begin{array}{l}75 \\
74 \\
69 \\
68 \\
75\end{array}$ & $\begin{array}{l}77 \\
78 \\
79 \\
89 \\
78\end{array}$ & $\begin{array}{l}83 \\
77 \\
81 \\
79 \\
84\end{array}$ & $\begin{array}{l}79 \\
87 \\
81 \\
76 \\
83\end{array}$ \\
\hline $\begin{array}{r}6 \\
7 \\
8 \\
9 \\
10\end{array}$ & $\begin{array}{l}-- \\
-- \\
-- \\
-- \\
59\end{array}$ & $\begin{array}{l}51 \\
49 \\
50 \\
50 \\
53\end{array}$ & $\begin{array}{l}52 \\
-- \\
-- \\
-- \\
--\end{array}$ & $\begin{array}{l}-- \\
-- \\
-- \\
-- \\
--\end{array}$ & $\begin{array}{l}51 \\
55 \\
55 \\
55 \\
54\end{array}$ & $\begin{array}{l}-- \\
-- \\
-- \\
-- \\
--\end{array}$ & $\begin{array}{l}-- \\
-- \\
-- \\
-- \\
--\end{array}$ & $\begin{array}{l}62 \\
64 \\
61 \\
62 \\
60\end{array}$ & $\begin{array}{l}70 \\
74 \\
79 \\
79 \\
79\end{array}$ & $\begin{array}{l}79 \\
79 \\
80 \\
86 \\
87\end{array}$ & $\begin{array}{l}88 \\
80 \\
79 \\
86 \\
84\end{array}$ & $\begin{array}{l}76 \\
76 \\
76 \\
77 \\
74\end{array}$ \\
\hline $\begin{array}{l}11 \\
12 \\
13 \\
14 \\
15\end{array}$ & $\begin{array}{l}61 \\
63 \\
66 \\
69 \\
66\end{array}$ & $\begin{array}{l}54 \\
54 \\
50 \\
56 \\
54\end{array}$ & $\begin{array}{l}48 \\
46 \\
44 \\
43 \\
43\end{array}$ & $\begin{array}{l}-- \\
-- \\
-- \\
-- \\
--\end{array}$ & $\begin{array}{l}55 \\
56 \\
53 \\
51 \\
56\end{array}$ & $\begin{array}{l}-- \\
-- \\
-- \\
-- \\
--\end{array}$ & $\begin{array}{l}-- \\
-- \\
-- \\
-- \\
59\end{array}$ & $\begin{array}{l}58 \\
54 \\
58 \\
60 \\
62\end{array}$ & $\begin{array}{l}79 \\
80 \\
80 \\
78 \\
78\end{array}$ & $\begin{array}{l}79 \\
89 \\
81 \\
81 \\
86\end{array}$ & $\begin{array}{l}81 \\
84 \\
86 \\
79 \\
87\end{array}$ & $\begin{array}{l}69 \\
78 \\
70 \\
80 \\
72\end{array}$ \\
\hline $\begin{array}{l}16 \\
17 \\
18 \\
19 \\
20\end{array}$ & $\begin{array}{l}64 \\
63 \\
64 \\
64 \\
--\end{array}$ & $\begin{array}{l}-- \\
-- \\
-- \\
48 \\
46\end{array}$ & $\begin{array}{l}42 \\
41 \\
42 \\
40 \\
41\end{array}$ & $\begin{array}{l}34 \\
34 \\
34 \\
35 \\
35\end{array}$ & $\begin{array}{l}\mathbf{5 7} \\
\mathbf{5 4} \\
\mathbf{5 2} \\
\mathbf{5 3} \\
\mathbf{5 2}\end{array}$ & $\begin{array}{l}-- \\
-- \\
-- \\
--\end{array}$ & $\begin{array}{l}59 \\
60 \\
72 \\
74 \\
69\end{array}$ & $\begin{array}{l}64 \\
64 \\
68 \\
68 \\
68\end{array}$ & $\begin{array}{l}74 \\
77 \\
79 \\
77 \\
84\end{array}$ & $\begin{array}{l}78 \\
80 \\
88 \\
83 \\
81\end{array}$ & $\begin{array}{l}86 \\
84 \\
79 \\
85 \\
86\end{array}$ & $\begin{array}{l}73 \\
79 \\
74 \\
80 \\
83\end{array}$ \\
\hline $\begin{array}{l}21 \\
22 \\
23 \\
24 \\
25\end{array}$ & $\begin{array}{l}-- \\
63 \\
63 \\
59 \\
59\end{array}$ & $\begin{array}{l}48 \\
52 \\
48 \\
46 \\
44\end{array}$ & $\begin{array}{l}40 \\
40 \\
37 \\
35 \\
41\end{array}$ & $\begin{array}{l}32 \\
32 \\
39 \\
41\end{array}$ & $\begin{array}{l}32 \\
32 \\
32 \\
32 \\
32\end{array}$ & $\begin{array}{l}= \\
-- \\
-- \\
--\end{array}$ & $\begin{array}{l}72 \\
72 \\
73 \\
74 \\
73\end{array}$ & $\begin{array}{l}75 \\
74 \\
74 \\
67 \\
64\end{array}$ & $\begin{array}{l}79 \\
79 \\
79 \\
79 \\
79\end{array}$ & $\begin{array}{l}88 \\
81 \\
81 \\
80 \\
89\end{array}$ & $\begin{array}{l}80 \\
76 \\
78 \\
78 \\
77\end{array}$ & $\begin{array}{l}77 \\
75 \\
66 \\
65 \\
78\end{array}$ \\
\hline $\begin{array}{l}26 \\
27 \\
28 \\
29 \\
30 \\
31\end{array}$ & $\begin{array}{l}58 \\
59 \\
55 \\
54 \\
55 \\
54\end{array}$ & $\begin{array}{l}48 \\
-- \\
-- \\
52 \\
-- \\
--\end{array}$ & $\begin{array}{l}42 \\
42 \\
42 \\
41 \\
40 \\
39\end{array}$ & $\begin{array}{l}41 \\
46 \\
44 \\
43 \\
48 \\
49\end{array}$ & $\begin{array}{l}32 \\
32 \\
32 \\
-- \\
-- \\
--\end{array}$ & $\begin{array}{l}-- \\
-- \\
-- \\
-- \\
-- \\
--\end{array}$ & $\begin{array}{l}71 \\
62 \\
61 \\
70 \\
66 \\
--\end{array}$ & $\begin{array}{l}68 \\
72 \\
70 \\
72 \\
72 \\
72\end{array}$ & $\begin{array}{l}79 \\
86 \\
78 \\
77 \\
77 \\
--\end{array}$ & $\begin{array}{l}83 \\
81 \\
80 \\
80 \\
79 \\
80\end{array}$ & $\begin{array}{l}81 \\
78 \\
79 \\
79 \\
78 \\
--\end{array}$ & $\begin{array}{l}-- \\
72 \\
72 \\
75 \\
72 \\
--\end{array}$ \\
\hline $\begin{array}{c}\text { Aver- } \\
\text { age }\end{array}$ & $=-$ & -- & -- & -- & 46 & $=$ & -- & 65 & 77 & 82 & 81 & 76 \\
\hline
\end{tabular}




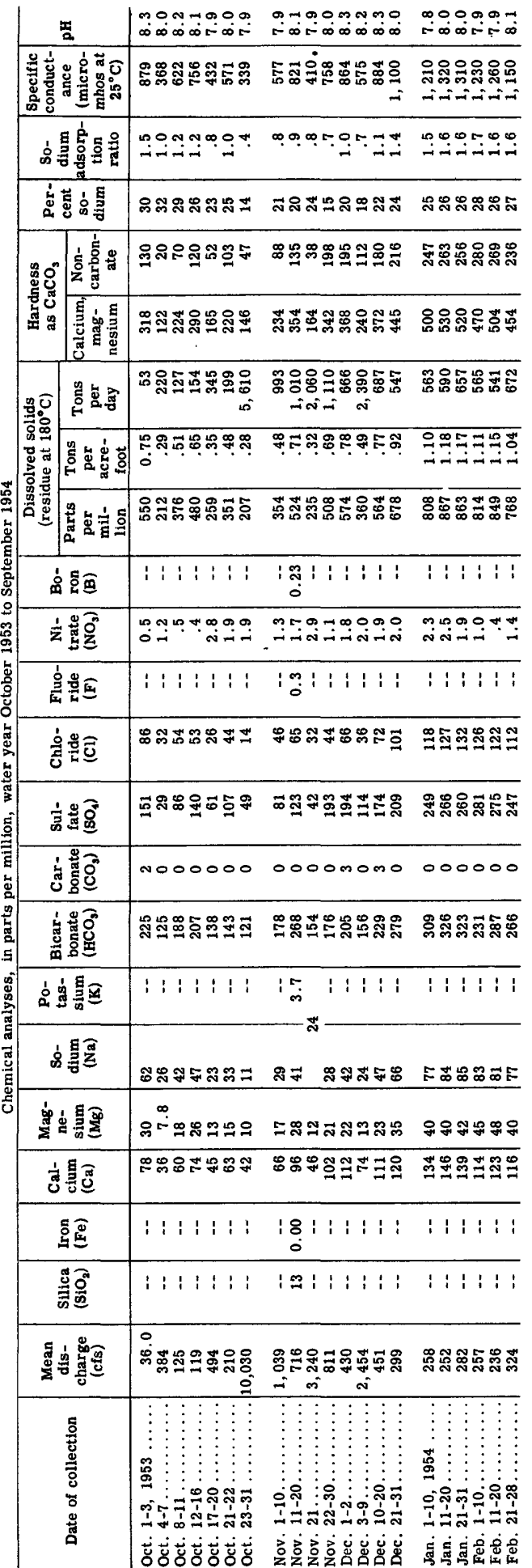




\begin{tabular}{|c|c|c|c|c|c|c|}
\hline 象 & 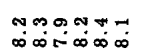 & $\prod_{\infty}^{\infty} \infty \infty+\infty \infty \infty \infty$ & $\underset{\infty}{\infty \infty \infty \infty \infty \infty}$ & 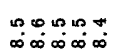 & 萬 & 舟 \\
\hline 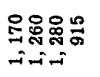 & 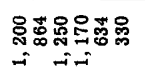 & 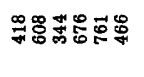 & 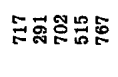 & 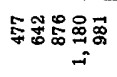 & 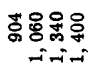 & $\begin{array}{l}\text { 윯윯융 } \\
\text {-iનi-i- }\end{array}$ \\
\hline 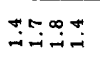 & 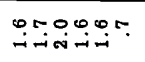 & $\bullet$ & 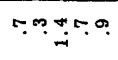 & 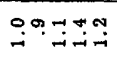 & 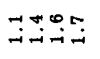 & O윰ำ \\
\hline 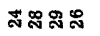 & 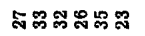 & 曱 & 묵్ㅇㅁㅇㅇ & ลึสสฺฐ & 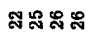 & 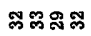 \\
\hline 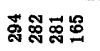 & 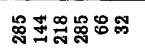 & 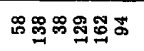 & 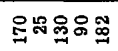 & 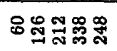 & 点罡菺菺 & 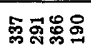 \\
\hline
\end{tabular}

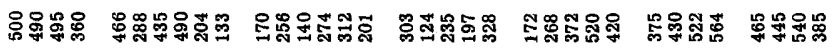

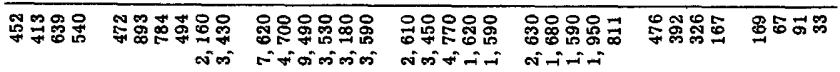

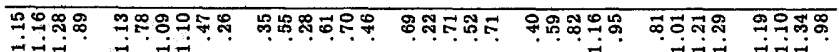

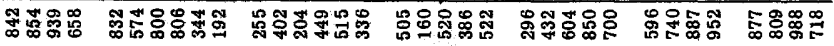

\begin{tabular}{|c|c|c|c|c|c|c|}
\hline$: 1: 1$ & $1: 1: 1:$ & $: 1: 1: 1: 1$ & $1: 1: 1$ & $1: 1: 1$ & $1: 8:$ & $1: 1:$ \\
\hline$\dddot{-1} \oplus$ & 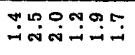 & 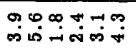 & ज़ण\% & 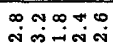 & 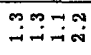 & 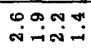 \\
\hline $1: 1:$ & : : : : : : & $i:$ & i & : : & $1: \infty 1$ & $1: i$ \\
\hline
\end{tabular}

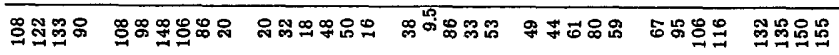

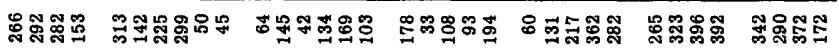

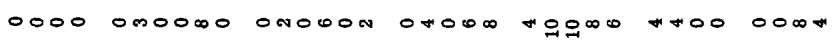

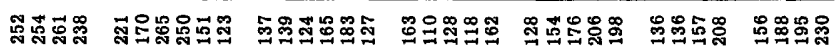

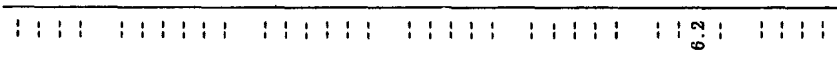

\begin{tabular}{|c|c|c|c|c|c|c|}
\hline 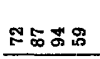 & 요요 & シざジ的ず & 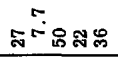 & の芯与゚号 & ஒேஃロ゙ & ప్రిఃః \\
\hline 正な品绐 & 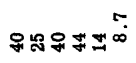 & 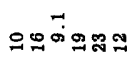 & = & మొ్ మొ & 足舟占 & เี้น็ำ \\
\hline 뎤용 & 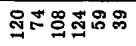 & 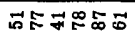 & Бㅇㅇㅀㅇㅛ & 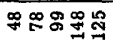 & 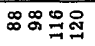 & œ \\
\hline
\end{tabular}

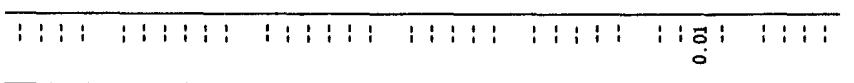

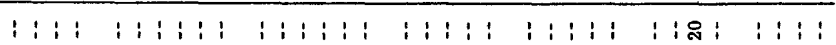

\begin{tabular}{|c|c|c|c|c|c|c|}
\hline 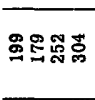 & 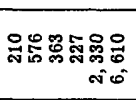 & 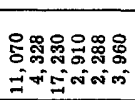 & 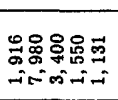 & 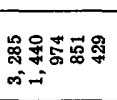 & 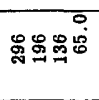 & 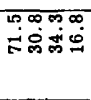 \\
\hline 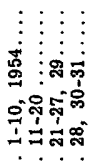 & 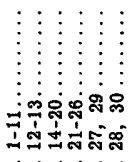 & 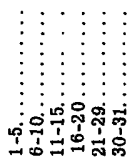 & $\begin{array}{c}\vdots \\
\vdots \\
\vdots \\
\vdots \\
\vdots \\
\vdots \\
\vdots\end{array}$ & 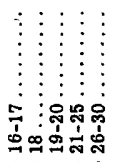 & 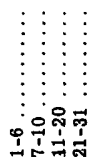 & 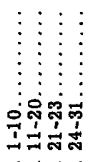 \\
\hline 这 & 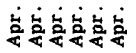 & 昰焉要焉 & 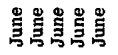 & 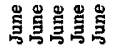 & 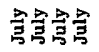 & 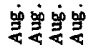 \\
\hline
\end{tabular}




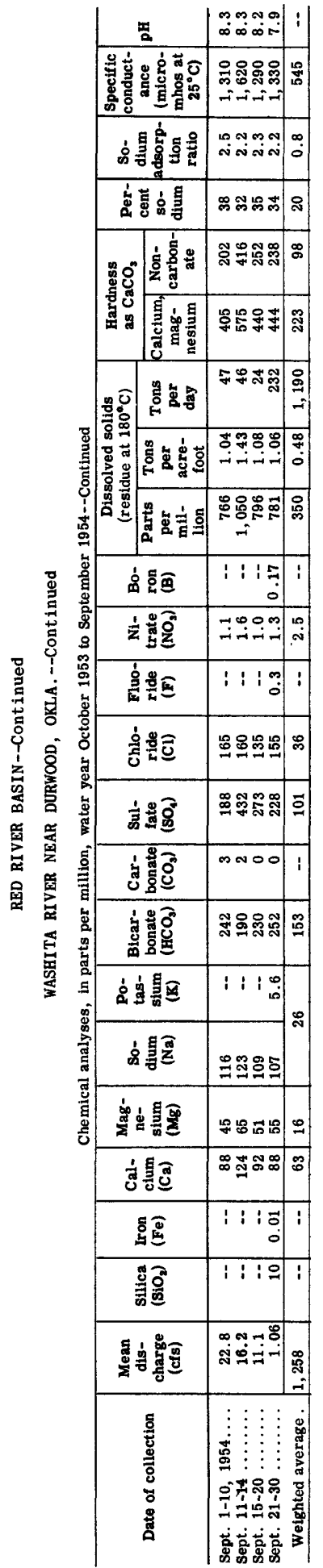


RED RIVER BASIN--Continued

WASHITA RIVER NEAR DURWOOD, OKLA.--Continued

Temperature $\left({ }^{\circ} \mathrm{F}\right)$ of water, water year October 1953 to Septe ber 1954

\begin{tabular}{|c|c|c|c|c|c|c|c|c|c|c|c|c|}
\hline Day & Oct. & Nov. & Dec. & Jan. & Feb. & Mar. & Apr. & May & June & July & Aug. & Sept. \\
\hline $\begin{array}{l}1 \\
2 \\
3 \\
4 \\
5\end{array}$ & $\begin{array}{l}65 \\
70 \\
74 \\
67 \\
65\end{array}$ & $\begin{array}{l}57 \\
56 \\
59 \\
61 \\
58\end{array}$ & $\begin{array}{l}\mathbf{5 3} \\
\mathbf{5 5} \\
\mathbf{5 3} \\
50 \\
\mathbf{5 0}\end{array}$ & $\begin{array}{l}33 \\
40 \\
39 \\
42 \\
41\end{array}$ & $\begin{array}{l}45 \\
47 \\
42 \\
47 \\
42\end{array}$ & $\begin{array}{l}45 \\
45 \\
40 \\
39 \\
40\end{array}$ & $\begin{array}{l}41 \\
51 \\
56 \\
64 \\
67\end{array}$ & $\begin{array}{l}62 \\
62 \\
57 \\
58 \\
58\end{array}$ & $\begin{array}{l}74 \\
74 \\
68 \\
68 \\
69\end{array}$ & $\begin{array}{l}82 \\
83 \\
80 \\
81 \\
82\end{array}$ & $\begin{array}{l}78 \\
75 \\
81 \\
81 \\
79\end{array}$ & $\begin{array}{l}72 \\
71 \\
75 \\
76 \\
74\end{array}$ \\
\hline $\begin{array}{r}6 \\
7 \\
8 \\
9 \\
10\end{array}$ & $\begin{array}{l}60 \\
57 \\
57 \\
60 \\
62\end{array}$ & $\begin{array}{l}50 \\
48 \\
53 \\
45 \\
47\end{array}$ & $\begin{array}{l}47 \\
46 \\
42 \\
44 \\
42\end{array}$ & $\begin{array}{l}42 \\
42 \\
48 \\
50 \\
38\end{array}$ & $\begin{array}{l}46 \\
43 \\
42 \\
50 \\
47\end{array}$ & $\begin{array}{l}38 \\
44 \\
46 \\
38 \\
52\end{array}$ & $\begin{array}{l}63 \\
63 \\
60 \\
60 \\
64\end{array}$ & $\begin{array}{l}62 \\
62 \\
62 \\
62 \\
55\end{array}$ & $\begin{array}{l}72 \\
75 \\
69 \\
74 \\
75\end{array}$ & $\begin{array}{l}81 \\
82 \\
81 \\
82 \\
82\end{array}$ & $\begin{array}{l}78 \\
78 \\
79 \\
77 \\
76\end{array}$ & $\begin{array}{l}74 \\
71 \\
75 \\
78 \\
74\end{array}$ \\
\hline $\begin{array}{l}11 \\
12 \\
13 \\
14 \\
15\end{array}$ & $\begin{array}{l}63 \\
64 \\
66 \\
66 \\
67\end{array}$ & $\begin{array}{l}48 \\
48 \\
50 \\
53 \\
52\end{array}$ & $\begin{array}{l}43 \\
42 \\
41 \\
39 \\
38\end{array}$ & $\begin{array}{l}34 \\
35 \\
35 \\
36 \\
42\end{array}$ & $\begin{array}{l}46 \\
44 \\
45 \\
52 \\
60\end{array}$ & $\begin{array}{l}44 \\
59 \\
41 \\
40 \\
42\end{array}$ & $\begin{array}{l}63 \\
60 \\
59 \\
63 \\
65\end{array}$ & $\begin{array}{l}53 \\
55 \\
55 \\
60 \\
64\end{array}$ & $\begin{array}{l}77 \\
78 \\
79 \\
73 \\
71\end{array}$ & $\begin{array}{l}83 \\
82 \\
84 \\
84 \\
83\end{array}$ & $\begin{array}{l}78 \\
76 \\
78 \\
79 \\
80\end{array}$ & $\begin{array}{l}69 \\
69 \\
68 \\
70 \\
64\end{array}$ \\
\hline $\begin{array}{l}16 \\
17 \\
18 \\
19 \\
20\end{array}$ & $\begin{array}{l}67 \\
66 \\
66 \\
67 \\
66\end{array}$ & $\begin{array}{l}53 \\
57 \\
58 \\
62 \\
53\end{array}$ & $\begin{array}{l}40 \\
39 \\
38 \\
40 \\
42\end{array}$ & $\begin{array}{l}38 \\
36 \\
40 \\
47 \\
55\end{array}$ & $\begin{array}{l}54 \\
49 \\
50 \\
58 \\
48\end{array}$ & $\begin{array}{l}46 \\
46 \\
51 \\
52 \\
52\end{array}$ & $\begin{array}{l}59 \\
58 \\
62 \\
60 \\
66\end{array}$ & $\begin{array}{l}67 \\
67 \\
62 \\
68 \\
67\end{array}$ & $\begin{array}{l}73 \\
76 \\
78 \\
81 \\
82\end{array}$ & $\begin{array}{l}82 \\
\therefore 84 \\
83 \\
81\end{array}$ & $\begin{array}{l}81 \\
80 \\
79 \\
78 \\
79\end{array}$ & $\begin{array}{l}73 \\
75 \\
76 \\
79 \\
79\end{array}$ \\
\hline $\begin{array}{l}21 \\
22 \\
23 \\
24 \\
25\end{array}$ & $\begin{array}{l}67 \\
78 \\
65 \\
62 \\
62\end{array}$ & $\begin{array}{l}49 \\
47 \\
46 \\
48 \\
47\end{array}$ & $\begin{array}{l}45 \\
37 \\
32 \\
32 \\
32\end{array}$ & $\begin{array}{l}32 \\
32 \\
32 \\
36 \\
44\end{array}$ & $\begin{array}{l}45 \\
50 \\
51 \\
48 \\
52\end{array}$ & $\begin{array}{l}50 \\
55 \\
58 \\
62 \\
60\end{array}$ & $\begin{array}{l}67 \\
67 \\
65 \\
66 \\
70\end{array}$ & $\begin{array}{l}65 \\
67 \\
70 \\
69 \\
70\end{array}$ & $\begin{array}{l}72 \\
82 \\
83 \\
85 \\
82\end{array}$ & $\begin{array}{l}80 \\
81 \\
81 \\
83 \\
82\end{array}$ & $\begin{array}{l}78 \\
79 \\
77 \\
79 \\
78\end{array}$ & $\begin{array}{l}72 \\
65 \\
65 \\
66 \\
69\end{array}$ \\
\hline $\begin{array}{l}26 \\
27 \\
28 \\
29 \\
30 \\
31\end{array}$ & $\begin{array}{l}58 \\
57 \\
66 \\
56 \\
55 \\
52 \\
\end{array}$ & $\begin{array}{l}45 \\
48 \\
48 \\
47 \\
47 \\
-- \\
\end{array}$ & $\begin{array}{l}32 \\
36 \\
36 \\
36 \\
36 \\
36 \\
\end{array}$ & $\begin{array}{l}36 \\
37 \\
40 \\
44 \\
48 \\
47 \\
\end{array}$ & $\begin{array}{l}50 \\
55 \\
42 \\
-- \\
-- \\
-- \\
\end{array}$ & $\begin{array}{l}57 \\
51 \\
59 \\
62 \\
48 \\
46\end{array}$ & $\begin{array}{l}70 \\
71 \\
64 \\
70 \\
67 \\
-- \\
\end{array}$ & $\begin{array}{l}70 \\
71 \\
75 \\
74 \\
74 \\
74 \\
\end{array}$ & $\begin{array}{l}82 \\
82 \\
81 \\
80 \\
81 \\
--\end{array}$ & $\begin{array}{l}83 \\
79 \\
79 \\
79 \\
78 \\
78 \\
\end{array}$ & $\begin{array}{l}79 \\
78 \\
80 \\
80 \\
80 \\
75 \\
\end{array}$ & $\begin{array}{l}69 \\
72 \\
75 \\
75 \\
75 \\
- \\
\end{array}$ \\
\hline $\begin{array}{c}\text { Aver- } \\
\text { age }\end{array}$ & 64 & 51 & 41 & 40 & 48 & 49 & 63 & 64 & 77 & 82 & 78 & 72 \\
\hline
\end{tabular}




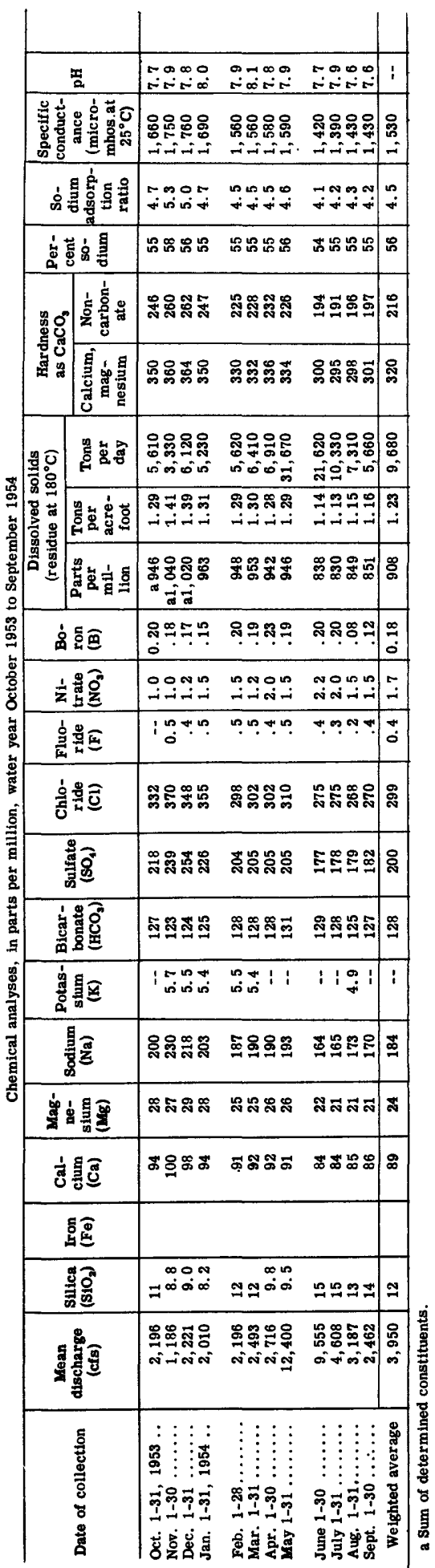

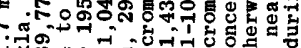

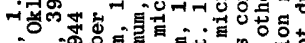

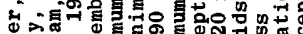
$>$ च

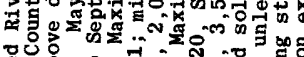

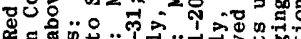

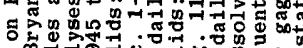

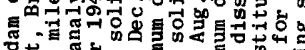

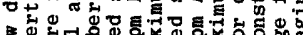

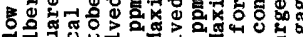
๑๐

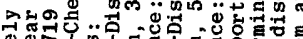

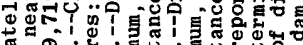
สี के 10 娄 in

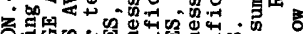
要 ड

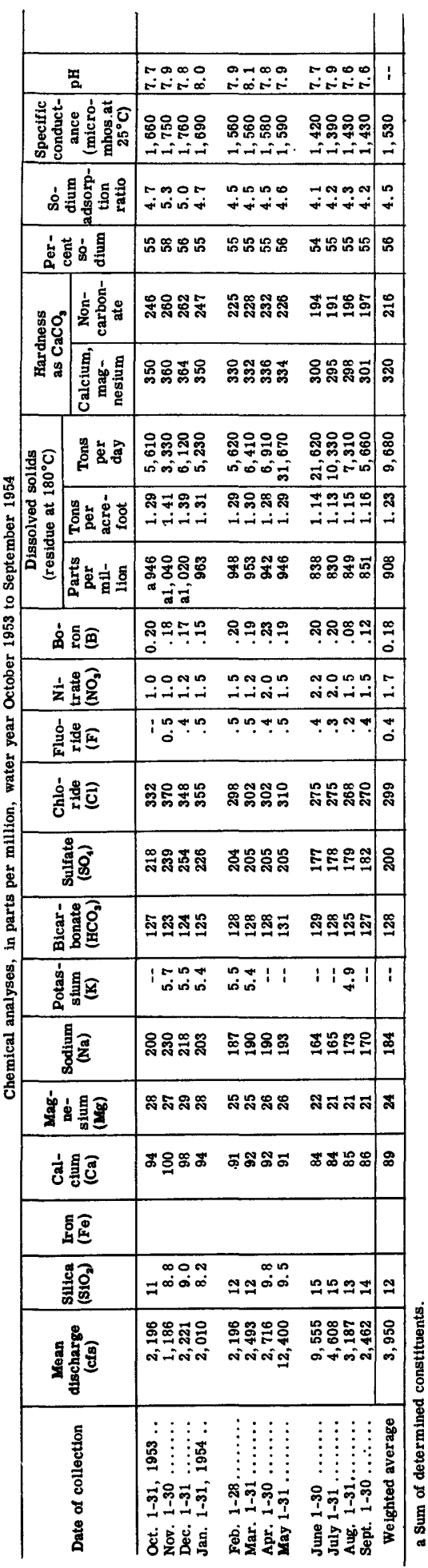


RED RIVER BASIN--Cont inued

RED RIVER AT DENISON DAM NEAR DENISON, TEX.--Continued

Temperature $\left({ }^{\circ} \mathrm{F}\right)$ of water, water year October 1953 to September 1954

\begin{tabular}{|c|c|c|c|c|c|c|c|c|c|c|c|c|}
\hline Day & Oct. & Nov. & Dec. & Jan. & Feb. & Mar. & Apr. & May & June & July & Aug. & Sept. \\
\hline $\begin{array}{l}1 \\
2 \\
3 \\
4 \\
5\end{array}$ & $\begin{array}{l}77 \\
78 \\
-- \\
76\end{array}$ & $\begin{array}{l}-- \\
67 \\
69 \\
69 \\
69\end{array}$ & $\begin{array}{l}59 \\
68 \\
58 \\
58 \\
--\end{array}$ & $\begin{array}{l}-- \\
-- \\
-- \\
48 \\
48\end{array}$ & $\begin{array}{l}45 \\
46 \\
46 \\
46 \\
46\end{array}$ & $\begin{array}{l}52 \\
51 \\
50 \\
49 \\
50\end{array}$ & $\begin{array}{l}52 \\
52 \\
-- \\
-- \\
53\end{array}$ & $\begin{array}{l}-- \\
-- \\
63 \\
61 \\
62\end{array}$ & $\begin{array}{l}68 \\
68 \\
68 \\
68 \\
--\end{array}$ & $\begin{array}{l}73 \\
72 \\
-- \\
-- \\
--\end{array}$ & $\begin{array}{l}7- \\
76 \\
76 \\
76 \\
76\end{array}$ & $\begin{array}{l}76 \\
76 \\
76 \\
- \\
-\end{array}$ \\
\hline $\begin{array}{r}6 \\
7 \\
8 \\
9 \\
10\end{array}$ & $\begin{array}{l}75 \\
75 \\
74 \\
74 \\
--\end{array}$ & $\begin{array}{l}67 \\
-- \\
-- \\
65 \\
65\end{array}$ & $\begin{array}{l}-- \\
68 \\
57 \\
57 \\
56\end{array}$ & $\begin{array}{l}48 \\
47 \\
47 \\
-- \\
--\end{array}$ & $\begin{array}{l}-- \\
-- \\
47 \\
46 \\
46\end{array}$ & $\begin{array}{l}-- \\
-- \\
51 \\
51 \\
51\end{array}$ & $\begin{array}{l}54 \\
54 \\
56 \\
54 \\
--\end{array}$ & $\begin{array}{l}63 \\
64 \\
=- \\
-- \\
62\end{array}$ & $\begin{array}{l}-- \\
68 \\
68 \\
68 \\
70\end{array}$ & $\begin{array}{l}73 \\
74 \\
73 \\
73 \\
--\end{array}$ & $\begin{array}{l}76 \\
-- \\
-- \\
76 \\
77\end{array}$ & $\begin{array}{l}78 \\
78 \\
78 \\
77\end{array}$ \\
\hline $\begin{array}{l}11 \\
12 \\
13 \\
14 \\
15\end{array}$ & $\begin{array}{l}-- \\
75 \\
74 \\
74 \\
75\end{array}$ & $\begin{array}{l}-- \\
63 \\
63 \\
-- \\
--\end{array}$ & $\begin{array}{l}56 \\
-- \\
-- \\
54 \\
54\end{array}$ & $\begin{array}{l}47 \\
46 \\
46 \\
46 \\
--\end{array}$ & $\begin{array}{l}47 \\
48 \\
-- \\
-- \\
48\end{array}$ & $\begin{array}{l}50 \\
51 \\
-- \\
-- \\
50\end{array}$ & $\begin{array}{l}-- \\
57 \\
57 \\
58 \\
58\end{array}$ & $\begin{array}{l}62 \\
62 \\
64 \\
64 \\
--\end{array}$ & $\begin{array}{l}69 \\
- \\
70 \\
70\end{array}$ & $\begin{array}{l}-- \\
74 \\
74 \\
73 \\
74\end{array}$ & $\begin{array}{l}77 \\
76 \\
76 \\
-- \\
--\end{array}$ & $\begin{array}{l}-- \\
77 \\
77 \\
78\end{array}$ \\
\hline $\begin{array}{l}16 \\
17 \\
18 \\
19 \\
20\end{array}$ & $\begin{array}{c}74 \\
-- \\
74 \\
74\end{array}$ & $\begin{array}{l}63 \\
62 \\
62 \\
62 \\
61\end{array}$ & $\begin{array}{l}53 \\
53 \\
53 \\
-- \\
--\end{array}$ & $\begin{array}{l}-- \\
-- \\
45 \\
45 \\
45\end{array}$ & $\begin{array}{l}49 \\
48 \\
48 \\
48 \\
--\end{array}$ & $\begin{array}{l}49 \\
-- \\
50 \\
51 \\
--\end{array}$ & $\begin{array}{l}60 \\
-- \\
-- \\
59 \\
60\end{array}$ & $\begin{array}{l}\overline{64} \\
65 \\
65 \\
64\end{array}$ & $\begin{array}{l}71 \\
71 \\
71 \\
-- \\
--\end{array}$ & $\begin{array}{l}74 \\
-- \\
-- \\
74 \\
73\end{array}$ & $\begin{array}{l}77 \\
77 \\
77 \\
76 \\
76\end{array}$ & $\begin{array}{l}79 \\
77 \\
-- \\
79\end{array}$ \\
\hline $\begin{array}{l}21 \\
22 \\
23 \\
24 \\
25\end{array}$ & $\begin{array}{l}73 \\
73 \\
73 \\
-- \\
--\end{array}$ & $\begin{array}{l}61 \\
-- \\
60 \\
60 \\
59\end{array}$ & $\begin{array}{l}53 \\
51 \\
50 \\
54 \\
--\end{array}$ & $\begin{array}{l}45 \\
43 \\
-- \\
-- \\
44\end{array}$ & $\begin{array}{l}-- \\
-- \\
51 \\
51 \\
52\end{array}$ & $\begin{array}{l}-- \\
54 \\
50 \\
51 \\
52\end{array}$ & $\begin{array}{l}60 \\
60 \\
60 \\
-- \\
--\end{array}$ & $\begin{array}{c}64 \\
-- \\
-- \\
65 \\
65\end{array}$ & $\begin{array}{l}72 \\
72 \\
73 \\
71 \\
72\end{array}$ & $\begin{array}{l}74 \\
74 \\
75 \\
-- \\
--\end{array}$ & $\begin{array}{l}-- \\
78 \\
78 \\
77\end{array}$ & $\begin{array}{l}75 \\
74 \\
73 \\
74 \\
-\end{array}$ \\
\hline $\begin{array}{l}26 \\
27 \\
28 \\
29 \\
30 \\
31\end{array}$ & $\begin{array}{l}71 \\
70 \\
70 \\
70 \\
69 \\
--\end{array}$ & $\begin{array}{l}-- \\
59 \\
-- \\
-- \\
68 \\
--\end{array}$ & $\begin{array}{l}-- \\
-- \\
49 \\
48 \\
47 \\
47\end{array}$ & $\begin{array}{l}44 \\
44 \\
44 \\
44 \\
-- \\
--\end{array}$ & $\begin{array}{l}52 \\
-- \\
-- \\
-- \\
-- \\
--\end{array}$ & $\begin{array}{l}52 \\
52 \\
-- \\
-- \\
-- \\
52\end{array}$ & $\begin{array}{l}60 \\
60 \\
-- \\
65 \\
64 \\
--\end{array}$ & $\begin{array}{l}66 \\
66 \\
68 \\
-- \\
-- \\
--\end{array}$ & $\begin{array}{l}-. \\
-- \\
71 \\
71 \\
72 \\
\ldots\end{array}$ & $\begin{array}{l}75 \\
75 \\
75 \\
75 \\
75 \\
--\end{array}$ & $\begin{array}{l}78 \\
78 \\
-- \\
79 \\
77\end{array}$ & $\begin{array}{l}-- \\
76 \\
77 \\
78 \\
78 \\
--\end{array}$ \\
\hline $\begin{array}{c}\text { Aver- } \\
\text { age }\end{array}$ & -- & $\therefore$ & - & - & -- & - & -- & -- & -- & -- & -- & -- \\
\hline
\end{tabular}




\begin{tabular}{|c|c|c|c|c|c|}
\hline 區 & $\stackrel{0}{\circ}$ & $\begin{array}{l}\infty \infty N \infty \\
0=0 \\
0\end{array}$ & $\begin{array}{l}n \infty \pi \infty 0 \\
0000 \\
0\end{array}$ & 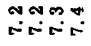 & i) \\
\hline 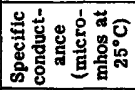 & & 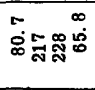 & 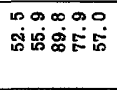 & ஜ்요용 & ìं \\
\hline 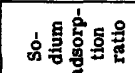 & $\ddot{0}$ & 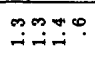 & $\varphi 0 \%$. & $\because r 0$ & $\begin{array}{l}0 \\
0\end{array}$ \\
\hline 它苔。最 & $\mathscr{\infty}$ & 尔品路 & 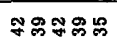 & 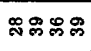 & $\mathscr{F}$ \\
\hline " & 0 & OMm & nengino & $000 N$ & -1 \\
\hline 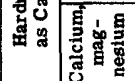 & ส & 으은은 & ฟ & ̊ㅗㅀㅇㅛ & 누 \\
\hline 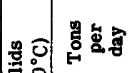 & $\stackrel{n}{-i}$ & 표 & 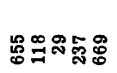 & $\stackrel{\square}{*}$ & 운 \\
\hline 品 & 5 & 등구옹으 & 웅용ㅇㅇㅇㅇㅇ & 동용ㅇㅇ & $\begin{array}{l}0 \\
0 \\
0\end{array}$ \\
\hline 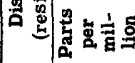 & 活 & 字はず & 융 주ㅇㅛㅠ: & นำ & 5 \\
\hline 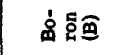 & $\underset{0}{0}$ & $1: 1:$ & 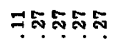 & 888 & $i$ \\
\hline मे & & $\stackrel{4}{0}$ & 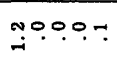 & 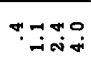 & $\stackrel{0}{0}$ \\
\hline 高害国 & & 1: $1:$ & ๓ & 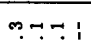 & it. \\
\hline 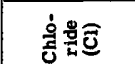 & & $\stackrel{0}{\sim}$ & 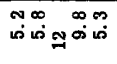 & ஸ் & $\overrightarrow{0}$ \\
\hline 实密 & $\stackrel{\pi}{*}$ & 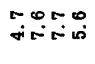 & ம் & 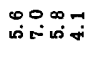 & $\begin{array}{l}0 \\
0 \\
0\end{array}$ \\
\hline 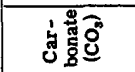 & 0 & 0000 & 00000 & 0000 & $i$ \\
\hline 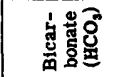 & $\stackrel{\infty}{\sim}$ & 品贴占 & カエッニ゚ & న్సిల్లెల్ల & $=$ \\
\hline 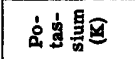 & $\vec{i}$ & $1: 1:$ & 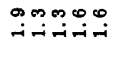 & $\begin{array}{lll}0 & 000 \\
\text { ifin } & 1\end{array}$ & $i$ \\
\hline 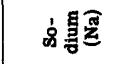 & $\infty$ & एँ & 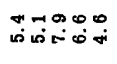 & 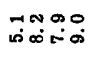 & $\begin{array}{c}m \\
\infty \\
\infty\end{array}$ \\
\hline 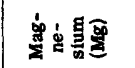 & $\stackrel{0}{i}$ & ஜேர் & 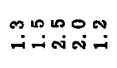 & 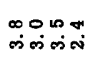 & 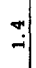 \\
\hline ชี่ & $\ddot{i}$ & $\omega_{ \pm \infty}^{\infty}$ & 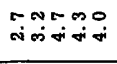 & 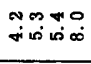 & $\begin{array}{c}0 \\
\dot{\infty}\end{array}$ \\
\hline 总 & ஜீ & $\begin{array}{lll}1 & 1 & 1\end{array}$ & 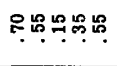 & 오꿍ㅇ : & $i$ \\
\hline 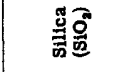 & is & $1: 1:$ & 0 & 응ㅇㅁ: & $i$ \\
\hline 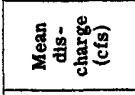 & & m & 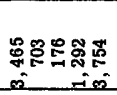 & 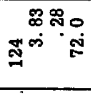 & 足 \\
\hline 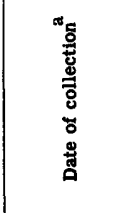 & 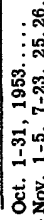 & 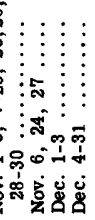 & 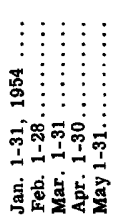 & 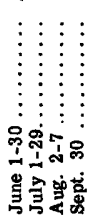 & 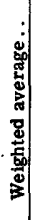 \\
\hline
\end{tabular}


RED RIVER BASIN--Continued

KIAMICHI RIVER NEAR BELZONI, OKLA.--Continued

Temperature $\left({ }^{\circ} \mathrm{F}\right)$ of water, water year October 1953 to September 1954

\begin{tabular}{|c|c|c|c|c|c|c|c|c|c|c|c|c|}
\hline Day & Oct. & Nov. & Dec. & Jan. & Feb. & Mar. & Apr. & May & June & July & Aug. & Sept. \\
\hline $\begin{array}{l}1 \\
2 \\
3 \\
4 \\
5\end{array}$ & $\begin{array}{l}80 \\
81 \\
80 \\
79 \\
70\end{array}$ & $\begin{array}{l}71 \\
70 \\
68 \\
61 \\
51\end{array}$ & $\begin{array}{l}63 \\
60 \\
54 \\
55 \\
57\end{array}$ & $\begin{array}{l}47 \\
50 \\
43 \\
45 \\
43\end{array}$ & $\begin{array}{l}55 \\
60 \\
58 \\
53 \\
61\end{array}$ & $\begin{array}{l}52 \\
40 \\
41 \\
39 \\
37\end{array}$ & $\begin{array}{l}60 \\
63 \\
67 \\
64 \\
60\end{array}$ & $\begin{array}{l}61 \\
63 \\
64 \\
65 \\
65\end{array}$ & $\begin{array}{l}80 \\
80 \\
81 \\
78 \\
73\end{array}$ & $\begin{array}{l}87 \\
86 \\
89 \\
88 \\
98\end{array}$ & $\begin{array}{l}-- \\
86 \\
85 \\
85 \\
88\end{array}$ & - \\
\hline $\begin{array}{r}6 \\
7 \\
8 \\
9 \\
10\end{array}$ & $\begin{array}{l}70 \\
76 \\
77 \\
82 \\
85\end{array}$ & $\begin{array}{l}55 \\
45 \\
47 \\
49 \\
55\end{array}$ & $\begin{array}{l}58 \\
52 \\
49 \\
45 \\
49\end{array}$ & $\begin{array}{l}42 \\
43 \\
40 \\
41 \\
35\end{array}$ & $\begin{array}{l}50 \\
50 \\
53 \\
57 \\
60\end{array}$ & $\begin{array}{l}40 \\
49 \\
65 \\
70 \\
71\end{array}$ & $\begin{array}{l}65 \\
63 \\
67 \\
64 \\
67\end{array}$ & $\begin{array}{l}69 \\
69 \\
66 \\
64 \\
63\end{array}$ & $\begin{array}{l}79 \\
77 \\
77 \\
83 \\
79\end{array}$ & $\begin{array}{l}81 \\
86 \\
84 \\
88 \\
85\end{array}$ & $\begin{array}{l}87 \\
85 \\
-- \\
-- \\
--\end{array}$ & \\
\hline $\begin{array}{l}11 \\
12 \\
13 \\
14 \\
15\end{array}$ & $\begin{array}{l}83 \\
82 \\
78 \\
76 \\
74\end{array}$ & $\begin{array}{l}59 \\
60 \\
66 \\
58 \\
54\end{array}$ & $\begin{array}{l}45 \\
45 \\
49 \\
48 \\
45\end{array}$ & $\begin{array}{l}43 \\
40 \\
37 \\
39 \\
44\end{array}$ & $\begin{array}{l}62 \\
55 \\
55 \\
59 \\
60\end{array}$ & $\begin{array}{l}68 \\
70 \\
48 \\
50 \\
47\end{array}$ & $\begin{array}{l}70 \\
65 \\
66 \\
69 \\
63\end{array}$ & $\begin{array}{l}65 \\
58 \\
64 \\
65 \\
65\end{array}$ & $\begin{array}{l}82 \\
87 \\
84 \\
85 \\
83\end{array}$ & $\begin{array}{l}89 \\
91 \\
90 \\
87 \\
87\end{array}$ & $\begin{array}{l}-- \\
-- \\
-- \\
- \\
--\end{array}$ & \\
\hline $\begin{array}{l}16 \\
17 \\
18 \\
19 \\
20\end{array}$ & $\begin{array}{l}72 \\
70 \\
83 \\
71 \\
73\end{array}$ & $\begin{array}{l}\mathbf{5 8} \\
\mathbf{5 4} \\
\mathbf{5 9} \\
\mathbf{5 2} \\
\mathbf{5 5}\end{array}$ & $\begin{array}{l}46 \\
44 \\
44 \\
48 \\
47\end{array}$ & $\begin{array}{l}45 \\
46 \\
45 \\
47 \\
47\end{array}$ & $\begin{array}{l}62 \\
60 \\
61 \\
55 \\
62\end{array}$ & $\begin{array}{l}50 \\
49 \\
55 \\
57 \\
59\end{array}$ & $\begin{array}{l}64 \\
67 \\
69 \\
66 \\
67\end{array}$ & $\begin{array}{l}67 \\
67 \\
68 \\
71 \\
71\end{array}$ & $\begin{array}{l}86 \\
83 \\
86 \\
86 \\
87\end{array}$ & $\begin{array}{l}87 \\
86 \\
86 \\
88 \\
89\end{array}$ & $\begin{array}{l}-- \\
-- \\
-- \\
-- \\
--\end{array}$ & \\
\hline $\begin{array}{l}21 \\
22 \\
23 \\
24 \\
25\end{array}$ & $\begin{array}{l}72 \\
75 \\
72 \\
71 \\
70\end{array}$ & $\begin{array}{l}54 \\
51 \\
49 \\
51 \\
50\end{array}$ & $\begin{array}{l}38 \\
36 \\
39 \\
38 \\
41\end{array}$ & $\begin{array}{l}32 \\
44 \\
44 \\
44 \\
44\end{array}$ & $\begin{array}{l}65 \\
60 \\
55 \\
64 \\
65\end{array}$ & $\begin{array}{l}56 \\
60 \\
63 \\
65 \\
68\end{array}$ & $\begin{array}{l}69 \\
71 \\
74 \\
76 \\
75\end{array}$ & $\begin{array}{l}70 \\
72 \\
70 \\
73 \\
71\end{array}$ & $\begin{array}{l}70 \\
87 \\
90 \\
91 \\
87\end{array}$ & $\begin{array}{l}86 \\
95 \\
89 \\
86 \\
87\end{array}$ & $\begin{array}{c}-- \\
-- \\
-- \\
-- \\
--\end{array}$ & \\
\hline $\begin{array}{l}26 \\
27 \\
28 \\
29 \\
30 \\
31\end{array}$ & $\begin{array}{l}69 \\
74 \\
73 \\
69 \\
65 \\
60\end{array}$ & $\begin{array}{l}53 \\
56 \\
60 \\
53 \\
54 \\
--\end{array}$ & $\begin{array}{l}52 \\
51 \\
45 \\
41 \\
50 \\
45\end{array}$ & $\begin{array}{l}46 \\
49 \\
50 \\
47 \\
54 \\
55\end{array}$ & $\begin{array}{c}60 \\
62 \\
58 \\
-- \\
- \\
--\end{array}$ & $\begin{array}{l}62 \\
63 \\
64 \\
60 \\
67 \\
57\end{array}$ & $\begin{array}{l}76 \\
77 \\
71 \\
68 \\
69 \\
--\end{array}$ & $\begin{array}{l}70 \\
70 \\
75 \\
79 \\
78 \\
77\end{array}$ & $\begin{array}{l}90 \\
90 \\
87 \\
90 \\
85 \\
--\end{array}$ & $\begin{array}{l}89 \\
86 \\
86 \\
85 \\
-- \\
--\end{array}$ & $\begin{array}{l}-- \\
-- \\
-- \\
-- \\
-- \\
--\end{array}$ & 80 \\
\hline $\begin{array}{c}\text { Aver - } \\
\text { age }\end{array}$ & 75 & 56 & 48 & 44 & 58 & 56 & 68 & 68 & 83 & 88 & -- & -- \\
\hline
\end{tabular}




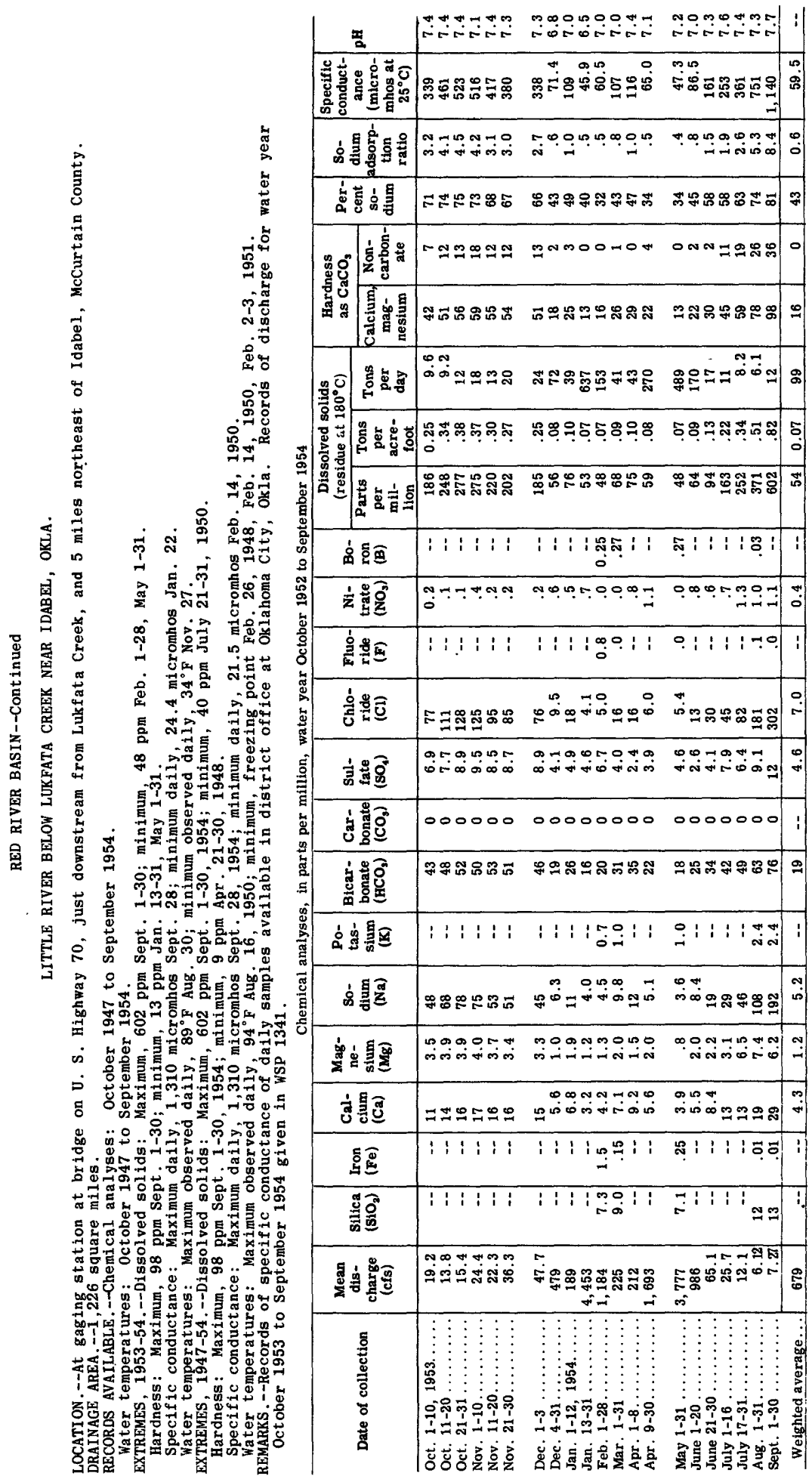


RED RIVER BASIN--Continued

LITTLE RIVER BELOW LUKFATA CREEK NEAR IDABEL, OKLA. --Continued

Temperature $\left({ }^{\circ} \mathrm{F}\right)$ of water, water year October 1953 to September 1954

\begin{tabular}{|c|c|c|c|c|c|c|c|c|c|c|c|c|}
\hline Day & Oct. & Nov. & Dec. & Jan. & Feb. & Mar. & Apr. & May & June & July & Aug. & Sept. \\
\hline $\begin{array}{l}1 \\
2 \\
3 \\
4 \\
5\end{array}$ & $\begin{array}{l}75 \\
76 \\
76 \\
75 \\
73\end{array}$ & $\begin{array}{l}60 \\
58 \\
58 \\
60 \\
58\end{array}$ & $\begin{array}{l}51 \\
52 \\
50 \\
51 \\
50\end{array}$ & $\begin{array}{l}41 \\
44 \\
42 \\
41 \\
41\end{array}$ & $\begin{array}{l}46 \\
48 \\
49 \\
50 \\
49\end{array}$ & $\begin{array}{l}50 \\
52 \\
48 \\
49 \\
49\end{array}$ & $\begin{array}{l}56 \\
58 \\
59 \\
61 \\
66\end{array}$ & $\begin{array}{l}72 \\
71 \\
63 \\
61 \\
63\end{array}$ & $\begin{array}{l}72 \\
75 \\
72 \\
74 \\
--\end{array}$ & $\begin{array}{l}86 \\
86 \\
83 \\
85 \\
84\end{array}$ & $\begin{array}{l}82 \\
81 \\
84 \\
82 \\
81\end{array}$ & $\begin{array}{l}80 \\
80 \\
77 \\
77 \\
78\end{array}$ \\
\hline $\begin{array}{r}6 \\
7 \\
8 \\
9 \\
10\end{array}$ & $\begin{array}{l}68 \\
66 \\
64 \\
64 \\
64\end{array}$ & $\begin{array}{l}\mathbf{5 5} \\
\mathbf{5 3} \\
\mathbf{5 3} \\
\mathbf{5 0} \\
\mathbf{5 0}\end{array}$ & $\begin{array}{l}48 \\
49 \\
48 \\
47 \\
46\end{array}$ & $\begin{array}{l}42 \\
42 \\
44 \\
48 \\
45\end{array}$ & $\begin{array}{l}50 \\
48 \\
46 \\
47 \\
48\end{array}$ & $\begin{array}{l}42 \\
46 \\
49 \\
48 \\
52\end{array}$ & $\begin{array}{l}67 \\
68 \\
65 \\
56 \\
64\end{array}$ & $\begin{array}{l}65 \\
64 \\
64 \\
64 \\
64\end{array}$ & $\begin{array}{l}74 \\
75 \\
71 \\
76 \\
77\end{array}$ & $\begin{array}{l}83 \\
83 \\
82 \\
85 \\
85\end{array}$ & $\begin{array}{l}81 \\
86 \\
87 \\
83 \\
81\end{array}$ & $\begin{array}{l}81 \\
80 \\
80 \\
77 \\
82\end{array}$ \\
\hline $\begin{array}{l}11 \\
12 \\
13 \\
14 \\
15\end{array}$ & $\begin{array}{l}65 \\
67 \\
69 \\
69 \\
69\end{array}$ & $\begin{array}{l}50 \\
50 \\
52 \\
50 \\
51\end{array}$ & $\begin{array}{l}46 \\
46 \\
44 \\
44 \\
44\end{array}$ & $\begin{array}{l}43 \\
42 \\
39 \\
40 \\
42\end{array}$ & $\begin{array}{l}50 \\
49 \\
42 \\
62 \\
53\end{array}$ & $\begin{array}{l}\mathbf{5 5} \\
\mathbf{5 8} \\
\mathbf{5 3} \\
\mathbf{5 1} \\
\mathbf{4 9}\end{array}$ & $\begin{array}{l}68 \\
65 \\
61 \\
64 \\
66\end{array}$ & $\begin{array}{l}60 \\
58 \\
59 \\
61 \\
64\end{array}$ & $\begin{array}{l}80 \\
82 \\
82 \\
82 \\
81\end{array}$ & $\begin{array}{l}85 \\
87 \\
87 \\
87 \\
88\end{array}$ & $\begin{array}{l}86 \\
84 \\
82 \\
82 \\
83\end{array}$ & $\begin{array}{l}70 \\
75 \\
72 \\
72 \\
76\end{array}$ \\
\hline $\begin{array}{l}16 \\
17 \\
18 \\
19 \\
20\end{array}$ & $\begin{array}{l}69 \\
67 \\
67 \\
68 \\
62\end{array}$ & $\begin{array}{l}50 \\
52 \\
55 \\
57 \\
53\end{array}$ & $\begin{array}{l}43 \\
42 \\
43 \\
44 \\
43\end{array}$ & $\begin{array}{l}43 \\
43 \\
46 \\
49 \\
48\end{array}$ & $\begin{array}{l}\mathbf{5 3} \\
55 \\
53 \\
\mathbf{6 1} \\
\mathbf{5 2}\end{array}$ & $\begin{array}{l}53 \\
63 \\
55 \\
55 \\
56\end{array}$ & $\begin{array}{l}65 \\
64 \\
53 \\
66 \\
66\end{array}$ & $\begin{array}{l}66 \\
67 \\
68 \\
69 \\
69\end{array}$ & $\begin{array}{l}82 \\
82 \\
83 \\
83 \\
84\end{array}$ & $\begin{array}{l}88 \\
88 \\
85 \\
85 \\
86\end{array}$ & $\begin{array}{l}86 \\
84 \\
84 \\
85 \\
84\end{array}$ & $\begin{array}{l}75 \\
71 \\
78 \\
79 \\
79\end{array}$ \\
\hline $\begin{array}{l}21 \\
22 \\
23 \\
24 \\
25\end{array}$ & $\begin{array}{l}66 \\
67 \\
66 \\
67 \\
66\end{array}$ & $\begin{array}{l}\mathbf{5 1} \\
\mathbf{5 1} \\
\mathbf{5 1} \\
\mathbf{5 8} \\
\mathbf{5 8}\end{array}$ & $\begin{array}{l}43 \\
39 \\
-- \\
39 \\
38\end{array}$ & $\begin{array}{l}50 \\
45 \\
44 \\
43 \\
44\end{array}$ & $\begin{array}{l}\mathbf{5 2} \\
\mathbf{5 2} \\
\mathbf{5 3} \\
\mathbf{5 2} \\
\mathbf{5 3}\end{array}$ & $\begin{array}{l}54 \\
54 \\
58 \\
59 \\
60\end{array}$ & $\begin{array}{l}67 \\
69 \\
69 \\
70 \\
72\end{array}$ & $\begin{array}{l}69 \\
71 \\
72 \\
72 \\
73\end{array}$ & $\begin{array}{l}85 \\
84 \\
86 \\
87 \\
85\end{array}$ & $\begin{array}{l}86 \\
85 \\
86 \\
87 \\
87\end{array}$ & $\begin{array}{l}82 \\
85 \\
82 \\
82 \\
82\end{array}$ & $\begin{array}{l}75 \\
71 \\
70 \\
71 \\
71\end{array}$ \\
\hline $\begin{array}{l}26 \\
27 \\
28 \\
29 \\
30 \\
31\end{array}$ & $\begin{array}{l}67 \\
60 \\
60 \\
58 \\
57 \\
59\end{array}$ & $\begin{array}{l}49 \\
34 \\
48 \\
48 \\
48 \\
--\end{array}$ & $\begin{array}{l}39 \\
40 \\
41 \\
41 \\
39 \\
41\end{array}$ & $\begin{array}{l}46 \\
46 \\
47 \\
49 \\
49 \\
49\end{array}$ & $\begin{array}{l}52 \\
58 \\
52 \\
-- \\
-- \\
--\end{array}$ & $\begin{array}{l}59 \\
58 \\
60 \\
63 \\
62 \\
59\end{array}$ & $\begin{array}{l}74 \\
74 \\
73 \\
73 \\
74 \\
--\end{array}$ & $\begin{array}{l}73 \\
69 \\
72 \\
71 \\
71 \\
71\end{array}$ & $\begin{array}{l}85 \\
86 \\
86 \\
86 \\
82 \\
--\end{array}$ & $\begin{array}{l}86 \\
85 \\
84 \\
83 \\
83 \\
84\end{array}$ & $\begin{array}{l}86 \\
83 \\
85 \\
85 \\
89 \\
82\end{array}$ & $\begin{array}{l}72 \\
76 \\
-- \\
68 \\
77 \\
--\end{array}$ \\
\hline $\begin{array}{c}\text { Aver- } \\
\text { age }\end{array}$ & $67^{\circ}$ & 52 & 44 & 44 & 51 & 54 & 66 & 67 & 81 & 85 & 84 & 76 \\
\hline
\end{tabular}




\begin{tabular}{|c|c|c|c|c|}
\hline \multicolumn{2}{|c|}{ ؛ํㅇㅇ } & $r \infty r_{\infty} \infty \infty$ & ఎ - & 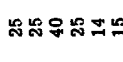 \\
\hline & 졈 & 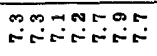 & 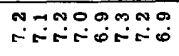 & 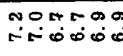 \\
\hline \multicolumn{2}{|c|}{ 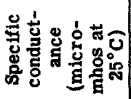 } & 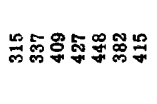 & 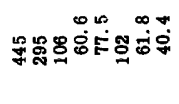 & 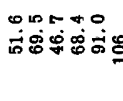 \\
\hline \multirow{2}{*}{ 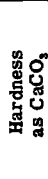 } & 容套 & 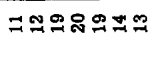 & $=$ T-OONONN & $-\pi-\infty$ tro \\
\hline & 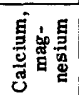 & 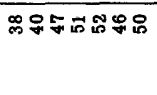 & ธ็์ & 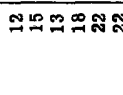 \\
\hline
\end{tabular}

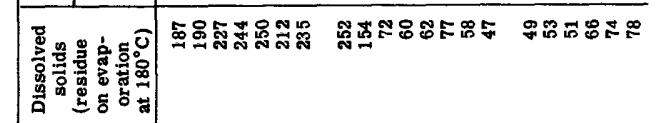

\begin{tabular}{|c|c|c|c|}
\hline 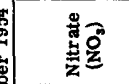 & 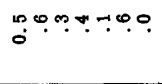 & نْ & 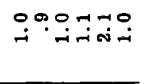 \\
\hline 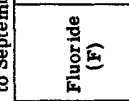 & 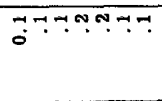 & 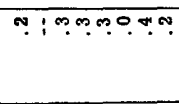 & 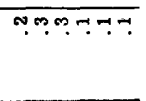 \\
\hline 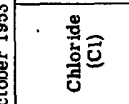 & 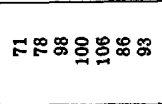 & 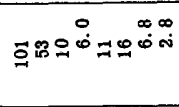 & 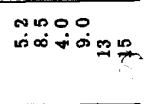 \\
\hline 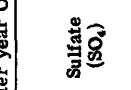 & 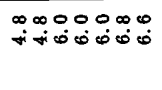 & 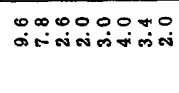 & 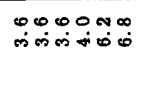 \\
\hline 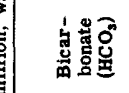 & 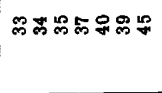 & 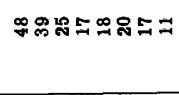 & 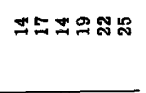 \\
\hline 通息可 & 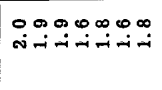 & 宓: & 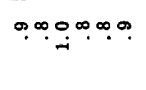 \\
\hline 毁要 & 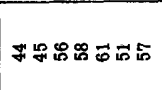 & 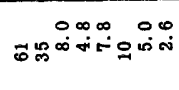 & 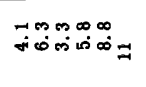 \\
\hline 息可 & 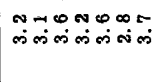 & 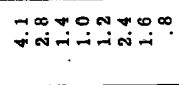 & 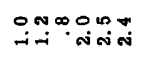 \\
\hline 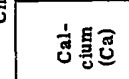 & 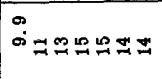 & 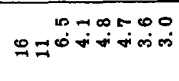 & 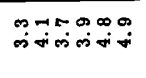 \\
\hline 间 & 50ढ் & $8: 895$ & 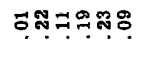 \\
\hline 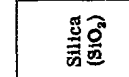 & 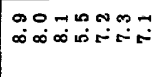 & 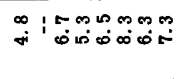 & 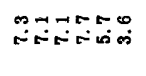 \\
\hline 惹总 & 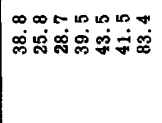 & 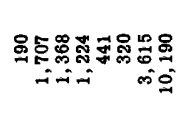 & 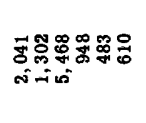 \\
\hline 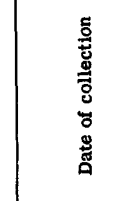 & 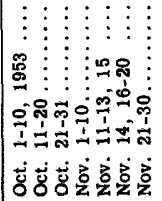 & $\begin{array}{r}\vdots \\
\vdots \\
\vdots \\
0\end{array}$ & 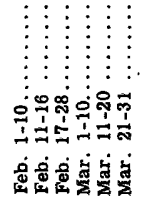 \\
\hline
\end{tabular}




\begin{tabular}{|c|c|c|c|}
\hline 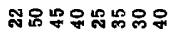 & 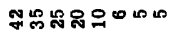 & $\infty-\infty \infty \infty \infty$ & - \\
\hline 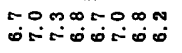 & 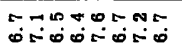 & 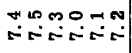 & $i$ \\
\hline 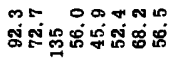 & 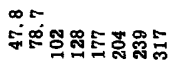 & 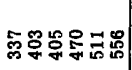 & 농 \\
\hline nomon-O & 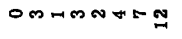 & $\underset{\sim}{\infty}$ సี & $\infty$ \\
\hline 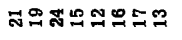 & 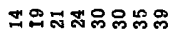 & 욱5尔品品品 & 요 \\
\hline 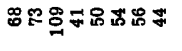 & 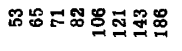 & 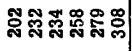 & ฐิ \\
\hline & $\underset{H}{0}$ & 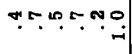 & $\begin{array}{l}\infty \\
0\end{array}$ \\
\hline 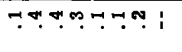 & 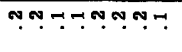 & $\because \because \dashv$ ๓ฺ & จ \\
\hline ๓ & 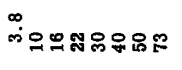 & 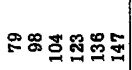 & 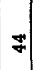 \\
\hline 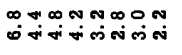 & 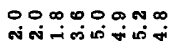 & 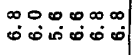 & 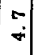 \\
\hline 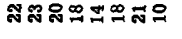 & 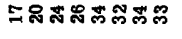 & 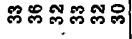 & ஸै \\
\hline 禺 & - & 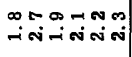 & + \\
\hline 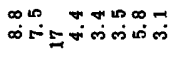 & 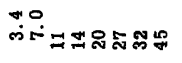 & テ5 & ง \\
\hline 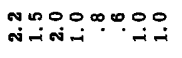 & 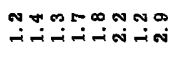 & 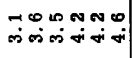 & $\begin{array}{l}\text { N } \\
\text { ஸे }\end{array}$ \\
\hline 迥 & 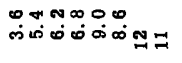 & 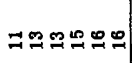 & $\infty$ \\
\hline 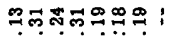 & 웓ㄷㄴㅇㅇㅇㅇㅇㅇㅇ. & 옹웅용ㅇㅇ요요 & 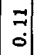 \\
\hline 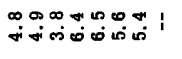 & 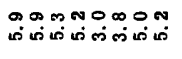 & 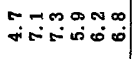 & - \\
\hline 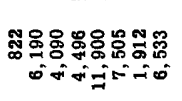 & 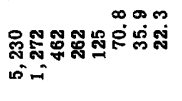 & 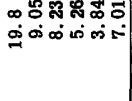 & $\begin{array}{l}\mathscr{8} \\
\infty \\
\infty \\
-1\end{array}$ \\
\hline 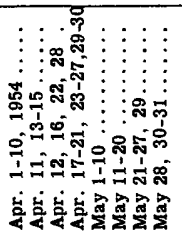 & 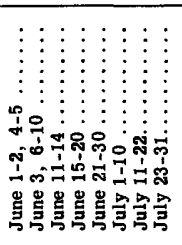 & 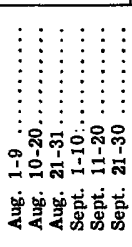 & \begin{tabular}{r|} 
\\
$\vdots$ \\
$\vdots$ \\
$\vdots$ \\
8 \\
5 \\
$\vdots$ \\
$\vdots$ \\
4
\end{tabular} \\
\hline
\end{tabular}


RED RIVER BASIN--Continued

LITTLE RIVER NEAR HORATIO, ARK.--Continued

Temperature $\left({ }^{\circ} \mathrm{F}\right)$ of water, water year October 1953 to September 1954

\begin{tabular}{|c|c|c|c|c|c|c|c|c|c|c|c|c|}
\hline Day & Oct. & Nov. & Dec. & Jan. & Feb. & Mar. & Apr. & May & June & July & Aug. & Sept. \\
\hline $\begin{array}{l}1 \\
2 \\
3 \\
4 \\
5\end{array}$ & $\begin{array}{l}77 \\
\overline{78} \\
77 \\
76\end{array}$ & $\begin{array}{l}58 \\
57 \\
57 \\
62 \\
59\end{array}$ & $\begin{array}{l}49 \\
49 \\
54 \\
51 \\
51\end{array}$ & $\begin{array}{l}39 \\
43 \\
41 \\
41 \\
41\end{array}$ & $\begin{array}{l}47 \\
47 \\
48 \\
48 \\
47\end{array}$ & $\begin{array}{l}50 \\
51 \\
48 \\
47 \\
46\end{array}$ & $\begin{array}{l}\mathbf{5 5} \\
53 \\
58 \\
62 \\
66\end{array}$ & $\begin{array}{l}69 \\
69 \\
-2 \\
62 \\
61\end{array}$ & $\begin{array}{l}72 \\
73 \\
71 \\
71 \\
72\end{array}$ & $\begin{array}{l}86 \\
86 \\
87 \\
87 \\
86\end{array}$ & $\begin{array}{l}80 \\
84 \\
84 \\
85 \\
86\end{array}$ & $\begin{array}{l}83 \\
82 \\
80 \\
80 \\
80\end{array}$ \\
\hline $\begin{array}{r}6 \\
7 \\
8 \\
9 \\
10\end{array}$ & $\begin{array}{l}70 \\
70 \\
67 \\
66 \\
--\end{array}$ & $\begin{array}{l}54 \\
55 \\
51 \\
49 \\
48\end{array}$ & $\begin{array}{l}51 \\
47 \\
49 \\
49 \\
45\end{array}$ & $\begin{array}{l}41 \\
41 \\
45 \\
50 \\
46\end{array}$ & $\begin{array}{l}48 \\
46 \\
44 \\
46 \\
48\end{array}$ & $\begin{array}{l}45 \\
45 \\
48 \\
49 \\
53\end{array}$ & $\begin{array}{l}68 \\
68 \\
68 \\
65 \\
67\end{array}$ & $\begin{array}{l}62 \\
63 \\
62 \\
64 \\
62\end{array}$ & $\begin{array}{l}73 \\
75 \\
75 \\
77 \\
78\end{array}$ & $\begin{array}{l}86 \\
86 \\
87 \\
87 \\
88\end{array}$ & $\begin{array}{l}86 \\
85 \\
85 \\
86 \\
84\end{array}$ & $\begin{array}{l}81 \\
80 \\
80 \\
81 \\
82\end{array}$ \\
\hline $\begin{array}{l}11 \\
12 \\
13 \\
14 \\
15\end{array}$ & $\begin{array}{l}65 \\
67 \\
68 \\
68 \\
69\end{array}$ & $\begin{array}{l}48 \\
48 \\
48 \\
47 \\
49\end{array}$ & $\begin{array}{l}47 \\
47 \\
44 \\
44 \\
42\end{array}$ & $\begin{array}{l}41 \\
40 \\
39 \\
39 \\
41\end{array}$ & $\begin{array}{l}50 \\
48 \\
46 \\
51 \\
53\end{array}$ & $\begin{array}{l}57 \\
60 \\
58 \\
50 \\
50\end{array}$ & $\begin{array}{l}68 \\
66 \\
63 \\
63 \\
67\end{array}$ & $\begin{array}{l}60 \\
60 \\
58 \\
58 \\
60\end{array}$ & $\begin{array}{l}80 \\
80 \\
82 \\
83 \\
83\end{array}$ & $\begin{array}{l}88 \\
88 \\
88 \\
89 \\
89\end{array}$ & $\begin{array}{l}85 \\
84 \\
85 \\
85 \\
86\end{array}$ & $\begin{array}{l}79 \\
77 \\
77 \\
75 \\
75\end{array}$ \\
\hline $\begin{array}{l}16 \\
17 \\
18 \\
19 \\
20\end{array}$ & $\begin{array}{l}68 \\
67 \\
- \\
67 \\
68\end{array}$ & $\begin{array}{l}49 \\
50 \\
57 \\
62 \\
55\end{array}$ & $\begin{array}{l}42 \\
42 \\
41 \\
42 \\
44\end{array}$ & $\begin{array}{l}43 \\
44 \\
44 \\
48 \\
55\end{array}$ & $\begin{array}{l}54 \\
51 \\
53 \\
56 \\
52\end{array}$ & $\begin{array}{l}51 \\
53 \\
56 \\
56 \\
56\end{array}$ & $\begin{array}{l}63 \\
61 \\
64 \\
63 \\
64\end{array}$ & $\begin{array}{l}63 \\
65 \\
69 \\
63 \\
68\end{array}$ & $\begin{array}{l}82 \\
83 \\
83 \\
83 \\
84\end{array}$ & $\begin{array}{l}89 \\
89 \\
89 \\
88 \\
87\end{array}$ & $\begin{array}{l}85 \\
86 \\
85 \\
86 \\
85\end{array}$ & $\begin{array}{l}76 \\
78 \\
78 \\
78 \\
80\end{array}$ \\
\hline $\begin{array}{l}21 \\
22 \\
23 \\
24 \\
25\end{array}$ & $\begin{array}{c}68 \\
\overline{70} \\
-- \\
68\end{array}$ & $\begin{array}{l}50 \\
51 \\
48 \\
49 \\
48\end{array}$ & $\begin{array}{l}46 \\
42 \\
38 \\
37 \\
35\end{array}$ & $\begin{array}{l}46 \\
40 \\
44 \\
43 \\
46\end{array}$ & $\begin{array}{l}\mathbf{5 0} \\
\mathbf{5 0} \\
\mathbf{5 2} \\
\mathbf{5 0} \\
\mathbf{5 2}\end{array}$ & $\begin{array}{l}56 \\
56 \\
57 \\
60 \\
61\end{array}$ & $\begin{array}{l}66 \\
67 \\
68 \\
69 \\
71\end{array}$ & $\begin{array}{l}67 \\
80 \\
71 \\
70 \\
72\end{array}$ & $\begin{array}{l}84 \\
85 \\
87 \\
87 \\
87\end{array}$ & $\begin{array}{l}87 \\
87 \\
87 \\
88 \\
88\end{array}$ & $\begin{array}{l}84 \\
84 \\
84 \\
83 \\
84\end{array}$ & $\begin{array}{l}80 \\
75 \\
73 \\
74 \\
72\end{array}$ \\
\hline $\begin{array}{l}26 \\
27 \\
28 \\
29 \\
30 \\
31\end{array}$ & $\begin{array}{l}67 \\
64 \\
61 \\
58 \\
57 \\
58\end{array}$ & $\begin{array}{l}47 \\
-- \\
49 \\
50 \\
49 \\
--\end{array}$ & $\begin{array}{l}37 \\
38 \\
41 \\
40 \\
40 \\
39\end{array}$ & $\begin{array}{l}48 \\
44 \\
45 \\
47 \\
48 \\
48\end{array}$ & $\begin{array}{l}51 \\
56 \\
52 \\
-- \\
-- \\
--\end{array}$ & $\begin{array}{l}60 \\
60 \\
60 \\
62 \\
- \\
59\end{array}$ & $\begin{array}{l}71 \\
74 \\
73 \\
72 \\
70 \\
--\end{array}$ & $\begin{array}{l}\mathbf{7 2} \\
\mathbf{7 3} \\
\mathbf{7 0} \\
\mathbf{7 1} \\
\mathbf{7 4} \\
\mathbf{7 2}\end{array}$ & $\begin{array}{l}87 \\
87 \\
87 \\
87 \\
85 \\
--\end{array}$ & $\begin{array}{l}87 \\
87 \\
86 \\
85 \\
86 \\
85\end{array}$ & $\begin{array}{l}84 \\
85 \\
85 \\
85 \\
85 \\
85\end{array}$ & $\begin{array}{l}73 \\
74 \\
72 \\
77 \\
77 \\
--\end{array}$ \\
\hline $\begin{array}{c}\text { Aver- } \\
\text { age }\end{array}$ & 68 & 52 & 44 & 44 & 50 & 54 & 66 & 66 & 81 & 87 & 85 & 78 \\
\hline
\end{tabular}




\begin{tabular}{|c|c|c|c|c|}
\hline \multicolumn{2}{|c|}{ ㅎํㅇ } & 을 & 우ำのロล & 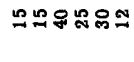 \\
\hline & 폄 & 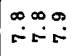 & 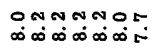 & 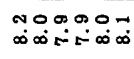 \\
\hline \multicolumn{2}{|c|}{ 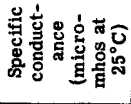 } & 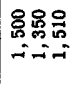 & 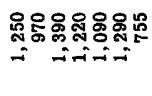 & 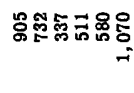 \\
\hline \multirow{2}{*}{ 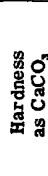 } & 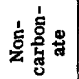 & อై? & 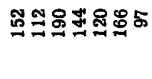 & 象里品 \\
\hline & 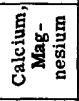 & कू్ల & 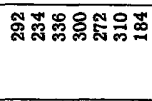 & 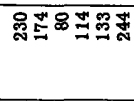 \\
\hline \multicolumn{2}{|c|}{ 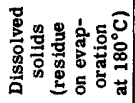 } & 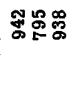 & 준 & 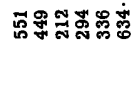 \\
\hline
\end{tabular}

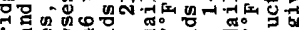
๘

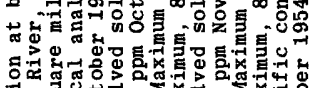

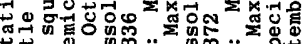

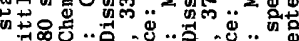

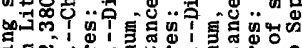

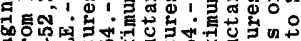

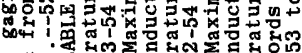
+ 뎔

\begin{tabular}{|c|c|c|c|}
\hline 总国 & $\because \div$ & $\because 1: \div \because \because$ & 0.0 .10 .00 \\
\hline 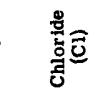 & 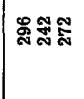 & 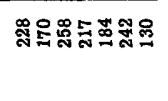 & : \\
\hline 密。 & 电卢 & 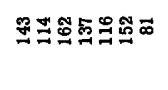 & 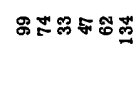 \\
\hline 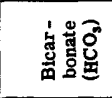 & 总蛋念 & 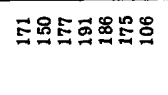 & 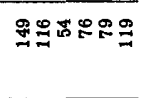 \\
\hline 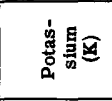 & $\begin{array}{l}0 \text { कon } \\
\text { is is is }\end{array}$ & 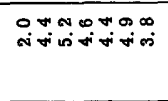 & 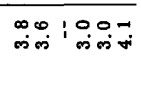 \\
\hline 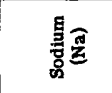 & $\mathscr{m} \mathscr{\sim}$ & 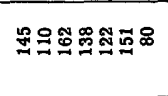 & 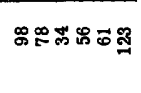 \\
\hline 额 & $\underset{2}{2}$ & จㄷษ & 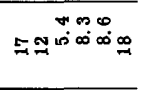 \\
\hline 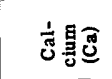 & 555 & 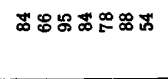 & ప品 జ్ల \\
\hline 总离 & \%8: & 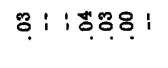 & 801858 \\
\hline 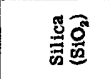 & 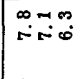 & 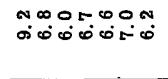 & कें \\
\hline 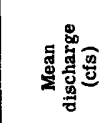 & 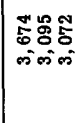 & 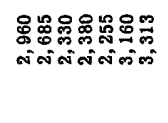 & 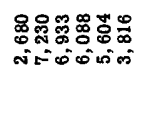 \\
\hline 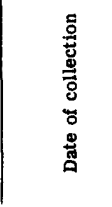 & 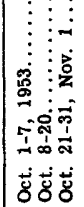 & 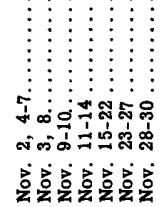 & 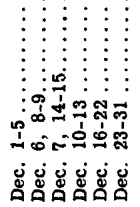 \\
\hline
\end{tabular}




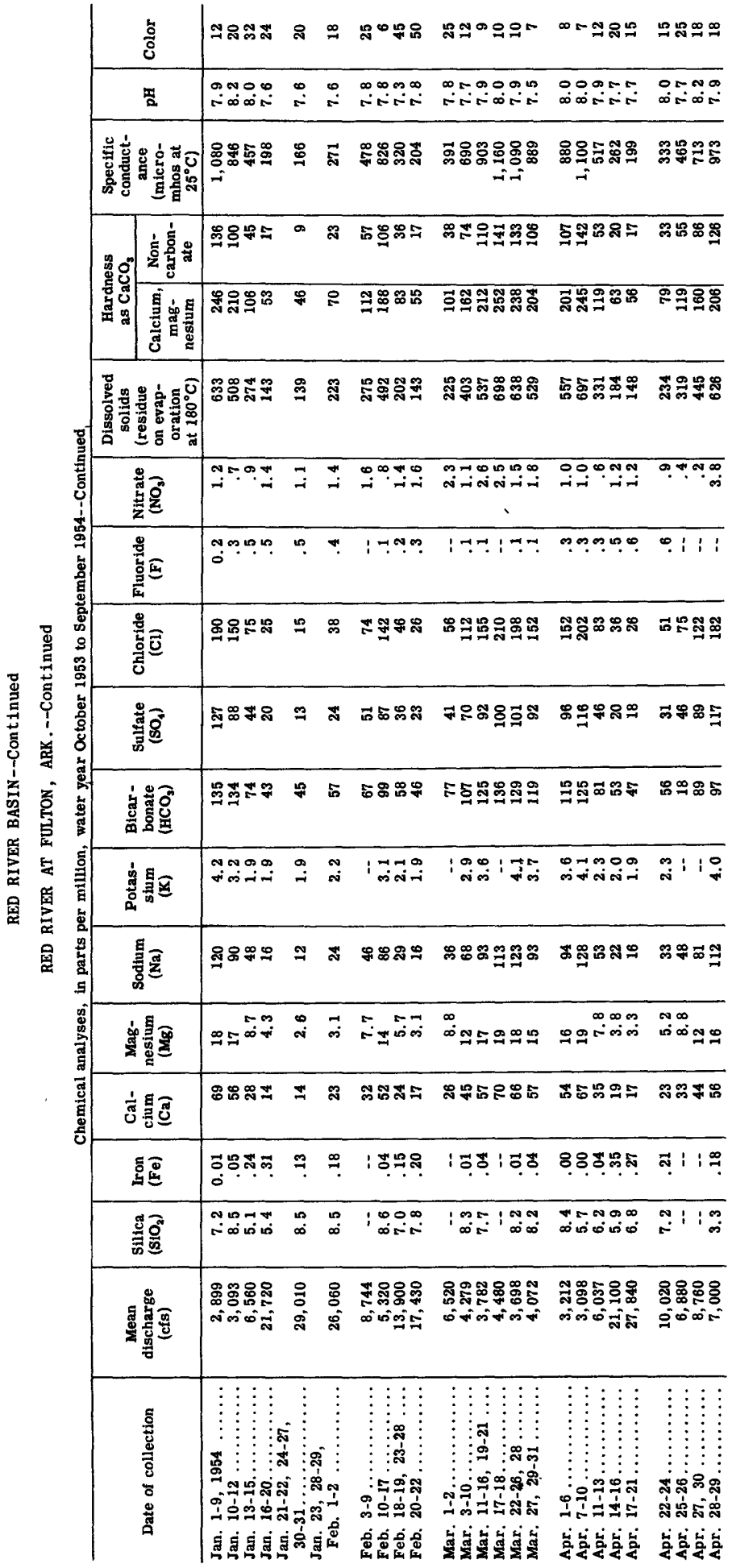




\begin{tabular}{|c|c|c|c|}
\hline 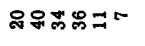 & gantonos & 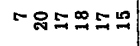 & $=$ \\
\hline 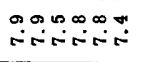 & 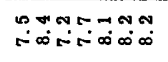 & 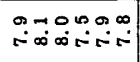 & 1 \\
\hline 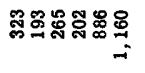 & 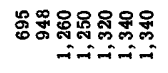 & 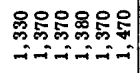 & 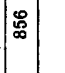 \\
\hline $\mathbb{N}^{\infty} 000$ & 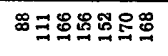 & 邑: & $\ddot{0}$ \\
\hline 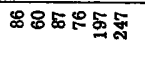 & 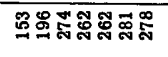 & 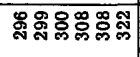 & $\cong$ \\
\hline 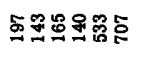 & 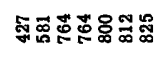 & 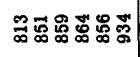 & 居 \\
\hline 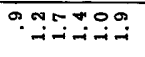 & "5. & $65000 \%$ & 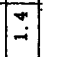 \\
\hline$::_{0}^{N}: \because=$ & $\because \because \infty-\because \div \div$ & $\because \square \square \square$ & $:$ \\
\hline 吅 & 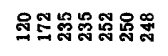 & 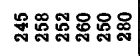 & $\dddot{2}$ \\
\hline 여요요 & 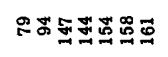 & 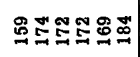 & $\%$ \\
\hline 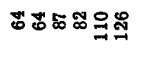 & 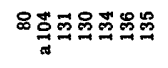 & 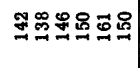 & $\equiv$ \\
\hline 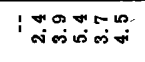 & 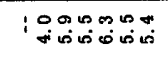 & 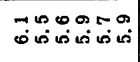 & : \\
\hline 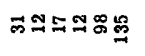 & 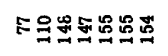 & 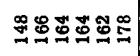 & 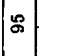 \\
\hline 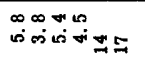 & 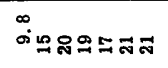 & 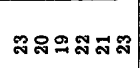 & $=$ \\
\hline 오ㅇㅠㅀㅛ & ケロ゙ミミ゙ミ゚ミ & $\vec{\infty} \bowtie \bowtie \bowtie \varpi$ & is \\
\hline 15055 & $15898 \%$ & 0.98888 & 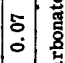 \\
\hline ฯ & 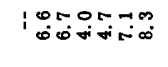 & 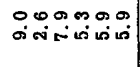 & $=\frac{0}{2}$ \\
\hline 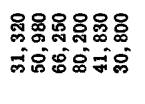 & 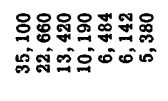 & 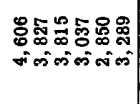 & 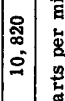 \\
\hline 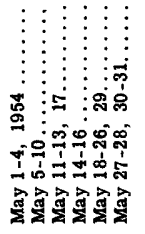 & 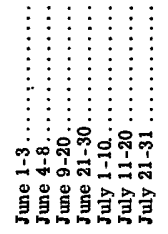 & 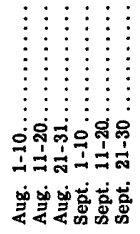 & 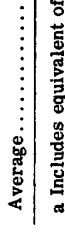 \\
\hline
\end{tabular}


RED RIVER BASIN--Continued

RED RIVER AT FULTON, ARK.--Continued

Temperature $\left({ }^{\circ} \mathrm{F}\right)$ of water, water year October 1953 to September 1954

\begin{tabular}{|c|c|c|c|c|c|c|c|c|c|c|c|c|}
\hline Day & Oct. & Nov. & Dec. & Jan. & Feb. & Mar. & Apr. & May & June & July & Aug. & Sept. \\
\hline 1 & 74 & 58 & 50 & 42 & 45 & 49 & 54 & 63 & 74 & 85 & 82 & 80 \\
\hline 2 & 74 & 58 & 50 & 42 & 46 & 50 & 55 & 63 & 74 & 85 & 82 & 80 \\
\hline 3 & 74 & 58 & 55 & 42 & 46 & 45 & 56 & 63 & 73 & 85 & 83 & 80 \\
\hline 4 & 74 & 58 & 53 & 43 & 47 & 44 & 61 & 60 & 73 & 85 & 84 & 80 \\
\hline 5 & -- & 58 & 53 & 43 & - & 45 & 64 & 60 & 74 & 85 & 84 & 80 \\
\hline 6 & -- & 50 & 50 & 43 & - - & 44 & 65 & 62 & 74 & 85 & 85 & 80 \\
\hline 7 & $\ldots$ & 50 & 50 & 43 & -- & 45 & 65 & 62 & 74 & 85 & 85 & 80 \\
\hline 8 & -- & 50 & 50 & 45 & -- & 48 & 63 & 62 & 74 & 85 & 85 & 80 \\
\hline 9 & -- & 50 & 49 & 49 & -. & 49 & 63 & 64 & 76 & 85 & 85 & 80 \\
\hline 10 & -- & 48 & 46 & 45 & 48 & 53 & 65 & 60 & 80 & 85 & 85 & 82 \\
\hline 11 & -- & 46 & 46 & 40 & 50 & 55 & 65 & 60 & 80 & 86 & 85 & 75 \\
\hline 12 & -- & 49 & 46 & 40 & 46 & 59 & 65 & 58 & 80 & 86 & 83 & 75 \\
\hline 13 & -- & 50 & 46 & 39 & 46 & 57 & 65 & 58 & 80 & 87 & 83 & 73 \\
\hline 14 & -- & 50 & 45 & 40 & 50 & 49 & 65 & 58 & 82 & 87 & 83 & 74 \\
\hline 15 & -- & 50 & 45 & 43 & 53 & 48 & 65 & 60 & 82 & 87 & 84 & 74 \\
\hline 16 & -- & 50 & 44 & 42 & 55 & 49 & 63 & 61 & 84 & 87 & 85 & 76 \\
\hline 17 & -- & 53 & 43 & 41 & 52 & 50 & 63 & 62 & 84 & 87 & 85 & 76 \\
\hline 18 & -- & 59 & 40 & 42 & 53 & 53 & 63 & 64 & 84 & 87 & 85 & 78 \\
\hline 19 & 70 & 60 & 40 & 45 & 53 & 54 & 63 & 63 & 84 & 86 & 85 & 80 \\
\hline 20 & 70 & 50 & 40 & 48 & 50 & 53 & 63 & 62 & 85 & 83 & 84 & 80 \\
\hline 21 & 70 & 53 & 45 & 40 & 49 & 54 & 63 & 65 & 85 & 85 & 84 & 72 \\
\hline 22 & 68 & 52 & 40 & 40 & 50 & 54 & 65 & 65 & 84 & 85 & 83 & 72 \\
\hline 23 & 68 & 47 & 35 & 40 & 51 & 56 & 64 & 68 & 84 & 85 & 82 & 72 \\
\hline 24 & 68 & 50 & 35 & 43 & -- & 58 & 65 & 68 & 85 & 86 & 82 & 70 \\
\hline 25 & 68 & 50 & -- & 45 & 51 & 60 & 72 & 70 & 85 & 86 & 80 & 70 \\
\hline 26 & 65 & 48 & 35 & 45 & 50 & 59 & 72 & 68 & 85 & 83 & 82 & 73 \\
\hline 27 & 64 & 48 & - & 43 & 55 & 59 & 72 & 68 & 85 & 83 & 83 & 73 \\
\hline 28 & 60 & 48 & 46 & 43 & 50 & 60 & 72 & 70 & 85 & 83 & 84 & 76 \\
\hline 29 & 59 & 48 & 46 & 40 & -- & 61 & 73 & 70 & 85 & 83 & 85 & 76 \\
\hline 30 & 58 & 50 & 46 & 46 & -- & 61 & 73 & 70 & 85 & 80 & 85 & 75 \\
\hline 31 & 58 & $\cdots$ & 46 & 45 & -- & 57 & -- & 70 & -- & 80 & 83 & $-\cdot$ \\
\hline Aver- & & & & & & & & & & & & \\
\hline age & - & 52 & 45 & 43 & -- & 53 & 65 & 64 & 81 & 85 & 84 & 76 \\
\hline
\end{tabular}




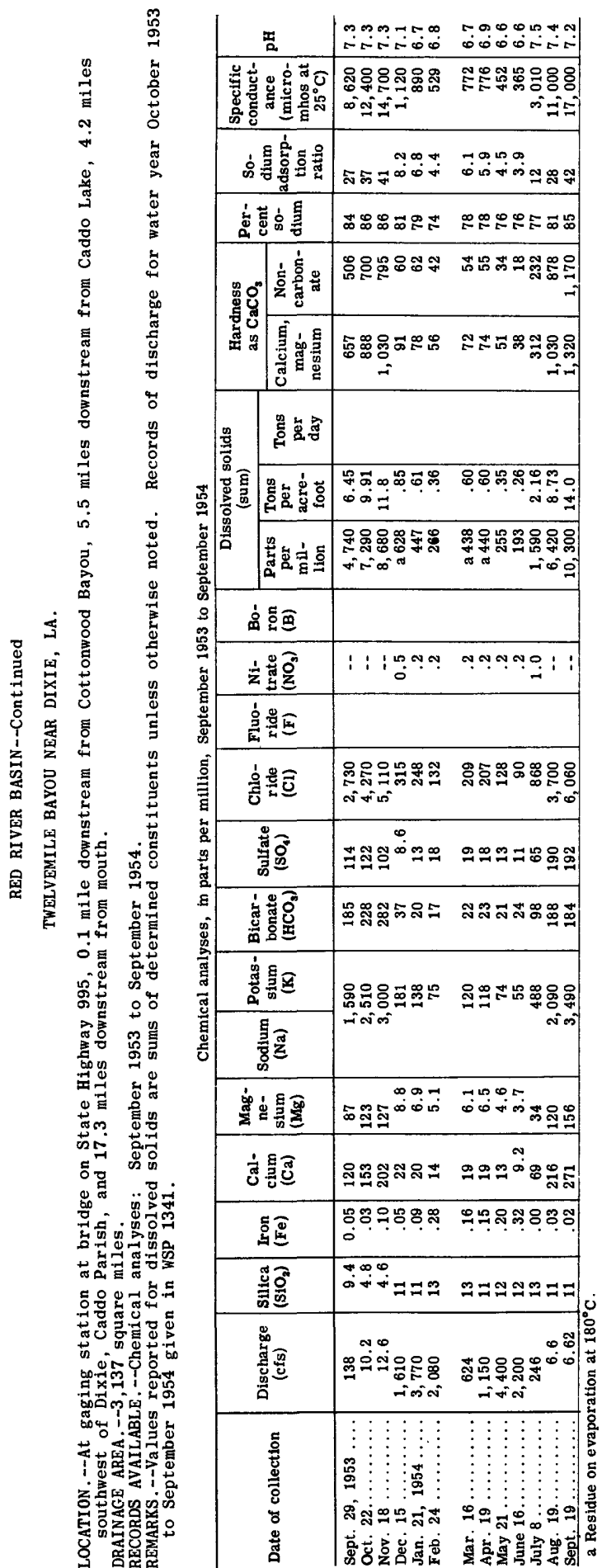




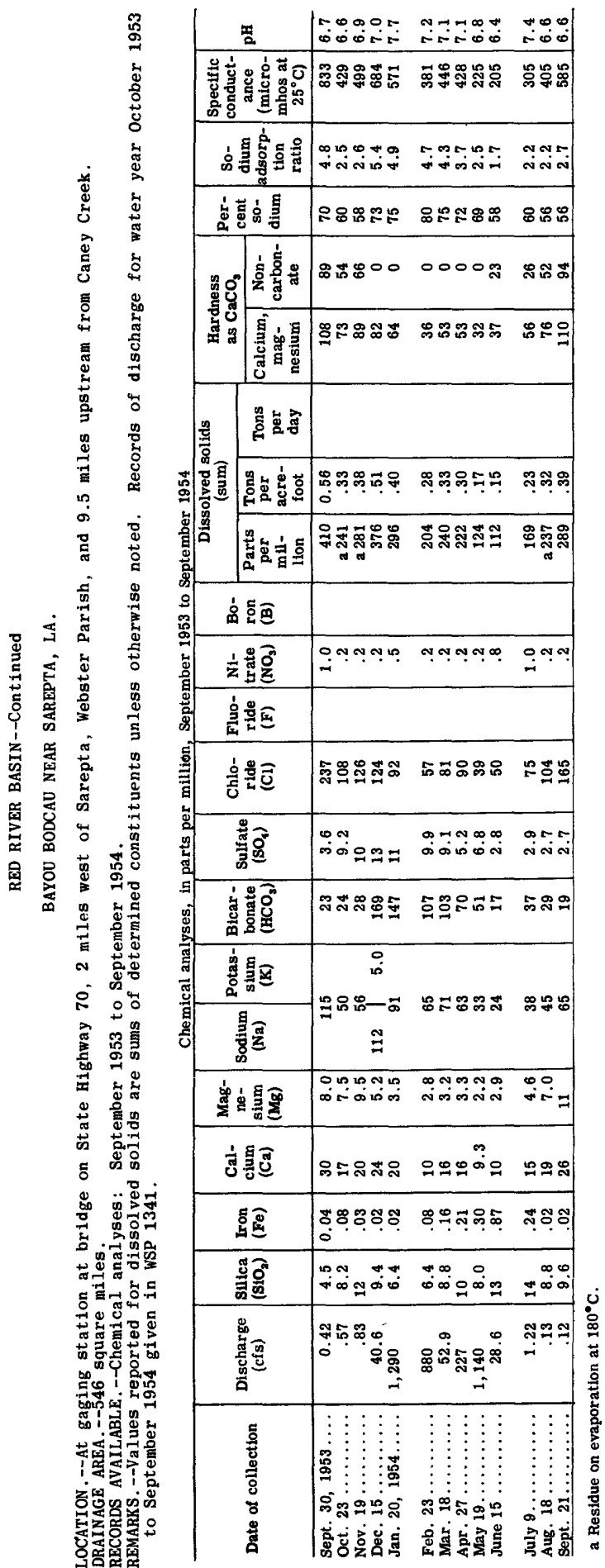




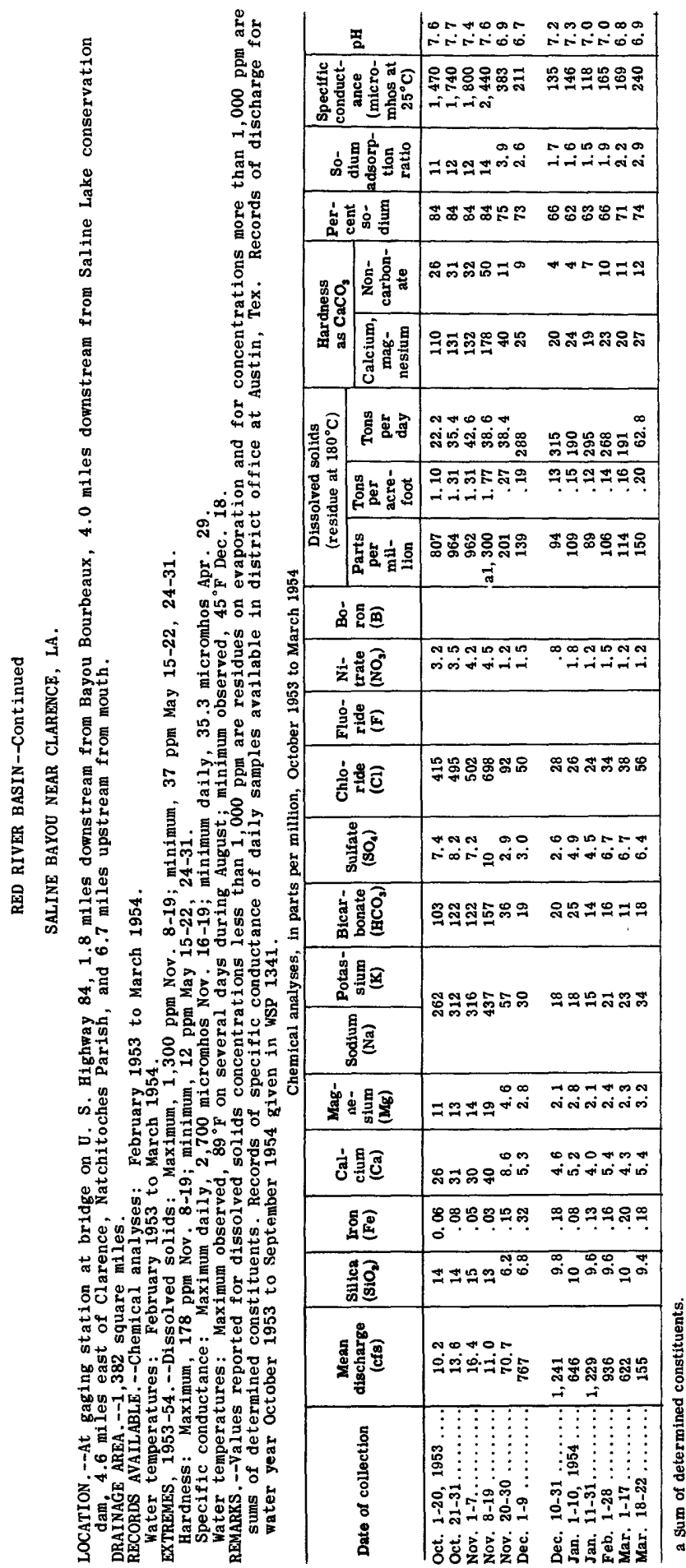




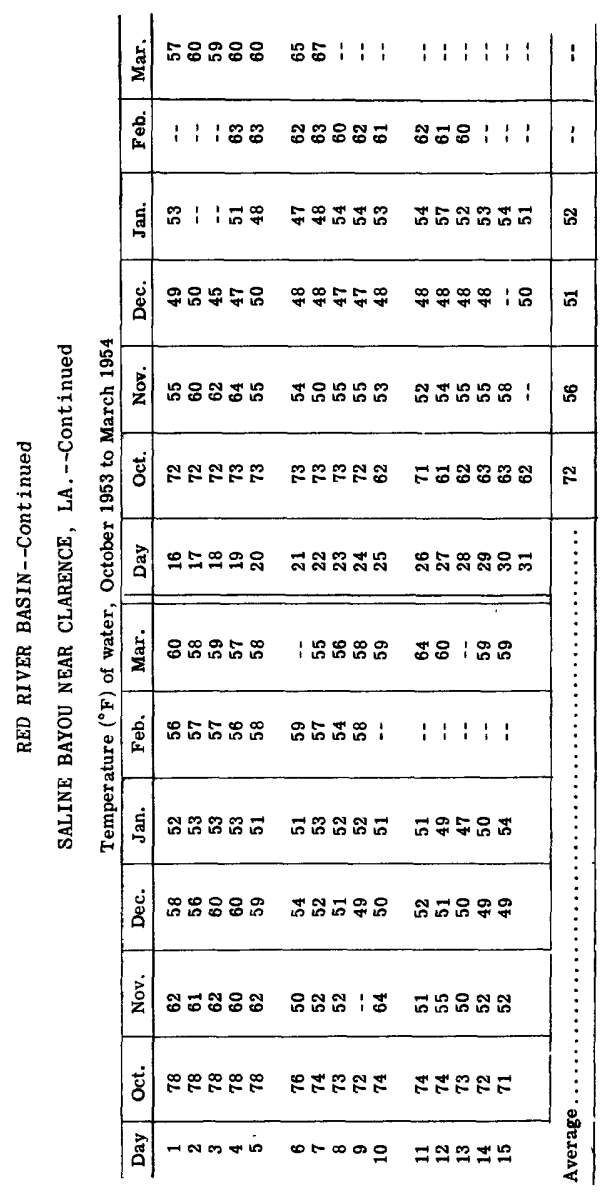




\begin{tabular}{|c|c|c|c|}
\hline 쫌 & 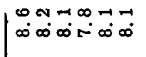 & 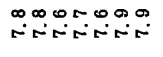 & 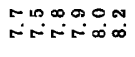 \\
\hline 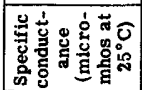 & 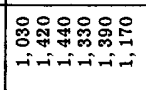 & 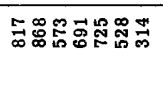 & ฉ̊ำ \\
\hline 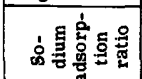 & 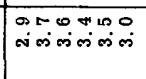 & 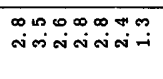 & 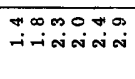 \\
\hline 高葶宫总 & 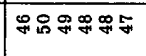 & 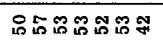 & 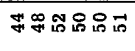 \\
\hline صू & జ & 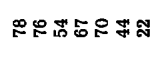 & 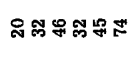 \\
\hline 匀 & 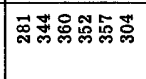 & 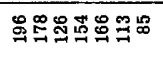 & 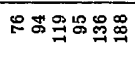 \\
\hline 号 & 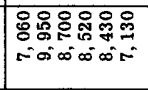 & 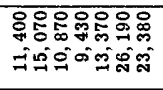 & 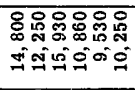 \\
\hline $\begin{array}{lll} & \\
0\end{array}$ & 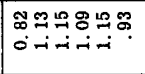 & ๕๕ீ유: & 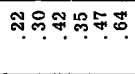 \\
\hline 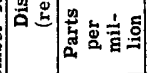 & 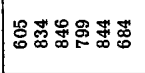 & 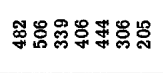 & 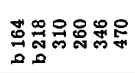 \\
\hline 宮㖞鱼 & & & \\
\hline 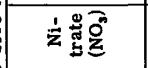 & 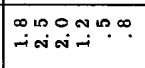 & 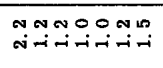 & i- \\
\hline 产总国 & & & \\
\hline 형휼 & 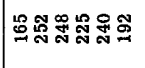 & ఫ్స & 요요욤 \\
\hline 实苞兽 & 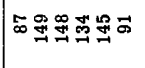 & 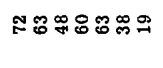 & 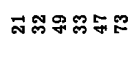 \\
\hline 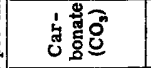 & & & \\
\hline 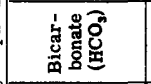 & 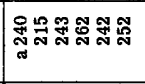 & $\mathbb{J} \mathbb{J}^{\infty} \infty 5$ & ஃேタトシの \\
\hline 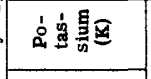 & \multirow{2}{*}{ 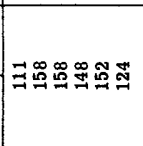 } & \multirow{2}{*}{ న } & \multirow{2}{*}{ 동요명 } \\
\hline 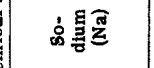 & & & \\
\hline 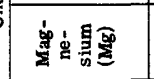 & 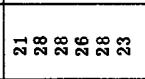 & 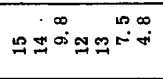 & 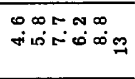 \\
\hline 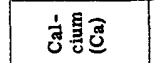 & ๓ & 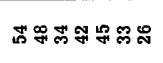 & 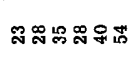 \\
\hline 跑 & 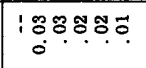 & 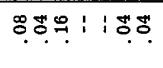 & 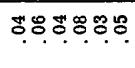 \\
\hline 解 & 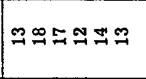 & 워ニッッエエ & 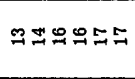 \\
\hline 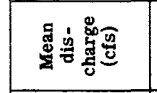 & 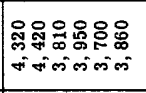 & 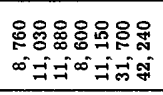 & 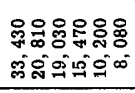 \\
\hline 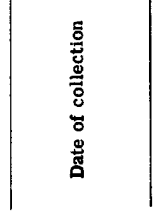 & 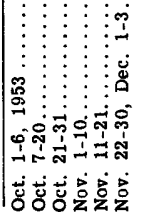 & 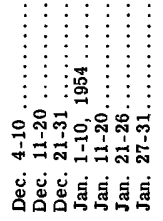 & 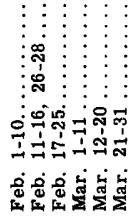 \\
\hline
\end{tabular}




\begin{tabular}{|c|c|c|c|c|c|}
\hline & 몀 & 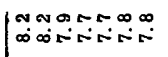 & 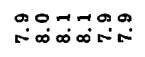 & 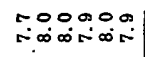 & \\
\hline & 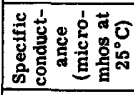 & 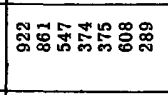 & 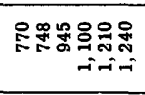 & 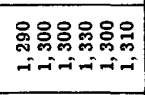 & 萬 \\
\hline & 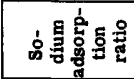 & जमmromo & 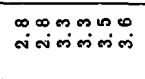 & 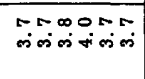 & is \\
\hline & 离志宫蒠 & 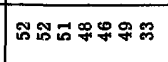 & 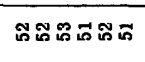 & 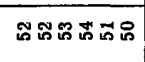 & is \\
\hline & פू. & 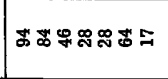 & 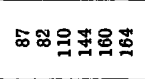 & 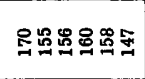 & హ \\
\hline & 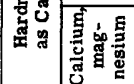 & สุฐ & 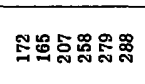 & క్లి: & ล̊ำ \\
\hline & 일일 & 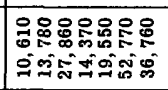 & 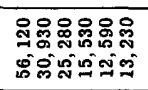 & 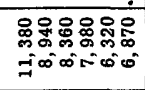 & \\
\hline E् & 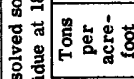 & 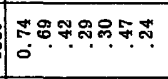 & రి: & 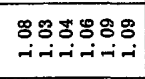 & P \\
\hline 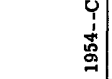 & 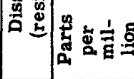 & 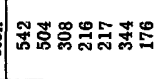 & 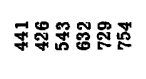 & 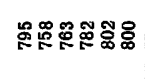 & $\stackrel{9}{10}$ \\
\hline 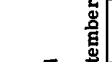 & 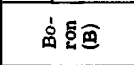 & & & & \\
\hline 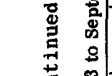 & 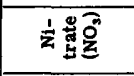 & 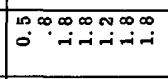 & 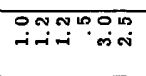 & $\begin{array}{l}0 \sin \\
\sin \pi\end{array}$ & $\stackrel{\infty}{-1}$ \\
\hline 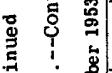 & 裹害国 & & & & \\
\hline $\begin{array}{ll}\unlhd & \overline{0} \\
\leq & 0 \\
\leq & 4\end{array}$ & ㅎํำ & 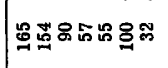 & 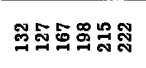 & 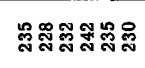 & 목 \\
\hline 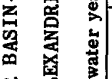 & 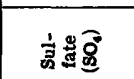 & ๓のボ & ๑ి: & 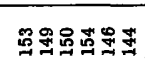 & 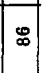 \\
\hline 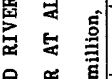 & 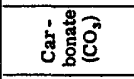 & & & & \\
\hline 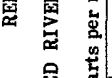 & 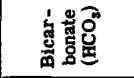 & 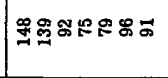 & 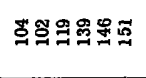 & 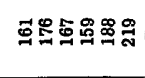 & 9 \\
\hline a. & 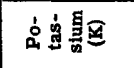 & 507 & 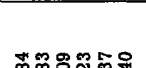 & & 5 \\
\hline 总 & 安竅要 & & - & 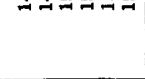 & \\
\hline : & 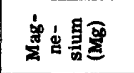 & 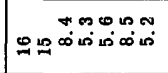 & 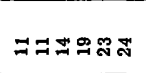 & 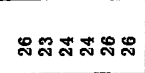 & 9 \\
\hline & 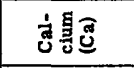 & 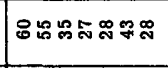 & โே & 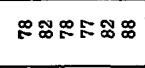 & in \\
\hline & 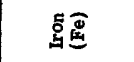 & 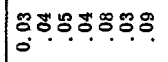 & 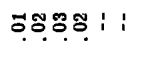 & :8ํํํำ. & $\left|\begin{array}{ll}0 \\
0 \\
0 \\
0\end{array}\right|$ \\
\hline & 胥产 & 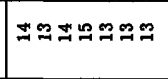 & ๙ิสี & 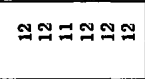 & \pm \\
\hline & 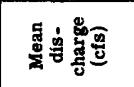 & 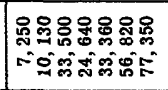 & 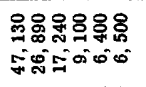 & 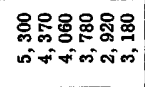 & 兽 \\
\hline & 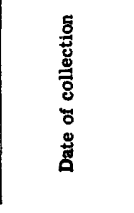 & 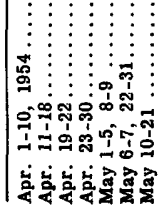 & 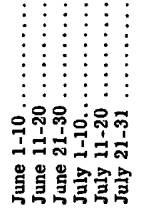 & 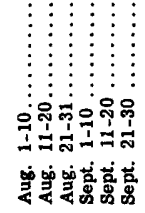 & $\underline{g}$ \\
\hline
\end{tabular}


RED RIVER BASIN--Continued

RED RIVER AT ALEXANDRIA, LA.--Continued

Temperature $\left({ }^{\circ} \mathrm{F}\right)$ of water, water year October 1953 to September 1954

\begin{tabular}{|c|c|c|c|c|c|c|c|c|c|c|c|c|}
\hline Day & Oct. & Nov. & Dec. & Jan. & Feb. & Mar. & Apr. & May & June & July & Aug. & Sept. \\
\hline $\begin{array}{l}1 \\
2 \\
3 \\
4 \\
5\end{array}$ & $\begin{array}{l}83 \\
83 \\
83 \\
81 \\
82\end{array}$ & $\begin{array}{l}65 \\
67 \\
67 \\
65 \\
64\end{array}$ & $\begin{array}{l}59 \\
60 \\
62 \\
60 \\
63\end{array}$ & $\begin{array}{l}50 \\
51 \\
50 \\
52 \\
50\end{array}$ & $\begin{array}{l}53 \\
54 \\
54 \\
55 \\
56\end{array}$ & $\begin{array}{l}58 \\
59 \\
56 \\
54 \\
53\end{array}$ & $\begin{array}{l}62 \\
68 \\
69 \\
70 \\
71\end{array}$ & $\begin{array}{l}78 \\
75 \\
72 \\
71 \\
71\end{array}$ & $\begin{array}{l}81 \\
81 \\
79 \\
80 \\
79\end{array}$ & $\begin{array}{l}91 \\
89 \\
88 \\
89 \\
90\end{array}$ & $\begin{array}{l}85 \\
87 \\
89 \\
89 \\
88\end{array}$ & $\begin{array}{l}88 \\
88 \\
87 \\
87 \\
87\end{array}$ \\
\hline $\begin{array}{r}6 \\
7 \\
8 \\
9 \\
10\end{array}$ & $\begin{array}{l}80 \\
79 \\
77 \\
75 \\
76\end{array}$ & $\begin{array}{l}61 \\
59 \\
59 \\
57 \\
59\end{array}$ & $\begin{array}{l}60 \\
58 \\
57 \\
56 \\
55\end{array}$ & $\begin{array}{l}52 \\
51 \\
52 \\
54 \\
52\end{array}$ & $\begin{array}{l}56 \\
53 \\
52 \\
55 \\
57\end{array}$ & $\begin{array}{l}54 \\
53 \\
56 \\
57 \\
58\end{array}$ & $\begin{array}{l}74 \\
75 \\
74 \\
73 \\
74\end{array}$ & $\begin{array}{l}71 \\
73 \\
72 \\
71 \\
69\end{array}$ & $\begin{array}{l}78 \\
79 \\
80 \\
81 \\
--\end{array}$ & $\begin{array}{l}88 \\
87 \\
87 \\
89 \\
90\end{array}$ & $\begin{array}{l}89 \\
90 \\
90 \\
91 \\
90\end{array}$ & $\begin{array}{l}85 \\
87 \\
85 \\
88 \\
88\end{array}$ \\
\hline $\begin{array}{l}11 \\
12 \\
13 \\
14 \\
15\end{array}$ & $\begin{array}{l}74 \\
75 \\
75 \\
75 \\
76\end{array}$ & $\begin{array}{l}-- \\
54 \\
59 \\
58 \\
57\end{array}$ & $\begin{array}{l}54 \\
53 \\
53 \\
52 \\
51\end{array}$ & $\begin{array}{l}51 \\
49 \\
48 \\
52 \\
54\end{array}$ & $\begin{array}{l}56 \\
59 \\
55 \\
58 \\
62\end{array}$ & $\begin{array}{l}62 \\
63 \\
64 \\
61 \\
58\end{array}$ & $\begin{array}{l}\mathbf{7 5} \\
\mathbf{7 5} \\
\mathbf{7 6} \\
\mathbf{7 8} \\
\mathbf{7 4}\end{array}$ & $\begin{array}{l}69 \\
68 \\
67 \\
68 \\
67\end{array}$ & $\begin{array}{l}85 \\
85 \\
84 \\
85 \\
84\end{array}$ & $\begin{array}{l}89 \\
90 \\
89 \\
90 \\
92\end{array}$ & $\begin{array}{l}90 \\
90 \\
89 \\
89 \\
91\end{array}$ & $\begin{array}{l}86 \\
85 \\
84 \\
86 \\
85\end{array}$ \\
\hline $\begin{array}{l}16 \\
17 \\
18 \\
19 \\
20\end{array}$ & $\begin{array}{l}75 \\
76 \\
75 \\
76 \\
74\end{array}$ & $\begin{array}{l}59 \\
61 \\
62 \\
62 \\
63\end{array}$ & $\begin{array}{l}50 \\
50 \\
49 \\
48 \\
48\end{array}$ & $\begin{array}{l}\mathbf{5 4} \\
\mathbf{5 2} \\
\mathbf{5 3} \\
\mathbf{5 3} \\
\mathbf{5 5}\end{array}$ & $\begin{array}{l}60 \\
60 \\
62 \\
63 \\
60\end{array}$ & $\begin{array}{l}59 \\
60 \\
61 \\
63 \\
62\end{array}$ & $\begin{array}{l}72 \\
72 \\
70 \\
69 \\
72\end{array}$ & $\begin{array}{l}67 \\
69 \\
70 \\
70 \\
70\end{array}$ & $\begin{array}{l}86 \\
86 \\
86 \\
85 \\
86\end{array}$ & $\begin{array}{l}92 \\
89 \\
90 \\
88 \\
90\end{array}$ & $\begin{array}{l}91 \\
90 \\
89 \\
87 \\
87\end{array}$ & $\begin{array}{l}82 \\
87 \\
84 \\
86 \\
87\end{array}$ \\
\hline $\begin{array}{l}21 \\
22 \\
23 \\
24 \\
25\end{array}$ & $\begin{array}{l}75 \\
75 \\
73 \\
75 \\
73\end{array}$ & $\begin{array}{l}61 \\
61 \\
60 \\
59 \\
58\end{array}$ & $\begin{array}{l}\mathbf{5 2} \\
\mathbf{5 0} \\
\mathbf{4 7} \\
\mathbf{4 7} \\
\mathbf{4 5}\end{array}$ & $\begin{array}{l}52 \\
50 \\
49 \\
50 \\
51\end{array}$ & $\begin{array}{l}61 \\
59 \\
58 \\
58 \\
60\end{array}$ & $\begin{array}{l}67 \\
65 \\
65 \\
67 \\
67\end{array}$ & $\begin{array}{l}72 \\
73 \\
74 \\
75 \\
76\end{array}$ & $\begin{array}{l}70 \\
72 \\
73 \\
73 \\
72\end{array}$ & $\begin{array}{l}87 \\
76 \\
88 \\
88 \\
87\end{array}$ & $\begin{array}{l}89 \\
89 \\
89 \\
91 \\
90\end{array}$ & $\begin{array}{l}88 \\
87 \\
87 \\
87 \\
89\end{array}$ & $\begin{array}{l}84 \\
83 \\
82 \\
82 \\
83\end{array}$ \\
\hline $\begin{array}{l}26 \\
27 \\
28 \\
29 \\
30 \\
31\end{array}$ & $\begin{array}{l}\mathbf{7 2} \\
\mathbf{7 0} \\
\mathbf{7 0} \\
\mathbf{6 8} \\
\mathbf{6 7} \\
\mathbf{6 5}\end{array}$ & $\begin{array}{l}58 \\
59 \\
57 \\
57 \\
54 \\
--\end{array}$ & $\begin{array}{l}47 \\
48 \\
48 \\
49 \\
50 \\
48\end{array}$ & $\begin{array}{l}51 \\
51 \\
52 \\
54 \\
53 \\
54\end{array}$ & $\begin{array}{l}61 \\
63 \\
58 \\
-- \\
-- \\
--\end{array}$ & $\begin{array}{l}68 \\
67 \\
68 \\
70 \\
72 \\
67\end{array}$ & $\begin{array}{l}77 \\
76 \\
78 \\
79 \\
75 \\
--\end{array}$ & $\begin{array}{l}74 \\
75 \\
76 \\
79 \\
80 \\
80\end{array}$ & $\begin{array}{l}90 \\
89 \\
90 \\
90 \\
89 \\
--\end{array}$ & $\begin{array}{l}91 \\
89 \\
87 \\
86 \\
83 \\
85\end{array}$ & $\begin{array}{l}88 \\
89 \\
90 \\
87 \\
90 \\
89 \\
\end{array}$ & $\begin{array}{l}84 \\
84 \\
83 \\
83 \\
82 \\
--\end{array}$ \\
\hline $\begin{array}{c}\text { Aver- } \\
\text { age }\end{array}$ & 75 & 60 & 53 & 52 & 58 & 62 & 73 & 72 & 84 & 89 & 89 & 85 \\
\hline
\end{tabular}




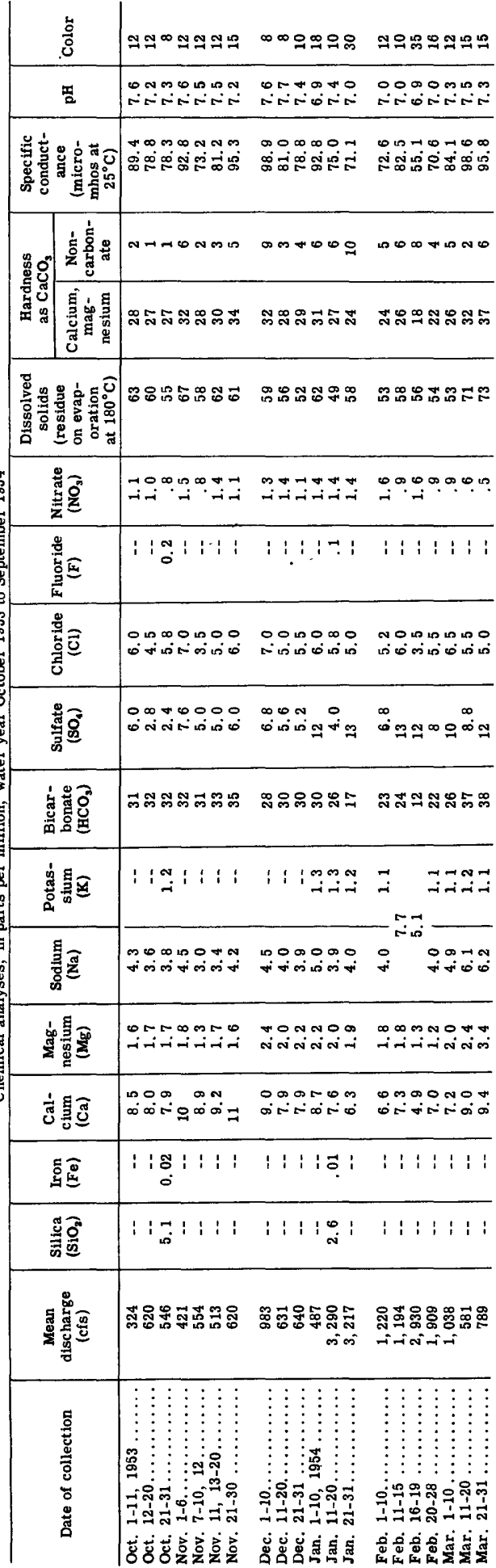




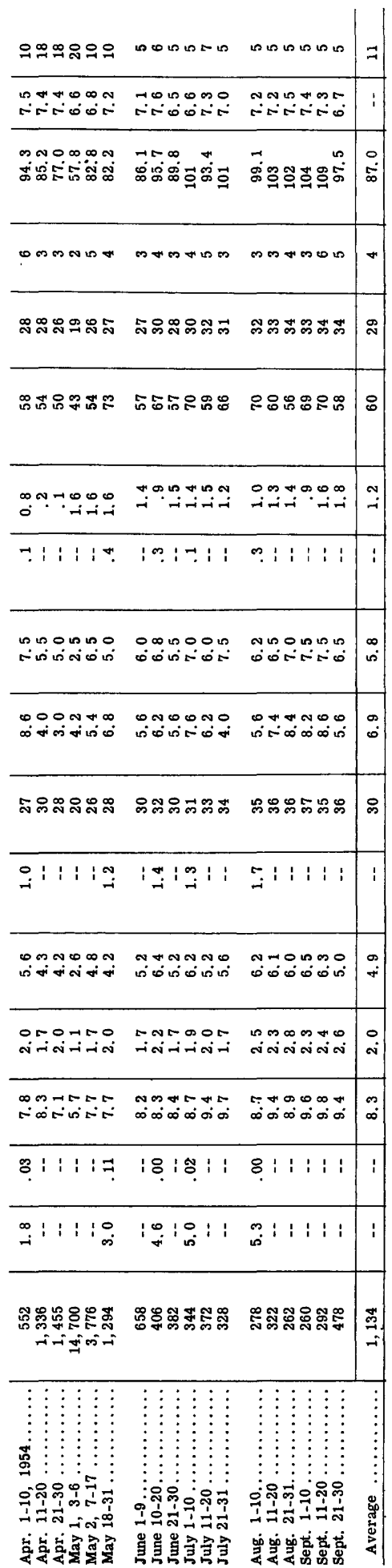


RED RIVER BASIN--Continued

OUACHITA RIVER AT ARKADELPHIA, ARK.--Continued

Temperature $\left({ }^{\circ} \mathrm{F}\right)$ of water, water year October 1953 to September 1954

\begin{tabular}{|c|c|c|c|c|c|c|c|c|c|c|c|c|}
\hline Day & Oct. & Nov. & Dec. & Jan. & Feb. & Mar. & Apr. & May & June & July & Aug. & Sept. \\
\hline $\begin{array}{l}1 \\
2 \\
3 \\
4 \\
5\end{array}$ & $\begin{array}{l}81 \\
80 \\
82 \\
81 \\
74\end{array}$ & $\begin{array}{l}63 \\
63 \\
63 \\
63 \\
55\end{array}$ & $\begin{array}{l}55 \\
58 \\
58 \\
56 \\
56\end{array}$ & $\begin{array}{l}46 \\
48 \\
48 \\
48 \\
48\end{array}$ & $\begin{array}{l}52 \\
55 \\
54 \\
55 \\
56\end{array}$ & $\begin{array}{l}54 \\
-- \\
50 \\
49 \\
55\end{array}$ & $\begin{array}{l}63 \\
64 \\
64 \\
66 \\
66\end{array}$ & $\begin{array}{l}68 \\
65 \\
65 \\
63 \\
64\end{array}$ & $\begin{array}{l}80 \\
80 \\
75 \\
75 \\
75\end{array}$ & $\begin{array}{l}89 \\
89 \\
93 \\
93 \\
93\end{array}$ & $\begin{array}{l}89 \\
89 \\
89 \\
89 \\
89\end{array}$ & $\begin{array}{l}84 \\
84 \\
83 \\
83 \\
83\end{array}$ \\
\hline $\begin{array}{r}6 \\
7 \\
8 \\
9 \\
10\end{array}$ & $\begin{array}{l}74 \\
71 \\
70 \\
70 \\
70\end{array}$ & $\begin{array}{l}51 \\
56 \\
-- \\
50 \\
50\end{array}$ & $\begin{array}{l}\mathbf{5 6} \\
\mathbf{5 6} \\
\mathbf{5 6} \\
\mathbf{5 2} \\
\mathbf{5 2}\end{array}$ & $\begin{array}{l}48 \\
48 \\
47 \\
50 \\
50\end{array}$ & $\begin{array}{l}50 \\
50 \\
53 \\
54 \\
53\end{array}$ & $\begin{array}{l}55 \\
55 \\
55 \\
55 \\
62\end{array}$ & $\begin{array}{l}72 \\
75 \\
75 \\
68 \\
70\end{array}$ & $\begin{array}{l}65 \\
62 \\
62 \\
63 \\
66\end{array}$ & $\begin{array}{l}75 \\
82 \\
82 \\
85 \\
85\end{array}$ & $\begin{array}{l}97 \\
91 \\
91 \\
89 \\
89\end{array}$ & $\begin{array}{l}89 \\
90 \\
91 \\
91 \\
90\end{array}$ & $\begin{array}{l}83 \\
80 \\
79 \\
78 \\
84\end{array}$ \\
\hline $\begin{array}{l}11 \\
12 \\
13 \\
14 \\
15\end{array}$ & $\begin{array}{l}70 \\
71 \\
74 \\
74 \\
=-\end{array}$ & $\begin{array}{l}50 \\
50 \\
57 \\
57 \\
60\end{array}$ & $\begin{array}{l}52 \\
50 \\
50 \\
49 \\
49\end{array}$ & $\begin{array}{l}45 \\
45 \\
45 \\
45 \\
45\end{array}$ & $\begin{array}{l}54 \\
52 \\
53 \\
54 \\
54\end{array}$ & $\begin{array}{l}63 \\
55 \\
55 \\
55 \\
56\end{array}$ & $\begin{array}{l}69 \\
69 \\
71 \\
70 \\
70\end{array}$ & $\begin{array}{l}64 \\
66 \\
67 \\
67 \\
67\end{array}$ & $\begin{array}{l}86 \\
87 \\
88 \\
88 \\
85\end{array}$ & $\begin{array}{l}90 \\
90 \\
92 \\
92 \\
\mathbf{8 1}\end{array}$ & $\begin{array}{l}90 \\
90 \\
88 \\
87 \\
90\end{array}$ & $\begin{array}{l}84 \\
86 \\
78 \\
78 \\
77\end{array}$ \\
\hline $\begin{array}{l}16 \\
17 \\
18 \\
19 \\
20\end{array}$ & $\begin{array}{l}74 \\
72 \\
73 \\
72 \\
72\end{array}$ & $\begin{array}{l}60 \\
60 \\
60 \\
62 \\
62\end{array}$ & $\begin{array}{l}49 \\
45 \\
45 \\
48\end{array}$ & $\begin{array}{l}44 \\
55 \\
45 \\
48 \\
48\end{array}$ & $\begin{array}{l}55 \\
55 \\
56 \\
57 \\
56\end{array}$ & $\begin{array}{l}56 \\
56 \\
60 \\
60 \\
60\end{array}$ & $\begin{array}{l}70 \\
69 \\
70 \\
70 \\
74\end{array}$ & $\begin{array}{l}68 \\
70 \\
74 \\
74 \\
74\end{array}$ & $\begin{array}{l}85 \\
89 \\
89 \\
88 \\
88\end{array}$ & $\begin{array}{l}92 \\
93 \\
93 \\
83 \\
83\end{array}$ & $\begin{array}{l}89 \\
89 \\
89 \\
87 \\
90\end{array}$ & $\begin{array}{l}77 \\
77 \\
79 \\
79 \\
86\end{array}$ \\
\hline $\begin{array}{l}21 \\
22 \\
23 \\
24 \\
25\end{array}$ & $\begin{array}{l}71 \\
71 \\
70 \\
70 \\
70\end{array}$ & $\begin{array}{l}60 \\
58 \\
54 \\
54 \\
56\end{array}$ & $\begin{array}{l}46 \\
45 \\
43 \\
43 \\
46\end{array}$ & $\begin{array}{l}44 \\
44 \\
44 \\
44 \\
55\end{array}$ & $\begin{array}{l}56 \\
57 \\
47 \\
58 \\
57\end{array}$ & $\begin{array}{l}58 \\
58 \\
58 \\
65 \\
65\end{array}$ & $\begin{array}{l}74 \\
74 \\
77 \\
78 \\
78\end{array}$ & $\begin{array}{l}76 \\
77 \\
77 \\
77 \\
76\end{array}$ & $\begin{array}{l}87 \\
87 \\
89 \\
88 \\
90\end{array}$ & $\begin{array}{l}88 \\
88 \\
88 \\
86 \\
86\end{array}$ & $\begin{array}{l}88 \\
87 \\
87 \\
88 \\
87\end{array}$ & $\begin{array}{l}85 \\
77 \\
77 \\
76 \\
76\end{array}$ \\
\hline $\begin{array}{l}26 \\
27 \\
28 \\
29 \\
30 \\
31\end{array}$ & $\begin{array}{l}68 \\
66 \\
65 \\
65 \\
63 \\
-- \\
\end{array}$ & $\begin{array}{l}56 \\
50 \\
50 \\
50 \\
55 \\
-- \\
\end{array}$ & $\begin{array}{l}46 \\
46 \\
46 \\
46 \\
47 \\
48 \\
\end{array}$ & $\begin{array}{l}55 \\
53 \\
54 \\
50 \\
50 \\
-\end{array}$ & $\begin{array}{l}57 \\
58 \\
58 \\
-- \\
-- \\
--\end{array}$ & $\begin{array}{l}-\overline{64} \\
65 \\
69 \\
69 \\
70\end{array}$ & $\begin{array}{l}78 \\
79 \\
\mathbf{7 9} \\
\mathbf{7 5} \\
\mathbf{7 4} \\
--\end{array}$ & $\begin{array}{l}76 \\
77 \\
77 \\
79 \\
79 \\
80\end{array}$ & $\begin{array}{l}90 \\
90 \\
90 \\
89 \\
87 \\
--\end{array}$ & $\begin{array}{l}87 \\
85 \\
86 \\
86 \\
86 \\
85\end{array}$ & $\begin{array}{l}88 \\
88 \\
89 \\
89 \\
88 \\
89\end{array}$ & $\begin{array}{l}78 \\
78 \\
78 \\
80 \\
80 \\
--\end{array}$ \\
\hline $\begin{array}{c}\text { Aver - } \\
\text { age }\end{array}$ & 72 & 56 & 50 & 48 & 54 & 59 & 72 & 70 & 85 & 89 & 89 & 80 \\
\hline
\end{tabular}




\begin{tabular}{|c|c|c|c|c|c|c|c|}
\hline$\frac{\check{0}}{8}$ & $\stackrel{\infty}{\infty} \cong$ & สีํำ & 禺웡요 & 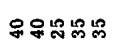 & 윰응요 & 응ㅇ & $\mathscr{\Re}$ \\
\hline 睘 & 華 & T20 & 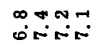 & 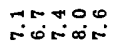 & $\begin{array}{l}-\infty 0 \mathrm{~m} \\
\dot{0} 00 \mathrm{~m}\end{array}$ & mis & i) \\
\hline 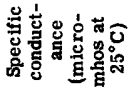 & N & $\overrightarrow{\mathscr{E}}$ & कீ & 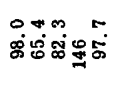 & 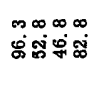 & \% & $\begin{array}{l}0 \\
\infty\end{array}$ \\
\hline 朐吊它总 & 000 & $\infty r$ & $\cos \pi$ & $\infty$ & $r$ & 00 & $m$ \\
\hline 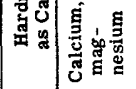 & 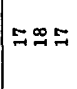 & लै & 觇유゙ & 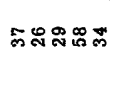 & 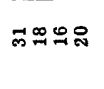 & $\because$ & : \\
\hline 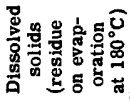 & 옹용유 & 85 & 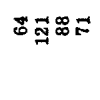 & 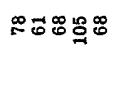 & ธำษ ำ & ษ & $ஜ$ \\
\hline 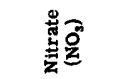 & ${ }_{0}^{\infty} \cdot \mathbf{n}$ & if & $\begin{array}{l}m \infty \pi m \\
\text { iñ-i }\end{array}$ & $\ddot{\infty}$ & 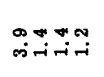 & - & $=$ \\
\hline 总国 & تั0. & m? & m" m. & $\because$ & 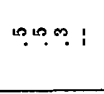 & "? & 0 \\
\hline 홀 & 象 & $\begin{array}{l}\text { no } \\
\text { fin }\end{array}$ & $\begin{array}{l}\ln 000 \\
\operatorname{lin} 00\end{array}$ & 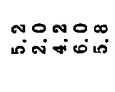 & พัน & लें & $\begin{array}{l}0 \\
\text { เ० }\end{array}$ \\
\hline 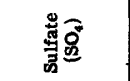 & $\begin{array}{l}\infty \times \infty \\
\infty-i-i\end{array}$ & $\begin{array}{l}\infty \\
\infty\end{array}$ & $\begin{array}{l}0 \\
\infty\end{array}$ & 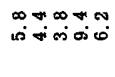 & 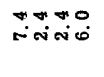 & की & is \\
\hline 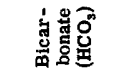 & 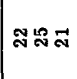 & 品 & జూ佀 & 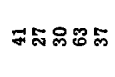 & ్ㅗㅇㅇㅛ & 오 ส & ल \\
\hline 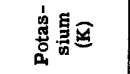 & - & Ni & oster & "i & $\stackrel{\sim}{\infty} \cdot$ ! & $\stackrel{\infty}{-N}$ & -1 \\
\hline 总预 & $\begin{array}{l}0 \text { oro } \\
\text { nition }\end{array}$ & $\begin{array}{l}00 \\
\text { +i } 0^{\circ}\end{array}$ & $\begin{array}{l}00+0 \\
+10+\%\end{array}$ & to & $\begin{array}{l}\infty 0 \infty \pi \\
\text { मiक जir: }\end{array}$ & के नें & m \\
\hline 总焉雷 & - & $\infty$. & מٓ & 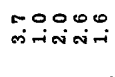 & $\begin{array}{l}00 \text { mk } \\
\text {-ifi-ifi }\end{array}$ & $\begin{array}{l}0 \% \\
-i \pi\end{array}$ & - \\
\hline 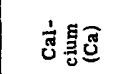 & $\mid \begin{array}{l}-00 \\
\text { 10 }\end{array}$ & $\infty$ & 웎 & $\begin{array}{l}\infty \infty \infty \\
\infty \infty \infty \sigma=1\end{array}$ & $\begin{array}{l}\infty \times+4 \\
\infty\end{array}$ & $+\infty$ & + \\
\hline 氮 & 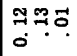 & 芯焉 & 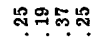 & 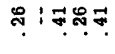 & 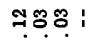 & 농용. & $\begin{array}{l}9 \\
0 \\
0\end{array}$ \\
\hline 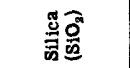 & $\mid \begin{array}{l}\text { काष } \\
\text { min }\end{array}$ & @ & 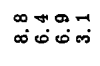 & م: & 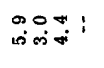 & Or & is \\
\hline 哭葛可 & 赵赵 & 总哭 & ヶ용ㅇㅇㅇㅇㅇㅇ & 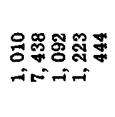 & 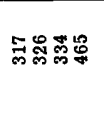 & 穷里 & 옹 \\
\hline 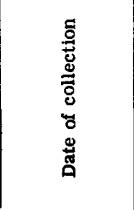 & 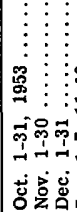 & 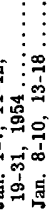 & 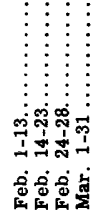 & 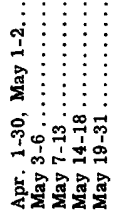 & 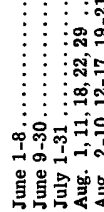 & 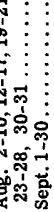 & $\begin{array}{c}\vdots \\
\vdots \\
\vdots \\
\vdots \\
5 \\
5 \\
5 \\
\vdots\end{array}$ \\
\hline
\end{tabular}


RED RIVER BASIN--Continued

LITTLE MISSOURI RIVER NEAR BOUGHTON, ARK.--Continued

Temperature $\left({ }^{\circ} \mathrm{F}\right)$ of water, water year October 1953 to September 1954

\begin{tabular}{|c|c|c|c|c|c|c|c|c|c|c|c|c|}
\hline Day & Oct. & Nov. & Dec. & Jan. & Feb. & Mar. & Apr. & May & June & July & Aug. & Sept. \\
\hline $\begin{array}{l}1 \\
2 \\
3 \\
4 \\
5\end{array}$ & & $\begin{array}{l}48 \\
47 \\
46 \\
47 \\
47\end{array}$ & $\begin{array}{l}50 \\
52 \\
53 \\
52 \\
49\end{array}$ & $\begin{array}{l}44 \\
45 \\
47 \\
44 \\
45\end{array}$ & $\begin{array}{l}48 \\
48 \\
49 \\
49 \\
48\end{array}$ & $\begin{array}{l}53 \\
54 \\
54 \\
55 \\
55\end{array}$ & $\begin{array}{l}62 \\
62 \\
63 \\
64 \\
64\end{array}$ & $\begin{array}{l}68 \\
68 \\
60 \\
59 \\
57\end{array}$ & $\begin{array}{l}70 \\
69 \\
72 \\
70 \\
73\end{array}$ & $\begin{array}{l}78 \\
78 \\
78 \\
78 \\
76\end{array}$ & $\begin{array}{l}80 \\
78 \\
80 \\
82 \\
82\end{array}$ & $\begin{array}{l}75 \\
72 \\
72 \\
73 \\
78\end{array}$ \\
\hline $\begin{array}{r}6 \\
7 \\
8 \\
9 \\
10\end{array}$ & & $\begin{array}{l}48 \\
55 \\
54 \\
47 \\
\mathbf{4 5}\end{array}$ & $\begin{array}{l}47 \\
47 \\
49 \\
48 \\
47\end{array}$ & $\begin{array}{l}45 \\
53 \\
43 \\
44 \\
46\end{array}$ & $\begin{array}{l}44 \\
46 \\
48 \\
49 \\
50\end{array}$ & $\begin{array}{l}\mathbf{5 5} \\
52 \\
52 \\
53 \\
54\end{array}$ & $\begin{array}{l}64 \\
65 \\
66 \\
67 \\
67\end{array}$ & $\begin{array}{l}61 \\
62 \\
62 \\
63 \\
61\end{array}$ & $\begin{array}{l}77 \\
72 \\
75 \\
70 \\
75\end{array}$ & $\begin{array}{l}78 \\
78 \\
80 \\
78 \\
80\end{array}$ & $\begin{array}{l}78 \\
80 \\
78 \\
78\end{array}$ & $\begin{array}{l}75 \\
78 \\
75 \\
76 \\
78\end{array}$ \\
\hline $\begin{array}{l}11 \\
12 \\
13 \\
14 \\
15\end{array}$ & & $\begin{array}{l}46 \\
46 \\
47 \\
48 \\
50\end{array}$ & $\begin{array}{l}45 \\
45 \\
44 \\
47 \\
46\end{array}$ & $\begin{array}{l}42 \\
43 \\
40 \\
41 \\
44\end{array}$ & $\begin{array}{l}\mathbf{5 1} \\
\mathbf{5 2} \\
\mathbf{5 2} \\
\mathbf{5 2} \\
\mathbf{5 3}\end{array}$ & $\begin{array}{l}57 \\
56 \\
57 \\
57 \\
57\end{array}$ & $\begin{array}{l}68 \\
66 \\
66 \\
67 \\
68\end{array}$ & $\begin{array}{l}60 \\
60 \\
59 \\
49 \\
49\end{array}$ & $\begin{array}{l}76 \\
75 \\
74 \\
74 \\
75\end{array}$ & $\begin{array}{l}78 \\
80 \\
78 \\
81 \\
80\end{array}$ & $\begin{array}{l}78 \\
78 \\
75 \\
76 \\
78\end{array}$ & $\begin{array}{l}76 \\
78 \\
75 \\
70 \\
70\end{array}$ \\
\hline $\begin{array}{l}16 \\
17 \\
18 \\
19 \\
20\end{array}$ & & $\begin{array}{l}49 \\
48 \\
53 \\
55 \\
51\end{array}$ & $\begin{array}{l}46 \\
47 \\
41 \\
42 \\
43\end{array}$ & $\begin{array}{l}45 \\
46 \\
45 \\
45 \\
55\end{array}$ & $\begin{array}{l}\mathbf{5 2} \\
\mathbf{5 2} \\
\mathbf{5 0} \\
\mathbf{5 2} \\
--\end{array}$ & $\begin{array}{l}\mathbf{5 8} \\
\mathbf{5 8} \\
\mathbf{5 8} \\
\mathbf{5 8} \\
\mathbf{5 9}\end{array}$ & $\begin{array}{l}69 \\
69 \\
67 \\
68 \\
68\end{array}$ & $\begin{array}{l}60 \\
63 \\
68 \\
68 \\
69\end{array}$ & $\begin{array}{l}75 \\
75 \\
74 \\
74 \\
74\end{array}$ & $\begin{array}{l}78 \\
80 \\
80 \\
78 \\
78\end{array}$ & $\begin{array}{l}78 \\
80 \\
80 \\
81 \\
78\end{array}$ & $\begin{array}{l}70 \\
74 \\
76 \\
75 \\
80\end{array}$ \\
\hline $\begin{array}{l}21 \\
22 \\
23 \\
24 \\
25\end{array}$ & & $\begin{array}{l}50 \\
49 \\
48 \\
49 \\
46\end{array}$ & $\begin{array}{l}45 \\
45 \\
43 \\
43 \\
42\end{array}$ & $\begin{array}{l}49 \\
48 \\
48 \\
49 \\
49\end{array}$ & $\begin{array}{l}50 \\
50 \\
54 \\
54 \\
54\end{array}$ & $\begin{array}{l}59 \\
59 \\
59 \\
60 \\
60\end{array}$ & $\begin{array}{l}69 \\
69 \\
68 \\
70 \\
70\end{array}$ & $\begin{array}{l}70 \\
66 \\
70 \\
69 \\
67\end{array}$ & $\begin{array}{l}75 \\
74 \\
75 \\
80 \\
80\end{array}$ & $\begin{array}{l}82 \\
82 \\
80 \\
82 \\
80\end{array}$ & $\begin{array}{l}\mathbf{7 7} \\
\mathbf{7 8} \\
\mathbf{7 5} \\
\mathbf{7 5} \\
\mathbf{7 8}\end{array}$ & $\begin{array}{l}78 \\
70 \\
68 \\
68 \\
68\end{array}$ \\
\hline $\begin{array}{l}26 \\
27 \\
28 \\
29 \\
30 \\
31\end{array}$ & & $\begin{array}{l}49 \\
50 \\
45 \\
52 \\
54 \\
-- \\
\end{array}$ & $\begin{array}{l}44 \\
43 \\
43 \\
43 \\
43 \\
43 \\
\end{array}$ & $\begin{array}{l}50 \\
51 \\
52 \\
53 \\
48 \\
48\end{array}$ & $\begin{array}{l}55 \\
54 \\
54 \\
-- \\
-- \\
--\end{array}$ & $\begin{array}{l}60 \\
61 \\
63 \\
62 \\
62 \\
60\end{array}$ & $\begin{array}{l}69 \\
69 \\
68 \\
69 \\
68 \\
-- \\
\end{array}$ & $\begin{array}{l}70 \\
69 \\
72 \\
69 \\
70 \\
69 \\
\end{array}$ & $\begin{array}{l}76 \\
80 \\
76 \\
78 \\
76 \\
-- \\
\end{array}$ & $\begin{array}{l}80 \\
78 \\
80 \\
78 \\
78 \\
80 \\
\end{array}$ & $\begin{array}{l}78 \\
78 \\
79 \\
80 \\
77 \\
79 \\
\end{array}$ & $\begin{array}{l}\mathbf{7 5} \\
\mathbf{7 0} \\
\mathbf{7 5} \\
\mathbf{7 8} \\
75 \\
-- \\
\end{array}$ \\
\hline $\begin{array}{c}\text { Aver- } \\
\text { age }\end{array}$ & & 49 & 46 & 47 & 51 & 57 & 67 & 64 & 75 & 79 & 78 & 74 \\
\hline
\end{tabular}




\begin{tabular}{|c|c|c|c|c|c|}
\hline : & 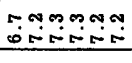 & 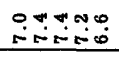 & 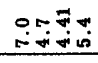 & 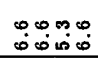 & 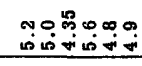 \\
\hline 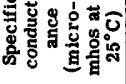 & 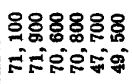 & 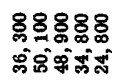 & 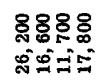 & 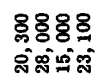 & 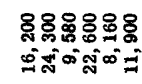 \\
\hline 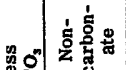 & 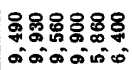 & 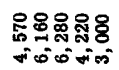 & 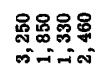 & 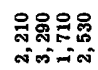 & 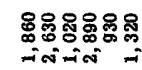 \\
\hline 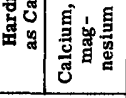 & 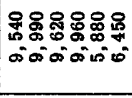 & 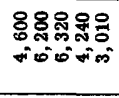 & 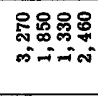 & 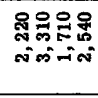 & 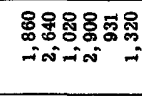 \\
\hline 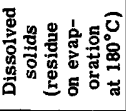 & 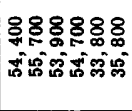 & 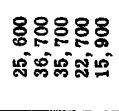 & 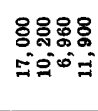 & 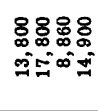 & 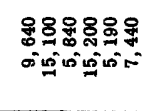 \\
\hline 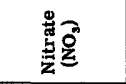 & & & & & \\
\hline 量 & & & & & \\
\hline 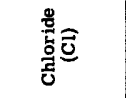 & 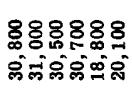 & 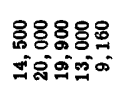 & 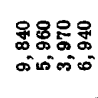 & 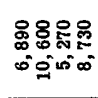 & 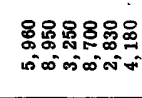 \\
\hline 离和 & 000000 & 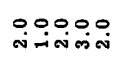 & $\begin{array}{l}\text { 웅요 } \\
\text { niviong }\end{array}$ & 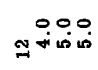 & 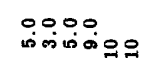 \\
\hline 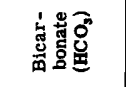 & 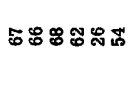 & 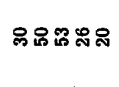 & N NOA & 유ำ & N \\
\hline 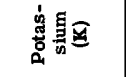 & 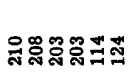 & 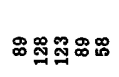 & 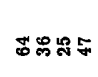 & 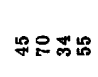 & ำ \\
\hline 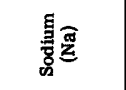 & 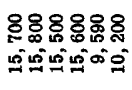 & 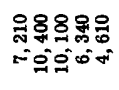 & 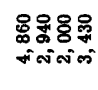 & 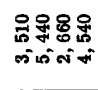 & 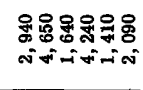 \\
\hline 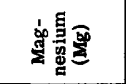 & 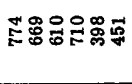 & 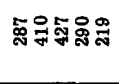 & జ & 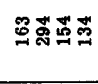 & 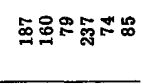 \\
\hline 항 & 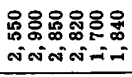 & 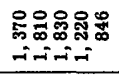 & 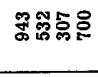 & 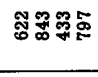 & 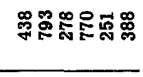 \\
\hline 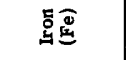 & & & & & \\
\hline 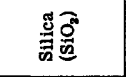 & & & & & \\
\hline 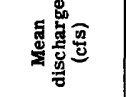 & & & & & \\
\hline 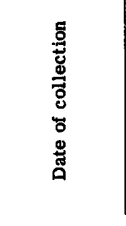 & $\begin{array}{l}\vdots \\
\vdots \\
0 \\
0 \\
0\end{array}$ & 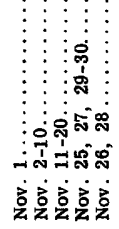 & 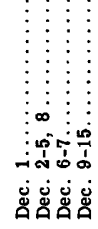 & 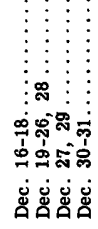 & 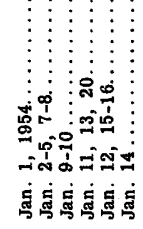 \\
\hline
\end{tabular}




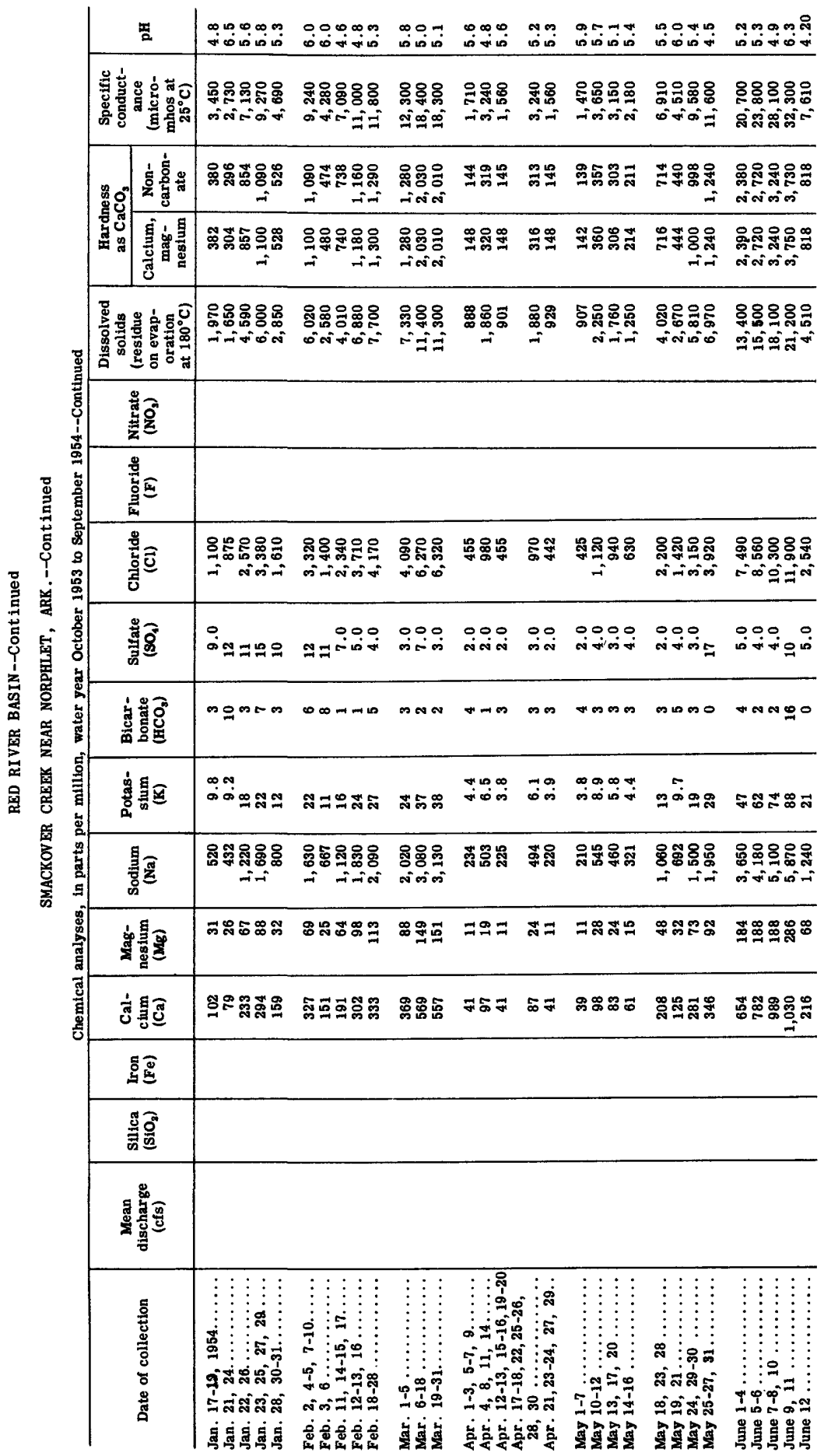




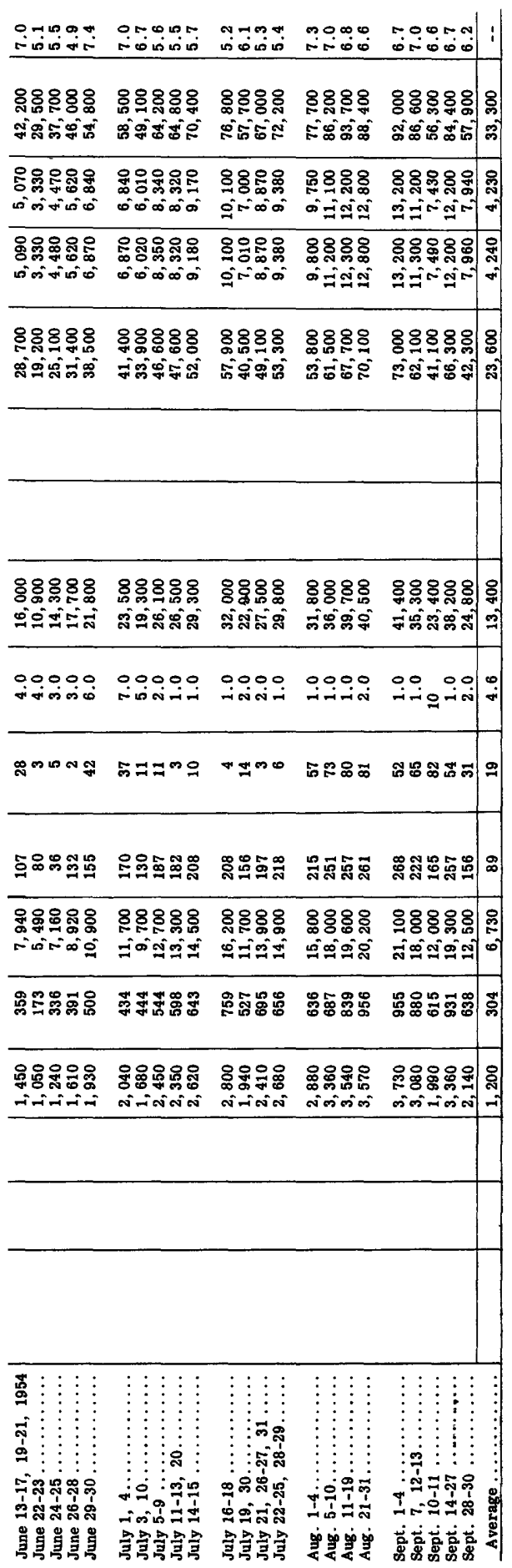


RED RIVER BASIN--Continued

SMACKOVER CREEK NEAR NORPHLET, ARK.--Continued

Temperature $\left({ }^{\circ} \mathrm{F}\right)$ of water, water year October 1953 to September 1954

\begin{tabular}{|c|c|c|c|c|c|c|c|c|c|c|c|c|}
\hline Day & Oct. & Nov. & Dec. & Jan. & Feb. & Mar. & Apr. & May & June & July & Aug. & Sept. \\
\hline $\begin{array}{l}1 \\
2 \\
3 \\
4 \\
5\end{array}$ & $\begin{array}{l}89 \\
88 \\
85 \\
85 \\
77\end{array}$ & $\begin{array}{l}67 \\
67 \\
65 \\
63 \\
60\end{array}$ & $\begin{array}{l}-- \\
-- \\
=- \\
--\end{array}$ & $\begin{array}{l}46 \\
47 \\
47 \\
48 \\
48\end{array}$ & $\begin{array}{l}48 \\
49 \\
50 \\
50 \\
50\end{array}$ & $\begin{array}{l}55 \\
53 \\
47 \\
51 \\
53\end{array}$ & $\begin{array}{l}57 \\
57 \\
57 \\
56 \\
57\end{array}$ & $\begin{array}{l}69 \\
68 \\
66 \\
66 \\
68\end{array}$ & $\begin{array}{l}79 \\
78 \\
76 \\
82 \\
82\end{array}$ & $\begin{array}{l}95 \\
-- \\
93 \\
97 \\
92\end{array}$ & $\begin{array}{r}87 \\
88 \\
100 \\
98 \\
99\end{array}$ & $\begin{array}{l}92 \\
96 \\
91 \\
98 \\
95\end{array}$ \\
\hline $\begin{array}{r}6 \\
7 \\
8 \\
9 \\
10\end{array}$ & $\begin{array}{l}77 \\
76 \\
78 \\
79 \\
80\end{array}$ & $\begin{array}{l}59 \\
55 \\
65 \\
55 \\
59\end{array}$ & $\begin{array}{l}-- \\
54 \\
51 \\
53 \\
49\end{array}$ & $\begin{array}{l}48 \\
48 \\
53 \\
48 \\
45\end{array}$ & $\begin{array}{l}50 \\
45 \\
45 \\
46 \\
46\end{array}$ & $\begin{array}{l}53 \\
53 \\
54 \\
54 \\
53\end{array}$ & $\begin{array}{l}58 \\
58 \\
57 \\
58 \\
58\end{array}$ & $\begin{array}{l}69 \\
69 \\
70 \\
68 \\
64\end{array}$ & $\begin{array}{l}83 \\
75 \\
77 \\
78 \\
85\end{array}$ & $\begin{array}{r}100 \\
98 \\
98 \\
97 \\
95\end{array}$ & $\begin{array}{r}100 \\
101 \\
97 \\
98 \\
101\end{array}$ & $\begin{array}{r}97 \\
97 \\
100 \\
99 \\
99\end{array}$ \\
\hline $\begin{array}{l}11 \\
12 \\
13 \\
14 \\
15\end{array}$ & $\begin{array}{l}81 \\
81 \\
83 \\
83 \\
83\end{array}$ & $\begin{array}{l}60 \\
60 \\
60 \\
59 \\
--\end{array}$ & $\begin{array}{l}50 \\
50 \\
49 \\
45 \\
46\end{array}$ & $\begin{array}{l}45 \\
42 \\
44 \\
45 \\
45\end{array}$ & $\begin{array}{l}47 \\
45 \\
53 \\
55 \\
59\end{array}$ & $\begin{array}{l}\mathbf{5 3} \\
54 \\
54 \\
54 \\
55\end{array}$ & $\begin{array}{l}58 \\
56 \\
56 \\
57 \\
58\end{array}$ & $\begin{array}{l}65 \\
64 \\
65 \\
66 \\
67\end{array}$ & $\begin{array}{l}89 \\
90 \\
92 \\
95 \\
94\end{array}$ & $\begin{array}{r}97 \\
99 \\
98 \\
98 \\
100\end{array}$ & $\begin{array}{r}99 \\
101 \\
100 \\
98 \\
101\end{array}$ & $\begin{array}{l}90 \\
93 \\
95 \\
94 \\
94\end{array}$ \\
\hline $\begin{array}{l}16 \\
17 \\
18 \\
19 \\
20\end{array}$ & $\begin{array}{l}83 \\
83 \\
80 \\
79 \\
80\end{array}$ & $\begin{array}{l}59 \\
62 \\
65 \\
-- \\
--\end{array}$ & $\begin{array}{l}46 \\
44 \\
44 \\
45 \\
45\end{array}$ & $\begin{array}{l}47 \\
48 \\
49 \\
-- \\
50\end{array}$ & $\begin{array}{l}59 \\
60 \\
60 \\
55 \\
53\end{array}$ & $\begin{array}{l}53 \\
53 \\
54 \\
54 \\
54\end{array}$ & $\begin{array}{l}58 \\
58 \\
60 \\
60 \\
61\end{array}$ & $\begin{array}{l}68 \\
75 \\
70 \\
80 \\
70\end{array}$ & $\begin{array}{l}92 \\
93 \\
87 \\
94 \\
95\end{array}$ & $\begin{array}{r}100 \\
101 \\
102 \\
101 \\
97\end{array}$ & $\begin{array}{r}100 \\
102 \\
101 \\
99 \\
100\end{array}$ & $\begin{array}{l}93 \\
90 \\
85 \\
84 \\
75\end{array}$ \\
\hline $\begin{array}{l}21 \\
22 \\
23 \\
24 \\
25\end{array}$ & $\begin{array}{l}80 \\
81 \\
76 \\
79 \\
76\end{array}$ & $\begin{array}{l}-- \\
=- \\
-- \\
=- \\
=-\end{array}$ & $\begin{array}{l}-- \\
43 \\
40 \\
42 \\
43\end{array}$ & $\begin{array}{l}42 \\
39 \\
39 \\
41 \\
43\end{array}$ & $\begin{array}{l}53 \\
54 \\
55 \\
55 \\
57\end{array}$ & $\begin{array}{l}\mathbf{5 2} \\
\mathbf{5 2} \\
\mathbf{5 4} \\
\mathbf{5 4} \\
\mathbf{5 4}\end{array}$ & $\begin{array}{l}61 \\
61 \\
62 \\
62 \\
63\end{array}$ & $\begin{array}{l}71 \\
75 \\
73 \\
70 \\
72\end{array}$ & $\begin{array}{l}95 \\
96 \\
90 \\
97 \\
96\end{array}$ & $\begin{array}{r}96 \\
101 \\
97 \\
102 \\
100\end{array}$ & $\begin{array}{r}100 \\
98 \\
101 \\
95 \\
95\end{array}$ & $\begin{array}{l}90 \\
84 \\
86 \\
86 \\
80\end{array}$ \\
\hline $\begin{array}{l}26 \\
27 \\
28 \\
29 \\
30 \\
31\end{array}$ & $\begin{array}{l}69 \\
67 \\
67 \\
67 \\
65 \\
63\end{array}$ & $\begin{array}{l}-- \\
-- \\
-- \\
-- \\
-- \\
--\end{array}$ & $\begin{array}{l}44 \\
45 \\
45 \\
45 \\
45 \\
46\end{array}$ & $\begin{array}{l}44 \\
45 \\
45 \\
45 \\
46 \\
48\end{array}$ & $\begin{array}{l}57 \\
56 \\
55 \\
-- \\
-- \\
--\end{array}$ & $\begin{array}{l}54 \\
55 \\
55 \\
56 \\
56 \\
56\end{array}$ & $\begin{array}{l}63 \\
63 \\
65 \\
65 \\
65 \\
--\end{array}$ & $\begin{array}{l}75 \\
76 \\
78 \\
77 \\
79 \\
79\end{array}$ & $\begin{array}{l}97 \\
98 \\
92 \\
92 \\
94 \\
--\end{array}$ & $\begin{array}{r}102 \\
100 \\
101 \\
98 \\
89 \\
88\end{array}$ & $\begin{array}{r}99 \\
100 \\
99 \\
100 \\
98 \\
100\end{array}$ & $\begin{array}{l}90 \\
90 \\
84 \\
86 \\
85 \\
--\end{array}$ \\
\hline $\begin{array}{c}\text { Aver - } \\
\text { age }\end{array}$ & 78 & -- & -- & 46 & 52 & 54 & 60 & 21 & 89 & 98 & 99 & 91 \\
\hline
\end{tabular}




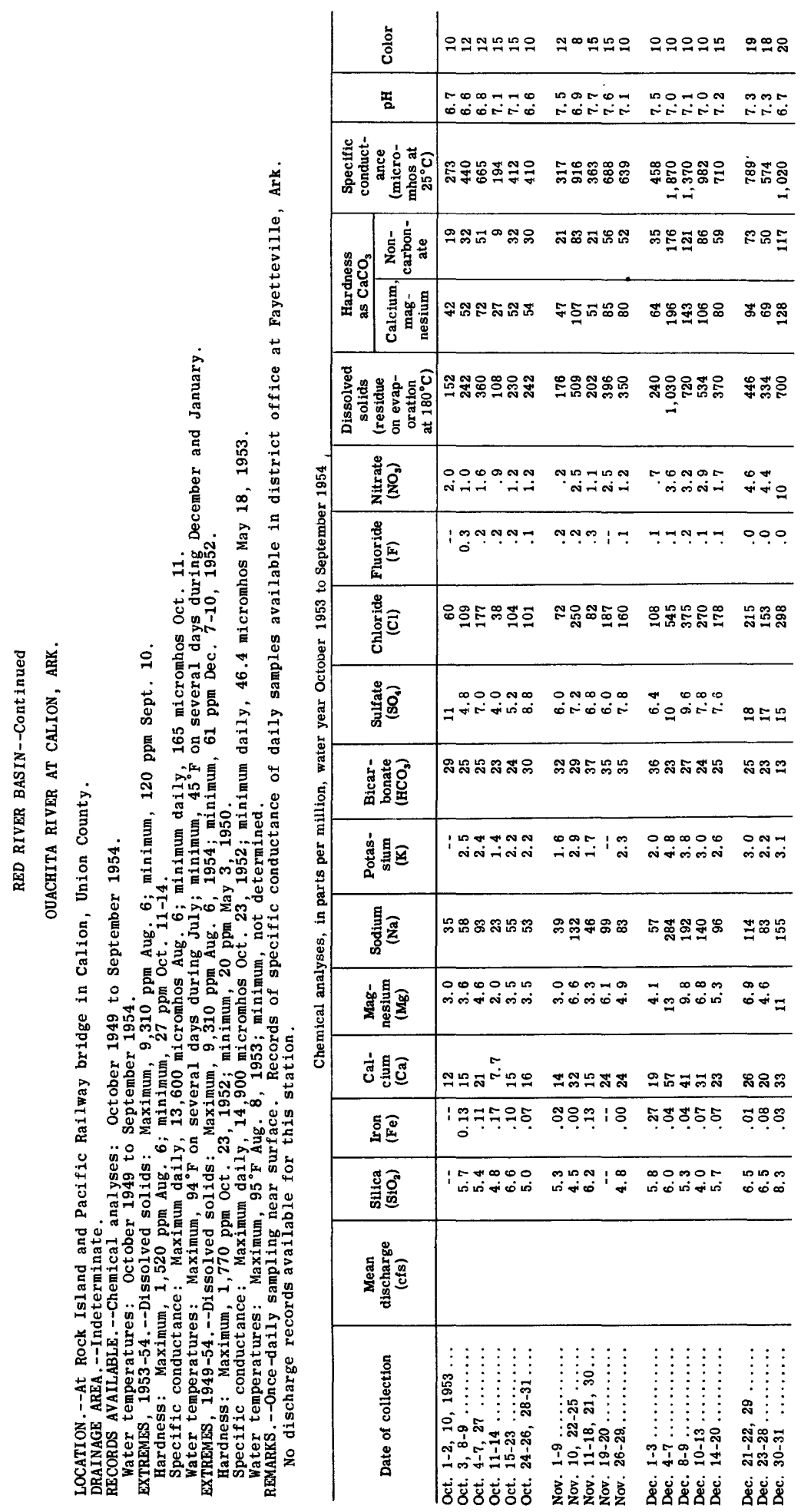




\begin{tabular}{|c|c|c|c|c|c|c|c|}
\hline & 융 & 꼬สลลำ & अ & 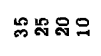 & 뚀 & 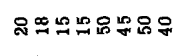 & 웁요응 \\
\hline & : & 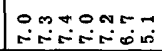 & 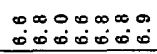 & $\begin{array}{l}\infty \\
0 \\
0 \\
0 \\
0\end{array}$ & $\begin{array}{l}+\infty 100 \\
+\infty 000 \\
-\infty\end{array}$ & 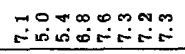 & $\begin{array}{l}7000 \\
2000\end{array}$ \\
\hline & 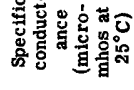 & 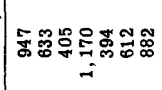 & 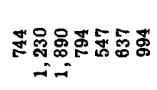 & 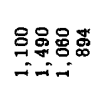 & 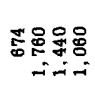 & 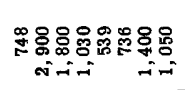 & ㅌ్ㅇ동영 \\
\hline & 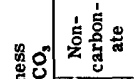 & 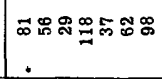 & 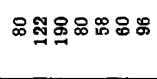 & 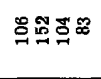 & 舟品品吕 & 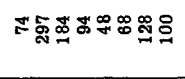 & ๓゚口 \\
\hline & 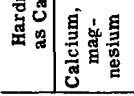 & 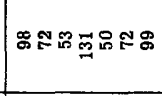 & 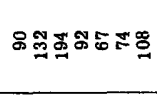 & 象占号 & 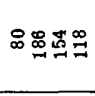 & 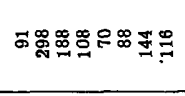 & 욤유: \\
\hline ¿ & 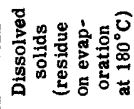 & 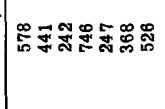 & 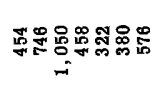 & 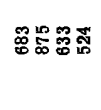 & 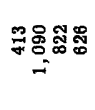 & 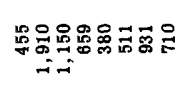 & 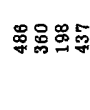 \\
\hline : & 䔸产 & 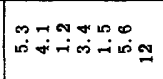 & 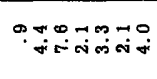 & 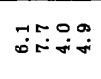 & 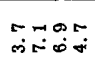 & 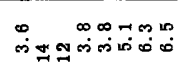 & 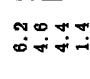 \\
\hline 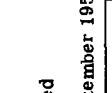 & 总国 & 0000.74 & $\because \cong: 1: 19$ & $\because \because \because m$ & menem. & 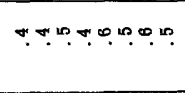 & 0.0. \\
\hline 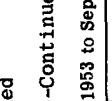 & 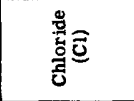 & 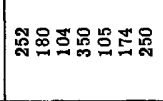 & 궁ํำ & 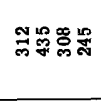 & 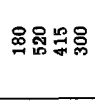 & 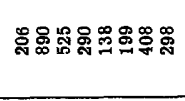 & 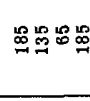 \\
\hline 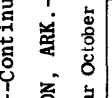 & 急 & $\cong \cong \approx \cong \cong \approx 尺$ & 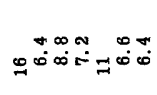 & 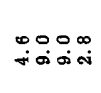 & 음유 & 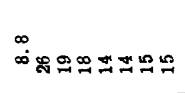 & 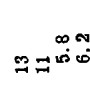 \\
\hline 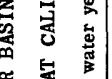 & 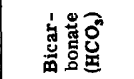 & สล & 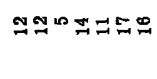 & 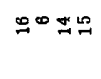 & ส요 & 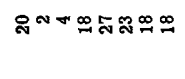 & 유 중 \\
\hline 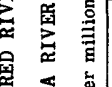 & 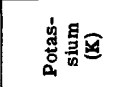 & 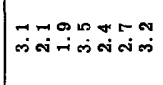 & 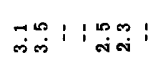 & $\begin{array}{l}\text { Nod } \\
\min \\
\min \end{array}$ & 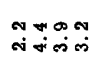 & 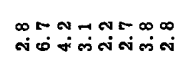 & 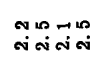 \\
\hline 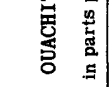 & 悬 & 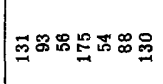 & 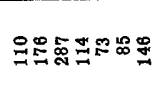 & 总品品蛋 & 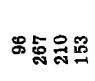 & 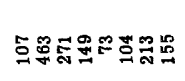 & ஃ̊ッ゙ \\
\hline 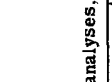 & 我昙 & की & 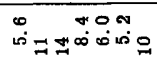 & $\begin{array}{l}\infty \\
\infty \\
\infty\end{array}$ & in & 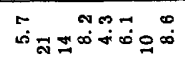 & 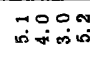 \\
\hline 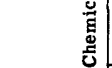 & 离星可 & 头สำำ & 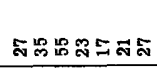 & 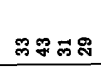 & 秘吕果志 & 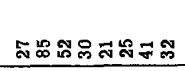 & สูกธ்ุ \\
\hline & 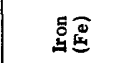 & 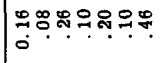 & 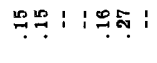 & 초ำㅇํำ & 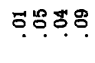 & 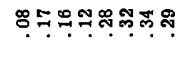 & ఇా్̣లి \\
\hline & 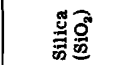 & 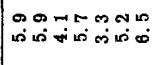 & $\begin{array}{l}\infty \\
\substack{\infty \\
\infty} \\
\infty\end{array}$ & 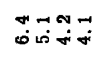 & 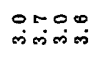 & 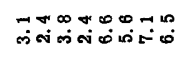 & 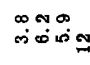 \\
\hline & 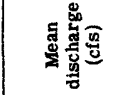 & & & & & & \\
\hline & 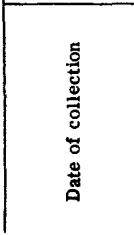 & 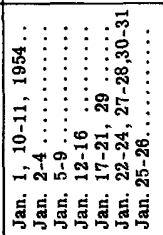 & 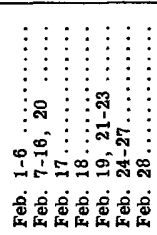 & 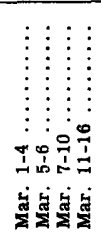 & 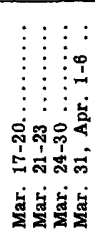 & 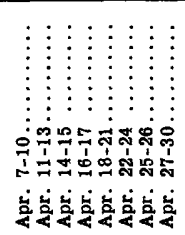 & $\begin{array}{c}\vdots \\
\vdots \\
\vdots \\
\vdots \\
\vdots \\
\vdots\end{array}$ \\
\hline
\end{tabular}




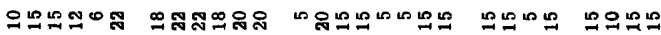

以

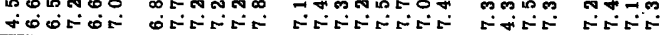

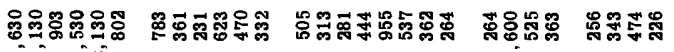

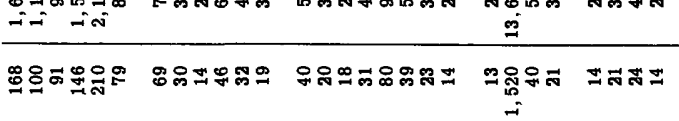

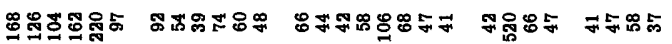

$-$

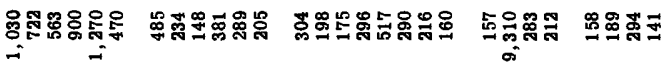

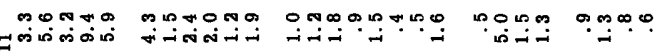

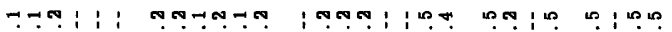

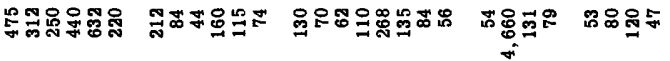

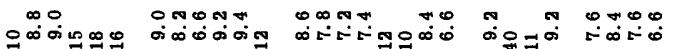

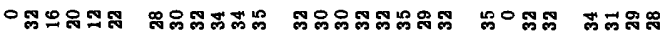

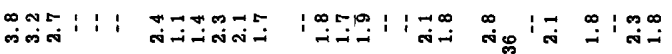

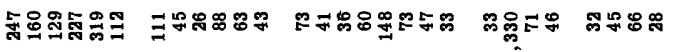

(2)

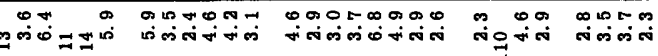

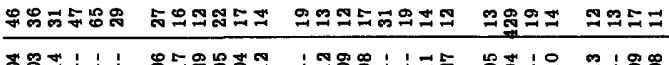

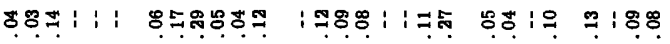

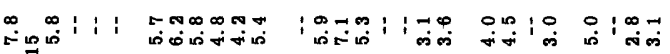

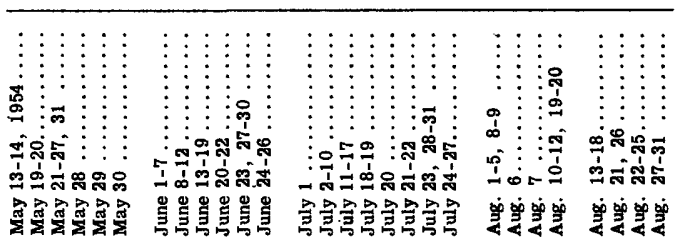




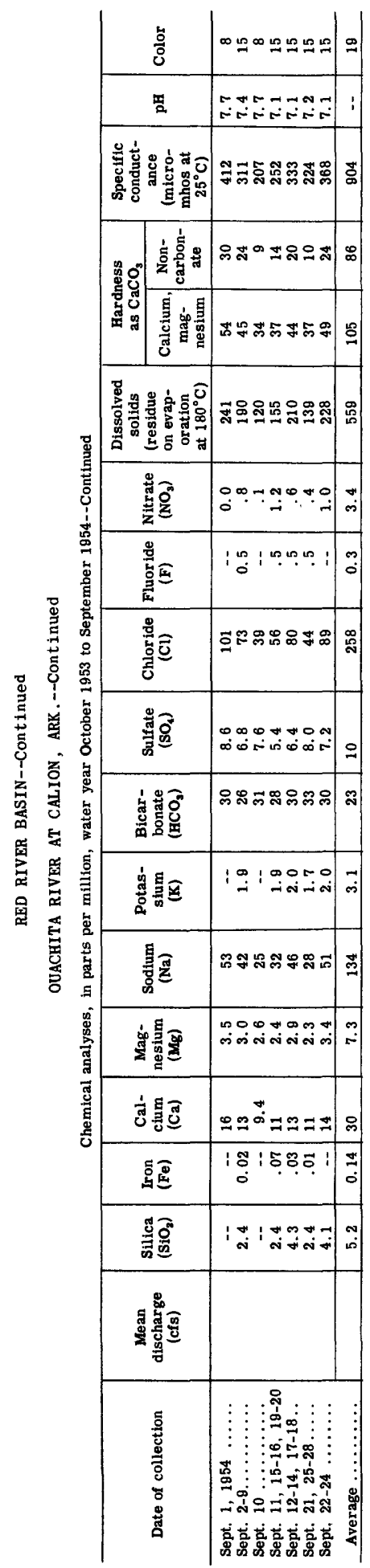


RED RIVER BASIN--Cont inued

OUACHITA RIVER NEAR CALION, ARK.--Continued

Temperature $\left({ }^{\circ} \mathrm{F}\right)$ of water, water year October 1953 to September 1954

\begin{tabular}{|c|c|c|c|c|c|c|c|c|c|c|c|c|}
\hline Day & Oct. & Nov. & Dec. & Jan. & Feb. & Mar. & Apr. & May & June & July & Aug. & Sept \\
\hline $\begin{array}{l}1 \\
2 \\
3 \\
4 \\
5\end{array}$ & $\begin{array}{l}80 \\
80 \\
80 \\
79 \\
78\end{array}$ & $\begin{array}{l}67 \\
67 \\
66 \\
65 \\
64\end{array}$ & $\begin{array}{l}58 \\
57 \\
-- \\
57 \\
57\end{array}$ & $\begin{array}{l}45 \\
46 \\
46 \\
46 \\
47\end{array}$ & $\begin{array}{l}55 \\
54 \\
55 \\
56 \\
56\end{array}$ & $\begin{array}{l}62 \\
61 \\
60 \\
58 \\
57\end{array}$ & $\begin{array}{l}67 \\
67 \\
69 \\
70 \\
70\end{array}$ & $\begin{array}{l}75 \\
73 \\
70 \\
70 \\
70\end{array}$ & $\begin{array}{l}84 \\
84 \\
83 \\
83 \\
82\end{array}$ & $\begin{array}{l}92 \\
92 \\
92 \\
92 \\
92\end{array}$ & $\begin{array}{l}91 \\
91 \\
91 \\
91 \\
91\end{array}$ & $\begin{array}{l}90 \\
90 \\
90 \\
89 \\
86\end{array}$ \\
\hline $\begin{array}{r}6 \\
7 \\
8 \\
9 \\
10\end{array}$ & $\begin{array}{l}78 \\
77 \\
77 \\
76 \\
75\end{array}$ & $\begin{array}{l}63 \\
59 \\
60 \\
60 \\
60\end{array}$ & $\begin{array}{l}56 \\
56 \\
57 \\
56 \\
56\end{array}$ & $\begin{array}{l}48 \\
52 \\
52 \\
51 \\
49\end{array}$ & $\begin{array}{l}57 \\
56 \\
53 \\
56 \\
57\end{array}$ & $\begin{array}{l}58 \\
58 \\
58 \\
59 \\
60\end{array}$ & $\begin{array}{l}70 \\
71 \\
70 \\
70 \\
69\end{array}$ & $\begin{array}{l}69 \\
68 \\
68 \\
65 \\
65\end{array}$ & $\begin{array}{l}86 \\
86 \\
87 \\
88 \\
89\end{array}$ & $\begin{array}{l}92 \\
93 \\
93 \\
93 \\
93\end{array}$ & $\begin{array}{l}91 \\
91 \\
93 \\
93 \\
93\end{array}$ & $\begin{array}{l}86 \\
89 \\
89 \\
89 \\
88\end{array}$ \\
\hline $\begin{array}{l}11 \\
12 \\
13 \\
14 \\
15\end{array}$ & $\begin{array}{l}77 \\
77 \\
76 \\
76 \\
75\end{array}$ & $\begin{array}{l}60 \\
60 \\
60 \\
60 \\
60\end{array}$ & $\begin{array}{l}55 \\
54 \\
-- \\
52 \\
--\end{array}$ & $\begin{array}{l}47 \\
45 \\
45 \\
47 \\
47\end{array}$ & $\begin{array}{l}57 \\
57 \\
55 \\
57 \\
57\end{array}$ & $\begin{array}{l}61 \\
62 \\
62 \\
60 \\
60\end{array}$ & $\begin{array}{l}70 \\
70 \\
70 \\
72 \\
73\end{array}$ & $\begin{array}{l}56 \\
65 \\
66 \\
68 \\
67\end{array}$ & $\begin{array}{l}88 \\
88 \\
88 \\
88 \\
89\end{array}$ & $\begin{array}{l}93 \\
93 \\
93 \\
93 \\
94\end{array}$ & $\begin{array}{l}93 \\
91 \\
91 \\
91 \\
92\end{array}$ & $\begin{array}{l}88 \\
86 \\
86 \\
86 \\
86\end{array}$ \\
\hline $\begin{array}{l}16 \\
17 \\
18 \\
19 \\
20\end{array}$ & $\begin{array}{l}75 \\
74 \\
76 \\
73 \\
74\end{array}$ & $\begin{array}{l}59 \\
59 \\
59 \\
59 \\
59\end{array}$ & $\begin{array}{l}52 \\
-- \\
52 \\
48 \\
--\end{array}$ & $\begin{array}{l}48 \\
50 \\
52 \\
55 \\
54\end{array}$ & $\begin{array}{l}57 \\
59 \\
60 \\
60 \\
56\end{array}$ & $\begin{array}{l}62 \\
63 \\
63 \\
63\end{array}$ & $\begin{array}{l}72 \\
72 \\
71 \\
71 \\
72\end{array}$ & $\begin{array}{l}70 \\
71 \\
71 \\
75 \\
72\end{array}$ & $\begin{array}{l}89 \\
90 \\
91 \\
91 \\
-2\end{array}$ & $\begin{array}{l}94 \\
94 \\
94 \\
94 \\
93\end{array}$ & $\begin{array}{l}92 \\
93 \\
93 \\
92 \\
92\end{array}$ & $\begin{array}{l}85 \\
85 \\
85 \\
86 \\
86\end{array}$ \\
\hline $\begin{array}{l}21 \\
22 \\
23 \\
24 \\
25\end{array}$ & $\begin{array}{l}74 \\
74 \\
23 \\
73 \\
73\end{array}$ & $\begin{array}{l}58 \\
58 \\
58 \\
58 \\
57\end{array}$ & $\begin{array}{l}48 \\
-- \\
45 \\
45 \\
45\end{array}$ & $\begin{array}{l}52 \\
48 \\
47 \\
50 \\
50\end{array}$ & $\begin{array}{l}60 \\
60 \\
62 \\
61\end{array}$ & $\begin{array}{l}64 \\
64 \\
65 \\
67 \\
67\end{array}$ & $\begin{array}{l}73 \\
74 \\
75 \\
76 \\
75\end{array}$ & $\begin{array}{l}73 \\
74 \\
75 \\
76 \\
77\end{array}$ & $\begin{array}{l}90 \\
91 \\
90 \\
92 \\
92\end{array}$ & $\begin{array}{l}93 \\
93 \\
93 \\
94 \\
94\end{array}$ & $\begin{array}{l}92 \\
91 \\
91 \\
91 \\
91\end{array}$ & $\begin{array}{l}86 \\
84 \\
81 \\
81 \\
81\end{array}$ \\
\hline $\begin{array}{l}26 \\
27 \\
28 \\
29 \\
30 \\
31\end{array}$ & $\begin{array}{l}72 \\
68 \\
67 \\
61 \\
66 \\
65\end{array}$ & $\begin{array}{l}58 \\
58 \\
58 \\
58 \\
58 \\
--\end{array}$ & $\begin{array}{l}45 \\
45 \\
45 \\
45 \\
45 \\
--\end{array}$ & $\begin{array}{l}50 \\
50 \\
51 \\
52 \\
54 \\
54\end{array}$ & $\begin{array}{l}62 \\
62 \\
62 \\
-- \\
-- \\
--\end{array}$ & $\begin{array}{l}67 \\
67 \\
70 \\
70 \\
67 \\
68\end{array}$ & $\begin{array}{l}75 \\
76 \\
78 \\
77 \\
77 \\
--\end{array}$ & $\begin{array}{l}77 \\
76 \\
70 \\
76 \\
82 \\
84\end{array}$ & $\begin{array}{l}92 \\
92 \\
92 \\
92 \\
92 \\
--\end{array}$ & $\begin{array}{l}94 \\
94 \\
94 \\
93 \\
92 \\
92\end{array}$ & $\begin{array}{l}91 \\
91 \\
91 \\
91 \\
91 \\
90\end{array}$ & $\begin{array}{l}84 \\
84 \\
84 \\
-- \\
-- \\
--\end{array}$ \\
\hline $\begin{array}{c}\text { Aver - } \\
\text { age }\end{array}$ & 74 & 60 & -- & 49 & 58 & 63 & 72 & 72 & 89 & 93 & 92 & 86 \\
\hline
\end{tabular}




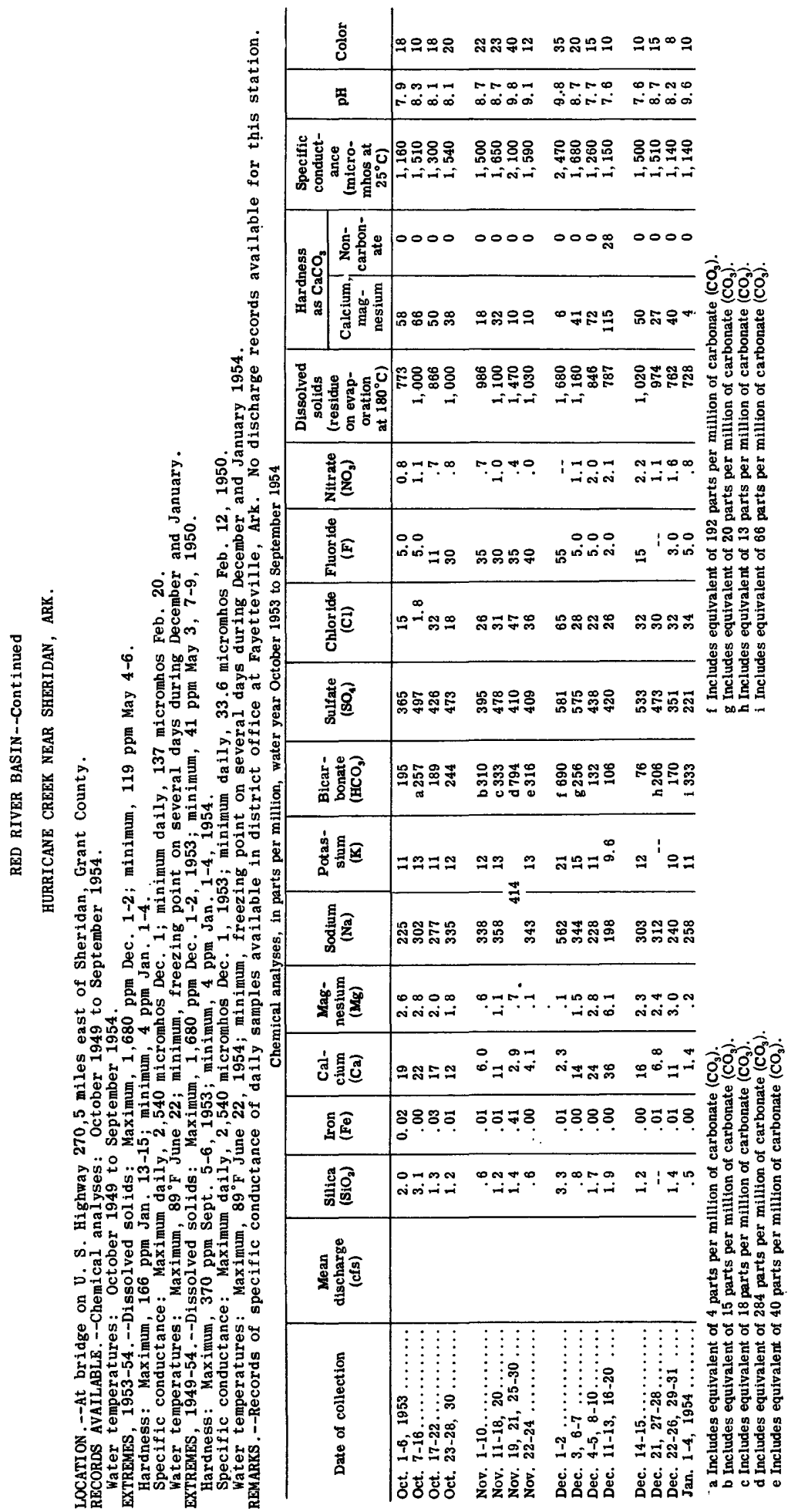




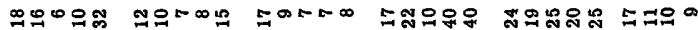

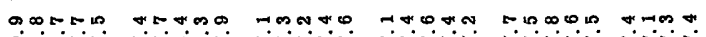

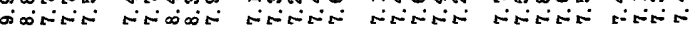

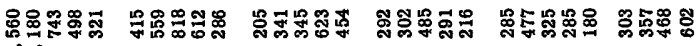
$\therefore=$

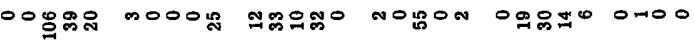

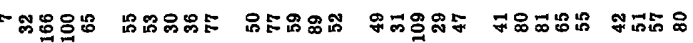

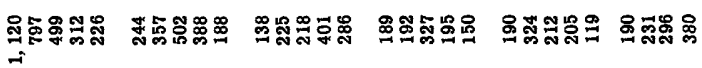

\begin{tabular}{|c|c|c|c|c|c|}
\hline تَّْْ & 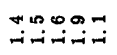 & 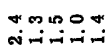 & تِ & 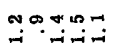 & $\ddot{-050}$ \\
\hline \begin{tabular}{l|l}
00 & 00 \\
$-i$ & 0
\end{tabular} & Oiforing & $\because$ กั & $\begin{array}{l}00000 \\
\text { Nifi }\end{array}$ & $\stackrel{0}{0}$ & ن요 \\
\hline 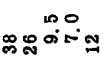 & $\stackrel{\infty}{=}$ & 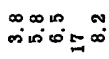 & 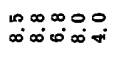 & 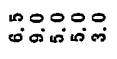 & $\stackrel{0}{\infty} \cos ^{\infty}=$ \\
\hline
\end{tabular}

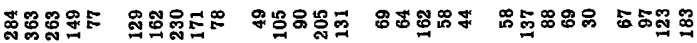

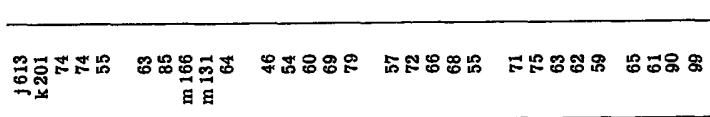

\begin{tabular}{|c|c|c|c|c|}
\hline$\pm=1$ is & 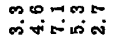 & 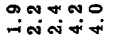 & 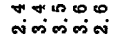 & 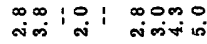 \\
\hline
\end{tabular}

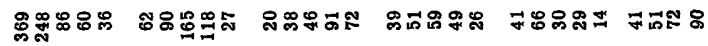

\begin{tabular}{|c|c|c|c|c|c|}
\hline $\begin{array}{l}0000=1 \\
0 \text { in }\end{array}$ & 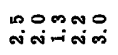 & 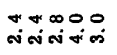 & 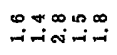 & 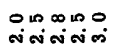 & 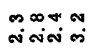 \\
\hline 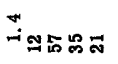 & $\infty_{\infty}^{\infty} \stackrel{\infty}{\infty}=\stackrel{乛}{=}$ & 노오요 & =우용 & 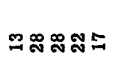 & ๑ำ오 \\
\hline 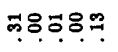 & ธํㅇㅇㅁㅇㅇㅇ & 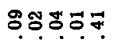 & 고곤 & 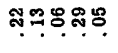 & 퐁옹요 \\
\hline 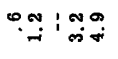 & 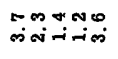 & 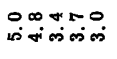 & 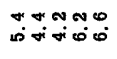 & $\underset{\omega}{N}: 51$ & $\begin{array}{l}\text { teno } 0 \\
\text { oinisio oi }\end{array}$ \\
\hline 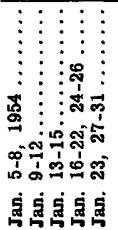 & 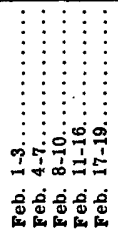 & 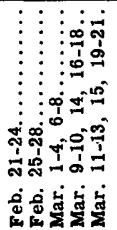 & 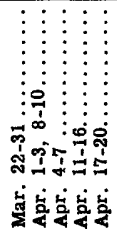 & 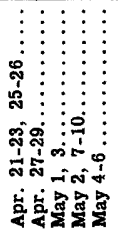 & 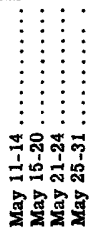 \\
\hline
\end{tabular}




\begin{tabular}{|c|c|c|c|c|c|c|c|}
\hline & 总 & $9^{\infty}=$ & 윰요요 & 우공저 & 고 엄유 워 & $\therefore$. & \\
\hline & 営 & $\underset{\sim}{\infty}$ & 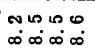 & $\begin{array}{l}0 \bullet m \pi \\
\infty \infty \infty \infty \infty \\
\infty \infty \infty\end{array}$ & 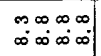 & & \\
\hline & 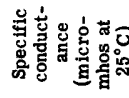 & 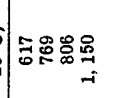 & 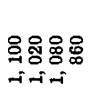 & 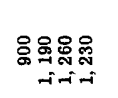 & 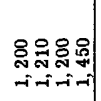 & : & \\
\hline & 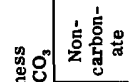 & 0000 & 0000 & 0000 & 0000 & 0 & \\
\hline & 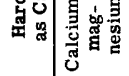 & 윰ํำ & ผลลลำ & 츙요 & 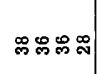 & $\stackrel{\infty}{+}$ & 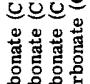 \\
\hline & 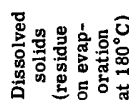 & 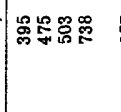 & 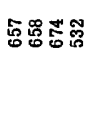 & 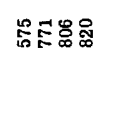 & 总옹몽요 & 恕 & 年 \\
\hline 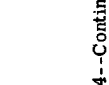 & 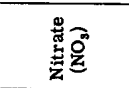 & 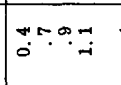 & Tr: & $\underset{-1 \rightarrow \infty}{\text { N. }}$ & $\ddot{i} 0.0$. & 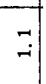 & \\
\hline 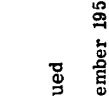 & 总 & $\begin{array}{l}000 \\
\text { Ni ผiं }\end{array}$ & $\begin{array}{l}\therefore 000 \\
\therefore \rightarrow \infty \\
\therefore \rightarrow \infty\end{array}$ & 1000 & $\begin{array}{l}0000 \\
\text { in } 0 \text { inis: }\end{array}$ & \begin{tabular}{l} 
\\
\hdashline
\end{tabular} & 范 \\
\hline 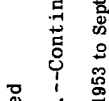 & 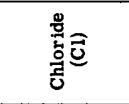 & 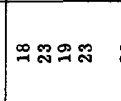 & ลิดิ లేని & 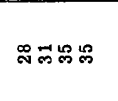 & 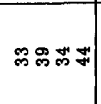 & ลิ & \\
\hline 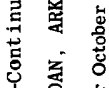 & 密。 & 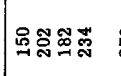 & 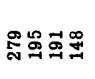 & 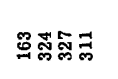 & 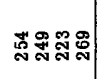 & ๙ & \\
\hline 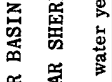 & 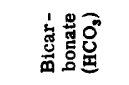 & 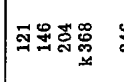 & 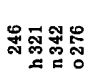 & 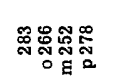 & 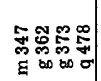 & $\stackrel{\infty}{9}$ & \\
\hline 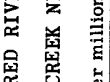 & 造高 & 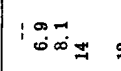 & 푸 & ' & ఇ모무 & $\stackrel{+}{\infty}$ & \\
\hline 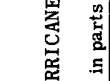 & 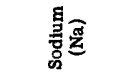 & 导总尊 & 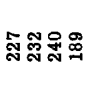 & 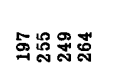 & స్త్ర: : : & $\stackrel{\infty}{=1}$ & \\
\hline 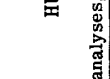 & 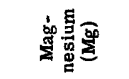 & 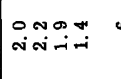 & 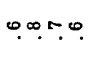 & 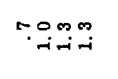 & morr. & $\begin{array}{l}0 \\
\text { ij }\end{array}$ & \\
\hline สี & 元漚可 & 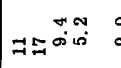 & $\begin{array}{l}0.00 \% \\
0.000 \\
0.000\end{array}$ & 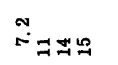 & 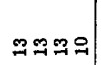 & 9 & \\
\hline & 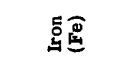 & 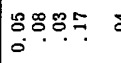 & 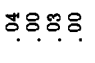 & 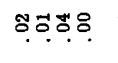 & 58용. & $\begin{array}{l}\infty \\
0 \\
0\end{array}$ & 施 \\
\hline & 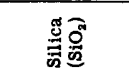 & 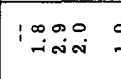 & $\begin{array}{l}0 \text { ofom } \\
\text { ition }\end{array}$ & 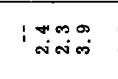 & 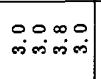 & $\overrightarrow{0}$ & 送 \\
\hline & 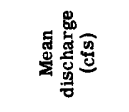 & & & & & & 洔 \\
\hline & 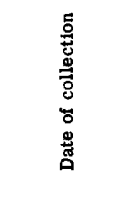 & 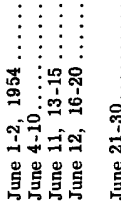 & 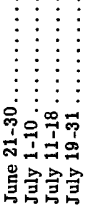 & 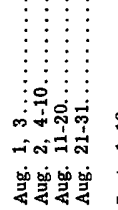 & 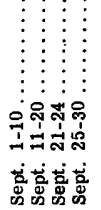 & | & o \\
\hline
\end{tabular}


RED RIVER BASIN--Continued

HURRICANE CREEK NEAR SHERIDAN, ARK.--Continued

Temperature $\left({ }^{\circ} \mathrm{F}\right.$ ) of water, water year October 1953 to September 1954

\begin{tabular}{|c|c|c|c|c|c|c|c|c|c|c|c|c|}
\hline Day & Oct. & Nov. & Dec. & Jan. & Feb. & Mar. & Apr. & May & June & July & Aug. & Sept. \\
\hline $\begin{array}{l}1 \\
2 \\
3 \\
4 \\
5\end{array}$ & $\begin{array}{l}69 \\
69 \\
68 \\
68 \\
66\end{array}$ & $\begin{array}{l}49 \\
48 \\
50 \\
48 \\
48\end{array}$ & $\begin{array}{l}43 \\
43 \\
44 \\
42 \\
43\end{array}$ & $\begin{array}{l}34 \\
33 \\
34 \\
34 \\
34\end{array}$ & $\begin{array}{l}45 \\
43 \\
43 \\
44 \\
45\end{array}$ & $\begin{array}{l}46 \\
43 \\
44 \\
46 \\
43\end{array}$ & $\begin{array}{l}49 \\
50 \\
52 \\
55 \\
59\end{array}$ & $\begin{array}{l}64 \\
64 \\
65 \\
62 \\
64\end{array}$ & $\begin{array}{l}74 \\
78 \\
76 \\
78 \\
78\end{array}$ & $\begin{array}{l}86 \\
84 \\
86 \\
85 \\
84\end{array}$ & $\begin{array}{l}85 \\
84 \\
86 \\
85 \\
86\end{array}$ & $\begin{array}{l}85 \\
85 \\
85 \\
87 \\
87\end{array}$ \\
\hline $\begin{array}{r}6 \\
7 \\
8 \\
9 \\
10\end{array}$ & $\begin{array}{l}66 \\
65 \\
65 \\
63 \\
62\end{array}$ & $\begin{array}{l}47 \\
46 \\
46 \\
44 \\
43\end{array}$ & $\begin{array}{l}43 \\
43 \\
42 \\
42 \\
42\end{array}$ & $\begin{array}{l}34 \\
35 \\
36 \\
34 \\
34\end{array}$ & $\begin{array}{l}44 \\
43 \\
43 \\
44 \\
43\end{array}$ & $\begin{array}{l}44 \\
45 \\
45 \\
46 \\
48\end{array}$ & $\begin{array}{l}59 \\
60 \\
62 \\
61 \\
60\end{array}$ & $\begin{array}{l}65 \\
63 \\
64 \\
65 \\
64\end{array}$ & $\begin{array}{l}76 \\
79 \\
80 \\
82 \\
84\end{array}$ & $\begin{array}{l}87 \\
88 \\
85 \\
86 \\
84\end{array}$ & $\begin{array}{l}87 \\
85 \\
87 \\
88 \\
87\end{array}$ & $\begin{array}{l}84 \\
85 \\
84 \\
84 \\
85\end{array}$ \\
\hline $\begin{array}{l}11 \\
12 \\
13 \\
14 \\
15\end{array}$ & $\begin{array}{l}62 \\
62 \\
62 \\
62 \\
60\end{array}$ & $\begin{array}{l}43 \\
42 \\
44 \\
43 \\
44\end{array}$ & $\begin{array}{l}42 \\
42 \\
42 \\
44 \\
42\end{array}$ & $\begin{array}{l}32 \\
32 \\
-- \\
31 \\
32\end{array}$ & $\begin{array}{l}-- \\
44 \\
46 \\
48 \\
50\end{array}$ & $\begin{array}{l}48 \\
50 \\
48 \\
46 \\
45\end{array}$ & $\begin{array}{l}60 \\
59 \\
60 \\
60 \\
60\end{array}$ & $\begin{array}{l}64 \\
64 \\
64 \\
65 \\
65\end{array}$ & $\begin{array}{l}86 \\
86 \\
88 \\
86 \\
86\end{array}$ & $\begin{array}{l}86 \\
85 \\
85 \\
88 \\
87\end{array}$ & $\begin{array}{l}88 \\
87 \\
88 \\
88 \\
88\end{array}$ & $\begin{array}{l}83 \\
79 \\
78 \\
78 \\
76\end{array}$ \\
\hline $\begin{array}{l}16 \\
17 \\
18 \\
19 \\
20\end{array}$ & $\begin{array}{l}60 \\
61 \\
60 \\
62 \\
60\end{array}$ & $\begin{array}{l}44 \\
46 \\
47 \\
48 \\
46\end{array}$ & $\begin{array}{l}41 \\
41 \\
42 \\
42 \\
42\end{array}$ & $\begin{array}{l}33 \\
34 \\
34 \\
35 \\
37\end{array}$ & $\begin{array}{l}46 \\
48 \\
49 \\
47 \\
46\end{array}$ & $\begin{array}{l}46 \\
45 \\
45 \\
45 \\
44\end{array}$ & $\begin{array}{l}60 \\
59 \\
59 \\
58 \\
60\end{array}$ & $\begin{array}{l}68 \\
67 \\
68 \\
67 \\
68\end{array}$ & $\begin{array}{l}86 \\
88 \\
87 \\
- \\
87\end{array}$ & $\begin{array}{l}88 \\
87 \\
88 \\
78 \\
79\end{array}$ & $\begin{array}{l}-- \\
88 \\
86 \\
88 \\
88\end{array}$ & $\begin{array}{l}76 \\
77 \\
76 \\
78 \\
76\end{array}$ \\
\hline $\begin{array}{l}21 \\
22 \\
23 \\
24 \\
25\end{array}$ & $\begin{array}{l}60 \\
60 \\
60 \\
59 \\
59\end{array}$ & $\begin{array}{l}45 \\
45 \\
44 \\
45 \\
44\end{array}$ & $\begin{array}{l}40 \\
38 \\
36 \\
34 \\
33\end{array}$ & $\begin{array}{l}34 \\
35 \\
34 \\
34 \\
36\end{array}$ & $\begin{array}{l}47 \\
46 \\
46 \\
47 \\
48\end{array}$ & $\begin{array}{l}45 \\
48 \\
48 \\
49 \\
50\end{array}$ & $\begin{array}{l}62 \\
65 \\
64 \\
64 \\
65\end{array}$ & $\begin{array}{l}68 \\
69 \\
70 \\
69 \\
69\end{array}$ & $\begin{array}{l}88 \\
89 \\
88 \\
88 \\
87\end{array}$ & $\begin{array}{l}85 \\
87 \\
85 \\
85 \\
86\end{array}$ & $\begin{array}{l}86 \\
86 \\
86 \\
86 \\
86\end{array}$ & $\begin{array}{l}78 \\
70 \\
70 \\
69 \\
69\end{array}$ \\
\hline $\begin{array}{l}26 \\
27 \\
28 \\
29 \\
30 \\
31\end{array}$ & $\begin{array}{l}56 \\
54 \\
53 \\
52 \\
50 \\
48\end{array}$ & $\begin{array}{l}43 \\
42 \\
43 \\
44 \\
43 \\
--\end{array}$ & $\begin{array}{l}32 \\
33 \\
33 \\
32 \\
31 \\
33\end{array}$ & $\begin{array}{l}34 \\
38 \\
39 \\
42 \\
44 \\
44\end{array}$ & $\begin{array}{l}48 \\
47 \\
46 \\
-- \\
-- \\
--\end{array}$ & $\begin{array}{l}49 \\
50 \\
51 \\
56 \\
50 \\
49\end{array}$ & $\begin{array}{l}66 \\
67 \\
64 \\
65 \\
63 \\
\ldots\end{array}$ & $\begin{array}{l}69 \\
70 \\
74 \\
74 \\
75 \\
78\end{array}$ & $\begin{array}{l}87 \\
88 \\
87 \\
87 \\
83 \\
--\end{array}$ & $\begin{array}{l}86 \\
85 \\
85 \\
86 \\
85 \\
86\end{array}$ & $\begin{array}{l}87 \\
87 \\
86 \\
86 \\
85 \\
84\end{array}$ & $\begin{array}{l}68 \\
69 \\
76 \\
74 \\
76 \\
--\end{array}$ \\
\hline $\begin{array}{c}\text { Aver - } \\
\text { age }\end{array}$ & 61 & 45 & 39 & 35 & 46 & 47 & 60 & 67 & 84 & 85 & 86 & 78 \\
\hline
\end{tabular}




\begin{tabular}{|c|c|c|c|c|c|c|c|}
\hline \multicolumn{2}{|c|}{ ㅎํㅇ } & $\infty \infty \backsim \cong \simeq$ 워 & 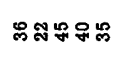 & 只品 & $=0$ & $\infty \infty$ & 绾 \\
\hline & 要 & $\begin{array}{l}00 \mathrm{n} \\
\therefore \mathrm{N}\end{array}$ & 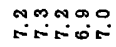 & 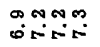 & $\begin{array}{l}0+54 \\
\text { rin }\end{array}$ & $\begin{array}{l}\text { on } \\
\text { L }\end{array}$ & $i$ \\
\hline \multicolumn{2}{|c|}{ 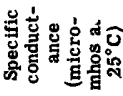 } & 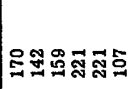 & 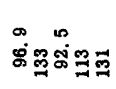 & 용ㅎㅀㅇㅛ & 品吕总 & 号 & 룩 \\
\hline \multirow{2}{*}{ 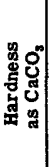 } & 흔을 & 000000 & $m \infty 9 m$ & $r$ & 000 & 00 & $*$ \\
\hline & 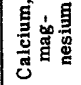 & 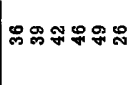 & 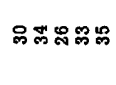 & 휴유옹 & 怘萬 & : & $\bar{m}$ \\
\hline \multicolumn{2}{|c|}{ 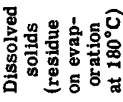 } & 녕 & 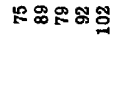 & 웅 塄 옹 : & トீす্口゙ & $\mathscr{\infty}$ & $\$$ \\
\hline \multicolumn{2}{|c|}{ 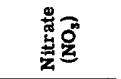 } & 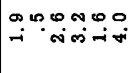 & نه & تか & $\begin{array}{l}\infty \infty \infty \\
-i \infty\end{array}$ & $\infty$ & $\begin{array}{l}0 \\
\mathbf{N}\end{array}$ \\
\hline \multicolumn{2}{|c|}{ 总医 } & mon. & $\because 7$ & & 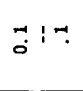 & 9.6 & $\stackrel{+}{\circ}$ \\
\hline \multicolumn{2}{|c|}{ 홀로 } & 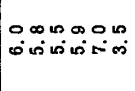 & $\begin{array}{l}\infty \\
\infty\end{array}$ & 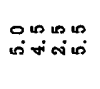 & $\infty \underset{\sim}{\infty} \infty$ & $\begin{array}{l}\infty \infty \\
\text { in in }\end{array}$ & is \\
\hline \multicolumn{2}{|c|}{ 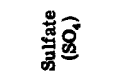 } & 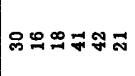 & 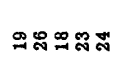 & $=\underset{\sim}{\infty}$ & $\varphi= \pm$ & $\Rightarrow=$ & ำ \\
\hline \multicolumn{2}{|c|}{ 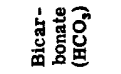 } & 요욤묨요 & 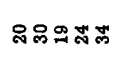 & 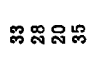 & 与果络 & 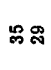 & 'ొ \\
\hline \multicolumn{2}{|c|}{ 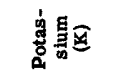 } & 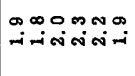 & نه & & in & 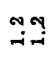 & 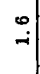 \\
\hline \multicolumn{2}{|c|}{ 总宽 } & $\stackrel{\infty}{\sim}=$ 웡ำ & $\omega^{\circ}=0$ & 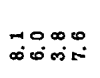 & 으눈 $=$ & $\nexists \approx$ & $\Rightarrow$ \\
\hline \multicolumn{2}{|c|}{ 息鸹点 } & 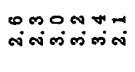 & $\begin{array}{l}\text { N } \\
\text { N } \\
\text { N }\end{array}$ & $\begin{array}{l}\infty 0 \infty \infty \\
\text { i⿻ }\end{array}$ & $\begin{array}{l}\infty \infty \infty \\
\text { ஸं }\end{array}$ & 5 & in \\
\hline \multicolumn{2}{|c|}{ 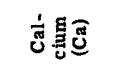 } & 오ッォ゙் & $\stackrel{\infty}{\sim 0}=\infty \infty \infty$ & 요 in & 퍼을음 & $\begin{array}{l}0 \\
0\end{array}$ & 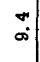 \\
\hline \multicolumn{2}{|c|}{ ㅎㅗㅂㅀㅗㄹ } & 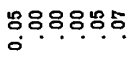 & 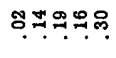 & 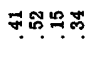 & $\underset{0}{ \pm}:$ : & 영 & $\stackrel{+}{\dot{0}}$ \\
\hline \multicolumn{2}{|c|}{ 总导 } & 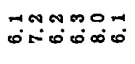 & 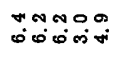 & 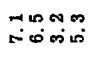 & ". & "n & $\begin{array}{l}\infty \\
\text { is }\end{array}$ \\
\hline \multicolumn{2}{|c|}{ 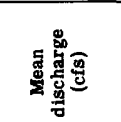 } & సึ心 & 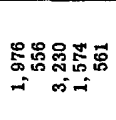 & 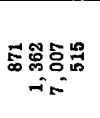 & 5 & क्ष & $\begin{array}{l}\infty \\
\mathbb{\&} \\
\mathbb{\infty}\end{array}$ \\
\hline \multicolumn{2}{|r|}{ 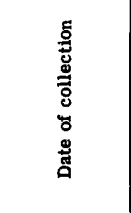 } & 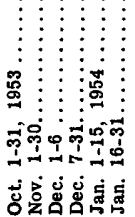 & 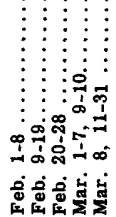 & 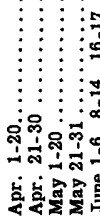 & 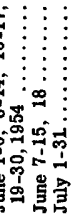 & 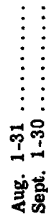 & 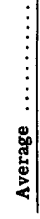 \\
\hline
\end{tabular}


RED RIVER BASIN--Cont inued

SALINE RIVER NEAR RYE, ARK.--Continued

Temperature $\left({ }^{\circ} \mathrm{F}\right)$ of water, water year October 1953 to September 1954

\begin{tabular}{|c|c|c|c|c|c|c|c|c|c|c|c|c|}
\hline Day & Oct. & Nov. & Dec. & Jan. & Feb. & Mar. & Apr. & May & June & July & Aug. & Sept. \\
\hline $\begin{array}{l}1 \\
2 \\
3 \\
4 \\
5\end{array}$ & $\begin{array}{l}80 \\
80 \\
80 \\
78 \\
74\end{array}$ & $\begin{array}{l}60 \\
61 \\
62 \\
-- \\
60\end{array}$ & $\begin{array}{l}49 \\
51 \\
52 \\
54 \\
55\end{array}$ & $\begin{array}{l}45 \\
43 \\
45 \\
48 \\
45\end{array}$ & $\begin{array}{l}47 \\
45 \\
47 \\
46 \\
47\end{array}$ & $\begin{array}{l}52 \\
49 \\
48 \\
50 \\
51\end{array}$ & $\begin{array}{l}69 \\
70 \\
70 \\
70 \\
71\end{array}$ & $\begin{array}{l}67 \\
64 \\
63 \\
62 \\
64\end{array}$ & $\begin{array}{l}73 \\
76 \\
75 \\
76 \\
75\end{array}$ & $\begin{array}{l}84 \\
83 \\
84 \\
84 \\
85\end{array}$ & $\begin{array}{l}88 \\
85 \\
87 \\
86 \\
87\end{array}$ & $\begin{array}{l}-- \\
-- \\
82 \\
83 \\
84\end{array}$ \\
\hline $\begin{array}{r}6 \\
7 \\
8 \\
9 \\
10\end{array}$ & $\begin{array}{l}70 \\
70 \\
70 \\
70 \\
72\end{array}$ & $\begin{array}{l}57 \\
56 \\
54 \\
51 \\
50\end{array}$ & $\begin{array}{l}56 \\
54 \\
50 \\
48 \\
44\end{array}$ & $\begin{array}{l}40 \\
45 \\
48 \\
50 \\
45\end{array}$ & $\begin{array}{l}47 \\
44 \\
40 \\
43 \\
48\end{array}$ & $\begin{array}{l}53 \\
54 \\
56 \\
56 \\
57\end{array}$ & $\begin{array}{l}72 \\
71 \\
73 \\
72 \\
69\end{array}$ & $\begin{array}{l}64 \\
63 \\
64 \\
63 \\
60\end{array}$ & $\begin{array}{l}76 \\
75 \\
76 \\
78 \\
79\end{array}$ & $\begin{array}{l}84 \\
84 \\
84 \\
85 \\
85\end{array}$ & $\begin{array}{l}87 \\
86 \\
87 \\
88 \\
88\end{array}$ & $\begin{array}{l}84 \\
85 \\
85 \\
86 \\
86\end{array}$ \\
\hline $\begin{array}{l}11 \\
12 \\
13 \\
14 \\
15\end{array}$ & $\begin{array}{l}75 \\
75 \\
72 \\
76 \\
71\end{array}$ & $\begin{array}{l}49 \\
48 \\
47 \\
49 \\
53\end{array}$ & $\begin{array}{l}46 \\
47 \\
46 \\
44 \\
43\end{array}$ & $\begin{array}{l}40 \\
39 \\
40 \\
39 \\
40\end{array}$ & $\begin{array}{l}44 \\
44 \\
44 \\
50 \\
56\end{array}$ & $\begin{array}{l}59 \\
57 \\
52 \\
53 \\
55\end{array}$ & $\begin{array}{l}68 \\
69 \\
68 \\
70 \\
67\end{array}$ & $\begin{array}{l}61 \\
60 \\
61 \\
63 \\
65\end{array}$ & $\begin{array}{l}79 \\
78 \\
80 \\
80 \\
81\end{array}$ & $\begin{array}{l}85 \\
86 \\
86 \\
86 \\
87\end{array}$ & $\begin{array}{l}89 \\
88 \\
87 \\
86 \\
87\end{array}$ & $\begin{array}{l}84 \\
83 \\
80 \\
79 \\
80\end{array}$ \\
\hline $\begin{array}{l}16 \\
17 \\
18 \\
19 \\
20\end{array}$ & $\begin{array}{l}70 \\
70 \\
70 \\
68 \\
70\end{array}$ & $\begin{array}{l}53 \\
50 \\
58 \\
60 \\
56\end{array}$ & $\begin{array}{l}42 \\
40 \\
41 \\
41 \\
41\end{array}$ & $\begin{array}{l}41 \\
44 \\
46 \\
47 \\
50\end{array}$ & $\begin{array}{l}\mathbf{5 2} \\
\mathbf{5 5} \\
\mathbf{5 5} \\
\mathbf{5 4} \\
\mathbf{5 3}\end{array}$ & $\begin{array}{l}54 \\
56 \\
58 \\
59 \\
59\end{array}$ & $\begin{array}{l}66 \\
65 \\
67 \\
69 \\
70\end{array}$ & $\begin{array}{l}64 \\
65 \\
68 \\
69 \\
68\end{array}$ & $\begin{array}{l}82 \\
82 \\
82 \\
81 \\
82\end{array}$ & $\begin{array}{l}87 \\
87 \\
83 \\
85 \\
85\end{array}$ & $\begin{array}{l}85 \\
86 \\
85 \\
86 \\
85\end{array}$ & $\begin{array}{l}81 \\
80 \\
83 \\
82 \\
80\end{array}$ \\
\hline $\begin{array}{l}21 \\
22 \\
23 \\
24 \\
25\end{array}$ & $\begin{array}{l}70 \\
72 \\
73 \\
68 \\
68\end{array}$ & $\begin{array}{l}50 \\
53 \\
46 \\
47 \\
47\end{array}$ & $\begin{array}{l}42 \\
43 \\
40 \\
40 \\
44\end{array}$ & $\begin{array}{l}45 \\
40 \\
39 \\
48 \\
49\end{array}$ & $\begin{array}{l}50 \\
50 \\
53 \\
48 \\
48\end{array}$ & $\begin{array}{l}58 \\
61 \\
63 \\
64 \\
63\end{array}$ & $\begin{array}{l}55 \\
57 \\
60 \\
65 \\
67\end{array}$ & $\begin{array}{l}68 \\
68 \\
68 \\
69 \\
70\end{array}$ & $\begin{array}{l}82 \\
82 \\
80 \\
82 \\
83\end{array}$ & $\begin{array}{l}85 \\
83 \\
84 \\
85 \\
84\end{array}$ & $\begin{array}{l}84 \\
85 \\
86 \\
87 \\
86\end{array}$ & $\begin{array}{l}79 \\
75 \\
74 \\
76 \\
78\end{array}$ \\
\hline $\begin{array}{l}26 \\
27 \\
28 \\
29 \\
30 \\
31\end{array}$ & $\begin{array}{l}67 \\
62 \\
60 \\
60 \\
61 \\
60 \\
\end{array}$ & $\begin{array}{l}48 \\
49 \\
49 \\
49 \\
50 \\
--\end{array}$ & $\begin{array}{l}43 \\
43 \\
44 \\
44 \\
45 \\
44 \\
\end{array}$ & $\begin{array}{l}50 \\
46 \\
43 \\
45 \\
49 \\
48\end{array}$ & $\begin{array}{l}51 \\
55 \\
54 \\
-- \\
-- \\
--\end{array}$ & $\begin{array}{l}63 \\
65 \\
64 \\
65 \\
61 \\
55\end{array}$ & $\begin{array}{l}68 \\
70 \\
67 \\
68 \\
69 \\
--\end{array}$ & $\begin{array}{l}70 \\
71 \\
73 \\
74 \\
75 \\
76\end{array}$ & $\begin{array}{l}82 \\
83 \\
84 \\
84 \\
84 \\
--\end{array}$ & $\begin{array}{l}84 \\
83 \\
83 \\
84 \\
85 \\
87\end{array}$ & $\begin{array}{l}87 \\
88 \\
87 \\
88 \\
85 \\
83\end{array}$ & $\begin{array}{l}78 \\
80 \\
80 \\
80 \\
80 \\
--\end{array}$ \\
\hline $\begin{array}{c}\text { Aver- } \\
\text { age }\end{array}$ & 70 & 52 & 46 & 45 & 49 & 57 & 68 & 66 & 80 & 85 & 86 & 81 \\
\hline
\end{tabular}




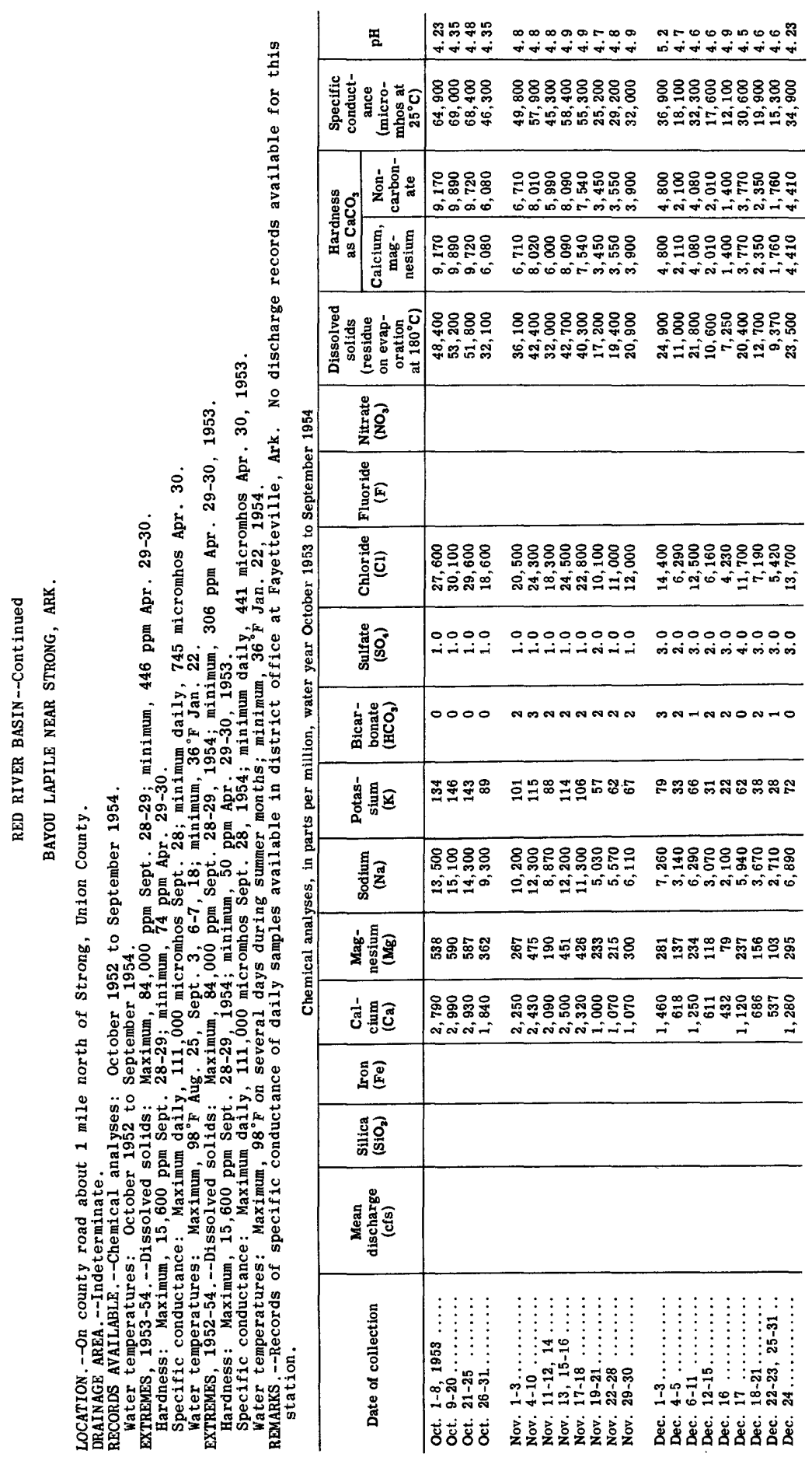




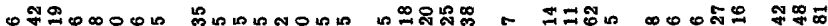

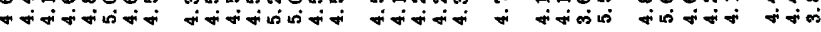

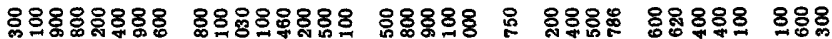

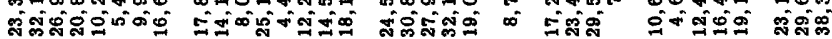

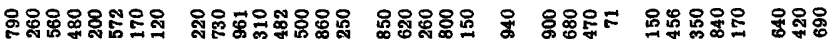

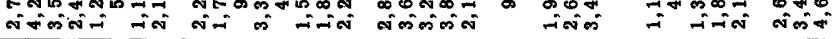

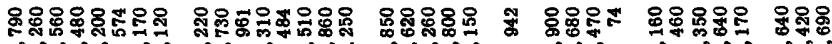

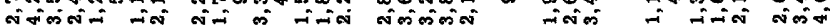

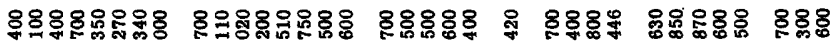

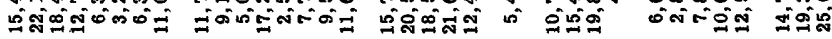

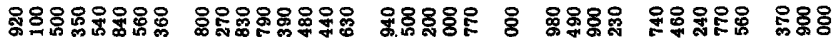

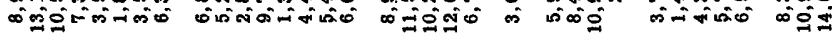

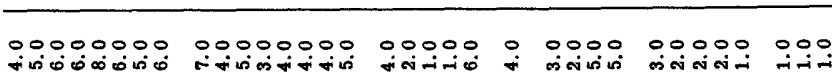

-00mmm-0 $0000 m m 0000000$ N 000 NHH00

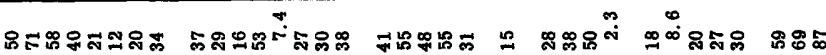

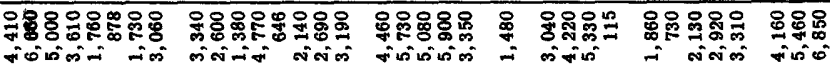

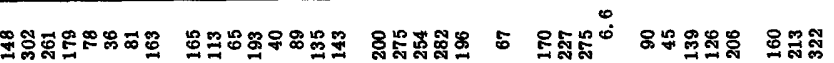

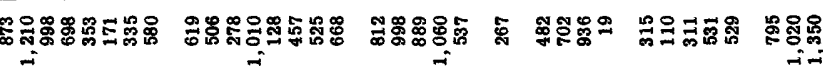

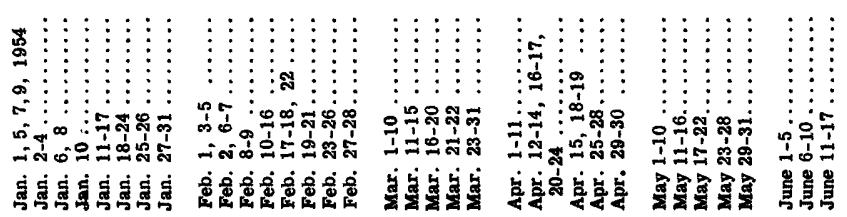

$4888170-59-17$ 


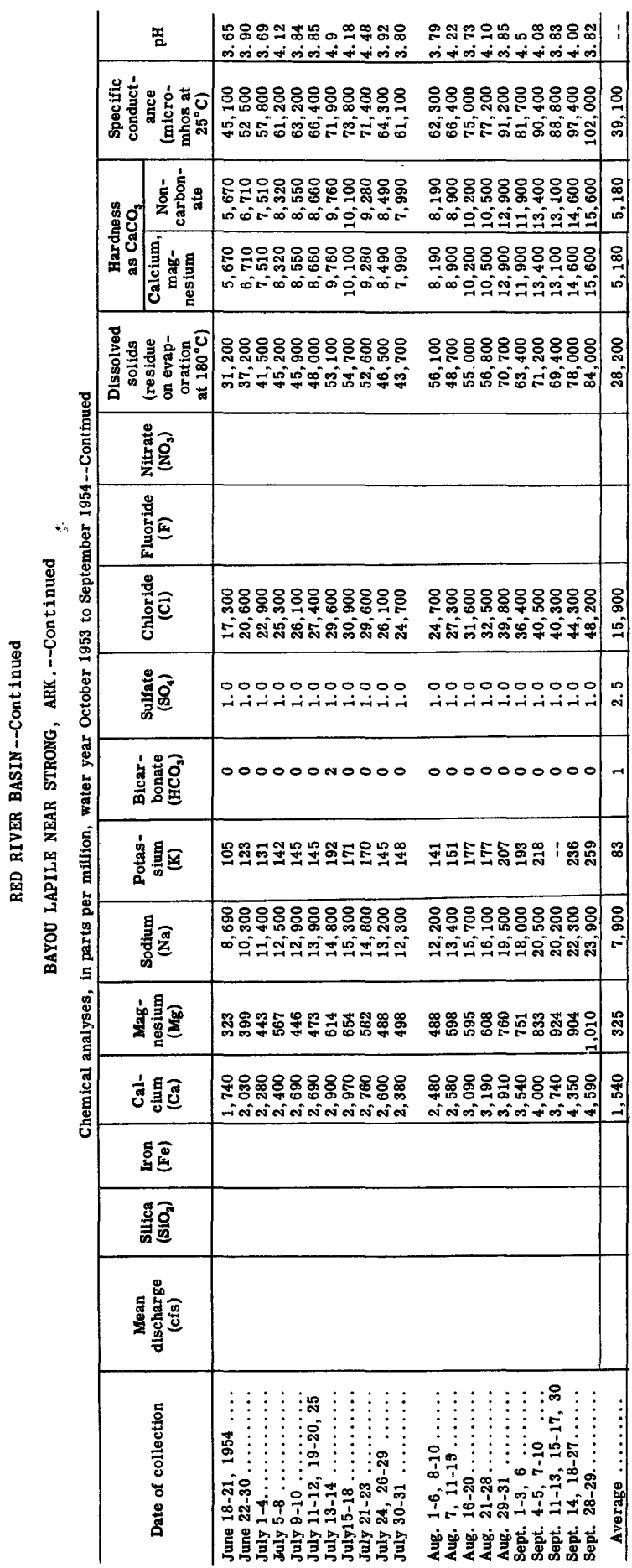


RED RIVER BASIN--Continued

BAYOU LAPILE NEAR STRONG, ARK.--Continued

Temperature $\left({ }^{\circ} \mathrm{F}\right)$ of water, water year October 1953 to September 1954

\begin{tabular}{|c|c|c|c|c|c|c|c|c|c|c|c|c|}
\hline Day & Oct. & Nov. & Dec. & Jan. & Feb. & Mar. & Apr. & May & June & July & Aug. & Sept. \\
\hline $\begin{array}{l}1 \\
2 \\
3 \\
4 \\
5\end{array}$ & $\begin{array}{l}90 \\
89 \\
91 \\
88 \\
88\end{array}$ & $\begin{array}{l}79 \\
77 \\
80 \\
78 \\
85\end{array}$ & $\begin{array}{l}69 \\
67 \\
64 \\
62 \\
63\end{array}$ & $\begin{array}{l}51 \\
49 \\
48 \\
53 \\
50\end{array}$ & $\begin{array}{l}51 \\
54 \\
52 \\
55 \\
57\end{array}$ & $\begin{array}{l}58 \\
60 \\
63 \\
55 \\
57\end{array}$ & $\begin{array}{l}60 \\
-- \\
66 \\
65 \\
69\end{array}$ & $\begin{array}{l}63 \\
60 \\
68 \\
65 \\
64\end{array}$ & $\begin{array}{l}85 \\
87 \\
78 \\
75 \\
77\end{array}$ & $\begin{array}{l}91 \\
86 \\
87 \\
89 \\
90\end{array}$ & $\begin{array}{l}81 \\
89 \\
93 \\
93 \\
83\end{array}$ & $\begin{array}{l}87 \\
74 \\
98 \\
75 \\
79\end{array}$ \\
\hline $\begin{array}{r}6 \\
7 \\
8 \\
9 \\
10\end{array}$ & $\begin{array}{l}89 \\
90 \\
90 \\
87 \\
88\end{array}$ & $\begin{array}{l}77 \\
76 \\
80 \\
95 \\
76\end{array}$ & $\begin{array}{l}64 \\
-- \\
60 \\
58 \\
59\end{array}$ & $\begin{array}{l}47 \\
49 \\
49 \\
52 \\
50\end{array}$ & $\begin{array}{l}61 \\
58 \\
59 \\
52 \\
61\end{array}$ & $\begin{array}{l}59 \\
56 \\
60 \\
63 \\
64\end{array}$ & $\begin{array}{l}71 \\
69 \\
72 \\
76 \\
77\end{array}$ & $\begin{array}{l}63 \\
67 \\
62 \\
64 \\
58\end{array}$ & $\begin{array}{l}88 \\
90 \\
89 \\
80 \\
85\end{array}$ & $\begin{array}{l}92 \\
91 \\
92 \\
90 \\
89\end{array}$ & $\begin{array}{l}93 \\
79 \\
88 \\
93 \\
79\end{array}$ & $\begin{array}{l}98 \\
98 \\
96 \\
92 \\
94\end{array}$ \\
\hline $\begin{array}{l}11 \\
12 \\
13 \\
14 \\
15\end{array}$ & $\begin{array}{l}90 \\
87 \\
88 \\
87 \\
--\end{array}$ & $\begin{array}{l}76 \\
78 \\
80 \\
81 \\
78\end{array}$ & $\begin{array}{l}-- \\
-- \\
51 \\
52 \\
--\end{array}$ & $\begin{array}{l}49 \\
50 \\
47 \\
45 \\
46\end{array}$ & $\begin{array}{l}54 \\
60 \\
63 \\
63 \\
59\end{array}$ & $\begin{array}{l}62 \\
64 \\
67 \\
59 \\
58\end{array}$ & $\begin{array}{l}61 \\
63 \\
67 \\
71 \\
73\end{array}$ & $\begin{array}{l}71 \\
69 \\
74 \\
70 \\
71\end{array}$ & $\begin{array}{l}90 \\
92 \\
90 \\
80 \\
87\end{array}$ & $\begin{array}{l}-- \\
-- \\
93 \\
91 \\
93\end{array}$ & $\begin{array}{l}94 \\
74 \\
94 \\
76 \\
86\end{array}$ & $\begin{array}{l}90 \\
74 \\
75 \\
70 \\
88\end{array}$ \\
\hline $\begin{array}{l}16 \\
17 \\
18 \\
19 \\
20\end{array}$ & $\begin{array}{l}90 \\
89 \\
89 \\
87 \\
89\end{array}$ & $\begin{array}{l}80 \\
77 \\
77 \\
74 \\
74\end{array}$ & $\begin{array}{l}49 \\
57 \\
48 \\
-- \\
56\end{array}$ & $\begin{array}{l}43 \\
45 \\
40 \\
42 \\
43\end{array}$ & $\begin{array}{l}63 \\
60 \\
58 \\
62 \\
63\end{array}$ & $\begin{array}{l}56 \\
55 \\
55 \\
57 \\
59\end{array}$ & $\begin{array}{l}76 \\
74 \\
69 \\
79 \\
74\end{array}$ & $\begin{array}{l}72 \\
75 \\
79 \\
77 \\
74\end{array}$ & $\begin{array}{l}90 \\
91 \\
81 \\
85 \\
90\end{array}$ & $\begin{array}{l}81 \\
93 \\
89 \\
82 \\
85\end{array}$ & $\begin{array}{l}93 \\
94 \\
97 \\
96 \\
96\end{array}$ & $\begin{array}{l}92 \\
92 \\
98 \\
81 \\
97\end{array}$ \\
\hline $\begin{array}{l}21 \\
22 \\
23 \\
24 \\
25\end{array}$ & $\begin{array}{l}86 \\
86 \\
85 \\
83 \\
82\end{array}$ & $\begin{array}{l}75 \\
74 \\
73 \\
72 \\
69\end{array}$ & $\begin{array}{l}46 \\
50 \\
-- \\
55 \\
53\end{array}$ & $\begin{array}{l}38 \\
36 \\
43 \\
45 \\
51\end{array}$ & $\begin{array}{l}59 \\
61 \\
63 \\
60 \\
60\end{array}$ & $\begin{array}{l}56 \\
57 \\
60 \\
61 \\
64\end{array}$ & $\begin{array}{l}79 \\
78 \\
81 \\
80 \\
69\end{array}$ & $\begin{array}{l}79 \\
80 \\
81 \\
82 \\
79\end{array}$ & $\begin{array}{l}89 \\
75 \\
90 \\
87 \\
92\end{array}$ & $\begin{array}{l}90 \\
91 \\
90 \\
92 \\
87\end{array}$ & $\begin{array}{l}93 \\
90 \\
90 \\
97 \\
98\end{array}$ & $\begin{array}{l}91 \\
84 \\
78 \\
92 \\
89\end{array}$ \\
\hline $\begin{array}{l}26 \\
27 \\
28 \\
29 \\
30 \\
31\end{array}$ & $\begin{array}{l}89 \\
88 \\
87 \\
86 \\
85 \\
88\end{array}$ & $\begin{array}{l}69 \\
71 \\
70 \\
63 \\
64 \\
--\end{array}$ & $\begin{array}{l}56 \\
55 \\
56 \\
53 \\
54 \\
58\end{array}$ & $\begin{array}{l}54 \\
49 \\
43 \\
46 \\
46 \\
45\end{array}$ & $\begin{array}{l}62 \\
60 \\
58 \\
-- \\
-- \\
--\end{array}$ & $\begin{array}{l}\mathbf{6 2} \\
60 \\
\mathbf{5 7} \\
\mathbf{5 9} \\
62 \\
54\end{array}$ & $\begin{array}{l}75 \\
74 \\
-- \\
69 \\
72 \\
--\end{array}$ & $\begin{array}{l}80 \\
80 \\
83 \\
80 \\
84 \\
85\end{array}$ & $\begin{array}{l}92 \\
85 \\
95 \\
89 \\
80 \\
--\end{array}$ & $\begin{array}{l}85 \\
90 \\
86 \\
82 \\
78 \\
75\end{array}$ & $\begin{array}{l}94 \\
95 \\
96 \\
85 \\
94 \\
93\end{array}$ & $\begin{array}{l}82 \\
83 \\
92 \\
90 \\
82 \\
--\end{array}$ \\
\hline $\begin{array}{c}\text { Aver- } \\
\text { age }\end{array}$ & 88 & 76 & 57 & 47 & 59 & 59 & 72 & 73 & 86 & 88 & 90 & 87 \\
\hline
\end{tabular}




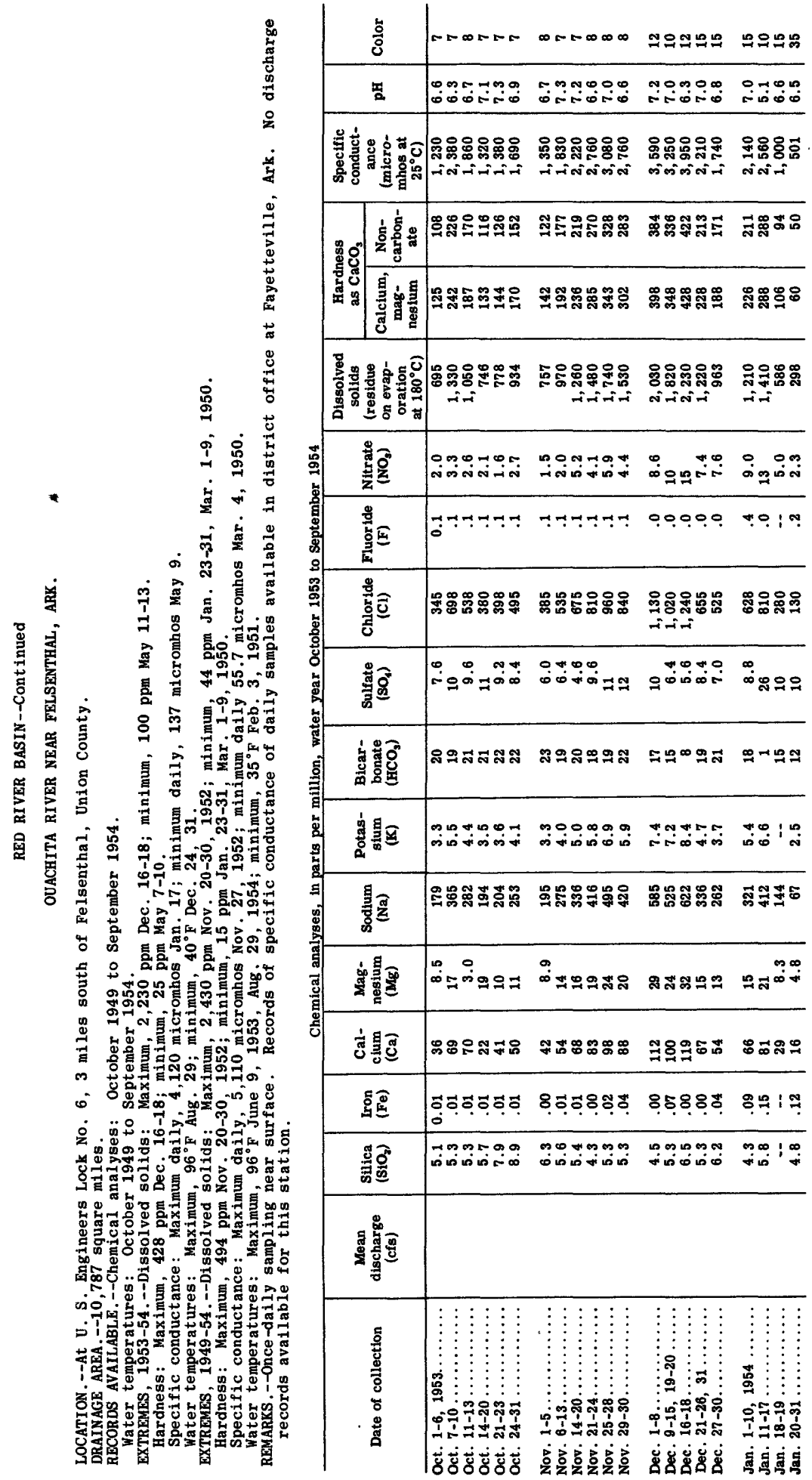




\begin{tabular}{|c|c|c|c|c|}
\hline & 䓞 & 젼 : 옹유만 & 유에 & \\
\hline & 浗 & 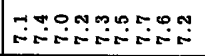 & 年 & $i$ \\
\hline & 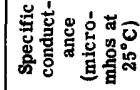 & 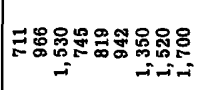 & 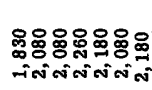 & \\
\hline & ص & 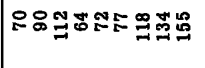 & 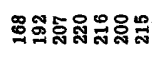 & $\sqrt[5]{-5}$ \\
\hline & 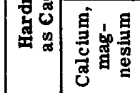 & வ & 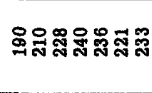 & $\stackrel{\mathscr{m}}{\sim}$ \\
\hline & 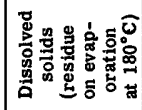 & 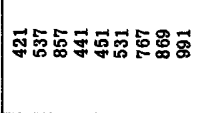 & 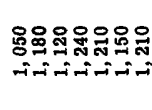 & 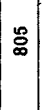 \\
\hline : & 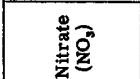 & 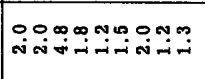 & 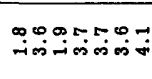 & is \\
\hline 离 & 总国 & 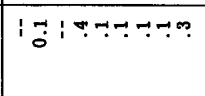 & 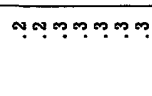 & $\begin{array}{l}1 \\
0 \\
0\end{array}$ \\
\hline $\begin{array}{ll}+ & 8 \\
0 & 0 \\
0 & 8 \\
& 8 \\
1 & 8\end{array}$ & 营 & 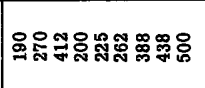 & 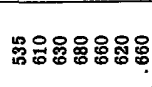 & 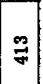 \\
\hline 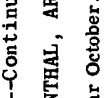 & 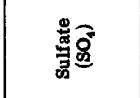 & 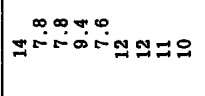 & 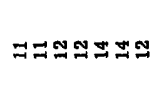 & 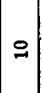 \\
\hline 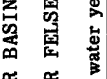 & 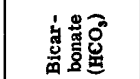 & సีส & เัสะ์ณฐณ & $\Phi$ \\
\hline 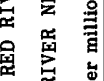 & 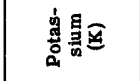 & | & 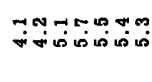 & $\left|\begin{array}{l}\infty \\
\infty \\
\infty\end{array}\right|$ \\
\hline 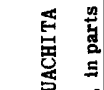 & 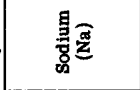 & 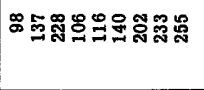 & 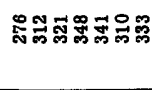 & $\overrightarrow{\vec{a}}$ \\
\hline 离 & 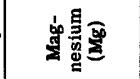 & 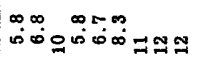 & $=9 \mathscr{9}$ & $\Rightarrow$ \\
\hline हूँ & 秀息要 & 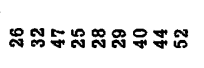 & 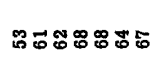 & 5 \\
\hline & 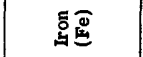 & 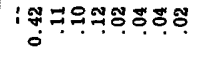 & 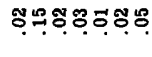 & \begin{tabular}{r}
2 \\
\hdashline \\
0
\end{tabular} \\
\hline & 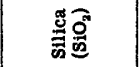 & 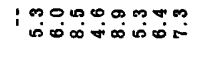 & 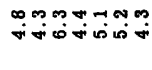 & \begin{tabular}{|c|c|}
0 \\
$i$
\end{tabular} \mid \\
\hline & 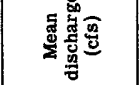 & & & \\
\hline & 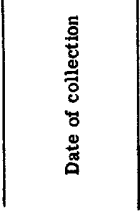 & 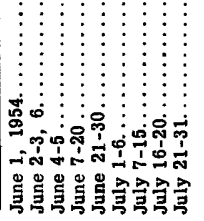 & 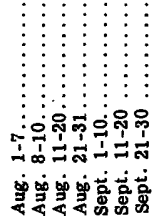 & 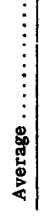 \\
\hline
\end{tabular}


RED RIVER BASIN--Continued

OUACHITA RIVER NEAR FELSENTHAL, ARK .--Continued

Temperature ( ${ }^{\circ}$ ) of water, water year October 1953 to September 1954

\begin{tabular}{|c|c|c|c|c|c|c|c|c|c|c|c|c|}
\hline Day & Oct. & Nov. & Dec. & Jan. & Feb. & Mar. & Apr. & May & June & July & Aug. & Sept. \\
\hline $\begin{array}{l}1 \\
2 \\
3 \\
4 \\
5\end{array}$ & $\begin{array}{l}80 \\
80 \\
80 \\
81 \\
80\end{array}$ & $\begin{array}{l}75 \\
67 \\
65 \\
66 \\
62\end{array}$ & $\begin{array}{l}55 \\
54 \\
55 \\
55 \\
55\end{array}$ & $\begin{array}{l}42 \\
45 \\
45 \\
46 \\
46\end{array}$ & $\begin{array}{l}-- \\
-- \\
52 \\
50 \\
54\end{array}$ & $\begin{array}{l}54 \\
55 \\
50 \\
49 \\
53\end{array}$ & $\begin{array}{l}65 \\
64 \\
69 \\
65 \\
67\end{array}$ & $\begin{array}{l}75 \\
76 \\
74 \\
67 \\
67\end{array}$ & $\begin{array}{l}80 \\
80 \\
80 \\
76 \\
76\end{array}$ & $\begin{array}{l}88 \\
89 \\
88 \\
93 \\
89\end{array}$ & $\begin{array}{l}-2 \\
86 \\
85 \\
87 \\
87\end{array}$ & $\begin{array}{l}91 \\
91 \\
92 \\
91 \\
89\end{array}$ \\
\hline $\begin{array}{r}6 \\
7 \\
8 \\
9 \\
10\end{array}$ & $\begin{array}{l}75 \\
73 \\
73 \\
73 \\
78\end{array}$ & $\begin{array}{l}62 \\
59 \\
59 \\
58 \\
61\end{array}$ & $\begin{array}{l}54 \\
48 \\
54 \\
54 \\
54\end{array}$ & $\begin{array}{l}54 \\
49 \\
51 \\
48 \\
48\end{array}$ & $\begin{array}{l}50 \\
50 \\
51 \\
51 \\
52\end{array}$ & $\begin{array}{l}50 \\
50 \\
54 \\
56 \\
51\end{array}$ & $\begin{array}{l}72 \\
68 \\
69 \\
70 \\
70\end{array}$ & $\begin{array}{l}67 \\
63 \\
67 \\
66 \\
64\end{array}$ & $\begin{array}{l}79 \\
82 \\
83 \\
85 \\
84\end{array}$ & $\begin{array}{l}89 \\
87 \\
89 \\
89 \\
88\end{array}$ & $\begin{array}{l}87 \\
87 \\
87 \\
87 \\
87\end{array}$ & $\begin{array}{l}89 \\
91 \\
91 \\
91 \\
91\end{array}$ \\
\hline $\begin{array}{l}11 \\
12 \\
13 \\
14 \\
15\end{array}$ & $\begin{array}{l}73 \\
75 \\
73 \\
73 \\
73\end{array}$ & $\begin{array}{l}-- \\
56 \\
60 \\
57 \\
63\end{array}$ & $\begin{array}{l}54 \\
50 \\
52 \\
50 \\
51\end{array}$ & $\begin{array}{l}49 \\
45 \\
45 \\
46 \\
47\end{array}$ & $\begin{array}{l}51 \\
49 \\
51 \\
52 \\
54\end{array}$ & $\begin{array}{l}64 \\
60 \\
59 \\
55 \\
55\end{array}$ & $\begin{array}{l}71 \\
70 \\
69 \\
75 \\
71\end{array}$ & $\begin{array}{l}64 \\
63 \\
64 \\
64 \\
69\end{array}$ & $\begin{array}{l}83 \\
87 \\
85 \\
86 \\
85\end{array}$ & $\begin{array}{l}88 \\
87 \\
90 \\
89 \\
87\end{array}$ & $\begin{array}{l}86 \\
87 \\
78 \\
89 \\
86\end{array}$ & $\begin{array}{l}89 \\
87 \\
89 \\
-- \\
--\end{array}$ \\
\hline $\begin{array}{l}16 \\
17 \\
18 \\
19 \\
20\end{array}$ & $\begin{array}{l}73 \\
76 \\
70 \\
74 \\
71\end{array}$ & $\begin{array}{l}55 \\
56 \\
60 \\
62 \\
60\end{array}$ & $\begin{array}{l}50 \\
46 \\
45 \\
45 \\
43\end{array}$ & $\begin{array}{l}47 \\
45 \\
45 \\
43 \\
52\end{array}$ & $\begin{array}{l}57 \\
54 \\
55 \\
55 \\
55\end{array}$ & $\begin{array}{l}58 \\
56 \\
53 \\
60 \\
59\end{array}$ & $\begin{array}{l}70 \\
67 \\
71 \\
70 \\
73\end{array}$ & $\begin{array}{l}67 \\
70 \\
69 \\
68 \\
70\end{array}$ & $\begin{array}{l}86 \\
87 \\
87 \\
85 \\
87\end{array}$ & $\begin{array}{l}89 \\
88 \\
90 \\
87 \\
88\end{array}$ & $\begin{array}{l}88 \\
88 \\
88 \\
87 \\
87\end{array}$ & $\begin{array}{l}- \\
-- \\
-- \\
--\end{array}$ \\
\hline $\begin{array}{l}21 \\
22 \\
23 \\
24 \\
25\end{array}$ & $\begin{array}{l}72 \\
71 \\
72 \\
71 \\
70\end{array}$ & $\begin{array}{l}60 \\
58 \\
53 \\
56 \\
54\end{array}$ & $\begin{array}{l}45 \\
42 \\
42 \\
40 \\
45\end{array}$ & $\begin{array}{l}-- \\
45 \\
44 \\
45 \\
48\end{array}$ & $\begin{array}{l}56 \\
55 \\
52 \\
55 \\
55\end{array}$ & $\begin{array}{l}54 \\
60 \\
61 \\
84 \\
63\end{array}$ & $\begin{array}{l}73 \\
70 \\
73 \\
70 \\
73\end{array}$ & $\begin{array}{l}66 \\
71 \\
72 \\
70 \\
72\end{array}$ & $\begin{array}{l}87 \\
88 \\
86 \\
86 \\
89\end{array}$ & $\begin{array}{l}89 \\
90 \\
90 \\
90 \\
90\end{array}$ & $\begin{array}{l}88 \\
85 \\
87 \\
85 \\
85\end{array}$ & $\begin{array}{l}80 \\
87 \\
82 \\
80 \\
82\end{array}$ \\
\hline $\begin{array}{l}26 \\
27 \\
28 \\
29 \\
30 \\
31\end{array}$ & $\begin{array}{l}-8 \\
68 \\
75 \\
65 \\
65 \\
67 \\
\end{array}$ & $\begin{array}{l}55 \\
53 \\
55 \\
54 \\
54 \\
-- \\
\end{array}$ & $\begin{array}{l}41 \\
45 \\
44 \\
45 \\
45 \\
40 \\
\end{array}$ & $\begin{array}{l}50 \\
46 \\
49 \\
47 \\
45 \\
47 \\
\end{array}$ & $\begin{array}{l}56 \\
59 \\
53 \\
-- \\
-- \\
-- \\
\end{array}$ & $\begin{array}{l}62 \\
64 \\
64 \\
65 \\
65 \\
-- \\
\end{array}$ & $\begin{array}{l}75 \\
73 \\
75 \\
75 \\
76 \\
-- \\
\end{array}$ & $\begin{array}{l}73 \\
\mathbf{7 5} \\
70 \\
\mathbf{7 4} \\
\mathbf{7 6} \\
\mathbf{7 9} \\
\end{array}$ & $\begin{array}{l}88 \\
90 \\
90 \\
90 \\
88 \\
--\end{array}$ & $\begin{array}{l}90 \\
90 \\
87 \\
88 \\
-- \\
85\end{array}$ & $\begin{array}{l}88 \\
92 \\
92 \\
96 \\
92 \\
91 \\
\end{array}$ & $\begin{array}{l}80 \\
81 \\
80 \\
83 \\
-- \\
-- \\
\end{array}$ \\
\hline $\begin{array}{c}\text { Aver- } \\
\text { age }\end{array}$ & 73 & 59 & 48 & 47 & 53 & 57 & 71 & 69 & 85 & 89 & 88 & -- \\
\hline
\end{tabular}




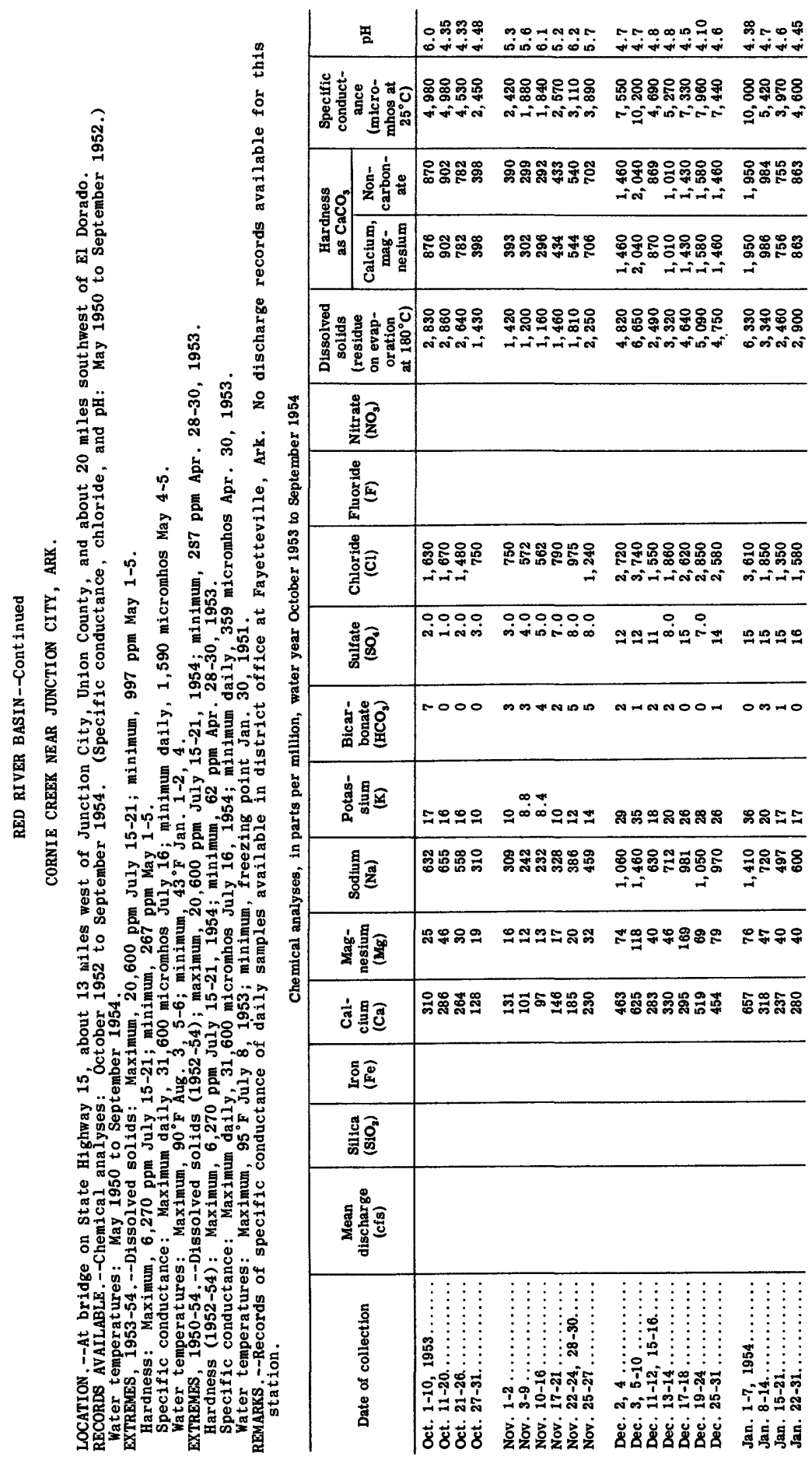




\begin{tabular}{|c|c|c|c|c|c|c|}
\hline ن & | & 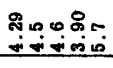 & 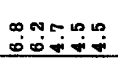 & 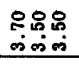 & 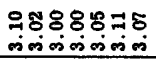 & 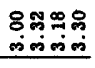 \\
\hline 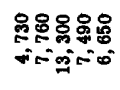 & 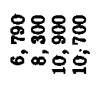 & 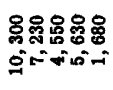 & 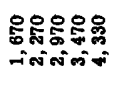 & 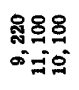 & 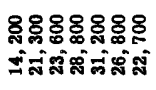 & 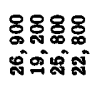 \\
\hline 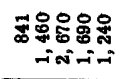 & 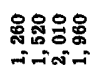 & 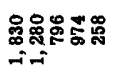 & 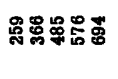 & 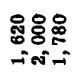 & 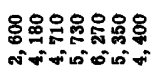 & 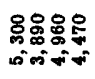 \\
\hline 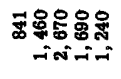 & 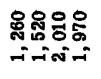 & 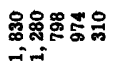 & 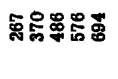 & 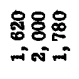 & 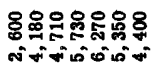 & 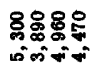 \\
\hline 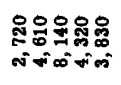 & 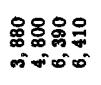 & 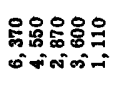 & 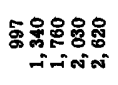 & 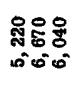 & 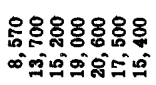 & \\
\hline
\end{tabular}

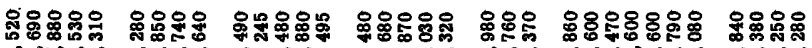

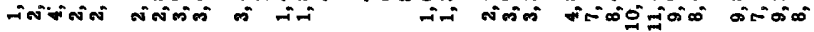

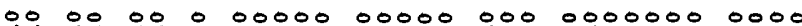
-

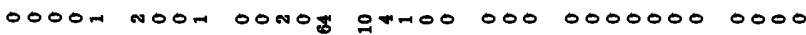

\begin{tabular}{|c|c|c|c|c|c|c|}
\hline ำเธ็ล & న令的易 & ה゙ッ & 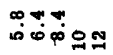 & స & 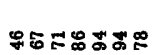 & ஃே゙ーの \\
\hline 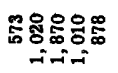 & \$융영 & 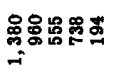 & 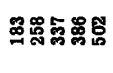 & 욤욜 & 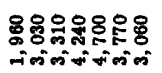 & 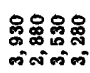 \\
\hline
\end{tabular}

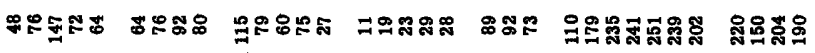

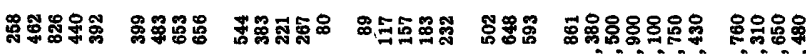

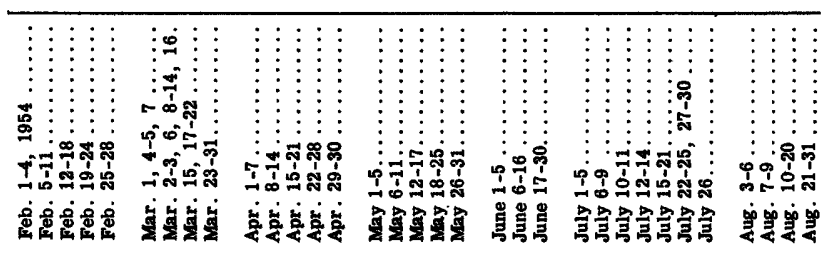




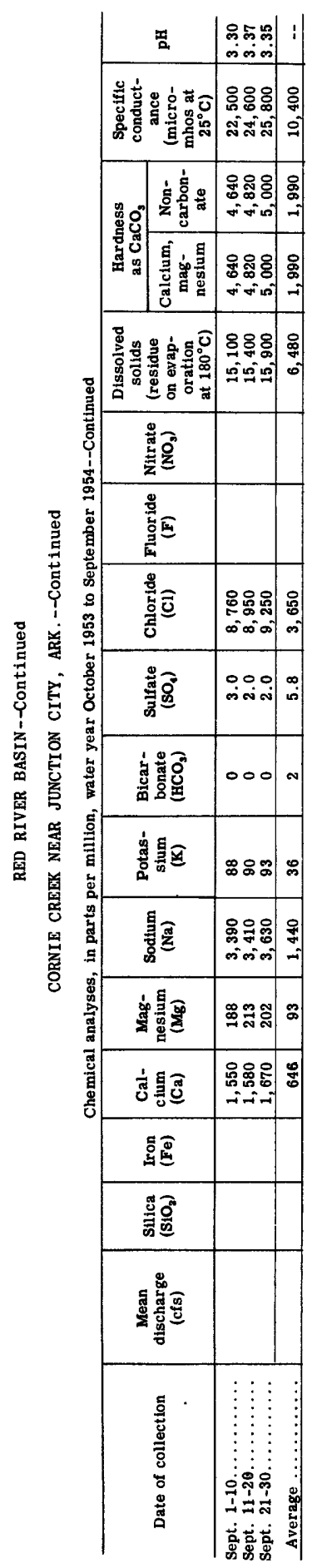


RED RIVER BASIN--Cont inued

CORNIE CREEK NEAR JUNCTION CITY, ARK.--Continued

Temperature ( ${ }^{\circ}$ ) of water, water year October 1953 to September 1954

\begin{tabular}{|c|c|c|c|c|c|c|c|c|c|c|c|c|}
\hline Day & Oct. & Nov. & Dec. & Jan. & Feb. & Mar. & Apr. & May & June & July & Aug. & Sept. \\
\hline $\begin{array}{l}1 \\
2 \\
3 \\
4 \\
5\end{array}$ & $\begin{array}{l}71 \\
73 \\
72 \\
72 \\
71\end{array}$ & $\begin{array}{l}58 \\
59 \\
59 \\
57 \\
51\end{array}$ & $\begin{array}{l}54 \\
52 \\
50 \\
50 \\
50\end{array}$ & $\begin{array}{l}43 \\
43 \\
44 \\
43 \\
45\end{array}$ & $\begin{array}{l}50 \\
51 \\
50 \\
50 \\
50\end{array}$ & $\begin{array}{l}\mathbf{5 2} \\
\mathbf{5 2} \\
\mathbf{5 0} \\
\mathbf{5 0} \\
\mathbf{5 1}\end{array}$ & $\begin{array}{l}68 \\
68 \\
70 \\
70 \\
69\end{array}$ & $\begin{array}{l}71 \\
71 \\
72 \\
73 \\
72\end{array}$ & $\begin{array}{l}80 \\
80 \\
86 \\
80 \\
79\end{array}$ & $\begin{array}{l}87 \\
87 \\
87 \\
87 \\
87\end{array}$ & $\begin{array}{l}-- \\
-- \\
90 \\
99 \\
90\end{array}$ & $\begin{array}{l}79 \\
79 \\
83 \\
83 \\
70\end{array}$ \\
\hline $\begin{array}{r}6 \\
7 \\
8 \\
9 \\
10\end{array}$ & $\begin{array}{l}71 \\
72 \\
73 \\
73 \\
75\end{array}$ & $\begin{array}{l}\mathbf{5 6} \\
\mathbf{5 6} \\
\mathbf{5 5} \\
\mathbf{5 6} \\
\mathbf{5 0}\end{array}$ & $\begin{array}{l}49 \\
49 \\
49 \\
47 \\
48\end{array}$ & $\begin{array}{l}45 \\
45 \\
45 \\
44 \\
44\end{array}$ & $\begin{array}{l}\mathbf{5 1} \\
\mathbf{5 0} \\
\mathbf{5 2} \\
\mathbf{5 2} \\
\mathbf{5 0}\end{array}$ & $\begin{array}{l}50 \\
50 \\
58 \\
56 \\
57\end{array}$ & $\begin{array}{l}70 \\
70 \\
69 \\
69 \\
69\end{array}$ & $\begin{array}{l}70 \\
68 \\
68 \\
67 \\
68\end{array}$ & $\begin{array}{l}79 \\
79 \\
80 \\
82 \\
80\end{array}$ & $\begin{array}{l}87 \\
87 \\
87 \\
68 \\
88\end{array}$ & $\begin{array}{l}90 \\
86 \\
87 \\
86 \\
88\end{array}$ & $\begin{array}{l}71 \\
73 \\
75 \\
78 \\
77\end{array}$ \\
\hline $\begin{array}{l}11 \\
12 \\
13 \\
14 \\
15\end{array}$ & $\begin{array}{l}74 \\
74 \\
75 \\
74 \\
73\end{array}$ & $\begin{array}{l}\mathbf{5 0} \\
\mathbf{5 2} \\
\mathbf{5 3} \\
\mathbf{5 2} \\
\mathbf{5 2}\end{array}$ & $\begin{array}{l}46 \\
46 \\
47 \\
46 \\
45\end{array}$ & $\begin{array}{l}45 \\
46 \\
48 \\
58 \\
48\end{array}$ & $\begin{array}{l}50 \\
52 \\
51 \\
52 \\
51\end{array}$ & $\begin{array}{l}59 \\
57 \\
56 \\
57 \\
57\end{array}$ & $\begin{array}{l}70 \\
70 \\
70 \\
70 \\
70\end{array}$ & $\begin{array}{l}68 \\
68 \\
66 \\
67 \\
65\end{array}$ & $\begin{array}{l}85 \\
85 \\
85 \\
85 \\
86\end{array}$ & $\begin{array}{l}86 \\
85 \\
85 \\
85 \\
88\end{array}$ & $\begin{array}{l}88 \\
86 \\
86 \\
86 \\
88\end{array}$ & $\begin{array}{l}77 \\
78 \\
77 \\
82 \\
80\end{array}$ \\
\hline $\begin{array}{l}16 \\
17 \\
18 \\
19 \\
20\end{array}$ & $\begin{array}{l}74 \\
74 \\
71 \\
71 \\
71\end{array}$ & $\begin{array}{l}53 \\
55 \\
55 \\
53 \\
55\end{array}$ & $\begin{array}{l}45 \\
47 \\
46 \\
47 \\
48\end{array}$ & $\begin{array}{l}48 \\
46 \\
45 \\
46 \\
46\end{array}$ & $\begin{array}{l}\mathbf{5 2} \\
\mathbf{5 1} \\
\mathbf{5 2} \\
\mathbf{5 3} \\
\mathbf{5 4}\end{array}$ & $\begin{array}{l}57 \\
59 \\
58 \\
59 \\
60\end{array}$ & $\begin{array}{l}\mathbf{7 2} \\
\mathbf{7 1} \\
\mathbf{7 2} \\
\mathbf{7 2} \\
\mathbf{7 2}\end{array}$ & $\begin{array}{l}67 \\
70 \\
72 \\
76 \\
76\end{array}$ & $\begin{array}{l}85 \\
84 \\
84 \\
83 \\
81\end{array}$ & $\begin{array}{l}87 \\
89 \\
89 \\
88 \\
88\end{array}$ & $\begin{array}{l}88 \\
87 \\
88 \\
86 \\
85\end{array}$ & $\begin{array}{l}78 \\
80 \\
80 \\
78 \\
79\end{array}$ \\
\hline $\begin{array}{l}21 \\
22 \\
23 \\
24 \\
25\end{array}$ & $\begin{array}{l}69 \\
70 \\
68 \\
68 \\
69\end{array}$ & $\begin{array}{l}54 \\
52 \\
54 \\
53 \\
51\end{array}$ & $\begin{array}{l}48 \\
50 \\
47 \\
48 \\
46\end{array}$ & $\begin{array}{l}48 \\
48 \\
50 \\
50 \\
49\end{array}$ & $\begin{array}{l}\mathbf{5 5} \\
\mathbf{5 4} \\
\mathbf{5 5} \\
\mathbf{5 5} \\
\mathbf{5 2}\end{array}$ & $\begin{array}{l}60 \\
59 \\
58 \\
59 \\
62\end{array}$ & $\begin{array}{l}72 \\
73 \\
73 \\
73 \\
74\end{array}$ & $\begin{array}{l}77 \\
76 \\
77 \\
78 \\
78\end{array}$ & $\begin{array}{l}85 \\
85 \\
86 \\
86 \\
87\end{array}$ & $\begin{array}{l}88 \\
88 \\
85 \\
80 \\
85\end{array}$ & $\begin{array}{l}86 \\
85 \\
84 \\
85 \\
85\end{array}$ & $\begin{array}{l}76 \\
76 \\
75 \\
73 \\
73\end{array}$ \\
\hline $\begin{array}{l}26 \\
27 \\
28 \\
29 \\
30 \\
31\end{array}$ & $\begin{array}{l}68 \\
66 \\
63 \\
63 \\
60 \\
58\end{array}$ & $\begin{array}{l}\mathbf{5 2} \\
52 \\
51 \\
51 \\
52 \\
--\end{array}$ & $\begin{array}{l}46 \\
45 \\
45 \\
46 \\
45 \\
45\end{array}$ & $\begin{array}{l}50 \\
48 \\
48 \\
50 \\
50 \\
51\end{array}$ & $\begin{array}{l}52 \\
52 \\
51 \\
-- \\
-- \\
--\end{array}$ & $\begin{array}{l}64 \\
64 \\
65 \\
65 \\
65 \\
65\end{array}$ & $\begin{array}{l}73 \\
73 \\
73 \\
71 \\
70 \\
-- \\
\end{array}$ & $\begin{array}{l}73 \\
73 \\
75 \\
75 \\
76 \\
75\end{array}$ & $\begin{array}{l}88 \\
88 \\
85 \\
85 \\
87 \\
--\end{array}$ & $\begin{array}{l}85 \\
87 \\
87 \\
85 \\
85 \\
--\end{array}$ & $\begin{array}{l}86 \\
85 \\
84 \\
84 \\
86 \\
86\end{array}$ & $\begin{array}{l}72 \\
74 \\
74 \\
76 \\
76 \\
--\end{array}$ \\
\hline $\begin{array}{c}\text { Aver- } \\
\text { age }\end{array}$ & 70 & 54 & 47 & 47 & 52 & 58 & 71 & 72 & 84 & 87 & 87 & 77 \\
\hline
\end{tabular}




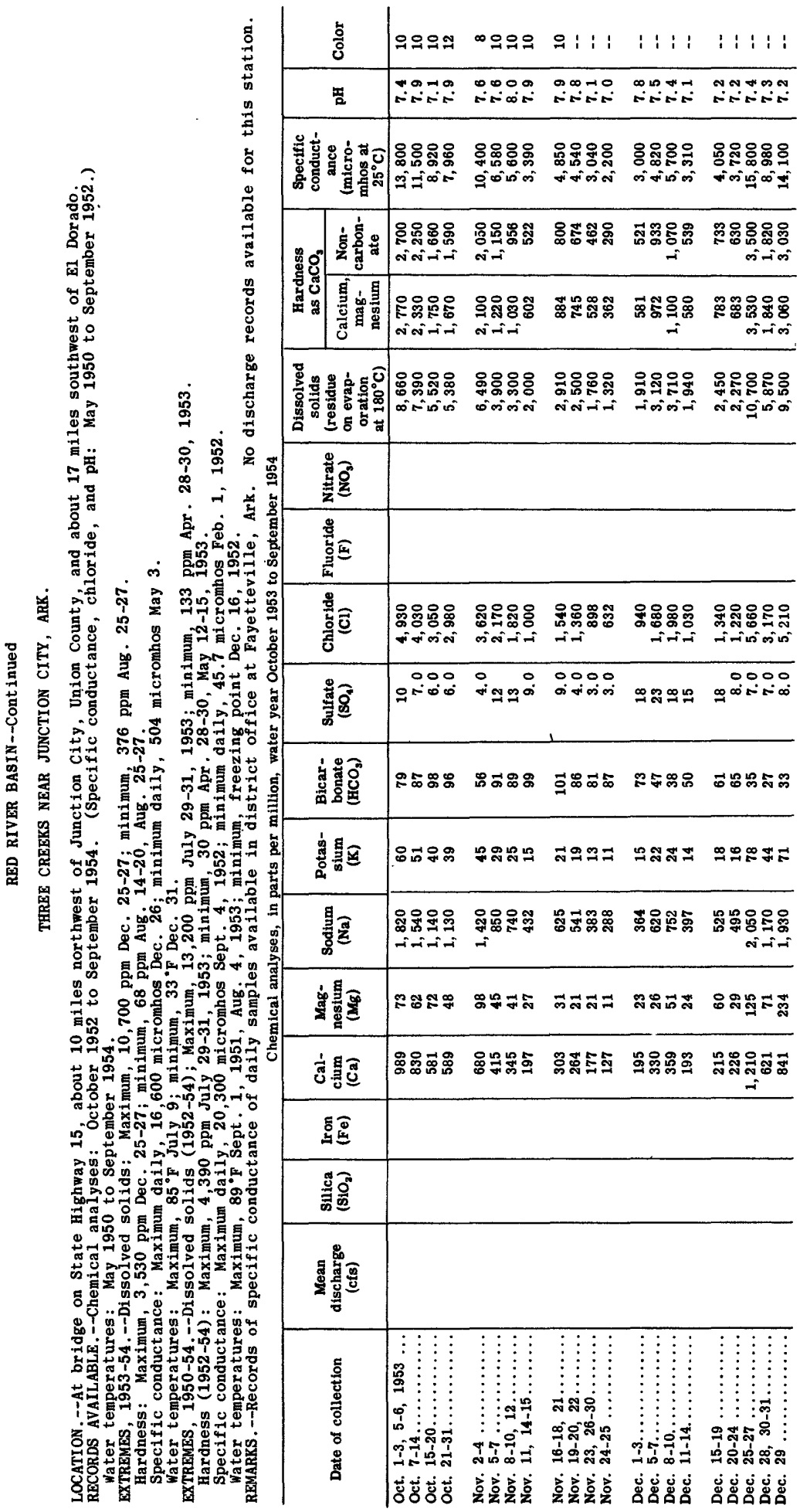




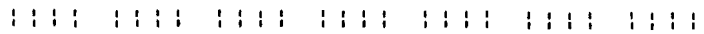

\begin{tabular}{|c|c|c|c|c|}
\hline$m$ & 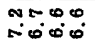 & 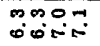 & 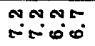 & "NN \\
\hline
\end{tabular}

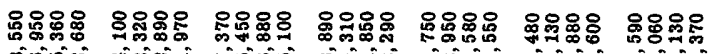

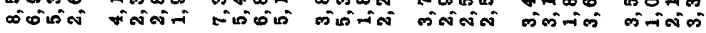

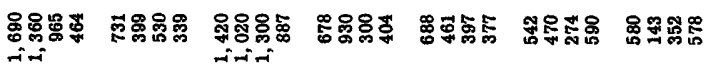
inimin

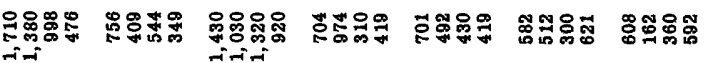

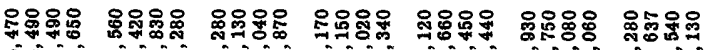

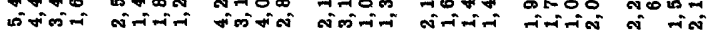

\begin{tabular}{|c|c|c|c|c|c|c|}
\hline $\begin{array}{l}\text { 骂杲最: } \\
\text { mint }\end{array}$ & 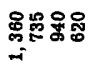 & 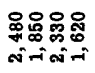 & 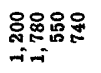 & 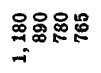 & 옹욤욤요 & 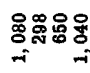 \\
\hline & & & & 워 & $\begin{array}{l}0000 \\
\text { tió. }\end{array}$ & \\
\hline
\end{tabular}

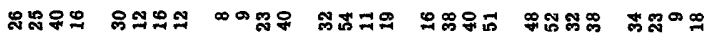

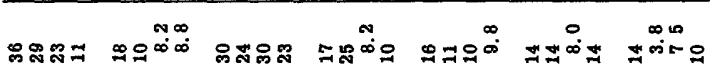

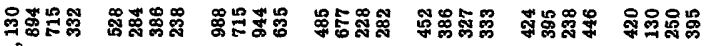
$\rightarrow$

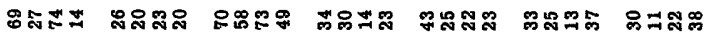

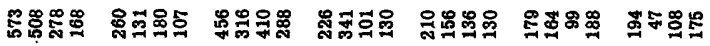

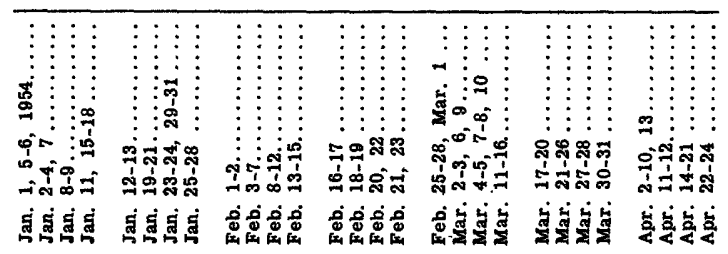




\begin{tabular}{|c|c|c|c|c|c|c|c|c|c|}
\hline & 总 & $\begin{array}{llll}1 & 1 & 1 & 1\end{array}$ & $1: 1:$ & $:: 1:$ & i $11: 1$ & : i i : & $\begin{array}{llll} & 1 & 1 & 1\end{array}$ & $1: 1: 1$ & : : : : : \\
\hline & 폄 & $\mid \begin{array}{ll}\because 100 \\
\therefore=00\end{array}$ & $\begin{array}{l}\text { meme } \\
\text { ivis: }\end{array}$ & 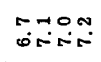 & 我o & 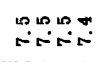 & 車 & $\stackrel{m}{*}=$ & $\begin{array}{l}0 \\
\infty \\
\infty\end{array}$ \\
\hline & 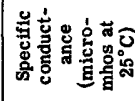 & 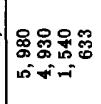 & 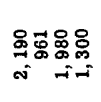 & 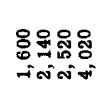 & 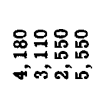 & 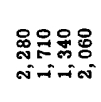 & 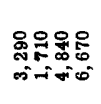 & 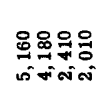 & $\begin{array}{l}\text { 옹영용요 } \\
-1-7\end{array}$ \\
\hline & 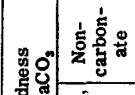 & 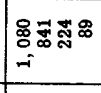 & 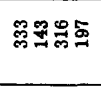 & 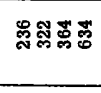 & 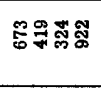 & క్టిత్తి: & 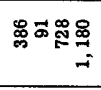 & 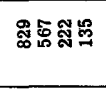 & 9000 \\
\hline & 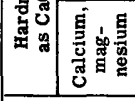 & 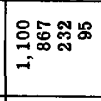 & 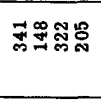 & స్సిల్లుల్లి & 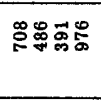 & & 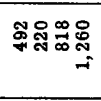 & ఫ゙ં & 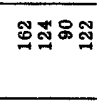 \\
\hline : & 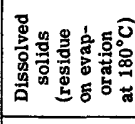 & 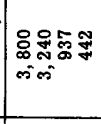 & 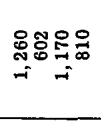 & 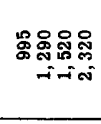 & $\begin{array}{l}\text { 웅영 } \\
\text { Nitition }\end{array}$ & 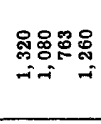 & 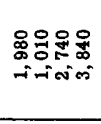 & 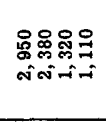 & 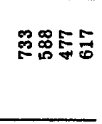 \\
\hline 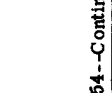 & 逽 & & & & & & & & \\
\hline 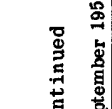 & 韋部 & & & & & & & & \\
\hline 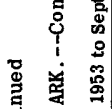 & 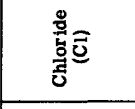 & 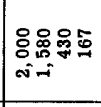 & 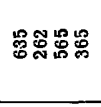 & 点웒윤영 & 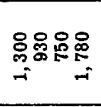 & 导总嵒品品 & 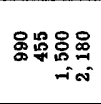 & 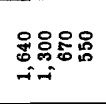 & 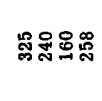 \\
\hline 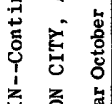 & 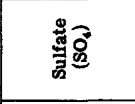 & 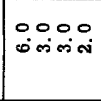 & 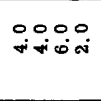 & $\begin{array}{l}0000 \\
\text { tistivi }\end{array}$ & $\therefore$ & $\begin{array}{l}0000 \\
\text { is is } 0 \text { \% }\end{array}$ & $\begin{array}{l}0000 \\
0009 \\
\text { 150 }\end{array}$ & $\begin{array}{l}0000 \\
\text { in in }\end{array}$ & $\begin{array}{l}0000 \\
\text { isiogio }\end{array}$ \\
\hline 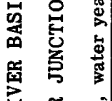 & 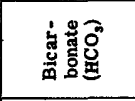 & సన ळ్లం & $900 \Omega$ & 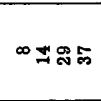 & 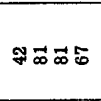 & 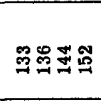 & 品: & 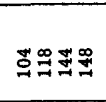 & 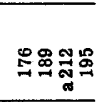 \\
\hline 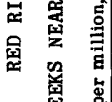 & 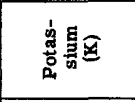 & 我文 & 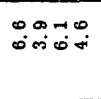 & 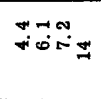 & 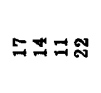 & $=$ के & $\stackrel{\infty}{\infty} \stackrel{\infty}{\infty} \stackrel{\infty}{\sim}$ & 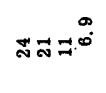 & 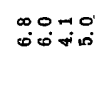 \\
\hline 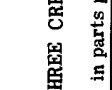 & 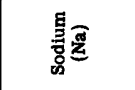 & 员哭三苛 & 品哩 స్తు & 饮 & 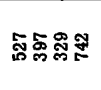 & 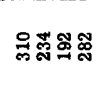 & 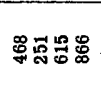 & 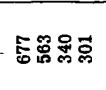 & 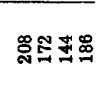 \\
\hline 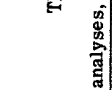 & 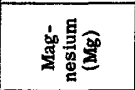 & 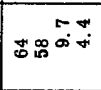 & 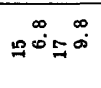 & 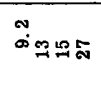 & 层 & $\underset{9 \infty}{\infty}$ & ส & ㅇㅗㅀㅛㄱㄲㅗ & 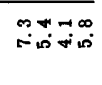 \\
\hline $\overrightarrow{\mathrm{s}}$ & 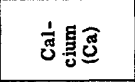 & 品哭に心 & 껵 유뮤. & 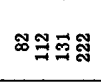 & 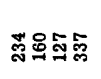 & 总怘品む & 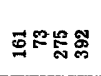 & 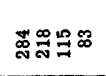 & ஜొ \\
\hline & 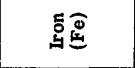 & & & & & & & & \\
\hline & 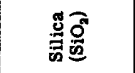 & & & & & & & & \\
\hline & 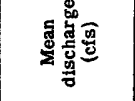 & & & & & & & & \\
\hline & 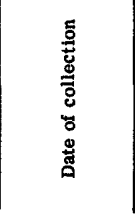 & 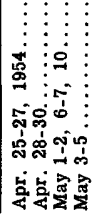 & 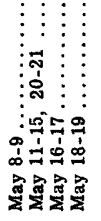 & 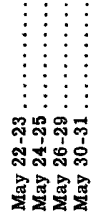 & 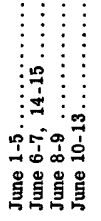 & 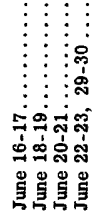 & 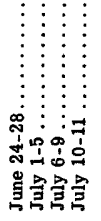 & 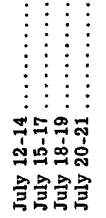 & 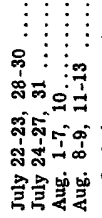 \\
\hline
\end{tabular}




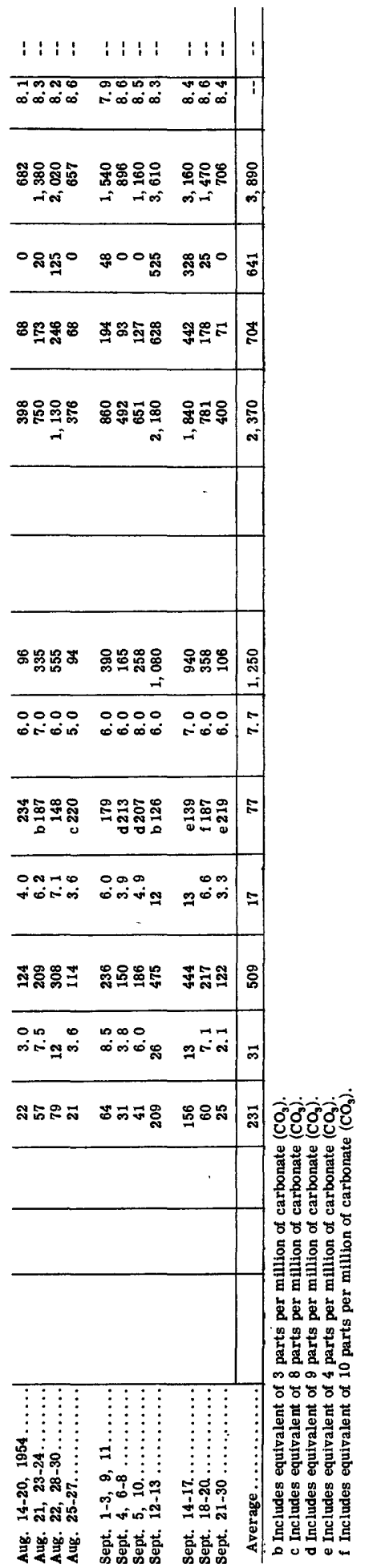


RED RIVER BASIN--Continued

THREE CREEKS NEAR JUNCTION CITY, ARK.--Continued

Temperature $\left({ }^{\circ} \mathrm{F}\right)$ of water, water year October 1953 to September 1954

\begin{tabular}{|c|c|c|c|c|c|c|c|c|c|c|c|c|}
\hline Day & Oct. & Nov. & Dec. & Jan. & Feb. & Mar. & Apr. & May & June & July & Aug. & Sept. \\
\hline $\begin{array}{l}1 \\
2 \\
3 \\
4 \\
5\end{array}$ & $\begin{array}{l}75 \\
75 \\
78 \\
79 \\
76\end{array}$ & $\begin{array}{l}\mathbf{5 5} \\
\mathbf{5 7} \\
\mathbf{5 9} \\
\mathbf{5 9} \\
\mathbf{5 5}\end{array}$ & $\begin{array}{l}51 \\
53 \\
52 \\
49 \\
47\end{array}$ & $\begin{array}{l}35 \\
39 \\
44 \\
44 \\
39\end{array}$ & $\begin{array}{l}45 \\
46 \\
45 \\
45 \\
45\end{array}$ & $\begin{array}{l}46 \\
47 \\
45 \\
37 \\
43\end{array}$ & $\begin{array}{l}46 \\
50 \\
56 \\
64 \\
65\end{array}$ & $\begin{array}{l}68 \\
70 \\
60 \\
53 \\
56\end{array}$ & $\begin{array}{l}75 \\
75 \\
75 \\
68 \\
65\end{array}$ & $\begin{array}{l}-- \\
-- \\
-- \\
--\end{array}$ & $\begin{array}{l}78 \\
79 \\
79 \\
79 \\
79\end{array}$ & $\begin{array}{l}74 \\
72 \\
70 \\
75 \\
76\end{array}$ \\
\hline $\begin{array}{r}6 \\
7 \\
8 \\
9 \\
10\end{array}$ & $\begin{array}{l}75 \\
64 \\
60 \\
60 \\
61\end{array}$ & $\begin{array}{l}49 \\
50 \\
48 \\
47 \\
46\end{array}$ & $\begin{array}{l}46 \\
44 \\
45 \\
47 \\
47\end{array}$ & $\begin{array}{l}38 \\
38 \\
43 \\
46 \\
47\end{array}$ & $\begin{array}{l}46 \\
44 \\
40 \\
42 \\
45\end{array}$ & $\begin{array}{r}42 \\
44 \\
46 \\
45 \\
51\end{array}$ & $\begin{array}{l}67 \\
68 \\
66 \\
63 \\
68\end{array}$ & $\begin{array}{l}56 \\
57 \\
60 \\
63 \\
60\end{array}$ & $\begin{array}{l}69 \\
72 \\
73 \\
75 \\
75\end{array}$ & $\begin{array}{l}-- \\
-- \\
-\overline{85} \\
83\end{array}$ & $\begin{array}{l}79 \\
78 \\
81 \\
80 \\
76\end{array}$ & $\begin{array}{l}75 \\
75 \\
73 \\
76 \\
72\end{array}$ \\
\hline $\begin{array}{l}11 \\
12 \\
13 \\
14 \\
15\end{array}$ & $\begin{array}{l}62 \\
63 \\
64 \\
66 \\
66\end{array}$ & $\begin{array}{l}44 \\
44 \\
44 \\
44 \\
44\end{array}$ & $\begin{array}{l}49 \\
49 \\
45 \\
45 \\
42\end{array}$ & $\begin{array}{l}35 \\
36 \\
37 \\
41 \\
49\end{array}$ & $\begin{array}{l}53 \\
46 \\
48 \\
50 \\
60\end{array}$ & $\begin{array}{l}59 \\
60 \\
60 \\
49 \\
46\end{array}$ & $\begin{array}{l}66 \\
66 \\
64 \\
68 \\
69\end{array}$ & $\begin{array}{l}\mathbf{5 9} \\
\mathbf{5 9} \\
\mathbf{5 9} \\
\mathbf{6 0} \\
\mathbf{6 0}\end{array}$ & $\begin{array}{l}75 \\
76 \\
76 \\
76 \\
76\end{array}$ & $\begin{array}{l}82 \\
81 \\
82 \\
83 \\
82\end{array}$ & $\begin{array}{l}73 \\
73 \\
72 \\
74 \\
76\end{array}$ & $\begin{array}{l}70 \\
69 \\
69 \\
69 \\
69\end{array}$ \\
\hline $\begin{array}{l}16 \\
17 \\
18 \\
19 \\
20\end{array}$ & $\begin{array}{l}64 \\
63 \\
62 \\
62 \\
62\end{array}$ & $\begin{array}{l}47 \\
49 \\
53 \\
57 \\
54\end{array}$ & $\begin{array}{l}43 \\
41 \\
42 \\
41 \\
43\end{array}$ & $\begin{array}{l}49 \\
47 \\
46 \\
48 \\
55\end{array}$ & $\begin{array}{l}59 \\
56 \\
56 \\
54 \\
46\end{array}$ & $\begin{array}{l}45 \\
59 \\
54 \\
54 \\
55\end{array}$ & $\begin{array}{l}64 \\
59 \\
59 \\
59 \\
62\end{array}$ & $\begin{array}{l}62 \\
64 \\
64 \\
64 \\
62\end{array}$ & $\begin{array}{l}77 \\
78 \\
78 \\
77 \\
76\end{array}$ & $\begin{array}{l}81 \\
82 \\
82 \\
82 \\
81\end{array}$ & $\begin{array}{l}77 \\
79 \\
79 \\
79 \\
80\end{array}$ & $\begin{array}{l}67 \\
76 \\
76 \\
75 \\
75\end{array}$ \\
\hline $\begin{array}{l}21 \\
22 \\
23 \\
24 \\
25\end{array}$ & $\begin{array}{l}62 \\
60 \\
64 \\
65 \\
64\end{array}$ & $\begin{array}{l}49 \\
49 \\
45 \\
52 \\
45\end{array}$ & $\begin{array}{l}46 \\
43 \\
38 \\
36 \\
36\end{array}$ & $\begin{array}{l}50 \\
42 \\
39 \\
41 \\
49\end{array}$ & $\begin{array}{l}47 \\
46 \\
52 \\
47 \\
48\end{array}$ & $\begin{array}{l}45 \\
44 \\
60 \\
65 \\
65\end{array}$ & $\begin{array}{l}63 \\
65 \\
68 \\
65 \\
67\end{array}$ & $\begin{array}{l}59 \\
60 \\
61 \\
64 \\
69\end{array}$ & $\begin{array}{l}75 \\
79 \\
80 \\
80 \\
81\end{array}$ & $\begin{array}{l}80 \\
80 \\
81 \\
80 \\
80\end{array}$ & $\begin{array}{l}80 \\
79 \\
79 \\
76 \\
76\end{array}$ & $\begin{array}{l}75 \\
72 \\
70 \\
69 \\
69\end{array}$ \\
\hline $\begin{array}{l}26 \\
27 \\
28 \\
29 \\
30 \\
31\end{array}$ & $\begin{array}{l}64 \\
59 \\
54 \\
52 \\
54 \\
54\end{array}$ & $\begin{array}{l}44 \\
42 \\
43 \\
46 \\
46 \\
--\end{array}$ & $\begin{array}{l}36 \\
37 \\
40 \\
46 \\
34 \\
33\end{array}$ & $\begin{array}{l}53 \\
53 \\
53 \\
48 \\
51 \\
49\end{array}$ & $\begin{array}{l}48 \\
58 \\
56 \\
-- \\
-- \\
--\end{array}$ & $\begin{array}{l}58 \\
60 \\
58 \\
62 \\
64 \\
55\end{array}$ & $\begin{array}{l}69 \\
69 \\
74 \\
70 \\
72 \\
--\end{array}$ & $\begin{array}{l}69 \\
70 \\
71 \\
72 \\
72 \\
72\end{array}$ & $\begin{array}{l}81 \\
81 \\
\ldots \\
-- \\
-- \\
--\end{array}$ & $\begin{array}{l}79 \\
80 \\
79 \\
79 \\
78 \\
77\end{array}$ & $\begin{array}{l}77 \\
77 \\
77 \\
76 \\
75 \\
-\end{array}$ & $\begin{array}{l}69 \\
68 \\
68 \\
67 \\
68 \\
--\end{array}$ \\
\hline $\begin{array}{c}\text { Aver- } \\
\text { age }\end{array}$ & 64 & 49 & 43 & 45 & 49 & 52 & 64 & 63 & 76 & -- & 77 & 72 \\
\hline
\end{tabular}




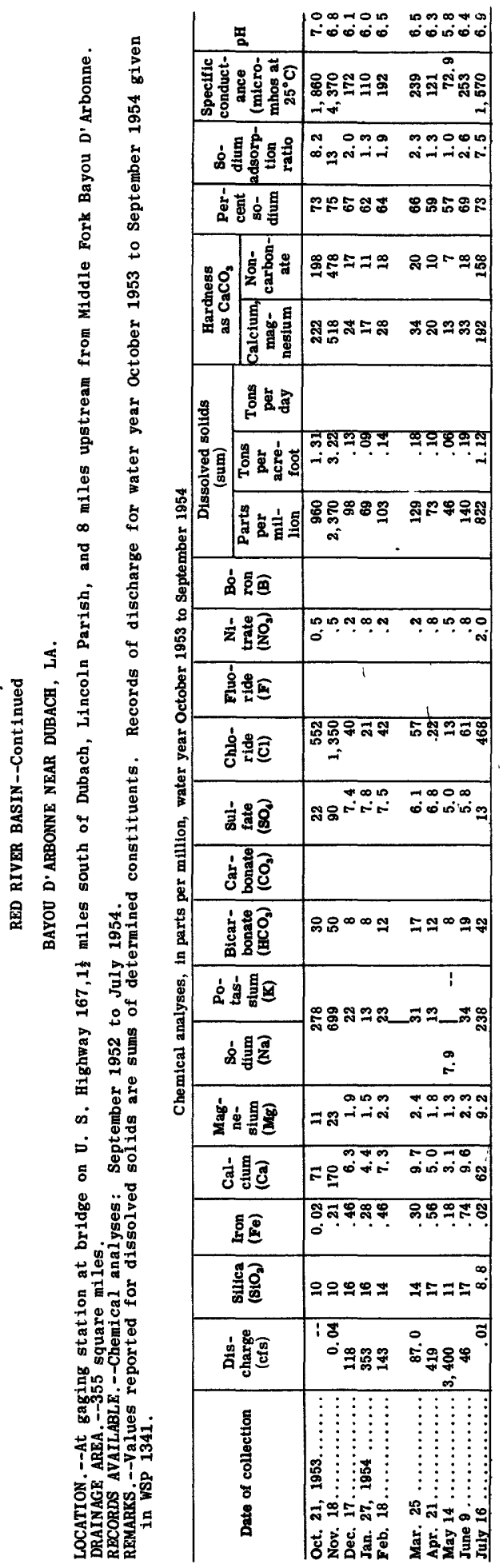




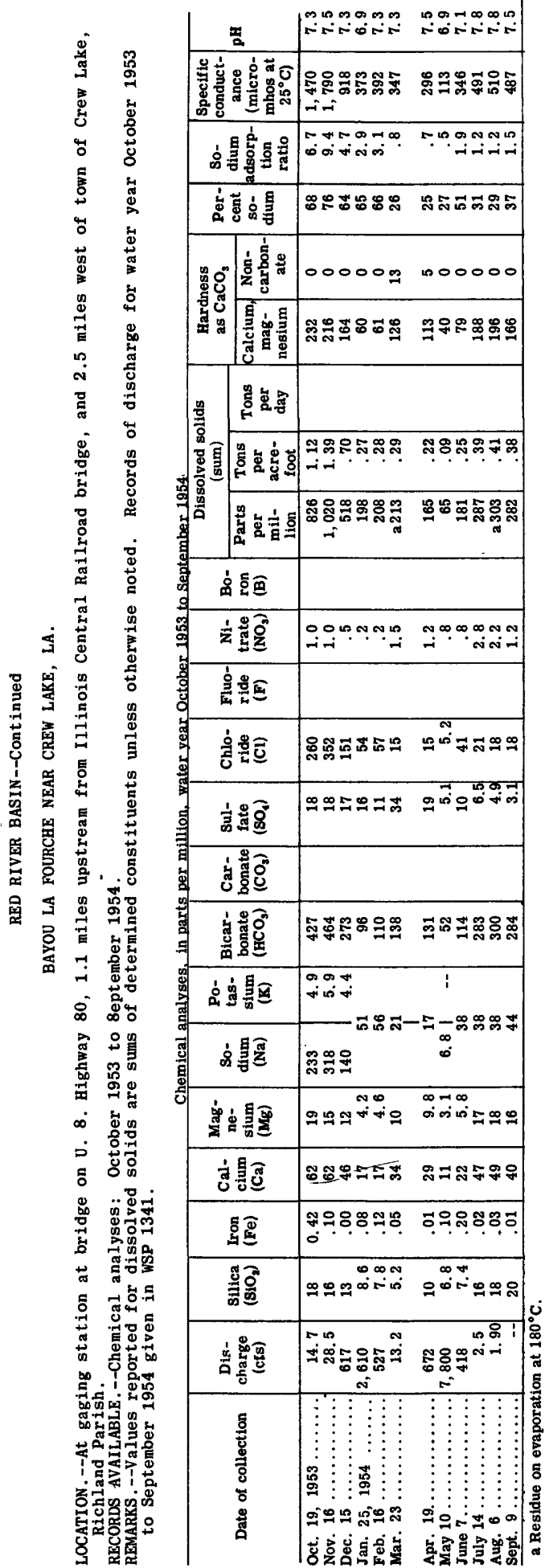




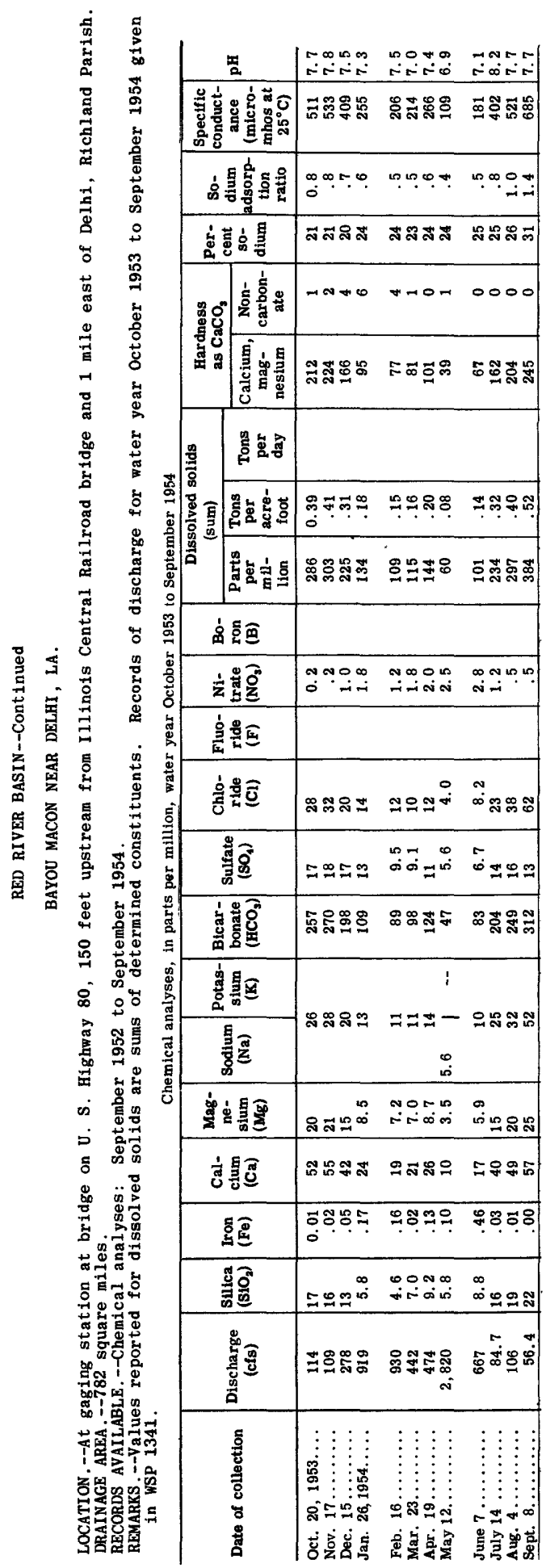




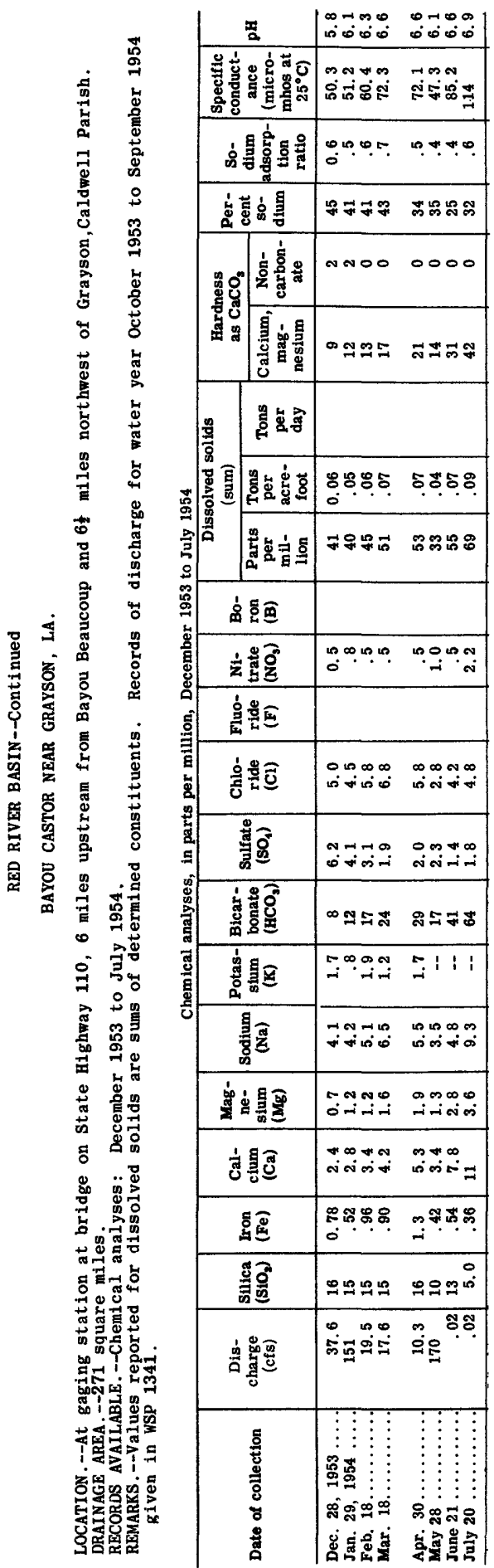




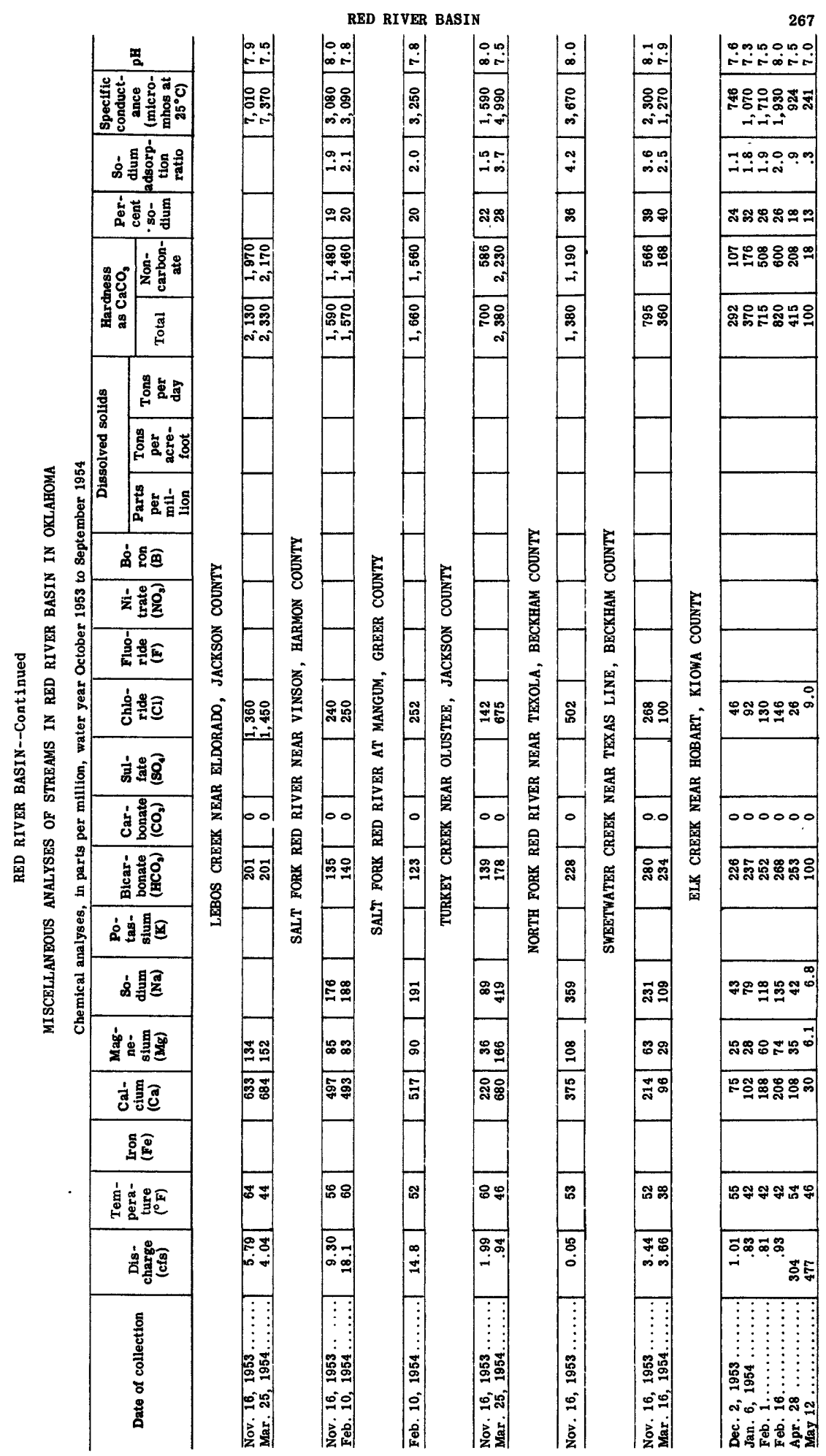




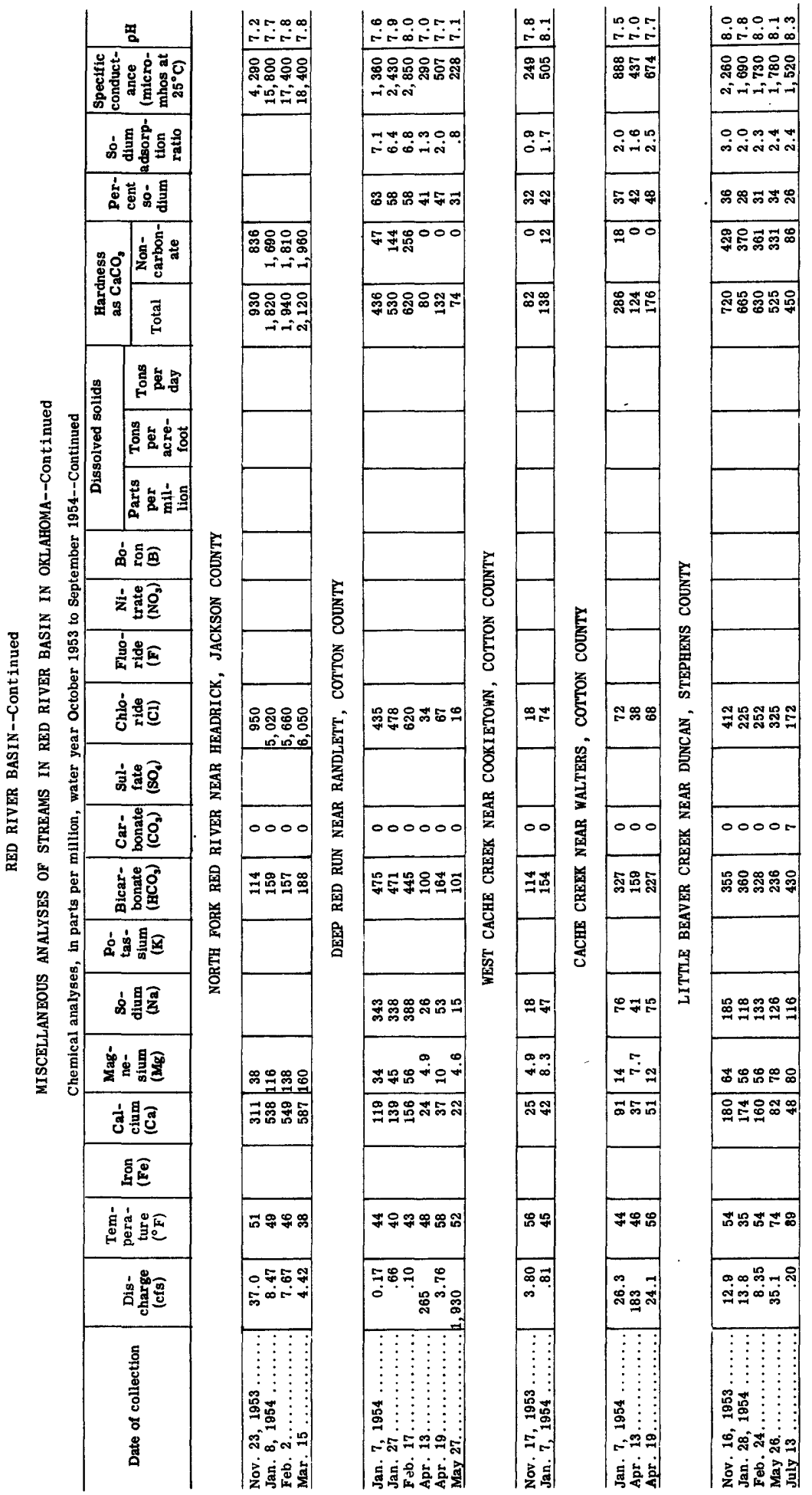


RED RIVER BASIN

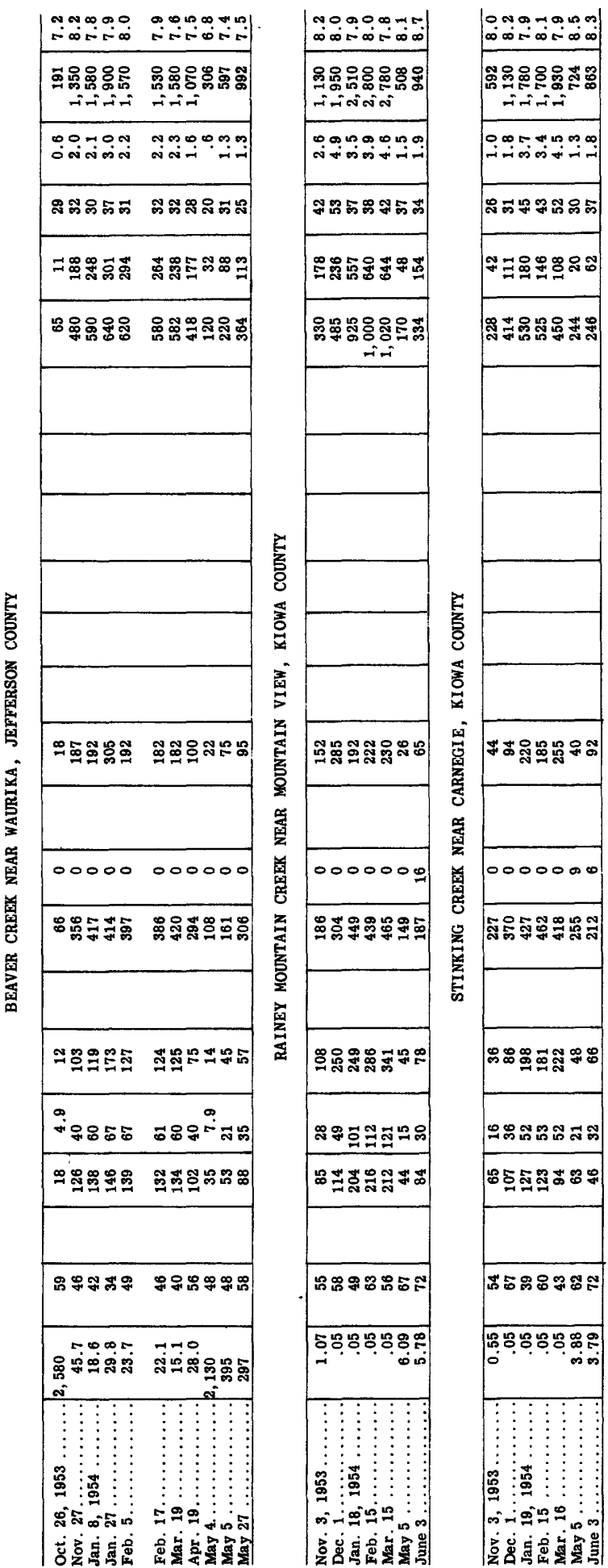




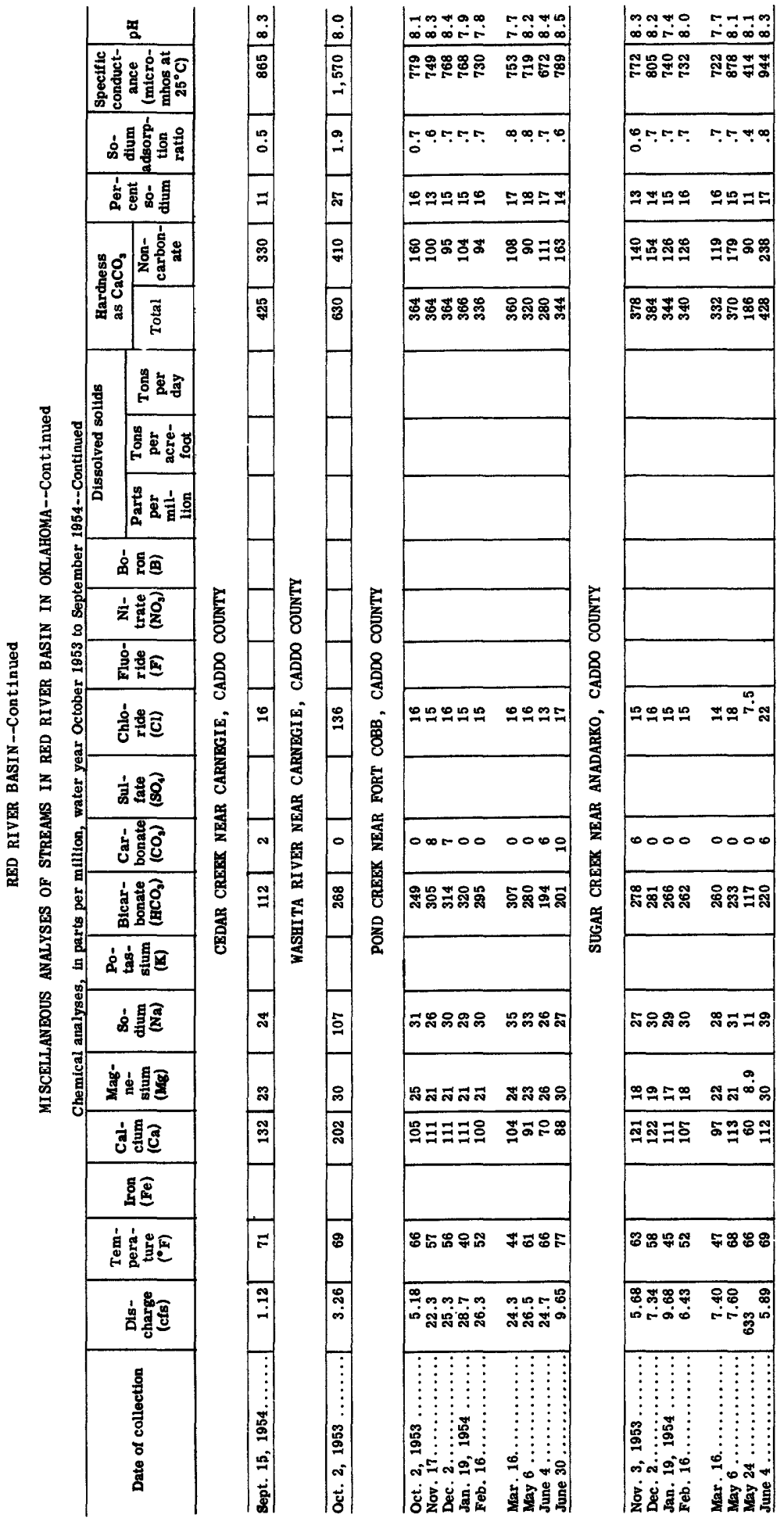




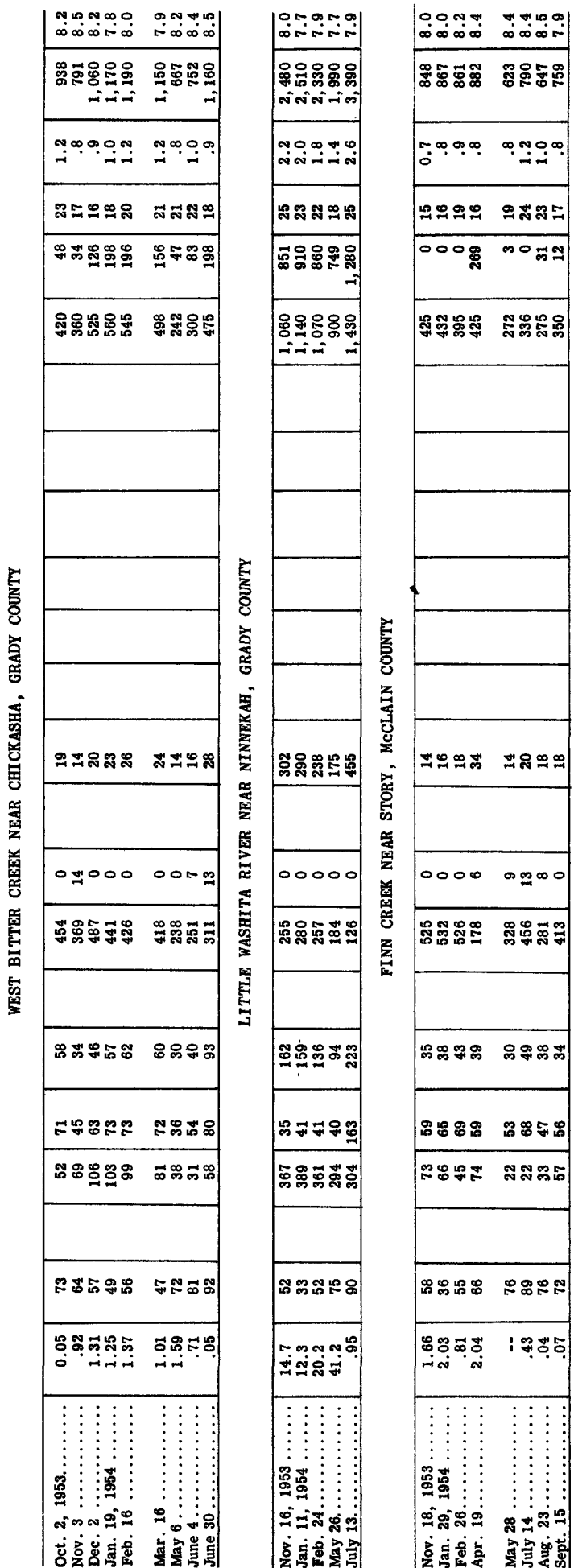




\begin{tabular}{|c|c|c|c|c|c|c|c|c|}
\hline & 国 & & 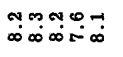 & 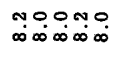 & $\vec{\infty} \vec{\infty} \vec{\infty}+\vec{\infty} \infty \vec{\infty}$ & 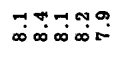 & 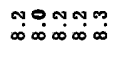 & 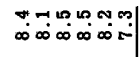 \\
\hline & 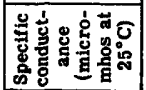 & & 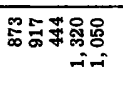 & 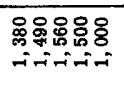 & 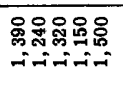 & 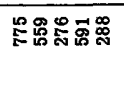 & 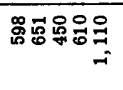 & 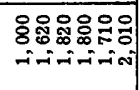 \\
\hline & 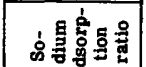 & & بْ & 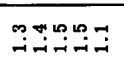 & 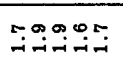 & بִ & تج & 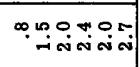 \\
\hline & 离葶宫量 & & 졿 ભ & สมกสมส & 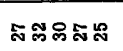 & 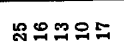 & 똠묘워어묘 & உన్సనంలి \\
\hline & 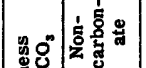 & & 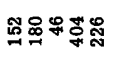 & 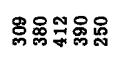 & 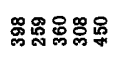 & 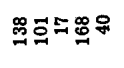 & 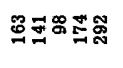 & 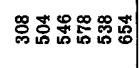 \\
\hline & 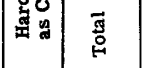 & & 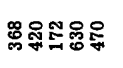 & 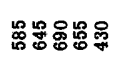 & 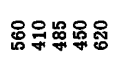 & 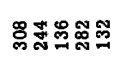 & 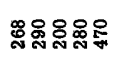 & 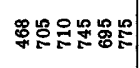 \\
\hline & 总 & & & & & & & \\
\hline 胥 & 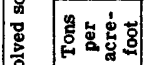 & & & & & & & \\
\hline $\begin{array}{ll}0 & 0 \\
1 & \vdots \\
1 & \end{array}$ & 曾 & & & & & & & \\
\hline 䟵 & 富莒魚 & 案 & & & & & & \\
\hline & 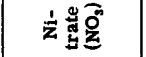 & $z$ & & & & & & \\
\hline 急 & 总量国 & 茯 & & & & & & \\
\hline 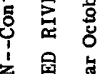 & 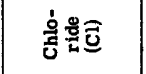 & $\stackrel{3}{3}$ & お品怘む゙ & ప゙ & 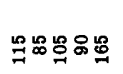 & ชะกำ & 尺゚゙ニ゙゚ & 吅워 \\
\hline z & 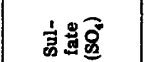 & 点 & & & & & & \\
\hline 番 & ป & 商 & 00000 & 00000 & 00000 & 00000 & 00000 & $-0 \cong-0$ \\
\hline $\begin{array}{ll}5 \\
5\end{array}$ & : & 嵹 & 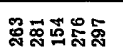 & 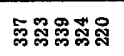 & 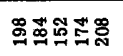 & 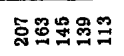 & 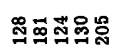 & 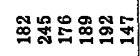 \\
\hline 热 & 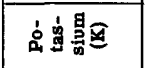 & $\stackrel{5}{5}$ & & & & & & \\
\hline 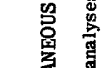 & 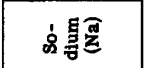 & & タ여ㅇㅛㅇㅀ & 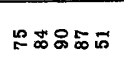 & 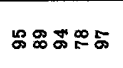 & テホง & テジのずす & 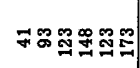 \\
\hline 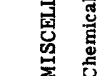 & 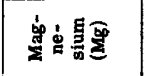 & & 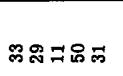 & 禺承我占品 & 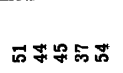 & 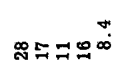 & $\stackrel{\sim}{2} \stackrel{\circ}{\infty} \infty$ & 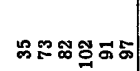 \\
\hline & 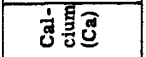 & & 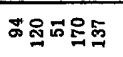 & 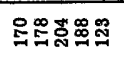 & 윰웛워워 & 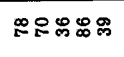 & 心 & 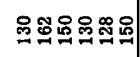 \\
\hline & 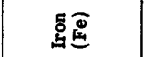 & & & & & & & \\
\hline & 跑起 & & 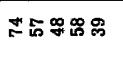 & 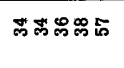 & 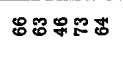 & 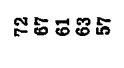 & 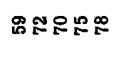 & ฉ \\
\hline & 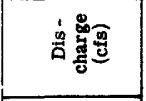 & & 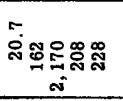 & ఊ & 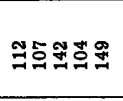 & 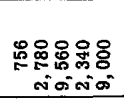 & 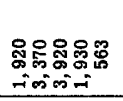 & 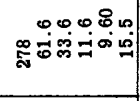 \\
\hline & 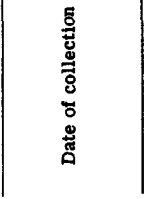 & & 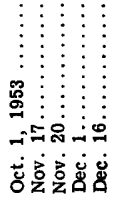 & 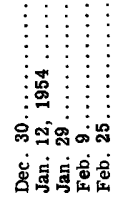 & 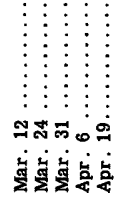 & 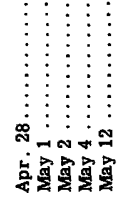 & 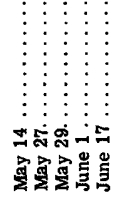 & 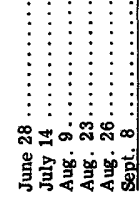 \\
\hline
\end{tabular}




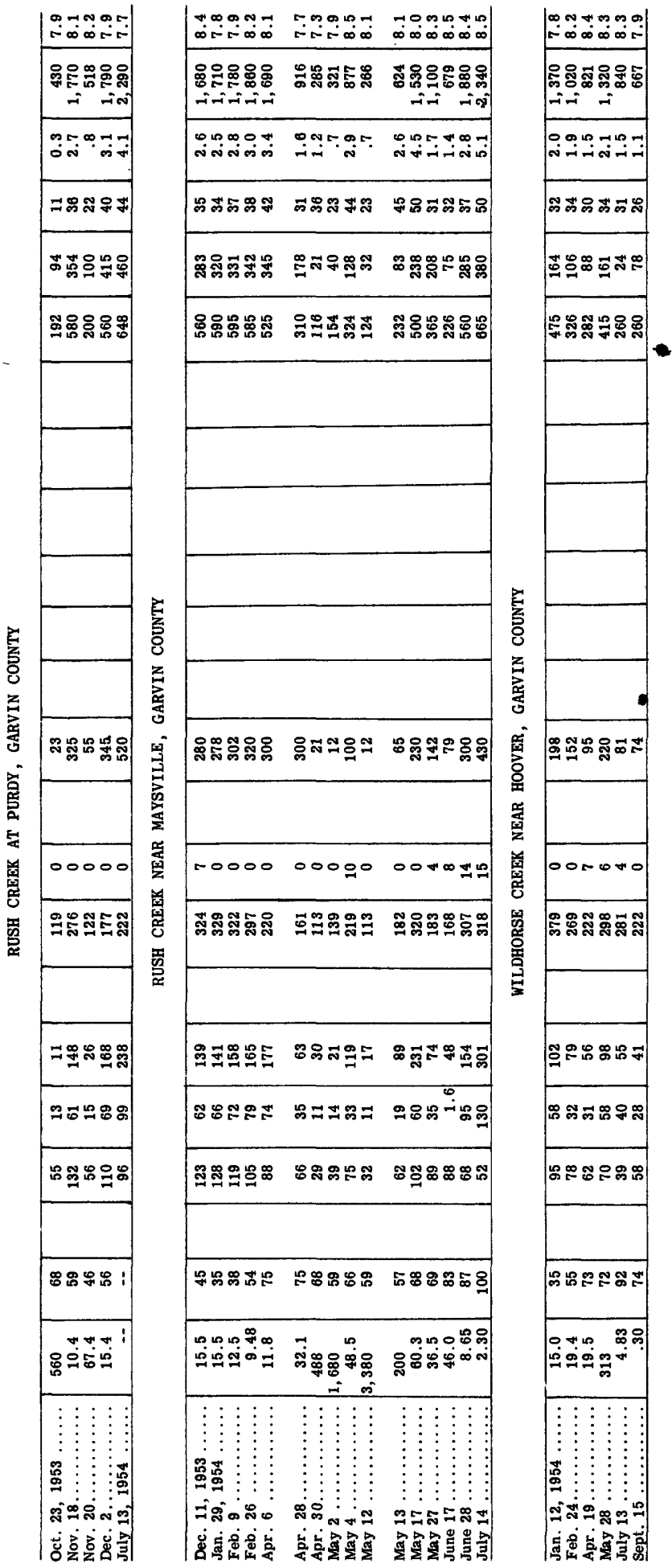




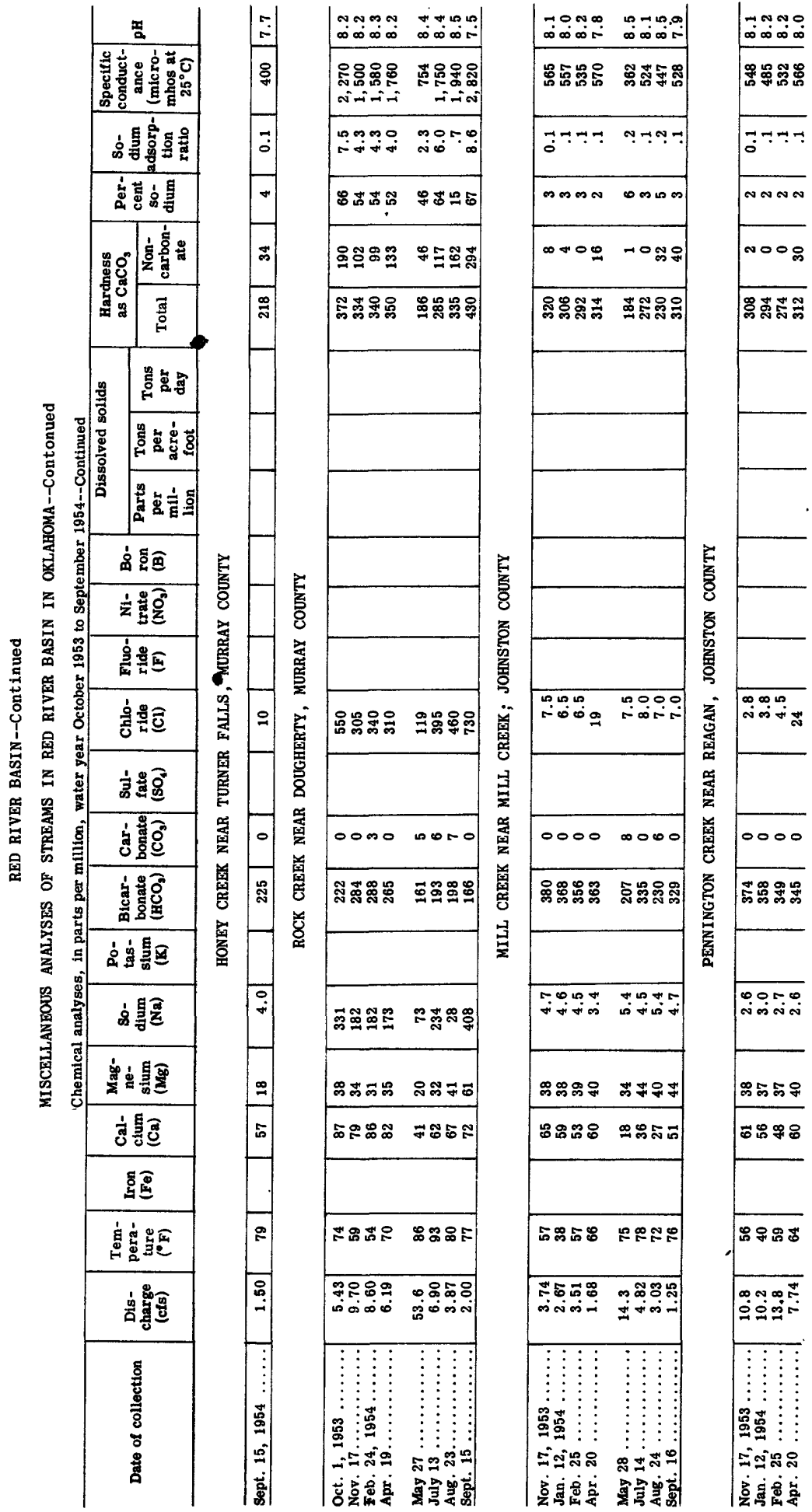




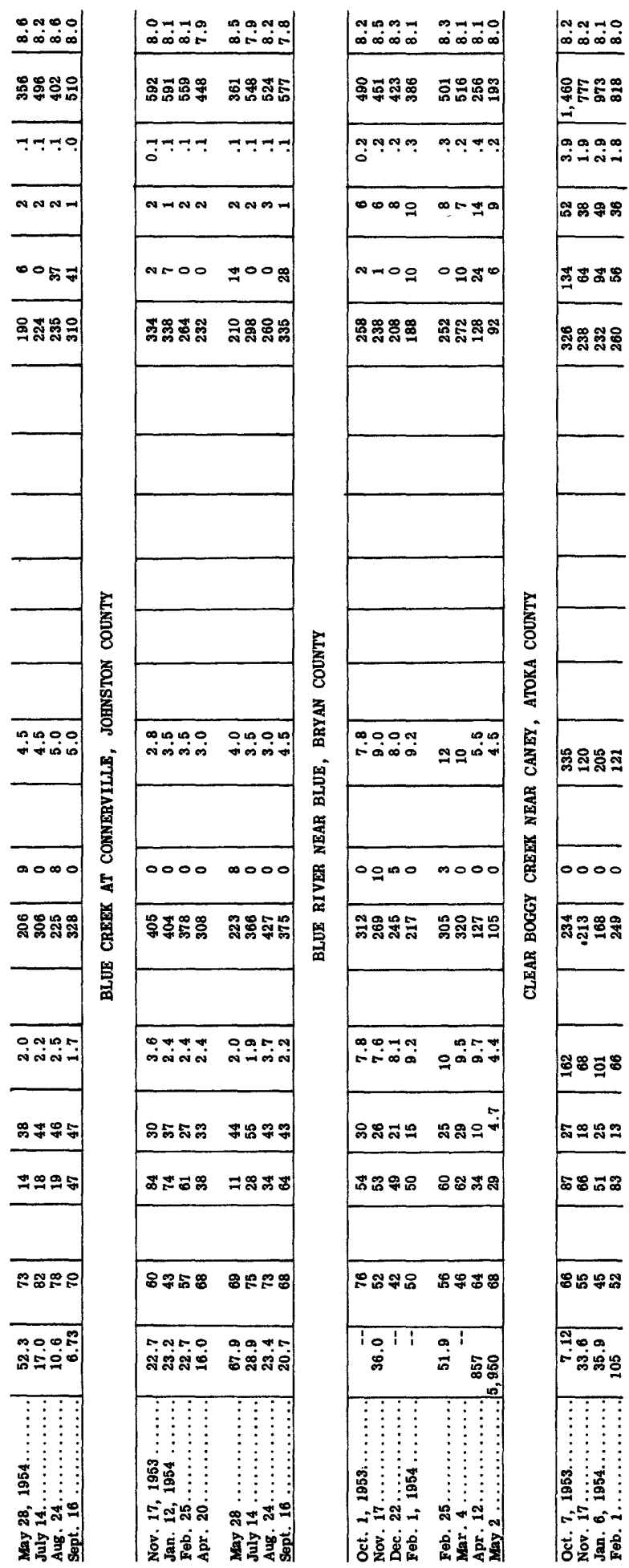




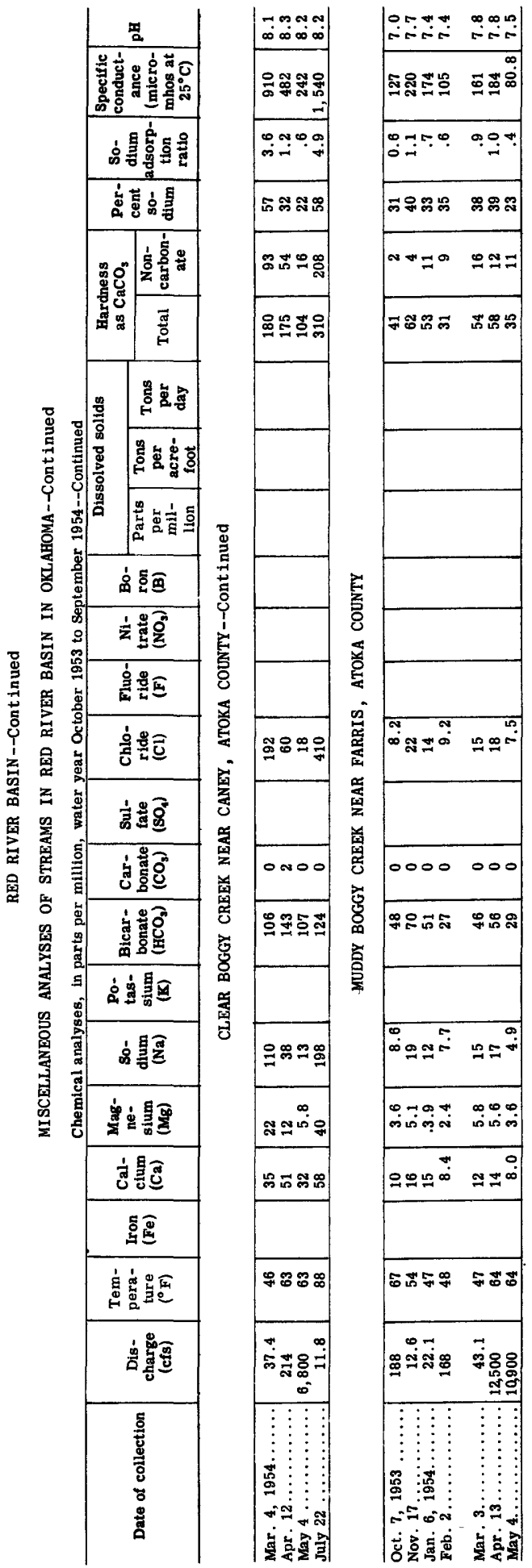




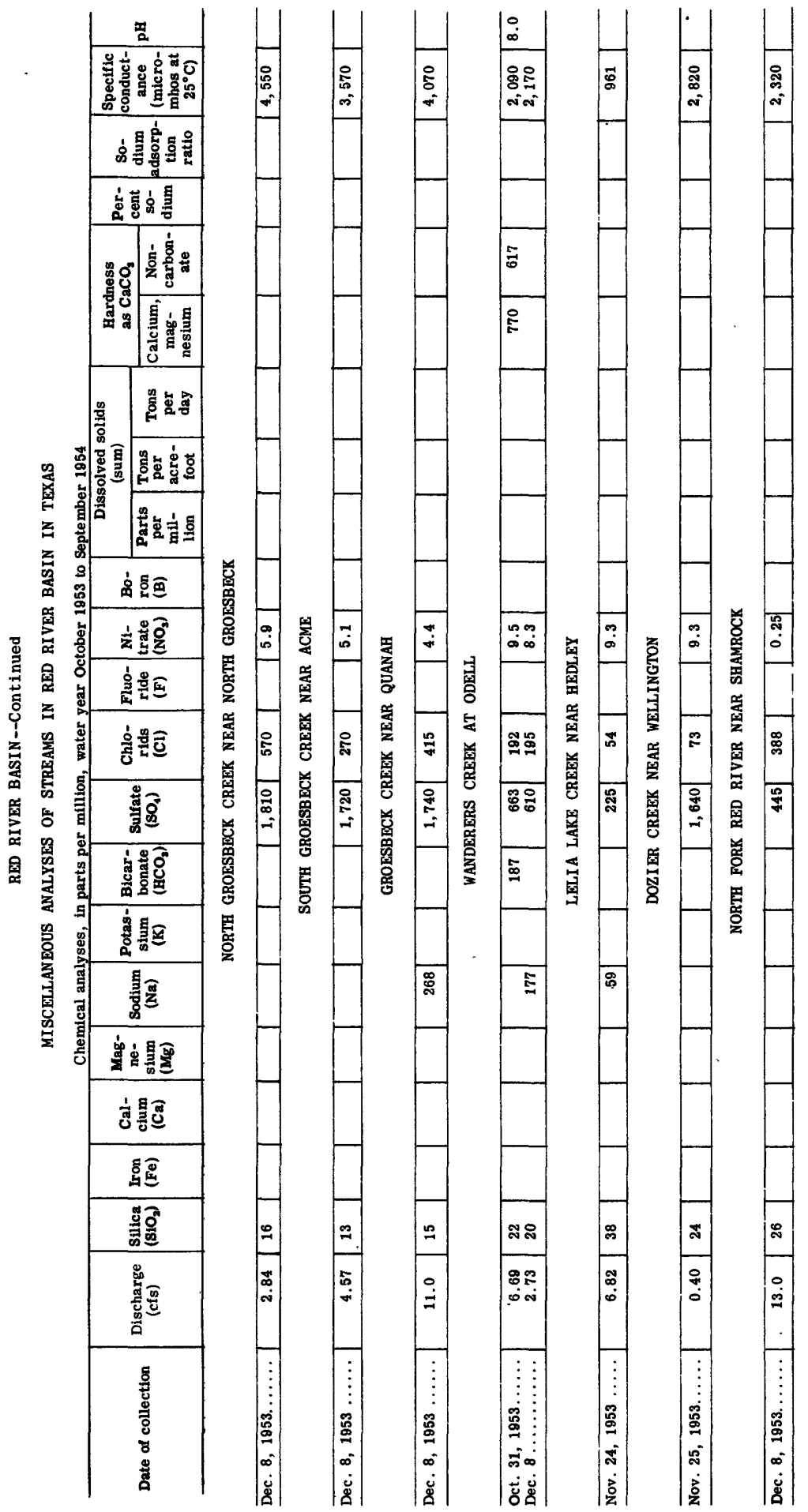




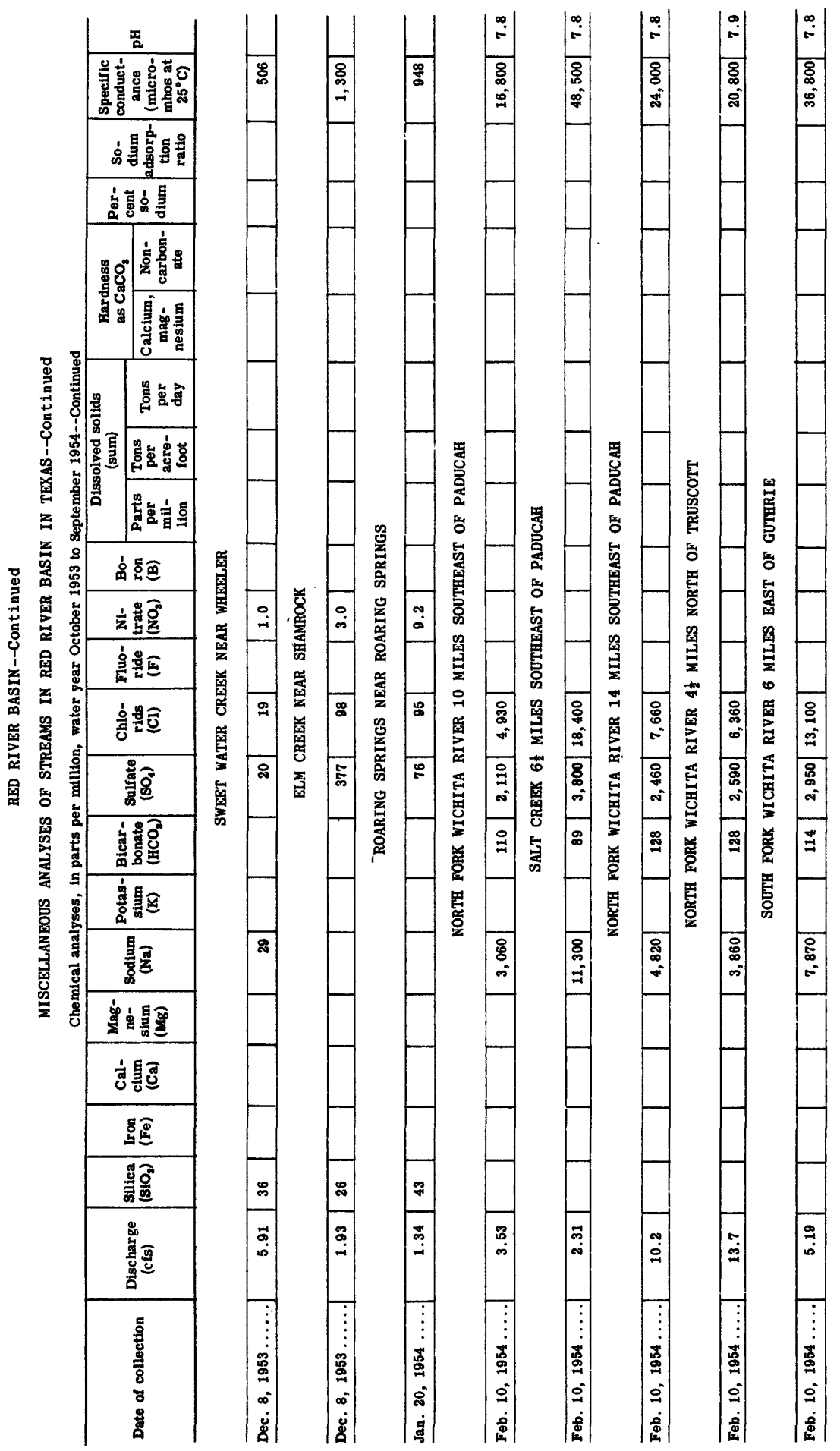




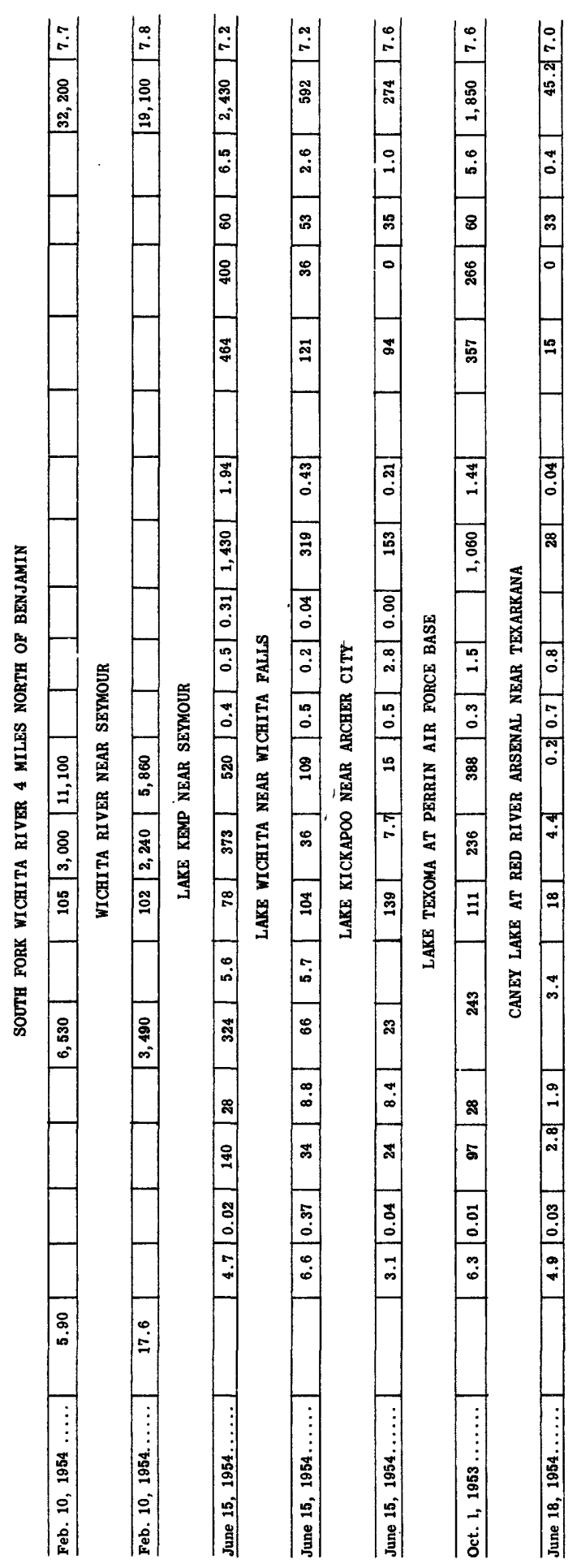




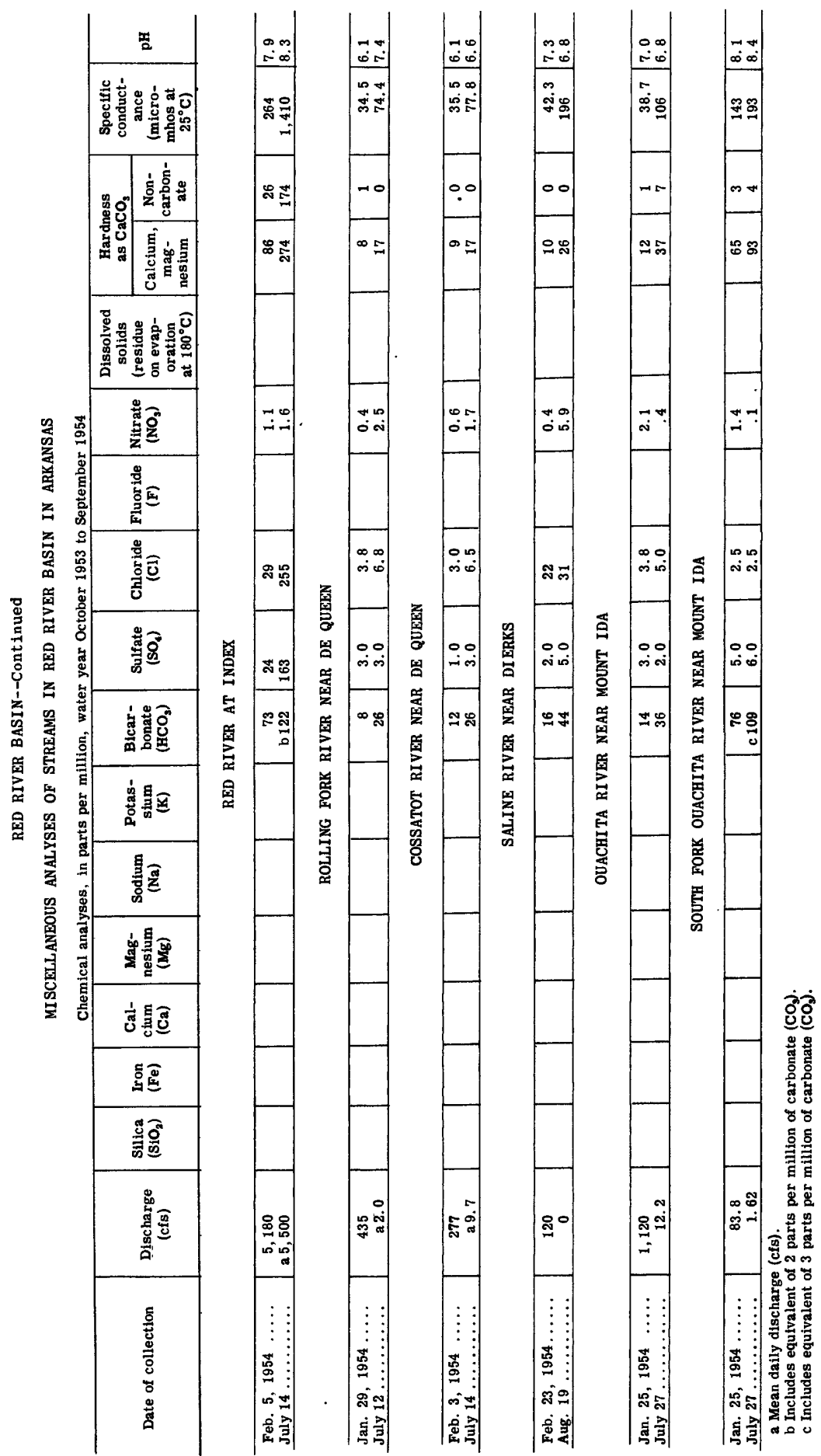




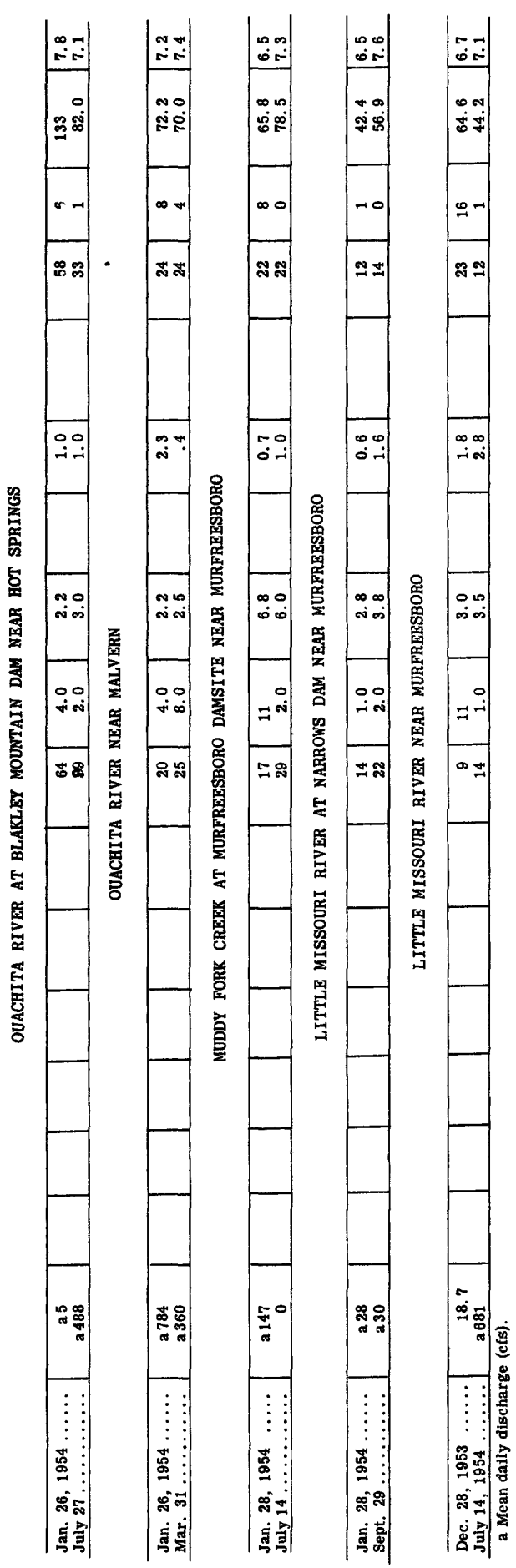




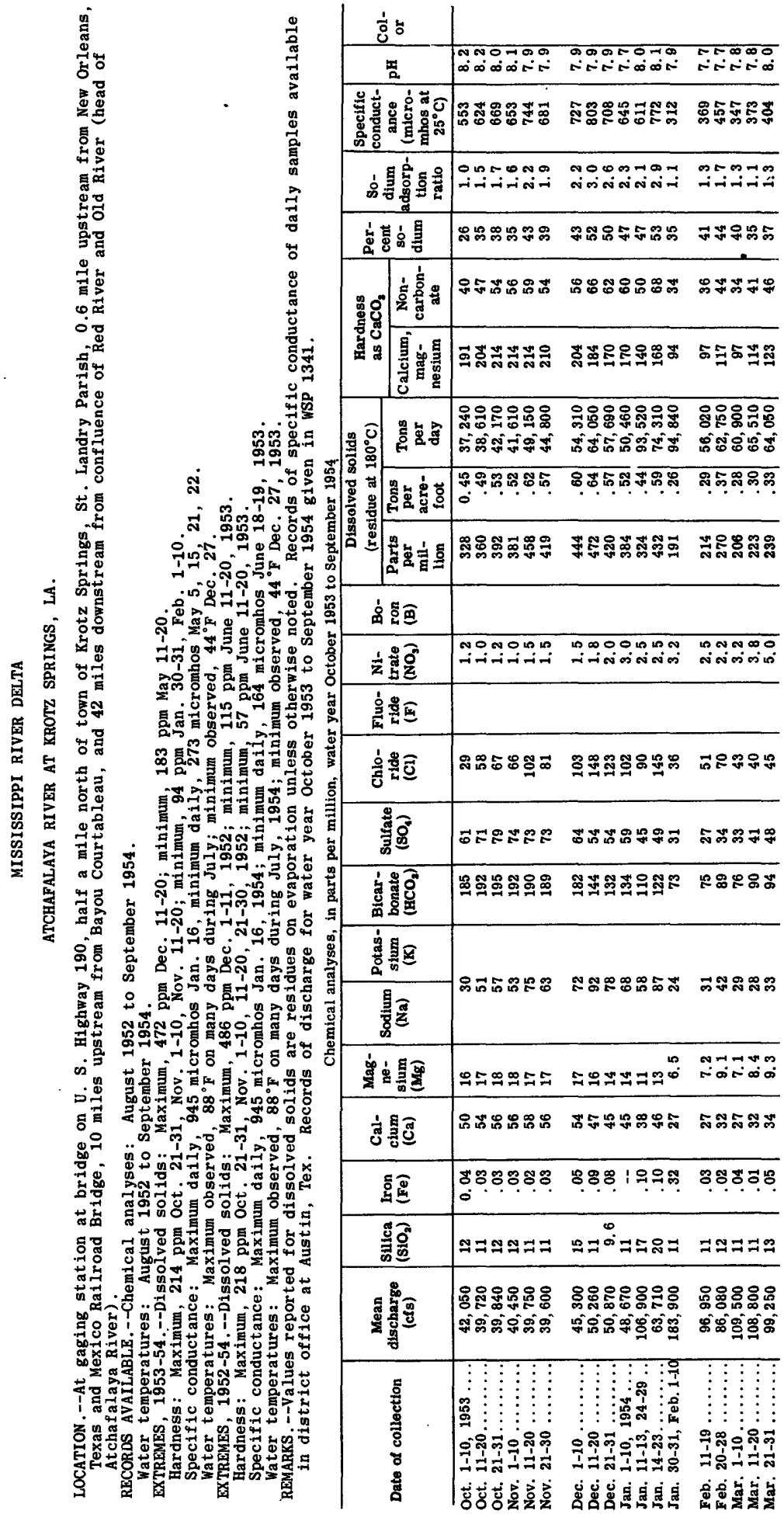




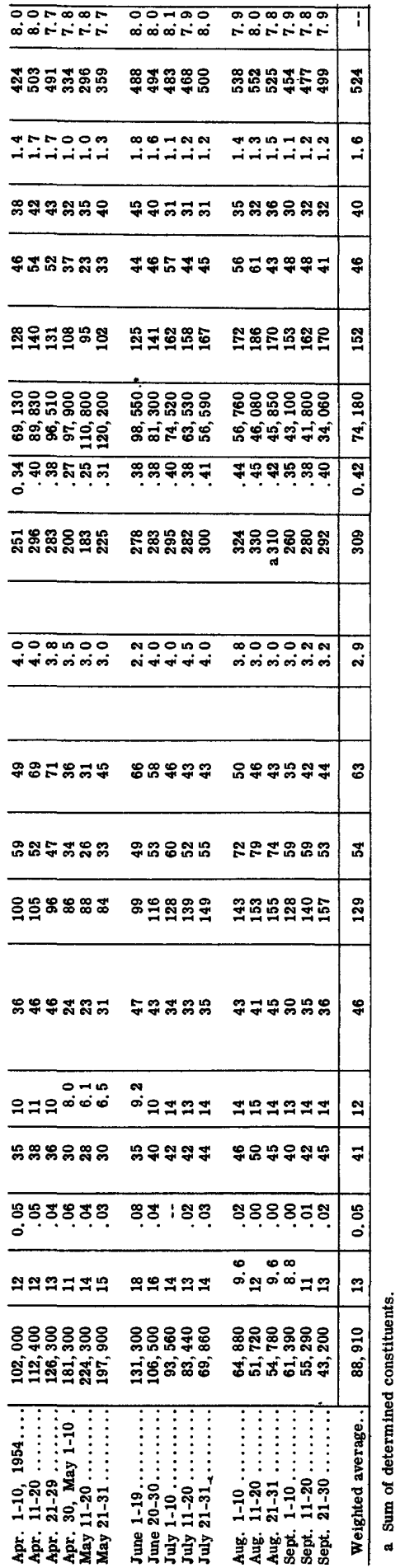


MISSISSIPPI RIVER DELTA--Continued

ATCHAFALAYA RIVER AT KROTZ SPRINGS, LA.--Continued

Temperature ( ${ }^{\circ} \mathrm{F}$ ) of water, water year October 1953 to September 1954

\begin{tabular}{|c|c|c|c|c|c|c|c|c|c|c|c|c|}
\hline Day & Oct. & Nov. & Dec. & Jan. & Feb. & Mar. & Apr. & May & June & July & Aug. & Sept. \\
\hline $\begin{array}{l}1 \\
2 \\
3 \\
4 \\
5\end{array}$ & $\begin{array}{l}77 \\
78 \\
78 \\
78 \\
78\end{array}$ & $\begin{array}{l}67 \\
66 \\
65 \\
64 \\
64\end{array}$ & $\begin{array}{l}54 \\
54 \\
54 \\
54 \\
54\end{array}$ & $\begin{array}{l}45 \\
45 \\
45 \\
45 \\
45\end{array}$ & $\begin{array}{l}46 \\
46 \\
47 \\
47 \\
47\end{array}$ & $\begin{array}{l}\mathbf{5 6} \\
\mathbf{5 3} \\
\mathbf{5 4} \\
\mathbf{5 3} \\
\mathbf{5 3}\end{array}$ & $\begin{array}{l}58 \\
58 \\
58 \\
58 \\
58\end{array}$ & $\begin{array}{l}71 \\
71 \\
71 \\
71 \\
70\end{array}$ & $\begin{array}{l}-- \\
-- \\
-- \\
--\end{array}$ & $\begin{array}{l}88 \\
88 \\
88 \\
88 \\
88\end{array}$ & $\begin{array}{l}87 \\
86 \\
86 \\
86 \\
86\end{array}$ & $\begin{array}{l}86 \\
86 \\
86 \\
85 \\
85\end{array}$ \\
\hline $\begin{array}{r}6 \\
7 \\
8 \\
9 \\
10\end{array}$ & $\begin{array}{l}77 \\
76 \\
76 \\
76 \\
75\end{array}$ & $\begin{array}{l}63 \\
63 \\
62 \\
61 \\
60\end{array}$ & $\begin{array}{l}\mathbf{5 4} \\
\mathbf{5 5} \\
\mathbf{5 5} \\
\mathbf{5 5} \\
\mathbf{5 5}\end{array}$ & $\begin{array}{l}45 \\
45 \\
45 \\
45 \\
45\end{array}$ & $\begin{array}{l}47 \\
47 \\
47 \\
48 \\
48\end{array}$ & $\begin{array}{l}\mathbf{5 2} \\
\mathbf{5 1} \\
\mathbf{5 1} \\
\mathbf{5 1} \\
\mathbf{5 2}\end{array}$ & $\begin{array}{l}58 \\
58 \\
59 \\
60 \\
60\end{array}$ & $\begin{array}{l}70 \\
69 \\
69 \\
69 \\
69\end{array}$ & $\begin{array}{l}-- \\
-- \\
78 \\
79 \\
79\end{array}$ & $\begin{array}{l}88 \\
88 \\
88 \\
88 \\
88\end{array}$ & $\begin{array}{l}86 \\
86 \\
86 \\
86 \\
86\end{array}$ & $\begin{array}{l}85 \\
85 \\
85 \\
84 \\
85\end{array}$ \\
\hline $\begin{array}{l}11 \\
12 \\
13 \\
14 \\
15\end{array}$ & $\begin{array}{l}74 \\
74 \\
74 \\
73 \\
73\end{array}$ & $\begin{array}{l}59 \\
59 \\
57 \\
56 \\
56\end{array}$ & $\begin{array}{l}\mathbf{5 4} \\
\mathbf{5 4} \\
\mathbf{5 3} \\
\mathbf{5 2} \\
\mathbf{5 1}\end{array}$ & $\begin{array}{l}45 \\
45 \\
45 \\
46 \\
46\end{array}$ & $\begin{array}{l}49 \\
49 \\
49 \\
49 \\
50\end{array}$ & $\begin{array}{l}-5 \\
53 \\
53 \\
53 \\
53\end{array}$ & $\begin{array}{l}62 \\
63 \\
63 \\
65 \\
64\end{array}$ & $\begin{array}{l}68 \\
68 \\
68 \\
66 \\
66\end{array}$ & $\begin{array}{l}80 \\
80 \\
81 \\
81 \\
81\end{array}$ & $\begin{array}{l}88 \\
88 \\
88 \\
88 \\
88\end{array}$ & $\begin{array}{l}87 \\
87 \\
87 \\
87 \\
87\end{array}$ & $\begin{array}{l}85 \\
84 \\
84 \\
84 \\
84\end{array}$ \\
\hline $\begin{array}{l}16 \\
17 \\
18 \\
19 \\
20\end{array}$ & $\begin{array}{l}73 \\
73 \\
74 \\
73 \\
73\end{array}$ & $\begin{array}{l}56 \\
56 \\
56 \\
56 \\
56\end{array}$ & $\begin{array}{l}50 \\
50 \\
50 \\
49 \\
49\end{array}$ & $\begin{array}{l}47 \\
47 \\
47 \\
47 \\
48\end{array}$ & $\begin{array}{l}50 \\
50 \\
51 \\
52 \\
53\end{array}$ & $\begin{array}{l}\mathbf{5 2} \\
\mathbf{5 2} \\
\mathbf{5 2} \\
\mathbf{5 2} \\
\mathbf{5 2}\end{array}$ & $\begin{array}{l}63 \\
63 \\
63 \\
64 \\
65\end{array}$ & $\begin{array}{l}66 \\
66 \\
66 \\
67 \\
67\end{array}$ & $\begin{array}{l}81 \\
81 \\
81 \\
81 \\
81\end{array}$ & $\begin{array}{l}88 \\
88 \\
88 \\
88 \\
88\end{array}$ & $\begin{array}{l}87 \\
87 \\
87 \\
87 \\
87\end{array}$ & $\begin{array}{l}84 \\
84 \\
84 \\
83 \\
82\end{array}$ \\
\hline $\begin{array}{l}21 \\
22 \\
23 \\
24 \\
25\end{array}$ & $\begin{array}{l}73 \\
73 \\
72 \\
72 \\
72\end{array}$ & $\begin{array}{l}57 \\
57 \\
57 \\
57 \\
57\end{array}$ & $\begin{array}{l}48 \\
47 \\
46 \\
45 \\
45\end{array}$ & $\begin{array}{l}48 \\
47 \\
48 \\
47 \\
46\end{array}$ & $\begin{array}{l}54 \\
54 \\
54 \\
55 \\
55\end{array}$ & $\begin{array}{l}\mathbf{5 2} \\
\mathbf{5 3} \\
\mathbf{5 4} \\
\mathbf{5 2} \\
\mathbf{5 5}\end{array}$ & $\begin{array}{l}65 \\
66 \\
66 \\
68 \\
69\end{array}$ & $\begin{array}{l}68 \\
68 \\
69 \\
69 \\
69\end{array}$ & $\begin{array}{l}82 \\
82 \\
83 \\
84 \\
84\end{array}$ & $\begin{array}{l}88 \\
88 \\
88 \\
88 \\
88\end{array}$ & $\begin{array}{l}87 \\
87 \\
87 \\
87 \\
87\end{array}$ & $\begin{array}{l}81 \\
81 \\
81 \\
80 \\
80\end{array}$ \\
\hline $\begin{array}{l}26 \\
27 \\
28 \\
29 \\
30 \\
31\end{array}$ & $\begin{array}{l}71 \\
71 \\
70 \\
-69 \\
68 \\
\end{array}$ & $\begin{array}{l}57 \\
57 \\
55 \\
55 \\
54 \\
-- \\
\end{array}$ & $\begin{array}{l}45 \\
44 \\
45 \\
45 \\
45 \\
45 \\
\end{array}$ & $\begin{array}{l}45 \\
45 \\
45 \\
45 \\
45 \\
45\end{array}$ & $\begin{array}{l}55 \\
55 \\
56 \\
-- \\
-- \\
-- \\
\end{array}$ & $\begin{array}{l}58 \\
58 \\
56 \\
56 \\
56 \\
58 \\
\end{array}$ & $\begin{array}{l}69 \\
70 \\
71 \\
71 \\
71 \\
-- \\
\end{array}$ & $\begin{array}{l}70 \\
70 \\
71 \\
72 \\
-- \\
-- \\
\end{array}$ & $\begin{array}{l}85 \\
85 \\
85 \\
86 \\
87 \\
-- \\
\end{array}$ & $\begin{array}{l}88 \\
88 \\
87 \\
87 \\
86 \\
86 \\
\end{array}$ & $\begin{array}{l}87 \\
87 \\
86 \\
86 \\
86 \\
86 \\
\end{array}$ & $\begin{array}{l}80 \\
80 \\
80 \\
79 \\
79 \\
-- \\
\end{array}$ \\
\hline $\begin{array}{c}\text { Aver- } \\
\text { age }\end{array}$ & 74 & 59 & 50 & 46 & 50 & 54 & 64 & 69 & $=$ & 88 & 87 & 83 \\
\hline
\end{tabular}


की

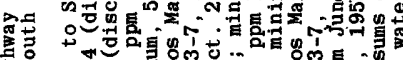

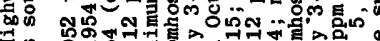
平 \% 范 ह

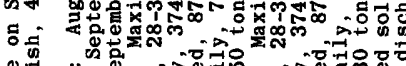
\&ั 苛 。 w

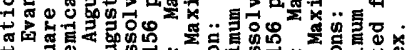
药

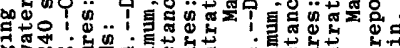

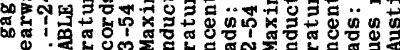

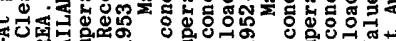

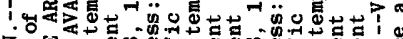

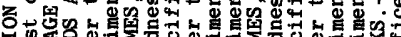

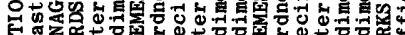

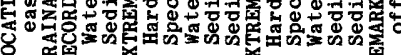

\begin{tabular}{|c|c|c|c|c|}
\hline & 폄 & 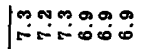 & 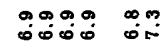 & $\stackrel{0}{\longrightarrow}$ \\
\hline & 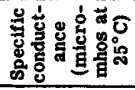 & $\begin{array}{l}0 \\
\dot{0} \\
1\end{array}$ & 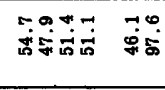 & 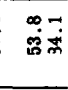 \\
\hline & 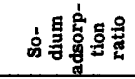 & 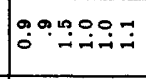 & بm. & $\stackrel{0}{9}$ \\
\hline & 它歖要 & 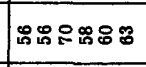 & 吅䓃芯 5F & 6웅 \\
\hline & 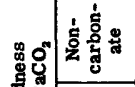 & 000000 & $0000=0$ & 00 \\
\hline & 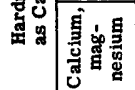 & 유유 $=0 \infty \infty$ & $\infty \backsim$ 욤요 & 오 \\
\hline & 홀 & 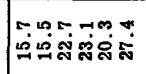 & 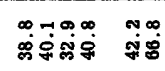 & สุ่ \\
\hline & 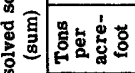 & 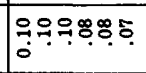 & $5850 \%$ & ๕̊?. \\
\hline & 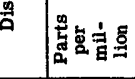 & 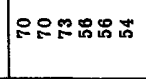 & 오유 & 5 \\
\hline & 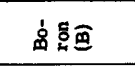 & & & \\
\hline & 立善家 & "ִ̣ & 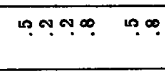 & ง พִ \\
\hline & 官害国 & & & \\
\hline & 웡혼 & | & 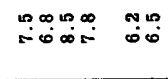 & 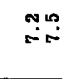 \\
\hline & 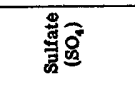 & ن & 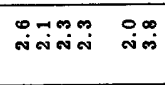 & 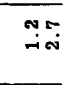 \\
\hline & 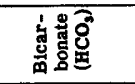 & 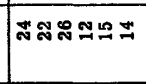 & 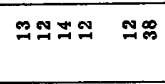 & 声 \\
\hline & 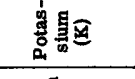 & تี & 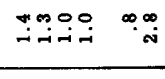 & $\stackrel{0}{-1}=$ \\
\hline & 急 & 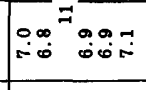 & 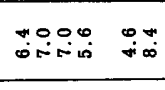 & \\
\hline & 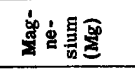 & שִ & 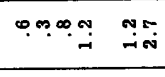 & $\begin{array}{r}7 \infty \\
-i \infty \\
\end{array}$ \\
\hline & 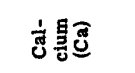 & 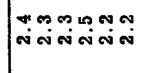 & 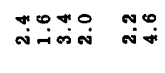 & 움 \\
\hline & 岛卖 & 5్ & 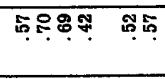 & $5 \%$ \\
\hline & 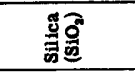 & D్లి요 & 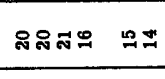 & จิสี \\
\hline & 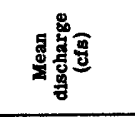 & œ0 & 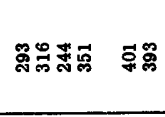 & 昜里 \\
\hline & 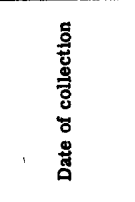 & 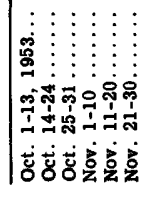 & 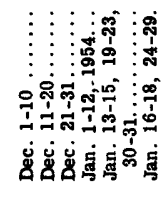 & 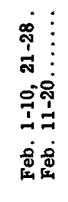 \\
\hline
\end{tabular}




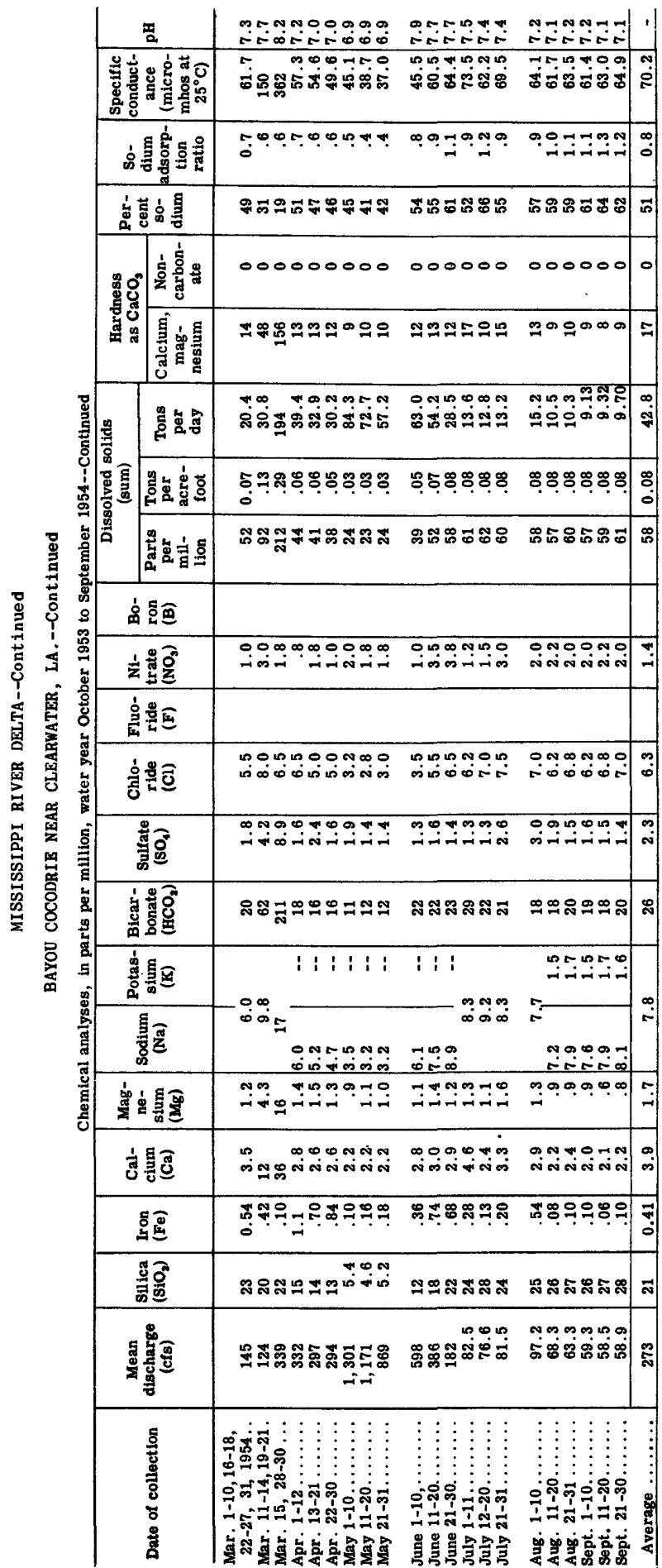


MISSISSIPPI RIVER DELTA--Continued

BAYOU COCODRIE NEAR CLEARWATER, LA.--Continued

Temperature $\left({ }^{\circ} \mathrm{F}\right)$ of water, water year October 1953 to September 1954

\begin{tabular}{|c|c|c|c|c|c|c|c|c|c|c|c|c|}
\hline Day & Oct. & Nov. & Dec. & Jan. & Feb. & Mar. & Apr. & May & June & July & Aug. & Sept \\
\hline $\begin{array}{l}1 \\
2 \\
3 \\
4 \\
5\end{array}$ & $\begin{array}{l}78 \\
80 \\
80 \\
81 \\
78\end{array}$ & $\begin{array}{l}63 \\
63 \\
64 \\
59 \\
49\end{array}$ & $\begin{array}{l}58 \\
58 \\
58 \\
58 \\
58\end{array}$ & $\begin{array}{l}55 \\
55 \\
55 \\
55 \\
55\end{array}$ & $\begin{array}{l}50 \\
49 \\
49 \\
49 \\
49\end{array}$ & $\begin{array}{l}\mathbf{5 0} \\
\mathbf{5 0} \\
\mathbf{5 0} \\
\mathbf{5 0} \\
\mathbf{5 0}\end{array}$ & $\begin{array}{l}63 \\
63 \\
65 \\
68 \\
68\end{array}$ & $\begin{array}{l}69 \\
70 \\
70 \\
70 \\
70\end{array}$ & $\begin{array}{l}75 \\
73 \\
72 \\
72 \\
74\end{array}$ & $\begin{array}{l}85 \\
85 \\
87 \\
87 \\
87\end{array}$ & $\begin{array}{l}78 \\
78 \\
80 \\
82 \\
85\end{array}$ & $\begin{array}{l}80 \\
80 \\
80 \\
79 \\
81\end{array}$ \\
\hline $\begin{array}{r}6 \\
7 \\
8 \\
9 \\
10\end{array}$ & $\begin{array}{l}78 \\
78 \\
66 \\
66 \\
66\end{array}$ & $\begin{array}{l}45 \\
40 \\
51 \\
54 \\
46\end{array}$ & $\begin{array}{l}56 \\
56 \\
55 \\
55 \\
55\end{array}$ & $\begin{array}{l}\mathbf{5 5} \\
\mathbf{5 2} \\
\mathbf{5 0} \\
\mathbf{5 0} \\
\mathbf{5 0}\end{array}$ & $\begin{array}{l}49 \\
49 \\
49 \\
49 \\
49\end{array}$ & $\begin{array}{l}\mathbf{5 0} \\
\mathbf{5 0} \\
\mathbf{5 0} \\
\mathbf{5 0} \\
\mathbf{5 0}\end{array}$ & $\begin{array}{l}68 \\
68 \\
71 \\
71 \\
71\end{array}$ & $\begin{array}{l}70 \\
70 \\
67 \\
67 \\
67\end{array}$ & $\begin{array}{l}74 \\
74 \\
76 \\
76 \\
76\end{array}$ & $\begin{array}{l}87 \\
87 \\
85 \\
85 \\
85\end{array}$ & $\begin{array}{l}85 \\
85 \\
85 \\
85 \\
87\end{array}$ & $\begin{array}{l}81 \\
82 \\
82 \\
82 \\
80\end{array}$ \\
\hline $\begin{array}{l}11 \\
12 \\
13 \\
14 \\
15\end{array}$ & $\begin{array}{l}68 \\
68 \\
70 \\
72 \\
72\end{array}$ & $\begin{array}{l}49 \\
49 \\
48 \\
48 \\
50\end{array}$ & $\begin{array}{l}56 \\
56 \\
56 \\
52 \\
52\end{array}$ & $\begin{array}{l}50 \\
50 \\
52 \\
55 \\
55\end{array}$ & $\begin{array}{l}49 \\
50 \\
50 \\
50 \\
50\end{array}$ & $\begin{array}{l}\mathbf{5 0} \\
\mathbf{5 0} \\
\mathbf{5 3} \\
\mathbf{5 3} \\
\mathbf{5 3}\end{array}$ & $\begin{array}{l}71 \\
74 \\
74 \\
76 \\
70\end{array}$ & $\begin{array}{l}70 \\
67 \\
67 \\
67 \\
68\end{array}$ & $\begin{array}{l}76 \\
78 \\
80 \\
80 \\
80\end{array}$ & $\begin{array}{l}85 \\
85 \\
85 \\
84 \\
84\end{array}$ & $\begin{array}{l}80 \\
85 \\
85 \\
85 \\
85\end{array}$ & $\begin{array}{l}75 \\
75 \\
75 \\
75 \\
72\end{array}$ \\
\hline $\begin{array}{l}16 \\
17 \\
18 \\
19 \\
20\end{array}$ & $\begin{array}{l}72 \\
72 \\
70 \\
68 \\
68\end{array}$ & $\begin{array}{l}50 \\
52 \\
55 \\
55 \\
55\end{array}$ & $\begin{array}{l}49 \\
46 \\
46 \\
46 \\
46\end{array}$ & $\begin{array}{l}\mathbf{5 5} \\
\mathbf{5 2} \\
\mathbf{5 0} \\
\mathbf{5 5} \\
\mathbf{5 7}\end{array}$ & $\begin{array}{l}\mathbf{5 0} \\
\mathbf{5 0} \\
\mathbf{5 0} \\
\mathbf{5 5} \\
\mathbf{5 7}\end{array}$ & $\begin{array}{l}56 \\
57 \\
57 \\
59 \\
60\end{array}$ & $\begin{array}{l}70 \\
72 \\
72 \\
68 \\
68\end{array}$ & $\begin{array}{l}70 \\
70 \\
71 \\
\mathbf{7 1} \\
\mathbf{7 1}\end{array}$ & $\begin{array}{l}80 \\
80 \\
80 \\
82 \\
83\end{array}$ & $\begin{array}{l}85 \\
85 \\
85 \\
85 \\
85\end{array}$ & $\begin{array}{l}85 \\
85 \\
85 \\
85 \\
85\end{array}$ & $\begin{array}{l}72 \\
72 \\
72 \\
80 \\
80\end{array}$ \\
\hline $\begin{array}{l}21 \\
22 \\
23 \\
24 \\
25\end{array}$ & $\begin{array}{l}68 \\
68 \\
68 \\
68 \\
68\end{array}$ & $\begin{array}{l}\mathbf{5 8} \\
\mathbf{5 8} \\
\mathbf{5 8} \\
\mathbf{5 8} \\
\mathbf{5 8}\end{array}$ & $\begin{array}{l}46 \\
46 \\
46 \\
38 \\
38\end{array}$ & $\begin{array}{l}\mathbf{5 0} \\
\mathbf{5 0} \\
\mathbf{5 0} \\
\mathbf{5 0} \\
\mathbf{5 0}\end{array}$ & $\begin{array}{l}57 \\
57 \\
57 \\
57 \\
55\end{array}$ & $\begin{array}{l}60 \\
60 \\
60 \\
60 \\
60\end{array}$ & $\begin{array}{l}69 \\
69 \\
70 \\
72 \\
72\end{array}$ & $\begin{array}{l}71 \\
72 \\
73 \\
73 \\
74\end{array}$ & $\begin{array}{l}83 \\
83 \\
83 \\
83 \\
83\end{array}$ & $\begin{array}{l}85 \\
85 \\
85 \\
85 \\
85\end{array}$ & $\begin{array}{l}85 \\
85 \\
85 \\
85 \\
85\end{array}$ & $\begin{array}{l}81 \\
80 \\
83 \\
83 \\
83\end{array}$ \\
\hline $\begin{array}{l}26 \\
27 \\
28 \\
29 \\
30 \\
31\end{array}$ & $\begin{array}{l}67 \\
67 \\
65 \\
65 \\
65 \\
62 \\
\end{array}$ & $\begin{array}{r}58 \\
55 \\
55 \\
55 \\
53 \\
-- \\
\end{array}$ & $\begin{array}{l}40 \\
43 \\
45 \\
48 \\
50 \\
50\end{array}$ & $\begin{array}{l}\mathbf{5 0} \\
\mathbf{5 0} \\
\mathbf{5 0} \\
\mathbf{5 0} \\
\mathbf{5 0} \\
\mathbf{5 0} \\
\end{array}$ & $\begin{array}{l}55 \\
56 \\
56 \\
-- \\
-- \\
-- \\
\end{array}$ & $\begin{array}{l}62 \\
62 \\
65 \\
65 \\
65 \\
65 \\
\end{array}$ & $\begin{array}{r}72 \\
72 \\
72 \\
70 \\
-70 \\
-- \\
\end{array}$ & $\begin{array}{l}73 \\
74 \\
75 \\
78 \\
75 \\
75 \\
\end{array}$ & $\begin{array}{l}85 \\
85 \\
80 \\
85 \\
85 \\
-- \\
\end{array}$ & $\begin{array}{l}85 \\
83 \\
80 \\
80 \\
80 \\
80 \\
\end{array}$ & $\begin{array}{l}86 \\
86 \\
85 \\
85 \\
85 \\
82 \\
\end{array}$ & $\begin{array}{l}85 \\
85 \\
85 \\
85 \\
85 \\
--\end{array}$ \\
\hline $\begin{array}{c}\text { Aver- } \\
\text { age }\end{array}$ & 70 & 54 & 50 & 52 & 52 & 56 & 70 & 71 & 79 & 85 & 84 & 80 \\
\hline
\end{tabular}


BAYOU COCODRIE NEAR CLEARWATER, LA. --Continued

Suspended sediment, water year October 1953 to September 1954

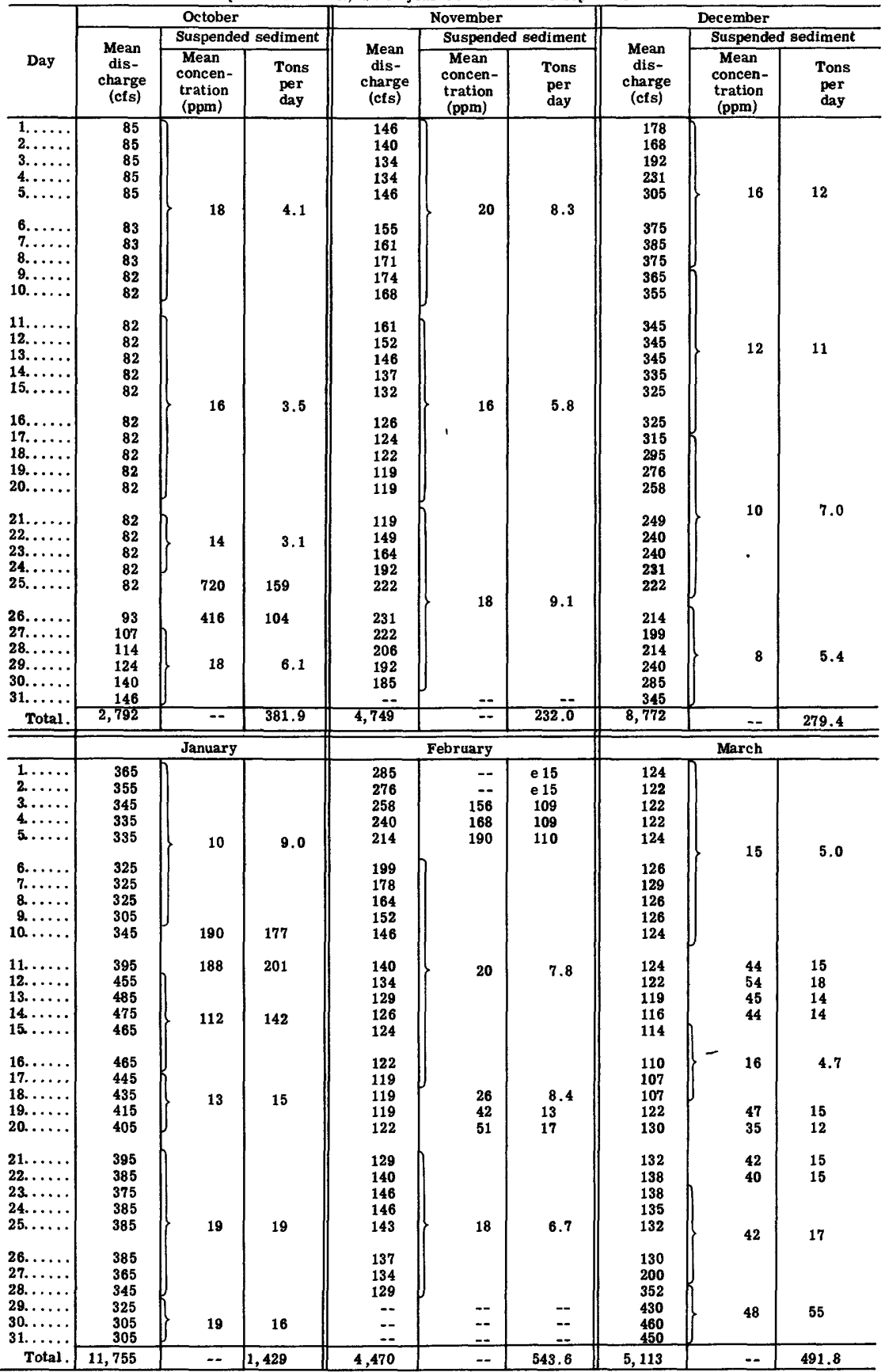

e Estimated. 
MISSISSIPPI RIVER DELTA--Cont inued

BAYOU COCODRIE NEAR CLEARWATER, LA.--Continued

Suspended sediment, water year October 1953 to September 1954--Continued

\begin{tabular}{|c|c|c|c|c|c|c|c|c|c|}
\hline \multirow[b]{3}{*}{ Day } & \multicolumn{3}{|c|}{ April } & \multicolumn{3}{|c|}{ May } & \multicolumn{3}{|c|}{ June } \\
\hline & \multirow[b]{2}{*}{$\begin{array}{l}\text { Mean } \\
\text { dis- } \\
\text { charge } \\
\text { (cfs) }\end{array}$} & \multicolumn{2}{|c|}{ Suspended sediment } & \multirow[b]{2}{*}{$\begin{array}{l}\text { Mean } \\
\text { dis- } \\
\text { charge } \\
\text { (cfs) }\end{array}$} & \multicolumn{2}{|c|}{ Suspended sediment } & \multirow[b]{2}{*}{$\begin{array}{l}\text { Mean } \\
\text { dis- } \\
\text { charge } \\
\text { (cfs) }\end{array}$} & \multicolumn{2}{|c|}{ Suspended sediment } \\
\hline & & $\begin{array}{l}\text { Mean } \\
\text { concen- } \\
\text { tration } \\
(\mathrm{ppm})\end{array}$ & $\begin{array}{l}\text { Tons } \\
\text { per } \\
\text { day }\end{array}$ & & $\begin{array}{l}\text { Mean } \\
\text { concen - } \\
\text { tration } \\
\text { (ppm) }\end{array}$ & $\begin{array}{l}\text { Tons } \\
\text { per } \\
\text { day }\end{array}$ & & $\begin{array}{l}\text { Mean } \\
\text { concen- } \\
\text { tration } \\
(\mathrm{ppm}) \\
\end{array}$ & $\begin{array}{l}\text { Tons } \\
\text { per } \\
\text { day }\end{array}$ \\
\hline 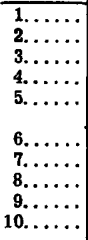 & $\begin{array}{l}440 \\
420 \\
400 \\
390 \\
370 \\
\\
352 \\
334 \\
307 \\
280 \\
255\end{array}$ & 10 & 9.6 & $\begin{array}{r}580 \\
1,090 \\
1,360 \\
1,520 \\
1,540 \\
1,490 \\
1,430 \\
1,370 \\
1,340 \\
1,290\end{array}$ & 125 & 411 & $\begin{array}{l}710 \\
686 \\
684 \\
631 \\
609 \\
587 \\
565 \\
532 \\
510 \\
490\end{array}$ & 26 & 41 \\
\hline $\begin{array}{l}11 \ldots \ldots \\
12 . \ldots \ldots \\
13 . \ldots \ldots \\
14 \ldots \ldots \\
15 \ldots \ldots\end{array}$ & $\begin{array}{l}231 \\
202 \\
174 \\
156 \\
156\end{array}$ & 115 & 61 & $\begin{array}{l}1,240 \\
1,240 \\
1,260 \\
1,240 \\
1,210\end{array}$ & $\begin{array}{l}270 \\
210 \\
230 \\
600 \\
690\end{array}$ & $\begin{array}{r}904 \\
703 \\
782 \\
2,010 \\
2,250\end{array}$ & $\begin{array}{l}470 \\
450 \\
430 \\
410 \\
390\end{array}$ & $\begin{array}{l}266 \\
326 \\
302 \\
332\end{array}$ & $\begin{array}{l}323 \\
378 \\
334 \\
350\end{array}$ \\
\hline $\begin{array}{l}16 \ldots \ldots \\
17 \ldots \ldots \\
18 \ldots \ldots \\
19 \ldots \ldots \\
20 \ldots \ldots\end{array}$ & $\begin{array}{l}263 \\
316 \\
390 \\
420 \\
410\end{array}$ & 54 & 56 & $\begin{array}{l}1,170 \\
1,140 \\
1,100 \\
1,070 \\
1,040\end{array}$ & $\begin{array}{l}400 \\
208 \\
168 \\
220 \\
230\end{array}$ & $\begin{array}{r}1,260 \\
640 \\
499 \\
636 \\
646\end{array}$ & $\begin{array}{l}370 \\
352 \\
334 \\
334 \\
316\end{array}$ & $\begin{array}{l}285 \\
224 \\
154 \\
154 \\
162\end{array}$ & $\begin{array}{l}285 \\
213 \\
139 \\
139 \\
138\end{array}$ \\
\hline $\begin{array}{l}21 \ldots \ldots \ldots \\
22 \ldots \ldots \ldots \\
23 \ldots \ldots \ldots \\
24 \ldots \ldots \ldots \\
25 \ldots \ldots \ldots\end{array}$ & $\begin{array}{l}390 \\
370 \\
352 \\
334 \\
316\end{array}$ & 14 & 12 & $\begin{array}{r}1,010 \\
974 \\
950 \\
926 \\
890\end{array}$ & $\begin{array}{l}197 \\
249 \\
131 \\
125 \\
260\end{array}$ & $\begin{array}{l}537 \\
655 \\
336 \\
313 \\
625\end{array}$ & $\begin{array}{l}298 \\
271 \\
239 \\
209 \\
181\end{array}$ & $\begin{array}{l}187 \\
225 \\
366 \\
343 \\
408\end{array}$ & $\begin{array}{l}150 \\
165 \\
236 \\
194 \\
199\end{array}$ \\
\hline $\begin{array}{l}26 \ldots \ldots \\
27 . \ldots \ldots \\
28 . \ldots \ldots \\
29 . \ldots \ldots \\
30 \ldots \ldots \\
31 \ldots \ldots\end{array}$ & $\begin{array}{r}298 \\
271 \\
247 \\
223 \\
239 \\
-- \\
\end{array}$ & $\begin{array}{l}56 \\
-- \\
\end{array}$ & $\begin{array}{r}36 \\
-- \\
\end{array}$ & $\begin{array}{l}866 \\
842 \\
818 \\
794 \\
758 \\
734 \\
\end{array}$ & $\begin{array}{r}210 \\
225 \\
250 \\
360 \\
108 \\
15 \\
\end{array}$ & $\begin{array}{r}491 \\
512 \\
552 \\
772 \\
221 \\
30 \\
\end{array}$ & $\begin{array}{r}156 \\
132 \\
117 \\
110 \\
102 \\
-- \\
\end{array}$ & $\begin{array}{r}595 \\
84 \\
-- \\
\end{array}$ & $\begin{array}{r}251 \\
26 \\
-- \\
\end{array}$ \\
\hline \multirow[t]{2}{*}{ Total. } & 9,306 & -- & 922 & 34,282 & $\because$ & 20,644 & 11,655 & -- & 4,049 \\
\hline & \multicolumn{3}{|c|}{ July } & \multicolumn{3}{|c|}{ August } & \multicolumn{3}{|c|}{ September } \\
\hline $\begin{array}{c}1 \ldots \ldots \\
2 \ldots \ldots \\
3 \ldots \ldots \\
4 \ldots \ldots \\
5 \ldots \ldots \\
6 \ldots \ldots \\
7 \ldots \ldots \\
8 \ldots \ldots \\
9 \ldots \ldots \\
10 \ldots \ldots\end{array}$ & $\begin{array}{l}95 \\
91 \\
87 \\
85 \\
83 \\
\\
81 \\
79 \\
79 \\
77 \\
75\end{array}$ & 27 & 6.1 & \begin{tabular}{|l|}
114 \\
114 \\
114 \\
107 \\
100 \\
93 \\
87 \\
83 \\
81 \\
79
\end{tabular} & $\begin{array}{l} \\
215 \\
214 \\
244 \\
177 \\
148\end{array}$ & $\begin{array}{l}54 \\
50 \\
55 \\
39 \\
32\end{array}$ & $\begin{array}{l}60 \\
60 \\
59 \\
59 \\
59 \\
\\
59 \\
59 \\
59 \\
59 \\
60\end{array}$ & $\begin{array}{l}\mathbf{5 1 0} \\
490 \\
350 \\
380 \\
640 \\
\\
561 \\
570 \\
480 \\
380 \\
300\end{array}$ & $\begin{array}{r}83 \\
79 \\
56 \\
61 \\
102 \\
\\
89 \\
91 \\
76 \\
61 \\
49\end{array}$ \\
\hline $\begin{array}{l}11 \ldots \ldots \\
12 \ldots \ldots \\
13 \ldots \ldots \\
14 \ldots \ldots \\
15 \ldots \ldots\end{array}$ & $\begin{array}{l}75 \\
77 \\
77 \\
75 \\
73\end{array}$ & 16 & 3.2 & $\begin{array}{l}77 \\
73 \\
71 \\
69 \\
69\end{array}$ & $\begin{array}{l}174 \\
133 \\
140 \\
169 \\
176\end{array}$ & $\begin{array}{l}36 \\
26 \\
27 \\
31 \\
33\end{array}$ & $\begin{array}{l}\mathbf{5 9} \\
\mathbf{5 9} \\
\mathbf{5 8} \\
\mathbf{5 8} \\
\mathbf{5 8}\end{array}$ & $\begin{array}{l}256 \\
400 \\
365 \\
372 \\
346\end{array}$ & $\begin{array}{l}41 \\
64 \\
57 \\
58 \\
54\end{array}$ \\
\hline $\begin{array}{l}16 \ldots \ldots \\
17 \ldots \ldots \\
18 \ldots \ldots \\
19 \ldots \ldots \\
20 \ldots \ldots\end{array}$ & $\begin{array}{l}\mathbf{7 1} \\
\mathbf{7 5} \\
\mathbf{7 9} \\
\mathbf{7 9} \\
\mathbf{8 3}\end{array}$ & $\begin{array}{l}157 \\
200 \\
220\end{array}$ & $\begin{array}{l}33 \\
43 \\
49\end{array}$ & $\begin{array}{l}67 \\
65 \\
64 \\
64 \\
64\end{array}$ & $\begin{array}{l}169 \\
134 \\
121 \\
300 \\
253\end{array}$ & $\begin{array}{l}31 \\
24 \\
21 \\
52 \\
44\end{array}$ & $\begin{array}{l}\mathbf{5 8} \\
58 \\
59 \\
59 \\
59\end{array}$ & \begin{tabular}{l|}
331 \\
322 \\
346 \\
346 \\
332
\end{tabular} & $\begin{array}{l}\mathbf{5 2} \\
\mathbf{5 0} \\
\mathbf{5 5} \\
\mathbf{5 5} \\
\mathbf{5 3}\end{array}$ \\
\hline $\begin{array}{l}21 \ldots \ldots \\
22 . \ldots \ldots \\
23 . \ldots \ldots \\
24 \ldots \ldots \\
25 . \ldots \ldots\end{array}$ & $\begin{array}{l}83 \\
83 \\
81 \\
79 \\
\mathbf{7 7}\end{array}$ & $\begin{array}{l}188 \\
380 \\
260 \\
164 \\
184\end{array}$ & $\begin{array}{l}42 \\
85 \\
57 \\
36 \\
38\end{array}$ & $\begin{array}{l}64 \\
64 \\
64 \\
64 \\
64 \\
\end{array}$ & $\begin{array}{l}243 \\
192 \\
168 \\
160 \\
208\end{array}$ & $\begin{array}{l}42 \\
33 \\
29 \\
28 \\
36\end{array}$ & $\begin{array}{l}\mathbf{5 9} \\
\mathbf{5 9} \\
\mathbf{5 9} \\
\mathbf{5 9} \\
\mathbf{5 9}\end{array}$ & \begin{tabular}{l|}
311 \\
288 \\
262 \\
238 \\
212
\end{tabular} & $\begin{array}{l}50 \\
46 \\
42 \\
38 \\
34\end{array}$ \\
\hline $\begin{array}{l}26 \ldots \ldots \\
27 . \ldots \ldots \\
28 . \ldots \ldots \\
29 \ldots \ldots \\
30 \ldots \ldots \\
31 \ldots \ldots\end{array}$ & $\begin{array}{r}75 \\
73 \\
71 \\
77 \\
91 \\
107 \\
\end{array}$ & $\begin{array}{r}293 \\
56 \\
238 \\
\mathbf{2 3 8} \\
\mathbf{2 5 2} \\
\mathbf{3 6 2} \\
\end{array}$ & $\begin{array}{r}59 \\
11 \\
46 \\
49 \\
62 \\
105 \\
\end{array}$ & $\begin{array}{l}64 \\
64 \\
64 \\
62 \\
62 \\
60 \\
\end{array}$ & $\begin{array}{l}285 \\
328 \\
289 \\
274 \\
250 \\
296\end{array}$ & $\begin{array}{l}49 \\
57 \\
50 \\
46 \\
42 \\
48\end{array}$ & $\begin{array}{l}58 \\
58 \\
59 \\
59 \\
60 \\
-- \\
\end{array}$ & $\begin{array}{l}200 \\
196 \\
268 \\
219 \\
201 \\
-\end{array}$ & $\begin{array}{l}31 \\
31 \\
43 \\
35 \\
33 \\
-- \\
\end{array}$ \\
\hline Total . & 2,493 & -- & 798.4 & 2,351 & -- & 1,170 & 1,767 & -- & 1,669 \\
\hline
\end{tabular}




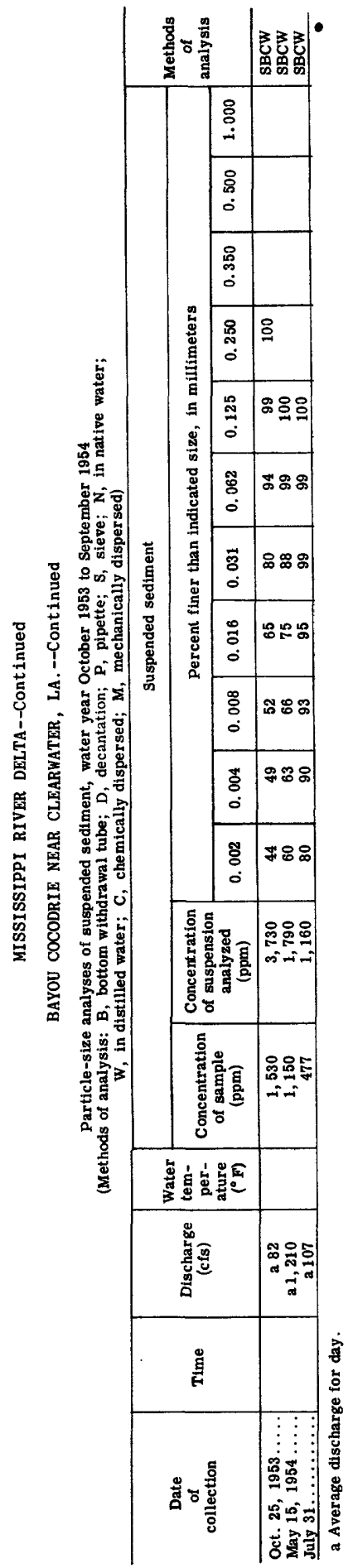


MISSISSIPPI RIVER DELTA--Continued

VERMILION RIVER AT BANCKER'S FERRY, LA.

LOCATION.--At Bancker's Ferry about 6 miles south of Abbeville, Vermilion Parish.

RECORDS AVAILABLE. --Chemical analyses: January 1949 to September 1954.

Water temperatures: January 1949 to September 1954

EXTREMES, 1953-54.--Specif ic conductance: Maximum daily, 21,200 micromhos Sept.18;

minimum daily, 60.2 micromhos Jan. 12 .

Water temperatures: Maximum observed, $90^{\circ} \mathrm{F}$ July 2, 4; minimum observed, $48^{\circ} \mathrm{F}$ Dec, 24.

EXTREMES, 1949-54.--Specific conductance: Maximum daily, 21,200 micromhos Sept.18,1954;

minimum daily, 47.7 micromhos May $20,1953$.

Water temperatures: Maximum observed, $98^{\circ} \mathrm{F}$ Aug. 9, Sept. 3, 1951; minimum observed, $38^{\circ} \mathrm{F}$ Jan. $30,1951$.

REMARKS. - No discharge records available for this station.

Specific conductance (micromhos at $25^{\circ} \mathrm{C}$ ) and chloride, in parts per million, water year October 1953 to September 1954

\begin{tabular}{|c|c|c|c|c|c|c|}
\hline \multirow{2}{*}{ Day } & \multicolumn{2}{|c|}{ October } & \multicolumn{2}{|c|}{ November } & \multicolumn{2}{|c|}{ December } \\
\hline & Conductance & Chloride & Conductance & Chloride & Conductance & Chloride \\
\hline $\begin{array}{l}1 \\
2 \\
3 \\
4 \\
5\end{array}$ & $\begin{array}{l}1,160 \\
1,770 \\
2,280 \\
1,960 \\
1,790\end{array}$ & $\begin{array}{l}300 \\
485 \\
642 \\
582 \\
485\end{array}$ & $\begin{array}{l}1,260 \\
1,160 \\
2,110 \\
3,250 \\
2,320\end{array}$ & $\begin{array}{l}315 \\
288 \\
585 \\
960 \\
635\end{array}$ & $\begin{array}{l}459 \\
309 \\
472 \\
154 \\
108\end{array}$ & $\begin{array}{r}115 \\
69 \\
117 \\
27 \\
23\end{array}$ \\
\hline $\begin{array}{r}6 \\
7 \\
8 \\
9 \\
10\end{array}$ & $\begin{array}{l}486 \\
400 \\
460 \\
628 \\
682 \\
\end{array}$ & $\begin{array}{r}109 \\
-- \\
102 \\
148 \\
--\end{array}$ & $\begin{array}{r}395 \\
3,840 \\
1,500 \\
389 \\
419\end{array}$ & $\begin{array}{r}65 \\
1,160 \\
390 \\
58 \\
68\end{array}$ & $\begin{array}{l}207 \\
392 \\
485 \\
504 \\
272\end{array}$ & $\begin{array}{r}42 \\
102 \\
131 \\
132 \\
59\end{array}$ \\
\hline $\begin{array}{l}11 \\
12 \\
13 \\
14 \\
15\end{array}$ & $\begin{array}{r}1,210 \\
1,070 \\
722 \\
534 \\
395\end{array}$ & $\begin{array}{r}320 \\
280 \\
172 \\
119 \\
-\quad 79\end{array}$ & $\begin{array}{l}526 \\
465 \\
465 \\
467 \\
509\end{array}$ & $\begin{array}{r}101 \\
82 \\
-- \\
-- \\
--\end{array}$ & $\begin{array}{c}167 \\
93.2 \\
246 \\
523 \\
516\end{array}$ & $\begin{array}{r}17 \\
14 \\
61 \\
137 \\
135\end{array}$ \\
\hline $\begin{array}{l}16 \\
17 \\
18 \\
19 \\
20\end{array}$ & $\begin{array}{r}347 \\
347 \\
343 \\
748 \\
1,670\end{array}$ & $\begin{array}{r}-- \\
-- \\
64 \\
185 \\
458\end{array}$ & $\begin{array}{r}502 \\
815 \\
1,200 \\
1,420 \\
654\end{array}$ & $\begin{array}{r}91 \\
186 \\
305 \\
370 \\
130\end{array}$ & $\begin{array}{l}532 \\
257 \\
270 \\
256 \\
221\end{array}$ & $\begin{array}{r}138 \\
54 \\
-- \\
-- \\
--\end{array}$ \\
\hline $\begin{array}{l}21 \\
22 \\
23 \\
24 \\
25\end{array}$ & $\begin{array}{l}1,870 \\
2,170 \\
1,590 \\
1,540 \\
2,000\end{array}$ & $\begin{array}{l}508 \\
598 \\
420 \\
410 \\
550\end{array}$ & $\begin{array}{c}1,240 \\
1,190 \\
78.6 \\
157 \\
431\end{array}$ & $\begin{array}{r}322 \\
318 \\
16 \\
31 \\
111\end{array}$ & $\begin{array}{l}184 \\
158 \\
149 \\
165 \\
184\end{array}$ & $\begin{array}{l}38 \\
28 \\
-- \\
-- \\
--\end{array}$ \\
\hline $\begin{array}{l}26 \\
27 \\
28 \\
29 \\
30 \\
31\end{array}$ & $\begin{array}{r}4,600 \\
371 \\
371 \\
504 \\
730 \\
1,850 \\
\end{array}$ & $\begin{array}{r}1,400 \\
64 \\
67 \\
106 \\
172 \\
510\end{array}$ & $\begin{array}{r}236 \\
291 \\
253 \\
260 \\
332 \\
--\end{array}$ & $\begin{array}{l}52 \\
66 \\
54 \\
56 \\
77 \\
--\end{array}$ & $\begin{array}{l}184 \\
191 \\
199 \\
202 \\
233 \\
161\end{array}$ & $\begin{array}{l}\cdots \\
36 \\
38 \\
45 \\
24\end{array}$ \\
\hline
\end{tabular}


MISSISSIPPI RIVER DELTA--Continued

VERMILION RIVER AT BANCKER'S FERRY,LA.--Continued

Specific conductance (micromhos at $25^{\circ} \mathrm{C}$ ) and chloride, in parts per million,

\begin{tabular}{|c|c|c|c|c|c|c|}
\hline \multirow{2}{*}{ Day } & \multicolumn{2}{|c|}{ January } & \multicolumn{2}{|c|}{ February } & \multicolumn{2}{|c|}{ March } \\
\hline & Conductance & Chloride & Conductance & Chloride & Conductance & Chloride \\
\hline $\begin{array}{l}1 \\
2 \\
3 \\
4 \\
\mathbf{5}\end{array}$ & $\begin{array}{l}192 \\
305 \\
216 \\
199 \\
431\end{array}$ & $\begin{array}{r}-\overline{65} \\
36 \\
33 \\
101\end{array}$ & $\begin{array}{l}227 \\
229 \\
172 \\
243 \\
273\end{array}$ & $\begin{array}{l}-- \\
43 \\
31 \\
44 \\
53\end{array}$ & $\begin{array}{l}389 \\
718 \\
411 \\
406 \\
388\end{array}$ & $\begin{array}{r}81 \\
172 \\
83 \\
-- \\
--\end{array}$ \\
\hline $\begin{array}{r}6 \\
7 \\
8 \\
9 \\
10\end{array}$ & $\begin{array}{l}137 \\
125 \\
216 \\
460 \\
272\end{array}$ & $\begin{array}{r}22 \\
21 \\
50 \\
123 \\
63\end{array}$ & $\begin{array}{l}243 \\
296 \\
417 \\
360 \\
275\end{array}$ & $\begin{array}{l}-2 \\
59 \\
94 \\
77 \\
52\end{array}$ & $\begin{array}{l}387 \\
292 \\
289 \\
451 \\
451\end{array}$ & $\begin{array}{l}70 \\
38 \\
37 \\
83 \\
--\end{array}$ \\
\hline $\begin{array}{l}11 \\
12 \\
13 \\
14 \\
15\end{array}$ & $\begin{array}{c}116 \\
60.2 \\
135 \\
453 \\
390\end{array}$ & $\begin{array}{c}15 \\
7.5 \\
26 \\
117 \\
101\end{array}$ & $\begin{array}{l}248 \\
263 \\
247 \\
263 \\
253\end{array}$ & $\begin{array}{l}-- \\
48 \\
42 \\
-- \\
--\end{array}$ & $\begin{array}{l}469 \\
469 \\
417 \\
544 \\
496\end{array}$ & $\begin{array}{r}-- \\
-- \\
78 \\
113 \\
101\end{array}$ \\
\hline $\begin{array}{l}16 \\
17 \\
18 \\
19 \\
20\end{array}$ & $\begin{array}{l}278 \\
245 \\
268 \\
188 \\
213\end{array}$ & $\begin{array}{l}66 \\
56 \\
60 \\
34 \\
44\end{array}$ & $\begin{array}{l}249 \\
527 \\
506 \\
471 \\
516\end{array}$ & $\begin{array}{r}41 \\
124 \\
117 \\
108 \\
120\end{array}$ & $\begin{array}{r}483 \\
479 \\
632 \\
1,000 \\
493\end{array}$ & $\begin{array}{r}-- \\
95 \\
139 \\
240 \\
91\end{array}$ \\
\hline $\begin{array}{l}21 \\
22 \\
23 \\
24 \\
25\end{array}$ & $\begin{array}{l}198 \\
211 \\
209 \\
253 \\
232\end{array}$ & $\begin{array}{l}-- \\
-- \\
38 \\
50 \\
42\end{array}$ & $\begin{array}{l}432 \\
450 \\
382 \\
520 \\
568\end{array}$ & $\begin{array}{r}91 \\
-- \\
71 \\
114 \\
126\end{array}$ & $\begin{array}{r}533 \\
591 \\
517 \\
583 \\
2,730\end{array}$ & $\begin{array}{r}101 \\
120 \\
96 \\
115 \\
768\end{array}$ \\
\hline \multirow[t]{2}{*}{$\begin{array}{l}26 \\
27 \\
28 \\
29 \\
30 \\
31 \\
\end{array}$} & $\begin{array}{l}224 \\
224 \\
273 \\
299 \\
297 \\
227 \\
\end{array}$ & $\begin{array}{l}-2 \\
38 \\
53 \\
61 \\
60 \\
42 \\
\end{array}$ & $\begin{array}{r}446 \\
477 \\
1,080 \\
-- \\
- \\
-\end{array}$ & $\begin{array}{r}90 \\
97 \\
280 \\
-- \\
-- \\
-- \\
\end{array}$ & $\begin{array}{l}631 \\
618 \\
469 \\
469 \\
473 \\
493 \\
\end{array}$ & $\begin{array}{r}-- \\
120 \\
72 \\
-- \\
-- \\
-- \\
\end{array}$ \\
\hline & \multicolumn{2}{|c|}{ April } & \multicolumn{2}{|c|}{ May } & \multicolumn{2}{|c|}{ June } \\
\hline $\begin{array}{l}1 \\
2 \\
3 \\
4 \\
5\end{array}$ & $\begin{array}{l}590 \\
583 \\
790 \\
386 \\
241\end{array}$ & $\begin{array}{r}-- \\
108 \\
181 \\
77 \\
36\end{array}$ & $\begin{array}{r}\mathbf{1}, 590 \\
7,430 \\
\mathbf{3 6 5} \\
\mathbf{3 4 4} \\
\mathbf{3 7 0}\end{array}$ & $\begin{array}{r}408 \\
2,290 \\
56 \\
-- \\
68\end{array}$ & $\begin{array}{l}154 \\
303 \\
203 \\
236 \\
213 \\
\end{array}$ & $\begin{array}{l}20 \\
65 \\
37 \\
-- \\
--\end{array}$ \\
\hline $\begin{array}{r}6 \\
7 \\
8 \\
9 \\
10\end{array}$ & $\begin{array}{l}211 \\
227 \\
371 \\
338 \\
241\end{array}$ & $\begin{array}{l}-- \\
33 \\
76 \\
65 \\
32\end{array}$ & $\begin{array}{l}280 \\
128 \\
137 \\
124 \\
193\end{array}$ & $\begin{array}{l}48 \\
18 \\
-- \\
-- \\
34\end{array}$ & $\begin{array}{r}170 \\
179 \\
208 \\
234 \\
1,090\end{array}$ & $\begin{array}{r}-- \\
-- \\
45 \\
280\end{array}$ \\
\hline $\begin{array}{l}11 \\
12 \\
13 \\
14 \\
15\end{array}$ & $\begin{array}{l}226 \\
238 \\
217 \\
215 \\
214\end{array}$ & $\begin{array}{l}27 \\
-- \\
-- \\
-- \\
--\end{array}$ & $\begin{array}{l}178 \\
149 \\
148 \\
176 \\
173\end{array}$ & $\begin{array}{l}30 \\
20 \\
-- \\
-- \\
--\end{array}$ & $\begin{array}{l}1,070 \\
1,570 \\
1,090 \\
1,500 \\
2,870\end{array}$ & $\begin{array}{r}270 \\
415 \\
-- \\
395 \\
830\end{array}$ \\
\hline $\begin{array}{l}16 \\
17 \\
18 \\
19 \\
20\end{array}$ & $\begin{array}{l}222 \\
223 \\
380 \\
355 \\
344\end{array}$ & $\begin{array}{l}22 \\
22 \\
-- \\
-- \\
65\end{array}$ & $\begin{array}{l}145 \\
145 \\
135 \\
173 \\
129\end{array}$ & $\begin{array}{l}-- \\
-- \\
24 \\
13\end{array}$ & $\begin{array}{r}3,990 \\
2,240 \\
926 \\
265 \\
281\end{array}$ & $\begin{array}{r}1,150 \\
608 \\
231 \\
46 \\
--\end{array}$ \\
\hline $\begin{array}{l}21 \\
22 \\
23 \\
24 \\
25\end{array}$ & $\begin{array}{l}391 \\
273 \\
352 \\
341 \\
401\end{array}$ & $\begin{array}{l}--\overline{34} \\
58 \\
-- \\
76\end{array}$ & $\begin{array}{l}134 \\
149 \\
236 \\
353 \\
312\end{array}$ & $\begin{array}{l}-- \\
19 \\
44 \\
78 \\
63\end{array}$ & $\begin{array}{l}248 \\
225 \\
236 \\
247 \\
250\end{array}$ & $\begin{array}{l}-- \\
\overline{40} \\
-- \\
--\end{array}$ \\
\hline $\begin{array}{l}26 \\
27 \\
28 \\
29 \\
30 \\
31\end{array}$ & $\begin{array}{r}300 \\
236 \\
223 \\
230 \\
270 \\
--\end{array}$ & $\begin{array}{l}47 \\
32 \\
-- \\
-- \\
38 \\
--\end{array}$ & $\begin{array}{r}244 \\
169 \\
132 \\
240 \\
168 \\
--\end{array}$ & $\begin{array}{l}45 \\
23 \\
-- \\
-- \\
-- \\
--\end{array}$ & $\begin{array}{r}255 \\
260 \\
272 \\
259 \\
491 \\
--\end{array}$ & $\begin{array}{r}-- \\
-- \\
\overline{44} \\
108 \\
--\end{array}$ \\
\hline
\end{tabular}


MI SSISSI PPI RIVER DELTA--Cont inued

VERMILION RIVER AT BANCKER'S FERRY, LA.--Cont inued

Specific conductance (micromhos at $25^{\circ} \mathrm{C}$ ) and chloride, in parts per million, water year October 1953 to September 1954--Continued

\begin{tabular}{|c|c|c|c|c|c|c|}
\hline \multirow{2}{*}{ Day } & \multicolumn{2}{|c|}{ July } & \multicolumn{2}{|c|}{ August } & \multicolumn{2}{|c|}{ September } \\
\hline & Conductance & Chloride & Conductance & Chloride & Conductance & Chloride \\
\hline $\begin{array}{l}1 \\
2 \\
3 \\
4 \\
5\end{array}$ & $\begin{array}{l}5,460 \\
8,050 \\
9,150 \\
9,460 \\
9,450\end{array}$ & $\begin{array}{r}1,640 \\
2,500 \\
2,870 \\
2,990 \\
--\end{array}$ & $\begin{array}{l}335 \\
334 \\
402 \\
598 \\
471\end{array}$ & $\begin{array}{r}75 \\
78 \\
96 \\
149 \\
--\end{array}$ & $\begin{array}{r}8,940 \\
10,700 \\
12,800 \\
14,500 \\
14,500\end{array}$ & $\begin{array}{r}2,850 \\
3,520 \\
4,240 \\
4,930 \\
--\end{array}$ \\
\hline $\begin{array}{r}6 \\
7 \\
8 \\
9 \\
10\end{array}$ & $\begin{array}{r}9,340 \\
9,390 \\
2,920 \\
1,270 \\
399\end{array}$ & $\begin{array}{r}2,980 \\
840 \\
320 \\
87\end{array}$ & $\begin{array}{l}458 \\
458 \\
358 \\
319 \\
322\end{array}$ & $\begin{array}{r}-- \\
105 \\
73 \\
-- \\
--\end{array}$ & $\begin{array}{l}14,300 \\
13,500 \\
13,500 \\
12,600 \\
12,500\end{array}$ & $\begin{array}{l}-- \\
-- \\
--\end{array}$ \\
\hline $\begin{array}{l}11 \\
12 \\
13 \\
14 \\
15\end{array}$ & $\begin{array}{r}393 \\
288 \\
576 \\
4,630 \\
4,690\end{array}$ & $\begin{array}{r}87 \\
57 \\
136 \\
1,410 \\
-\end{array}$ & $\begin{array}{r}365 \\
368 \\
1,780 \\
2,190 \\
4,410\end{array}$ & $\begin{array}{l}-- \\
75 \\
-- \\
-- \\
--\end{array}$ & $\begin{array}{l}11,800 \\
11,200 \\
12,900 \\
14,700 \\
16,100\end{array}$ & $\begin{array}{r}-- \\
-- \\
4,290 \\
5,000 \\
5,500\end{array}$ \\
\hline $\begin{array}{l}16 \\
17 \\
18 \\
19 \\
20\end{array}$ & $\begin{array}{l}5,700 \\
7,860 \\
8,860 \\
9,750 \\
9,870\end{array}$ & $\begin{array}{r}1,740 \\
2,450 \\
2,770 \\
3,100 \\
--\end{array}$ & $\begin{array}{l}4,560 \\
6,130 \\
7,690 \\
8,690 \\
8,910\end{array}$ & $\begin{array}{r}1,880 \\
2,400 \\
2,770 \\
-.\end{array}$ & $\begin{array}{l}18,400 \\
20,800 \\
21,200 \\
20,100 \\
18,500\end{array}$ & $\begin{array}{r}6,370 \\
7,250 \\
-- \\
-- \\
--\end{array}$ \\
\hline $\begin{array}{l}21 \\
22 \\
23 \\
24 \\
25\end{array}$ & $\begin{array}{r}10,300 \\
10,400 \\
10,200 \\
9,630 \\
9,510\end{array}$ & $\begin{array}{l}-- \\
=- \\
-- \\
=-\end{array}$ & $\begin{array}{l}8,590 \\
6,940 \\
6,330 \\
6,720 \\
4,300\end{array}$ & $\begin{array}{r}-- \\
-- \\
1,950 \\
2,110 \\
--\end{array}$ & $\begin{array}{l}17,600 \\
14,300 \\
13,900 \\
16,000 \\
17,300\end{array}$ & $\begin{array}{r}-- \\
-- \\
4,660 \\
5,530 \\
--\end{array}$ \\
\hline $\begin{array}{l}26 \\
27 \\
28 \\
29 \\
30 \\
31\end{array}$ & $\begin{array}{r}9,600 \\
10,700 \\
10,700 \\
11,500 \\
799 \\
690\end{array}$ & $\begin{array}{r}3,020 \\
3,440 \\
-2 \\
3,740 \\
202 \\
154\end{array}$ & $\begin{array}{l}2,350 \\
3,920 \\
5,190 \\
5,190 \\
4,090 \\
8,850\end{array}$ & $\begin{array}{r}-- \\
-- \\
-- \\
-- \\
2,800\end{array}$ & $\begin{array}{r}18,300 \\
17,900 \\
18,400 \\
15,900 \\
15,700 \\
--\end{array}$ & $\begin{array}{r}-- \\
-- \\
-- \\
-- \\
5,330 \\
--\end{array}$ \\
\hline
\end{tabular}


MISSISSIPPI RIVER DELTA--Continued

VERMILION RIVER AT BANCKER'S FERRX, LA.--Continued

Temperature $\left({ }^{\circ} \mathrm{F}\right)$ of water, water year October 1953 to September 1954.

\begin{tabular}{|c|c|c|c|c|c|c|c|c|c|c|c|c|}
\hline Day & Oct. & Nov. & Dec. & Jan. & Feb. & Mar. & Apr. & May & June & July & Aug. & Sept. \\
\hline $\begin{array}{l}1 \\
2 \\
3 \\
4 \\
5\end{array}$ & $\begin{array}{l}80 \\
80 \\
80 \\
80 \\
80\end{array}$ & $\begin{array}{l}69 \\
61 \\
69 \\
67 \\
69\end{array}$ & $\begin{array}{l}60 \\
61 \\
62 \\
64 \\
64\end{array}$ & $\begin{array}{l}\mathbf{5 4} \\
\mathbf{5 4} \\
\mathbf{5 0} \\
\mathbf{5 6} \\
\mathbf{5 5}\end{array}$ & $\begin{array}{l}60 \\
59 \\
60 \\
60 \\
60\end{array}$ & $\begin{array}{l}61 \\
63 \\
60 \\
59 \\
58\end{array}$ & $\begin{array}{l}70 \\
71 \\
70 \\
71 \\
73\end{array}$ & $\begin{array}{l}79 \\
80 \\
78 \\
73 \\
73\end{array}$ & $\begin{array}{l}84 \\
83 \\
84 \\
82 \\
81\end{array}$ & $\begin{array}{l}89 \\
90 \\
89 \\
90 \\
89\end{array}$ & $\begin{array}{l}81 \\
82 \\
83 \\
84 \\
85\end{array}$ & $\begin{array}{l}85 \\
85 \\
85 \\
86 \\
85\end{array}$ \\
\hline $\begin{array}{r}6 \\
7 \\
8 \\
9 \\
10\end{array}$ & $\begin{array}{l}79 \\
77 \\
76 \\
76 \\
76\end{array}$ & $\begin{array}{l}67 \\
65 \\
64 \\
65 \\
62\end{array}$ & $\begin{array}{l}62 \\
60 \\
60 \\
61 \\
57\end{array}$ & $\begin{array}{l}57 \\
57 \\
56 \\
56 \\
50\end{array}$ & $\begin{array}{l}60 \\
60 \\
57 \\
60 \\
58\end{array}$ & $\begin{array}{l}58 \\
-- \\
-- \\
-- \\
--\end{array}$ & $\begin{array}{l}73 \\
75 \\
75 \\
74 \\
75\end{array}$ & $\begin{array}{l}72 \\
71 \\
71 \\
72 \\
73\end{array}$ & $\begin{array}{l}82 \\
82 \\
83 \\
83 \\
83\end{array}$ & $\begin{array}{l}88 \\
88 \\
85 \\
84 \\
83\end{array}$ & $\begin{array}{l}86 \\
88 \\
87 \\
89 \\
89\end{array}$ & $\begin{array}{l}86 \\
85 \\
85 \\
85 \\
84\end{array}$ \\
\hline $\begin{array}{l}11 \\
12 \\
13 \\
14 \\
15\end{array}$ & $\begin{array}{l}75 \\
75 \\
76 \\
75 \\
75\end{array}$ & $\begin{array}{l}61 \\
61 \\
60 \\
61 \\
60\end{array}$ & $\begin{array}{l}\mathbf{5 7} \\
57 \\
\mathbf{5 5} \\
\mathbf{5 2} \\
\mathbf{5 0}\end{array}$ & $\begin{array}{l}\mathbf{5 5} \\
\mathbf{5 1} \\
\mathbf{5 0} \\
\mathbf{5 0} \\
\mathbf{5 2}\end{array}$ & $\begin{array}{l}60 \\
59 \\
59 \\
60 \\
61\end{array}$ & $\begin{array}{l}-- \\
-- \\
-- \\
-- \\
--\end{array}$ & $\begin{array}{l}75 \\
77 \\
77 \\
78 \\
78\end{array}$ & $\begin{array}{l}74 \\
74 \\
74 \\
73 \\
71\end{array}$ & $\begin{array}{l}84 \\
85 \\
85 \\
85 \\
85\end{array}$ & $\begin{array}{l}85 \\
86 \\
84 \\
85 \\
87\end{array}$ & $\begin{array}{l}88 \\
87 \\
88 \\
87 \\
86\end{array}$ & $\begin{array}{l}84 \\
83 \\
82 \\
84 \\
83\end{array}$ \\
\hline $\begin{array}{l}16 \\
17 \\
18 \\
19 \\
20\end{array}$ & $\begin{array}{l}75 \\
75 \\
75 \\
75 \\
75\end{array}$ & $\begin{array}{l}59 \\
61 \\
61 \\
62 \\
62\end{array}$ & $\begin{array}{l}\mathbf{5 0} \\
\mathbf{5 0} \\
\mathbf{5 0} \\
\mathbf{5 0} \\
\mathbf{5 0}\end{array}$ & $\begin{array}{l}\mathbf{5 5} \\
\mathbf{5 6} \\
\mathbf{5 6} \\
\mathbf{5 7} \\
\mathbf{5 9}\end{array}$ & $\begin{array}{l}63 \\
63 \\
65 \\
65 \\
64\end{array}$ & $\begin{array}{l}-\overline{6} \\
60 \\
61 \\
64 \\
62\end{array}$ & $\begin{array}{l}77 \\
74 \\
74 \\
75 \\
74\end{array}$ & $\begin{array}{l}72 \\
73 \\
74 \\
74 \\
75\end{array}$ & $\begin{array}{l}86 \\
85 \\
86 \\
85 \\
84\end{array}$ & $\begin{array}{l}87 \\
87 \\
88 \\
88 \\
88\end{array}$ & $\begin{array}{l}86 \\
87 \\
87 \\
88 \\
86\end{array}$ & $\begin{array}{l}82 \\
82 \\
81 \\
83 \\
83\end{array}$ \\
\hline $\begin{array}{l}21 \\
22 \\
23 \\
24 \\
25\end{array}$ & $\begin{array}{l}75 \\
75 \\
75 \\
75 \\
75\end{array}$ & $\begin{array}{l}63 \\
63 \\
63 \\
60 \\
60\end{array}$ & $\begin{array}{l}\mathbf{5 1} \\
\mathbf{5 0} \\
\mathbf{5 2} \\
\mathbf{4 8} \\
\mathbf{4 9}\end{array}$ & $\begin{array}{l}59 \\
56 \\
55 \\
55 \\
56\end{array}$ & $\begin{array}{l}64 \\
64 \\
64 \\
63 \\
63\end{array}$ & $\begin{array}{l}65 \\
64 \\
65 \\
67 \\
67\end{array}$ & $\begin{array}{l}75 \\
76 \\
77 \\
75 \\
75\end{array}$ & $\begin{array}{l}75 \\
74 \\
75 \\
76 \\
76\end{array}$ & $\begin{array}{l}85 \\
85 \\
85 \\
86 \\
85\end{array}$ & $\begin{array}{l}88 \\
87 \\
88 \\
89 \\
89\end{array}$ & $\begin{array}{l}86 \\
86 \\
85 \\
85 \\
86\end{array}$ & $\begin{array}{l}84 \\
83 \\
81 \\
80 \\
82\end{array}$ \\
\hline $\begin{array}{l}26 \\
27 \\
28 \\
29 \\
30 \\
31\end{array}$ & $\begin{array}{l}74 \\
73 \\
71 \\
71 \\
71 \\
70 \\
\end{array}$ & $\begin{array}{l}59 \\
60 \\
60 \\
60 \\
60 \\
-- \\
\end{array}$ & $\begin{array}{l}49 \\
50 \\
50 \\
51 \\
53 \\
52 \\
\end{array}$ & $\begin{array}{l}\mathbf{5 7} \\
\mathbf{5 8} \\
\mathbf{5 5} \\
\mathbf{5 7} \\
\mathbf{5 8} \\
\mathbf{5 9}\end{array}$ & $\begin{array}{l}63 \\
64 \\
63 \\
-- \\
-- \\
-- \\
\end{array}$ & $\begin{array}{l}68 \\
68 \\
68 \\
70 \\
69 \\
71 \\
\end{array}$ & $\begin{array}{l}78 \\
78 \\
77 \\
78 \\
78 \\
-- \\
\end{array}$ & $\begin{array}{l}77 \\
78 \\
78 \\
79 \\
80 \\
-- \\
\end{array}$ & $\begin{array}{l}86 \\
87 \\
87 \\
87 \\
87 \\
-- \\
\end{array}$ & $\begin{array}{l}89 \\
88 \\
87 \\
86 \\
78 \\
-- \\
\end{array}$ & $\begin{array}{l}85 \\
85 \\
86 \\
85 \\
86 \\
88 \\
\end{array}$ & $\begin{array}{l}83 \\
83 \\
83 \\
83 \\
83 \\
-- \\
\end{array}$ \\
\hline $\begin{array}{c}\text { Aver- } \\
\text { age }\end{array}$ & 75 & 62 & 54 & 55 & 61 & -. & 75 & 75 & 85 & 87 & 86 & 83 \\
\hline
\end{tabular}




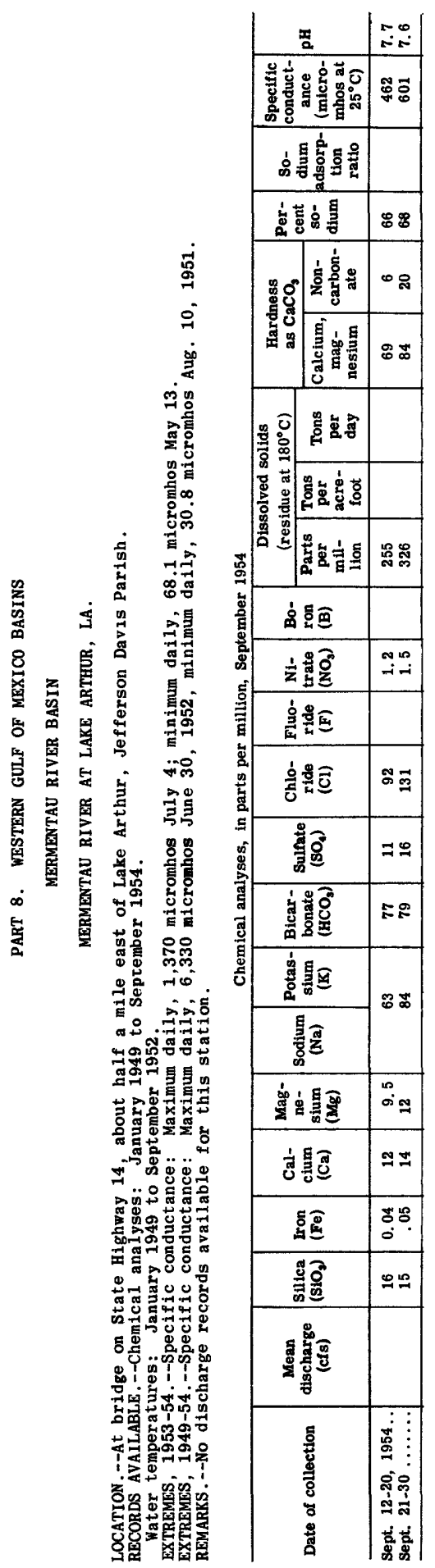


MERMENTAU RIVER BASIN--Cont inued

MERMENTAU RIVER AT LAKE ARTHUR, LA.--Continued

Specific conductance (micromhos at $25^{\circ} \mathrm{C}$ ) and chloride, in parts per million,

water year October 1953 to September 1954

\begin{tabular}{|c|c|c|c|c|c|c|}
\hline \multirow{2}{*}{ Day } & \multicolumn{2}{|c|}{ October } & \multicolumn{2}{|c|}{ November } & \multicolumn{2}{|c|}{ December } \\
\hline & Conductance & Chloride & Conductance & Chloride & Conductance & Chloride \\
\hline \begin{tabular}{l|}
1 \\
2 \\
3 \\
4 \\
5
\end{tabular} & $\begin{array}{l}152 \\
138 \\
135 \\
137 \\
160\end{array}$ & $\begin{array}{l}16 \\
14 \\
-- \\
-- \\
21\end{array}$ & $\begin{array}{l}153 \\
161 \\
160 \\
159 \\
148\end{array}$ & $\begin{array}{l}18 \\
18 \\
-2 \\
20 \\
16\end{array}$ & $\begin{array}{l}410 \\
224 \\
224 \\
225 \\
225\end{array}$ & $\begin{array}{l}91 \\
41 \\
-- \\
-- \\
--\end{array}$ \\
\hline $\begin{array}{r}6 \\
7 \\
8 \\
9 \\
10\end{array}$ & $\begin{array}{l}138 \\
133 \\
143 \\
140 \\
147\end{array}$ & $\begin{array}{l}14 \\
-- \\
-- \\
15 \\
16\end{array}$ & $\begin{array}{r}160 \\
164 \\
155 \\
155 \\
--\end{array}$ & $\begin{array}{l}18 \\
18 \\
18 \\
-- \\
--\end{array}$ & $\begin{array}{l}233 \\
225 \\
255 \\
225 \\
527\end{array}$ & $\begin{array}{r}-- \\
-- \\
57 \\
42 \\
141\end{array}$ \\
\hline $\begin{array}{l}11 \\
12 \\
13 \\
14 \\
15\end{array}$ & $\begin{array}{l}143 \\
143 \\
142 \\
147 \\
165\end{array}$ & $\begin{array}{l}-- \\
-- \\
-- \\
16 \\
19\end{array}$ & $\begin{array}{l}149 \\
149 \\
160 \\
162 \\
161\end{array}$ & $\begin{array}{l}-- \\
20 \\
22 \\
-- \\
--\end{array}$ & $\begin{array}{l}528 \\
534 \\
169 \\
160 \\
159\end{array}$ & $\begin{array}{r}143 \\
142 \\
32 \\
-- \\
--\end{array}$ \\
\hline $\begin{array}{l}16 \\
17 \\
18 \\
19 \\
20\end{array}$ & $\begin{array}{l}156 \\
149 \\
157 \\
148 \\
148\end{array}$ & $\begin{array}{l}18 \\
16 \\
19 \\
17 \\
--\end{array}$ & $\begin{array}{l}164 \\
190 \\
164 \\
164 \\
165\end{array}$ & $\begin{array}{l}23 \\
25 \\
-- \\
-- \\
--\end{array}$ & $\begin{array}{l}169 \\
165 \\
203 \\
184 \\
240\end{array}$ & $\begin{array}{l}31 \\
42 \\
39 \\
53\end{array}$ \\
\hline $\begin{array}{l}21 \\
22 \\
23 \\
24 \\
25\end{array}$ & $\begin{array}{l}140 \\
140 \\
145 \\
145 \\
145\end{array}$ & $\begin{array}{l}-- \\
-- \\
-- \\
-- \\
--\end{array}$ & $\begin{array}{l}174 \\
399 \\
412 \\
407 \\
408\end{array}$ & $\begin{array}{l}24 \\
89 \\
89 \\
-- \\
--\end{array}$ & $\begin{array}{l}243 \\
245 \\
245 \\
277 \\
258\end{array}$ & $\begin{array}{l}-- \\
-- \\
55 \\
61 \\
56\end{array}$ \\
\hline \multirow[t]{2}{*}{$\begin{array}{l}26 \\
27 \\
28 \\
29 \\
30 \\
31\end{array}$} & $\begin{array}{l}146 \\
155 \\
154 \\
151 \\
151 \\
150\end{array}$ & $\begin{array}{l}18 \\
18 \\
17 \\
17 \\
-- \\
--\end{array}$ & $\begin{array}{r}415 \\
409 \\
411 \\
408 \\
407 \\
--\end{array}$ & $\begin{array}{l}-- \\
-- \\
-- \\
-- \\
--\end{array}$ & $\begin{array}{l}245 \\
249 \\
416 \\
411 \\
365 \\
411\end{array}$ & $\begin{array}{r}54 \\
55 \\
108 \\
102 \\
94 \\
--\end{array}$ \\
\hline & \multicolumn{2}{|c|}{ January } & \multicolumn{2}{|c|}{ February } & \multicolumn{2}{|c|}{ March } \\
\hline \begin{tabular}{l|}
1 \\
2 \\
3 \\
4 \\
5
\end{tabular} & $\begin{array}{l}396 \\
390 \\
390 \\
324 \\
306\end{array}$ & $\begin{array}{l}-- \\
-- \\
99 \\
78 \\
--\end{array}$ & $\begin{array}{r}101 \\
- \\
110 \\
104 \\
112\end{array}$ & $\begin{array}{l}\cdots- \\
-- \\
-\overline{16} \\
17\end{array}$ & $\begin{array}{l}144 \\
141 \\
144 \\
150 \\
165\end{array}$ & $\begin{array}{l}-- \\
-- \\
21 \\
23 \\
23\end{array}$ \\
\hline \begin{tabular}{r|}
6 \\
7 \\
8 \\
9 \\
10
\end{tabular} & $\begin{array}{r}312 \\
- \\
306 \\
309 \\
104\end{array}$ & $\begin{array}{l}73 \\
-7 \\
74 \\
74 \\
16\end{array}$ & $\begin{array}{l}112 \\
116 \\
136 \\
115 \\
113\end{array}$ & $\begin{array}{l}-7 \\
18 \\
22 \\
17 \\
16\end{array}$ & $\begin{array}{l}-\overline{145} \\
146 \\
148 \\
150\end{array}$ & $\begin{array}{l}-- \\
24 \\
-- \\
--\end{array}$ \\
\hline $\begin{array}{l}11 \\
12 \\
13 \\
14 \\
15\end{array}$ & $\begin{array}{l}108 \\
116 \\
125 \\
117 \\
109\end{array}$ & $\begin{array}{l}17 \\
18 \\
20 \\
-- \\
--\end{array}$ & $\begin{array}{r}113 \\
112 \\
114 \\
-- \\
--\end{array}$ & $\begin{array}{l}-- \\
-- \\
-- \\
--\end{array}$ & $\begin{array}{l}148 \\
135 \\
136 \\
148 \\
152\end{array}$ & $\begin{array}{l}26 \\
22 \\
22 \\
25 \\
25\end{array}$ \\
\hline $\begin{array}{l}16 \\
17 \\
18 \\
19 \\
20\end{array}$ & $\begin{array}{r}101 \\
96.9 \\
96.4 \\
89.6 \\
79.6\end{array}$ & $\begin{array}{l}-- \\
-- \\
17 \\
11 \\
--\end{array}$ & $\begin{array}{l}117 \\
119 \\
123 \\
123 . \\
119\end{array}$ & $\begin{array}{l}-- \\
-- \\
-- \\
18 \\
18\end{array}$ & $\begin{array}{l}147 \\
144 \\
141 \\
139 \\
141\end{array}$ & $\begin{array}{l}-- \\
-- \\
-- \\
23 \\
23\end{array}$ \\
\hline $\begin{array}{l}21 \\
22 \\
23 \\
24 \\
25\end{array}$ & $\begin{array}{l}78.6 \\
79.4 \\
78.7 \\
83.0 \\
80.1\end{array}$ & $\begin{array}{l}-- \\
-- \\
11 \\
12 \\
11\end{array}$ & $\begin{array}{l}134 \\
135 \\
141 \\
134 \\
137\end{array}$ & $\begin{array}{l}20 \\
-- \\
-- \\
21\end{array}$ & $\begin{array}{l}146 \\
144 \\
150 \\
158 \\
183\end{array}$ & $\begin{array}{l}24 \\
-- \\
-- \\
-- \\
--\end{array}$ \\
\hline $\begin{array}{l}26 \\
27 \\
28 \\
29 \\
30 \\
31\end{array}$ & $\begin{array}{l}113 \\
100 \\
98.0 \\
101 \\
101\end{array}$ & $\begin{array}{l}-- \\
17 \\
15 \\
-- \\
-- \\
--\end{array}$ & $\begin{array}{r}135 \\
146 \\
142 \\
-- \\
-- \\
--\end{array}$ & $\begin{array}{l}20 \\
21 \\
21 \\
-- \\
-- \\
--\end{array}$ & $\begin{array}{l}180 \\
160 \\
158 \\
159 \\
187 \\
185\end{array}$ & $\begin{array}{l}29 \\
26 \\
-2 \\
26 \\
34 \\
--\end{array}$ \\
\hline
\end{tabular}


MERMENTAU RIVER BASIN--Continued

MERMENTAU RIVER A'T LAKE ARTHUR, LA.--Continued

Specific conductance (micromhos at $25^{\circ} \mathrm{C}$ ) and chloride, in parts per million, water year October 1953 to September 1954--Continued

\begin{tabular}{|c|c|c|c|c|c|c|}
\hline \multirow[t]{2}{*}{ Day } & \multicolumn{2}{|c|}{ April } & \multicolumn{2}{|c|}{ May } & \multicolumn{2}{|c|}{ June } \\
\hline & Conductance & Chloride & Conductance & Chloride & Conductance & Chloride \\
\hline $\begin{array}{l}1 \\
2 \\
3 \\
4 \\
5\end{array}$ & $\begin{array}{l}189 \\
192 \\
192 \\
192 \\
190\end{array}$ & $\begin{array}{l}34 \\
-- \\
-- \\
-- \\
--\end{array}$ & $\begin{array}{l}173 \\
165 \\
166 \\
167 \\
165\end{array}$ & $\begin{array}{l}-- \\
-- \\
--\end{array}$ & $\begin{array}{r}90.0 \\
88.7 \\
92.4 \\
142 \\
142\end{array}$ & $\begin{array}{l}-- \\
-- \\
12 \\
23 \\
--\end{array}$ \\
\hline $\begin{array}{r}6 \\
7 \\
8 \\
9 \\
10\end{array}$ & $\begin{array}{l}195 \\
190 \\
192 \\
190 \\
188\end{array}$ & $\begin{array}{l}36 \\
35 \\
\ldots \\
35 \\
34\end{array}$ & $\begin{array}{c}191 \\
193 \\
192 \\
97.2 \\
147\end{array}$ & $\begin{array}{l}34^{--} \\
13 \\
25\end{array}$ & $\begin{array}{l}132 \\
122 \\
149 \\
185 \\
330\end{array}$ & $\begin{array}{l}-- \\
-- \\
38 \\
71\end{array}$ \\
\hline $\begin{array}{l}11 \\
12 \\
13 \\
14 \\
15\end{array}$ & $\begin{array}{l}184 \\
228 \\
198 \\
178 \\
182\end{array}$ & $\begin{array}{l}32 \\
44 \\
33 \\
31 \\
--\end{array}$ & $\begin{array}{c}82.6 \\
75.6 \\
68.1 \\
102 \\
94.2\end{array}$ & $\begin{array}{c}12 \\
8,0 \\
16\end{array}$ & $\begin{array}{l}331 \\
330 \\
459 \\
456 \\
459\end{array}$ & $\begin{array}{r}-- \\
71 \\
102 \\
103 \\
104\end{array}$ \\
\hline $\begin{array}{l}16 \\
17 \\
18 \\
19 \\
20\end{array}$ & $\begin{array}{l}182 \\
184 \\
197 \\
182 \\
185\end{array}$ & $\begin{array}{l}-- \\
-- \\
34 \\
33 \\
--\end{array}$ & $\begin{array}{c}94.8 \\
94.5 \\
89.3 \\
89.8 \\
103\end{array}$ & $11^{--}$ & $\begin{array}{l}503 \\
507 \\
510 \\
511 \\
491\end{array}$ & $\begin{array}{r}117 \\
-- \\
-- \\
-- \\
--\end{array}$ \\
\hline $\begin{array}{l}21 \\
22 \\
23 \\
24 \\
25\end{array}$ & $\begin{array}{l}186 \\
183 \\
182 \\
180 \\
178\end{array}$ & $\begin{array}{l}30 \\
-- \\
-- \\
-- \\
--\end{array}$ & $\begin{array}{r}95.0 \\
-- \\
97.8 \\
91.1 \\
98.7\end{array}$ & $\begin{array}{l}-- \\
-- \\
-- \\
--\end{array}$ & $\begin{array}{l}489 \\
508 \\
490 \\
490 \\
584\end{array}$ & $\begin{array}{r}-- \\
-- \\
111 \\
136\end{array}$ \\
\hline $\begin{array}{l}26 \\
27 \\
28 \\
29 \\
30\end{array}$ & $\begin{array}{l}178 \\
180 \\
182 \\
173 \\
171\end{array}$ & $\begin{array}{l}-- \\
-- \\
-- \\
-- \\
28\end{array}$ & $\begin{array}{l}89.0 \\
96.2 \\
90.8 \\
88.0 \\
87.4\end{array}$ & $\begin{array}{l}-- \\
-- \\
12 \\
12 \\
--\end{array}$ & $\begin{array}{l}587 \\
582 \\
584 \\
642 \\
962\end{array}$ & $\begin{array}{r}-- \\
-- \\
135 \\
153 \\
243\end{array}$ \\
\hline \multirow[t]{2}{*}{31} & - & -- & - & -- & - & - \\
\hline & \multicolumn{2}{|c|}{ July } & \multicolumn{2}{|c|}{ August } & \multicolumn{2}{|c|}{ September } \\
\hline $\begin{array}{l}1 \\
2 \\
3 \\
4 \\
5\end{array}$ & $\begin{array}{r}971 \\
974 \\
968 \\
1,370 \\
1,330\end{array}$ & $\begin{array}{r}-- \\
242 \\
352 \\
--\end{array}$ & $\begin{array}{l}332 \\
325 \\
283 \\
285 \\
293\end{array}$ & $\begin{array}{l}-- \\
43 \\
43 \\
-- \\
--\end{array}$ & $\begin{array}{l}347 \\
409 \\
390 \\
353 \\
351\end{array}$ & $\begin{array}{l}-- \\
73 \\
67 \\
66 \\
--\end{array}$ \\
\hline $\begin{array}{r}6 \\
7 \\
8 \\
9 \\
10\end{array}$ & $\begin{array}{l}1,330 \\
1,290 \\
1,320 \\
1,280 \\
1,280\end{array}$ & $\begin{array}{l}-- \\
-- \\
-- \\
330\end{array}$ & $\begin{array}{l}282 \\
336 \\
287 \\
289 \\
285\end{array}$ & $\begin{array}{l}42 \\
52 \\
44 \\
-- \\
--\end{array}$ & $\begin{array}{l}\mathbf{3 5 3} \\
\mathbf{3 5 2} \\
\mathbf{3 4 9} \\
\mathbf{3 5 1} \\
\mathbf{3 5 3}\end{array}$ & $\begin{array}{l}-- \\
-- \\
65 \\
--\end{array}$ \\
\hline $\begin{array}{l}11 \\
12 \\
13 \\
14 \\
15\end{array}$ & $\begin{array}{r}829 \\
826 \\
1,090 \\
1,090 \\
1,090\end{array}$ & $\begin{array}{r}-- \\
204 \\
282 \\
275 \\
--\end{array}$ & $\begin{array}{l}301 \\
281 \\
284 \\
283 \\
278\end{array}$ & $\begin{array}{l}-- \\
43 \\
-- \\
--\end{array}$ & $\begin{array}{l}395 \\
378 \\
377 \\
331\end{array}$ & $\begin{array}{l}-- \\
-- \\
-- \\
-- \\
--\end{array}$ \\
\hline $\begin{array}{l}16 \\
17 \\
18 \\
19 \\
20\end{array}$ & $\begin{array}{r}1,100 \\
397 \\
397 \\
1,080 \\
1,080\end{array}$ & $\begin{array}{r}275 \\
79 \\
78 \\
278 \\
--\end{array}$ & $\begin{array}{l}294 \\
290 \\
278 \\
294 \\
256\end{array}$ & $\begin{array}{l}-7 \\
37 \\
43 \\
-- \\
--\end{array}$ & $\begin{array}{l}514 \\
522 \\
519 \\
521 \\
521\end{array}$ & $\begin{array}{l}-- \\
-- \\
-- \\
--\end{array}$ \\
\hline $\begin{array}{l}21 \\
22\end{array}$ & $\begin{array}{l}1,090 \\
1,090\end{array}$ & $\begin{array}{l}278 \\
281\end{array}$ & $\begin{array}{l}258 \\
268\end{array}$ & -- & $\begin{array}{l}\mathbf{5 3 1} \\
504\end{array}$ & -- \\
\hline $\begin{array}{l}23 \\
24 \\
25\end{array}$ & $\begin{array}{r}398 \\
394 \\
--\end{array}$ & -- & $\begin{array}{l}266 \\
248 \\
252\end{array}$ & $\begin{array}{l}-- \\
39 \\
37\end{array}$ & $\begin{array}{l}512 \\
530 \\
513\end{array}$ & $\begin{array}{l}-- \\
--\end{array}$ \\
\hline $\begin{array}{l}26 \\
27 \\
28 \\
29 \\
30 \\
31\end{array}$ & $\begin{array}{l}406 \\
401 \\
402 \\
400 \\
325 \\
332\end{array}$ & $\begin{array}{l}-- \\
-- \\
-2 \\
78 \\
43 \\
-2\end{array}$ & $\begin{array}{l}253 \\
257 \\
253 \\
253 \\
255 \\
253\end{array}$ & $\begin{array}{l}-- \\
-- \\
-- \\
-- \\
37\end{array}$ & $\begin{array}{r}524 \\
515 \\
777 \\
794 \\
791 \\
--\end{array}$ & $\begin{array}{l}-- \\
-- \\
-- \\
-- \\
--\end{array}$ \\
\hline
\end{tabular}




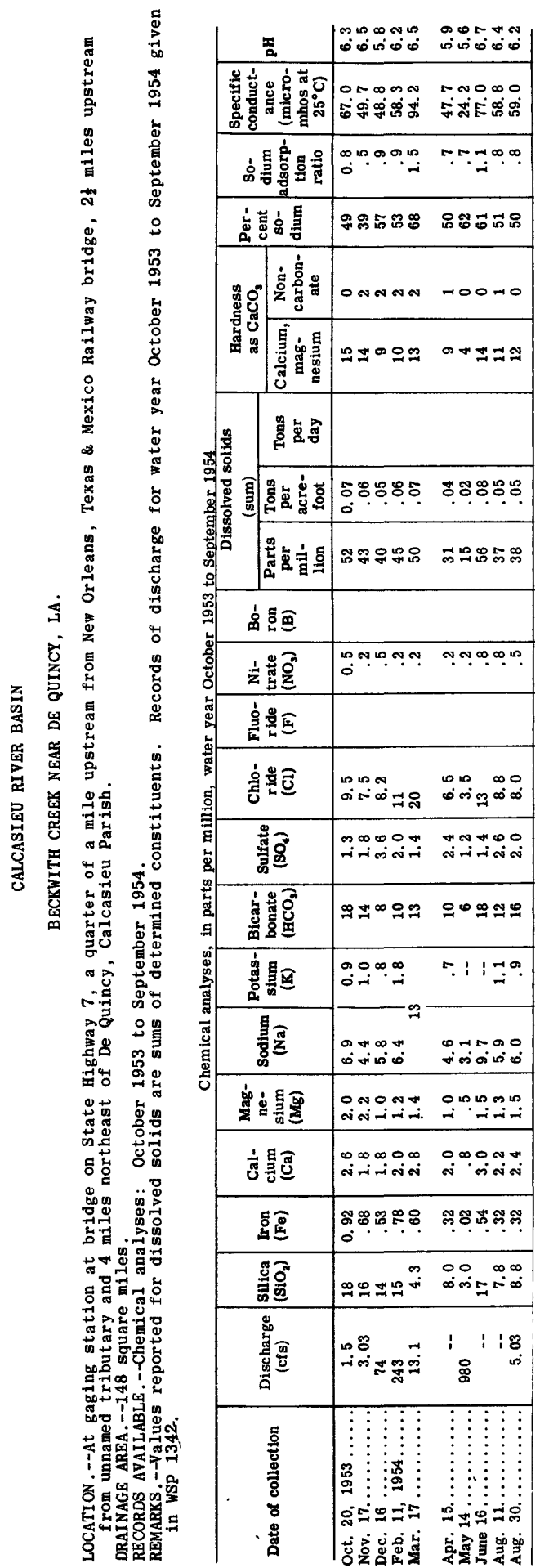


CALCASIEU RIVER BASIN - - Continued

CALCASIEU RIVER AT MOSS BLUFF, LA.

LOCATION.--At bridge on U. S. Highway 171 at Moss Bluff, Calcasieu Parish, 5 miles northeast of Lake Charles.

RECORDS AVAILABLE.--Chemical analyses: October 1951 to September 1954.

Water temperatures: October 1951 to September 1954.

EXTREMES, 1953-54.--Specific conductance: Top samples- Maximum daily, 22,700 micromhos Sept. 19; minimum daily, 25.8 micromhos May 9. Bottom samples-Maximum daily, 36, 200 micromhios Sept. 18; minimum daily, 34.6 micromhos May 13 .

Water temperatures: Maximum observed, $88^{\circ} \mathrm{F}$ July 1 ; minimum observed, $43^{\circ} \mathrm{F} \mathrm{Dec} .24$.

EXTREMES, 1952-54.--Specific conductance: Top samples-Maximum daily, 22,700 micromhos Sept. 19, 1954; minimum daily, 23.9 micromhos May 7-9, 1953. Bot tom samples-Maximum daily, 36,200 micromhos Sept. 18, 1954; minimum daily, 26.8 micromhos May 5, 1953.

Water temperatures: Maximum observed, $88^{\circ} \mathrm{F}$ June 22, 25, July 9-10, 1953, July 1, 1954: minimum observed, $43^{\circ} \mathrm{F}$ Dec. 24,1953 .

REMARKS.--Top and bottom samples collected at this station. No discharge records available.

Specific conductance (micromhios at $25^{\circ} \mathrm{C}$ ) and chloride, in parts per million, water year October 1953 to September 1954

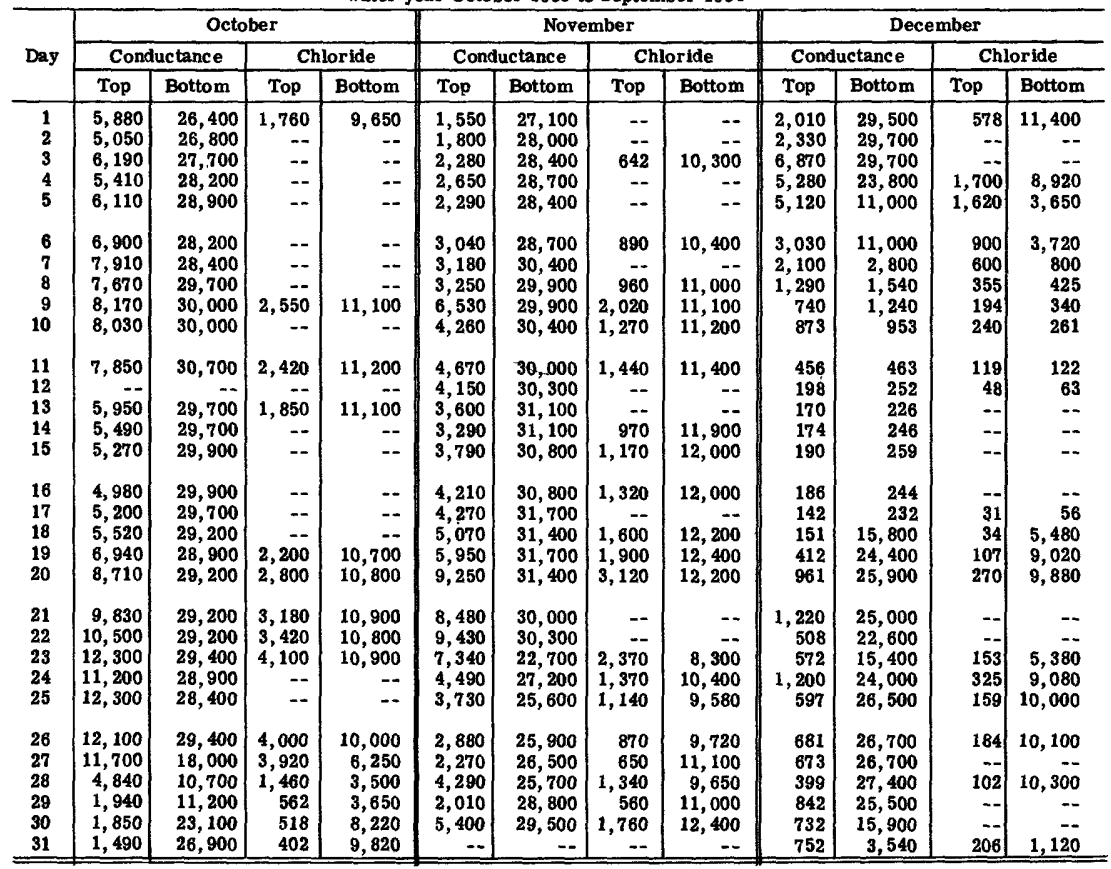


CALCASIEU RIVER BASIN--Continued

CALCASIEU RIVER AT MOSS BLUFF, LA.--Continued

Specific conductance (micromhos at $25^{\circ} \mathrm{C}$ ) and chloride, in parts per million, water year October 1953 to September 1954--Continued

\begin{tabular}{|c|c|c|c|c|c|c|c|c|c|c|c|c|}
\hline \multirow{3}{*}{ Day } & \multicolumn{4}{|c|}{ January } & \multicolumn{4}{|c|}{ February } & \multicolumn{4}{|c|}{ March } \\
\hline & \multicolumn{2}{|c|}{ Conductance } & \multicolumn{2}{|c|}{ Chloride } & \multicolumn{2}{|c|}{ Conductance } & \multicolumn{2}{|c|}{ Chloride } & \multicolumn{2}{|c|}{ Conductance } & \multicolumn{2}{|c|}{ Chloride } \\
\hline & Top & Bottom & Top & Bottom & Top & Bottom & Top & Bottom & Top & Bottom & Top & Bottom \\
\hline $\begin{array}{l}1 \\
2 \\
3 \\
4 \\
5\end{array}$ & $\begin{array}{l}514 \\
296 \\
199 \\
210 \\
184\end{array}$ & $\begin{array}{r}809 \\
1,060 \\
448 \\
422 \\
241\end{array}$ & $\begin{array}{r}131 \\
74 \\
48 \\
-- \\
--\end{array}$ & $\begin{array}{r}222 \\
305 \\
123 \\
-- \\
--\end{array}$ & \begin{tabular}{r|}
137 \\
70.0 \\
83.9 \\
78.8 \\
86.5
\end{tabular} & $\begin{array}{c}256 \\
94.4 \\
115 \\
79.4 \\
102\end{array}$ & $\begin{array}{l}30 \\
12 \\
16 \\
14 \\
--\end{array}$ & $\begin{array}{l}60 \\
18 \\
24 \\
14 \\
--\end{array}$ & $\begin{array}{r}731 \\
1,180 \\
1,070 \\
951 \\
1,330\end{array}$ & $\begin{array}{l}22,100 \\
22,900 \\
19,000 \\
17,800 \\
20,800\end{array}$ & $\begin{array}{r}188 \\
315 \\
-- \\
-- \\
--\end{array}$ & $\begin{array}{r}7,750 \\
8,020 \\
-- \\
-- \\
--\end{array}$ \\
\hline $\begin{array}{r}6 \\
7 \\
8 \\
9 \\
10\end{array}$ & $\begin{array}{l}257 \\
185 \\
122 \\
117 \\
125\end{array}$ & $\begin{array}{l}318 \\
330 \\
144 \\
121 \\
168\end{array}$ & $\begin{array}{l}44^{--} \\
27^{--} \\
--\end{array}$ & $\begin{array}{l}85^{--} \\
32 \\
-- \\
--\end{array}$ & $\begin{array}{c}82.0 \\
83.5 \\
131 \\
447 \\
509\end{array}$ & $\begin{array}{r}83.7 \\
143 \\
2,850 \\
16,000 \\
17,800\end{array}$ & $\begin{array}{r}-- \\
14 \\
25 \\
111 \\
128\end{array}$ & $\begin{array}{r}-2 \\
30 \\
820 \\
5,400 \\
6,020\end{array}$ & $\begin{array}{l}1,210 \\
1,490 \\
1,490 \\
1,360 \\
1,210\end{array}$ & $\begin{array}{l}19,500 \\
22,600 \\
23,000 \\
24,500 \\
24,300\end{array}$ & $\begin{array}{l}-- \\
-- \\
-- \\
322\end{array}$ & $\begin{array}{r}= \\
=- \\
-- \\
8,620\end{array}$ \\
\hline $\begin{array}{l}11 \\
12 \\
13 \\
14 \\
15\end{array}$ & $\begin{array}{r}116 \\
93.0 \\
61.2 \\
53.4 \\
55.3\end{array}$ & $\begin{array}{r}203 \\
132 \\
60.8 \\
54.5 \\
57.1\end{array}$ & $\begin{array}{r}24 \\
18 \\
11 \\
8.8 \\
--\end{array}$ & $\begin{array}{l}46 \\
28 \\
10 \\
8.5 \\
--\end{array}$ & $\begin{array}{l}524 \\
459 \\
748 \\
806 \\
965\end{array}$ & $\begin{array}{l}16,500 \\
16,200 \\
21,500 \\
22,300 \\
20,600\end{array}$ & $\begin{array}{r}-- \\
\overline{-} \\
194 \\
-- \\
255\end{array}$ & $\begin{array}{r}-- \\
7,500 \\
7,150\end{array}$ & $\begin{array}{r}2,090 \\
1,960 \\
1,040 \\
839 \\
1,280\end{array}$ & $\begin{array}{r}24,600 \\
8,790 \\
24,000 \\
24,300 \\
22,100\end{array}$ & $\begin{array}{r}588 \\
552 \\
275 \\
218 \\
--\end{array}$ & $\begin{array}{r}8,800 \\
2,750 \\
8,480 \\
8,620 \\
--\end{array}$ \\
\hline $\begin{array}{l}16 \\
17 \\
18 \\
19 \\
20\end{array}$ & $\begin{array}{l}55.9 \\
61.0 \\
74.3 \\
89.1 \\
89.6\end{array}$ & $\begin{array}{r}56.4 \\
59.9 \\
76.9 \\
94.7 \\
105\end{array}$ & $18^{--}$ & $18^{--}$ & \begin{tabular}{|r|}
1,440 \\
800 \\
734 \\
800 \\
3,450
\end{tabular} & $\begin{array}{l}21,700 \\
21,200 \\
21,900 \\
23,200 \\
19,500\end{array}$ & $\begin{array}{r}392 \\
209 \\
-- \\
-- \\
1,020\end{array}$ & $\begin{array}{r}7,550 \\
7,420 \\
-- \\
-- \\
6,700\end{array}$ & $\begin{array}{l}1,510 \\
1,590 \\
1,850 \\
2,100 \\
1,890\end{array}$ & $\begin{array}{l}21,400 \\
25,400 \\
22,700 \\
22,600 \\
20,800\end{array}$ & $\begin{array}{r}-- \\
432 \\
515 \\
585 \\
--\end{array}$ & $\begin{array}{r}-- \\
9,050 \\
8,000 \\
7,950 \\
--\end{array}$ \\
\hline $\begin{array}{l}21 \\
22 \\
23 \\
24 \\
25\end{array}$ & $\begin{array}{r}87.8 \\
83.5 \\
90.2 \\
100 \\
114\end{array}$ & $\begin{array}{c}88.3 \\
84.2 \\
90.9 \\
101 \\
116\end{array}$ & $\begin{array}{l}16 \\
17^{--} \\
19\end{array}$ & $\begin{array}{l}16 \\
16 \\
19 \\
--\end{array}$ & $\begin{array}{r}1,160 \\
973 \\
1,000 \\
991 \\
997\end{array}$ & $\begin{array}{l}22,000 \\
22,400 \\
17,200 \\
22,300 \\
22,400\end{array}$ & $\begin{array}{r}318 \\
-- \\
-- \\
-- \\
--\end{array}$ & $\begin{array}{r}7,700 \\
-- \\
-- \\
- \\
-\end{array}$ & $\begin{array}{l}2,160 \\
1,870 \\
1,940 \\
1,360 \\
4,060\end{array}$ & $\begin{array}{l}25,900 \\
22,900 \\
21,400 \\
23,700 \\
26,200\end{array}$ & $\begin{array}{r}615 \\
-- \\
-- \\
372 \\
1,210\end{array}$ & $\begin{array}{r}9,350 \\
-- \\
- \\
8,400 \\
9,480\end{array}$ \\
\hline \multirow[t]{2}{*}{$\begin{array}{l}26 \\
27 \\
28 \\
29 \\
30 \\
31 \\
\end{array}$} & \begin{tabular}{|c|}
86.3 \\
66.2 \\
60.1 \\
70.4 \\
102 \\
86.9 \\
\end{tabular} & $\begin{array}{r}88.9 \\
66.2 \\
61.3 \\
69.6 \\
1,280 \\
714 \\
\end{array}$ & $\begin{array}{l}16 \\
11 \\
13 \\
13 \\
22 \\
16 \\
\end{array}$ & $\begin{array}{c}17 \\
12 \\
12 \\
12 \\
345 \\
188 \\
\end{array}$ & $\begin{array}{r}1,050 \\
1,340 \\
879 \\
- \\
- \\
- \\
\end{array}$ & $\begin{array}{r}19,700 \\
17,700 \\
19,900 \\
-- \\
-\therefore \\
-- \\
\end{array}$ & $\begin{array}{r}-- \\
370 \\
230 \\
-- \\
-- \\
-- \\
\end{array}$ & $\begin{array}{r}5,980 \\
6,900 \\
-- \\
-- \\
-- \\
\end{array}$ & $\begin{array}{r}2,140 \\
2,040 \\
1,500 \\
1,240 \\
1,230 \\
926 \\
\end{array}$ & $\begin{array}{l}25,100 \\
21,400 \\
25,800 \\
25,900 \\
25,500 \\
19,100 \\
\end{array}$ & $\begin{array}{r}605 \\
-- \\
-- \\
-- \\
335 \\
249 \\
\end{array}$ & $\begin{array}{r}8,980 \\
-- \\
-- \\
-- \\
9,150 \\
-- \\
\end{array}$ \\
\hline & \multicolumn{4}{|c|}{ April } & \multicolumn{4}{|c|}{ May } & \multicolumn{4}{|c|}{ June } \\
\hline $\begin{array}{l}1 \\
2 \\
3 \\
4 \\
5\end{array}$ & $\begin{array}{r}1,020 \\
1,070 \\
1,020 \\
1,120 \\
866\end{array}$ & $\begin{array}{l}19,100 \\
18,400 \\
18,200 \\
24,800 \\
24,900\end{array}$ & $\begin{array}{r}280 \\
260 \\
-- \\
-- \\
234\end{array}$ & $\begin{array}{r}4,850 \\
6,250 \\
-- \\
-- \\
9,050\end{array}$ & $\begin{array}{c}2,760 \\
2,710 \\
1,330 \\
169 \\
67.1\end{array}$ & $\begin{array}{r}10,200 \\
11,700 \\
2,060 \\
204\end{array}$ & $\begin{array}{r}780^{--} \\
358 \\
38 \\
12\end{array}$ & $\begin{array}{r}3,840 \\
552 \\
45 \\
--\end{array}$ & $\begin{array}{c}126 \\
96.4 \\
122 \\
107\end{array}$ & $\begin{array}{l}202 \\
354 \\
164 \\
109 \\
163\end{array}$ & $\begin{array}{l}-- \\
16 \\
23 \\
-- \\
--\end{array}$ & $\begin{array}{l}-- \\
86 \\
34 \\
-- \\
--\end{array}$ \\
\hline $\begin{array}{r}6 \\
7 \\
8 \\
9 \\
10\end{array}$ & $\begin{array}{r}884 \\
875 \\
1,030 \\
748 \\
766\end{array}$ & $\begin{array}{l}25,100 \\
24,500 \\
24,300 \\
24,000 \\
18,800\end{array}$ & $\begin{array}{c}-- \\
-- \\
201 \\
205\end{array}$ & $\begin{array}{r}-- \\
- \\
-- \\
6,420 \\
4,300\end{array}$ & $\begin{array}{l}39.4 \\
27.7 \\
26.8 \\
25.8 \\
27.6\end{array}$ & $\begin{array}{l}-- \\
-- \\
-- \\
--\end{array}$ & $\begin{array}{l}-- \\
-- \\
-- \\
-- \\
--\end{array}$ & $\begin{array}{l}-- \\
-- \\
-- \\
--\end{array}$ & $\begin{array}{c}93.4 \\
262 \\
364 \\
699 \\
834\end{array}$ & $\begin{array}{r}620 \\
4,390 \\
8,130 \\
3,580 \\
6,220\end{array}$ & $\begin{array}{r}14 \\
61 \\
86 \\
180 \\
--\end{array}$ & $\begin{array}{r}158 \\
1,320 \\
2,550 \\
1,050 \\
--\end{array}$ \\
\hline $\begin{array}{l}11 \\
12 \\
13 \\
14 \\
15\end{array}$ & $\begin{array}{r}659 \\
517 \\
1,060 \\
790 \\
627\end{array}$ & $\begin{array}{l}13,100 \\
16,200 \\
16,700 \\
20,500 \\
21,300\end{array}$ & $\begin{array}{r}172 \\
131 \\
288 \\
-- \\
--\end{array}$ & $\begin{array}{r}3,900 \\
5,480 \\
5,650 \\
-2 \\
--\end{array}$ & $\begin{array}{l}27.6 \\
30.3 \\
32.6 \\
38.6 \\
45.0\end{array}$ & $\begin{array}{r}-- \\
-- \\
34.6 \\
40.1 \\
42.3\end{array}$ & $\begin{array}{r}-- \\
-- \\
3.5 \\
--\end{array}$ & $\begin{array}{r}-- \\
3.2 \\
-- \\
--\end{array}$ & $\begin{array}{r}765 \\
856 \\
1,150 \\
1,540 \\
1,910\end{array}$ & $\begin{array}{l}5,560 \\
5,020 \\
5,480 \\
6,090 \\
7,100\end{array}$ & $\begin{array}{r}-- \\
224 \\
302 \\
-- \\
--\end{array}$ & $\begin{array}{r}-- \\
1,510 \\
1,660 \\
-- \\
--\end{array}$ \\
\hline $\begin{array}{l}16 \\
17 \\
18 \\
19 \\
20\end{array}$ & $\begin{array}{l}676 \\
531 \\
577 \\
462 \\
410\end{array}$ & $\begin{array}{r}15,300 \\
13,600 \\
2,530 \\
949 \\
1,040\end{array}$ & $\begin{array}{l}179 \\
137 \\
151 \\
117 \\
106\end{array}$ & $\begin{array}{r}5,120 \\
4,520 \\
710 \\
256 \\
282\end{array}$ & $\begin{array}{l}39.9 \\
41.1 \\
39.5 \\
41.4 \\
43.6\end{array}$ & $\begin{array}{l}41.4 \\
42.2 \\
40.0 \\
42.6 \\
43.9\end{array}$ & $\begin{array}{c}-- \\
5.0 \\
-- \\
--\end{array}$ & $\begin{array}{r}-- \\
4.8 \\
-- \\
-- \\
--\end{array}$ & $\begin{array}{l}2,280 \\
2,490 \\
2,500 \\
2,070 \\
2,180\end{array}$ & $\begin{array}{r}9,780 \\
10,200 \\
7,950 \\
10,800 \\
13,100\end{array}$ & $\begin{array}{r}-\overline{702} \\
705 \\
578 \\
--\end{array}$ & $\begin{array}{r}-- \\
3,250 \\
2,500 \\
3,520 \\
--\end{array}$ \\
\hline $\begin{array}{l}21 \\
22 \\
23 \\
24 \\
25\end{array}$ & $\begin{array}{l}425 \\
231 \\
197 \\
144 \\
117\end{array}$ & $\begin{array}{l}774 \\
615 \\
289 \\
237 \\
138\end{array}$ & $\begin{array}{r}104 \\
55 \\
46 \\
+- \\
--\end{array}$ & $\begin{array}{r}200 \\
159 \\
70 \\
-- \\
--\end{array}$ & $\begin{array}{l}47.0 \\
52.1 \\
55.6 \\
54.4 \\
57.6\end{array}$ & $\begin{array}{l}47.8 \\
52.4 \\
55.2 \\
54.5 \\
58.7\end{array}$ & $\begin{array}{l}-- \\
-- \\
-- \\
-- \\
--\end{array}$ & $\begin{array}{l}-- \\
-- \\
-- \\
--\end{array}$ & $\begin{array}{l}2,540 \\
1,930 \\
2,090 \\
2,470 \\
2,960\end{array}$ & $\begin{array}{l}11,700 \\
15,000 \\
16,500 \\
17,200 \\
18,300\end{array}$ & $\begin{array}{r}722 \\
\because- \\
-- \\
870\end{array}$ & $\begin{array}{r}3,840 \\
- \\
- \\
6,320\end{array}$ \\
\hline $\begin{array}{l}26 \\
27 \\
28 \\
29 \\
30 \\
31 \\
\end{array}$ & $\begin{array}{c}74.9 \\
72.9 \\
79.7 \\
440 \\
723 \\
---\end{array}$ & $\begin{array}{r}130 \\
318 \\
5,120 \\
8,010 \\
11,900 \\
--\end{array}$ & $\begin{array}{r}-. \\
12 \\
14 \\
112 \\
189 \\
--\end{array}$ & $\begin{array}{r}77 \\
77 \\
1,560 \\
2,500 \\
3,890 \\
--\end{array}$ & $\begin{array}{c}61.6 \\
59.1 \\
195 \\
298 \\
162 \\
217\end{array}$ & $\begin{array}{l}81.8 \\
110 \\
639 \\
738 \\
672 \\
502\end{array}$ & $\begin{array}{c}8.2 \\
44 \\
-- \\
-- \\
--\end{array}$ & $\begin{array}{r}22^{--} \\
166 \\
-- \\
--\end{array}$ & $\begin{array}{r}3,570 \\
3,800 \\
3,810 \\
4,300 \\
4,140 \\
\ldots\end{array}$ & $\begin{array}{r}16,800 \\
18,200 \\
18,200 \\
16,800 \\
16,300 \\
--\end{array}$ & $\begin{array}{r}-- \\
-- \\
1,240 \\
--\end{array}$ & $\begin{array}{r}-- \\
-- \\
-- \\
-- \\
5,530 \\
--\end{array}$ \\
\hline
\end{tabular}


CALCASIEU RIVER BASIN--Continued

CALCASIEU RIVER AT MOSS BLUFF, LA.--Continued

Specific conductance (micromhos at $25^{\circ} \mathrm{C}$ ) and chloride, in parts per million, water year October 1953 to September 1954--Continued

\begin{tabular}{|c|c|c|c|c|c|c|c|c|c|c|c|c|}
\hline \multirow{3}{*}{ Day } & \multicolumn{4}{|c|}{ July } & \multicolumn{4}{|c|}{ August } & \multicolumn{4}{|c|}{ September } \\
\hline & \multicolumn{2}{|c|}{ Conductance } & \multicolumn{2}{|c|}{ Chloride } & \multicolumn{2}{|c|}{ Conductance } & \multicolumn{2}{|c|}{ Chloride } & \multicolumn{2}{|c|}{ Conductance } & \multicolumn{2}{|c|}{ Chloride } \\
\hline & Top & Bottom & Top & Bottom & Top & Bottom & Top & Bottom & Top & Bottom & Top & Bottom \\
\hline $\begin{array}{l}1 \\
2 \\
3 \\
4 \\
5\end{array}$ & $\begin{array}{l}4,520 \\
4,680 \\
5,070 \\
4,900 \\
5,170\end{array}$ & $\begin{array}{l}17,500 \\
17,300 \\
16,900 \\
19,400 \\
19,000\end{array}$ & $\begin{array}{r}= \\
=- \\
= \\
1,580\end{array}$ & $\begin{array}{r}-- \\
-- \\
-- \\
-- \\
6,560\end{array}$ & $\begin{array}{l}7,770 \\
5,190 \\
3,720 \\
2,520 \\
2,610\end{array}$ & $\begin{array}{l}24,100 \\
25,100 \\
24,100 \\
23,500 \\
29,400\end{array}$ & $\begin{array}{r}1,560 \\
1,090 \\
-- \\
--\end{array}$ & $\begin{array}{r}9,170 \\
8,680 \\
-- \\
--\end{array}$ & $\begin{array}{r}8,140 \\
-- \\
7,980 \\
8,830 \\
7,260\end{array}$ & $\begin{array}{l}34,000 \\
34,400 \\
34,300 \\
32,200 \\
35,400\end{array}$ & $\begin{array}{r}\overline{-} \\
- \\
- \\
2,270\end{array}$ & $\begin{array}{r}-- \\
-- \\
-- \\
13,500\end{array}$ \\
\hline $\begin{array}{r}6 \\
7 \\
8 \\
9 \\
10\end{array}$ & $\begin{array}{l}5,570 \\
6,160 \\
5,720 \\
5,670 \\
5,550\end{array}$ & $\begin{array}{l}21,300 \\
23,000 \\
23,400 \\
23,900 \\
23,400\end{array}$ & $\begin{array}{r}-- \\
-- \\
-- \\
1,690\end{array}$ & $\begin{array}{r}-- \\
-- \\
-- \\
-- \\
8,410\end{array}$ & $\begin{array}{l}2,580 \\
2,650 \\
2,940 \\
3,570 \\
3,400\end{array}$ & $\begin{array}{l}29,400 \\
25,500 \\
25,300 \\
28,800 \\
27,200\end{array}$ & $\begin{array}{l}-- \\
-- \\
-- \\
990\end{array}$ & $\begin{array}{r}-- \\
-- \\
-- \\
9,900\end{array}$ & $\begin{array}{r}12,050 \\
8,430 \\
10,100 \\
10,900 \\
12,600\end{array}$ & $\begin{array}{l}32,800 \\
32,400 \\
33,800 \\
32,300 \\
35,600\end{array}$ & $\begin{array}{r}4,020 \\
- \\
3,5 \\
4,190\end{array}$ & $\begin{array}{r}12,600 \\
-- \\
12,300 \\
13,800\end{array}$ \\
\hline $\begin{array}{l}11 \\
12 \\
13 \\
14 \\
15\end{array}$ & $\begin{array}{l}5,450 \\
6,760 \\
7,090 \\
8,340 \\
9,780\end{array}$ & $\begin{array}{r}23,200 \\
8,520 \\
8,340 \\
8,660 \\
22,700\end{array}$ & $\begin{array}{r}1,700 \\
2,090 \\
- \\
3,170\end{array}$ & $\begin{array}{r}8,280 \\
2,720 \\
-- \\
-- \\
8,160\end{array}$ & $\begin{array}{l}3,830 \\
4,950 \\
5,490 \\
6,800 \\
6,860\end{array}$ & $\begin{array}{l}28,300 \\
26,000 \\
30,000 \\
31,400 \\
31,700\end{array}$ & $\begin{array}{r}1,140 \\
-- \\
1,680 \\
2,100 \\
--\end{array}$ & $\begin{array}{r}10,500 \\
-- \\
11,300 \\
11,800 \\
--\end{array}$ & $\begin{array}{l}14,000 \\
14,000 \\
13,000 \\
15,200 \\
14,600\end{array}$ & $\begin{array}{l}34,900 \\
32,600 \\
34,600 \\
33,200 \\
33,700\end{array}$ & $\begin{array}{r}4,830 \\
-- \\
- \\
- \\
-\end{array}$ & $\begin{array}{r}13,700 \\
-- \\
-- \\
=- \\
--\end{array}$ \\
\hline $\begin{array}{l}16 \\
17 \\
18 \\
19 \\
20\end{array}$ & $\begin{array}{r}10,000 \\
9,420 \\
9,260 \\
8,540 \\
7,970\end{array}$ & $\begin{array}{r}20,600 \\
22,800 \\
11,900 \\
\cdot 23,900 \\
24,400\end{array}$ & $\begin{array}{r}-- \\
-- \\
2,700 \\
--\end{array}$ & $\begin{array}{r}-- \\
-- \\
-- \\
8,580 \\
--\end{array}$ & $\begin{array}{r}10,600 \\
7,540 \\
8,210 \\
9,170 \\
8,660\end{array}$ & $\begin{array}{l}31,700 \\
32,500 \\
32,900 \\
33,900 \\
33,800\end{array}$ & $\begin{array}{r}3,470 \\
- \\
- \\
2,770\end{array}$ & $\begin{array}{r}11,900 \\
- \\
\cdots \\
12,900\end{array}$ & $\begin{array}{l}19,100 \\
19,300 \\
21,300 \\
22,700 \\
21,600\end{array}$ & $\begin{array}{r}36,100 \\
29,000 \\
36,200 \\
36,000 \\
33,400\end{array}$ & $\begin{array}{r}6,760 \\
6,910 \\
- \\
-- \\
--\end{array}$ & $\begin{array}{r}14,400 \\
10,900 \\
-- \\
--\end{array}$ \\
\hline $\begin{array}{l}21 \\
22 \\
23 \\
24 \\
25\end{array}$ & $\begin{array}{l}7,000 \\
6,900 \\
6,190 \\
5,930 \\
5,080\end{array}$ & $\begin{array}{l}22,400 \\
27,100 \\
27,100 \\
27,600 \\
26,700\end{array}$ & $\begin{array}{r}-- \\
-- \\
1,890 \\
-- \\
--\end{array}$ & $\begin{array}{r}-- \\
\overline{--} \\
9,900 \\
-- \\
--\end{array}$ & $\begin{array}{l}8,610 \\
7,820 \\
8,260 \\
8,820 \\
9,410\end{array}$ & $\begin{array}{l}33,400 \\
32,800 \\
33,800 \\
34,000 \\
33,700\end{array}$ & $\begin{array}{r}-- \\
-- \\
-- \\
2,850 \\
3,050\end{array}$ & $\begin{array}{r}\cdots \\
\cdots \\
13,000 \\
12,800\end{array}$ & $\begin{array}{l}20,800 \\
18,700 \\
15,200 \\
13,800 \\
13,800\end{array}$ & $\begin{array}{l}35,100 \\
34,700 \\
35,100 \\
35,400 \\
34,800\end{array}$ & $\begin{array}{l}-- \\
-- \\
-- \\
--\end{array}$ & $\begin{array}{l}-- \\
-- \\
--\end{array}$ \\
\hline $\begin{array}{l}26 \\
27 \\
28 \\
29 \\
30 \\
31 \\
\end{array}$ & $\begin{array}{l}5,200 \\
5,760 \\
6,010 \\
6,560 \\
9,780 \\
8,850 \\
\end{array}$ & $\begin{array}{l}26,400 \\
14,200 \\
24,300 \\
24,900 \\
27,300 \\
28,100 \\
\end{array}$ & $\begin{array}{r}-- \\
1,780 \\
1,860 \\
-- \\
3,150 \\
--\end{array}$ & $\begin{array}{r}-\overline{ } \\
4,710 \\
8,920 \\
-- \\
9,900 \\
--\end{array}$ & $\begin{array}{l}9,610 \\
9,850 \\
9,790 \\
9,390 \\
8,000 \\
8,370\end{array}$ & $\begin{array}{l}33,900 \\
34,300 \\
33,700 \\
33,900 \\
33,300 \\
34,400\end{array}$ & $\begin{array}{l}-- \\
-- \\
-- \\
-- \\
--\end{array}$ & $\begin{array}{l}-- \\
-- \\
-- \\
-- \\
--\end{array}$ & $\begin{array}{r}14,100 \\
14,400 \\
14,300 \\
14,700 \\
15,000 \\
\ldots\end{array}$ & $\begin{array}{r}\mathbf{3 4 , 9 0 0} \\
\mathbf{3 4 , 9 0 0} \\
\mathbf{3 5 , 4 0 0} \\
\mathbf{3 5 , 0 0 0} \\
\mathbf{3 5 , 7 0 0} \\
--\end{array}$ & $\begin{array}{r}-- \\
- \\
- \\
5,230 \\
--\end{array}$ & 14,300 \\
\hline
\end{tabular}

Temperature $\left({ }^{\circ} \mathrm{F}\right)$ of water, water year October 1953 to September 1954

\begin{tabular}{|c|c|c|c|c|c|c|c|c|c|c|c|c|}
\hline Day & Oct. & Nov. & Dec. & Jan. & Feb. & Mar. & Apr. & May & June & July & Aug. & Sept. \\
\hline $\begin{array}{l}1 \\
2 \\
3 \\
4 \\
5\end{array}$ & $\begin{array}{l}80 \\
80 \\
80 \\
81 \\
79\end{array}$ & $\begin{array}{l}63 \\
65 \\
68 \\
66 \\
64\end{array}$ & $\begin{array}{l}60 \\
61 \\
63 \\
61 \\
63\end{array}$ & $\begin{array}{l}53 \\
53 \\
53 \\
54 \\
54\end{array}$ & $\begin{array}{l}56 \\
55 \\
61 \\
61 \\
62\end{array}$ & $\begin{array}{l}58 \\
61 \\
58 \\
57 \\
55\end{array}$ & $\begin{array}{l}68 \\
62 \\
67 \\
69 \\
70\end{array}$ & $\begin{array}{l}76 \\
76 \\
72 \\
68 \\
66\end{array}$ & $\begin{array}{l}79 \\
79 \\
80 \\
79 \\
78\end{array}$ & $\begin{array}{l}88 \\
86 \\
87 \\
86 \\
82\end{array}$ & $\begin{array}{l}84 \\
85 \\
86 \\
86 \\
86\end{array}$ & $\begin{array}{l}83 \\
83 \\
82 \\
82 \\
84\end{array}$ \\
\hline $\begin{array}{r}6 \\
7 \\
8 \\
9 \\
10\end{array}$ & $\begin{array}{l}76 \\
73 \\
73 \\
72 \\
73\end{array}$ & $\begin{array}{l}62 \\
60 \\
59 \\
58 \\
59\end{array}$ & $\begin{array}{l}62 \\
58 \\
59 \\
58 \\
53\end{array}$ & $\begin{array}{l}54 \\
53 \\
54 \\
55 \\
56\end{array}$ & $\begin{array}{l}\mathbf{5 9} \\
\mathbf{5 8} \\
\mathbf{5 4} \\
\mathbf{5 7} \\
\mathbf{5 9}\end{array}$ & $\begin{array}{l}\mathbf{5 4} \\
\mathbf{5 5} \\
56 \\
58 \\
\mathbf{5 9}\end{array}$ & $\begin{array}{l}70 \\
71 \\
73 \\
69 \\
72\end{array}$ & $\begin{array}{l}68 \\
68 \\
68 \\
69 \\
68\end{array}$ & $\begin{array}{l}78 \\
81 \\
82 \\
82 \\
83\end{array}$ & $\begin{array}{l}86 \\
84 \\
86 \\
85 \\
86\end{array}$ & $\begin{array}{l}86 \\
85 \\
87 \\
87 \\
87\end{array}$ & $\begin{array}{l}84 \\
83 \\
84 \\
83 \\
85\end{array}$ \\
\hline $\begin{array}{l}11 \\
12 \\
13 \\
14 \\
15\end{array}$ & $\begin{array}{l}73 \\
-- \\
77 \\
72 \\
73\end{array}$ & $\begin{array}{l}\mathbf{5 8} \\
\mathbf{5 9} \\
\mathbf{5 8} \\
\mathbf{5 9} \\
\mathbf{5 9}\end{array}$ & $\begin{array}{l}53 \\
54 \\
54 \\
53 \\
51\end{array}$ & $\begin{array}{l}\mathbf{5 1} \\
\mathbf{5 1} \\
\mathbf{5 0} \\
\mathbf{5 2} \\
\mathbf{5 6}\end{array}$ & $\begin{array}{l}60 \\
56 \\
57 \\
59 \\
58\end{array}$ & $\begin{array}{l}62 \\
63 \\
62 \\
56 \\
56\end{array}$ & $\begin{array}{l}73 \\
75 \\
75 \\
75 \\
76\end{array}$ & $\begin{array}{l}70 \\
68 \\
66 \\
68 \\
69\end{array}$ & $\begin{array}{l}83 \\
84 \\
84 \\
84 \\
84\end{array}$ & $\begin{array}{l}-- \\
-- \\
-- \\
-- \\
87\end{array}$ & $\begin{array}{l}85 \\
85 \\
86 \\
87 \\
87\end{array}$ & $\begin{array}{l}83 \\
80 \\
80 \\
82 \\
82\end{array}$ \\
\hline $\begin{array}{l}16 \\
17 \\
18 \\
19 \\
20\end{array}$ & $\begin{array}{l}73 \\
73 \\
74 \\
75 \\
76\end{array}$ & $\begin{array}{l}60 \\
60 \\
63 \\
66 \\
63\end{array}$ & $\begin{array}{l}\mathbf{5 2} \\
\mathbf{5 1} \\
\mathbf{5 0} \\
\mathbf{4 8} \\
\mathbf{5 2}\end{array}$ & $\begin{array}{l}53 \\
53 \\
53 \\
-- \\
57\end{array}$ & $\begin{array}{l}64 \\
61 \\
60 \\
64 \\
60\end{array}$ & $\begin{array}{l}55 \\
58 \\
60 \\
64 \\
63\end{array}$ & $\begin{array}{l}72 \\
71 \\
72 \\
72 \\
70\end{array}$ & $\begin{array}{l}70 \\
71 \\
71 \\
71 \\
72\end{array}$ & $\begin{array}{l}85 \\
85 \\
85 \\
83 \\
82\end{array}$ & $\begin{array}{l}86 \\
85 \\
86 \\
85 \\
84\end{array}$ & $\begin{array}{l}87 \\
87 \\
87 \\
86 \\
86\end{array}$ & $\begin{array}{l}81 \\
81 \\
84 \\
85 \\
86\end{array}$ \\
\hline $\begin{array}{l}21 \\
22 \\
23 \\
24 \\
25\end{array}$ & $\begin{array}{l}74 \\
76 \\
73 \\
74 \\
73\end{array}$ & $\begin{array}{l}80 \\
79 \\
81 \\
74 \\
58\end{array}$ & $\begin{array}{l}51 \\
52 \\
47 \\
43 \\
48\end{array}$ & $\begin{array}{l}\mathbf{5 7} \\
52 \\
52 \\
54 \\
57\end{array}$ & $\begin{array}{l}61 \\
61 \\
62 \\
61 \\
62\end{array}$ & $\begin{array}{l}62 \\
63 \\
66 \\
66 \\
68\end{array}$ & $\begin{array}{l}69 \\
71 \\
70 \\
71 \\
72\end{array}$ & $\begin{array}{l}69 \\
73 \\
74 \\
74 \\
74\end{array}$ & $\begin{array}{l}84 \\
84 \\
84 \\
85 \\
86\end{array}$ & $\begin{array}{l}86 \\
87 \\
87 \\
86 \\
86\end{array}$ & $\begin{array}{l}85 \\
84 \\
84 \\
83 \\
82\end{array}$ & $\begin{array}{l}85 \\
80 \\
77 \\
78 \\
81\end{array}$ \\
\hline $\begin{array}{l}26 \\
27 \\
28 \\
29 \\
30 \\
31\end{array}$ & $\begin{array}{l}72 \\
71 \\
77 \\
66 \\
64 \\
64\end{array}$ & $\begin{array}{l}59 \\
58 \\
58 \\
57 \\
64 \\
--\end{array}$ & $\begin{array}{l}49 \\
50 \\
\mathbf{5 3} \\
\mathbf{5 0} \\
\mathbf{5 1} \\
\mathbf{5 0}\end{array}$ & $\begin{array}{l}\mathbf{5 7} \\
57 \\
54 \\
57 \\
58 \\
57\end{array}$ & $\begin{array}{l}63 \\
65 \\
62 \\
-- \\
-- \\
--\end{array}$ & $\begin{array}{l}65 \\
66 \\
66 \\
68 \\
69 \\
70\end{array}$ & $\begin{array}{l}73 \\
75 \\
73 \\
75 \\
77 \\
--\end{array}$ & $\begin{array}{l}74 \\
76 \\
76 \\
77 \\
78 \\
78\end{array}$ & $\begin{array}{l}86 \\
86 \\
87 \\
86 \\
86 \\
--\end{array}$ & $\begin{array}{l}87 \\
86 \\
84 \\
82 \\
84 \\
82\end{array}$ & $\begin{array}{l}85 \\
86 \\
85 \\
84 \\
84 \\
85\end{array}$ & $\begin{array}{l}80 \\
82 \\
83 \\
81 \\
82 \\
--\end{array}$ \\
\hline $\begin{array}{c}\text { Aver- } \\
\text { age }\end{array}$ & 74 & 63 & 54 & 54 & 60 & 61 & 71 & 72 & 83 & 85 & 85 & 83 \\
\hline
\end{tabular}




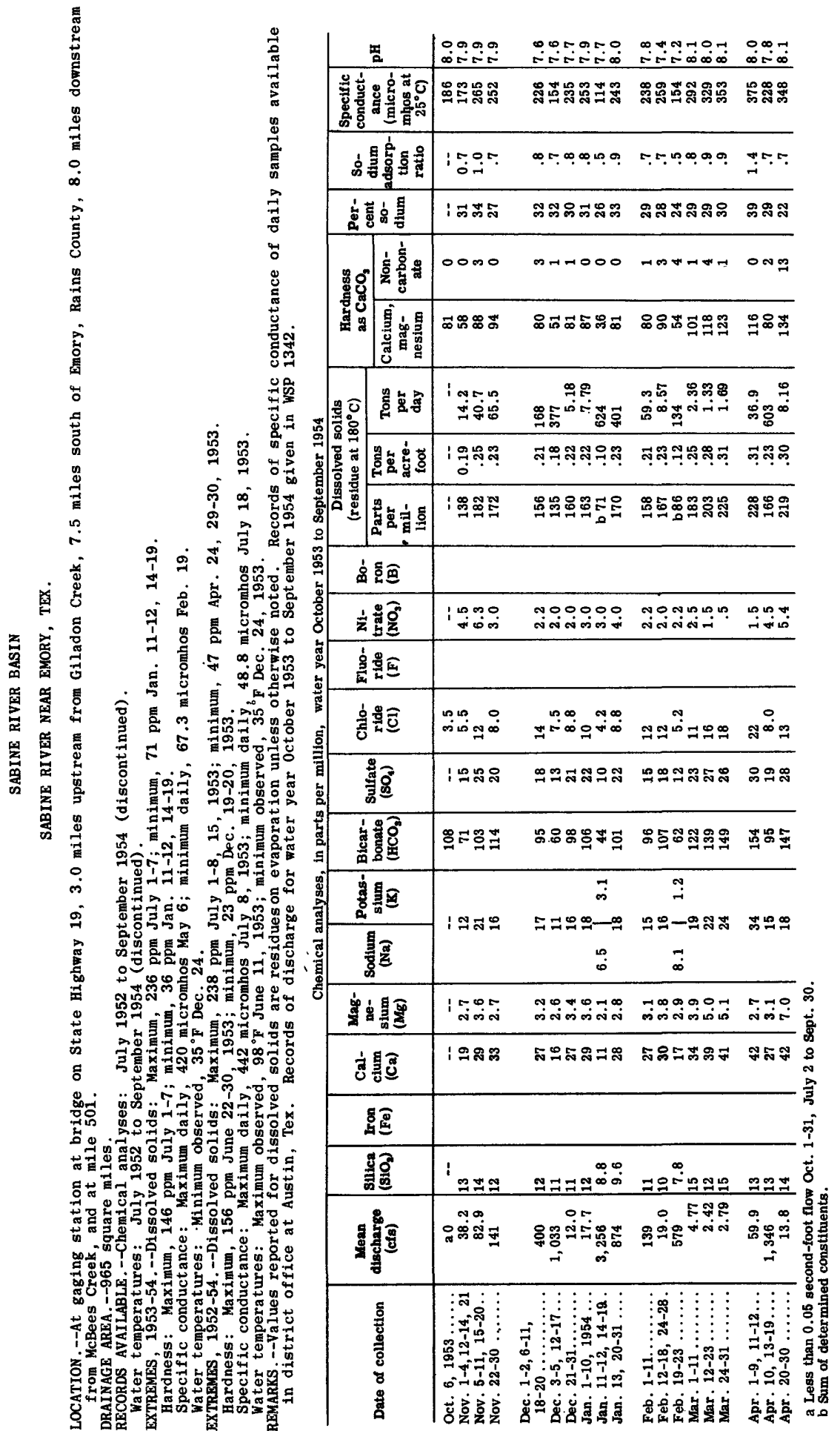




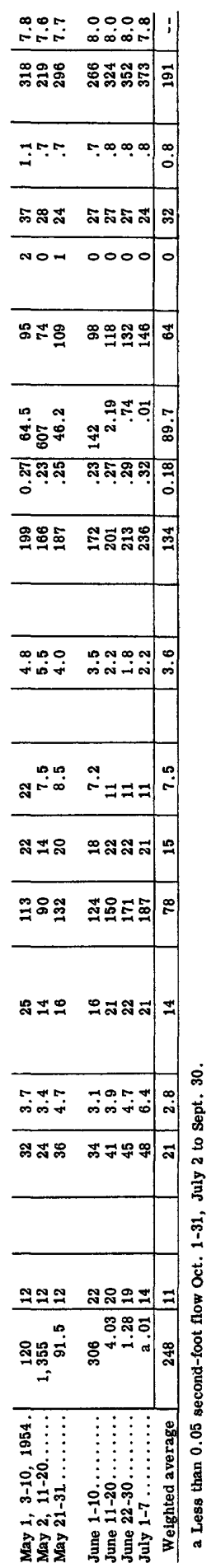


SABINE RIVER BASIN--Continued

SABINE RIVER NEAR EMORY, TEX.--Cont inued

Temperature $\left({ }^{\circ} \mathrm{F}\right)$ of water, water year October 1953 to September 1954

\begin{tabular}{|c|c|c|c|c|c|c|c|c|c|c|c|c|}
\hline Day & Oct. & Nov. & Dec. & Jan. & Feb. & Mar. & Apr. & May & June & July & Aug. & Sept. \\
\hline $\begin{array}{l}1 \\
2 \\
3 \\
4 \\
5\end{array}$ & & $\begin{array}{l}61 \\
61 \\
60 \\
-- \\
58\end{array}$ & $\begin{array}{l}56 \\
60 \\
62 \\
54 \\
55\end{array}$ & $\begin{array}{l}46 \\
50 \\
43 \\
49 \\
47\end{array}$ & $\begin{array}{l}55 \\
55 \\
56 \\
59 \\
56\end{array}$ & $\begin{array}{l}57 \\
52 \\
-2 \\
44 \\
44\end{array}$ & $\begin{array}{l}62 \\
67 \\
75 \\
72 \\
73\end{array}$ & $\begin{array}{l}74 \\
70 \\
65 \\
64 \\
65\end{array}$ & $\begin{array}{l}82 \\
80 \\
-2 \\
73 \\
73\end{array}$ & $\begin{array}{l}-- \\
87 \\
78 \\
92 \\
90\end{array}$ & & \\
\hline $\begin{array}{r}6 \\
7 \\
8 \\
9 \\
10\end{array}$ & 68 & $\begin{array}{l}56 \\
47 \\
51 \\
53 \\
51\end{array}$ & $\begin{array}{l}52 \\
49 \\
52 \\
-- \\
45\end{array}$ & $\begin{array}{l}42 \\
42 \\
49 \\
56 \\
44\end{array}$ & $\begin{array}{l}53 \\
52 \\
55 \\
60 \\
59\end{array}$ & $\begin{array}{l}51 \\
57 \\
60 \\
49 \\
69\end{array}$ & $\begin{array}{l}75 \\
78 \\
70 \\
68 \\
70\end{array}$ & $\begin{array}{l}69 \\
72 \\
74 \\
67 \\
61\end{array}$ & $\begin{array}{l}77 \\
74 \\
81 \\
85 \\
85\end{array}$ & $\begin{array}{l}93 \\
89 \\
-- \\
-- \\
--\end{array}$ & & \\
\hline $\begin{array}{l}11 \\
12 \\
13 \\
14 \\
15\end{array}$ & & $\begin{array}{l}54 \\
54 \\
54 \\
54 \\
55\end{array}$ & $\begin{array}{l}46 \\
47 \\
45 \\
44 \\
--\end{array}$ & $\begin{array}{l}38 \\
37 \\
37 \\
40 \\
43\end{array}$ & $\begin{array}{l}56 \\
53 \\
52 \\
62 \\
65\end{array}$ & $\begin{array}{l}64 \\
66 \\
-- \\
57\end{array}$ & $\begin{array}{l}73 \\
68 \\
66 \\
69 \\
70\end{array}$ & $\begin{array}{l}59 \\
60 \\
63 \\
65 \\
71\end{array}$ & $\begin{array}{l}80 \\
87 \\
79 \\
85 \\
83\end{array}$ & $\begin{array}{l}-- \\
\cdots \\
- \\
--\end{array}$ & & \\
\hline $\begin{array}{l}16 \\
17 \\
18 \\
19 \\
20\end{array}$ & & $\begin{array}{l}57 \\
-5 \\
60 \\
67 \\
55\end{array}$ & $\begin{array}{l}44 \\
43 \\
48 \\
48 \\
47\end{array}$ & $\begin{array}{l}-- \\
45 \\
46 \\
51 \\
53\end{array}$ & $\begin{array}{l}63 \\
61 \\
61 \\
62 \\
56\end{array}$ & $\begin{array}{l}56 \\
53 \\
53 \\
63 \\
62\end{array}$ & $\begin{array}{l}69 \\
66 \\
69 \\
73 \\
74\end{array}$ & $\begin{array}{l}71 \\
73 \\
74 \\
76 \\
73\end{array}$ & $\begin{array}{l}87 \\
88 \\
86 \\
86 \\
85\end{array}$ & $\begin{array}{l}-- \\
-- \\
-- \\
--\end{array}$ & & \\
\hline $\begin{array}{l}21 \\
22 \\
23 \\
24 \\
25\end{array}$ & & $\begin{array}{l}50 \\
50 \\
48 \\
50 \\
54\end{array}$ & $\begin{array}{l}-- \\
42 \\
40 \\
35 \\
36\end{array}$ & $\begin{array}{l}-2 \\
42 \\
39 \\
46 \\
54\end{array}$ & $\begin{array}{l}58 \\
56 \\
60 \\
59 \\
62\end{array}$ & $\begin{array}{l}63 \\
61 \\
68 \\
72 \\
72\end{array}$ & $\begin{array}{l}75 \\
75 \\
76 \\
70 \\
77\end{array}$ & $\begin{array}{l}76 \\
76 \\
71 \\
77 \\
76\end{array}$ & $\begin{array}{l}-- \\
90 \\
88 \\
87 \\
86\end{array}$ & $\begin{array}{l}-- \\
-- \\
-- \\
--\end{array}$ & & \\
\hline $\begin{array}{l}26 \\
27 \\
28 \\
29 \\
30 \\
31\end{array}$ & & $\begin{array}{l}54 \\
53 \\
49 \\
50 \\
53 \\
--\end{array}$ & $\begin{array}{l}38 \\
39 \\
46 \\
45 \\
44 \\
41 \\
\end{array}$ & $\begin{array}{l}-2 \\
51 \\
46 \\
53 \\
56 \\
56 \\
\end{array}$ & $\begin{array}{l}63 \\
61 \\
56 \\
-- \\
-- \\
-- \\
\end{array}$ & $\begin{array}{l}68 \\
71 \\
75 \\
73 \\
60 \\
54 \\
\end{array}$ & $\begin{array}{l}79 \\
77 \\
72 \\
75 \\
77 \\
-- \\
\end{array}$ & $\begin{array}{l}75 \\
81 \\
83 \\
75 \\
77 \\
\mathbf{7 5}\end{array}$ & $\begin{array}{l}86 \\
83 \\
85 \\
86 \\
83 \\
-- \\
\end{array}$ & $\begin{array}{l}-- \\
-- \\
-- \\
-- \\
-- \\
--\end{array}$ & & \\
\hline $\begin{array}{c}\text { Aver- } \\
\text { age }\end{array}$ & & 54 & 47 & 46 & 58 & 60 & 72 & 71 & 83 & -- & & \\
\hline
\end{tabular}




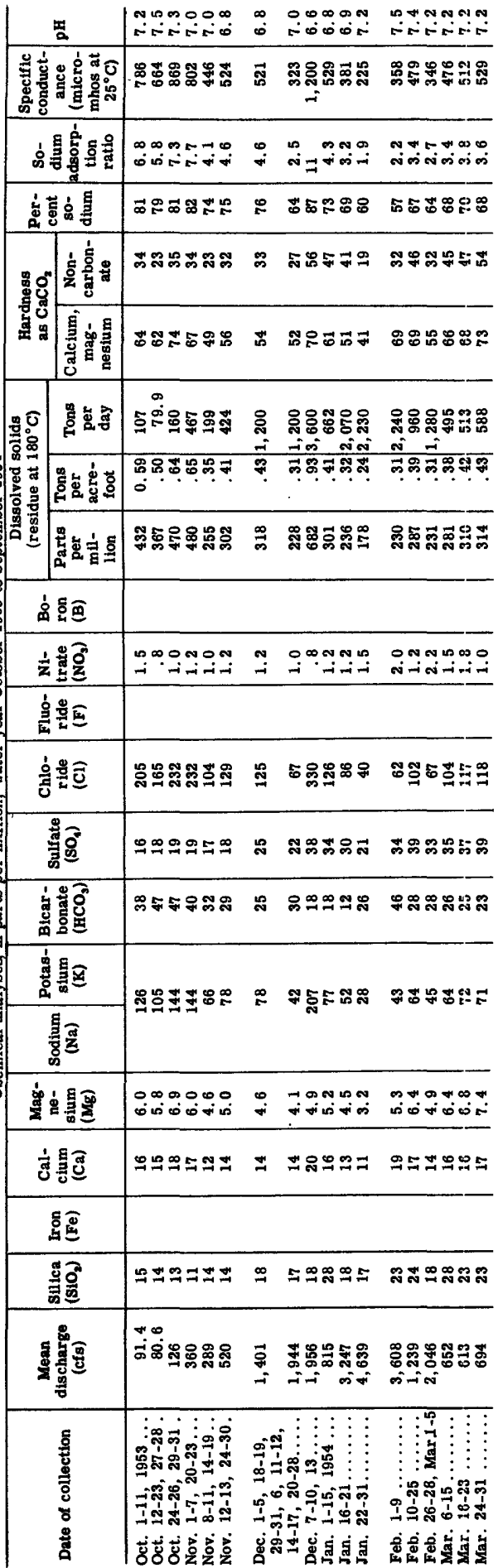




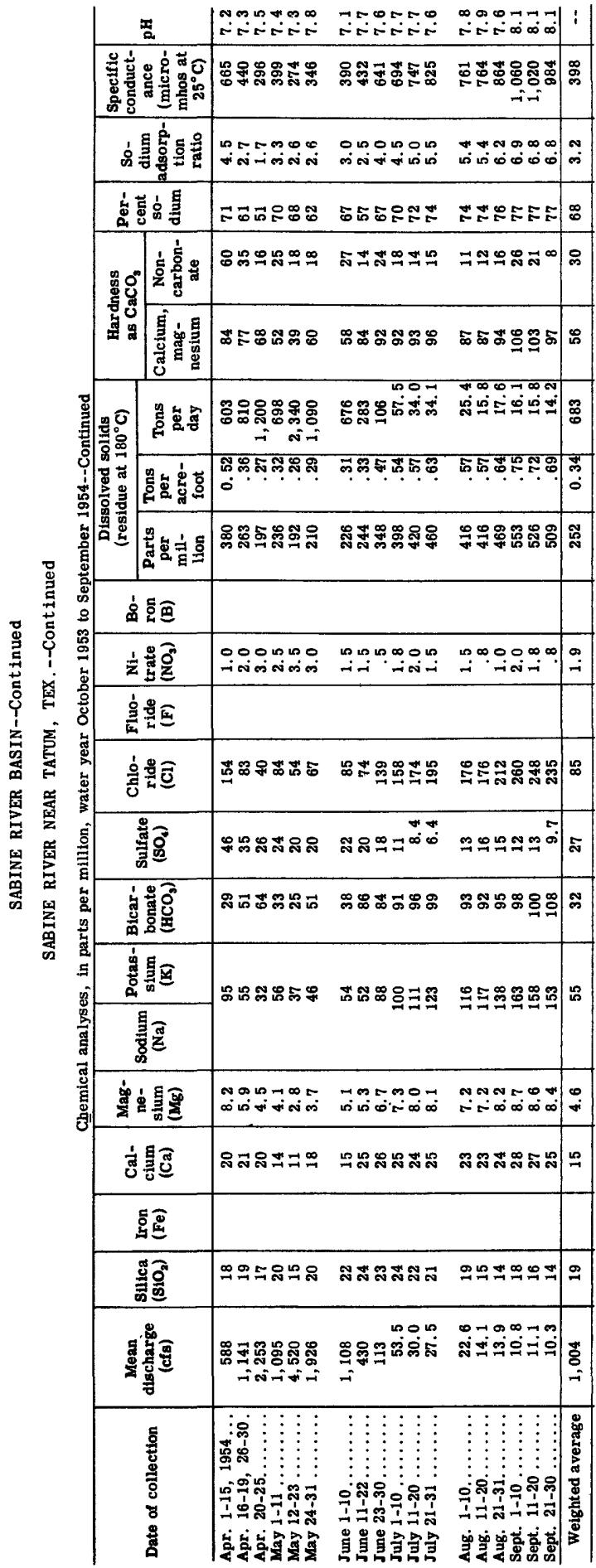


SABINE RIVER BASIN--Cont inued

SABINE RIVER NEAR TATUM, TEX.--Continued

Temperature $\left({ }^{\circ} \mathrm{F}\right)$ of water, water year October 1953 to September 1954

\begin{tabular}{|c|c|c|c|c|c|c|c|c|c|c|c|c|}
\hline Day & Oct. & Nov. & Dec. & Jan. & Feb. & Mar. & Apr. & May & June & July & Aug. & Sept. \\
\hline $\begin{array}{l}1 \\
2 \\
3 \\
4 \\
5\end{array}$ & $\begin{array}{l}80 \\
80 \\
80 \\
78 \\
78\end{array}$ & $\begin{array}{l}66 \\
65 \\
64 \\
65 \\
64\end{array}$ & $\begin{array}{l}54 \\
54 \\
54 \\
58 \\
58\end{array}$ & $\begin{array}{l}45 \\
47 \\
47 \\
47 \\
46\end{array}$ & $\begin{array}{l}53 \\
53 \\
53 \\
53 \\
54\end{array}$ & $\begin{array}{l}58 \\
56 \\
56 \\
52 \\
53\end{array}$ & $\begin{array}{l}65 \\
67 \\
68 \\
70 \\
72\end{array}$ & $\begin{array}{l}74 \\
73 \\
70 \\
73 \\
73\end{array}$ & $\begin{array}{l}79 \\
82 \\
80 \\
80 \\
80\end{array}$ & $\begin{array}{l}92 \\
- \\
92 \\
87 \\
93\end{array}$ & $\begin{array}{l}91 \\
92 \\
93 \\
93 \\
88\end{array}$ & $\begin{array}{l}91 \\
89 \\
91 \\
91 \\
89\end{array}$ \\
\hline $\begin{array}{r}6 \\
7 \\
8 \\
9 \\
10\end{array}$ & $\begin{array}{l}78 \\
78 \\
77 \\
76 \\
79\end{array}$ & $\begin{array}{l}59 \\
59 \\
58 \\
56 \\
55\end{array}$ & $\begin{array}{l}58 \\
-- \\
54 \\
54 \\
54\end{array}$ & $\begin{array}{l}46 \\
48 \\
48 \\
48 \\
46\end{array}$ & $\begin{array}{l}54 \\
55 \\
53 \\
51 \\
52\end{array}$ & $\begin{array}{l}53 \\
55 \\
54 \\
51 \\
58\end{array}$ & $\begin{array}{l}72 \\
73 \\
72 \\
70 \\
74\end{array}$ & $\begin{array}{l}73 \\
73 \\
70 \\
68 \\
67\end{array}$ & $\begin{array}{l}82 \\
82 \\
82 \\
84 \\
85\end{array}$ & $\begin{array}{l}93 \\
95 \\
93 \\
93 \\
93\end{array}$ & $\begin{array}{l}88 \\
88 \\
88 \\
88 \\
90\end{array}$ & $\begin{array}{l}89 \\
89 \\
89 \\
89 \\
89\end{array}$ \\
\hline $\begin{array}{l}11 \\
12 \\
13 \\
14 \\
15\end{array}$ & $\begin{array}{l}77 \\
77 \\
72 \\
72 \\
72\end{array}$ & $\begin{array}{l}\mathbf{5 5} \\
\mathbf{5 5} \\
\mathbf{5 5} \\
\mathbf{5 2} \\
\mathbf{5 1}\end{array}$ & $\begin{array}{l}\mathbf{5 2} \\
\mathbf{5 1} \\
\mathbf{5 1} \\
\mathbf{5 1} \\
\mathbf{5 0}\end{array}$ & $\begin{array}{l}45 \\
45 \\
46 \\
46 \\
48\end{array}$ & $\begin{array}{l}53 \\
52 \\
53 \\
55 \\
55\end{array}$ & $\begin{array}{l}65 \\
65 \\
58 \\
59 \\
55\end{array}$ & $\begin{array}{l}73 \\
73 \\
74 \\
75 \\
75\end{array}$ & $\begin{array}{l}65 \\
64 \\
65 \\
65 \\
64\end{array}$ & $\begin{array}{l}85 \\
85 \\
83 \\
84 \\
84\end{array}$ & $\begin{array}{l}93 \\
90 \\
95 \\
94 \\
94\end{array}$ & $\begin{array}{l}90 \\
92 \\
92 \\
92 \\
--\end{array}$ & $\begin{array}{l}89 \\
79 \\
79 \\
84 \\
85\end{array}$ \\
\hline $\begin{array}{l}16 \\
17 \\
18 \\
19 \\
20\end{array}$ & $\begin{array}{l}76 \\
75 \\
75 \\
74 \\
76\end{array}$ & $\begin{array}{l}51 \\
57 \\
60 \\
61 \\
55\end{array}$ & $\begin{array}{l}\mathbf{5 0} \\
\mathbf{5 0} \\
\mathbf{5 0} \\
\mathbf{5 0} \\
\mathbf{5 0}\end{array}$ & $\begin{array}{l}48 \\
50 \\
50 \\
52 \\
55\end{array}$ & $\begin{array}{l}57 \\
58 \\
52 \\
57 \\
57\end{array}$ & $\begin{array}{l}56 \\
58 \\
59 \\
60 \\
61\end{array}$ & $\begin{array}{l}74 \\
75 \\
74 \\
74 \\
74\end{array}$ & $\begin{array}{l}65 \\
68 \\
70 \\
72 \\
72\end{array}$ & $\begin{array}{l}86 \\
86 \\
80 \\
86 \\
86\end{array}$ & $\begin{array}{l}94 \\
94 \\
94 \\
89 \\
94\end{array}$ & $\begin{array}{l}92 \\
92 \\
-- \\
92 \\
93\end{array}$ & $\begin{array}{l}85 \\
83 \\
88 \\
88 \\
88\end{array}$ \\
\hline $\begin{array}{l}21 \\
22 \\
23 \\
24 \\
25\end{array}$ & $\begin{array}{l}76 \\
75 \\
76 \\
74 \\
74\end{array}$ & $\begin{array}{l}55 \\
56 \\
56 \\
57 \\
55\end{array}$ & $\begin{array}{l}57 \\
45 \\
45 \\
45 \\
46\end{array}$ & $\begin{array}{l}48 \\
45 \\
48 \\
52 \\
50\end{array}$ & $\begin{array}{l}57 \\
57 \\
56 \\
60 \\
60\end{array}$ & $\begin{array}{l}61 \\
62 \\
62 \\
66 \\
66\end{array}$ & $\begin{array}{l}72 \\
75 \\
75 \\
74 \\
73\end{array}$ & $\begin{array}{l}72 \\
72 \\
72 \\
72 \\
75\end{array}$ & $\begin{array}{l}87 \\
87 \\
90 \\
90 \\
90\end{array}$ & $\begin{array}{l}94 \\
90 \\
89 \\
94 \\
94\end{array}$ & $\begin{array}{l}92 \\
91 \\
92 \\
86 \\
90\end{array}$ & $\begin{array}{l}86 \\
80 \\
74 \\
84 \\
84\end{array}$ \\
\hline $\begin{array}{l}26 \\
27 \\
28 \\
29 \\
30 \\
31\end{array}$ & $\begin{array}{l}72 \\
72 \\
70 \\
66 \\
66 \\
66 \\
\end{array}$ & $\begin{array}{l}55 \\
55 \\
52 \\
54 \\
54 \\
--\end{array}$ & $\begin{array}{l}45 \\
48 \\
48 \\
48 \\
48 \\
45\end{array}$ & $\begin{array}{l}-- \\
48 \\
48 \\
49 \\
49 \\
49\end{array}$ & $\begin{array}{l}61 \\
61 \\
50 \\
-- \\
-- \\
--\end{array}$ & $\begin{array}{l}67 \\
68 \\
69 \\
70 \\
68 \\
65\end{array}$ & $\begin{array}{l}76 \\
76 \\
76 \\
75 \\
74 \\
-- \\
\end{array}$ & $\begin{array}{l}75 \\
75 \\
75 \\
77 \\
79 \\
77\end{array}$ & $\begin{array}{l}92 \\
90 \\
88 \\
90 \\
91 \\
--\end{array}$ & $\begin{array}{l}90 \\
90 \\
91 \\
92 \\
92 \\
91\end{array}$ & $\begin{array}{l}91 \\
91 \\
92 \\
92 \\
88 \\
86\end{array}$ & $\begin{array}{l}84 \\
80 \\
83 \\
83 \\
82 \\
--\end{array}$ \\
\hline $\begin{array}{c}\text { Aver- } \\
\text { age }\end{array}$ & 75 & 58 & 51 & 48 & 55 & 60 & 73 & 71 & 85 & 92 & 91 & 85 \\
\hline
\end{tabular}




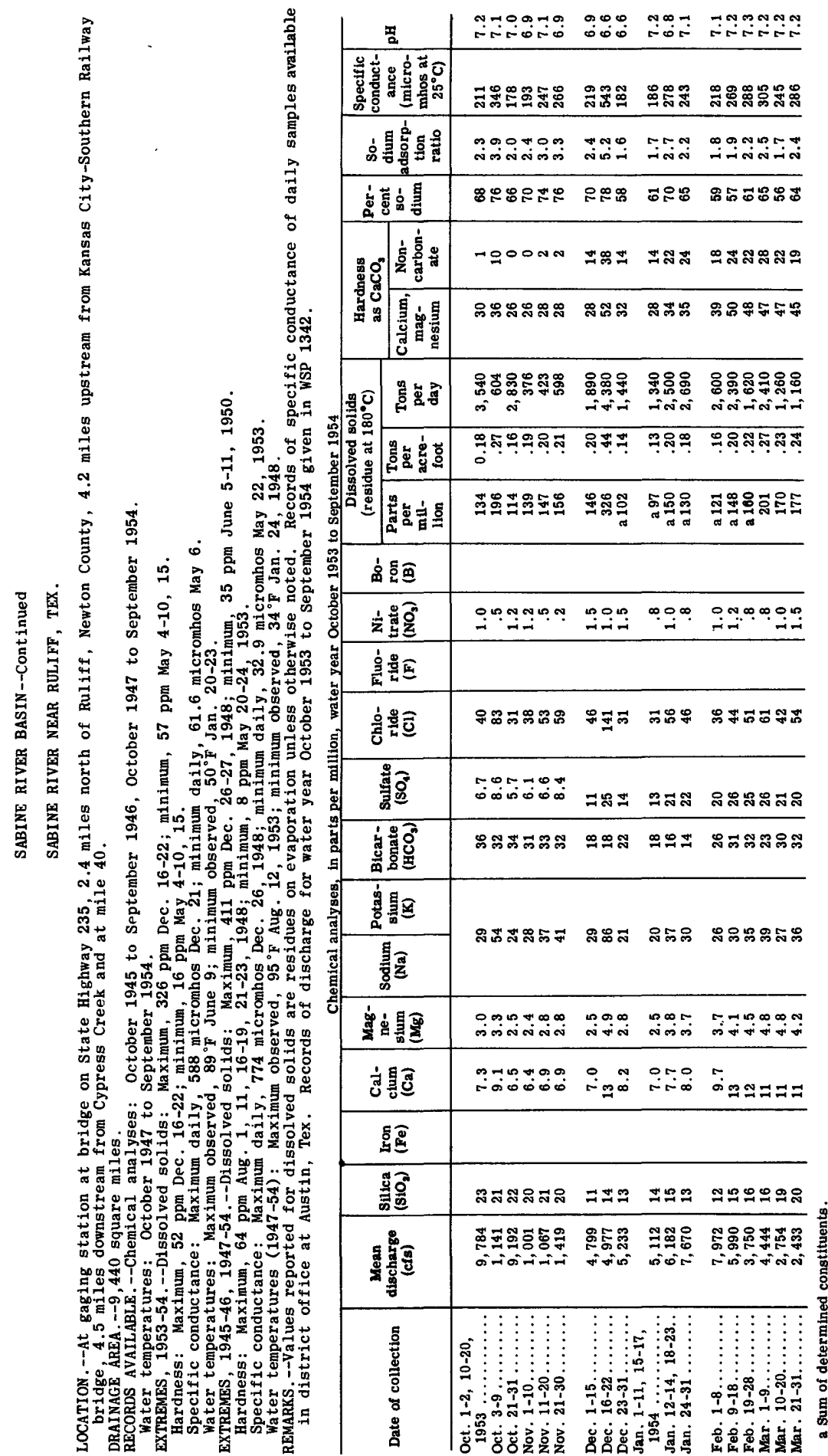




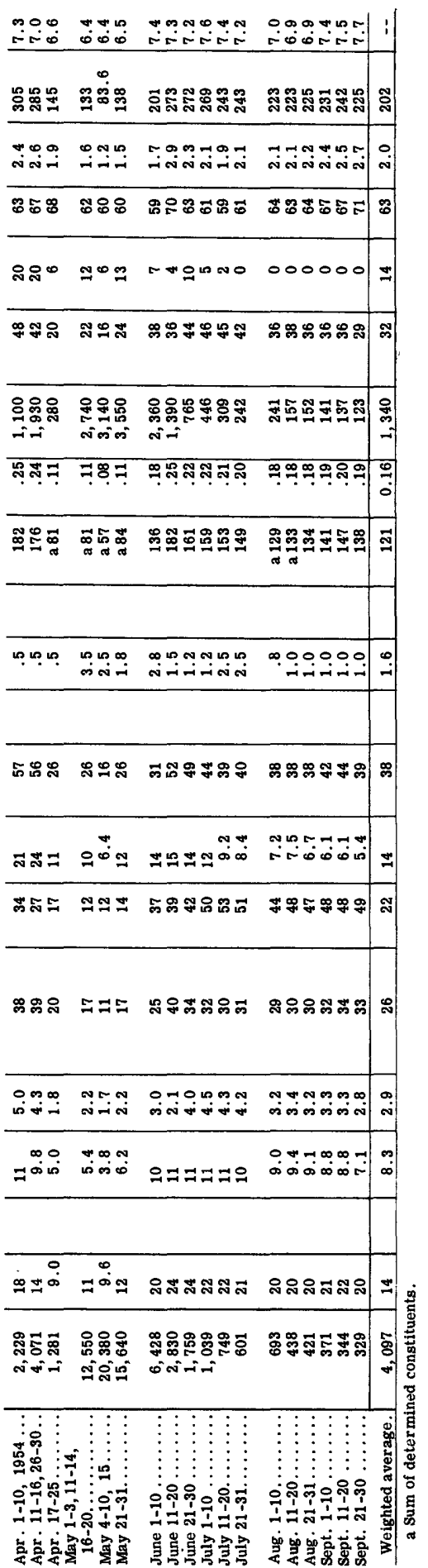


SABINE RIVER BASIN--Continued

SABINE RIVER NEAR RULIFF, TEX.--Cont inued

Temperature $\left({ }^{\circ} \mathrm{F}\right)$ of water, water year October 1953 to September 1954

\begin{tabular}{|c|c|c|c|c|c|c|c|c|c|c|c|c|}
\hline Day & Oct. & Nov. & Dec. & Jan. & Feb. & Mar. & Apr. & May & June & July & Aug. & Sept. \\
\hline $\begin{array}{l}1 \\
2 \\
3 \\
4 \\
5\end{array}$ & $\begin{array}{l}83 \\
86 \\
87 \\
85 \\
85\end{array}$ & $\begin{array}{l}70 \\
70 \\
74 \\
72 \\
71\end{array}$ & $\begin{array}{l}68 \\
68 \\
68 \\
68 \\
68\end{array}$ & $\begin{array}{l}55 \\
-- \\
55 \\
55 \\
57\end{array}$ & $\begin{array}{l}55 \\
54 \\
53 \\
55 \\
53\end{array}$ & $\begin{array}{l}61 \\
60 \\
58 \\
58 \\
55\end{array}$ & $\begin{array}{l}70 \\
71 \\
70 \\
72 \\
73\end{array}$ & $\begin{array}{l}72 \\
70 \\
69 \\
69 \\
72\end{array}$ & $\begin{array}{l}77 \\
80 \\
80 \\
80 \\
80\end{array}$ & $\begin{array}{l}86 \\
85 \\
86 \\
86 \\
86\end{array}$ & $\begin{array}{l}81 \\
81 \\
81 \\
82 \\
83\end{array}$ & $\begin{array}{l}86 \\
86 \\
85 \\
84 \\
84\end{array}$ \\
\hline $\begin{array}{r}6 \\
7 \\
8 \\
9 \\
10\end{array}$ & $\begin{array}{l}83 \\
75 \\
74 \\
72 \\
76\end{array}$ & $\begin{array}{l}70 \\
69 \\
68 \\
67 \\
68\end{array}$ & $\begin{array}{l}60 \\
68 \\
67 \\
67 \\
68\end{array}$ & $\begin{array}{l}55 \\
54 \\
55 \\
56 \\
56\end{array}$ & $\begin{array}{l}53 \\
52 \\
52 \\
54 \\
56\end{array}$ & $\begin{array}{l}54 \\
53 \\
55 \\
55 \\
59\end{array}$ & $\begin{array}{l}74 \\
75 \\
75 \\
76 \\
76\end{array}$ & $\begin{array}{l}72 \\
72 \\
72 \\
72 \\
72\end{array}$ & $\begin{array}{l}80 \\
80 \\
89 \\
81 \\
82\end{array}$ & $\begin{array}{l}86 \\
86 \\
86 \\
86 \\
86\end{array}$ & $\begin{array}{l}84 \\
85 \\
84 \\
84 \\
84\end{array}$ & $\begin{array}{l}83 \\
83 \\
83 \\
83 \\
83\end{array}$ \\
\hline $\begin{array}{l}11 \\
12 \\
13 \\
14 \\
15\end{array}$ & $\begin{array}{l}77 \\
78 \\
80 \\
80 \\
76\end{array}$ & $\begin{array}{l}68 \\
68 \\
68 \\
67 \\
67\end{array}$ & $\begin{array}{l}67 \\
65 \\
66 \\
64 \\
63\end{array}$ & $\begin{array}{l}\mathbf{5 4} \\
\mathbf{5 2} \\
\mathbf{5 2} \\
\mathbf{5 2} \\
\mathbf{5 2}\end{array}$ & $\begin{array}{l}57 \\
55 \\
56 \\
56 \\
57\end{array}$ & $\begin{array}{l}60 \\
57 \\
58 \\
63 \\
--\end{array}$ & $\begin{array}{l}75 \\
75 \\
76 \\
76 \\
76\end{array}$ & $\begin{array}{l}70 \\
70 \\
69 \\
68 \\
68\end{array}$ & $\begin{array}{l}83 \\
84 \\
84 \\
84 \\
84\end{array}$ & $\begin{array}{l}86 \\
86 \\
86 \\
86 \\
86\end{array}$ & $\begin{array}{l}85 \\
85 \\
85 \\
85 \\
85\end{array}$ & $\begin{array}{l}83 \\
73 \\
83 \\
82 \\
82\end{array}$ \\
\hline $\begin{array}{l}16 \\
17 \\
18 \\
19 \\
20\end{array}$ & $\begin{array}{l}77 \\
80 \\
79 \\
82 \\
80\end{array}$ & $\begin{array}{l}67 \\
66 \\
67 \\
67 \\
65\end{array}$ & $\begin{array}{l}63 \\
64 \\
64 \\
64 \\
64\end{array}$ & $\begin{array}{l}\mathbf{5 2} \\
\mathbf{5 1} \\
\mathbf{5 1} \\
\mathbf{5 1} \\
\mathbf{5 0}\end{array}$ & $\begin{array}{l}57 \\
59 \\
60 \\
59 \\
63\end{array}$ & $\begin{array}{l}-- \\
58 \\
58 \\
59 \\
65\end{array}$ & $\begin{array}{l}75 \\
73 \\
69 \\
69 \\
69\end{array}$ & $\begin{array}{l}68 \\
68 \\
68 \\
70 \\
70\end{array}$ & $\begin{array}{l}84 \\
84 \\
84 \\
84 \\
83\end{array}$ & $\begin{array}{l}86 \\
86 \\
85 \\
86 \\
86\end{array}$ & $\begin{array}{l}86 \\
86 \\
86 \\
86 \\
86\end{array}$ & $\begin{array}{l}82 \\
82 \\
82 \\
82 \\
82\end{array}$ \\
\hline $\begin{array}{l}21 \\
22 \\
23 \\
24 \\
25\end{array}$ & $\begin{array}{l}79 \\
80 \\
77 \\
79 \\
78\end{array}$ & $\begin{array}{l}67 \\
67 \\
67 \\
67 \\
68\end{array}$ & $\begin{array}{l}63 \\
63 \\
64 \\
64 \\
61\end{array}$ & $\begin{array}{l}\mathbf{5 0} \\
\mathbf{5 0} \\
\mathbf{5 0} \\
\mathbf{5 1} \\
\mathbf{5 2}\end{array}$ & $\begin{array}{l}62 \\
64 \\
62 \\
62 \\
62\end{array}$ & $\begin{array}{l}65 \\
66 \\
-- \\
-- \\
69\end{array}$ & $\begin{array}{l}69 \\
69 \\
69 \\
70 \\
72\end{array}$ & $\begin{array}{l}70 \\
71 \\
71 \\
73 \\
70\end{array}$ & $\begin{array}{l}83 \\
84 \\
84 \\
85 \\
86\end{array}$ & $\begin{array}{l}76 \\
-- \\
86 \\
86 \\
86\end{array}$ & $\begin{array}{l}85 \\
85 \\
85 \\
85 \\
85\end{array}$ & $\begin{array}{l}82 \\
82 \\
82 \\
82 \\
82\end{array}$ \\
\hline $\begin{array}{l}26 \\
27 \\
28 \\
29 \\
30 \\
31\end{array}$ & $\begin{array}{l}77 \\
76 \\
75 \\
75 \\
75 \\
75 \\
\end{array}$ & $\begin{array}{l}65 \\
66 \\
67 \\
67 \\
68 \\
-- \\
\end{array}$ & $\begin{array}{l}63 \\
62 \\
65 \\
65 \\
65 \\
64 \\
\end{array}$ & $\begin{array}{l}52 \\
53 \\
53 \\
54 \\
-- \\
55 \\
\end{array}$ & $\begin{array}{c}62 \\
62 \\
61 \\
-- \\
-- \\
--\end{array}$ & $\begin{array}{l}70 \\
69 \\
70 \\
70 \\
70 \\
70\end{array}$ & $\begin{array}{l}74 \\
76 \\
77 \\
78 \\
78 \\
-- \\
\end{array}$ & $\begin{array}{l}70 \\
70 \\
71 \\
73 \\
74 \\
75 \\
\end{array}$ & $\begin{array}{l}86 \\
86 \\
86 \\
86 \\
86 \\
-- \\
\end{array}$ & $\begin{array}{l}86 \\
86 \\
86 \\
86 \\
-- \\
81\end{array}$ & $\begin{array}{l}85 \\
85 \\
85 \\
85 \\
85 \\
85 \\
\end{array}$ & $\begin{array}{l}81 \\
81 \\
81 \\
81 \\
80 \\
--\end{array}$ \\
\hline $\begin{array}{l}\text { Aver- } \\
\text { age }\end{array}$ & 79 & 68 & 65 & 53 & 58 & 62 & 73 & 71 & 83 & 85 & 85 & 82 \\
\hline
\end{tabular}




\begin{tabular}{|c|c|}
\hline a & 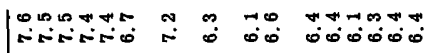 \\
\hline 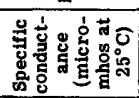 & 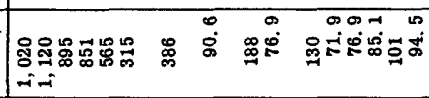 \\
\hline हो & 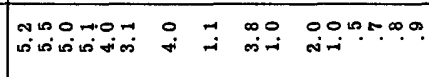 \\
\hline
\end{tabular}

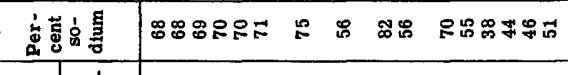

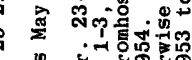

-

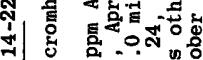

ก

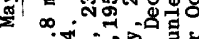

佥

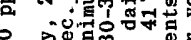

\begin{tabular}{|c|c|}
\hline 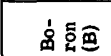 & \\
\hline$\frac{1}{\mathrm{z}} \frac{\mathrm{g}}{\mathrm{g}}$ & 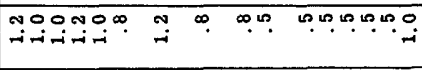 \\
\hline 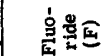 & \\
\hline
\end{tabular}

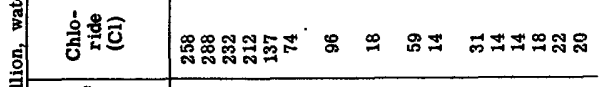

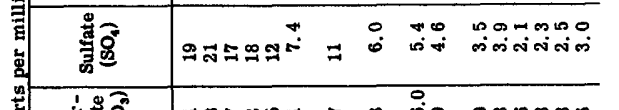

\begin{tabular}{|c|c|}
\hline \multicolumn{2}{|r|}{ 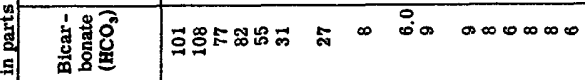 } \\
\hline 悬西 & \\
\hline
\end{tabular}

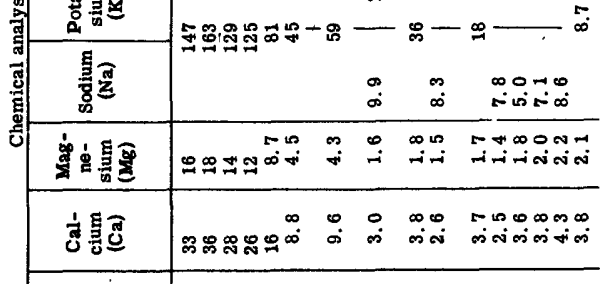

\begin{tabular}{|c|c|c|c|c|}
\hline 홈월 & & & & \\
\hline 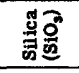 & 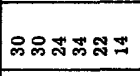 & $=0$ & $\begin{array}{ll}0 & 0 \\
0 & 0 \\
0 & =1\end{array}$ & 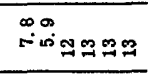 \\
\hline 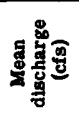 & 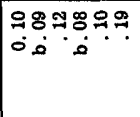 & $\vec{a}$ & F. & 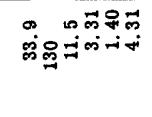 \\
\hline 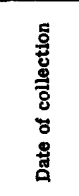 & 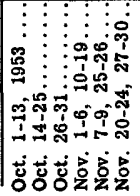 & 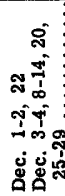 & 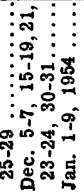 & 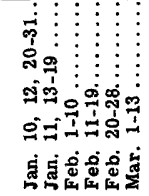 \\
\hline
\end{tabular}




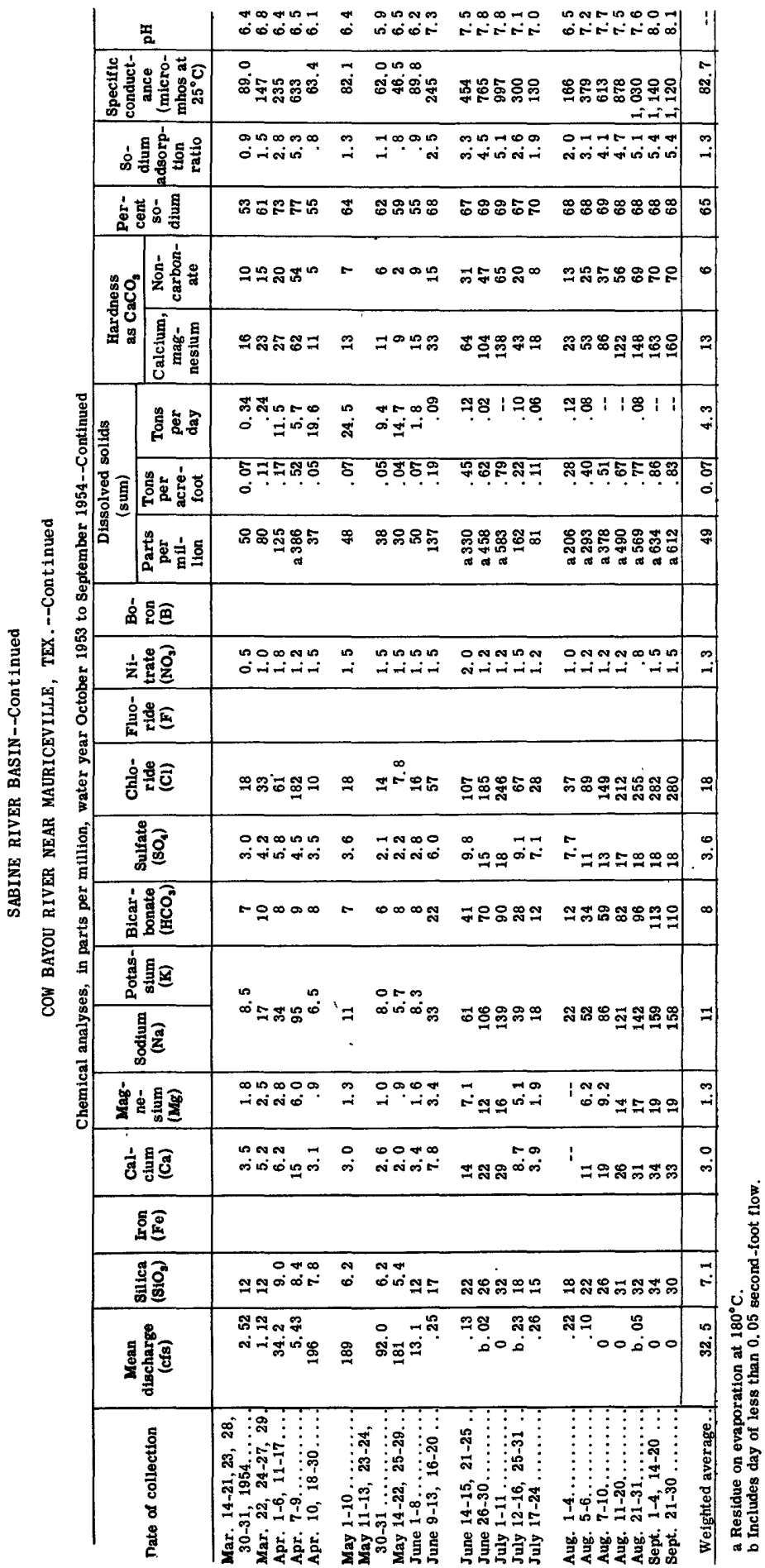


SABINE RIVER BASIN--Cont inued

COW BAYOU NEAR MAURICEVILLE, TEX.--Cont inued

Temperature $\left({ }^{\circ} \mathrm{F}\right)$ of water, water year October 1953 to September 1954

\begin{tabular}{|c|c|c|c|c|c|c|c|c|c|c|c|c|}
\hline Day & Oct. & Nov. & Dec. & Jan. & Feb. & Mar. & Apr. & May & June & July & Aug. & Sept. \\
\hline $\begin{array}{l}1 \\
2 \\
3 \\
4 \\
5\end{array}$ & $\begin{array}{l}83 \\
83 \\
84 \\
82 \\
73\end{array}$ & $\begin{array}{l}62 \\
62 \\
67 \\
66 \\
61\end{array}$ & $\begin{array}{l}58 \\
62 \\
67 \\
58 \\
58\end{array}$ & $\begin{array}{l}48 \\
52 \\
57 \\
55 \\
55\end{array}$ & $\begin{array}{l}58 \\
61 \\
60 \\
62 \\
58\end{array}$ & $\begin{array}{l}60 \\
56 \\
53 \\
51 \\
50\end{array}$ & $\begin{array}{l}65 \\
-5 \\
75 \\
--\end{array}$ & $\begin{array}{l}75 \\
77 \\
69 \\
65 \\
64\end{array}$ & $\begin{array}{l}74 \\
73 \\
76 \\
75 \\
76\end{array}$ & $\begin{array}{l}76 \\
78 \\
78 \\
76 \\
78\end{array}$ & $\begin{array}{l}77 \\
76 \\
77 \\
-2 \\
75\end{array}$ & $\begin{array}{l}75 \\
75 \\
76 \\
71 \\
--\end{array}$ \\
\hline $\begin{array}{r}6 \\
7 \\
8 \\
9 \\
10\end{array}$ & $\begin{array}{l}71 \\
69 \\
71 \\
-- \\
70\end{array}$ & $\begin{array}{l}56 \\
55 \\
57 \\
56 \\
--\end{array}$ & $\begin{array}{l}61 \\
-- \\
60 \\
55 \\
51\end{array}$ & $\begin{array}{l}\mathbf{5 0} \\
\mathbf{5 0} \\
\mathbf{5 2} \\
\mathbf{5 5} \\
\mathbf{5 0}\end{array}$ & $\begin{array}{l}\mathbf{6 3} \\
\mathbf{5 5} \\
50 \\
\mathbf{5 3} \\
\mathbf{5 8}\end{array}$ & $\begin{array}{l}50 \\
52 \\
60 \\
59 \\
61\end{array}$ & $\begin{array}{l}-- \\
70 \\
75 \\
70 \\
71\end{array}$ & $\begin{array}{l}67 \\
73 \\
73 \\
75 \\
73\end{array}$ & $\begin{array}{l}76 \\
75 \\
-- \\
78 \\
78\end{array}$ & $\begin{array}{l}77 \\
79 \\
78 \\
76 \\
--\end{array}$ & $\begin{array}{l}77 \\
76 \\
-- \\
-- \\
--\end{array}$ & $\begin{array}{l}-- \\
-- \\
-- \\
--\end{array}$ \\
\hline $\begin{array}{l}11 \\
12 \\
13 \\
14 \\
15\end{array}$ & $\begin{array}{l}74 \\
76 \\
- \\
76 \\
--\end{array}$ & $\begin{array}{l}-32 \\
50 \\
49 \\
59\end{array}$ & $\begin{array}{l}50 \\
-- \\
54 \\
48 \\
45\end{array}$ & $\begin{array}{l}49 \\
44 \\
43 \\
50 \\
57\end{array}$ & $\begin{array}{l}62 \\
58 \\
52 \\
60 \\
60\end{array}$ & $\begin{array}{l}69 \\
67 \\
68 \\
59 \\
60\end{array}$ & $\begin{array}{l}71 \\
75 \\
75 \\
72 \\
71\end{array}$ & $\begin{array}{l}73 \\
70 \\
69 \\
69 \\
68\end{array}$ & $\begin{array}{l}76 \\
77 \\
-2 \\
81 \\
83\end{array}$ & $\begin{array}{l}7- \\
79 \\
78 \\
78 \\
78\end{array}$ & $\begin{array}{l}76 \\
76 \\
75 \\
76 \\
76\end{array}$ & $\begin{array}{l}-- \\
-- \\
\overline{74} \\
75\end{array}$ \\
\hline $\begin{array}{l}16 \\
17 \\
18 \\
19 \\
20\end{array}$ & $\begin{array}{l}78 \\
73 \\
80 \\
-7 \\
78\end{array}$ & $\begin{array}{l}55 \\
-- \\
64 \\
66 \\
64\end{array}$ & $\begin{array}{l}45 \\
47 \\
-- \\
-- \\
50\end{array}$ & $\begin{array}{l}\mathbf{5 7} \\
\mathbf{5 5} \\
\mathbf{5 1} \\
\mathbf{5 2} \\
\mathbf{6 0}\end{array}$ & $\begin{array}{l}62 \\
65 \\
61 \\
65 \\
52\end{array}$ & $\begin{array}{l}61 \\
62 \\
63 \\
63 \\
63\end{array}$ & $\begin{array}{l}68 \\
70 \\
65 \\
66 \\
69\end{array}$ & $\begin{array}{l}72 \\
72 \\
69 \\
71 \\
73\end{array}$ & $\begin{array}{l}76 \\
76 \\
74 \\
75 \\
76\end{array}$ & $\begin{array}{l}78 \\
76 \\
77 \\
79 \\
78\end{array}$ & $\begin{array}{l}77 \\
77 \\
76 \\
78 \\
75\end{array}$ & $\begin{array}{l}76 . \\
76 \\
76 \\
75 \\
75\end{array}$ \\
\hline $\begin{array}{l}21 \\
22 \\
23 \\
24 \\
25\end{array}$ & $\begin{array}{l}78 \\
78 \\
78 \\
79 \\
72\end{array}$ & $\begin{array}{l}54 \\
63 \\
52 \\
58 \\
59\end{array}$ & $\begin{array}{l}54 \\
53 \\
43 \\
41 \\
45\end{array}$ & $\begin{array}{l}61 \\
50 \\
45 \\
51 \\
52\end{array}$ & $\begin{array}{l}57 \\
60 \\
61 \\
51 \\
60\end{array}$ & $\begin{array}{l}65 \\
70 \\
69 \\
67 \\
65\end{array}$ & $\begin{array}{l}68 \\
7 \overrightarrow{74} \\
75 \\
75\end{array}$ & $\begin{array}{l}69 \\
73 \\
72 \\
-- \\
78\end{array}$ & $\begin{array}{l}75 \\
76 \\
76 \\
\cdots \\
76\end{array}$ & $\begin{array}{l}78 \\
77 \\
76 \\
78 \\
76\end{array}$ & $\begin{array}{l}-- \\
-- \\
75 \\
71\end{array}$ & $\begin{array}{l}76 \\
74 \\
74 \\
73 \\
75\end{array}$ \\
\hline $\begin{array}{l}26 \\
27 \\
28 \\
29 \\
30 \\
31\end{array}$ & $\begin{array}{l}77 \\
65 \\
-65 \\
57 \\
60 \\
\end{array}$ & $\begin{array}{l}59 \\
53 \\
57 \\
58 \\
60 \\
--\end{array}$ & $\begin{array}{l}42 \\
47 \\
51 \\
-- \\
53 \\
48 \\
\end{array}$ & $\begin{array}{l}58 \\
60 \\
57 \\
60 \\
60 \\
55\end{array}$ & $\begin{array}{l}63 \\
65 \\
54 \\
-- \\
-- \\
--\end{array}$ & $\begin{array}{l}65 \\
67 \\
71 \\
70 \\
71 \\
70 \\
\end{array}$ & $\begin{array}{l}74 \\
73 \\
75 \\
75 \\
75 \\
-- \\
\end{array}$ & $\begin{array}{l}74 \\
-- \\
76 \\
-76 \\
73 \\
\end{array}$ & $\begin{array}{l}76 \\
75 \\
76 \\
76 \\
76 \\
-- \\
\end{array}$ & $\begin{array}{l}77 \\
76 \\
76 \\
-- \\
75 \\
-- \\
\end{array}$ & $\begin{array}{l}75 \\
75 \\
71 \\
75 \\
77 \\
76 \\
\end{array}$ & $\begin{array}{l}75 \\
76 \\
76 \\
75 \\
76 \\
-- \\
\end{array}$ \\
\hline $\begin{array}{c}\text { Aver- } \\
\text { age }\end{array}$ & 74 & 59 & 52 & 53 & 59 & 62 & 71 & 72 & 76 & 77 & $=$ & $=$ \\
\hline
\end{tabular}




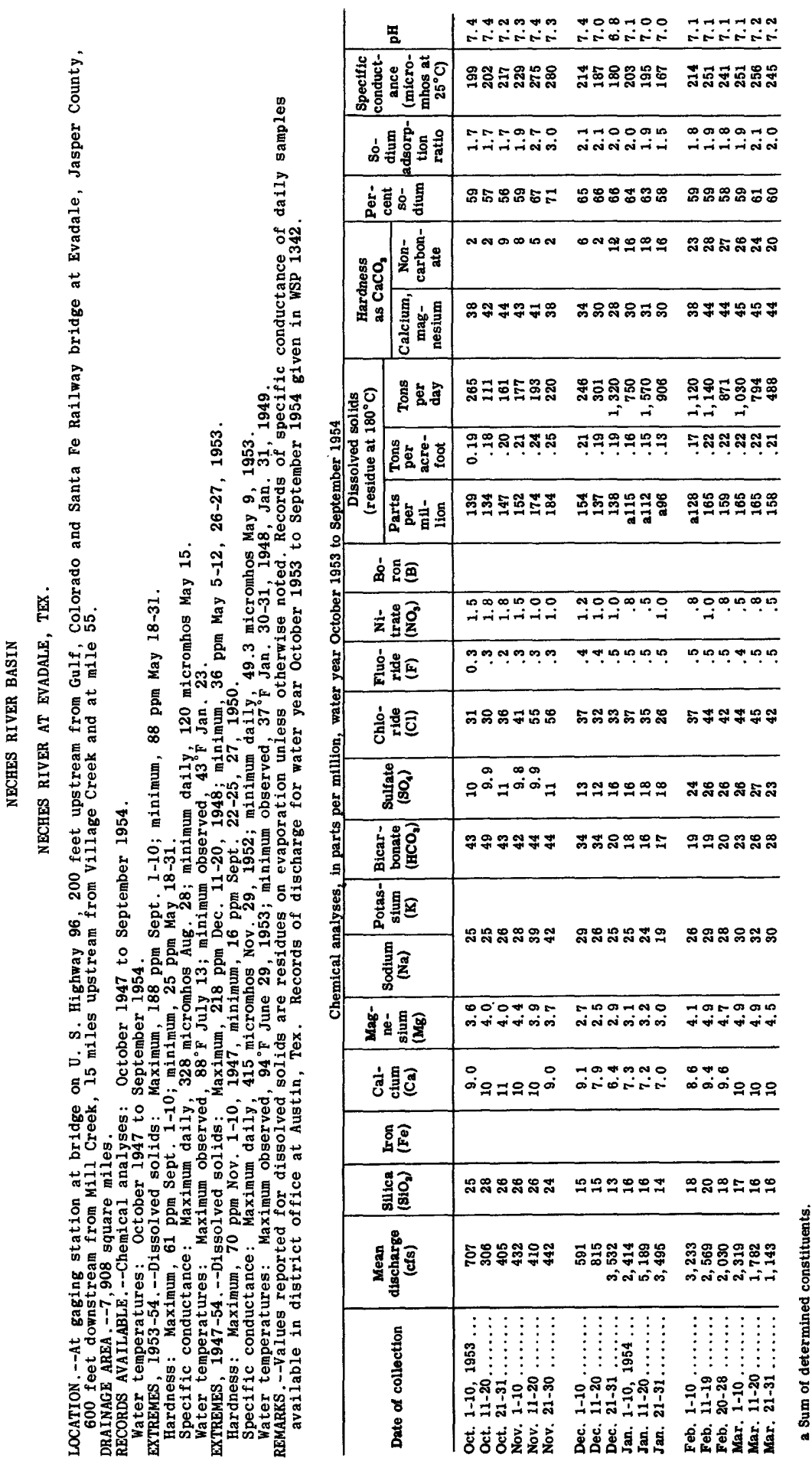




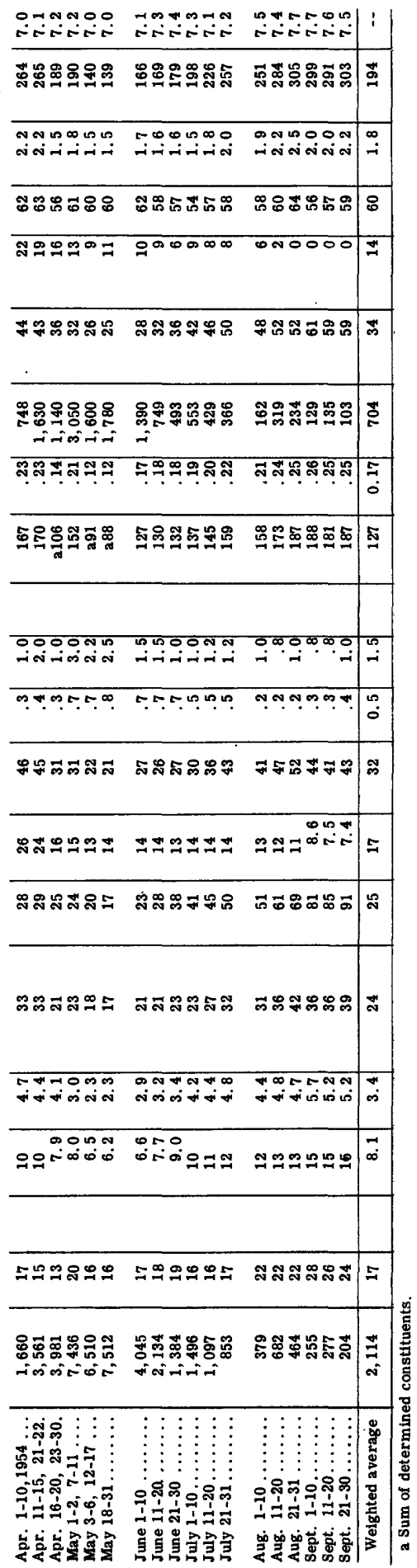


NECHES RIVER BASIN--Continued

NECHES RIVER AT EVADALE, TEX.---Continued

Temperature $\left({ }^{\circ} \mathrm{F}\right)$ of water, water year October 1953 to September 1954

\begin{tabular}{|c|c|c|c|c|c|c|c|c|c|c|c|c|}
\hline Day & Oct. & Nov. & Dec. & Jan. & Feb. & Mar. & Apr. & May & June & July & Aug. & Sept. \\
\hline $\begin{array}{l}1 \\
2 \\
3 \\
4 \\
5\end{array}$ & $\begin{array}{l}80 \\
80 \\
80 \\
79 \\
78\end{array}$ & $\begin{array}{l}63 \\
63 \\
64 \\
65 \\
64\end{array}$ & $\begin{array}{l}57 \\
60 \\
62 \\
59 \\
60\end{array}$ & $\begin{array}{l}46 \\
49 \\
50 \\
51 \\
50\end{array}$ & $\begin{array}{l}55 \\
56 \\
54 \\
56 \\
55\end{array}$ & $\begin{array}{l}55 \\
58 \\
55 \\
54 \\
53\end{array}$ & $\begin{array}{l}65 \\
64 \\
66 \\
69 \\
70\end{array}$ & $\begin{array}{l}75 \\
75 \\
69 \\
68 \\
67\end{array}$ & $\begin{array}{l}78 \\
79 \\
79 \\
78 \\
76\end{array}$ & $\begin{array}{l}-2 \\
86 \\
84 \\
85 \\
86\end{array}$ & $\begin{array}{l}79 \\
80 \\
82 \\
83 \\
84\end{array}$ & $\begin{array}{l}84 \\
82 \\
80 \\
81 \\
82\end{array}$ \\
\hline $\begin{array}{r}6 \\
7 \\
8 \\
9 \\
10\end{array}$ & $\begin{array}{l}\mathbf{7 7} \\
\mathbf{7 2} \\
\mathbf{7 2} \\
\mathbf{7 0} \\
\mathbf{7 0}\end{array}$ & $\begin{array}{l}-2 \\
59 \\
58 \\
54 \\
--\end{array}$ & $\begin{array}{l}57 \\
54 \\
58 \\
57 \\
53\end{array}$ & $\begin{array}{l}50 \\
50 \\
-- \\
52 \\
55\end{array}$ & $\begin{array}{l}55 \\
55 \\
55 \\
54 \\
55\end{array}$ & $\begin{array}{l}50 \\
50 \\
51 \\
54 \\
56\end{array}$ & $\begin{array}{l}70 \\
71 \\
72 \\
70 \\
70\end{array}$ & $\begin{array}{l}66 \\
68 \\
69 \\
69 \\
71\end{array}$ & $\begin{array}{l}78 \\
79 \\
-- \\
80 \\
80\end{array}$ & $\begin{array}{l}85 \\
85 \\
84 \\
85 \\
85\end{array}$ & $\begin{array}{l}84 \\
85 \\
85 \\
-- \\
87\end{array}$ & $\begin{array}{l}83 \\
81 \\
82 \\
79 \\
82\end{array}$ \\
\hline $\begin{array}{l}11 \\
12 \\
13 \\
14 \\
15\end{array}$ & $\begin{array}{l}\mathbf{7 1} \\
\mathbf{7 1} \\
\mathbf{7 1} \\
\mathbf{7 2} \\
\mathbf{7 0}\end{array}$ & $\begin{array}{l}55 \\
54 \\
56 \\
53 \\
57\end{array}$ & $\begin{array}{l}53 \\
54 \\
54 \\
50 \\
46\end{array}$ & $\begin{array}{l}49 \\
48 \\
45 \\
49 \\
51\end{array}$ & $\begin{array}{l}57 \\
55 \\
55 \\
58 \\
60\end{array}$ & $\begin{array}{l}60 \\
63 \\
64 \\
55 \\
55\end{array}$ & $\begin{array}{l}73 \\
73 \\
74 \\
74 \\
74\end{array}$ & $\begin{array}{l}70 \\
71 \\
69 \\
67 \\
70\end{array}$ & $\begin{array}{l}86 \\
81 \\
83 \\
83 \\
82\end{array}$ & $\begin{array}{l}85 \\
87 \\
88 \\
86 \\
86\end{array}$ & $\begin{array}{l}83 \\
82 \\
85 \\
86 \\
86\end{array}$ & $\begin{array}{l}82 \\
77 \\
76 \\
78 \\
80\end{array}$ \\
\hline $\begin{array}{l}16 \\
17 \\
18 \\
19 \\
20\end{array}$ & $\begin{array}{l}\mathbf{7 2} \\
\mathbf{7 2} \\
\mathbf{7 2} \\
\mathbf{7 0} \\
\mathbf{7 3}\end{array}$ & $\begin{array}{l}55 \\
57 \\
60 \\
62 \\
60\end{array}$ & $\begin{array}{l}48 \\
49 \\
49 \\
47 \\
50\end{array}$ & $\begin{array}{l}-- \\
52 \\
50 \\
52 \\
56\end{array}$ & $\begin{array}{l}61 \\
60 \\
60 \\
62 \\
60\end{array}$ & $\begin{array}{l}56 \\
54 \\
57 \\
59 \\
60\end{array}$ & $\begin{array}{l}70 \\
68 \\
66 \\
68 \\
69\end{array}$ & $\begin{array}{l}70 \\
70 \\
72 \\
71 \\
71\end{array}$ & $\begin{array}{l}84 \\
83 \\
84 \\
84 \\
84\end{array}$ & $\begin{array}{l}86 \\
83 \\
83 \\
84 \\
85\end{array}$ & $\begin{array}{l}86 \\
81 \\
85 \\
83 \\
84\end{array}$ & $\begin{array}{l}79 \\
80 \\
80 \\
81 \\
83\end{array}$ \\
\hline $\begin{array}{l}21 \\
22 \\
23 \\
24 \\
25\end{array}$ & $\begin{array}{c}75 \\
72 \\
72 \\
-- \\
72\end{array}$ & $\begin{array}{l}59 \\
59 \\
55 \\
57 \\
55\end{array}$ & $\begin{array}{l}50 \\
51 \\
47 \\
45 \\
45\end{array}$ & $\begin{array}{l}55 \\
45 \\
43 \\
50 \\
51\end{array}$ & $\begin{array}{l}58 \\
58 \\
60 \\
58 \\
60\end{array}$ & $\begin{array}{l}60 \\
62 \\
64 \\
65 \\
57\end{array}$ & $\begin{array}{l}68 \\
74 \\
73 \\
69 \\
73\end{array}$ & $\begin{array}{l}71 \\
70 \\
-- \\
86 \\
73\end{array}$ & $\begin{array}{l}-- \\
83 \\
85 \\
85 \\
85\end{array}$ & $\begin{array}{l}86 \\
84 \\
85 \\
86 \\
--\end{array}$ & $\begin{array}{l}85 \\
86 \\
86 \\
83 \\
86\end{array}$ & $\begin{array}{l}82 \\
78 \\
74 \\
79 \\
77\end{array}$ \\
\hline $\begin{array}{l}\mathbf{2 6} \\
\mathbf{2 7} \\
\mathbf{2 8} \\
\mathbf{2 9} \\
\mathbf{3 0} \\
\mathbf{3 1}\end{array}$ & $\begin{array}{l}70 \\
68 \\
65 \\
65 \\
62 \\
63\end{array}$ & $\begin{array}{l}58 \\
54 \\
57 \\
58 \\
58 \\
--\end{array}$ & $\begin{array}{l}46 \\
45 \\
46 \\
47 \\
48 \\
48\end{array}$ & $\begin{array}{l}53 \\
54 \\
51 \\
59 \\
56 \\
57\end{array}$ & $\begin{array}{l}60 \\
63 \\
60 \\
-- \\
-- \\
--\end{array}$ & $\begin{array}{l}66 \\
67 \\
55 \\
67 \\
69 \\
71\end{array}$ & $\begin{array}{l}73 \\
74 \\
74 \\
75 \\
76 \\
--\end{array}$ & $\begin{array}{l}-- \\
-- \\
-- \\
75 \\
75 \\
--\end{array}$ & $\begin{array}{l}85 \\
85 \\
85 \\
86 \\
87 \\
--\end{array}$ & $\begin{array}{l}85 \\
86 \\
86 \\
84 \\
80 \\
80\end{array}$ & $\begin{array}{l}83 \\
84 \\
81 \\
82 \\
84 \\
84\end{array}$ & $\begin{array}{l}77 \\
79 \\
80 \\
78 \\
81 \\
--\end{array}$ \\
\hline $\begin{array}{c}\text { Aver- } \\
\text { age }\end{array}$ & 72 & 58 & 51 & 51 & 58 & 59 & 71 & 71 & 82 & 85 & 84 & 80 \\
\hline
\end{tabular}




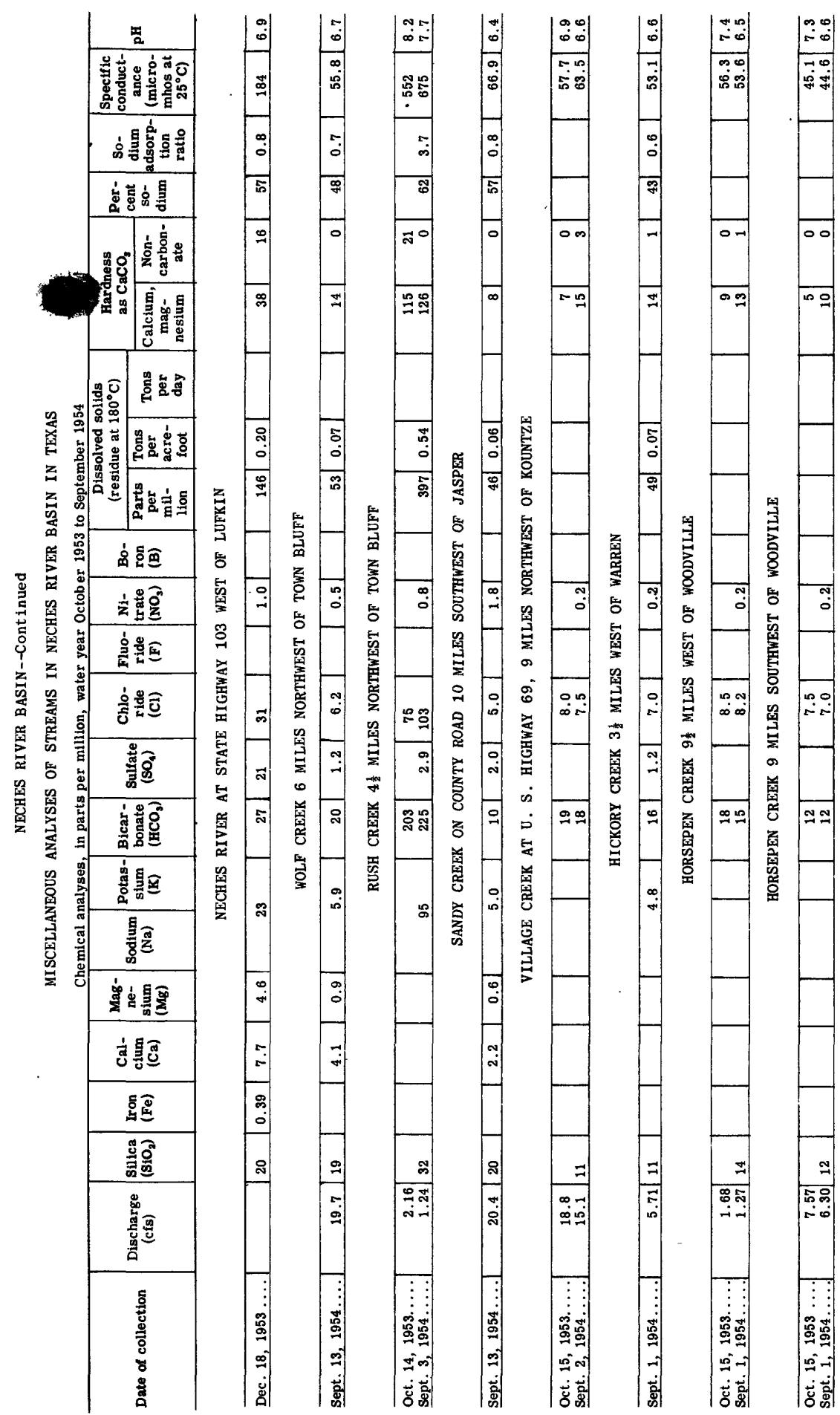




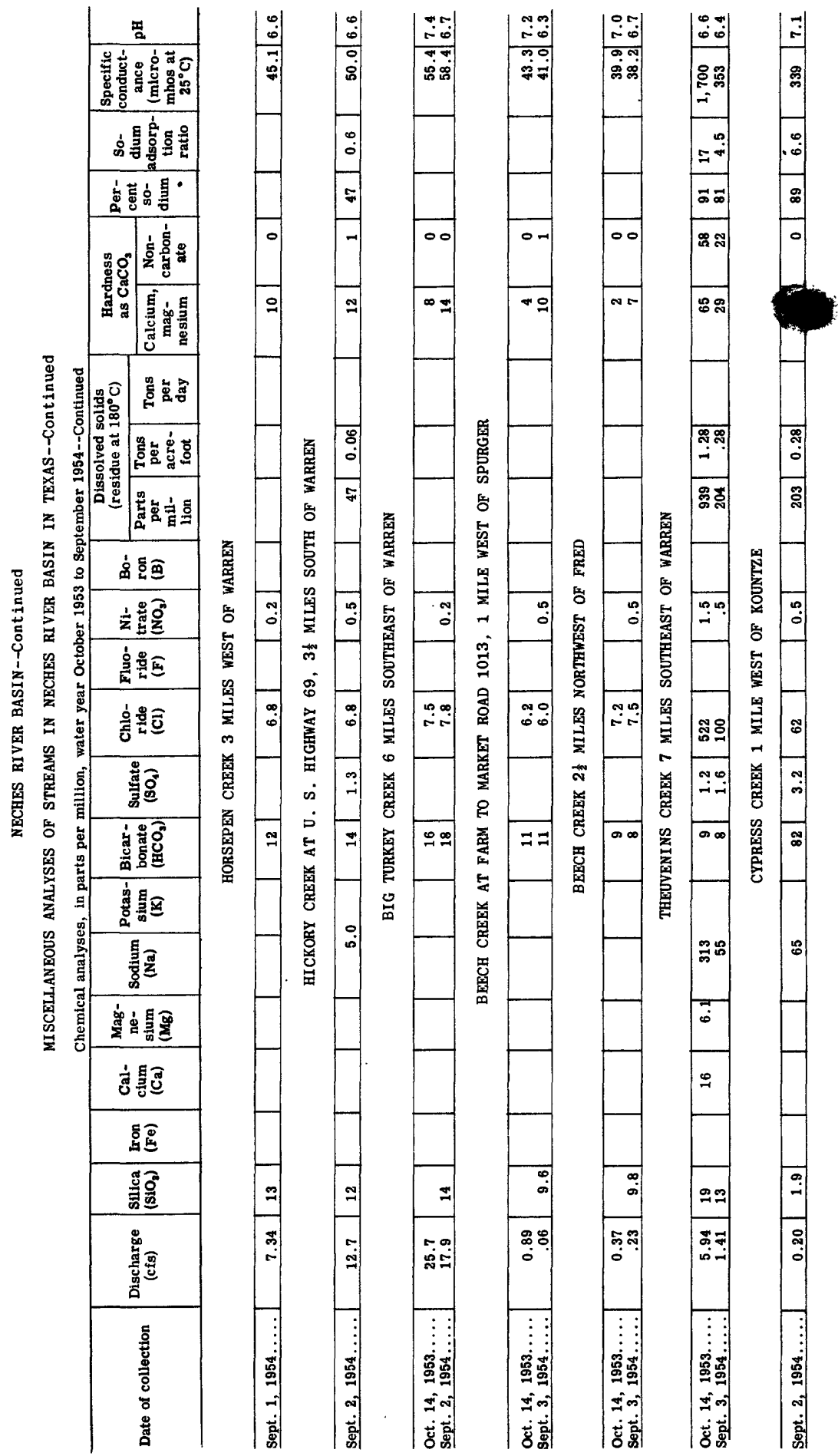




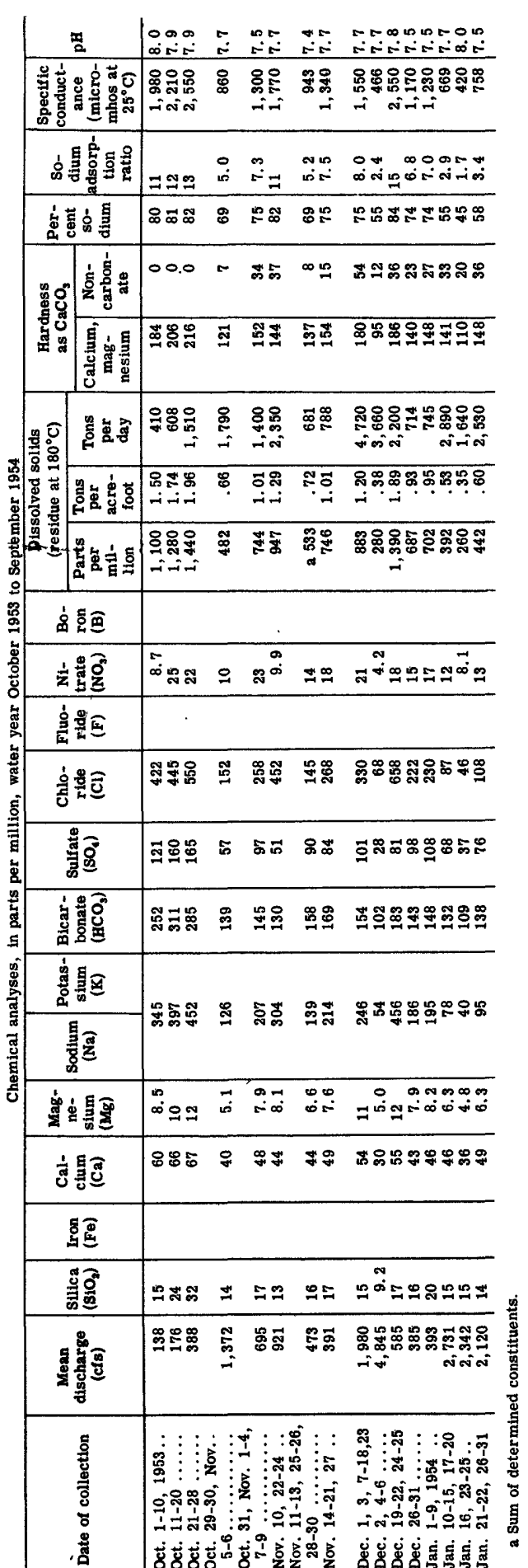




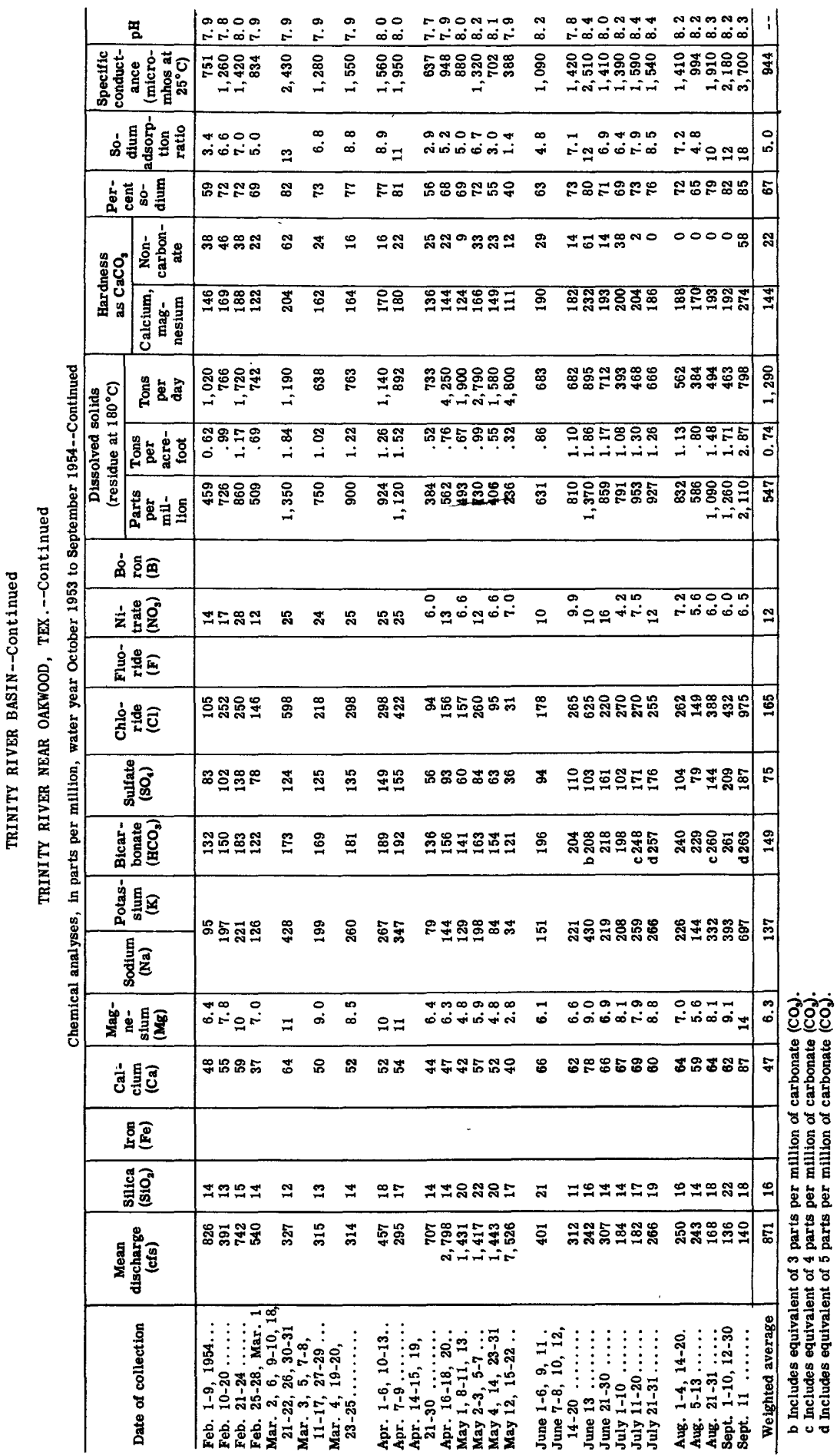


TRINITY RIVER BASIN--Continued

TRINITY RIVER NEAR OAKWOOD, TEX.--Continued

Temperature $\left({ }^{\circ} \mathrm{F}\right)$ of water, water year October 1953 to September 1954

\begin{tabular}{|c|c|c|c|c|c|c|c|c|c|c|c|c|}
\hline Day & Oct. & Nov. & Dec. & Jan. & Feb. & Mar. & Apr. & May & June & July & Aug. & Sept. \\
\hline $\begin{array}{l}1 \\
2 \\
3 \\
4 \\
5\end{array}$ & $\begin{array}{l}79 \\
79 \\
79 \\
78 \\
75\end{array}$ & $\begin{array}{l}62 \\
60 \\
63 \\
62 \\
60\end{array}$ & $\begin{array}{l}55 \\
57 \\
59 \\
56 \\
57\end{array}$ & $\begin{array}{l}56 \\
54 \\
55 \\
56 \\
53\end{array}$ & $\begin{array}{l}50 \\
53 \\
52 \\
53 \\
52\end{array}$ & $\begin{array}{l}\mathbf{5 3} \\
\mathbf{5 5} \\
\mathbf{5 1} \\
\mathbf{5 1} \\
\mathbf{5 1}\end{array}$ & $\begin{array}{l}56 \\
67 \\
65 \\
69 \\
69\end{array}$ & $\begin{array}{c}75 \\
70 \\
65 \\
61 \\
64\end{array}$ & $\begin{array}{l}82 \\
83 \\
79 \\
78 \\
75\end{array}$ & $\begin{array}{l}84 \\
85 \\
85 \\
85 \\
85\end{array}$ & $\begin{array}{l}82 \\
81 \\
83 \\
83 \\
84\end{array}$ & $\begin{array}{l}83 \\
83 \\
80 \\
83 \\
80\end{array}$ \\
\hline $\begin{array}{r}6 \\
7 \\
8 \\
9 \\
10\end{array}$ & $\begin{array}{l}60 \\
65 \\
68 \\
65 \\
65\end{array}$ & $\begin{array}{l}58 \\
64 \\
65 \\
54 \\
52\end{array}$ & $\begin{array}{l}53 \\
57 \\
56 \\
56 \\
56\end{array}$ & $\begin{array}{l}56 \\
56 \\
57 \\
56 \\
54\end{array}$ & $\begin{array}{l}53 \\
50 \\
50 \\
50 \\
52\end{array}$ & $\begin{array}{l}45 \\
50 \\
51 \\
52 \\
59\end{array}$ & $\begin{array}{l}70 \\
70 \\
70 \\
70 \\
71\end{array}$ & $\begin{array}{l}67 \\
70 \\
71 \\
73 \\
72\end{array}$ & $\begin{array}{l}77 \\
80 \\
81 \\
80 \\
81\end{array}$ & $\begin{array}{l}85 \\
85 \\
84 \\
85 \\
84\end{array}$ & $\begin{array}{l}84 \\
88 \\
83 \\
85 \\
85\end{array}$ & $\begin{array}{l}82 \\
83 \\
83 \\
83 \\
83\end{array}$ \\
\hline $\begin{array}{l}11 \\
12 \\
13 \\
14 \\
15\end{array}$ & $\begin{array}{l}68 \\
68 \\
65 \\
65 \\
67\end{array}$ & $\begin{array}{l}52 \\
51 \\
53 \\
53 \\
52\end{array}$ & $\begin{array}{l}\mathbf{5 6} \\
\mathbf{5 4} \\
\mathbf{5 6} \\
\mathbf{5 6} \\
\mathbf{5 8}\end{array}$ & $\begin{array}{l}54 \\
53 \\
52 \\
52 \\
53\end{array}$ & $\begin{array}{l}53 \\
52 \\
53 \\
65 \\
60\end{array}$ & $\begin{array}{l}65 \\
65 \\
60 \\
64 \\
55\end{array}$ & $\begin{array}{l}70 \\
73 \\
72 \\
71 \\
73\end{array}$ & $\begin{array}{l}68 \\
62 \\
62 \\
64 \\
65\end{array}$ & $\begin{array}{l}81 \\
82 \\
83 \\
82 \\
80\end{array}$ & $\begin{array}{l}85 \\
85 \\
85 \\
86 \\
--\end{array}$ & $\begin{array}{l}85 \\
84 \\
82 \\
85 \\
85\end{array}$ & $\begin{array}{l}82 \\
81 \\
81 \\
81 \\
80\end{array}$ \\
\hline $\begin{array}{l}16 \\
17 \\
18 \\
19 \\
20\end{array}$ & $\begin{array}{l}68 \\
67 \\
65 \\
67 \\
65\end{array}$ & $\begin{array}{l}53 \\
58 \\
60 \\
62 \\
62\end{array}$ & $\begin{array}{l}56 \\
58 \\
57 \\
56 \\
56\end{array}$ & $\begin{array}{l}54 \\
54 \\
53 \\
53 \\
52\end{array}$ & $\begin{array}{l}60 \\
55 \\
60 \\
62 \\
58\end{array}$ & $\begin{array}{l}54 \\
54 \\
55 \\
58 \\
65\end{array}$ & $\begin{array}{l}70 \\
68 \\
70 \\
68 \\
69\end{array}$ & $\begin{array}{l}65 \\
68 \\
68 \\
50 \\
70\end{array}$ & $\begin{array}{l}83 \\
83 \\
84 \\
84 \\
85\end{array}$ & $\begin{array}{l}84 \\
85 \\
85 \\
86 \\
86\end{array}$ & $\begin{array}{l}84 \\
85 \\
85 \\
84 \\
85\end{array}$ & $\begin{array}{l}-- \\
-- \\
--\end{array}$ \\
\hline $\begin{array}{l}21 \\
22 \\
23 \\
24 \\
25\end{array}$ & $\begin{array}{l}68 \\
65 \\
84 \\
63 \\
71\end{array}$ & $\begin{array}{l}\mathbf{5 5} \\
56 \\
55 \\
54 \\
52\end{array}$ & $\begin{array}{l}57 \\
54 \\
57 \\
56 \\
56\end{array}$ & $\begin{array}{l}48 \\
47 \\
45 \\
45 \\
50\end{array}$ & $\begin{array}{l}58 \\
56 \\
58 \\
55 \\
56\end{array}$ & $\begin{array}{l}61 \\
60 \\
65 \\
68 \\
65\end{array}$ & $\begin{array}{l}70 \\
71 \\
71 \\
70 \\
72\end{array}$ & $\begin{array}{l}70 \\
71 \\
73 \\
74 \\
74\end{array}$ & $\begin{array}{l}84 \\
85 \\
83 \\
84 \\
85\end{array}$ & $\begin{array}{l}84 \\
84 \\
85 \\
85 \\
84\end{array}$ & $\begin{array}{l}84 \\
82 \\
83 \\
84 \\
83\end{array}$ & $\begin{array}{l}-- \\
-- \\
--\end{array}$ \\
\hline $\begin{array}{l}26 \\
27 \\
28 \\
29 \\
30 \\
31\end{array}$ & $\begin{array}{l}60 \\
65 \\
65 \\
60 \\
60 \\
62 \\
\end{array}$ & $\begin{array}{l}52 \\
52 \\
53 \\
53 \\
55 \\
-- \\
\end{array}$ & $\begin{array}{l}56 \\
57 \\
58 \\
54 \\
55 \\
56 \\
\end{array}$ & $\begin{array}{l}50 \\
50 \\
49 \\
53 \\
53 \\
52 \\
\end{array}$ & $\begin{array}{l}56 \\
60 \\
55 \\
-- \\
-- \\
-- \\
\end{array}$ & $\begin{array}{l}65 \\
68 \\
65 \\
65 \\
64 \\
64 \\
\end{array}$ & $\begin{array}{l}73 \\
72 \\
71 \\
75 \\
75 \\
-- \\
\end{array}$ & $\begin{array}{l}74 \\
75 \\
76 \\
76 \\
80 \\
82 \\
\end{array}$ & $\begin{array}{l}83 \\
84 \\
85 \\
84 \\
85 \\
-- \\
\end{array}$ & $\begin{array}{l}88 \\
87 \\
87 \\
84 \\
82 \\
84 \\
\end{array}$ & $\begin{array}{l}83 \\
83 \\
85 \\
85 \\
84 \\
83 \\
\end{array}$ & $\begin{array}{l}-- \\
-- \\
-- \\
-- \\
-\end{array}$ \\
\hline $\begin{array}{c}\text { Aver- } \\
\text { age }\end{array}$ & 67 & 57 & 56 & 52 & 55 & 59 & 70 & 70 & 82 & 85 & 84 & - \\
\hline
\end{tabular}




\begin{tabular}{|c|c|c|c|c|}
\hline 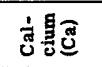 & 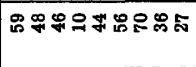 & 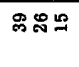 & $\infty$ & $\mathscr{\infty}$ \\
\hline 愘这 & & & & \\
\hline 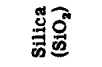 & 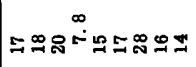 & 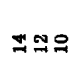 & สลสฏ & స్쥬ల్ల \\
\hline 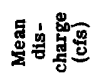 & 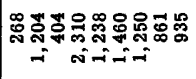 & 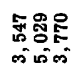 & 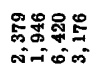 & 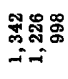 \\
\hline 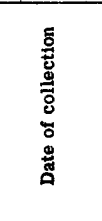 & 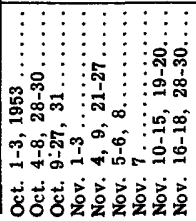 & 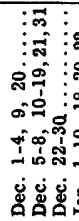 & 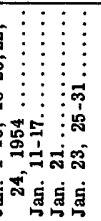 & 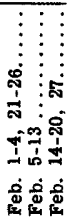 \\
\hline
\end{tabular}




\begin{tabular}{|c|c|c|c|c|}
\hline $\begin{array}{l}\infty 00 \\
-\infty \infty \\
\end{array}$ & 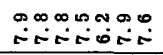 & 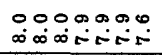 & 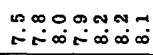 & i \\
\hline 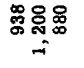 & 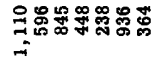 & 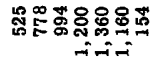 & 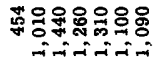 & 怘 \\
\hline Fion & 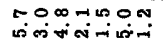 & 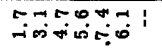 & 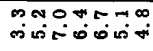 & $\begin{array}{l}N \\
\infty\end{array}$ \\
\hline$\because 00$ & 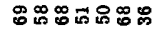 & 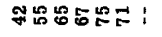 & ธ゚ロニニニロ & $\ddot{0}$ \\
\hline Ұ포ำ & 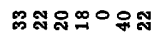 & 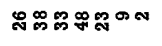 & 0 in & $\stackrel{\infty}{\rightarrow}$ \\
\hline 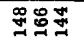 & 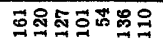 & 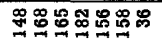 & విర్తి: & \$े \\
\hline 웡్ㅀ & 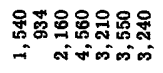 & 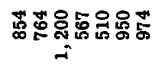 & 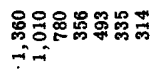 & $\begin{array}{l}8 \\
8 \\
0 \\
-1\end{array}$ \\
\hline ๆ๐ุ & 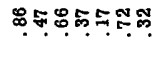 & 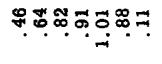 & 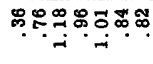 & 5 \\
\hline 芦巨芯怘 & 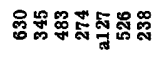 & 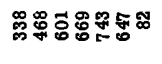 & 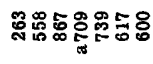 & 趈 \\
\hline $\begin{array}{l}\infty 00 \\
\sin \end{array}$ & 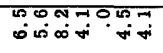 & 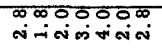 & 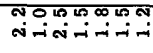 & + \\
\hline 蛋 웛 & 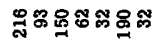 & 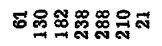 & 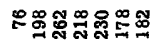 & $\infty$ \\
\hline$=\infty 8$ & 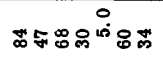 & 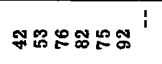 & 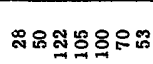 & i \\
\hline 馬备馬 & 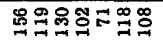 & 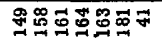 & 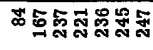 & $\stackrel{80}{9}$ \\
\hline 芯点 & 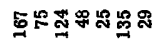 & 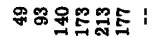 & 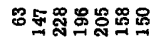 & 2 \\
\hline 禹是: & 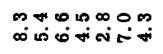 & $\begin{array}{l}\infty \\
\infty \\
\infty \\
0\end{array}$ & 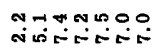 & 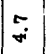 \\
\hline 悉芯杲 & 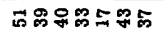 & 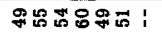 & 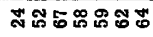 & m \\
\hline & 4 & & & \\
\hline エஉีี & 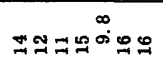 & 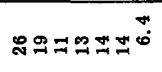 & 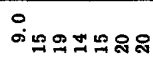 & $\stackrel{n}{=}$ \\
\hline 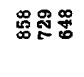 & 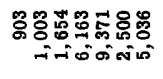 & 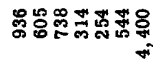 & 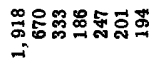 & 总 \\
\hline 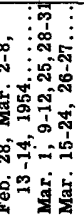 & 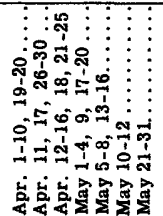 & 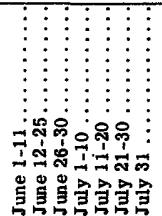 & 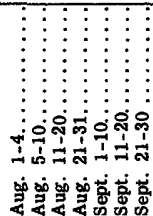 & 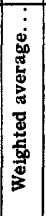 \\
\hline
\end{tabular}


TRINITY RIVER BASIN--Continued

TRINITY RIVER AT ROMAYOR, TEX.--Continued

Temperature $\left({ }^{\circ} \mathrm{F}\right)$ of water, water year October 1953 to September 1954

\begin{tabular}{|c|c|c|c|c|c|c|c|c|c|c|c|c|}
\hline Day & Oct. & Nov. & Dec. & Jan. & Feb. & Mar. & Apr. & May & June & July & Aug. & Sept. \\
\hline $\begin{array}{l}1 \\
2 \\
3 \\
4 \\
5\end{array}$ & $\begin{array}{l}80 \\
80 \\
73 \\
80 \\
80\end{array}$ & $\begin{array}{l}60 \\
65 \\
65 \\
65 \\
65\end{array}$ & $\begin{array}{l}55 \\
60 \\
58 \\
60 \\
55\end{array}$ & $\begin{array}{l}40 \\
50 \\
-- \\
50 \\
50\end{array}$ & $\begin{array}{l}-- \\
50 \\
50 \\
55 \\
50\end{array}$ & $\begin{array}{l}58 \\
58 \\
55 \\
58 \\
55\end{array}$ & $\begin{array}{l}68 \\
72 \\
71 \\
73 \\
73\end{array}$ & $\begin{array}{l}77 \\
76 \\
72 \\
72 \\
68\end{array}$ & $\begin{array}{l}86 \\
86 \\
86 \\
85 \\
80\end{array}$ & $\begin{array}{l}92 \\
88 \\
86 \\
88 \\
88\end{array}$ & $\begin{array}{l}80 \\
82 \\
82 \\
85 \\
85\end{array}$ & $\begin{array}{l}84 \\
84 \\
84 \\
83 \\
88\end{array}$ \\
\hline $\begin{array}{r}6 \\
7 \\
8 \\
9 \\
10\end{array}$ & $\begin{array}{l}75 \\
75 \\
75 \\
75 \\
75\end{array}$ & $\begin{array}{l}65 \\
60 \\
60 \\
60 \\
65\end{array}$ & $\begin{array}{l}55 \\
60 \\
60 \\
60 \\
60\end{array}$ & $\begin{array}{l}50 \\
50 \\
50 \\
50 \\
50\end{array}$ & $\begin{array}{l}45 \\
50 \\
45 \\
50 \\
50\end{array}$ & $\begin{array}{l}52 \\
54 \\
55 \\
59 \\
62\end{array}$ & $\begin{array}{l}73 \\
74 \\
- \\
74 \\
75\end{array}$ & $\begin{array}{l}70 \\
71 \\
75 \\
75 \\
76\end{array}$ & $\begin{array}{l}85 \\
86 \\
87 \\
87 \\
86\end{array}$ & $\begin{array}{l}88 \\
89 \\
89 \\
90 \\
89\end{array}$ & $\begin{array}{l}85 \\
85 \\
91 \\
88 \\
88\end{array}$ & $\begin{array}{l}86 \\
84 \\
84 \\
84 \\
83\end{array}$ \\
\hline $\begin{array}{l}11 \\
12 \\
13 \\
14 \\
15\end{array}$ & $\begin{array}{l}75 \\
78 \\
80 \\
75 \\
80\end{array}$ & $\begin{array}{l}60 \\
65 \\
60 \\
65 \\
65\end{array}$ & $\begin{array}{l}58 \\
60 \\
50 \\
50 \\
50\end{array}$ & $\begin{array}{l}50 \\
50 \\
50 \\
50 \\
50\end{array}$ & $\begin{array}{l}50 \\
55 \\
55 \\
55 \\
55\end{array}$ & $\begin{array}{l}68 \\
68 \\
68 \\
59 \\
58\end{array}$ & $\begin{array}{l}75 \\
72 \\
76 \\
78 \\
76\end{array}$ & $\begin{array}{l}76 \\
74 \\
68 \\
68 \\
70\end{array}$ & $\begin{array}{l}88 \\
86 \\
89 \\
88 \\
88\end{array}$ & $\begin{array}{l}92 \\
91 \\
91 \\
91 \\
92\end{array}$ & $\begin{array}{l}88 \\
88 \\
88 \\
68 \\
88\end{array}$ & $\begin{array}{l}84 \\
84 \\
83 \\
80 \\
81\end{array}$ \\
\hline $\begin{array}{l}16 \\
17 \\
18 \\
19 \\
20\end{array}$ & $\begin{array}{l}80 \\
75 \\
75 \\
75 \\
80\end{array}$ & $\begin{array}{l}60 \\
65 \\
60 \\
60 \\
65\end{array}$ & $\begin{array}{l}50 \\
50 \\
50 \\
50 \\
50\end{array}$ & $\begin{array}{l}50 \\
50 \\
50 \\
50 \\
55\end{array}$ & \begin{tabular}{l|}
60 \\
60 \\
60 \\
60 \\
60
\end{tabular} & $\begin{array}{l}58 \\
58 \\
59 \\
60 \\
61\end{array}$ & $\begin{array}{l}72 \\
69 \\
73 \\
74 \\
75\end{array}$ & $\begin{array}{l}70 \\
73 \\
74 \\
74 \\
74\end{array}$ & $\begin{array}{l}87 \\
90 \\
91 \\
8 B \\
85\end{array}$ & $\begin{array}{l}93 \\
93 \\
88 \\
88 \\
88\end{array}$ & $\begin{array}{l}68 \\
68 \\
88 \\
B 8 \\
68\end{array}$ & $\begin{array}{l}82 \\
82 \\
82 \\
82 \\
82\end{array}$ \\
\hline $\begin{array}{l}21 \\
22 \\
23 \\
24 \\
25\end{array}$ & $\begin{array}{l}75 \\
79 \\
70 \\
75 \\
75\end{array}$ & $\begin{array}{l}60 \\
60 \\
60 \\
60 \\
60\end{array}$ & $\begin{array}{l}50 \\
48 \\
45 \\
45 \\
45\end{array}$ & $\begin{array}{l}45 \\
45 \\
45 \\
48 \\
50\end{array}$ & $\begin{array}{l}60 \\
60 \\
60 \\
60 \\
--\end{array}$ & $\begin{array}{l}62 \\
67 \\
67 \\
68 \\
70\end{array}$ & $\begin{array}{l}74 \\
75 \\
76 \\
75 \\
76\end{array}$ & $\begin{array}{l}74 \\
72 \\
73 \\
76 \\
74\end{array}$ & $\begin{array}{l}88 \\
87 \\
90 \\
91 \\
91\end{array}$ & $\begin{array}{l}89 \\
88 \\
90 \\
92 \\
88\end{array}$ & $\begin{array}{l}88 \\
\mathbf{B 5} \\
\mathbf{8 5} \\
\mathbf{B 4} \\
\mathbf{B 4}\end{array}$ & $\begin{array}{l}82 \\
81 \\
79 \\
78 \\
78\end{array}$ \\
\hline $\begin{array}{l}26 \\
27 \\
28 \\
29 \\
30 \\
31\end{array}$ & $\begin{array}{l}70 \\
70 \\
70 \\
-65 \\
65 \\
\end{array}$ & $\begin{array}{l}60 \\
62 \\
62 \\
65 \\
55 \\
-- \\
\end{array}$ & $\begin{array}{l}50 \\
40 \\
50 \\
-- \\
45 \\
45 \\
\end{array}$ & $\begin{array}{l}50 \\
50 \\
55 \\
55 \\
55 \\
55\end{array}$ & $\begin{array}{l}60 \\
60 \\
60 \\
-- \\
-- \\
--\end{array}$ & $\begin{array}{l}70 \\
69 \\
72 \\
72 \\
75 \\
73 \\
\end{array}$ & $\begin{array}{l}75 \\
78 \\
78 \\
80 \\
75 \\
-- \\
\end{array}$ & $\begin{array}{l}77 \\
78 \\
75 \\
82 \\
84 \\
85 \\
\end{array}$ & $\begin{array}{l}91 \\
91 \\
.92 \\
92 \\
93 \\
-2\end{array}$ & $\begin{array}{l}91 \\
91 \\
88 \\
86 \\
76 \\
76 \\
\end{array}$ & $\begin{array}{l}84 \\
84 \\
84 \\
85 \\
87 \\
\end{array}$ & $\begin{array}{l}82 \\
81 \\
81 \\
82 \\
83 \\
-- \\
\end{array}$ \\
\hline $\begin{array}{c}\text { Aver- } \\
\text { age }\end{array}$ & 75 & 62 & 52 & 50 & 55 & 63 & 74 & 74 & 88 & 89 & 86 & 82 \\
\hline
\end{tabular}




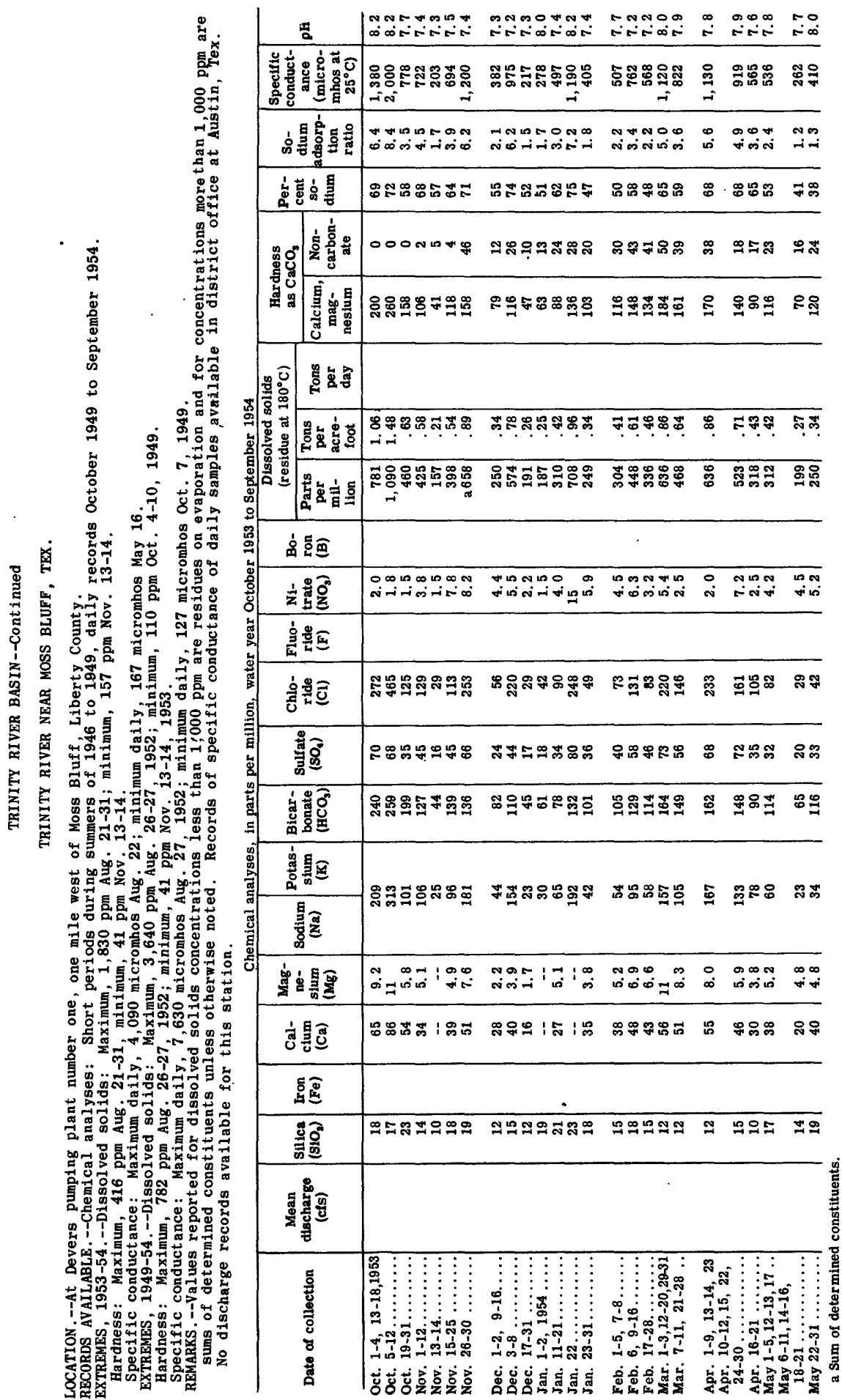




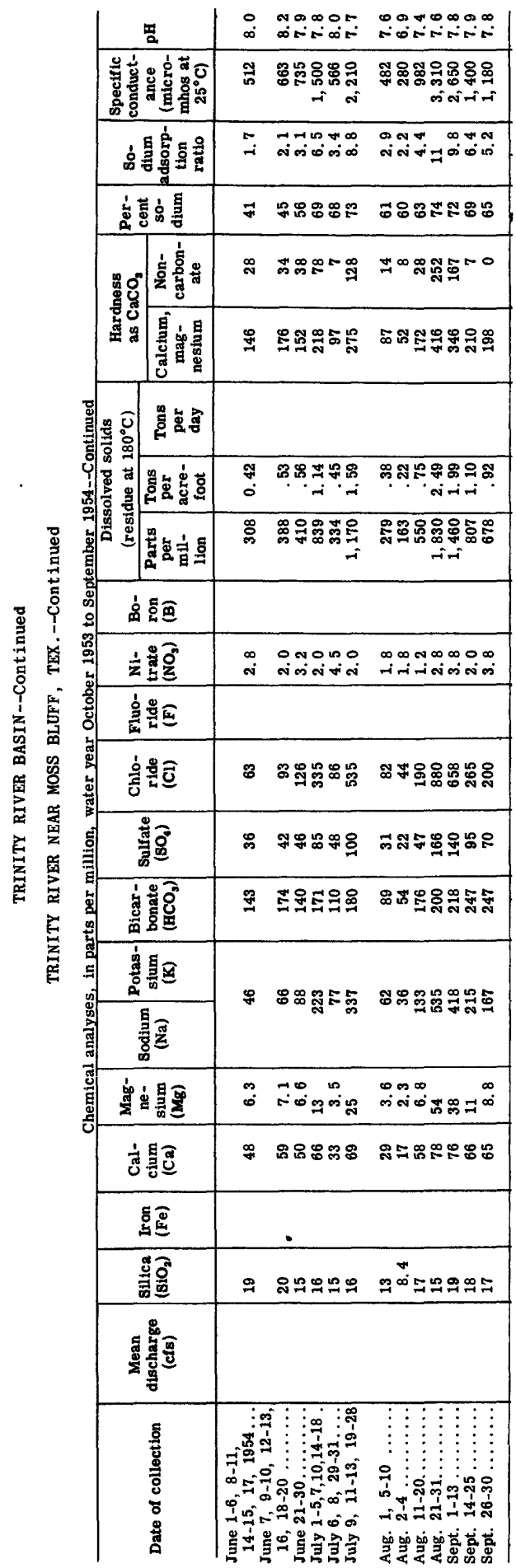




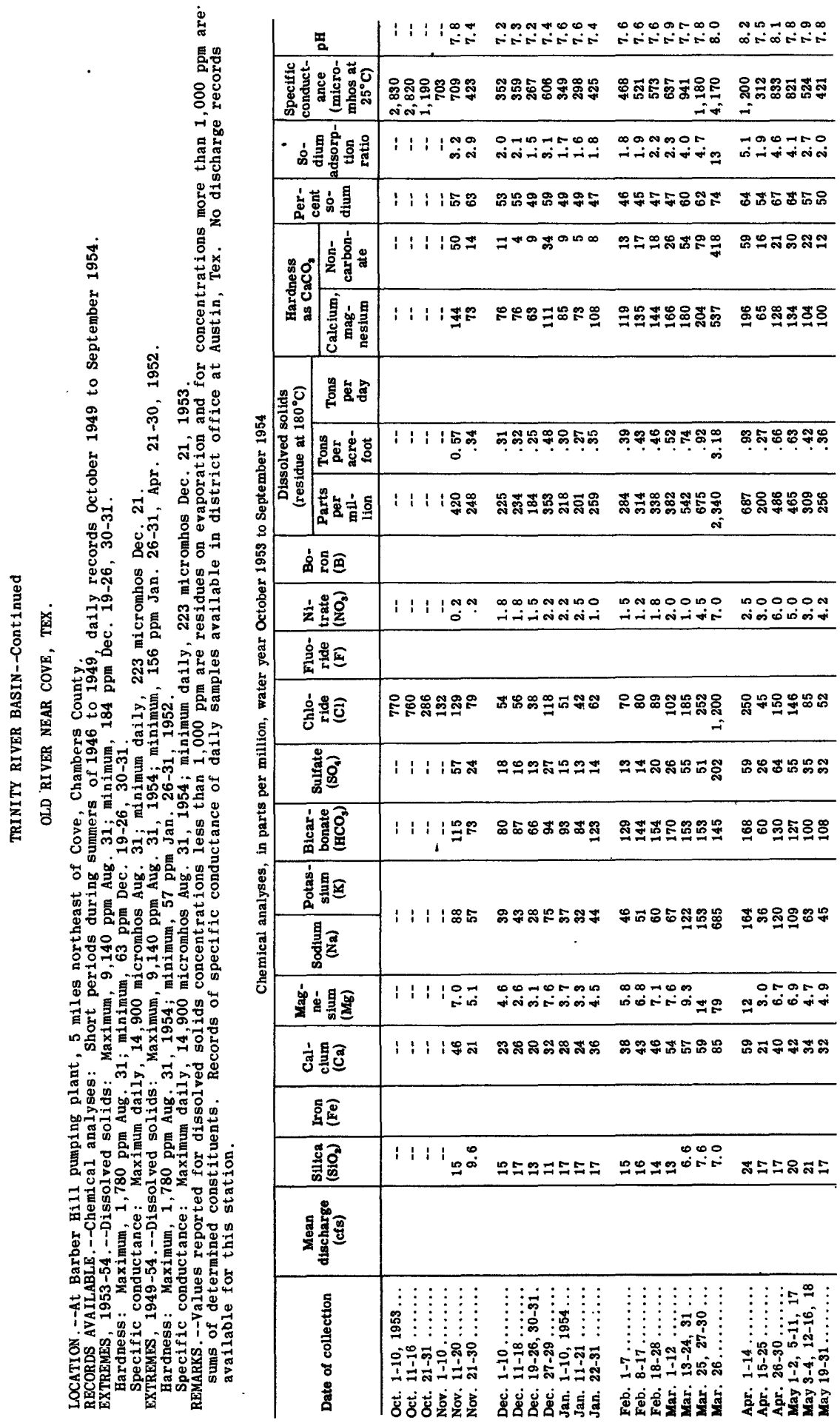




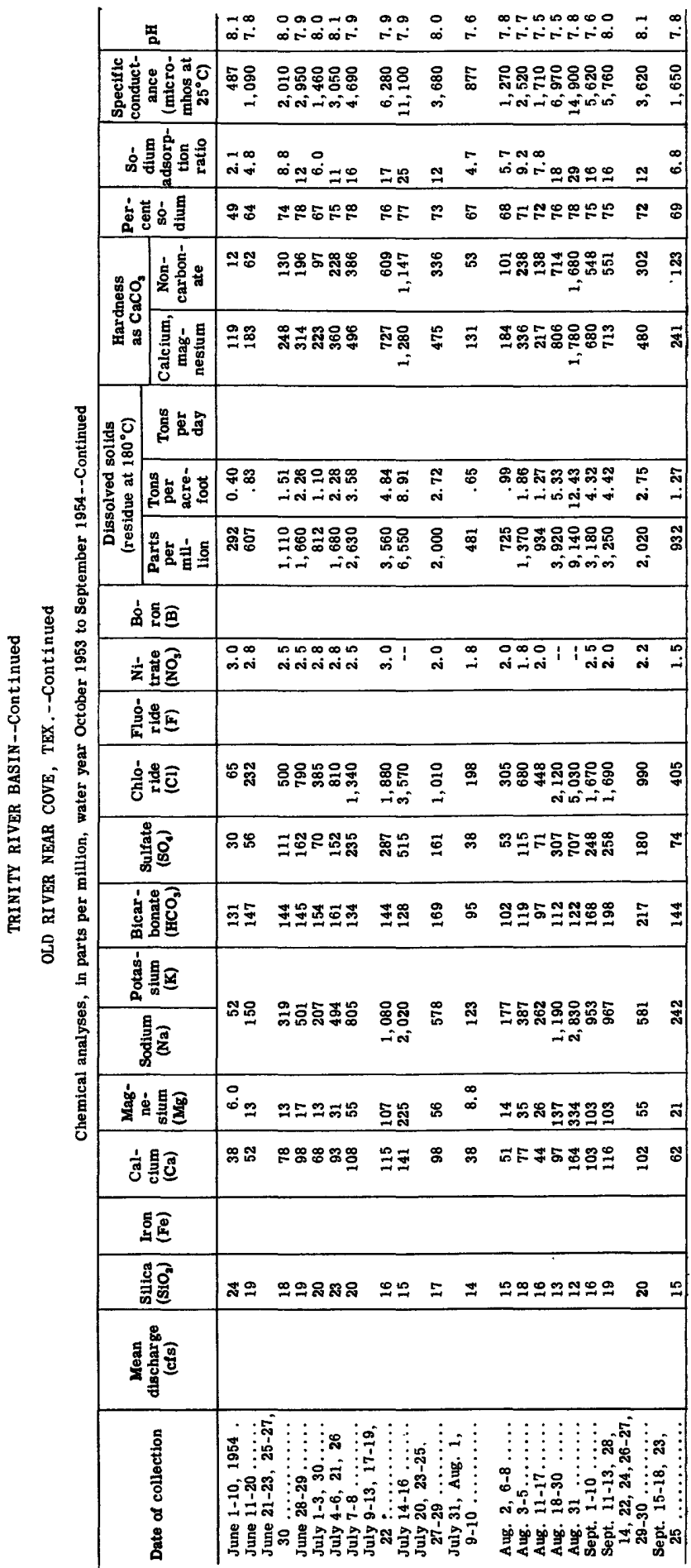




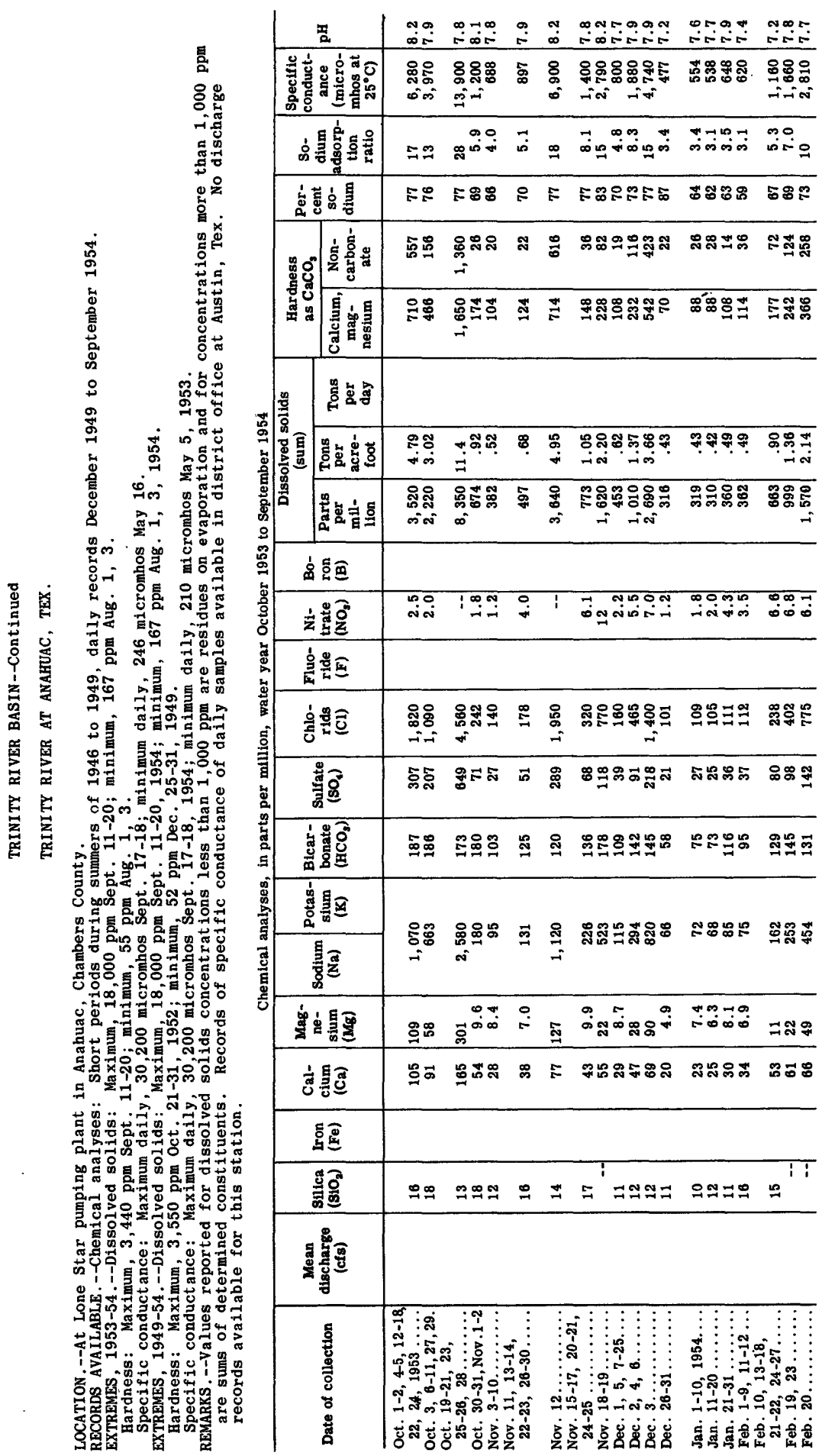




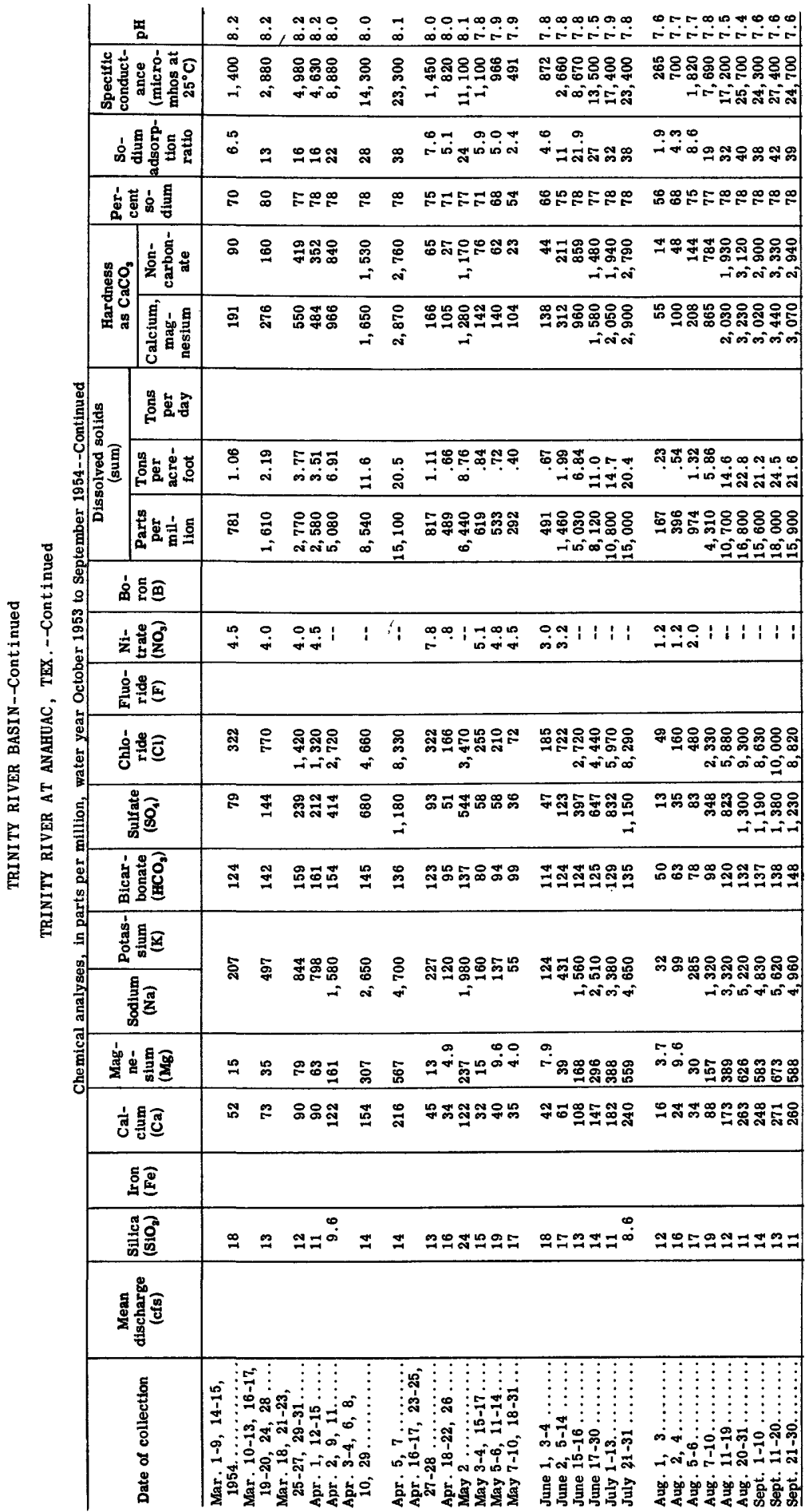


TRINITY RIVER BASIN

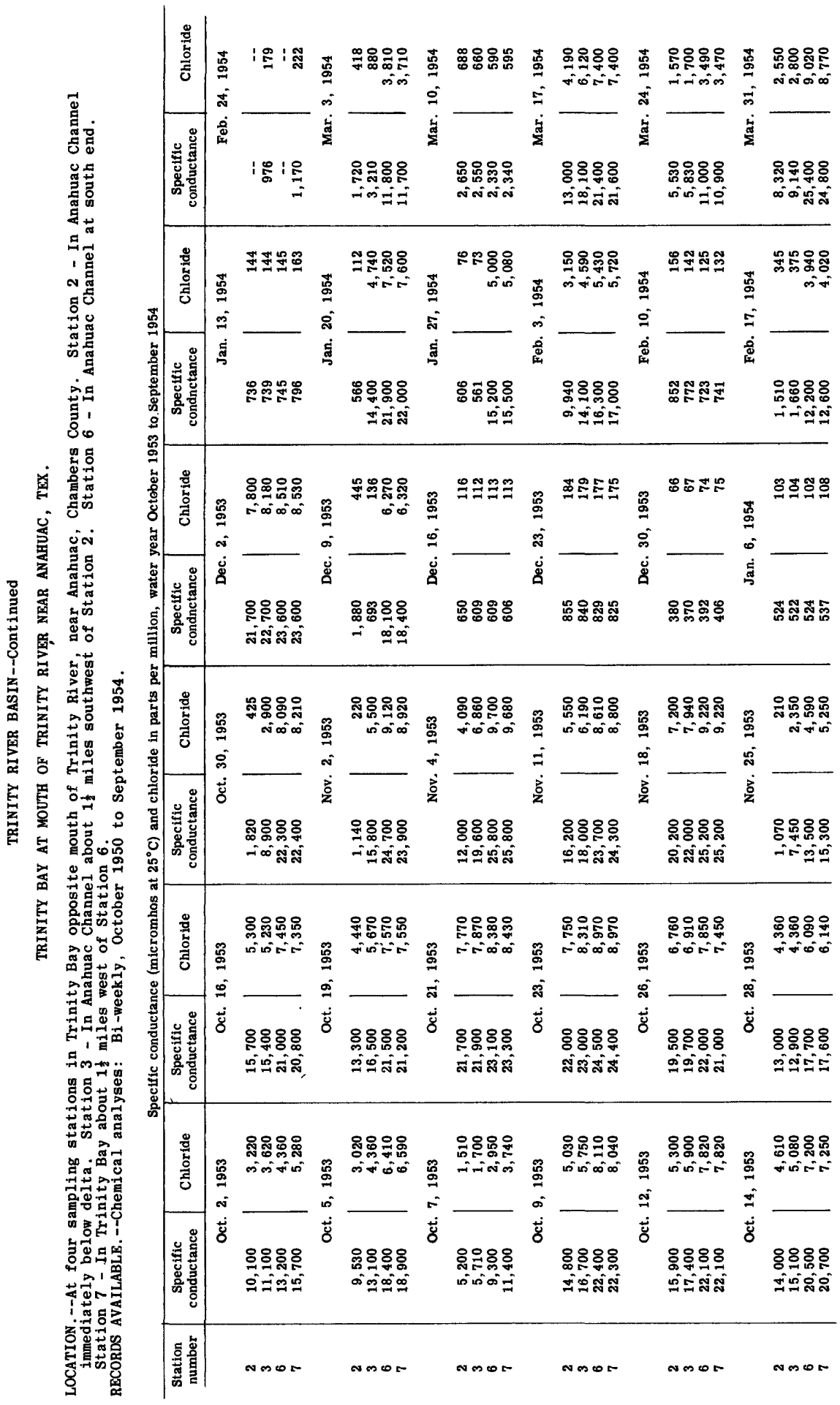




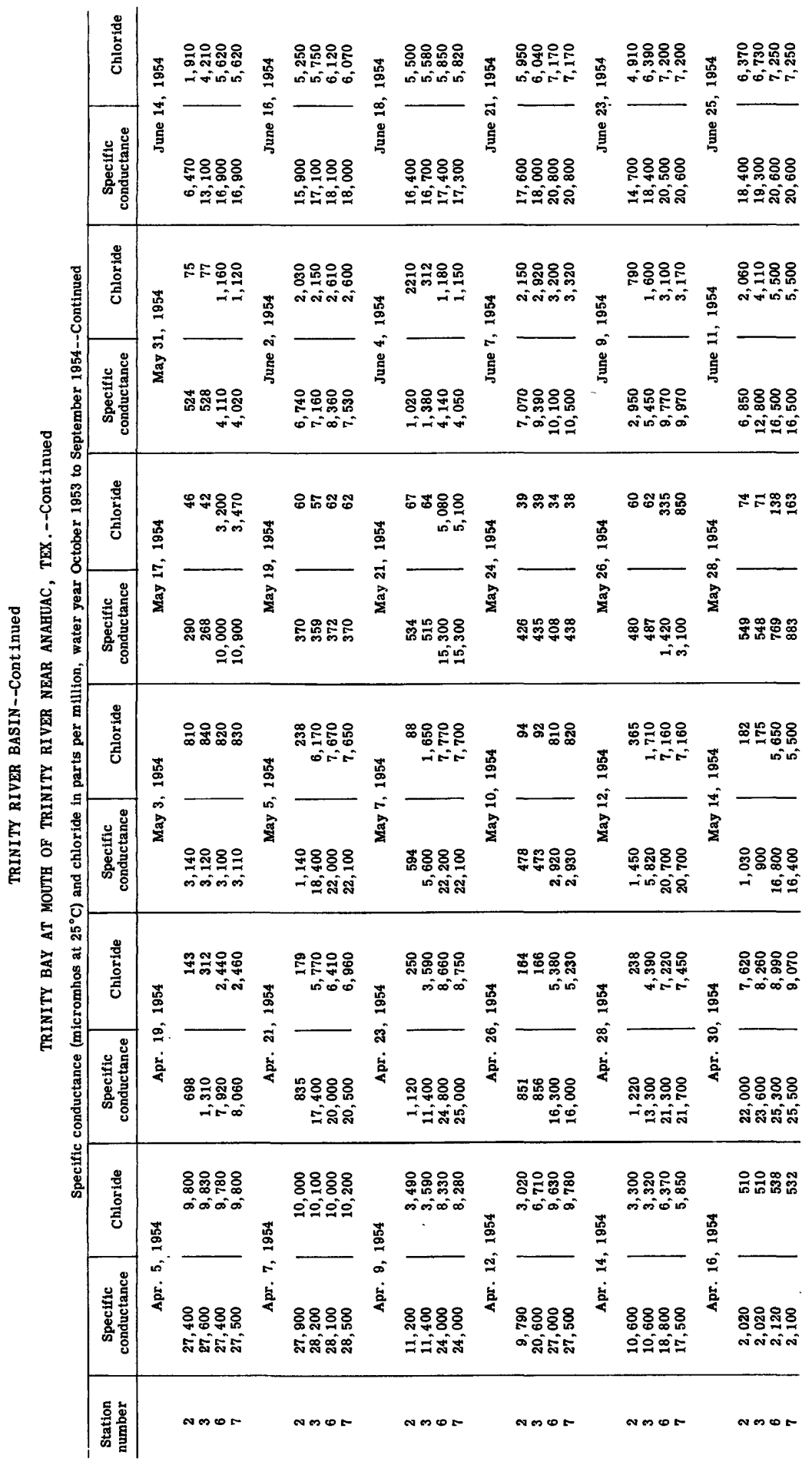




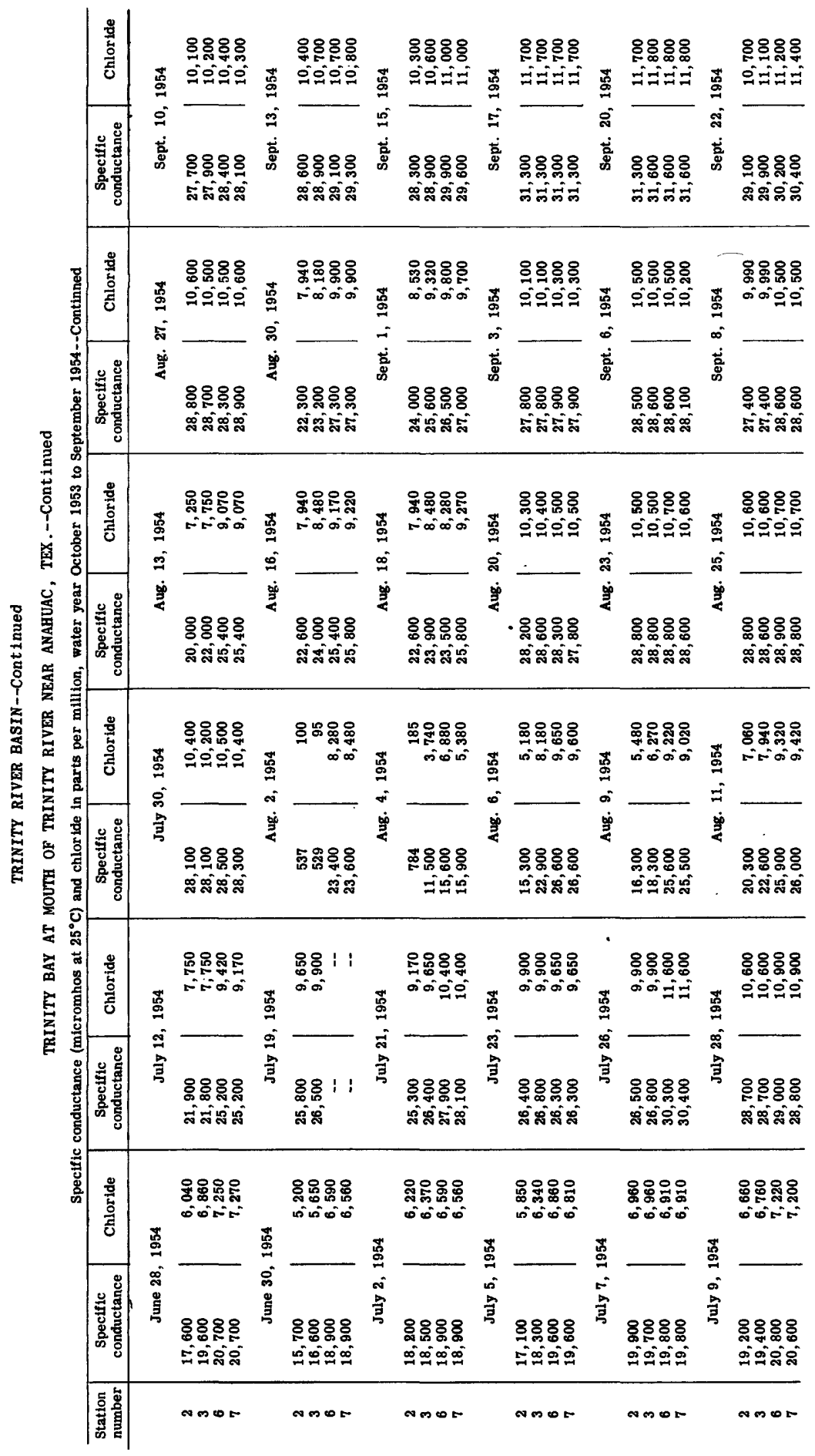




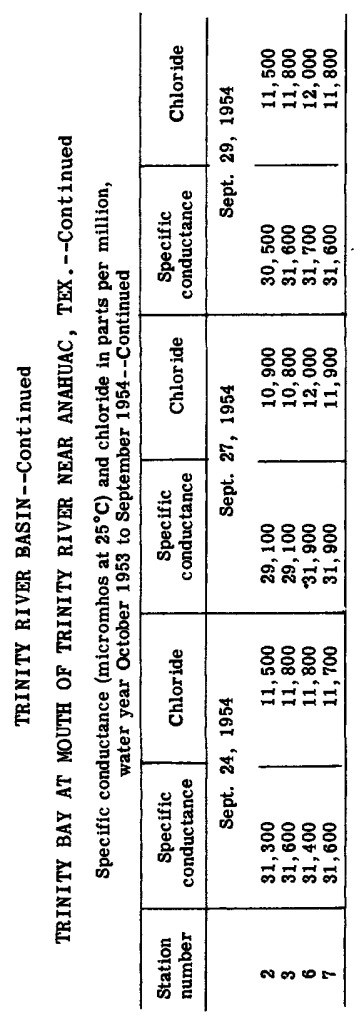




\begin{tabular}{|c|c|c|c|c|}
\hline 回 & 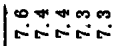 & $\stackrel{\leftrightarrow}{\sim}$ & 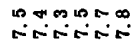 & $\begin{array}{l}\infty \infty \infty \infty \infty \infty \\
\sim\end{array}$ \\
\hline 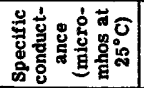 & 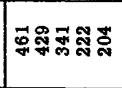 & $\vec{D}$ & 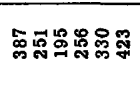 & 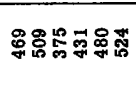 \\
\hline d & $0 \infty N$ & $\infty$ & $10 \mathrm{~m} \mathrm{nol}$ & \\
\hline
\end{tabular}

\begin{tabular}{|c|c|c|c|c|}
\hline 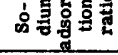 & 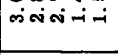 & $\dot{\sim}$ & จิ-i-i-i & 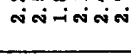 \\
\hline 它苛宫㟟 & 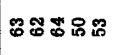 & 모 & 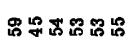 & 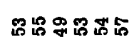 \\
\hline
\end{tabular}

\begin{tabular}{|c|c|c|c|c|}
\hline \multirow{2}{*}{ 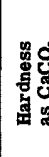 } & 客高 & 009000 & - ogrm品 & 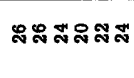 \\
\hline & 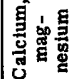 & 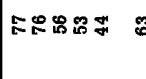 & 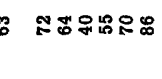 & 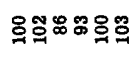 \\
\hline
\end{tabular}

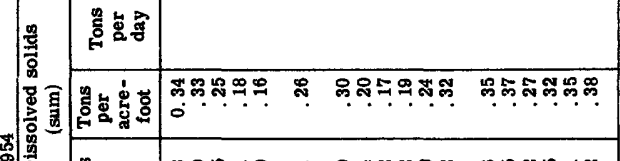

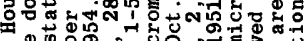
क त o

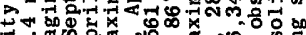
00 ถ⿻ oิ 0.

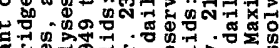

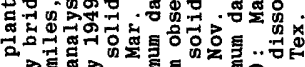
of

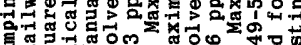

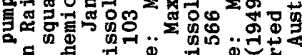

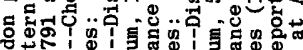
0 क

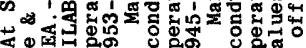
4

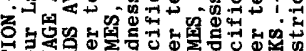
磁 등

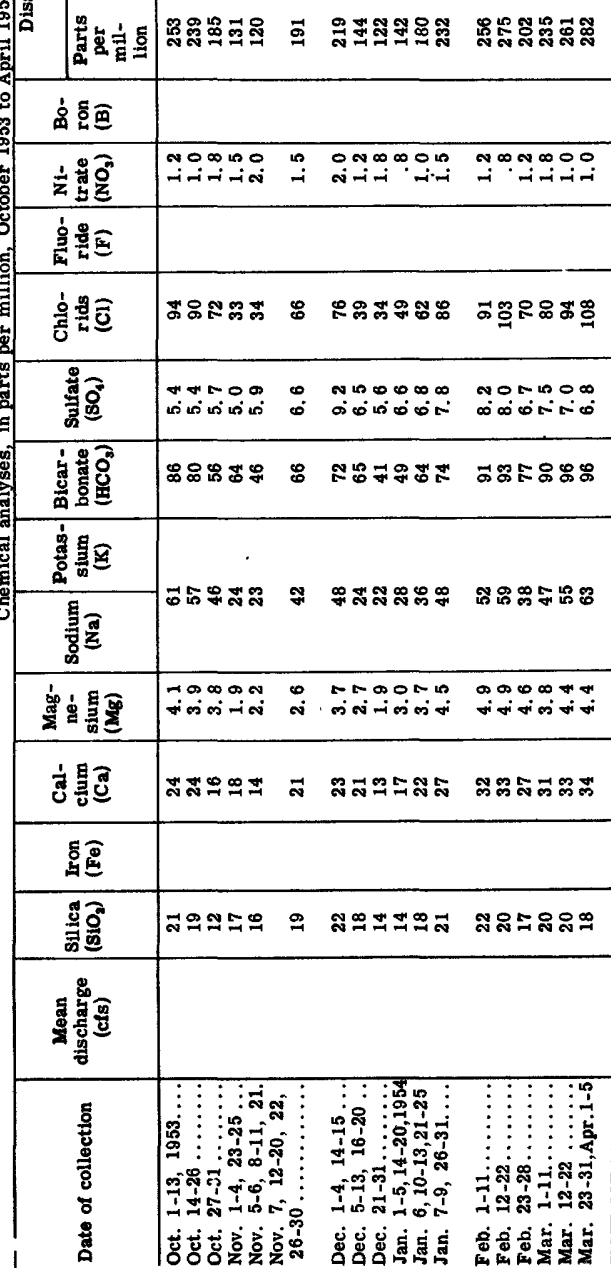


SAN JACINTO RIVER BASIN--Cont inued

SAN JACINTO RIVER NEAR HUFFMAN, TEX.--Continued

Temperature ( ${ }^{\circ} \mathrm{F}$ ) of water, October 1953 to April 1954

\begin{tabular}{|c|c|c|c|c|c|c|c|c|c|c|c|c|}
\hline Day & Oct. & Nov. & Dec. & Jan. & Feb. & Mar. & Apr. & May & June & July & Aug. & Sept. \\
\hline $\begin{array}{l}1 \\
2 \\
3 \\
4 \\
5\end{array}$ & $\begin{array}{l}83 \\
82 \\
82 \\
80 \\
81\end{array}$ & $\begin{array}{l}62 \\
68 \\
67 \\
65 \\
65\end{array}$ & $\begin{array}{l}68 \\
64 \\
62 \\
60 \\
65\end{array}$ & $\begin{array}{l}48 \\
50 \\
53 \\
64 \\
56\end{array}$ & $\begin{array}{l}61 \\
66 \\
64 \\
65 \\
65\end{array}$ & $\begin{array}{l}65 \\
62 \\
62 \\
50 \\
61\end{array}$ & $\begin{array}{l}65 \\
67 \\
70 \\
70 \\
72\end{array}$ & & & & & \\
\hline $\begin{array}{r}6 \\
7 \\
8 \\
9 \\
10\end{array}$ & $\begin{array}{l}86 \\
79 \\
70 \\
71 \\
65\end{array}$ & $\begin{array}{l}69 \\
60 \\
65 \\
65 \\
60\end{array}$ & $\begin{array}{l}53 \\
60 \\
64 \\
64 \\
50\end{array}$ & $\begin{array}{l}58 \\
57 \\
56 \\
60 \\
53\end{array}$ & $\begin{array}{l}58 \\
64 \\
58 \\
68 \\
70\end{array}$ & $\begin{array}{l}43 \\
48 \\
64 \\
65 \\
68\end{array}$ & $\begin{array}{l}-- \\
=- \\
=- \\
--\end{array}$ & & & & & \\
\hline $\begin{array}{l}11 \\
12 \\
13 \\
14 \\
15\end{array}$ & $\begin{array}{l}70 \\
80 \\
80 \\
79 \\
74\end{array}$ & $\begin{array}{l}\mathbf{5 3} \\
\mathbf{5 8} \\
\mathbf{5 9} \\
\mathbf{5 2} \\
\mathbf{5 4}\end{array}$ & $\begin{array}{l}\mathbf{5 5} \\
\mathbf{5 5} \\
\mathbf{5 2} \\
\mathbf{5 3} \\
\mathbf{5 3}\end{array}$ & $\begin{array}{l}63 \\
68 \\
59 \\
63 \\
64\end{array}$ & $\begin{array}{l}60 \\
59 \\
58 \\
60 \\
68\end{array}$ & $\begin{array}{l}70 \\
69 \\
67 \\
69 \\
61\end{array}$ & $\begin{array}{l}-- \\
-- \\
-- \\
--\end{array}$ & & & & & \\
\hline $\begin{array}{l}16 \\
17 \\
18 \\
19 \\
20\end{array}$ & $\begin{array}{l}73 \\
70 \\
70 \\
78 \\
78\end{array}$ & $\begin{array}{l}63 \\
70 \\
68 \\
67 \\
65\end{array}$ & $\begin{array}{l}\mathbf{5 1} \\
\mathbf{5 0} \\
\mathbf{5 0} \\
\mathbf{5 0} \\
\mathbf{5 3}\end{array}$ & $\begin{array}{l}55 \\
68 \\
60 \\
60 \\
64\end{array}$ & $\begin{array}{l}66 \\
64 \\
67 \\
66 \\
52\end{array}$ & $\begin{array}{l}59 \\
63 \\
62 \\
63 \\
59\end{array}$ & $\begin{array}{l}-- \\
-- \\
--\end{array}$ & & & & & \\
\hline $\begin{array}{l}21 \\
22 \\
23 \\
24 \\
25\end{array}$ & $\begin{array}{l}76 \\
78 \\
76 \\
76 \\
74\end{array}$ & $\begin{array}{l}59 \\
55 \\
60 \\
60 \\
56\end{array}$ & $\begin{array}{l}60 \\
50 \\
45 \\
44 \\
44\end{array}$ & $\begin{array}{l}54 \\
60 \\
65 \\
53 \\
58\end{array}$ & $\begin{array}{l}52 \\
60 \\
63 \\
64 \\
63\end{array}$ & $\begin{array}{l}61 \\
68 \\
69 \\
71 \\
69\end{array}$ & $\begin{array}{l}-- \\
-- \\
-- \\
-- \\
--\end{array}$ & & & & & \\
\hline $\begin{array}{l}\mathbf{2 6} \\
\mathbf{2 7} \\
\mathbf{2 8} \\
\mathbf{2 9} \\
\mathbf{3 0} \\
\mathbf{3 1}\end{array}$ & $\begin{array}{l}71 \\
70 \\
72 \\
64 \\
62 \\
61\end{array}$ & $\begin{array}{l}56 \\
57 \\
63 \\
60 \\
63 \\
--\end{array}$ & $\begin{array}{l}43 \\
46 \\
52 \\
54 \\
54 \\
49\end{array}$ & $\begin{array}{l}65 \\
50 \\
59 \\
59 \\
63 \\
63\end{array}$ & $\begin{array}{l}62 \\
65 \\
62 \\
-- \\
-- \\
--\end{array}$ & $\begin{array}{l}70 \\
68 \\
66 \\
70 \\
74 \\
72\end{array}$ & $\begin{array}{l}-- \\
-- \\
-- \\
-- \\
--\end{array}$ & & & & & \\
\hline $\begin{array}{c}\text { Aver- } \\
\text { age }\end{array}$ & 75 & 61 & 54 & 59 & 62 & 64 & -- & & & & & \\
\hline
\end{tabular}




\begin{tabular}{|c|c|c|c|c|}
\hline 졈 & 要 & $=0$ & 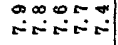 & \\
\hline 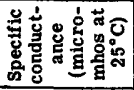 & 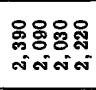 & 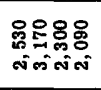 & 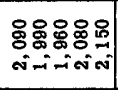 & $\begin{array}{l}8 \\
-1 \\
-1\end{array}$ \\
\hline 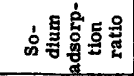 & 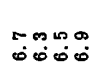 & 我 & 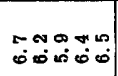 & $\because$ \\
\hline 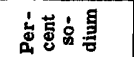 & 옹뽕 & む゙すむ゙ゅ & 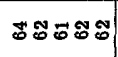 & 8 \\
\hline
\end{tabular}

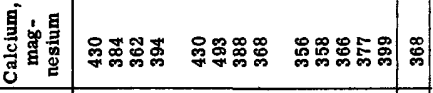

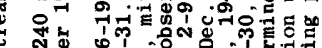

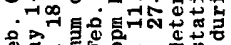

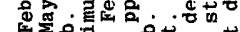
然

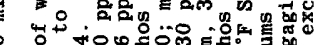

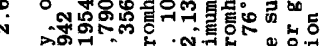
Dें

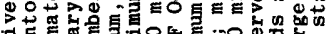
돈

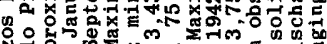

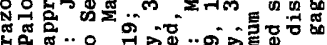
수

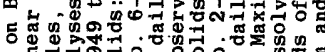

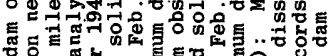
西 定

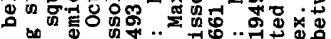

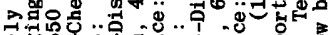
ब कू⿻ क्ष

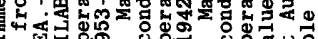
1 ह 출

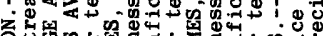

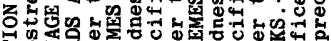

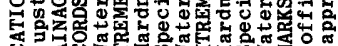
出

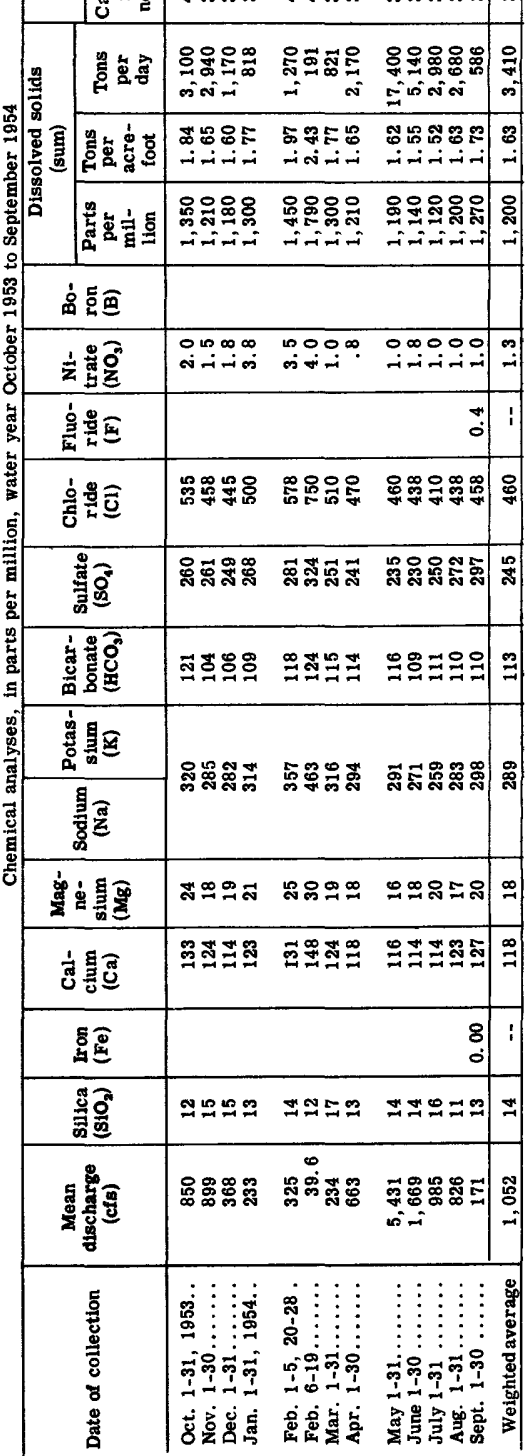


BRAZOS RIVER BASIN--Continued

BRAZOS RIVER AT POSSUM KINGDOM DAM NEAR GRAFORD, TEX.--Continued

Temperature $\left({ }^{\circ} \mathrm{F}\right)$ of water, water year October 1953 to September 1954

\begin{tabular}{|c|c|c|c|c|c|c|c|c|c|c|c|c|}
\hline Day & Oct. & Nov. & Dec. & Jan. & Feb. & Mar. & Apr. & May & June & July & Aug. & Sept. \\
\hline $\begin{array}{l}1 \\
2 \\
3 \\
4 \\
5\end{array}$ & $\begin{array}{l}74 \\
74 \\
74 \\
74 \\
74\end{array}$ & $\begin{array}{l}69 \\
69 \\
69 \\
68 \\
68\end{array}$ & $\begin{array}{l}60 \\
60 \\
60 \\
60 \\
60\end{array}$ & $\begin{array}{l}51 \\
51 \\
61 \\
51 \\
51\end{array}$ & $\begin{array}{l}48 \\
48 \\
48 \\
48 \\
48\end{array}$ & $\begin{array}{l}\mathbf{5 1} \\
\mathbf{5 1} \\
\mathbf{5 0} \\
\mathbf{5 0} \\
\mathbf{5 0}\end{array}$ & $\begin{array}{l}\mathbf{5 0} \\
\mathbf{5 0} \\
\mathbf{5 0} \\
\mathbf{5 0} \\
\mathbf{5 0}\end{array}$ & $\begin{array}{l}53 \\
53 \\
53 \\
53 \\
54\end{array}$ & $\begin{array}{l}63 \\
64 \\
64 \\
64 \\
64\end{array}$ & $\begin{array}{l}65 \\
65 \\
65 \\
65 \\
65\end{array}$ & $\begin{array}{l}68 \\
68 \\
68 \\
66 \\
68\end{array}$ & $\begin{array}{l}70 \\
67 \\
67 \\
67 \\
67\end{array}$ \\
\hline $\begin{array}{r}6 \\
7 \\
8 \\
9 \\
10\end{array}$ & $\begin{array}{l}74 \\
71 \\
71 \\
71 \\
75\end{array}$ & $\begin{array}{l}68 \\
68 \\
68 \\
68 \\
68\end{array}$ & $\begin{array}{l}60 \\
60 \\
60 \\
57 \\
57\end{array}$ & $\begin{array}{l}\mathbf{5 0} \\
\mathbf{5 0} \\
\mathbf{5 0} \\
\mathbf{5 0} \\
\mathbf{5 0}\end{array}$ & $\begin{array}{l}48 \\
48 \\
48 \\
48 \\
48\end{array}$ & $\begin{array}{l}-- \\
50 \\
50 \\
50 \\
50\end{array}$ & $\begin{array}{l}\mathbf{5 0} \\
52 \\
52 \\
52 \\
52\end{array}$ & $\begin{array}{l}54 \\
54 \\
54 \\
54 \\
54\end{array}$ & $\begin{array}{l}64 \\
64 \\
64 \\
64 \\
64\end{array}$ & $\begin{array}{l}-\overline{65} \\
64 \\
64 \\
64\end{array}$ & $\begin{array}{l}66 \\
66 \\
66 \\
66 \\
66\end{array}$ & $\begin{array}{l}67 \\
67 \\
70 \\
70 \\
70\end{array}$ \\
\hline $\begin{array}{l}11 \\
12 \\
13 \\
14 \\
15\end{array}$ & $\begin{array}{l}71 \\
71 \\
71 \\
69 \\
69\end{array}$ & $\begin{array}{l}65 \\
65 \\
65 \\
65 \\
65\end{array}$ & $\begin{array}{l}\mathbf{5 7} \\
\mathbf{5 7} \\
\mathbf{5 7} \\
\mathbf{5 7} \\
\mathbf{5 7}\end{array}$ & $\begin{array}{l}\mathbf{5 0} \\
\mathbf{5 0} \\
\mathbf{5 0} \\
\mathbf{5 0} \\
\mathbf{5 0}\end{array}$ & $\begin{array}{l}51 \\
51 \\
51 \\
51 \\
51\end{array}$ & $\begin{array}{l}50 \\
50 \\
50 \\
50 \\
50\end{array}$ & $\begin{array}{l}\mathbf{5 2} \\
\mathbf{5 2} \\
\mathbf{5 2} \\
\mathbf{5 2} \\
\mathbf{5 2}\end{array}$ & $\begin{array}{l}54 \\
55 \\
55 \\
55 \\
55\end{array}$ & $\begin{array}{l}64 \\
64 \\
64 \\
64 \\
64\end{array}$ & $\begin{array}{l}64 \\
64 \\
64 \\
65 \\
65\end{array}$ & $\begin{array}{l}68 \\
68 \\
68 \\
68 \\
68\end{array}$ & $\begin{array}{l}70 \\
70 \\
70 \\
70 \\
68\end{array}$ \\
\hline $\begin{array}{l}16 \\
17 \\
18 \\
19 \\
20\end{array}$ & $\begin{array}{l}60 \\
69 \\
69 \\
69 \\
69\end{array}$ & $\begin{array}{l}65 \\
65 \\
64 \\
64 \\
64\end{array}$ & $\begin{array}{l}65 \\
55 \\
55 \\
55 \\
55\end{array}$ & $\begin{array}{l}\mathbf{5 0} \\
\mathbf{5 0} \\
\mathbf{5 0} \\
\mathbf{5 0} \\
\mathbf{5 0}\end{array}$ & $\begin{array}{l}\mathbf{5 1} \\
\mathbf{5 1} \\
\mathbf{5 1} \\
\mathbf{5 1} \\
\mathbf{5 1}\end{array}$ & $\begin{array}{l}\mathbf{5 0} \\
\mathbf{5 0} \\
\mathbf{5 1} \\
\mathbf{5 1} \\
\mathbf{5 1}\end{array}$ & $\begin{array}{l}\mathbf{5 2} \\
\mathbf{5 2} \\
\mathbf{5 2} \\
\mathbf{5 2} \\
\mathbf{5 2}\end{array}$ & $\begin{array}{l}\mathbf{5 5} \\
\mathbf{5 5} \\
\mathbf{5 5} \\
\mathbf{5 9} \\
\mathbf{5 9}\end{array}$ & $\begin{array}{l}64 \\
64 \\
64 \\
64 \\
64\end{array}$ & $\begin{array}{l}65 \\
65 \\
65 \\
65 \\
65\end{array}$ & $\begin{array}{l}68 \\
68 \\
69 \\
69 \\
69\end{array}$ & $\begin{array}{l}68 \\
68 \\
68 \\
68 \\
68\end{array}$ \\
\hline $\begin{array}{l}21 \\
22 \\
23 \\
24 \\
25\end{array}$ & $\begin{array}{l}69 \\
69 \\
69 \\
69 \\
69\end{array}$ & $\begin{array}{l}64 \\
64 \\
64 \\
64 \\
60\end{array}$ & $\begin{array}{l}55 \\
55 \\
55 \\
54 \\
54\end{array}$ & $\begin{array}{l}\mathbf{5 0} \\
\mathbf{5 0} \\
\mathbf{5 0} \\
\mathbf{5 0} \\
\mathbf{5 0}\end{array}$ & $\begin{array}{l}\mathbf{5 1} \\
51 \\
51 \\
51 \\
51\end{array}$ & $\begin{array}{l}51 \\
51 \\
51 \\
52 \\
52\end{array}$ & $\begin{array}{l}\mathbf{5 0} \\
\mathbf{5 0} \\
\mathbf{5 0} \\
\mathbf{5 0} \\
\mathbf{5 0}\end{array}$ & $\begin{array}{l}59 \\
59 \\
59 \\
59 \\
59\end{array}$ & $\begin{array}{l}64 \\
64 \\
65 \\
65 \\
65\end{array}$ & $\begin{array}{l}65 \\
66 \\
66 \\
66 \\
66\end{array}$ & $\begin{array}{l}69 \\
69 \\
69 \\
69 \\
70\end{array}$ & $\begin{array}{l}-- \\
68 \\
68 \\
68 \\
68\end{array}$ \\
\hline $\begin{array}{l}26 \\
27 \\
28 \\
29 \\
30 \\
31\end{array}$ & $\begin{array}{l}69 \\
69 \\
69 \\
69 \\
69 \\
69\end{array}$ & $\begin{array}{l}60 \\
60 \\
60 \\
60 \\
60 \\
--\end{array}$ & $\begin{array}{l}54 \\
54 \\
54 \\
54 \\
51 \\
51\end{array}$ & $\begin{array}{l}50 \\
48 \\
48 \\
48 \\
48 \\
48\end{array}$ & $\begin{array}{l}51 \\
51 \\
51 \\
-- \\
-- \\
--\end{array}$ & $\begin{array}{l}\mathbf{5 3} \\
\mathbf{5 2} \\
\mathbf{5 2} \\
\mathbf{5 2} \\
\mathbf{5 2} \\
\mathbf{5 0}\end{array}$ & $\begin{array}{l}50 \\
50 \\
50 \\
53 \\
53 \\
--\end{array}$ & $\begin{array}{l}63 \\
63 \\
63 \\
63 \\
63 \\
63\end{array}$ & $\begin{array}{l}65 \\
65 \\
65 \\
65 \\
65 \\
-\end{array}$ & $\begin{array}{l}66 \\
65 \\
68 \\
68 \\
68 \\
68\end{array}$ & $\begin{array}{l}70 \\
70 \\
70 \\
70 \\
70 \\
70\end{array}$ & $\begin{array}{l}68 \\
68 \\
68 \\
70 \\
70 \\
--\end{array}$ \\
\hline $\begin{array}{c}\text { Aver- } \\
\text { age }\end{array}$ & 71 & 65 & 56 & 50 & 50 & 51 & 51 & 57 & 64 & 65 & 68 & 68 \\
\hline
\end{tabular}




$$
\text { 政 }
$$

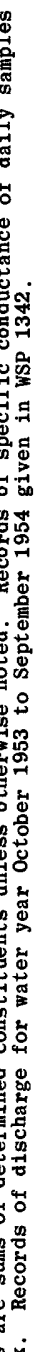

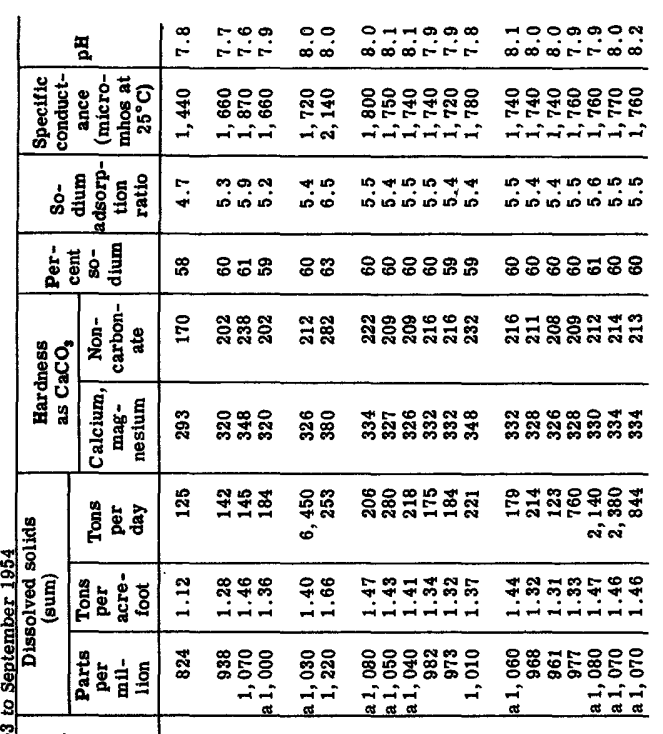
\begin{tabular}{l|l}
\hline \\
\hline
\end{tabular}

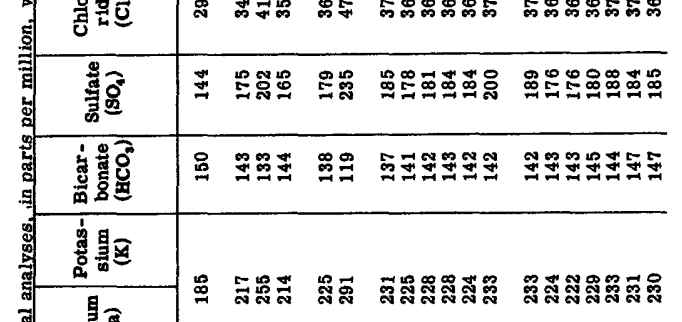
o 020 要 क d สิ (1) 薄 急 D.

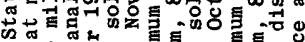

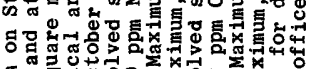
要

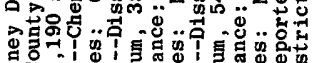
cou

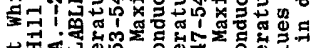

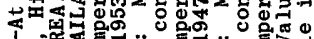

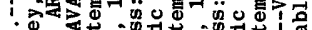

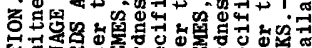

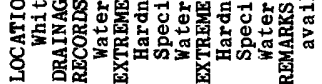




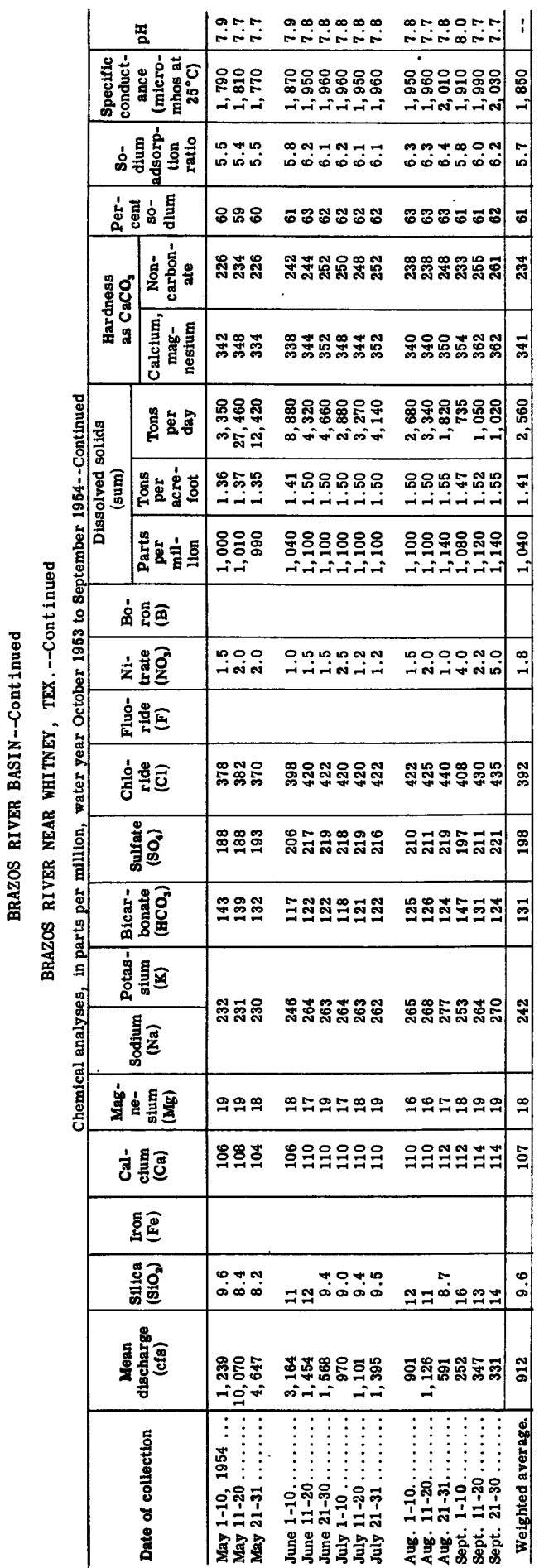


| 


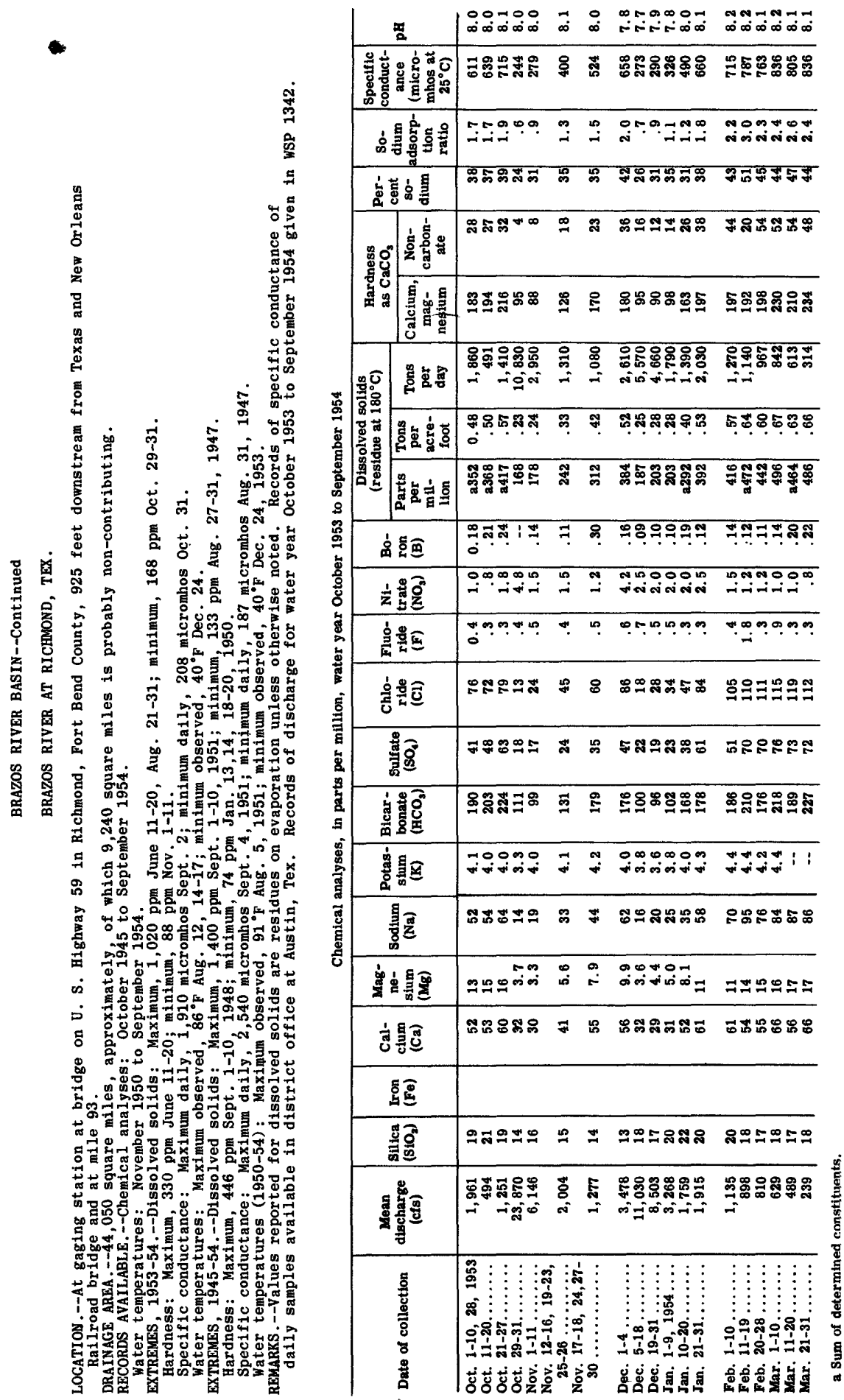




\begin{tabular}{|c|c|}
\hline 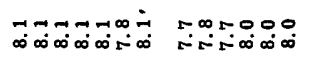 & 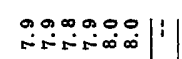 \\
\hline 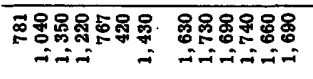 & 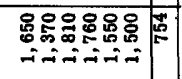 \\
\hline 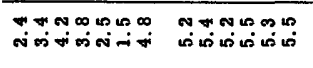 & 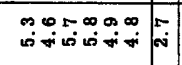 \\
\hline 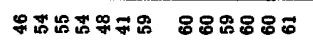 & 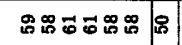 \\
\hline 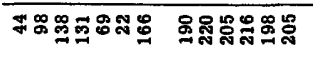 & 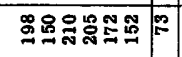 \\
\hline 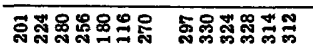 & 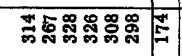 \\
\hline 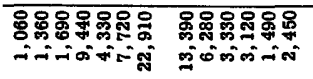 & 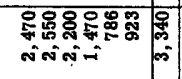 \\
\hline 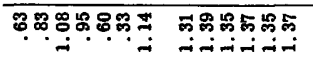 & 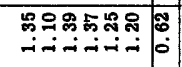 \\
\hline 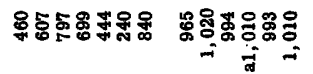 & 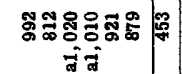 \\
\hline 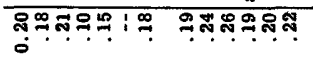 & 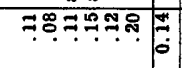 \\
\hline 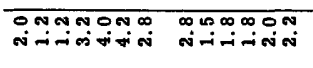 & 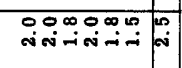 \\
\hline 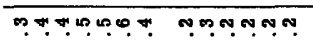 & $\mid$ \\
\hline 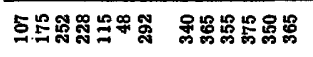 & 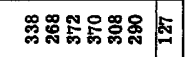 \\
\hline 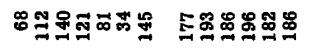 & 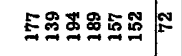 \\
\hline 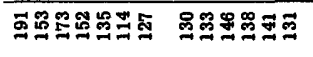 & 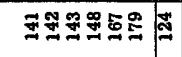 \\
\hline 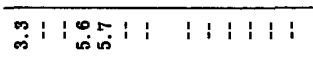 & 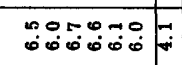 \\
\hline 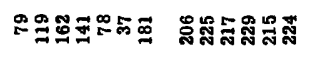 & 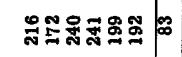 \\
\hline 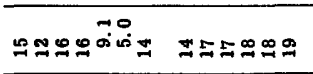 & 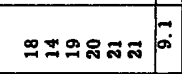 \\
\hline 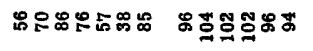 & \& \\
\hline 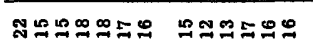 & 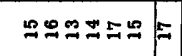 \\
\hline 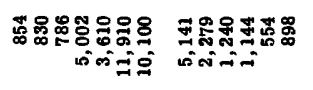 & 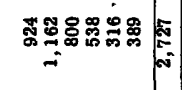 \\
\hline 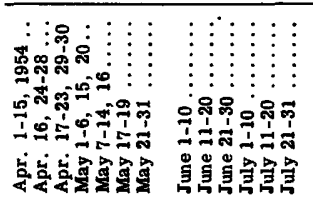 & 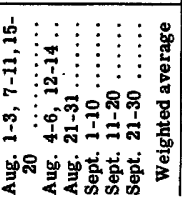 \\
\hline
\end{tabular}


BRAZOS RIVER BASIN--Continued

BRAZOS RIVER AT RICHMOND, TEX.--Cont inued

Temperature $\left({ }^{\circ} \mathrm{F}\right)$ of water, water year October 1953 to September 1954

\begin{tabular}{|c|c|c|c|c|c|c|c|c|c|c|c|c|}
\hline Day & Oct. & Nov. & Dec. & Jan. & Feb. & Mar. & Apr. & May & June & July & Aug. & Sept. \\
\hline $\begin{array}{l}1 \\
2 \\
3 \\
4 \\
5\end{array}$ & $\begin{array}{l}80 \\
82 \\
82 \\
80 \\
78\end{array}$ & $\begin{array}{l}62 \\
61 \\
64 \\
65 \\
63\end{array}$ & $\begin{array}{l}58 \\
58 \\
62 \\
60 \\
61\end{array}$ & $\begin{array}{l}45 \\
47 \\
47 \\
47 \\
48\end{array}$ & $\begin{array}{l}58 \\
58 \\
57 \\
58 \\
58\end{array}$ & $\begin{array}{l}53 \\
59 \\
52 \\
50 \\
48\end{array}$ & $\begin{array}{l}64 \\
64 \\
64 \\
64 \\
67\end{array}$ & $\begin{array}{l}77 \\
78 \\
65 \\
62 \\
68\end{array}$ & $\begin{array}{l}80 \\
79 \\
79 \\
76 \\
78\end{array}$ & $\begin{array}{l}-- \\
-- \\
83 \\
84 \\
--\end{array}$ & $\begin{array}{l}84 \\
83 \\
84 \\
84 \\
84\end{array}$ & $\begin{array}{l}85 \\
85 \\
85 \\
84 \\
84\end{array}$ \\
\hline $\begin{array}{r}6 \\
7 \\
8 \\
9 \\
10\end{array}$ & $\begin{array}{l}70 \\
68 \\
68 \\
67 \\
66\end{array}$ & $\begin{array}{l}60 \\
61 \\
60 \\
59 \\
54\end{array}$ & $\begin{array}{l}58 \\
56 \\
60 \\
59 \\
50\end{array}$ & $\begin{array}{l}48 \\
49 \\
50 \\
55 \\
52\end{array}$ & $\begin{array}{l}58 \\
51 \\
52 \\
54 \\
58\end{array}$ & $\begin{array}{l}45 \\
47 \\
-- \\
50 \\
58\end{array}$ & $\begin{array}{l}68 \\
74 \\
74 \\
70 \\
71\end{array}$ & $\begin{array}{l}68 \\
69 \\
70 \\
72 \\
75\end{array}$ & $\begin{array}{l}78 \\
80 \\
80 \\
80 \\
81\end{array}$ & $\begin{array}{l}84 \\
82 \\
82 \\
84 \\
84\end{array}$ & $\begin{array}{l}85 \\
84 \\
85 \\
85 \\
84\end{array}$ & $\begin{array}{l}84 \\
82 \\
83 \\
83 \\
83\end{array}$ \\
\hline $\begin{array}{l}11 \\
12 \\
13 \\
14 \\
15\end{array}$ & $\begin{array}{l}69 \\
70 \\
71 \\
73 \\
74\end{array}$ & $\begin{array}{l}53 \\
55 \\
53 \\
55 \\
56\end{array}$ & $\begin{array}{l}53 \\
53 \\
54 \\
53 \\
49\end{array}$ & $\begin{array}{l}55 \\
47 \\
44 \\
51 \\
57\end{array}$ & $\begin{array}{l}58 \\
55 \\
54 \\
58 \\
60\end{array}$ & $\begin{array}{l}55 \\
66 \\
66 \\
54 \\
51\end{array}$ & $\begin{array}{l}70 \\
75 \\
75 \\
75 \\
73\end{array}$ & $\begin{array}{l}75 \\
72 \\
70 \\
69 \\
70\end{array}$ & $\begin{array}{l}81 \\
81 \\
82 \\
81 \\
81\end{array}$ & $\begin{array}{l}84 \\
85 \\
85 \\
85 \\
84\end{array}$ & $\begin{array}{l}85 \\
86 \\
85 \\
86 \\
86\end{array}$ & $\begin{array}{l}81 \\
80 \\
76 \\
76 \\
80\end{array}$ \\
\hline $\begin{array}{l}16 \\
17 \\
18 \\
19 \\
20\end{array}$ & $\begin{array}{l}73 \\
73 \\
74 \\
74 \\
74\end{array}$ & $\begin{array}{l}57 \\
60 \\
65 \\
65 \\
62\end{array}$ & $\begin{array}{l}49 \\
50 \\
50 \\
49 \\
50\end{array}$ & $\begin{array}{l}\mathbf{5 4} \\
\mathbf{5 2} \\
\mathbf{5 4} \\
\mathbf{5 8} \\
\mathbf{6 4}\end{array}$ & $\begin{array}{l}64 \\
60 \\
60 \\
65 \\
60\end{array}$ & $\begin{array}{l}50 \\
52 \\
57 \\
62 \\
63\end{array}$ & $\begin{array}{l}71 \\
66 \\
65 \\
69 \\
71\end{array}$ & $\begin{array}{l}71 \\
70 \\
72 \\
74 \\
76\end{array}$ & $\begin{array}{l}81 \\
81 \\
81 \\
83 \\
83\end{array}$ & $\begin{array}{l}84 \\
85 \\
85 \\
85 \\
85\end{array}$ & $\begin{array}{l}86 \\
86 \\
83 \\
84 \\
84\end{array}$ & $\begin{array}{l}81 \\
81 \\
81 \\
83 \\
82\end{array}$ \\
\hline $\begin{array}{l}21 \\
22 \\
23 \\
24 \\
25\end{array}$ & $\begin{array}{l}75 \\
76 \\
75 \\
74 \\
71\end{array}$ & $\begin{array}{l}62 \\
60 \\
56 \\
58 \\
55\end{array}$ & $\begin{array}{l}50 \\
49 \\
43 \\
40 \\
42\end{array}$ & $\begin{array}{l}60 \\
48 \\
44 \\
52 \\
54\end{array}$ & $\begin{array}{l}58 \\
58 \\
61 \\
60 \\
60\end{array}$ & $\begin{array}{l}63 \\
66 \\
67 \\
70 \\
71\end{array}$ & $\begin{array}{l}72 \\
72 \\
74 \\
75 \\
75\end{array}$ & $\begin{array}{l}76 \\
76 \\
76 \\
75 \\
75\end{array}$ & $\begin{array}{l}83 \\
82 \\
82 \\
84 \\
84\end{array}$ & $\begin{array}{l}85 \\
85 \\
84 \\
84 \\
84\end{array}$ & $\begin{array}{l}85 \\
85 \\
80 \\
81 \\
83\end{array}$ & $\begin{array}{l}83 \\
82 \\
74 \\
74 \\
77\end{array}$ \\
\hline $\begin{array}{l}26 \\
27 \\
28 \\
29 \\
30 \\
31\end{array}$ & $\begin{array}{l}65 \\
66 \\
65 \\
65 \\
63 \\
63\end{array}$ & $\begin{array}{l}56 \\
56 \\
56 \\
58 \\
58 \\
--\end{array}$ & $\begin{array}{l}42 \\
44 \\
46 \\
45 \\
44 \\
44\end{array}$ & $\begin{array}{l}59 \\
59 \\
58 \\
58 \\
58 \\
60\end{array}$ & $\begin{array}{l}60 \\
61 \\
58 \\
-- \\
-- \\
--\end{array}$ & $\begin{array}{l}67 \\
70 \\
70 \\
70 \\
70 \\
75\end{array}$ & $\begin{array}{l}76 \\
76 \\
73 \\
77 \\
78 \\
--\end{array}$ & $\begin{array}{l}75 \\
75 \\
76 \\
76 \\
76 \\
78\end{array}$ & $\begin{array}{l}83 \\
84 \\
84 \\
83 \\
84 \\
--\end{array}$ & $\begin{array}{l}83 \\
84 \\
84 \\
84 \\
85 \\
81\end{array}$ & $\begin{array}{l}84 \\
82 \\
83 \\
83 \\
83 \\
83\end{array}$ & $\begin{array}{l}75 \\
76 \\
75 \\
80 \\
81 \\
--\end{array}$ \\
\hline $\begin{array}{c}\text { Aver- } \\
\text { age }\end{array}$ & 72 & 59 & 51 & 53 & 58 & 60 & 71 & 73 & 81 & 84 & 84 & 81 \\
\hline
\end{tabular}




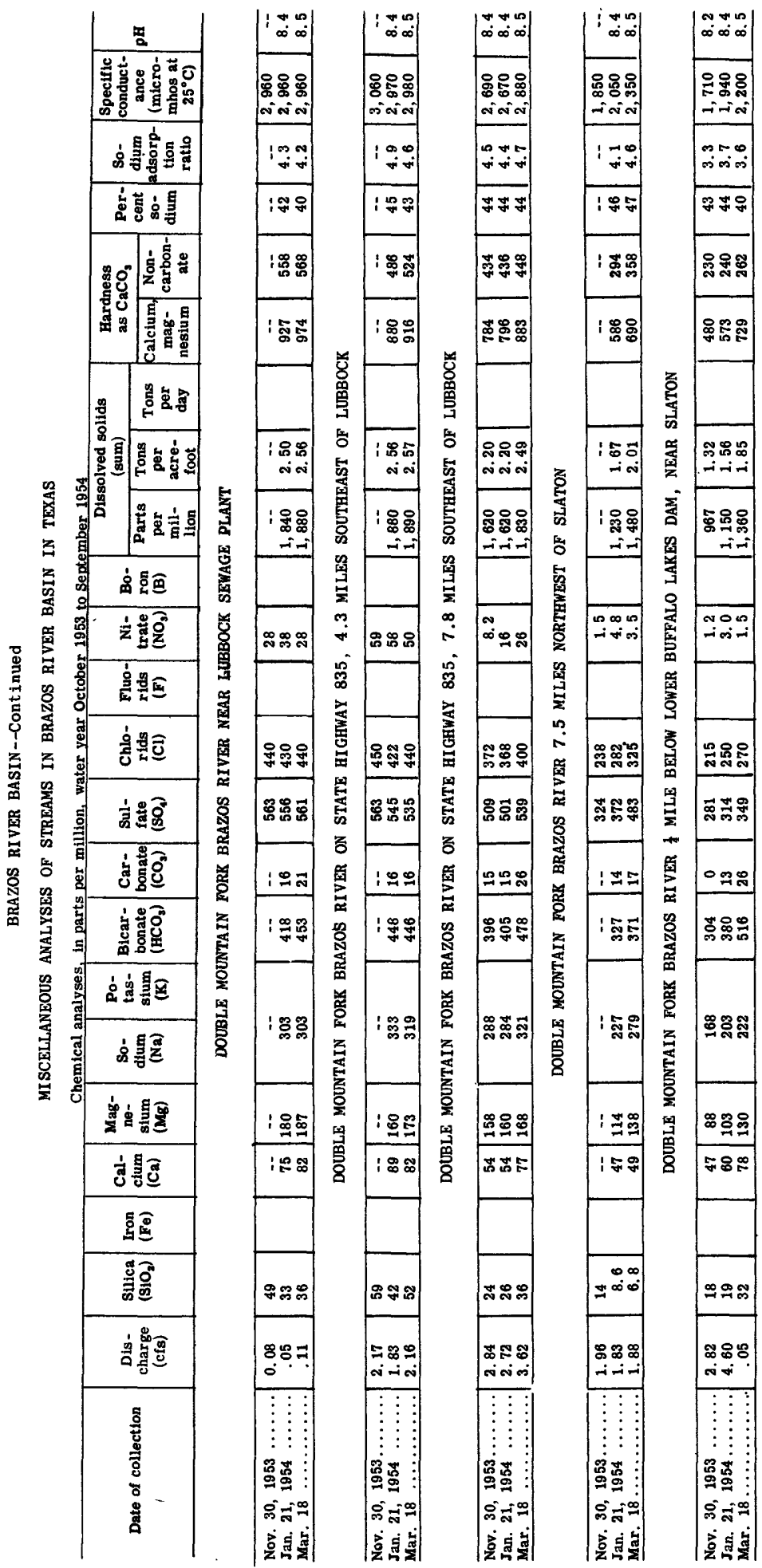




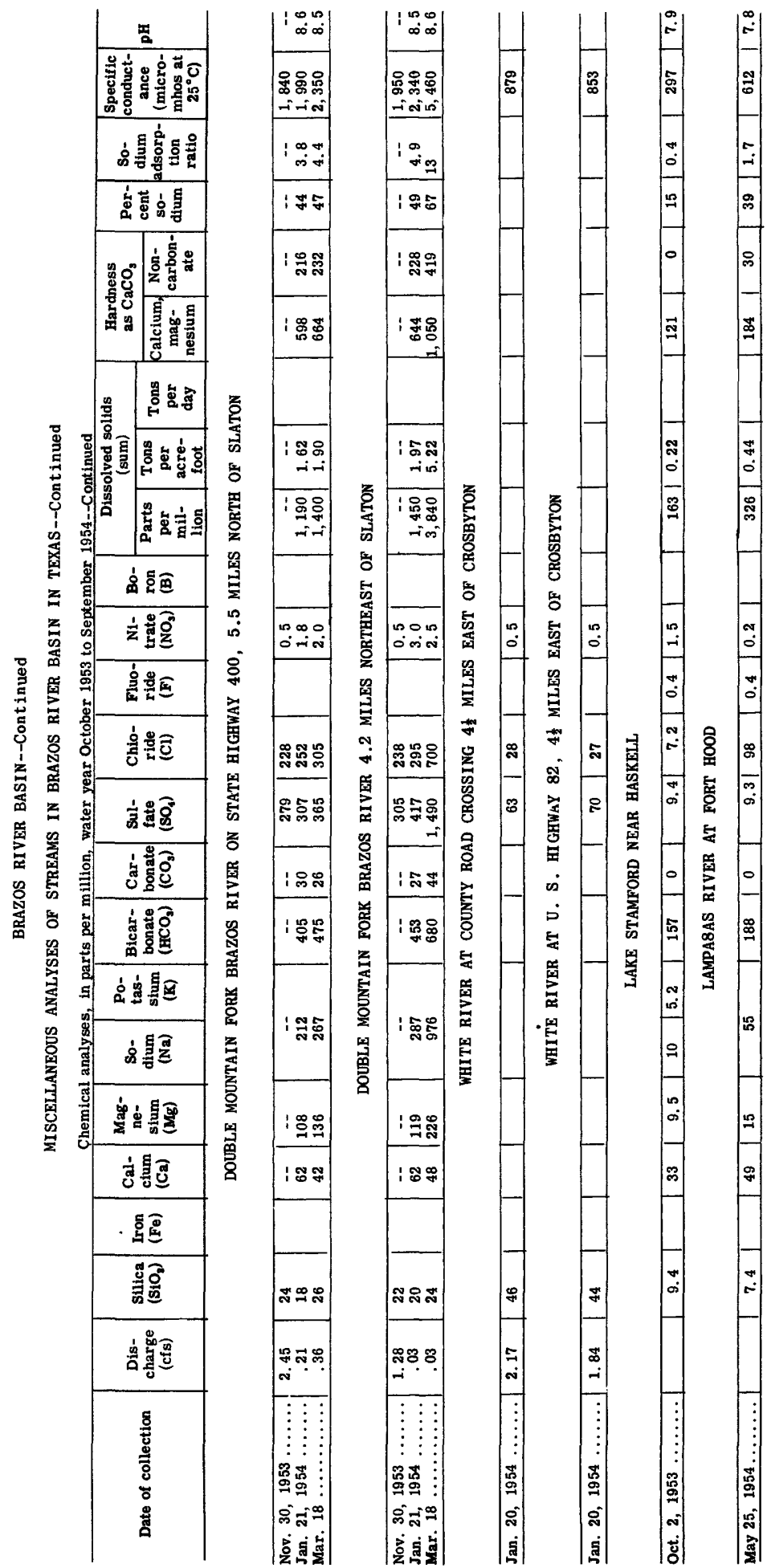




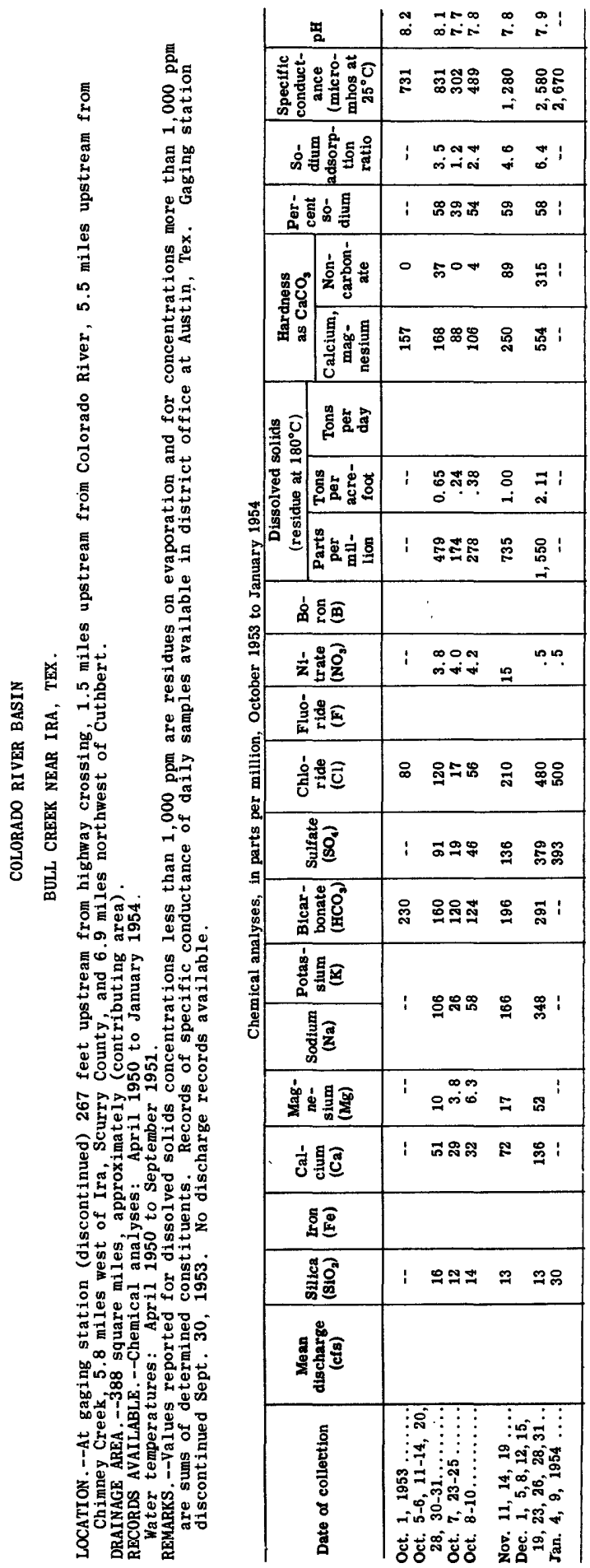




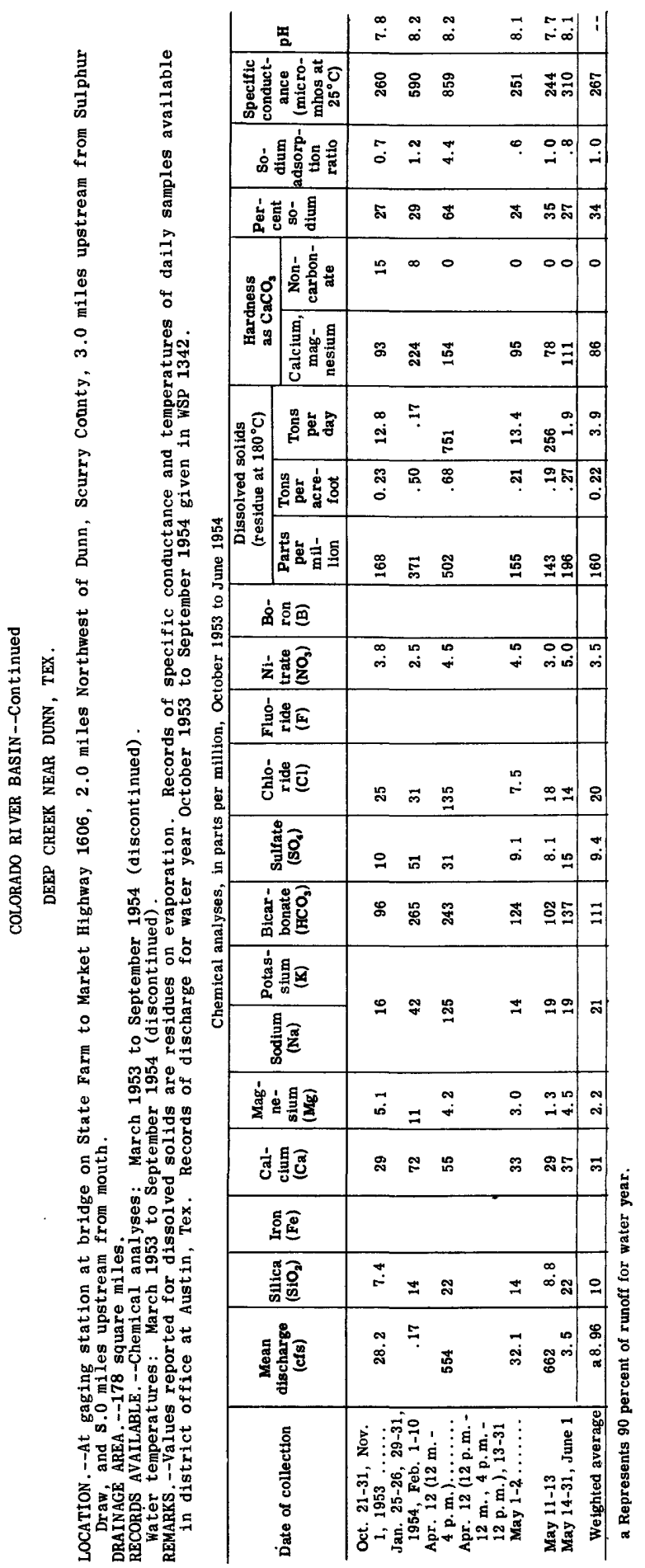




\begin{tabular}{|c|c|c|c|c|c|c|}
\hline $\mathbf{x}$ & 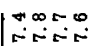 & 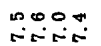 & 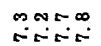 & 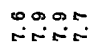 & 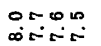 & \\
\hline 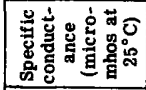 & 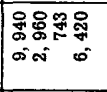 & 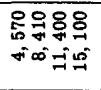 & 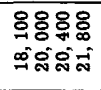 & 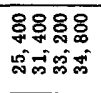 & 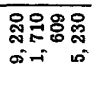 & \\
\hline 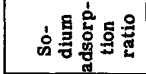 & 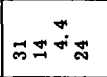 & ๑ลパ & 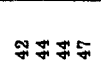 & 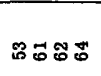 & $\mathscr{D}^{-\infty} \cos ^{-\infty}$ & \\
\hline 离葶宫亳 & 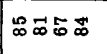 & 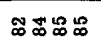 & ஹがが & $\mathscr{\infty} \infty \mathscr{D}_{\infty}^{\infty}$ & இஷむ゙ & \\
\hline 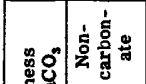 & : & 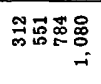 & 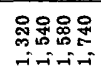 & 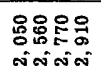 & 怘 & \\
\hline 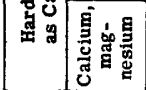 & 焁哭声总 & 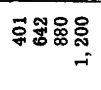 & 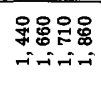 & 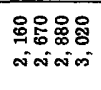 & 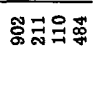 & \\
\hline 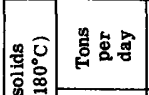 & 递罟芯志 & 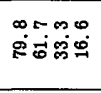 & 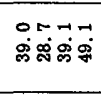 & 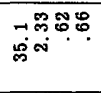 & 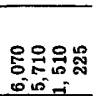 & \\
\hline 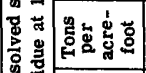 & 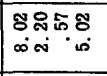 & 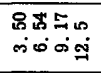 & 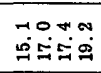 & 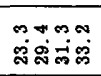 & 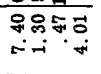 & \\
\hline 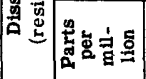 & 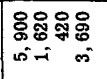 & 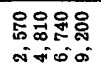 & 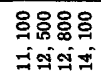 & 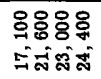 & 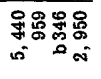 & \\
\hline 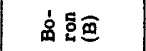 & & & & & & \\
\hline 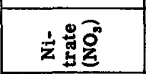 & 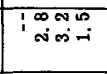 & $\begin{array}{l:ll}0 & 1 \\
& 1\end{array}$ & ! & 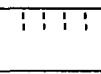 & $\begin{array}{l}\text { ToNo } \\
\text { vivion }\end{array}$ & : \\
\hline 实总国 & & & & & & \\
\hline 형흔 & 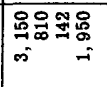 & $\begin{array}{l}\text { 융앵ㅇㅇㅇㅇ } \\
\text { tiviont }\end{array}$ & 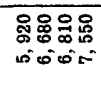 & 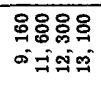 & 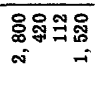 & $\vec{a}$ \\
\hline 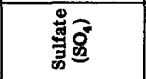 & 糸恕䧄 & 矛品盟品 & 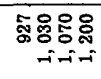 & 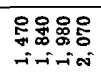 & 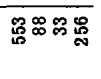 & $\stackrel{m}{-1}$ \\
\hline 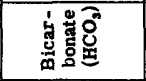 & œఖ్ష & 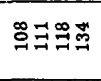 & 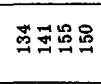 & 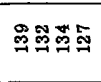 & 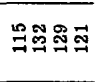 & $\cong$ \\
\hline 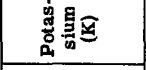 & 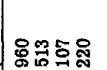 & 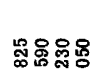 & 융్ㅠర్లిం & ్ㅜㅇ్ㅀㅇ్ㅇㅇㅛ & & $\overrightarrow{0}$ \\
\hline 㺃哥 & & Ficion & & कि $=5-\infty$ & & \\
\hline 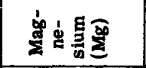 & ะேำ & கొఃః & 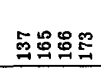 & 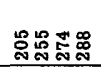 & 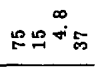 & s \\
\hline 岳思可 & 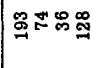 & 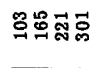 & 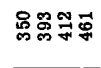 & 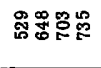 & జ్ఞ & \\
\hline 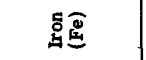 & & & & & & \\
\hline 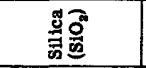 & 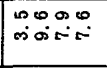 & 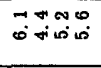 & 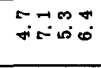 & $\begin{array}{l}\text { mot } \\
\text { Tim }\end{array}$ & 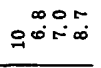 & $\dot{\mathrm{g}}$ \\
\hline हूँ & 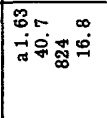 & 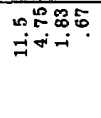 & 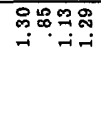 & 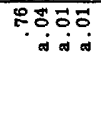 & 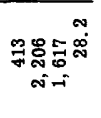 & 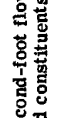 \\
\hline 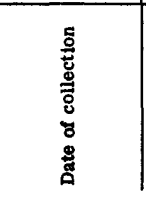 & 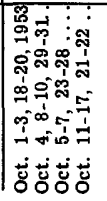 & 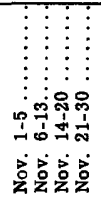 & 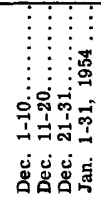 & 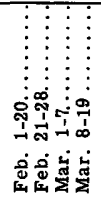 & 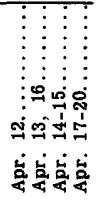 & 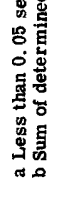 \\
\hline
\end{tabular}




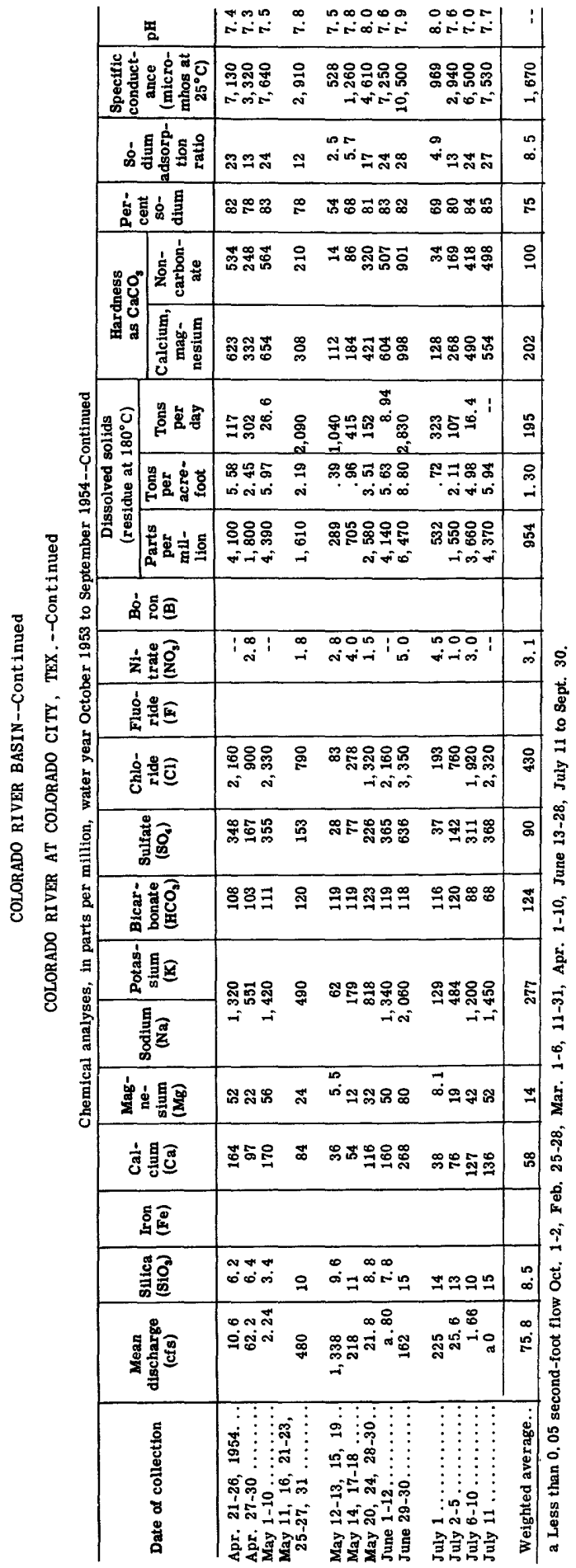


COLORADO RIVER BASIN--Continued

COLORADO RIVER AT COLORADO CITY, TEX.--Continued

Temperature $\left({ }^{\circ} \mathrm{F}\right)$ of water, water year October 1953 to September 1954

\begin{tabular}{|c|c|c|c|c|c|c|c|c|c|c|c|c|}
\hline Day & Oct. & Nov. & Dec. & Jan. & Feb. & Mar. & Apr. & May & June & July & Aug. & Sept. \\
\hline $\begin{array}{l}1 \\
2 \\
3 \\
4 \\
5\end{array}$ & $\begin{array}{l}-- \\
\overline{70} \\
71 \\
76\end{array}$ & $\begin{array}{l}75 \\
75 \\
60 \\
53 \\
55\end{array}$ & $\begin{array}{l}61 \\
63 \\
43 \\
45 \\
42\end{array}$ & $\begin{array}{l}55 \\
60 \\
59 \\
62 \\
--\end{array}$ & $\begin{array}{l}65 \\
75 \\
76 \\
80 \\
75\end{array}$ & $\begin{array}{l}66 \\
64 \\
69 \\
67 \\
66\end{array}$ & $\begin{array}{l}-- \\
-- \\
-- \\
-- \\
--\end{array}$ & $\begin{array}{l}79 \\
78 \\
-- \\
--\end{array}$ & & & & \\
\hline $\begin{array}{r}6 \\
7 \\
8 \\
9 \\
10\end{array}$ & $\begin{array}{l}64 \\
65 \\
68 \\
69 \\
74\end{array}$ & $\begin{array}{l}57 \\
58 \\
69 \\
70 \\
68\end{array}$ & $\begin{array}{l}59 \\
59 \\
58 \\
58 \\
60\end{array}$ & $\begin{array}{l}-- \\
-- \\
-- \\
--\end{array}$ & $\begin{array}{l}76 \\
76 \\
-\overline{75} \\
63\end{array}$ & $\begin{array}{l}68 \\
65 \\
68 \\
56 \\
58\end{array}$ & $\begin{array}{l}-- \\
-- \\
-- \\
--\end{array}$ & $\begin{array}{l}80 \\
\mathbf{7 5} \\
60 \\
59 \\
58\end{array}$ & & & & \\
\hline $\begin{array}{l}11 \\
12 \\
13 \\
14 \\
15\end{array}$ & $\begin{array}{l}85 \\
80 \\
75 \\
74 \\
85\end{array}$ & $\begin{array}{l}65 \\
68 \\
66 \\
71 \\
70\end{array}$ & $\begin{array}{l}50 \\
49 \\
50 \\
55 \\
49\end{array}$ & $\begin{array}{l}-- \\
-- \\
\overline{71} \\
64\end{array}$ & $\begin{array}{l}66 \\
69 \\
70 \\
72 \\
68\end{array}$ & $\begin{array}{l}60 \\
55 \\
54 \\
55 \\
--\end{array}$ & $\begin{array}{l}-- \\
-- \\
67 \\
71 \\
69\end{array}$ & $\begin{array}{l}55 \\
65 \\
67 \\
79 \\
80\end{array}$ & & & & \\
\hline $\begin{array}{l}16 \\
17 \\
18 \\
19 \\
20\end{array}$ & $\begin{array}{l}76 \\
74 \\
76 \\
71 \\
76\end{array}$ & $\begin{array}{l}72 \\
70 \\
57 \\
58 \\
--\end{array}$ & $\begin{array}{l}55 \\
53 \\
50 \\
54 \\
55\end{array}$ & $\begin{array}{l}60 \\
55 \\
54 \\
60 \\
67\end{array}$ & $\begin{array}{l}73 \\
55 \\
54 \\
60 \\
54\end{array}$ & $\begin{array}{l}-- \\
-- \\
-- \\
-- \\
--\end{array}$ & $\begin{array}{l}69 \\
76 \\
78 \\
79 \\
69\end{array}$ & $\begin{array}{l}78 \\
67 \\
68 \\
68 \\
70\end{array}$ & & & & \\
\hline $\begin{array}{l}21 \\
22 \\
23 \\
24 \\
25\end{array}$ & $\begin{array}{l}89 \\
69 \\
70 \\
66 \\
80\end{array}$ & $\begin{array}{l}78 \\
57 \\
56 \\
57 \\
58\end{array}$ & $\begin{array}{l}57 \\
55 \\
56 \\
60 \\
--\end{array}$ & $\begin{array}{l}50 \\
65 \\
62 \\
65 \\
62\end{array}$ & $\begin{array}{l}55 \\
55 \\
53 \\
55 \\
68\end{array}$ & $\begin{array}{l}-- \\
-- \\
-- \\
=- \\
--\end{array}$ & $\begin{array}{l}70 \\
-- \\
80 \\
76 \\
75\end{array}$ & $\begin{array}{l}81 \\
77 \\
78 \\
-- \\
--\end{array}$ & & & & \\
\hline $\begin{array}{l}26 \\
27 \\
28 \\
29 \\
30 \\
31\end{array}$ & $\begin{array}{l}69 \\
70 \\
69 \\
74 \\
73 \\
78 \\
\end{array}$ & $\begin{array}{l}59 \\
57 \\
58 \\
62 \\
68 \\
-- \\
\end{array}$ & $\begin{array}{l}70 \\
65 \\
60 \\
65 \\
59 \\
58 \\
\end{array}$ & $\begin{array}{l}63 \\
59 \\
63 \\
60 \\
65 \\
60 \\
\end{array}$ & $\begin{array}{l}69 \\
69 \\
65 \\
-- \\
-- \\
-- \\
\end{array}$ & $\begin{array}{l}-- \\
-- \\
-- \\
-- \\
-- \\
--\end{array}$ & $\begin{array}{l}78 \\
70 \\
78 \\
74 \\
72 \\
-- \\
\end{array}$ & $\begin{array}{l}-- \\
-- \\
-- \\
-- \\
-- \\
--\end{array}$ & & & & \\
\hline $\begin{array}{c}\text { Aver - } \\
\text { age }\end{array}$ & 74 & 64 & 56 & - & 66 & -- & -- & -- & & & & \\
\hline
\end{tabular}




\begin{tabular}{|c|c|c|c|c|c|}
\hline \multicolumn{2}{|c|}{ 폄 } & Nִ & $\stackrel{0}{\infty}$ & $\begin{array}{l}0 \\
\infty \\
\infty\end{array}$ & 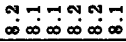 \\
\hline \multicolumn{2}{|c|}{ 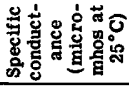 } & 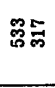 & 递 & : & 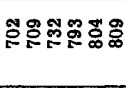 \\
\hline \multicolumn{2}{|c|}{ 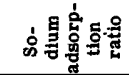 } & $\stackrel{\square}{\pi}$ & $\ddot{n}$ & ๆุ & تُّ \\
\hline \multicolumn{2}{|c|}{ 它范宫悬 } & జ్లే & $\mathscr{q}$ & 8 & 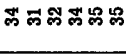 \\
\hline \multirow{2}{*}{ 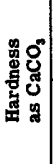 } & 它 & స్ల & 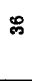 & 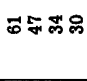 & 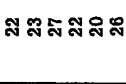 \\
\hline & 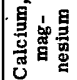 & 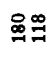 & \pm & 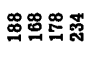 & 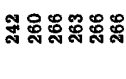 \\
\hline
\end{tabular}

\begin{tabular}{|c|c|}
\hline 可 & 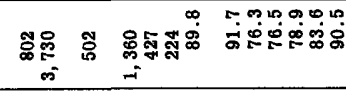 \\
\hline 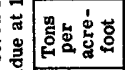 & 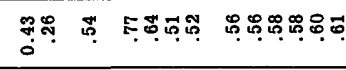 \\
\hline 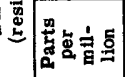 & 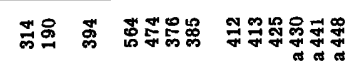 \\
\hline
\end{tabular}

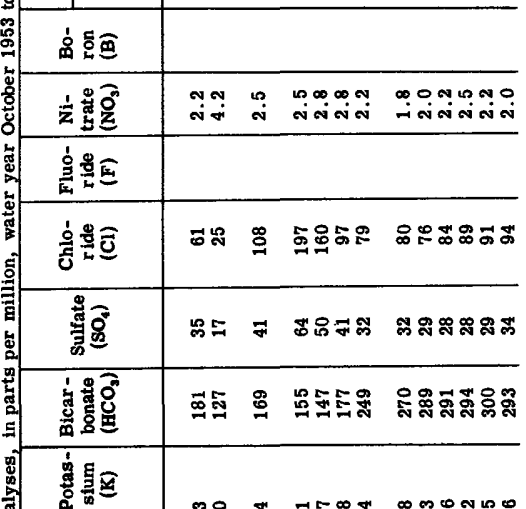

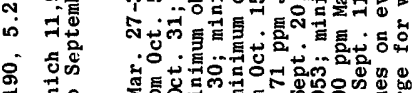
Ef.

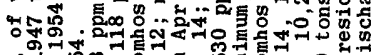
रे 造出

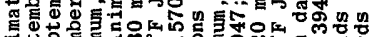
Tे 他 웡 ब...

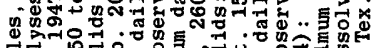
7.1 0

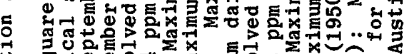

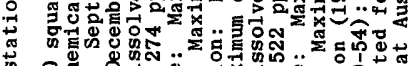
范 o कo

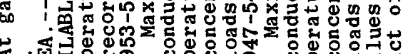

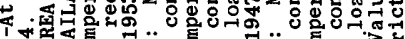

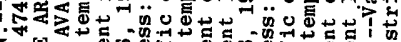

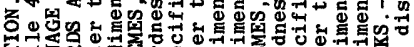

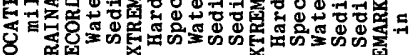

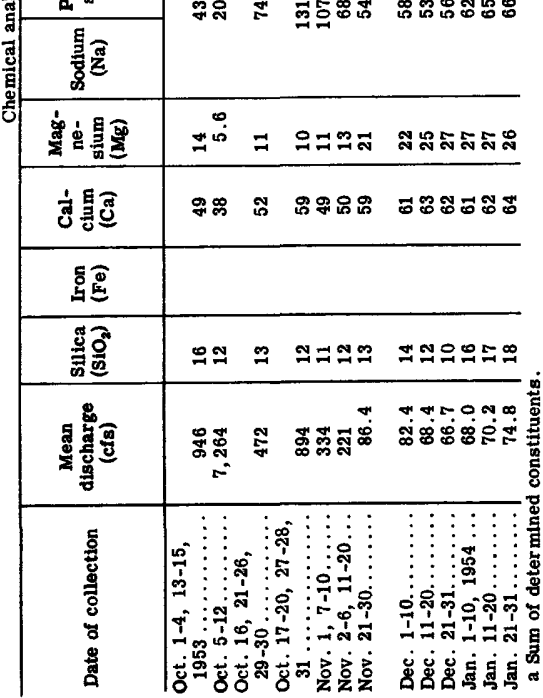




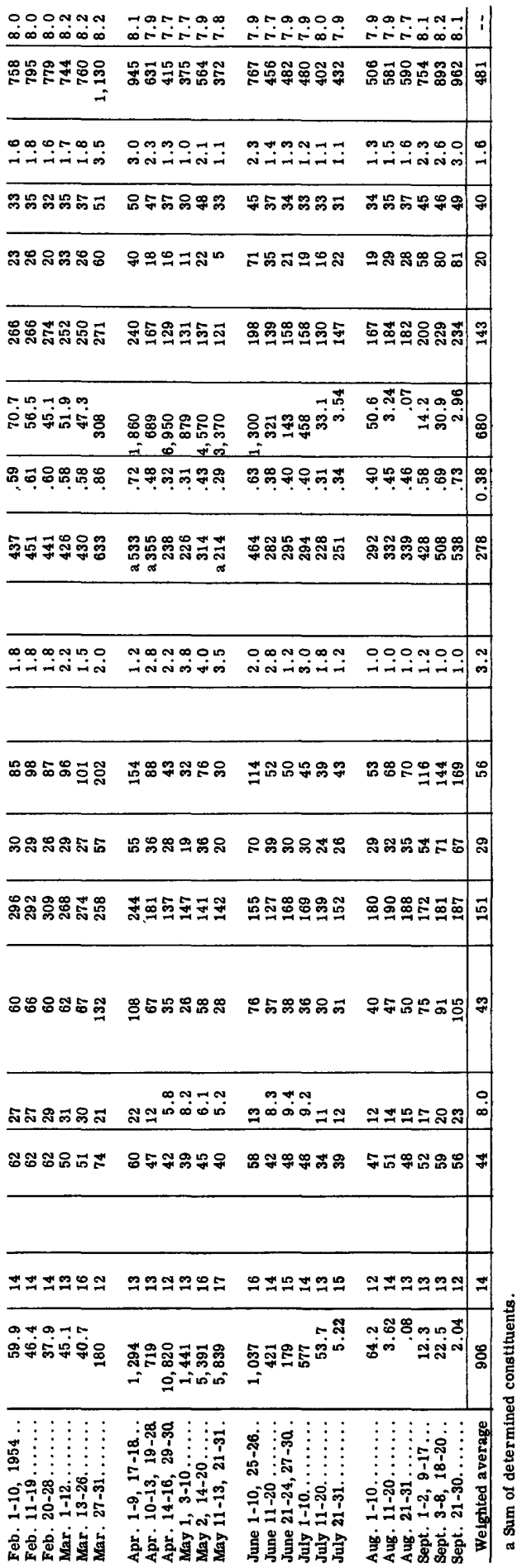


COLORADO RIVER BASIN--Continued

COLORADO RIVER NEAR SAN SABA, TEX.--Continued

Temperature $\left({ }^{\circ} \mathrm{F}\right)$ of water, water year October 1953 to September 1954

\begin{tabular}{|c|c|c|c|c|c|c|c|c|c|c|c|c|}
\hline Day & Oct. & Nov. & Dec. & Jan. & Feb. & Mar. & Apr. & May & June & July & Aug. & Sept \\
\hline $\begin{array}{l}1 \\
2 \\
3 \\
4 \\
5\end{array}$ & $\begin{array}{l}78 \\
75 \\
80 \\
70 \\
67\end{array}$ & $\begin{array}{l}65 \\
58 \\
63 \\
64 \\
60\end{array}$ & $\begin{array}{l}60 \\
60 \\
56 \\
51 \\
60\end{array}$ & $\begin{array}{l}41 \\
41 \\
56 \\
55 \\
56\end{array}$ & $\begin{array}{l}60 \\
55 \\
52 \\
45 \\
43\end{array}$ & $\begin{array}{l}54 \\
52 \\
45 \\
62 \\
56\end{array}$ & $\begin{array}{l}55 \\
56 \\
60 \\
64 \\
69\end{array}$ & $\begin{array}{l}70 \\
69 \\
64 \\
62 \\
69\end{array}$ & $\begin{array}{l}80 \\
85 \\
76 \\
76 \\
76\end{array}$ & $\begin{array}{l}86 \\
84 \\
-- \\
83 \\
85\end{array}$ & $\begin{array}{l}-- \\
85 \\
-- \\
86 \\
86\end{array}$ & $\begin{array}{l}81 \\
90 \\
78 \\
84 \\
85\end{array}$ \\
\hline $\begin{array}{r}6 \\
7 \\
8 \\
9 \\
10\end{array}$ & $\begin{array}{l}65 \\
65 \\
65 \\
65 \\
66\end{array}$ & $\begin{array}{l}58 \\
58 \\
55 \\
57 \\
--\end{array}$ & $\begin{array}{l}58 \\
52 \\
53 \\
53 \\
51\end{array}$ & $\begin{array}{l}48 \\
50 \\
49 \\
48 \\
45\end{array}$ & $\begin{array}{l}62 \\
54 \\
48 \\
-- \\
60\end{array}$ & $\begin{array}{l}45 \\
56 \\
54 \\
53 \\
69\end{array}$ & $\begin{array}{l}70 \\
79 \\
74 \\
69 \\
70\end{array}$ & $\begin{array}{l}65 \\
67 \\
67 \\
70 \\
70\end{array}$ & $\begin{array}{l}82 \\
78 \\
90 \\
78 \\
77\end{array}$ & $\begin{array}{l}84 \\
84 \\
88 \\
85 \\
84\end{array}$ & $\begin{array}{l}88 \\
89 \\
87 \\
88 \\
90\end{array}$ & $\begin{array}{l}87 \\
88 \\
86 \\
86 \\
84\end{array}$ \\
\hline $\begin{array}{l}11 \\
12 \\
13 \\
14 \\
15\end{array}$ & $\begin{array}{l}78 \\
67 \\
69 \\
69 \\
71\end{array}$ & $\begin{array}{l}51 \\
58 \\
57 \\
57 \\
64\end{array}$ & $\begin{array}{l}\mathbf{5 3} \\
\mathbf{4 5} \\
\mathbf{5 6} \\
\mathbf{4 8} \\
\mathbf{5 1}\end{array}$ & $\begin{array}{l}38 \\
40 \\
42 \\
42 \\
47\end{array}$ & $\begin{array}{l}55 \\
50 \\
60 \\
63 \\
64\end{array}$ & $\begin{array}{l}65 \\
64 \\
53 \\
48 \\
50\end{array}$ & $\begin{array}{l}72 \\
74 \\
70 \\
67 \\
--\end{array}$ & $\begin{array}{l}69 \\
65 \\
65 \\
69 \\
64\end{array}$ & $\begin{array}{l}76 \\
78 \\
81 \\
84 \\
77\end{array}$ & $\begin{array}{l}90 \\
92 \\
82 \\
90 \\
90\end{array}$ & $\begin{array}{l}-- \\
90 \\
90 \\
84 \\
90\end{array}$ & $\begin{array}{l}-- \\
85 \\
-- \\
80\end{array}$ \\
\hline $\begin{array}{l}16 \\
17 \\
18 \\
19 \\
20\end{array}$ & $\begin{array}{l}71 \\
74 \\
76 \\
70 \\
--\end{array}$ & $\begin{array}{l}58 \\
59 \\
62 \\
-- \\
65\end{array}$ & $\begin{array}{l}47 \\
44 \\
46 \\
48 \\
50\end{array}$ & $\begin{array}{l}44 \\
45 \\
55 \\
60 \\
60\end{array}$ & $\begin{array}{l}60 \\
56 \\
60 \\
60 \\
54\end{array}$ & $\begin{array}{l}59 \\
56 \\
62 \\
65 \\
67\end{array}$ & $\begin{array}{l}65 \\
68 \\
63 \\
67 \\
67\end{array}$ & $\begin{array}{l}66 \\
68 \\
70 \\
71 \\
71\end{array}$ & $\begin{array}{l}85 \\
81 \\
82 \\
83 \\
83\end{array}$ & $\begin{array}{l}90 \\
-- \\
88 \\
91 \\
89\end{array}$ & $\begin{array}{l}90 \\
89 \\
-- \\
87 \\
82\end{array}$ & $\begin{array}{l}85 \\
77 \\
86 \\
78 \\
84\end{array}$ \\
\hline $\begin{array}{l}21 \\
22 \\
23 \\
24 \\
25\end{array}$ & $\begin{array}{l}76 \\
75 \\
70 \\
68 \\
73\end{array}$ & $\begin{array}{l}54 \\
57 \\
-- \\
55 \\
53\end{array}$ & $\begin{array}{l}52 \\
45 \\
42 \\
41 \\
46\end{array}$ & $\begin{array}{l}43 \\
38 \\
41 \\
50 \\
60\end{array}$ & $\begin{array}{l}-- \\
55 \\
56 \\
55 \\
57\end{array}$ & $\begin{array}{l}70 \\
71 \\
68 \\
70 \\
65\end{array}$ & $\begin{array}{l}67 \\
67 \\
71 \\
73 \\
76\end{array}$ & $\begin{array}{l}74 \\
72 \\
71 \\
72 \\
72\end{array}$ & $\begin{array}{l}82 \\
-- \\
83 \\
83 \\
83\end{array}$ & $\begin{array}{l}85 \\
88 \\
89 \\
84 \\
84\end{array}$ & $\begin{array}{l}82 \\
85 \\
87 \\
84 \\
88\end{array}$ & $\begin{array}{l}81 \\
74 \\
75 \\
75 \\
73\end{array}$ \\
\hline $\begin{array}{l}26 \\
27 \\
28 \\
29 \\
30 \\
31\end{array}$ & $\begin{array}{l}66 \\
60 \\
67 \\
68 \\
65 \\
60\end{array}$ & $\begin{array}{l}62 \\
52 \\
56 \\
56 \\
57 \\
-\cdots\end{array}$ & $\begin{array}{l}41 \\
51 \\
55 \\
41 \\
46 \\
46\end{array}$ & $\begin{array}{l}50 \\
52 \\
55 \\
55 \\
56 \\
60\end{array}$ & $\begin{array}{l}58 \\
62 \\
55 \\
-- \\
-- \\
--\end{array}$ & $\begin{array}{l}63 \\
63 \\
74 \\
64 \\
62 \\
60\end{array}$ & $\begin{array}{l}70 \\
72 \\
70 \\
71 \\
68 \\
--\end{array}$ & $\begin{array}{l}72 \\
75 \\
74 \\
75 \\
80 \\
78\end{array}$ & $\begin{array}{l}82 \\
85 \\
81 \\
84 \\
89 \\
--\end{array}$ & $\begin{array}{l}-- \\
84 \\
84 \\
85 \\
-- \\
82\end{array}$ & $\begin{array}{l}88 \\
89 \\
86 \\
-- \\
84 \\
--\end{array}$ & $\begin{array}{l}84 \\
-- \\
77 \\
78 \\
-- \\
--\end{array}$ \\
\hline $\begin{array}{c}\text { Aver- } \\
\text { age }\end{array}$ & 70 & 58 & 50 & 49 & 56 & 60 & 68 & 70 & 81 & 86 & 87 & 82 \\
\hline
\end{tabular}


COLORADO RIVER BASIN

COLORADO RIVER BASIN--Continued

COLORADO RIVER NEAR SAN SABA, TEX.--Continued

Suspended sediment, water year October 1953 to September 1954

\begin{tabular}{|c|c|c|c|c|c|c|c|c|c|}
\hline \multirow[b]{3}{*}{ Day } & \multicolumn{3}{|c|}{ October } & \multicolumn{3}{|c|}{ November } & \multicolumn{3}{|c|}{ December } \\
\hline & \multirow[b]{2}{*}{$\begin{array}{l}\text { Mean } \\
\text { dis- } \\
\text { charge } \\
\text { (cfs) }\end{array}$} & \multicolumn{2}{|c|}{ Suspended sediment } & \multirow[b]{2}{*}{$\begin{array}{l}\text { Mean } \\
\text { dis- } \\
\text { charge } \\
\text { (cfs) }\end{array}$} & \multicolumn{2}{|c|}{ Suspended sediment } & \multirow[b]{2}{*}{$\begin{array}{l}\text { Mean } \\
\text { dis- } \\
\text { charge } \\
\text { (cfs) }\end{array}$} & \multicolumn{2}{|c|}{ Suspended sediment } \\
\hline & & $\begin{array}{l}\text { Mean } \\
\text { concen- } \\
\text { tration } \\
\text { (ppm) }\end{array}$ & $\begin{array}{l}\text { Tons } \\
\text { per } \\
\text { day }\end{array}$ & & $\begin{array}{l}\text { Mean } \\
\text { concen- } \\
\text { tration } \\
\text { (ppm) }\end{array}$ & $\begin{array}{l}\text { Tons } \\
\text { per } \\
\text { day }\end{array}$ & & $\begin{array}{c}\text { Mean } \\
\text { concen- } \\
\text { tration } \\
\text { (ppm) }\end{array}$ & $\begin{array}{l}\text { Tons } \\
\text { per } \\
\text { day }\end{array}$ \\
\hline $\begin{array}{l}1 \ldots \ldots \\
2 \ldots \ldots \\
3 . \ldots \ldots \\
4 \ldots \ldots \\
5 \ldots \ldots\end{array}$ & $\begin{array}{r}45 \\
44 \\
42 \\
4,480 \\
22,600\end{array}$ & $\begin{array}{r}58 \\
3,570 \\
2,900\end{array}$ & $\begin{array}{r}7.0 \\
s 86,700 \\
177,000\end{array}$ & $\begin{array}{l}535 \\
420 \\
364 \\
332 \\
355\end{array}$ & $\begin{array}{l}750 \\
510 \\
400 \\
300 \\
350\end{array}$ & $\begin{array}{r}1, \mathbf{0 8 0} \\
\mathbf{5 7 8} \\
\mathbf{3 9 3} \\
\mathbf{2 6 9} \\
\mathbf{3 3 5}\end{array}$ & $\begin{array}{l}74 \\
78 \\
74 \\
80 \\
85\end{array}$ & & \\
\hline $\begin{array}{r}6 \ldots \ldots \\
7 \ldots \ldots \\
8 \ldots \ldots \\
9 \ldots \ldots \\
10 \ldots \ldots\end{array}$ & $\begin{array}{r}19,200 \\
7,100 \\
2,410 \\
2,790 \\
1,790\end{array}$ & $\begin{array}{l}2,960 \\
2,410 \\
1,800 \\
1,450 \\
1,100\end{array}$ & $\begin{array}{r}149,000 \\
843,300 \\
11,700 \\
10,900 \\
5,320\end{array}$ & $\begin{array}{l}505 \\
386 \\
302 \\
246 \\
202\end{array}$ & $\begin{array}{l}350 \\
300 \\
200 \\
197 \\
160\end{array}$ & $\begin{array}{r}477 \\
313 \\
163 \\
131 \\
87\end{array}$ & $\begin{array}{r}110 \\
96 \\
82 \\
74 \\
71\end{array}$ & 42 & 9.5 \\
\hline $\begin{array}{l}11 \ldots \ldots \\
12 \ldots \ldots \\
13 \ldots \ldots \\
14 \ldots \ldots \\
15 \ldots \ldots\end{array}$ & $\begin{array}{r}1,280 \\
940 \\
704 \\
655 \\
650\end{array}$ & $\begin{array}{l}790 \\
610 \\
384 \\
264 \\
352\end{array}$ & $\begin{array}{r}2,730 \\
1,550 \\
730 \\
467 \\
618\end{array}$ & $\begin{array}{l}180 \\
162 \\
149 \\
134 \\
128\end{array}$ & $\begin{array}{r}144 \\
138 \\
90 \\
124 \\
108\end{array}$ & $\begin{array}{l}70 \\
60 \\
36 \\
45 \\
37\end{array}$ & $\begin{array}{l}71 \\
69 \\
69 \\
67 \\
67\end{array}$ & & \\
\hline $\begin{array}{l}16 \ldots \ldots \\
17 \ldots \ldots \ldots \\
18 \ldots \ldots \\
19 \ldots \ldots \\
20 \ldots \ldots\end{array}$ & $\begin{array}{l}585 \\
550 \\
530 \\
500 \\
490\end{array}$ & $\begin{array}{l}268 \\
196 \\
186 \\
162 \\
170\end{array}$ & $\begin{array}{r}423 \\
291 \\
266 \\
219 \\
\text { a } 220\end{array}$ & $\begin{array}{l}122 \\
118 \\
118 \\
112 \\
110\end{array}$ & $\begin{array}{l}88 \\
92 \\
90\end{array}$ & $\begin{array}{l}29 \\
29 \\
29\end{array}$ & $\begin{array}{l}65 \\
65 \\
67 \\
71 \\
73\end{array}$ & 30 & 0.0 \\
\hline $\begin{array}{l}21 \ldots \ldots \\
22 \ldots \ldots \ldots \\
23 . \ldots \ldots \\
24 \ldots \ldots \\
25 \ldots \ldots\end{array}$ & $\begin{array}{l}400 \\
238 \\
183 \\
162 \\
158\end{array}$ & $\begin{array}{l}182 \\
166 \\
144 \\
130 \\
124\end{array}$ & $\begin{array}{r}197 \\
107 \\
71 \\
57 \\
53\end{array}$ & $\begin{array}{r}105 \\
100 \\
98 \\
93 \\
93\end{array}$ & 40 & 11 & $\begin{array}{l}71 \\
69 \\
67 \\
65 \\
64\end{array}$ & 24 & 4.3 \\
\hline $\begin{array}{l}26 \ldots \ldots \\
27 \ldots \ldots \\
28 \ldots \ldots \\
29 . \ldots \\
30 \ldots \ldots \\
31 \ldots \ldots\end{array}$ & $\begin{array}{r}158 \\
1,950 \\
1,520 \\
1,320 \\
1,040 \\
716 \\
\end{array}$ & $\begin{array}{r}126 \\
721 \\
1,270 \\
2,900 \\
2,650 \\
950\end{array}$ & $\begin{array}{r}54 \\
3,800 \\
\mathrm{~s} 5,060 \\
10,300 \\
7,440 \\
1,840\end{array}$ & $\begin{array}{l}82 \\
74 \\
73 \\
73 \\
73 \\
-\end{array}$ & $\begin{array}{l}52 \\
--\end{array}$ & 11 & $\begin{array}{l}65 \\
65 \\
65 \\
65 \\
67 \\
71 \\
\end{array}$ & 36 & 6.6 \\
\hline \multirow[t]{2}{*}{ Total. } & 75,230 & -- & 520,434 & 5,844 & -- & 4,293 & 2,242 & $m$ & 202.2 \\
\hline & \multicolumn{3}{|c|}{ January } & \multicolumn{3}{|c|}{ February } & \multicolumn{3}{|c|}{ March } \\
\hline $\begin{array}{r}1 \ldots \ldots \\
2 \ldots \ldots \\
3 \ldots \ldots \\
4 \ldots \ldots \\
5 \ldots \ldots \\
6 \ldots \\
7 \ldots \ldots \\
8 \ldots \ldots \\
9 \ldots \ldots \\
10 \ldots \ldots\end{array}$ & $\begin{array}{l}76 \\
74 \\
71 \\
67 \\
65 \\
\\
63 \\
65 \\
67 \\
67 \\
65\end{array}$ & 58 & 11 & $\begin{array}{l}67 \\
67 \\
67 \\
65 \\
63 \\
\\
56 \\
54 \\
54 \\
54 \\
52\end{array}$ & 100 & 16 & $\begin{array}{l}33 \\
36 \\
33 \\
33 \\
36 \\
\\
46 \\
59 \\
56 \\
56 \\
59\end{array}$ & 80 & 9.7 \\
\hline $\begin{array}{l}11 \ldots \ldots \\
12 \ldots \ldots \\
13 \ldots \ldots \\
14 \ldots \ldots \\
15 \ldots \ldots\end{array}$ & $\begin{array}{l}63 \\
61 \\
61 \\
63 \\
74\end{array}$ & & & $\begin{array}{l}46 \\
48 \\
52 \\
50 \\
46\end{array}$ & & & $\begin{array}{l}52 \\
42 \\
33 \\
27 \\
31\end{array}$ & & \\
\hline $\begin{array}{l}16 \ldots \ldots \\
17 \ldots \ldots \\
18 \ldots \ldots \\
19 \ldots \ldots \\
20 . \ldots \ldots\end{array}$ & $\begin{array}{l}74 \\
74 \\
76 \\
78 \\
78\end{array}$ & 58 & 11 & $\begin{array}{l}44 \\
44 \\
46 \\
42 \\
38\end{array}$ & 88 & 11 & $\begin{array}{l}31 \\
31 \\
33 \\
33 \\
38\end{array}$ & 102 & 9.7 \\
\hline $\begin{array}{l}21 \ldots \ldots \\
22 \ldots \ldots \ldots \\
23 \ldots \ldots \\
24 \ldots \ldots \\
25 \ldots \ldots\end{array}$ & \begin{tabular}{l|l|}
78 \\
76 \\
76 \\
76 \\
74
\end{tabular} & & & $\begin{array}{l}38 \\
40 \\
38 \\
36 \\
36\end{array}$ & 66 & 6.7 & $\begin{array}{l}40 \\
40 \\
42 \\
44 \\
46\end{array}$ & & \\
\hline $\begin{array}{l}26 . \ldots \ldots \\
27 \ldots \ldots \\
28 . \ldots \ldots \\
29 . \ldots \ldots \\
30 . \ldots \ldots \\
31 \ldots \ldots\end{array}$ & $\begin{array}{l}74 \\
74 \\
74 \\
76 \\
74 \\
7 i \\
\end{array}$ & 54 & 11 & $\begin{array}{l}40 \\
40 \\
35 \\
-- \\
-- \\
-- \\
\end{array}$ & $\begin{array}{l}-- \\
-- \\
-\end{array}$ & $\begin{array}{l}-- \\
-- \\
--\end{array}$ & $\begin{array}{r}101 \\
415 \\
196 \\
126 \\
89 \\
74\end{array}$ & 99 & 29 \\
\hline Total & 2,205 & -- & 341 & 1,358 & -- & 323.6 & 2,011 & $\cdots$ & 513.0 \\
\hline
\end{tabular}

s Computed by subdividing day.

a Computed from estimated concentration graph. 
COLORADO RIVER BASIN--Continued

COLORADO RIVER NEAR SAN SABA, TEX.--Continued

Suspended sediment, water year October 1953 to September 1954 --Continued

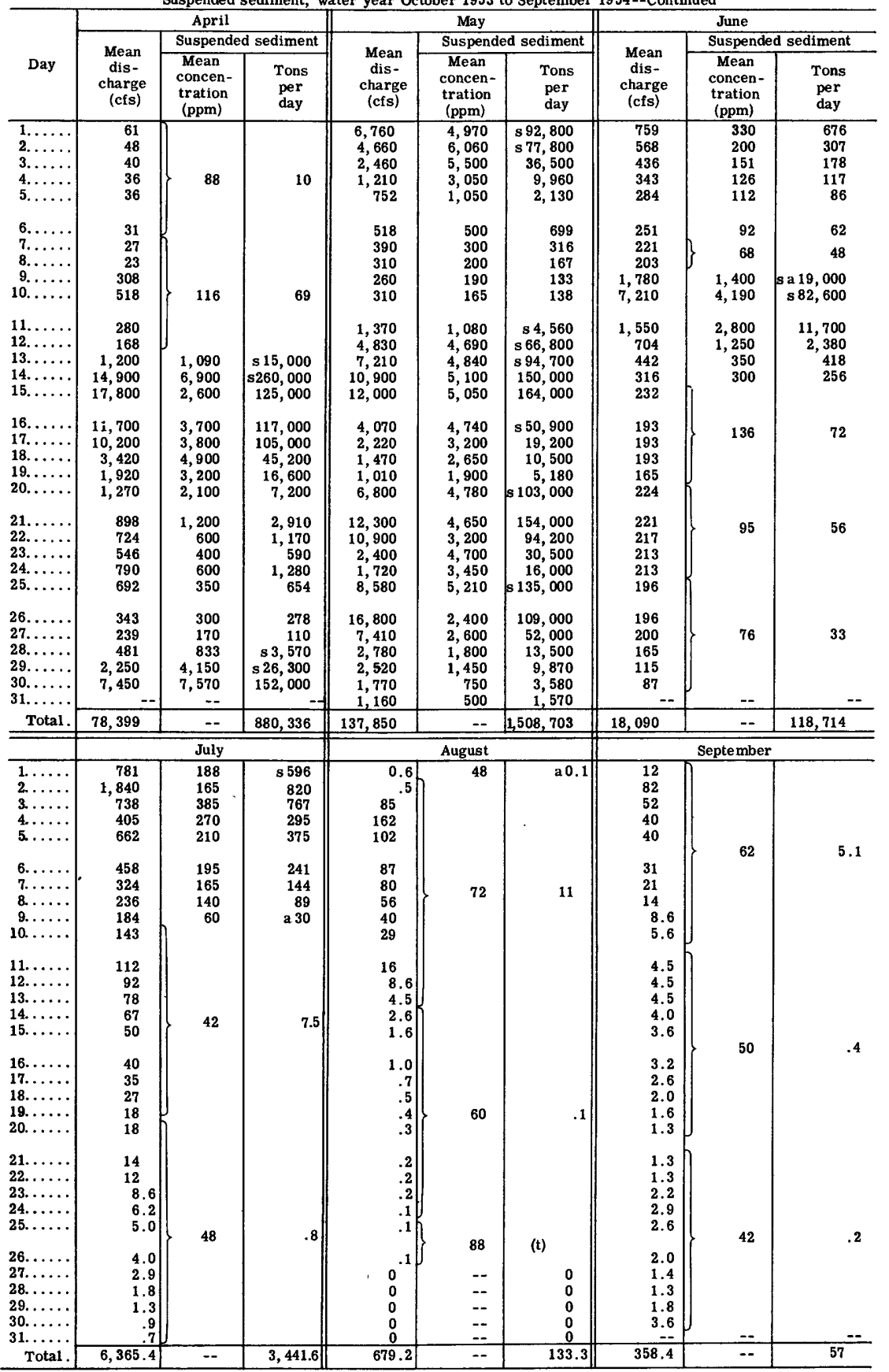

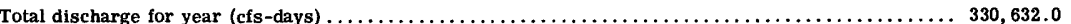

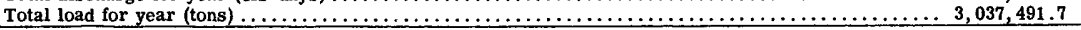

s Computed by subdividing day.

$t$ Less than 0.05 ton.

a Computed from estimated concentration graph. 
COLORADO RIVER BASIN

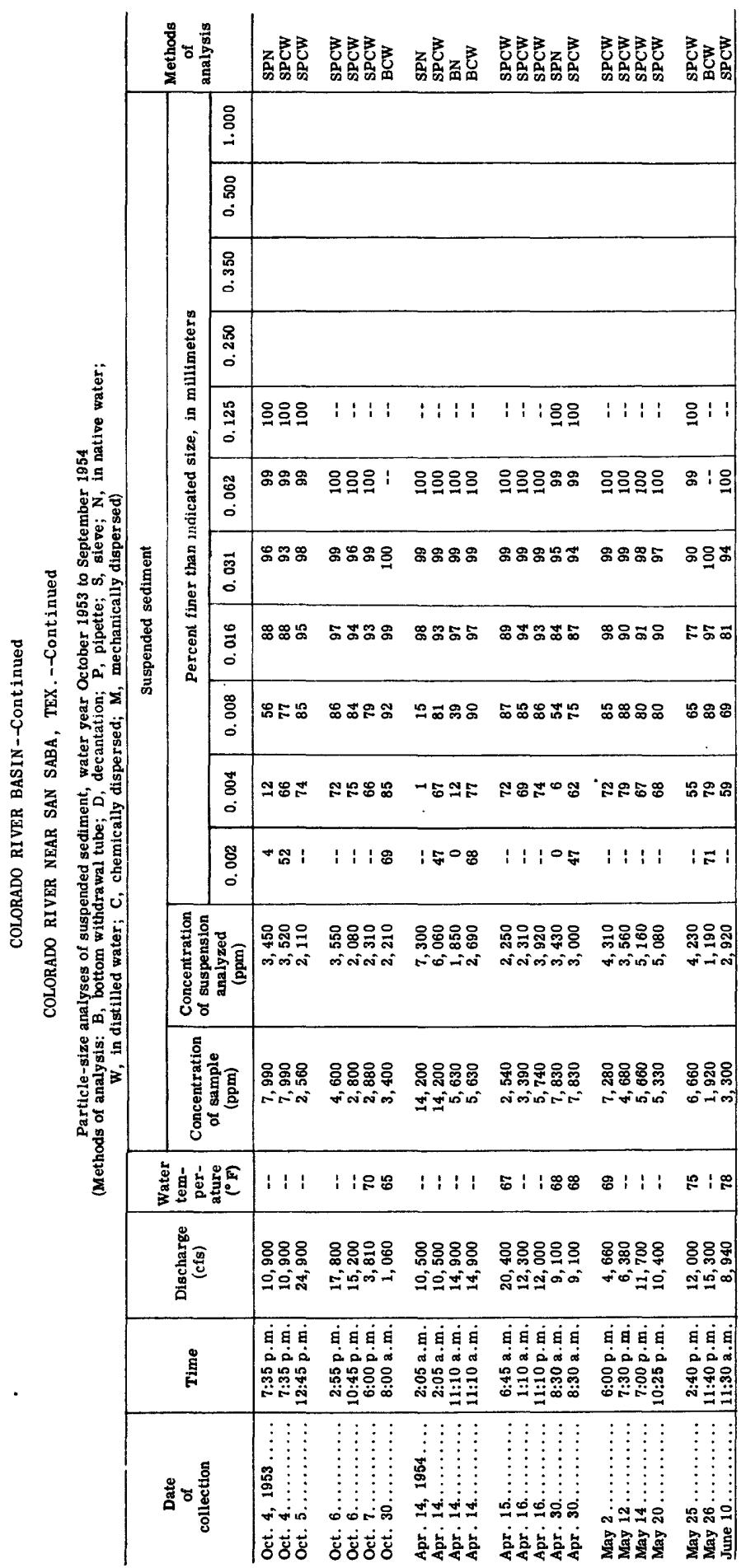




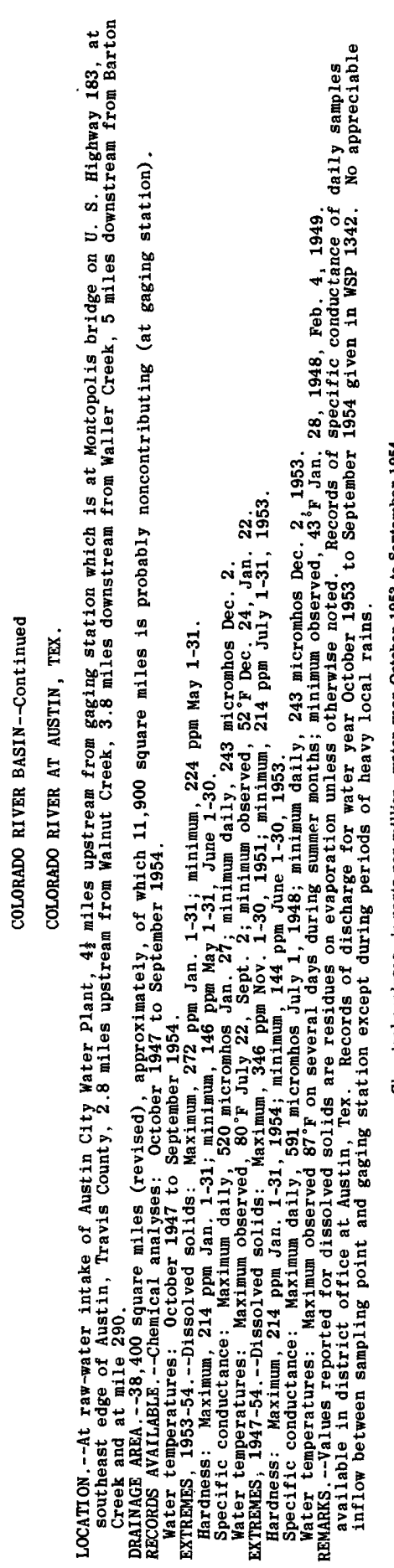

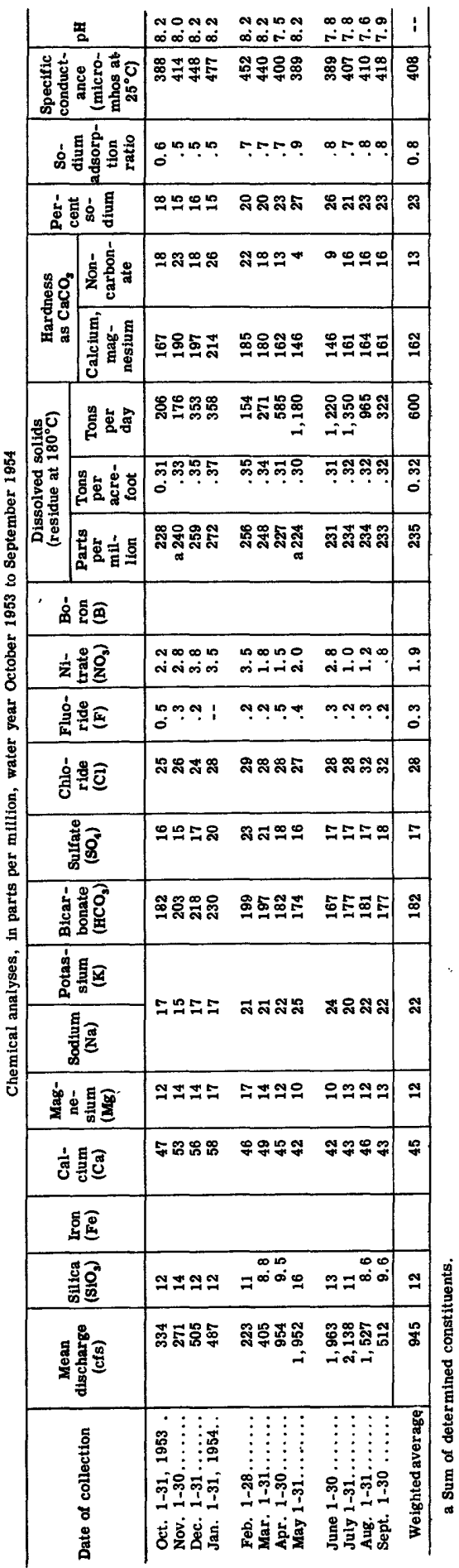


COLORADO RIVER BASIN--Continued

COLORADO RIVER AT AUSTIN, TEX,--Continued

Temperature $\left({ }^{\circ} \mathrm{F}\right)$ of water, water year October 1953 to September 1954

\begin{tabular}{|c|c|c|c|c|c|c|c|c|c|c|c|c|}
\hline Day & Oct. & Nov. & Dec. & Jan. & Feb. & Mar. & Apr. & May & June & July & Aug. & Sept. \\
\hline $\begin{array}{l}1 \\
2 \\
3 \\
4 \\
5\end{array}$ & $\begin{array}{l}74 \\
76 \\
75 \\
75 \\
75\end{array}$ & $\begin{array}{l}68 \\
68 \\
69 \\
70 \\
69\end{array}$ & $\begin{array}{l}65 \\
65 \\
64 \\
63 \\
63\end{array}$ & $\begin{array}{l}54 \\
57 \\
57 \\
58 \\
54\end{array}$ & $\begin{array}{l}62 \\
64 \\
62 \\
62 \\
62\end{array}$ & $\begin{array}{l}60 \\
64 \\
60 \\
58 \\
59\end{array}$ & $\begin{array}{l}64 \\
63 \\
65 \\
67 \\
68\end{array}$ & $\begin{array}{l}-- \\
70 \\
66 \\
66 \\
66\end{array}$ & $\begin{array}{l}-- \\
70 \\
71 \\
73 \\
71\end{array}$ & $\begin{array}{l}71 \\
70 \\
69 \\
72 \\
70\end{array}$ & $\begin{array}{l}71 \\
73 \\
73 \\
73 \\
73\end{array}$ & $\begin{array}{l}79 \\
80 \\
78 \\
78 \\
76\end{array}$ \\
\hline $\begin{array}{r}6 \\
7 \\
8 \\
9 \\
10\end{array}$ & $\begin{array}{l}\mathbf{7 2} \\
\mathbf{7 2} \\
\mathbf{7 1} \\
\mathbf{7 1} \\
\mathbf{7 2}\end{array}$ & $\begin{array}{l}67 \\
67 \\
65 \\
64 \\
63\end{array}$ & $\begin{array}{l}62 \\
60 \\
62 \\
59 \\
58\end{array}$ & $\begin{array}{l}\mathbf{5 4} \\
\mathbf{5 4} \\
\mathbf{5 5} \\
\mathbf{5 5} \\
\mathbf{5 7}\end{array}$ & $\begin{array}{l}62 \\
60 \\
60 \\
61\end{array}$ & $\begin{array}{l}56 \\
59 \\
59 \\
61 \\
64\end{array}$ & $\begin{array}{l}72 \\
69 \\
68 \\
69 \\
69\end{array}$ & $\begin{array}{l}68 \\
66 \\
69 \\
66 \\
70\end{array}$ & $\begin{array}{l}70 \\
-- \\
-- \\
-- \\
--\end{array}$ & $\begin{array}{l}71 \\
70 \\
-- \\
71 \\
72\end{array}$ & $\begin{array}{l}73 \\
77 \\
75 \\
76 \\
76\end{array}$ & $\begin{array}{l}77 \\
78 \\
77 \\
78 \\
78\end{array}$ \\
\hline $\begin{array}{l}11 \\
12 \\
13 \\
14 \\
15\end{array}$ & $\begin{array}{l}72 \\
72 \\
72 \\
74 \\
74\end{array}$ & $\begin{array}{l}63 \\
63 \\
64 \\
63 \\
63\end{array}$ & $\begin{array}{l}\mathbf{5 9} \\
\mathbf{5 9} \\
\mathbf{5 8} \\
\mathbf{5 9} \\
--\end{array}$ & $\begin{array}{l}54 \\
54 \\
54 \\
55 \\
56\end{array}$ & $\begin{array}{l}61 \\
59 \\
61 \\
61 \\
65\end{array}$ & $\begin{array}{l}63 \\
65 \\
64 \\
58 \\
60\end{array}$ & $\begin{array}{l}70 \\
68 \\
70 \\
68 \\
63\end{array}$ & $\begin{array}{l}69 \\
68 \\
68 \\
67 \\
66\end{array}$ & $\begin{array}{l}-- \\
-- \\
-- \\
-\end{array}$ & $\begin{array}{l}73 \\
73 \\
74 \\
72 \\
70\end{array}$ & $\begin{array}{l}76 \\
75 \\
74 \\
74 \\
76\end{array}$ & $\begin{array}{l}77 \\
76 \\
77 \\
78 \\
78\end{array}$ \\
\hline $\begin{array}{l}16 \\
17 \\
18 \\
19 \\
20\end{array}$ & $\begin{array}{l}74 \\
72 \\
72 \\
72 \\
72\end{array}$ & $\begin{array}{l}64 \\
65 \\
65 \\
67 \\
65\end{array}$ & $\begin{array}{l}57 \\
58 \\
57 \\
58 \\
58\end{array}$ & $\begin{array}{l}58 \\
58 \\
58 \\
60 \\
62\end{array}$ & $\begin{array}{l}64 \\
65 \\
62 \\
64 \\
62\end{array}$ & $\begin{array}{l}60 \\
69 \\
60 \\
62 \\
62\end{array}$ & $\begin{array}{l}66 \\
70 \\
70 \\
67 \\
68\end{array}$ & $\begin{array}{l}66 \\
68 \\
69 \\
69 \\
70\end{array}$ & $\begin{array}{l}73 \\
72 \\
-- \\
74 \\
72\end{array}$ & $\begin{array}{l}72 \\
73 \\
72 \\
\mathbf{7 1}\end{array}$ & $\begin{array}{l}76 \\
75 \\
75 \\
75 \\
75\end{array}$ & $\begin{array}{l}78 \\
77 \\
77 \\
78 \\
78\end{array}$ \\
\hline $\begin{array}{l}21 \\
22 \\
23 \\
24 \\
25\end{array}$ & $\begin{array}{l}73 \\
73 \\
- \\
74 \\
74\end{array}$ & $\begin{array}{l}64 \\
62 \\
61 \\
62 \\
62\end{array}$ & $\begin{array}{l}\mathbf{5 8} \\
\mathbf{5 7} \\
\mathbf{5 4} \\
\mathbf{5 2} \\
\mathbf{5 4}\end{array}$ & $\begin{array}{l}-2 \\
52 \\
54 \\
56 \\
60\end{array}$ & $\begin{array}{l}61 \\
-- \\
64 \\
61 \\
61\end{array}$ & $\begin{array}{l}62 \\
62 \\
63 \\
64 \\
63\end{array}$ & $\begin{array}{l}69 \\
70 \\
69 \\
69 \\
71\end{array}$ & $\begin{array}{l}69 \\
66 \\
66 \\
66 \\
68\end{array}$ & $\begin{array}{l}72 \\
72 \\
72 \\
70 \\
68\end{array}$ & $\begin{array}{l}71 \\
80 \\
74 \\
75 \\
74\end{array}$ & $\begin{array}{l}77 \\
77 \\
77 \\
77 \\
77\end{array}$ & $\begin{array}{l}79 \\
75 \\
73 \\
75 \\
76\end{array}$ \\
\hline $\begin{array}{l}26 \\
27 \\
28 \\
29 \\
30 \\
31\end{array}$ & $\begin{array}{l}-- \\
68 \\
68 \\
69 \\
70 \\
68\end{array}$ & $\begin{array}{l}61 \\
61 \\
62 \\
63 \\
65 \\
--\end{array}$ & $\begin{array}{l}\mathbf{5 3} \\
\mathbf{5 5} \\
\mathbf{5 6} \\
\mathbf{5 5} \\
\mathbf{5 5} \\
\mathbf{5 4}\end{array}$ & $\begin{array}{l}63 \\
61 \\
60 \\
62 \\
63 \\
63\end{array}$ & $\begin{array}{l}62 \\
64 \\
61 \\
-- \\
-- \\
--\end{array}$ & $\begin{array}{l}64 \\
66 \\
65 \\
67 \\
67 \\
64\end{array}$ & $\begin{array}{l}69 \\
69 \\
68 \\
67 \\
68 \\
-2\end{array}$ & $\begin{array}{l}69 \\
68 \\
68 \\
69 \\
68 \\
70\end{array}$ & $\begin{array}{l}69 \\
69 \\
70 \\
68 \\
76 \\
--\end{array}$ & $\begin{array}{l}76 \\
76 \\
76 \\
74 \\
76 \\
73\end{array}$ & $\begin{array}{l}75 \\
76 \\
76 \\
76 \\
78 \\
78\end{array}$ & $\begin{array}{l}77 \\
77 \\
77 \\
78 \\
78 \\
--\end{array}$ \\
\hline $\begin{array}{l}\text { Aver- } \\
\text { age }\end{array}$ & 72 & 64 & 58 & 57 & 62 & 62 & 68 & 68 & -- & 73 & 75 & 77 \\
\hline
\end{tabular}

$4888170-59-24$ 


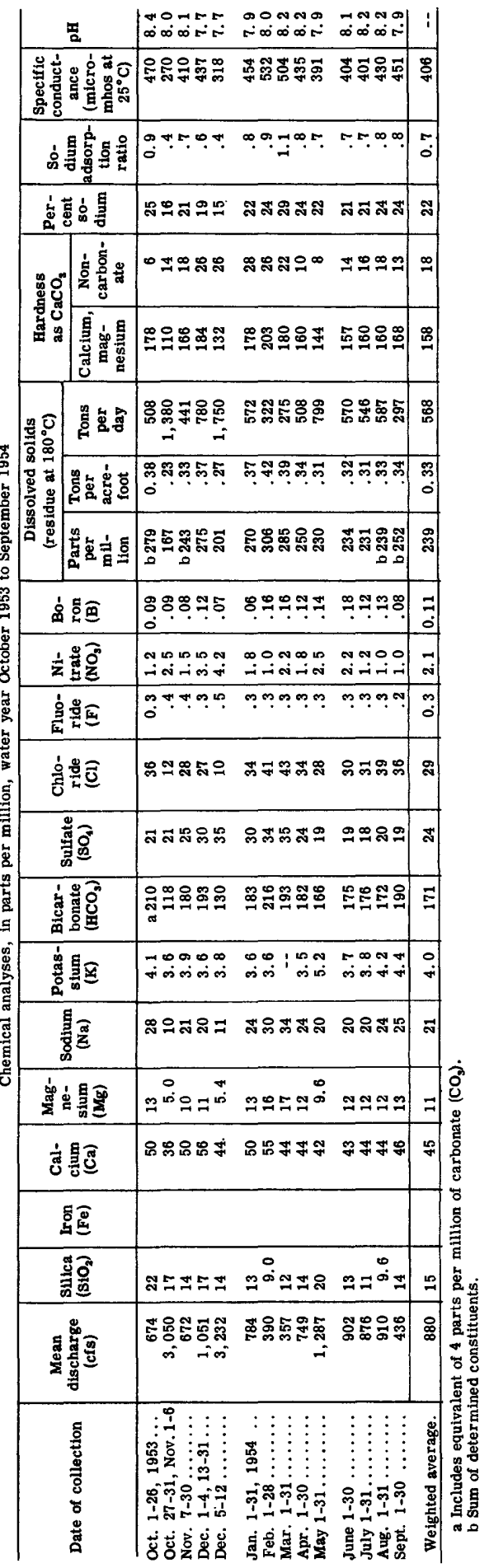


COLORADO RIVER BASIN--Continued

COLORADO RIVER AT WHARTON, TEX.--Continued

Temperature $\left({ }^{\circ} \mathrm{F}\right)$ of water, water year October 1953 to September 1954

\begin{tabular}{|c|c|c|c|c|c|c|c|c|c|c|c|c|}
\hline Day & Oct. & Nov. & Dec. & Jan. & Feb. & Mar. & Apr. & May & June & July & Aug. & Sept. \\
\hline $\begin{array}{l}1 \\
2 \\
3 \\
4 \\
5\end{array}$ & $\begin{array}{l}78 \\
79 \\
79 \\
78 \\
78\end{array}$ & $\begin{array}{l}63 \\
63 \\
67 \\
66 \\
66\end{array}$ & $\begin{array}{l}63 \\
65 \\
65 \\
64 \\
65\end{array}$ & $\begin{array}{l}48 \\
54 \\
56 \\
59 \\
56\end{array}$ & $\begin{array}{l}60 \\
65 \\
60 \\
58 \\
60\end{array}$ & $\begin{array}{l}53 \\
59 \\
52 \\
52 \\
49\end{array}$ & $\begin{array}{l}62 \\
65 \\
70 \\
72 \\
74\end{array}$ & $\begin{array}{l}78 \\
79 \\
67 \\
64 \\
67\end{array}$ & $\begin{array}{l}82 \\
82 \\
82 \\
77 \\
76\end{array}$ & $\begin{array}{l}89 \\
96 \\
90 \\
88 \\
90\end{array}$ & $\begin{array}{l}82 \\
83 \\
83 \\
85 \\
84\end{array}$ & $\begin{array}{l}86 \\
83 \\
81 \\
82\end{array}$ \\
\hline $\begin{array}{r}6 \\
7 \\
8 \\
9 \\
10\end{array}$ & $\begin{array}{l}70 \\
67 \\
66 \\
67 \\
68\end{array}$ & $\begin{array}{l}62 \\
\mathbf{6 3} \\
58 \\
\mathbf{5 1} \\
\mathbf{5 5}\end{array}$ & $\begin{array}{l}61 \\
57 \\
59 \\
58 \\
55\end{array}$ & $\begin{array}{l}55 \\
55 \\
58 \\
62 \\
57\end{array}$ & $\begin{array}{l}59 \\
55 \\
52 \\
52 \\
58\end{array}$ & $\begin{array}{l}46 \\
50 \\
56 \\
59 \\
62\end{array}$ & $\begin{array}{l}74 \\
75 \\
76 \\
74 \\
72\end{array}$ & $\begin{array}{l}69 \\
71 \\
74 \\
84 \\
81\end{array}$ & $\begin{array}{l}79 \\
81 \\
81 \\
80 \\
81\end{array}$ & $\begin{array}{l}84 \\
81 \\
83 \\
84 \\
84\end{array}$ & $\begin{array}{l}82 \\
82 \\
83 \\
85 \\
85\end{array}$ & $\begin{array}{l}81 \\
82 \\
82 \\
83 \\
84\end{array}$ \\
\hline $\begin{array}{l}11 \\
12 \\
13 \\
14 \\
15\end{array}$ & $\begin{array}{l}72 \\
74 \\
72 \\
74 \\
74\end{array}$ & $\begin{array}{l}63 \\
57 \\
58 \\
58 \\
59\end{array}$ & $\begin{array}{l}55 \\
56 \\
52 \\
53 \\
48\end{array}$ & $\begin{array}{l}50 \\
52 \\
50 \\
56 \\
62\end{array}$ & $\begin{array}{l}61 \\
57 \\
58 \\
59 \\
67\end{array}$ & $\begin{array}{l}68 \\
70 \\
68 \\
52 \\
51\end{array}$ & $\begin{array}{l}75 \\
76 \\
76 \\
75 \\
76\end{array}$ & $\begin{array}{l}82 \\
75 \\
77 \\
78 \\
73\end{array}$ & $\begin{array}{l}82 \\
81 \\
81 \\
81 \\
80\end{array}$ & $\begin{array}{l}84 \\
85 \\
85 \\
85 \\
82\end{array}$ & $\begin{array}{l}85 \\
83 \\
86 \\
84 \\
84\end{array}$ & $\begin{array}{l}90 \\
88 \\
88 \\
91 \\
89\end{array}$ \\
\hline $\begin{array}{l}16 \\
17 \\
18 \\
19 \\
20\end{array}$ & $\begin{array}{l}73 \\
73 \\
72 \\
73 \\
69\end{array}$ & $\begin{array}{l}63 \\
63 \\
67 \\
74 \\
65\end{array}$ & $\begin{array}{l}51 \\
53 \\
50 \\
48 \\
50\end{array}$ & $\begin{array}{l}60 \\
58 \\
58 \\
64 \\
68\end{array}$ & $\begin{array}{l}68 \\
61 \\
63 \\
68 \\
60\end{array}$ & $\begin{array}{l}55 \\
52 \\
60 \\
66 \\
65\end{array}$ & $\begin{array}{l}72 \\
67 \\
66 \\
70 \\
70\end{array}$ & $\begin{array}{l}74 \\
74 \\
75 \\
78 \\
80\end{array}$ & $\begin{array}{l}81 \\
82 \\
83 \\
82 \\
82\end{array}$ & $\begin{array}{l}83 \\
85 \\
83 \\
85 \\
85\end{array}$ & $\begin{array}{r}83 \\
83 \\
90 \\
.85 \\
90\end{array}$ & $\begin{array}{l}90 \\
90 \\
82 \\
82 \\
80\end{array}$ \\
\hline $\begin{array}{l}21 \\
22 \\
23 \\
24 \\
25\end{array}$ & $\begin{array}{l}75 \\
75 \\
75 \\
73 \\
74\end{array}$ & $\begin{array}{l}62 \\
59 \\
56 \\
50 \\
56\end{array}$ & $\begin{array}{l}51 \\
51 \\
43 \\
43 \\
--\end{array}$ & $\begin{array}{l}57 \\
45 \\
45 \\
50 \\
61\end{array}$ & $\begin{array}{l}68 \\
60 \\
63 \\
57 \\
59\end{array}$ & $\begin{array}{l}65 \\
67 \\
70 \\
70 \\
72\end{array}$ & $\begin{array}{l}72 \\
73 \\
74 \\
75 \\
75\end{array}$ & $\begin{array}{l}79 \\
75 \\
75 \\
75 \\
75\end{array}$ & $\begin{array}{l}84 \\
83 \\
81 \\
84 \\
84\end{array}$ & $\begin{array}{l}84 \\
85 \\
84 \\
93 \\
90\end{array}$ & $\begin{array}{l}88 \\
83 \\
85 \\
80 \\
82\end{array}$ & $\begin{array}{l}82 \\
75 \\
72 \\
85 \\
79\end{array}$ \\
\hline $\begin{array}{l}26 \\
27 \\
28 \\
29 \\
30 \\
31\end{array}$ & $\begin{array}{l}74 \\
69 \\
67 \\
66 \\
65 \\
65\end{array}$ & $\begin{array}{l}55 \\
57 \\
63 \\
65 \\
61 \\
--\end{array}$ & $\begin{array}{l}42 \\
45 \\
51 \\
49 \\
48 \\
48\end{array}$ & $\begin{array}{l}61 \\
61 \\
60 \\
62 \\
71 \\
65\end{array}$ & $\begin{array}{l}68 \\
68 \\
57 \\
-- \\
-- \\
--\end{array}$ & $\begin{array}{l}67 \\
68 \\
70 \\
70 \\
73 \\
76\end{array}$ & $\begin{array}{l}76 \\
-- \\
78 \\
78 \\
--\end{array}$ & $\begin{array}{l}76 \\
78 \\
76 \\
79 \\
81 \\
81\end{array}$ & $\begin{array}{l}83 \\
90 \\
82 \\
82 \\
85 \\
--\end{array}$ & $\begin{array}{l}95 \\
93 \\
92 \\
89 \\
84 \\
83\end{array}$ & $\begin{array}{l}82 \\
82 \\
83 \\
81 \\
83 \\
83\end{array}$ & $\begin{array}{l}80 \\
80 \\
79 \\
80 \\
82 \\
--\end{array}$ \\
\hline $\begin{array}{l}\text { Aver- } \\
\text { age }\end{array}$ & 72 & 61 & 53 & 57 & 61 & 62 & 73 & 76 & 82 & 87 & 84 & 83 \\
\hline
\end{tabular}




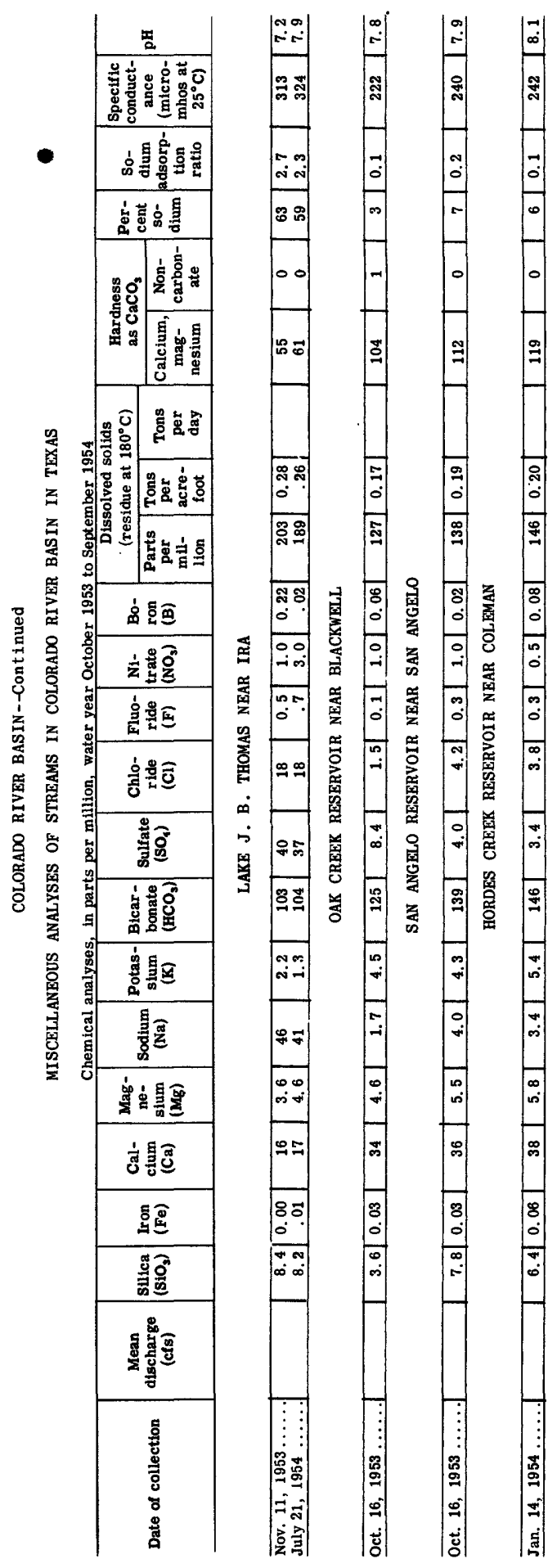




\begin{tabular}{|c|c|c|c|c|}
\hline 要 & 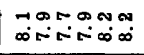 & $\begin{array}{l}70 \text { N } \\
\infty \infty \infty \\
\infty\end{array}$ & $\stackrel{0}{\infty} \underset{\infty}{\infty}$ & 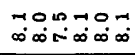 \\
\hline 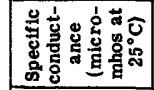 & 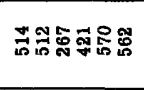 & 蛋동 & 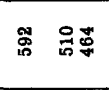 & 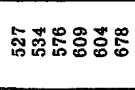 \\
\hline 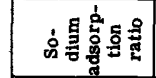 & $\ddot{-1} 0.000$ & $\stackrel{0}{i} \cdot \stackrel{0}{-}$ & $=\stackrel{-\infty}{-i}$ & 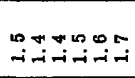 \\
\hline 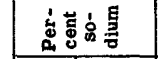 & 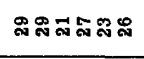 & มีกส & \& & 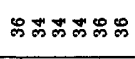 \\
\hline 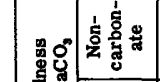 & 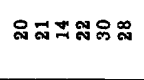 & 유ㅇㅝㅠㅇㅠ & హ & 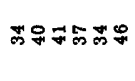 \\
\hline 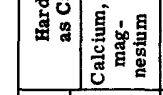 & 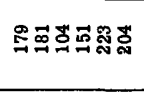 & 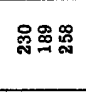 & 욤요 & ஜ유 జ \\
\hline 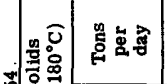 & 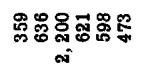 & 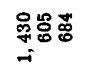 & 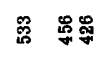 & 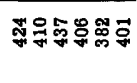 \\
\hline 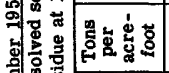 & 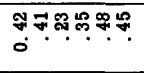 & 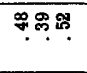 & 5. ฮ్లి & 국운 \\
\hline 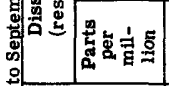 & 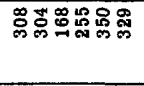 & 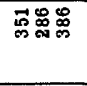 & 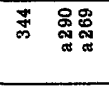 & 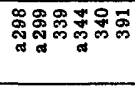 \\
\hline 施哭旬 & 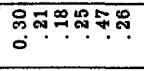 & 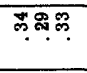 & $\stackrel{0}{\circ} 8 \%$ & 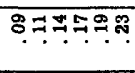 \\
\hline 芸焉总 & 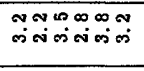 & $\begin{array}{l}\infty \text { is } \\
\sin \theta\end{array}$ & $\because$ Fin & 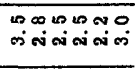 \\
\hline 峦弯正 & क๓ & ตุ? & $m$ m. & 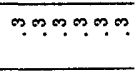 \\
\hline 总峦可 & 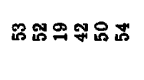 & 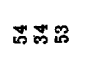 & 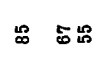 & ๕ロポ゚゙タ \\
\hline 胥。 & 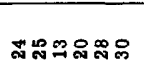 & รกำ & ణ్ల న్లే & 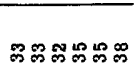 \\
\hline 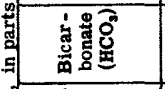 & 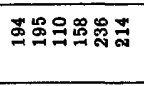 & 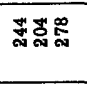 & 吕 す急 & 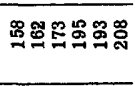 \\
\hline 量最司 & 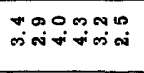 & 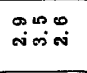 & $\vec{\infty}$ को क & 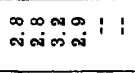 \\
\hline 量卷 & 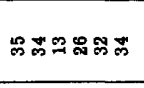 & 号些邑 & 영 尔号 & 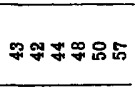 \\
\hline 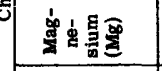 & 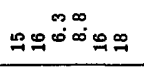 & $\stackrel{\mathscr{1}}{2} \cong$ & $\stackrel{9}{\rightarrow}$ & ำลำล옻 \\
\hline 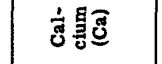 & 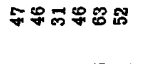 & シ゚ジ & న్ల న్లేన్ల & 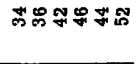 \\
\hline 占す & & & & \\
\hline ङึํํํํํํ & ส゚ロ゙゚ロ゚̊ & 뜬 & ส $9 \vec{\sim}$ & 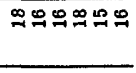 \\
\hline 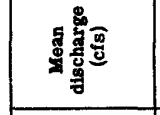 & 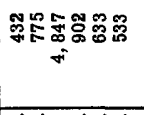 & 营莒: & 点 路 & 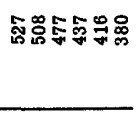 \\
\hline 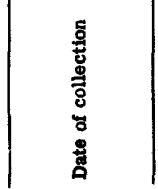 & 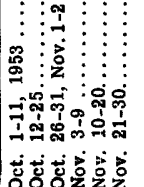 & 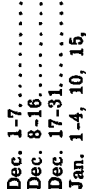 & 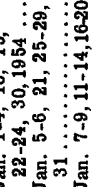 & 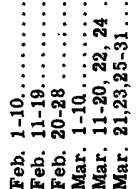 \\
\hline
\end{tabular}




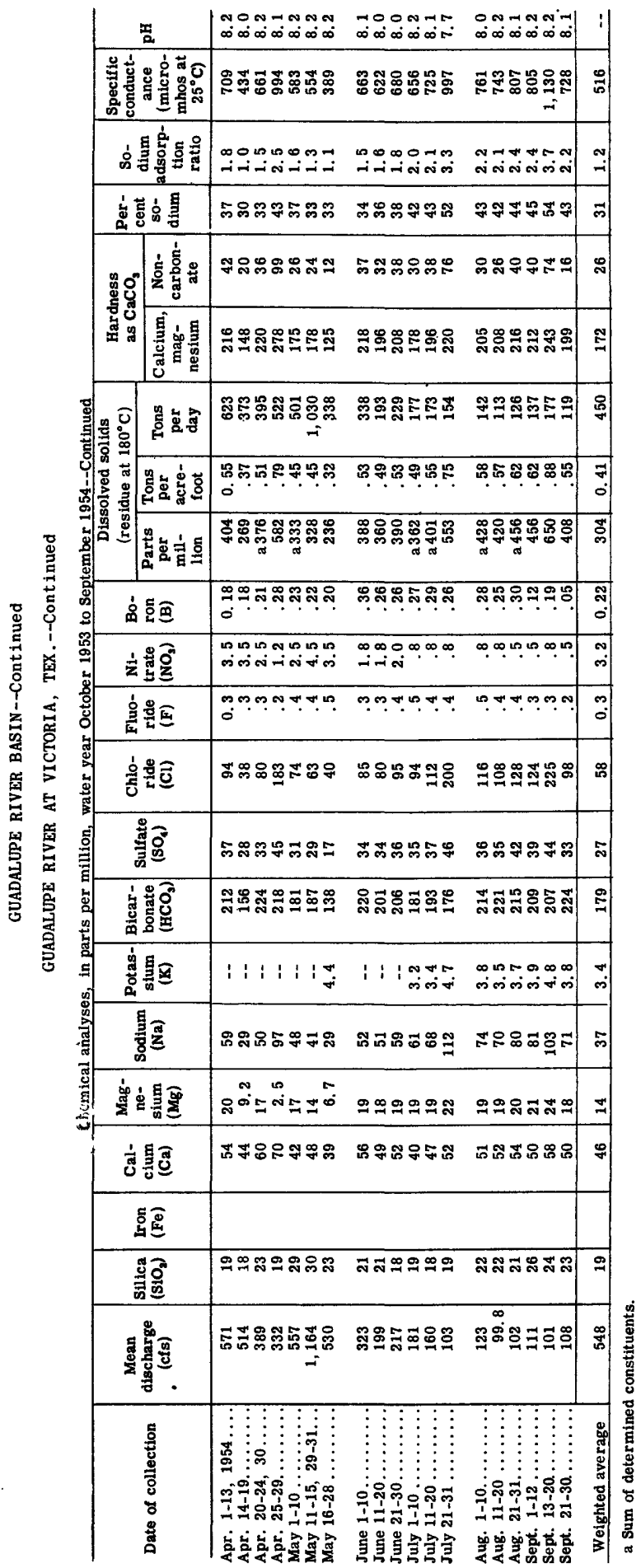


GUADALUPE RIVER BASIN--Continued

GUADALUPE RIVER AT VICTORIA, TEX.--Continued

Temperature $\left({ }^{\circ} \mathrm{F}\right)$ of water, water year October 1953 to September 1954

\begin{tabular}{|c|c|c|c|c|c|c|c|c|c|c|c|c|}
\hline Day & Oct. & Nov. & Dec. & Jan. & Feb. & Mar. & Apr. & May & June & July & Aug. & Sept. \\
\hline $\begin{array}{l}1 \\
2 \\
3 \\
4 \\
5\end{array}$ & $\begin{array}{l}-- \\
81 \\
79 \\
-- \\
--\end{array}$ & $\begin{array}{l}64 \\
66 \\
68 \\
67 \\
66\end{array}$ & $\begin{array}{l}65 \\
-- \\
-- \\
64 \\
66\end{array}$ & $\begin{array}{l}51 \\
54 \\
62 \\
58 \\
57\end{array}$ & $\begin{array}{l}62 \\
62 \\
63 \\
61 \\
61\end{array}$ & $\begin{array}{l}60 \\
61 \\
59 \\
-- \\
54\end{array}$ & $\begin{array}{l}65 \\
66 \\
70 \\
73 \\
74\end{array}$ & $\begin{array}{l}-- \\
-- \\
-- \\
--\end{array}$ & $\begin{array}{l}82 \\
83 \\
84 \\
80 \\
79\end{array}$ & $\begin{array}{l}83 \\
82 \\
84 \\
82 \\
84\end{array}$ & $\begin{array}{l}84 \\
83 \\
85 \\
86 \\
86\end{array}$ & $\begin{array}{l}84 \\
85 \\
84 \\
82 \\
81\end{array}$ \\
\hline $\begin{array}{r}6 \\
7 \\
8 \\
9 \\
10\end{array}$ & $\begin{array}{l}74 \\
70 \\
70 \\
-- \\
74\end{array}$ & $\begin{array}{l}65 \\
66 \\
62 \\
59 \\
59\end{array}$ & $\begin{array}{l}63 \\
58 \\
62 \\
54 \\
56\end{array}$ & $\begin{array}{l}56 \\
54 \\
56 \\
58 \\
57\end{array}$ & $\begin{array}{l}62 \\
-- \\
59 \\
56 \\
62\end{array}$ & $\begin{array}{l}53 \\
58 \\
59 \\
60 \\
62\end{array}$ & $\begin{array}{l}75 \\
-- \\
76 \\
-- \\
73\end{array}$ & $\begin{array}{l}-- \\
-- \\
-- \\
--\end{array}$ & $\begin{array}{l}82 \\
82 \\
83 \\
89 \\
83\end{array}$ & $\begin{array}{l}85 \\
85 \\
86 \\
85 \\
85\end{array}$ & $\begin{array}{l}85 \\
86 \\
84 \\
84 \\
86\end{array}$ & $\begin{array}{l}80 \\
84 \\
83 \\
83 \\
84\end{array}$ \\
\hline $\begin{array}{l}11 \\
12 \\
13 \\
14 \\
15\end{array}$ & $\begin{array}{l}72 \\
73 \\
73 \\
72 \\
74\end{array}$ & $\begin{array}{l}56 \\
58 \\
64 \\
68 \\
62\end{array}$ & $\begin{array}{l}-\overline{52} \\
-\overline{55} \\
56\end{array}$ & $\begin{array}{l}\mathbf{5 0} \\
\mathbf{5 2} \\
\mathbf{5 1} \\
\mathbf{5 6} \\
\mathbf{6 1}\end{array}$ & $\begin{array}{l}63 \\
58 \\
58 \\
62 \\
65\end{array}$ & $\begin{array}{l}66 \\
70 \\
68 \\
-- \\
58\end{array}$ & $\begin{array}{l}75 \\
74 \\
74 \\
76 \\
76\end{array}$ & $\begin{array}{l}-- \\
-- \\
-- \\
--\end{array}$ & $\begin{array}{l}84 \\
84 \\
83 \\
85 \\
83\end{array}$ & $\begin{array}{l}84 \\
86 \\
86 \\
86 \\
85\end{array}$ & $\begin{array}{l}86 \\
87 \\
86 \\
87 \\
87\end{array}$ & $\begin{array}{l}82 \\
80 \\
80 \\
82 \\
83\end{array}$ \\
\hline $\begin{array}{l}16 \\
17 \\
18 \\
19 \\
20\end{array}$ & $\begin{array}{l}72 \\
73 \\
74 \\
75 \\
75\end{array}$ & $\begin{array}{l}64 \\
-- \\
-- \\
69 \\
66\end{array}$ & $\begin{array}{l}54 \\
54 \\
55 \\
53 \\
--\end{array}$ & $\begin{array}{c}57 \\
- \\
57 \\
-- \\
61\end{array}$ & $\begin{array}{l}65 \\
63 \\
63 \\
66 \\
63\end{array}$ & $\begin{array}{l}59 \\
59 \\
62 \\
67 \\
65\end{array}$ & $\begin{array}{l}72 \\
69 \\
72 \\
71 \\
73\end{array}$ & $\begin{array}{l}-- \\
-- \\
-- \\
--\end{array}$ & $\begin{array}{l}-- \\
84 \\
83 \\
83 \\
84\end{array}$ & $\begin{array}{l}86 \\
85 \\
86 \\
86 \\
85\end{array}$ & $\begin{array}{l}86 \\
85 \\
86 \\
85 \\
86\end{array}$ & $\begin{array}{l}80 \\
83 \\
82 \\
84 \\
84\end{array}$ \\
\hline $\begin{array}{l}21 \\
22 \\
23 \\
24 \\
25\end{array}$ & $\begin{array}{l}76 \\
76 \\
-- \\
- \\
73\end{array}$ & $\begin{array}{l}75 \\
63 \\
60 \\
62 \\
58\end{array}$ & $\begin{array}{l}55 \\
55 \\
-- \\
44 \\
46\end{array}$ & $\begin{array}{l}56 \\
51 \\
54 \\
57 \\
59\end{array}$ & $\begin{array}{l}61 \\
62 \\
64 \\
62 \\
60\end{array}$ & $\begin{array}{l}67 \\
68 \\
69 \\
63 \\
70\end{array}$ & $\begin{array}{l}74 \\
-- \\
74 \\
75 \\
76\end{array}$ & $\begin{array}{l}79 \\
78 \\
78 \\
75 \\
76\end{array}$ & $\begin{array}{l}84 \\
83 \\
82 \\
82 \\
84\end{array}$ & $\begin{array}{l}84 \\
84 \\
-- \\
86 \\
86\end{array}$ & $\begin{array}{l}85 \\
85 \\
86 \\
84 \\
83\end{array}$ & $\begin{array}{l}83 \\
80 \\
78 \\
76 \\
78\end{array}$ \\
\hline $\begin{array}{l}26 \\
27 \\
28 \\
29 \\
30 \\
31\end{array}$ & $\begin{array}{l}73 \\
69 \\
68 \\
-- \\
67 \\
-- \\
\end{array}$ & $\begin{array}{l}57 \\
59 \\
62 \\
62 \\
64 \\
-- \\
\end{array}$ & $\begin{array}{l}-- \\
50 \\
-- \\
50 \\
50 \\
50\end{array}$ & $\begin{array}{l}64 \\
63 \\
60 \\
60 \\
63 \\
64 \\
\end{array}$ & $\begin{array}{l}63 \\
67 \\
61 \\
-- \\
-- \\
-- \\
\end{array}$ & $\begin{array}{l}68 \\
67 \\
70 \\
72 \\
74 \\
74 \\
\end{array}$ & $\begin{array}{l}76 \\
76 \\
72 \\
77 \\
78 \\
--\end{array}$ & $\begin{array}{l}77 \\
78 \\
79 \\
80 \\
82 \\
80 \\
\end{array}$ & $\begin{array}{l}82 \\
83 \\
83 \\
84 \\
84 \\
--\end{array}$ & $\begin{array}{l}86 \\
86 \\
86 \\
87 \\
85 \\
86 \\
\end{array}$ & $\begin{array}{l}-- \\
85 \\
85 \\
82 \\
83 \\
82 \\
\end{array}$ & $\begin{array}{l}80 \\
80 \\
82 \\
81 \\
83 \\
-- \\
\end{array}$ \\
\hline $\begin{array}{c}\text { Aver- } \\
\text { age }\end{array}$ & -- & 63 & $=$ & 57 & 62 & 64 & 73 & - & 83 & 85 & 85 & 82 \\
\hline
\end{tabular}




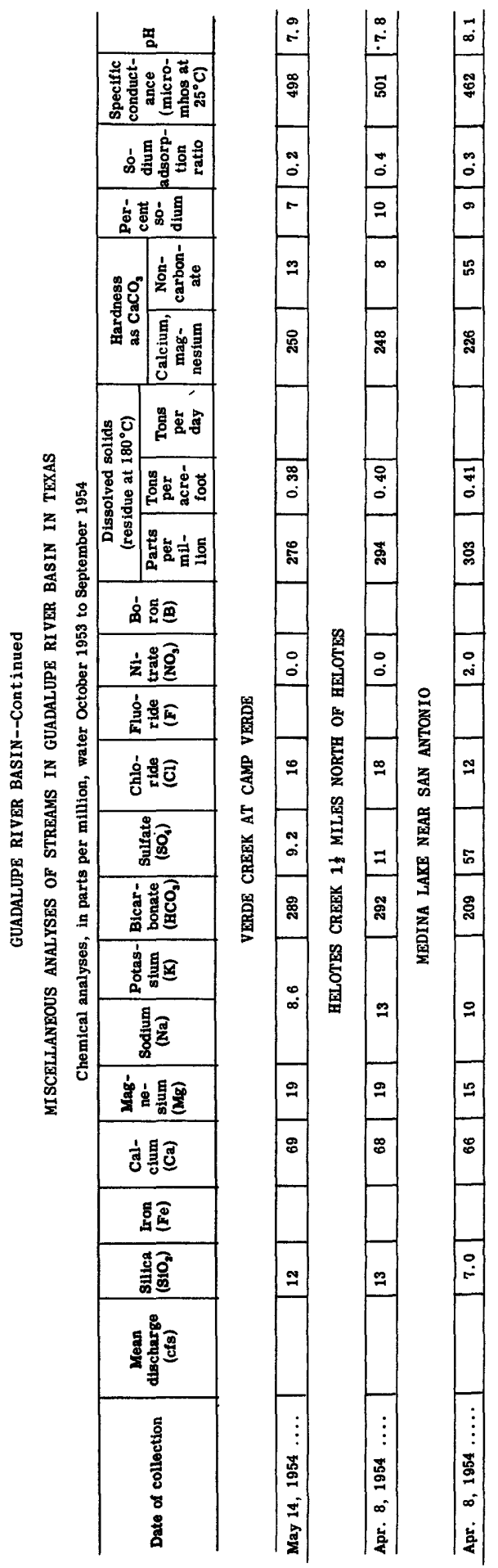




\begin{tabular}{|c|c|c|c|c|c|}
\hline 폴 & 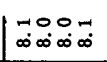 & 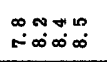 & 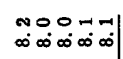 & & \\
\hline 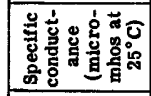 & 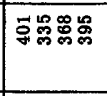 & 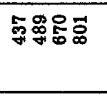 & 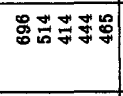 & ज్ & \\
\hline 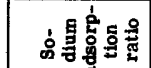 & 궆ำ & 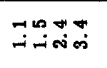 & 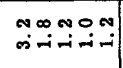 & $\Rightarrow$ & \\
\hline 离葶宫意 & 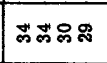 & 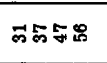 & 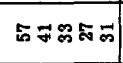 & - & \\
\hline 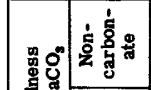 & 0000 & 0000 & 00000 & 0 & \\
\hline 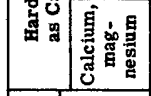 & జ్ & 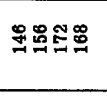 & 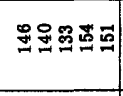 & 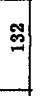 & \\
\hline 을 & †휴요요 & 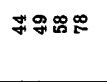 & 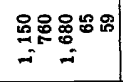 & of & \\
\hline 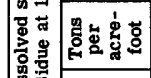 & 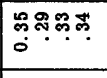 & 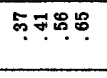 & 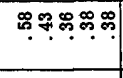 & . & \\
\hline 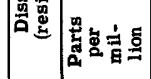 & 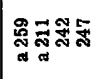 & 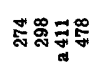 & 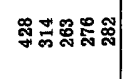 & ڤั & \\
\hline 奋宫鱼 & 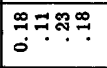 & ำลำ & Эิ & : ํำ & \\
\hline 完量苞 & : & 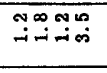 & 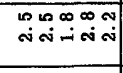 & ㅇ. & \\
\hline 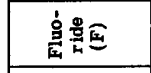 & 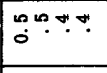 & פִ & 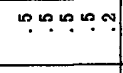 & :. & \\
\hline ㅎํㅇㅎㅠ & ( & నณ๊ః & 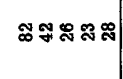 & के & \\
\hline 范 & 잃 & 영용ㅇㅇㅇㅛ & ำ ำสำ & ลี & \\
\hline 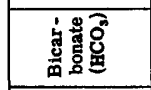 & 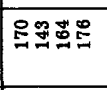 & 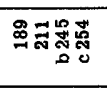 & 엻ำ & $\stackrel{\infty}{=}$ & \\
\hline 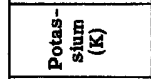 & 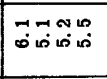 & 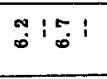 & 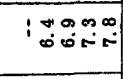 & : & \\
\hline 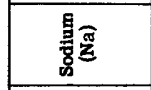 & ก็ำ & 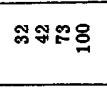 & ฌఖ్లజ జ & $\infty$ & \\
\hline 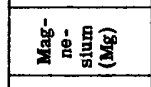 & 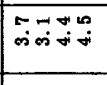 & F⿻ำ & 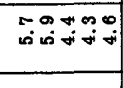 & 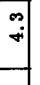 & क्रेंड \\
\hline 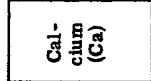 & 舟怘节与 & เที & 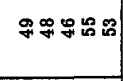 & का & \\
\hline 害高 & & & & & \\
\hline 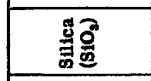 & 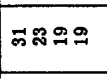 & 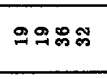 & จณ & $\approx$ & \\
\hline 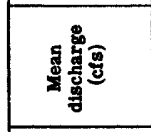 & 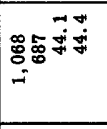 & 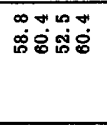 & 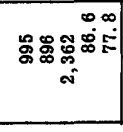 & : & 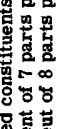 \\
\hline 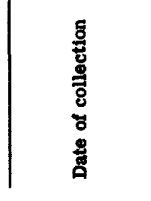 & 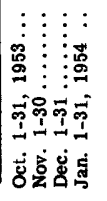 & 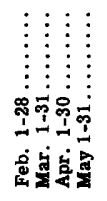 & 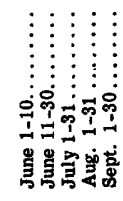 & : & \\
\hline
\end{tabular}


NUECES RIVER BASIN -Cont inued

NUECES RIVER NEAR MATHIS, TEX.--Cont inued

Temperature $\left({ }^{\circ} \mathrm{F}\right)$ of water, water year October 1953 to September 1954

\begin{tabular}{|c|c|c|c|c|c|c|c|c|c|c|c|c|}
\hline Day & Oct. & Nov. & Dec. & Jan. & Feb. & Mar. & Apr. & May & June & July & Aug. & Sept. \\
\hline $\begin{array}{l}1 \\
2 \\
3 \\
4 \\
5\end{array}$ & $\begin{array}{l}80 \\
82 \\
-2 \\
81 \\
78\end{array}$ & $\begin{array}{l}67 \\
68 \\
-\overline{69} \\
69\end{array}$ & $\begin{array}{l}\overline{66} \\
66 \\
67 \\
66\end{array}$ & $\begin{array}{l}-- \\
-- \\
55 \\
60 \\
--\end{array}$ & $\begin{array}{l}63 \\
63 \\
64 \\
65 \\
65\end{array}$ & $\begin{array}{l}59 \\
60 \\
55 \\
56 \\
53\end{array}$ & $\begin{array}{l}68 \\
69 \\
71 \\
73 \\
74\end{array}$ & $\begin{array}{l}78 \\
73 \\
70 \\
68 \\
69\end{array}$ & $\begin{array}{l}79 \\
79 \\
79 \\
78 \\
78\end{array}$ & $\begin{array}{l}82 \\
83 \\
83 \\
83 \\
83\end{array}$ & $\begin{array}{l}83 \\
83 \\
82 \\
81 \\
83\end{array}$ & $\begin{array}{l}82 \\
83 \\
83 \\
82 \\
82\end{array}$ \\
\hline $\begin{array}{r}6 \\
7 \\
8 \\
9 \\
10\end{array}$ & $\begin{array}{l}76 \\
76 \\
75 \\
-- \\
76\end{array}$ & $\begin{array}{l}68 \\
68 \\
62 \\
61 \\
--\end{array}$ & $\begin{array}{l}66 \\
62 \\
-- \\
62 \\
60\end{array}$ & $\begin{array}{l}54 \\
57 \\
57 \\
57 \\
57\end{array}$ & $\begin{array}{l}65 \\
62 \\
60 \\
60 \\
61\end{array}$ & $\begin{array}{l}56 \\
57 \\
57 \\
60 \\
60\end{array}$ & $\begin{array}{l}75 \\
76 \\
78 \\
77 \\
75\end{array}$ & $\begin{array}{l}70 \\
70 \\
72 \\
72 \\
72\end{array}$ & $\begin{array}{l}78 \\
78 \\
78 \\
78 \\
78\end{array}$ & $\begin{array}{l}83 \\
84 \\
84 \\
84 \\
84\end{array}$ & $\begin{array}{l}83 \\
84 \\
84 \\
84 \\
84\end{array}$ & $\begin{array}{l}82 \\
83 \\
82 \\
83 \\
83\end{array}$ \\
\hline $\begin{array}{l}11 \\
12 \\
13 \\
14 \\
15\end{array}$ & $\begin{array}{l}74 \\
74 \\
- \\
76 \\
75\end{array}$ & $\begin{array}{l}66 \\
65 \\
66 \\
62 \\
65\end{array}$ & $\begin{array}{c}60 \\
-- \\
-- \\
46 \\
--\end{array}$ & $\begin{array}{l}56 \\
52 \\
53 \\
55 \\
58\end{array}$ & $\begin{array}{l}62 \\
62 \\
63 \\
64 \\
66\end{array}$ & $\begin{array}{l}63 \\
64 \\
61 \\
60 \\
59\end{array}$ & $\begin{array}{l}75 \\
76 \\
76 \\
76 \\
75\end{array}$ & $\begin{array}{l}74 \\
76 \\
76 \\
75 \\
76\end{array}$ & $\begin{array}{l}79 \\
78 \\
78 \\
78 \\
78\end{array}$ & $\begin{array}{l}84 \\
84 \\
84 \\
84 \\
83\end{array}$ & $\begin{array}{l}64 \\
84 \\
84 \\
84 \\
84\end{array}$ & $\begin{array}{l}82 \\
82 \\
82 \\
82 \\
82\end{array}$ \\
\hline $\begin{array}{l}16 \\
17 \\
18 \\
19 \\
20\end{array}$ & $\begin{array}{l}75 \\
75 \\
76 \\
-- \\
76\end{array}$ & $\begin{array}{l}64 \\
-5 \\
65 \\
67 \\
65\end{array}$ & $\begin{array}{l}56 \\
57 \\
55 \\
55 \\
--\end{array}$ & $\begin{array}{l}58 \\
58 \\
58 \\
64 \\
63\end{array}$ & $\begin{array}{l}64 \\
64 \\
64 \\
67 \\
66\end{array}$ & $\begin{array}{l}59 \\
59 \\
63 \\
63 \\
65\end{array}$ & $\begin{array}{l}74 \\
74 \\
74 \\
74 \\
75\end{array}$ & $\begin{array}{l}77 \\
77 \\
78 \\
78 \\
78\end{array}$ & $\begin{array}{l}79 \\
80 \\
80 \\
81 \\
82\end{array}$ & $\begin{array}{l}83 \\
83 \\
84 \\
84 \\
84\end{array}$ & $\begin{array}{l}64 \\
84 \\
83 \\
83 \\
83\end{array}$ & $\begin{array}{l}82 \\
82 \\
82 \\
82 \\
83\end{array}$ \\
\hline $\begin{array}{l}21 \\
22 \\
23 \\
24 \\
25\end{array}$ & $\begin{array}{l}77 \\
78 \\
77 \\
80 \\
77\end{array}$ & $\begin{array}{l}66 \\
64 \\
66 \\
\overline{64}\end{array}$ & $\begin{array}{l}56 \\
-- \\
46 \\
-- \\
50\end{array}$ & $\begin{array}{l}58 \\
54 \\
56 \\
57 \\
60\end{array}$ & $\begin{array}{l}63 \\
63 \\
66 \\
62 \\
65\end{array}$ & $\begin{array}{l}66 \\
67 \\
68 \\
70 \\
70\end{array}$ & $\begin{array}{l}77 \\
78 \\
78 \\
78 \\
78\end{array}$ & $\begin{array}{l}78 \\
78 \\
77 \\
78 \\
78\end{array}$ & $\begin{array}{l}82 \\
83 \\
83 \\
84 \\
82\end{array}$ & $\begin{array}{l}85 \\
84 \\
84 \\
84 \\
84\end{array}$ & $\begin{array}{l}83 \\
83 \\
83 \\
83 \\
83\end{array}$ & $\begin{array}{l}83 \\
81 \\
81 \\
81 \\
82\end{array}$ \\
\hline $\begin{array}{l}26 \\
27 \\
28 \\
29 \\
30 \\
31\end{array}$ & $\begin{array}{l}-- \\
-\overline{71} \\
72 \\
71 \\
69\end{array}$ & $\begin{array}{l}65 \\
-- \\
65 \\
66 \\
65 \\
--\end{array}$ & $\begin{array}{l}50 \\
-- \\
50 \\
-- \\
49 \\
--\end{array}$ & $\begin{array}{l}61 \\
62 \\
62 \\
62 \\
62 \\
62\end{array}$ & $\begin{array}{l}68 \\
67 \\
66 \\
-- \\
-- \\
--\end{array}$ & $\begin{array}{l}69 \\
72 \\
74 \\
79 \\
79 \\
78\end{array}$ & $\begin{array}{l}78 \\
78 \\
77 \\
77 \\
77 \\
--\end{array}$ & $\begin{array}{l}76 \\
78 \\
78 \\
78 \\
78 \\
79\end{array}$ & $\begin{array}{l}80 \\
81 \\
82 \\
81 \\
82 \\
--\end{array}$ & $\begin{array}{l}84 \\
84 \\
84 \\
84 \\
85 \\
84\end{array}$ & $\begin{array}{l}83 \\
83 \\
83 \\
83 \\
84 \\
83\end{array}$ & $\begin{array}{l}82 \\
82 \\
82 \\
82 \\
81 \\
--\end{array}$ \\
\hline $\begin{array}{c}\text { Aver- } \\
\text { age }\end{array}$ & 76 & 66 & -- & 58 & 64 & 64 & 75 & 75 & 80 & 84 & 83 & 82 \\
\hline
\end{tabular}




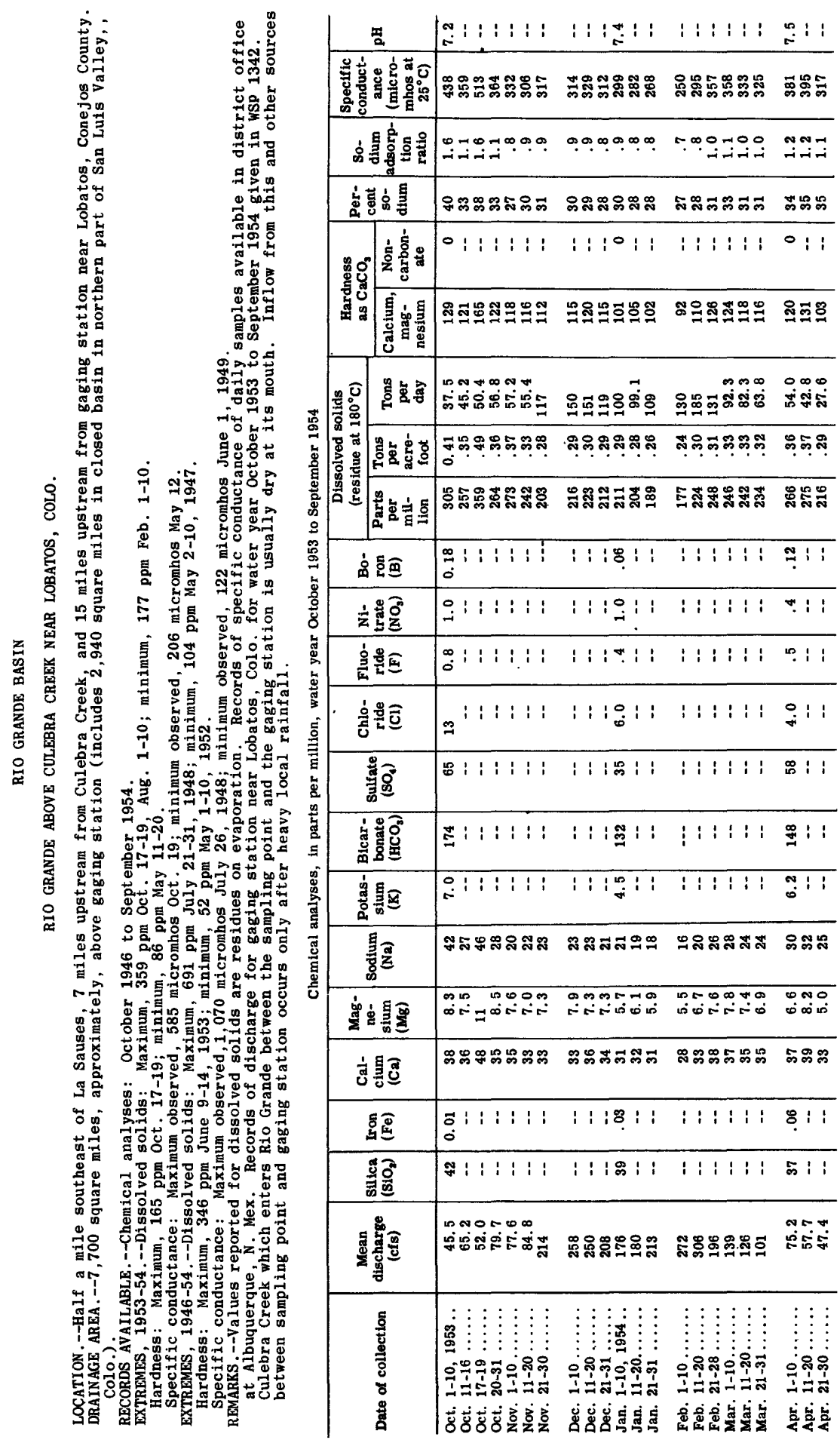




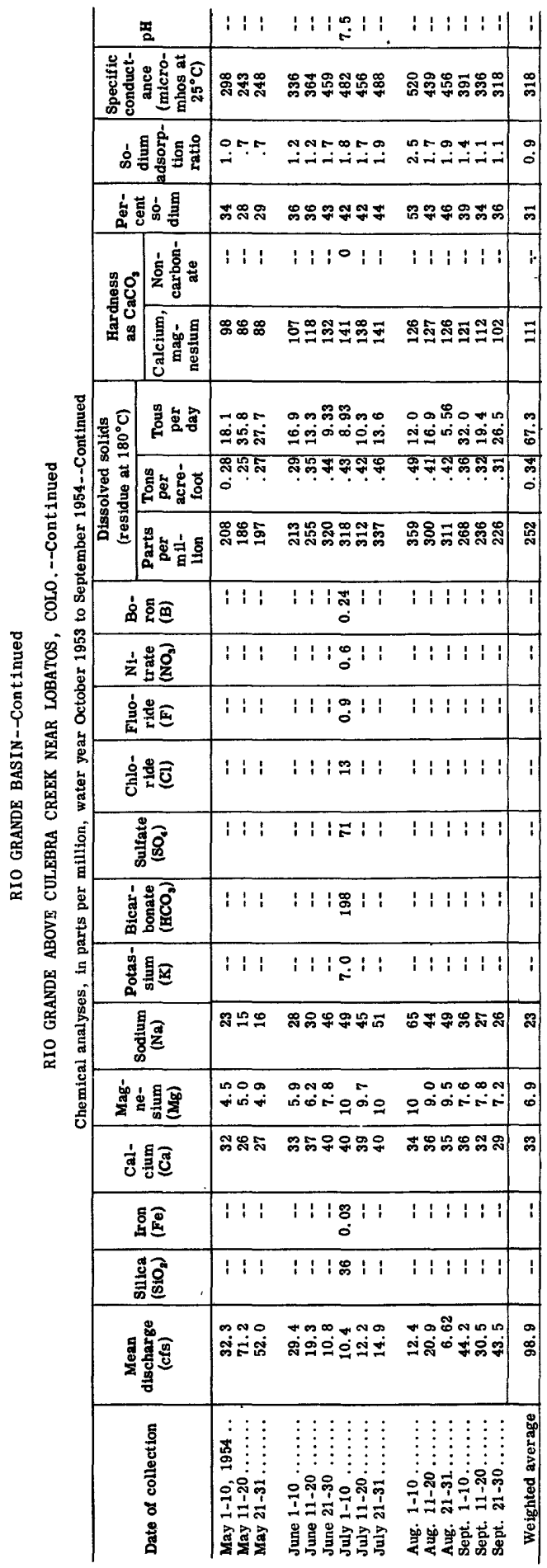




\section{RIO GRANDE BASIN--Continued}

RIO GRANDE AT EMBUDO, N. MEX.

LOCATION. --At gaging station a quarter of a mile downstream from bridge at Embudo, Rio Arriba County and $2 \frac{1}{2}$ miles downstream from Embudo Creek.

DRAINAGE AREA.--10,400 square miles, approximately (includes 2,940 square miles in closed basin in northern part of San Luis Valley, Colo.).

RECORDS AVAILABLE. - Water temperatures: October 1948 to September 1954

Sediment records: January 1948 to September 1954

EXTREMES, 1953-54.--Water temperatures: Maximum observed, $75^{\circ} \mathrm{F}$ June 28 , July 2 ; minimum, freezing point on several days during December and January.

Sediment concentrations: Maximum daily, 7,270 ppm Aug. 7; minimum daily, 4 ppm June 4. Sediment loads: Maximum daily, 18,100 tons Aug. 7; minimum daily, 4 tons June 4 .

EXTREMES, 1948-54.--Water temperatures: Maximum observed, $78^{\circ} \mathrm{F}$ Aug. 4, 1953 ; minimum, freezing point on many days during winter months.

Sediment concentrations: Maximum daily, 10,200 ppm Aug. 5, 1948; minimum daily, 4 ppm June 4,1954 .

Sediment loads: Maximum daily, 51,000 tons May 25, 1948; minimum daily, 4 tons June 4,1954 .

REMARKS.--Maximum observed sediment concentration during water year 40,600 ppm Aug. 7 . Records of discharge for water year October 1953 to September 1954 given in WSP 1342 Stage-discharge relation affected by ice Dec. 8-12.

Temperature $\left({ }^{\circ} \mathrm{F}\right)$ of water, water year October 1953 to September 1954 /Once-daily measurement generally taken after $6 \mathrm{p} . \mathrm{m.} .7$

\begin{tabular}{|c|c|c|c|c|c|c|c|c|c|c|c|c|}
\hline Day & Oct. & Nov. & Dec. & Jan. & Feb. & Mar. & Apr. & May & June & July & Aug. & Sept. \\
\hline $\begin{array}{l}1 \\
2 \\
3 \\
4 \\
5\end{array}$ & $\begin{array}{l}58 \\
-- \\
-- \\
-- \\
--\end{array}$ & $\begin{array}{l}52 \\
52 \\
52 \\
52 \\
--\end{array}$ & $\begin{array}{r}37 \\
36 \\
34 \\
\mathbf{2} 34 \\
34\end{array}$ & $\begin{array}{l}33 \\
34 \\
35 \\
33 \\
33\end{array}$ & $\begin{array}{l}41 \\
39 \\
40 \\
37 \\
43\end{array}$ & $\begin{array}{l}42 \\
42 \\
40 \\
42 \\
45\end{array}$ & $\begin{array}{r}\text { a } 50 \\
\text { a } 48 \\
-- \\
\text { a } 47 \\
--\end{array}$ & $\begin{array}{r}\text { a } 50 \\
\text { a } 49 \\
-- \\
-- \\
--\end{array}$ & $\begin{array}{r}-- \\
-- \\
\text { b } 68 \\
--\end{array}$ & $\begin{array}{r}\text { a } 68 \\
75 \\
\text { a } 72 \\
\text { a } 67 \\
\text { a } 68\end{array}$ & $\begin{array}{l}-- \\
-- \\
\overline{-} \\
\text { a } 71\end{array}$ & $\begin{array}{l}\text { a } 71 \\
\text { a } 73 \\
\text { a } 70 \\
\text { a } 72 \\
\text { a } 70\end{array}$ \\
\hline $\begin{array}{r}6 \\
7 \\
8 \\
9 \\
10\end{array}$ & $\begin{array}{l}59 \\
58 \\
58 \\
58 \\
58\end{array}$ & $\begin{array}{c}\text { b } 49 \\
-- \\
-- \\
--\end{array}$ & $\begin{array}{l}32 \\
33 \\
32 \\
-- \\
--\end{array}$ & $\begin{array}{l}32 \\
33 \\
33 \\
34 \\
33\end{array}$ & $\begin{array}{l}42 \\
45 \\
-- \\
-- \\
--\end{array}$ & $\begin{array}{l}44 \\
44 \\
45 \\
45 \\
47\end{array}$ & $\begin{array}{l}-- \\
-- \\
\text { a } 51 \\
\text { a } 49\end{array}$ & $\begin{array}{r}\text { a } 55 \\
-- \\
-\bar{a} \\
\text { a } 51 \\
\text { a } 52\end{array}$ & $\begin{array}{l}-- \\
-- \\
-- \\
\text { b } 67\end{array}$ & $\begin{array}{l}\text { a } 68 \\
\text { a } 69 \\
\text { a } 70 \\
\text { a } 70 \\
\text { a } 72\end{array}$ & $\begin{array}{l}\text { a } 70 \\
\text { a } 73 \\
\text { a } 68 \\
\text { a } 69 \\
\text { a } 68\end{array}$ & $\begin{array}{r}\text { a } 69 \\
- \\
\text { a } 69 \\
\text { b } 68 \\
--\end{array}$ \\
\hline $\begin{array}{l}11 \\
12 \\
13 \\
14 \\
15\end{array}$ & $\begin{array}{l}\mathbf{5 8} \\
\mathbf{5 7} \\
\mathbf{5 5} \\
\mathbf{5 4} \\
\mathbf{5 5}\end{array}$ & $\begin{array}{r}-- \\
\overline{51} \\
\overline{58}\end{array}$ & $\begin{array}{l}33 \\
32 \\
34 \\
34 \\
35\end{array}$ & $\begin{array}{l}33 \\
32 \\
32 \\
33 \\
33\end{array}$ & $\begin{array}{l}-- \\
-- \\
-- \\
-- \\
--\end{array}$ & $\begin{array}{l}42 \\
45 \\
44 \\
44 \\
43\end{array}$ & $\begin{array}{r}55 \\
\text { a } 49 \\
\text { a } 48 \\
\text { a } 49 \\
\text { a } 52\end{array}$ & $\begin{array}{l}\text { a } 55 \\
\text { a } 54 \\
\text { a } 53 \\
\text { a } 54 \\
\text { a } 56\end{array}$ & $\begin{array}{l}-- \\
-- \\
-- \\
-- \\
--\end{array}$ & $\begin{array}{l}\text { b71 } \\
\text { a } 68 \\
\text { a } 73 \\
\text { a } 74 \\
\text { a } 70\end{array}$ & $\begin{array}{r}\text { a } 70 \\
\text { a } 69 \\
\text { a } 69 \\
-- \\
--\end{array}$ & $\begin{array}{l}-- \\
-- \\
-- \\
--\end{array}$ \\
\hline $\begin{array}{l}16 \\
17 \\
18 \\
19 \\
20\end{array}$ & $\begin{array}{l}54 \\
-- \\
-- \\
-- \\
52\end{array}$ & $\begin{array}{l}47 \\
-- \\
-- \\
-- \\
--\end{array}$ & $\begin{array}{l}34 \\
34 \\
35 \\
35 \\
36\end{array}$ & $\begin{array}{l}34 \\
33 \\
33 \\
34 \\
33\end{array}$ & $\begin{array}{r}-- \\
\text { b42 } \\
-- \\
-- \\
--\end{array}$ & $\begin{array}{l}44 \\
-- \\
-- \\
43 \\
43\end{array}$ & $\begin{array}{l}\text { a } 55 \\
\text { a } 57 \\
\text { a } 53 \\
\text { a } 50 \\
\text { a } 52\end{array}$ & $\begin{array}{r}\text { a } 54 \\
57 \\
\text { a } 54 \\
\text { a } 56 \\
\text { a } 56\end{array}$ & $\begin{array}{r}-- \\
-- \\
\text { b } 73 \\
\text { a } 69 \\
\text { a } 68\end{array}$ & $\begin{array}{r}\text { a } 68 \\
-- \\
-- \\
\bar{a} 69\end{array}$ & $\begin{array}{r}a 63 \\
a 68 \\
\overline{-} \\
a 67 \\
a 64\end{array}$ & $\begin{array}{r}-- \\
\text { b70 } \\
\text { b } 63 \\
\text { b } 66 \\
64\end{array}$ \\
\hline $\begin{array}{l}21 \\
22 \\
23 \\
24 \\
25\end{array}$ & $\begin{array}{l}52 \\
52 \\
-- \\
-- \\
49\end{array}$ & $\begin{array}{l}38 \\
36 \\
-- \\
-- \\
--\end{array}$ & $\begin{array}{l}\mathbf{3 3} \\
\mathbf{3 2} \\
\mathbf{3 3} \\
\mathbf{3 3} \\
\mathbf{3 4}\end{array}$ & $\begin{array}{l}33 \\
32 \\
32 \\
33 \\
34\end{array}$ & $\begin{array}{l}45 \\
46 \\
46 \\
46 \\
46\end{array}$ & 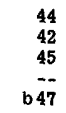 & $\begin{array}{r}54 \\
\text { a } 52 \\
\text { a } 54 \\
\text { a } 56 \\
\text { a } 53\end{array}$ & $\begin{array}{r}\text { a } 56 \\
\text { a } 55 \\
-- \\
-- \\
--\end{array}$ & $\begin{array}{l}\text { a } 70 \\
\text { a } 67 \\
\text { a } 65 \\
\text { a } 67 \\
\text { a } 67\end{array}$ & $\begin{array}{r}\text { a } 70 \\
68 \\
\text { a } 72 \\
-- \\
--\end{array}$ & $\begin{array}{r}\text { a } 63 \\
65 \\
\text { a } 64 \\
\text { b } 65 \\
--\end{array}$ & $\begin{array}{r}\text { b } 64 \\
\text { a } 56 \\
- \\
-- \\
\text { b } 65\end{array}$ \\
\hline $\begin{array}{l}26 \\
27 \\
28 \\
29 \\
30 \\
31\end{array}$ & $\begin{array}{l}48 \\
48 \\
49 \\
49 \\
-- \\
52\end{array}$ & $\begin{array}{r}\text { b } 45 \\
43 \\
45 \\
42 \\
--\end{array}$ & $\begin{array}{r}\mathbf{3 4} \\
\mathbf{3 3} \\
\mathbf{3 2} \\
\mathbf{3 2} \\
\mathbf{3 2} \\
\text { b } \mathbf{3 5}\end{array}$ & $\begin{array}{l}36 \\
36 \\
38 \\
36 \\
37 \\
38\end{array}$ & $\begin{array}{l}45 \\
46 \\
44 \\
-- \\
-- \\
--\end{array}$ & $\begin{array}{r}49 \\
\text { b } 51 \\
51 \\
- \\
52\end{array}$ & $\begin{array}{r}\text { a } 54 \\
\text { a } 56 \\
\text { a } 52 \\
\text { a } 52 \\
\text { a } 51 \\
-\end{array}$ & $\begin{array}{l}-- \\
-- \\
-- \\
-- \\
--\end{array}$ & $\begin{array}{r}69 \\
-- \\
\text { a } 75 \\
\text { a } 65 \\
\text { a } 68 \\
--\end{array}$ & $\begin{array}{r}273 \\
-- \\
-- \\
-- \\
74 \\
--\end{array}$ & $\begin{array}{r}62 \\
\text { a } 70 \\
\text { a } 68 \\
\text { a } 70 \\
\text { a } 72 \\
\text { a } 71\end{array}$ & $\begin{array}{r}-- \\
\text { b } 64 \\
-- \\
--\end{array}$ \\
\hline $\begin{array}{c}\text { Aver- } \\
\text { age }\end{array}$ & -- & -. & 34 & 34 & - & 45 & 52 & -- & -- & - & - & $\cdots$ \\
\hline
\end{tabular}

a Measurement made before 11 a.m.

b Measurement between 11 a.m. and 6 p.m. 
RIO GRANDE BASIN--Continued

RIO GRANDE AT EMBUDO, N. MEX.--Continued

Suspended sediment, water year October 1953 to September 1954

\begin{tabular}{|c|c|c|c|c|c|c|c|c|c|}
\hline \multirow[b]{3}{*}{ Day } & \multicolumn{3}{|c|}{ October } & \multicolumn{3}{|c|}{ November } & \multicolumn{3}{|c|}{ December } \\
\hline & \multirow[b]{2}{*}{$\begin{array}{l}\text { Mean } \\
\text { dis- } \\
\text { charge } \\
\text { (cfs) }\end{array}$} & \multicolumn{2}{|c|}{ Suspended sediment } & \multirow[b]{2}{*}{$\begin{array}{l}\text { Mean } \\
\text { dis- } \\
\text { charge } \\
\text { (cfs) }\end{array}$} & \multicolumn{2}{|c|}{ Suspended sediment } & \multirow[b]{2}{*}{$\begin{array}{l}\text { Mean } \\
\text { dis- } \\
\text { charge } \\
\text { (cfs) }\end{array}$} & \multicolumn{2}{|c|}{ Suspended sediment } \\
\hline & & $\begin{array}{l}\text { Mean } \\
\text { concen- } \\
\text { tration } \\
\text { (ppm) } \\
\end{array}$ & $\begin{array}{l}\text { Tons } \\
\text { per } \\
\text { day }\end{array}$ & & $\begin{array}{c}\text { Mean } \\
\text { concen- } \\
\text { tration } \\
(\mathrm{ppm})\end{array}$ & $\begin{array}{l}\text { Tons } \\
\text { per } \\
\text { day }\end{array}$ & & $\begin{array}{c}\text { Mean } \\
\text { concen- } \\
\text { tration } \\
(\mathrm{ppm}) \\
\end{array}$ & $\begin{array}{l}\text { Tons } \\
\text { per } \\
\text { day }\end{array}$ \\
\hline $\begin{array}{l}1 \ldots \ldots \\
2 \ldots \ldots \\
3 . \ldots \ldots \\
4 \ldots \ldots \\
5 . \ldots \ldots\end{array}$ & $\begin{array}{l}205 \\
211 \\
214 \\
214 \\
217\end{array}$ & & & $\begin{array}{l}282 \\
279 \\
276 \\
272 \\
296\end{array}$ & $\begin{array}{r}20 \\
20 \\
31 \\
41 \\
448\end{array}$ & $\begin{array}{r}15 \\
15 \\
23 \\
30 \\
358\end{array}$ & $\begin{array}{l}525 \\
550 \\
587 \\
525 \\
475\end{array}$ & & \\
\hline $\begin{array}{r}6 \ldots \ldots \\
7 \ldots \ldots \\
8 \ldots \ldots \\
9 \ldots \ldots \\
10 \ldots \ldots\end{array}$ & $\begin{array}{l}220 \\
229 \\
229 \\
229 \\
229\end{array}$ & 35 & 21 & $\begin{array}{l}505 \\
335 \\
318 \\
310 \\
314\end{array}$ & $\begin{array}{r}2,320 \\
37 \\
46 \\
36 \\
24\end{array}$ & $\begin{array}{r}\mathbf{s} 3,840 \\
33 \\
39 \\
30 \\
20\end{array}$ & $\begin{array}{l}371 \\
355 \\
410 \\
420 \\
410\end{array}$ & 35 & 44 \\
\hline $\begin{array}{l}11 \ldots \ldots \\
12 . \ldots \ldots \\
13 . \ldots \\
14 . \ldots \\
15 . \ldots\end{array}$ & $\begin{array}{l}232 \\
235 \\
244 \\
250 \\
250\end{array}$ & $\begin{array}{l}\mathbf{3 8} \\
\mathbf{3 3} \\
\mathbf{5 6} \\
\mathbf{3 0} \\
\mathbf{2 3}\end{array}$ & $\begin{array}{l}24 \\
21 \\
37 \\
20 \\
16\end{array}$ & $\begin{array}{l}324 \\
321 \\
321 \\
321 \\
324\end{array}$ & & 21 & $\begin{array}{l}440 \\
420 \\
416 \\
470 \\
456\end{array}$ & & \\
\hline $\begin{array}{l}16 \ldots \ldots \\
17 \ldots \ldots \\
18 \ldots \ldots \\
19 \ldots \ldots \\
20 \ldots \ldots\end{array}$ & $\begin{array}{l}262 \\
259 \\
259 \\
259 \\
272\end{array}$ & $\begin{array}{r}30 \\
19 \\
20 \\
38 \\
145\end{array}$ & $\begin{array}{r}21 \\
13 \\
14 \\
27 \\
106\end{array}$ & $\begin{array}{l}324 \\
324 \\
332 \\
343 \\
343\end{array}$ & 24 & 21 & $\begin{array}{l}465 \\
480 \\
490 \\
490 \\
500\end{array}$ & 17 & 81 \\
\hline $\begin{array}{l}21 . \ldots \ldots \\
22 . \ldots \ldots \\
23 . \ldots \ldots \\
24 \ldots \ldots \\
25 . \ldots \ldots\end{array}$ & $\begin{array}{l}279 \\
279 \\
296 \\
380 \\
324\end{array}$ & $\begin{array}{r}120 \\
33 \\
56 \\
510 \\
250\end{array}$ & $\begin{array}{r}90 \\
25 \\
\text { a 45 } \\
523 \\
219\end{array}$ & $\begin{array}{l}321 \\
293 \\
324 \\
335 \\
367\end{array}$ & & & $\begin{array}{l}500 \\
490 \\
452 \\
442 \\
447\end{array}$ & & \\
\hline $\begin{array}{l}26 \ldots \ldots \\
27 . \ldots \ldots \\
28 . \ldots \ldots \\
29 . \ldots \ldots \\
30 \ldots \ldots \\
31 . \ldots \ldots\end{array}$ & $\begin{array}{l}304 \\
300 \\
296 \\
286 \\
286 \\
282 \\
\end{array}$ & $\begin{array}{l}\mathbf{8 0} \\
34 \\
28 \\
25 \\
50 \\
42 \\
\end{array}$ & $\begin{array}{l}66 \\
28 \\
22 \\
19 \\
39 \\
32 \\
\end{array}$ & $\begin{array}{r}393 \\
424 \\
460 \\
510 \\
515 \\
--- \\
\end{array}$ & 53 & 56 & $\begin{array}{l}447 \\
442 \\
424 \\
416 \\
416 \\
411 \\
\end{array}$ & 21 & 28 \\
\hline \multirow[t]{2}{*}{ Total. } & 8,031 & -- & 1,617 & 10,406 & $=$ & 5,173 & 14,142 & $=$ & 958 \\
\hline & \multicolumn{3}{|c|}{ January } & \multicolumn{3}{|c|}{ February } & \multicolumn{3}{|c|}{ March } \\
\hline $\begin{array}{c}1 \ldots \ldots \\
2 \ldots \ldots \\
3 \ldots \ldots \\
4 \ldots \ldots \\
5 \ldots \ldots \\
6 . \ldots \ldots \\
7 \ldots \ldots \\
8 \ldots \ldots \\
9 \ldots \ldots \\
10 . \ldots .\end{array}$ & $\begin{array}{l}393 \\
398 \\
402 \\
406 \\
406 \\
\\
411 \\
416 \\
429 \\
434 \\
442\end{array}$ & 14 & 16 & $\begin{array}{l}\mathbf{5 1 0} \\
\mathbf{5 1 0} \\
\mathbf{5 1 5} \\
\mathbf{5 2 0} \\
\mathbf{5 4 0} \\
\\
\mathbf{5 4 5} \\
\mathbf{5 4 0} \\
\mathbf{5 4 5} \\
\mathbf{5 5 0} \\
\mathbf{5 6 5}\end{array}$ & 23 & 33 & $\begin{array}{l}420 \\
393 \\
388 \\
335 \\
406 \\
\\
447 \\
406 \\
393 \\
388 \\
384\end{array}$ & 17 & 18 \\
\hline $\begin{array}{l}11 \ldots \ldots \\
12 \ldots \ldots \\
13 . \ldots \\
14 \ldots \ldots \\
15 . \ldots \ldots\end{array}$ & $\begin{array}{l}429 \\
438 \\
438 \\
447 \\
434\end{array}$ & & & $\begin{array}{l}576 \\
592 \\
609 \\
631 \\
604\end{array}$ & 26 & b 50 & $\begin{array}{l}388 \\
380 \\
363 \\
351 \\
332\end{array}$ & & \\
\hline $\begin{array}{l}16 \ldots \ldots \\
17 \ldots \ldots \\
18 \ldots \ldots \\
19 \ldots \ldots \\
20 \ldots \ldots\end{array}$ & $\begin{array}{l}438 \\
438 \\
438 \\
447 \\
452\end{array}$ & 12 & 14 & $\begin{array}{l}587 \\
582 \\
570 \\
565 \\
\mathbf{5 1 5}\end{array}$ & $\begin{array}{l}62 \\
23 \\
28 \\
26\end{array}$ & $\begin{array}{l}97 \\
35 \\
43 \\
36\end{array}$ & $\begin{array}{l}393 \\
375 \\
351 \\
332 \\
343\end{array}$ & 16 & 16 \\
\hline $\begin{array}{l}21 \ldots \ldots \\
22 . \ldots \ldots \\
23 . \ldots \ldots \\
24 \ldots \ldots \\
25 . \ldots \ldots\end{array}$ & $\begin{array}{l}465 \\
447 \\
442 \\
456 \\
465\end{array}$ & & & $\begin{array}{l}490 \\
510 \\
500 \\
500 \\
490\end{array}$ & 25 & 33 & $\begin{array}{l}347 \\
355 \\
460 \\
550 \\
480\end{array}$ & $\begin{array}{r}28 \\
27 \\
110 \\
150 \\
118\end{array}$ & $\begin{array}{r}26 \\
26 \\
137 \\
\mathrm{a} 220 \\
153\end{array}$ \\
\hline $\begin{array}{l}26 \ldots \ldots \\
27 . \ldots \ldots \\
28 . \ldots \ldots \\
29 . \ldots \ldots \\
30 \ldots \ldots \\
31 \ldots \ldots\end{array}$ & $\begin{array}{l}470 \\
470 \\
470 \\
480 \\
490 \\
505 \\
\end{array}$ & 18 & 23 & $\begin{array}{r}480 \\
456 \\
429 \\
-- \\
-- \\
- \\
\end{array}$ & $\begin{array}{l}-- \\
-- \\
-- \\
\end{array}$ & $\begin{array}{l}-- \\
-- \\
=-\end{array}$ & $\begin{array}{l}429 \\
420 \\
411 \\
411 \\
406 \\
398 \\
\end{array}$ & $\begin{array}{l}71 \\
38 \\
35 \\
25 \\
27 \\
23 \\
\end{array}$ & $\begin{array}{r}82 \\
43 \\
39 \\
28 \\
30 \\
25 \\
\end{array}$ \\
\hline Total. & 13,696 & -- & 553 & 15,026 & -- & 1,095 & 12,235 & $\cdots$ & 1,149 \\
\hline
\end{tabular}

8 Computed by subdividing day.

a Computed from estimated concentration graph.

b Computed from water-sediment discharge curve. 
RIO GRANDE BASIN--Cont inued

RIO GRANDE AT EMBUDO, N. MEX.--Continued

Suspended sediment, water year October 1953 to September 1954 --Continued

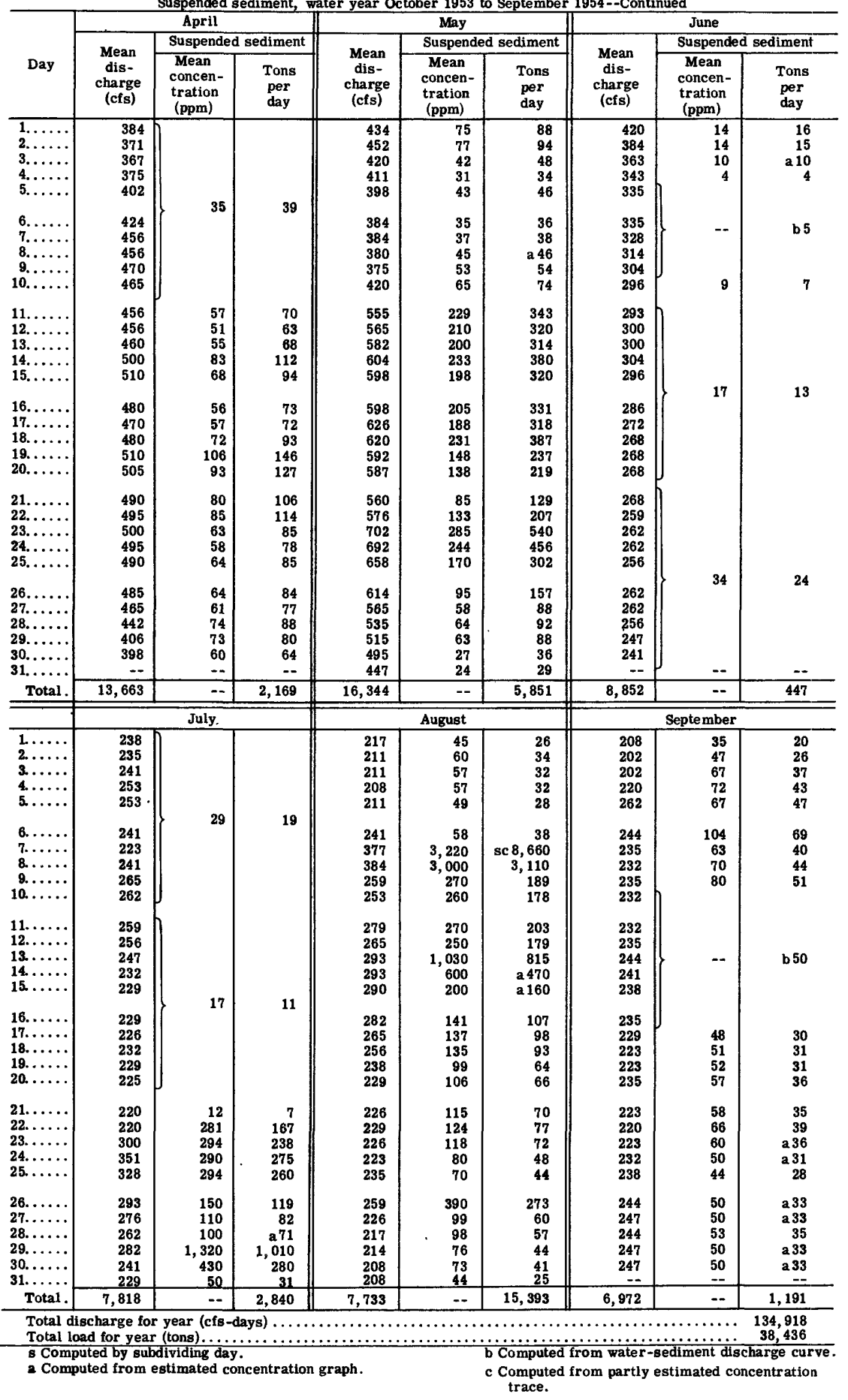




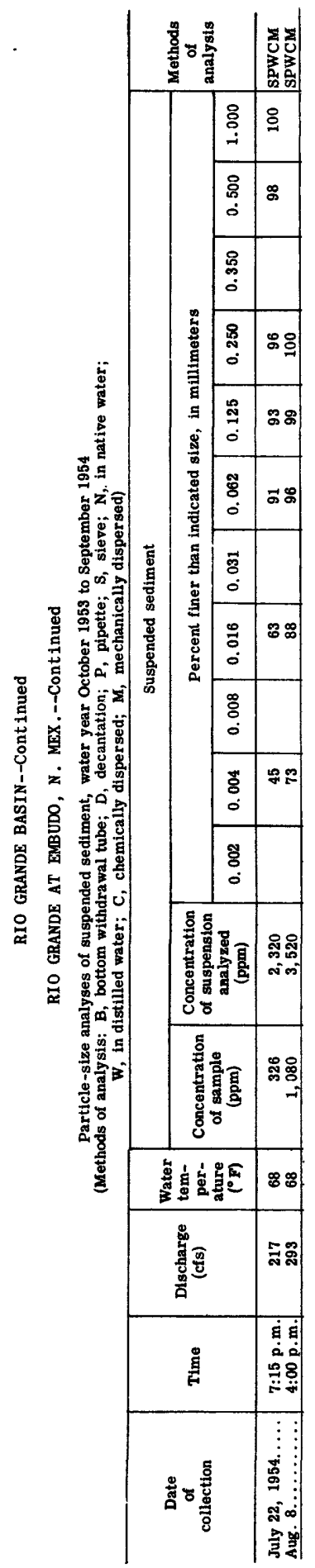


RIO GRANDE BASIN--Cont i nued

RIO CHAMA NEAR ABIQUIU, N. MEX.

LOCATION.--At gaging station at bridge on State Highway 96,13 miles upstream from El Rito Creek, 5 miles downstream from Abiquiu, Rio Arriba county, and 13.5 miles downstream from Abiquiu dam site.

DRAINAGE AREA - - 2,170 square miles, approximately

RECORDS AVAILABLE, --Sediment records: January 1948 to September 1954

EXTREMES, 1953-54,--Sediment concentrations: Maximum daily, 29,100 ppm Mar. 24; minimum daily, 11 ppm Jan. 2

Sediment loads: Maximum datly, 50,600 tons Sept. 13; minimum daily, less than 0.50 ton on many days.

EXTREMES, 1948-54,--Sediment concentrations: Maximum daily, 53,000 ppm July 30, 1953; minimum daily, 3 ppm Mar 30,1951

Sediment loads: Maximum daily, 113,000 tons July 28, 1952; minimum daily, less than 0.50 ton on many days.

REMARKS. --Maximum observed sediment concentration during water year, 53,900 ppm Sept. 4. Records of discharge for water year October 1953 to September 1954 given in WSp 1342 . Stage-discharge relation affected by ice Dec.4-16, 18-31, Jan. 1-6, 11-19, 23-28.

Suspended sediment, water year October 1953 to September 1954

\begin{tabular}{|c|c|c|c|c|c|c|c|c|c|}
\hline \multirow[b]{3}{*}{ Day } & \multicolumn{3}{|c|}{ October } & \multicolumn{3}{|c|}{ November } & \multicolumn{3}{|c|}{ December } \\
\hline & \multirow[b]{2}{*}{$\begin{array}{c}\text { Mean } \\
\text { dis- } \\
\text { charge } \\
\text { (cfs) }\end{array}$} & \multicolumn{2}{|c|}{ Suspended sediment } & \multirow[b]{2}{*}{$\begin{array}{c}\text { Mean } \\
\text { dis- } \\
\text { charge } \\
\text { (cfs) }\end{array}$} & \multicolumn{2}{|c|}{ Suspended sediment } & \multirow[b]{2}{*}{$\begin{array}{l}\text { Mean } \\
\text { dis- } \\
\text { charge } \\
\text { (cfs) }\end{array}$} & \multicolumn{2}{|c|}{ Suspended sediment } \\
\hline & & $\begin{array}{c}\text { Mean } \\
\text { concen- } \\
\text { tration } \\
(\text { ppm) }\end{array}$ & $\begin{array}{l}\text { Tons } \\
\text { per } \\
\text { day }\end{array}$ & & $\begin{array}{c}\text { Mean } \\
\text { concen- } \\
\text { tration } \\
\text { (ppm) }\end{array}$ & $\begin{array}{l}\text { Tons } \\
\text { per } \\
\text { day }\end{array}$ & & $\begin{array}{c}\text { Mean } \\
\text { concen- } \\
\text { tration } \\
\text { (ppm) }\end{array}$ & $\begin{array}{l}\text { Tons } \\
\text { per } \\
\text { day }\end{array}$ \\
\hline $\begin{array}{l}1 \ldots \ldots \\
2 \ldots \ldots \\
3 \ldots \ldots \\
4 \ldots \ldots \\
5 \ldots \ldots\end{array}$ & $\begin{array}{l}4.1 \\
5.0 \\
4.4 \\
4.1 \\
5.0\end{array}$ & & & $\begin{array}{l}44 \\
41 \\
42 \\
45 \\
54\end{array}$ & $\begin{array}{l}226 \\
209 \\
209 \\
198 \\
247\end{array}$ & $\begin{array}{l}27 \\
23 \\
24 \\
24 \\
36\end{array}$ & $\begin{array}{r}22 \\
21 \\
20 \\
8 \\
7\end{array}$ & $\begin{array}{r}130 \\
116 \\
96 \\
93 \\
87\end{array}$ & $\begin{array}{r}08 \\
7 \\
5 \\
2 \\
2\end{array}$ \\
\hline $\begin{array}{r}6 . \ldots \ldots \\
7 \ldots \ldots \\
8 . \ldots \ldots \\
9 . \ldots \ldots \\
10 . \ldots \ldots\end{array}$ & $\begin{array}{l}4.6 \\
5.3 \\
4.4 \\
4.6 \\
5.7\end{array}$ & 30 & (t) & $\begin{array}{r}100 \\
110 \\
90 \\
75 \\
60\end{array}$ & $\begin{array}{r}1,670 \\
1,690 \\
3,920 \\
1,920 \\
772\end{array}$ & $\begin{array}{l}451 \\
502 \\
953 \\
389 \\
125\end{array}$ & $\begin{array}{l}7 \\
7 \\
6 \\
6 \\
6\end{array}$ & $\begin{array}{l}71 \\
66 \\
87 \\
31 \\
41\end{array}$ & $\begin{array}{l}1 \\
1 \\
1 \\
1 \\
1\end{array}$ \\
\hline $\begin{array}{l}11 \ldots \ldots \\
12 . \ldots \ldots \\
13 . \ldots \ldots \\
14 . \ldots \ldots \\
15 \ldots \ldots\end{array}$ & $\begin{array}{r}5.7 \\
3.7 \\
8.5 \\
9.5 \\
16\end{array}$ & & & $\begin{array}{l}\mathbf{5 0} \\
\mathbf{5 0} \\
\mathbf{5 2} \\
\mathbf{5 3} \\
\mathbf{5 4}\end{array}$ & $\begin{array}{l}395 \\
453 \\
423 \\
270 \\
269\end{array}$ & $\begin{array}{l}53 \\
61 \\
59 \\
39 \\
39\end{array}$ & $\begin{array}{l}7 \\
8 \\
8 \\
8 \\
8\end{array}$ & $\begin{array}{l}28 \\
30 \\
28 \\
37 \\
87\end{array}$ & $\begin{array}{r}1 \\
\mathrm{a} 1 \\
1 \\
1 \\
2\end{array}$ \\
\hline $\begin{array}{l}16 . \ldots \ldots \\
17 . \ldots \ldots \\
18 \ldots \ldots \\
19 . \ldots \ldots \\
20 . \ldots \ldots\end{array}$ & $\begin{array}{l}22 \\
12 \\
16 \\
34 \\
45\end{array}$ & 296 & 36 & $\begin{array}{l}56 \\
60 \\
65 \\
70 \\
70\end{array}$ & $\begin{array}{l}215 \\
206 \\
326 \\
166 \\
159\end{array}$ & $\begin{array}{l}33 \\
33 \\
57 \\
31 \\
30\end{array}$ & $\begin{array}{r}9 \\
10 \\
11 \\
12 \\
10\end{array}$ & $\begin{array}{l}20 \\
26 \\
30 \\
31 \\
25\end{array}$ & (t) $\begin{array}{l} \\
\\
\\
\\
\\
1 \\
1 \\
1\end{array}$ \\
\hline $\begin{array}{l}21 . \ldots \ldots \\
22 . \ldots \ldots \\
23 . \ldots \ldots \\
24 . \ldots \ldots \\
25 . \ldots \ldots\end{array}$ & $\begin{array}{l}75 \\
90 \\
80 \\
70 \\
60\end{array}$ & $\begin{array}{r}800 \\
5,040 \\
6,160 \\
1,000 \\
2,820\end{array}$ & $\begin{array}{r}162 \\
1,220 \\
1,330 \\
189 \\
457\end{array}$ & $\begin{array}{l}55 \\
55 \\
62 \\
69 \\
57\end{array}$ & $\begin{array}{l}247 \\
182 \\
386 \\
215 \\
177\end{array}$ & $\begin{array}{l}37 \\
27 \\
65 \\
40 \\
27\end{array}$ & $\begin{array}{l}7 \\
7 \\
7 \\
8 \\
9\end{array}$ & $\begin{array}{l}55 \\
40 \\
30 \\
27 \\
19\end{array}$ & $\begin{array}{rr} & 1 \\
& 1 \\
& 1 \\
& 1\end{array}$ \\
\hline $\begin{array}{l}26 \ldots \ldots \\
27 . \ldots \ldots \\
28 \ldots \ldots \\
29 \ldots \ldots \\
30 \ldots \ldots \\
31 . \ldots \ldots\end{array}$ & $\begin{array}{l}60 \\
50 \\
45 \\
45 \\
45 \\
47 \\
\end{array}$ & $\begin{array}{r}1,810 \\
520 \\
263 \\
270 \\
304 \\
272 \\
\end{array}$ & $\begin{array}{r}293 \\
70 \\
32 \\
33 \\
37 \\
35 \\
\end{array}$ & $\begin{array}{l}71 \\
69 \\
69 \\
59 \\
28 \\
-- \\
\end{array}$ & \begin{tabular}{r|}
218 \\
185 \\
222 \\
196 \\
156 \\
- \\
\end{tabular} & $\begin{array}{l}42 \\
34 \\
41 \\
31 \\
12 \\
--\end{array}$ & $\begin{array}{r}10 \\
9 \\
9 \\
9 \\
8 \\
8 \\
\end{array}$ & $\begin{array}{l}41 \\
28 \\
36 \\
34 \\
16 \\
20 \\
\end{array}$ & $\begin{array}{ll} & 1 \\
& 1 \\
& 1 \\
& 1 \\
\text { (t) } & \\
\end{array}$ \\
\hline Total. & 888.6 & -- & 3,915 & 1,835 & -- & 3,345 & 292 & - & 49 \\
\hline
\end{tabular}

$t$ Less than 0.50 ton.

a Computed from estimated concentration graph.

$4888170-59-25$ 
RIO GRANDE BASIN--Continued

RIO CHAMA NEAR ABIQUIU, N. MEX.--Continued

Suspended sediment, water year October 1953 to September 1954--Continued

\begin{tabular}{|c|c|c|c|c|c|c|c|c|c|}
\hline \multirow[b]{3}{*}{ Day } & \multicolumn{3}{|c|}{ January } & \multicolumn{3}{|c|}{ February } & \multicolumn{3}{|c|}{ March } \\
\hline & \multirow[b]{2}{*}{$\begin{array}{c}\text { Mean } \\
\text { dis- } \\
\text { charge } \\
\text { (cfs) }\end{array}$} & \multicolumn{2}{|c|}{ Suspended sediment } & \multirow[b]{2}{*}{$\begin{array}{c}\text { Mean } \\
\text { dis- } \\
\text { charge } \\
\text { (cfs) }\end{array}$} & \multicolumn{2}{|c|}{ Suspended sediment } & \multirow[b]{2}{*}{$\begin{array}{c}\text { Mean } \\
\text { dis- } \\
\text { charge } \\
\text { (cfs) }\end{array}$} & \multicolumn{2}{|c|}{ Suspended sediment } \\
\hline & & $\begin{array}{c}\text { Mean } \\
\text { concen- } \\
\text { tration } \\
(\mathrm{ppm})\end{array}$ & $\begin{array}{l}\text { Tons } \\
\text { per } \\
\text { day }\end{array}$ & & $\begin{array}{l}\text { Mean } \\
\text { concen- } \\
\text { tration } \\
(\mathbf{p p m})\end{array}$ & $\begin{array}{l}\text { Tons } \\
\text { per } \\
\text { day }\end{array}$ & & $\begin{array}{l}\text { Mean } \\
\text { concen- } \\
\text { tration } \\
(\mathrm{ppm})\end{array}$ & $\begin{array}{l}\text { Tons } \\
\text { per } \\
\text { day }\end{array}$ \\
\hline $\begin{array}{l}1 \ldots \ldots \\
2 . \ldots \ldots \\
3 . \ldots \ldots \\
4 \ldots \ldots \\
5 . \ldots \ldots\end{array}$ & $\begin{array}{l}8 \\
8 \\
8 \\
8 \\
8\end{array}$ & $\begin{array}{l}13 \\
11 \\
14 \\
21 \\
34\end{array}$ & $\begin{array}{ll}(t) & \\
(t) & \\
(t) & \\
(t) & \\
& 1\end{array}$ & $\begin{array}{l}17 \\
17 \\
17 \\
17 \\
17\end{array}$ & $\begin{array}{l}19 \\
18 \\
28 \\
31 \\
25\end{array}$ & $\begin{array}{l}1 \\
1 \\
1 \\
1 \\
1\end{array}$ & $\begin{array}{l}44 \\
35 \\
31 \\
34 \\
32\end{array}$ & $\begin{array}{r}170 \\
64 \\
102 \\
54 \\
42\end{array}$ & $\begin{array}{r}20 \\
6 \\
9 \\
5 \\
4\end{array}$ \\
\hline $\begin{array}{r}6 \ldots \ldots \\
7 . \ldots \ldots \\
8 . \ldots \ldots \\
9 . \ldots \ldots \\
10 . \ldots \ldots\end{array}$ & $\begin{array}{r}8 \\
10 \\
11 \\
12 \\
11\end{array}$ & $\begin{array}{l}19 \\
30 \\
42 \\
12 \\
16\end{array}$ & $\begin{array}{ll}\text { (t) } & \\
& 1 \\
& 1 \\
(t) & \\
(t) & \end{array}$ & $\begin{array}{l}17 \\
17 \\
26 \\
27 \\
27\end{array}$ & $\begin{array}{l}22 \\
40 \\
54 \\
36 \\
42\end{array}$ & $\begin{array}{l}1 \\
2 \\
4 \\
3 \\
3\end{array}$ & $\begin{array}{r}32 \\
29 \\
29 \\
28 \\
307\end{array}$ & $\begin{array}{r}78 \\
62 \\
380 \\
93 \\
2,380\end{array}$ & $\begin{array}{r}7 \\
5 \\
30 \\
7 \\
\mathrm{~s} 4,020\end{array}$ \\
\hline $\begin{array}{l}11 \ldots \ldots \\
12 \ldots \ldots \\
13 \ldots \ldots \\
14 \ldots \ldots \\
15 \ldots \ldots\end{array}$ & $\begin{array}{r}10 \\
10 \\
10 \\
8 \\
13\end{array}$ & $\begin{array}{l}30 \\
28 \\
28 \\
28 \\
31\end{array}$ & $\begin{array}{l}1 \\
1 \\
1 \\
1 \\
1\end{array}$ & $\begin{array}{r}25 \\
28 \\
274 \\
255 \\
241\end{array}$ & $\begin{array}{r}47 \\
49 \\
5,250 \\
2,500 \\
1,450\end{array}$ & $\begin{array}{r}3 \\
4 \\
54,760 \\
1,720 \\
944\end{array}$ & $\begin{array}{r}684 \\
665 \\
352 \\
86 \\
47\end{array}$ & $\begin{array}{r}3,800 \\
2,170 \\
708 \\
120 \\
96\end{array}$ & $\begin{array}{r}7,020 \\
3,900 \\
5821 \\
28 \\
12\end{array}$ \\
\hline $\begin{array}{l}16 \ldots \ldots \\
17 \ldots \ldots \\
18 \ldots \ldots \\
19 \ldots \ldots \\
20 . \ldots \ldots\end{array}$ & $\begin{array}{l}14 \\
10 \\
17 \\
14 \\
16\end{array}$ & $\begin{array}{l}27 \\
25 \\
17 \\
44 \\
30\end{array}$ & $\begin{array}{l}1 \\
1 \\
1 \\
2 \\
1\end{array}$ & $\begin{array}{l}213 \\
213 \\
142 \\
132 \\
132\end{array}$ & $\begin{array}{r}1,500 \\
740 \\
220 \\
260 \\
480\end{array}$ & $\begin{array}{r}863 \\
426 \\
84 \\
93 \\
171\end{array}$ & $\begin{array}{l}38 \\
35 \\
31 \\
32 \\
31\end{array}$ & $\begin{array}{r}118 \\
75 \\
148 \\
148 \\
41\end{array}$ & $\begin{array}{r}12 \\
7 \\
12 \\
13 \\
3\end{array}$ \\
\hline $\begin{array}{l}21 \ldots \ldots \\
22 \ldots \ldots \\
23 \ldots \ldots \\
24 \ldots \ldots \\
25 . \ldots \ldots\end{array}$ & $\begin{array}{l}14 \\
12 \\
12 \\
12 \\
12\end{array}$ & $\begin{array}{l}51 \\
46 \\
27 \\
27 \\
24\end{array}$ & $\begin{array}{l}2 \\
1 \\
1 \\
1 \\
1\end{array}$ & $\begin{array}{l}136 \\
132 \\
132 \\
136 \\
302\end{array}$ & $\begin{array}{r}323 \\
352 \\
260 \\
295 \\
3,550\end{array}$ & $\begin{array}{r}119 \\
125 \\
93 \\
108 \\
\mathrm{~s} 3,940\end{array}$ & $\begin{array}{r}32 \\
35 \\
102 \\
457 \\
477\end{array}$ & $\begin{array}{r}89 \\
84 \\
2,080 \\
29,100 \\
11,700\end{array}$ & $\begin{array}{r}8 \\
8 \\
\mathrm{~s} 1,450 \\
\mathrm{~s} 41,400 \\
15,100\end{array}$ \\
\hline $\begin{array}{l}26 \ldots \ldots \\
27 \ldots \ldots \\
28 \ldots \ldots \\
29 \ldots \ldots \\
30 \ldots \ldots \\
31 \ldots \ldots\end{array}$ & $\begin{array}{l}16 \\
11 \\
12 \\
17 \\
19 \\
18 \\
\end{array}$ & $\begin{array}{l}46 \\
33 \\
38 \\
41 \\
42 \\
26 \\
\end{array}$ & $\begin{array}{l}2 \\
1 \\
1 \\
2 \\
2 \\
1 \\
\end{array}$ & $\begin{array}{r}297 \\
81 \\
45 \\
-- \\
-- \\
-- \\
\end{array}$ & $\begin{array}{r}1,780 \\
420 \\
200 \\
-- \\
-- \\
-- \\
\end{array}$ & $\begin{array}{r}\text { s 1, } 640 \\
92 \\
24 \\
-- \\
-- \\
-- \\
\end{array}$ & $\begin{array}{l}455 \\
314 \\
179 \\
146 \\
394 \\
665 \\
\end{array}$ & $\begin{array}{l}2,600 \\
1,500 \\
2,320 \\
2,860 \\
3,950 \\
2,100 \\
\end{array}$ & $\begin{array}{r}3,190 \\
1,270 \\
1,120 \\
1,130 \\
\mathrm{~s} 4,990 \\
3,770 \\
\end{array}$ \\
\hline \multirow[t]{2}{*}{ Total. } & 369 & $=$ & 32 & 3,115 & $\cdots$ & 15,227 & 5,858 & $=$ & 89,377 \\
\hline & \multicolumn{3}{|c|}{ April } & \multicolumn{3}{|c|}{ May } & \multicolumn{3}{|c|}{ June } \\
\hline $\begin{array}{l}1 . \ldots \ldots \\
2 . \ldots \ldots \\
3 . \ldots \ldots \\
4 \ldots \\
5 \ldots \ldots\end{array}$ & $\begin{array}{l}500 \\
241 \\
167 \\
167 \\
179\end{array}$ & $\begin{array}{r}1,610 \\
1,160 \\
1,040 \\
990 \\
1,200\end{array}$ & $\begin{array}{r}2,170 \\
755 \\
469 \\
446 \\
580\end{array}$ & $\begin{array}{r}1,240 \\
1,220 \\
874 \\
637 \\
637\end{array}$ & $\begin{array}{l}3,400 \\
1,690 \\
1,600 \\
1,410 \\
1,160\end{array}$ & $\begin{array}{r}11,400 \\
5,570 \\
23,800 \\
2,430 \\
2,000\end{array}$ & $\begin{array}{l}695 \\
695 \\
675 \\
675 \\
675\end{array}$ & $\begin{array}{l}610 \\
520 \\
440 \\
500 \\
500\end{array}$ & $\begin{array}{r}, 140 \\
976 \\
802 \\
911 \\
911\end{array}$ \\
\hline $\begin{array}{r}6 . \ldots \ldots \\
7 \ldots \ldots \\
8 . \ldots \ldots \\
9 . \ldots \ldots \\
10 . \ldots\end{array}$ & $\begin{array}{l}208 \\
241 \\
425 \\
705 \\
758\end{array}$ & $\begin{array}{l}\mathbf{1}, \mathbf{5 5 0} \\
\mathbf{2}, \mathbf{3 6 0} \\
\mathbf{3}, \mathbf{9 1 0} \\
4, \mathbf{3 0 0} \\
\mathbf{5 , 1 5 0}\end{array}$ & $\begin{array}{r}870 \\
1,540 \\
4,490 \\
8,190 \\
10,500\end{array}$ & $\begin{array}{l}646 \\
637 \\
637 \\
646 \\
684\end{array}$ & $\begin{array}{r}1,300 \\
1,240 \\
960 \\
1,410 \\
1,620\end{array}$ & $\begin{array}{l}2,270 \\
2,130 \\
1,650 \\
2,460 \\
2,990\end{array}$ & $\begin{array}{l}675 \\
675 \\
675 \\
675 \\
675\end{array}$ & $\begin{array}{l}500 \\
500 \\
510 \\
480 \\
410\end{array}$ & $\begin{array}{r}911 \\
911 \\
\mathrm{a} 930 \\
875 \\
747\end{array}$ \\
\hline $\begin{array}{l}11 . \ldots \\
12 . \ldots \\
13 . \ldots \\
14 \ldots \\
15 . \ldots\end{array}$ & $\begin{array}{l}850 \\
823 \\
910 \\
936 \\
668\end{array}$ & $\begin{array}{l}5,660 \\
6,100 \\
5,900 \\
5,100 \\
2,690\end{array}$ & $\begin{array}{r}13,000 \\
\text { a } 15,000 \\
\text { a } 14,000 \\
12,900 \\
\text { s5,560 }\end{array}$ & $\begin{array}{r}737 \\
726 \\
726 \\
737 \\
1,260\end{array}$ & $\begin{array}{l}1,910 \\
1,940 \\
1,680 \\
1,990 \\
3,260\end{array}$ & $\begin{array}{r}3,800 \\
3,800 \\
3,290 \\
3,960 \\
11,100\end{array}$ & $\begin{array}{l}665 \\
665 \\
675 \\
646 \\
646\end{array}$ & $\begin{array}{l}480 \\
510 \\
480 \\
410 \\
500\end{array}$ & $\begin{array}{l}862 \\
916 \\
875 \\
715 \\
872\end{array}$ \\
\hline $\begin{array}{l}16 \ldots \ldots \\
17 . \ldots \ldots \\
18 . \ldots \ldots \\
19 . \ldots \ldots \\
20 . \ldots \ldots\end{array}$ & $\begin{array}{l}227 \\
132 \\
120 \\
126 \\
132\end{array}$ & $\begin{array}{l}640 \\
500 \\
320 \\
770 \\
970\end{array}$ & $\begin{array}{l}392 \\
178 \\
104 \\
262 \\
346\end{array}$ & $\begin{array}{l}1,280 \\
1,270 \\
1,280 \\
1,240 \\
1,270\end{array}$ & $\begin{array}{l}2,260 \\
2,220 \\
2,350 \\
2,120 \\
2,070\end{array}$ & $\begin{array}{l}7,810 \\
7,610 \\
8,120 \\
7,100 \\
7,100\end{array}$ & $\begin{array}{r}637 \\
253 \\
65 \\
38 \\
32\end{array}$ & $\begin{array}{r}490 \\
250 \\
50 \\
17 \\
19\end{array}$ & $\begin{array}{r}843 \\
171 \\
9 \\
2 \\
2\end{array}$ \\
\hline $\begin{array}{l}21 . \ldots \ldots \\
22 . \ldots \ldots \\
23 . \ldots \ldots \\
24 \ldots \ldots \\
25 . \ldots\end{array}$ & $\begin{array}{r}126 \\
112 \\
101 \\
98 \\
98\end{array}$ & $\begin{array}{r}910 \\
1,150 \\
660 \\
1,200 \\
800\end{array}$ & $\begin{array}{l}310 \\
348 \\
180 \\
318 \\
212\end{array}$ & $\begin{array}{l}1,240 \\
1,280 \\
1,270 \\
1,260 \\
1,240\end{array}$ & $\begin{array}{l}2,030 \\
2,160 \\
2,010 \\
1,990 \\
1,930\end{array}$ & $\begin{array}{l}6,800 \\
7,460 \\
6,890 \\
6,770 \\
6,460\end{array}$ & \begin{tabular}{c|}
22 \\
11 \\
9.5 \\
7.0 \\
6.0
\end{tabular} & $\begin{array}{l}18 \\
12 \\
90 \\
28 \\
29\end{array}$ & 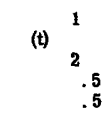 \\
\hline $\begin{array}{l}26 \ldots \ldots \\
27 \ldots \ldots \\
28 . \ldots \ldots \\
29 . \ldots \ldots \\
30 \ldots \ldots \\
31 \ldots \ldots\end{array}$ & $\begin{array}{r}81 \\
75 \\
63 \\
47 \\
1,010 \\
\end{array}$ & $\begin{array}{r}570 \\
770 \\
790 \\
680 \\
6,040 \\
-- \\
\end{array}$ & $\begin{array}{r}125 \\
156 \\
134 \\
86 \\
\mathrm{~s} 20,000 \\
--- \\
\end{array}$ & $\begin{array}{r}1,220 \\
898 \\
716 \\
705 \\
705 \\
695 \\
\end{array}$ & $\begin{array}{r}1,350 \\
1,030 \\
800 \\
660 \\
640 \\
600 \\
\end{array}$ & $\begin{array}{l}4,450 \\
2,500 \\
1,550 \\
1,260 \\
1,220 \\
1,130 \\
\end{array}$ & $\begin{array}{r}8.5 \\
8.0 \\
57 \\
54 \\
71 \\
-\end{array}$ & $\begin{array}{r}26 \\
40 \\
68 \\
79 \\
2,160 \\
\end{array}$ & $\begin{array}{r}.6 \\
10^{.9} \\
12 \\
\mathrm{~s} 550 \\
\end{array}$ \\
\hline Total & 10,426 & $\ldots$ & 113,621 & 29,613 & -- & 146,880 & $11,366,0$ & -- & 14,959 \\
\hline
\end{tabular}

s Computed by subdividing day.

$t$ Less than 0.50 ton.

a Computed from estimated concentration graph. 
RIO GRANDE BASIN--Continued

RIO CHAMA NEAR ABIQUIU, N. MEX.--Continued

Suspended sediment, water year October 1953 to September 1954--Continued

\begin{tabular}{|c|c|c|c|c|c|c|c|c|c|}
\hline \multirow[b]{3}{*}{ Day } & \multicolumn{3}{|c|}{ July } & \multicolumn{3}{|c|}{ August } & \multicolumn{3}{|c|}{ September } \\
\hline & \multirow[b]{2}{*}{$\begin{array}{c}\text { Mean } \\
\text { dis- } \\
\text { charge } \\
\text { (cfs) }\end{array}$} & \multicolumn{2}{|c|}{ Suspended sediment } & \multirow[b]{2}{*}{$\begin{array}{c}\text { Mean } \\
\text { dis- } \\
\text { charge } \\
\text { (cfs) }\end{array}$} & \multicolumn{2}{|c|}{ Suspended sediment } & \multirow[b]{2}{*}{$\begin{array}{l}\text { Mean } \\
\text { dis- } \\
\text { charge } \\
\text { (cfs) }\end{array}$} & \multicolumn{2}{|c|}{ Suspended sediment } \\
\hline & & $\begin{array}{l}\text { Mean } \\
\text { concen- } \\
\text { tration } \\
\text { (ppm) }\end{array}$ & $\begin{array}{l}\text { Tons } \\
\text { per } \\
\text { day }\end{array}$ & & $\begin{array}{l}\text { Mean } \\
\text { concen- } \\
\text { tration } \\
\text { (ppm) }\end{array}$ & $\begin{array}{l}\text { Tons } \\
\text { per } \\
\text { day }\end{array}$ & & $\begin{array}{l}\text { Mean } \\
\text { concen- } \\
\text { tration } \\
\text { (ppm) }\end{array}$ & $\begin{array}{l}\text { Tons } \\
\text { per } \\
\text { day }\end{array}$ \\
\hline $\begin{array}{l}1 \ldots \ldots \\
2 . \ldots \ldots \\
3 \ldots \ldots \\
4 \ldots \ldots \\
5 \ldots \ldots\end{array}$ & $\begin{array}{l}52 \\
56 \\
49 \\
47 \\
54\end{array}$ & $\begin{array}{r}1,250 \\
1,400 \\
1,000 \\
600 \\
700\end{array}$ & $\begin{array}{r}176 \\
212 \\
132 \\
76 \\
102\end{array}$ & $\begin{array}{l}20 \\
16 \\
13 \\
10 \\
12\end{array}$ & $\begin{array}{r}100 \\
80 \\
77 \\
69 \\
76\end{array}$ & $\begin{array}{r}25 \\
3 \\
3 \\
2 \\
2\end{array}$ & \begin{tabular}{r|}
56 \\
24 \\
18 \\
400 \\
769
\end{tabular} & $\begin{array}{r}21,100 \\
2,000 \\
900 \\
18,100 \\
7,000\end{array}$ & $\begin{array}{r}\mathrm{s} 4,320 \\
130 \\
44 \\
\mathrm{~s} 38,600 \\
14,500\end{array}$ \\
\hline $\begin{array}{r}6 \ldots \ldots \\
7 \ldots \ldots \\
8 \ldots \ldots \\
9 . \ldots \ldots \\
10 . \ldots \ldots\end{array}$ & $\begin{array}{r}56 \\
54 \\
550 \\
1,140 \\
1,040\end{array}$ & $\begin{array}{r}800 \\
400 \\
2,980 \\
11,800 \\
7,200\end{array}$ & $\begin{array}{r}121 \\
58 \\
\mathrm{s7}, 160 \\
\mathrm{~s} 33,300 \\
20,200\end{array}$ & $\begin{array}{r}54 \\
140 \\
75 \\
124 \\
93\end{array}$ & $\begin{array}{r}1,620 \\
12,200 \\
6,000 \\
10,300 \\
5,820\end{array}$ & $\begin{array}{r}\mathrm{s} 543 \\
\mathrm{~s} \mathbf{4 , 8 0 0} \\
1,220 \\
\mathrm{~s} 6, \mathbf{4 9 0} \\
\mathrm{s} \mathbf{2}, \mathbf{9 0 0}\end{array}$ & $\begin{array}{l}507 \\
470 \\
468 \\
448 \\
468\end{array}$ & $\begin{array}{l}5,000 \\
2,500 \\
1,000 \\
1,400 \\
2,750\end{array}$ & $\begin{array}{r}6,840 \\
3,170 \\
1,250 \\
1,690 \\
\mathrm{~s} 4,060\end{array}$ \\
\hline $\begin{array}{l}11 \ldots \ldots \\
12 . \ldots \ldots \\
13 . \ldots \ldots \\
14 \ldots \ldots \\
15 . \ldots \ldots\end{array}$ & $\begin{array}{l}705 \\
748 \\
705 \\
665 \\
665\end{array}$ & $\begin{array}{r}800 \\
12,000 \\
1,800 \\
850 \\
380\end{array}$ & $\begin{array}{r}1,520 \\
\mathrm{~s} 27,100 \\
3,430 \\
1,530 \\
682\end{array}$ & $\begin{array}{l}86 \\
50 \\
96 \\
52 \\
34\end{array}$ & $\begin{array}{r}6,800 \\
4,600 \\
19,200 \\
6,600 \\
2,800\end{array}$ & $\begin{array}{r}1,580 \\
a 620 \\
\mathbf{5} 5,460 \\
927 \\
257\end{array}$ & $\begin{array}{l}463 \\
463 \\
846 \\
380 \\
355\end{array}$ & $\begin{array}{r}6,100 \\
1,500 \\
20,400 \\
12,500 \\
900\end{array}$ & $\begin{array}{r}7,630 \\
1,8 \mathrm{BO} \\
\mathrm{s} 50,600 \\
12,800 \\
863\end{array}$ \\
\hline $\begin{array}{l}16 . \ldots \ldots \\
17 . \ldots \ldots \\
18 . \ldots \ldots \\
19 . \ldots \ldots \\
20 . \ldots \ldots\end{array}$ & $\begin{array}{l}737 \\
628 \\
665 \\
609 \\
590\end{array}$ & $\begin{array}{r}1,880 \\
1,600 \\
11,200 \\
2,400 \\
500\end{array}$ & $\begin{array}{r}\mathrm{s} 4,980 \\
2,710 \\
20,100 \\
\mathbf{3}, 950 \\
\mathbf{7 9 6}\end{array}$ & $\begin{array}{l}41 \\
78 \\
54 \\
42 \\
84\end{array}$ & $\begin{array}{r}2,300 \\
6,970 \\
1,600 \\
650 \\
7,770\end{array}$ & $\begin{array}{r}255 \\
\mathrm{~s} 2,660 \\
233 \\
74 \\
\mathrm{~s} 3,910\end{array}$ & $\begin{array}{r}297 \\
142 \\
56 \\
41 \\
32\end{array}$ & $\begin{array}{l}600 \\
198 \\
138 \\
108 \\
100\end{array}$ & $\begin{array}{r}481 \\
76 \\
21 \\
12 \\
29\end{array}$ \\
\hline $\begin{array}{l}21 . \ldots \ldots \\
22 . \ldots \ldots \\
23 . \ldots \ldots \\
24 \ldots \ldots \\
25 . \ldots \ldots\end{array}$ & $\begin{array}{l}573 \\
573 \\
716 \\
372 \\
123\end{array}$ & $\begin{array}{r}380 \\
300 \\
4,800 \\
5,000 \\
800\end{array}$ & $\begin{array}{r}588 \\
464 \\
9,280 \\
5,020 \\
266\end{array}$ & $\begin{array}{l}56 \\
50 \\
28 \\
25 \\
25\end{array}$ & $\begin{array}{r}5,650 \\
2,400 \\
2,150 \\
1,350 \\
600\end{array}$ & $\begin{array}{r}854 \\
324 \\
163 \\
91 \\
40\end{array}$ & $\begin{array}{l}29 \\
29 \\
26 \\
26 \\
29\end{array}$ & $\begin{array}{r}96 \\
84 \\
118 \\
118 \\
72\end{array}$ & $\begin{array}{l}8 \\
7 \\
8 \\
8 \\
6\end{array}$ \\
\hline $\begin{array}{l}26 \ldots \ldots \\
27 \ldots \ldots \ldots \\
28 \ldots \ldots \\
29 . \ldots \ldots \\
30 \ldots \ldots \\
31 \ldots \ldots\end{array}$ & $\begin{array}{l}89 \\
50 \\
35 \\
29 \\
23 \\
25\end{array}$ & $\begin{array}{l}600 \\
500 \\
146 \\
170 \\
125 \\
292\end{array}$ & $\begin{array}{r}a 140^{\circ} \\
68 \\
14 \\
13 \\
8 \\
20\end{array}$ & $\begin{array}{l}42 \\
23 \\
19 \\
19 \\
17 \\
23\end{array}$ & $\begin{array}{r}6,000 \\
4,100 \\
2,000 \\
1,000 \\
431 \\
1,050\end{array}$ & $\begin{array}{r}680 \\
255 \\
\times 200 \\
\text { a } 51 \\
20 \\
65\end{array}$ & $\begin{array}{l}59 \\
67 \\
75 \\
59 \\
41 \\
- \\
\end{array}$ & $\begin{array}{r}583 \\
653 \\
588 \\
3,570 \\
2,010 \\
-\end{array}$ & $\begin{array}{r}93 \\
1.18 \\
118 \\
569 \\
223 \\
\end{array}$ \\
\hline Total. & 12,423 & $\cdots$ & 144,216 & 1,501 & -- & 34,587 & 7,138 & $\cdots$ & 150,135 \\
\hline
\end{tabular}

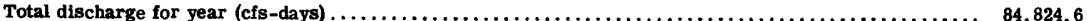

Total load for year (tons)

s Computed by subdividing day.

Less than 0.50 ton.

a Computed from estimated concentration graph. 


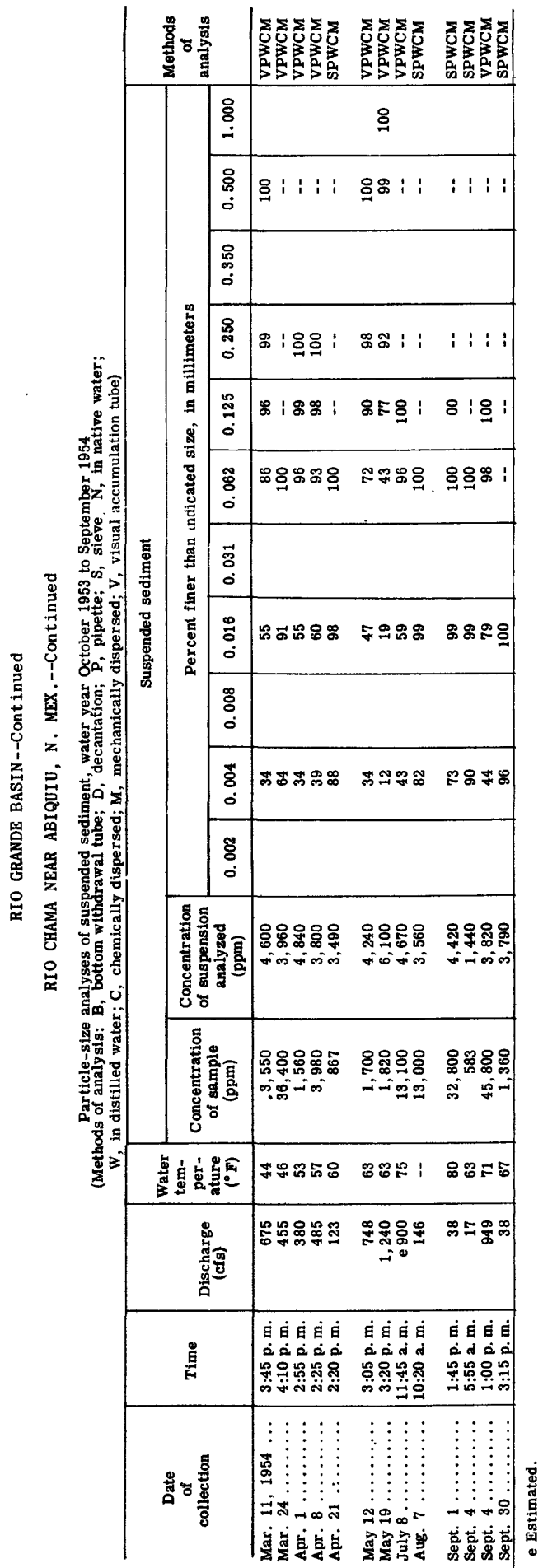




\section{RIO GRANDE BASIN--Continued}

RIO CHAMA NEAR CHAMITA, N. MEX.

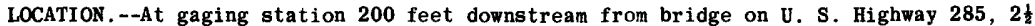
miles upstream from mouth, and $2 \frac{1}{2}$ miles northwest of Chamita, Rio Arriba County.

DRAINAGE AREA. --3,200 square miles, approximately.

RECORDS AVAILABLE. - -Water temperatures: October ig50 to september 1954.

Sediment records: October 1947 to September 1954.

EXTREMES, 1953-54.--Water temperatures: Maximum observed, $88^{\circ} \mathrm{F}$ June 28 , July 28 ;

minimum, freezing point on many days during December and January.

Sediment concentrations: Maximum daily, 36,000 ppm Aug. 6; minimum daily, 12 ppm June 21.

Sediment loads: Maximum daily, 46,600 tons Sept. 13; minimum daily, less than 0.50 ton, on many days.

EXTREMES, 1947-54. - Water temperatures (1950-54): Maximum observed, 89 July 19, 1951; minimum, freezing point on many days during winter months.

Sediment concentrations: Maximum daily, 40,100 ppm Aug. 3, 1950; minimum, no flow on many days.

Sediment loads: Maximum daily, 139,000 tons May 17, 1952; minimum daily, 0 tons on many days.

REMARKS. --Maximum observed sediment concentration during water year 62,700 ppm Sept. 4 . Records of discharge for water year October 1953 to September 1954 given in wSP 1342 . Stage-discharge relation affected by ice Dec. 4 to Jan. 28.

Temperature $\left({ }^{\circ} \mathrm{F}\right)$ of water, water year October 1953 to September 1954 Önce-dailv measurement generally between 11 a.m. and $6 . \mathrm{m} .7$

\begin{tabular}{|c|c|c|c|c|c|c|c|c|c|c|c|c|}
\hline Day & Oct. & Nov. & Dec. & Jan. & Feb. & Mar. & Apr. & May & June & July & Aug. & Sept. \\
\hline $\begin{array}{l}1 \\
2 \\
3 \\
4 \\
5\end{array}$ & $\begin{array}{r}70 \\
71 \\
\text { a } 53 \\
\text { a } 60 \\
\text { a } 62\end{array}$ & $\begin{array}{l}55 \\
57 \\
56 \\
55 \\
46\end{array}$ & $\begin{array}{r}43 \\
\mathbf{4} 42 \\
42 \\
32 \\
--\end{array}$ & $\begin{array}{r}32 \\
\mathrm{a} 32 \\
32 \\
\mathrm{a} 32 \\
32\end{array}$ & $\begin{array}{r}50 \\
47 \\
48 \\
\text { a } 34 \\
51\end{array}$ & $\begin{array}{l}48 \\
48 \\
41 \\
51 \\
50\end{array}$ & $\begin{array}{r}53 \\
\text { a } 44 \\
\text { a } 44 \\
\text { a } 46 \\
62\end{array}$ & $\begin{array}{r}62 \\
\mathrm{a} 50 \\
61 \\
62 \\
\mathrm{a} 55\end{array}$ & $\begin{array}{r}69 \\
66 \\
67 \\
69 \\
\text { b } 66\end{array}$ & $\begin{array}{r}75 \\
82 \\
\mathrm{a} 65 \\
75 \\
--\end{array}$ & $\begin{array}{r}80 \\
81 \\
80 \\
-- \\
\text { b } 75\end{array}$ & $\begin{array}{l}86 \\
81 \\
77 \\
75 \\
73\end{array}$ \\
\hline $\begin{array}{r}6 \\
7 \\
8 \\
9 \\
10\end{array}$ & $\begin{array}{l}69 \\
71 \\
73 \\
71 \\
70\end{array}$ & $\begin{array}{l}48 \\
49 \\
49 \\
49 \\
47\end{array}$ & $\begin{array}{r}\text { a } 32 \\
35 \\
\text { a } 32 \\
34 \\
34\end{array}$ & $\begin{array}{l}32 \\
33 \\
33 \\
32 \\
32\end{array}$ & $\begin{array}{l}46 \\
51 \\
50 \\
48 \\
47\end{array}$ & $\begin{array}{l}\mathbf{5 0} \\
\mathbf{5 5} \\
\mathbf{5 5} \\
\mathbf{5 2} \\
\mathbf{6 0}\end{array}$ & $\begin{array}{r}65 \\
61 \\
56 \\
63 \\
\text { b } 56\end{array}$ & $\begin{array}{r}68 \\
\text { a } 59 \\
\text { a } 55 \\
\text { b } 61 \\
57\end{array}$ & $\begin{array}{r}\mathbf{6} 67 \\
66 \\
67 \\
\mathbf{a} 64 \\
70\end{array}$ & $\begin{array}{r}-- \\
82 \\
80 \\
\text { b } 71 \\
\text { a } 69\end{array}$ & $\begin{array}{r}\text { a } 72 \\
-- \\
\text { a } 63 \\
\text { a } 68 \\
\text { b } 69\end{array}$ & $\begin{array}{r}75 \\
\text { a } 65 \\
72 \\
72 \\
69\end{array}$ \\
\hline $\begin{array}{l}11 \\
12 \\
13 \\
14 \\
15\end{array}$ & $\begin{array}{r}69 \\
70 \\
\mathrm{a} 60 \\
70 \\
68\end{array}$ & $\begin{array}{r}\text { a } 38 \\
\text { a } 38 \\
51 \\
\text { b } 49 \\
51\end{array}$ & $\begin{array}{r}\mathbf{3} 3 \mathbf{2} \\
\mathbf{3 2} \\
\mathbf{3 3} \\
\mathbf{3 5} \\
\mathbf{3 3}\end{array}$ & $\begin{array}{l}32 \\
32 \\
32 \\
33 \\
34\end{array}$ & $\begin{array}{l}51 \\
-- \\
-- \\
-- \\
--\end{array}$ & $\begin{array}{r}44 \\
40 \\
\mathrm{a} 32 \\
49 \\
44\end{array}$ & $\begin{array}{r}\mathbf{5 6} \\
58 \\
59 \\
58 \\
61\end{array}$ & $\begin{array}{r}\text { b } 51 \\
65 \\
63 \\
68 \\
\mathbf{9 6 3}\end{array}$ & $\begin{array}{r}71 \\
\mathrm{a} 60 \\
65 \\
\mathrm{~b} 63 \\
71\end{array}$ & $\begin{array}{r}\text { a } 64 \\
-- \\
77 \\
\text { a } 71 \\
75\end{array}$ & $\begin{array}{r}\text { b 73 } \\
\text { a } 63 \\
\text { b 73 } \\
\text { a } 63 \\
--\end{array}$ & $\begin{array}{r}-- \\
\text { b } 65 \\
\text { b } 68 \\
71 \\
\text { b } 68\end{array}$ \\
\hline $\begin{array}{l}16 \\
17 \\
18 \\
19 \\
20\end{array}$ & $\begin{array}{r}63 \\
\mathrm{a} 61 \\
64 \\
64 \\
57\end{array}$ & $\begin{array}{l}53 \\
49 \\
49 \\
42 \\
42\end{array}$ & $\begin{array}{r}33 \\
32 \\
\text { a } 32 \\
\text { a } 32 \\
\text { a } 34\end{array}$ & $\begin{array}{l}33 \\
32 \\
34 \\
39\end{array}$ & $\begin{array}{r}-- \\
\text { a } 37 \\
43 \\
43 \\
45\end{array}$ & $\begin{array}{l}45 \\
48 \\
50 \\
41 \\
48\end{array}$ & $\begin{array}{r}\text { a } 45 \\
\text { a } 65 \\
57 \\
61 \\
63\end{array}$ & $\begin{array}{r}-- \\
\text { a } 52 \\
\text { a } 53 \\
68 \\
67\end{array}$ & $\begin{array}{r}74 \\
- \\
74 \\
72 \\
--\end{array}$ & $\begin{array}{r}72 \\
a 76 \\
-2 \\
76 \\
80\end{array}$ & $\begin{array}{r}\text { a } 63 \\
\text { a } 65 \\
\text { a } 63 \\
\text { a } 58 \\
--\end{array}$ & $\begin{array}{r}71 \\
75 \\
\text { a } 66 \\
\text { a } 58 \\
75\end{array}$ \\
\hline $\begin{array}{l}21 \\
22 \\
23 \\
24 \\
25\end{array}$ & $\begin{array}{r}\text { a } 49 \\
55 \\
57 \\
\text { a } 49 \\
53\end{array}$ & $\begin{array}{r}42 \\
\text { a } 32 \\
43 \\
44 \\
40\end{array}$ & $\begin{array}{l}40 \\
33 \\
32 \\
32 \\
--\end{array}$ & $\begin{array}{l}40 \\
41 \\
40 \\
40 \\
37\end{array}$ & $\begin{array}{l}46 \\
48 \\
48 \\
43 \\
52\end{array}$ & $\begin{array}{r}\text { a } 39 \\
52 \\
48 \\
48 \\
45\end{array}$ & $\begin{array}{r}61 \\
62 \\
61 \\
\text { a } 52 \\
\text { a } 57\end{array}$ & $\begin{array}{r}69 \\
63 \\
\mathrm{a} 56 \\
61 \\
63\end{array}$ & $\begin{array}{r}82 \\
\text { b 74 } \\
83 \\
\text { b } 77 \\
85\end{array}$ & $\begin{array}{r}79 \\
73 \\
\text { a } 76 \\
\text { a } 71 \\
\text { a } 76\end{array}$ & $\begin{array}{r}-- \\
-- \\
\text { a } 63 \\
\text { a } 59 \\
\text { a } 63\end{array}$ & $\begin{array}{r}72 \\
\mathrm{a} 60 \\
71 \\
-- \\
67\end{array}$ \\
\hline $\begin{array}{l}26 \\
27 \\
28 \\
29 \\
30 \\
31\end{array}$ & $\begin{array}{l}56 \\
58 \\
57 \\
58 \\
58 \\
58\end{array}$ & $\begin{array}{r}45 \\
43 \\
\text { a } 40 \\
\text { a } 40 \\
45 \\
--\end{array}$ & $\begin{array}{r}\mathbf{a} \mathbf{3 2} \\
\mathbf{3 2} \\
\mathbf{3 2} \\
\mathbf{3 2} \\
\mathbf{3 2} \\
\mathbf{3 2}\end{array}$ & $\begin{array}{l}39 \\
42 \\
43 \\
48 \\
49 \\
50\end{array}$ & $\begin{array}{r}50 \\
\text { a } 36 \\
44 \\
-- \\
- \\
--\end{array}$ & $\begin{array}{r}50 \\
\mathrm{a} 40 \\
49 \\
53 \\
53 \\
52\end{array}$ & $\begin{array}{l}65 \\
67 \\
67 \\
61 \\
54 \\
--\end{array}$ & $\begin{array}{r}66 \\
66 \\
63 \\
66 \\
63 \\
\mathrm{a} 59 \\
\end{array}$ & $\begin{array}{r}\text { b } 70 \\
83 \\
88 \\
87 \\
82 \\
--\end{array}$ & $\begin{array}{r}82 \\
80 \\
88 \\
86 \\
78 \\
\text { b } 76 \\
\end{array}$ & $\begin{array}{r}\text { a } 62 \\
-- \\
-- \\
\text { a } 70 \\
82 \\
82\end{array}$ & $\begin{array}{r}\text { a } 58 \\
\text { a } 58 \\
70 \\
65 \\
67 \\
--\end{array}$ \\
\hline $\begin{array}{c}\text { Aver- } \\
\text { age }\end{array}$ & 62 & 46 & 34 & 36 & 46 & 48 & 58 & 61 & 72 & 76 & - & 70 \\
\hline
\end{tabular}

Measurement before 11 a.m.

b Measurement after 6 p.m. 
RIO GRANDE BASIN--Continued

RIO CHAMA NEAR CHAMITA, N. MEX.--Cont inued

Suspended sediment, water year October 1953 to September 1954

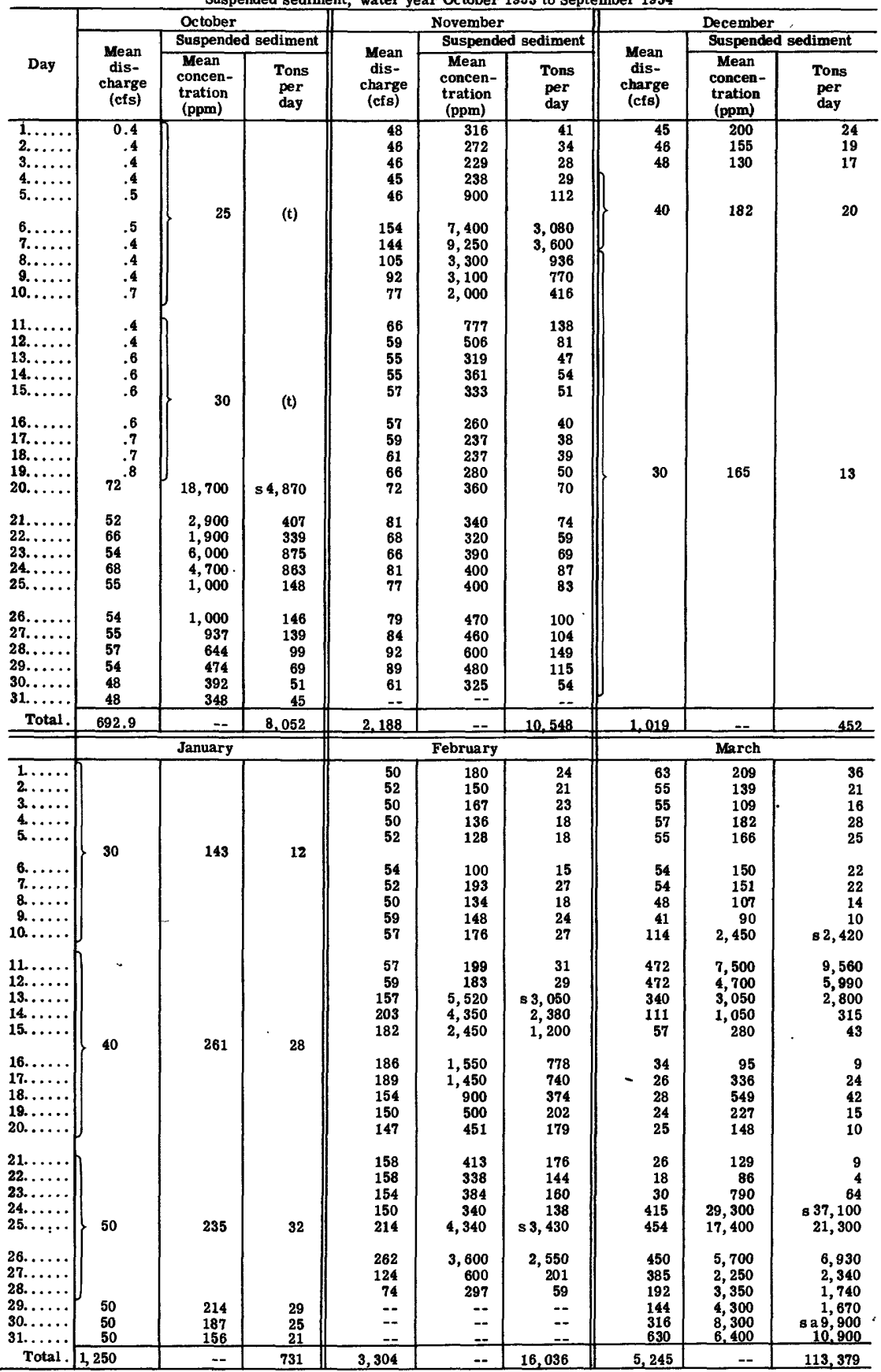

s Computed by subdividing day.

$t$ Less than 0.50 ton.

a Computed from estimated concentration graph. 
RIO GRANDE BASIN--Continued

RIO CHAMA NEAR CHAMITA, N. MEX.---Continued

Suspended sediment, water year October 1953 to September 1954 --Continued

\begin{tabular}{|c|c|c|c|c|c|c|c|c|c|}
\hline \multirow[b]{3}{*}{ Day } & \multicolumn{3}{|c|}{ April } & \multicolumn{3}{|c|}{ May } & \multicolumn{3}{|c|}{ June } \\
\hline & \multirow[b]{2}{*}{$\begin{array}{l}\text { Mean } \\
\text { dis- } \\
\text { charge } \\
\text { (cfs) }\end{array}$} & \multicolumn{2}{|c|}{ Suspended sediment } & \multirow[b]{2}{*}{$\begin{array}{c}\text { Mean } \\
\text { dis- } \\
\text { charge } \\
\text { (cfs) }\end{array}$} & \multicolumn{2}{|c|}{ Suspended sediment } & \multirow[b]{2}{*}{$\begin{array}{l}\text { Mean } \\
\text { dis- } \\
\text { charge } \\
\text { (cfs) }\end{array}$} & \multicolumn{2}{|c|}{ Suspended sediment } \\
\hline & & $\begin{array}{l}\text { Mean } \\
\text { concen- } \\
\text { tration } \\
\text { (ppm) }\end{array}$ & $\begin{array}{l}\text { Tons } \\
\text { per } \\
\text { day }\end{array}$ & & $\begin{array}{l}\text { Mean } \\
\text { concen- } \\
\text { tration } \\
\text { (ppm) }\end{array}$ & $\begin{array}{l}\text { Tons } \\
\text { per } \\
\text { day }\end{array}$ & & $\begin{array}{l}\text { Mean } \\
\text { concen- } \\
\text { tration } \\
\text { (ppm) }\end{array}$ & $\begin{array}{l}\text { Tons } \\
\text { per } \\
\text { day }\end{array}$ \\
\hline $\begin{array}{l}1 \ldots \ldots \\
2 \ldots \ldots \\
3 . \ldots \ldots \\
4 \ldots \ldots \\
5 . \ldots \ldots\end{array}$ & $\begin{array}{l}546 \\
312 \\
189 \\
196 \\
206\end{array}$ & $\begin{array}{r}3,200 \\
1,200 \\
600 \\
480 \\
450\end{array}$ & $\begin{array}{r}4,720 \\
1,010 \\
306 \\
254 \\
250\end{array}$ & $\begin{array}{r}1,250 \\
1,210 \\
1,090 \\
900 \\
702\end{array}$ & $\begin{array}{l}7,200 \\
5,650 \\
4,450 \\
2,900 \\
2,000\end{array}$ & $\begin{array}{r}24,300 \\
18,500 \\
13,100 \\
7,050 \\
3,790\end{array}$ & $\begin{array}{l}654 \\
654 \\
630 \\
638 \\
616\end{array}$ & $\begin{array}{r}1,180 \\
940 \\
881 \\
826 \\
827\end{array}$ & $\begin{array}{l}2,080 \\
1,660 \\
1,500 \\
1,420 \\
1,380\end{array}$ \\
\hline $\begin{array}{r}6 \ldots \ldots \\
7 \ldots \ldots \\
8 \ldots \ldots \\
9 \ldots \ldots \\
10 \ldots \ldots\end{array}$ & $\begin{array}{l}286 \\
358 \\
518 \\
820 \\
860\end{array}$ & $\begin{array}{l}1,150 \\
2,800 \\
5,200 \\
6,750 \\
6,800\end{array}$ & $\begin{array}{r}888 \\
2,710 \\
7,270 \\
14,900 \\
15,800\end{array}$ & $\begin{array}{l}654 \\
646 \\
630 \\
595 \\
581\end{array}$ & $\begin{array}{l}1,850 \\
2,000 \\
2,200 \\
2,150 \\
2,450\end{array}$ & $\begin{array}{l}3,270 \\
3,490 \\
3,740 \\
3,450 \\
3,840\end{array}$ & $\begin{array}{l}623 \\
616 \\
616 \\
623 \\
616\end{array}$ & $\begin{array}{r}949 \\
802 \\
674 \\
838 \\
1,130\end{array}$ & $\begin{array}{l}1,600 \\
1,330 \\
1,120 \\
1,410 \\
1,880\end{array}$ \\
\hline $\begin{array}{l}11 \ldots \ldots \\
12 . \ldots \ldots \\
13 . \ldots \ldots \\
14 \ldots \ldots \\
15 . \ldots \ldots\end{array}$ & $\begin{array}{l}1,020 \\
1,110 \\
1,130 \\
1,270 \\
1,140\end{array}$ & $\begin{array}{l}6,550 \\
6,400 \\
5,550 \\
5,800 \\
4,100\end{array}$ & $\begin{array}{l}18,000 \\
19,200 \\
16,900 \\
19,900 \\
12,600\end{array}$ & $\begin{array}{r}678 \\
702 \\
719 \\
710 \\
1,080\end{array}$ & $\begin{array}{l}3,550 \\
3,350 \\
2,750 \\
2,150 \\
6,100\end{array}$ & $\begin{array}{r}6,500 \\
6,350 \\
5,340 \\
4,120 \\
17,800\end{array}$ & $\begin{array}{l}623 \\
609 \\
609 \\
602 \\
588\end{array}$ & $\begin{array}{l}705 \\
744 \\
898 \\
625 \\
744\end{array}$ & $\begin{array}{l}1,190 \\
1,220 \\
1,480 \\
1,020 \\
1,180\end{array}$ \\
\hline $\begin{array}{l}16 \ldots \ldots \\
17 . \ldots \ldots \\
18 \ldots \ldots \\
19 \ldots \ldots \\
20 \ldots \ldots\end{array}$ & $\begin{array}{l}595 \\
466 \\
472 \\
448 \\
405\end{array}$ & $\begin{array}{l}2,050 \\
3,100 \\
2,050 \\
1,200 \\
1,650\end{array}$ & $\begin{array}{l}3,290 \\
3,900 \\
2,610 \\
1,450 \\
1,800\end{array}$ & $\begin{array}{l}1,270 \\
1,420 \\
1,400 \\
1,340 \\
1,340\end{array}$ & $\begin{array}{l}6,450 \\
5,650 \\
4,750 \\
4,350 \\
3,650\end{array}$ & $\begin{array}{l}22,100 \\
21,700 \\
18,000 \\
15,700 \\
13,200\end{array}$ & $\begin{array}{r}574 \\
335 \\
63 \\
26 \\
13\end{array}$ & $\begin{array}{r}230 \\
115 \\
52 \\
26 \\
.23\end{array}$ & $\begin{array}{r}356 \\
104 \\
9 \\
2 \\
1\end{array}$ \\
\hline $\begin{array}{l}21 \ldots \ldots \\
22 . \ldots \ldots \\
23 \ldots \ldots \\
24 \ldots \ldots \\
25 . \ldots \ldots\end{array}$ & $\begin{array}{l}348 \\
290 \\
262 \\
230 \\
206\end{array}$ & $\begin{array}{l}800 \\
563 \\
557 \\
511 \\
629\end{array}$ & $\begin{array}{l}752 \\
441 \\
394 \\
317 \\
350\end{array}$ & $\begin{array}{l}1,270 \\
1,270 \\
1,290 \\
1,220 \\
1,180\end{array}$ & $\begin{array}{l}2,740 \\
2,770 \\
2,820 \\
2,760 \\
2,220\end{array}$ & $\begin{array}{l}9,400 \\
9,500 \\
9,820 \\
9,090 \\
7,070\end{array}$ & $\begin{array}{r}7.5 \\
5.7 \\
5.7 \\
5.7 \\
12\end{array}$ & $\begin{array}{r}12 \\
22 \\
15 \\
28 \\
157\end{array}$ & $\begin{array}{ll}(t) & \\
(t) & \\
(t) & \\
(t) & \\
& 5\end{array}$ \\
\hline $\begin{array}{l}26 \ldots \ldots \\
27 . \ldots \ldots \\
28 . \ldots \ldots \\
29 . \ldots \ldots \\
30 \ldots \ldots \\
31 . \ldots \ldots\end{array}$ & $\begin{array}{r}189 \\
172 \\
140 \\
121 \\
818 \\
-- \\
\end{array}$ & $\begin{array}{r}331 \\
314 \\
302 \\
229 \\
8,750 \\
--- \\
\end{array}$ & $\begin{array}{r}169 \\
146 \\
114 \\
75 \\
\mathrm{8} 26,800 \\
--\end{array}$ & $\begin{array}{r}1,200 \\
977 \\
773 \\
737 \\
719 \\
\mathbf{6 8 6} \\
\end{array}$ & $\begin{array}{l}2,230 \\
1,640 \\
1,600 \\
1,330 \\
1,240 \\
1,510 \\
\end{array}$ & $\begin{array}{l}7,230 \\
4,330 \\
3,340 \\
2,650 \\
2,410 \\
2,800 \\
\end{array}$ & $\begin{array}{c}10 \\
8 \\
6 \\
4 \\
5.6 \\
-- \\
\end{array}$ & $\begin{array}{r}220 \\
82 \\
90 \\
99 \\
970 \\
-- \\
\end{array}$ & $\begin{array}{r}6 \\
2 \\
1 \\
1 \\
\mathrm{sa} 230 \\
\end{array}$ \\
\hline \multirow[t]{2}{*}{ Total. } & 15,123 & -- & 177,316 & 30,239 & $\because$ & 282,980 & $10,398.2$ & -- & 22,188 \\
\hline & \multicolumn{3}{|c|}{ July } & \multicolumn{3}{|c|}{ August } & \multicolumn{3}{|c|}{ September } \\
\hline $\begin{array}{l}1 . \ldots \ldots \\
2 \ldots \ldots \\
3 \ldots \ldots \\
4 \ldots \ldots \\
5 \ldots \ldots\end{array}$ & $\begin{array}{l}52 \\
31 \\
38 \\
28 \\
31\end{array}$ & $\begin{array}{r}15,200 \\
6,600 \\
800 \\
350 \\
400\end{array}$ & $\begin{array}{r}2,130 \\
552 \\
82 \\
26 \\
33\end{array}$ & $\begin{array}{r}4.3 \\
2.9 \\
2.0 \\
1.0 \\
115\end{array}$ & $\begin{array}{r}\mathbf{5 4} \\
\mathbf{5 7} \\
\mathbf{5 8} \\
\mathbf{4 5} \\
\mathbf{7 , 5 6 0}\end{array}$ & $\begin{array}{c}{ }^{1} \\
(t) \\
(t) \\
(t) \\
s 24,800\end{array}$ & $\begin{array}{r}22 \\
16 \\
12 \\
200 \\
750\end{array}$ & $\begin{array}{r}10,800 \\
10,600 \\
3,100 \\
13,400 \\
19,900\end{array}$ & $\begin{array}{r}\mathbf{s 1 , 3 8 0} \\
458 \\
100 \\
7,240 \\
40,300\end{array}$ \\
\hline $\begin{array}{r}6 \ldots \ldots \\
7 \ldots \ldots \\
8 \ldots \ldots \\
9 \ldots \ldots \\
10 \ldots \ldots\end{array}$ & $\begin{array}{c}15 \\
8.0 \\
230 \\
1,090 \\
1,070\end{array}$ & $\begin{array}{r}900 \\
1,050 \\
3,150 \\
6,500 \\
8,000\end{array}$ & $\begin{array}{r}36 \\
23 \\
87,290 \\
19,100 \\
23,100\end{array}$ & $\begin{array}{r}141 \\
114 \\
52 \\
47 \\
98\end{array}$ & $\begin{array}{r}36,000 \\
13,800 \\
7,000 \\
18,700 \\
22,600\end{array}$ & $\begin{array}{r}\mathrm{s} 2,400 \\
4,250 \\
983 \\
\mathrm{~s} 3,550 \\
\mathrm{s7}, 690\end{array}$ & $\begin{array}{l}586 \\
448 \\
466 \\
460 \\
460\end{array}$ & $\begin{array}{l}7,450 \\
3,200 \\
2,700 \\
2,050 \\
2,100\end{array}$ & $\begin{array}{r}\mathbf{s} 12,500 \\
3,870 \\
3,400 \\
2,550 \\
2,610\end{array}$ \\
\hline $\begin{array}{l}11 \ldots \ldots \\
12 \ldots \ldots \\
13 . \ldots \ldots \\
14 \ldots \ldots \\
15 \ldots \ldots\end{array}$ & $\begin{array}{l}737 \\
686 \\
638 \\
602 \\
595\end{array}$ & $\begin{array}{r}2,050 \\
10,300 \\
2,720 \\
990 \\
750\end{array}$ & $\begin{array}{r}4,080 \\
19,100 \\
4,690 \\
1,610 \\
1,200\end{array}$ & $\begin{array}{r}94 \\
52 \\
134 \\
57 \\
35\end{array}$ & $\begin{array}{r}23,000 \\
6,500 \\
16,400 \\
14,100 \\
4,500\end{array}$ & $\begin{array}{r}\mathrm{s}, 120 \\
913 \\
\mathrm{~s} 7,130 \\
2,170 \\
425\end{array}$ & $\begin{array}{l}472 \\
454 \\
783 \\
410 \\
376\end{array}$ & $\begin{array}{r}10,200 \\
4,100 \\
18,700 \\
29,800 \\
4,600\end{array}$ & $\begin{array}{r}13,000 \\
5,030 \\
s 46,600 \\
33,000 \\
4,670\end{array}$ \\
\hline $\begin{array}{l}16 \ldots \ldots \\
17 . \ldots \ldots \\
18 \ldots \ldots \\
19 . \ldots \ldots \\
20 \ldots \ldots\end{array}$ & $\begin{array}{l}595 \\
623 \\
616 \\
567 \\
532\end{array}$ & $\begin{array}{r}2,080 \\
11,800 \\
15,500 \\
7,000 \\
1,000\end{array}$ & $\begin{array}{r}3,340 \\
19,800 \\
25,800 \\
10,700 \\
1,440\end{array}$ & $\begin{array}{c}20 \\
45 \\
23 \\
12 \\
9.5\end{array}$ & $\begin{array}{r}1,000 \\
5,960 \\
5,900 \\
700 \\
300\end{array}$ & $\begin{array}{r}54 \\
\mathrm{~s} 1,560 \\
366 \\
23 \\
8\end{array}$ & $\begin{array}{r}344 \\
176 \\
41 \\
25 \\
19\end{array}$ & $\begin{array}{r}1,700 \\
840 \\
360 \\
200 \\
130\end{array}$ & $\begin{array}{r}1,580 \\
399 \\
40 \\
14 \\
7\end{array}$ \\
\hline $\begin{array}{l}21 \ldots \ldots \\
22 . \ldots \ldots \\
23 . \ldots \ldots \\
24 \ldots \ldots \\
25 \ldots \ldots\end{array}$ & $\begin{array}{l}532 \\
525 \\
764 \\
553 \\
168\end{array}$ & $\begin{array}{r}600 \\
650 \\
4,000 \\
6,500 \\
1,100\end{array}$ & $\begin{array}{r}862 \\
921 \\
8,250 \\
9,710 \\
499\end{array}$ & $\begin{array}{r}53 \\
35 \\
15 \\
10 \\
7\end{array}$ & $\begin{array}{r}10,700 \\
3,700 \\
1,700 \\
1,300 \\
2,600\end{array}$ & $\begin{array}{r}\mathrm{s} 2,210 \\
350 \\
69 \\
35 \\
49\end{array}$ & $\begin{array}{l}14 \\
14 \\
11 \\
28 \\
16\end{array}$ & $\begin{array}{r}100 \\
65 \\
70 \\
679 \\
865\end{array}$ & $\begin{array}{r}4 \\
2 \\
2 \\
8123 \\
37\end{array}$ \\
\hline $\begin{array}{l}26 \ldots \ldots \\
27 . \ldots \ldots \\
28 . \ldots \ldots \\
29 . \ldots \ldots \\
30 \ldots \ldots \\
31 \ldots \ldots\end{array}$ & $\begin{array}{c}89 \\
57 \\
24 \\
14 \\
8.0 \\
6.2 \\
\end{array}$ & $\begin{array}{r}420 \\
598 \\
290 \\
187 \\
107 \\
83 \\
\end{array}$ & $\begin{array}{r}101 \\
92 \\
19 \\
7 \\
2 \\
1 \\
\end{array}$ & \begin{tabular}{c|}
26 \\
7.1 \\
4.8 \\
3.9 \\
3.9 \\
3.4 \\
\end{tabular} & $\begin{array}{r}10,000 \\
1,100 \\
597 \\
231 \\
153 \\
197 \\
\end{array}$ & $\begin{array}{r}702 \\
21 \\
8 \\
2 \\
2 \\
2 \\
\end{array}$ & $\begin{array}{l}43 \\
50 \\
52 \\
59 \\
38 \\
-- \\
\end{array}$ & $\begin{array}{r}580 \\
755 \\
720 \\
1,000 \\
1,760 \\
\end{array}$ & $\begin{array}{r}67 \\
102 \\
101 \\
159 \\
181 \\
- \\
\end{array}$ \\
\hline Total. & $11,524.2$ & -- & 164,596 & $1,227.8$ & - & 85,894 & 6,845 & $\cdots$ & 179,526 \\
\hline
\end{tabular}

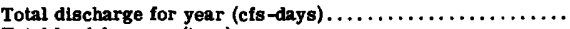

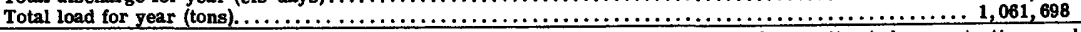

$s$ Computed by subdividing day.

a Computed from estimated concentration graph.

t Less than 0.50 ton. 


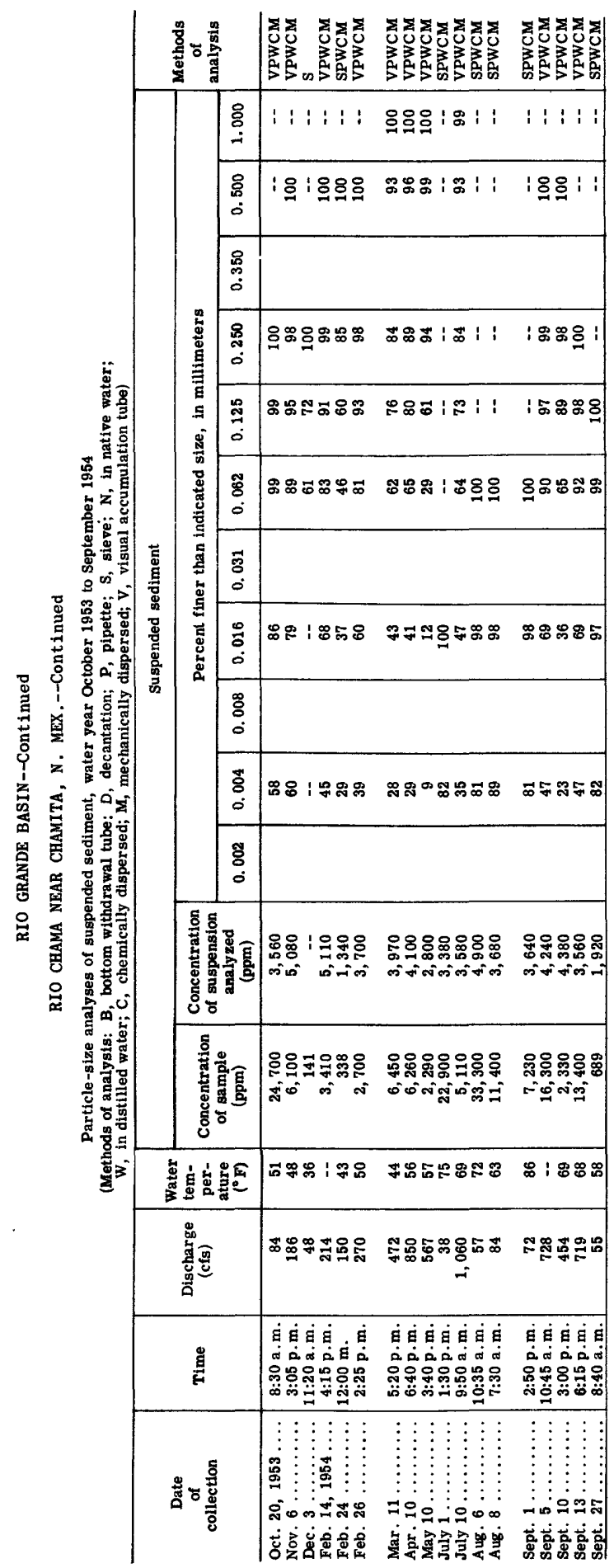


$\stackrel{\square}{\stackrel{0}{*}}$

$\Rightarrow$

- -

要

ช0.

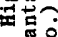

ฝึ.

范然

ธ็ำ

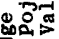

둥잉

穿苋

है की

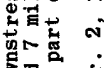

递

\begin{tabular}{|c|c|c|c|}
\hline İ & Fis & $\rightarrow \infty$ & \\
\hline 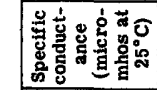 & 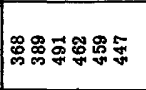 & 蹋器 & 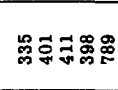 \\
\hline 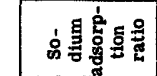 & & & \\
\hline 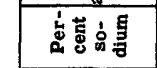 & 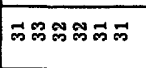 & 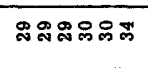 & 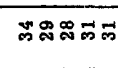 \\
\hline 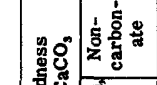 & $009 \approx \approx=$ & N & \\
\hline 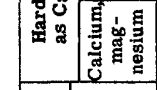 & 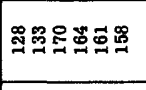 & స్తి స్ & 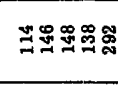 \\
\hline 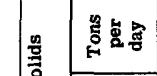 & 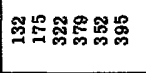 & 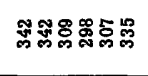 & 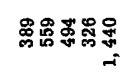 \\
\hline 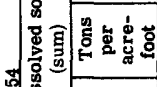 & 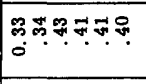 & ల్లాణ్లైల్లే & ణ్లో \\
\hline 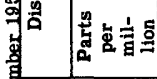 & 纸芯 & 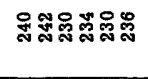 & జ్ส: ప్స : \\
\hline 官哭鱼 & & & \\
\hline 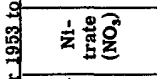 & $a_{0}^{\infty}:$ & & \\
\hline 乌。 & & & \\
\hline 형현 & $\cong \approx$ & 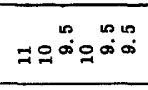 & in \\
\hline 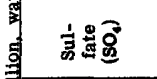 & 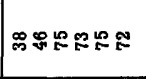 & 우 & 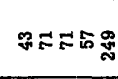 \\
\hline ปู & 000000 & 000000 & 000 \\
\hline 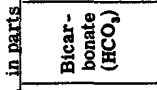 & 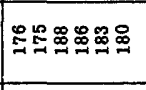 & 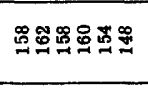 & 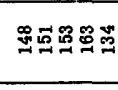 \\
\hline 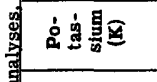 & $\begin{array}{lllllll}1 & 1 & 1 & 1 & 1 & 1 \\
\end{array}$ & 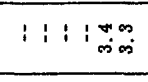 & 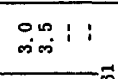 \\
\hline 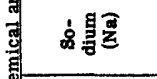 & 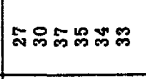 & 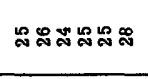 & 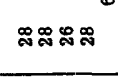 \\
\hline 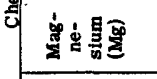 & 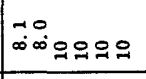 & 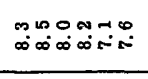 & 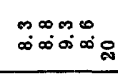 \\
\hline 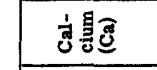 & 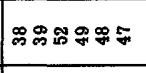 & 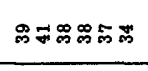 & జี \\
\hline 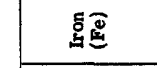 & & & \\
\hline 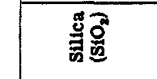 & 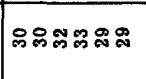 & 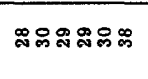 & ๒งลลㅇำ \\
\hline 氙孚 & 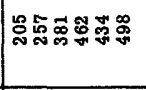 & 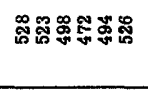 & น̊ํำ: \\
\hline 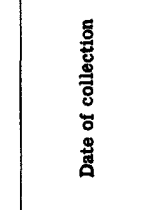 & 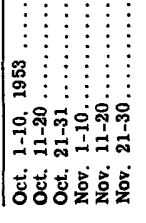 & 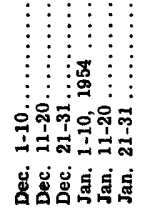 & 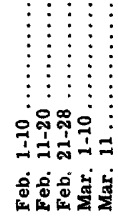 \\
\hline
\end{tabular}




\begin{tabular}{|c|c|c|c|c|c|c|}
\hline & Iㅁ & 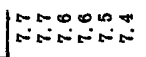 & 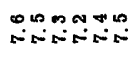 & 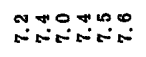 & 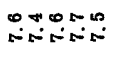 & \\
\hline & 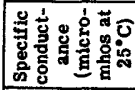 & 陆 & 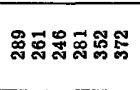 & 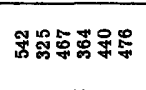 & 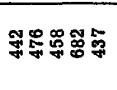 & : \\
\hline & 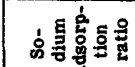 & if. & ? & $\dddot{N}^{\circ}$ & 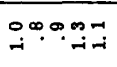 & $\infty$ \\
\hline & 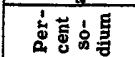 & 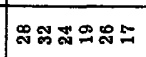 & 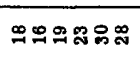 & ชัสฏณณ & 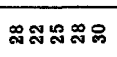 & 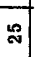 \\
\hline & 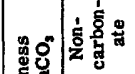 & 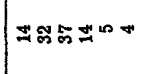 & 000000 & 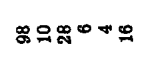 & 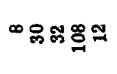 & \pm \\
\hline & 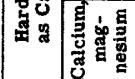 & 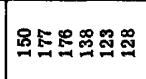 & 承荨음워 & 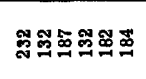 & 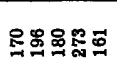 & 9 \\
\hline & 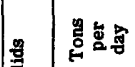 & 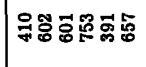 & 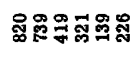 & 品 & 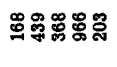 & 8 \\
\hline & 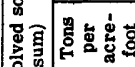 & 品 & 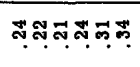 & 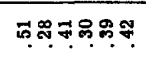 & 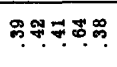 & $\mid$ \\
\hline 节 & 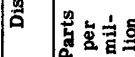 & 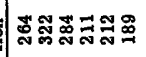 & 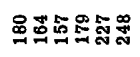 & 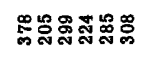 & 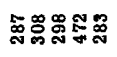 & พ \\
\hline$\dot{x}$ & 㝘 & & & & & \\
\hline $\begin{array}{ll}\frac{\omega}{2} & \bar{g} \\
\dot{z} & \stackrel{5}{2}\end{array}$ & 立造家 & | & זידים ים ידי & 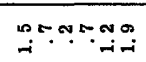 & " & 0 \\
\hline 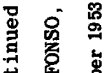 & 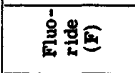 & & & & & \\
\hline 岂 & 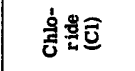 & $\mid \begin{array}{lll}\ln \\
\infty \\
\infty \\
\infty\end{array}$ & 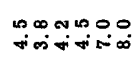 & $\begin{array}{l}\text { onous } \\
\text { insionitiso }\end{array}$ & 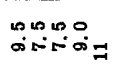 & $\infty$ \\
\hline 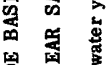 & 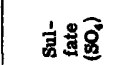 & 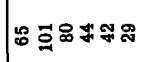 & 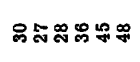 & 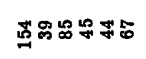 & 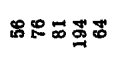 & $\infty$ \\
\hline 电 & मी & 1000000 & 000000 & 000000 & 00000 & 0 \\
\hline 害 & 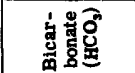 & 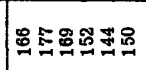 & 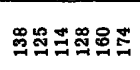 & 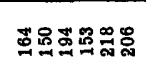 & 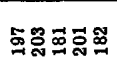 & $\tilde{\omega}$ \\
\hline 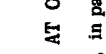 & 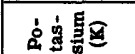 & 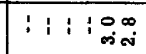 & 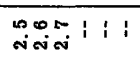 & $1: 11: 11$ & 1:1:1 & $i$ \\
\hline 宸 & 安害要 & 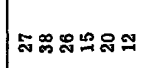 & 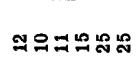 & 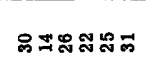 & 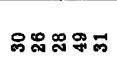 & ส \\
\hline 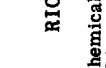 & 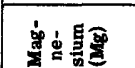 & 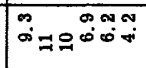 & 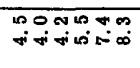 & 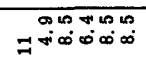 & 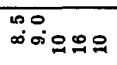 & 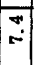 \\
\hline & 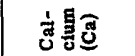 & 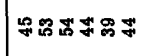 & 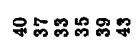 & 오무요요 & 보요 & $\$$ \\
\hline & : & & & & & \\
\hline & 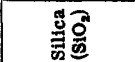 & స & 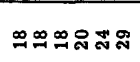 & 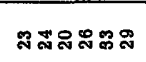 & 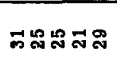 & 电 \\
\hline & 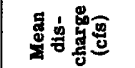 & 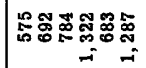 & 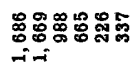 & 웅 & 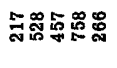 & : \\
\hline & 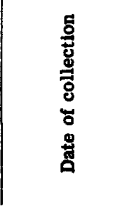 & 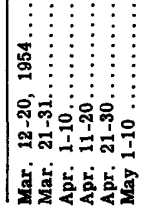 & 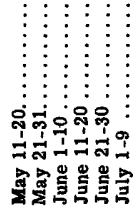 & 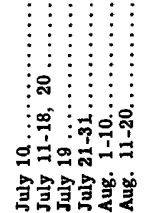 & 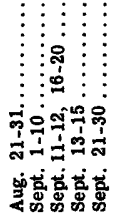 & 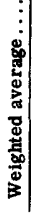 \\
\hline
\end{tabular}




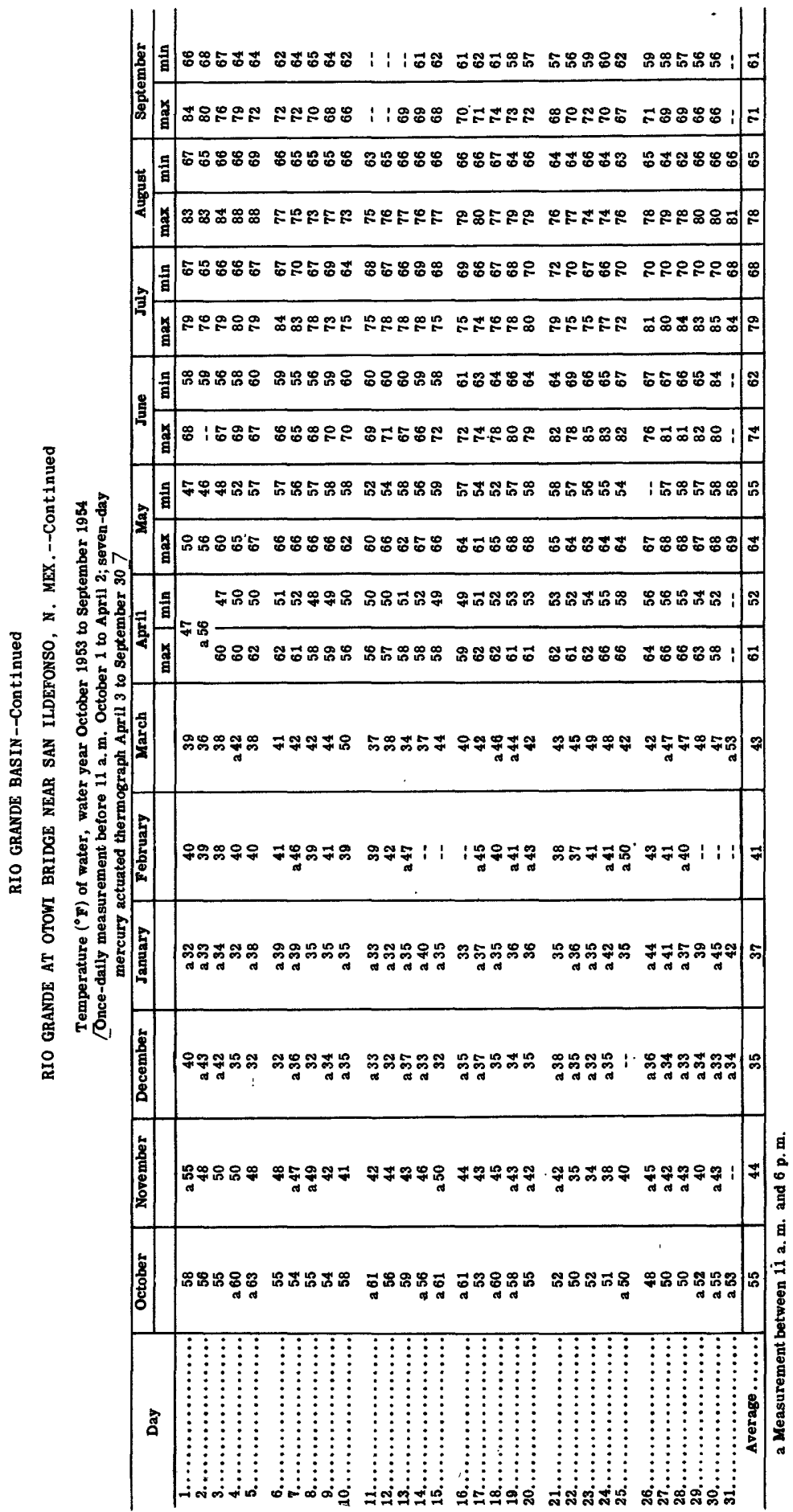


RIO GRANDE BASIN--Continued

RIO GRANDE AT OTOWI BRIDGE NEAR SAN ILDEFONSO, N. MEX.--Continued

Suspended sediment, water year October 1953 to September 1954

\begin{tabular}{|c|c|c|c|c|c|c|c|c|c|}
\hline \multirow[b]{3}{*}{ Day } & \multicolumn{3}{|c|}{ October } & \multicolumn{3}{|c|}{ November } & \multicolumn{3}{|c|}{ December } \\
\hline & \multirow[b]{2}{*}{$\begin{array}{l}\text { Mean } \\
\text { dis- } \\
\text { charge } \\
\text { (cfs) }\end{array}$} & \multicolumn{2}{|c|}{ Suspended sediment } & \multirow[b]{2}{*}{$\begin{array}{c}\text { Mean } \\
\text { dis- } \\
\text { charge } \\
\text { (cfs) }\end{array}$} & \multicolumn{2}{|c|}{ Suspended sediment } & \multirow[b]{2}{*}{$\begin{array}{c}\text { Mean } \\
\text { dis- } \\
\text { charge } \\
\text { (cfs) }\end{array}$} & \multicolumn{2}{|c|}{ Suspended sediment } \\
\hline & & $\begin{array}{l}\text { Mean } \\
\text { concen- } \\
\text { tration } \\
(\mathrm{ppm})\end{array}$ & $\begin{array}{l}\text { Tons } \\
\text { per } \\
\text { day }\end{array}$ & & $\begin{array}{c}\text { Mean } \\
\text { concen- } \\
\text { tration } \\
\text { (ppm) }\end{array}$ & $\begin{array}{l}\text { Tons } \\
\text { per } \\
\text { day }\end{array}$ & & $\begin{array}{l}\text { Mean } \\
\text { concen- } \\
\text { tration } \\
(\mathrm{ppm})\end{array}$ & $\begin{array}{l}\text { Tons } \\
\text { per } \\
\text { day }\end{array}$ \\
\hline $\begin{array}{l}\ldots \ldots \\
2 \ldots \ldots \\
3 \ldots \ldots \\
4 \ldots \ldots \\
5 . \ldots \ldots\end{array}$ & $\begin{array}{l}196 \\
194 \\
194 \\
203 \\
206\end{array}$ & $\begin{array}{l}27 \\
21 \\
28 \\
26 \\
24\end{array}$ & $\begin{array}{l}14 \\
11 \\
15 \\
14 \\
13\end{array}$ & $\begin{array}{l}360 \\
360 \\
360 \\
355 \\
350\end{array}$ & $\begin{array}{r}119 \\
114 \\
125 \\
94 \\
97\end{array}$ & $\begin{array}{r}116 \\
111 \\
122 \\
90 \\
92\end{array}$ & $\begin{array}{l}591 \\
630 \\
665 \\
635 \\
549\end{array}$ & $\begin{array}{l}223 \\
300 \\
260 \\
140 \\
148\end{array}$ & $\begin{array}{l}356 \\
510 \\
467 \\
240 \\
219\end{array}$ \\
\hline $\begin{array}{r}6 \ldots \ldots \\
7 \ldots \ldots \\
8 \ldots \ldots \\
9 \ldots \ldots \\
10 \ldots \ldots\end{array}$ & $\begin{array}{l}206 \\
216 \\
211 \\
216 \\
211\end{array}$ & $\begin{array}{l}25 \\
29 \\
53 \\
40 \\
35\end{array}$ & $\begin{array}{l}14 \\
17 \\
30 \\
23 \\
20\end{array}$ & $\begin{array}{l}781 \\
635 \\
491 \\
473 \\
451\end{array}$ & $\begin{array}{r}3,350 \\
1,160 \\
500 \\
770 \\
600\end{array}$ & $\begin{array}{r}\text { s 7, } 830 \\
1,990 \\
663 \\
983 \\
731\end{array}$ & $\begin{array}{l}478 \\
397 \\
418 \\
456 \\
464\end{array}$ & $\begin{array}{r}95 \\
76 \\
57 \\
60 \\
117\end{array}$ & $\begin{array}{r}123 \\
81 \\
64 \\
74 \\
147\end{array}$ \\
\hline $\begin{array}{l}11 \ldots \ldots \\
12 \ldots \ldots \\
13 \ldots \ldots \\
14 \ldots \ldots \\
15 \ldots \ldots\end{array}$ & $\begin{array}{l}221 \\
229 \\
237 \\
251 \\
256\end{array}$ & $\begin{array}{l}43 \\
40 \\
43 \\
43 \\
55\end{array}$ & $\begin{array}{l}26 \\
25 \\
28 \\
29 \\
38\end{array}$ & $\begin{array}{r}434 \\
434 \\
-430 \\
426 \\
426\end{array}$ & $\begin{array}{l}290 \\
175 \\
157 \\
121 \\
112\end{array}$ & $\begin{array}{l}340 \\
205 \\
182 \\
139 \\
129\end{array}$ & $\begin{array}{l}496 \\
496 \\
460 \\
501 \\
510\end{array}$ & $\begin{array}{r}162 \\
134 \\
107 \\
99 \\
109\end{array}$ & $\begin{array}{l}217 \\
179 \\
133 \\
134 \\
150\end{array}$ \\
\hline $\begin{array}{l}16 \ldots \ldots \\
17 \ldots \ldots \\
18 \ldots \ldots \\
19 \ldots \ldots \\
20 \ldots \ldots\end{array}$ & $\begin{array}{l}254 \\
254 \\
254 \\
248 \\
369\end{array}$ & $\begin{array}{r}43 \\
60 \\
45 \\
37 \\
8,280\end{array}$ & $\begin{array}{r}29 \\
41 \\
31 \\
25 \\
\mathrm{~s} 10,400\end{array}$ & $\begin{array}{l}422 \\
422 \\
430 \\
460 \\
451\end{array}$ & $\begin{array}{r}127 \\
99 \\
99 \\
137 \\
113\end{array}$ & $\begin{array}{l}145 \\
113 \\
115 \\
170 \\
138\end{array}$ & $\begin{array}{l}\mathbf{5 2 4} \\
\mathbf{5 4 9} \\
\mathbf{5 6 0} \\
\mathbf{5 6 5} \\
\mathbf{5 7 0}\end{array}$ & $\begin{array}{r}61 \\
58 \\
78 \\
118 \\
85\end{array}$ & $\begin{array}{r}86 \\
86 \\
118 \\
180 \\
131\end{array}$ \\
\hline $\begin{array}{l}21 \ldots \ldots \\
22 \ldots \ldots \\
23 \ldots \ldots \\
24 \ldots \ldots \\
25 \ldots \ldots\end{array}$ & $\begin{array}{l}359 \\
350 \\
360 \\
422 \\
442\end{array}$ & $\begin{array}{r}3,750 \\
600 \\
400 \\
2,800 \\
1,500\end{array}$ & $\begin{array}{r}3,630 \\
567 \\
389 \\
3,190 \\
1,790\end{array}$ & $\begin{array}{l}456 \\
418 \\
405 \\
456 \\
464\end{array}$ & $\begin{array}{r}123 \\
77 \\
114 \\
153 \\
110\end{array}$ & $\begin{array}{r}151 \\
87 \\
125 \\
188 \\
138\end{array}$ & $\begin{array}{l}580 \\
560 \\
510 \\
456 \\
487\end{array}$ & $\begin{array}{r}88 \\
84 \\
130 \\
109 \\
120\end{array}$ & $\begin{array}{r}138 \\
127 \\
179 \\
134 \\
\mathrm{a} 160\end{array}$ \\
\hline $\begin{array}{l}26 \ldots \ldots \\
27 \ldots \ldots \\
28 . \ldots \ldots \\
29 \ldots \ldots \\
30 \ldots \ldots \\
31 \ldots \ldots\end{array}$ & $\begin{array}{l}389 \\
386 \\
386 \\
382 \\
360 \\
360 \\
\end{array}$ & $\begin{array}{l}345 \\
256 \\
223 \\
164 \\
131 \\
120 \\
\end{array}$ & $\begin{array}{l}362 \\
267 \\
232 \\
169 \\
127 \\
117 \\
\end{array}$ & $\begin{array}{c}496 \\
520 \\
565 \\
608 \\
596 \\
-- \\
\end{array}$ & $\begin{array}{l}117 \\
181 \\
196 \\
225 \\
196 \\
-- \\
\end{array}$ & $\begin{array}{c}157 \\
254 \\
299 \\
369 \\
315 \\
-- \\
\end{array}$ & $\begin{array}{l}510 \\
491 \\
491 \\
473 \\
464 \\
460 \\
\end{array}$ & $\begin{array}{r}144 \\
88 \\
92 \\
100 \\
63 \\
79 \\
\end{array}$ & $\begin{array}{r}198 \\
117 \\
122 \\
128 \\
79 \\
98 \\
\end{array}$ \\
\hline \multirow[t]{2}{*}{ Total. } & 8,822 & -- & 21,683 & 13,935 & -- & 16,487 & 15,996 & - & 5,175 \\
\hline & \multicolumn{3}{|c|}{ January } & \multicolumn{3}{|c|}{ February } & \multicolumn{3}{|c|}{ March } \\
\hline $\begin{array}{l}1 \ldots \ldots \\
2 \ldots \ldots \\
3 . \ldots \\
4 \ldots \ldots \\
5 \ldots \ldots\end{array}$ & $\begin{array}{l}434 \\
447 \\
462 \\
466 \\
466\end{array}$ & $\begin{array}{r}112 \\
97 \\
94 \\
96 \\
82\end{array}$ & $\begin{array}{l}131 \\
117 \\
117 \\
121 \\
103\end{array}$ & $\begin{array}{l}579 \\
584 \\
574 \\
574 \\
589\end{array}$ & \begin{tabular}{r|}
98 \\
121 \\
131 \\
114 \\
108
\end{tabular} & $\begin{array}{l}153 \\
191 \\
203 \\
177 \\
172\end{array}$ & $\begin{array}{l}515 \\
478 \\
474 \\
447 \\
447\end{array}$ & $\begin{array}{r}134 \\
145 \\
120 \\
90 \\
125\end{array}$ & $\begin{array}{l}186 \\
187 \\
154 \\
109 \\
151\end{array}$ \\
\hline $\begin{array}{r}6 \ldots \ldots \\
7 \ldots \ldots \\
8 \ldots \ldots \\
9 \ldots \ldots \\
10 \ldots \ldots\end{array}$ & $\begin{array}{l}470 \\
482 \\
503 \\
499 \\
495\end{array}$ & $\begin{array}{r}81 \\
80 \\
100 \\
81 \\
71\end{array}$ & $\begin{array}{r}103 \\
104 \\
136 \\
109 \\
95\end{array}$ & $\begin{array}{l}603 \\
603 \\
598 \\
613 \\
629\end{array}$ & $\begin{array}{r}117 \\
103 \\
95 \\
84 \\
90\end{array}$ & $\begin{array}{l}190 \\
168 \\
153 \\
139 \\
153\end{array}$ & $\begin{array}{l}507 \\
486 \\
470 \\
466 \\
462 \\
\end{array}$ & $\begin{array}{r}110 \\
100 \\
80 \\
90 \\
100\end{array}$ & $\begin{array}{l}151 \\
131 \\
102 \\
113 \\
125\end{array}$ \\
\hline $\begin{array}{l}11 \ldots \ldots \\
12 \ldots \ldots \\
13 \ldots \ldots \\
14 \ldots \ldots \\
15 \ldots \ldots\end{array}$ & $\begin{array}{r}482 \\
\quad 474 \\
478 \\
515 \\
495\end{array}$ & $\begin{array}{r}67 \\
74 \\
89 \\
76 \\
105\end{array}$ & $\begin{array}{r}87 \\
95 \\
115 \\
106 \\
140\end{array}$ & $\begin{array}{l}634 \\
645 \\
764 \\
946 \\
914\end{array}$ & $\begin{array}{r}144 \\
160 \\
921 \\
1,620 \\
1,020\end{array}$ & $\begin{array}{r}246 \\
279 \\
\mathrm{~s} 2,270 \\
4,140 \\
2,520\end{array}$ & $\begin{array}{r}994 \\
1,110 \\
938 \\
533 \\
451\end{array}$ & $\begin{array}{r}3,580 \\
2,180 \\
1,410 \\
470 \\
140\end{array}$ & $\begin{array}{r}\mathbf{1 0 ,} \mathbf{2 0 0} \\
6,530 \\
3,570 \\
676 \\
170\end{array}$ \\
\hline $\begin{array}{l}16 \ldots \ldots \\
17 \ldots \ldots \\
18 \ldots \ldots \\
19 \ldots \ldots \\
20 . \ldots \ldots\end{array}$ & $\begin{array}{l}482 \\
490 \\
490 \\
511 \\
520\end{array}$ & $\begin{array}{r}84 \\
73 \\
67 \\
89 \\
103\end{array}$ & $\begin{array}{r}109 \\
97 \\
89 \\
123 \\
145\end{array}$ & $\begin{array}{l}848 \\
821 \\
762 \\
724 \\
701\end{array}$ & $\begin{array}{l}730 \\
590 \\
430 \\
345 \\
280\end{array}$ & $\begin{array}{r}1,670 \\
1,310 \\
885 \\
674 \\
530\end{array}$ & $\begin{array}{l}440 \\
466 \\
432 \\
418 \\
389\end{array}$ & $\begin{array}{r}100 \\
120 \\
120 \\
89 \\
99\end{array}$ & $\begin{array}{l}119 \\
151 \\
140 \\
100 \\
104\end{array}$ \\
\hline $\begin{array}{l}21 \ldots \ldots \\
22 . \ldots \ldots \\
23 . \ldots \ldots \\
24 \ldots \ldots \\
25 . \ldots \ldots\end{array}$ & $\begin{array}{l}511 \\
503 \\
482 \\
490 \\
529\end{array}$ & $\begin{array}{r}80 \\
77 \\
93 \\
110 \\
114\end{array}$ & $\begin{array}{l}110 \\
105 \\
121 \\
146 \\
163\end{array}$ & $\begin{array}{l}684 \\
666 \\
678 \\
672 \\
684 \\
\end{array}$ & $\begin{array}{l}195 \\
170 \\
190 \\
160 \\
432\end{array}$ & $\begin{array}{l}360 \\
306 \\
348 \\
290 \\
798\end{array}$ & $\begin{array}{r}407 \\
407 \\
462 \\
808 \\
1,020\end{array}$ & $\begin{array}{r}135 \\
100 \\
120 \\
3,590 \\
11,600\end{array}$ & $\begin{array}{r}148 \\
110 \\
150 \\
7,830 \\
31,900\end{array}$ \\
\hline $\begin{array}{l}26 \ldots \ldots \\
27 \ldots \ldots \\
28 . \ldots \ldots \\
29 \ldots \ldots \\
30 \ldots \ldots \\
31 \ldots \ldots\end{array}$ & $\begin{array}{l}551 \\
533 \\
533 \\
542 \\
551 \\
565 \\
\end{array}$ & $\begin{array}{r}98 \\
75 \\
89 \\
111 \\
112 \\
81 \\
\end{array}$ & $\begin{array}{l}146 \\
108 \\
128 \\
162 \\
167 \\
124 \\
\end{array}$ & $\begin{array}{r}969 \\
678 \\
555 \\
-- \\
-- \\
- \\
\end{array}$ & $\begin{array}{r}1,550 \\
520 \\
160 \\
-- \\
-- \\
\end{array}$ & $\begin{array}{r}4,060 \\
952 \\
240 \\
-. \\
-- \\
- \\
\end{array}$ & $\begin{array}{r}930 \\
848 \\
608 \\
579 \\
533 \\
1,010 \\
\end{array}$ & $\begin{array}{r}4,190 \\
1,380 \\
700 \\
2,700 \\
1,300 \\
5,900 \\
\end{array}$ & $\begin{array}{r}10,500 \\
3,160 \\
1,150 \\
4,220 \\
1,870 \\
16,100\end{array}$ \\
\hline Total. & 15,451 & -- & 3,722 & 19,291 & $\ldots$ & 23,577 & 18,535 & $=$ & 100,307 \\
\hline
\end{tabular}


RIO GRANDE BASIN--Continued

RIO GRANDE AT OTOWI BRIDGE NEAR SAN ILDEFONSO, N. MEX.--Continued

Suspended sediment, water year October 1953 to September 1954 --Continued

\begin{tabular}{|c|c|c|c|c|c|c|c|c|c|}
\hline \multirow[b]{3}{*}{ Day } & \multicolumn{3}{|c|}{ April } & \multicolumn{3}{|c|}{ May } & \multicolumn{3}{|c|}{ June } \\
\hline & \multirow[b]{2}{*}{$\begin{array}{c}\text { Mean } \\
\text { dis - } \\
\text { charge } \\
\text { (cfs) }\end{array}$} & \multicolumn{2}{|c|}{ Suspended sediment } & \multirow[b]{2}{*}{$\begin{array}{l}\text { Mean } \\
\text { dis- } \\
\text { charge } \\
\text { (cfs) }\end{array}$} & \multicolumn{2}{|c|}{ Suspended sediment } & \multirow[b]{2}{*}{$\begin{array}{c}\text { Mean } \\
\text { dis- } \\
\text { charge } \\
\text { (cfs) }\end{array}$} & \multicolumn{2}{|c|}{ Suspended sediment } \\
\hline & & $\begin{array}{l}\text { Mean } \\
\text { concen- } \\
\text { tration } \\
(\mathrm{ppm}) \\
\end{array}$ & $\begin{array}{l}\text { Tons } \\
\text { per } \\
\text { day }\end{array}$ & & $\begin{array}{l}\text { Mean } \\
\text { concen- } \\
\text { tration } \\
\text { (ppm) } \\
\end{array}$ & $\begin{array}{l}\text { Tons } \\
\text { per } \\
\text { day }\end{array}$ & & $\begin{array}{c}\text { Mean } \\
\text { concen- } \\
\text { tration } \\
(\mathrm{ppm})\end{array}$ & $\begin{array}{l}\text { Tons } \\
\text { per } \\
\text { day }\end{array}$ \\
\hline $\begin{array}{l}1, \ldots \ldots \\
2 . \ldots \ldots \\
3 . \ldots \ldots \\
4 \ldots \ldots \\
5 \ldots \ldots\end{array}$ & $\begin{array}{l}969 \\
706 \\
533 \\
524 \\
537\end{array}$ & $\begin{array}{r}2,040 \\
920 \\
310 \\
240 \\
260\end{array}$ & $\begin{array}{r}5,340 \\
1,750 \\
446 \\
340 \\
377\end{array}$ & $\begin{array}{l}1,790 \\
1,850 \\
1,550 \\
1,270 \\
1,110\end{array}$ & $\begin{array}{l}4,730 \\
4,650 \\
2,630 \\
1,650 \\
1,300\end{array}$ & $\begin{array}{r}22,900 \\
23,200 \\
11,000 \\
5,660 \\
3,900\end{array}$ & $\begin{array}{r}1,150 \\
1,090 \\
1,010 \\
993 \\
997\end{array}$ & $\begin{array}{l}780 \\
570 \\
665 \\
740 \\
725\end{array}$ & $\begin{array}{l}2,420 \\
1,680 \\
1,810 \\
1,980 \\
1,950\end{array}$ \\
\hline $\begin{array}{r}6 \ldots \ldots \\
7 \ldots \ldots \\
8 \ldots \ldots \\
9 \ldots \ldots \\
10 \ldots \ldots\end{array}$ & $\begin{array}{r}579 \\
672 \\
794 \\
1,170 \\
1,360\end{array}$ & $\begin{array}{r}400 \\
540 \\
1,100 \\
2,600 \\
3,120\end{array}$ & $\begin{array}{r}625 \\
980 \\
2,360 \\
8,210 \\
11,500\end{array}$ & $\begin{array}{l}1,080 \\
1,070 \\
1,040 \\
1,040 \\
1,070\end{array}$ & $\begin{array}{r}1,080 \\
1,000 \\
1,000 \\
920 \\
900\end{array}$ & $\begin{array}{l}3,150 \\
2,890 \\
2,810 \\
2,580 \\
2,600\end{array}$ & $\begin{array}{l}961 \\
954 \\
946 \\
930 \\
870\end{array}$ & $\begin{array}{l}700 \\
610 \\
610 \\
615 \\
615\end{array}$ & $\begin{array}{r}1,820 \\
748 \\
1,560 \\
1,540 \\
1,440\end{array}$ \\
\hline $\begin{array}{l}11 . \ldots \ldots \\
12 \ldots \ldots \\
13 . \ldots \ldots \\
14 \ldots \ldots \\
15 \ldots \ldots\end{array}$ & $\begin{array}{l}1,470 \\
1,560 \\
1,620 \\
1,780 \\
1,770\end{array}$ & $\begin{array}{l}3,500 \\
4,000 \\
4,080 \\
4,880 \\
3,580\end{array}$ & $\begin{array}{l}13,900 \\
16,800 \\
17,800 \\
23,500 \\
17,100\end{array}$ & $\begin{array}{l}1,420 \\
1,430 \\
1,370 \\
1,360 \\
1,670\end{array}$ & $\begin{array}{l}2,100 \\
1,960 \\
1,890 \\
1,320 \\
2,750\end{array}$ & $\begin{array}{r}8,050 \\
7,570 \\
6,990 \\
4,850 \\
12,400\end{array}$ & $\begin{array}{l}863 \\
848 \\
885 \\
878 \\
834\end{array}$ & $\begin{array}{l}505 \\
405 \\
445 \\
370 \\
490\end{array}$ & $\begin{array}{r}1,180 \\
927 \\
1,060 \\
877 \\
1,100\end{array}$ \\
\hline $\begin{array}{l}16 . \ldots \ldots \\
17 . \ldots \ldots \\
18 . \ldots \\
19 . \ldots \\
20 \ldots \ldots\end{array}$ & $\begin{array}{r}1,150 \\
993 \\
993 \\
993 \\
892\end{array}$ & $\begin{array}{r}1,480 \\
1,200 \\
1,200 \\
1,100 \\
790\end{array}$ & $\begin{array}{l}4,600 \\
3,220 \\
3,220 \\
2,950 \\
1,900\end{array}$ & $\begin{array}{l}1,910 \\
2,030 \\
1,970 \\
1,850 \\
1,850\end{array}$ & $\begin{array}{l}3,300 \\
2,940 \\
2,950 \\
2,190 \\
2,130\end{array}$ & $\begin{array}{l}17,000 \\
16,100 \\
15,700 \\
10,900 \\
10,600\end{array}$ & $\begin{array}{l}814 \\
666 \\
348 \\
271 \\
246\end{array}$ & $\begin{array}{r}500 \\
330 \\
150 \\
95 \\
80\end{array}$ & $\begin{array}{r}1,100 \\
593 \\
141 \\
70 \\
53\end{array}$ \\
\hline $\begin{array}{l}21 \ldots \ldots \\
22 . \ldots \ldots \\
23 . \ldots \ldots \\
24 \ldots \ldots \\
25 . \ldots \ldots\end{array}$ & $\begin{array}{l}781 \\
737 \\
731 \\
689 \\
655\end{array}$ & $\begin{array}{l}410 \\
330 \\
400 \\
495 \\
610\end{array}$ & $\begin{array}{r}865 \\
657 \\
789 \\
921 \\
1,080\end{array}$ & $\begin{array}{l}1,790 \\
1,850 \\
2,030 \\
2,030 \\
1,970\end{array}$ & $\begin{array}{l}2,530 \\
2,000 \\
2,240 \\
2,440 \\
2,000\end{array}$ & $\begin{array}{r}12,200 \\
9,990 \\
12,300 \\
13,400 \\
10,600\end{array}$ & $\begin{array}{l}246 \\
220 \\
211 \\
206 \\
209\end{array}$ & $\begin{array}{l}85 \\
54 \\
70 \\
53 \\
48\end{array}$ & $\begin{array}{l}56 \\
32 \\
40 \\
29 \\
27\end{array}$ \\
\hline $\begin{array}{l}26 \ldots \ldots \\
27 . \ldots \ldots \\
28 . \ldots \ldots \\
29 . \ldots \ldots \\
30 \ldots \ldots \\
31 \ldots \ldots\end{array}$ & $\begin{array}{r}655 \\
593 \\
560 \\
503 \\
925 \\
-- \\
\end{array}$ & $\begin{array}{r}320 \\
285 \\
200 \\
190 \\
3,600 \\
---\end{array}$ & $\begin{array}{r}566 \\
456 \\
302 \\
258 \\
\mathrm{~s} 14,900\end{array}$ & $\begin{array}{l}1,970 \\
1,700 \\
1,330 \\
1,230 \\
1,240 \\
1,220 \\
\end{array}$ & $\begin{array}{r}2,030 \\
1,660 \\
1,100 \\
1,000 \\
1,130 \\
940 \\
\end{array}$ & $\begin{array}{r}10,800 \\
7,620 \\
3,950 \\
3,320 \\
3,780 \\
3,100 \\
\end{array}$ & $\begin{array}{r}261 \\
251 \\
225 \\
213 \\
213 \\
- \\
\end{array}$ & $\begin{array}{r}480 \\
190 \\
77 \\
73 \\
650 \\
-- \\
\end{array}$ & $\begin{array}{r}338 \\
129 \\
47 \\
42 \\
374 \\
--\end{array}$ \\
\hline \multirow[t]{2}{*}{ Total. } & 27,894 & -- & 157,712 & 48,090 & - & 281,910 & 18,789 & -- & 25,163 \\
\hline & \multicolumn{3}{|c|}{ July } & \multicolumn{3}{|c|}{ August } & \multicolumn{3}{|c|}{ September } \\
\hline $\begin{array}{l}1 . \ldots \ldots \\
2 . \ldots \ldots \\
3 . \ldots \\
4 \ldots \\
5 \ldots\end{array}$ & $\begin{array}{l}255 \\
225 \\
234 \\
237 \\
251\end{array}$ & $\begin{array}{r}970 \\
1,410 \\
290 \\
240 \\
185\end{array}$ & $\begin{array}{l}589 \\
857 \\
183 \\
154 \\
125\end{array}$ & $\begin{array}{l}184 \\
174 \\
172 \\
165 \\
165\end{array}$ & $\begin{array}{l}570 \\
233 \\
175 \\
166 \\
200\end{array}$ & $\begin{array}{r}283 \\
109 \\
81 \\
74 \\
89\end{array}$ & $\begin{array}{l}178 \\
197 \\
184 \\
206 \\
890\end{array}$ & $\begin{array}{r}1,190 \\
2,370 \\
2,800 \\
3,200 \\
23,400\end{array}$ & $\begin{array}{r}572 \\
1,260 \\
1,390 \\
1,780 \\
\mathbf{5 7}, 900\end{array}$ \\
\hline $\begin{array}{r}6 \ldots \ldots \\
7 \ldots \ldots \\
8 \ldots \\
9 \ldots \\
10 . \ldots\end{array}$ & $\begin{array}{r}225 \\
206 \\
206 \\
1,220 \\
1,310\end{array}$ & $\begin{array}{r}105 \\
170 \\
100 \\
5,200 \\
4,800\end{array}$ & $\begin{array}{r}64 \\
95 \\
56 \\
17,100 \\
17,000\end{array}$ & $\begin{array}{l}348 \\
411 \\
490 \\
304 \\
492\end{array}$ & $\begin{array}{l}34,400 \\
29,500 \\
14,000 \\
10,800 \\
28,900\end{array}$ & $\begin{array}{r}s 43,600 \\
s 37,000 \\
18,500 \\
8,860 \\
\text { s } 73,700\end{array}$ & $\begin{array}{l}872 \\
688 \\
694 \\
694 \\
682\end{array}$ & $\begin{array}{l}8,000 \\
4,300 \\
2,600 \\
2,000 \\
1,800\end{array}$ & $\begin{array}{r}18,800 \\
7,990 \\
4,870 \\
3,750 \\
3,310\end{array}$ \\
\hline $\begin{array}{l}11 . \ldots \ldots \\
12 . \ldots \ldots \\
13 . \ldots \ldots \\
14 . \ldots \\
15 . \ldots \ldots\end{array}$ & $\begin{array}{r}1,040 \\
863 \\
794 \\
768 \\
755\end{array}$ & $\begin{array}{r}1,820 \\
4,680 \\
2,400 \\
920 \\
800\end{array}$ & $\begin{array}{r}5,110 \\
10,900 \\
5,150 \\
1,910 \\
1,630\end{array}$ & $\begin{array}{l}376 \\
250 \\
404 \\
382 \\
446\end{array}$ & $\begin{array}{r}25,100 \\
9,000 \\
8,450 \\
7,000 \\
12,700\end{array}$ & $\begin{array}{r}s 30,300 \\
6,080 \\
s 9,630 \\
7,220 \\
s 37,400\end{array}$ & $\begin{array}{l}676 \\
657 \\
898 \\
726 \\
651\end{array}$ & $\begin{array}{r}2,000 \\
2,100 \\
13,400 \\
20,100 \\
5,400\end{array}$ & $\begin{array}{r}3,650 \\
3,730 \\
\mathrm{~s} 39,200 \\
39,400 \\
9,490\end{array}$ \\
\hline $\begin{array}{l}16 . \ldots \ldots \\
17 . \ldots \ldots \\
18 \ldots \ldots \\
19 . \ldots \ldots \\
20 . \ldots \ldots\end{array}$ & $\begin{array}{l}743 \\
787 \\
781 \\
743 \\
718\end{array}$ & $\begin{array}{r}940 \\
1,800 \\
6,500 \\
7,180 \\
1,350\end{array}$ & $\begin{array}{r}1,890 \\
3,820 \\
\mathrm{a} 14,000 \\
14,400 \\
2,620\end{array}$ & $\begin{array}{l}329 \\
265 \\
273 \\
226 \\
213\end{array}$ & $\begin{array}{l}9,000 \\
3,600 \\
8,300 \\
2,100 \\
2,000\end{array}$ & $\begin{array}{l}7,990 \\
2,580 \\
6,120 \\
1,280 \\
1,150\end{array}$ & $\begin{array}{l}581 \\
460 \\
330 \\
250 \\
247\end{array}$ & $\begin{array}{r}1,740 \\
1,250 \\
640 \\
346 \\
370\end{array}$ & $\begin{array}{r}2,730 \\
1,550 \\
570 \\
234 \\
247\end{array}$ \\
\hline $\begin{array}{l}21 . \ldots \ldots \\
22 . \ldots \ldots \\
23 . \ldots \ldots \\
24 \ldots \ldots \\
25 . \ldots \ldots\end{array}$ & $\begin{array}{r}701 \\
684 \\
870 \\
1,400 \\
560\end{array}$ & $\begin{array}{r}600 \\
880 \\
3,200 \\
10,600 \\
1,700\end{array}$ & $\begin{array}{r}1,140 \\
1,630 \\
7,520 \\
\mathrm{~s} 4,800 \\
2,570\end{array}$ & $\begin{array}{l}244 \\
240 \\
258 \\
222 \\
213\end{array}$ & $\begin{array}{r}10,200 \\
3,000 \\
12,800 \\
4,200 \\
2,000\end{array}$ & $\begin{array}{r}6,720 \\
1,940 \\
\mathrm{~s} 12,700 \\
2,520 \\
1,150\end{array}$ & $\begin{array}{l}230 \\
222 \\
216 \\
226 \\
262\end{array}$ & $\begin{array}{l}352 \\
221 \\
243 \\
269 \\
938\end{array}$ & $\begin{array}{l}219 \\
132 \\
142 \\
164 \\
664\end{array}$ \\
\hline $\begin{array}{l}26 . \ldots \ldots \\
27 . \ldots \ldots \\
28 . \ldots \ldots \\
29 . \ldots \ldots \\
30 \ldots \ldots \\
31 \ldots \ldots\end{array}$ & $\begin{array}{l}428 \\
363 \\
318 \\
287 \\
244 \\
291 \\
\end{array}$ & $\begin{array}{l}760 \\
555 \\
395 \\
500 \\
400 \\
762 \\
\end{array}$ & $\begin{array}{r}878 \\
544 \\
339 \\
387 \\
264 \\
\mathbf{5} 743 \\
\end{array}$ & $\begin{array}{l}236 \\
233 \\
193 \\
190 \\
175 \\
184 \\
\end{array}$ & $\begin{array}{l}9,100 \\
2,600 \\
1,900 \\
4,000 \\
1,620 \\
1,190 \\
\end{array}$ & $\begin{array}{r}5,800 \\
1,640 \\
990 \\
2,050 \\
765 \\
591 \\
\end{array}$ & $\begin{array}{r}262 \\
304 \\
321 \\
321 \\
300 \\
-- \\
\end{array}$ & $\begin{array}{r}452 \\
1,180 \\
693 \\
492 \\
396 \\
\end{array}$ & $\begin{array}{l}320 \\
969 \\
601 \\
426 \\
321\end{array}$ \\
\hline Total. & 18,477 & -- & 158,468 & 8,457 & $\ldots$ & 328,912 & 13,425 & $=$ & 206,381 \\
\hline
\end{tabular}

Total discharge for year (cfs-days)

227,162

Total load for year (tons)

$1,329,497$

Computed by subdividing day. 


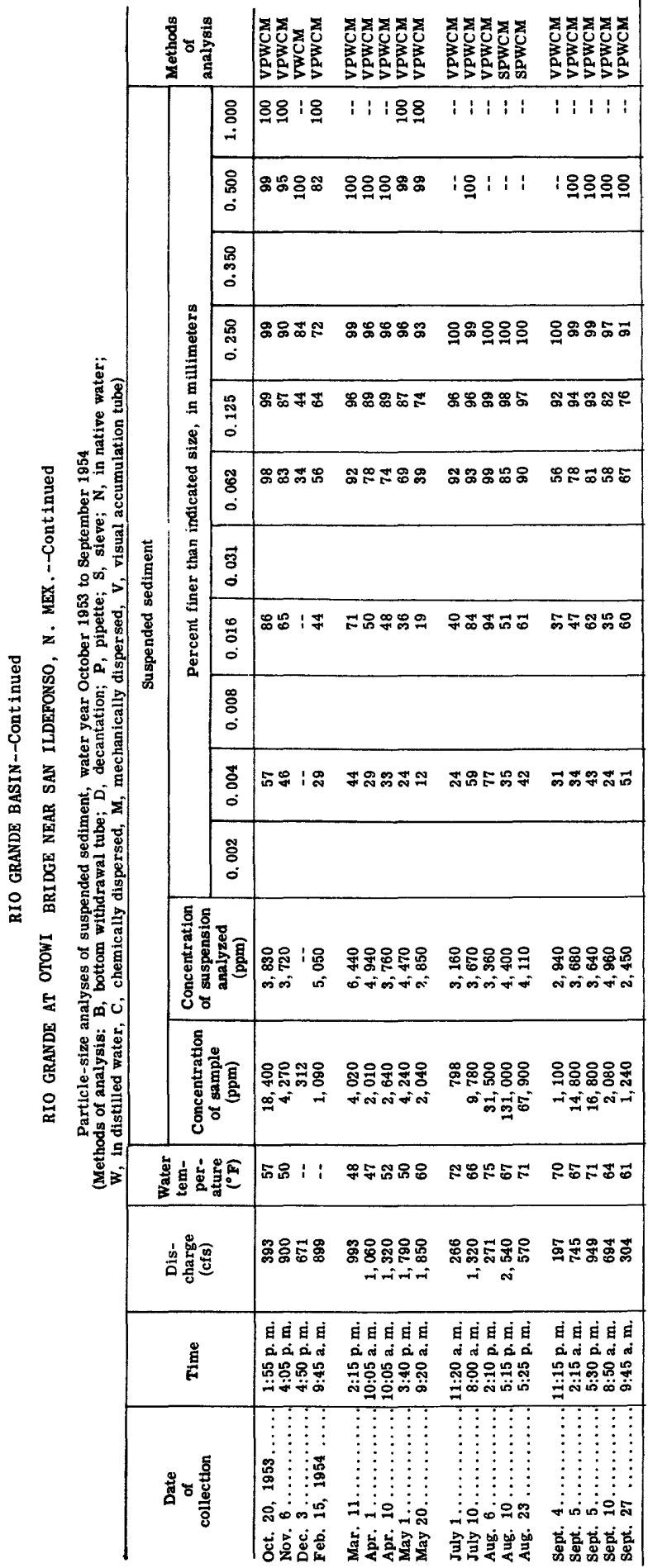


RIO GRANDE BASIN--Continued

GALISTEO CREEK AT DOMINGO, N. MEX.

LOCATION.--At gaging station in Santo Domingo Pueblo Grant, at highway bridge 0.3 mile northeast of Domingo, Sandoval County, 25 miles east of Santo Domingo Pueblo, and 4 miles upstream from mouth.

DRAINAGE AREA. -640 square miles, approximately.

RECORDS AVAILABLE. --Sediment records: January 1948 to September 1954.

EXTREMES, 1953-54.--Sediment concentrations: Maximum daily, 59,000 ppm May 11; minimum datly, no flow on many days.

Sediment loads: Maximum daily, 252,000 tons Aug. 10; minimum daily, 0 tons on many days.

EXTREMES, 1948-54.--Sediment concentrations: Maximum daily, 88,800 ppm July 4, 1952;

minimum daily, no flow on many days.

Sediment loads: Maximum datly, 360,000 tons Aug. 11, 1952; minimum datly, 0 tons on many days.

REMARKS.--Maximum observed sediment concentration during year, 153,000 ppm Aug. 10. Records of discharge for water year October 1953 to September 1954 given in wSP 1342 Stage discharge relation affected by ice Dec. 16-29, Jan. 6-7, 10-11, 13-19, 21-26.

Suspended sediment, water year October 1953 to September 1954

\begin{tabular}{|c|c|c|c|c|c|c|c|c|c|}
\hline \multirow[b]{3}{*}{ Day } & \multicolumn{3}{|c|}{ October } & \multicolumn{3}{|c|}{ November } & \multicolumn{3}{|c|}{ December } \\
\hline & \multirow[b]{2}{*}{$\begin{array}{c}\text { Mean } \\
\text { dis- } \\
\text { charge } \\
\text { (cfs) }\end{array}$} & \multicolumn{2}{|c|}{ Suspended sediment } & \multirow[b]{2}{*}{$\begin{array}{l}\text { Mean } \\
\text { dis- } \\
\text { charge } \\
\text { (cfs) }\end{array}$} & \multicolumn{2}{|c|}{ Suspended sediment } & \multirow[b]{2}{*}{$\begin{array}{l}\text { Mean } \\
\text { dis- } \\
\text { charge } \\
\text { (cfs) }\end{array}$} & \multicolumn{2}{|c|}{ Suspended sedimen } \\
\hline & & $\begin{array}{l}\text { Mean } \\
\text { concen- } \\
\text { tration } \\
\text { (ppm) }\end{array}$ & $\begin{array}{l}\text { Tons } \\
\text { per } \\
\text { day }\end{array}$ & & $\begin{array}{c}\text { Mean } \\
\text { concen- } \\
\text { tration } \\
\text { (ppm) }\end{array}$ & $\begin{array}{l}\text { Tons } \\
\text { per } \\
\text { day }\end{array}$ & & $\begin{array}{c}\text { Mean } \\
\text { concen- } \\
\text { tration } \\
\text { (ppm) }\end{array}$ & $\begin{array}{l}\text { Tons } \\
\text { per } \\
\text { day }\end{array}$ \\
\hline $\begin{array}{l}1, \ldots \ldots \\
2 \ldots \ldots \\
3 \ldots \ldots \\
4 \ldots \ldots \\
5 . \ldots \ldots\end{array}$ & $\begin{array}{l}0 \\
0 \\
0 \\
0 \\
0\end{array}$ & & & $\begin{array}{l}0 \\
\therefore 1 \\
\therefore 1 \\
0 \\
1\end{array}$ & $\begin{array}{l}-- \\
-- \\
-- \\
--\end{array}$ & $\begin{array}{r}0 \\
-- \\
- \\
0 \\
--\end{array}$ & $\begin{array}{l}0 \\
.8 \\
.2 \\
.2 \\
6\end{array}$ & $\begin{array}{l}-- \\
-- \\
-- \\
--\end{array}$ & $\begin{array}{l}.0 \\
-- \\
-- \\
-- \\
--\end{array}$ \\
\hline $\begin{array}{r}6 . \ldots \ldots \\
7 . \ldots \ldots \\
8 \ldots \ldots \\
9 \ldots \ldots \\
10 \ldots \ldots\end{array}$ & $\begin{array}{l}0 \\
0 \\
0 \\
0 \\
0\end{array}$ & -- & 0 & $\begin{array}{r}17 \\
1 \\
.8 \\
.5 \\
.2\end{array}$ & $\begin{array}{l}-- \\
-- \\
924\end{array}$ & $\begin{array}{l}-- \\
-- \\
--\end{array}$ & $\begin{array}{l}0 \\
0 \\
0 \\
0 \\
0\end{array}$ & & \\
\hline $\begin{array}{l}11 \ldots \ldots \\
12 \ldots \ldots \\
13 \ldots \ldots \\
14 \ldots \ldots \\
15 \ldots \ldots\end{array}$ & $\begin{array}{l}0 \\
0 \\
0 \\
0 \\
0\end{array}$ & & & $\begin{array}{r}.2 \\
.3 \\
.2 \\
.2 \\
.2\end{array}$ & $\begin{array}{l}-- \\
-- \\
-- \\
--\end{array}$ & & $\begin{array}{l}0 \\
0 \\
0 \\
0 \\
0\end{array}$ & & 0 \\
\hline $\begin{array}{l}16 \ldots \ldots \\
17 \ldots \ldots \ldots \\
18 \ldots \ldots \ldots \\
19 . \ldots \ldots \\
20 \ldots \ldots \ldots\end{array}$ & $\begin{array}{l}0 \\
0 \\
0 \\
0 \\
.4\end{array}$ & 667 & $\mathbf{s} 2$ & $\begin{array}{r}.2 \\
.2 \\
.4 \\
.3 \\
.4\end{array}$ & $\begin{array}{r}-- \\
1,200 \\
-- \\
--\end{array}$ & 1 & $\begin{array}{l}.3 \\
.3 \\
.3 \\
.4 \\
.5\end{array}$ & $\begin{array}{c}996 \\
-- \\
-- \\
-- \\
--\end{array}$ & \\
\hline $\begin{array}{l}21 \ldots \ldots \ldots \\
22 . \ldots \ldots \\
23 . \ldots \ldots \\
24 . \ldots \ldots \\
25 . \ldots \ldots\end{array}$ & $\begin{array}{l}0 \\
0 \\
0 \\
.3 \\
.1\end{array}$ & $\begin{array}{l}-- \\
--\end{array}$ & $\begin{array}{r}0 \\
\text { (b) }(t)^{b 1}\end{array}$ & $\begin{array}{l}.4 \\
.3 \\
0 \\
0\end{array}$ & $\begin{array}{l}-- \\
--\end{array}$ & & $\begin{array}{l}.5 \\
.4 \\
.1 \\
.2 \\
.2\end{array}$ & $\begin{array}{l}-- \\
-- \\
-- \\
--\end{array}$ & 1 \\
\hline $\begin{array}{l}26 \ldots \ldots \\
27 . \ldots \ldots \\
28 . \ldots \ldots \\
29 \ldots \ldots \\
30 \ldots \ldots \\
31 \ldots \ldots\end{array}$ & $\begin{array}{l}0 \\
.1 \\
.1 \\
.1 \\
.1 \\
.1\end{array}$ & $\begin{array}{r}-- \\
-- \\
348 \\
-- \\
--\end{array}$ & (t) & $\begin{array}{l}0 \\
0 \\
0 \\
0 \\
0 \\
- \\
\end{array}$ & -- & 0 & $\begin{array}{l}.2 \\
.2 \\
.2 \\
.2 \\
.2 \\
.2 \\
\end{array}$ & $\begin{array}{l}-- \\
-- \\
-- \\
-- \\
--\end{array}$ & \\
\hline Total. & 1.3 & - & 5 & 24.5 & -- & b 420 & 11.6 & -- & b 56 \\
\hline
\end{tabular}

s Computed by subdividing day.

$t$ Less than 0.50 ton.

b Computed from water-sediment discharge curve. 
RIO GRANDE BASIN--Continued

GALISTEO CREEK AT DOMINGO, N. MEX.--Continued

Suspended sediment, water year October 1953 to September 1954 --Continued

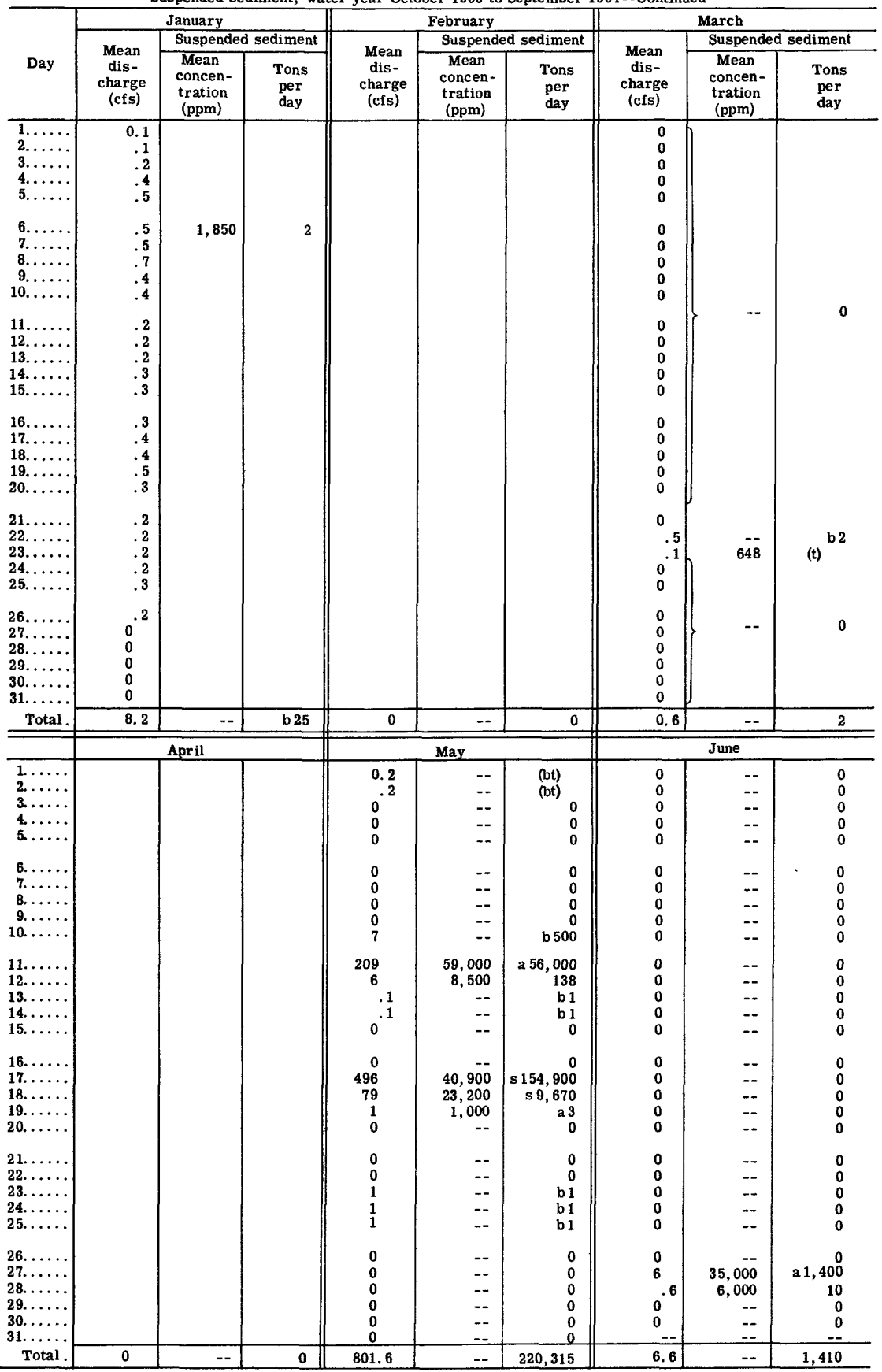

s Computed by subdividing day.

$t$ Less than 0.50 ton.

a Computed from estimated concentration graph.

b Computed from water-sediment discharge curve. 
RIO GRANDE BASIN

RIO GRANDE BASIN--Continued

GALISTEO CREEK AT DOMINGO, N. MEX.--Continued

Suspended sediment, water year October 1953 to September 1954 --Continued

\begin{tabular}{|c|c|c|c|c|c|c|c|c|c|}
\hline \multirow[b]{3}{*}{ Day } & \multicolumn{3}{|c|}{ July } & \multicolumn{3}{|c|}{ August } & \multicolumn{3}{|c|}{ September } \\
\hline & \multirow[b]{2}{*}{$\begin{array}{l}\text { Mean } \\
\text { dis- } \\
\text { charge } \\
\text { (cfs) }\end{array}$} & \multicolumn{2}{|c|}{ Suspended sediment } & \multirow[b]{2}{*}{$\begin{array}{l}\text { Mean } \\
\text { dis- } \\
\text { charge } \\
\text { (cfs) }\end{array}$} & \multicolumn{2}{|c|}{ Suspended sediment } & \multirow[b]{2}{*}{$\begin{array}{l}\text { Mean } \\
\text { dis - } \\
\text { charge } \\
\text { (cfs) }\end{array}$} & \multicolumn{2}{|c|}{ Suspended sediment } \\
\hline & & $\begin{array}{l}\text { Mean } \\
\text { concen- } \\
\text { tration } \\
\text { (ppm) }\end{array}$ & $\begin{array}{l}\text { Tons } \\
\text { per } \\
\text { day }\end{array}$ & & $\begin{array}{c}\text { Mean } \\
\text { concen- } \\
\text { tration } \\
\text { (ppm) }\end{array}$ & $\begin{array}{l}\text { Tons } \\
\text { per } \\
\text { day }\end{array}$ & & $\begin{array}{c}\text { Mean } \\
\text { concen- } \\
\text { tration } \\
\text { (ppm) }\end{array}$ & $\begin{array}{l}\text { Tons } \\
\text { per } \\
\text { day }\end{array}$ \\
\hline $\begin{array}{l}1 \ldots \ldots \\
2 \ldots \ldots \\
3 \ldots \ldots \\
4 \ldots \ldots \\
5 \ldots \ldots\end{array}$ & $\begin{array}{c}0 \\
0 \\
0.2 \\
28 \\
3\end{array}$ & $\begin{array}{r}-- \\
44,200 \\
6,000\end{array}$ & $\begin{array}{r}0 \\
0 \\
\text { b } 2 \\
\mathrm{~s} 4,730 \\
\text { a } 50\end{array}$ & $\begin{array}{r}0 \\
0 \\
0 \\
0 \\
66\end{array}$ & $\begin{array}{l}-- \\
-- \\
--\end{array}$ & $\begin{array}{r}0 \\
0 \\
0 \\
0 \\
\text { b } 16,000\end{array}$ & $\begin{array}{r}40 \\
18 \\
9 \\
4 \\
2\end{array}$ & $\begin{array}{r}33,200 \\
10,000 \\
- \\
- \\
-\end{array}$ & $\begin{array}{r}\text { s4, } 880 \\
\text { a } 490 \\
\text { b } 50 \\
\text { b } 6 \\
\text { b } 1\end{array}$ \\
\hline $\begin{array}{r}6 \ldots \ldots \\
7 \ldots \ldots \\
8 \ldots \ldots \\
9 \ldots \ldots \\
10 \ldots \ldots\end{array}$ & $\begin{array}{r}1 \\
2 \\
1 \\
11 \\
4\end{array}$ & $\begin{array}{r}1,000 \\
9,000 \\
1,000 \\
-- \\
--\end{array}$ & $\begin{array}{r}\text { a } 3 \\
\text { a } 50 \\
3 \\
\text { b1, } 000 \\
\text { b } 200\end{array}$ & $\begin{array}{r}4 \\
182 \\
57 \\
1 \\
860\end{array}$ & $\begin{array}{r}39,000 \\
39,200 \\
6,000 \\
37,600\end{array}$ & $\begin{array}{r}\text { b } 500 \\
\text { s 66,700 } \\
s 9,770 \\
16 \\
\mathrm{~s} 252,000\end{array}$ & $\begin{array}{r}1 \\
1 \\
1 \\
1 \\
11\end{array}$ & 10, 600 & (b) (t) \\
\hline $\begin{array}{l}11 . \ldots \\
12 \ldots \ldots \\
13 . \ldots \\
14 \ldots \ldots \\
15 . \ldots\end{array}$ & $\begin{array}{l}0 \\
0 \\
0 \\
0 \\
0\end{array}$ & $\begin{array}{l}-- \\
-- \\
-- \\
--\end{array}$ & $\begin{array}{l}0 \\
0 \\
0 \\
0 \\
0\end{array}$ & $\begin{array}{r}133 \\
58 \\
32 \\
6 \\
45\end{array}$ & $\begin{array}{r}45,100 \\
34,700 \\
37,200 \\
-- \\
--\end{array}$ & $\begin{array}{r}\text { s 21, 300 } \\
\text { s 7, 370 } \\
\text { s 4, 100 } \\
\text { b } 500 \\
\text { b 7, 000 }\end{array}$ & $\begin{array}{r}55 \\
77 \\
1 \\
1 \\
0\end{array}$ & $\begin{array}{r}33,000 \\
34,800 \\
5,000 \\
3,000 \\
=-\end{array}$ & $\begin{array}{r}\mathrm{sa} 9,400 \\
\mathrm{~s} 14,900 \\
14 \\
8 \\
0\end{array}$ \\
\hline $\begin{array}{l}16 \ldots \ldots \\
17 \ldots \ldots \\
18 \ldots \ldots \\
19 . \ldots \\
20 \ldots \ldots\end{array}$ & $\begin{array}{l}0 \\
0 \\
0 \\
1 \\
3\end{array}$ & $\begin{array}{l}-- \\
-- \\
=- \\
--\end{array}$ & $\begin{array}{r}0 \\
0 \\
0 \\
\text { b } 5 \\
\text { b } 100\end{array}$ & $\begin{array}{r}8 \\
78 \\
33 \\
8 \\
3\end{array}$ & $\begin{array}{r}-- \\
38,600 \\
22,000 \\
4,000 \\
960\end{array}$ & $\begin{array}{r}\text { b } 600 \\
\mathrm{~s} 19,900 \\
\mathrm{a} 2,000 \\
\mathrm{a} 90 \\
8\end{array}$ & $\begin{array}{l}0 \\
0 \\
0 \\
0 \\
0\end{array}$ & $\begin{array}{l}-- \\
-- \\
-- \\
--\end{array}$ & $\begin{array}{l}0 \\
0 \\
0 \\
0 \\
0\end{array}$ \\
\hline $\begin{array}{l}21 \ldots \ldots \\
22 \ldots \ldots \\
23 \ldots \ldots \\
24 \ldots \ldots \\
25 . \ldots \ldots\end{array}$ & $\begin{array}{r}18 \\
19 \\
14 \\
43 \\
2\end{array}$ & $\begin{array}{r}13,100 \\
39,600 \\
16,900 \\
29,900 \\
--\end{array}$ & $\begin{array}{r}4,990 \\
\mathrm{~s} 3,210 \\
\mathrm{~s} 1,610 \\
\mathrm{~s} 10,600 \\
\mathrm{~b} 3\end{array}$ & $\begin{array}{r}71 \\
27 \\
197 \\
328 \\
52\end{array}$ & $\begin{array}{r}- \\
13,000 \\
36,200 \\
10,000\end{array}$ & $\begin{array}{r}\text { b } 9,000 \\
\text { b3,000 } \\
\text { sa } 36,000 \\
\text { s } 50,300 \\
1,400\end{array}$ & $\begin{array}{l}0 \\
0 \\
0 \\
4 \\
2\end{array}$ & $\begin{array}{r}- \\
- \\
22,000 \\
6,000\end{array}$ & $\begin{array}{r}0 \\
0 \\
0 \\
238 \\
32\end{array}$ \\
\hline $\begin{array}{l}26 \ldots \ldots \\
27 \ldots \ldots \\
28 \ldots \ldots \\
29 \ldots \ldots \\
30 \ldots \ldots \\
31 \ldots \ldots\end{array}$ & $\begin{array}{r}1 \\
82 \\
8 \\
12 \\
1\end{array}$ & $\begin{array}{r}335 \\
-- \\
\overline{-} \\
34,000 \\
3,000\end{array}$ & $\begin{array}{r}(t)^{b 1} \\
b 14,000 \\
b 150 \\
1,140 \\
8\end{array}$ & $\begin{array}{r}10 \\
5 \\
2 \\
1 \\
58 \\
64\end{array}$ & $\begin{array}{r}-- \\
- \\
-- \\
40,000 \\
37,400\end{array}$ & $\begin{array}{r}\text { b } 60 \\
\text { b } 15 \\
b 10 \\
\text { b5 } \\
\text { a } 6,500 \\
\text { s } 10,900\end{array}$ & \begin{tabular}{r|}
2 \\
6 \\
3 \\
2 \\
1 \\
--
\end{tabular} & $\begin{array}{r}3,000 \\
-- \\
-- \\
-- \\
--\end{array}$ & $\begin{array}{r}\text { a } 16 \\
\text { b } 320 \\
\text { b 45 } \\
\text { b14 } \\
\text { b 2 } \\
--\end{array}$ \\
\hline Total. & 254.3 & -- & 41,855 & 2,389 & $\cdots$ & 525,044 & 242 & -- & 31,124 \\
\hline
\end{tabular}

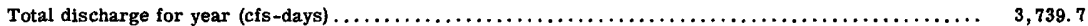

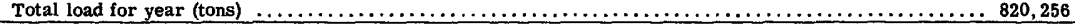

s Computed by subdividing day.

$t$ Less than 0.50 ton.

a Computed from estimated concentration graph.

b Computed from water-sediment discharge curve.

$4888170-59-26$ 
RIO GRANDE BASIN--Cont inued

JEMEZ RIVER BELOW JEMEZ CANYON DAM, N. MEX

(Formerly published as Jemez River near Bernalillo)

LOCATION.--At gaging station three-quarters of a mile downstream from Jemez Canyon Dam, $1 \frac{1}{2}$ miles upstream from mouth, and 6 miles north of Bernalillo, Sandoval County. DRAINAGE AREA. - -1,040 square miles, approximately.

RECORDS AVAILABLE, - Water temperatures: October 1950 to September 1954.

Sediment records: April 1948 to September 1954 .

EXTREMES, 1953-54. - Water temperatures: Maximum observed, $92{ }^{\circ} \mathrm{F}$ July 3, 27; minimum, freezing on several days in December and January.

Sediment concentrations: Maximum daily, 52,000 ppm July 23; minimum daily, no flow on many days.

Sediment loads: Maximum daily, 150,000 tons (estimated) Sept. 26; minimum daily, 0 tons on many days.

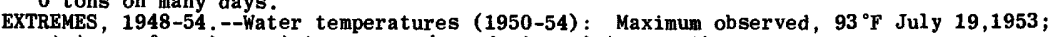
minimum, freezing point on many days during winter months.

Sediment concentrations: Maximum daily 66,700 ppm Sept. 20, 1950; minimum daily, no flow on many days.

Sediment loads: Maximum daily, 167,000 tons July 25, 1951; minimum daily, 0 tons on many days.

REMARKS. --Maximum observed sediment concentration during water year, 92,400 ppm July 23, Records of specific conductance of daily samples available in district office at

Albuquerque, N. Mex. Records of discharge for water year October 1953 to

September 1954 given in wsp 1342. Stage-discharge relation affected by ice Dec. 5-14, 22-31, Jan. 1-5.

Temperature $\left({ }^{\circ} \mathrm{F}\right)$ of water, water year October 1953 to September 1954

/Once-daily measurement generally between $11 \mathrm{a} . \mathrm{m}$. and $6 \mathrm{p} . \mathrm{m}$.

\begin{tabular}{|c|c|c|c|c|c|c|c|c|c|c|c|c|}
\hline Day & Oct. & Nov. & Dec. & Jan. & Feb & Mar & Anr & Mav & June & tulv & Ang & Sont \\
\hline 1 & 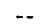 & -- & 50 & -- & 55 & 55 & 58 & - & & $\therefore$ & -- & -- \\
\hline 2 & -. & -- & .. & -- & 55 & 50 & 55 & $\ldots$ & & -- & -- & - \\
\hline 3 & - & 64 & 38 & 36 & 60 & $\ldots$ & 77 & 76 & & 92 & -- & -- \\
\hline 4 & -- & $=$ & 32 & 34 & 58 & 53 & .. & a 68 & & -- & .. & -. \\
\hline 5 & -. & - & -- & 35 & 59 & 64 & 65 & 84 & & -- & -- & -- \\
\hline 6 & -. & a 56 & -. & 34 & -- & 58 & 70 & 78 & & - & -- & - \\
\hline 7 & $\cdots$ & 42 & -. & 36 & $\cdots$ & $\ldots$ & 68 & 85 & & -- & -- & -- \\
\hline 8 & $\cdots$ & $=$ & - & 45 & 57 & 62 & 70 & 84 & & $=$ & -- & -- \\
\hline 9 & -- & 57 & $\cdots$ & - & 57 & 64 & 71 & -- & & $\cdots$ & -- & -- \\
\hline 10 & -- & -- & 32 & -- & 55 & 61 & -- & a 74 & & -- & -- & -- \\
\hline 11 & -- & - & 32 & 34 & 58 & 58 & -. & 66 & & -- & a 71 & $\ldots$ \\
\hline 12 & -- & -- & - & 31 & 61 & 40 & 71 & 84 & & -- & -- & -- \\
\hline 13 & $\cdots$ & 60 & $\cdots$ & 31 & -- & 39 & 74 & 68 & & -- & -- & -- \\
\hline 14 & -- & - & - & 33 & $=-$ & -- & 64 & 84 & & -- & -- & 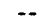 \\
\hline 15 & -- & - & - & 32 & 51 & 52 & 65 & 65 & & - & - & - \\
\hline 16 & - & - & $=$ & 36 & 60 & 55 & 72 & - & & $\ldots$ & 84 & -. \\
\hline 17 & -- & -- & -- & $\ldots$ & 60 & 56 & 75 & 79 & & -- & a 68 & -- \\
\hline 18 & -- & 50 & 39 & 35 & 60 & 51 & - & 77 & & -- & -- & -- \\
\hline 19 & -- & 37 & $=$ & 36 & 40 & 56 & 75 & 66 & & -- & -- & $\ldots$ \\
\hline 20 & -- & 49 & - & 35 & 42 & 47 & 75 & 79 & & -- & $\cdots$ & $\cdots$ \\
\hline 21 & -- & 42 & 42 & 37 & $\cdots$ & $\ldots$ & 79 & 70 & & -- & -- & - \\
\hline 22 & -- & -- & 32 & 36 & 55 & 58 & 79 & $\ldots$ & & -- & - & - \\
\hline 23 & - & -- & 34 & -- & 61 & 56 & 78 & -- & & 85 & -- & - \\
\hline 24 & 69 & -- & 32 & -- & 52 & 45 & 82 & 65 & & 73 & a 72 & $\sim$ \\
\hline 25 & -- & 50 & -- & 35 & 58 & 55 & -- & 84 & & 89 & -- & -- \\
\hline 26 & -- & $\ldots$ & 32 & 52 & 52 & 65 & a 61 & 70 & & 88 & -- & -- \\
\hline 27 & 64 & 49 & -- & 41 & 42 & -- & 80 & 75 & & 92 & -- & 68 \\
\hline 28 & - & $\Rightarrow$ & 34 & 52 & $m$ & -- & 75 & 72 & & - & - & 69 \\
\hline 29 & $=$ & $=$ & 35 & 51 & - & 62 & 71 & -- & & - & -- & 73 \\
\hline 30 & -- & -- & 32 & -- & -- & 57 & a 54 & -- & & -. & -- & 75 \\
\hline 31 & -- & -- & 32 & -- & -- & 51 & -- & -- & & -- & $\cdots$ & -- \\
\hline $\begin{array}{c}\text { Aver- } \\
\text { age }\end{array}$ & -- & $=$ & -- & - & 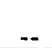 & 55 & 71 & - & & -- & - & -- \\
\hline
\end{tabular}

a Measurement prior to 11 a. m. 
RIO GRANDE BASIN--Continued

JEMEZ RIVER BELOW JEMEZ CANYON DAM, N. MEX.--Continued

Suspended sediment, water year October 1953 to September 1954

\begin{tabular}{|c|c|c|c|c|c|c|c|c|c|}
\hline \multirow[b]{3}{*}{ Day } & \multicolumn{3}{|c|}{ October } & \multicolumn{3}{|c|}{ November } & \multicolumn{3}{|c|}{ December } \\
\hline & \multirow[b]{2}{*}{$\begin{array}{c}\text { Mean } \\
\text { dis- } \\
\text { charge } \\
\text { (cfs) }\end{array}$} & \multicolumn{2}{|c|}{ Suspended sediment } & \multirow[b]{2}{*}{$\begin{array}{l}\text { Mean } \\
\text { dis- } \\
\text { charge } \\
\text { (cfs) }\end{array}$} & \multicolumn{2}{|c|}{ Suspended sediment } & \multirow[b]{2}{*}{$\begin{array}{l}\text { Mean } \\
\text { dis- } \\
\text { charge } \\
\text { (cfs) }\end{array}$} & \multicolumn{2}{|c|}{ Suspended sediment } \\
\hline & & $\begin{array}{l}\text { Mean } \\
\text { concen- } \\
\text { tration } \\
\text { (ppm) }\end{array}$ & $\begin{array}{l}\text { Tons } \\
\text { per } \\
\text { day }\end{array}$ & & $\begin{array}{l}\text { Mean } \\
\text { concen- } \\
\text { tration } \\
\text { (ppm) }\end{array}$ & $\begin{array}{l}\text { Tons } \\
\text { per } \\
\text { day }\end{array}$ & & $\begin{array}{l}\text { Mean } \\
\text { concen- } \\
\text { tration } \\
(\mathrm{ppm})\end{array}$ & $\begin{array}{l}\text { Tons } \\
\text { per } \\
\text { day }\end{array}$ \\
\hline $\begin{array}{l}1 \ldots \ldots \\
2 \ldots \ldots \\
3 \ldots \ldots \\
4 \ldots \ldots \\
5 . \ldots \ldots\end{array}$ & $\begin{array}{l}0 \\
0 \\
0 \\
0 \\
0\end{array}$ & $\begin{array}{l}-- \\
-- \\
-- \\
--\end{array}$ & $\begin{array}{l}0 \\
0 \\
0 \\
0 \\
0\end{array}$ & $\begin{array}{r}0.4 \\
.2 \\
.8 \\
1.2 \\
3.3\end{array}$ & $\begin{array}{r}1,000 \\
800 \\
2,200 \\
2,300 \\
4,500\end{array}$ & $\begin{array}{r}a 1 \\
\text { (a)(t) } \\
5 \\
a 7 \\
a 40\end{array}$ & $\begin{array}{c}16 \\
18 \\
16 \\
3.1 \\
2\end{array}$ & $\begin{array}{l}8,060 \\
6,400 \\
7,000 \\
1,850 \\
2,800\end{array}$ & $\begin{array}{l}\text { s } 352 \\
\text { a } 310 \\
\text { s } 333 \\
\text { s } 25 \\
\text { a } 15\end{array}$ \\
\hline $\begin{array}{r}6 . \ldots \ldots \\
7 \ldots \ldots \\
8 \ldots \ldots \\
9 \ldots \ldots \\
10 \ldots \ldots\end{array}$ & $\begin{array}{l}0 \\
0 \\
0 \\
0 \\
0\end{array}$ & $\begin{array}{l}-- \\
-- \\
-- \\
--\end{array}$ & $\begin{array}{l}0 \\
0 \\
0 \\
0 \\
0\end{array}$ & $\begin{array}{r}65 \\
12 \\
8.8 \\
6.0 \\
5.0\end{array}$ & $\begin{array}{r}32,600 \\
16,400 \\
14,000 \\
7,500 \\
5,100\end{array}$ & $\begin{array}{r}\mathrm{s} 8,480 \\
531 \\
\mathrm{a} 330 \\
122 \\
69\end{array}$ & $\stackrel{5}{5}_{3}^{2}$ & $\begin{array}{l}2,200 \\
1,800 \\
5,200 \\
5,800 \\
5,120\end{array}$ & $\begin{array}{r}\text { a } 12 \\
\text { a } 2 \\
\text { a } 70 \\
\text { a } 47 \\
28\end{array}$ \\
\hline $\begin{array}{l}11 \ldots \ldots \\
12 \ldots \ldots \\
13 \ldots \ldots \\
14 \ldots \ldots \\
15 . \ldots \ldots\end{array}$ & $\begin{array}{l}0 \\
0 \\
0 \\
0 \\
0\end{array}$ & $\begin{array}{l}\ldots \\
-- \\
-- \\
--\end{array}$ & $\begin{array}{l}0 \\
0 \\
0 \\
0 \\
0\end{array}$ & $\begin{array}{l}6.4 \\
7.9 \\
6.0 \\
5.5 \\
6.5\end{array}$ & $\begin{array}{l}7,300 \\
9,400 \\
7,300 \\
6,900 \\
8,800\end{array}$ & $\begin{array}{r}\text { a } 130 \\
\text { a } 200 \\
118 \\
\text { a } 100 \\
\text { a } 150\end{array}$ & $\begin{array}{r}4 \\
5 \\
6 \\
9 \\
24\end{array}$ & $\begin{array}{l}3,700 \\
1,400 \\
1,100 \\
2,000 \\
3,900\end{array}$ & $\begin{array}{r}40 \\
\text { a } 19 \\
\text { a } 18 \\
\text { a } 49 \\
\text { a } 250\end{array}$ \\
\hline $\begin{array}{l}16 \ldots \ldots \\
17 \ldots \ldots \\
18 \ldots \ldots \\
19 \ldots \ldots \\
20 \ldots \ldots\end{array}$ & $\begin{array}{l}0 \\
0 \\
0 \\
0 \\
0\end{array}$ & $\begin{array}{l}-- \\
-- \\
-- \\
--\end{array}$ & $\begin{array}{l}0 \\
0 \\
0 \\
0 \\
0\end{array}$ & \begin{tabular}{l|l|}
7.6 \\
4.7 \\
3.7 \\
5.3 \\
8.3
\end{tabular} & $\begin{array}{l}9,000 \\
4,400 \\
4,800 \\
6,400 \\
5,700\end{array}$ & $\begin{array}{r}\text { a } 180 \\
\text { a } 60 \\
\text { s } 64 \\
92 \\
128\end{array}$ & $\begin{array}{l}28 \\
44 \\
36 \\
29 \\
23\end{array}$ & $\begin{array}{l}4,200 \\
9,820 \\
7,780 \\
5,000 \\
3,500\end{array}$ & $\begin{array}{r}2320 \\
\text { s } 1,640 \\
\text { s } 806 \\
\text { a } 390 \\
\text { a 220 }\end{array}$ \\
\hline $\begin{array}{l}21 \ldots \ldots \\
22 \ldots \ldots \ldots \\
23 \ldots \ldots \\
24 \ldots \ldots \\
25 \ldots \ldots\end{array}$ & $\begin{array}{r}0 \\
0 \\
0 \\
21 \\
2.3\end{array}$ & $\begin{array}{r}-- \\
-- \\
33,300 \\
26,000\end{array}$ & $\begin{array}{r}0 \\
0 \\
0 \\
\mathrm{~s} 2,090 \\
\mathrm{sa} 200\end{array}$ & $\begin{array}{l}7.2 \\
3.0 \\
9.9 \\
12 \\
13\end{array}$ & $\begin{array}{l}6,000 \\
3,500 \\
7,800 \\
8,700 \\
8,690\end{array}$ & $\begin{array}{r}117 \\
\text { a } 28 \\
\text { sa } 310 \\
\text { sa } 290 \\
\text { s337 }\end{array}$ & $\begin{array}{r}14 \\
4.2 \\
.5 \\
.7 \\
.5\end{array}$ & $\begin{array}{r}\mathbf{4}, 020 \\
\mathbf{2}, 750 \\
800 \\
580 \\
570\end{array}$ & $\begin{array}{r}\text { s } 195 \\
\text { s } 52 \\
1 \\
1 \\
\text { a } 1\end{array}$ \\
\hline $\begin{array}{l}26 \ldots \ldots \\
27 \ldots \ldots \\
28 \ldots \ldots \\
29 \ldots \ldots \\
30 \ldots \ldots \\
31 \ldots \ldots\end{array}$ & $\begin{array}{r}.3 \\
.6 \\
1.0 \\
.4 \\
.1 \\
.4\end{array}$ & $\begin{array}{r}7,050 \\
1,570 \\
800 \\
400 \\
900 \\
1,400\end{array}$ & 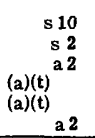 & $\begin{array}{l}15 \\
14 \\
17 \\
15 \\
14 \\
-\cdots\end{array}$ & $\begin{array}{r}8,100 \\
7,150 \\
8,200 \\
7,300 \\
8,000 \\
-.\end{array}$ & $\begin{array}{r}\text { sa } 370 \\
\text { s } 296 \\
\text { a } 380 \\
\text { sa } 320 \\
\text { sa } 320 \\
\ldots\end{array}$ & $\begin{array}{r}4 \\
8 \\
10 \\
12 \\
15 \\
10 \\
\end{array}$ & $\begin{array}{r}1,390 \\
1,500 \\
800 \\
860 \\
990 \\
880 \\
\end{array}$ & $\begin{array}{r}15 \\
\text { a } 32 \\
22 \\
28 \\
40 \\
24 \\
\end{array}$ \\
\hline \multirow[t]{2}{*}{ Total. } & 26.1 & -- & $2, x^{n n}$ & 284.7 & -- & 13,575 & 354.5 & -- & 5,357 \\
\hline & \multicolumn{3}{|c|}{ January } & \multicolumn{3}{|c|}{ February } & \multicolumn{3}{|c|}{ March } \\
\hline $\begin{array}{l}1 \ldots \ldots \\
2 \ldots \ldots \\
3 \ldots \ldots \\
4 \ldots \ldots \\
5 . \ldots \ldots\end{array}$ & $\begin{array}{l}12 \\
15 \\
18 \\
20 \\
25\end{array}$ & $\begin{array}{l}1,000 \\
1,600 \\
1,520 \\
2,100 \\
1,590\end{array}$ & $\begin{array}{r}32 \\
\text { a } 65 \\
74 \\
113 \\
107\end{array}$ & $\begin{array}{l}16 \\
16 \\
17 \\
17 \\
18\end{array}$ & $\begin{array}{l}5,200 \\
4,770 \\
4,900 \\
4,700 \\
4,300\end{array}$ & $\begin{array}{l}225 \\
206 \\
225 \\
216 \\
209\end{array}$ & $\begin{array}{l}32 \\
28 \\
31 \\
25 \\
28\end{array}$ & $\begin{array}{l}8,510 \\
6,840 \\
5,490 \\
7,920 \\
7,750\end{array}$ & $\begin{array}{r}\text { s } 807 \\
\text { s } 599 \\
\text { s } 670 \\
\text { s } 572 \\
586\end{array}$ \\
\hline $\begin{array}{r}6 \ldots \ldots \\
7 \ldots \ldots \\
8 \ldots \ldots \\
9 \ldots \ldots \\
10 \ldots \ldots\end{array}$ & $\begin{array}{r}33 \\
45 \\
32 \\
15 \\
2\end{array}$ & $\begin{array}{l}2,020 \\
3,200 \\
5,480 \\
2,300 \\
1,200\end{array}$ & $\begin{array}{r}\text { s } 247 \\
\text { s } 529 \\
473 \\
\text { a } 93 \\
\text { a } 27\end{array}$ & $\begin{array}{l}16 \\
18 \\
18 \\
19 \\
19\end{array}$ & $\begin{array}{l}4,400 \\
4,600 \\
3,750 \\
4,230 \\
5,050\end{array}$ & $\begin{array}{r}a 190 \\
\text { a } 220 \\
182 \\
217 \\
259\end{array}$ & $\begin{array}{l}34 \\
23 \\
33 \\
38 \\
62\end{array}$ & $\begin{array}{r}8,080 \\
6,600 \\
7,300 \\
7,500 \\
16,200\end{array}$ & $\begin{array}{r}\text { s } 831 \\
\text { sa } 460 \\
\text { s 705 } \\
\text { s 768 } \\
\text { s } 3,030\end{array}$ \\
\hline $\begin{array}{l}11 . \ldots \ldots \\
12 . \ldots \ldots \\
13 . \ldots \ldots \\
14 \ldots \ldots \\
15 . \ldots\end{array}$ & 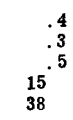 & $\begin{array}{l}1,820 \\
1,100 \\
1,150 \\
2,280 \\
2,530\end{array}$ & $\begin{array}{r}6 \\
1 \\
2 \\
s 209 \\
260\end{array}$ & $\begin{array}{l}18 \\
20 \\
22 \\
21 \\
34\end{array}$ & $\begin{array}{l}5,100 \\
5,500 \\
6,000 \\
5,300 \\
6,800\end{array}$ & $\begin{array}{r}248 \\
297 \\
\text { a } 360 \\
\text { a } 300 \\
624\end{array}$ & $\begin{array}{l}46 \\
24 \\
27 \\
22 \\
25\end{array}$ & $\begin{array}{r}13,500 \\
8,000 \\
12,200 \\
12,700 \\
8,770\end{array}$ & $\begin{array}{r}\text { s } 1,800 \\
\text { s } 644 \\
\text { s } 1,090 \\
\text { a } 750 \\
\text { s } 813\end{array}$ \\
\hline $\begin{array}{l}16 \ldots \ldots \\
17 \ldots \ldots \\
18 \ldots \ldots \\
19 \ldots \ldots \\
20 \ldots \ldots\end{array}$ & $\begin{array}{l}40 \\
28 \\
23 \\
28 \\
22\end{array}$ & $\begin{array}{l}2,100 \\
1,530 \\
2,180 \\
4,990 \\
5,600\end{array}$ & $\begin{array}{r}227 \\
\text { a } 120 \\
\text { s } 250 \\
\text { s } 454 \\
333\end{array}$ & $\begin{array}{l}17 \\
13 \\
5 \\
2.5 \\
15\end{array}$ & $\begin{array}{l}4,400 \\
3,920 \\
3,900 \\
3,550 \\
5,670\end{array}$ & $\begin{array}{r}202 \\
138 \\
53 \\
24 \\
\mathbf{5} 350\end{array}$ & $\begin{array}{l}14 \\
10 \\
4.5 \\
7.7 \\
7.5\end{array}$ & $\begin{array}{l}4,810 \\
3,470 \\
1,190 \\
3,400 \\
1,570\end{array}$ & $\begin{array}{r}182 \\
94 \\
14 \\
\text { s } 88 \\
32\end{array}$ \\
\hline $\begin{array}{l}21 \ldots \ldots \\
22 \ldots \ldots \\
23 \ldots \ldots \\
24 \ldots \ldots \\
25 \ldots \ldots\end{array}$ & $\begin{array}{l}36 \\
20 \\
18 \\
18 \\
20\end{array}$ & $\begin{array}{l}5,610 \\
4,500 \\
4,000 \\
4,400 \\
5,880\end{array}$ & $\begin{array}{r}\text { s } 648 \\
243 \\
\text { sa } 230 \\
\text { sa } 270 \\
318\end{array}$ & $\begin{array}{r}15 \\
14 \\
6.6 \\
6.6 \\
7.8\end{array}$ & $\begin{array}{l}6,400 \\
7,780 \\
3,950 \\
3,950 \\
4,800\end{array}$ & $\begin{array}{r}\text { sa } 320 \\
294 \\
70 \\
70 \\
101\end{array}$ & $\begin{array}{r}7.8 \\
19 \\
67 \\
313 \\
95\end{array}$ & $\begin{array}{r}1,500 \\
4,250 \\
15,800 \\
16,600 \\
17,200\end{array}$ & $\begin{array}{r}\text { a 32 } \\
218 \\
\text { s } 3,550 \\
\mathrm{~s} 12,700 \\
\mathrm{~s} 4,530\end{array}$ \\
\hline $\begin{array}{l}26 \ldots \ldots \\
27 \ldots \ldots \\
28 \ldots \ldots \\
29 \ldots \ldots \\
30 \ldots \ldots \\
31 \ldots \ldots\end{array}$ & $\begin{array}{l}26 \\
18 \\
15 \\
18 \\
16 \\
17 \\
\end{array}$ & $\begin{array}{l}9,200 \\
6,850 \\
5,200 \\
6,200 \\
5,600 \\
5,600 \\
\end{array}$ & $\begin{array}{r}646 \\
333 \\
211 \\
301 \\
\text { a } 240 \\
\text { a } 260 \\
\end{array}$ & $\begin{array}{l}30 \\
51 \\
44 \\
-- \\
-- \\
--\end{array}$ & $\begin{array}{r}9,250 \\
10,200 \\
8,500 \\
-- \\
-- \\
- \\
\end{array}$ & $\begin{array}{r}\mathrm{s} 871 \\
\mathrm{~s} 1,460 \\
\text { sa } 1,200 \\
-. \\
-- \\
\end{array}$ & $\begin{array}{l}45 \\
30 \\
32 \\
45 \\
49 \\
44\end{array}$ & $\begin{array}{r}10,200 \\
7,900 \\
9,800 \\
8,420 \\
13,200 \\
10,000 \\
\end{array}$ & $\begin{array}{r}1,240 \\
\text { a } 640 \\
\text { a } 850 \\
\text { s } 1,050 \\
1,750 \\
1,190 \\
\end{array}$ \\
\hline Total & 634.2 & -- & 7,322 & 516.5 & - & 9,131 & $1,268.5$ & -- & 42,285 \\
\hline
\end{tabular}

$s$ Computed by subdividing day.

$t$ Less than 0.50 ton.

a Computed from estimated concentration graph. 
RIO GRANDE BASIN

RIO GRANDE BASIN--Continued

JEMEZ RIVER BELOW JEMEZ CANYON DAM, N. MEX.--Continued

Suspended sediment, water year October 1953 to September, 1954--Continued

\begin{tabular}{|c|c|c|c|c|c|c|c|c|c|}
\hline \multirow[b]{3}{*}{ Day } & \multicolumn{3}{|c|}{ April } & \multicolumn{3}{|c|}{ May } & \multicolumn{3}{|c|}{ June } \\
\hline & \multirow[b]{2}{*}{$\begin{array}{c}\text { Mean } \\
\text { dis- } \\
\text { charge } \\
\text { (cfs) }\end{array}$} & \multicolumn{2}{|c|}{ Suspended sediment } & \multirow[b]{2}{*}{$\begin{array}{l}\text { Mean } \\
\text { dis- } \\
\text { charge } \\
\text { (cfs) }\end{array}$} & \multicolumn{2}{|c|}{ Suspended sediment } & \multirow[b]{2}{*}{$\begin{array}{l}\text { Mean } \\
\text { dis- } \\
\text { charge } \\
\text { (cfs) }\end{array}$} & \multicolumn{2}{|c|}{ Suspended sediment } \\
\hline & & $\begin{array}{l}\text { Mean } \\
\text { concen- } \\
\text { tration } \\
\text { (ppm) }\end{array}$ & $\begin{array}{l}\text { Tons } \\
\text { per } \\
\text { day }\end{array}$ & & $\begin{array}{l}\text { Mean } \\
\text { concen- } \\
\text { tration } \\
\text { (ppm) }\end{array}$ & $\begin{array}{l}\text { Tons } \\
\text { per } \\
\text { day }\end{array}$ & & $\begin{array}{l}\text { Mean } \\
\text { concen- } \\
\text { tration } \\
\text { (ppm) }\end{array}$ & $\begin{array}{l}\text { Tons } \\
\text { per } \\
\text { day }\end{array}$ \\
\hline $\begin{array}{l}1 \ldots \ldots \\
2 \ldots \ldots \\
3 \ldots \ldots \\
4 \ldots \ldots \\
5 \ldots \ldots\end{array}$ & $\begin{array}{r}40 \\
32 \\
33 \\
43 \\
158\end{array}$ & $\begin{array}{l}6,250 \\
6,100 \\
4,700 \\
6,200 \\
9,280\end{array}$ & $\begin{array}{r}675 \\
527 \\
419 \\
\mathrm{a} 720 \\
\mathrm{~s} 4,460\end{array}$ & $\begin{array}{l}40 \\
44 \\
32 \\
37 \\
49\end{array}$ & $\begin{array}{l}3,400 \\
4,000 \\
4,420 \\
4,100 \\
4,000\end{array}$ & $\begin{array}{r}370 \\
\text { a } 480 \\
382 \\
410 \\
529\end{array}$ & & & \\
\hline $\begin{array}{r}6 \ldots \ldots \\
7 \ldots \ldots \\
8 \ldots \ldots \\
9 \ldots \ldots \\
10 \ldots \ldots\end{array}$ & $\begin{array}{l}48 \\
46 \\
56 \\
64 \\
58\end{array}$ & $\begin{array}{l}8,400 \\
6,600 \\
7,200 \\
7,900 \\
8,400\end{array}$ & $\begin{array}{r}1,090 \\
820 \\
1,090 \\
1,370 \\
\mathrm{a} 1,300\end{array}$ & $\begin{array}{l}43 \\
30 \\
24 \\
20 \\
53\end{array}$ & $\begin{array}{l}4,000 \\
3,500 \\
3,300 \\
3,100 \\
6,060\end{array}$ & $\begin{array}{r}464 \\
284 \\
\text { a } 210 \\
\text { a } 170 \\
\text { s } 3,730\end{array}$ & & & \\
\hline $\begin{array}{l}11 \ldots \ldots \\
12 \ldots \ldots \\
13 \ldots \ldots \\
14 \ldots \ldots \\
15 \ldots \ldots\end{array}$ & $\begin{array}{r}58 \\
59 \\
101 \\
111 \\
120\end{array}$ & $\begin{array}{r}8,100 \\
8,000 \\
8,400 \\
10,000 \\
9,000\end{array}$ & $\begin{array}{r}\text { a } 1,300 \\
1,270 \\
2,290 \\
3,000 \\
2,920\end{array}$ & $\begin{array}{r}353 \\
143 \\
98 \\
67 \\
53\end{array}$ & $\begin{array}{r}31,900 \\
19,800 \\
12,800 \\
8,810 \\
6,400\end{array}$ & $\begin{array}{r}\mathrm{s} 37,200 \\
7,640 \\
\mathrm{~s} 3,420 \\
1,590 \\
916\end{array}$ & & & \\
\hline $\begin{array}{l}16 \ldots \ldots \\
17 . \ldots \ldots \\
18 \ldots \ldots \\
19 . \ldots \ldots \\
20 \ldots \ldots\end{array}$ & $\begin{array}{l}116 \\
126 \\
152 \\
166 \\
118\end{array}$ & $\begin{array}{l}9,000 \\
8,600 \\
9,600 \\
8,450 \\
8,820\end{array}$ & $\begin{array}{r}2,820 \\
2,930 \\
\text { sa 4, 100 } \\
\mathrm{s} 3,830 \\
2,810\end{array}$ & $\begin{array}{r}42 \\
39 \\
163 \\
32 \\
20\end{array}$ & $\begin{array}{r}5,300 \\
4,500 \\
23,400 \\
11,000 \\
7,300\end{array}$ & $\begin{array}{r}\text { a } 600 \\
474 \\
\mathrm{~s} 14,200 \\
950 \\
394\end{array}$ & & & \\
\hline $\begin{array}{l}21 \ldots \ldots \\
22 \ldots \ldots \ldots \\
23 \ldots \ldots \ldots \\
24 \ldots \ldots \\
25 . \ldots \ldots\end{array}$ & $\begin{array}{r}100 \\
88 \\
67 \\
67 \\
60\end{array}$ & $\begin{array}{l}6,750 \\
6,200 \\
4,800 \\
5,000 \\
4,800\end{array}$ & $\begin{array}{r}1,820 \\
1,470 \\
868 \\
904 \\
\text { a } 780\end{array}$ & $\begin{array}{l}12 \\
16 \\
24 \\
50 \\
25\end{array}$ & $\begin{array}{r}5,300 \\
5,900 \\
7,000 \\
13,700 \\
6,800\end{array}$ & $\begin{array}{r}172 \\
\mathrm{a} 250 \\
\mathrm{a} 450 \\
\mathrm{~s} 2,020 \\
459\end{array}$ & & & \\
\hline $\begin{array}{l}26 \ldots \ldots \\
27 . \ldots \ldots \\
28 . \ldots \ldots \\
29 . \ldots \ldots \\
30 \ldots \ldots \\
31 . \ldots \ldots\end{array}$ & $\begin{array}{l}64 \\
57 \\
43 \\
32 \\
28 \\
-- \\
\end{array}$ & $\begin{array}{r}3,600 \\
4,300 \\
5,000 \\
3,600 \\
2,800 \\
-- \\
\end{array}$ & \begin{tabular}{r|}
622 \\
662 \\
580 \\
311 \\
212 \\
-- \\
\end{tabular} & $\begin{array}{c}12 \\
5.4 \\
.9 \\
0 \\
0 \\
0 \\
\end{array}$ & $\begin{array}{r}4,600 \\
2,450 \\
725 \\
-- \\
-- \\
-- \\
\end{array}$ & $\begin{array}{r}149 \\
36 \\
\text { s } 3 \\
0 \\
0 \\
0 \\
0\end{array}$ & & & \\
\hline \multirow[t]{2}{*}{ Tota1. } & 2,311 & -- & 47,970 & . $1,527.3$ & -- & 77,952 & 0 & -- & 0 \\
\hline & \multicolumn{3}{|c|}{ July } & \multicolumn{3}{|c|}{ August } & \multicolumn{3}{|c|}{ September } \\
\hline $\begin{array}{l}1 \ldots \ldots \\
2 \ldots \ldots \\
3 \ldots \ldots \\
4 \ldots \ldots \\
5 \ldots \ldots\end{array}$ & $\begin{array}{c}1.4 \\
1.4 \\
40 \\
3 \\
0\end{array}$ & $\begin{array}{r}-- \\
35,800 \\
14,300\end{array}$ & $\begin{array}{r}\text { e } 70 \\
e 40 \\
\mathrm{~s} 4,860 \\
116 \\
0\end{array}$ & $\begin{array}{r}154 \\
2 \\
0 \\
0 \\
0\end{array}$ & $\begin{array}{r}45,000 \\
-- \\
-- \\
-- \\
--\end{array}$ & $\begin{array}{r}a 28,000 \\
\text { e } 40 \\
0 \\
0 \\
0\end{array}$ & $\begin{array}{l}0 \\
0 \\
0 \\
0 \\
0\end{array}$ & $\begin{array}{l}-- \\
-- \\
-- \\
-- \\
--\end{array}$ & $\begin{array}{l}0 \\
0 \\
0 \\
0 \\
0\end{array}$ \\
\hline $\begin{array}{r}6 \ldots \ldots \\
7 \ldots \ldots \\
8 \ldots \ldots \\
9 \ldots \ldots \\
10 \ldots \ldots\end{array}$ & $\begin{array}{l}0 \\
0 \\
0 \\
0 \\
0\end{array}$ & $\begin{array}{l}-- \\
-- \\
-- \\
--\end{array}$ & $\begin{array}{l}0 \\
0 \\
0 \\
0 \\
0\end{array}$ & $\begin{array}{l}0 \\
0 \\
0 \\
0 \\
0\end{array}$ & $\begin{array}{l}-- \\
-- \\
-- \\
--\end{array}$ & $\begin{array}{l}0 \\
0 \\
0 \\
0 \\
0\end{array}$ & $\begin{array}{l}0 \\
0 \\
0 \\
0 \\
0\end{array}$ & $\begin{array}{l}-- \\
-- \\
-- \\
-- \\
--\end{array}$ & $\begin{array}{l}0 \\
0 \\
0 \\
0 \\
0\end{array}$ \\
\hline $\begin{array}{l}11 \ldots \ldots \\
12 \ldots \ldots \\
13 \ldots \ldots \\
14 \ldots \ldots \\
15 \ldots \ldots\end{array}$ & $\begin{array}{l}0 \\
0 \\
0 \\
0 \\
0\end{array}$ & $\begin{array}{l}-- \\
-- \\
-- \\
--\end{array}$ & $\begin{array}{l}0 \\
0 \\
0 \\
0 \\
0\end{array}$ & $\begin{array}{l}3 \\
0 \\
0 \\
0 \\
0\end{array}$ & $\begin{array}{r}28,000 \\
-- \\
-- \\
-- \\
--\end{array}$ & $\begin{array}{r}227 \\
0 \\
0 \\
0 \\
0\end{array}$ & $\begin{array}{l}-1 \\
1.8 \\
0 \\
0 \\
0\end{array}$ & $\begin{array}{l}-- \\
-- \\
=- \\
-- \\
--\end{array}$ & $\begin{array}{r}\text { e } 5 \\
\text { e 40 } \\
0 \\
0 \\
0\end{array}$ \\
\hline $\begin{array}{l}16 \ldots \ldots \\
17 \ldots \ldots \\
18 \ldots \ldots \\
19 . \ldots \ldots \\
20 . \ldots \ldots\end{array}$ & $\begin{array}{l}0 \\
0 \\
0 \\
0 \\
0\end{array}$ & $\begin{array}{l}-- \\
-- \\
-- \\
--\end{array}$ & $\begin{array}{l}0 \\
0 \\
0 \\
0 \\
0\end{array}$ & $\begin{array}{r}450 \\
10 \\
1 \\
0 \\
0\end{array}$ & $\begin{array}{r}46,600 \\
14,600 \\
2,800 \\
-- \\
=-\end{array}$ & $\begin{array}{r}\text { s 77, } 100 \\
394 \\
\text { a } 8 \\
0 \\
0\end{array}$ & $\begin{array}{l}0 \\
0 \\
0 \\
0 \\
0\end{array}$ & $\begin{array}{l}-- \\
-- \\
-- \\
-- \\
--\end{array}$ & $\begin{array}{l}0 \\
0 \\
0 \\
0 \\
0\end{array}$ \\
\hline $\begin{array}{l}21 \ldots \ldots \\
22 . \ldots \ldots \\
23 . \ldots . \\
24 \ldots \ldots \\
25 . \ldots \ldots\end{array}$ & $\begin{array}{r}0 \\
0 \\
416 \\
1,110 \\
66\end{array}$ & $\begin{array}{r}-- \\
52,000 \\
33,700 \\
13,200\end{array}$ & $\begin{array}{r}0 \\
0 \\
\mathrm{~s} 67,400 \\
\mathrm{~s} 128,000 \\
2,350\end{array}$ & $\begin{array}{c}96 \\
6 \\
28 \\
3.0 \\
0\end{array}$ & $\begin{array}{r}37,200 \\
11,000 \\
18,000 \\
32,000 \\
--\end{array}$ & $\begin{array}{r}\mathrm{s} 13,900 \\
\mathrm{a} 180 \\
\mathrm{sa} 6,200 \\
\mathrm{~s} 377 \\
0\end{array}$ & $\begin{array}{l}0 \\
0 \\
0 \\
0 \\
0\end{array}$ & $\begin{array}{l}-- \\
-- \\
-- \\
-- \\
--\end{array}$ & $\begin{array}{l}0 \\
0 \\
0 \\
0 \\
0\end{array}$ \\
\hline $\begin{array}{l}26 . \ldots \ldots \\
27 . \ldots \ldots \\
28 . \ldots \\
29 . \ldots \\
30 \ldots \ldots \\
31 \ldots \ldots\end{array}$ & $\begin{array}{r}24 \\
9.7 \\
.8 \\
.6 \\
.3 \\
3.2 \\
\end{array}$ & $\begin{array}{r}7,800 \\
3,700 \\
1,900 \\
12,000 \\
9,000 \\
12,000 \\
\end{array}$ & $\begin{array}{r}505 \\
97 \\
a 4 \\
\text { sa } 30 \\
\text { sa } 15 \\
\text { a } 100 \\
\end{array}$ & $\begin{array}{l}0 \\
0 \\
0 \\
0 \\
0 \\
0 \\
\end{array}$ & $\begin{array}{l}-- \\
-- \\
-- \\
-- \\
--\end{array}$ & $\begin{array}{l}0 \\
0 \\
0 \\
0 \\
0 \\
0 \\
\end{array}$ & $\begin{array}{c}726 \\
68 \\
19 \\
7.2 \\
4 \\
\end{array}$ & $\begin{array}{r}49,000 \\
17,600 \\
16,900 \\
12,000 \\
8,600 \\
-\end{array}$ & $\begin{array}{r}\text { sa150, 000 } \\
\text { s 3, 820 } \\
867 \\
233 \\
93 \\
\end{array}$ \\
\hline Total. & $1,676.4$ & -- & 203,587 & 753.0 & -- & 126,426 & 826. 1 & -- & 155,058 \\
\hline
\end{tabular}




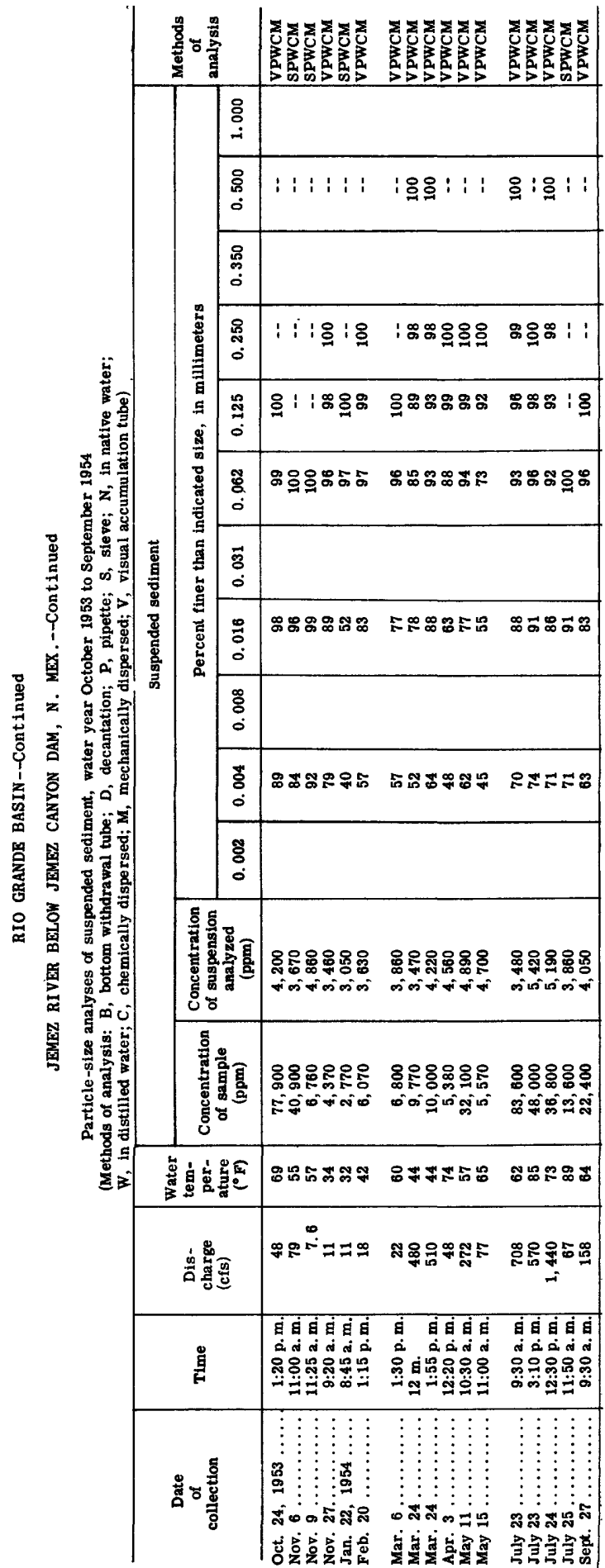


RIO GRANDE BASIN--Continued

RIO GRANDE NEAR BERNALILLO, N. MEX.

LOCATION.--At gaging station 2 miles northwest of Sandia Pueblo, 3 miles southwest of Bernalillo, Sandoval County, 3.5 miles downstream from State Highway 44 , and 8.5 miles downstream from Jemez River.

DRAINAGE AREA. - -17,300 square miles, approximately (includes 2,940 square miles in closed basin in northern part of San Luis Valley, Colo.).

RBCORDS AVAILABLE. - Water temperatures: October 1948 to September 1954.

Sediment records: November 1947 to September 1954.

EXTREMES, 1953-54.--Water temperatures: Maximum observed, $87^{\circ} \mathrm{F}$ Aug. 5; minimum observed, freezing point on many days in December and January.

Sediment concentrations: Maximum daily, 49,600 ppm Aug. 11; minimum daily, 40 ppm June 23.

Sediment loads: Maximum dally, 145,000 tons July 24; minimum daily, 1 ton on several days.

EXTREMES, 1947-54,--Water temperatures (1948-54): Maximum observed, 93 ${ }^{\circ} \mathrm{F}$ Aug. 18, 1951; minimum observed, freezing point on many days during winter months.

Sediment concentrations: Maximum daily, 50,300 ppm Aug. 2, 1950; minimum daily, 18 ppm May 13, 17, 1950 .

Sediment loads: Maximum daily, 320,000 tons July 24, 1949; minimum daily, less than 0.50 ton Sept. 25, 1953 .

REMARKS. - Records of specific conductance of daily samples available in district office at Albuquerque, $N$. Mex. Records of discharge for water year October 1953 to

September 1954 given in wSp 1342. Stage-discharge relation affected by ice Dec. 23 , 29, Jan. 1-5.

Temperature $\left({ }^{\circ} \mathrm{F}\right)$ of water, water year October 1953 to September 1954

\begin{tabular}{|c|c|c|c|c|c|c|c|c|c|c|c|c|}
\hline Day & Oct. & Nov. & Dec. & Jan. & Feb. & Mar. & Apr. & May & Jnne & July & Aug. & Sept. \\
\hline $\begin{array}{l}1 \\
2 \\
3 \\
4 \\
5\end{array}$ & $\begin{array}{r}270 \\
48 \\
58 \\
55 \\
47\end{array}$ & $\begin{array}{l}49 \\
46 \\
48 \\
48 \\
48\end{array}$ & $\begin{array}{r}38 \\
41 \\
\text { b39 } \\
\text { b36 } \\
34\end{array}$ & $\begin{array}{l}31 \\
31 \\
31 \\
31 \\
31\end{array}$ & $\begin{array}{r}40 \\
\mathrm{a} 46 \\
39 \\
39 \\
39\end{array}$ & $\begin{array}{l}39 \\
39 \\
32 \\
37 \\
39\end{array}$ & $\begin{array}{l}43 \\
44 \\
47 \\
50 \\
51\end{array}$ & $\begin{array}{r}46 \\
46 \\
261 \\
54 \\
58\end{array}$ & $\begin{array}{r}60 \\
65 \\
\text { b } 67 \\
62 \\
53\end{array}$ & $\begin{array}{r}65 \\
66 \\
64 \\
-\quad 75 \\
69\end{array}$ & $\begin{array}{r}72 \\
61 \\
64 \\
\mathbf{b} 87\end{array}$ & $\begin{array}{l}74 \\
74 \\
73 \\
74 \\
67\end{array}$ \\
\hline $\begin{array}{r}6 \\
7 \\
8 \\
9 \\
10\end{array}$ & $\begin{array}{l}49 \\
45 \\
45 \\
45 \\
53\end{array}$ & $\begin{array}{l}45 \\
42 \\
42 \\
40 \\
40\end{array}$ & $\begin{array}{r}\text { b31 } \\
-- \\
31 \\
\text { b 31 } \\
31\end{array}$ & $\begin{array}{l}31 \\
32 \\
36 \\
38 \\
32\end{array}$ & $\begin{array}{r}\mathbf{4} 46 \\
39 \\
39 \\
39 \\
38\end{array}$ & $\begin{array}{l}37 \\
37 \\
43 \\
42 \\
49\end{array}$ & $\begin{array}{l}49 \\
49 \\
47 \\
51 \\
52\end{array}$ & $\begin{array}{l}59 \\
59 \\
63 \\
62 \\
64\end{array}$ & $\begin{array}{l}\mathbf{6 2} \\
\mathbf{5 6} \\
\mathbf{6 6} \\
\mathbf{5 8} \\
\mathbf{5 6}\end{array}$ & $\begin{array}{l}67 \\
67 \\
65 \\
62 \\
69\end{array}$ & $\begin{array}{l}65 \\
66 \\
61 \\
62 \\
68\end{array}$ & $\begin{array}{l}64 \\
69 \\
71 \\
69 \\
69\end{array}$ \\
\hline $\begin{array}{l}11 \\
12 \\
13 \\
14 \\
15\end{array}$ & $\begin{array}{l}51 \\
48 \\
53 \\
46 \\
47\end{array}$ & $\begin{array}{l}39 \\
40 \\
40 \\
43 \\
44\end{array}$ & $\begin{array}{r}\text { b 31 } \\
\text { b 31 } \\
\text { b 31 } \\
\text { a 34 } \\
\mathbf{3 1}\end{array}$ & $\begin{array}{r}31 \\
32 \\
31 \\
\text { b 40 } \\
31\end{array}$ & $\begin{array}{l}38 \\
40 \\
41 \\
42 \\
42\end{array}$ & $\begin{array}{l}45 \\
35 \\
35 \\
36 \\
38\end{array}$ & $\begin{array}{l}55 \\
53 \\
53 \\
54 \\
53\end{array}$ & $\begin{array}{l}54 \\
58 \\
61 \\
61 \\
65\end{array}$ & $\begin{array}{l}58 \\
60 \\
63 \\
60 \\
60\end{array}$ & $\begin{array}{l}70 \\
69 \\
68 \\
68 \\
68\end{array}$ & $\begin{array}{r}64 \\
59 \\
66 \\
\text { b } 84 \\
73\end{array}$ & $\begin{array}{l}62 \\
67 \\
67 \\
67 \\
67\end{array}$ \\
\hline $\begin{array}{l}16 \\
17 \\
18 \\
19 \\
20\end{array}$ & $\begin{array}{l}47 \\
49 \\
52 \\
48 \\
54\end{array}$ & $\begin{array}{l}43 \\
42 \\
43 \\
39 \\
33\end{array}$ & $\begin{array}{l}31 \\
34 \\
33 \\
35 \\
37\end{array}$ & $\begin{array}{l}32 \\
33 \\
32 \\
34 \\
35\end{array}$ & $\begin{array}{r}38 \\
40 \\
39 \\
33 \\
b 45\end{array}$ & $\begin{array}{l}38 \\
39 \\
37 \\
39 \\
43\end{array}$ & $\begin{array}{r}50 \\
53 \\
\text { b } 66 \\
54 \\
55\end{array}$ & $\begin{array}{l}63 \\
63 \\
56 \\
62 \\
64\end{array}$ & $\begin{array}{l}61 \\
63 \\
60 \\
63 \\
66\end{array}$ & $\begin{array}{l}68 \\
68 \\
70 \\
70 \\
70\end{array}$ & $\begin{array}{l}65 \\
65 \\
65 \\
63 \\
72\end{array}$ & $\begin{array}{l}66 \\
67 \\
60 \\
61 \\
63\end{array}$ \\
\hline $\begin{array}{l}21 \\
22 \\
23 \\
24 \\
25\end{array}$ & $\begin{array}{r}45 \\
\text { b 59 } \\
48 \\
51 \\
46\end{array}$ & $\begin{array}{r}\text { b38 } \\
33 \\
32 \\
36 \\
\mathbf{3 7}\end{array}$ & $\begin{array}{l}33 \\
32 \\
31 \\
31 \\
31\end{array}$ & $\begin{array}{l}33 \\
32 \\
32 \\
34 \\
35\end{array}$ & $\begin{array}{l}39 \\
40 \\
40 \\
41 \\
43\end{array}$ & $\begin{array}{l}45 \\
48 \\
50 \\
46 \\
39\end{array}$ & $\begin{array}{l}53 \\
53 \\
-- \\
-- \\
--\end{array}$ & $\begin{array}{r}64 \\
64 \\
62 \\
59 \\
265\end{array}$ & $\begin{array}{l}61 \\
70 \\
63 \\
62 \\
61\end{array}$ & $\begin{array}{l}72 \\
69 \\
62 \\
73 \\
75\end{array}$ & $\begin{array}{l}64 \\
67 \\
69 \\
65 \\
65\end{array}$ & $\begin{array}{r}62 \\
61 \\
60 \\
64 \\
\text { b63 }\end{array}$ \\
\hline $\begin{array}{l}26 \\
27 \\
28 \\
29 \\
30 \\
31\end{array}$ & $\begin{array}{l}45 \\
43 \\
43 \\
45 \\
44 \\
46\end{array}$ & $\begin{array}{l}38 \\
39 \\
40 \\
39 \\
37 \\
--\end{array}$ & $\begin{array}{l}31 \\
31 \\
31 \\
31 \\
31 \\
31\end{array}$ & $\begin{array}{r}\text { b46 } \\
35 \\
36 \\
37 \\
40 \\
37\end{array}$ & $\begin{array}{l}43 \\
39 \\
37 \\
-- \\
-- \\
--\end{array}$ & $\begin{array}{l}42 \\
43 \\
47 \\
48 \\
43 \\
42\end{array}$ & $\begin{array}{r}-- \\
\text { a } 68 \\
54 \\
55 \\
52 \\
--\end{array}$ & $\begin{array}{r}\text { a } 66 \\
\text { a 67 } \\
\mathbf{2} 69 \\
60 \\
62 \\
60\end{array}$ & $\begin{array}{l}60 \\
63 \\
62 \\
65 \\
61 \\
--\end{array}$ & $\begin{array}{l}73 \\
72 \\
69 \\
70 \\
70 \\
64\end{array}$ & $\begin{array}{l}63 \\
65 \\
68 \\
67 \\
72 \\
70\end{array}$ & $\begin{array}{l}61 \\
56 \\
57 \\
55 \\
53 \\
--\end{array}$ \\
\hline $\begin{array}{c}\text { Aver- } \\
\text { age }\end{array}$ & 49 & 41 & 33 & 34 & 40 & 41 & 52 & 61 & 62 & 69 & 67 & 65 \\
\hline
\end{tabular}

a Measurement after $6 \mathrm{p.m}$

b Measurement between 11 a.m. and 6 p.m. 
RIO GRANDE BASIN--Continued

RIO GRANDE NEAR BERNALILLO, N. MEX.--Continued

Suspended sediment, water year October 1953 to September 1954

\begin{tabular}{|c|c|c|c|c|c|c|c|c|c|}
\hline \multirow[b]{3}{*}{ Day } & \multicolumn{3}{|c|}{ October } & \multicolumn{3}{|c|}{ November } & \multicolumn{3}{|c|}{ December } \\
\hline & \multirow[b]{2}{*}{$\begin{array}{l}\text { Mean } \\
\text { dis- } \\
\text { charge } \\
\text { (cfs) }\end{array}$} & \multicolumn{2}{|c|}{ Suspended sediment } & \multirow[b]{2}{*}{$\begin{array}{l}\text { Mean } \\
\text { dis- } \\
\text { charge } \\
\text { (cfs) }\end{array}$} & \multicolumn{2}{|c|}{ Suspended sediment } & \multirow[b]{2}{*}{$\begin{array}{l}\text { Mean } \\
\text { dis- } \\
\text { charge } \\
\text { (cfs) }\end{array}$} & \multicolumn{2}{|c|}{ Suspended sediment } \\
\hline & & $\begin{array}{l}\text { Mean } \\
\text { concen- } \\
\text { tration } \\
\text { (ppm) }\end{array}$ & $\begin{array}{l}\text { Tons } \\
\text { per } \\
\text { day }\end{array}$ & & $\begin{array}{l}\text { Mean } \\
\text { concen- } \\
\text { tration } \\
\text { (ppm) }\end{array}$ & $\begin{array}{l}\text { Tons } \\
\text { per } \\
\text { day }\end{array}$ & & $\begin{array}{l}\text { Mean } \\
\text { concen- } \\
\text { tration } \\
(\mathrm{ppm})\end{array}$ & $\begin{array}{l}\text { Tons } \\
\text { per } \\
\text { day }\end{array}$ \\
\hline $\begin{array}{l}1 \ldots \ldots \\
2 \ldots \ldots \\
3 \ldots \ldots \\
4 \ldots \ldots \\
5 \ldots \ldots\end{array}$ & $\begin{array}{r}3 \\
5 \\
4 \\
3 \\
13\end{array}$ & $\begin{array}{r}58 \\
108 \\
106 \\
75 \\
131\end{array}$ & $\begin{array}{r}\text { s } 1 \\
\text { s } 2 \\
1 \\
1 \\
5\end{array}$ & $\begin{array}{l}280 \\
336 \\
100 \\
145 \\
169\end{array}$ & $\begin{array}{r}1,020 \\
900 \\
550 \\
600 \\
450\end{array}$ & $\begin{array}{r}\mathrm{s} 845 \\
816 \\
\mathrm{~s} 183 \\
235 \\
205\end{array}$ & $\begin{array}{l}588 \\
600 \\
612 \\
600 \\
572\end{array}$ & $\begin{array}{l}1,320 \\
1,340 \\
1,320 \\
1,630 \\
1,100\end{array}$ & $\begin{array}{l}2,100 \\
2,170 \\
2,180 \\
2,640 \\
1,700\end{array}$ \\
\hline $\begin{array}{r}6 \ldots \ldots \\
7 \ldots \ldots \\
8 \ldots \ldots \\
9 \ldots \ldots \\
10 \ldots \ldots\end{array}$ & $\begin{array}{l}14 \\
16 \\
18 \\
20 \\
14\end{array}$ & $\begin{array}{r}112 \\
110 \\
100 \\
140 \\
90\end{array}$ & $\begin{array}{l}4 \\
5 \\
5 \\
8 \\
3\end{array}$ & $\begin{array}{l}284 \\
412 \\
505 \\
448 \\
430\end{array}$ & $\begin{array}{l}1,430 \\
3,710 \\
4,930 \\
2,370 \\
1,530\end{array}$ & $\begin{array}{r}1,100 \\
\mathrm{~s} 4,590 \\
6,720 \\
2,870 \\
1,780\end{array}$ & $\begin{array}{l}509 \\
448 \\
406 \\
418 \\
460\end{array}$ & $\begin{array}{l}895 \\
360 \\
460 \\
670 \\
590\end{array}$ & $\begin{array}{r}1,230 \\
435 \\
504 \\
756 \\
733\end{array}$ \\
\hline $\begin{array}{l}11 \ldots \ldots \\
12 \ldots \ldots \\
13 \ldots \ldots \\
14 \ldots \\
15 \ldots \ldots\end{array}$ & $\begin{array}{l}15 \\
18 \\
23 \\
24 \\
32\end{array}$ & $\begin{array}{r}97 \\
96 \\
141 \\
150 \\
228\end{array}$ & $\begin{array}{r}4 \\
5 \\
9 \\
10 \\
20\end{array}$ & $\begin{array}{l}420 \\
407 \\
394 \\
384 \\
389\end{array}$ & $\begin{array}{r}1,700 \\
1,390 \\
1,180 \\
1,030 \\
970\end{array}$ & $\begin{array}{l}1,930 \\
1,530 \\
1,260 \\
1,070 \\
1,020\end{array}$ & $\begin{array}{l}488 \\
495 \\
488 \\
481 \\
495\end{array}$ & $\begin{array}{r}940 \\
920 \\
1,030 \\
740 \\
735\end{array}$ & $\begin{array}{r}1,240 \\
1,230 \\
1,360 \\
961 \\
982\end{array}$ \\
\hline $\begin{array}{l}16 \ldots \ldots \\
17 \ldots \ldots \\
18 \ldots \ldots \\
19 \ldots \ldots \\
20 \ldots \ldots\end{array}$ & $\begin{array}{l}32 \\
34 \\
39 \\
32 \\
52\end{array}$ & $\begin{array}{l}176 \\
147 \\
144 \\
127 \\
350\end{array}$ & $\begin{array}{l}15 \\
13 \\
15 \\
11 \\
49\end{array}$ & $\begin{array}{l}398 \\
407 \\
412 \\
420 \\
425\end{array}$ & $\begin{array}{l}880 \\
830 \\
830 \\
780 \\
860\end{array}$ & $\begin{array}{l}946 \\
912 \\
923 \\
884 \\
987\end{array}$ & $\begin{array}{l}509 \\
530 \\
544 \\
558 \\
558\end{array}$ & $\begin{array}{r}840 \\
955 \\
1,170 \\
1,080 \\
1,160\end{array}$ & $\begin{array}{l}1,150 \\
1,370 \\
1,720 \\
1,630 \\
1,750\end{array}$ \\
\hline $\begin{array}{l}21 \ldots \ldots \ldots \\
22 \ldots \ldots \ldots \\
23 \ldots \ldots \ldots \\
24 \ldots \ldots \ldots \\
25 \ldots \ldots \ldots\end{array}$ & $\begin{array}{r}42 \\
72 \\
55 \\
57 \\
334\end{array}$ & $\begin{array}{r}530 \\
2,790 \\
4,300 \\
1,150 \\
3,760\end{array}$ & $\begin{array}{r}60 \\
542 \\
639 \\
177 \\
\mathrm{~s} 3,360\end{array}$ & $\begin{array}{l}443 \\
434 \\
420 \\
416 \\
448\end{array}$ & $\begin{array}{r}850 \\
910 \\
860 \\
1,000 \\
1,010\end{array}$ & $\begin{array}{r}1,020 \\
1,070 \\
975 \\
1,120 \\
1,220\end{array}$ & $\begin{array}{l}551 \\
558 \\
540 \\
470 \\
450\end{array}$ & $\begin{array}{r}1,090 \\
1,000 \\
810 \\
1,100 \\
780\end{array}$ & $\begin{array}{r}1,620 \\
1,510 \\
1,180 \\
1,400 \\
948\end{array}$ \\
\hline $\begin{array}{l}26 \ldots \ldots \\
27 \ldots \ldots \\
28 \ldots \ldots \\
29 \ldots \ldots \\
30 \ldots \ldots \\
31 \ldots \ldots\end{array}$ & $\begin{array}{r}380 \\
75 \\
50 \\
66 \\
35 \\
34 \\
\end{array}$ & $\begin{array}{r}2,500 \\
1,100 \\
620 \\
480 \\
340 \\
230 \\
\end{array}$ & $\begin{array}{r}2,560 \\
\text { s } 282 \\
84 \\
86 \\
32 \\
21 \\
\end{array}$ & $\begin{array}{r}470 \\
490 \\
510 \\
540 \\
588 \\
-- \\
\end{array}$ & $\begin{array}{r}950 \\
1,000 \\
1,360 \\
1,370 \\
1,140 \\
-- \\
\end{array}$ & $\begin{array}{r}1,210 \\
1,320 \\
1,870 \\
2,000 \\
1,810 \\
-- \\
\end{array}$ & $\begin{array}{l}480 \\
500 \\
510 \\
520 \\
495 \\
448 \\
\end{array}$ & $\begin{array}{l}270 \\
390 \\
900 \\
520 \\
\mathbf{4 7 0} \\
\mathbf{5 7 0} \\
\end{array}$ & $\begin{array}{r}350 \\
526 \\
1,240 \\
730 \\
628 \\
689 \\
\end{array}$ \\
\hline \multirow[t]{2}{*}{ Total } & 1,611 & -- & 8,029 & 11,924 & $=$ & 44,421 & 15,421 & $=$ & 38,662 \\
\hline & \multicolumn{3}{|c|}{ January } & \multicolumn{3}{|c|}{ February } & \multicolumn{3}{|c|}{ March } \\
\hline $\begin{array}{l}1 . \ldots \\
2 \ldots \ldots \\
3 \ldots \ldots \\
4 \ldots \ldots \\
5 \ldots \ldots\end{array}$ & $\begin{array}{l}440 \\
430 \\
440 \\
450 \\
450\end{array}$ & $\begin{array}{l}5,20 \\
690 \\
630 \\
900 \\
860\end{array}$ & $\begin{array}{r}618 \\
801 \\
748 \\
1,090 \\
1,040\end{array}$ & $\begin{array}{l}558 \\
558 \\
572 \\
565 \\
579\end{array}$ & $\begin{array}{l}810 \\
770 \\
930 \\
920 \\
910\end{array}$ & $\begin{array}{l}1,220 \\
1,160 \\
1,440 \\
1,400 \\
1,420\end{array}$ & $\begin{array}{l}424 \\
325 \\
275 \\
247 \\
231\end{array}$ & $\begin{array}{r}990 \\
970 \\
700 \\
1,040 \\
1,000\end{array}$ & $\begin{array}{r}1,130 \\
851 \\
520 \\
694 \\
624\end{array}$ \\
\hline $\begin{array}{r}6 \ldots \ldots \\
7 \ldots \ldots \\
8 \ldots \ldots \\
9 \ldots \ldots \\
10 \ldots \ldots\end{array}$ & $\begin{array}{l}460 \\
460 \\
495 \\
502 \\
502\end{array}$ & $\begin{array}{r}820 \\
990 \\
1,270 \\
1,000 \\
840\end{array}$ & $\begin{array}{l}1,020 \\
1,230 \\
1,700 \\
1,360 \\
1,140\end{array}$ & $\begin{array}{l}593 \\
600 \\
586 \\
579 \\
579\end{array}$ & $\begin{array}{l}910 \\
870 \\
780 \\
740 \\
870\end{array}$ & $\begin{array}{l}1,460 \\
1,410 \\
1,230 \\
1,160 \\
1,360\end{array}$ & $\begin{array}{l}188 \\
426 \\
438 \\
215 \\
227\end{array}$ & $\begin{array}{r}800 \\
610 \\
800 \\
1,060 \\
1,150\end{array}$ & $\begin{array}{l}406 \\
702 \\
946 \\
615 \\
705\end{array}$ \\
\hline $\begin{array}{l}11 . \ldots \ldots \\
12 \ldots \ldots \\
13 \ldots \ldots \\
14 \ldots \ldots \\
15 \ldots \ldots\end{array}$ & $\begin{array}{l}502 \\
502 \\
502 \\
502 \\
537\end{array}$ & $\begin{array}{l}630 \\
820 \\
900 \\
650 \\
780\end{array}$ & $\begin{array}{r}854 \\
1,110 \\
1,220 \\
881 \\
1,130\end{array}$ & $\begin{array}{l}624 \\
664 \\
680 \\
858 \\
932\end{array}$ & $\begin{array}{r}750 \\
800 \\
1,010 \\
1,150 \\
3,200\end{array}$ & $\begin{array}{l}1,260 \\
1,430 \\
.1,850 \\
2,660 \\
8,050\end{array}$ & $\begin{array}{l}267 \\
618 \\
688 \\
730 \\
528\end{array}$ & $\begin{array}{l}2,080 \\
2,810 \\
2,490 \\
2,460 \\
1,500\end{array}$ & $\begin{array}{l}1,500 \\
4,690 \\
4,630 \\
4,850 \\
2,140\end{array}$ \\
\hline $\begin{array}{l}16 \ldots \ldots \\
17 \ldots \ldots \\
18 . \ldots \ldots \\
19 . \ldots \ldots \\
20 \ldots \ldots\end{array}$ & $\begin{array}{l}516 \\
509 \\
502 \\
509 \\
530\end{array}$ & $\begin{array}{r}1,040 \\
960 \\
860 \\
780 \\
930\end{array}$ & $\begin{array}{l}1,450 \\
1,320 \\
1,170 \\
1,070 \\
1,330\end{array}$ & $\begin{array}{l}858 \\
825 \\
761 \\
689 \\
664\end{array}$ & $\begin{array}{r}2,430 \\
1,880 \\
1,410 \\
1,260 \\
970\end{array}$ & $\begin{array}{l}5,630 \\
4,190 \\
2,900 \\
2,340 \\
1,740\end{array}$ & $\begin{array}{l}255 \\
215 \\
310 \\
199 \\
178\end{array}$ & $\begin{array}{l}825 \\
708 \\
879 \\
420 \\
400\end{array}$ & $\begin{array}{r}568 \\
\text { s } 566 \\
\text { s } 845 \\
226 \\
192\end{array}$ \\
\hline $\begin{array}{l}21 \ldots \ldots \\
22 \ldots \ldots \\
23 \ldots \ldots \\
24 \ldots \ldots \\
25 \ldots \ldots\end{array}$ & $\begin{array}{l}530 \\
523 \\
502 \\
495 \\
509\end{array}$ & $\begin{array}{r}910 \\
1,030 \\
960 \\
830 \\
1,040\end{array}$ & $\begin{array}{l}1,300 \\
1,450 \\
1,300 \\
1,110 \\
1,430\end{array}$ & $\begin{array}{l}656 \\
656 \\
648 \\
648 \\
664 \\
\end{array}$ & $\begin{array}{r}1,020 \\
910 \\
940 \\
800 \\
860\end{array}$ & $\begin{array}{l}1,810 \\
1,610 \\
1,640 \\
1,400 \\
1,540\end{array}$ & $\begin{array}{l}375 \\
390 \\
188 \\
380 \\
540\end{array}$ & $\begin{array}{r}590 \\
530 \\
950 \\
4,080 \\
5,620\end{array}$ & $\begin{array}{r}597 \\
558 \\
482 \\
4,190 \\
8,190\end{array}$ \\
\hline $\begin{array}{l}26 \ldots \ldots \\
27 . \ldots \ldots \\
28 . \ldots \ldots \\
29 . \ldots \ldots \\
30 \ldots \ldots \\
31 \ldots \ldots\end{array}$ & $\begin{array}{l}\mathbf{5 2 3} \\
530 \\
\mathbf{5 2 3} \\
537 \\
544 \\
551 \\
\end{array}$ & $\begin{array}{r}1,180 \\
940 \\
890 \\
780 \\
900 \\
790\end{array}$ & $\begin{array}{l}1,670 \\
1,350 \\
1,260 \\
1,130 \\
1,320 \\
1,180\end{array}$ & $\begin{array}{r}715 \\
880 \\
656 \\
-- \\
-- \\
--\end{array}$ & $\begin{array}{r}870 \\
2,040 \\
1,600 \\
-- \\
-- \\
--\end{array}$ & $\begin{array}{r}1,680 \\
4,850 \\
2,830 \\
-- \\
-- \\
--\end{array}$ & $\begin{array}{l}600 \\
528 \\
695 \\
570 \\
325 \\
293 \\
\end{array}$ & $\begin{array}{r}11,900 \\
7,050 \\
3,820 \\
2,050 \\
1,840 \\
3,540 \\
\end{array}$ & $\begin{array}{r}19,300 \\
10,000 \\
7,170 \\
3,150 \\
1,610 \\
2,800\end{array}$ \\
\hline Total & 15,507 & -- & 36,782 & 18,848 & -- & 62,670 & 11,868 & -- & 85,447 \\
\hline
\end{tabular}

s Computed by subdividing day. 
RIO GRANDE BASIN--Continued

RIO GRANDE NEAR BERNALILLO, N. MEX.--Continued

Suspended sediment, water year October 1953 to September 1954 --Continued

\begin{tabular}{|c|c|c|c|c|c|c|c|c|c|}
\hline \multirow[b]{3}{*}{ Day } & \multicolumn{3}{|c|}{ April } & \multicolumn{3}{|c|}{ May } & \multicolumn{3}{|c|}{ June } \\
\hline & \multirow[b]{2}{*}{$\begin{array}{l}\text { Mean } \\
\text { dis- } \\
\text { charge } \\
\text { (cfs) }\end{array}$} & \multicolumn{2}{|c|}{ Suspended sediment } & \multirow[b]{2}{*}{$\begin{array}{c}\text { Mean } \\
\text { dis- } \\
\text { charge } \\
\text { (cfs) }\end{array}$} & \multicolumn{2}{|c|}{ Suspended sediment } & \multirow[b]{2}{*}{$\begin{array}{l}\text { Mean } \\
\text { dis- } \\
\text { charge } \\
\text { (cfs) }\end{array}$} & \multicolumn{2}{|c|}{ Suspended sediment } \\
\hline & & $\begin{array}{l}\text { Mean } \\
\text { concen- } \\
\text { tration } \\
(\mathrm{ppm})\end{array}$ & $\begin{array}{l}\text { Tons } \\
\text { per } \\
\text { day }\end{array}$ & & $\begin{array}{l}\text { Mean } \\
\text { concen- } \\
\text { tration } \\
\text { (ppm) }\end{array}$ & $\begin{array}{l}\text { Tons } \\
\text { per } \\
\text { day }\end{array}$ & & $\begin{array}{l}\text { Mean } \\
\text { concen- } \\
\text { tration } \\
\text { (ppm) }\end{array}$ & $\begin{array}{l}\text { Tons } \\
\text { per } \\
\text { day }\end{array}$ \\
\hline $\begin{array}{l}1 . \ldots \ldots \\
2 \ldots \ldots \\
3 \ldots \ldots \\
4 \ldots \ldots \\
5 \ldots \ldots\end{array}$ & $\begin{array}{l}570 \\
600 \\
456 \\
522 \\
522\end{array}$ & $\begin{array}{l}4,000 \\
2,500 \\
1,340 \\
1,350 \\
2,090\end{array}$ & $\begin{array}{l}6,160 \\
4,050 \\
1,650 \\
1,900 \\
2,950\end{array}$ & $\begin{array}{r}522 \\
1,420 \\
1,620 \\
1,100 \\
920\end{array}$ & $\begin{array}{l}1,700 \\
5,320 \\
3,300 \\
2,000 \\
1,320\end{array}$ & $\begin{array}{r}s 4,230 \\
20,400 \\
14,400 \\
5,940 \\
3,280\end{array}$ & $\begin{array}{l}588 \\
522 \\
516 \\
480 \\
462\end{array}$ & $\begin{array}{r}750 \\
830 \\
1,300 \\
570 \\
510\end{array}$ & $\begin{array}{r}1,190 \\
1,170 \\
1,810 \\
739 \\
636\end{array}$ \\
\hline $\begin{array}{r}6 \ldots \ldots \\
7 \ldots \ldots \\
8 \ldots \ldots \\
9 \ldots \ldots \\
10 \ldots \ldots\end{array}$ & $\begin{array}{l}306 \\
302 \\
370 \\
540 \\
730\end{array}$ & $\begin{array}{r}1,400 \\
1,020 \\
950 \\
1,550 \\
2,720\end{array}$ & $\begin{array}{r}1,160 \\
832 \\
949 \\
2,260 \\
5,360\end{array}$ & $\begin{array}{r}840 \\
765 \\
723 \\
1,000 \\
944\end{array}$ & $\begin{array}{r}1,200 \\
950 \\
860 \\
1,750 \\
1,120\end{array}$ & $\begin{array}{l}2,720 \\
1,960 \\
1,680 \\
4,720 \\
2,850\end{array}$ & $\begin{array}{l}779 \\
737 \\
438 \\
432 \\
444\end{array}$ & $\begin{array}{r}1,350 \\
1,050 \\
450 \\
450 \\
430\end{array}$ & $\begin{array}{r}2,840 \\
\\
532 \\
525 \\
515\end{array}$ \\
\hline $\begin{array}{l}11 \ldots \ldots \\
12 \ldots \ldots \\
13 . \ldots \ldots \\
14 \ldots \ldots \\
15 \ldots \ldots\end{array}$ & $\begin{array}{l}1,030 \\
1,100 \\
1,150 \\
1,250 \\
1,270\end{array}$ & $\begin{array}{l}5,400 \\
4,320 \\
4,300 \\
4,100 \\
4,700\end{array}$ & $\begin{array}{l}15,000 \\
12,800 \\
13,400 \\
13,800 \\
16,100\end{array}$ & $\begin{array}{r}1,070 \\
944 \\
944 \\
920 \\
944\end{array}$ & $\begin{array}{r}13,800 \\
4,500 \\
2,900 \\
1,950 \\
1,530\end{array}$ & $\begin{array}{r}\mathrm{s} 43,600 \\
11,500 \\
7,390 \\
4,840 \\
3,900\end{array}$ & $\begin{array}{l}415 \\
410 \\
450 \\
700 \\
614\end{array}$ & $\begin{array}{r}300 \\
228 \\
1,210 \\
624 \\
490\end{array}$ & $\begin{array}{r}336 \\
252 \\
1,470 \\
1,180 \\
812\end{array}$ \\
\hline $\begin{array}{l}16 \ldots \ldots \ldots \\
17 \ldots \ldots \\
18 \ldots \ldots \\
19 . \ldots \ldots \\
20 . \ldots \ldots\end{array}$ & $\begin{array}{r}1,200 \\
944 \\
1,050 \\
987 \\
723\end{array}$ & $\begin{array}{l}3,950 \\
2,300 \\
2,800 \\
2,230 \\
1,940\end{array}$ & $\begin{array}{r}12,800 \\
5,860 \\
7,940 \\
5,940 \\
3,790\end{array}$ & $\begin{array}{l}1,620 \\
1,680 \\
1,830 \\
1,490 \\
1,420\end{array}$ & $\begin{array}{r}3,400 \\
3,000 \\
16,600 \\
4,200 \\
2,000\end{array}$ & $\begin{array}{r}14,900 \\
13,600 \\
\mathrm{~s} 86,300 \\
16,900 \\
7,670\end{array}$ & $\begin{array}{r}350 \\
340 \\
280 \\
96 \\
207\end{array}$ & $\begin{array}{l}300 \\
250 \\
220 \\
140 \\
220\end{array}$ & $\begin{array}{r}283 \\
229 \\
166 \\
36 \\
123\end{array}$ \\
\hline $\begin{array}{l}21 . \ldots \ldots \\
22 \ldots \ldots \ldots \\
23 . \ldots \ldots \\
24 \ldots \ldots \\
25 . \ldots \ldots\end{array}$ & $\begin{array}{l}642 \\
528 \\
468 \\
420 \\
618\end{array}$ & $\begin{array}{r}1,300 \\
1,200 \\
1,100 \\
820 \\
1,340\end{array}$ & $\begin{array}{r}2,250 \\
1,710 \\
1,390 \\
930 \\
2,240\end{array}$ & $\begin{array}{l}1,360 \\
1,340 \\
1,920 \\
1,900 \\
1,470\end{array}$ & $\begin{array}{l}1,420 \\
2,100 \\
3,010 \\
3,100 \\
2,380\end{array}$ & $\begin{array}{r}5,210 \\
7,600 \\
15,600 \\
15,900 \\
9,450\end{array}$ & $\begin{array}{r}231 \\
34 \\
11 \\
7 \\
5\end{array}$ & $\begin{array}{r}190 \\
130 \\
40 \\
100 \\
80\end{array}$ & $\begin{array}{r}118 \\
-\quad 12 \\
1 \\
2 \\
1\end{array}$ \\
\hline $\begin{array}{l}26 \ldots \ldots \\
27 . \ldots \ldots \\
28 \ldots \ldots \\
29 . \ldots \ldots \\
30 \ldots \ldots \\
31 \ldots \ldots\end{array}$ & $\begin{array}{r}582 \\
311 \\
235 \\
188 \\
150 \\
--\end{array}$ & $\begin{array}{c}990 \\
620 \\
940 \\
600 \\
330 \\
--\end{array}$ & $\begin{array}{r}1,560 \\
521 \\
596 \\
305 \\
134 \\
--\end{array}$ & $\begin{array}{r}1,420 \\
1,390 \\
1,090 \\
765 \\
1,060 \\
969\end{array}$ & $\begin{array}{r}1,880 \\
1,430 \\
1,100 \\
1,020 \\
740 \\
795\end{array}$ & $\begin{array}{l}7,210 \\
5,370 \\
3,240 \\
2,110 \\
2,120 \\
2,080\end{array}$ & $\begin{array}{r}10 \\
194 \\
211 \\
24 \\
11 \\
--\end{array}$ & $\begin{array}{r}180 \\
3,110 \\
1,780 \\
738 \\
1,200 \\
--\end{array}$ & $\begin{array}{r}5 \\
\mathrm{~s} 1,880 \\
1,010 \\
\mathrm{~s} 98 \\
36 \\
--\end{array}$ \\
\hline \multirow[t]{2}{*}{ Total. } & 19,764 & -- & 146,337 & 37,400 & -- & 348,670 & 9,998 & -- & 20,097 \\
\hline & \multicolumn{3}{|c|}{ July } & \multicolumn{3}{|c|}{ August } & \multicolumn{3}{|c|}{ September } \\
\hline $\begin{array}{l}1 . \ldots \ldots \\
2 \ldots \ldots \\
3 \ldots \ldots \\
4 \ldots \ldots \\
5 \ldots \ldots\end{array}$ & $\begin{array}{r}4 \\
2 \\
18 \\
134 \\
188\end{array}$ & $\begin{array}{r}380 \\
220 \\
15,700 \\
4,000 \\
3,750\end{array}$ & $\begin{array}{r}4 \\
1 \\
\mathrm{~s} 1,340 \\
1,450 \\
1,900\end{array}$ & $\begin{array}{r}225 \\
215 \\
123 \\
90 \\
78\end{array}$ & $\begin{array}{r}15,100 \\
6,150 \\
6,100 \\
1,000 \\
800\end{array}$ & $\begin{array}{r}\mathrm{s} 11,400 \\
3,570 \\
2,030 \\
\mathrm{a} 240 \\
168\end{array}$ & $\begin{array}{r}26 \\
20 \\
17 \\
18 \\
101\end{array}$ & $\begin{array}{r}14,000 \\
9,150 \\
3,600 \\
2,700 \\
5,700\end{array}$ & $\begin{array}{r}983 \\
494 \\
165 \\
131 \\
1,550\end{array}$ \\
\hline $\begin{array}{r}6 \ldots \ldots \\
7 . \ldots \ldots \\
8 \ldots \ldots \\
9 \ldots \ldots \\
10 \ldots \ldots\end{array}$ & $\begin{array}{r}23 \\
17 \\
17 \\
8 \\
532\end{array}$ & $\begin{array}{r}500 \\
500 \\
700 \\
550 \\
5,720\end{array}$ & $\begin{array}{r}31 \\
23 \\
32 \\
12 \\
\mathrm{~s} 10,100\end{array}$ & $\begin{array}{r}87 \\
223 \\
420 \\
420 \\
345\end{array}$ & $\begin{array}{l}10,700 \\
11,700 \\
37,600 \\
27,400 \\
15,000\end{array}$ & $\begin{array}{r}\mathrm{s} 3,000 \\
\mathrm{~s} 6,320 \\
\mathrm{~s} 48,000 \\
31,100 \\
14,000\end{array}$ & $\begin{array}{l}600 \\
400 \\
255 \\
298 \\
320\end{array}$ & $\begin{array}{r}26,000 \\
12,000 \\
5,000 \\
3,800 \\
3,700\end{array}$ & $\begin{array}{r}42,100 \\
13,000 \\
3,440 \\
3,060 \\
3,200\end{array}$ \\
\hline $\begin{array}{l}11 \ldots \ldots \\
12 \ldots \ldots \\
13 \ldots \ldots \\
14 \ldots \ldots \\
15 \ldots \ldots\end{array}$ & $\begin{array}{l}978 \\
779 \\
588 \\
415 \\
410\end{array}$ & $\begin{array}{l}5,250 \\
3,250 \\
1,500 \\
2,600 \\
1,700\end{array}$ & $\begin{array}{r}13,900 \\
6,840 \\
2,380 \\
2,910 \\
1,880\end{array}$ & $\begin{array}{r}760 \\
59 \\
36 \\
23 \\
40\end{array}$ & $\begin{array}{r}49,600 \\
30,000 \\
18,000 \\
9,900 \\
7,900\end{array}$ & $\begin{array}{r}\mathrm{s} 130,000 \\
4,780 \\
1,750 \\
615 \\
853\end{array}$ & $\begin{array}{l}382 \\
593 \\
570 \\
614 \\
345\end{array}$ & $\begin{array}{r}7,730 \\
14,900 \\
10,500 \\
11,700 \\
10,100\end{array}$ & $\begin{array}{r}\mathrm{s} 7,860 \\
23,900 \\
16,200 \\
\mathrm{~s} 20,100 \\
9,410\end{array}$ \\
\hline $\begin{array}{l}16 \ldots \ldots \\
17 \ldots \ldots \\
18 \ldots \ldots \\
19 \ldots \ldots \\
20 . \ldots \ldots\end{array}$ & $\begin{array}{l}375 \\
360 \\
642 \\
648 \\
492\end{array}$ & $\begin{array}{r}900 \\
900 \\
1,750 \\
2,700 \\
1,500\end{array}$ & $\begin{array}{r}911 \\
875 \\
3,030 \\
4,720 \\
1,990\end{array}$ & $\begin{array}{r}473 \\
130 \\
51 \\
17 \\
12\end{array}$ & $\begin{array}{r}38,000 \\
23,200 \\
14,000 \\
5,300 \\
1,800\end{array}$ & $\begin{array}{r}\mathrm{s} 67,600 \\
\mathrm{~s} 7,520 \\
1,930 \\
243 \\
58\end{array}$ & $\begin{array}{l}231 \\
192 \\
134 \\
259 \\
219\end{array}$ & $\begin{array}{r}14,900 \\
4,950 \\
1,600 \\
2,000 \\
1,500\end{array}$ & $\begin{array}{r}9,290 \\
2,570 \\
579 \\
1,400 \\
887\end{array}$ \\
\hline $\begin{array}{l}21 \ldots \ldots \\
22 \ldots \ldots \\
23 . \ldots \ldots \\
24 \ldots \ldots \\
25 \ldots \ldots\end{array}$ & $\begin{array}{r}385 \\
512 \\
900 \\
1,540 \\
695\end{array}$ & $\begin{array}{r}3,500 \\
19,000 \\
30,300 \\
31,800 \\
15,300\end{array}$ & $\begin{array}{r}3,640 \\
\mathrm{~s} 27,200 \\
\mathrm{~s} 79,100 \\
\mathrm{~s} 145,000 \\
28,700\end{array}$ & $\begin{array}{r}50 \\
150 \\
231 \\
495 \\
118\end{array}$ & $\begin{array}{r}26,500 \\
17,600 \\
6,920 \\
46,900 \\
30,400\end{array}$ & $\begin{array}{r}s 5,630 \\
7,130 \\
s 6,610 \\
s 87,400 \\
s 10,200\end{array}$ & $\begin{array}{l}203 \\
150 \\
128 \\
125 \\
138\end{array}$ & $\begin{array}{r}1,100 \\
950 \\
800 \\
700 \\
3,100\end{array}$ & $\begin{array}{r}603 \\
385 \\
276 \\
236 \\
1,160\end{array}$ \\
\hline $\begin{array}{l}26 \ldots \ldots \\
27 \ldots \ldots \\
28 \ldots \ldots \\
29 \ldots \ldots \\
30 \ldots \ldots \\
31 \ldots \ldots\end{array}$ & $\begin{array}{l}415 \\
199 \\
181 \\
138 \\
231 \\
181 \\
\end{array}$ & $\begin{array}{r}5,800 \\
1,400 \\
750 \\
2,200 \\
1,700 \\
1,800 \\
\end{array}$ & $\begin{array}{r}6,500 \\
752 \\
366 \\
820 \\
1,060 \\
880 \\
\end{array}$ & $\begin{array}{l}36 \\
31 \\
28 \\
26 \\
28 \\
29 \\
\end{array}$ & $\begin{array}{l}9,300 \\
2,200 \\
1,600 \\
2,200 \\
2,000 \\
5,000\end{array}$ & $\begin{array}{l}904 \\
184 \\
121 \\
154 \\
151 \\
391 \\
\end{array}$ & $\begin{array}{r}570 \\
275 \\
85 \\
51 \\
46 \\
-- \\
\end{array}$ & $\begin{array}{r}35,800 \\
8,600 \\
5,050 \\
2,350 \\
1,400\end{array}$ & $\begin{array}{r}\mathbf{s} 82,500 \\
6,380 \\
1,160 \\
324 \\
174 \\
\end{array}$ \\
\hline Total. & 12,007 & -- & 348,347 & 5,049 & -- & 454,052 & 7,365 & -- & 253,517 \\
\hline
\end{tabular}

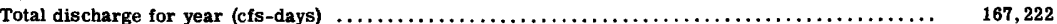

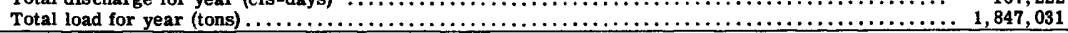

s Computed by subdividing day.

a Computed from estimated concentration graph. 


\begin{tabular}{|c|c|c|c|c|c|c|c|c|}
\hline & & 票 & & 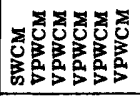 & 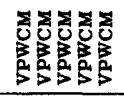 & 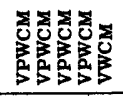 & 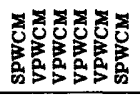 & 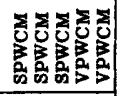 \\
\hline & & & ڤ్రి & & & & & \\
\hline & & & 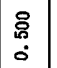 & 잉్ㅇ్ㅇ్ㅇ్ㅇㅇㅣ & 잉ㅇㅁ윰 : & 1:8: :8 & : : : : : & :8: : : \\
\hline & & & 总 & & & & & \\
\hline & & 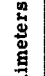 & 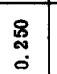 & ஃ̊ஃ̊ஃロ & 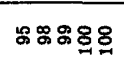 & 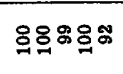 & | & | \\
\hline & & $\begin{array}{l}n \\
5 \\
8\end{array}$ & $\stackrel{\leftrightarrow}{\dddot{7}}$ & 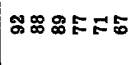 & 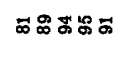 & ロேஃタ & ! ஃ5ธஃ5 & ! \& ! \& \& \\
\hline 要 & & 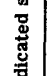 & $\stackrel{8}{8}$ & 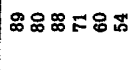 & 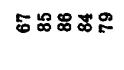 & ธะ8によ & 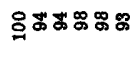 & 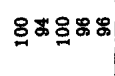 \\
\hline 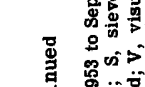 & 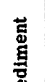 & 焉 & $\begin{array}{l}\ddot{0} \\
\stackrel{0}{0} \\
0\end{array}$ & & & & & \\
\hline 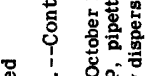 & 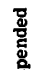 & 离 & : & 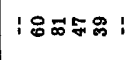 & 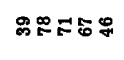 & 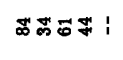 & ロロヒロッ & ஃேロ \\
\hline 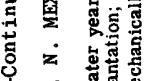 & $\bar{\omega}$ & & : & & & & & \\
\hline 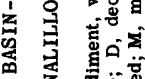 & & & $\begin{array}{l}\text { ઠे } \\
0 \\
0\end{array}$ & ; & 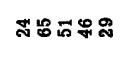 & 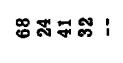 & 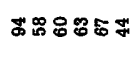 & ஜ \\
\hline 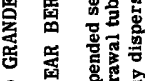 & & & o̊ & & & & & \\
\hline 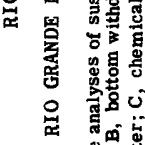 & & 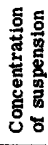 & 这 & 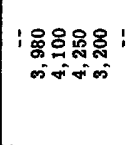 & 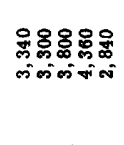 & 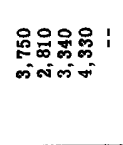 & 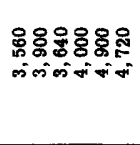 & 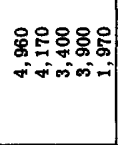 \\
\hline 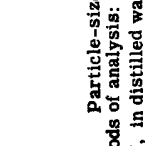 & & 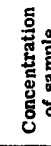 & 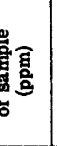 & 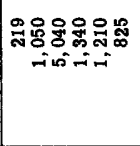 & 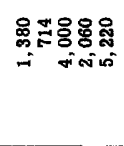 & 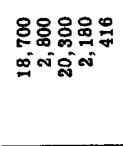 & 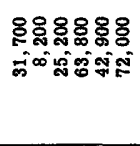 & 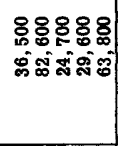 \\
\hline हี้ & & $\Phi$ & & ธี่ & ำระำ & 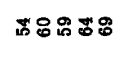 & こ゚このロ & ธ่ธ \\
\hline & & 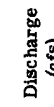 & & 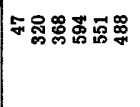 & 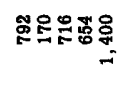 & 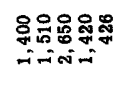 & 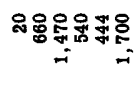 & 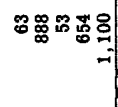 \\
\hline & & 惫 & & 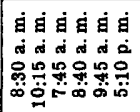 & 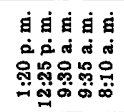 & 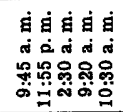 & 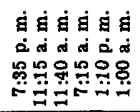 & 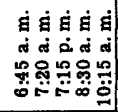 \\
\hline & & & & 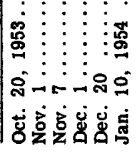 & 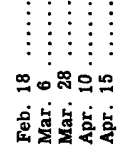 & 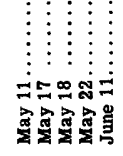 & 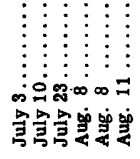 & 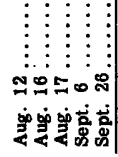 \\
\hline
\end{tabular}


RIO GRANDE NEAR BERNARDO, N. MEX.

LOCATION. - At gaging station at bridge on $U$. S. Highway 60,2 miles east of Bernardo, Socorro County, and $3 \frac{1}{2}$ miles upstream from Rio Puerco. Gage is on a conveyance channel, 5 miles downstream from heading, formerly San Francisco riverside drain. DRAINAGE AREA. --19,230 square miles, approximately (includes 2,940 square miles in closed basin in northern part of San Luis Valley, Colo.).

RECORDS AVAILABLE.--Sediment records: October 1947 to September 1954

EXTREMES, 1953-54.--Sediment concentrations: Maximum daily, 29,000 ppm Sept. 27; mintmum daily, only flow from drain on many days.

Sediment loads: Maximum daily, 47,600 tons July 25; minimum daily, less than 0.50 ton on many days.

EXTREMES, 1947-54.--Sediment concentrations: Maximum daily, 42,400 ppm Aug. 3, 1950; minimum daily, no river flow on many days. Not determined in interior drain.

Sediment loads: Maximum dajiy, 240,000 tons July 24, 1949; minimum daily, 0 tons in river on many days. Less than 0.50 ton in interior drain and conveyance channel on many days.

REMARKS.--Maximum observed sediment concentration during water year, 64,200 ppm Sept. 27. Records are summation of water and sediment discharges in main channel, conveyance channel (formerly San Francisco riverside drain), and Bernardo interior drain. Daily sediment concentrations not listed because a composite concentration of more than one channel is meaningless. Tables for particle-size analyses for each channel are published separately and show water discharges and concentrations in those channels at the time of sampling. Records of discharge for water year October 1953 to September 1954 given in WSP 1342 .

Suspended sediment, water year October 1953 to September 1954

\begin{tabular}{|c|c|c|c|c|c|c|c|c|c|}
\hline \multirow[b]{3}{*}{ Day } & \multicolumn{3}{|c|}{ October } & \multicolumn{3}{|c|}{ November } & \multicolumn{3}{|c|}{ December } \\
\hline & \multirow[b]{2}{*}{$\begin{array}{c}\text { Mean } \\
\text { dis- } \\
\text { charge } \\
\text { (cfs) }\end{array}$} & \multicolumn{2}{|c|}{ Suspended sediment } & \multirow[b]{2}{*}{$\begin{array}{l}\text { Mean } \\
\text { dis- } \\
\text { charge } \\
\text { (cfs) }\end{array}$} & \multicolumn{2}{|c|}{ Suspended sediment } & \multirow[b]{2}{*}{$\begin{array}{l}\text { Mean } \\
\text { dis- } \\
\text { charge } \\
\text { (cfs) }\end{array}$} & \multicolumn{2}{|c|}{ Suspended sediment } \\
\hline & & $\begin{array}{l}\text { Mean } \\
\text { concen- } \\
\text { tration } \\
(\mathrm{ppm})\end{array}$ & $\begin{array}{l}\text { Tons } \\
\text { per } \\
\text { day }\end{array}$ & & $\begin{array}{c}\text { Mean } \\
\text { concen- } \\
\text { tration } \\
(\mathrm{ppm})\end{array}$ & $\begin{array}{l}\text { Tons } \\
\text { per } \\
\text { day }\end{array}$ & & $\begin{array}{c}\text { Mean } \\
\text { concen- } \\
\text { tration } \\
\text { (ppm) }\end{array}$ & $\begin{array}{l}\text { Tons } \\
\text { per } \\
\text { day }\end{array}$ \\
\hline $\begin{array}{l}1 \ldots \ldots \\
2 \ldots \ldots \\
3 \ldots \ldots \\
4 \ldots \ldots \\
5 \ldots \ldots\end{array}$ & $\begin{array}{l}1 \\
1 \\
1 \\
1 \\
1\end{array}$ & & & $\begin{array}{r}8 \\
10 \\
11 \\
11 \\
15\end{array}$ & & $\begin{array}{l}\mathbf{2} \\
\mathbf{3} \\
\mathbf{3} \\
3 \\
9\end{array}$ & $\begin{array}{l}364 \\
424 \\
476 \\
528 \\
584\end{array}$ & & $\begin{array}{l}3,100 \\
3,730 \\
5,290 \\
5,630 \\
5,720\end{array}$ \\
\hline $\begin{array}{r}6 \ldots \ldots \\
7 \ldots \ldots \\
8 \ldots \ldots \\
9 \ldots \ldots \\
10 \ldots \ldots\end{array}$ & $\begin{array}{l}1 \\
1 \\
2 \\
1 \\
1\end{array}$ & & & $\begin{array}{l}16 \\
13 \\
13 \\
19 \\
50\end{array}$ & & $\begin{array}{r}12 \\
8 \\
6 \\
10 \\
178\end{array}$ & $\begin{array}{l}584 \\
564 \\
524 \\
480 \\
424\end{array}$ & & $\begin{array}{l}5,110 \\
5,530 \\
4,750 \\
3,430 \\
2,720\end{array}$ \\
\hline $\begin{array}{l}11 \ldots \ldots \\
12 \ldots \ldots \ldots \\
13 \ldots \ldots \ldots \\
14 \ldots \ldots \\
15 \ldots \ldots\end{array}$ & $\begin{array}{l}1 \\
1 \\
1 \\
1 \\
1\end{array}$ & & & $\begin{array}{l}\mathbf{6 1} \\
52 \\
52 \\
52 \\
56\end{array}$ & & $\begin{array}{l}277 \\
193 \\
172 \\
132 \\
142\end{array}$ & $\begin{array}{l}464 \\
496 \\
500 \\
512 \\
525\end{array}$ & & $\begin{array}{l}3,370 \\
3,790 \\
3,640 \\
3,590 \\
3,820\end{array}$ \\
\hline $\begin{array}{l}16 \ldots \ldots \\
17 \ldots \ldots \ldots \\
18 \ldots \ldots \\
19 \ldots \ldots \\
20 \ldots \ldots\end{array}$ & $\begin{array}{l}1 \\
1 \\
1 \\
1 \\
2\end{array}$ & & & $\begin{array}{r}60 \\
55 \\
52 \\
67 \\
104\end{array}$ & & $\begin{array}{r}152 \\
100 \\
79 \\
138 \\
439\end{array}$ & $\begin{array}{l}\mathbf{5 2 5} \\
\mathbf{5 3 3} \\
\mathbf{5 4 5} \\
\mathbf{5 5 7} \\
\mathbf{5 6 5}\end{array}$ & & $\begin{array}{l}3,790 \\
4,080 \\
5,160 \\
5,530 \\
4,780\end{array}$ \\
\hline $\begin{array}{l}21 \ldots \ldots \\
22 \ldots \ldots \ldots \\
23 \ldots \ldots \ldots \\
24 \ldots \ldots \\
25 \ldots \ldots\end{array}$ & $\begin{array}{l}4 \\
4 \\
4 \\
4 \\
5\end{array}$ & & $\begin{array}{l}2 \\
2 \\
1 \\
1 \\
2\end{array}$ & $\begin{array}{l}139 \\
150 \\
185 \\
211 \\
214\end{array}$ & & $\begin{array}{r}841 \\
722 \\
1,260 \\
1,330 \\
1,240\end{array}$ & $\begin{array}{l}565 \\
553 \\
545 \\
553 \\
561\end{array}$ & & $\begin{array}{l}4,450 \\
3,860 \\
3,920 \\
4,360 \\
4,370\end{array}$ \\
\hline $\begin{array}{l}26 \ldots \ldots \\
27 . \ldots \ldots \\
28 \ldots \ldots \\
29 \ldots \ldots \\
30 \ldots \ldots \\
31 \ldots \ldots\end{array}$ & $\begin{array}{l}5 \\
6 \\
6 \\
9 \\
8 \\
8 \\
\end{array}$ & & $\begin{array}{l}1 \\
2 \\
2 \\
4 \\
3 \\
3 \\
\end{array}$ & $\begin{array}{r}205 \\
201 \\
246 \\
276 \\
318 \\
-- \\
\end{array}$ & & $\begin{array}{r}1,300 \\
1,330 \\
1,760 \\
2,120 \\
2,710 \\
-- \\
\end{array}$ & $\begin{array}{l}525 \\
495 \\
495 \\
509 \\
525 \\
497 \\
\end{array}$ & & $\begin{array}{l}3,480 \\
2,840 \\
2,980 \\
2,910 \\
2,950 \\
3,070 \\
\end{array}$ \\
\hline Total. & 85 & & 24 & 2,922 & & 16,671 & 15,997 & & 125,750 \\
\hline
\end{tabular}

t Less than 0.50 ton. 
RIO GRANDE BASIN--Cont inued

RIO GRANDE NEAR BERNARDO, N. MEX.--Cont inued

Suspended sediment, water year October 1953 to September 1954--Continued

\begin{tabular}{|c|c|c|c|c|c|c|c|c|c|}
\hline \multirow[b]{3}{*}{ Day } & \multicolumn{3}{|c|}{ January } & \multicolumn{3}{|c|}{ February } & \multicolumn{3}{|c|}{ March } \\
\hline & \multirow[b]{2}{*}{$\begin{array}{l}\text { Mean } \\
\text { dis- } \\
\text { charge } \\
\text { (cfs) }\end{array}$} & \multicolumn{2}{|c|}{ Suspended sediment } & \multirow[b]{2}{*}{$\begin{array}{c}\text { Mean } \\
\text { dis- } \\
\text { charge } \\
\text { (cfs) }\end{array}$} & \multicolumn{2}{|c|}{ Suspended sediment } & \multirow[b]{2}{*}{$\begin{array}{l}\text { Mean } \\
\text { dis- } \\
\text { charge } \\
\text { (cfs) }\end{array}$} & \multicolumn{2}{|c|}{ Suspended sediment } \\
\hline & & $\begin{array}{l}\text { Mean } \\
\text { concen- } \\
\text { tration } \\
(\mathrm{ppm})\end{array}$ & $\begin{array}{l}\text { Tons } \\
\text { per } \\
\text { day }\end{array}$ & & $\begin{array}{l}\text { Mean } \\
\text { concen- } \\
\text { tration } \\
\text { (ppm) }\end{array}$ & $\begin{array}{l}\text { Tons } \\
\text { per } \\
\text { day }\end{array}$ & & $\begin{array}{c}\text { Mean } \\
\text { concen- } \\
\text { tration } \\
\text { (ppm) }\end{array}$ & $\begin{array}{l}\text { Tons } \\
\text { per } \\
\text { day }\end{array}$ \\
\hline $\begin{array}{l}1 \ldots \ldots \\
2 \ldots \ldots \\
3 \ldots \ldots \\
4 \ldots \ldots \\
5 \ldots \ldots\end{array}$ & $\begin{array}{l}497 \\
505 \\
494 \\
489 \\
485\end{array}$ & & $\begin{array}{l}3,080 \\
2,960 \\
2,770 \\
2,630 \\
2,660\end{array}$ & $\begin{array}{l}556 \\
556 \\
568 \\
581 \\
594\end{array}$ & & \begin{tabular}{l|}
2,450 \\
2,390 \\
2,320 \\
2,750 \\
2,780
\end{tabular} & $\begin{array}{l}836 \\
556 \\
481 \\
373 \\
351\end{array}$ & & $\begin{array}{l}5,400 \\
2,930 \\
2,180 \\
1,340 \\
1,120\end{array}$ \\
\hline $\begin{array}{r}6 \ldots \ldots \\
7 \ldots \ldots \\
8 \ldots \ldots \\
9 \ldots \ldots \\
10 \ldots \ldots\end{array}$ & $\begin{array}{l}480 \\
505 \\
543 \\
556 \\
556\end{array}$ & & $\begin{array}{l}2,820 \\
2,700 \\
2,880 \\
3,240 \\
3,270\end{array}$ & $\begin{array}{l}594 \\
594 \\
594 \\
606 \\
606\end{array}$ & & $\begin{array}{l}3,000 \\
2,520 \\
2,680 \\
2,660 \\
2,580\end{array}$ & $\begin{array}{l}287 \\
251 \\
211 \\
213 \\
219\end{array}$ & & $\begin{array}{l}615 \\
595 \\
393 \\
453 \\
518\end{array}$ \\
\hline $\begin{array}{l}11 \ldots \ldots \\
12 \ldots \ldots \\
13 \ldots \ldots \\
14 \ldots \ldots \\
15 \ldots \ldots\end{array}$ & $\begin{array}{l}\mathbf{5 4 4} \\
\mathbf{5 3 1} \\
\mathbf{5 4 4} \\
\mathbf{5 4 4} \\
\mathbf{5 3 1}\end{array}$ & & $\begin{array}{l}3,360 \\
2,880 \\
3,780 \\
2,960 \\
2,820\end{array}$ & $\begin{array}{l}621 \\
621 \\
621 \\
661 \\
676\end{array}$ & & $\begin{array}{l}2,510 \\
2,540 \\
2,570 \\
2,510 \\
2,730\end{array}$ & $\begin{array}{l}185 \\
202 \\
204 \\
422 \\
518\end{array}$ & & $\begin{array}{r}362 \\
426 \\
553 \\
\mathrm{~s} 2,810 \\
3,440\end{array}$ \\
\hline $\begin{array}{l}16 \ldots \ldots \\
17 . \ldots \ldots \\
18 \ldots \ldots \\
19 \ldots \ldots \\
20 \ldots \ldots\end{array}$ & $\begin{array}{l}518 \\
544 \\
656 \\
531 \\
\mathbf{5 3 1}\end{array}$ & & $\begin{array}{l}2,280 \\
2,700 \\
2,960 \\
2,640 \\
2,280\end{array}$ & $\begin{array}{l}806 \\
926 \\
837 \\
762 \\
749\end{array}$ & & $\begin{array}{r}4,580 \\
7,950 \\
6,500 \\
\text { a } 5,480 \\
\text { a 4,610 }\end{array}$ & $\begin{array}{l}381 \\
222 \\
227 \\
205 \\
181\end{array}$ & & $\begin{array}{r}2,270 \\
755 \\
591 \\
430 \\
236\end{array}$ \\
\hline $\begin{array}{l}21 \ldots \ldots \\
22 \ldots \ldots \\
23 \ldots \ldots \\
24 \ldots \ldots \\
25 \ldots \ldots\end{array}$ & $\begin{array}{l}544 \\
568 \\
581 \\
568 \\
556\end{array}$ & & $\begin{array}{l}2,640 \\
2,850 \\
3,230 \\
3,490 \\
2,900\end{array}$ & $\begin{array}{l}704 \\
691 \\
691 \\
661 \\
648\end{array}$ & & $\begin{array}{r}\mathbf{3}, 490 \\
3,630 \\
3,530 \\
3,150 \\
2,790\end{array}$ & $\begin{array}{l}155 \\
125 \\
151 \\
160 \\
116\end{array}$ & & $\begin{array}{r}93 \\
65 \\
150 \\
226 \\
87\end{array}$ \\
\hline $\begin{array}{l}26 \ldots \ldots \\
27 \ldots \ldots \\
28 \ldots \ldots \\
29 \ldots \ldots \\
30 \ldots \ldots \\
31 \ldots \ldots\end{array}$ & $\begin{array}{l}556 \\
556 \\
568 \\
581 \\
568 \\
556 \\
\end{array}$ & & $\begin{array}{l}2,820 \\
2,640 \\
2,810 \\
2,810 \\
2,760 \\
2,560\end{array}$ & $\begin{array}{r}648 \\
648 \\
691 \\
-- \\
-- \\
-- \\
\end{array}$ & & $\begin{array}{r}2,960 \\
2,910 \\
3,590 \\
-- \\
-- \\
-- \\
\end{array}$ & $\begin{array}{l}141 \\
263 \\
342 \\
377 \\
417 \\
326 \\
\end{array}$ & & $\begin{array}{r}158 \\
979 \\
1,730 \\
3,720 \\
4,340 \\
1,600 \\
\end{array}$ \\
\hline \multirow[t]{2}{*}{ Total. } & 16,686 & & 89,170 & 18,511 & & 94,160 & 9,098 & & 40,565 \\
\hline & \multicolumn{3}{|c|}{ April } & \multicolumn{3}{|c|}{ May } & \multicolumn{3}{|c|}{ June } \\
\hline $\begin{array}{l}1 \ldots \ldots \\
2 \ldots \ldots \\
3 . \ldots \ldots \\
4 . \ldots \ldots \\
5 \ldots \ldots\end{array}$ & $\begin{array}{l}230 \\
185 \\
237 \\
359 \\
295\end{array}$ & & $\begin{array}{r}547 \\
333 \\
717 \\
1,720 \\
835\end{array}$ & $\begin{array}{l}101 \\
150 \\
611 \\
745 \\
761\end{array}$ & & $\begin{array}{r}42 \\
221 \\
\mathrm{a} 6,190 \\
7,230 \\
\mathrm{a} 5,730\end{array}$ & $\begin{array}{r}429 \\
248 \\
131 \\
103 \\
97\end{array}$ & & $\begin{array}{r}1,840 \\
397 \\
97 \\
57 \\
53\end{array}$ \\
\hline $\begin{array}{c}6 \ldots \ldots \\
7 \ldots \ldots \\
8 . \ldots \ldots \\
9 . \ldots \ldots \\
10 \ldots \ldots\end{array}$ & $\begin{array}{l}209 \\
225 \\
196 \\
161 \\
133\end{array}$ & & $\begin{array}{l}384 \\
420 \\
413 \\
237 \\
145\end{array}$ & $\begin{array}{l}430 \\
330 \\
240 \\
249 \\
219\end{array}$ & & $\begin{array}{r}1,740 \\
965 \\
533 \\
417 \\
348\end{array}$ & $\begin{array}{l}91 \\
86 \\
70 \\
67 \\
61\end{array}$ & & $\begin{array}{l}43 \\
45 \\
13 \\
14 \\
12\end{array}$ \\
\hline $\begin{array}{l}11 \ldots \ldots \\
12 \ldots \ldots \\
13 . \ldots \ldots \\
14 \ldots \ldots \\
15 \ldots \ldots\end{array}$ & $\begin{array}{l}190 \\
450 \\
662 \\
807 \\
837\end{array}$ & & $\begin{array}{r}305 \\
\mathrm{~s} 4,200 \\
5,980 \\
8,060 \\
6,450\end{array}$ & $\begin{array}{l}369 \\
484 \\
714 \\
659 \\
689\end{array}$ & & $\begin{array}{l}1,100 \\
2,550 \\
9,580 \\
7,980 \\
6,180\end{array}$ & $\begin{array}{l}53 \\
51 \\
42 \\
36 \\
41\end{array}$ & & $\begin{array}{r}6 \\
11 \\
14 \\
6 \\
11\end{array}$ \\
\hline $\begin{array}{l}16 \ldots \ldots \\
17 \ldots \ldots \\
18 \ldots \ldots \\
19 \ldots \ldots \\
20 \ldots \ldots\end{array}$ & $\begin{array}{r}902 \\
1,030 \\
720 \\
506 \\
506\end{array}$ & & $\begin{array}{r}\text { a } 7,000 \\
\text { a } 8,660 \\
\text { a } 5,020 \\
2,690 \\
2,520\end{array}$ & $\begin{array}{r}689 \\
992 \\
1,420 \\
1,700 \\
980\end{array}$ & & $\begin{array}{r}3,770 \\
s 12,100 \\
\text { s } 26,200 \\
\text { s } 44,000 \\
17,300\end{array}$ & $\begin{array}{l}47 \\
79 \\
45 \\
40 \\
38\end{array}$ & & $\begin{array}{r}9 \\
76 \\
10 \\
8 \\
7\end{array}$ \\
\hline $\begin{array}{l}21 . \ldots \ldots \\
22 . \ldots \ldots \\
23 . \ldots \ldots \\
24 \ldots \ldots \\
25 . \ldots \ldots\end{array}$ & $\begin{array}{l}375 \\
308 \\
258 \\
216 \\
252\end{array}$ & & $\begin{array}{r}1,180 \\
810 \\
533 \\
336 \\
667\end{array}$ & $\begin{array}{l}1,030 \\
1,110 \\
1,130 \\
1,470 \\
1,360\end{array}$ & & $\begin{array}{r}13,200 \\
7,500 \\
12,500 \\
\mathrm{~s} 18,900 \\
13,400\end{array}$ & $\begin{array}{l}33 \\
29 \\
28 \\
28 \\
30\end{array}$ & & $\begin{array}{l}6 \\
4 \\
4 \\
3 \\
3 \\
3\end{array}$ \\
\hline $\begin{array}{l}26 \ldots \ldots \\
27 . \ldots \ldots \\
28 . \ldots \ldots \\
29 \ldots \ldots \\
30 . \ldots \ldots \\
31 \ldots \ldots\end{array}$ & $\begin{array}{r}168 \\
155 \\
159 \\
110 \\
100 \\
--\end{array}$ & & $\begin{array}{r}260 \\
169 \\
149 \\
60 \\
47 \\
--\end{array}$ & $\begin{array}{r}1,260 \\
1,140 \\
1,140 \\
965 \\
660 \\
482 \\
\end{array}$ & & $\begin{array}{r}\mathbf{s} 11,800 \\
7,420 \\
6,960 \\
\mathbf{5}, 080 \\
2,760 \\
1,150 \\
\end{array}$ & $\begin{array}{l}34 \\
35 \\
40 \\
38 \\
27 \\
-- \\
\end{array}$ & & $\begin{array}{r}7 \\
14 \\
9 \\
10 \\
7 \\
-- \\
\end{array}$ \\
\hline Total. & 10,931 & & 60,837 & 24,269 & & 254,846 & 2,177 & & 2,796 \\
\hline
\end{tabular}

s Computed by subdividing day.

a Partly estimated. 
RIO GRANDE BASIN--Continued

RIO GRANDE NEAR BERNARDO, N. MEX .--Cont inued

\begin{tabular}{|c|c|c|c|c|c|c|c|c|c|}
\hline \multirow[b]{3}{*}{ Day } & \multicolumn{3}{|c|}{ July } & \multicolumn{3}{|c|}{ August } & \multicolumn{3}{|c|}{ September } \\
\hline & \multirow[b]{2}{*}{$\begin{array}{l}\text { Mean } \\
\text { dis- } \\
\text { charge } \\
\text { (cfs) }\end{array}$} & \multicolumn{2}{|c|}{ Suspended sediment } & \multirow[b]{2}{*}{$\begin{array}{l}\text { Mean } \\
\text { dis- } \\
\text { charge } \\
\text { (cfs) }\end{array}$} & \multicolumn{2}{|c|}{ Suspended sediment } & \multirow[b]{2}{*}{$\begin{array}{c}\text { Mean } \\
\text { dis- } \\
\text { charge } \\
\text { (cfs) }\end{array}$} & \multicolumn{2}{|c|}{ Suspended sediment } \\
\hline & & $\begin{array}{l}\text { Mean } \\
\text { concen- } \\
\text { tration } \\
\text { (ppm) }\end{array}$ & $\begin{array}{l}\text { Tons } \\
\text { per } \\
\text { day }\end{array}$ & & $\begin{array}{c}\text { Mean } \\
\text { concen- } \\
\text { tration } \\
\text { (ppm) }\end{array}$ & $\begin{array}{l}\text { Tons } \\
\text { per } \\
\text { day }\end{array}$ & & $\begin{array}{c}\text { Mean } \\
\text { concen - } \\
\text { tration } \\
\text { (ppm) }\end{array}$ & $\begin{array}{l}\text { Tons } \\
\text { per } \\
\text { day }\end{array}$ \\
\hline $\begin{array}{l}1 \ldots \ldots \\
2 \ldots \ldots \\
3 . \ldots \ldots \\
4 \ldots \ldots \\
5 . \ldots \ldots\end{array}$ & $\begin{array}{l}26 \\
24 \\
28 \\
25 \\
27\end{array}$ & & $\begin{array}{l}7 \\
3 \\
7 \\
4 \\
5\end{array}$ & $\begin{array}{l}30 \\
23 \\
22 \\
25 \\
26\end{array}$ & & $\begin{array}{l}33 \\
14 \\
11 \\
16 \\
11\end{array}$ & $\begin{array}{l}14 \\
12 \\
17 \\
14 \\
14\end{array}$ & & $\begin{array}{r}8 \\
7 \\
11 \\
6 \\
7\end{array}$ \\
\hline $\begin{array}{r}6 \ldots \ldots \\
7 \ldots \ldots \\
8 \ldots \ldots \\
9 \ldots \ldots \\
10 \ldots \ldots\end{array}$ & $\begin{array}{l}45 \\
23 \\
20 \\
23 \\
25\end{array}$ & & $\begin{array}{r}13 \\
5 \\
5 \\
4 \\
4\end{array}$ & $\begin{array}{l}30 \\
34 \\
36 \\
71 \\
39\end{array}$ & & $\begin{array}{r}12 \\
165 \\
97 \\
\mathrm{~s} 976 \\
337\end{array}$ & $\begin{array}{l}14 \\
12 \\
12 \\
14 \\
12\end{array}$ & & $\begin{array}{r}7 \\
7 \\
5 \\
211 \\
10\end{array}$ \\
\hline $\begin{array}{l}11 \ldots \ldots \\
12 \ldots \ldots \\
13 \ldots \ldots \\
14 \ldots \ldots \\
15 . \ldots \ldots\end{array}$ & $\begin{array}{l}23 \\
23 \\
23 \\
21 \\
20\end{array}$ & & $\begin{array}{l}7 \\
5 \\
4 \\
4 \\
2\end{array}$ & $\begin{array}{r}69 \\
111 \\
48 \\
31 \\
26\end{array}$ & & $\begin{array}{r}708 \\
\mathrm{~s} 8,080 \\
855 \\
48 \\
20\end{array}$ & $\begin{array}{l}83 \\
39 \\
18 \\
18 \\
19\end{array}$ & & $\begin{array}{r}\mathrm{s} 4,140 \\
\mathrm{~s} 3, \mathbf{1 7 0} \\
73 \\
24 \\
28\end{array}$ \\
\hline $\begin{array}{l}16 \ldots \ldots \\
17 . \ldots \ldots \\
18 . \ldots \ldots \\
19 . \ldots \ldots \\
20 \ldots \ldots\end{array}$ & $\begin{array}{l}19 \\
19 \\
19 \\
18 \\
20\end{array}$ & & $\begin{array}{l}\mathbf{2} \\
\mathbf{2} \\
\mathbf{2} \\
\mathbf{3} \\
\mathbf{2}\end{array}$ & $\begin{array}{l}25 \\
24 \\
23 \\
21 \\
20\end{array}$ & & $\begin{array}{r}15 \\
10 \\
11 \\
8 \\
5\end{array}$ & $\begin{array}{l}27 \\
20 \\
18 \\
14 \\
16\end{array}$ & & $\begin{array}{r}219 \\
54 \\
22 \\
10 \\
9\end{array}$ \\
\hline $\begin{array}{l}21 \ldots \ldots \\
22 . \ldots \ldots \\
23 \ldots \ldots \\
24 \ldots \ldots \\
25 . \ldots \ldots\end{array}$ & $\begin{array}{r}18 \\
19 \\
26 \\
127 \\
480\end{array}$ & & $\begin{array}{r}3 \\
2 \\
98 \\
\mathrm{~s} 7,140 \\
\mathrm{~s} 47,600\end{array}$ & $\begin{array}{l}26 \\
22 \\
17 \\
26 \\
30\end{array}$ & & $\begin{array}{r}161 \\
131 \\
23 \\
\mathrm{~s} 107 \\
130\end{array}$ & $\begin{array}{l}17 \\
15 \\
15 \\
20 \\
27\end{array}$ & & $\begin{array}{r}9 \\
8 \\
5 \\
10 \\
44\end{array}$ \\
\hline $\begin{array}{l}26 \ldots \ldots \\
27 . \ldots \ldots \\
28 \ldots \ldots \\
29 . \ldots \ldots \\
30 \ldots \ldots \\
31 \ldots \ldots\end{array}$ & $\begin{array}{r}131 \\
61 \\
42 \\
37 \\
27 \\
27 \\
\end{array}$ & & $\begin{array}{r}4,990 \\
494 \\
111 \\
245 \\
44 \\
25 \\
\end{array}$ & $\begin{array}{l}20 \\
21 \\
19 \\
16 \\
16 \\
15\end{array}$ & & $\begin{array}{r}140 \\
139 \\
38 \\
12 \\
11 \\
9\end{array}$ & $\begin{array}{r}87 \\
264 \\
134 \\
107 \\
89 \\
-- \\
\end{array}$ & & $\begin{array}{r}\text { s 5, 430 } \\
\text { s } 33,400 \\
7,680 \\
2,000 \\
594 \\
--\end{array}$ \\
\hline Total. & 1,466 & & 60,842 & 962 & & 12,333 & 1,182 & & 57,008 \\
\hline Total & arge & $\operatorname{ar}(c$ & 8).. & & & & & ... & $\begin{array}{l}104,286 \\
815,002 \\
\end{array}$ \\
\hline
\end{tabular}

s Computed by subdividing day.

a Partly estimated. 
\&

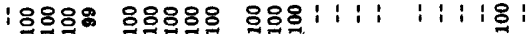

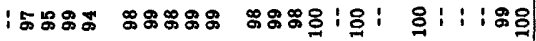

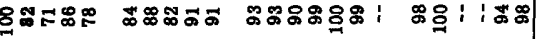

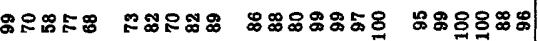

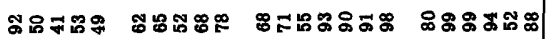

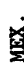

.

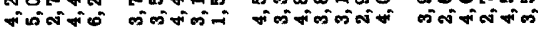

$\approx$

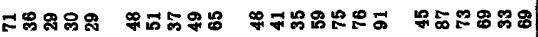

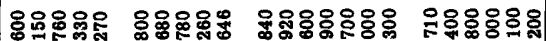

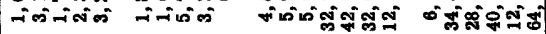$$
\text { पूक }
$$

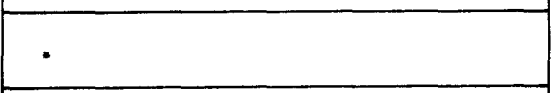

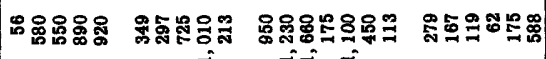

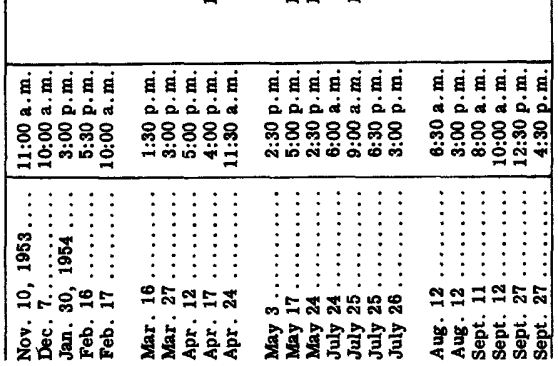




\section{RIO GRANDE BASIN--Continued}

RIO PUERCO BELOW CABEZON, N. MEX.

LOCATION. - - One-fourth mile upstream from mouth of Chico Arroyo, $4 \frac{1}{2} \mathrm{miles}$ southwest of Cabezon, Sandoval County, and 1$\}$ miles downstream from gaging station above Chico Arroyo near Guadalupe.

DRAINAGE AREA. --420 square miles approximately, at gaging station above Chico Arroyo near Guadalupe.

RECORDS AVAILABLE.--Sediment records: April 1948 to September 1954.

EXTREMES, 1953-54.--Sediment concentrations: Maximum daily, 150,000 ppm July 23; minimum daily, no flow on many days.

Sediment loads: Maximum daily, 198,000 tons July 23; minimum daily, 0 tons on many days

EXTREMES, 1948-54, --Sediment concentrations: Maximum daily, 166,000 ppm July 31 , 1953; minimum daily, no flow on many days.

Sediment loads: Maximum daily 219,000 tons Aug. 1, 1953; minimum daily 0 tons- on many days.

REMARKS --Maximum observed sediment concentration during water year, $331,000 \mathrm{ppm} \mathrm{July} 22$ Records of discharge for Rio puerco above Chico Arroyo near Guadalupe, $N$. Mex., for water year October 1953 to September 1954 given in wSp 1342. No appreciable inflow between sampling point and gaging station except during periods of heavy local runoff.

Suspended sediment, water year October 1953 to September 1954

\begin{tabular}{|c|c|c|c|c|c|c|c|c|c|}
\hline \multirow[b]{3}{*}{ Day } & \multicolumn{3}{|c|}{ October } & \multicolumn{3}{|c|}{ November } & \multicolumn{3}{|c|}{ December } \\
\hline & \multirow[b]{2}{*}{$\begin{array}{c}\text { Mean } \\
\text { dis- } \\
\text { charge } \\
\text { (cfs) }\end{array}$} & \multicolumn{2}{|c|}{ Suspended sediment } & \multirow[b]{2}{*}{$\begin{array}{l}\text { Mean } \\
\text { dis- } \\
\text { charge } \\
\text { (cis) }\end{array}$} & \multicolumn{2}{|c|}{ Suspended sediment } & \multirow[b]{2}{*}{$\begin{array}{c}\text { Mean } \\
\text { dis- } \\
\text { charge } \\
\text { (cfs) }\end{array}$} & \multicolumn{2}{|c|}{ Suspended sediment } \\
\hline & & $\begin{array}{l}\text { Mean } \\
\text { concen- } \\
\text { tration } \\
\text { (ppm) }\end{array}$ & $\begin{array}{l}\text { Tons } \\
\text { per } \\
\text { day }\end{array}$ & & $\begin{array}{l}\text { Mean } \\
\text { concen- } \\
\text { tration } \\
\text { (ppm) }\end{array}$ & $\begin{array}{l}\text { Tons } \\
\text { per } \\
\text { day }\end{array}$ & & $\begin{array}{c}\text { Mean } \\
\text { concen- } \\
\text { tration } \\
\text { (ppm) }\end{array}$ & $\begin{array}{l}\text { Tons } \\
\text { per } \\
\text { day }\end{array}$ \\
\hline $\begin{array}{l}1 \ldots \ldots \\
2 \ldots \ldots \\
3 \ldots \ldots \\
4 \ldots \ldots \\
5 . \ldots \ldots\end{array}$ & $\begin{array}{l}0 \\
0 \\
0 \\
0 \\
0\end{array}$ & $\begin{array}{l}-- \\
-- \\
-- \\
--\end{array}$ & $\begin{array}{l}0 \\
0 \\
0 \\
0 \\
0\end{array}$ & $\begin{array}{r}0 \\
0 \\
0 \\
0 \\
34\end{array}$ & 32,000 & $\begin{array}{r}0 \\
0 \\
0 \\
0 \\
\text { sa10, } 000 \\
\end{array}$ & $\begin{array}{r}0.2 \\
.3 \\
.2 \\
.3 \\
.2\end{array}$ & & $\begin{array}{l}-- \\
-- \\
-- \\
--\end{array}$ \\
\hline $\begin{array}{r}6 \ldots \ldots \\
7 \ldots \ldots \\
8 \ldots \ldots \\
9 \ldots \ldots \\
10 \ldots \ldots\end{array}$ & $\begin{array}{l}0 \\
0 \\
0 \\
0 \\
0\end{array}$ & $\begin{array}{l}-- \\
-- \\
-- \\
--\end{array}$ & $\begin{array}{l}0 \\
0 \\
0 \\
0 \\
0\end{array}$ & $\begin{array}{r}206 \\
7 \\
2 \\
1 \\
\quad .5\end{array}$ & $\begin{array}{r}92,100 \\
40,000 \\
-- \\
-- \\
--\end{array}$ & $\begin{array}{r}\mathrm{s} 84,200 \\
\text { a 780 } \\
\text { b } 90 \\
\text { b } 30 \\
\text { b9 }\end{array}$ & $\begin{array}{l}0^{.1} \\
0 \\
0 \\
0\end{array}$ & & $\begin{array}{l}- \\
0 \\
0 \\
0 \\
0\end{array}$ \\
\hline $\begin{array}{l}11 . \ldots \ldots \\
12 . \ldots \ldots \\
13 . \ldots \ldots \\
14 . \ldots \ldots \\
15 . \ldots \ldots\end{array}$ & $\begin{array}{l}0 \\
0 \\
0 \\
0 \\
0\end{array}$ & $\begin{array}{l}-- \\
-- \\
-- \\
--\end{array}$ & $\begin{array}{l}0 \\
0 \\
0 \\
0 \\
0\end{array}$ & $\begin{array}{l}.3 \\
.2 \\
.1 \\
.1\end{array}$ & $\begin{array}{l}-- \\
-- \\
-- \\
--\end{array}$ & $\begin{array}{l}\text { b4 } \\
\text { b2 } \\
\text { b1 } \\
\text { b1 } \\
0\end{array}$ & $\begin{array}{l}0 \\
0 \\
0 \\
0 \\
0\end{array}$ & & $\begin{array}{l}0 \\
0 \\
0 \\
0 \\
0\end{array}$ \\
\hline $\begin{array}{l}16 . \ldots \ldots \\
17 . \ldots \ldots \\
18 . \ldots \ldots \\
19 . \ldots \ldots \\
20 \ldots \ldots\end{array}$ & $\begin{array}{r}0 \\
0 \\
0 \\
0 \\
23\end{array}$ & $\begin{array}{r}-- \\
\ldots \\
\cdots, 000\end{array}$ & $\begin{array}{r}0 \\
0 \\
0 \\
0 \\
\operatorname{sa~7,~} 400\end{array}$ & $\begin{array}{l}0 \\
0 \\
0 \\
0 \\
0\end{array}$ & $\begin{array}{l}= \\
-- \\
--\end{array}$ & $\begin{array}{l}0 \\
0 \\
0 \\
0 \\
0\end{array}$ & $\begin{array}{l}0 \\
0 \\
0 \\
0 \\
0\end{array}$ & & $\begin{array}{l}0 \\
0 \\
0 \\
0 \\
0\end{array}$ \\
\hline $\begin{array}{l}21 \ldots \ldots \\
22 . \ldots \ldots \\
23 . \ldots \ldots \\
24 \ldots \ldots \\
25 . \ldots \ldots\end{array}$ & $\begin{array}{r}34 \\
10 \\
16 \\
7 \\
1\end{array}$ & $\begin{array}{r}97,800 \\
69,000 \\
60,000 \\
44,000 \\
--\end{array}$ & $\begin{array}{r}811,100 \\
\text { a } 1,900 \\
\text { sa } 3,700 \\
\text { a } 860 \\
\text { b 25 }\end{array}$ & $\begin{array}{l}0 \\
0 \\
0 \\
0 \\
0\end{array}$ & $\begin{array}{l}-- \\
-- \\
-- \\
--\end{array}$ & $\begin{array}{l}0 \\
0 \\
0 \\
0 \\
0\end{array}$ & $\begin{array}{l}0 \\
0 \\
0 \\
0 \\
0\end{array}$ & & $\begin{array}{l}0 \\
0 \\
0 \\
0 \\
0\end{array}$ \\
\hline $\begin{array}{l}26 \ldots \ldots \\
27 . \ldots \ldots \\
28 . \ldots \ldots \\
28 . \ldots \ldots \\
30 . \ldots \ldots \\
31 . \ldots .\end{array}$ & $\begin{array}{l}.5 \\
.1 \\
0 \\
0 \\
0 \\
0\end{array}$ & $\begin{array}{l}-- \\
-- \\
-- \\
--\end{array}$ & $\begin{array}{l}\text { b } 7 \\
\text { b } 3 \\
0 \\
0 \\
0 \\
0 \\
0\end{array}$ & $\begin{array}{l}0 \\
0 \\
.3 \\
.9 \\
.6 \\
-- \\
\end{array}$ & $\begin{array}{l}-- \\
-- \\
-- \\
--\end{array}$ & $\begin{array}{r}0 \\
0 \\
\mathrm{e} \\
\mathrm{e} \\
\mathrm{e} \\
\mathrm{e} \\
--\end{array}$ & $\begin{array}{l}0 \\
0 \\
0 \\
0 \\
0 \\
0\end{array}$ & & $\begin{array}{l}0 \\
0 \\
0 \\
0 \\
0 \\
0 \\
\end{array}$ \\
\hline Total. & 91.6 & -- & 24,895 & 253.0 & - & 95,156 & 1.3 & & e 15 \\
\hline
\end{tabular}

e Estimated.

Computed by aubdividing day.

a Computed from estimated concentration graph.

b Computed from water-sediment discharge curve. 
RIO GRANDE BASIN--Continued

RIO PUERCO BELOW CABEZON, N. MEX.--Continued

Suspended sedimeut, water year October 1953 to September 1954 --Continued

\begin{tabular}{|c|c|c|c|c|c|c|c|c|c|}
\hline \multirow[b]{3}{*}{ Day } & \multicolumn{3}{|c|}{ January } & \multicolumn{3}{|c|}{ February } & \multicolumn{3}{|c|}{ March } \\
\hline & \multirow[b]{2}{*}{$\begin{array}{l}\text { Mean } \\
\text { dis- } \\
\text { charge } \\
\text { (cfs) }\end{array}$} & \multicolumn{2}{|c|}{ Suspended sediment } & \multirow[b]{2}{*}{$\begin{array}{c}\text { Mean } \\
\text { dis- } \\
\text { charge } \\
\text { (cfs) }\end{array}$} & \multicolumn{2}{|c|}{ Suspended sediment } & \multirow[b]{2}{*}{$\begin{array}{l}\text { Mean } \\
\text { dis- } \\
\text { charge } \\
\text { (cfs) }\end{array}$} & \multicolumn{2}{|c|}{ Suspended sediment } \\
\hline & & $\begin{array}{l}\text { Mean } \\
\text { concen- } \\
\text { tration } \\
\text { (ppm) }\end{array}$ & $\begin{array}{l}\text { Tons } \\
\text { per } \\
\text { day }\end{array}$ & & $\begin{array}{c}\text { Mean } \\
\text { concen- } \\
\text { tration } \\
\text { (ppm) }\end{array}$ & $\begin{array}{l}\text { Tons } \\
\text { per } \\
\text { day }\end{array}$ & & $\begin{array}{l}\text { Mean } \\
\text { concen- } \\
\text { tration } \\
\text { (ppm) }\end{array}$ & $\begin{array}{l}\text { Tons } \\
\text { per } \\
\text { day }\end{array}$ \\
\hline $\begin{array}{l}1 \ldots \ldots \\
2 \ldots \ldots \\
3 \ldots \ldots \\
4 \ldots \ldots \\
5 \ldots \ldots\end{array}$ & * & & & $\begin{array}{r}10 \\
20 \\
12 \\
10 \\
6\end{array}$ & $\begin{array}{r}-- \\
30,500 \\
25,500 \\
23,800\end{array}$ & $\begin{array}{r}e 800 \\
e 1,800 \\
988 \\
688 \\
386\end{array}$ & $\begin{array}{l}0 \\
0^{.1} \\
0 \\
0\end{array}$ & $\begin{array}{l}-- \\
-- \\
-- \\
--\end{array}$ & $\begin{array}{r}0 \\
\mathrm{e} \\
0 \\
0 \\
0 \\
0\end{array}$ \\
\hline $\begin{array}{r}6 \ldots \ldots \\
7 \ldots \ldots \\
8 \ldots \ldots \\
9 \ldots \ldots \\
10 \ldots \ldots\end{array}$ & & & & $\begin{array}{l}7 \\
4 \\
1 \\
1 \\
\quad .7\end{array}$ & $\begin{array}{r}25,500 \\
=- \\
-- \\
=- \\
=-\end{array}$ & $\begin{array}{r}482 \\
\text { b } 240 \\
\text { b } 40 \\
\text { b 40 } \\
\text { b 26 }\end{array}$ & $\begin{array}{l}0 \\
0 \\
0 \\
0 \\
0\end{array}$ & $\begin{array}{l}-- \\
-- \\
-- \\
--\end{array}$ & $\begin{array}{l}0 \\
0 \\
0 \\
0 \\
0\end{array}$ \\
\hline $\begin{array}{l}11 \ldots \ldots \\
12 \ldots \ldots \\
13 \ldots \ldots \\
14 \ldots \ldots \\
15 \ldots \ldots\end{array}$ & & & & $\begin{array}{l}.2 \\
0^{.2} \\
0 \\
0\end{array}$ & $\begin{array}{l}-- \\
-- \\
-- \\
--\end{array}$ & $\begin{array}{r}\text { b5 } \\
\text { b5 } \\
0 \\
0 \\
0\end{array}$ & $\begin{array}{l}0 \\
.1 \\
.1 \\
0.1\end{array}$ & $\begin{array}{l}-- \\
-- \\
-- \\
--\end{array}$ & $\begin{array}{r}0 \\
\text { e } 4 \\
\text { e } 3 \\
\text { e } 3 \\
0\end{array}$ \\
\hline $\begin{array}{l}16 \ldots \ldots \\
17 . \ldots \ldots \\
18 . \ldots \ldots \\
19 . \ldots \ldots \\
20 \ldots \ldots\end{array}$ & & & & $\begin{array}{l}0 \\
0 \\
0 \\
.1 \\
.1\end{array}$ & $\begin{array}{l}-- \\
-- \\
-- \\
-- \\
--\end{array}$ & $\begin{array}{r}0 \\
0 \\
0 \\
\text { e } 3 \\
\text { e } 2\end{array}$ & $\begin{array}{l}0 \\
.1 \\
.2 \\
.1 \\
.1\end{array}$ & $\begin{array}{l}-- \\
-- \\
-- \\
--\end{array}$ & $\begin{array}{r}0 \\
\text { e } 4 \\
\text { e } 6 \\
\text { e } 3 \\
\text { e } 3\end{array}$ \\
\hline $\begin{array}{l}21 \ldots \ldots \\
22 \ldots \ldots \ldots \\
23 . \ldots \ldots \\
24 \ldots \ldots \\
25 . \ldots \ldots\end{array}$ & & & & $\begin{array}{l}0 \\
0 \\
0 \\
0 \\
0\end{array}$ & $\begin{array}{l}-- \\
-- \\
-- \\
-- \\
--\end{array}$ & $\begin{array}{l}0 \\
0 \\
0 \\
0 \\
0\end{array}$ & $\begin{array}{r}.1 \\
28 \\
103 \\
47\end{array}$ & $\begin{array}{r}-- \\
26,000 \\
89,000 \\
72,000\end{array}$ & $\begin{array}{r}e^{3} \\
e^{6} \\
\operatorname{sa} 6,800 \\
s a 28,000 \\
s 9,740\end{array}$ \\
\hline $\begin{array}{l}26 \ldots \ldots \\
27 \ldots \ldots \\
28 \ldots \ldots \\
29 . \ldots \ldots \\
30 \ldots \ldots \\
31 \ldots \ldots\end{array}$ & & & & $\begin{array}{l}0 \\
0 \\
.1 \\
-- \\
-- \\
-- \\
\end{array}$ & $\begin{array}{l}-- \\
-- \\
-- \\
-- \\
-- \\
\end{array}$ & $\begin{array}{r}0 \\
0 \\
\text { e } 3 \\
-- \\
-- \\
-- \\
\end{array}$ & $\begin{array}{r}25 \\
16 \\
7 \\
4 \\
2 \\
1 \\
\end{array}$ & $\begin{array}{r}50,000 \\
50,300 \\
36,000 \\
-- \\
-- \\
-- \\
\end{array}$ & $\begin{array}{r}\text { a 3,500 } \\
\text { s 2, } 410 \\
\text { a } 710 \\
\text { b } 350 \\
\text { b } 130 \\
\text { b } 50 \\
\end{array}$ \\
\hline \multirow[t]{2}{*}{ Total. } & 0 & & 0 & 72,4 & - & 5,508 & 234.2 & -- & 51,728 \\
\hline & \multicolumn{3}{|c|}{ April } & \multicolumn{3}{|c|}{ May } & \multicolumn{3}{|c|}{ June } \\
\hline $\begin{array}{l}1 \ldots \ldots \\
2 \ldots \ldots \\
3 \ldots \ldots \\
4 \ldots \\
5 \ldots \ldots\end{array}$ & $\begin{array}{l}0.8 \\
.5 \\
.2 \\
.1 \\
0\end{array}$ & $\begin{array}{l}-- \\
-- \\
-- \\
-- \\
--\end{array}$ & $\begin{array}{r}\text { b } 35 \\
\text { b } 19 \\
\text { b } 5 \\
\text { b } 2 \\
0\end{array}$ & $\begin{array}{c}0 \\
5 \\
3 \\
22\end{array}$ & $\begin{array}{l}-- \\
-- \\
-- \\
-- \\
--\end{array}$ & $\begin{array}{r}0 \\
\mathrm{e} 16 \\
\mathrm{e} 290 \\
\mathrm{e} 130 \\
\mathrm{e} 2,300\end{array}$ & $\begin{array}{l}0 \\
0 \\
0 \\
0 \\
0\end{array}$ & $\begin{array}{l}-- \\
-- \\
-- \\
--\end{array}$ & $\begin{array}{l}0 \\
0 \\
0 \\
0 \\
0\end{array}$ \\
\hline $\begin{array}{r}6 \ldots \ldots \\
7 \ldots \ldots \\
8 \ldots \ldots \\
9 \ldots \ldots \\
10 \ldots \ldots\end{array}$ & $\begin{array}{l}0 \\
0 \\
0 \\
0 \\
0\end{array}$ & $\begin{array}{l}-- \\
-- \\
-- \\
-- \\
--\end{array}$ & $\begin{array}{l}0 \\
0 \\
0 \\
0 \\
0\end{array}$ & $\begin{array}{r}20 \\
10 \\
5 \\
2 \\
27\end{array}$ & $\begin{array}{l}-- \\
-- \\
-- \\
--\end{array}$ & $\begin{array}{r}\text { e } 2,000 \\
\text { e } 800 \\
\text { e } 290 \\
\text { e } 76 \\
\text { e } 3,200\end{array}$ & $\begin{array}{l}0 \\
0 \\
0 \\
0 \\
0\end{array}$ & $\begin{array}{l}-- \\
-- \\
-- \\
--\end{array}$ & $\begin{array}{l}0 \\
0 \\
0 \\
0 \\
0\end{array}$ \\
\hline $\begin{array}{l}11 \ldots \ldots \\
12 \ldots \ldots \\
13 \ldots \ldots \\
14 \ldots \ldots \\
15 . \ldots \ldots\end{array}$ & $\begin{array}{r}5 \\
9 \\
16 \\
21\end{array}$ & $\begin{array}{l}-- \\
-- \\
-- \\
--\end{array}$ & $\begin{array}{r}\text { b9 } \\
\text { b } 260 \\
\text { b } 680 \\
\text { b } 1,700 \\
\text { b } 2,600\end{array}$ & $\begin{array}{l}34 \\
53 \\
41 \\
25 \\
19\end{array}$ & $\begin{array}{r}55,800 \\
48,000 \\
35,500 \\
--\end{array}$ & $\begin{array}{r}\text { e } 4,400 \\
\text { s } 8,880 \\
\text { a } 5,500 \\
2,480 \\
\text { b } 1,600\end{array}$ & $\begin{array}{l}0 \\
0 \\
0 \\
0 \\
0\end{array}$ & $\begin{array}{l}-- \\
-- \\
-- \\
--\end{array}$ & $\begin{array}{l}0 \\
0 \\
0 \\
0 \\
0\end{array}$ \\
\hline $\begin{array}{l}16 \ldots \ldots \\
17 \ldots \ldots \\
18 \ldots \ldots \\
19 \ldots \ldots \\
20 \ldots \ldots\end{array}$ & $\begin{array}{l}19 \\
24 \\
38 \\
50 \\
37\end{array}$ & $\begin{array}{c}-- \\
-- \\
-- \\
58,200\end{array}$ & $\begin{array}{r}\text { b } 2,200 \\
\text { b } 3,200 \\
\text { b } 6,600 \\
\text { b } 10,000 \\
\text { s } 6,120\end{array}$ & $\begin{array}{l}14 \\
23 \\
20 \\
12 \\
26\end{array}$ & $\begin{array}{l}-- \\
-- \\
-- \\
--\end{array}$ & $\begin{array}{r}\text { b.1,000 } \\
\text { e } 2,300 \\
\text { e } 1,800 \\
\text { e } 760 \\
\text { e } 2,800\end{array}$ & $\begin{array}{l}0 \\
0 \\
0 \\
0 \\
0\end{array}$ & $\begin{array}{l}-- \\
-- \\
-- \\
-- \\
--\end{array}$ & $\begin{array}{l}0 \\
0 \\
0 \\
0 \\
0\end{array}$ \\
\hline $\begin{array}{l}21 \ldots \ldots \\
22 . \ldots \ldots \\
23 \ldots \ldots \\
24 \ldots \ldots \\
25 . \ldots \ldots\end{array}$ & $\begin{array}{r}26 \\
13 \\
10 \\
9 \\
5\end{array}$ & $\begin{array}{r}43,000 \\
33,000 \\
28,000 \\
32,000 \\
--\end{array}$ & $\begin{array}{r}\text { s 3, 340 } \\
\text { s 1, 360 } \\
\text { a 760 } \\
\text { s } 815 \\
\text { b } 260\end{array}$ & $\begin{array}{r}10 \\
7 \\
12 \\
25 \\
14\end{array}$ & $\begin{array}{l}-- \\
-- \\
-- \\
--\end{array}$ & $\begin{array}{r}\text { e } 570 \\
\text { e } 300 \\
\text { e } 760 \\
\text { e } 2,500 \\
\text { e } 1,000\end{array}$ & $\begin{array}{l}0 \\
0 \\
0 \\
0 \\
0\end{array}$ & $\begin{array}{l}-- \\
-- \\
-- \\
-- \\
--\end{array}$ & $\begin{array}{l}0 \\
0 \\
0 \\
0 \\
0\end{array}$ \\
\hline $\begin{array}{l}26 \ldots \ldots \\
27 . \ldots \ldots \\
28 . \ldots \ldots \\
29 . \ldots \ldots \\
30 \ldots \ldots \\
31 \ldots \ldots\end{array}$ & $\begin{array}{l}2 \\
4 \\
.8 \\
.2 \\
.1 \\
-- \\
\end{array}$ & $\begin{array}{l}-- \\
-- \\
-- \\
-- \\
--\end{array}$ & $\begin{array}{r}\text { b } 60 \\
\text { b } 180 \\
\text { b } 14 \\
\text { b2 } \\
\text { b1 } \\
- \\
\end{array}$ & $\begin{array}{l}7 \\
2 \\
.2 \\
.1 \\
0 \\
\end{array}$ & $\begin{array}{l}-- \\
-- \\
-- \\
-- \\
-- \\
--\end{array}$ & $\begin{array}{r}\text { e } 300 \\
\text { e } 38 \\
e 1 \\
(e)(t) \\
(e)(t) \\
0\end{array}$ & $\begin{array}{c}14.2 \\
0^{.2} \\
0 \\
5 \\
\end{array}$ & $\begin{array}{l}-- \\
-- \\
-- \\
-- \\
-- \\
-\end{array}$ & \begin{tabular}{r}
-- \\
\hdashline 0 \\
0 \\
-- \\
-
\end{tabular} \\
\hline Total & 291.3 & - & 40,222 & 439.1 & -- & 46,091 & 19.2 & -- & e 1,500 \\
\hline
\end{tabular}


RIO GRANDE BASIN

RIO GRANDE BASIN--Continued

RIO PUERCO BELOW CABEZON, N. MEX.--Continued

Stspended sediment, water year October 1953 to September 1954--Continued

\begin{tabular}{|c|c|c|c|c|c|c|c|c|c|}
\hline \multirow[b]{3}{*}{ Day } & \multicolumn{3}{|c|}{ July } & \multicolumn{3}{|c|}{ August } & \multicolumn{3}{|c|}{ September } \\
\hline & \multirow[b]{2}{*}{$\begin{array}{c}\text { Mean } \\
\text { dis- } \\
\text { charge } \\
\text { (cfs) }\end{array}$} & \multicolumn{2}{|c|}{ Suspended sediment } & \multirow[b]{2}{*}{$\begin{array}{l}\text { Mean } \\
\text { dis- } \\
\text { charge } \\
\text { (cfs) }\end{array}$} & \multicolumn{2}{|c|}{ Suspended sediment } & \multirow[b]{2}{*}{$\begin{array}{l}\text { Mean } \\
\text { dis- } \\
\text { charge } \\
\text { (cfs) }\end{array}$} & \multicolumn{2}{|c|}{ Suspended sediment } \\
\hline & & $\begin{array}{l}\text { Mean } \\
\text { concen- } \\
\text { tration } \\
\text { (ppm) }\end{array}$ & $\begin{array}{l}\text { Tons } \\
\text { per } \\
\text { day }\end{array}$ & & $\begin{array}{c}\text { Mean } \\
\text { concen- } \\
\text { tration } \\
\text { (ppm) }\end{array}$ & $\begin{array}{l}\text { Tons } \\
\text { per } \\
\text { day }\end{array}$ & & $\begin{array}{l}\text { Mean } \\
\text { concen- } \\
\text { tration } \\
\text { (ppm) }\end{array}$ & $\begin{array}{l}\text { Tons } \\
\text { per } \\
\text { day }\end{array}$ \\
\hline $\begin{array}{l}1 . \ldots \ldots \\
2 \ldots \ldots \\
3 . \ldots \ldots \\
4 \ldots \ldots \\
5 . \ldots \ldots\end{array}$ & $\begin{array}{l}0.5 \\
0 \\
0 \\
0 \\
0\end{array}$ & $\begin{array}{l}-- \\
-- \\
-- \\
--\end{array}$ & $\begin{array}{r}10 \\
0 \\
0 \\
0 \\
0\end{array}$ & $\begin{array}{l}1 \\
0 \\
0 \\
0\end{array}$ & $\begin{array}{r}35,000 \\
10,000 \\
=- \\
=- \\
=-\end{array}$ & $\begin{array}{r}98 \\
\text { a } 3 \\
0 \\
0 \\
0\end{array}$ & $\begin{array}{l}0.3 \\
0 \\
0 \\
24 \\
7\end{array}$ & $\begin{array}{r}35,000 \\
-- \\
90,200 \\
118,000\end{array}$ & 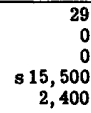 \\
\hline $\begin{array}{r}6 . \ldots \ldots \\
7 . \ldots \ldots \\
8 \ldots \ldots \\
9 \ldots \ldots \\
10 \ldots \ldots\end{array}$ & $\begin{array}{r}0 \\
11 \\
16 \\
12 \\
1\end{array}$ & $\begin{array}{r}=- \\
90,600 \\
60,200 \\
55,000\end{array}$ & $\begin{array}{r}0 \\
\text { b 3, 000 } \\
\text { s 5, 990 } \\
\text { s } 3,630 \\
154\end{array}$ & $\begin{array}{r}0 \\
0 \\
4 \\
2 \\
13\end{array}$ & $\begin{array}{r}-- \\
13,000 \\
22,500 \\
32,000\end{array}$ & $\begin{array}{r}0 \\
0 \\
\text { sa } 530 \\
\text { s } 282 \\
\text { s } 5,280\end{array}$ & $0_{0}^{3} .3$ & $\begin{array}{r}83,000 \\
53,000 \\
33,000 \\
-- \\
--\end{array}$ & $\begin{array}{r}697 \\
45 \\
29 \\
0 \\
0\end{array}$ \\
\hline $\begin{array}{l}11 \ldots \ldots \\
12 \ldots \ldots \\
13 . \ldots \ldots \\
14 \ldots \ldots \\
15 \ldots \ldots\end{array}$ & $\begin{array}{l}0^{.3} \\
0 \\
0 \\
0\end{array}$ & $\begin{array}{l}-- \\
-- \\
-- \\
--\end{array}$ & $\begin{array}{r}\text { b40 } \\
0 \\
0 \\
0 \\
0\end{array}$ & $\begin{array}{c}49 \\
3 \\
0 \\
0 \\
378\end{array}$ & $\begin{array}{r}98,000 \\
65,000 \\
55,000 \\
-- \\
51,900\end{array}$ & $\begin{array}{r}\mathrm{s} 17,000 \\
546 \\
108 \\
0 \\
\mathrm{~s} 160,000\end{array}$ & $\begin{array}{r}16 \\
25 \\
282 \\
18 \\
4\end{array}$ & $\begin{array}{r}95,400 \\
98,500 \\
140,000 \\
65,000 \\
48,000\end{array}$ & $\begin{array}{r}\mathrm{s} 8,760 \\
\mathrm{~s} 12,600 \\
\mathrm{~s} 182,000 \\
3,280 \\
\mathrm{a} 540\end{array}$ \\
\hline $\begin{array}{l}16 \ldots \ldots \\
17 \ldots \ldots \\
18 \ldots \ldots \\
19 \ldots \ldots \\
20 \ldots \ldots\end{array}$ & $\begin{array}{l}0 \\
0 \\
0 \\
0\end{array}$ & $\begin{array}{l}-- \\
-- \\
-- \\
--\end{array}$ & $\begin{array}{r}0 \\
\text { e } 20 \\
0 \\
0 \\
0\end{array}$ & $\begin{array}{r}55 \\
24 \\
10 \\
5 \\
30\end{array}$ & $\begin{array}{r}28,600 \\
25,500 \\
21,000 \\
6,000 \\
30,500\end{array}$ & $\begin{array}{r}\mathrm{s} 5,240 \\
\mathrm{~s} 2,110 \\
567 \\
81 \\
\mathrm{~s} 6,860\end{array}$ & $\begin{array}{l}1 \\
.2 \\
.1 \\
.1\end{array}$ & $\begin{array}{r}32,000 \\
-- \\
-- \\
-- \\
--\end{array}$ & $\begin{array}{r}\text { a } 90 \\
\text { b } 14 \\
\text { b } 6 \\
\text { b 5 } \\
0\end{array}$ \\
\hline $\begin{array}{l}21 \ldots \ldots \\
22 . \ldots \ldots \\
23 . \ldots \ldots \\
24 \ldots \ldots \\
25 . \ldots \ldots\end{array}$ & $\begin{array}{r}0 \\
170 \\
442 \\
61 \\
12\end{array}$ & $\begin{array}{r}105,000 \\
150,000 \\
61,700 \\
25,000\end{array}$ & $\begin{array}{r}0 \\
\mathrm{~s} 93,100 \\
\mathrm{~s} 198,000 \\
\mathrm{~s} 13,800 \\
810\end{array}$ & $\begin{array}{r}17 \\
4 \\
1 \\
1 \\
26\end{array}$ & $\begin{array}{r}27,000 \\
-- \\
- \\
92,200\end{array}$ & $\begin{array}{r}\mathbf{s} 1,960 \\
b 56 \\
b 5 \\
b 3 \\
\mathbf{s} 15,700\end{array}$ & $\begin{array}{r}0 \\
0 \\
4 \\
52 \\
492\end{array}$ & $\begin{array}{r}-- \\
26,400 \\
28,100 \\
44,800\end{array}$ & $\begin{array}{r}0 \\
0 \\
\mathbf{s 1 , 0 4 0} \\
\mathbf{s 2 3 , 1 0 0} \\
\mathbf{s 1 2 1 , 0 0 0}\end{array}$ \\
\hline $\begin{array}{l}26 \ldots \ldots \\
27 \ldots \ldots \\
28 \ldots \ldots \\
29 \ldots \ldots \\
30 \ldots \ldots \\
31 \ldots \ldots\end{array}$ & $\begin{array}{l}3 \\
2 \\
.9 \\
.5 \\
.1\end{array}$ & $\begin{array}{r}-- \\
-- \\
-- \\
19,000\end{array}$ & $\begin{array}{r}\text { b 140 } \\
\text { b 76 } \\
\text { b22 } \\
\text { b9 } \\
\text { b 1 } \\
\text { s 1, 370 }\end{array}$ & $\begin{array}{c}6 \\
. .4 \\
0 \\
17 \\
14\end{array}$ & $\begin{array}{r}110,000 \\
41,000 \\
15,000 \\
-- \\
124,000 \\
108,000\end{array}$ & $\begin{array}{r}1,910 \\
246 \\
24 \\
0 \\
\mathrm{s11,100} \\
\mathrm{s6}, 540\end{array}$ & $\begin{array}{r}240 \\
59 \\
12 \\
5 \\
3 \\
--\end{array}$ & $\begin{array}{r}77,500 \\
41,000 \\
19,000 \\
14,000 \\
4,000 \\
--\end{array}$ & $\begin{array}{r}\text { s 64, } 700 \\
\text { sa 7, } 500 \\
616 \\
189 \\
32 \\
-\end{array}$ \\
\hline Total. & 735.5 & $\ldots$ & 320,172 & 661.3 & - & 236,029 & $1,248.1$ & -- & 443,552 \\
\hline
\end{tabular}

e Estimated.

$s$ Computed by subdividing day.

a Computed from estimated concentration graph.

b Computed from water-sediment discharge curve.

$4888170-59-27$ 


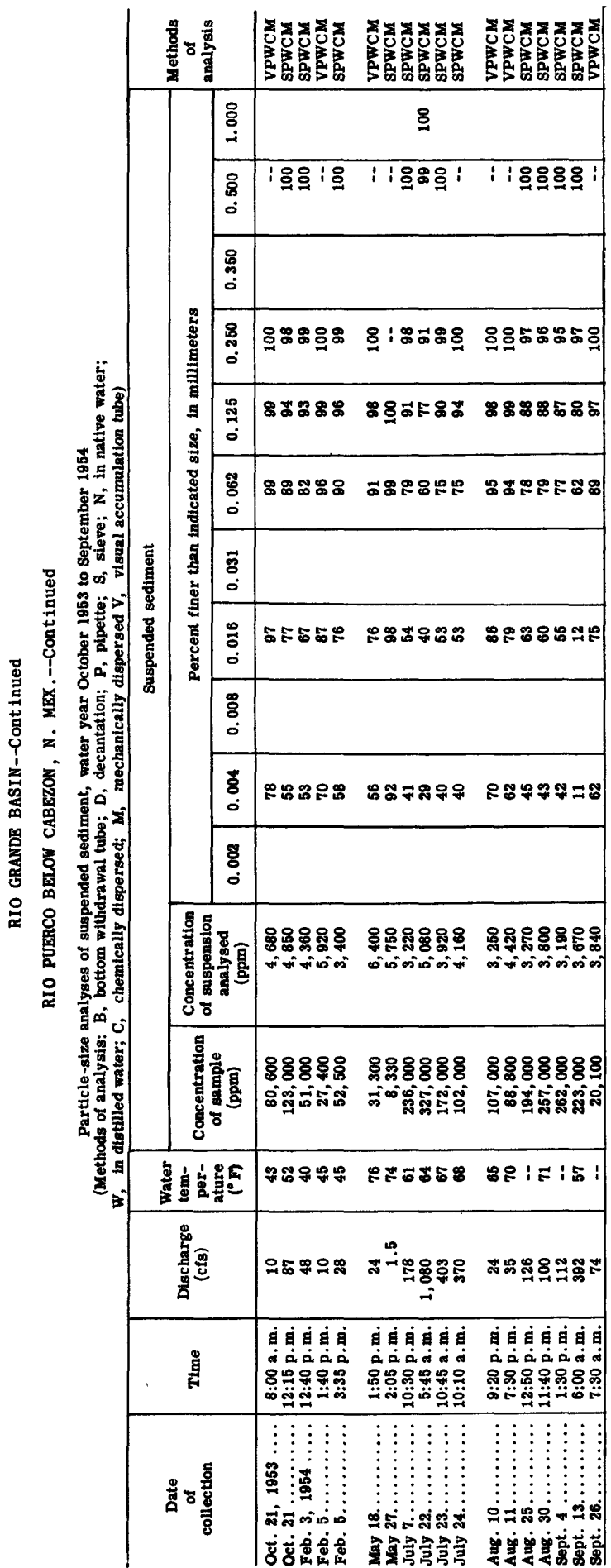


RIO GRANDE BASIN--Continued

CHICO ARROYO NEAR GUADALUPE, N. MEX.

LOCATION, --At gaging station a quarter of a mile upstream from mouth, $4 \frac{1}{2}$ miles northwest of Guadalupe, Sandoval County, and 5 miles southwest of Cabezon.

DRAINAGE AREA $-1,390$ square miles, approximately.

RECORDS AVAILABLE. --Sediment records: July 1948 to September 1954

EXTREMES, 1953-54.--Sediment concentrations: Maximum daily, 87,500 ppm July 23; minimum daily, no flow on many days.

Sediment loads: Maximum daily, 480,000 tons July 24; minimum daily, 0 tons on many days. EXTREMES, 1948-54.--Sediment concentrations: Maximuin daily, 113,000 ppia July 23, 1949; minimun daily, no flow on many days.

Sediment loads: Maximum daily, 1,220,000 tons July 17, 1953; minimum daily, 0 tons on many days.

REMARKS.--Maximum observed sediment concentration during water year, 175,000 ppm Aug. 15. No flow during December, February, and Apri1; tabulation omitted for these months.

Records of discharge for water year October 1953 to September 1954 given in WSP 1342.

Suspended sediment, water year October 1953 to September 1954

\begin{tabular}{|c|c|c|c|c|c|c|c|c|c|}
\hline \multirow[b]{3}{*}{ Day } & \multicolumn{3}{|c|}{ October } & \multicolumn{3}{|c|}{ November } & \multicolumn{3}{|c|}{ January } \\
\hline & \multirow[b]{2}{*}{$\begin{array}{l}\text { Mean } \\
\text { dis - } \\
\text { charge } \\
\text { (cfs) }\end{array}$} & \multicolumn{2}{|c|}{ Suspended sediment } & \multirow[b]{2}{*}{$\begin{array}{l}\text { Mean } \\
\text { dis- } \\
\text { charge } \\
\text { (cfs) }\end{array}$} & \multicolumn{2}{|c|}{ Suspended sediment } & \multirow[b]{2}{*}{$\begin{array}{l}\text { Mean } \\
\text { dis- } \\
\text { charge } \\
\text { (cfs) }\end{array}$} & \multicolumn{2}{|c|}{ Suspended sediment } \\
\hline & & $\begin{array}{l}\text { Mean } \\
\text { concen- } \\
\text { tration } \\
\text { (ppm) }\end{array}$ & $\begin{array}{l}\text { Tons } \\
\text { per } \\
\text { day }\end{array}$ & & $\begin{array}{l}\text { Mean } \\
\text { concen- } \\
\text { tration } \\
\text { (ppm) }\end{array}$ & $\begin{array}{l}\text { Tons } \\
\text { per } \\
\text { day }\end{array}$ & & $\begin{array}{l}\text { Mean } \\
\text { concen- } \\
\text { tration } \\
(\mathrm{ppm})\end{array}$ & $\begin{array}{l}\text { Tons } \\
\text { per } \\
\text { day }\end{array}$ \\
\hline $\begin{array}{l}1 \ldots \ldots \\
2 \ldots \ldots \\
3 \ldots \ldots \\
4 \ldots \ldots \\
5 \ldots \ldots\end{array}$ & $\begin{array}{l}0 \\
0 \\
0 \\
0 \\
0\end{array}$ & $\begin{array}{l}-- \\
-- \\
-- \\
--\end{array}$ & $\begin{array}{l}0 \\
0 \\
0 \\
0 \\
0\end{array}$ & $\begin{array}{l}0 \\
0 \\
0 \\
0 \\
0\end{array}$ & $\begin{array}{l}-- \\
-- \\
-- \\
--\end{array}$ & $\begin{array}{l}0 \\
0 \\
0 \\
0 \\
0\end{array}$ & $\begin{array}{l}0 \\
0 \\
0 \\
0 \\
0\end{array}$ & & $\begin{array}{l}0 \\
0 \\
0 \\
0 \\
0\end{array}$ \\
\hline $\begin{array}{r}6 \ldots \ldots \\
7 \ldots \ldots \\
8 \ldots \ldots \\
9 \ldots \ldots \\
10 \ldots \ldots\end{array}$ & $\begin{array}{l}0 \\
0 \\
0 \\
0 \\
0\end{array}$ & $\begin{array}{l}-- \\
-- \\
-- \\
--\end{array}$ & $\begin{array}{l}0 \\
0 \\
0 \\
0 \\
0\end{array}$ & $\begin{array}{l}80 \\
6 \\
2 \\
0^{.5}\end{array}$ & $\begin{array}{r}51,000 \\
16,000 \\
=- \\
-- \\
=-\end{array}$ & $\begin{array}{r}8 a 18,000 \\
a 260 \\
b 40 \\
b 4 \\
0\end{array}$ & $\begin{array}{l}0 \\
0 \\
0 \\
0 \\
0\end{array}$ & . & $\begin{array}{l}0 \\
0 \\
0 \\
0 \\
0\end{array}$ \\
\hline $\begin{array}{l}11 \ldots \ldots \\
12 \ldots \ldots \\
13 \ldots \ldots \\
14 \ldots \ldots \\
15 \ldots \ldots\end{array}$ & $\begin{array}{l}0 \\
0 \\
0 \\
0 \\
0\end{array}$ & $\begin{array}{l}-- \\
-- \\
-- \\
--\end{array}$ & $\begin{array}{l}0 \\
0 \\
0 \\
0 \\
0\end{array}$ & $\begin{array}{l}0 \\
0 \\
0 \\
0 \\
0\end{array}$ & $\begin{array}{l}-- \\
-- \\
- \\
-\end{array}$ & $\begin{array}{l}0 \\
0 \\
0 \\
0 \\
0\end{array}$ & $\begin{array}{l}0 \\
0 \\
0 \\
0 \\
0\end{array}$ & & $\begin{array}{l}0 \\
0 \\
0 \\
0 \\
0\end{array}$ \\
\hline $\begin{array}{l}16 \ldots \ldots \\
17 \ldots \ldots \\
18 \ldots \ldots \\
19 . \ldots \ldots \\
20 \ldots \ldots\end{array}$ & $\begin{array}{l}0 \\
0 \\
0 \\
56\end{array}$ & $\begin{array}{r}-- \\
37,000 \\
44,000\end{array}$ & $\begin{array}{r}0 \\
0 \\
0 \\
\operatorname{sa110} \\
\operatorname{sa} 8,100\end{array}$ & $\begin{array}{l}0 \\
0 \\
0 \\
0 \\
0\end{array}$ & $\begin{array}{l}-- \\
-- \\
-- \\
--\end{array}$ & $\begin{array}{l}0 \\
0 \\
0 \\
0 \\
0\end{array}$ & $\begin{array}{l}0 \\
0 \\
0 \\
0 \\
\quad .1\end{array}$ & & $\begin{array}{l}0 \\
0 \\
0 \\
0\end{array}$ \\
\hline $\begin{array}{l}21 \ldots \ldots \ldots \\
22 . \ldots \ldots \\
23 . \ldots \ldots \\
24 \ldots \ldots \\
25 . \ldots \ldots\end{array}$ & $\begin{array}{l}4 \\
8^{.1} \\
2 \\
0\end{array}$ & $\begin{array}{r}21,000 \\
11,000 \\
-- \\
-- \\
=\end{array}$ & $\begin{array}{r}\text { s } 225 \\
3 \\
\text { b } 400 \\
\text { b } 40 \\
0\end{array}$ & $\begin{array}{l}0 \\
0 \\
0 \\
0 \\
0\end{array}$ & $\begin{array}{l}-- \\
-- \\
-- \\
--\end{array}$ & $\begin{array}{l}0 \\
0 \\
0 \\
0 \\
0\end{array}$ & $\begin{array}{l}.1 \\
.1 \\
.1 \\
0\end{array}$ & -- & $\begin{array}{c}(b)(t) \\
0 \\
0\end{array}$ \\
\hline $\begin{array}{l}26 \ldots \ldots \ldots \\
27 . \ldots \ldots \\
28 \ldots \ldots \\
29 \ldots \ldots \\
30 \ldots \ldots \\
31 \ldots \ldots\end{array}$ & $\begin{array}{l}0 \\
0 \\
0 \\
0 \\
0 \\
0\end{array}$ & $\begin{array}{l}-- \\
-- \\
-- \\
-- \\
--\end{array}$ & $\begin{array}{l}0 \\
0 \\
0 \\
0 \\
0 \\
0\end{array}$ & $\begin{array}{l}0 \\
0 \\
0 \\
0 \\
0 \\
--\end{array}$ & $\begin{array}{l}-- \\
-- \\
-- \\
--\end{array}$ & $\begin{array}{r}0 \\
0 \\
0 \\
0 \\
0 \\
-- \\
\end{array}$ & $\begin{array}{l}0 \\
0 \\
0 \\
0 \\
0 \\
0\end{array}$ & & $\begin{array}{l}0 \\
0 \\
0 \\
0 \\
0 \\
0\end{array}$ \\
\hline Total. & 70.7 & $m$ & 8,878 & 88.5 & $\overline{-}$ & 18,304 & 0.4 & -- & 1.0 \\
\hline
\end{tabular}

s Computed by subdividing day.

Less than 0.50 ton.

Computed from estimated concentration graph.

b Computed from water-sediment discharge curve. 
RIO GRANDE BASIN--Continued

CHI CO ARROYO NEAR GUADALUPE, N. MEX.--Continued

Suspended sediment, water year October 1953 to September 1954 --Continued

\begin{tabular}{|c|c|c|c|c|c|c|c|c|c|}
\hline \multirow[b]{3}{*}{ Day } & \multicolumn{3}{|c|}{ March } & \multicolumn{3}{|c|}{ May } & \multicolumn{3}{|c|}{ June } \\
\hline & \multirow[b]{2}{*}{$\begin{array}{l}\text { Mean } \\
\text { dis- } \\
\text { charge } \\
\text { (cfs) }\end{array}$} & \multicolumn{2}{|c|}{ Suspended sediment } & \multirow[b]{2}{*}{$\begin{array}{c}\text { Mean } \\
\text { dis- } \\
\text { charge } \\
\text { (cfs) }\end{array}$} & \multicolumn{2}{|c|}{ Suspended sediment } & \multirow[b]{2}{*}{$\begin{array}{l}\text { Mean } \\
\text { dis- } \\
\text { charge } \\
\text { (cfs) }\end{array}$} & \multicolumn{2}{|c|}{ Suspended sediment } \\
\hline & & $\begin{array}{c}\text { Mean } \\
\text { concen- } \\
\text { tration } \\
(\text { ppm) }\end{array}$ & $\begin{array}{l}\text { Tons } \\
\text { per } \\
\text { day }\end{array}$ & & $\begin{array}{c}\text { Mean } \\
\text { concen- } \\
\text { tration } \\
\text { (ppm) }\end{array}$ & $\begin{array}{l}\text { Tons } \\
\text { per } \\
\text { day }\end{array}$ & & $\begin{array}{c}\text { Mean } \\
\text { concen- } \\
\text { tration } \\
\text { (ppm) }\end{array}$ & $\begin{array}{l}\text { Tons } \\
\text { per } \\
\text { day }\end{array}$ \\
\hline $\begin{array}{l}1 \ldots \ldots \\
2 \ldots \ldots \\
3 \ldots \ldots \\
4 \ldots \ldots \\
5 \ldots \ldots\end{array}$ & $\begin{array}{l}0 \\
0 \\
0 \\
0 \\
0\end{array}$ & $\begin{array}{l}-- \\
=- \\
=- \\
-- \\
--\end{array}$ & $\begin{array}{l}0 \\
0 \\
0 \\
0 \\
0\end{array}$ & $\begin{array}{l}0 \\
0 \\
0 \\
0 \\
0\end{array}$ & $\begin{array}{l}-- \\
-- \\
-- \\
--\end{array}$ & $\begin{array}{l}0 \\
0 \\
0 \\
0 \\
0\end{array}$ & $\begin{array}{l}0 \\
0 \\
0 \\
0 \\
0\end{array}$ & & $\begin{array}{l}0 \\
0 \\
0 \\
0 \\
0\end{array}$ \\
\hline $\begin{array}{r}6 \ldots \ldots \\
7 \ldots \ldots \\
8 \ldots \ldots \\
9 \ldots \ldots \\
10 \ldots \ldots\end{array}$ & $\begin{array}{l}0 \\
0 \\
0 \\
0 \\
0\end{array}$ & $\begin{array}{l}-- \\
-- \\
-- \\
--\end{array}$ & $\begin{array}{l}0 \\
0 \\
0 \\
0 \\
0\end{array}$ & $\begin{array}{l}0 \\
0 \\
0 \\
0 \\
\\
\\
.5\end{array}$ & $\begin{array}{l}-- \\
-- \\
-- \\
--\end{array}$ & $\begin{array}{r}0 \\
0 \\
0 \\
0 \\
\text { b20 }\end{array}$ & $\begin{array}{l}0 \\
0 \\
0 \\
0 \\
0\end{array}$ & & $\begin{array}{l}0 \\
0 \\
0 \\
0 \\
0\end{array}$ \\
\hline $\begin{array}{l}11 \ldots \ldots \\
12, \ldots \ldots \\
13 \ldots \ldots \\
14, \ldots \ldots \\
15, \ldots \ldots\end{array}$ & $\begin{array}{l}0 \\
0 \\
0 \\
0 \\
0\end{array}$ & $\begin{array}{l}-- \\
-- \\
-- \\
--\end{array}$ & $\begin{array}{l}0 \\
0 \\
0 \\
0 \\
0\end{array}$ & $\begin{array}{l}.1 \\
0 \\
0 \\
0 \\
0\end{array}$ & $\begin{array}{l}-- \\
-- \\
-- \\
--\end{array}$ & $\begin{array}{c}(b)(t) \\
0 \\
0 \\
0 \\
0\end{array}$ & $\begin{array}{l}0 \\
0 \\
0 \\
0 \\
0\end{array}$ & & $\begin{array}{l}0 \\
0 \\
0 \\
0 \\
0\end{array}$ \\
\hline $\begin{array}{l}16 \ldots \ldots \\
17 . \ldots \ldots \\
18 . \ldots \ldots \\
19 \ldots \ldots \\
20 \ldots \ldots\end{array}$ & $\begin{array}{l}0 \\
0 \\
0 \\
0 \\
0\end{array}$ & $\begin{array}{l}-- \\
-- \\
-- \\
--\end{array}$ & $\begin{array}{l}0 \\
0 \\
0 \\
0 \\
0\end{array}$ & $\begin{array}{r}0 \\
234 \\
53 \\
2 \\
\quad 3\end{array}$ & $\begin{array}{r}-- \\
16,000 \\
26,300 \\
-- \\
--\end{array}$ & $\begin{array}{r}0 \\
3 a 45,800 \\
\text { s5,200 } \\
\text { b 25 } \\
\text { b } 2\end{array}$ & $\begin{array}{l}0 \\
0 \\
0 \\
0 \\
0\end{array}$ & & $\begin{array}{l}0 \\
0 \\
0 \\
0 \\
0\end{array}$ \\
\hline $\begin{array}{l}21 \ldots \ldots \\
22 \ldots \ldots \\
23 . \ldots \ldots \\
24 \ldots \ldots \\
25 \ldots \ldots\end{array}$ & $\begin{array}{r}0 \\
0 \\
0 \\
12 \\
20\end{array}$ & $\begin{array}{r}-- \\
-- \\
43,000 \\
61,400\end{array}$ & $\begin{array}{r}0 \\
0 \\
0 \\
0 \\
\text { sa 2,400 } \\
\text { s } 3,360\end{array}$ & $\begin{array}{c}0 \\
12 \\
7 \\
3 \\
\quad .5\end{array}$ & $\begin{array}{r}-- \\
49,000 \\
-- \\
--\end{array}$ & $\begin{array}{r}0 \\
\text { sa 2, 200 } \\
\text { b 1, 300 } \\
\text { b } 300 \\
\text { b 20 }\end{array}$ & $\begin{array}{l}0 \\
0 \\
0 \\
0 \\
0\end{array}$ & & $\begin{array}{l}0 \\
0 \\
0 \\
0 \\
0\end{array}$ \\
\hline $\begin{array}{l}26 \ldots \ldots \\
27 \ldots \ldots \\
28 \ldots \ldots \\
29 \ldots \ldots \\
30 \ldots \ldots \\
31 \ldots \ldots\end{array}$ & $\begin{array}{l}7 \\
3 \\
1 \\
0^{.5} \\
0 \\
\end{array}$ & $\begin{array}{r}78,000 \\
52,000 \\
29,000 \\
-- \\
-- \\
-- \\
\end{array}$ & $\begin{array}{r}a 1,500 \\
437 \\
a 80 \\
\text { b5 } \\
0 \\
0 \\
\end{array}$ & $\begin{array}{l}.2 \\
0 \\
0 \\
0 \\
0 \\
0\end{array}$ & $\begin{array}{l}-- \\
-- \\
-- \\
-- \\
-\end{array}$ & $\begin{array}{r}\mathbf{b} \mathbf{3} \\
0 \\
0 \\
0 \\
0 \\
0 \\
0 \\
\end{array}$ & $\begin{array}{r}0 \\
84 \\
5 \\
1 \\
0 \\
-- \\
\end{array}$ & & $\begin{array}{r}0 \\
\text { b } 14,000 \\
\text { b } 600 \\
\text { b } 20 \\
0 \\
-\end{array}$ \\
\hline \multirow[t]{2}{*}{ Total. } & 43.5 & $=$ & 7,802 & 312.6 & -- & 54,870 & 90 & & 14,620 \\
\hline & \multicolumn{3}{|c|}{ July } & \multicolumn{3}{|c|}{ August } & \multicolumn{3}{|c|}{ September } \\
\hline $\begin{array}{l}1 \ldots \ldots \\
2 \ldots \ldots \\
3 \ldots \ldots \\
4 \ldots \ldots \\
5 \ldots \ldots\end{array}$ & $\begin{array}{r}72 \\
43 \\
7 \\
45 \\
9\end{array}$ & $\begin{array}{l}47,000 \\
77,100 \\
52,000 \\
72,600 \\
78,000\end{array}$ & $\begin{array}{r}\mathrm{sa13,000} \\
\mathrm{s} 11,200 \\
1,020 \\
15,000 \\
\mathrm{~s} 1,890\end{array}$ & $\begin{array}{l}0.6 \\
0 \\
0 \\
0 \\
0\end{array}$ & $\begin{array}{r}48,000 \\
-- \\
-- \\
-- \\
--\end{array}$ & $\begin{array}{r}81 \\
0 \\
0 \\
0 \\
0\end{array}$ & $\begin{array}{l}3 \\
83^{.4} \\
69 \\
40\end{array}$ & $\begin{array}{r}38,000 \\
8,000 \\
13,600 \\
45,400 \\
37,000\end{array}$ & $\begin{array}{r}319 \\
9 \\
\mathrm{~s} 19,300 \\
\mathrm{~s} 9,590 \\
\mathrm{~s} 4,790\end{array}$ \\
\hline $\begin{array}{r}6 \ldots \ldots \\
7 . \ldots \ldots \\
8 \ldots \ldots \\
9 . \ldots \ldots \\
10 . \ldots \ldots\end{array}$ & $\begin{array}{r}1 \\
1 \\
17 \\
33 \\
30\end{array}$ & $\begin{array}{l}40,500 \\
14,600 \\
50,500 \\
55,900 \\
39,100\end{array}$ & $\begin{array}{r}181 \\
8107 \\
\mathrm{~s} 3,600 \\
\mathrm{~s} 6,420 \\
\mathrm{~s} 3,950\end{array}$ & $\begin{array}{r}930 \\
64 \\
15 \\
10 \\
100\end{array}$ & $\begin{array}{l}71,100 \\
33,500 \\
19,400 \\
12,900 \\
17,400\end{array}$ & $\begin{array}{r}8210,000 \\
86,800 \\
8751 \\
8389 \\
820,300\end{array}$ & $\begin{array}{r}100 \\
6 \\
2 \\
13 \\
59\end{array}$ & $\begin{array}{l}54,600 \\
29,000 \\
14,000 \\
10,900 \\
39,000\end{array}$ & $\begin{array}{r}818,500 \\
470 \\
76 \\
81,860 \\
\mathrm{~s} 11,700\end{array}$ \\
\hline $\begin{array}{l}11 \ldots \ldots \\
12 . \ldots \ldots \\
13 \ldots \ldots \\
14 \ldots \ldots \\
15 \ldots \ldots\end{array}$ & $\begin{array}{l}5 \\
0^{.3} \\
0 \\
0\end{array}$ & $\begin{array}{r}29,200 \\
5,800 \\
-- \\
-- \\
--\end{array}$ & $\begin{array}{r}\text { s } 443 \\
\text { sa } 9 \\
0 \\
0 \\
0\end{array}$ & $\begin{array}{r}390 \\
42 \\
94 \\
33 \\
1,270\end{array}$ & $\begin{array}{l}69,700 \\
26,000 \\
43,500 \\
26,200 \\
54,300\end{array}$ & $\begin{array}{r}8103,000 \\
2,950 \\
11,400 \\
82,790 \\
8433,000\end{array}$ & $\begin{array}{r}257 \\
1,200 \\
1,460 \\
90 \\
17\end{array}$ & $\begin{array}{l}67,800 \\
52,600 \\
75,600 \\
27,000 \\
13,000\end{array}$ & $\begin{array}{r}872,600 \\
8246,000 \\
8360,000 \\
87,520 \\
\mathrm{a} 600\end{array}$ \\
\hline $\begin{array}{l}16 \ldots \ldots \\
17 \ldots \ldots \\
18 \ldots \ldots \\
19 \ldots \ldots \\
20 . \ldots \ldots\end{array}$ & $\begin{array}{l}0 \\
0 \\
0 \\
0 \\
0\end{array}$ & $\begin{array}{l}-- \\
-- \\
-- \\
--\end{array}$ & $\begin{array}{l}0 \\
0 \\
0 \\
0 \\
0\end{array}$ & $\begin{array}{r}1,560 \\
645 \\
880 \\
45 \\
\mathbf{5 5 0}\end{array}$ & $\begin{array}{l}86,500 \\
54,200 \\
65,900 \\
25,500 \\
34,000\end{array}$ & $\begin{array}{r}\text { s } 437,000 \\
\text { s } 112,000 \\
\text { s } 192,000 \\
3,100 \\
\text { s } 155,000\end{array}$ & $\begin{array}{l}7 \\
3 \\
2 \\
0\end{array}$ & $\begin{array}{r}7,500 \\
3,000 \\
507 \\
55 \\
--\end{array}$ & $\begin{array}{r}142 \\
24 \\
3 \\
\text { (t) } \\
\\
\end{array}$ \\
\hline $\begin{array}{l}21 . \ldots \ldots \\
22 . \ldots \ldots \\
23 . \ldots \ldots \\
24 \ldots \ldots \\
25 . \ldots \ldots\end{array}$ & $\begin{array}{r}0 \\
140 \\
1,420 \\
1,950 \\
317\end{array}$ & $\begin{array}{l}59,000 \\
87,500 \\
86,300 \\
69,200\end{array}$ & $\begin{array}{r}0 \\
828,400 \\
8385,000 \\
8480,000 \\
868,700\end{array}$ & $\begin{array}{r}312 \\
19 \\
12 \\
86 \\
73\end{array}$ & $\begin{array}{r}50,000 \\
18,800 \\
7,000 \\
37,300 \\
35,600\end{array}$ & $\begin{array}{r}864,700 \\
964 \\
227 \\
s 10,300 \\
810,300\end{array}$ & $\begin{array}{r}0 \\
0 \\
34 \\
203 \\
1,690\end{array}$ & $\begin{array}{r}\cdots \\
16,000 \\
31,200 \\
75,700\end{array}$ & $\begin{array}{r}0 \\
0 \\
\mathbf{8 4 , 5 3 0} \\
\mathbf{8 3 8 , 1 0 0} \\
\mathbf{8 4 1 9 , 0 0 0}\end{array}$ \\
\hline $\begin{array}{l}26 . \ldots \ldots \\
27 . \ldots \ldots \\
28 . \ldots \ldots \\
29 . \ldots \ldots \\
30 \ldots \ldots \\
31 \ldots \ldots\end{array}$ & $\begin{array}{r}14 \\
8 \\
4 \\
3 \\
2 \\
2 \\
\end{array}$ & $\begin{array}{r}29,500 \\
18,200 \\
8,000 \\
2,000 \\
4,510 \\
28,800 \\
\end{array}$ & $\begin{array}{r}1,120 \\
393 \\
86 \\
16 \\
24 \\
156 \\
\end{array}$ & $\begin{array}{r}5 \\
.8 \\
.6 \\
.2 \\
.2 \\
34 \\
\end{array}$ & $\begin{array}{r}12,000 \\
7,000 \\
5,000 \\
3,000 \\
1,500 \\
60,500 \\
\end{array}$ & $\begin{array}{r}162 \\
15 \\
8 \\
2 \\
1 \\
88,850 \\
\end{array}$ & $\begin{array}{r}1,460 \\
74 \\
20 \\
7 \\
3 \\
- \\
\end{array}$ & $\begin{array}{r}83,100 \\
33,500 \\
14,200 \\
8,000 \\
3,500 \\
-\end{array}$ & $\begin{array}{r}\mathbf{8 4 2 8 , 0 0 0} \\
6,940 \\
767 \\
151 \\
28 \\
-- \\
\end{array}$ \\
\hline Total. & $4,123.3$ & - & $1,020,715$ & $7,171.4$ & - & $1,786,090$ & $6,902.6$ & -- & $1,651,019$ \\
\hline
\end{tabular}

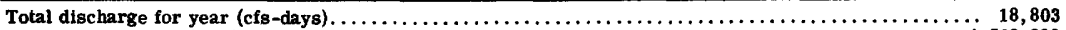

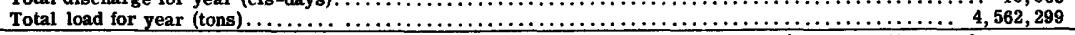

Computed by subdividing day.

Computed from estimated concentration graph.

Less than 0.50 ton. 
RIO GRANDE BASIN

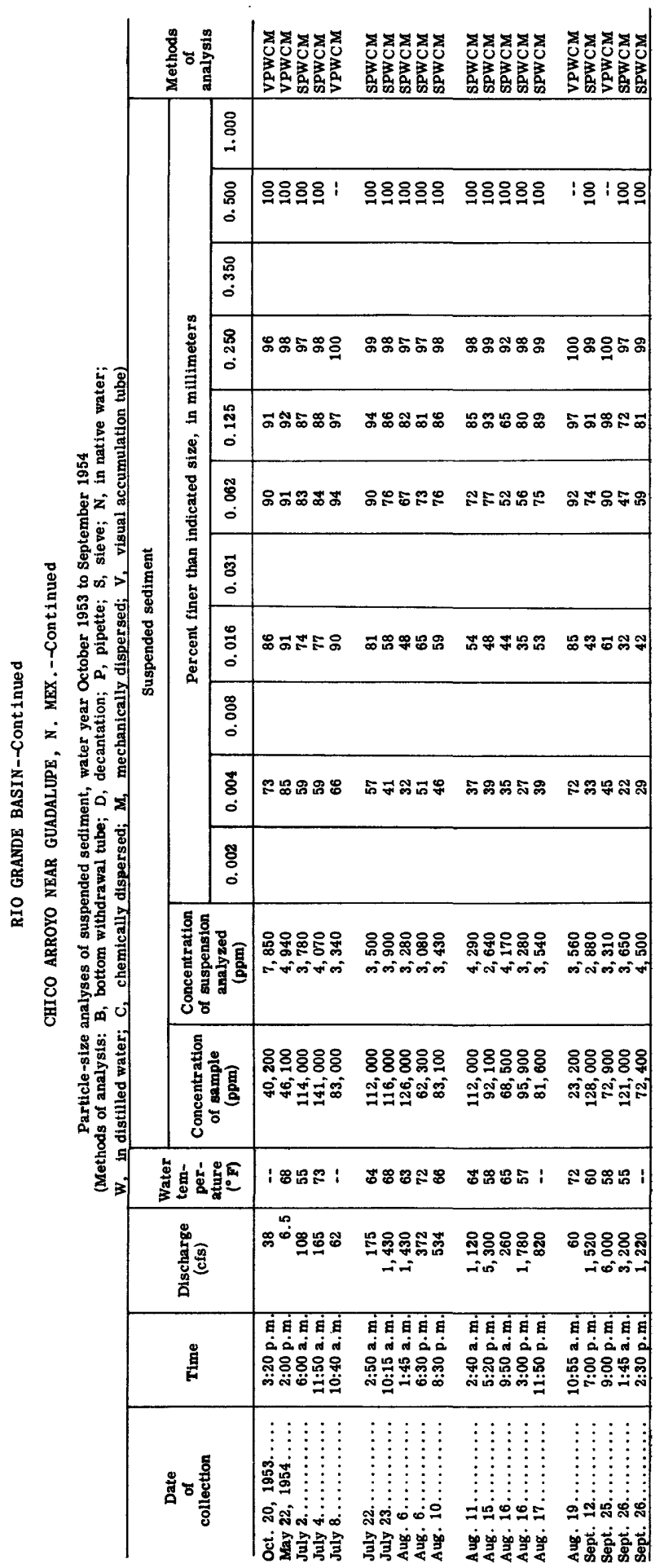


RIO GRANDE BASIN--Continued

SAN JOSE RIVER AT CORREO, N. MEX.

LOCATION. --At gaging station 0.6 mile upstream from $U$. $S$. Highway $66,0.7$ mile northeast of Correo, Valencia County, and 13 miles upstream from mouth.

DRAINAGE AREA . $-2,610$ square miles, approximately.

RECORDS AVAILABLE. --Sediment records: July 1948 to September 1954

EXTREMES, 1953-54,--Sediment concentrations: Maximum daily, 57,800 ppm July 3; mintmum daily, no flow on many days.

Sediment loads: Maximum daliy, 250,000 tons Aug. 24; minimum daily, 0 tons on many days. EXTREMES, 1948-54.--Sediment concentrations: Maximum daily, 58,800 ppm Aug. 29, 1952; minimum daily, no flow on many days.

Sediment loads: Maximum daily, 250,000 tons Aug. 24, 1954; minimum daily, 0 tons on many days.

REMARKS. --Maximum observed sediment concentration during water year, $183,000 \mathrm{ppm} \mathrm{July} 24$. No fiow Oct. 1 to May 10, May 20 to June 30 ; tabulation omitted for these periods. Records of discharge for water year October 1953 to September 1954 given in WSP 1342 .

Suspended sediment. water vear October 1953 to Sentember 1954

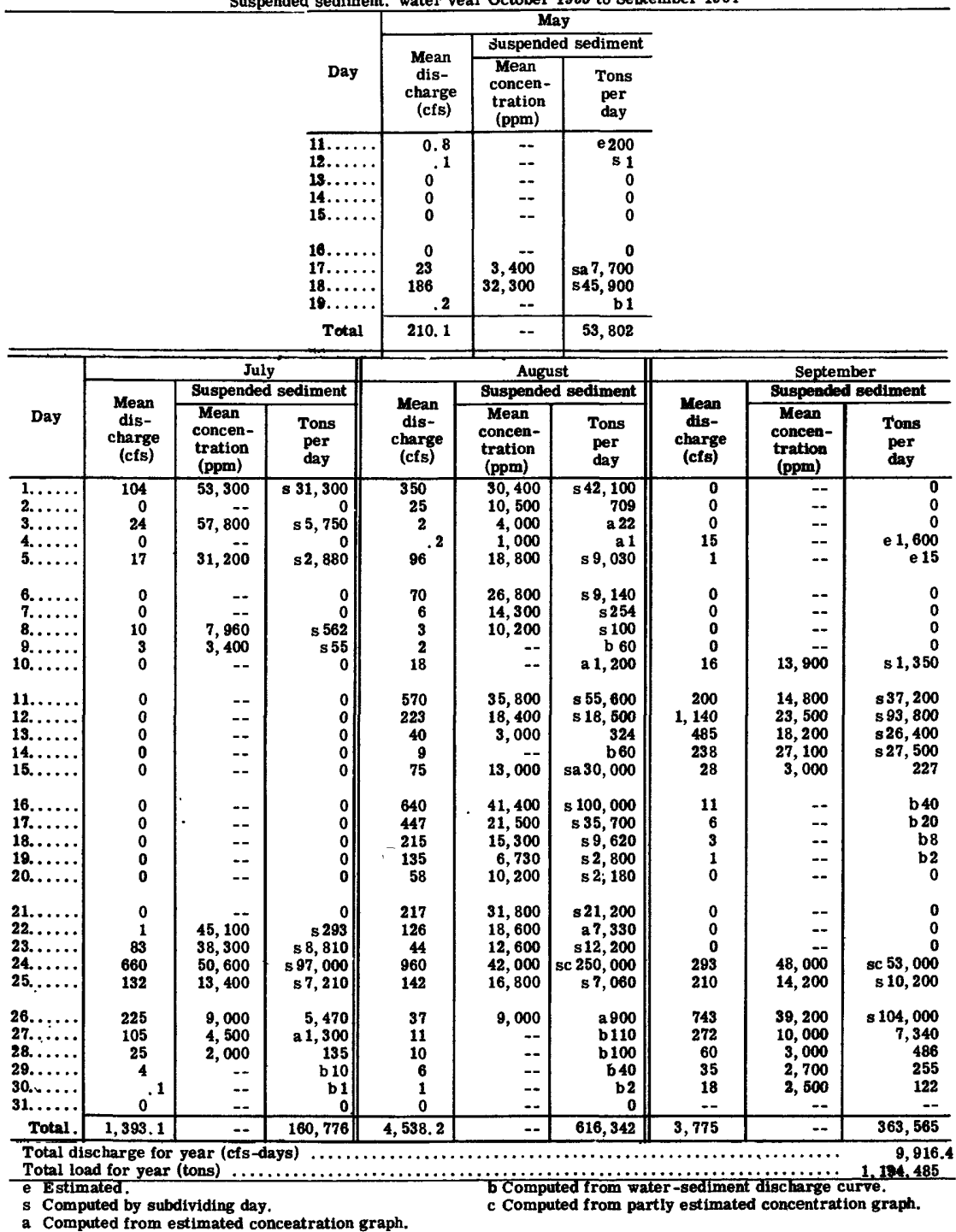




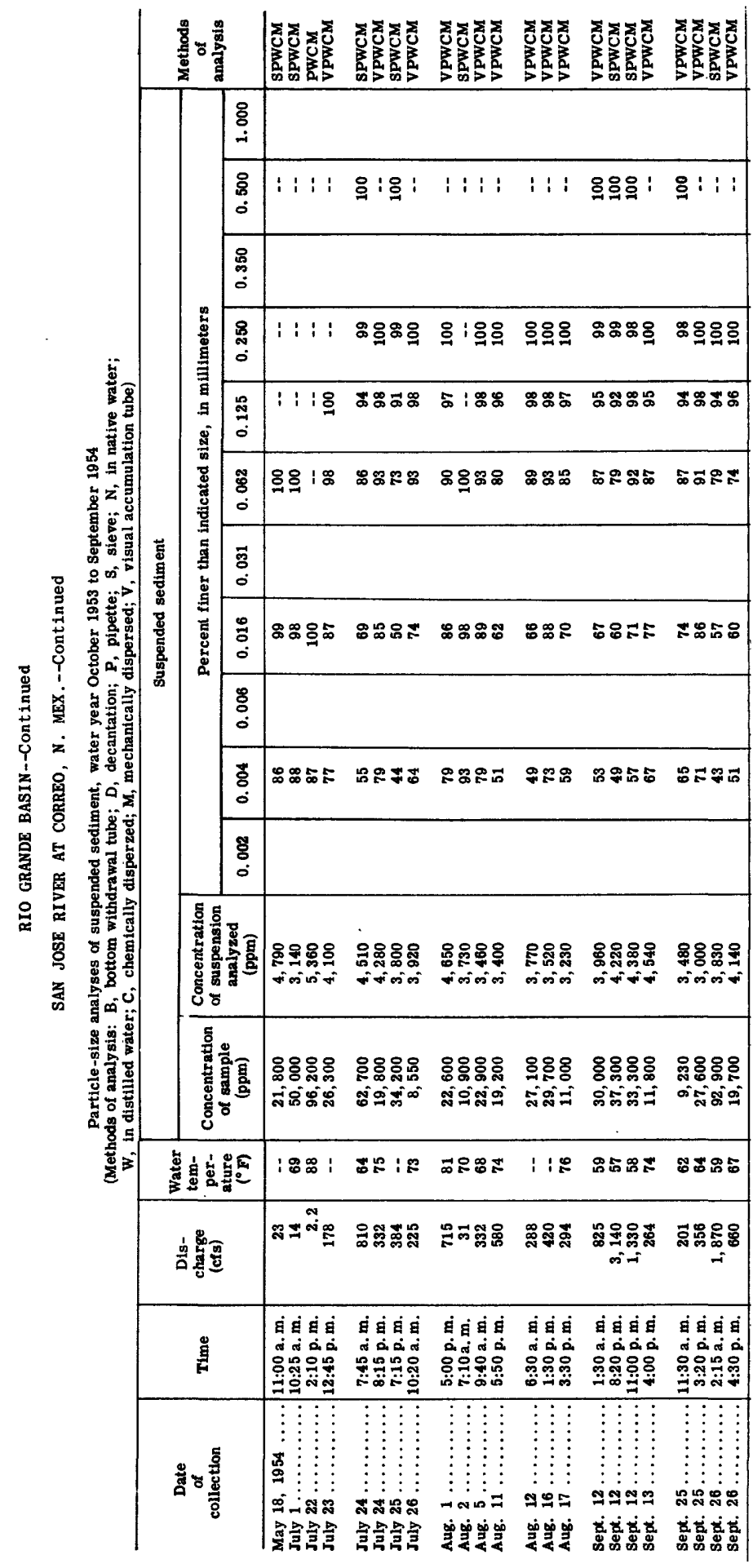


RIO GRANDE BASIN--Continued

RIO PUERCO AT RIO PUERCO, N. MEX.

LOCATION. --At gaging station at Atchison, Topeka and Santa Fe Railway bridge, 7 miles downstream from San Jose River, and 15 miles west of Los Lunas, Valencia County.

DRAINAGE AREA. $-\mathbf{- 5 , 1 6 0}$ square miles, approximately.

RECORDS AVAILABLE.--Water temperatures: October 1949 to September 1952.

Sediment records: July 1948 to September 1954.

EXTREMES, 1953-54.--Sediment concentrations: Maximum daily, 149,000 ppm Nov. 7; minimum daily, no flow on many days.

Sediment loads: Maximum daily, 1,800,000 tons July 24; minimum daily, 0 tons on many days. EXTREMES, 1948-54.--Sediment concentrations: Maximum daily, 195,000 ppm Aug. 8, 1949;

minimum daily, no flow on many days.

Sediment loads: Maximum daily, 1,800,000 tons July 24, 1954; minimum daily, 0 tons on many days.

REMARKS.--Maximum observed sediment concentrations during water year 351,000 ppm Aug. 7 .

Miscellaneous temperature measurements for water year October 1953 to September 1954

available in district office at Albuquerque, $N$. Mex. Records of discharge for water year

October 1953 to September 1954 given in WSP' 1342 .

Suspended sediment, water year October 1953 to September 1954

\begin{tabular}{|c|c|c|c|c|c|c|c|c|c|}
\hline \multirow[b]{3}{*}{ Day } & \multicolumn{3}{|c|}{ October } & \multicolumn{3}{|c|}{ November } & \multicolumn{3}{|c|}{ December } \\
\hline & \multirow[b]{2}{*}{$\begin{array}{l}\text { Mean } \\
\text { dis- } \\
\text { charge } \\
\text { (cfs) }\end{array}$} & \multicolumn{2}{|c|}{ Suspended sediment } & \multirow[b]{2}{*}{$\begin{array}{c}\text { Mean } \\
\text { dis- } \\
\text { charge } \\
\text { (cfs) }\end{array}$} & \multicolumn{2}{|c|}{ Suspended sediment } & \multirow[b]{2}{*}{$\begin{array}{l}\text { Mean } \\
\text { dis- } \\
\text { charge } \\
\text { (cfs) }\end{array}$} & \multicolumn{2}{|c|}{ Suspended sediment } \\
\hline & & $\begin{array}{l}\text { Mean } \\
\text { concen- } \\
\text { tration } \\
(\mathrm{ppm})\end{array}$ & $\begin{array}{l}\text { Tons } \\
\text { per } \\
\text { day }\end{array}$ & & $\begin{array}{c}\text { Mean } \\
\text { concen- } \\
\text { tration } \\
\text { (ppm) }\end{array}$ & $\begin{array}{l}\text { Tons } \\
\text { per } \\
\text { day }\end{array}$ & & $\begin{array}{l}\text { Mean } \\
\text { concen- } \\
\text { tration } \\
\text { (ppm) }\end{array}$ & $\begin{array}{l}\text { Tons } \\
\text { per } \\
\text { day }\end{array}$ \\
\hline $\begin{array}{l}1 . \ldots \ldots \\
2 \ldots \ldots \\
3 . \ldots \ldots \\
4 \ldots \ldots \\
5 \ldots \ldots\end{array}$ & $\begin{array}{l}0 \\
0 \\
0 \\
0 \\
0\end{array}$ & $\begin{array}{l}-- \\
-- \\
-- \\
--\end{array}$ & $\begin{array}{l}0 \\
0 \\
0 \\
0 \\
0\end{array}$ & $\begin{array}{l}0.1 \\
0 \\
0 \\
0 \\
0\end{array}$ & $\begin{array}{l}-- \\
-- \\
-- \\
--\end{array}$ & $\begin{array}{r}\mathbf{e} 5 \\
0 \\
0 \\
0 \\
0\end{array}$ & $\begin{array}{l}0.4 \\
.2 \\
.1 \\
0 \\
0\end{array}$ & $\begin{array}{l}-- \\
-- \\
-- \\
-- \\
--\end{array}$ & $\begin{array}{r}\text { e } 35 \\
\text { e } 15 \\
\text { e } 7 \\
0 \\
0\end{array}$ \\
\hline $\begin{array}{r}6 \ldots \ldots \\
7 \ldots \ldots \\
8 \ldots \ldots \\
9 \ldots \ldots \\
10 \ldots \ldots\end{array}$ & $\begin{array}{l}0 \\
0 \\
0 \\
0 \\
0\end{array}$ & $\begin{array}{l}-- \\
-- \\
-- \\
--\end{array}$ & $\begin{array}{l}0 \\
0 \\
0 \\
0 \\
0\end{array}$ & $\begin{array}{r}212 \\
31 \\
12 \\
7\end{array}$ & $\begin{array}{r}- \\
149,000 \\
103,000 \\
87,000 \\
--\end{array}$ & $\begin{array}{r}\text { e } 50 \\
\mathrm{~s} 109,000 \\
9,260 \\
3,030 \\
\mathrm{e} 1,400\end{array}$ & $\begin{array}{l}0 \\
0 \\
0 \\
0 \\
0\end{array}$ & $\begin{array}{l}-- \\
-- \\
-- \\
--\end{array}$ & $\begin{array}{l}0 \\
0 \\
0 \\
0 \\
0\end{array}$ \\
\hline $\begin{array}{l}11 . \ldots \ldots \\
12 . \ldots \ldots \\
13 . \ldots \ldots \\
14 . \ldots \ldots \\
15 \ldots \ldots\end{array}$ & $\begin{array}{l}0 \\
0 \\
0 \\
0 \\
0\end{array}$ & $\begin{array}{l}-- \\
-- \\
-- \\
-- \\
--\end{array}$ & $\begin{array}{l}0 \\
0 \\
0 \\
0 \\
0\end{array}$ & $\begin{array}{l}4 \\
3 \\
3 \\
2 \\
2\end{array}$ & $\begin{array}{l}-- \\
-- \\
-- \\
--\end{array}$ & $\begin{array}{l}\text { e } 700 \\
\text { e } 500 \\
\text { e } 450 \\
\text { e } 250 \\
\text { e } 200\end{array}$ & $\begin{array}{l}0 \\
0 \\
0 \\
0 \\
0\end{array}$ & $\begin{array}{l}-- \\
-- \\
-- \\
--\end{array}$ & $\begin{array}{l}0 \\
0 \\
0 \\
0 \\
0\end{array}$ \\
\hline $\begin{array}{l}16 . \ldots \ldots \\
17 \ldots \ldots \\
18 \ldots \ldots \\
19 \ldots \ldots \\
20 . \ldots \ldots\end{array}$ & $\begin{array}{l}0 \\
0 \\
0 \\
0 \\
0\end{array}$ & $\begin{array}{l}- \\
-- \\
-- \\
-- \\
--\end{array}$ & $\begin{array}{l}0 \\
0 \\
0 \\
0 \\
0\end{array}$ & $\begin{array}{l}.3 \\
.2 \\
.2 \\
.3 \\
.1\end{array}$ & $\begin{array}{l}-- \\
-- \\
-- \\
--\end{array}$ & $\begin{array}{r}\text { e } 25 \\
\text { e } 15 \\
\text { e } 15 \\
\text { e } 20 \\
\text { e } 7\end{array}$ & $\begin{array}{l}0 \\
.5 \\
.2 \\
.2 \\
.2\end{array}$ & $\begin{array}{l}-- \\
-- \\
-- \\
--\end{array}$ & $\begin{array}{r}0 \\
\text { e } 45 \\
\text { e } 15 \\
\text { e } 15 \\
\text { e } 10\end{array}$ \\
\hline $\begin{array}{l}21 . \ldots \ldots \\
22 . \ldots \ldots \\
23 . \ldots \ldots \\
24 . \ldots \ldots \\
25 . \ldots \ldots\end{array}$ & $\begin{array}{r}0 \\
0 \\
0 \\
61 \\
68\end{array}$ & $\begin{array}{r}- \\
37,000 \\
110,000\end{array}$ & $\begin{array}{r}0 \\
0 \\
0 \\
\operatorname{sa} 34,000 \\
\operatorname{sa} 23,000\end{array}$ & $\begin{array}{r}.3 \\
.1 \\
.6 \\
.3\end{array}$ & $\begin{array}{l}-- \\
-- \\
-- \\
--\end{array}$ & $\begin{array}{r}\text { e } 25 \\
\text { e } \\
0 \\
\text { e } 50 \\
\text { e } 25\end{array}$ & $\begin{array}{l}.1 \\
0 \\
0 \\
0 \\
0\end{array}$ & $\begin{array}{l}-- \\
-- \\
-- \\
-- \\
--\end{array}$ & $\begin{array}{r}\text { e } \\
0 \\
0 \\
0 \\
0\end{array}$ \\
\hline $\begin{array}{l}26 \ldots \ldots \\
27 . \ldots \ldots \\
28 . \ldots \ldots \\
29 . \ldots \ldots \\
30 \ldots \ldots \\
31 . \ldots \ldots\end{array}$ & $\begin{array}{r}12 \\
3 \\
1 \\
.2 \\
.1 \\
.1 \\
.1\end{array}$ & $\begin{array}{r}67,500 \\
45,500 \\
35,000 \\
25,000 \\
-- \\
-. \\
\end{array}$ & $\begin{array}{r}2,270 \\
382 \\
\mathrm{a} 100 \\
\mathrm{a} 15 \\
\mathrm{e} 7 \\
\mathrm{e} 6 \\
\end{array}$ & $\begin{array}{l}.2 \\
.4 \\
.2 \\
0 \\
0 \\
. .\end{array}$ & $\begin{array}{l}-- \\
-- \\
-- \\
-- \\
--\end{array}$ & $\begin{array}{r}\text { e } 15 \\
\text { e } 35 \\
\text { e } 15 \\
0 \\
0 \\
-- \\
\end{array}$ & $\begin{array}{l}0 \\
0 \\
0 \\
0 \\
0 \\
0\end{array}$ & $\begin{array}{l}-- \\
-- \\
-- \\
-- \\
--\end{array}$ & $\begin{array}{l}0 \\
0 \\
0 \\
0 \\
0 \\
0 \\
\end{array}$ \\
\hline Total. & 145.4 & -- & 59,780 & 279.9 & -- & 125,099 & 1.9 & -- & 149 \\
\hline
\end{tabular}

Estimated.

s Computed by subdividing day.

a Computed from esti mated concentration graph. 
RIO GRANDE BASIN

RIO GRANDE BASIN--Cont inued

RIO PUERCO AT RIO PUERCO, N. MEX.--Continued

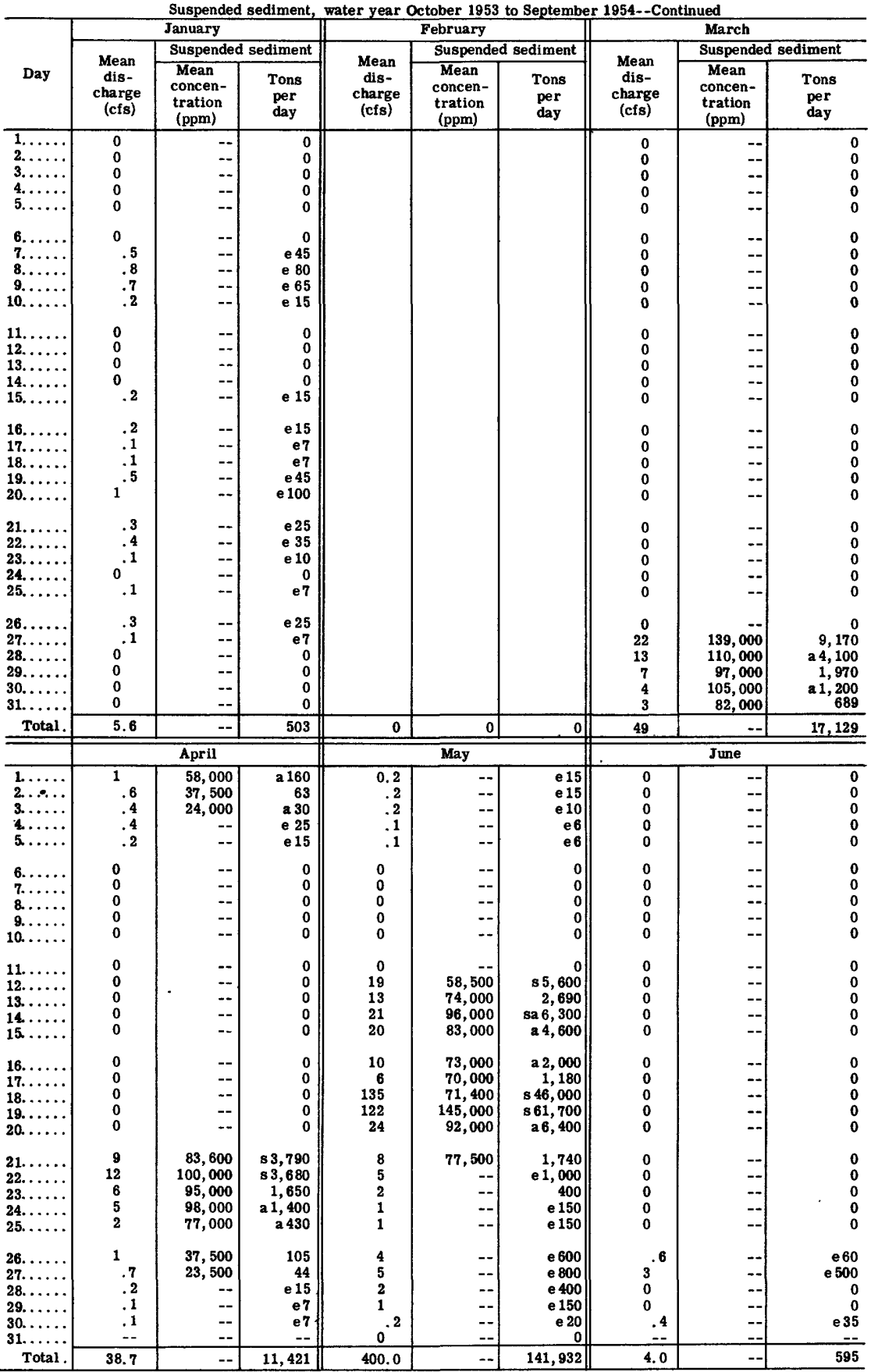

e Estimated.

s Computed by subdividing day.

a Computed from estimated concentration graph. 
RIO GRANDE BASIN--Continued

RIO PUERCO AT RIO PUERCO, N. MEX.--Continued

Suspended sediment, water year October 1953 to September 1954--Continued

\begin{tabular}{|c|c|c|c|c|c|c|c|c|c|}
\hline \multirow[b]{3}{*}{ Day } & \multicolumn{3}{|c|}{ July } & \multicolumn{3}{|c|}{ August } & \multicolumn{3}{|c|}{ September } \\
\hline & \multirow[b]{2}{*}{$\begin{array}{l}\text { Mean } \\
\text { dis - } \\
\text { charge } \\
\text { (cfs) }\end{array}$} & \multicolumn{2}{|c|}{ Suspended sediment } & \multirow[b]{2}{*}{$\begin{array}{l}\text { Mean } \\
\text { dis- } \\
\text { charge } \\
\text { (cfs) }\end{array}$} & \multicolumn{2}{|c|}{ Suspended sediment } & \multirow[b]{2}{*}{$\begin{array}{l}\text { Mean } \\
\text { dis- } \\
\text { charge } \\
\text { (cfs) }\end{array}$} & \multicolumn{2}{|c|}{ Suspended sediment } \\
\hline & & $\begin{array}{l}\text { Mean } \\
\text { concen- } \\
\text { tration } \\
\text { (ppm) }\end{array}$ & $\begin{array}{l}\text { Tons } \\
\text { per } \\
\text { day }\end{array}$ & & $\begin{array}{l}\text { Mean } \\
\text { concen- } \\
\text { tration } \\
\text { (ppm) }\end{array}$ & $\begin{array}{l}\text { Tons } \\
\text { per } \\
\text { day }\end{array}$ & & $\begin{array}{c}\text { Mean } \\
\text { concen- } \\
\text { tration } \\
(\mathrm{ppm})\end{array}$ & $\begin{array}{l}\text { Tons } \\
\text { per } \\
\text { day }\end{array}$ \\
\hline $\begin{array}{l}1 . \ldots \ldots \\
2 \ldots \ldots \\
3 . \ldots \ldots \\
4 \ldots \ldots \\
5 . \ldots \ldots\end{array}$ & $\begin{array}{r}377 \\
22 \\
18 \\
10 \\
9\end{array}$ & $\begin{array}{l}82,600 \\
74,500 \\
82,000 \\
72,500 \\
86,900\end{array}$ & \begin{tabular}{|r|}
$\mathrm{s} 106,000$ \\
4,590 \\
4,130 \\
2,030 \\
$\mathrm{~s} 2,500$ \\
\end{tabular} & $\begin{array}{c}275 \\
142 \\
11 \\
45\end{array} .8$ & $\begin{array}{r}42,300 \\
28,000 \\
10,000 \\
1,500 \\
29,800\end{array}$ & $\begin{array}{r}\mathrm{s} 42,400 \\
10,700 \\
297 \\
3 \\
\mathrm{~s} 13,100\end{array}$ & $\begin{array}{r}\mathbf{0} \\
0 \\
0 \\
0 \\
81\end{array}$ & 106,000 & $\begin{array}{r}0 \\
0 \\
0 \\
\mathbf{0} 33,200\end{array}$ \\
\hline $\begin{array}{r}6 . \ldots \ldots \\
7 . \ldots \ldots \\
8 \ldots \ldots \\
9 \ldots \ldots \\
10 . \ldots \ldots\end{array}$ & $\begin{array}{l}9 \\
1 \\
1 \\
6 \\
3\end{array}$ & $\begin{array}{r}95,000 \\
76,000 \\
-- \\
-- \\
--\end{array}$ & $\begin{array}{r}2,480 \\
2210 \\
2200 \\
1,700 \\
1900\end{array}$ & $\begin{array}{r}69 \\
1,070 \\
177 \\
-45 \\
164\end{array}$ & $\begin{array}{r}33,100 \\
141,000 \\
78,600 \\
53,100 \\
63,000\end{array}$ & $\begin{array}{r}87,240 \\
8577,000 \\
849,600 \\
7,820 \\
\mathrm{sa} \mathrm{73,000}\end{array}$ & $\begin{array}{l}30 \\
79 \\
20 \\
14 \\
15\end{array}$ & $\begin{array}{l}70,000 \\
66,000 \\
41,000 \\
51,000 \\
85,000\end{array}$ & $\begin{array}{r}5,880 \\
\operatorname{sa~} 18,000 \\
\mathrm{a2}, 300 \\
\mathrm{sa} 3,400 \\
3,570\end{array}$ \\
\hline $\begin{array}{l}11 . \ldots \ldots \\
12 . \ldots \ldots \\
13 . \ldots \ldots \\
14 \ldots \ldots \\
15 . \ldots \ldots\end{array}$ & $\begin{array}{r}10 \\
14 \\
2 \\
.7 \\
.4\end{array}$ & $\begin{array}{l}-- \\
-- \\
-- \\
--\end{array}$ & $\begin{array}{r}\mathrm{3}, 000 \\
\mathrm{e}, 000 \\
\mathrm{e} 500 \\
\mathrm{e} 130 \\
\mathrm{e} 60\end{array}$ & $\begin{array}{r}677 \\
1,000 \\
150 \\
36 \\
42\end{array}$ & $\begin{array}{r}87,300 \\
110,000 \\
54,000 \\
-- \\
--\end{array}$ & $\begin{array}{r}8155,000 \\
\mathrm{~s} 351,000 \\
22,700 \\
\mathrm{e} 4,000 \\
\mathrm{e} 5,000\end{array}$ & $\begin{array}{r}8 \\
917 \\
3,150 \\
1,260 \\
165\end{array}$ & $\begin{array}{r}40,000 \\
69,500 \\
98,400 \\
128,000 \\
88,000\end{array}$ & $\begin{array}{r}898 \\
\mathrm{~s} 225,000 \\
\mathrm{~s} 987,000 \\
\mathrm{~s} 498,000 \\
31,400\end{array}$ \\
\hline $\begin{array}{l}16 . \ldots \ldots \\
17 . \ldots \ldots \\
18 \ldots \ldots \\
19 . \ldots \ldots \\
20 . \ldots \ldots\end{array}$ & $\stackrel{0}{0}^{.2}$ & $\begin{array}{l}-- \\
-- \\
-- \\
-- \\
--\end{array}$ & $\begin{array}{r}e 20 \\
0 \\
0 \\
e 80 \\
e 700\end{array}$ & $\begin{array}{r}2,980 \\
2,300 \\
1,170 \\
1,000 \\
193\end{array}$ & $\begin{array}{r}119,000 \\
122,000 \\
108,000 \\
100,000 \\
39,000\end{array}$ & \begin{tabular}{|r|}
$1,300,000$ \\
8863,000 \\
8388,000 \\
280,000 \\
21,100
\end{tabular} & $\begin{array}{r}28 \\
15 \\
6 \\
2 \\
.6\end{array}$ & $\begin{array}{r}47,500 \\
38,000 \\
-- \\
-- \\
--\end{array}$ & $\begin{array}{r}3,720 \\
1,600 \\
\text { } 500 \\
\text { e } 150 \\
\text { e25 }\end{array}$ \\
\hline $\begin{array}{l}21 . \ldots \ldots \\
22 . \ldots \ldots \\
23 . \ldots \ldots \\
24 \ldots \ldots \\
25 . \ldots \ldots\end{array}$ & $\begin{array}{r}10 \\
772 \\
2,330 \\
4,400 \\
1,110\end{array}$ & $\begin{array}{r}99,100 \\
145,000 \\
140,000 \\
114,000\end{array}$ & $\begin{array}{r}\mathrm{e} 3,000 \\
\mathbf{2} 250,000 \\
\mathrm{~s}, 030,000 \\
\mathrm{~s}, 800,000 \\
\mathbf{8 3 8 5 , 0 0 0}\end{array}$ & $\begin{array}{r}2,060 \\
460 \\
132 \\
1,510 \\
239\end{array}$ & $\begin{array}{r}118,000 \\
77,000 \\
42,000 \\
81,700 \\
28,000\end{array}$ & $\begin{array}{r}\mathrm{s} 945,000 \\
99,200 \\
15,500 \\
\mathrm{~s} 458,000 \\
18,100\end{array}$ & $\begin{array}{r}0^{-1} \\
231 \\
1,260\end{array}$ & $\begin{array}{r}- \\
21,000 \\
54,800 \\
77,000\end{array}$ & $\begin{array}{r}\mathrm{e} 3 \\
0 \\
\mathrm{sa} 13,000 \\
\mathrm{~s} 37,800 \\
\mathrm{~s} 602,000\end{array}$ \\
\hline $\begin{array}{l}26 \ldots \ldots \\
27 \ldots \ldots \\
28 . \ldots \ldots \\
29 . \ldots \ldots \\
30 . \ldots \ldots \\
31 \ldots \ldots\end{array}$ & $\begin{array}{r}590 \\
200 \\
30 \\
17 \\
3 \\
35 \\
\end{array}$ & $\begin{array}{r}74,000 \\
48,000 \\
27,500 \\
17,000 \\
9,000 \\
27,000 \\
\end{array}$ & $\begin{array}{r}122,000 \\
\mathrm{a} 27,000 \\
2,230 \\
780 \\
\mathrm{a} 70 \\
\mathrm{sa} \mathrm{10,000} \\
\end{array}$ & $\begin{array}{r}90 \\
15 \\
5 \\
1 \\
.2 \\
0\end{array}$ & $\begin{array}{l}-- \\
-- \\
-- \\
-- \\
-- \\
-\end{array}$ & $\begin{array}{r}\mathrm{e} 10,000 \\
\mathrm{e} 1,000 \\
\mathrm{e} 700 \\
\mathrm{e} 100 \\
\mathrm{e} 15 \\
0 \\
\end{array}$ & $\begin{array}{r}3,860 \\
1,680 \\
250 \\
95 \\
30 \\
-- \\
\end{array}$ & $\begin{array}{r}134,000 \\
94,100 \\
59,000 \\
37,000 \\
25,000 \\
-- \\
\end{array}$ & $\begin{array}{r}\mathrm{s} 1,470,000 \\
\mathrm{~s} 480,000 \\
41,300 \\
9,840 \\
2,020 \\
--\end{array}$ \\
\hline Total. & $9,983.9$ & -- & $3,763,310$ & $16,069.0$ & -- & $5,726,575$ & $13,229.7$ & $\cdots$ & $4,470,604$ \\
\hline
\end{tabular}

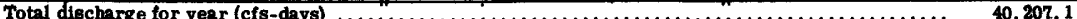

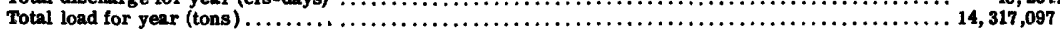

Tstimated.

s Computed by subdividing day.

a Computed from estimated concentration graph. 


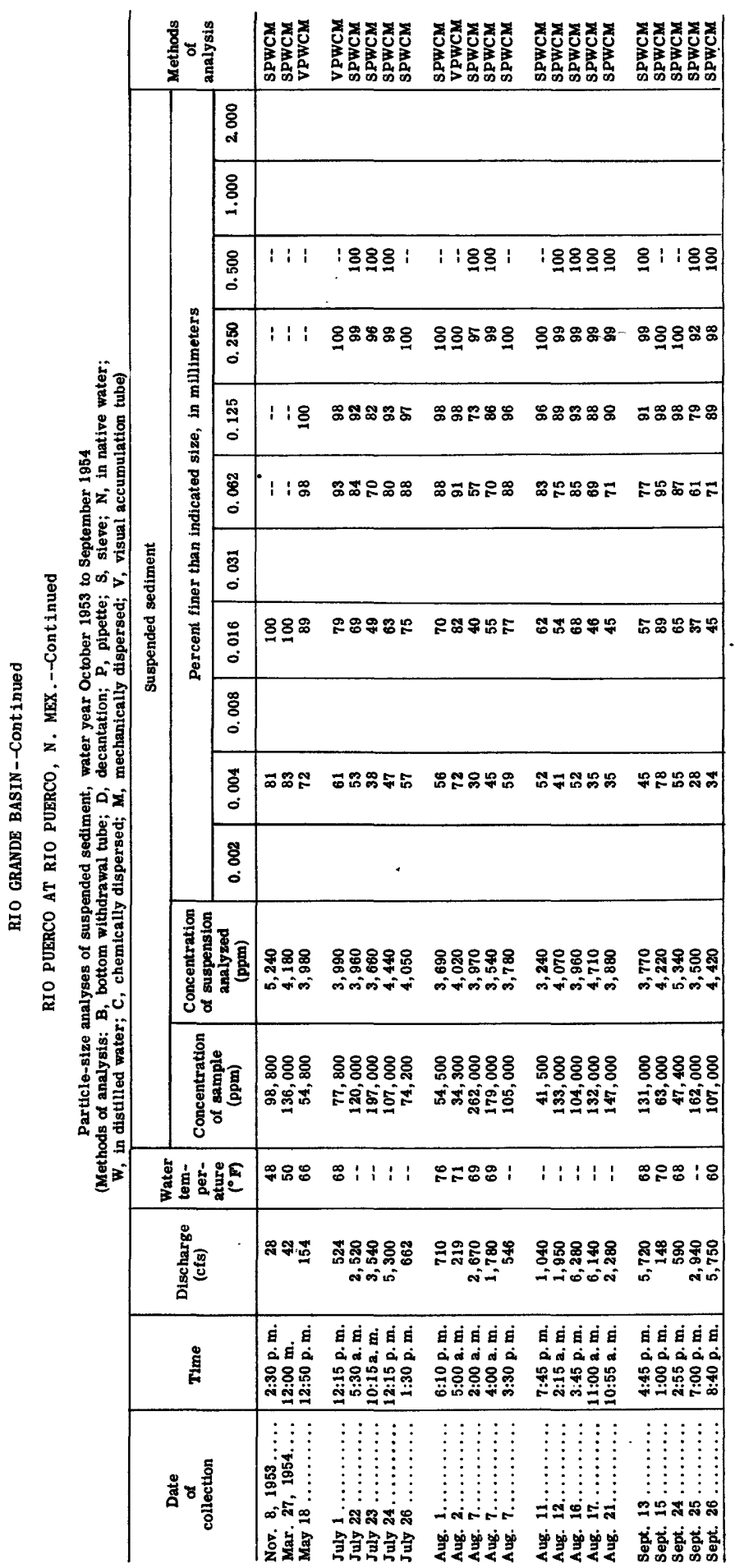


RIO GRANDE BASIN--Continued

RIO PUERCO NEAR BERNARDO, N. MEX.

LOCATION.--At gaging station at bridge on $U$. $S$. Highway $85,1.2$ miles southwest of Bernardo,

Socorro Count y, 3 miles upstream from mouth, and 16 miles south of Belen.
DRAINAGE AREA. - 5,860 square miles, approximately.

RECORDS AVAILABLE. --Sediment records: October 1947 to September 1954.

EXTREMES, 1953-54.--Sediment concentrations: Maximum daily, 172,000 ppm Sept. 26; minimum daily, no flow on many days.

Sediment loads: Maximum daily, 1,740,000 tons Sept. 26; minimum daily, 0 tons on many days. EXTREMES, 1947-54.--Sediment concentrations: Maximum daily, 215,000 ppm July 22, 1949; minimum daily, no flow on many days.

Sediment loads: Maximum daily, 1,740,000 tons Sept. 26, 1954; minimum daily, 0 tons on

many days.
REMARKS.--Maximum observed sediment concentration during water year, 264,000 ppan Aug. 16. No flow during period January to March; tabulation omitted for that period. Records of discharge for water year October 1953 to September 1954 given in WSP 1342.

Suspended sediment, water year October 1953 to September 1954

\begin{tabular}{|c|c|c|c|c|c|c|c|c|c|}
\hline \multirow[b]{3}{*}{ Day } & \multicolumn{3}{|c|}{ October } & \multicolumn{3}{|c|}{ November } & \multicolumn{3}{|c|}{ December } \\
\hline & \multirow[b]{2}{*}{$\begin{array}{c}\text { Mean } \\
\text { dis - } \\
\text { charge } \\
\text { (cfs) }\end{array}$} & \multicolumn{2}{|c|}{ Suspended sediment } & \multirow[b]{2}{*}{$\begin{array}{c}\text { Mean } \\
\text { dis- } \\
\text { charge } \\
\text { (cfs) }\end{array}$} & \multicolumn{2}{|c|}{ Suspended sediment } & \multirow[b]{2}{*}{$\begin{array}{c}\text { Mean } \\
\text { dis- } \\
\text { charge } \\
\text { (cfs) }\end{array}$} & \multicolumn{2}{|c|}{ Suspended sediment } \\
\hline & & $\begin{array}{l}\text { Mean } \\
\text { concen- } \\
\text { tration } \\
\text { (ppm) }\end{array}$ & $\begin{array}{l}\text { Tons } \\
\text { per } \\
\text { day }\end{array}$ & & $\begin{array}{c}\text { Mean } \\
\text { concen- } \\
\text { tration } \\
\text { (ppm) }\end{array}$ & $\begin{array}{l}\text { Tons } \\
\text { per } \\
\text { day }\end{array}$ & & $\begin{array}{c}\text { Mean } \\
\text { concen- } \\
\text { tration } \\
\text { (ppm) }\end{array}$ & $\begin{array}{l}\text { Tons } \\
\text { per } \\
\text { day }\end{array}$ \\
\hline $\begin{array}{l}1 . \ldots \ldots \\
2 \ldots \ldots \\
3 \ldots \ldots \\
4 \ldots \ldots \\
5 \ldots \ldots\end{array}$ & $\begin{array}{l}0 \\
0 \\
0 \\
0 \\
0\end{array}$ & $\begin{array}{l}-- \\
-- \\
-- \\
--\end{array}$ & $\begin{array}{l}0 \\
0 \\
0 \\
0 \\
0\end{array}$ & $\begin{array}{l}0 \\
0 \\
0 \\
0 \\
0\end{array}$ & $\begin{array}{l}-- \\
-- \\
-- \\
-- \\
--\end{array}$ & $\begin{array}{l}0 \\
0 \\
0 \\
0 \\
0\end{array}$ & & & \\
\hline $\begin{array}{r}6 \ldots \ldots \\
7 \ldots \ldots \\
8 \ldots \ldots \\
9 \ldots \ldots \\
10 \ldots \ldots\end{array}$ & $\begin{array}{l}0 \\
0 \\
0 \\
0 \\
0\end{array}$ & $\begin{array}{l}-- \\
-- \\
-- \\
--\end{array}$ & $\begin{array}{l}0 \\
0 \\
0 \\
0 \\
0\end{array}$ & $\begin{array}{r}0 \\
60 \\
113 \\
32 \\
9\end{array}$ & $\begin{array}{r}31,000 \\
135,000 \\
118,000 \\
98,000\end{array}$ & $\begin{array}{r}0 \\
\mathrm{sa} 36,000 \\
\mathrm{~s} 46,000 \\
11,000 \\
2,560\end{array}$ & & & \\
\hline $\begin{array}{l}11 \ldots \ldots \\
12 \ldots \ldots \\
13 . \ldots \ldots \\
14 \ldots \ldots \\
15 \ldots \ldots\end{array}$ & $\begin{array}{l}0 \\
0 \\
0 \\
0 \\
0\end{array}$ & $\begin{array}{l}-- \\
-- \\
-- \\
-- \\
--\end{array}$ & $\begin{array}{l}0 \\
0 \\
0 \\
0 \\
0\end{array}$ & $\begin{array}{r}6 \\
4 \\
1 \\
.5 \\
.2\end{array}$ & $\begin{array}{l}87,000 \\
75,000 \\
54,000 \\
34,000 \\
20,000\end{array}$ & $\begin{array}{r}1,510 \\
840 \\
151 \\
\text { a } 50 \\
\text { a } 10\end{array}$ & & & \\
\hline $\begin{array}{l}16 \ldots \ldots \\
17 \ldots \ldots \\
18 \ldots \ldots \\
19 \ldots \ldots \\
20 \ldots \ldots\end{array}$ & $\begin{array}{l}0 \\
0 \\
0 \\
0 \\
0\end{array}$ & $\begin{array}{l}-- \\
-- \\
-- \\
--\end{array}$ & $\begin{array}{l}0 \\
0 \\
0 \\
0 \\
0\end{array}$ & $\begin{array}{l}.1 \\
0 \\
0 \\
0\end{array}$ & $\begin{array}{r}12,000 \\
-- \\
-- \\
-- \\
=-\end{array}$ & $\begin{array}{l}3 \\
0 \\
0 \\
0 \\
0\end{array}$ & & & \\
\hline $\begin{array}{l}21 \ldots \ldots \\
22 \ldots \ldots \\
23 \ldots \ldots \\
24 \ldots \ldots \\
25 . \ldots \ldots\end{array}$ & $\begin{array}{r}0 \\
0 \\
0 \\
0 \\
25\end{array}$ & $\begin{array}{r}=- \\
-- \\
-- \\
34,000\end{array}$ & $\begin{array}{r}0 \\
0 \\
0 \\
0 \\
\text { sa 12, } 000\end{array}$ & $\begin{array}{l}0 \\
0 \\
0 \\
0 \\
0\end{array}$ & $\begin{array}{l}-- \\
-- \\
-- \\
-- \\
--\end{array}$ & $\begin{array}{l}0 \\
0 \\
0 \\
0 \\
0\end{array}$ & & & \\
\hline $\begin{array}{l}26 . \ldots \ldots \\
27 . \ldots \ldots \\
28 . \ldots \ldots \\
29 \ldots \ldots \\
30 \ldots \ldots \\
31 \ldots \ldots\end{array}$ & $\begin{array}{l}38 \\
8 \\
2 \\
.5 \\
0 \\
0\end{array}$ & $\begin{array}{r}117,000 \\
98,000 \\
65,000 \\
12,000 \\
6,700 \\
-- \\
\end{array}$ & $\begin{array}{r}\mathrm{s} 13,700 \\
2,270 \\
364 \\
16 \\
2 \\
0 \\
\end{array}$ & $\begin{array}{l}0 \\
0 \\
0 \\
0 \\
0 \\
-\end{array}$ & $\begin{array}{l}-- \\
-- \\
-- \\
-- \\
-- \\
--\end{array}$ & $\begin{array}{l}0 \\
0 \\
0 \\
0 \\
0 \\
-\end{array}$ & & & \\
\hline Total. & 73.6 & -- & 28,352 & 225.8 & -- & 98,524 & 0 & & 0 \\
\hline
\end{tabular}

s Computed by subdividing day.

a Computed from estimated concentration graph. 
RIO GRANDE BASIN

RIO GRANDE BASIN--Continued

RIO PUERCO NEAR BERNARDO, N. MEX.--Continued

Suspended sediment, water year October 1953 to September 1954--Continued

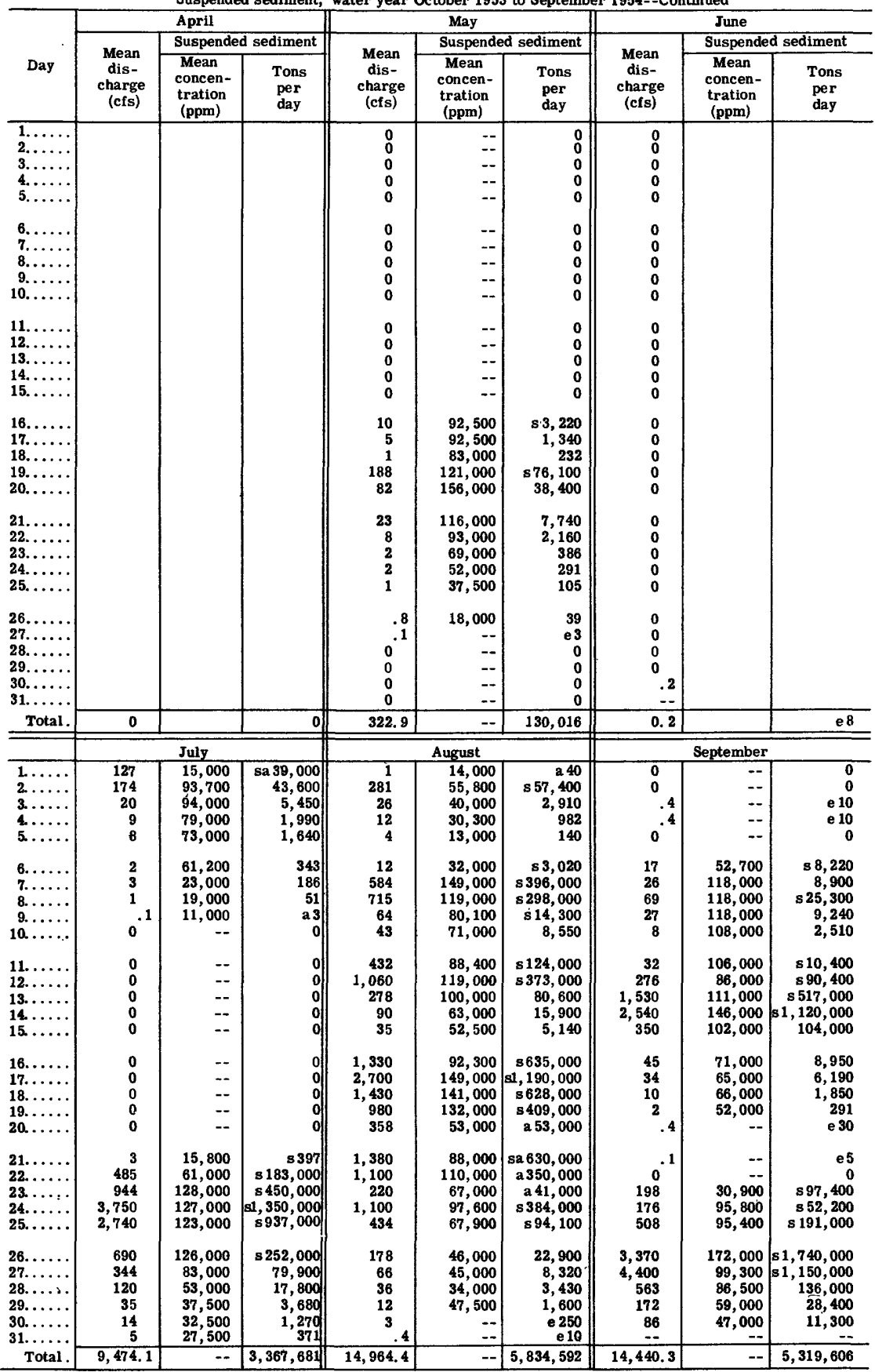

Total discharge for year (cfs-days)

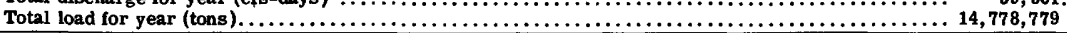

e Estimated.

s Computed by subdividing day.

a Computed from estimated concentration graph. 


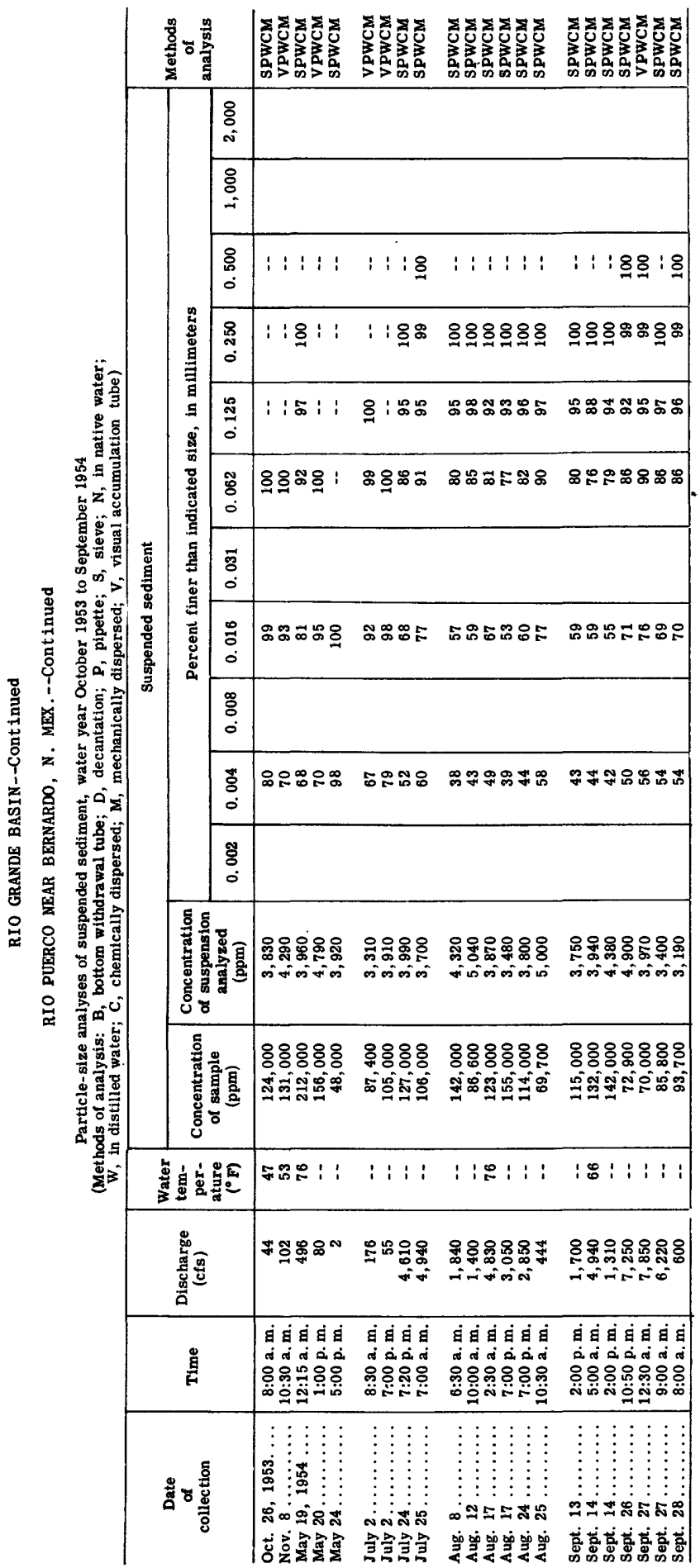


RIO GRANDE BASIN--Continued

RIO SALADO NEAR SAN ACACIA, N. MEX.

LOCATION. --At gaging station, 1 mile upstream from mouth, 2 miles northeast of San Acacia, Socorro County, 1.7 miles downstream from bridge on $U$. S. Highway 85 , and 15 miles north of Socorro.

DRAINAGE AREA. - -1,380 square miles, approximately

RECORDS AVAILABLE, --Sediment records: July 1948 to September 1954

EXTREMES, 1953-54.--Sediment concentrations: Maximum daily, 151,000 ppm July 24; minimum daily, no flow on many days

Sediment loads: Maximum daily, 776,000 tons Sept, 25; minimum daily, 0 tons on many days. EXTREMES, 1948-54.--Sediment concentrations: Maximum daily, 182,000 ppm Aug. 13, 1953; minimum daily, no flow on many days each year.

Sediment loads: Maximum daily, 793,000 tons Aug. 13, 1953; minimum daily, 0 tons on many days each year.

REMARKS. --Maximum observed sediment concentrations during water year, 234,000 ppm July 24. No flow during period Oct. 1 to Apr. 12; tabulation omitted for that period. Records of specific conductance and some temperature observations for individual samples on file in the Albuquerque office. Records of discharge for water year October 1953 to September 1953 given in WSP 1342 .

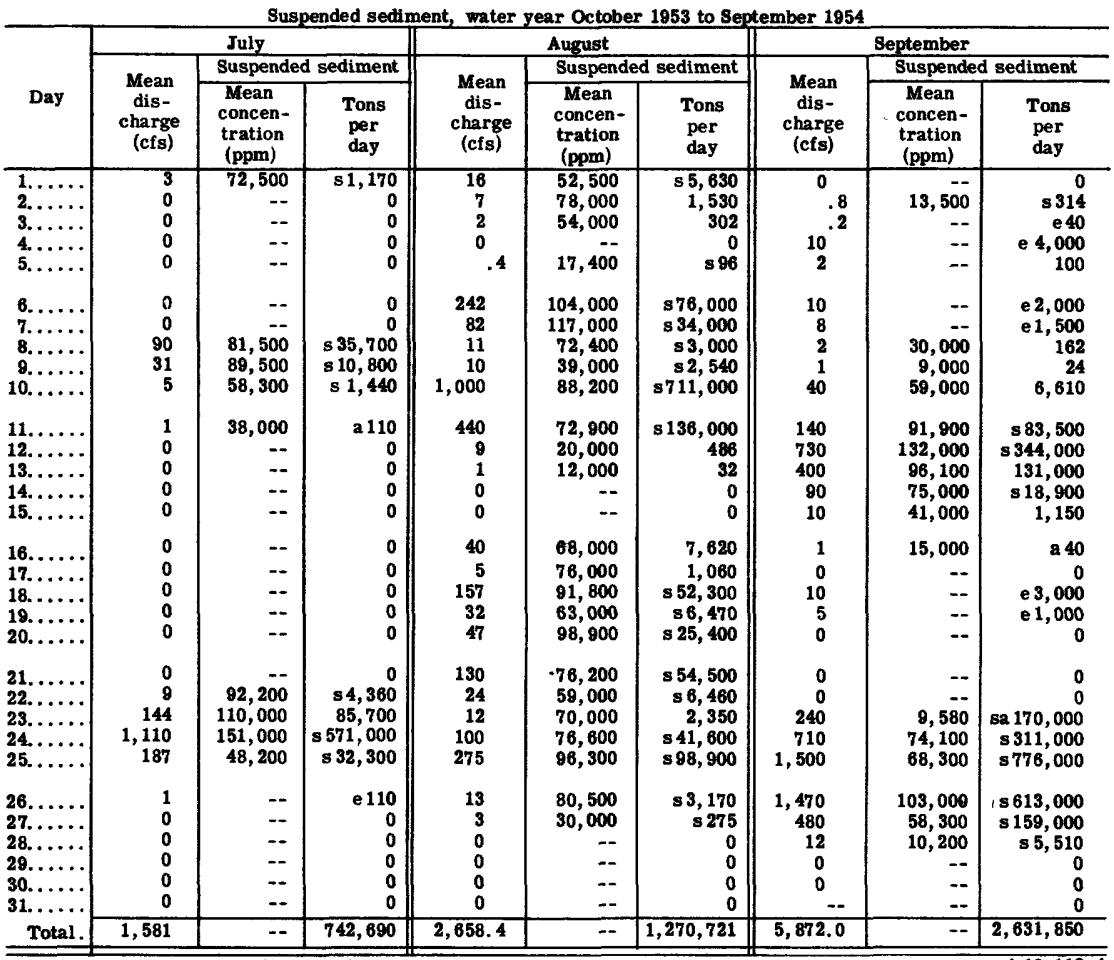

$\ldots \ldots \ldots \ldots \ldots \ldots \ldots \ldots \ldots \ldots \ldots$, b10,12.4

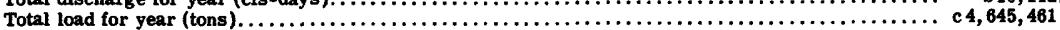

e Estimated.

s Computed by subdividing day.

Computed from estimated concentration graph. b Includes mean discharge of 1 for Apr. 13.

c Includes estimated total of 200 tons for April 


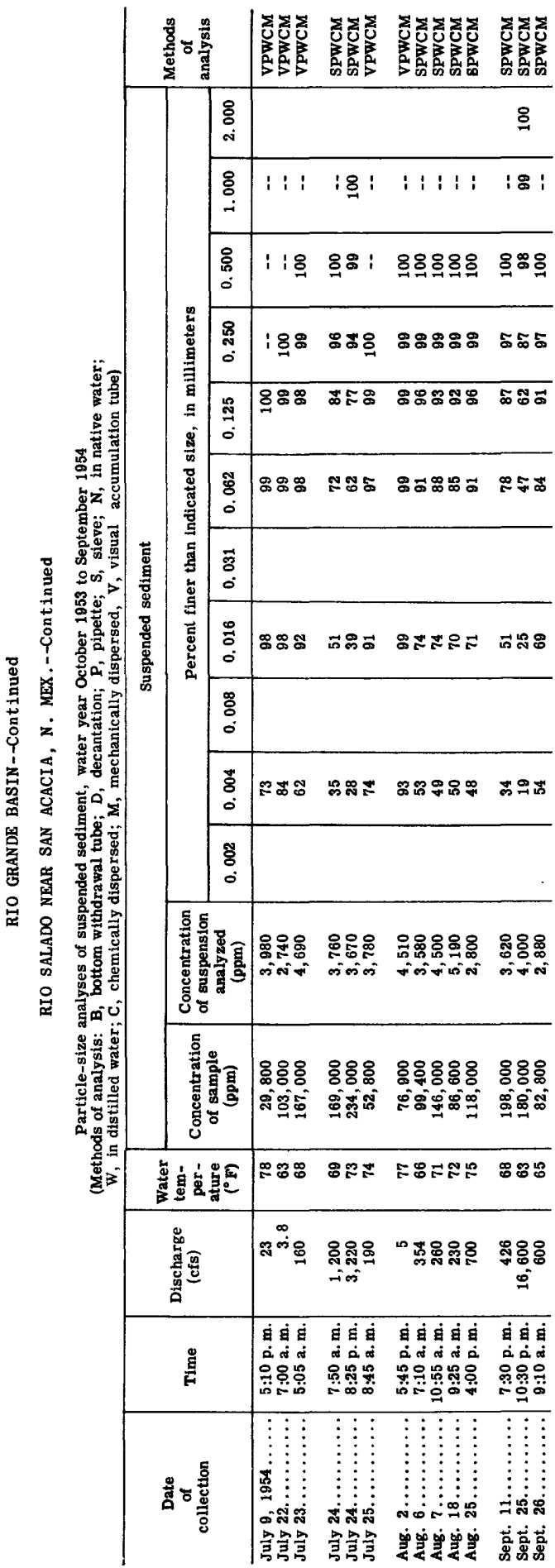


RIO GRANDE BASIN--Continued

SOCORRO MAIN CANAL NORTH AT SAN ACACIA, N. MEX.

LOCATION.--At San Acacia diversion dam, half a mile upstream from canal gaging station, and 0.7 mile east of San Acacia, Socorro County.

RECORDS AVAILABLE. --Sediment records: October 1947 to September 1954

EXTREMES, 1953-54.--Sediment loads: Maximum daily, 43,200 tons Aug. 19; minimun daily,

0 tons on many days.

EXTREMES, 1947-54,--Sediment loads: Maximum daily, 47,900 tons Aug. 12, 1953; minimum

daily, 0 tons on many days

REMARKS.--Records of discharge for water year October 1953 to September 1954 given in WSP 1342 .

Monthly and annual summary of suspended-sediment discharge, water year October 1953 to September 1954

\begin{tabular}{|c|c|c|}
\hline Month & $\begin{array}{l}\text { Discharge } \\
\text { (cfs-days) }\end{array}$ & $\begin{array}{l}\text { Suspended sediment } \\
\text { (tons) }\end{array}$ \\
\hline 1953 & & \\
\hline 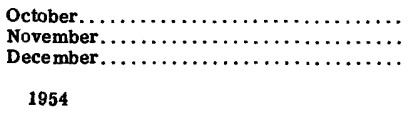 & $\begin{array}{r}157 \\
1,632 \\
419\end{array}$ & $\begin{array}{r}8,674 \\
12,943 \\
6,034\end{array}$ \\
\hline 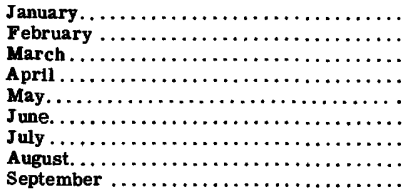 & $\begin{array}{r}0 \\
855 \\
2,855 \\
3,735 \\
4,486 \\
2,089 \\
1,448 \\
2,218 \\
704\end{array}$ & $\begin{array}{r}0 \\
12,433 \\
14,830 \\
19,942 \\
59,308 \\
4,640 \\
182,675 \\
371,966 \\
116,931 \\
\end{array}$ \\
\hline Total for year $\ldots \ldots \ldots \ldots \ldots \ldots \ldots$ & 20,598 & a 810,376 \\
\hline
\end{tabular}

a Total suspended load for Rio Grande at San Acacia diversion dam is the sum of the load for Rio Grande at San Acacia and the load for Socorro main canal north, or 15,517,555 tons. Suspended sediment records for Rio Grande at San Acacia are given on page 427.

488817 O - $59-28$ 


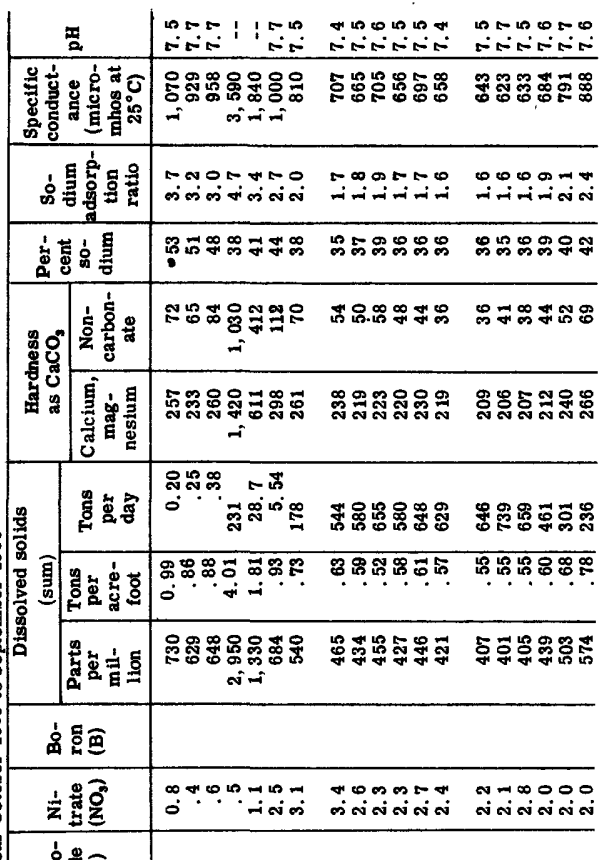

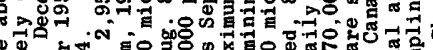
政语

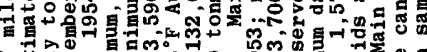

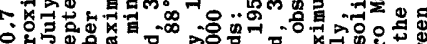

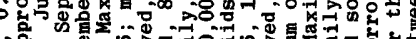

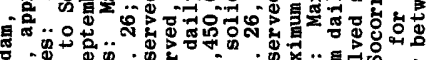

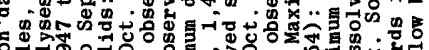

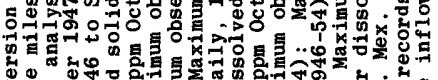

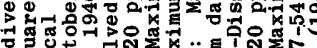
sक

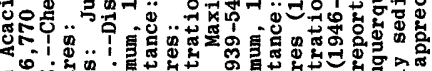

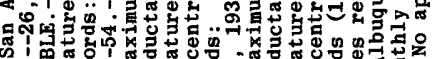

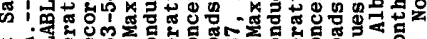

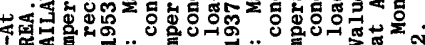

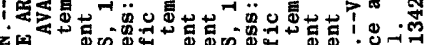

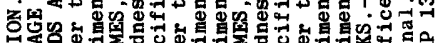

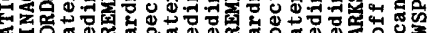

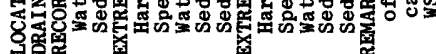

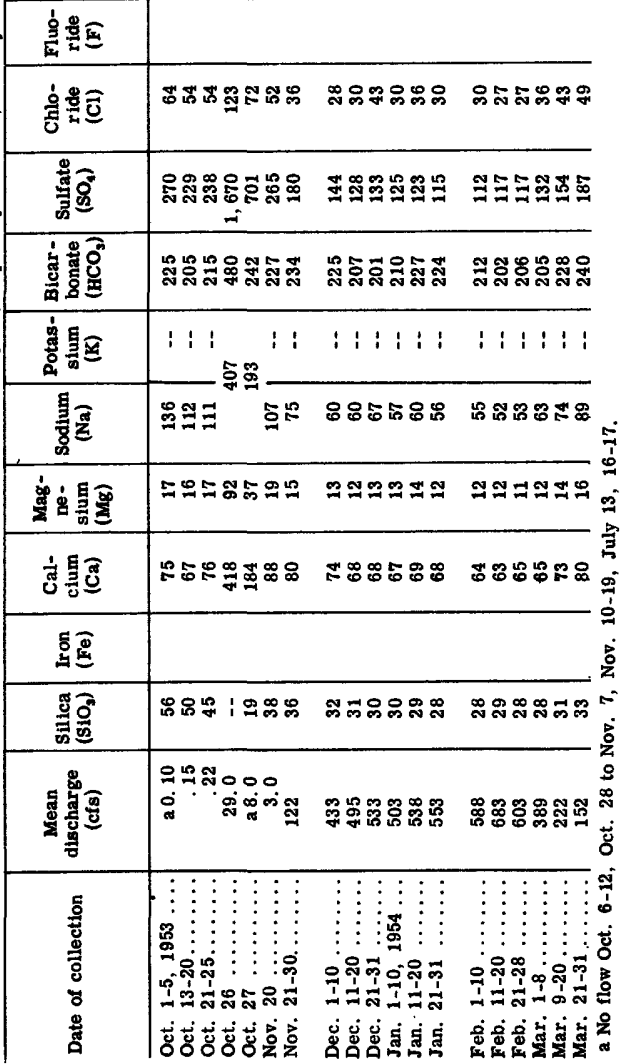




\begin{tabular}{|c|c|c|c|c|}
\hline 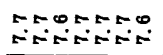 & 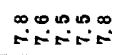 & $\stackrel{\infty}{\leftarrow=\infty}$ & 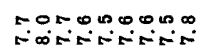 & 1 \\
\hline 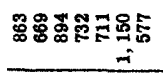 & 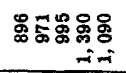 & 융ㅇㅇ용 & 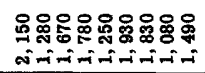 & : \\
\hline 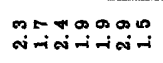 & 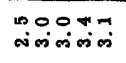 & लिज्ञ & 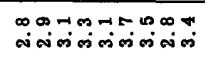 & a \\
\hline 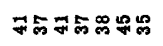 & サ果思果5 & 岁ま & 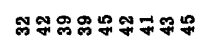 & 우 \\
\hline 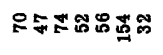 & 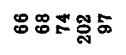 & 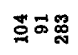 & 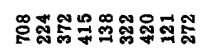 & $\Xi$ \\
\hline 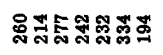 & 芯颌与总 & 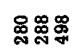 & 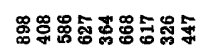 & 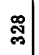 \\
\hline 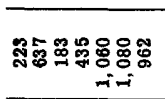 & 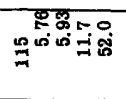 & 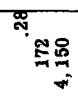 & 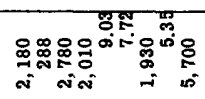 & 원 \\
\hline 우ㅇㅛㅛ & 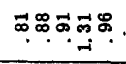 & 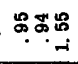 & 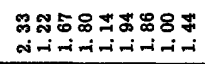 & $\begin{array}{c}\$ \\
5 \\
\dot{0}\end{array}$ \\
\hline 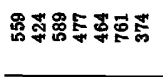 & : & 용욤요 & 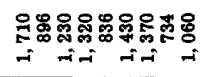 & ฐ \\
\hline 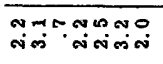 & 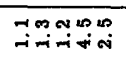 & and & 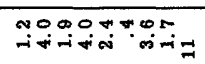 & क \\
\hline 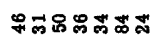 & 品品占染 & $\because 00$ & 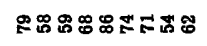 & F \\
\hline 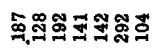 & 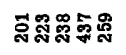 & 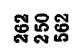 & 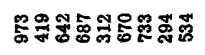 & बं \\
\hline 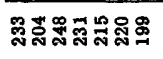 & 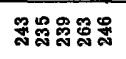 & 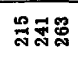 & 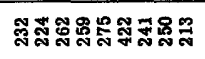 & జึ้ \\
\hline 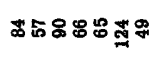 & 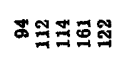 & ్ㅠ్ㅀ్ㅀ & 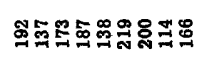 & \& \\
\hline のッேジェの & 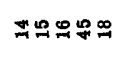 & ニッ゚ & 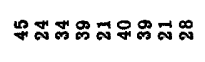 & $\Phi$ \\
\hline ஐタッポ゚サ & ஐ & 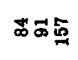 & 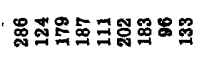 & ‡ \\
\hline 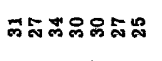 & 为丈유 & 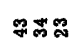 & 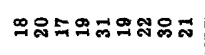 & กั \\
\hline 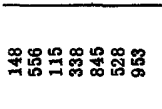 & 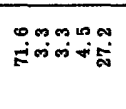 & $\stackrel{n}{\sim}$ & 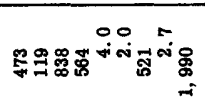 & 离 \\
\hline 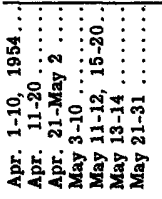 & 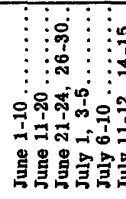 & 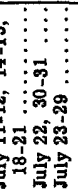 & 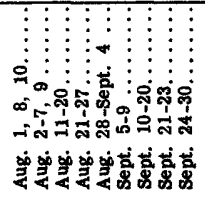 & 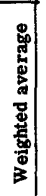 \\
\hline
\end{tabular}


RIO GRANDE BASIN--Continued

RIO GRANDE AT SAN ACACIA, N. MEX,--Continued

Temperature $\left({ }^{\circ} \mathrm{F}\right)$ of water, water year October 1953 to September 1954 Once-daily measurement, usually between $11 \mathrm{a} . \mathrm{m}$. and $6 \mathrm{p} . \mathrm{m} .7$

\begin{tabular}{|c|c|c|c|c|c|c|c|c|c|c|c|c|}
\hline Day & Oct. & Nov. & Dec. & Jan. & Feb. & Mar. & Apr. & May & June & July & Aug. & Sept. \\
\hline $\begin{array}{l}1 \\
2 \\
3 \\
4 \\
5\end{array}$ & $\begin{array}{r}73 \\
76 \\
74 \\
\mathbf{a} 52 \\
72\end{array}$ & $\begin{array}{l}-- \\
-- \\
-- \\
--\end{array}$ & $\begin{array}{r}50 \\
41 \\
\mathrm{a} 34 \\
45 \\
40\end{array}$ & $\begin{array}{r}-77 \\
38 \\
\text { a } 33 \\
40\end{array}$ & $\begin{array}{l}51 \\
52 \\
53 \\
54 \\
55\end{array}$ & $\begin{array}{l}\mathbf{5 5} \\
\mathbf{5 3} \\
\mathbf{5 8} \\
\mathbf{5 5} \\
\mathbf{5 5}\end{array}$ & $\begin{array}{r}61 \\
63 \\
63 \\
\text { a } 49 \\
\text { b } 63\end{array}$ & $\begin{array}{r}52 \\
-- \\
\text { b } 60 \\
\text { b } 69 \\
70\end{array}$ & $\begin{array}{r}a 61 \\
78 \\
b 78 \\
75 \\
a 61\end{array}$ & $\begin{array}{r}\text { b77 } \\
80 \\
79 \\
-- \\
80\end{array}$ & $\begin{array}{r}\text { b } 80 \\
80 \\
74 \\
\text { a } 76\end{array}$ & $\begin{array}{r}\text { a } 65 \\
\text { b } 75 \\
75 \\
76 \\
--\end{array}$ \\
\hline $\begin{array}{r}6 \\
7 \\
8 \\
9 \\
10\end{array}$ & $\begin{array}{l}-- \\
-- \\
-- \\
--\end{array}$ & $\begin{array}{l}-- \\
-- \\
55 \\
--\end{array}$ & $\begin{array}{l}-- \\
-- \\
-- \\
-- \\
--\end{array}$ & $\begin{array}{l}39 \\
42 \\
48 \\
46 \\
--\end{array}$ & $\begin{array}{r}54 \\
240 \\
54 \\
57 \\
57\end{array}$ & $\begin{array}{r}\mathbf{2 4 1} \\
57 \\
58 \\
60 \\
58\end{array}$ & $\begin{array}{l}66 \\
68 \\
61 \\
65 \\
67\end{array}$ & $\begin{array}{r}\text { a } 60 \\
81 \\
\text { a } 61 \\
-- \\
\text { b } 67\end{array}$ & $\begin{array}{r}-- \\
\text { b } 63 \\
78 \\
72 \\
75\end{array}$ & $\begin{array}{r}\text { b79 } \\
78 \\
81 \\
\text { b81 } \\
81\end{array}$ & $\begin{array}{r}\text { b81 } \\
\bar{a} 8 \overline{8} \\
78 \\
\text { b78 }\end{array}$ & $\begin{array}{r}\text { a } 64 \\
\text { b77 } \\
78 \\
\text { b75 } \\
78\end{array}$ \\
\hline $\begin{array}{l}11 \\
12 \\
13 \\
14 \\
15\end{array}$ & $\begin{array}{l}-- \\
-\overline{-} \\
65 \\
63 \\
66\end{array}$ & $\begin{array}{l}-- \\
-- \\
-- \\
-- \\
--\end{array}$ & $\begin{array}{l}-- \\
-- \\
-- \\
--\end{array}$ & $\begin{array}{l}36 \\
35 \\
36 \\
43 \\
45\end{array}$ & $\begin{array}{r}56 \\
56 \\
57 \\
\mathbf{2} 45 \\
52\end{array}$ & $\begin{array}{r}50 \\
\mathrm{a33} \\
50 \\
\overline{49}\end{array}$ & $\begin{array}{r}-- \\
68 \\
68 \\
67 \\
\text { b } 67\end{array}$ & $\begin{array}{r}\text { b } 75 \\
\text { a } 56 \\
79 \\
\text { a } 61 \\
\text { b } 79\end{array}$ & $\begin{array}{r}75 \\
\text { b } 76 \\
-- \\
\text { b } 76 \\
\text { a } 61\end{array}$ & $\begin{array}{r}\text { a } 67 \\
\text { b } 81 \\
- \\
84 \\
\text { a } 69\end{array}$ & $\begin{array}{r}\mathbf{2 6 7} \\
80 \\
\mathrm{a} 78 \\
\mathbf{a} 68 \\
78\end{array}$ & $\begin{array}{r}76 \\
-- \\
78 \\
\text { a } 71 \\
76\end{array}$ \\
\hline $\begin{array}{l}16 \\
17 \\
18 \\
19 \\
20\end{array}$ & $\begin{array}{l}64 \\
65 \\
-- \\
65 \\
64\end{array}$ & $\begin{array}{l}-- \\
-- \\
-- \\
50\end{array}$ & $\begin{array}{l}-- \\
-- \\
-- \\
-- \\
46\end{array}$ & $\begin{array}{l}40 \\
45 \\
45 \\
46 \\
45\end{array}$ & $\begin{array}{l}53 \\
57 \\
55 \\
60 \\
58\end{array}$ & $\begin{array}{r}50 \\
50 \\
50 \\
\mathrm{a} 46 \\
60\end{array}$ & $\begin{array}{r}\text { a } 49 \\
\text { a } 56 \\
68 \\
69 \\
69\end{array}$ & $\begin{array}{r}-- \\
\text { b } 78 \\
\text { b } 68 \\
71 \\
75\end{array}$ & $\begin{array}{r}79 \\
\text { b 79 } \\
\text { b } 79 \\
\text { a } 68 \\
--\end{array}$ & $\begin{array}{r}-- \\
\overline{84} \\
\overline{2} 68\end{array}$ & $\begin{array}{r}\text { a } 68 \\
\text { a } 65 \\
\text { a } 65 \\
-- \\
=-\end{array}$ & $\begin{array}{r}71 \\
\text { a } 63 \\
\text { b } 77 \\
\text { a } 64 \\
75\end{array}$ \\
\hline $\begin{array}{l}21 \\
22 \\
23 \\
24 \\
25\end{array}$ & $\begin{array}{l}62 \\
66 \\
61 \\
64 \\
59\end{array}$ & $\begin{array}{l}45 \\
45 \\
45 \\
49 \\
48\end{array}$ & $\begin{array}{l}42 \\
35 \\
33 \\
36 \\
--\end{array}$ & $\begin{array}{l}45 \\
46 \\
47 \\
45 \\
43\end{array}$ & $\begin{array}{l}-- \\
53 \\
55 \\
55 \\
58\end{array}$ & $\begin{array}{r}65 \\
57 \\
59 \\
\mathrm{a} 47 \\
55\end{array}$ & $\begin{array}{r}\text { b } 69 \\
\text { b } 69 \\
\text { a } 56 \\
70 \\
--\end{array}$ & $\begin{array}{r}70 \\
68 \\
-- \\
\text { a } 59 \\
69\end{array}$ & $\begin{array}{r}80 \\
81 \\
80 \\
\text { b } 80 \\
73\end{array}$ & $\begin{array}{l}-- \\
69 \\
80 \\
81 \\
80\end{array}$ & $\begin{array}{r}-- \\
-- \\
\overline{6} 65 \\
75\end{array}$ & $\begin{array}{l}75 \\
74 \\
-- \\
70 \\
70\end{array}$ \\
\hline $\begin{array}{l}26 \\
27 \\
28 \\
29 \\
30 \\
31\end{array}$ & $\begin{array}{l}51 \\
55 \\
-- \\
-- \\
-- \\
-- \\
\end{array}$ & $\begin{array}{l}-- \\
48 \\
51 \\
50 \\
49 \\
--\end{array}$ & $\begin{array}{l}35 \\
35 \\
36 \\
36 \\
38 \\
36 \\
\end{array}$ & $\begin{array}{l}48 \\
50 \\
51 \\
52 \\
50 \\
--\end{array}$ & $\begin{array}{l}57 \\
55 \\
-- \\
-- \\
-- \\
--\end{array}$ & $\begin{array}{r}a 41 \\
60 \\
-\overline{60} \\
245 \\
45\end{array}$ & $\begin{array}{r}\text { a } 56 \\
71 \\
\text { a } 58 \\
\text { a } 55 \\
\text { b } 60 \\
--\end{array}$ & $\begin{array}{r}\text { b 70 } \\
75 \\
\text { b 76 } \\
76 \\
-- \\
\text { b } 74\end{array}$ & $\begin{array}{r}\text { a } 65 \\
\text { b 80 } \\
81 \\
\text { a 69 } \\
\text { b 78 } \\
--\end{array}$ & $\begin{array}{r}83 \\
83 \\
-- \\
\text { b } 83 \\
\mathbf{a} 66 \\
83\end{array}$ & $\begin{array}{r}\text { a } 65 \\
\text { b } 74 \\
\text { a } 63 \\
- \\
\text { b 74 } \\
77\end{array}$ & $\begin{array}{r}\text { a } 65 \\
67 \\
73 \\
-- \\
68 \\
--\end{array}$ \\
\hline $\begin{array}{c}\text { Aver- } \\
\text { age }\end{array}$ & 64 & 49 & -- & 43 & 54 & 52 & 63 & 69 & 74 & 78 & - & 72 \\
\hline
\end{tabular}

a Measurement before 11 a. $\mathrm{m}$

b Measurement after $6 \mathrm{p} . \mathrm{m}$. 
RIO GRANDE BASIN--Continued

RIO GRANDE AT SAN ACACIA, N. MEX.--Continued

Suspended sediment, water year October 1953 to September 1954

\begin{tabular}{|c|c|c|c|c|c|c|c|c|c|}
\hline \multirow[b]{3}{*}{ Day } & \multicolumn{3}{|c|}{ October } & \multicolumn{3}{|c|}{ November } & \multicolumn{3}{|c|}{ December } \\
\hline & \multirow[b]{2}{*}{$\begin{array}{c}\text { Mean } \\
\text { dis- } \\
\text { charge } \\
\text { (cfs) }\end{array}$} & \multicolumn{2}{|c|}{ Suspended sediment } & \multirow[b]{2}{*}{$\begin{array}{c}\text { Mean } \\
\text { dis- } \\
\text { charge } \\
\text { (cfs) }\end{array}$} & \multicolumn{2}{|c|}{ Suspended sediment } & \multirow[b]{2}{*}{$\begin{array}{c}\text { Mean } \\
\text { dis- } \\
\text { charge } \\
\text { (cfs) }\end{array}$} & \multicolumn{2}{|c|}{ Suspended sediment } \\
\hline & & $\begin{array}{l}\text { Mean } \\
\text { ccncen- } \\
\text { tration } \\
\text { (jpm) }\end{array}$ & $\begin{array}{l}\text { Tons } \\
\text { per } \\
\text { day }\end{array}$ & & $\begin{array}{l}\text { Mean } \\
\text { concen- } \\
\text { tration } \\
\text { (ppm) }\end{array}$ & $\begin{array}{l}\text { Tons } \\
\text { per } \\
\text { day }\end{array}$ & & $\begin{array}{l}\text { Mean } \\
\text { concen- } \\
\text { tration } \\
\text { (ppm) }\end{array}$ & $\begin{array}{l}\text { Tons } \\
\text { per } \\
\text { day }\end{array}$ \\
\hline $\begin{array}{l}1 \ldots \ldots \\
2 \ldots \ldots \\
3 \ldots \ldots \\
4 \ldots \ldots \\
5 \ldots \ldots\end{array}$ & $\begin{array}{r}0.1 \\
.1 \\
.1 \\
.1 \\
.1\end{array}$ & $\begin{array}{l}288 \\
425 \\
458 \\
150 \\
167\end{array}$ & $\begin{array}{l}(t) \\
(t) \\
(t) \\
(t) \\
(t)\end{array}$ & $\begin{array}{l}0 \\
0 \\
0 \\
0 \\
0\end{array}$ & $\begin{array}{l}-- \\
-- \\
-- \\
-- \\
--\end{array}$ & $\begin{array}{l}0 \\
0 \\
0 \\
0 \\
0\end{array}$ & $\begin{array}{l}270 \\
285 \\
321 \\
371 \\
438\end{array}$ & $\begin{array}{l}4,500 \\
4,960 \\
5,200 \\
5,800 \\
8,400\end{array}$ & $\begin{array}{l}3,280 \\
3,820 \\
4,510 \\
5,810 \\
9,930\end{array}$ \\
\hline $\begin{array}{r}6 \ldots \ldots \\
7 \ldots \ldots \\
8 \ldots \ldots \\
9 \ldots \ldots \\
10 \ldots \ldots\end{array}$ & $\begin{array}{l}0 \\
0 \\
0 \\
0 \\
0\end{array}$ & $\begin{array}{l}-- \\
-- \\
-- \\
--\end{array}$ & $\begin{array}{l}0 \\
0 \\
0 \\
0 \\
0\end{array}$ & $\begin{array}{rr}0 & \\
0 \\
33 & \\
& 1 \\
& 0\end{array}$ & $\begin{array}{l}-- \\
-- \\
-- \\
-- \\
--\end{array}$ & $\begin{array}{r}0 \\
0 \\
\mathrm{~b} 4,500 \\
(\mathrm{~b})(\mathrm{t}) \\
0\end{array}$ & $\begin{array}{l}544 \\
569 \\
578 \\
512 \\
438\end{array}$ & $\begin{array}{r}9,000 \\
11,400 \\
5,890 \\
5,580 \\
6,000\end{array}$ & $\begin{array}{r}13,000 \\
17,500 \\
9,190 \\
7,710 \\
7,100\end{array}$ \\
\hline $\begin{array}{l}11 \ldots \ldots \\
12 \ldots \ldots \\
13 \ldots \ldots \\
14 \ldots \ldots \\
15 \ldots \ldots\end{array}$ & $\begin{array}{l}0 \\
0 \\
.1 \\
.1 \\
.1\end{array}$ & $\begin{array}{r}-- \\
305 \\
180 \\
174\end{array}$ & $\begin{array}{r}0 \\
0 \\
(t) \\
(t) \\
(t)\end{array}$ & $\begin{array}{l}0 \\
0 \\
0 \\
0 \\
0\end{array}$ & $\begin{array}{l}-- \\
-- \\
-- \\
--\end{array}$ & $\begin{array}{l}0 \\
0 \\
0 \\
0 \\
0\end{array}$ & $\begin{array}{l}417 \\
431 \\
445 \\
473 \\
512\end{array}$ & $\begin{array}{l}6,600 \\
7,400 \\
4,580 \\
1,900 \\
4,000\end{array}$ & $\begin{array}{l}7,430 \\
8,610 \\
5,500 \\
2,430 \\
5,530\end{array}$ \\
\hline $\begin{array}{l}16 \ldots \ldots \\
17 \ldots \ldots \\
18 \ldots \ldots \\
19 . \ldots \ldots \\
20 . \ldots \ldots\end{array}$ & $\begin{array}{l}.1 \\
.2 \\
.2 \\
.2 \\
.2\end{array}$ & $\begin{array}{l}195 \\
260 \\
350 \\
319 \\
331\end{array}$ & $\begin{array}{l}(t) \\
(t) \\
(t) \\
(t) \\
(t)\end{array}$ & $\begin{array}{l}0 \\
0 \\
0 \\
0 \\
3\end{array}$ & $\begin{array}{r}- \\
- \\
-- \\
2,620\end{array}$ & $\begin{array}{r}0 \\
0 \\
0 \\
0 \\
21\end{array}$ & $\begin{array}{l}\mathbf{5 2 0} \\
\mathbf{5 2 0} \\
\mathbf{5 2 0} \\
\mathbf{5 2 8} \\
\mathbf{5 8 7}\end{array}$ & $\begin{array}{r}3,400 \\
2,900 \\
3,460 \\
7,200 \\
13,100\end{array}$ & $\begin{array}{r}4,770 \\
4,070 \\
4,860 \\
10,300 \\
20,800\end{array}$ \\
\hline $\begin{array}{l}21 \ldots \ldots \\
22 \ldots \ldots \\
23 . \ldots \ldots \\
24 \ldots \ldots \\
25 . \ldots \ldots\end{array}$ & $\begin{array}{l}.2 \\
.3 \\
.2 \\
.2 \\
.2\end{array}$ & $\begin{array}{l}273 \\
271 \\
230 \\
230 \\
249\end{array}$ & $\begin{array}{l}(\mathrm{t}) \\
(\mathrm{t}) \\
(\mathrm{t}) \\
(\mathrm{t}) \\
(\mathrm{t})\end{array}$ & \begin{tabular}{r|}
$\mathbf{3 3}$ \\
$\mathbf{6 5}$ \\
$\mathbf{6 7}$ \\
88 \\
138
\end{tabular} & $\begin{array}{r}3,090 \\
19,900 \\
5,000 \\
4,600 \\
4,250\end{array}$ & $\begin{array}{r}275 \\
\mathrm{~s} 4,920 \\
904 \\
1,090 \\
1,580\end{array}$ & $\begin{array}{l}\mathbf{5 7 8} \\
\mathbf{5 5 2} \\
\mathbf{5 6 0} \\
\mathbf{5 6 0} \\
\mathbf{5 6 9}\end{array}$ & $\begin{array}{l}9,600 \\
4,100 \\
6,180 \\
4,950 \\
2,500\end{array}$ & $\begin{array}{r}15,000 \\
6,110 \\
9,340 \\
7,480 \\
\text { a3, 800 }\end{array}$ \\
\hline $\begin{array}{l}26 \ldots \ldots \\
27 . \ldots \ldots \\
28 . \ldots \ldots \\
29 . \ldots \ldots \\
30 \ldots \ldots \\
31 . \ldots \ldots\end{array}$ & $\begin{array}{r}29 \\
8 \\
0 \\
0 \\
0 \\
0\end{array}$ & $\begin{array}{r}102,000 \\
95,500 \\
-- \\
=- \\
-- \\
--\end{array}$ & $\begin{array}{r}\mathrm{s} 11,300 \\
\mathrm{~s} 2,670 \\
0 \\
0 \\
0 \\
0\end{array}$ & $\begin{array}{r}190 \\
126 \\
124 \\
172 \\
215 \\
--\end{array}$ & $\begin{array}{r}2,800 \\
3,500 \\
3,800 \\
4,100 \\
4,200 \\
--\end{array}$ & $\begin{array}{r}\text { a } 1,400 \\
1,190 \\
1,270 \\
1,900 \\
2,440 \\
-\end{array}$ & $\begin{array}{l}544 \\
480 \\
488 \\
512 \\
528 \\
488 \\
\end{array}$ & $\begin{array}{l}2,400 \\
2,600 \\
7,290 \\
5,780 \\
6,200 \\
2,700\end{array}$ & $\begin{array}{l}3,530 \\
3,370 \\
9,610 \\
7,990 \\
8,840 \\
3,560\end{array}$ \\
\hline \multirow[t]{2}{*}{ Total. } & 39.8 & $\cdots$ & 13,972 & $1,254.1$ & - & 21,490 & 15,138 & - & 234,780 \\
\hline & \multicolumn{3}{|c|}{ January } & \multicolumn{3}{|c|}{ February } & \multicolumn{3}{|c|}{ March } \\
\hline $\begin{array}{l}1 \ldots \ldots \\
2 \ldots \\
3 \ldots \\
4 \ldots \\
5 \ldots\end{array}$ & $\begin{array}{l}480 \\
488 \\
488 \\
488 \\
480\end{array}$ & $\begin{array}{l}3,600 \\
4,600 \\
2,200 \\
7,550 \\
9,600\end{array}$ & $\begin{array}{r}\mathrm{a} 4,700 \\
6,060 \\
2,900 \\
9,950 \\
12,400\end{array}$ & $\begin{array}{l}578 \\
560 \\
569 \\
578 \\
596\end{array}$ & $\begin{array}{l}3,580 \\
4,300 \\
3,570 \\
4,800 \\
6,700\end{array}$ & $\begin{array}{r}5,590 \\
6,500 \\
5,480 \\
7,490 \\
10,800\end{array}$ & $\begin{array}{l}810 \\
560 \\
416 \\
340 \\
295\end{array}$ & $\begin{array}{l}6,700 \\
4,000 \\
3,000 \\
2,730 \\
2,070\end{array}$ & $\begin{array}{r}14,700 \\
6,050 \\
3,370 \\
2,510 \\
1,650\end{array}$ \\
\hline $\begin{array}{r}6 \ldots \ldots \\
7 \ldots \ldots \\
8 \ldots \ldots \\
9 \ldots \\
10 \ldots \ldots\end{array}$ & $\begin{array}{l}473 \\
480 \\
544 \\
552 \\
560\end{array}$ & $\begin{array}{l}4,830 \\
1,900 \\
2,930 \\
2,900 \\
1,500\end{array}$ & $\begin{array}{r}6,170 \\
2,460 \\
4,300 \\
4,320 \\
\text { a } 2,300\end{array}$ & $\begin{array}{l}605 \\
623 \\
605 \\
578 \\
587\end{array}$ & $\begin{array}{l}6,800 \\
6,900 \\
5,970 \\
4,350 \\
5,640\end{array}$ & $\begin{array}{r}11,100 \\
11,600 \\
9,750 \\
6,790 \\
8,940\end{array}$ & $\begin{array}{l}280 \\
240 \\
170 \\
160 \\
145\end{array}$ & $\begin{array}{l}1,290 \\
1,300 \\
1,580 \\
1,610 \\
1,590\end{array}$ & $\begin{array}{l}976 \\
842 \\
725 \\
696 \\
622\end{array}$ \\
\hline $\begin{array}{l}11 \ldots \ldots \\
12 . \ldots \ldots \\
13 . \ldots \ldots \\
14 . \ldots \ldots \\
15 . \ldots \ldots\end{array}$ & $\begin{array}{l}\mathbf{5 6 0} \\
\mathbf{5 2 0} \\
\mathbf{5 6 0} \\
\mathbf{5 2 0} \\
\mathbf{5 2 8}\end{array}$ & $\begin{array}{l}2,900 \\
3,500 \\
4,660 \\
3,220 \\
3,200\end{array}$ & $\begin{array}{l}4,380 \\
4,910 \\
7,050 \\
4,520 \\
4,560\end{array}$ & $\begin{array}{l}623 \\
614 \\
614 \\
632 \\
650\end{array}$ & $\begin{array}{l}3,890 \\
2,560 \\
5,200 \\
6,570 \\
7,520\end{array}$ & $\begin{array}{r}6,540 \\
4,240 \\
8,620 \\
11,200 \\
13,200\end{array}$ & $\begin{array}{l}140 \\
115 \\
105 \\
342 \\
496\end{array}$ & $\begin{array}{l}2,020 \\
1,000 \\
1,300 \\
1,700 \\
2,160\end{array}$ & $\begin{array}{r}764 \\
310 \\
369 \\
\text { a } 1,600 \\
2,890\end{array}$ \\
\hline $\begin{array}{l}16 \ldots \ldots \\
17 \ldots \ldots \\
18 \ldots \ldots \\
19 \ldots \ldots \\
20 . \ldots \ldots\end{array}$ & $\begin{array}{l}\mathbf{5 2 0} \\
\mathbf{5 4 4} \\
\mathbf{5 6 9} \\
\mathbf{5 5 2} \\
\mathbf{5 1 2}\end{array}$ & $\begin{array}{l}2,650 \\
4,300 \\
4,500 \\
5,420 \\
9,800\end{array}$ & $\begin{array}{r}3,720 \\
6,320 \\
6,910 \\
8,080 \\
13,500\end{array}$ & $\begin{array}{l}623 \\
810 \\
790 \\
760 \\
713\end{array}$ & $\begin{array}{l}4,460 \\
5,100 \\
7,550 \\
5,000 \\
5,400\end{array}$ & $\begin{array}{r}7,500 \\
11,200 \\
16,100 \\
a 10,000 \\
10,400\end{array}$ & $\begin{array}{r}400 \\
240 \\
240 \\
190 \\
97\end{array}$ & $\begin{array}{l}2,410 \\
2,550 \\
1,320 \\
1,880 \\
1,230\end{array}$ & $\begin{array}{r}2,600 \\
1,650 \\
855 \\
964 \\
322\end{array}$ \\
\hline $\begin{array}{l}21 \ldots \ldots \\
22 \ldots \ldots \\
23 . \ldots \ldots \\
24 \ldots \ldots \\
25 \ldots \ldots\end{array}$ & $\begin{array}{l}\mathbf{5 3 6} \\
\mathbf{5 6 0} \\
\mathbf{5 7 8} \\
\mathbf{5 4 4} \\
\mathbf{5 3 6}\end{array}$ & $\begin{array}{l}7,700 \\
2,400 \\
2,520 \\
2,400 \\
4,210\end{array}$ & $\begin{array}{r}11,100 \\
3,630 \\
3,930 \\
3,530 \\
6,090\end{array}$ & $\begin{array}{l}686 \\
605 \\
614 \\
605 \\
560\end{array}$ & $\begin{array}{l}6,100 \\
5,500 \\
5,800 \\
7,600 \\
5,220\end{array}$ & $\begin{array}{r}a 11,000 \\
8,980 \\
9,620 \\
12,400 \\
7,890\end{array}$ & $\begin{array}{l}85 \\
66 \\
52 \\
66 \\
60\end{array}$ & $\begin{array}{r}1,110 \\
1,100 \\
690 \\
690 \\
930\end{array}$ & $\begin{array}{r}255 \\
196 \\
97 \\
123 \\
151\end{array}$ \\
\hline $\begin{array}{l}26 \ldots \ldots \\
27 \ldots \ldots \\
28 \ldots \ldots \\
29 \ldots \ldots \\
30 \ldots \ldots \\
31 \ldots \ldots\end{array}$ & $\begin{array}{l}\mathbf{5 4 4} \\
\mathbf{5 5 2} \\
\mathbf{5 5 2} \\
\mathbf{5 6 0} \\
\mathbf{5 5 2} \\
\mathbf{5 6 9} \\
\end{array}$ & $\begin{array}{l}4,100 \\
3,160 \\
4,210 \\
4,600 \\
6,400 \\
3,200 \\
\end{array}$ & $\begin{array}{r}6,020 \\
4,710 \\
6,280 \\
6,960 \\
9,540 \\
24,900 \\
\end{array}$ & $\begin{array}{r}560 \\
569 \\
623 \\
-- \\
-- \\
- \\
\end{array}$ & $\begin{array}{r}3,400 \\
5,280 \\
8,700 \\
-- \\
-- \\
-\end{array}$ & $\begin{array}{r}5,140 \\
8,110 \\
\mathrm{a} 15,000 \\
-- \\
-\cdots\end{array}$ & $\begin{array}{r}56 \\
105 \\
250 \\
310 \\
325 \\
295 \\
\end{array}$ & $\begin{array}{r}740 \\
1,660 \\
1,800 \\
2,950 \\
3,790 \\
2,580 \\
\end{array}$ & $\begin{array}{r}112 \\
471 \\
\text { a } 1,200 \\
2,470 \\
3,330 \\
2,050\end{array}$ \\
\hline Total. & 16,501 & - & 186,200 & 17,530 & -- & 261,180 & 7,451 & $\ldots$ & 54,920 \\
\hline
\end{tabular}

$s$ Computed by subdivided day method.

$t$ Less than 0.50 ton.

a Computed from estimated concentration graph.

b Computed from water -sediment discharge curve. 
RIO GRANDE BASIN--Continued

RIO GRANDE AT SAN ACACIA, N. MEX.--Continued

Suspended sediment, water year October 1953 to September 1954--Continued

\begin{tabular}{|c|c|c|c|c|c|c|c|c|c|}
\hline \multirow[b]{3}{*}{ Day } & \multicolumn{3}{|c|}{ April } & \multicolumn{3}{|c|}{ May } & \multicolumn{3}{|c|}{ June } \\
\hline & \multirow[b]{2}{*}{$\begin{array}{l}\text { Mean } \\
\text { dis- } \\
\text { charge } \\
\text { (cfs) }\end{array}$} & \multicolumn{2}{|c|}{ Suspended sediment } & \multirow[b]{2}{*}{$\begin{array}{c}\text { Mean } \\
\text { dis- } \\
\text { charge } \\
(\mathrm{cfs})\end{array}$} & \multicolumn{2}{|c|}{ Suspended sediment } & \multirow[b]{2}{*}{$\begin{array}{l}\text { Mean } \\
\text { dis- } \\
\text { charge } \\
\text { (cfs) }\end{array}$} & \multicolumn{2}{|c|}{ Suspended sediment } \\
\hline & & $\begin{array}{c}\text { Mean } \\
\text { concen- } \\
\text { tration } \\
\text { (ppm) }\end{array}$ & $\begin{array}{l}\text { Tons } \\
\text { per } \\
\text { day }\end{array}$ & & $\begin{array}{c}\text { Mean } \\
\text { concen } \\
\text { tration } \\
\text { (ppm) }\end{array}$ & $\begin{array}{l}\text { Tons } \\
\text { per } \\
\text { day }\end{array}$ & & $\begin{array}{c}\text { Mean } \\
\text { concen- } \\
\text { tration } \\
\text { (ppm) }\end{array}$ & $\begin{array}{l}\text { Tons } \\
\text { per } \\
\text { day }\end{array}$ \\
\hline $\begin{array}{l}1 \ldots \ldots \\
2 \ldots \ldots \\
3 \ldots \ldots \\
4 \ldots \ldots \\
5 \ldots \ldots\end{array}$ & $\begin{array}{l}200 \\
150 \\
110 \\
200 \\
250\end{array}$ & $\begin{array}{l}1,840 \\
1,260 \\
1,050 \\
1,140 \\
1,590\end{array}$ & $\begin{array}{r}994 \\
510 \\
312 \\
616 \\
1,070\end{array}$ & $\begin{array}{r}43 \\
44 \\
490 \\
596 \\
650\end{array}$ & $\begin{array}{r}600 \\
590 \\
2,330 \\
3,200 \\
3,120\end{array}$ & $\begin{array}{r}70 \\
\mathrm{a} 70 \\
\mathrm{~s} 6,170 \\
5,150 \\
5,480\end{array}$ & $\begin{array}{r}390 \\
195 \\
76 \\
26 \\
8\end{array}$ & $\begin{array}{r}2,900 \\
800 \\
900 \\
690 \\
470\end{array}$ & $\begin{array}{r}3,050 \\
421 \\
185 \\
48 \\
10\end{array}$ \\
\hline $\begin{array}{r}6 \ldots \ldots \\
7 \ldots \ldots \\
8 \ldots \ldots \\
9 \ldots \ldots \\
10 \ldots \ldots\end{array}$ & $\begin{array}{r}120 \\
135 \\
145 \\
97 \\
76\end{array}$ & $\begin{array}{r}1,410 \\
1,400 \\
1,430 \\
1,100 \\
890\end{array}$ & $\begin{array}{l}457 \\
510 \\
560 \\
288 \\
183\end{array}$ & $\begin{array}{l}340 \\
265 \\
135 \\
120 \\
105\end{array}$ & $\begin{array}{r}2,100 \\
1,880 \\
1,580 \\
1,300 \\
900\end{array}$ & $\begin{array}{r}1,930 \\
1,350 \\
576 \\
a 420 \\
255\end{array}$ & $\begin{array}{l}5 \\
4 \\
4 \\
4 \\
4\end{array}$ & $\begin{array}{l}470 \\
510 \\
530 \\
409 \\
379\end{array}$ & $\begin{array}{r}\text { a } 6 \\
6 \\
6 \\
4 \\
4\end{array}$ \\
\hline $\begin{array}{l}11 \ldots \ldots \\
12 \ldots \ldots \\
13 \ldots \ldots \\
14 \ldots \ldots \\
15 \ldots \ldots\end{array}$ & $\begin{array}{r}73 \\
139 \\
704 \\
788 \\
704\end{array}$ & $\begin{array}{r}800 \\
4,780 \\
7,200 \\
4,900 \\
4,100\end{array}$ & $\begin{array}{r}\text { a } 160 \\
\text { s 3, 570 } \\
13,700 \\
10,400 \\
7,790\end{array}$ & $\begin{array}{l}220 \\
325 \\
512 \\
544 \\
596\end{array}$ & $\begin{array}{l}1,200 \\
2,090 \\
4,100 \\
3,780 \\
3,560\end{array}$ & $\begin{array}{r}713 \\
1,830 \\
5,670 \\
5,550 \\
5,730\end{array}$ & $\begin{array}{l}\mathbf{3} \\
\mathbf{3} \\
\mathbf{5} \\
\mathbf{3} \\
\mathbf{3}\end{array}$ & $\begin{array}{l}396 \\
428 \\
430 \\
420 \\
545\end{array}$ & $\begin{array}{r}b \\
3 \\
\mathrm{a} 6 \\
3 \\
4\end{array}$ \\
\hline $\begin{array}{l}16 \ldots \ldots \\
17 \ldots \ldots \\
18 \ldots \ldots \\
18 \ldots \ldots \\
20 \ldots \ldots\end{array}$ & $\begin{array}{l}762 \\
916 \\
650 \\
464 \\
365\end{array}$ & $\begin{array}{l}5,000 \\
3,700 \\
2,500 \\
2,100 \\
2,150\end{array}$ & $\begin{array}{r}10,300 \\
9,200 \\
4,390 \\
2,630 \\
2,120\end{array}$ & $\begin{array}{r}596 \\
834 \\
1,380 \\
1,960 \\
850\end{array}$ & $\begin{array}{r}3,500 \\
4,420 \\
5,130 \\
28,900 \\
20,500\end{array}$ & $\begin{array}{r}\text { a } 5,600 \\
\text { s } 11,700 \\
\text { s } 21,200 \\
\text { s } 177,000 \\
47,000\end{array}$ & $\begin{array}{l}3 \\
3 \\
4 \\
3 \\
3\end{array}$ & $\begin{array}{l}495 \\
300 \\
383 \\
290 \\
300\end{array}$ & $\begin{array}{r}4 \\
2 \\
4 \\
2 \\
\mathbf{a} 2\end{array}$ \\
\hline $\begin{array}{l}21 \ldots \ldots \ldots \\
22 \ldots \ldots \ldots \\
23 \ldots \ldots \ldots \\
24 \ldots \ldots \ldots \\
25 . \ldots \ldots\end{array}$ & $\begin{array}{l}280 \\
265 \\
170 \\
140 \\
125\end{array}$ & $\begin{array}{l}1,800 \\
1,500 \\
1,250 \\
1,200 \\
1,200\end{array}$ & $\begin{array}{r}1,360 \\
1,070 \\
574 \\
454 \\
\text { a } 400\end{array}$ & $\begin{array}{r}740 \\
894 \\
1,210 \\
1,570 \\
1,240\end{array}$ & $\begin{array}{r}11,200 \\
6,000 \\
5,500 \\
5,200 \\
6,400\end{array}$ & $\begin{array}{r}22,400 \\
14,500 \\
\text { a } 18,000 \\
22,000 \\
21,400\end{array}$ & $\begin{array}{r}4 \\
3 \\
3 \\
2 \\
116\end{array}$ & $\begin{array}{r}221 \\
180 \\
160 \\
163 \\
2,680\end{array}$ & $\begin{array}{r}2 \\
1 \\
1 \\
1 \\
\text { s } 3,960\end{array}$ \\
\hline $\begin{array}{l}26 \ldots \ldots \\
27 \ldots \ldots \\
28 \ldots \ldots \\
29 \ldots \ldots \\
30 \ldots \ldots \\
31 \ldots \ldots \\
\end{array}$ & $\begin{array}{l}97 \\
60 \\
68 \\
50 \\
40 \\
-- \\
\end{array}$ & $\begin{array}{r}1,100 \\
710 \\
830 \\
820 \\
800 \\
-- \\
\end{array}$ & $\begin{array}{r}288 \\
115 \\
152 \\
111 \\
86 \\
-- \\
\end{array}$ & $\begin{array}{r}1,080 \\
960 \\
1,010 \\
916 \\
504 \\
358 \\
\end{array}$ & $\begin{array}{l}5,000 \\
5,200 \\
5,000 \\
5,000 \\
4,000 \\
4,600\end{array}$ & $\begin{array}{r}14,600 \\
13,500 \\
13,600 \\
12,400 \\
\text { a } 5,400 \\
3,870 \\
\end{array}$ & $\begin{array}{r}3 \\
4 \\
4 \\
3 \\
4 \\
- \\
\end{array}$ & $\begin{array}{r}1,200 \\
614 \\
170 \\
135 \\
180 \\
\end{array}$ & $\begin{array}{r}10 \\
7 \\
2 \\
1 \\
2 \\
\end{array}$ \\
\hline \multirow[t]{2}{*}{ Total. } & 8,343 & -- & 74,370 & 21,087 & - & 465,134 & 895 & $\ldots$ & 7,760 \\
\hline & \multicolumn{3}{|c|}{ July } & \multicolumn{3}{|c|}{ August } & \multicolumn{3}{|c|}{ September } \\
\hline $\begin{array}{l}1 . \ldots . \\
2 \ldots \ldots \\
3 \ldots \ldots \\
4 \ldots \ldots \\
5 \ldots \ldots\end{array}$ & $\begin{array}{r}4 \\
156 \\
8 \\
3 \\
3\end{array}$ & $\begin{array}{r}160 \\
59,700 \\
30,500 \\
7,100 \\
16,000\end{array}$ & $\begin{array}{r}2 \\
\mathbf{s} 36,900 \\
5934 \\
\text { a } 58 \\
130\end{array}$ & $\begin{array}{r}4 \\
135 \\
9 \\
10 \\
15\end{array}$ & $\begin{array}{r}4,100 \\
46,200 \\
32,500 \\
17,100 \\
3,250\end{array}$ & $\begin{array}{r}\mathrm{a} 44 \\
\mathrm{~s} 24,500 \\
\mathrm{~s} 1,080 \\
\mathrm{~s} 418 \\
\mathrm{~s} 168\end{array}$ & $\begin{array}{l}4 \\
4 \\
3 \\
3 \\
3\end{array}$ & $\begin{array}{r}490 \\
500 \\
5,200 \\
3,500 \\
3,200\end{array}$ & $\begin{array}{r}5 \\
5 \\
42 \\
28 \\
\text { a } 26\end{array}$ \\
\hline $\begin{array}{r}6 . \ldots \ldots \\
7 \ldots \ldots \\
8 \ldots \ldots \\
9 \ldots \ldots \\
10 \ldots \ldots\end{array}$ & $\begin{array}{r}3 \\
2 \\
85 \\
28 \\
18\end{array}$ & $\begin{array}{r}6,000 \\
1,800 \\
29,800 \\
31,500 \\
15,100\end{array}$ & $\begin{array}{r}49 \\
10 \\
\mathrm{~s} 15,500 \\
\mathrm{~s} 3,660 \\
\mathrm{~s} 2,170\end{array}$ & $\begin{array}{l}136 \\
430 \\
924 \\
100 \\
490\end{array}$ & $\begin{array}{r}40,700 \\
103,000 \\
107,000 \\
68,700 \\
84,300\end{array}$ & $\begin{array}{r}\mathrm{s} 23,400 \\
\mathrm{~s} 229,000 \\
\mathrm{~s} 351,000 \\
\mathrm{~s} 30,600 \\
\mathrm{~s} 269,000\end{array}$ & $\begin{array}{r}3 \\
2 \\
1 \\
1 \\
35\end{array}$ & $\begin{array}{l}46,000 \\
45,000 \\
78,000 \\
90,000 \\
97,800\end{array}$ & $\begin{array}{r}386 \\
252 \\
218 \\
261 \\
\mathrm{~s} 11,700\end{array}$ \\
\hline $\begin{array}{l}11 \ldots \ldots \\
12 . \ldots \ldots \\
13 . \ldots \ldots \\
14 . \ldots \ldots \\
15 . \ldots \ldots\end{array}$ & $\begin{array}{r}.2 \\
.2 \\
.1 \\
.1\end{array}$ & $\begin{array}{r}2,900 \\
308 \\
-- \\
299 \\
278\end{array}$ & $\begin{array}{l}(t)^{2} \\
0 \\
(t) \\
(t)\end{array}$ & $\begin{array}{r}950 \\
900 \\
400 \\
35 \\
1\end{array}$ & $\begin{array}{r}91,600 \\
66,800 \\
61,500 \\
20,500 \\
3,000\end{array}$ & $\begin{array}{r}\mathrm{s} 298,000 \\
\mathrm{~s} 179,000 \\
\mathrm{~s} 81,300 \\
\mathrm{~s} 2,560 \\
8\end{array}$ & $\begin{array}{r}285 \\
750 \\
1,540 \\
2,430 \\
580\end{array}$ & $\begin{array}{r}94,600 \\
100,000 \\
120,000 \\
132,000 \\
82,000\end{array}$ & $\begin{array}{r}\mathrm{s} 109,000 \\
\mathrm{sa} 230,000 \\
\mathrm{~s} 556,000 \\
\mathrm{~s} 935,000 \\
\mathrm{~s} 148,000\end{array}$ \\
\hline $\begin{array}{l}16 \ldots \ldots \\
17 . \ldots \ldots \\
18 . \ldots \ldots \\
19 \ldots \ldots \\
20 . \ldots \ldots\end{array}$ & $\begin{array}{l}0 \\
0 \\
.1 \\
.1 \\
.2\end{array}$ & $\begin{array}{r}\ldots \\
200 \\
318 \\
400\end{array}$ & $\begin{array}{c}0 \\
0 \\
(a)(t)^{0} \\
(t) \\
(t)\end{array}$ & $\begin{array}{r}235 \\
2,890 \\
1,680 \\
875 \\
410\end{array}$ & $\begin{array}{r}52,500 \\
118,000 \\
104,000 \\
120,000 \\
71,000\end{array}$ & $\begin{array}{r}\text { s } 104,000 \\
\text { s1,030,000 } \\
8556,000 \\
\text { sa } 330,000 \\
\text { sa } 94,000\end{array}$ & $\begin{array}{r}90 \\
10 \\
6 \\
6 \\
4\end{array}$ & $\begin{array}{r}55,100 \\
35,000 \\
23,000 \\
19,000 \\
5,000\end{array}$ & $\begin{array}{r}\text { s 13, } 500 \\
\text { a } 980 \\
373 \\
308 \\
54\end{array}$ \\
\hline $\begin{array}{l}21 \ldots \ldots \\
22 . \ldots \ldots \\
23 . \ldots \ldots \\
24 \ldots \ldots \\
25 . \ldots .\end{array}$ & $\begin{array}{r}267^{.2} \\
481 \\
4,130 \\
3,650\end{array}$ & $\begin{array}{r}361 \\
37,900 \\
82,200 \\
118,000 \\
90,800\end{array}$ & $\begin{array}{c}(t) \\
s 115,000 \\
s 129,000 \\
s 1400,000 \\
s 978,000\end{array}$ & $\begin{array}{r}760 \\
1,220 \\
270 \\
760 \\
696\end{array}$ & $\begin{array}{l}92,000 \\
86,000 \\
68,000 \\
78,800 \\
56,800\end{array}$ & $\begin{array}{r}\text { s2 } 250,000 \\
\text { sa } 330,000 \\
51,400 \\
\text { s276, 000 } \\
\text { s } 124,000\end{array}$ & $\begin{array}{r}4 \\
2 \\
2 \\
1,420 \\
840\end{array}$ & $\begin{array}{r}1,100 \\
900 \\
44,000 \\
67,000 \\
82,200\end{array}$ & $\begin{array}{r}12 \\
5 \\
246 \\
\text { s } 536,000 \\
\mathrm{~s} 344,000\end{array}$ \\
\hline $\begin{array}{l}26 \ldots \ldots \\
27 \ldots \ldots \\
28 . \ldots \ldots \\
29 . \ldots \ldots \\
30 . \ldots \ldots \\
31 \ldots \ldots\end{array}$ & $\begin{array}{r}795 \\
317 \\
67 \\
6 \\
4 \\
4 \\
\end{array}$ & $\begin{array}{r}83,000 \\
45,100 \\
25,000 \\
23,000 \\
8,000 \\
1,900 \\
\end{array}$ & $\begin{array}{r}185,000 \\
843,300 \\
a 4,500 \\
373 \\
86 \\
21 \\
\end{array}$ & $\begin{array}{r}210 \\
31 \\
6 \\
4 \\
4 \\
4 \\
\end{array}$ & $\begin{array}{r}38,000 \\
29,000 \\
23,000 \\
6,000 \\
10,000 \\
2,000 \\
\end{array}$ & $\begin{array}{r}22,300 \\
2,430 \\
373 \\
\mathrm{a} 65 \\
108 \\
22 \\
\end{array}$ & $\begin{array}{r}4,540 \\
5,770 \\
910 \\
308 \\
143 \\
- \\
\end{array}$ & $\begin{array}{r}102,000 \\
80,800 \\
43,100 \\
29,000 \\
27,000 \\
\end{array}$ & $\begin{array}{r}\$ 1,450,000 \\
1,310,000 \\
\text { s } 131,000 \\
24,100 \\
10,400 \\
\end{array}$ \\
\hline Total. & $10,032.2$ & -- & $2,914,696$ & 14,594 & - & $4,660,776$ & 19,699 & - & $5,811,901$ \\
\hline
\end{tabular}

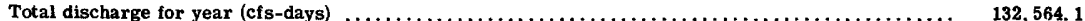

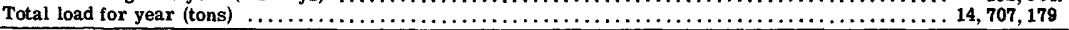

$\mathrm{s}$ Computed by subdivided day method.

$t$ Less than 0.50 ton.

a Computed from estimated concentration graph. 


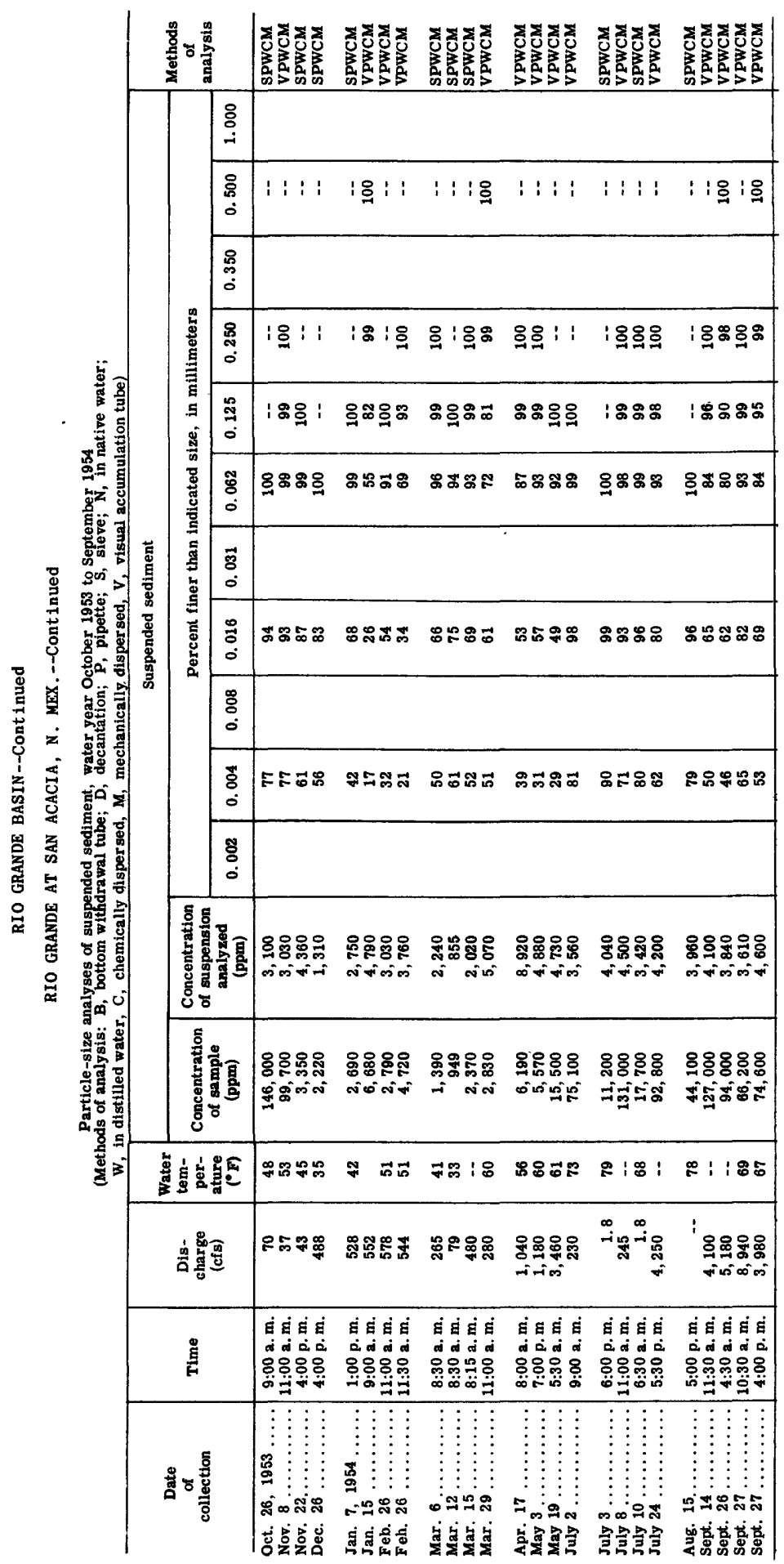




\section{RIO GRANDE BASIN--Continued}

RIO GRANDE AT SAN ANTONIO, N. MEX.

LOCATION.--At gaging station at bridge on U. S. Highway 380 , about 0.9 mile east of San Antonio, Socorro County.

DRAINAGE AREA.--27,400 square miles, approximately (includes 2,940 square miles in closed basin in northern part of San Luis Valley, Colo.).

RECORDS AVAILABLE. --Water temperatures: August 1951 to September 1954.

Sediment records: August 1951 to September 1954

EXTREMES 1953-54.--Water temperatures: Maximum observed, $88^{\circ} \mathrm{F}$ July 3; minimum observed, freezing point Dec. 15, Jan. 2.

Sediment concentrations: Maximum daily, $122,000 \mathrm{ppm}$ Sept. 14; minimum daily, no flow on many days.

Sediment loads: Maximum daily, 1,200,000 tons Sept. 27; minimum daily, 0 tons on many days.

EXTREMES, 1951-54,--Water temperatures: Maximum observed, $95^{\circ} \mathrm{F}$ July 1, 1953 ; minimum observed, freezing point Feb. 2, Dec. 25, 1952 , Dec. 15, 1953, Jan. 3, 1954

Sediment concentrations: Maximum daily, 122,000 ppm Sept. 14, 1954; minimum daily, no flow on many days.

Sediment loads: Maximum daily, 1,200,000 tons Sept. 27, 1954; minimum daily, 0 tons on many days.

REMARKS.--Maximum observed sediment concentration during water year, $142,000 \mathrm{ppm}$ Sept 14. Records of specific conductance of daily samples available in district office at Albuquerque, N. Mex. Records of discharge for water year October 1953 to September 1954 given in WSP 1342. Stage-discharge relation af fected by ice Dec. 11-17, 24-31, Jan. 1-12.

Temperature $\left({ }^{\circ} \mathrm{F}\right)$ of water, water year October 1953 to September 1954 OOnce-datly measurement between $11 \mathrm{a} . \mathrm{m}$. and $6 \mathrm{p} . \mathrm{m}$

\begin{tabular}{|c|c|c|c|c|c|c|c|c|c|c|c|c|}
\hline Day & Oct. & Nov. & Dec. & Jan. & Feb. & Mar. & Apr. & May & June & July & Aug. & Sept. \\
\hline $\begin{array}{l}1 \\
2 \\
3 \\
4 \\
5\end{array}$ & $\begin{array}{l}-- \\
-- \\
-- \\
-- \\
--\end{array}$ & $\begin{array}{l}55 \\
62 \\
65 \\
58 \\
54\end{array}$ & $\begin{array}{l}47 \\
49 \\
46 \\
-- \\
44\end{array}$ & $\begin{array}{l}-- \\
32 \\
33 \\
34 \\
34\end{array}$ & $\begin{array}{l}39 \\
42 \\
48 \\
41 \\
47\end{array}$ & $\begin{array}{r}52 \\
52 \\
46 \\
51 \\
\text { a } 38\end{array}$ & $\begin{array}{r}\text { a } 58 \\
66 \\
\text { a } 63 \\
\text { a } 64 \\
\text { a } 65\end{array}$ & $\begin{array}{l}67 \\
71 \\
-- \\
64 \\
71\end{array}$ & $\begin{array}{r}-- \\
\text { a } 69 \\
73 \\
-- \\
--\end{array}$ & $\begin{array}{l}-- \\
-- \\
88 \\
79 \\
--\end{array}$ & $\begin{array}{l}-- \\
-- \\
-- \\
76\end{array}$ & $\begin{array}{l}-- \\
-- \\
-- \\
--\end{array}$ \\
\hline $\begin{array}{r}6 \\
7 \\
8 \\
9 \\
10\end{array}$ & $\begin{array}{l}-- \\
-- \\
-- \\
--\end{array}$ & $\begin{array}{l}58 \\
60 \\
-- \\
56 \\
56\end{array}$ & $\begin{array}{l}\mathbf{3 4} \\
\mathbf{5 4} \\
\mathbf{3 3} \\
\mathbf{3 4} \\
\mathbf{3 4}\end{array}$ & $\begin{array}{l}-- \\
44 \\
48 \\
42 \\
39\end{array}$ & $\begin{array}{l}44 \\
50 \\
51 \\
52 \\
51\end{array}$ & $\begin{array}{l}-\overline{5} \\
56 \\
59 \\
56\end{array}$ & $\begin{array}{r}\text { a } 66 \\
\text { a } 66 \\
69 \\
66 \\
68\end{array}$ & $\begin{array}{l}69 \\
74 \\
71 \\
69 \\
74\end{array}$ & $\begin{array}{l}-- \\
-- \\
-- \\
--\end{array}$ & $\begin{array}{l}-- \\
-- \\
--\end{array}$ & $\begin{array}{l}79 \\
75 \\
81 \\
72 \\
--\end{array}$ & $\begin{array}{l}-- \\
-- \\
-- \\
-- \\
--\end{array}$ \\
\hline $\begin{array}{l}11 \\
12 \\
13 \\
14 \\
15\end{array}$ & $\begin{array}{l}-- \\
-- \\
-- \\
-- \\
--\end{array}$ & $\begin{array}{l}\mathbf{5 3} \\
54 \\
51 \\
\mathbf{5 3} \\
\mathbf{5 6}\end{array}$ & $\begin{array}{l}-- \\
33 \\
-- \\
41 \\
32\end{array}$ & $\begin{array}{l}46 \\
42 \\
48 \\
40 \\
--\end{array}$ & $\begin{array}{l}41 \\
40 \\
51 \\
54 \\
55\end{array}$ & $\begin{array}{l}51 \\
54 \\
57 \\
56 \\
48\end{array}$ & $\begin{array}{l}67 \\
69 \\
68 \\
67 \\
64\end{array}$ & $\begin{array}{l}72 \\
75 \\
74 \\
69 \\
74\end{array}$ & $\begin{array}{l}-- \\
-- \\
-- \\
--\end{array}$ & $\begin{array}{l}-- \\
-- \\
-- \\
-- \\
--\end{array}$ & $\begin{array}{r}72 \\
73 \\
75 \\
\mathbf{a} 80 \\
82\end{array}$ & $\begin{array}{l}-- \\
74 \\
64 \\
75 \\
64\end{array}$ \\
\hline $\begin{array}{l}16 \\
17 \\
18 \\
19 \\
20\end{array}$ & $\begin{array}{l}-- \\
-- \\
-- \\
--\end{array}$ & $\begin{array}{l}56 \\
64 \\
66 \\
40 \\
38\end{array}$ & $\begin{array}{l}35 \\
-- \\
43 \\
47 \\
48\end{array}$ & $\begin{array}{l}43 \\
41 \\
46 \\
46 \\
48\end{array}$ & $\begin{array}{l}54 \\
49 \\
59 \\
58 \\
54\end{array}$ & $\begin{array}{l}51 \\
50 \\
49 \\
51 \\
47\end{array}$ & $\begin{array}{r}67 \\
71 \\
67 \\
62 \\
\mathrm{a} 71\end{array}$ & $\begin{array}{l}76 \\
76 \\
71 \\
-- \\
72\end{array}$ & $\begin{array}{l}-- \\
-- \\
-- \\
--\end{array}$ & $\begin{array}{l}-- \\
-- \\
-- \\
-- \\
--\end{array}$ & $\begin{array}{r}-- \\
75 \\
72 \\
\text { b } 75 \\
75\end{array}$ & $\begin{array}{r}71 \\
72 \\
70 \\
276 \\
--\end{array}$ \\
\hline $\begin{array}{l}21 \\
22 \\
23 \\
24 \\
25\end{array}$ & $\begin{array}{l}-- \\
-- \\
-- \\
-- \\
--\end{array}$ & $\begin{array}{l}40 \\
51 \\
52 \\
-- \\
49\end{array}$ & $\begin{array}{l}41 \\
38 \\
34 \\
36 \\
39\end{array}$ & $\begin{array}{l}51 \\
45 \\
51 \\
48 \\
48\end{array}$ & $\begin{array}{l}\mathbf{5 6} \\
50 \\
54 \\
54 \\
\mathbf{5 8}\end{array}$ & $\begin{array}{l}58 \\
54 \\
58 \\
61 \\
60\end{array}$ & $\begin{array}{l}\text { a } 64 \\
\text { b } 56 \\
\text { b } 54 \\
\text { b } 63 \\
\text { b } 66\end{array}$ & $\begin{array}{l}74 \\
74 \\
71 \\
69 \\
68\end{array}$ & $\begin{array}{l}-- \\
-- \\
-- \\
--\end{array}$ & $\begin{array}{l}-- \\
-- \\
59 \\
79 \\
83\end{array}$ & $\begin{array}{r}76 \\
\text { b } 68 \\
79 \\
76 \\
\text { b } 64\end{array}$ & $\begin{array}{l}-- \\
-- \\
-- \\
69 \\
72\end{array}$ \\
\hline $\begin{array}{l}26 \\
27 \\
28 \\
29 \\
30 \\
31\end{array}$ & $\begin{array}{l}-- \\
-- \\
-- \\
64 \\
60\end{array}$ & $\begin{array}{l}51 \\
48 \\
53 \\
48 \\
53 \\
--\end{array}$ & $\begin{array}{l}36 \\
35 \\
38 \\
38 \\
41 \\
36\end{array}$ & $\begin{array}{l}-- \\
50 \\
47 \\
48 \\
51 \\
41\end{array}$ & $\begin{array}{l}51 \\
48 \\
56 \\
-- \\
-- \\
--\end{array}$ & $\begin{array}{l}56 \\
59 \\
61 \\
59 \\
61 \\
59\end{array}$ & $\begin{array}{l}69 \\
67 \\
64 \\
73 \\
69 \\
--\end{array}$ & $\begin{array}{l}69 \\
74 \\
68 \\
71 \\
69 \\
75\end{array}$ & $\begin{array}{l}-- \\
-- \\
-- \\
-- \\
--\end{array}$ & $\begin{array}{l}86 \\
86 \\
-- \\
78 \\
81 \\
--\end{array}$ & $\begin{array}{l}76 \\
79 \\
81 \\
-- \\
-- \\
--\end{array}$ & $\begin{array}{r}69 \\
69 \\
72 \\
72 \\
\text { a } 69 \\
--\end{array}$ \\
\hline $\begin{array}{c}\text { Aver- } \\
\text { age }\end{array}$ & - & 54 & 39 & ${ }_{44}$ & 50 & 54 & 66 & 71 & -- & 80 & -- & -- \\
\hline
\end{tabular}

a Measurement after $6 \mathrm{p.m}$

b Measurement before 11 a.m. 
RIO GRANDE BASIN

RIO GRANDE BASIN--Continued

RIO GRANDE AT SAN ANTONIO, N. MEX.--Continued

Suspended sediment, water year October 1953 to September 1954

\begin{tabular}{|c|c|c|c|c|c|c|c|c|c|}
\hline \multirow[b]{3}{*}{ Day } & \multicolumn{3}{|c|}{ October } & \multicolumn{3}{|c|}{ November } & \multicolumn{3}{|c|}{ December } \\
\hline & \multirow[b]{2}{*}{$\begin{array}{c}\text { Mean } \\
\text { dis- } \\
\text { charge } \\
\text { (cfs) }\end{array}$} & \multicolumn{2}{|c|}{ Suspended sediment } & \multirow[b]{2}{*}{$\begin{array}{l}\text { Mean } \\
\text { dis- } \\
\text { charge } \\
\text { (cfs) }\end{array}$} & \multicolumn{2}{|c|}{ Suspended sediment } & \multirow[b]{2}{*}{$\begin{array}{l}\text { Mean } \\
\text { dis- } \\
\text { charge } \\
\text { (cfs) }\end{array}$} & \multicolumn{2}{|c|}{ Suspended sediment } \\
\hline & & $\begin{array}{l}\text { Mean } \\
\text { concen- } \\
\text { tration } \\
\text { (ppm) }\end{array}$ & $\begin{array}{l}\text { Tons } \\
\text { per } \\
\text { day }\end{array}$ & & $\begin{array}{l}\text { Mean } \\
\text { concen- } \\
\text { tration } \\
\text { (ppm) }\end{array}$ & $\begin{array}{l}\text { Tons } \\
\text { per } \\
\text { day }\end{array}$ & & $\begin{array}{l}\text { Mean } \\
\text { concen- } \\
\text { tration } \\
\text { (ppm) }\end{array}$ & $\begin{array}{l}\text { Tons } \\
\text { per } \\
\text { day }\end{array}$ \\
\hline $\begin{array}{l}1 \ldots \ldots \\
2 \ldots \ldots \\
3 \ldots \ldots \\
4 \ldots \ldots \\
5 \ldots \ldots\end{array}$ & $\begin{array}{l}0 \\
0 \\
0 \\
0 \\
0\end{array}$ & $\begin{array}{l}-- \\
-- \\
-- \\
-- \\
--\end{array}$ & $\begin{array}{l}0 \\
0 \\
0 \\
0 \\
0\end{array}$ & $\begin{array}{l}3 \\
5 \\
2 \\
2 \\
2\end{array}$ & $\begin{array}{r}7,000 \\
2,000 \\
500 \\
629 \\
290\end{array}$ & $\begin{array}{r}57 \\
27 \\
3 \\
3 \\
2\end{array}$ & $\begin{array}{l}163 \\
193 \\
247 \\
292 \\
350\end{array}$ & $\begin{array}{r}9,700 \\
11,300 \\
11,700 \\
12,500 \\
13,700\end{array}$ & $\begin{array}{r}4,270 \\
5,890 \\
7,800 \\
\text { a, } 900 \\
12,900\end{array}$ \\
\hline $\begin{array}{r}6 . \ldots \ldots \\
7 \ldots \ldots \\
8 \ldots \ldots \\
9 \ldots \ldots \\
10 \ldots \ldots\end{array}$ & $\begin{array}{l}0 \\
0 \\
0 \\
0 \\
0\end{array}$ & $\begin{array}{l}-- \\
-- \\
-- \\
--\end{array}$ & $\begin{array}{l}0 \\
0 \\
0 \\
0 \\
0\end{array}$ & $\begin{array}{r}2 \\
1 \\
2 \\
50 \\
15\end{array}$ & $\begin{array}{r}447 \\
474 \\
- \\
78,600 \\
69,000\end{array}$ & $\begin{array}{r}2 \\
1 \\
\mathrm{e} 1 \\
\mathrm{~s} 14,000 \\
2,900\end{array}$ & $\begin{array}{l}422 \\
498 \\
422 \\
370 \\
382\end{array}$ & $\begin{array}{r}10,000 \\
11,200 \\
11,400 \\
8,300 \\
8,000\end{array}$ & $\begin{array}{r}11,400 \\
15,100 \\
13,000 \\
8,290 \\
8,250\end{array}$ \\
\hline $\begin{array}{l}11 \ldots \ldots \\
12 . \ldots \ldots \\
13 \ldots \ldots \\
14 \ldots \ldots \\
15 \ldots \ldots\end{array}$ & $\begin{array}{l}0 \\
0 \\
0 \\
0 \\
0\end{array}$ & $\begin{array}{l}-- \\
-- \\
-- \\
-- \\
--\end{array}$ & $\begin{array}{l}0 \\
0 \\
0 \\
0 \\
0\end{array}$ & $\begin{array}{r}13 \\
28 \\
6 \\
5 \\
8\end{array}$ & $\begin{array}{r}39,000 \\
17,500 \\
6,500 \\
3,000 \\
4,000\end{array}$ & $\begin{array}{r}1,420 \\
1,320 \\
105 \\
40 \\
\text { a90 }\end{array}$ & $\begin{array}{l}390 \\
360 \\
350 \\
370 \\
400\end{array}$ & $\begin{array}{l}7,900 \\
7,200 \\
7,700 \\
9,700 \\
9,000\end{array}$ & $\begin{array}{r}\text { a, 300 } \\
7,000 \\
\text { a } 7,300 \\
9,690 \\
\text { a } 9,700\end{array}$ \\
\hline $\begin{array}{l}16 . \ldots \ldots \\
17 \ldots \ldots \\
18 \ldots \ldots \\
19 . \ldots \ldots \\
20 . \ldots \ldots\end{array}$ & $\begin{array}{l}0 \\
0 \\
0 \\
0 \\
0\end{array}$ & $\begin{array}{l}-- \\
-- \\
-- \\
-- \\
--\end{array}$ & $\begin{array}{l}0 \\
0 \\
0 \\
0 \\
0\end{array}$ & $\begin{array}{r}8 \\
10 \\
7 \\
6 \\
10\end{array}$ & $\begin{array}{l}3,000 \\
2,000 \\
2,500 \\
3,500 \\
5,500\end{array}$ & $\begin{array}{r}\text { a } 60 \\
54 \\
47 \\
57 \\
148\end{array}$ & $\begin{array}{l}380 \\
370 \\
370 \\
382 \\
415\end{array}$ & $\begin{array}{r}10,500 \\
9,000 \\
7,600 \\
7,800 \\
7,800\end{array}$ & $\begin{array}{r}10,800 \\
\mathrm{a} 9,000 \\
7,590 \\
8,040 \\
8,740\end{array}$ \\
\hline $\begin{array}{l}21 . \ldots \ldots \\
22 \ldots \ldots \ldots \\
23 . \ldots \ldots \\
24 . \ldots \ldots \\
25 . \ldots \ldots\end{array}$ & $\begin{array}{l}0 \\
0 \\
0 \\
0 \\
0\end{array}$ & $\begin{array}{l}-- \\
-- \\
-- \\
-- \\
--\end{array}$ & $\begin{array}{l}0 \\
0 \\
0 \\
0 \\
0\end{array}$ & $\begin{array}{l}20 \\
50 \\
60 \\
77 \\
84\end{array}$ & $\begin{array}{l}\mathbf{6}, 000 \\
7,150 \\
7,290 \\
6,900 \\
\mathbf{6 , 7 0 0}\end{array}$ & $\begin{array}{r}324 \\
965 \\
1,180 \\
\mathrm{a} 1,400 \\
1,520\end{array}$ & $\begin{array}{l}445 \\
445 \\
402 \\
350 \\
300\end{array}$ & $\begin{array}{l}8,700 \\
5,800 \\
5,400 \\
4,100 \\
3,200\end{array}$ & $\begin{array}{r}10,500 \\
6,970 \\
5,860 \\
3,870 \\
2,590\end{array}$ \\
\hline $\begin{array}{l}26 . \ldots \ldots \\
27 . \ldots \ldots \\
28 . \ldots \ldots \\
29 . \ldots \\
30 \ldots \ldots \\
31 \ldots \ldots\end{array}$ & $\begin{array}{l}0 \\
0 \\
1 \\
2^{.9} \\
3\end{array}$ & $\begin{array}{r}-- \\
-- \\
-- \\
-- \\
2,300 \\
8,100 \\
\end{array}$ & $\begin{array}{r}0 \\
0 \\
\text { e } 3 \\
\text { e } 2 \\
12 \\
66 \\
\end{array}$ & $\begin{array}{r}104 \\
91 \\
75 \\
113 \\
133 \\
-- \\
\end{array}$ & $\begin{array}{r}7,800 \\
8,200 \\
6,300 \\
7,000 \\
7,200 \\
-\cdots\end{array}$ & $\begin{array}{r}2,190 \\
2,010 \\
1,280 \\
2,140 \\
2,590 \\
.-\end{array}$ & $\begin{array}{l}320 \\
350 \\
400 \\
450 \\
470 \\
450 \\
\end{array}$ & $\begin{array}{l}4,000 \\
5,400 \\
4,900 \\
4,500 \\
5,800 \\
4,600\end{array}$ & $\begin{array}{l}3,460 \\
5,100 \\
5,290 \\
5,470 \\
7,360 \\
5,590\end{array}$ \\
\hline \multirow[t]{2}{*}{ Total. } & 6.9 & -- & 83 & 992 & $\cdots$ & 35,936 & 11,508 & -- & 245,020 \\
\hline & \multicolumn{3}{|c|}{ January } & \multicolumn{3}{|c|}{ February } & \multicolumn{3}{|c|}{ March } \\
\hline $\begin{array}{l}1 . \ldots \ldots \\
2 \ldots \ldots \\
3 \ldots \ldots \\
4 \ldots \ldots \\
5 \ldots \ldots\end{array}$ & $\begin{array}{l}350 \\
300 \\
350 \\
400 \\
450\end{array}$ & $\begin{array}{r}-- \\
-- \\
4,000 \\
3,100 \\
5,800\end{array}$ & $\begin{array}{r}\text { e } 3,800 \\
\text { e } 3,000 \\
3,780 \\
3,350 \\
7,050\end{array}$ & $\begin{array}{l}475 \\
468 \\
468 \\
475 \\
482\end{array}$ & $\begin{array}{l}\mathbf{5}, \mathbf{3 0 0} \\
\mathbf{6}, 300 \\
\mathbf{6}, 400 \\
\mathbf{6}, \mathbf{5 0 0} \\
\mathbf{5}, 100\end{array}$ & $\begin{array}{l}6,800 \\
7,960 \\
8,090 \\
8,340 \\
6,640\end{array}$ & $\begin{array}{l}650 \\
700 \\
428 \\
410 \\
304\end{array}$ & $\begin{array}{r}10,300 \\
7,300 \\
4,800 \\
4,500 \\
3,700\end{array}$ & $\begin{array}{r}18,100 \\
13,800 \\
5,550 \\
4,980 \\
3,040\end{array}$ \\
\hline $\begin{array}{r}6 \ldots \ldots \\
7 \ldots \ldots \\
8 \ldots \ldots \\
9 . \ldots \\
10 . \ldots\end{array}$ & $\begin{array}{l}500 \\
500 \\
480 \\
470 \\
450\end{array}$ & $\begin{array}{r}10,000 \\
10,900 \\
9,800 \\
9,200 \\
9,700\end{array}$ & $\begin{array}{r}\text { a } 14,000 \\
14,700 \\
12,700 \\
11,700 \\
11,800\end{array}$ & $\begin{array}{l}490 \\
514 \\
506 \\
506 \\
522\end{array}$ & $\begin{array}{l}5,200 \\
6,700 \\
7,000 \\
5,900 \\
5,300\end{array}$ & $\begin{array}{l}6,880 \\
9,300 \\
9,560 \\
8,060 \\
7,470\end{array}$ & $\begin{array}{l}255 \\
206 \\
166 \\
134 \\
117\end{array}$ & $\begin{array}{l}2,900 \\
2,500 \\
1,550 \\
1,880 \\
1,580\end{array}$ & $\begin{array}{r}\text { a 2, } 000 \\
1,390 \\
695 \\
680 \\
499\end{array}$ \\
\hline $\begin{array}{l}11 . \ldots \ldots \\
12 . \ldots \ldots \\
13 . \ldots \ldots \\
14 \ldots \ldots \\
15 \ldots \ldots\end{array}$ & $\begin{array}{l}430 \\
530 \\
498 \\
452 \\
422\end{array}$ & $\begin{array}{l}8,000 \\
7,500 \\
6,500 \\
7,500 \\
7,500\end{array}$ & $\begin{array}{r}9,290 \\
10,700 \\
8,740 \\
9,150 \\
\text { a } 8,500\end{array}$ & $\begin{array}{l}530 \\
510 \\
530 \\
540 \\
550\end{array}$ & $\begin{array}{l}\mathbf{5}, 400 \\
\mathbf{5}, 800 \\
\mathbf{5}, 500 \\
\mathbf{5}, 200 \\
\mathbf{5}, 000\end{array}$ & $\begin{array}{l}7,730 \\
7,990 \\
7,870 \\
7,580 \\
7,420\end{array}$ & $\begin{array}{r}134 \\
101 \\
70 \\
117 \\
346\end{array}$ & $\begin{array}{l}1,630 \\
1,640 \\
2,810 \\
2,700 \\
4,000\end{array}$ & $\begin{array}{r}590 \\
447 \\
531 \\
853 \\
3,740\end{array}$ \\
\hline $\begin{array}{l}16 \ldots \ldots \\
17 . \ldots \ldots \\
18 . \ldots \ldots \\
19 \ldots \ldots \\
20 . \ldots \ldots\end{array}$ & $\begin{array}{l}415 \\
415 \\
475 \\
460 \\
460\end{array}$ & $\begin{array}{l}7,500 \\
7,300 \\
7,600 \\
9,200 \\
9,000\end{array}$ & $\begin{array}{r}8,400 \\
8,180 \\
9,750 \\
11,400 \\
11,200\end{array}$ & $\begin{array}{l}600 \\
670 \\
780 \\
710 \\
700\end{array}$ & $\begin{array}{l}7,700 \\
7,200 \\
6,300 \\
7,800 \\
6,200\end{array}$ & $\begin{array}{l}12,500 \\
13,000 \\
13,300 \\
15,000 \\
11,700\end{array}$ & $\begin{array}{l}410 \\
310 \\
245 \\
184 \\
170\end{array}$ & $\begin{array}{l}4,400 \\
2,700 \\
2,550 \\
2,640 \\
1,780\end{array}$ & $\begin{array}{r}4,870 \\
2,260 \\
1,690 \\
1,310 \\
817\end{array}$ \\
\hline $\begin{array}{l}21 \ldots \ldots \\
22 \ldots \ldots \ldots \\
23 \ldots \ldots \\
24 \ldots \ldots \\
25 \ldots \ldots\end{array}$ & $\begin{array}{l}445 \\
430 \\
452 \\
468 \\
475\end{array}$ & $\begin{array}{l}7,500 \\
7,400 \\
8,000 \\
5,500 \\
7,300\end{array}$ & $\begin{array}{l}9,010 \\
8,590 \\
9,760 \\
6,950 \\
9,360\end{array}$ & $\begin{array}{l}680 \\
640 \\
630 \\
610 \\
570\end{array}$ & $\begin{array}{l}5,700 \\
5,800 \\
5,000 \\
4,400 \\
5,000\end{array}$ & $\begin{array}{r}10,500 \\
10,000 \\
8,500 \\
7,250 \\
7,700\end{array}$ & $\begin{array}{l}98 \\
66 \\
40 \\
38 \\
32\end{array}$ & $\begin{array}{l}838 \\
804 \\
906 \\
700 \\
709\end{array}$ & $\begin{array}{r}222 \\
143 \\
98 \\
72 \\
61\end{array}$ \\
\hline $\begin{array}{l}26 \ldots \ldots \\
27 . \ldots \ldots \\
28 \ldots \ldots \\
29 . \ldots \ldots \\
30 \ldots \ldots \\
31 \ldots \ldots\end{array}$ & $\begin{array}{l}468 \\
460 \\
460 \\
468 \\
475 \\
482 \\
\end{array}$ & $\begin{array}{l}6,700 \\
5,800 \\
6,200 \\
5,200 \\
5,800 \\
4,650 \\
\end{array}$ & $\begin{array}{r}8,500 \\
7,200 \\
7,700 \\
6,570 \\
7,440 \\
6,050 \\
\end{array}$ & $\begin{array}{r}580 \\
530 \\
510 \\
\ldots \\
\ldots \\
\ldots\end{array}$ & $\begin{array}{r}4,500 \\
5,300 \\
6,900 \\
-- \\
-- \\
\end{array}$ & $\begin{array}{r}7,050 \\
7,580 \\
9,500 \\
-- \\
-- \\
-\end{array}$ & $\begin{array}{r}38 \\
32 \\
81 \\
272 \\
298 \\
265 \\
\end{array}$ & $\begin{array}{r}829 \\
634 \\
1,500 \\
2,700 \\
4,100 \\
4,700 \\
\end{array}$ & $\begin{array}{r}85 \\
55 \\
328 \\
1,980 \\
3,300 \\
3,360\end{array}$ \\
\hline Total . & 13,890 & -- & 268,300 & 15,776 & -- & 241,270 & 6,717 & -- & 77,546 \\
\hline
\end{tabular}

s Computed by subdividing day.

a Computed from estimated concentration graph. 
RIO GRANDE BASIN--Continued

RIO GRANDE AT SAN ANTONIO, N, MEX.--Continued

Suspended sediment, water year October 1953 to September 1954--Continued

\begin{tabular}{|c|c|c|c|c|c|c|c|c|c|}
\hline \multirow[b]{3}{*}{ Day } & \multicolumn{3}{|c|}{ April } & \multicolumn{3}{|c|}{ May } & \multicolumn{3}{|c|}{ June } \\
\hline & \multirow[b]{2}{*}{$\begin{array}{l}\text { Mean } \\
\text { dis- } \\
\text { charge } \\
\text { (cfs) }\end{array}$} & \multicolumn{2}{|c|}{ Suspended sediment } & \multirow[b]{2}{*}{$\begin{array}{l}\text { Mean } \\
\text { dis- } \\
\text { charge } \\
\text { (cfs) }\end{array}$} & \multicolumn{2}{|c|}{ Suspended sediment } & \multirow[b]{2}{*}{$\begin{array}{l}\text { Mean } \\
\text { dis- } \\
\text { charge } \\
\text { (cfs) }\end{array}$} & \multicolumn{2}{|c|}{ Suspended sediment } \\
\hline & & $\begin{array}{l}\text { Mean } \\
\text { concen- } \\
\text { tration } \\
\text { (ppm) } \\
\end{array}$ & $\begin{array}{l}\text { Tons } \\
\text { per } \\
\text { day }\end{array}$ & & $\begin{array}{l}\text { Mean } \\
\text { concen- } \\
\text { tration } \\
(p p m)\end{array}$ & $\begin{array}{l}\text { Tons } \\
\text { per } \\
\text { day }\end{array}$ & & $\begin{array}{l}\text { Mean } \\
\text { concen- } \\
\text { tration } \\
\text { (ppm) }\end{array}$ & $\begin{array}{l}\text { Tons } \\
\text { per } \\
\text { day }\end{array}$ \\
\hline $\begin{array}{l}1 \ldots \ldots \\
2 \ldots \ldots \\
3 \ldots \ldots \\
4 \ldots \ldots \\
5 \ldots \ldots\end{array}$ & $\begin{array}{r}206 \\
101 \\
72 \\
93 \\
138\end{array}$ & $\begin{array}{l}3,300 \\
1,760 \\
1,500 \\
2,520 \\
2,480\end{array}$ & $\begin{array}{r}1,840 \\
480 \\
292 \\
633 \\
924\end{array}$ & $\begin{array}{c}0.3 \\
6 \\
11 \\
373 \\
500\end{array}$ & $\begin{array}{r}750 \\
721 \\
800 \\
4,750 \\
4,000\end{array}$ & $\begin{array}{r}1 \\
12 \\
\mathrm{a} 24 \\
\mathrm{~s} 7,260 \\
5,400\end{array}$ & $\begin{array}{r}278 \\
206 \\
97 \\
8 \\
0\end{array}$ & $\begin{array}{r}2,500 \\
1,600 \\
1,000 \\
-- \\
--\end{array}$ & $\begin{array}{r}1,880 \\
890 \\
262 \\
\text { e } 15 \\
0\end{array}$ \\
\hline $\begin{array}{r}6 \ldots \ldots \\
7 \ldots \ldots \\
8 \ldots \ldots \\
9 \ldots \ldots \\
10 \ldots \ldots\end{array}$ & $\begin{array}{r}166 \\
95 \\
62 \\
57 \\
34\end{array}$ & $\begin{array}{l}2,240 \\
1,470 \\
1,420 \\
1,480 \\
1,220\end{array}$ & $\begin{array}{r}1,000 \\
377 \\
238 \\
228 \\
112\end{array}$ & $\begin{array}{r}370 \\
179 \\
130 \\
90 \\
85\end{array}$ & $\begin{array}{l}3,700 \\
2,200 \\
1,600 \\
1,200 \\
1,300\end{array}$ & $\begin{array}{r}3,700 \\
1,060 \\
562 \\
292 \\
298\end{array}$ & $\begin{array}{l}0 \\
0 \\
0 \\
0 \\
0\end{array}$ & $\begin{array}{l}-- \\
-- \\
-- \\
-- \\
--\end{array}$ & $\begin{array}{l}0 \\
0 \\
0 \\
0 \\
0\end{array}$ \\
\hline $\begin{array}{l}11 \ldots \ldots \\
12 \ldots \ldots \\
13 \ldots \ldots \\
14 \ldots \ldots \\
15 \ldots \ldots\end{array}$ & $\begin{array}{r}17 \\
25 \\
236 \\
620 \\
680\end{array}$ & $\begin{array}{r}867 \\
800 \\
5,340 \\
9,800 \\
6,600\end{array}$ & $\begin{array}{r}40 \\
54 \\
s 7,720 \\
16,400 \\
12,100\end{array}$ & $\begin{array}{r}72 \\
210 \\
317 \\
473 \\
482\end{array}$ & $\begin{array}{l}2,000 \\
2,500 \\
3,600 \\
5,500 \\
4,700\end{array}$ & $\begin{array}{r}389 \\
1,420 \\
3,080 \\
7,020 \\
6,120\end{array}$ & $\begin{array}{l}0 \\
0 \\
0 \\
0 \\
0\end{array}$ & $\begin{array}{l}-- \\
-- \\
-- \\
--\end{array}$ & $\begin{array}{l}0 \\
0 \\
0 \\
0 \\
0\end{array}$ \\
\hline $\begin{array}{l}16 \ldots \ldots \\
17 \ldots \ldots \\
18 . \ldots \ldots \\
19 . \ldots \ldots \\
20 \ldots \ldots\end{array}$ & $\begin{array}{l}600 \\
700 \\
770 \\
455 \\
310\end{array}$ & $\begin{array}{l}6,300 \\
7,200 \\
8,100 \\
5,000 \\
2,400\end{array}$ & $\begin{array}{r}10,200 \\
13,600 \\
16,800 \\
6,140 \\
2,010\end{array}$ & $\begin{array}{r}520 \\
530 \\
1,000 \\
1,520 \\
980\end{array}$ & $\begin{array}{r}6,100 \\
5,100 \\
9,300 \\
16,000 \\
23,100\end{array}$ & $\begin{array}{r}8,560 \\
7,300 \\
\text { s } 26,200 \\
\mathrm{sa} 88,000 \\
\mathrm{~s} 61,200\end{array}$ & $\begin{array}{l}0 \\
0 \\
0 \\
0 \\
0\end{array}$ & $\begin{array}{l}-- \\
-- \\
-- \\
--\end{array}$ & $\begin{array}{l}0 \\
0 \\
0 \\
0 \\
0\end{array}$ \\
\hline $\begin{array}{l}21 \ldots \ldots \\
22 \ldots \ldots \ldots \\
23 . \ldots \ldots \\
24 \ldots \ldots \\
25 \ldots \ldots\end{array}$ & $\begin{array}{r}272 \\
230 \\
174 \\
98 \\
77\end{array}$ & $\begin{array}{l}4,000 \\
2,200 \\
1,600 \\
1,490 \\
1,370\end{array}$ & $\begin{array}{r}2,940 \\
1,370 \\
752 \\
394 \\
285\end{array}$ & $\begin{array}{r}822 \\
811 \\
912 \\
1,010 \\
1,330\end{array}$ & $\begin{array}{r}16,500 \\
10,900 \\
7,500 \\
6,600 \\
6,800\end{array}$ & $\begin{array}{l}36,600 \\
23,900 \\
18,500 \\
18,000 \\
24,400\end{array}$ & $\begin{array}{l}0 \\
0 \\
0 \\
0 \\
0\end{array}$ & $\begin{array}{l}-- \\
-- \\
-- \\
--\end{array}$ & $\begin{array}{l}0 \\
0 \\
0 \\
0 \\
0\end{array}$ \\
\hline $\begin{array}{l}26 \ldots \ldots \\
27 . \ldots \ldots \\
28 . \ldots \ldots \\
29 \ldots \ldots \\
30 \ldots \ldots \\
31 \ldots \ldots\end{array}$ & $\begin{array}{l}64 \\
45 \\
57 \\
28 \\
15 \\
---\end{array}$ & $\begin{array}{r}879 \\
785 \\
922 \\
981 \\
797 \\
-- \\
\end{array}$ & $\begin{array}{r}152 \\
95 \\
142 \\
74 \\
32 \\
-- \\
\end{array}$ & $\begin{array}{r}1,210 \\
936 \\
912 \\
912 \\
630 \\
338 \\
\end{array}$ & $\begin{array}{l}7,600 \\
8,000 \\
5,400 \\
4,200 \\
3,700 \\
2,600 \\
\end{array}$ & $\begin{array}{r}24,800 \\
20,200 \\
13,300 \\
10,300 \\
6,290^{\prime} \\
2,370 \\
\end{array}$ & $\begin{array}{r}0 \\
0 \\
0 \\
0 \\
0 \\
- \\
\end{array}$ & $\begin{array}{l}-- \\
-- \\
-- \\
-- \\
--\end{array}$ & $\begin{array}{r}0 \\
0 \\
0 \\
0 \\
0 \\
--\end{array}$ \\
\hline \multirow[t]{2}{*}{ Total. } & 6,497 & $\cdots$ & 97,424 & $17,671.3$ & $=$ & 426,558 & 589 & -- & 3,047 \\
\hline & \multicolumn{3}{|c|}{ July } & \multicolumn{3}{|c|}{ August } & \multicolumn{3}{|c|}{ September } \\
\hline $\begin{array}{l}1 \ldots \ldots \\
2 \ldots \ldots \\
3 \ldots \ldots \\
4 \ldots \ldots \\
5 \ldots \ldots\end{array}$ & $\begin{array}{l}0 \\
0 \\
4 \\
0 \\
0.2\end{array}$ & $\begin{array}{r}- \\
51,200 \\
7,500 \\
-\end{array}$ & $\begin{array}{r}0 \\
0 \\
\mathbf{s} 578 \\
\mathbf{s} 6 \\
0\end{array}$ & $\begin{array}{r}0 \\
0 \\
0 \\
8 \\
42\end{array}$ & $\begin{array}{r}-- \\
-- \\
=- \\
3,120 \\
24,200\end{array}$ & $\begin{array}{r}0 \\
0 \\
0 \\
\mathbf{8} 910 \\
\mathbf{8 2 , 8 2 0}\end{array}$ & $\begin{array}{l}0 \\
0 \\
0 \\
0 \\
0\end{array}$ & $\begin{array}{l}-- \\
-- \\
-- \\
--\end{array}$ & $\begin{array}{l}0 \\
0 \\
0 \\
0 \\
0\end{array}$ \\
\hline $\begin{array}{r}6 \ldots \ldots \\
7 \ldots \ldots \\
8 \ldots \ldots \\
9 \ldots \ldots \\
10 . \ldots \ldots\end{array}$ & $\begin{array}{l}0 \\
0 \\
0 \\
0 \\
0\end{array}$ & $\begin{array}{l}-- \\
-- \\
-- \\
--\end{array}$ & $\begin{array}{l}0 \\
0 \\
0 \\
0 \\
0\end{array}$ & $\begin{array}{l}290 \\
139 \\
790 \\
278 \\
151\end{array}$ & $\begin{array}{l}38,900 \\
66,000 \\
85,500 \\
61,000 \\
42,500\end{array}$ & $\begin{array}{r}\mathrm{s} 82,200 \\
\mathrm{~s} 33,000 \\
\mathrm{~s} 199,000 \\
\mathrm{~s} 56,100 \\
\mathrm{~s} 21,200\end{array}$ & $\begin{array}{l}0 \\
0 \\
0 \\
0 \\
0\end{array}$ & $\begin{array}{l}-- \\
-- \\
-- \\
--\end{array}$ & $\begin{array}{l}0 \\
0 \\
0 \\
0 \\
0\end{array}$ \\
\hline $\begin{array}{l}11 \ldots \ldots \\
12 \ldots \ldots \\
13 \ldots \ldots \\
14 \ldots \ldots \\
15 \ldots \ldots\end{array}$ & $\begin{array}{l}0 \\
0 \\
0 \\
0 \\
0\end{array}$ & $\begin{array}{l}-- \\
-- \\
-- \\
--\end{array}$ & $\begin{array}{l}0 \\
0 \\
0 \\
0 \\
0\end{array}$ & $\begin{array}{r}1,310 \\
555 \\
570 \\
135 \\
22\end{array}$ & $\begin{array}{l}61,600 \\
66,300 \\
78,400 \\
63,600 \\
41,500\end{array}$ & $\begin{array}{r}\mathrm{s} 301,000 \\
\mathrm{~s} 107,000 \\
8127,000 \\
\mathrm{~s} 25,200 \\
\mathbf{8 2 , 5 9 0}\end{array}$ & $\begin{array}{r}0 \\
360 \\
1,020 \\
2,050 \\
830\end{array}$ & $\begin{array}{r}89,000 \\
100,000 \\
122,000 \\
94,100\end{array}$ & $\begin{array}{r}0 \\
\text { sa } 96,000 \\
\text { sa } 310,000 \\
\text { s } 738,000 \\
\text { s } 239,000\end{array}$ \\
\hline $\begin{array}{l}16 \ldots \ldots \\
17 . \ldots \ldots \\
18 \ldots \ldots \\
19 \ldots \ldots \\
20 . \ldots \ldots\end{array}$ & $\begin{array}{l}0 \\
0 \\
0 \\
0 \\
0\end{array}$ & $\begin{array}{l}-- \\
-- \\
--\end{array}$ & $\begin{array}{l}0 \\
0 \\
0 \\
0 \\
0\end{array}$ & $\begin{array}{r}5 \\
1,580 \\
1,780 \\
865 \\
646\end{array}$ & $\begin{array}{l}18,000 \\
81,200 \\
88,000 \\
78,800 \\
90,500\end{array}$ & $\begin{array}{r}243 \\
\text { s } 557,000 \\
\text { s } 457,000 \\
\text { s } 195,000 \\
\text { s } 176,000\end{array}$ & $\begin{array}{r}164 \\
51 \\
17 \\
3 \\
2\end{array}$ & $\begin{array}{r}86,100 \\
48,000 \\
34,500 \\
9,500 \\
--\end{array}$ & $\begin{array}{r}839,600 \\
87,270 \\
1,640 \\
77 \\
\text { e } 50\end{array}$ \\
\hline $21 \ldots \ldots$ & $\begin{array}{l}0 \\
0\end{array}$ & $=$ & 0 & $\begin{array}{r}350 \\
1,380\end{array}$ & $\begin{array}{l}77,900 \\
92,100\end{array}$ & $\begin{array}{r}s 78,100 \\
s 487,000\end{array}$ & 1.7 & -- & $\begin{array}{l}\text { e } 20 \\
\text { e } 10\end{array}$ \\
\hline $\begin{array}{l}23 . \ldots \ldots \\
24 \ldots \ldots \\
25 . \ldots \ldots\end{array}$ & $\begin{array}{r}87 \\
1,200 \\
4,000\end{array}$ & $\begin{array}{l}36,200 \\
96,600 \\
92,000\end{array}$ & $\begin{array}{r}\mathrm{s} 26,500 \\
\mathrm{~s} 404,000 \\
1,070,000\end{array}$ & $\begin{array}{r}395 \\
111 \\
1,110\end{array}$ & $\begin{array}{l}69,900 \\
66,100 \\
92,200\end{array}$ & $\begin{array}{r}\mathbf{s 7 7 , 0 0 0} \\
\mathbf{s} 20,700 \\
\mathbf{s} 337,000\end{array}$ & $565^{.4}$ & $\begin{array}{l}40,900 \\
38,700\end{array}$ & $\begin{array}{r}e 5 \\
s 127,000 \\
817,000\end{array}$ \\
\hline $\begin{array}{l}26 . \ldots \ldots \\
27 . \ldots \ldots \\
28 . \ldots \ldots\end{array}$ & $\begin{array}{r}1,050 \\
440 \\
110\end{array}$ & $\begin{array}{l}75,400 \\
70,900 \\
23,000\end{array}$ & $\begin{array}{r}\mathbf{s} 219,000 \\
890,700 \\
6,830\end{array}$ & $\begin{array}{r}290 \\
99 \\
20\end{array}$ & $\begin{array}{l}66,400 \\
29,900 \\
24,500\end{array}$ & $\begin{array}{r}\mathbf{5 5}, 500 \\
\mathrm{~s} 8,900 \\
1,320\end{array}$ & $\begin{array}{l}3,070 \\
4,700 \\
1,860\end{array}$ & $\begin{array}{l}90,100 \\
88,000 \\
68,600\end{array}$ & $\begin{array}{r}8813,000 \\
81,200,000 \\
8409,000\end{array}$ \\
\hline $\begin{array}{l}29 \ldots \ldots \\
30 . \ldots \ldots\end{array}$ & $\begin{array}{r}25 \\
1\end{array}$ & $\begin{array}{r}2,500 \\
702\end{array}$ & $\begin{array}{r}169 \\
2\end{array}$ & $\begin{array}{l}5 \\
6\end{array}$ & - & $\begin{array}{l}\text { e } 240 \\
\text { e } 290\end{array}$ & $\begin{array}{l}340 \\
156\end{array}$ & $\begin{array}{l}55,500 \\
42,800\end{array}$ & $\begin{array}{l}\text { s } 53,700 \\
\text { s } 18,900\end{array}$ \\
\hline $31 . \ldots \ldots$ & 0 & - & 0 & .8 & - & e 20 & -- & -- & \\
\hline Total & $6,917.2$ & -- & $1,817,785$ & $12,932.8$ & -- & $3,359,333$ & $15,343.1$ & -- & $4,070,272$ \\
\hline
\end{tabular}

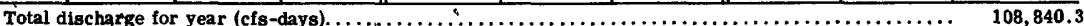

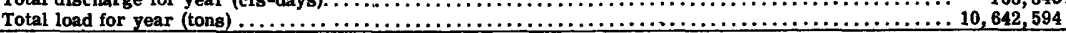

e Estimated.

s Computed by subdividing day.

a Computed from estimated concentration graph. 


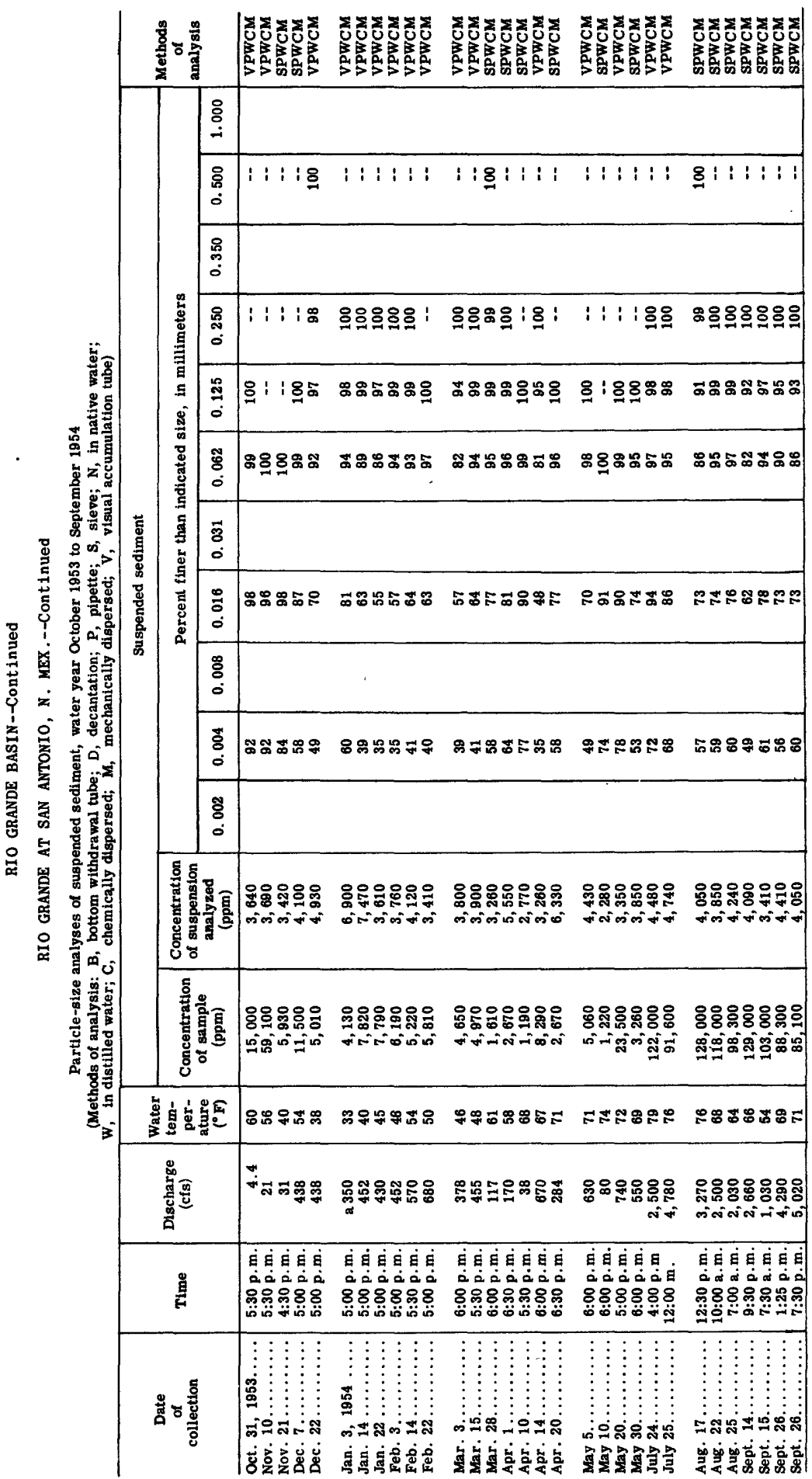


RIO GRANDE CONVEYANCE CHANNEL BELOW HEADING NEAR SAN MARCIAL, N. MEX.

LOCATION. - At heading structure 1,250 feet upstream from gaging station, 6 miles upstream from former site of San Marciai, Socorro County, and 13.4 miles southwest of San Antonio. RECORDS AVAILABLE. --Water temperatures: March to September 1954.

Sediment records: March to September 1954.

EXTREMES, March to September 1954.--Wa ter temperatures: Maximum observed, $85^{\circ} \mathrm{F}$ Ju1y 27 , Aug. 6, Sept. 1; minimum observed, $37^{\circ} \mathrm{F}$ Mar. 13, 14 .

Sediment concentrations: Maximum dáily, $95,000 \mathrm{ppm}$ Aug. 22 ;minimum daily $32 \mathrm{ppm}$ Sept, 23. Sediment loads: Maximum daily,271,000 tons July 25 ; minimum daily, less than 0.50 tons Sept. 23.

REMARKS.--Records of specific conductance of daily samples available in district of fice at Albuquerque, N.Mex. Records of discharge for period March to September 1954 given in WSP 1342 .

Temperature ("F) of water, March to September 1954 Once-daily measurement, generally between $11 \mathrm{a} . \mathrm{m}$. and $6 \mathrm{p.m}$.

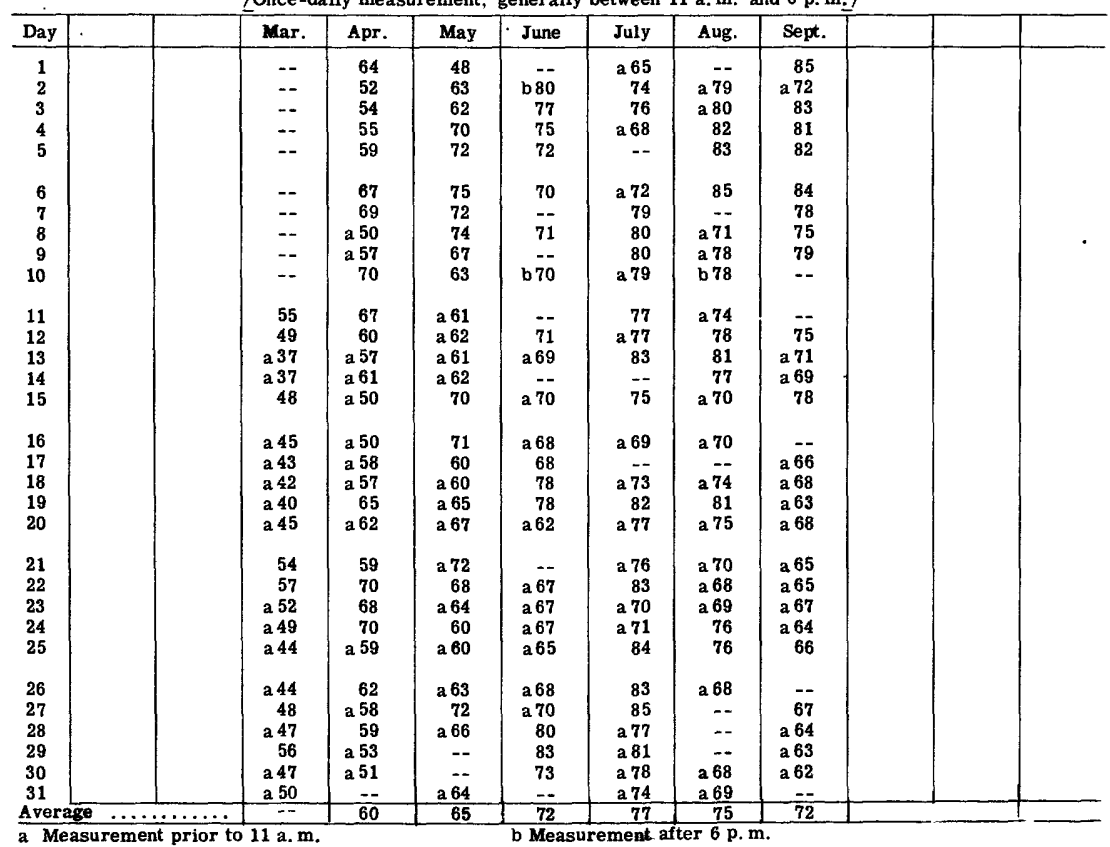

Suspended sediment, March to September 1954

\begin{tabular}{|c|c|c|c|}
\hline \multirow[b]{3}{*}{ Day } & \multicolumn{3}{|c|}{ March } \\
\hline & \multirow[b]{2}{*}{$\begin{array}{c}\text { Mean } \\
\text { dis- } \\
\text { charge } \\
\text { (cfs) }\end{array}$} & \multicolumn{2}{|c|}{ Suspended sediment } \\
\hline & & $\begin{array}{l}\text { Mean } \\
\text { concen- } \\
\text { tration } \\
\text { (ppm) }\end{array}$ & $\begin{array}{l}\text { Tons } \\
\text { per } \\
\text { day }\end{array}$ \\
\hline $\begin{array}{l}11 \ldots \ldots \\
12 \ldots \ldots \\
13 \ldots \ldots \\
14 \ldots \ldots \\
15 \ldots \ldots\end{array}$ & $\begin{array}{r}41 \\
83 \\
55 \\
49 \\
117\end{array}$ & $\begin{array}{r}3,280 \\
1,700 \\
840 \\
620 \\
2,190\end{array}$ & $\begin{array}{r}\text { s } 470 \\
381 \\
125 \\
82 \\
\text { s } 788\end{array}$ \\
\hline $\begin{array}{l}16 \ldots \ldots \\
17 \ldots \ldots \\
18 \ldots \ldots \\
19 \ldots \ldots \\
20 \ldots \ldots\end{array}$ & $\begin{array}{l}334 \\
282 \\
185 \\
138 \\
129\end{array}$ & $\begin{array}{l}3,400 \\
2,810 \\
2,060 \\
1,670 \\
1,350\end{array}$ & $\begin{array}{r}3,070 \\
\mathrm{~s} 2,200 \\
1,030 \\
622 \\
470\end{array}$ \\
\hline $\begin{array}{l}21 \ldots \ldots \\
22 \ldots \ldots \\
23 \ldots \ldots \\
24 \ldots \ldots \\
25 \ldots \ldots\end{array}$ & $\begin{array}{l}79 \\
58 \\
27 \\
16 \\
13\end{array}$ & $\begin{array}{l}980 \\
960 \\
650 \\
440 \\
380\end{array}$ & $\begin{array}{r}209 \\
150 \\
47 \\
19 \\
13\end{array}$ \\
\hline $\begin{array}{c}26 \ldots \ldots \\
27 \ldots \ldots \\
28 \\
29 \\
29 \\
30 \\
31\end{array} \ldots$ & $\begin{array}{r}13 \\
14 \\
12 \\
98 \\
167 \\
206\end{array}$ & $\begin{array}{r}360 \\
360 \\
350 \\
1,870 \\
2,250 \\
2,670\end{array}$ & $\begin{array}{r}13 \\
14 \\
11 \\
\mathrm{~s} 513 \\
1,010 \\
1,490\end{array}$ \\
\hline Total. . & 2,116 & - & 12,727 \\
\hline
\end{tabular}


RIO GRANDE BASIN--Continued

RIO GRANDE CONVEYANCE CHANNEL BELOW HEADING NEAR SAN MARCIAL, N. MEX.--Continued

\begin{tabular}{|c|c|c|c|c|c|c|c|c|c|}
\hline \multirow[b]{3}{*}{ Day } & \multicolumn{3}{|c|}{ April } & \multicolumn{3}{|c|}{ May } & \multicolumn{3}{|c|}{ June } \\
\hline & \multirow[b]{2}{*}{$\begin{array}{c}\text { Mean } \\
\text { dis- } \\
\text { charge } \\
\text { (cfs) }\end{array}$} & \multicolumn{2}{|c|}{ Suspended sediment } & \multirow[b]{2}{*}{$\begin{array}{l}\text { Mean } \\
\text { dis- } \\
\text { charge } \\
\text { (cfs) }\end{array}$} & \multicolumn{2}{|c|}{ Suspended sediment } & \multirow[b]{2}{*}{$\begin{array}{c}\text { Mean } \\
\text { dis- } \\
\text { charge } \\
\text { (cfs) }\end{array}$} & \multicolumn{2}{|c|}{ Suspended sediment } \\
\hline & & $\begin{array}{l}\text { Mean } \\
\text { concen- } \\
\text { tration } \\
(\mathrm{ppm})\end{array}$ & $\begin{array}{l}\text { Tons } \\
\text { per } \\
\text { day }\end{array}$ & & $\begin{array}{c}\text { Mean } \\
\text { concen } \\
\text { tration } \\
(\mathrm{ppm})\end{array}$ & $\begin{array}{l}\text { Tons } \\
\text { per } \\
\text { day }\end{array}$ & & $\begin{array}{l}\text { Mean } \\
\text { concen- } \\
\text { tration } \\
(\text { ppm })\end{array}$ & $\begin{array}{l}\text { Tons } \\
\text { per } \\
\text { day }\end{array}$ \\
\hline $\begin{array}{l}1 \ldots \ldots \\
2 \ldots \ldots \\
3 \ldots \ldots \\
4 \ldots \ldots \\
5 \ldots \ldots\end{array}$ & $\begin{array}{r}182 \\
95 \\
57 \\
48 \\
77\end{array}$ & $\begin{array}{l}2,440 \\
1,460 \\
1,080 \\
1,050 \\
1,500\end{array}$ & $\begin{array}{r}1,200 \\
374 \\
166 \\
136 \\
312\end{array}$ & $\begin{array}{r}12 \\
10 \\
9 \\
58 \\
278\end{array}$ & $\begin{array}{r}450 \\
200 \\
150 \\
1,160 \\
1,650\end{array}$ & $\begin{array}{r}15 \\
5 \\
4 \\
5469 \\
1,240\end{array}$ & $\begin{array}{l}55 \\
49 \\
24 \\
19 \\
10\end{array}$ & $\begin{array}{r}2,390 \\
2,400 \\
1,400 \\
838 \\
520\end{array}$ & $\begin{array}{r}355 \\
318 \\
91 \\
\text { s } 46 \\
14\end{array}$ \\
\hline $\begin{array}{r}6 \ldots \ldots \\
7 \ldots \ldots \\
8 \ldots \ldots \\
9 \ldots \ldots \\
10 \ldots \ldots\end{array}$ & $\begin{array}{r}107 \\
77 \\
39 \\
34 \\
26\end{array}$ & $\begin{array}{r}1,820 \\
1,260 \\
1,070 \\
890 \\
740\end{array}$ & $\begin{array}{r}526 \\
262 \\
113 \\
82 \\
52\end{array}$ & $\begin{array}{r}422 \\
342 \\
163 \\
76 \\
56\end{array}$ & $\begin{array}{r}720 \\
760 \\
2,750 \\
1,480 \\
1,840\end{array}$ & $\begin{array}{r}820 \\
702 \\
1,210 \\
304 \\
278\end{array}$ & $\begin{array}{l}8 \\
7 \\
7 \\
6 \\
6\end{array}$ & $\begin{array}{l}300 \\
250 \\
245 \\
116 \\
110\end{array}$ & $\begin{array}{r}6 \\
\mathbf{2} 5 \\
5 \\
2 \\
2\end{array}$ \\
\hline $\begin{array}{l}11 \ldots \ldots \\
12 \ldots \ldots \\
13 \ldots \ldots \\
14 \ldots \ldots \\
15 \ldots \ldots\end{array}$ & $\begin{array}{r}13 \\
4 \\
12 \\
333 \\
557\end{array}$ & $\begin{array}{r}480 \\
280 \\
333 \\
3,240 \\
4,630\end{array}$ & $\begin{array}{r}17 \\
3 \\
\mathrm{~s} 12 \\
\mathrm{~s} 3,130 \\
6,960\end{array}$ & $\begin{array}{r}46 \\
87 \\
170 \\
275 \\
370\end{array}$ & $\begin{array}{r}1,140 \\
1,480 \\
1,680 \\
1,600 \\
460\end{array}$ & $\begin{array}{r}142 \\
\mathrm{~s} 414 \\
771 \\
1,190 \\
460\end{array}$ & $\begin{array}{l}5 \\
5 \\
5 \\
5 \\
4\end{array}$ & $\begin{array}{l}110 \\
149 \\
120 \\
110 \\
114\end{array}$ & $\begin{array}{r}a 1 \\
2 \\
2 \\
1 \\
1\end{array}$ \\
\hline $\begin{array}{l}16 \ldots \ldots \\
17 . \ldots \ldots \\
18 \ldots \ldots \\
19 . \ldots \ldots \\
20 . \ldots \ldots\end{array}$ & $\begin{array}{l}534 \\
566 \\
696 \\
520 \\
275\end{array}$ & $\begin{array}{l}4,200 \\
3,300 \\
3,430 \\
3,100 \\
2,640\end{array}$ & $\begin{array}{l}6,060 \\
5,040 \\
6,450 \\
4,350 \\
1,960\end{array}$ & $\begin{array}{l}394 \\
406 \\
450 \\
835 \\
919\end{array}$ & $\begin{array}{r}780 \\
1,900 \\
915 \\
1,950 \\
3,480\end{array}$ & $\begin{array}{r}830 \\
2,080 \\
1,110 \\
4,400 \\
\mathrm{~s} 8,870\end{array}$ & $\begin{array}{l}4 \\
4 \\
4 \\
4 \\
4\end{array}$ & $\begin{array}{r}77 \\
83 \\
105 \\
92 \\
78\end{array}$ & $\begin{array}{l}1 \\
1 \\
1 \\
1 \\
1\end{array}$ \\
\hline $\begin{array}{l}21 \ldots \ldots \\
22 \ldots \ldots \\
23 . \ldots \ldots \\
24 \ldots \ldots \\
25 \ldots \ldots\end{array}$ & $\begin{array}{r}246 \\
158 \\
119 \\
80 \\
53\end{array}$ & $\begin{array}{l}2,320 \\
1,930 \\
1,920 \\
1,920 \\
1,310\end{array}$ & $\begin{array}{r}1,540 \\
823 \\
617 \\
415 \\
187\end{array}$ & $\begin{array}{l}770 \\
924 \\
980 \\
904 \\
968\end{array}$ & $\begin{array}{l}1,120 \\
1,830 \\
1,750 \\
1,500 \\
1,730\end{array}$ & $\begin{array}{r}2,330 \\
\mathrm{~s} 5,570 \\
4,630 \\
3,660 \\
4,520\end{array}$ & $\begin{array}{l}4 \\
4 \\
4 \\
4 \\
3\end{array}$ & $\begin{array}{l}110 \\
124 \\
126 \\
122 \\
102\end{array}$ & $\begin{array}{l}1 \\
1 \\
1 \\
1 \\
1\end{array}$ \\
\hline $\begin{array}{l}26 \ldots \ldots \\
27 \ldots \ldots \\
28 \ldots \ldots \\
29 \ldots \ldots \\
30 \ldots \ldots \\
31 \ldots \ldots\end{array}$ & $\begin{array}{l}40 \\
40 \\
34 \\
23 \\
16 \\
-- \\
\end{array}$ & $\begin{array}{r}900 \\
930 \\
750 \\
550 \\
410 \\
-- \\
\end{array}$ & $\begin{array}{r}97 \\
100 \\
69 \\
34 \\
18 \\
-- \\
\end{array}$ & $\begin{array}{r}1,080 \\
940 \\
386 \\
330 \\
235 \\
104 \\
\end{array}$ & $\begin{array}{r}1,150 \\
825 \\
3,500 \\
4,870 \\
4,500 \\
3,380 \\
\end{array}$ & $\begin{array}{r}3,350 \\
\mathrm{~s} 2,020 \\
\mathrm{sa} 3,700 \\
4,340 \\
\mathrm{a} 2,900 \\
949 \\
\end{array}$ & $\begin{array}{r}4 \\
3 \\
3 \\
3 \\
3 \\
- \\
\end{array}$ & $\begin{array}{l}170 \\
184 \\
153 \\
157 \\
165 \\
- \\
\end{array}$ & $\begin{array}{r}2 \\
1 \\
1 \\
1 \\
1 \\
- \\
\end{array}$ \\
\hline \multirow[t]{2}{*}{ Total. } & 5,061 & -- & 41,105 & 12,999 & -- & 63,283 & 270. & $=$ & 867 \\
\hline & \multicolumn{3}{|c|}{ July } & \multicolumn{3}{|c|}{ August } & \multicolumn{3}{|c|}{ September } \\
\hline $\begin{array}{l}1 . \ldots \ldots \\
2 . \ldots \ldots \\
3 \ldots \ldots \\
4 \ldots \ldots \\
5 \ldots \ldots\end{array}$ & $\begin{array}{l}3 \\
3 \\
3 \\
3 \\
3\end{array}$ & $\begin{array}{r}115 \\
133 \\
137 \\
96 \\
170\end{array}$ & $\begin{array}{r}1 \\
1 \\
1 \\
1 \\
\text { a } 1\end{array}$ & $\begin{array}{r}7 \\
7 \\
21 \\
27 \\
29\end{array}$ & $\begin{array}{r}341 \\
83 \\
-- \\
30,000\end{array}$ & $\begin{array}{r}\mathrm{e} 10 \\
6 \\
5 \\
\mathrm{e} 2,000 \\
2,350\end{array}$ & $\begin{array}{l}\mathbf{5} \\
\mathbf{5} \\
\mathbf{5} \\
\mathbf{5} \\
\mathbf{5}\end{array}$ & $\begin{array}{r}212 \\
132 \\
104 \\
48 \\
87\end{array}$ & $\begin{array}{l}3 \\
2 \\
1 \\
1 \\
1\end{array}$ \\
\hline $\begin{array}{r}6 \ldots \ldots \\
7 \ldots \ldots \\
8 \ldots \ldots \\
9 \ldots \ldots \\
10 \ldots \ldots\end{array}$ & $\begin{array}{l}3 \\
3 \\
3 \\
3 \\
3\end{array}$ & $\begin{array}{l}200 \\
150 \\
113 \\
104 \\
110\end{array}$ & $\begin{array}{l}2 \\
1 \\
1 \\
1 \\
1\end{array}$ & $\begin{array}{r}54 \\
150 \\
156 \\
224 \\
72\end{array}$ & $\begin{array}{r}13,000 \\
-- \\
-- \\
-- \\
--\end{array}$ & $\begin{array}{r}1,900 \\
\mathrm{e} 30,000 \\
\mathrm{e} 31,000 \\
\mathrm{e} 46,000 \\
\mathrm{e} 11,000\end{array}$ & $\begin{array}{l}4 \\
4 \\
4 \\
3 \\
3\end{array}$ & $\begin{array}{r}1,860 \\
802 \\
793 \\
773 \\
326\end{array}$ & $\begin{array}{r}20 \\
9 \\
9 \\
6 \\
3\end{array}$ \\
\hline $\begin{array}{l}11 \ldots \ldots \\
12 \ldots \ldots \\
13 \ldots \ldots \\
14 \ldots \ldots \\
15 \ldots \ldots\end{array}$ & $\begin{array}{l}3 \\
3 \\
3 \\
3 \\
3\end{array}$ & $\begin{array}{l}106 \\
130 \\
146 \\
130 \\
125\end{array}$ & $\begin{array}{r}1 \\
1 \\
1 \\
\mathrm{a} 1 \\
1\end{array}$ & $\begin{array}{r}288 \\
245 \\
333 \\
98 \\
46\end{array}$ & $\begin{array}{r}59,900 \\
56,900 \\
62,300 \\
66,900 \\
--\end{array}$ & $\begin{array}{r}s 66,000 \\
s 35,900 \\
s 59,200 \\
s 18,200 \\
\text { e } 6,000\end{array}$ & $\begin{array}{r}4 \\
60 \\
170 \\
617 \\
707\end{array}$ & $\begin{array}{r}360 \\
50,800 \\
80,500 \\
70,700 \\
68,400\end{array}$ & $\begin{array}{r}a 4 \\
8,530 \\
38,300 \\
s 124,000 \\
135,000\end{array}$ \\
\hline $\begin{array}{l}16 \ldots \ldots \\
17 \ldots \ldots \\
18 \ldots \ldots\end{array}$ & $\begin{array}{l}3 \\
3 \\
3\end{array}$ & $\begin{array}{r}111 \\
130 \\
95\end{array}$ & $\begin{array}{r}1 \\
\mathrm{a} 1 \\
1\end{array}$ & $\begin{array}{r}30 \\
260 \\
946\end{array}$ & 76,000 & $\begin{array}{r}e 3,300 \\
e 52,000 \\
201,000\end{array}$ & $\begin{array}{r}115 \\
33 \\
15\end{array}$ & $\begin{array}{l}76,000 \\
63,000 \\
49,500\end{array}$ & $\begin{array}{r}\mathrm{sa} 25,000 \\
5,820 \\
2,080\end{array}$ \\
\hline $\begin{array}{l}19 . \ldots \ldots \\
20 . \ldots \ldots\end{array}$ & $\begin{array}{l}3 \\
3\end{array}$ & $\begin{array}{l}113 \\
105\end{array}$ & $\begin{array}{l}1 \\
1\end{array}$ & $\begin{array}{l}465 \\
309\end{array}$ & $\begin{array}{l}65,400 \\
63,800\end{array}$ & $\begin{array}{l}\mathrm{s} 86,900 \\
\mathrm{~s} 60,300\end{array}$ & $\begin{array}{l}9 \\
7\end{array}$ & $\begin{array}{r}36,500 \\
3,010\end{array}$ & $\begin{array}{r}920 \\
57\end{array}$ \\
\hline $\begin{array}{l}21 \ldots \ldots \\
22 \ldots \ldots \\
23 \ldots \ldots \\
24 \ldots \ldots \\
25 \ldots \ldots \\
\end{array}$ & $\begin{array}{r}2 \\
2 \\
3 \\
118 \\
1,060\end{array}$ & $\begin{array}{r}99 \\
125 \\
178 \\
66,900 \\
93,400\end{array}$ & $\begin{array}{r}1 \\
1 \\
1 \\
\mathrm{~s} 29,900 \\
s 271,000\end{array}$ & $\begin{array}{r}137 \\
430 \\
216 \\
63 \\
212\end{array}$ & $\begin{array}{l}60,100 \\
95,000 \\
64,600 \\
63,000 \\
62,000\end{array}$ & $\begin{array}{r}s 25,700 \\
s 134,000 \\
s 42,300 \\
s 11,300 \\
s 245,000\end{array}$ & $\begin{array}{r}5 \\
4 \\
4 \\
143 \\
120\end{array}$ & $\begin{array}{r}221 \\
109 \\
32 \\
30,500 \\
45,000\end{array}$ & $\begin{array}{c}{ }^{3} \\
{ }^{1} \\
\mathrm{~s} 31,500 \\
15,100\end{array}$ \\
\hline $\begin{array}{l}26 \ldots \ldots \\
27 \ldots \ldots \\
28 . \ldots \ldots \\
29 . \ldots \ldots \\
30 \ldots \ldots \\
31 \ldots \ldots\end{array}$ & $\begin{array}{r}1,230 \\
353 \\
82 \\
40 \\
27 \\
12 \\
\end{array}$ & $\begin{array}{r}64,100 \\
76,100 \\
55,900 \\
39,500 \\
25,500 \\
2,000 \\
\end{array}$ & $\begin{array}{r}\mathrm{s} 24,000 \\
\mathrm{~s} 77,200 \\
\mathrm{~s} 13,100 \\
4,420 \\
1,860 \\
65 \\
\end{array}$ & $\begin{array}{r}154 \\
70 \\
27 \\
13 \\
6 \\
6 \\
\end{array}$ & $\begin{array}{r}42,400 \\
44,500 \\
19,000 \\
5,000 \\
498 \\
884 \\
\end{array}$ & $\begin{array}{r}\text { s18, 500 } \\
8,720 \\
\text { a } 1,400 \\
176 \\
88 \\
\end{array}$ & $\begin{array}{r}547 \\
934 \\
1,380 \\
439 \\
65 \\
\end{array}$ & $\begin{array}{l}59,600 \\
46,800 \\
43,500 \\
43,000 \\
38,500\end{array}$ & $\begin{array}{r}\mathrm{s} 89,100 \\
\mathrm{~s} 123,000 \\
168,000 \\
52,900 \\
\mathrm{~s} 7,100\end{array}$ \\
\hline Total. & 2,989 & -- & 621,569 & 5,101 & - & $1,000,189$ & 5,421 & $=$ & 826,470 \\
\hline
\end{tabular}

Total discharge for period (cfs-days) Mar. 11 to Sept. $30 \ldots 3,957$

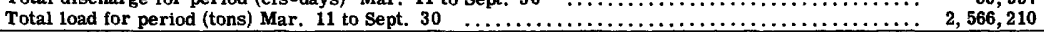

e Estimated.

s Computed by subdividing day.

$t$ Less than 0,50 ton.

a Computed from estimated concentration graph. 


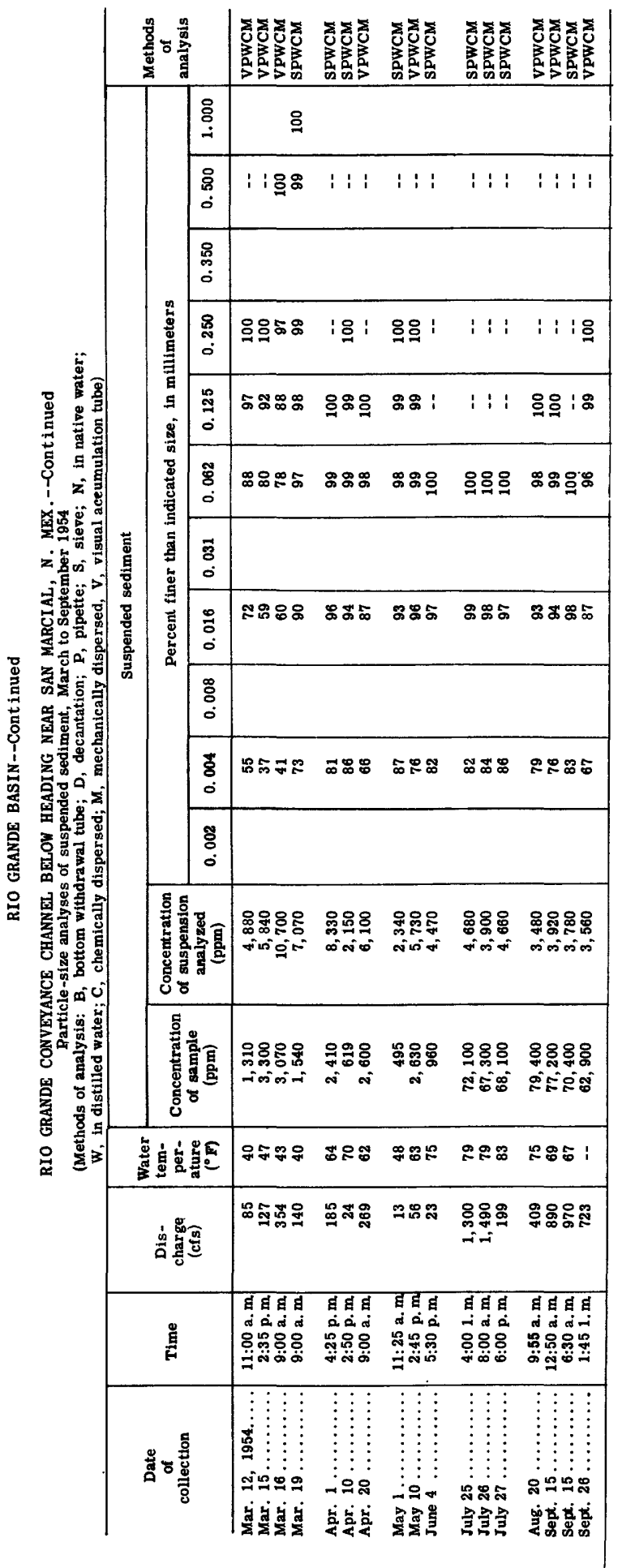




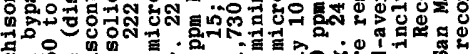
รี

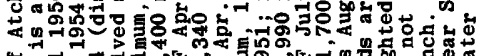
17-7

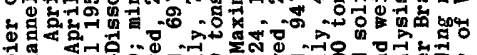
可.. 5 0 \% 楁

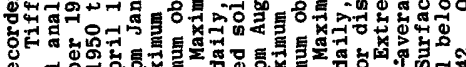

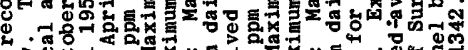

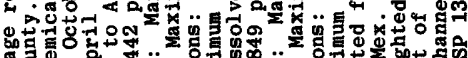
कै p

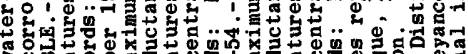

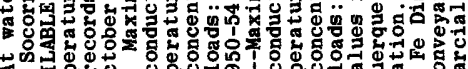

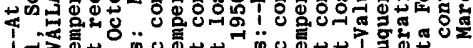

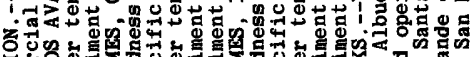

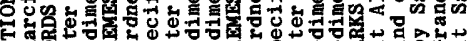

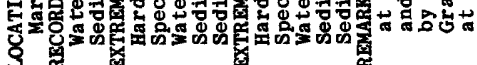

\begin{tabular}{|c|c|}
\hline 䞤密可 & 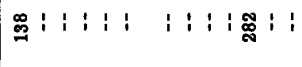 \\
\hline 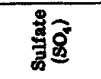 & 品 $:$ : $:$ : $:$ : $1:$ : : : \\
\hline 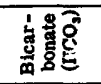 & 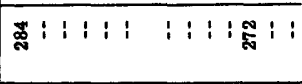 \\
\hline 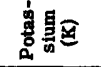 & 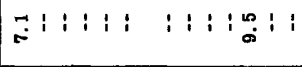 \\
\hline 急要 & 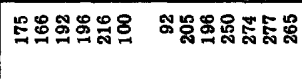 \\
\hline 题安量要 & 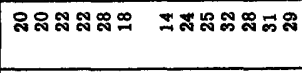 \\
\hline 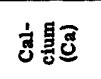 & 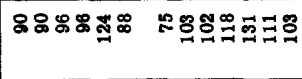 \\
\hline 象通 & $5: 1: 1: 1 \quad 1: 1: 5: 1$ \\
\hline 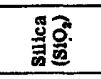 & $\bar{\infty}: 1: 1: 1: 1: \infty 1:$ \\
\hline 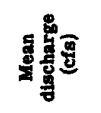 & 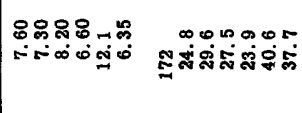 \\
\hline 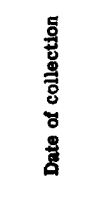 & 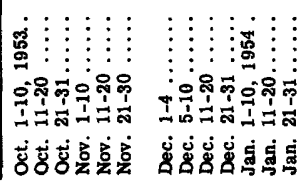 \\
\hline
\end{tabular}




\begin{tabular}{|c|c|c|c|c|}
\hline & 固 & 1：：：：：：： & i & $:$ \\
\hline & 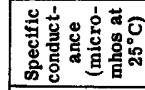 & 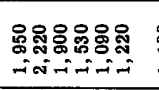 & 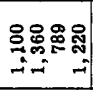 & i \\
\hline & 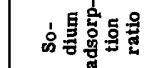 & 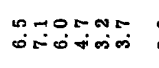 & 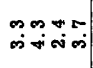 & i \\
\hline & 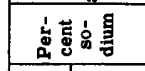 & ஜேஃ\%ッ & 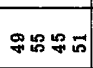 & $i$ \\
\hline & 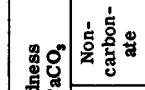 & $1: 1: 1: 1:$ & $\begin{array}{llll:}\infty & 1 & : & \vdots \\
\end{array}$ & 1 \\
\hline & 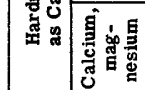 & 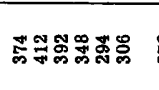 & స๊స్టిస్టి & $i$ \\
\hline & 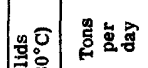 & \$5్లో & 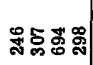 & 9 \\
\hline 总总 & 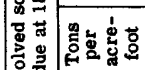 & 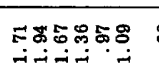 & 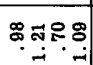 & 1 \\
\hline 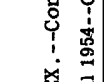 & 罢要 & 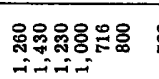 & 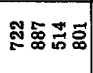 & $i$ \\
\hline 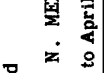 & 宮总鱼 & $1: 1: 11$ & $\begin{array}{lllll}8 & 1 & 1 & i \\
0 & 1 & & \end{array}$ & $i$ \\
\hline 总运照 & 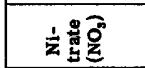 & $1: 1: 1: 1$ & $\begin{array}{lllll}5 & 1 & 1 & 1 \\
0\end{array}$ & 1 \\
\hline 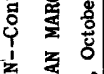 & 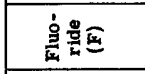 & $1: 11: 11$ & $\begin{array}{lllll}0 & 1 & 1 & 1 \\
0 & & \end{array}$ & $i$ \\
\hline 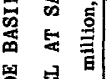 & 형훈? & 1:1:1:1: & $\begin{array}{lllll}8 & 1 & 1 & 1\end{array}$ & $:$ \\
\hline 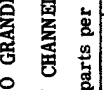 & 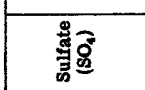 & $11: 1: 1$ & ๙ & i \\
\hline 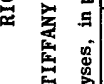 & 穿若 & $1: 1: 14: 19$ & 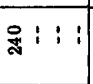 & $:$ \\
\hline 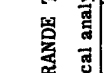 & 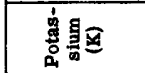 & 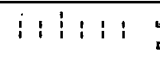 & 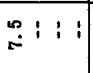 & $i$ \\
\hline 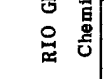 & 息 & 跑 & ్ㅜㄷㅀㅇ & $i$ \\
\hline & 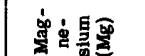 & 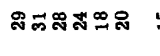 & ロエジニ & $i$ \\
\hline & ฮึ & 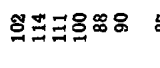 & $\varpi \approx \nsubseteq \infty$ & $i$ \\
\hline & 후워 & $1: 1: 1:$ & $\begin{array}{lllll}5 & 1 & 1 & \vdots \\
0 & & \end{array}$ & 1 \\
\hline & 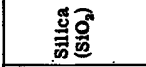 & $1: 1: 1: 8$ & 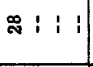 & i \\
\hline & 递要 & 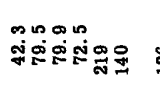 & 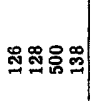 & $\begin{array}{l}0 \\
0 \\
0\end{array}$ \\
\hline & 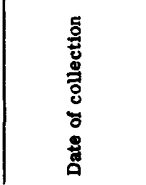 & 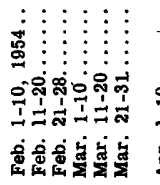 & 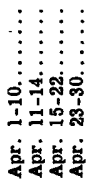 & 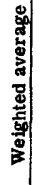 \\
\hline
\end{tabular}


RIO GRANDE BASIN

RIO GRANDE BASIN--Continued

RIO GRANDE TIFFANY CHANNEL AT SAN MARCIAL, N. MEX.--Continued

Temperature $\left({ }^{\circ} \mathrm{F}\right)$ of water October 1953 to April 1954

Once-daily measurement, generally between 11 a.m. and 6 p.m.

\begin{tabular}{|c|c|c|c|c|c|c|c|c|c|c|c|c|}
\hline Day & Oct. & Nov. & Dec. & Jan. & Feb. & Mar. & Apr. & May & June & July & Aug. & Sept. \\
\hline $\begin{array}{l}1 \\
2\end{array}$ & $\begin{array}{r}\text { a } 53 \\
62\end{array}$ & $\ddot{--}$ & 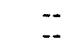 & $\begin{array}{l}35 \\
40\end{array}$ & $\begin{array}{l}47 \\
45\end{array}$ & $\begin{array}{l}48 \\
48\end{array}$ & $\begin{array}{l}61 \\
55\end{array}$ & & & & & \\
\hline $\begin{array}{l}2 \\
3\end{array}$ & -- & - & - & 35 & 44 & $\begin{array}{l}48 \\
48\end{array}$ & $\begin{array}{l}30 \\
56\end{array}$ & & & & & \\
\hline 4 & a 55 & -- & 33 & $=$ & 46 & -- & 58 & & & & & \\
\hline 5 & & -- & -- & & 48 & 53 & 59 & & & & & \\
\hline 6 & a 56 & - & 36 & 35 & 46 & -- & 66 & & & & & \\
\hline 7 & $=-$ & -- & 36 & 35 & 48 & 48 & 67 & & & & & \\
\hline 8 & a 53 & -- & 36 & 37 & 45 & a 48 & a 49 & & & & & \\
\hline 9 & -- & -- & 34 & 40 & 45 & a 50 & a 51 & & & & & \\
\hline 10 & -- & -- & -- & & - & 57 & 65 & & & & & \\
\hline 11 & 55 & -- & 36 & 35 & - & 55 & 65 & & & & & \\
\hline 12 & -- & a 42 & 35 & 34 & a 48 & 42 & 51 & & & & & \\
\hline 13 & -- & $=$ & 35 & a 36 & 53 & 38 & a 58 & & & & & \\
\hline 14 & -- & 50 & a 34 & 38 & a 48 & 45 & 59 & & & & & \\
\hline 15 & -- & a 38 & a 35 & - & 50 & 45 & a 53 & & & & & \\
\hline 16 & 55 & 42 & 39 & 38 & a 46 & a 45 & a 50 & & & & & \\
\hline 17 & 55 & -- & -- & -- & 51 & a 42 & a 57 & & & & & \\
\hline 18 & 55 & $-\cdot$ & a 37 & ت- & a 47 & a 43 & a 57 & & & & & \\
\hline 19 & 57 & $\because$ & $\begin{array}{r}\text { a 37 } \\
38\end{array}$ & $\begin{array}{l}44 \\
44\end{array}$ & $\begin{array}{l}49 \\
48\end{array}$ & $\begin{array}{r}\text { a } 42 \\
48\end{array}$ & 67 & & & & & \\
\hline 20 & 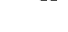 & & 00 & 44 & & & d ou & & & & & \\
\hline 21 & - & -- & 38 & -- & 48 & 57 & 59 & & & & & \\
\hline 22 & -- & 39 & $=$ & 44 & 50 & 56 & 69 & & & & & \\
\hline 23 & -- & -- & 34 & 41 & 53 & a 53 & 67 & & & & & \\
\hline $\begin{array}{l}24 \\
25\end{array}$ & $=$ & 45 & 32 & $\overline{42}$ & $\begin{array}{l}53 \\
52\end{array}$ & $\begin{array}{l}\text { a } 51 \\
\text { a } 45\end{array}$ & $\begin{array}{r}66 \\
\mathrm{a} 61\end{array}$ & & & & & \\
\hline & 54 & & & 44 & 50 & & 62 & & & & & \\
\hline $\begin{array}{l}26 \\
27\end{array}$ & - & 42 & 35 & 44 & 51 & $\begin{array}{r}247 \\
56\end{array}$ & $\begin{array}{r}62 \\
\text { a } 59\end{array}$ & & & & & \\
\hline 28 & -- & 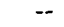 & a 35 & 46 & 44 & 55 & a 62 & & & & & \\
\hline 29 & $=$ & -- & 36 & 45 & - & 53 & a 53 & & & & & \\
\hline 30 & $\begin{array}{l}55 \\
55\end{array}$ & 39 & $\begin{array}{l}36 \\
34\end{array}$ & $\begin{array}{l}48 \\
44\end{array}$ & -- & a 48 & a 58 & & & & & \\
\hline 31 & & & & & & $2+0$ & - & & & & & \\
\hline Aver- & - & & & & & & & & & & & \\
\hline age & - & -- & $\sim$ & 48 & 48 & 49 & 59 & & & & & \\
\hline
\end{tabular}

a Measurement before 11 a. m.

Suspended sediment for period October 1953 to April 1954

\begin{tabular}{|c|c|c|c|c|c|c|c|c|c|}
\hline \multirow[b]{3}{*}{ Day } & \multicolumn{3}{|c|}{ October } & \multicolumn{3}{|c|}{ November } & \multicolumn{3}{|c|}{ December } \\
\hline & \multirow[b]{2}{*}{$\begin{array}{l}\text { Mean } \\
\text { dis- } \\
\text { charge } \\
\text { (cfs) }\end{array}$} & \multicolumn{2}{|c|}{ Suspended sediment } & \multirow[b]{2}{*}{$\begin{array}{l}\text { Mean } \\
\text { dis- } \\
\text { charge } \\
\text { (cfs) }\end{array}$} & \multicolumn{2}{|c|}{ Suspended sediment } & \multirow[b]{2}{*}{$\begin{array}{l}\text { Mean } \\
\text { dis- } \\
\text { charge } \\
\text { (cfs) }\end{array}$} & \multicolumn{2}{|c|}{ Suspended sediment } \\
\hline & & $\begin{array}{l}\text { Mean } \\
\text { concen- } \\
\text { tration } \\
\text { (ppm) }\end{array}$ & $\begin{array}{l}\text { Tons } \\
\text { per } \\
\text { day }\end{array}$ & & $\begin{array}{c}\text { Mean } \\
\text { concen- } \\
\text { tration } \\
\text { (ppm) }\end{array}$ & $\begin{array}{l}\text { Tons } \\
\text { per } \\
\text { day }\end{array}$ & & $\begin{array}{c}\text { Mean } \\
\text { concen- } \\
\text { tration } \\
(\mathrm{ppm})\end{array}$ & $\begin{array}{l}\text { Tons } \\
\text { per } \\
\text { day }\end{array}$ \\
\hline $\begin{array}{l}1 . \ldots \ldots \\
2 . \ldots \ldots \\
3 . \ldots \ldots \\
4 \ldots \ldots \\
5 . \ldots \ldots\end{array}$ & $\begin{array}{l}9 \\
9 \\
9 \\
6 \\
8\end{array}$ & $\begin{array}{l}295 \\
275 \\
260 \\
293 \\
270\end{array}$ & $\begin{array}{r}7 \\
7 \\
\times 6 \\
5 \\
6\end{array}$ & $\begin{array}{l}7 \\
7 \\
7 \\
7 \\
7\end{array}$ & $\begin{array}{l}192 \\
190 \\
180 \\
200 \\
226\end{array}$ & $\begin{array}{r}4 \\
24 \\
3 \\
4 \\
4\end{array}$ & $\begin{array}{r}122 \\
151 \\
187 \\
228 \\
40\end{array}$ & $\begin{array}{l}5,400 \\
5,900 \\
6,900 \\
7,340 \\
2,900\end{array}$ & $\begin{array}{r}\text { a } 1,800 \\
\text { a } 2,400 \\
\text { a } 3,500 \\
4,520 \\
\text { sa } 430\end{array}$ \\
\hline $\begin{array}{r}6 \ldots \ldots \\
7 \ldots \ldots \\
8 \ldots \ldots \\
9 . \ldots \ldots \\
10 . \ldots \ldots\end{array}$ & $\begin{array}{r}10 \\
7 \\
6 \\
6 \\
6\end{array}$ & $\begin{array}{l}263 \\
230 \\
200 \\
200 \\
200\end{array}$ & $\begin{array}{r}7 \\
\text { a } 4 \\
3 \\
\text { a } 3 \\
\text { a } 3\end{array}$ & $\begin{array}{l}7 \\
6 \\
6 \\
6 \\
6\end{array}$ & $\begin{array}{l}205 \\
190 \\
170 \\
150 \\
166\end{array}$ & $\begin{array}{r}4 \\
\text { a } 3 \\
\text { a } 3 \\
\text { a } 2 \\
3\end{array}$ & $\begin{array}{l}18 \\
19 \\
28 \\
22 \\
22\end{array}$ & $\begin{array}{l}390 \\
150 \\
300 \\
350 \\
141\end{array}$ & $\begin{array}{r}19 \\
8 \\
23 \\
21 \\
8\end{array}$ \\
\hline $\begin{array}{l}11 \ldots \ldots \\
12 \ldots \ldots \\
13 \ldots \ldots \\
14 \ldots \\
15 . \ldots\end{array}$ & $\begin{array}{l}6 \\
6 \\
6 \\
6 \\
7\end{array}$ & $\begin{array}{l}208 \\
240 \\
285 \\
240 \\
180\end{array}$ & $\begin{array}{r}3 \\
\mathrm{a} 4 \\
5 \\
\mathrm{a} 4 \\
\mathrm{a} 3\end{array}$ & $\begin{array}{l}13 \\
11 \\
21 \\
17 \\
10\end{array}$ & $\begin{array}{l}350 \\
340 \\
290 \\
302 \\
250\end{array}$ & $\begin{array}{r}12 \\
10 \\
\mathrm{a} 16 \\
14 \\
7\end{array}$ & $\begin{array}{l}22 \\
23 \\
22 \\
22 \\
22\end{array}$ & $\begin{array}{r}227 \\
122 \\
144 \\
89 \\
89\end{array}$ & $\begin{array}{r}13 \\
8 \\
9 \\
5 \\
5\end{array}$ \\
\hline $\begin{array}{l}16 \ldots \ldots \\
17 \ldots \ldots \\
18 \ldots \ldots \\
19 \ldots \ldots \\
20 \ldots \ldots\end{array}$ & $\begin{array}{l}9 \\
8 \\
8 \\
8 \\
9\end{array}$ & $\begin{array}{l}210 \\
240 \\
263 \\
223 \\
265\end{array}$ & $\begin{array}{l}5 \\
5 \\
6 \\
5 \\
6\end{array}$ & $\begin{array}{r}9 \\
9 \\
10 \\
11 \\
10\end{array}$ & $\begin{array}{l}225 \\
197 \\
245 \\
218 \\
133\end{array}$ & $\begin{array}{l}5 \\
5 \\
7 \\
6 \\
4\end{array}$ & $\begin{array}{l}23 \\
56 \\
46 \\
33 \\
27\end{array}$ & $\begin{array}{r}110 \\
140 \\
110 \\
81 \\
100\end{array}$ & $\begin{array}{r}7 \\
\times 21 \\
14 \\
7 \\
7\end{array}$ \\
\hline $\begin{array}{l}21 \ldots \ldots \\
22 \ldots \ldots \\
23 . \ldots \\
24 \ldots \\
25 . \ldots\end{array}$ & $\begin{array}{l}9 \\
9 \\
8 \\
8 \\
8\end{array}$ & $\begin{array}{l}250 \\
232 \\
220 \\
210 \\
200\end{array}$ & $\begin{array}{r}\text { a } 6 \\
6 \\
\text { a } 5 \\
\text { a } 5 \\
\text { a } 4\end{array}$ & $\begin{array}{r}8 \\
11 \\
30 \\
58 \\
65\end{array}$ & $\begin{array}{r}70 \\
105 \\
1,200 \\
1,800 \\
815\end{array}$ & $\begin{array}{r}\text { a } 2 \\
3 \\
\text { sa } 120 \\
\text { a } 280 \\
143\end{array}$ & $\begin{array}{l}26 \\
25 \\
23 \\
24 \\
26\end{array}$ & $\begin{array}{r}122 \\
120 \\
112 \\
91 \\
--\end{array}$ & $\begin{array}{r}9 \\
\mathrm{a} 8 \\
7 \\
6 \\
\mathrm{e} 8\end{array}$ \\
\hline $\begin{array}{l}26 \ldots \ldots \\
27 \ldots \ldots \\
28 . \ldots \ldots \\
29 \ldots \ldots \\
30 \ldots \ldots \\
31 \ldots \ldots\end{array}$ & $\begin{array}{l}8 \\
8 \\
8 \\
8 \\
8 \\
8 \\
\end{array}$ & $\begin{array}{l}206 \\
180 \\
162 \\
180 \\
207 \\
192 \\
\end{array}$ & $\begin{array}{r}4 \\
\mathrm{a} 4 \\
3 \\
\mathrm{a} 4 \\
4 \\
4\end{array}$ & $\begin{array}{r}71 \\
81 \\
117 \\
90 \\
104 \\
--\end{array}$ & $\begin{array}{l}2,840 \\
3,070 \\
4,200 \\
4,800 \\
4,900 \\
\end{array}$ & $\begin{array}{r}544 \\
671 \\
\text { sa } 1,600 \\
\text { a 1, 200 } \\
1,380 \\
-- \\
\end{array}$ & $\begin{array}{l}27 \\
30 \\
30 \\
30 \\
31 \\
30 \\
\end{array}$ & $\begin{array}{r}135 \\
130 \\
66 \\
113 \\
430 \\
480 \\
\end{array}$ & $\begin{array}{r}10 \\
11 \\
5 \\
9 \\
36 \\
39 \\
\end{array}$ \\
\hline Total. & 239 & -- & 146 & 822 & -- & 6,063 & 1,435 & $\cdots$ & 12,973 \\
\hline
\end{tabular}

e Estimated.

s Computed by subdividing day.

a Computed from estimated concentration graph.

$4888170-59-29$ 
RIO GRANDE BASIN--Continued

RIO GRANDE TIFFANY CHANNEL AT SAN MARCIAL, N. MEX.--Continued

Suspended sediment for period October 1953 to April 1954--Continued

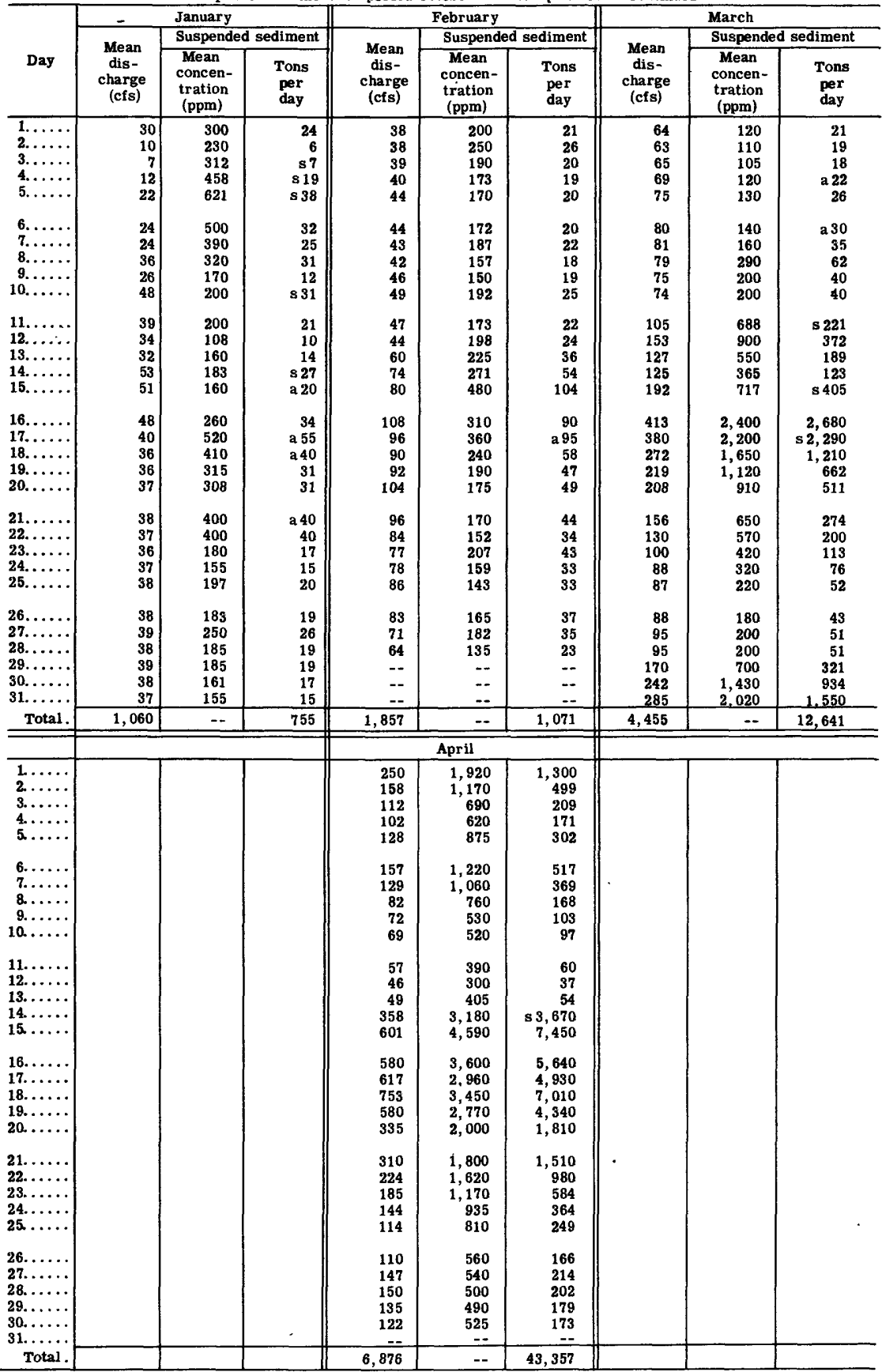

Total discharge for period (cfs-days) $\ldots \ldots \ldots \ldots \ldots \ldots \ldots \ldots \ldots \ldots \ldots \ldots \ldots \ldots \ldots \ldots \ldots \ldots \ldots, \mathbf{7 4 4}$

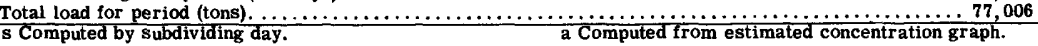




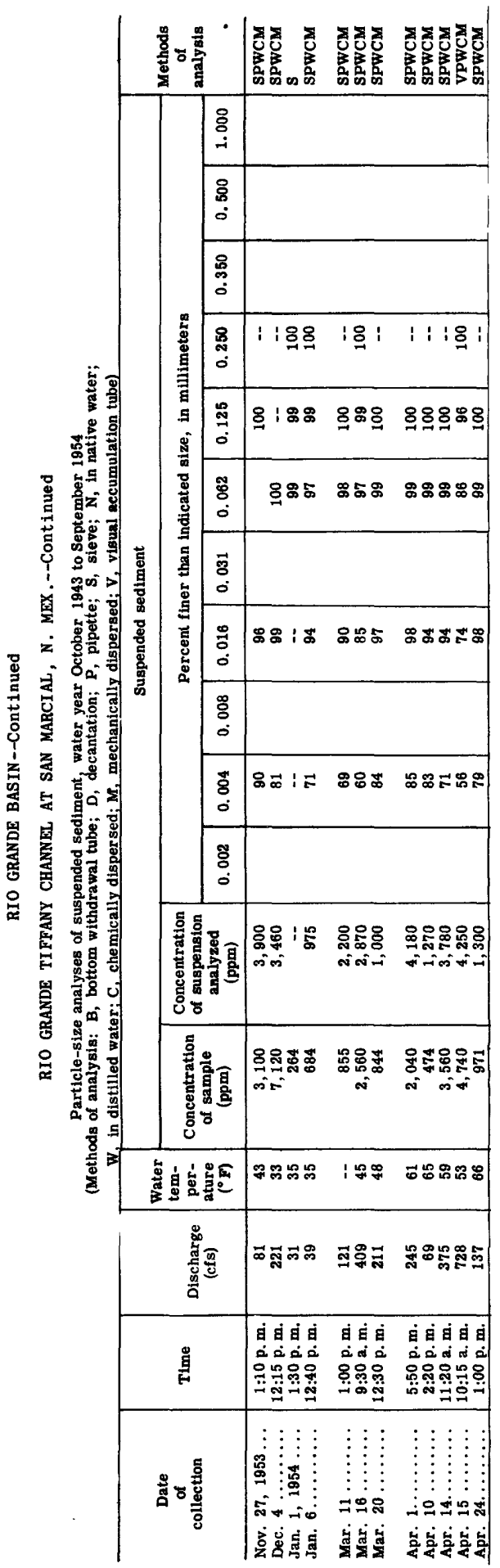




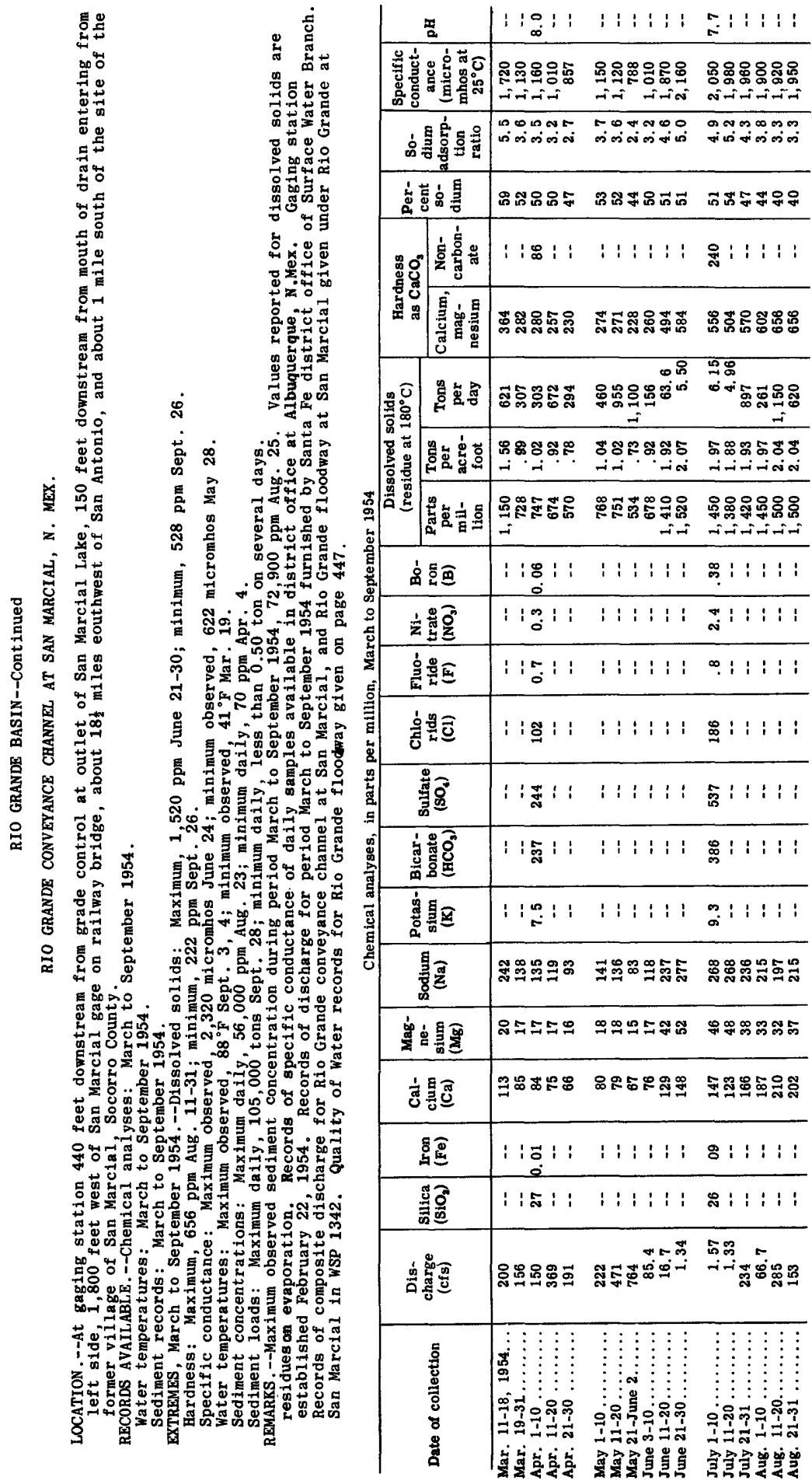




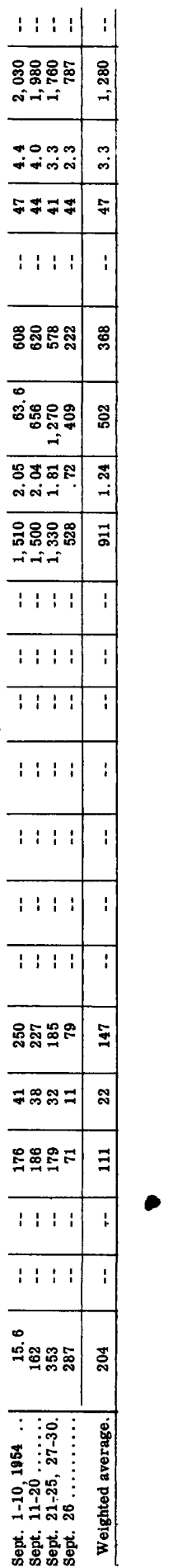


RIO GRANDE BASIN--Continued

RIO GRANDE CONVEYANCE CHANNEL AT SAN MARCIAL, N. MEX.--Continued

Temperature $\left({ }^{\circ} \mathrm{F}\right)$ of water March to September 1954

Once-daily measurement, generally between $10 \mathrm{a} . \mathrm{m}$. and $6 \mathrm{p.m}$.

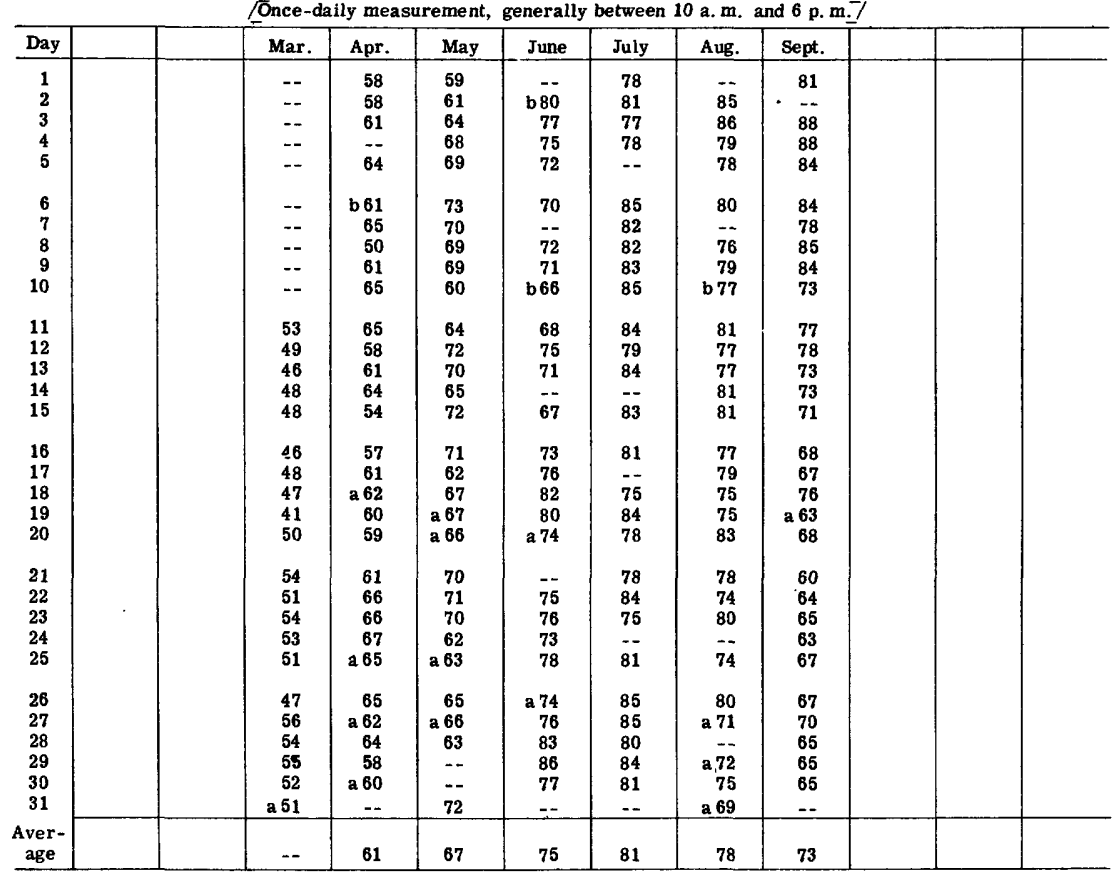

a Measurement prior to 10 a. $\mathrm{m}$.

b Measurement after 6 p.m.

Suspended sediment, March to September 1954

\begin{tabular}{|c|c|c|c|}
\hline \multirow[b]{3}{*}{ Day } & \multicolumn{3}{|c|}{ March } \\
\hline & \multirow[b]{2}{*}{$\begin{array}{l}\text { Mean } \\
\text { dis - } \\
\text { charge } \\
\text { (cfs) }\end{array}$} & \multicolumn{2}{|c|}{ Suspended sediment } \\
\hline & & $\begin{array}{c}\text { Mean } \\
\text { concen- } \\
\text { tration } \\
\text { (ppm) }\end{array}$ & $\begin{array}{l}\text { Tons } \\
\text { per } \\
\text { day }\end{array}$ \\
\hline $\begin{array}{l}11 \ldots \ldots \\
12 \ldots \ldots \ldots \\
13 \ldots \ldots \ldots \\
14 \ldots \ldots \ldots \\
15 . \ldots \ldots\end{array}$ & \begin{tabular}{r|}
65 \\
116 \\
131 \\
126 \\
143
\end{tabular} & $\begin{array}{l}254 \\
222 \\
168 \\
120 \\
146\end{array}$ & $\begin{array}{r}846 \\
70 \\
69 \\
41 \\
66\end{array}$ \\
\hline $\begin{array}{l}16 \ldots \ldots \\
17 \ldots \ldots \\
18 \ldots \ldots \\
19 \ldots \ldots \\
20 \ldots \ldots\end{array}$ & $\begin{array}{l}270 \\
392 \\
365 \\
284 \\
242\end{array}$ & $\begin{array}{l}317 \\
175 \\
209 \\
162 \\
110\end{array}$ & $\begin{array}{r}\text { s } 222 \\
185 \\
200 \\
117 \\
72\end{array}$ \\
\hline $\begin{array}{l}21 \ldots \ldots \\
22 . \ldots \ldots \\
23 . \ldots \ldots \\
24 . \ldots \ldots \\
25 . \ldots \ldots\end{array}$ & $\begin{array}{r}207 \\
160 \\
126 \\
110 \\
96\end{array}$ & $\begin{array}{l}153 \\
190 \\
173 \\
180 \\
280\end{array}$ & $\begin{array}{l}86 \\
82 \\
59 \\
53 \\
73\end{array}$ \\
\hline $\begin{array}{l}26 \ldots \ldots \\
27 . \ldots \ldots \\
28 . \ldots \ldots \\
29 . \ldots \ldots \\
30 \ldots \ldots \\
31 . \ldots \ldots\end{array}$ & $\begin{array}{r}94 \\
91 \\
92 \\
106 \\
170 \\
250 \\
\end{array}$ & $\begin{array}{l}147 \\
141 \\
125 \\
153 \\
182 \\
182 \\
\end{array}$ & $\begin{array}{r}37 \\
35 \\
31 \\
44 \\
84 \\
123 \\
\end{array}$ \\
\hline Total. & 3,626 & -- & 1,775 \\
\hline
\end{tabular}


RIO GRANDE BASIN--Continued

RIO GRANDE CONVEYANCE CHANNEL AT SAN MARCIAL, N, MEX.--Continued

Suspended sediment, March to September 1954--Continued

\begin{tabular}{|c|c|c|c|c|c|c|c|c|c|}
\hline \multirow[b]{3}{*}{ Day } & \multicolumn{3}{|c|}{ April } & \multicolumn{3}{|c|}{ May } & \multicolumn{3}{|c|}{ June } \\
\hline & \multirow[b]{2}{*}{$\begin{array}{c}\text { Mean } \\
\text { dis- } \\
\text { charge } \\
\text { (cfs) }\end{array}$} & \multicolumn{2}{|c|}{ Suspended sediment } & \multirow[b]{2}{*}{$\begin{array}{l}\text { Mean } \\
\text { dis- } \\
\text { charge } \\
\text { (cfs) }\end{array}$} & \multicolumn{2}{|c|}{ Suspended sediment } & \multirow[b]{2}{*}{$\begin{array}{l}\text { Mean } \\
\text { diss- } \\
\text { charge } \\
\text { (cfs) }\end{array}$} & \multicolumn{2}{|c|}{ Suspended sediment } \\
\hline & & $\begin{array}{l}\text { Mean } \\
\text { concen- } \\
\text { tration } \\
\text { (ppm) }\end{array}$ & $\begin{array}{l}\text { Tons } \\
\text { per } \\
\text { day }\end{array}$ & & $\begin{array}{l}\text { Mean } \\
\text { concen- } \\
\text { tration } \\
\text { (ppm) }\end{array}$ & $\begin{array}{l}\text { Tons } \\
\text { per } \\
\text { day }\end{array}$ & & $\begin{array}{c}\text { Mean } \\
\text { concen- } \\
\text { tration } \\
(\text { ppm) }\end{array}$ & $\begin{array}{l}\text { Tons } \\
\text { per } \\
\text { day }\end{array}$ \\
\hline $\begin{array}{l}1 \ldots \ldots \\
2 \ldots \ldots \\
3 . \ldots \ldots \\
4 \ldots \ldots \\
5 \ldots \ldots\end{array}$ & $\begin{array}{l}276 \\
234 \\
165 \\
130 \\
120\end{array}$ & $\begin{array}{r}134 \\
112 \\
87 \\
70 \\
110\end{array}$ & $\begin{array}{r}100 \\
71 \\
39 \\
\mathrm{a} 25 \\
36\end{array}$ & $\begin{array}{l}113 \\
112 \\
106 \\
103 \\
192\end{array}$ & \begin{tabular}{l|l|}
258 \\
178 \\
163 \\
190 \\
168
\end{tabular} & $\begin{array}{r}\mathrm{s} 78 \\
54 \\
47 \\
53 \\
87\end{array}$ & $\begin{array}{r}198 \\
161 \\
134 \\
112 \\
96\end{array}$ & $\begin{array}{l}165 \\
178 \\
233 \\
261 \\
308\end{array}$ & $\begin{array}{l}88 \\
77 \\
84 \\
79 \\
80\end{array}$ \\
\hline $\begin{array}{r}6 \ldots \ldots \\
7 \ldots \ldots \\
8 \ldots \ldots \\
9 \ldots \ldots \\
10 \ldots \ldots\end{array}$ & $\begin{array}{r}134 \\
147 \\
121 \\
92 \\
81\end{array}$ & $\begin{array}{l}148 \\
198 \\
190 \\
196 \\
203\end{array}$ & $\begin{array}{l}54 \\
79 \\
62 \\
49 \\
44\end{array}$ & $\begin{array}{l}360 \\
456 \\
350 \\
244 \\
185\end{array}$ & $\begin{array}{r}98 \\
134 \\
110 \\
140 \\
265\end{array}$ & $\begin{array}{r}95 \\
165 \\
104 \\
92 \\
132\end{array}$ & $\begin{array}{l}83 \\
\mathbf{7 7} \\
\mathbf{6 9} \\
\mathbf{5 9} \\
\mathbf{5 3}\end{array}$ & $\begin{array}{l}407 \\
310 \\
263 \\
325 \\
231\end{array}$ & $\begin{array}{r}91 \\
264 \\
49 \\
52 \\
33\end{array}$ \\
\hline $\begin{array}{l}11 \ldots \ldots \\
12 \ldots \ldots \\
13 \ldots \ldots \\
14 . \ldots \ldots \\
15 \ldots \ldots\end{array}$ & \begin{tabular}{r|}
76 \\
56 \\
49 \\
111 \\
409
\end{tabular} & $\begin{array}{l}335 \\
322 \\
222 \\
300 \\
525\end{array}$ & $\begin{array}{r}69 \\
49 \\
29 \\
\text { s } 106 \\
\text { s } 574\end{array}$ & $\begin{array}{l}174 \\
177 \\
244 \\
310 \\
445\end{array}$ & $\begin{array}{l}246 \\
172 \\
163 \\
167 \\
134\end{array}$ & \begin{tabular}{r|r}
116 \\
82 \\
107 \\
140 \\
161
\end{tabular} & $\begin{array}{c}47 \\
44 \\
41 \\
28 \\
1.2\end{array}$ & $\begin{array}{l}230 \\
273 \\
237 \\
254 \\
215\end{array}$ & $\begin{array}{r}\mathrm{a} 29 \\
32 \\
26 \\
\mathrm{~s} 16 \\
1\end{array}$ \\
\hline $\begin{array}{l}16 \ldots \ldots \\
17 \ldots \ldots \\
18 \ldots \ldots \\
19 \ldots \ldots \\
20 . \ldots \ldots\end{array}$ & $\begin{array}{l}570 \\
600 \\
660 \\
680 \\
480\end{array}$ & $\begin{array}{l}370 \\
138 \\
210 \\
318 \\
194\end{array}$ & $\begin{array}{l}569 \\
224 \\
374 \\
584 \\
251\end{array}$ & $\begin{array}{r}512 \\
534 \\
546 \\
731 \\
1,040\end{array}$ & $\begin{array}{l}135 \\
180 \\
170 \\
292 \\
258\end{array}$ & $\begin{array}{r}187 \\
260 \\
251 \\
\text { s } 592 \\
\text { s 719 }\end{array}$ & $\begin{array}{l}1.1 \\
1.2 \\
1.2 \\
1.2 \\
1.2\end{array}$ & $\begin{array}{l}157 \\
150 \\
123 \\
120 \\
123\end{array}$ & $\begin{array}{l}(\mathrm{t}) \\
(\mathrm{t}) \\
(\mathrm{t}) \\
(\mathrm{t}) \\
(\mathrm{t})\end{array}$ \\
\hline $\begin{array}{l}21 \ldots \ldots \\
22 \ldots \ldots \\
23 \ldots \ldots \\
24 \ldots \ldots \\
25 \ldots \ldots\end{array}$ & $\begin{array}{l}364 \\
302 \\
250 \\
192 \\
153\end{array}$ & $\begin{array}{l}110 \\
130 \\
235 \\
184 \\
182\end{array}$ & $\begin{array}{r}108 \\
106 \\
159 \\
95 \\
75\end{array}$ & $\begin{array}{r}935 \\
910 \\
1,160 \\
1,110 \\
1,080\end{array}$ & $\begin{array}{l}208 \\
162 \\
212 \\
344 \\
222\end{array}$ & $\begin{array}{r}525 \\
\mathrm{~s} 398 \\
664 \\
1,030 \\
647\end{array}$ & $\begin{array}{l}1.2 \\
1.1 \\
1.0 \\
1.1 \\
1.6\end{array}$ & $\begin{array}{l}130 \\
180 \\
187 \\
173 \\
127\end{array}$ & (t) $\begin{array}{l} \\
1 \\
1 \\
1 \\
1\end{array}$ \\
\hline $\begin{array}{l}26 . \ldots \ldots \\
27 . \ldots \ldots \\
28 \ldots \ldots \\
29 . \ldots \ldots \\
30 . \ldots \ldots \\
31 . \ldots .\end{array}$ & $\begin{array}{r}129 \\
124 \\
132 \\
140 \\
125 \\
--\end{array}$ & $\begin{array}{r}214 \\
176 \\
164 \\
165 \\
161 \\
-- \\
\end{array}$ & $\begin{array}{l}75 \\
59 \\
58 \\
62 \\
54 \\
--\end{array}$ & $\begin{array}{r}1,210 \\
1,210 \\
733 \\
489 \\
423 \\
310 \\
\end{array}$ & $\begin{array}{l}209 \\
215 \\
196 \\
143 \\
200 \\
188\end{array}$ & $\begin{array}{r}683 \\
702 \\
\mathrm{~s} 396 \\
189 \\
\mathrm{a} 230 \\
157\end{array}$ & $\begin{array}{r}1.4 \\
1.5 \\
1.5 \\
1.5 \\
1.5 \\
--\end{array}$ & $\begin{array}{r}201 \\
188 \\
200 \\
183 \\
207 \\
--\end{array}$ & $\begin{array}{r}1 \\
1 \\
1 \\
1 \\
1 \\
--\end{array}$ \\
\hline \multirow[t]{2}{*}{ Total. } & 7,102 & -- & 4,239 & 16,504 & -- & 9,143 & $1,222,5$ & - & 813 \\
\hline & \multicolumn{3}{|c|}{ July } & \multicolumn{3}{|c|}{ August } & \multicolumn{3}{|c|}{ September } \\
\hline $\begin{array}{l}1 . \ldots \ldots \\
2 \ldots \ldots \\
3 \ldots \ldots \\
4 \ldots \ldots \\
5 . \ldots \ldots\end{array}$ & $\begin{array}{l}1.5 \\
1.5 \\
1.6 \\
1.6 \\
1.6\end{array}$ & $\begin{array}{l}120 \\
115 \\
125 \\
135 \\
160\end{array}$ & $\begin{array}{ll}(t) & \\
(t) & \\
& 1 \\
& 1 \\
& 1 \\
& 1\end{array}$ & $\begin{array}{l}38 \\
24 \\
19 \\
18 \\
17\end{array}$ & $\begin{array}{l}450 \\
400 \\
360 \\
305 \\
282\end{array}$ & $\begin{array}{r}246 \\
26 \\
18 \\
15 \\
13\end{array}$ & $\begin{array}{l}27 \\
21 \\
22 \\
18 \\
18\end{array}$ & $\begin{array}{l}900 \\
860 \\
750 \\
586 \\
545\end{array}$ & $\begin{array}{r}66 \\
\mathrm{a} 49 \\
45 \\
28 \\
26\end{array}$ \\
\hline $\begin{array}{r}6 \ldots \ldots \\
7 \ldots \ldots \\
8 \ldots \ldots \\
9 \ldots \ldots \\
10 \ldots \ldots\end{array}$ & $\begin{array}{l}1.7 \\
1.6 \\
1.6 \\
1.5 \\
1.5\end{array}$ & $\begin{array}{l}208 \\
150 \\
122 \\
183 \\
177\end{array}$ & $\begin{array}{l}1 \\
1 \\
1 \\
1 \\
1\end{array}$ & $\begin{array}{r}19 \\
67 \\
105 \\
205 \\
155\end{array}$ & $\begin{array}{l}258 \\
360 \\
312 \\
223 \\
222\end{array}$ & $\begin{array}{r}13 \\
\text { sa } 70 \\
88 \\
123 \\
93\end{array}$ & $\begin{array}{c}16 \\
13 \\
10 \\
9.0 \\
2.0\end{array}$ & $\begin{array}{l}450 \\
575 \\
475 \\
345 \\
475\end{array}$ & $\begin{array}{r}19 \\
20 \\
13 \\
8 \\
3\end{array}$ \\
\hline $\begin{array}{l}11 \ldots \ldots \\
12 \ldots \ldots \\
13 \ldots \ldots \\
14 \ldots \ldots \\
15 \ldots \ldots\end{array}$ & $\begin{array}{l}1.4 \\
1.4 \\
1.4 \\
1.3 \\
1.3\end{array}$ & $\begin{array}{l}180 \\
182 \\
180 \\
190 \\
195\end{array}$ & $\begin{array}{r}1 \\
1 \\
1 \\
a 1 \\
1\end{array}$ & $\begin{array}{l}133 \\
320 \\
288 \\
216 \\
111\end{array}$ & $\begin{array}{l}229 \\
200 \\
220 \\
205 \\
209\end{array}$ & $\begin{array}{r}\text { s } 85 \\
173 \\
171 \\
120 \\
63\end{array}$ & $\begin{array}{r}1.9 \\
2.7 \\
43 \\
324 \\
699\end{array}$ & $\begin{array}{r}500 \\
485 \\
925 \\
2,570 \\
40,600\end{array}$ & $\begin{array}{r}3 \\
4 \\
\mathrm{~s} 100 \\
\mathrm{~s} 3,000 \\
\mathrm{~s} 80,300\end{array}$ \\
\hline $\begin{array}{l}16 \ldots \ldots \\
17 \ldots \ldots \\
18 \ldots \ldots \\
19 \ldots \ldots \\
20 . \ldots \ldots\end{array}$ & $\begin{array}{l}1.3 \\
1.3 \\
1.3 \\
1.3 \\
1.3\end{array}$ & $\begin{array}{l}193 \\
190 \\
187 \\
187 \\
184\end{array}$ & $\begin{array}{r}1 \\
21 \\
1 \\
1 \\
1\end{array}$ & $\begin{array}{r}70 \\
59 \\
554 \\
701 \\
401\end{array}$ & $\begin{array}{r}268 \\
2,130 \\
40,500 \\
33,000 \\
46,300\end{array}$ & $\begin{array}{r}51 \\
339 \\
\mathrm{~s} 63,300 \\
\mathrm{~s} 64,900 \\
52,000\end{array}$ & $\begin{array}{r}\mathbf{3 3 0} \\
\mathbf{1 0 0} \\
\mathbf{5 5} \\
\mathbf{3 9} \\
\mathbf{3 0}\end{array}$ & $\begin{array}{r}29,200 \\
26,100 \\
15,500 \\
5,800 \\
1,700\end{array}$ & $\begin{array}{r}\mathrm{s} 27,600 \\
\mathrm{~s} 6,990 \\
2,300 \\
611 \\
138\end{array}$ \\
\hline $\begin{array}{l}21 \ldots \ldots \\
22 \ldots \ldots \\
23 \ldots \ldots \\
24 \ldots \ldots \\
25 \ldots \ldots\end{array}$ & $\begin{array}{r}1.4 \\
1.4 \\
1.4 \\
1.3 \\
192\end{array}$ & $\begin{array}{l}203 \\
199 \\
234 \\
230 \\
165\end{array}$ & $\begin{array}{r}1 \\
1 \\
1 \\
21 \\
86\end{array}$ & $\begin{array}{l}221 \\
207 \\
417 \\
158 \\
125\end{array}$ & $\begin{array}{l}37,600 \\
36,500 \\
56,000 \\
39,800 \\
51,500\end{array}$ & $\begin{array}{l}\text { s } 22,800 \\
\text { s } 22,600 \\
\text { sa } 66,000 \\
\text { s } 17,900 \\
\text { s } 18,700\end{array}$ & $\begin{array}{r}23 \\
18 \\
17 \\
25 \\
136\end{array}$ & $\begin{array}{r}1,040 \\
685 \\
650 \\
692 \\
2,870\end{array}$ & $\begin{array}{r}\mathrm{s} 66 \\
33 \\
30 \\
\mathrm{~s} 49 \\
\mathrm{~s} 1,060\end{array}$ \\
\hline $\begin{array}{l}26 \ldots \ldots \\
27 \ldots \ldots \\
28 . \ldots \ldots \\
29 . \ldots \ldots \\
30 \ldots \ldots \\
31 \ldots \ldots\end{array}$ & $\begin{array}{r}1,090 \\
753 \\
280 \\
128 \\
78 \\
53 \\
\end{array}$ & $\begin{array}{r}1,820 \\
1,560 \\
810 \\
690 \\
765 \\
570 \\
\end{array}$ & $\begin{array}{r}\text { s 5, } 650 \\
\text { s } 3,380 \\
612 \\
238 \\
161 \\
\text { a } 82\end{array}$ & $\begin{array}{r}246 \\
132 \\
67 \\
44 \\
32 \\
34 \\
\end{array}$ & $\begin{array}{r}24,500 \\
31,400 \\
21,000 \\
7,500 \\
1,430 \\
1,300 \\
\end{array}$ & $\begin{array}{r}16,300 \\
11,200 \\
\mathrm{a} 3,800 \\
891 \\
124 \\
119\end{array}$ & $\begin{array}{r}287 \\
786 \\
1,050 \\
912 \\
214 \\
-\end{array}$ & $\begin{array}{r}2,620 \\
24,300 \\
35,400 \\
21,600 \\
27,800 \\
\end{array}$ & $\begin{array}{r}\mathrm{s} 2,710 \\
\mathrm{~s} 52,300 \\
\mathrm{~s} 105,000 \\
\mathrm{~s} 57,100 \\
16,100 \\
\end{array}$ \\
\hline Total. & $2,608.5$ & -- & 10,232 & 5,203 & -- & 362,141 & $5,248.6$ & -- & 355,771 \\
\hline
\end{tabular}

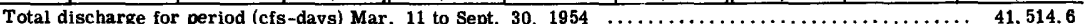

Total discharge for period (cfs-days) Mar. 11 to Sept. $30,1954 \ldots \ldots \ldots \ldots \ldots \ldots \ldots \ldots \ldots \ldots \ldots \ldots \ldots \ldots \ldots \ldots \ldots \ldots$
Total load for period (tons) Mar. 11 to Sept. $30,1954 \ldots \ldots \ldots \ldots \ldots \ldots \ldots \ldots \ldots$

s Computed by subdividing day.

$t$ Less than 0.50 ton.

a Computed from estimated concentration graph. 


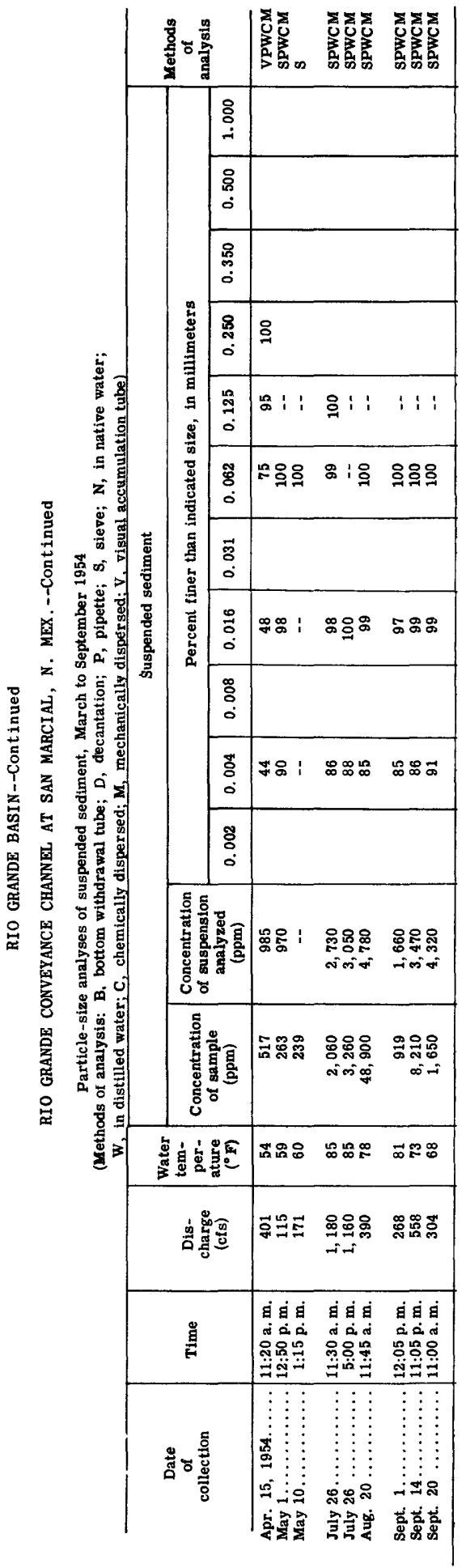




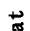

วิ

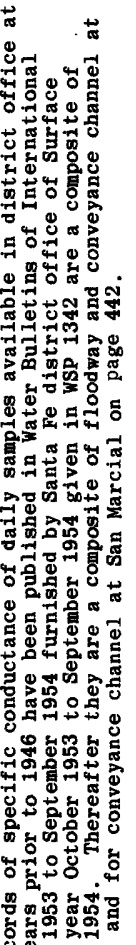

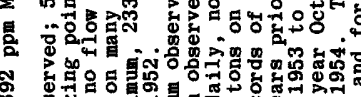
* 80 象

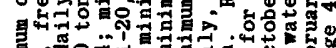

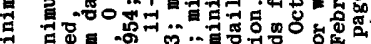

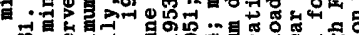

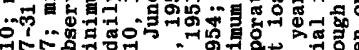

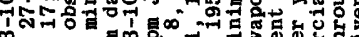

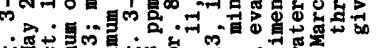

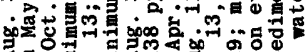

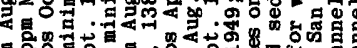

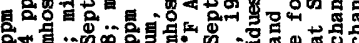

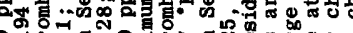

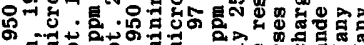

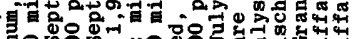

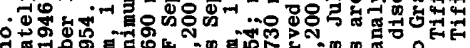

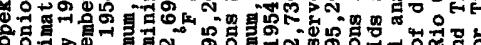
O일 둔류. 50 它

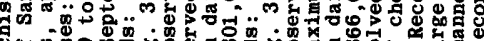

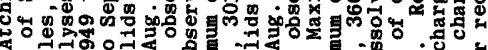

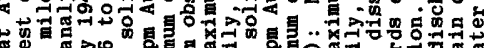
。

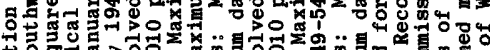

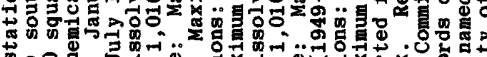

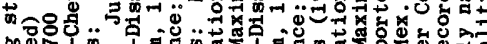
ส0

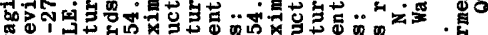

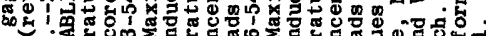

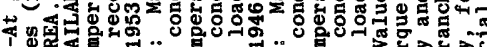

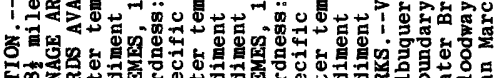

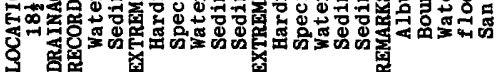

\begin{tabular}{|c|c|c|}
\hline 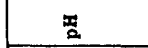 & & $\stackrel{\infty}{\infty}$ \\
\hline 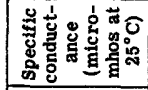 & 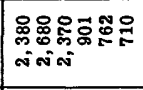 & 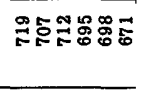 \\
\hline 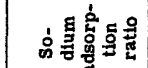 & 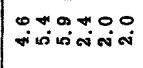 & 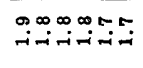 \\
\hline 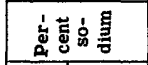 & 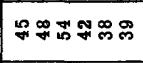 & 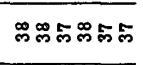 \\
\hline 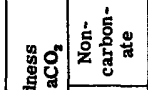 & & $\overrightarrow{5}$ \\
\hline 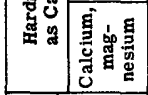 & 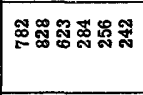 & 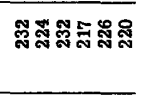 \\
\hline 萦家 & 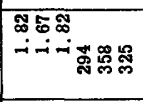 & 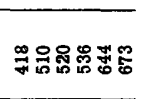 \\
\hline 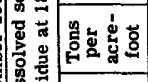 & 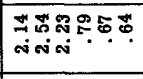 & 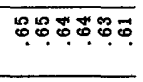 \\
\hline 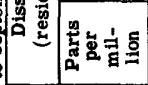 & 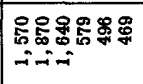 & 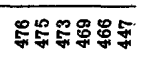 \\
\hline 富总奥 & & $\stackrel{0}{0}$ \\
\hline 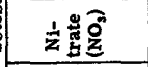 & & $\stackrel{\infty}{-}$ \\
\hline 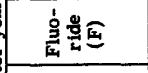 & & $\check{0}$ \\
\hline 형휼 & & ๗ \\
\hline 壱。 & & $\stackrel{?}{=}$ \\
\hline 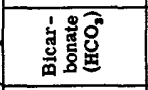 & & శ్తి \\
\hline 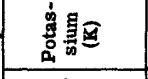 & & $\stackrel{\circ}{\circ}$ \\
\hline 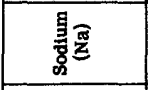 & 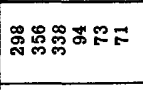 & 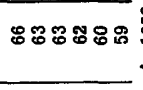 \\
\hline 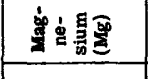 & 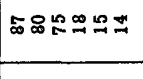 & $\cong \cong \simeq ニ \cong \cong$ \\
\hline डิ & 윰ㅇ్లో & 오요요 \\
\hline 동 & & $\stackrel{1}{\circ}$ \\
\hline 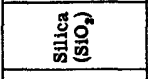 & & 5 \\
\hline 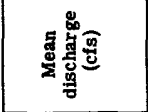 & 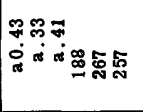 & 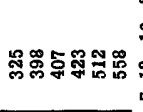 \\
\hline 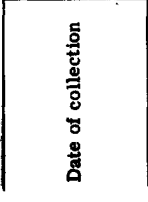 & 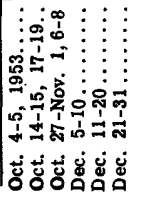 & 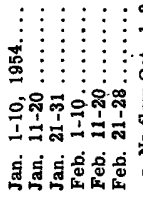 \\
\hline
\end{tabular}




\begin{tabular}{|c|c|c|c|c|c|}
\hline & $a$ & & & & \\
\hline & 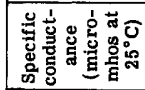 & 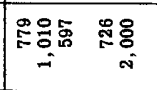 & 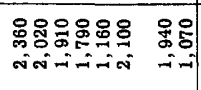 & $\begin{array}{l}0 \\
\vdots \\
-1\end{array}$ & \\
\hline & 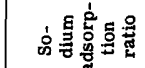 & $\mid \begin{array}{cc}0 \infty 00 \\
\text { nisi-i }\end{array}$ & 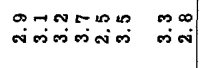 & $\stackrel{\infty}{\sim}$ & \\
\hline & 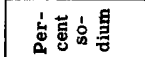 & 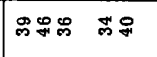 & 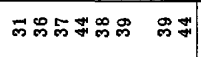 & $\infty$ & \\
\hline & 点 & & & $i$ & \\
\hline & 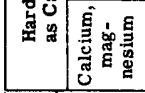 & 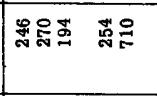 & 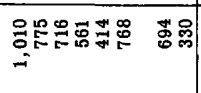 & 옳 & \\
\hline$\Xi$ & 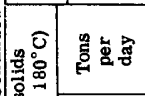 & 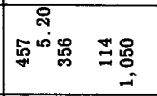 & 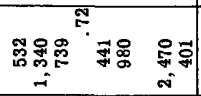 & 芯 & . \\
\hline む & 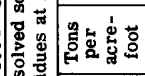 & 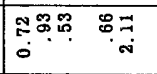 & 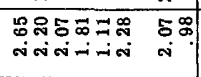 & $\begin{array}{c}0 \\
\\
-i\end{array}$ & † \\
\hline 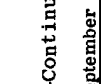 & 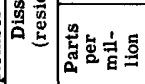 & 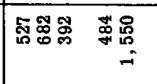 & 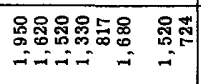 & $\overrightarrow{\mathbf{0}}$ & \\
\hline & 高总鱼 & & & $:$ & \\
\hline & 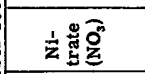 & & & $:$ & \\
\hline 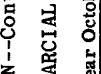 & 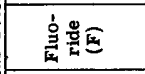 & & & : & \\
\hline 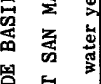 & 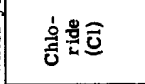 & & & : & \\
\hline 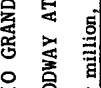 & 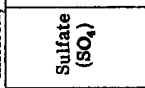 & & & : & 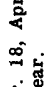 \\
\hline 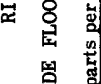 & 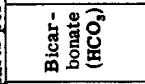 & & & : & \\
\hline 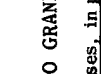 & 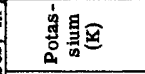 & & & : & \\
\hline శే & 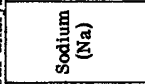 & =임ำ & 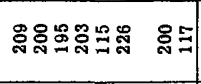 & 品 & \\
\hline 령 & 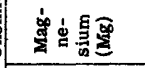 & 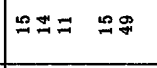 & 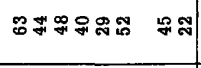 & สี & \\
\hline & 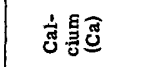 & 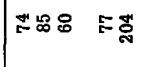 & 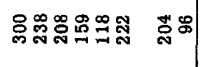 & $\Xi$ & \\
\hline & 实包 & & & $:$ & \\
\hline & 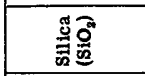 & & & 1 & \\
\hline & 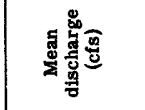 & 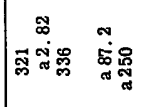 & 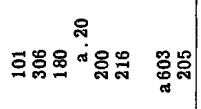 & 5 & $\vec{m}$ \\
\hline & 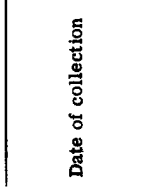 & 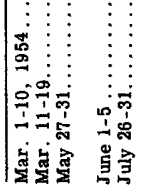 & 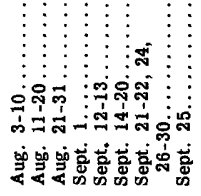 & 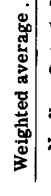 & 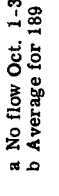 \\
\hline
\end{tabular}


RIO GRANDE BASIN--Continued

RIO GRANDE FLOODWAY AT SAN MARCIAL, N. MEX.--Continued

Temperature $\left({ }^{\circ} \mathrm{F}\right)$ of water, water year October 1953 to September 1954

/Ōnce-daily measurement, generally between $11 \mathrm{a} . \mathrm{m}$. and $6 \mathrm{p.m}$._/

\begin{tabular}{|c|c|c|c|c|c|c|c|c|c|c|c|c|}
\hline Day & Oct. & Nov. & Dec. & Jan. & Feb. & Mar. & Apr. & May & June & July & Aug. & Sept. \\
\hline $\begin{array}{l}1 \\
2 \\
3 \\
4 \\
5\end{array}$ & $\begin{array}{l}-- \\
-- \\
-- \\
--\end{array}$ & & $\begin{array}{l}-- \\
-- \\
-- \\
-- \\
--\end{array}$ & $\begin{array}{l}33 \\
-- \\
33 \\
33 \\
35\end{array}$ & $\begin{array}{r}44 \\
\mathrm{a} 43 \\
\mathrm{a} 43 \\
\mathrm{a} 43 \\
46\end{array}$ & $\begin{array}{r}\text { a } 42 \\
43 \\
\text { a } 42 \\
44 \\
49\end{array}$ & & $\begin{array}{l}-- \\
-- \\
-- \\
--\end{array}$ & $\begin{array}{l}-- \\
80 \\
77 \\
-- \\
--\end{array}$ & $\begin{array}{l}-- \\
-- \\
-- \\
--\end{array}$ & $\begin{array}{l}-- \\
-- \\
-- \\
--\end{array}$ & $\begin{array}{l}92 \\
-- \\
-- \\
-- \\
--\end{array}$ \\
\hline $\begin{array}{r}6 \\
7 \\
8 \\
9 \\
10\end{array}$ & $\begin{array}{r}\text { a } 53 \\
-- \\
-- \\
-- \\
--\end{array}$ & & $\begin{array}{l}34 \\
-- \\
35 \\
33 \\
32\end{array}$ & $\begin{array}{r}\text { a } 32 \\
\text { a } 32 \\
35 \\
38 \\
\text { a } 33\end{array}$ & $\begin{array}{r}44 \\
42 \\
\mathrm{a} 40 \\
\mathrm{a} 40 \\
49\end{array}$ & $\begin{array}{r}- \\
\text { a } 45 \\
\text { a } 46 \\
48 \\
\text { a } 55\end{array}$ & & $\begin{array}{l}-- \\
-- \\
-- \\
--\end{array}$ & $\begin{array}{l}-- \\
-- \\
-- \\
--\end{array}$ & $\begin{array}{l}-- \\
-- \\
-- \\
--\end{array}$ & $\begin{array}{r}-. \\
76 \\
78 \\
\text { b78 }\end{array}$ & $\begin{array}{l}-- \\
-- \\
-- \\
-\end{array}$ \\
\hline $\begin{array}{l}11 \\
12 \\
13 \\
14 \\
15\end{array}$ & $\begin{array}{l}-- \\
-- \\
-- \\
--\end{array}$ & & $\begin{array}{l}33 \\
32 \\
35 \\
34 \\
33\end{array}$ & $\begin{array}{r}\text { a } 32 \\
\text { a } 32 \\
33 \\
35 \\
--\end{array}$ & $\begin{array}{r}49 \\
\text { a } 45 \\
51 \\
\text { a } 44 \\
\text { a } 46\end{array}$ & $\begin{array}{l}-- \\
48 \\
41 \\
49 \\
53\end{array}$ & & $\begin{array}{l}-- \\
-- \\
-- \\
--\end{array}$ & $\begin{array}{l}-- \\
-- \\
--\end{array}$ & $\begin{array}{l}-- \\
-- \\
-- \\
--\end{array}$ & $\begin{array}{l}80 \\
76 \\
76 \\
77 \\
81\end{array}$ & $\begin{array}{r}-- \\
\text { b } 67 \\
69 \\
78\end{array}$ \\
\hline $\begin{array}{l}16 \\
17 \\
18 \\
19 \\
20\end{array}$ & $\begin{array}{r}-- \\
\text { a } 57 \\
\text { a } 55 \\
-- \\
--\end{array}$ & . & $\begin{array}{r}32 \\
34 \\
37 \\
\mathrm{a} 33 \\
35\end{array}$ & $\begin{array}{r}32 \\
\mathbf{2} 34 \\
35 \\
39 \\
\mathbf{2} 41\end{array}$ & $\begin{array}{r}\text { a } 41 \\
\text { a } 45 \\
\text { a } 48 \\
43 \\
46\end{array}$ & $\begin{array}{r}49 \\
49 \\
51 \\
\text { a } 50 \\
56\end{array}$ & & $\begin{array}{l}-- \\
-- \\
-- \\
--\end{array}$ & $\begin{array}{l}-- \\
-- \\
-- \\
--\end{array}$ & $\begin{array}{l}-- \\
-- \\
-- \\
--\end{array}$ & $\begin{array}{r}\mathbf{7 7} \\
80 \\
76 \\
80 \\
77\end{array}$ & $\begin{array}{r}\text { a } 63 \\
\text { a } 67 \\
72 \\
\text { a } 71 \\
\text { a } 77\end{array}$ \\
\hline $\begin{array}{l}21 \\
22 \\
23 \\
24 \\
25\end{array}$ & $\begin{array}{l}-- \\
-- \\
-- \\
--\end{array}$ & & $\begin{array}{r}36 \\
-- \\
\mathbf{3 2} \\
\mathbf{2} 32 \\
--\end{array}$ & $\begin{array}{r}41 \\
\text { 2 } 39 \\
37 \\
- \\
\text { a } 38\end{array}$ & $\begin{array}{r}\text { a } 45 \\
\text { a } 44 \\
-- \\
\text { a } 43 \\
\text { a } 47\end{array}$ & $\begin{array}{l}69 \\
-- \\
-- \\
-- \\
--\end{array}$ & & $\begin{array}{l}-- \\
-- \\
-- \\
--\end{array}$ & $\begin{array}{l}- \\
-- \\
-- \\
--\end{array}$ & $\begin{array}{l}-- \\
-- \\
-- \\
-\end{array}$ & $\begin{array}{r}73 \\
\mathrm{a} 70 \\
-- \\
71 \\
73\end{array}$ & $\begin{array}{r}\text { a } 66 \\
\text { a } 66 \\
-- \\
\text { a } 65 \\
65\end{array}$ \\
\hline $\begin{array}{l}26 \\
27 \\
28 \\
29 \\
30 \\
31\end{array}$ & $\begin{array}{l}-- \\
-- \\
-- \\
- \\
60 \\
60\end{array}$ & & $\begin{array}{r}\text { a } 32 \\
32 \\
33 \\
\text { a } 32 \\
\text { a } 33 \\
33\end{array}$ & $\begin{array}{r}\text { a } 42 \\
\text { a } 42 \\
38 \\
\text { a } 43 \\
48 \\
\text { a } 41\end{array}$ & $\begin{array}{r}47 \\
\mathrm{a} 47 \\
\mathrm{a} 38 \\
-- \\
-- \\
--\end{array}$ & $\begin{array}{l}-- \\
-- \\
-- \\
-- \\
--\end{array}$ & & $\begin{array}{l}-- \\
-\overline{62} \\
-- \\
-- \\
64\end{array}$ & $\begin{array}{l}-- \\
-- \\
-- \\
-- \\
--\end{array}$ & $\begin{array}{l}85 \\
85 \\
79 \\
86 \\
88 \\
--\end{array}$ & $\begin{array}{r}\mathbf{2 7 1} \\
71 \\
7 \\
78 \\
77 \\
\mathrm{a} 80\end{array}$ & $\begin{array}{r}66 \\
\text { a } 69 \\
\text { a } 64 \\
\text { a } 65 \\
\text { a } 62 \\
--\end{array}$ \\
\hline $\begin{array}{c}\text { Aver- } \\
\text { age }\end{array}$ & -- & & -- & 37 & 45 & $=$ & & -- & - & 85 & -- & 65 \\
\hline
\end{tabular}

a Me surement before $11 \mathrm{a}, \mathrm{m}$.

b Misurement after 6 p. m. 
RIO GRANDE BASIN--Cont inued

RIO GRANDE FLOODWAY AT SAN MARCIAL, N. MEX.- Continued

Suspended sediment, water year October 1953 to September 1954

\begin{tabular}{|c|c|c|c|c|c|c|c|c|c|}
\hline \multirow[b]{3}{*}{ Day } & \multicolumn{3}{|c|}{ October } & \multicolumn{3}{|c|}{ November } & \multicolumn{3}{|c|}{ December } \\
\hline & \multirow[b]{2}{*}{$\begin{array}{l}\text { Mean } \\
\text { dis- } \\
\text { charge } \\
\text { (cfs) }\end{array}$} & \multicolumn{2}{|c|}{ Suspended sediment } & \multirow[b]{2}{*}{$\begin{array}{l}\text { Mean } \\
\text { dis- } \\
\text { charge } \\
\text { (cfs) }\end{array}$} & \multicolumn{2}{|c|}{ Suspended sediment } & \multirow[b]{2}{*}{$\begin{array}{c}\text { Mean } \\
\text { dis- } \\
\text { charge } \\
\text { (cfs) }\end{array}$} & \multicolumn{2}{|c|}{ Suspended sediment } \\
\hline & & $\begin{array}{l}\text { Mean } \\
\text { concen- } \\
\text { tration } \\
\text { (ppm) }\end{array}$ & $\begin{array}{l}\text { Tons } \\
\text { per } \\
\text { day }\end{array}$ & & $\begin{array}{l}\text { Mean } \\
\text { concen- } \\
\text { tration } \\
\text { (ppm) }\end{array}$ & $\begin{array}{l}\text { Tons } \\
\text { per } \\
\text { day }\end{array}$ & & $\begin{array}{c}\text { Mean } \\
\text { concen- } \\
\text { tration } \\
(\mathrm{ppm})\end{array}$ & $\begin{array}{l}\text { Tons } \\
\text { per } \\
\text { day }\end{array}$ \\
\hline $\begin{array}{l}1 \ldots \ldots \\
2 \ldots \ldots \\
3 \ldots \ldots \\
4 \ldots \ldots \\
5 \ldots \ldots\end{array}$ & $\begin{array}{l}0 \\
0 \\
0 \\
.5 \\
.6\end{array}$ & $\begin{array}{c}-- \\
-- \\
-- \\
-- \\
890\end{array}$ & $\begin{array}{r}0 \\
0 \\
0 \\
b 1 \\
21\end{array}$ & $\begin{array}{l}0.2 \\
0 \\
0 \\
0 \\
0\end{array}$ & $\begin{array}{r}183 \\
-- \\
-- \\
-- \\
--\end{array}$ & $\begin{array}{ll}\text { (t) } & \\
& 0 \\
0 \\
0 \\
0\end{array}$ & $\begin{array}{r}0 \\
0 \\
0 \\
0 \\
169\end{array}$ & $\begin{array}{r}-- \\
-- \\
-- \\
-- \\
6,000\end{array}$ & $\begin{array}{r}0 \\
0 \\
0 \\
0 \\
22,700\end{array}$ \\
\hline $\begin{array}{r}6 \ldots \ldots \\
7 \ldots \ldots \\
8 \ldots \ldots \\
9 \ldots \ldots \\
10 \ldots \ldots\end{array}$ & $\begin{array}{l}0^{.2} \\
0 \\
0 \\
0\end{array}$ & $\begin{array}{c}470 \\
-- \\
-- \\
-- \\
--\end{array}$ & (t) $\begin{array}{l}0 \\
0 \\
0 \\
0\end{array}$ & $1_{0}^{.1}$ & $\begin{array}{l}-- \\
-- \\
-- \\
--\end{array}$ & $\begin{array}{r}(b)(t) \\
b 4 \\
(b)(t) \\
0 \\
0\end{array}$ & $\begin{array}{l}193 \\
205 \\
212 \\
179 \\
173\end{array}$ & $\begin{array}{l}5,770 \\
5,000 \\
4,350 \\
2,860 \\
2,300\end{array}$ & $\begin{array}{r}3,010 \\
\text { a 2, 800 } \\
2,490 \\
\text { s1, 400 } \\
1,070\end{array}$ \\
\hline $\begin{array}{l}11 \ldots \ldots \\
12 \ldots \ldots \\
13 \ldots \ldots \\
14 \ldots \ldots \\
15 \ldots \ldots\end{array}$ & $\begin{array}{l}0 \\
0 \\
0 \\
1 \\
.1\end{array}$ & $\begin{array}{l}-- \\
-- \\
-- \\
--\end{array}$ & $\begin{array}{r}0 \\
0 \\
0 \\
b 4 \\
(b)(t)\end{array}$ & $\begin{array}{l}0 \\
0 \\
0 \\
0 \\
0\end{array}$ & $\begin{array}{l}-- \\
-- \\
-- \\
--\end{array}$ & $\begin{array}{l}0 \\
0 \\
0 \\
0 \\
0\end{array}$ & $\begin{array}{l}181 \\
170 \\
155 \\
190 \\
215\end{array}$ & $\begin{array}{l}2,350 \\
1,760 \\
1,200 \\
1,830 \\
1,870\end{array}$ & $\begin{array}{r}1,150 \\
808 \\
502 \\
\mathrm{~s} 992 \\
1,090\end{array}$ \\
\hline $\begin{array}{l}16 \ldots \ldots \\
17 \ldots \ldots \\
18 \ldots \ldots \\
19 \ldots \ldots \\
20 \ldots \ldots\end{array}$ & $\begin{array}{l}0 \\
.6 \\
.2 \\
.1 \\
0\end{array}$ & $\begin{array}{l}-- \\
-- \\
-- \\
--\end{array}$ & $\begin{array}{r}0 \\
b 2 \\
\text { (b) (t) } \\
\text { (b) }(t) \\
0\end{array}$ & $\begin{array}{l}0 \\
0 \\
0 \\
0 \\
0\end{array}$ & $\begin{array}{l}-- \\
-- \\
-- \\
-- \\
--\end{array}$ & $\begin{array}{l}0 \\
0 \\
0 \\
0 \\
0\end{array}$ & $\begin{array}{l}218 \\
384 \\
425 \\
388 \\
342\end{array}$ & $\begin{array}{l}1,880 \\
4,100 \\
5,200 \\
4,820 \\
5,600\end{array}$ & $\begin{array}{r}\mathrm{s} 1,120 \\
\mathrm{~s} 4,360 \\
5,970 \\
5,050 \\
5,170\end{array}$ \\
\hline $\begin{array}{l}21 \ldots \ldots \\
22 \ldots \ldots \\
23 \ldots \ldots \\
24 \ldots \ldots \\
25 \ldots \ldots\end{array}$ & $\begin{array}{l}0 \\
0 \\
0 \\
0 \\
0\end{array}$ & $\begin{array}{l}-- \\
-- \\
-- \\
--\end{array}$ & $\begin{array}{l}0 \\
0 \\
0 \\
0 \\
0\end{array}$ & $\begin{array}{l}0 \\
0 \\
0 \\
0 \\
0\end{array}$ & $\begin{array}{l}-- \\
-- \\
-- \\
-- \\
--\end{array}$ & $\begin{array}{l}0 \\
0 \\
0 \\
0 \\
0\end{array}$ & $\begin{array}{l}352 \\
350 \\
250 \\
160 \\
100\end{array}$ & $\begin{array}{r}4,750 \\
4,600 \\
4,100 \\
1,800 \\
800\end{array}$ & $\begin{array}{r}4,510 \\
\mathrm{a} 4,300 \\
2,770 \\
778 \\
\mathrm{a} 220\end{array}$ \\
\hline $\begin{array}{l}26 \ldots \ldots \\
27 \ldots \ldots \\
28 \ldots \ldots \\
29 \ldots \ldots \\
30 \ldots \ldots \\
31 \ldots \ldots\end{array}$ & $\begin{array}{l}0 \\
.7 \\
.6 \\
.2 \\
.4 \\
.4 \\
\end{array}$ & $\begin{array}{r}-- \\
-- \\
-- \\
216 \\
274\end{array}$ & $\begin{array}{r}0 \\
b 3 \\
b 2 \\
(b)(t) \\
(t) \\
(t) \\
\end{array}$ & $\begin{array}{l}0 \\
0 \\
0 \\
0 \\
0 \\
--\end{array}$ & $\begin{array}{l}-- \\
-- \\
-- \\
-- \\
--\end{array}$ & $\begin{array}{c}0 \\
0 \\
0 \\
0 \\
0 \\
--\end{array}$ & $\begin{array}{l}190 \\
250 \\
290 \\
270 \\
260 \\
350\end{array}$ & $\begin{array}{l}1,150 \\
1,310 \\
1,480 \\
1,500 \\
1,520 \\
1,610\end{array}$ & $\begin{array}{r}590 \\
884 \\
1,160 \\
1,090 \\
1,070 \\
1,520\end{array}$ \\
\hline \multirow[t]{2}{*}{ Total. } & 5.6 & -- & 15 & 1.4 & - & 4 & 6,621 & -- & 58,574 \\
\hline & \multicolumn{3}{|c|}{ January } & \multicolumn{3}{|c|}{ February } & \multicolumn{3}{|c|}{ March } \\
\hline $\begin{array}{l}1 . \ldots \ldots \\
2 . \ldots \ldots \\
3 . \ldots \ldots \\
4 \ldots \ldots \\
5 . \ldots \ldots\end{array}$ & $\begin{array}{l}170 \\
180 \\
190 \\
225 \\
262\end{array}$ & $\begin{array}{l}1,360 \\
1,190 \\
1,280 \\
1,400 \\
1,620\end{array}$ & $\begin{array}{r}624 \\
578 \\
657 \\
850 \\
1,150\end{array}$ & $\begin{array}{l}425 \\
425 \\
412 \\
400 \\
388\end{array}$ & $\begin{array}{l}2,920 \\
3,500 \\
3,850 \\
2,910 \\
2,900\end{array}$ & $\begin{array}{l}3,350 \\
4,020 \\
4,280 \\
3,140 \\
3,040\end{array}$ & $\begin{array}{l}450 \\
495 \\
555 \\
438 \\
388\end{array}$ & $\begin{array}{l}2,480 \\
2,690 \\
2,070 \\
2,420 \\
2,950\end{array}$ & $\begin{array}{l}3,010 \\
3,600 \\
3,100 \\
2,860 \\
3,090\end{array}$ \\
\hline $\begin{array}{r}6 \ldots \ldots \\
7 \ldots \ldots \\
8 \ldots \ldots \\
9 \ldots \ldots \\
10 \ldots \ldots\end{array}$ & $\begin{array}{l}365 \\
495 \\
525 \\
438 \\
400\end{array}$ & $\begin{array}{l}2,000 \\
3,000 \\
4,000 \\
4,270 \\
4,520\end{array}$ & $\begin{array}{l}1,970 \\
4,010 \\
5,670 \\
5,050 \\
4,880\end{array}$ & $\begin{array}{l}412 \\
438 \\
450 \\
438 \\
438\end{array}$ & $\begin{array}{l}2,880 \\
2,510 \\
2,400 \\
2,450 \\
2,900\end{array}$ & $\begin{array}{l}3,200 \\
2,970 \\
2,920 \\
2,900 \\
3,430\end{array}$ & $\begin{array}{l}278 \\
212 \\
166 \\
127 \\
104\end{array}$ & $\begin{array}{l}2,640 \\
2,350 \\
2,010 \\
1,560 \\
1,410\end{array}$ & $\begin{array}{r}1,980 \\
1,350 \\
901 \\
535 \\
396\end{array}$ \\
\hline $\begin{array}{l}11 . \ldots \ldots \\
12 \ldots \ldots \\
13 \ldots \ldots \\
14 \ldots \ldots \\
15 \ldots \ldots\end{array}$ & $\begin{array}{l}375 \\
390 \\
400 \\
450 \\
425\end{array}$ & $\begin{array}{l}3,990 \\
3,530 \\
2,900 \\
3,730 \\
4,200\end{array}$ & $\begin{array}{r}4,040 \\
3,720 \\
3,130 \\
4,530 \\
\mathrm{a} 4,800\end{array}$ & $\begin{array}{l}450 \\
450 \\
450 \\
450 \\
465\end{array}$ & $\begin{array}{l}2,600 \\
2,410 \\
2,420 \\
2,400 \\
2,780\end{array}$ & $\begin{array}{l}3,160 \\
2,930 \\
2,940 \\
2,920 \\
3,490\end{array}$ & $\begin{array}{r}12 \\
5 \\
3 \\
2 \\
1\end{array}$ & $\begin{array}{r}750 \\
310 \\
135 \\
90 \\
72\end{array}$ & $\begin{array}{r}24 \\
4 \\
1 \\
\text { (t) } \\
\text { (t) }\end{array}$ \\
\hline $\begin{array}{l}16 \ldots \ldots \\
17 \ldots \ldots \\
18 \ldots \ldots \\
19 \ldots \ldots \\
20 \ldots \ldots\end{array}$ & $\begin{array}{l}370 \\
375 \\
370 \\
412 \\
412\end{array}$ & $\begin{array}{l}3,910 \\
3,750 \\
3,740 \\
3,590 \\
3,800\end{array}$ & $\begin{array}{r}3,910 \\
3,800 \\
3,740 \\
3,990 \\
24,200\end{array}$ & $\begin{array}{l}480 \\
495 \\
555 \\
660 \\
660\end{array}$ & $\begin{array}{l}2,560 \\
2,480 \\
2,580 \\
1,900 \\
1,800\end{array}$ & $\begin{array}{l}3,320 \\
3,310 \\
3,870 \\
3,390 \\
3,210\end{array}$ & $\begin{array}{l}1 \\
1 \\
.2 \\
.2\end{array}$ & $\begin{array}{r}96 \\
96 \\
115 \\
74 \\
--\end{array}$ & $\begin{array}{l}(\mathrm{t}) \\
(\mathrm{t}) \\
(\mathrm{t}) \\
(\mathrm{t}) \\
\\
\end{array}$ \\
\hline $\begin{array}{l}21 . \ldots \ldots \\
22 . \ldots \ldots \\
23 \ldots \ldots \\
24 \ldots \ldots \\
25 . \ldots \ldots\end{array}$ & $\begin{array}{l}412 \\
400 \\
388 \\
412 \\
425\end{array}$ & $\begin{array}{l}3,750 \\
3,700 \\
3,600 \\
3,500 \\
3,530\end{array}$ & $\begin{array}{r}4,170 \\
4,000 \\
3,770 \\
\mathrm{a} 3,900 \\
4,050\end{array}$ & $\begin{array}{l}640 \\
640 \\
600 \\
570 \\
540\end{array}$ & $\begin{array}{l}1,600 \\
1,710 \\
1,990 \\
2,220 \\
2,140\end{array}$ & $\begin{array}{l}2,760 \\
2,950 \\
3,220 \\
3,420 \\
3,120\end{array}$ & $\begin{array}{l}0 \\
0 \\
0 \\
0 \\
0\end{array}$ & $\begin{array}{l}-- \\
-- \\
-- \\
-- \\
--\end{array}$ & $\begin{array}{l}0 \\
0 \\
0 \\
0 \\
0\end{array}$ \\
\hline $\begin{array}{l}26 \ldots \ldots \\
27 . \ldots \ldots \\
28 \ldots \ldots \\
29 . \ldots \ldots \\
30 \ldots \ldots \\
31 \ldots \ldots\end{array}$ & $\begin{array}{l}412 \\
412 \\
388 \\
388 \\
412 \\
425 \\
\end{array}$ & $\begin{array}{l}3,090 \\
2,900 \\
3,080 \\
3,130 \\
3,250 \\
3,170 \\
\end{array}$ & $\begin{array}{l}3,440 \\
3,230 \\
3,230 \\
3,280 \\
3,620 \\
3,640 \\
\end{array}$ & $\begin{array}{r}510 \\
495 \\
465 \\
-- \\
-- \\
-- \\
\end{array}$ & $\begin{array}{r}2,190 \\
2,420 \\
2,360 \\
-- \\
-- \\
- \\
\end{array}$ & $\begin{array}{r}3,020 \\
3,230 \\
2,960 \\
-- \\
-- \\
-- \\
\end{array}$ & $\begin{array}{l}0 \\
0 \\
0 \\
0 \\
0 \\
0 \\
\end{array}$ & $\begin{array}{l}-- \\
-- \\
-- \\
-- \\
-- \\
-\end{array}$ & $\begin{array}{l}0 \\
0 \\
0 \\
0 \\
0 \\
0\end{array}$ \\
\hline Total. & 11,703 & -4 & 105,629 & 13,801 & -- & 90,470 & $3,238.4$ & -- & 20,852 \\
\hline
\end{tabular}

s Computed by subdividing day.

$t$ Less than 0.50 tons.

a Computed from estimated concentration graph.

b Computed from water-sediment discharge curve. 
RIO GRANDE BASIN

RIO GRANDE BASIN--Continuled

RIO GRANDE FLOODWAY AT SAN MARCIAL, N. MEX.--Continued

Suspended sediment, water year October 1953 to September 1954--Continued

\begin{tabular}{|c|c|c|c|c|c|c|c|c|c|}
\hline \multirow[b]{3}{*}{ Day } & \multicolumn{3}{|c|}{ April } & \multicolumn{3}{|c|}{ May } & \multicolumn{3}{|c|}{ June } \\
\hline & \multirow[b]{2}{*}{$\begin{array}{l}\text { Mean } \\
\text { dis- } \\
\text { charge } \\
\text { (cfs) }\end{array}$} & \multicolumn{2}{|c|}{ Suspended sediment } & \multirow[b]{2}{*}{$\begin{array}{l}\text { Mean } \\
\text { dis- } \\
\text { charge } \\
\text { (cfs) }\end{array}$} & \multicolumn{2}{|c|}{ Suspended sediment } & \multirow[b]{2}{*}{$\begin{array}{c}\text { Mean } \\
\text { dis- } \\
\text { charge } \\
\text { (cfs) }\end{array}$} & \multicolumn{2}{|c|}{ Suspended sediment } \\
\hline & & $\begin{array}{l}\text { Mean } \\
\text { concen- } \\
\text { tration } \\
(\mathrm{ppm})\end{array}$ & $\begin{array}{l}\text { Tons } \\
\text { per } \\
\text { day }\end{array}$ & & $\begin{array}{l}\text { Mean } \\
\text { concen- } \\
\text { tration } \\
\text { (ppm) }\end{array}$ & $\begin{array}{l}\text { Tons } \\
\text { per } \\
\text { day }\end{array}$ & & $\begin{array}{l}\text { Mean } \\
\text { concen- } \\
\text { tration } \\
\text { (ppm) }\end{array}$ & $\begin{array}{l}\text { Tons } \\
\text { per } \\
\text { day }\end{array}$ \\
\hline $\begin{array}{l}1 . \ldots \ldots \\
2 \ldots \ldots \\
3 . \ldots \ldots \\
4 \ldots \ldots \\
5 \ldots \ldots\end{array}$ & $\begin{array}{l}0 \\
0 \\
0 \\
0 \\
0\end{array}$ & & & $\begin{array}{l}0 \\
0 \\
0 \\
0 \\
0\end{array}$ & $\begin{array}{l}-- \\
-- \\
-- \\
--\end{array}$ & $\begin{array}{l}0 \\
0 \\
0 \\
0 \\
0\end{array}$ & $\begin{array}{r}164 \\
164 \\
83 \\
25 \\
.2\end{array}$ & $\begin{array}{r}3,100 \\
2,850 \\
2,050 \\
1,300 \\
650\end{array}$ & $\begin{array}{r}1,370 \\
1,260 \\
459 \\
\text { a } 90 \\
\text { (a)(t) }\end{array}$ \\
\hline $\begin{array}{r}6 \ldots \ldots \\
7 \ldots \ldots \\
8 \ldots \ldots \\
9 . \ldots \ldots \\
10 \ldots \ldots\end{array}$ & $\begin{array}{l}0 \\
0 \\
0 \\
0 \\
0\end{array}$ & & & $\begin{array}{l}0 \\
0 \\
0 \\
0 \\
0\end{array}$ & $\begin{array}{l}-- \\
-- \\
-- \\
--\end{array}$ & $\begin{array}{l}0 \\
0 \\
0 \\
0 \\
0\end{array}$ & $\begin{array}{l}0 \\
0 \\
0 \\
0 \\
0\end{array}$ & $\begin{array}{l}-- \\
-- \\
-- \\
--\end{array}$ & $\begin{array}{l}0 \\
0 \\
0 \\
0 \\
0\end{array}$ \\
\hline $\begin{array}{l}11 \ldots \ldots \\
12 . \ldots \ldots \\
13 \ldots \ldots \\
14 \ldots \ldots \\
15 . \ldots\end{array}$ & $\begin{array}{l}0 \\
0 \\
0 \\
0 \\
0\end{array}$ & & & $\begin{array}{l}0 \\
0 \\
0 \\
0 \\
0\end{array}$ & $\begin{array}{l}-- \\
-- \\
-- \\
--\end{array}$ & $\begin{array}{l}0 \\
0 \\
0 \\
0 \\
0\end{array}$ & $\begin{array}{l}0 \\
0 \\
0 \\
0 \\
0\end{array}$ & $\begin{array}{l}-- \\
-- \\
-- \\
--\end{array}$ & $\begin{array}{l}0 \\
0 \\
0 \\
0 \\
0\end{array}$ \\
\hline $\begin{array}{l}16 \ldots \ldots \\
17 \ldots \ldots \\
18 \ldots \ldots \\
19 . \ldots \\
20 \ldots \ldots\end{array}$ & $\begin{array}{r}0 \\
0 \\
0 \\
34 \\
13\end{array}$ & & & $\begin{array}{l}0 \\
0 \\
0 \\
0 \\
0\end{array}$ & $\begin{array}{l}-- \\
-- \\
-- \\
--\end{array}$ & $\begin{array}{l}0 \\
0 \\
0 \\
0 \\
0\end{array}$ & $\begin{array}{l}0 \\
0 \\
0 \\
0 \\
0\end{array}$ & $\begin{array}{l}-- \\
-- \\
-- \\
--\end{array}$ & $\begin{array}{l}0 \\
0 \\
0 \\
0 \\
0\end{array}$ \\
\hline $\begin{array}{l}21 \ldots \ldots \\
22 . \ldots \ldots \\
23 \ldots \ldots \\
24 \ldots \ldots \\
25 . \ldots \ldots\end{array}$ & $\begin{array}{l}2 \\
0 \\
0 \\
0 \\
0\end{array}$ & & & $\begin{array}{l}0 \\
0 \\
0 \\
0 \\
0\end{array}$ & $\begin{array}{l}-- \\
-- \\
-- \\
--\end{array}$ & $\begin{array}{l}0 \\
0 \\
0 \\
0 \\
0\end{array}$ & $\begin{array}{l}0 \\
0 \\
0 \\
0 \\
0\end{array}$ & $\begin{array}{l}- \\
-- \\
-- \\
--\end{array}$ & $\begin{array}{l}0 \\
0 \\
0 \\
0 \\
0\end{array}$ \\
\hline $\begin{array}{l}26 \ldots \ldots \\
27 \ldots \ldots \\
28 \ldots \ldots \\
29 \ldots \ldots \\
30 \ldots \ldots \\
31 \ldots \ldots\end{array}$ & $\begin{array}{r}0 \\
0 \\
0 \\
0 \\
0 \\
--\end{array}$ & & & $\begin{array}{r}0 \\
27 \\
466 \\
465 \\
438 \\
282 \\
\end{array}$ & $\begin{array}{r}858 \\
4,420 \\
3,720 \\
3,750 \\
3,580 \\
\end{array}$ & $\begin{array}{r}0 \\
\text { s 505 } \\
\text { s 5, 310 } \\
4,670 \\
4,430 \\
2,730 \\
\end{array}$ & $\begin{array}{l}0 \\
0 \\
0 \\
0 \\
0 \\
--\end{array}$ & $\begin{array}{l}-- \\
-- \\
-- \\
-- \\
--\end{array}$ & $\begin{array}{c}0 \\
0 \\
0 \\
0 \\
0 \\
--\end{array}$ \\
\hline \multirow[t]{2}{*}{ Total } & 49 & & b 140 & 1,678 & -- & 17,645 & 436.2 & $-\infty$ & 3,179 \\
\hline & \multicolumn{3}{|c|}{ July } & \multicolumn{3}{|c|}{ August } & \multicolumn{3}{|c|}{ September } \\
\hline $\begin{array}{l}1 \ldots \ldots \\
2 \ldots \ldots \\
3 \ldots \ldots \\
4 \ldots \ldots \\
5 \ldots \ldots\end{array}$ & $\begin{array}{l}0 \\
0 \\
0 \\
0 \\
0\end{array}$ & $\begin{array}{l}-- \\
-- \\
-- \\
--\end{array}$ & $\begin{array}{l}0 \\
0 \\
0 \\
0 \\
0\end{array}$ & $\begin{array}{l}0 \\
0 \\
3 \\
8 \\
6\end{array}$ & $\begin{array}{l}-- \\
-- \\
-- \\
--\end{array}$ & $\begin{array}{r}0 \\
0 \\
\text { b } 200 \\
\text { b700 } \\
\text { b } 500\end{array}$ & $\begin{array}{l}0.2 \\
0 \\
0 \\
0 \\
0\end{array}$ & $\begin{array}{r}300 \\
-- \\
-- \\
-- \\
--\end{array}$ & $\begin{array}{r}(a)(t) \\
0 \\
0 \\
0 \\
0\end{array}$ \\
\hline $\begin{array}{r}6 . \ldots \ldots \\
7 \ldots \ldots \\
8 . \ldots \\
9 . \ldots \ldots \\
10 . \ldots\end{array}$ & $\begin{array}{l}0 \\
0 \\
0 \\
0 \\
0\end{array}$ & $\begin{array}{l}-- \\
-- \\
-- \\
--\end{array}$ & $\begin{array}{l}0 \\
0 \\
0 \\
0 \\
0\end{array}$ & $\begin{array}{r}11 \\
150 \\
198 \\
341 \\
90\end{array}$ & $\begin{array}{r}\cdots \\
49,800 \\
54,200 \\
41,200\end{array}$ & $\begin{array}{r}\text { b } 400 \\
\text { b } 25,000 \\
\text { s } 40,800 \\
\text { s } 56,900 \\
\text { s } 11,600\end{array}$ & $\begin{array}{l}0 \\
0 \\
0 \\
0 \\
0\end{array}$ & $\begin{array}{l}-- \\
-- \\
-- \\
--\end{array}$ & $\begin{array}{l}0 \\
0 \\
0 \\
0 \\
0\end{array}$ \\
\hline $\begin{array}{l}11 \ldots \ldots \\
12 \ldots \ldots \\
13 \ldots \ldots \\
14 \ldots \ldots \\
15 \ldots \ldots\end{array}$ & $\begin{array}{l}0 \\
0 \\
0 \\
0 \\
0\end{array}$ & $\begin{array}{l}-- \\
-- \\
-- \\
-- \\
--\end{array}$ & $\begin{array}{l}0 \\
0 \\
0 \\
0 \\
0\end{array}$ & $\begin{array}{r}212 \\
379 \\
401 \\
140 \\
26\end{array}$ & $\begin{array}{l}61,900 \\
60,200 \\
53,000 \\
74,600 \\
57,400\end{array}$ & $\begin{array}{r}\text { s } 53,200 \\
\text { s77, 900 } \\
59,500 \\
\text { s } 29,600 \\
4,180\end{array}$ & $\begin{array}{r}0 \\
96 \\
304 \\
540 \\
710\end{array}$ & $\begin{array}{l}-\overline{42,000} \\
95,200 \\
82,000 \\
72,000\end{array}$ & $\begin{array}{r}0 \\
\text { sa } 21,000 \\
\text { s } 84,600 \\
124,000 \\
143,000\end{array}$ \\
\hline $\begin{array}{l}16 \ldots \ldots \\
17 \ldots \ldots \\
18 \ldots \ldots \\
19 \ldots \ldots \\
20 \ldots \ldots\end{array}$ & $\begin{array}{l}0 \\
0 \\
0 \\
0 \\
0\end{array}$ & $\begin{array}{l}-- \\
-- \\
-- \\
--\end{array}$ & $\begin{array}{l}0 \\
0 \\
0 \\
0 \\
0\end{array}$ & $\begin{array}{r}6 \\
147 \\
730 \\
619 \\
398\end{array}$ & $\begin{array}{l}31,000 \\
42,000 \\
75,000 \\
71,100 \\
67,800\end{array}$ & $\begin{array}{r}502 \\
\mathrm{sa} 42,000 \\
153,000 \\
\mathrm{~s} 127,000 \\
\mathrm{~s} 77,300\end{array}$ & $\begin{array}{r}171 \\
56 \\
21 \\
9 \\
2\end{array}$ & $\begin{array}{r}\mathbf{7 6}, 000 \\
\mathbf{7 1}, \mathbf{5 0 0} \\
\mathbf{5 7}, \mathbf{5 0 0} \\
\mathbf{3 5}, 000 \\
\mathbf{4 , 0 0 0}\end{array}$ & $\begin{array}{r}\text { s } 35,200 \\
11,200 \\
3,380 \\
882 \\
22\end{array}$ \\
\hline $\begin{array}{l}21 . \ldots . \\
22 . \ldots . \\
23 . \ldots \\
24 \ldots \ldots \\
25 . \ldots .\end{array}$ & $\begin{array}{l}0 \\
0 \\
0 \\
0 \\
0\end{array}$ & $\begin{array}{l}-- \\
-- \\
-- \\
-- \\
--\end{array}$ & $\begin{array}{l}0 \\
0 \\
0 \\
0 \\
0\end{array}$ & $\begin{array}{l}243 \\
382 \\
439 \\
113 \\
382\end{array}$ & $\begin{array}{l}59,100 \\
84,500 \\
74,000 \\
66,000 \\
73,300\end{array}$ & $\begin{array}{r}\mathrm{s} 42,100 \\
\mathrm{~s} 106,000 \\
\mathrm{a} 91,000 \\
20,900 \\
\mathrm{~s} 87,400\end{array}$ & $\begin{array}{c}0^{2} \\
122 \\
205\end{array}$ & $\begin{array}{r}232 \\
157 \\
-- \\
21,000 \\
45,900\end{array}$ & 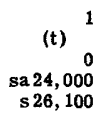 \\
\hline $\begin{array}{l}26 \ldots \ldots \\
27 . \ldots \ldots \\
28 . \ldots \ldots \\
29 \ldots \ldots \\
30 \ldots \ldots \\
31 . \ldots \ldots\end{array}$ & $\begin{array}{r}440 \\
896 \\
134 \\
26 \\
2 \\
\quad .2 \\
\end{array}$ & $\begin{array}{r}54,500 \\
79,300 \\
56,300 \\
17,900 \\
-- \\
-- \\
\end{array}$ & $\begin{array}{r}\mathrm{s} 154,000 \\
\mathrm{~s} 215,000 \\
\mathrm{~s} 22,800 \\
\mathrm{~s} 1,560 \\
\mathrm{~b} 10 \\
\mathrm{~b} 1\end{array}$ & $\begin{array}{r}278 \\
110 \\
30 \\
2 \\
2^{.3} \\
\end{array}$ & $\begin{array}{r}56,500 \\
48,000 \\
12,000 \\
100 \\
121 \\
8,100 \\
\end{array}$ & $\begin{array}{r}44,000 \\
s 15,700 \\
\text { a } 970 \\
\text { a }^{\text {a } 1} \\
\text { (t) } \\
\text { sa 140 }\end{array}$ & $\begin{array}{r}422 \\
1,090 \\
2,500 \\
1,120 \\
170 \\
-- \\
\end{array}$ & $\begin{array}{r}70,200 \\
51,600 \\
43,000 \\
40,000 \\
42,500 \\
--\end{array}$ & $\begin{array}{r}\text { s } 81,600 \\
157,000 \\
301,000 \\
125,000 \\
20,200 \\
-\end{array}$ \\
\hline Total & $1,498.2$ & $-\infty$ & 393,371 & $5,846.3$ & -- & $1,168,493$ & $7,540.4$ & $\cdots$ & $1,158,185$ \\
\hline
\end{tabular}

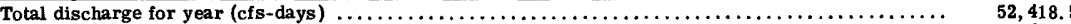

Total load for year (tons) $\ldots \ldots \ldots \ldots \ldots \ldots \ldots \ldots \ldots \ldots \ldots \ldots \ldots \ldots \ldots \ldots \ldots \ldots \ldots \ldots \ldots \ldots \ldots, 3,016,557$

s Computed by subdividing day.

$t$ Less than 0.50 tons.

a Computed from estimated concentration graph.

b Computed from water-sediment discharge curve. 


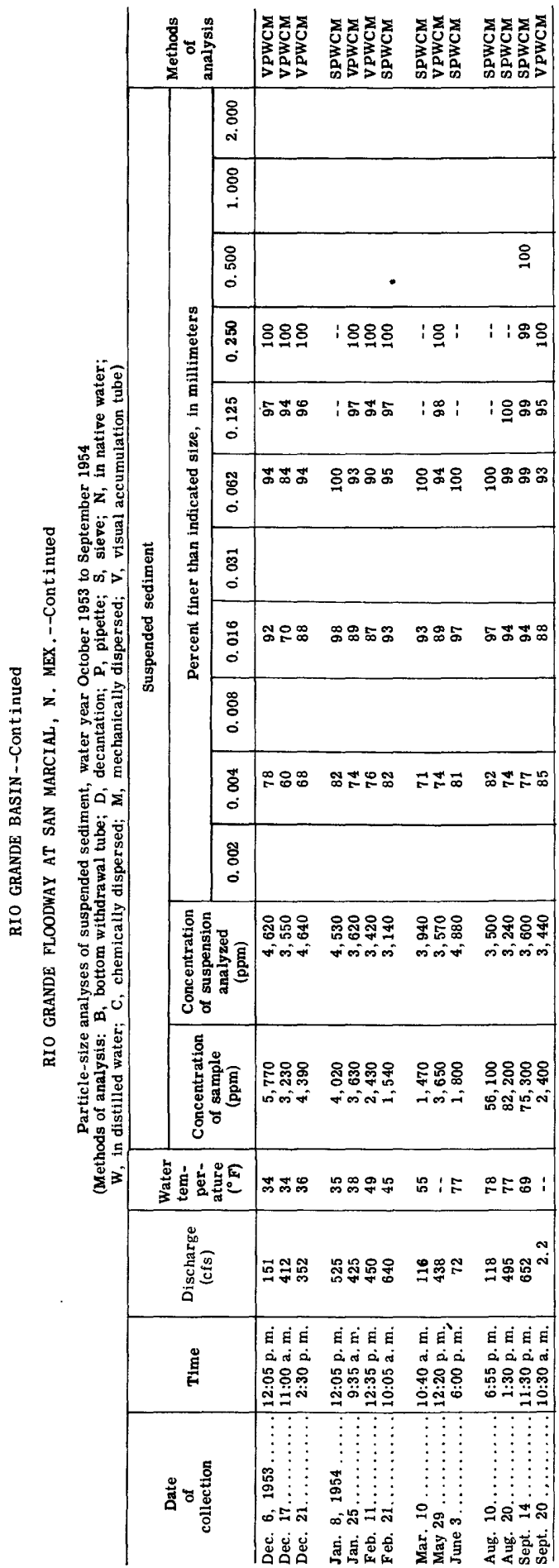




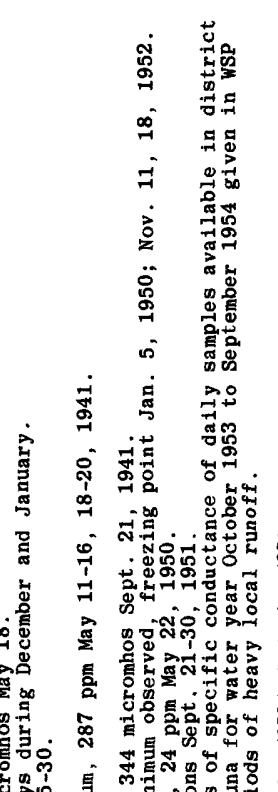

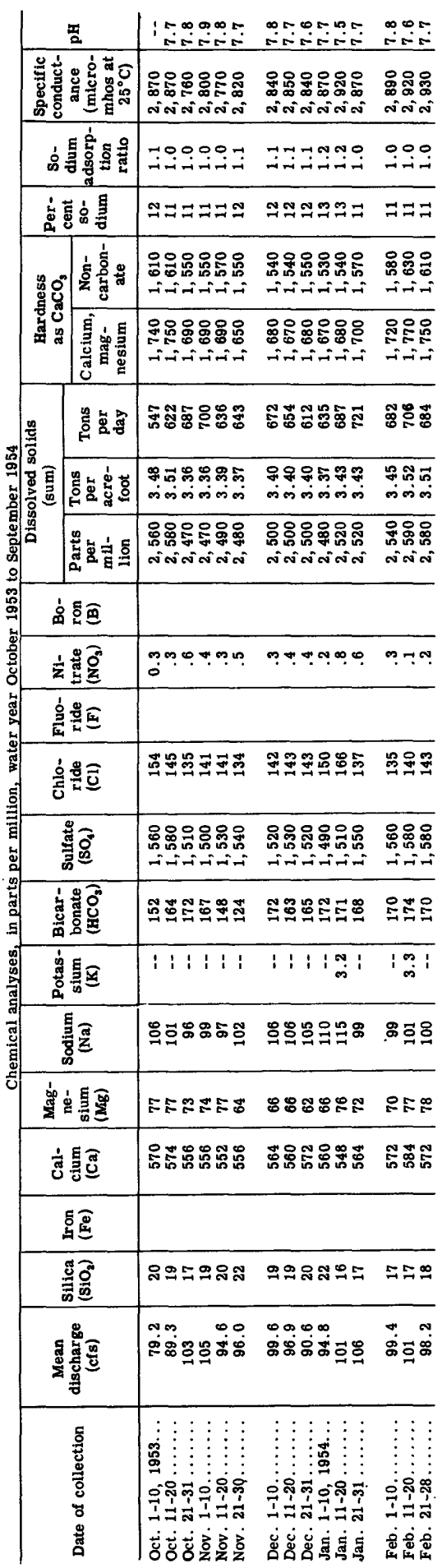
†연,

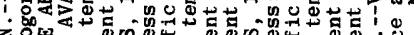

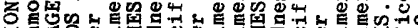

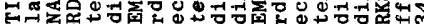

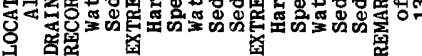

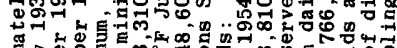

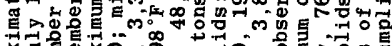

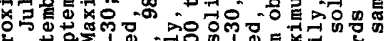
-

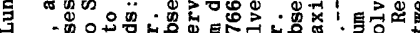
¿

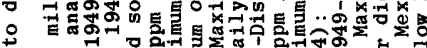
舟政 0

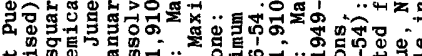
क 1 क o

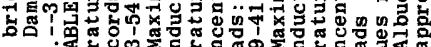




\begin{tabular}{|c|c|c|c|c|c|c|c|}
\hline & 咅 & 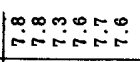 & 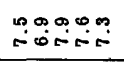 & بִ & 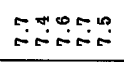 & 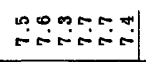 & \\
\hline & 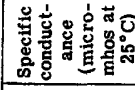 & 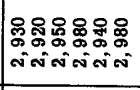 & 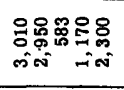 & 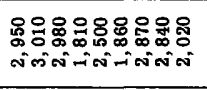 & 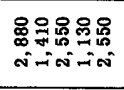 & 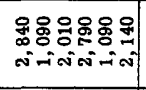 & 염 \\
\hline & 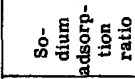 & 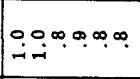 & $\infty=$ & 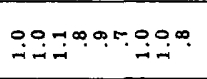 & 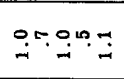 & $=70$ & $\stackrel{0}{0}$ \\
\hline & 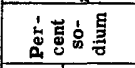 & $\approx=0000$ & 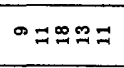 & 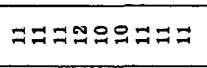 & $\Xi \Xi \approx 0$ 요 & $\nabla^{\infty}=\beth^{\infty}$ & $=$ \\
\hline & 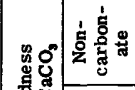 & 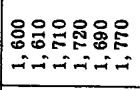 & 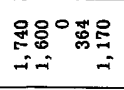 & 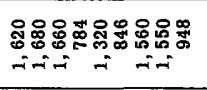 & 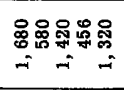 & 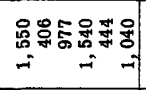 & $=$ \\
\hline & 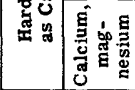 & 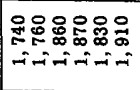 & 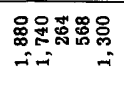 & 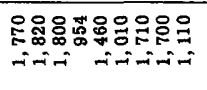 & 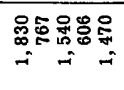 & 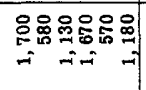 & เ \\
\hline$\Xi$ & 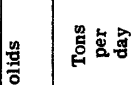 & 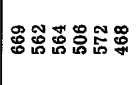 & สิธ్์ & 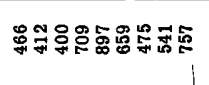 & 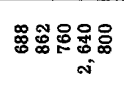 & 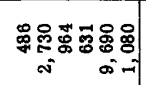 & ㅇำ \\
\hline 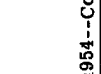 & 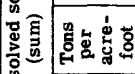 & 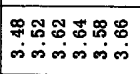 & 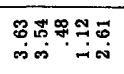 & 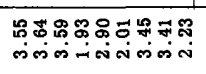 & 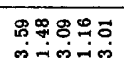 & 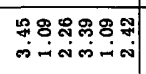 & \& \\
\hline 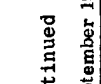 & 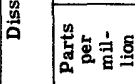 & 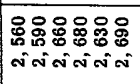 & 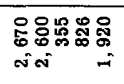 & 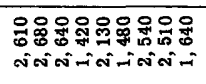 & 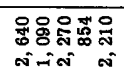 & 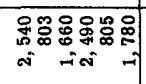 & : \\
\hline & 䱣点可 & & & & & & \\
\hline & 完焉总 & 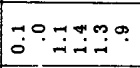 & 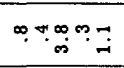 & 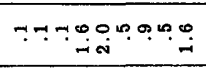 & 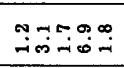 & 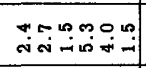 & i \\
\hline $\begin{array}{ll}z & \overline{8} \\
\bar{\alpha} & 0 \\
z & 4\end{array}$ & 层害画 & & & & & & \\
\hline 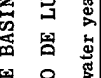 & 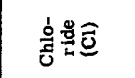 & 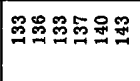 & 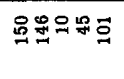 & 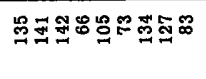 & 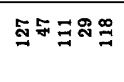 & 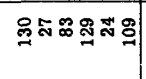 & \% \\
\hline 置 & 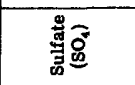 & 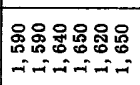 & 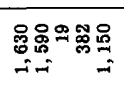 & 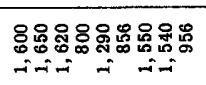 & 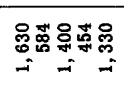 & 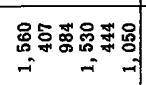 & : \\
\hline 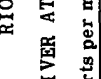 & 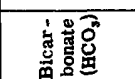 & 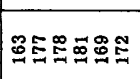 & 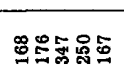 & 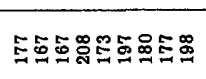 & 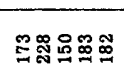 & 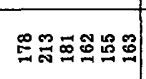 & $\stackrel{\infty}{=}$ \\
\hline & 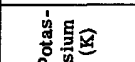 & $\begin{array}{llllll}1 & 1 & 1 & 1 & 1 & 1\end{array}$ & $1: 1:$ & $1: 1: 1: 1: 1: 11$ & : $1: 1: 1$ & $1: 1: 1: 1: 1$ & $i$ \\
\hline a & 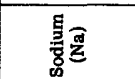 & 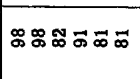 & D志 & 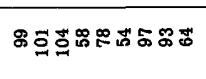 & 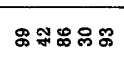 & 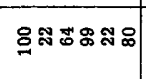 & : \\
\hline$\stackrel{\mathscr{\nu}}{0}$ & 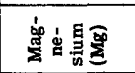 & 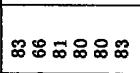 & 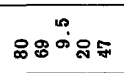 & 요요8 & న్ని & 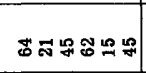 & เ \\
\hline & 过兒总 & 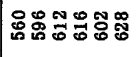 & สิธ์ & 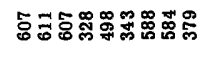 & 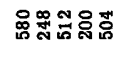 & 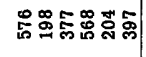 & 条 \\
\hline & 它馬 & & & & & & \\
\hline & 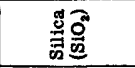 & 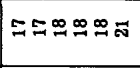 & ๑ลำณฐี & สสรลำลำสสลสำ & ลลิสะกส & 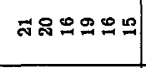 & $=$ \\
\hline & 递尊 & 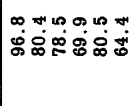 & 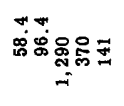 & $\begin{array}{l}\overrightarrow{0} \\
\dot{8} \\
\dot{0}\end{array}$ & 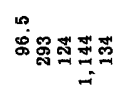 & 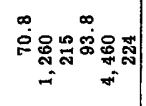 & $\mathbb{*}$ \\
\hline & 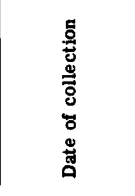 & 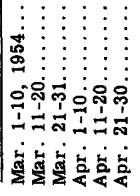 & 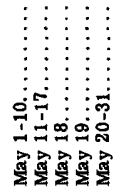 & 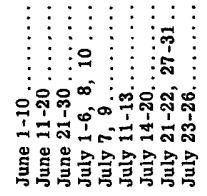 & 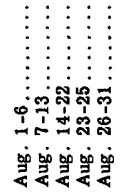 & 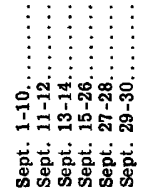 & : \\
\hline
\end{tabular}


RIO GRANDE BASIN--Continued

PECOS RIVER AT PUERTO DE LUNA, N. MEX.--Continued

Temperature ( $\mathrm{F}$ ) of water, water year October 1953 to September 1954

Once-daily measurement, generally between $11 \mathrm{a}, \mathrm{m}$. and $6 \mathrm{p.m} .7$

\begin{tabular}{|c|c|c|c|c|c|c|c|c|c|c|c|c|}
\hline Day & Oct. & Nov. & Dec. & Jan. & Feb. & Mar. & Apr. & May & June & July & Aug. & Sept. \\
\hline $\begin{array}{l}1 \\
2 \\
3 \\
4 \\
5\end{array}$ & $\begin{array}{l}70 \\
=- \\
-- \\
-- \\
--\end{array}$ & $\begin{array}{l}-- \\
-- \\
-- \\
--\end{array}$ & $\begin{array}{l}50 \\
50 \\
50 \\
48 \\
48\end{array}$ & $\begin{array}{l}48 \\
50 \\
50 \\
50 \\
50\end{array}$ & $\begin{array}{l}50 \\
45 \\
50 \\
60 \\
60\end{array}$ & $\begin{array}{l}50 \\
40 \\
40 \\
50 \\
50\end{array}$ & $\begin{array}{l}70 \\
70 \\
70 \\
70 \\
70\end{array}$ & $\begin{array}{l}60 \\
62 \\
60 \\
70 \\
72\end{array}$ & $\begin{array}{r}a 78 \\
78 \\
\text { b72 } \\
80 \\
80\end{array}$ & $\begin{array}{r}68 \\
79 \\
79 \\
\text { b 79 } \\
79\end{array}$ & $\begin{array}{r}\mathbf{8} 80 \\
90 \\
80 \\
80 \\
90\end{array}$ & $\begin{array}{l}80 \\
80 \\
80 \\
80 \\
80\end{array}$ \\
\hline $\begin{array}{r}6 \\
7 \\
8 \\
9 \\
10\end{array}$ & $\begin{array}{l}-- \\
60 \\
75 \\
60\end{array}$ & $\begin{array}{l}-- \\
-- \\
--\end{array}$ & $\begin{array}{l}38 \\
38 \\
40 \\
38 \\
--\end{array}$ & $\begin{array}{l}\mathbf{5 0} \\
\mathbf{5 0} \\
\mathbf{5 0} \\
\mathbf{5 0} \\
\mathbf{5 0}\end{array}$ & $\begin{array}{l}60 \\
60 \\
60 \\
60 \\
60\end{array}$ & $\begin{array}{l}50 \\
60 \\
60 \\
60 \\
60\end{array}$ & $\begin{array}{l}70 \\
60 \\
60 \\
50 \\
50\end{array}$ & $\begin{array}{l}65 \\
68 \\
70 \\
70 \\
70\end{array}$ & $\begin{array}{r}79 \\
70 \\
\text { b } 86 \\
79 \\
78\end{array}$ & $\begin{array}{r}\text { b 75 } \\
78 \\
78 \\
79 \\
70\end{array}$ & $\begin{array}{l}90 \\
70 \\
-- \\
80 \\
80\end{array}$ & $\begin{array}{l}80 \\
80 \\
80 \\
80 \\
80\end{array}$ \\
\hline $\begin{array}{l}11 \\
12 \\
13 \\
14 \\
15\end{array}$ & $\begin{array}{l}62 \\
64 \\
65 \\
60 \\
--\end{array}$ & $\begin{array}{l}-- \\
-- \\
-- \\
--\end{array}$ & $\begin{array}{l}40 \\
40 \\
50 \\
50 \\
40\end{array}$ & $\begin{array}{l}\mathbf{5 0} \\
50 \\
50 \\
45 \\
\mathbf{4 5}\end{array}$ & $\begin{array}{l}60 \\
60 \\
62 \\
60 \\
60\end{array}$ & $\begin{array}{l}60 \\
62 \\
50 \\
50 \\
60\end{array}$ & $\begin{array}{l}60 \\
60 \\
65 \\
60 \\
60\end{array}$ & $\begin{array}{l}60 \\
70 \\
65 \\
65 \\
55\end{array}$ & $\begin{array}{l}80 \\
-- \\
80 \\
80 \\
80\end{array}$ & $\begin{array}{r}\text { b 70 } \\
69 \\
80 \\
78 \\
90\end{array}$ & $\begin{array}{l}80 \\
80 \\
80 \\
80 \\
80\end{array}$ & $\begin{array}{r}65 \\
80 \\
\text { b } 80 \\
80 \\
80\end{array}$ \\
\hline $\begin{array}{l}16 \\
17 \\
18 \\
19 \\
20\end{array}$ & $\begin{array}{l}-- \\
-- \\
-- \\
-- \\
--\end{array}$ & $\begin{array}{l}-- \\
-- \\
-- \\
50\end{array}$ & $\begin{array}{l}48 \\
40 \\
40 \\
40 \\
50\end{array}$ & $\begin{array}{r}40 \\
248 \\
48 \\
48 \\
43\end{array}$ & $\begin{array}{l}60 \\
60 \\
60 \\
60 \\
60\end{array}$ & $\begin{array}{l}60 \\
60 \\
50 \\
65 \\
50\end{array}$ & $\begin{array}{l}60 \\
60 \\
60 \\
60 \\
50\end{array}$ & $\begin{array}{l}60 \\
70 \\
60 \\
70 \\
80\end{array}$ & $\begin{array}{r}80 \\
85 \\
82 \\
\text { b 78 } \\
87\end{array}$ & $\begin{array}{l}60 \\
80 \\
80 \\
80 \\
90\end{array}$ & $\begin{array}{l}90 \\
80 \\
80 \\
80 \\
80\end{array}$ & $\begin{array}{l}80 \\
80 \\
80 \\
80 \\
70\end{array}$ \\
\hline $\begin{array}{l}21 \\
22 \\
23 \\
24 \\
25\end{array}$ & $\begin{array}{l}-- \\
-- \\
-- \\
--\end{array}$ & $\begin{array}{l}42 \\
40 \\
50 \\
48 \\
60\end{array}$ & $\begin{array}{l}50 \\
40 \\
38 \\
40 \\
40\end{array}$ & $\begin{array}{l}38 \\
38 \\
60 \\
60 \\
58\end{array}$ & $\begin{array}{l}60 \\
60 \\
50 \\
50 \\
50\end{array}$ & $\begin{array}{l}50 \\
60 \\
50 \\
50 \\
50\end{array}$ & $\begin{array}{l}60 \\
60 \\
50 \\
50 \\
50\end{array}$ & $\begin{array}{r}70 \\
70 \\
65 \\
60 \\
\mathbf{a} 62\end{array}$ & $\begin{array}{r}85 \\
85 \\
80 \\
\text { b } 79 \\
80\end{array}$ & $\begin{array}{l}80 \\
80 \\
78 \\
80 \\
98\end{array}$ & $\begin{array}{l}80 \\
80 \\
70 \\
70 \\
80\end{array}$ & $\begin{array}{r}70 \\
70 \\
70 \\
\mathrm{a} 60 \\
\mathbf{a} 68\end{array}$ \\
\hline $\begin{array}{l}26 \\
27 \\
28 \\
29 \\
30 \\
31\end{array}$ & $\begin{array}{l}-- \\
-- \\
-- \\
-- \\
--\end{array}$ & $\begin{array}{r}58 \\
58 \\
\text { b 60 } \\
\text { b58 } \\
60 \\
--\end{array}$ & $\begin{array}{l}40 \\
40 \\
40 \\
40 \\
40 \\
40\end{array}$ & $\begin{array}{l}60 \\
-- \\
60 \\
60 \\
60 \\
60\end{array}$ & $\begin{array}{l}50 \\
50 \\
50 \\
-- \\
-- \\
--\end{array}$ & $\begin{array}{r}50 \\
50 \\
50 \\
50 \\
\mathbf{2} 60 \\
60\end{array}$ & $\begin{array}{l}60 \\
60 \\
70 \\
68 \\
66 \\
--\end{array}$ & $\begin{array}{r}75 \\
\text { b 70 } \\
\text { b } 68 \\
75 \\
\text { b 72 } \\
75\end{array}$ & $\begin{array}{l}85 \\
78 \\
78 \\
80 \\
78 \\
--\end{array}$ & $\begin{array}{l}90 \\
90 \\
90 \\
90 \\
80 \\
80\end{array}$ & $\begin{array}{r}\text { b } 80 \\
\text { b } 80 \\
80 \\
80 \\
80 \\
\text { a 78 }\end{array}$ & $\begin{array}{l}70 \\
60 \\
70 \\
70 \\
70 \\
--\end{array}$ \\
\hline $\begin{array}{c}\text { Aver- } \\
\text { age }\end{array}$ & -- & -- & 43 & 51 & 57 & 54 & 61 & 67 & 80 & 80 & 80 & 75 \\
\hline
\end{tabular}

a Measurem

b Measurement after $6 \mathrm{p.m}$. 
RIO GRANDE BASIN--Continued

PECOS RIVER AT PUERTO DE LUNA, N. MEX.--Continued

Suspended sediment, water year October 1953 to September 1954

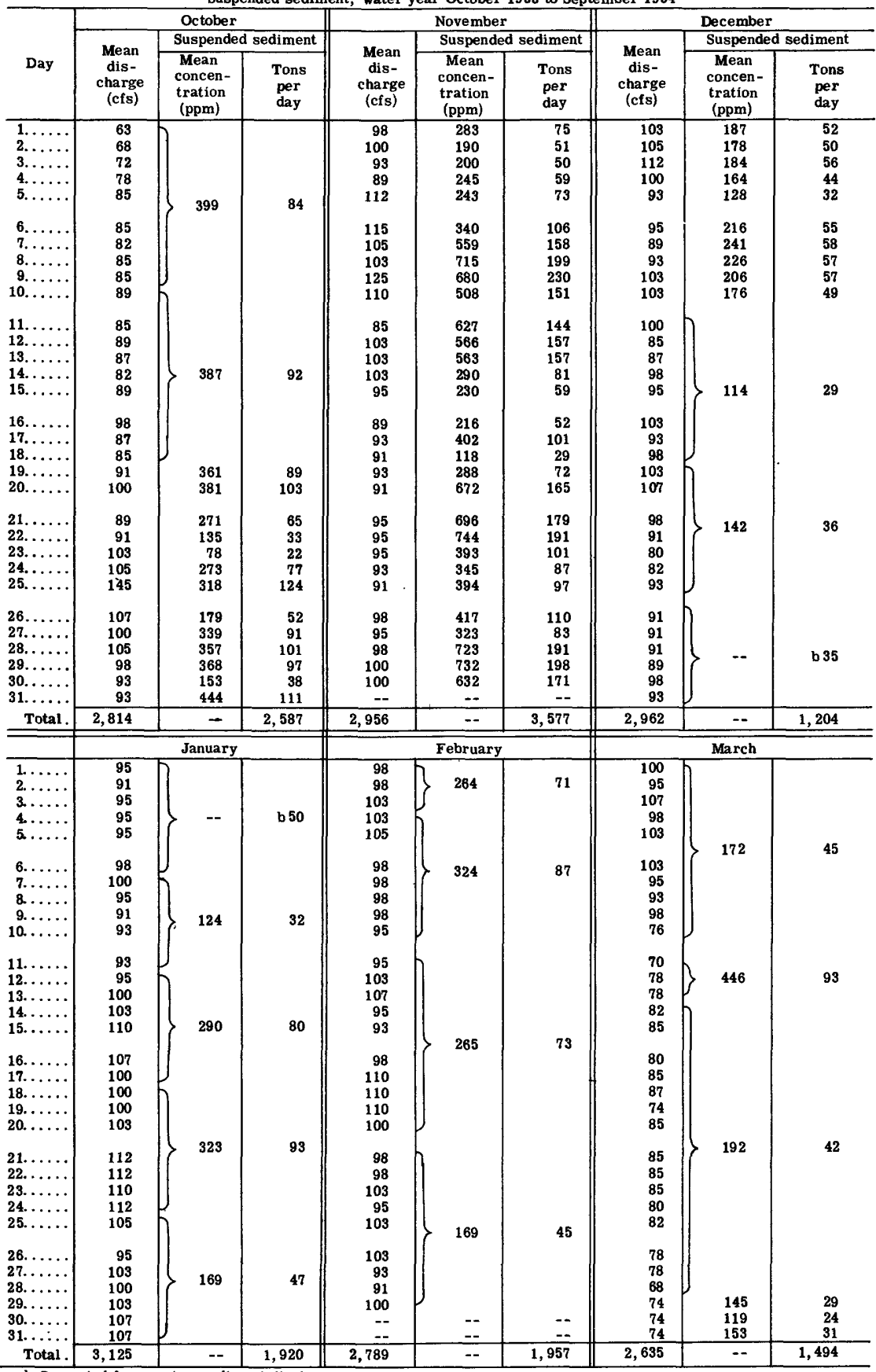

b Computed from water-sediment discharge curve. 
RIO GRANDE BASIN--Continued

PECOS RIVER AT PUERTO DE LUNA, N. MEX.--Continued

Suspended sediment, water year October 1953 to September 1954--Continued

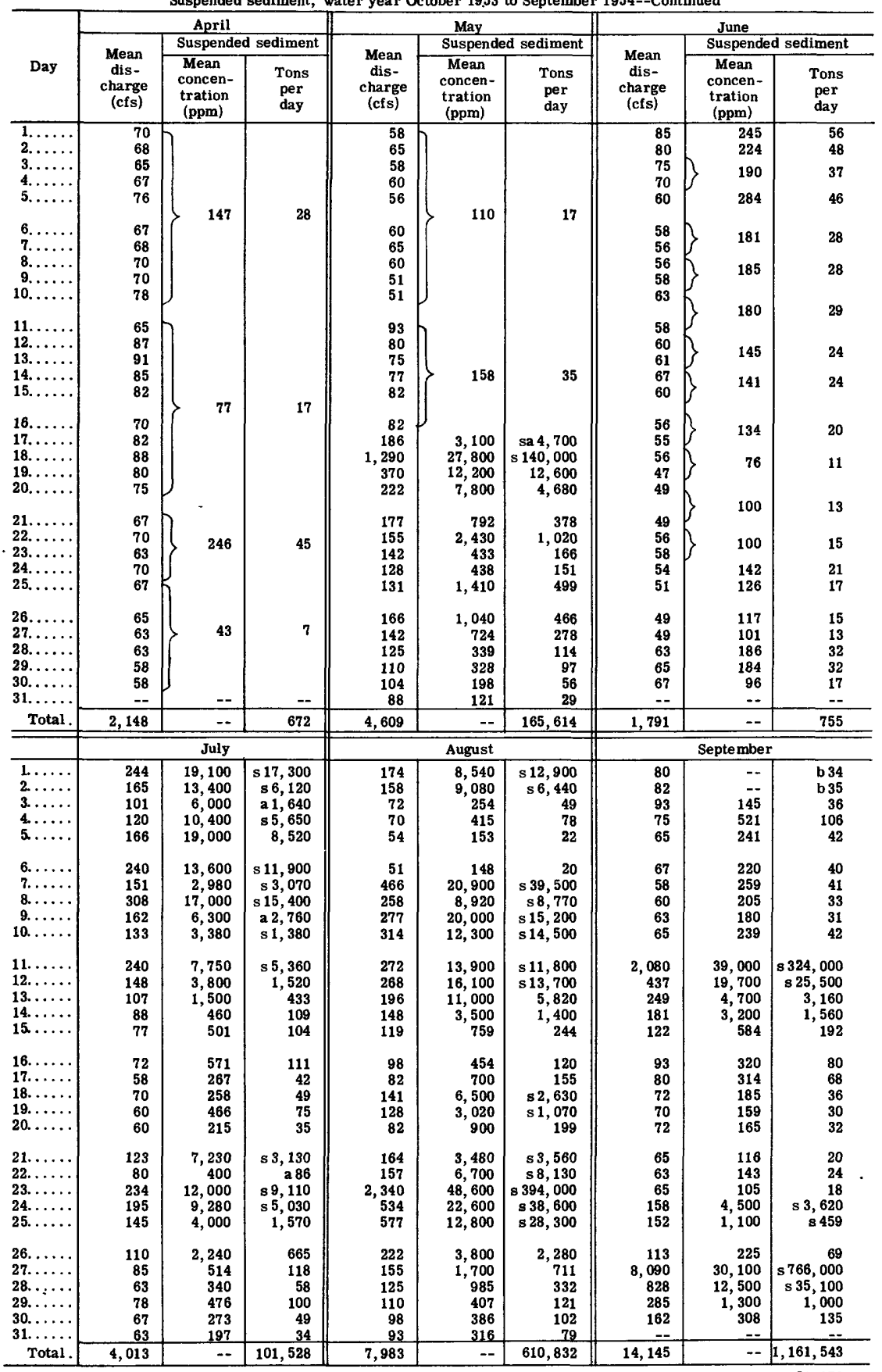

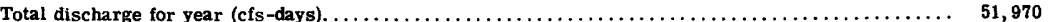

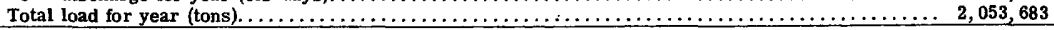

s Computed by subdividing day.

b Computed from water-sediment discharge curve.

a Computed from estimated concentration graph. 


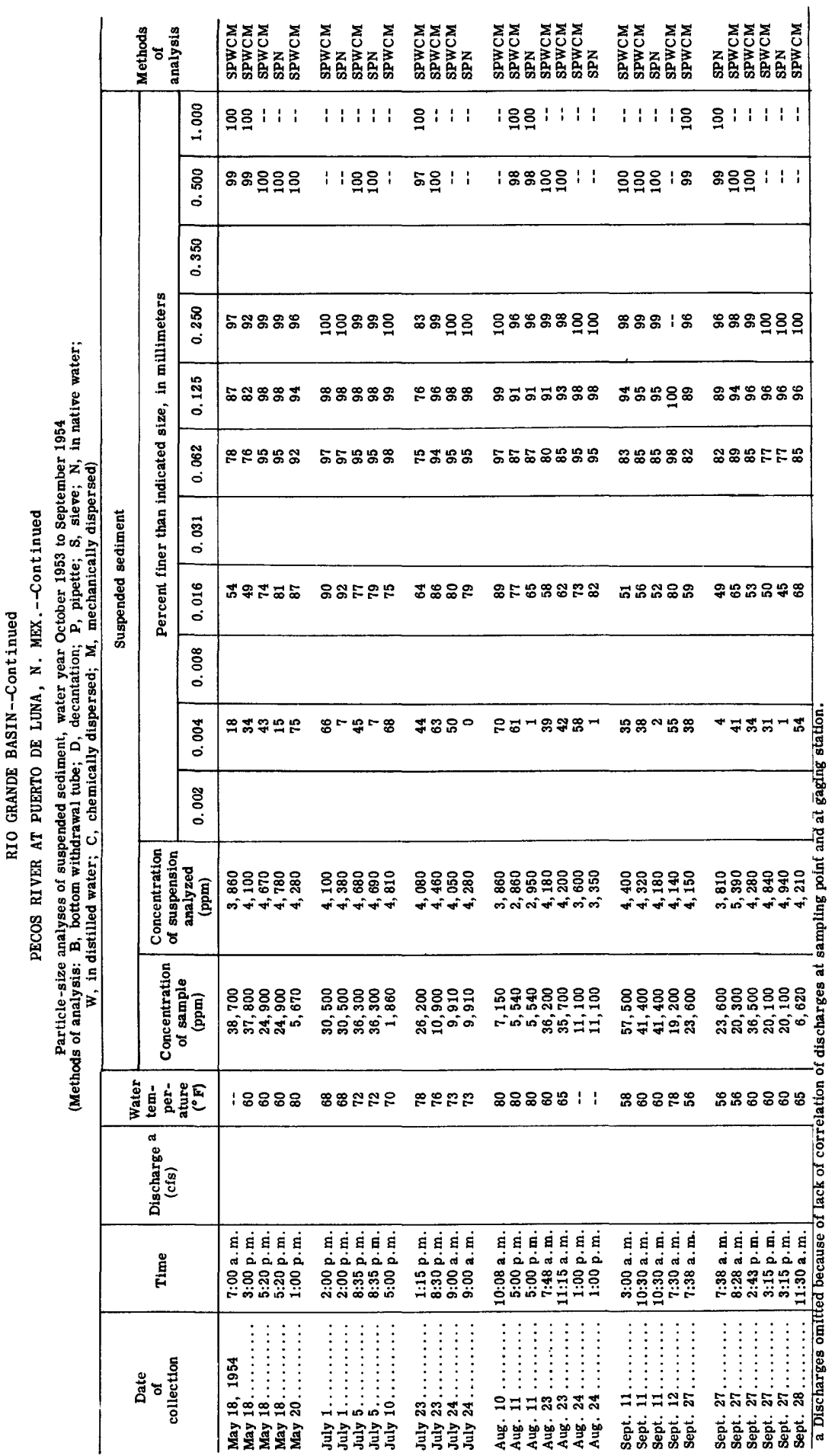




\begin{tabular}{|c|c|c|c|c|c|c|}
\hline & $\ddot{0}$ & 혐 & | & 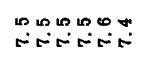 & 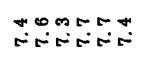 & 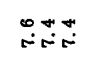 \\
\hline & 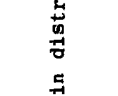 & 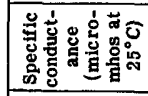 & 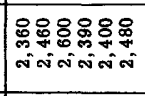 & 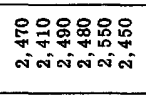 & 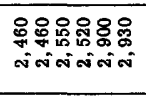 & $\begin{array}{l}\text { 용영 } \\
\text { sinis }\end{array}$ \\
\hline & $\underset{\pi}{\pi}$ & 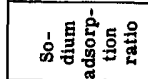 & 000000 & 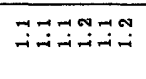 & $\exists \exists=00$. & $\infty$ \\
\hline & $\stackrel{\pi}{3}$ & 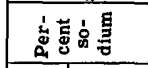 & 응ㅇㅇ워줘조 & 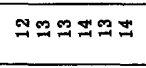 & 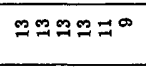 & $\infty \infty 0 \infty$ \\
\hline & 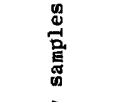 & 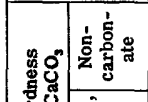 & 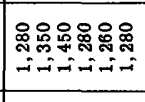 & 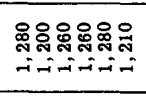 & 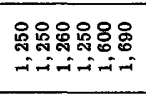 & 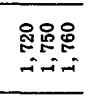 \\
\hline & 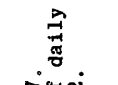 & 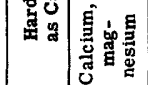 & 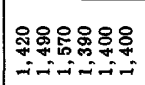 & 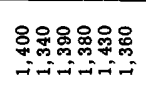 & 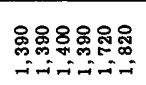 & 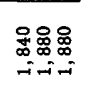 \\
\hline & 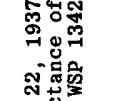 & 宽 & 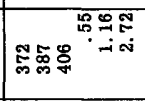 & 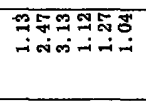 & 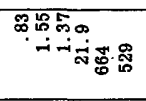 & 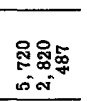 \\
\hline & 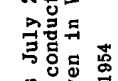 & 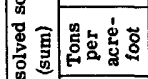 & 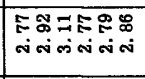 & 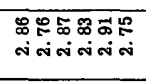 & 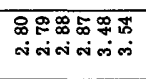 & 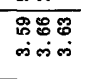 \\
\hline 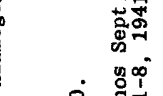 & 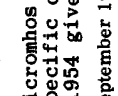 & 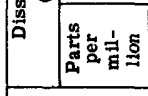 & 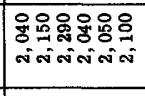 & 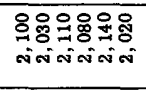 & 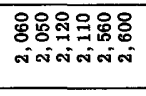 & 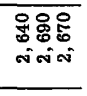 \\
\hline & & 㝘㤐鱼 & & & & \\
\hline 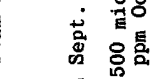 & 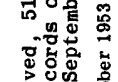 & 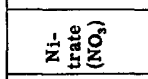 & $\because 90000$ & F⿻ & म्लm & \\
\hline 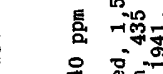 & $\begin{array}{ll}\infty & 0 \\
0 & 0 \\
0 & 8 \\
0 & 8 \\
0 & 0\end{array}$ & 产害西 & & & & \\
\hline ह & 苋 & ㅎํㅇㅝㅠำ & \& & 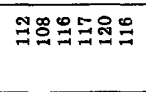 & 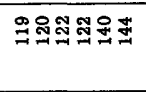 & 忒部哭 \\
\hline 告。 & 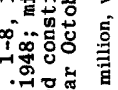 & 总 & 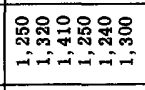 & 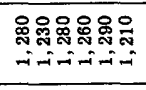 & 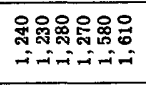 & 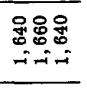 \\
\hline है & 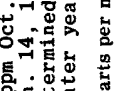 & 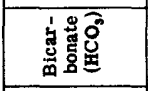 & 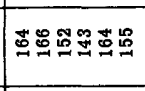 & 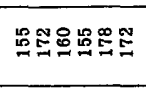 & 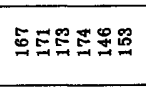 & 象名是 \\
\hline & $\begin{array}{ll}0 \\
0\end{array}$ & 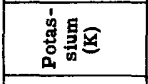 & & & & \\
\hline 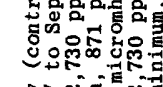 & 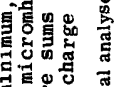 & 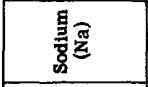 & 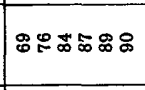 & 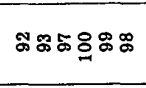 & 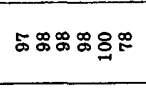 & $\stackrel{\infty}{\infty}$ \\
\hline 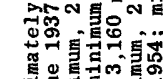 & 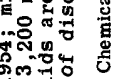 & 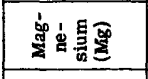 & 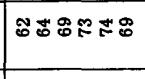 & 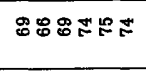 & இஐテロ品め & $\vec{\infty} \varpi$ \\
\hline 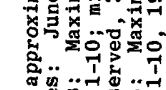 & 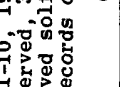 & 过晨可 & 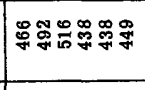 & 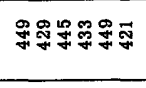 & 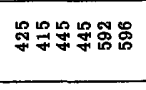 & 品芯芯 \\
\hline 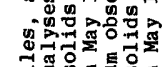 & 旨. & 实预 & & & & \\
\hline สำ워 & & 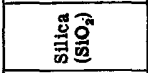 & ニッォニ & 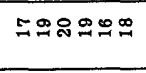 & 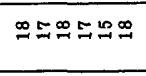 & $\stackrel{\infty}{\sim}$ \\
\hline 엄둥 & 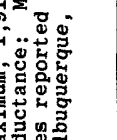 & 绨哥 & 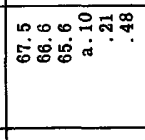 & 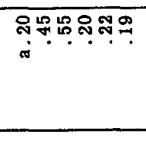 & 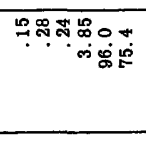 & 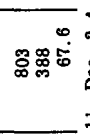 \\
\hline 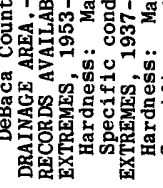 & 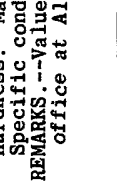 & 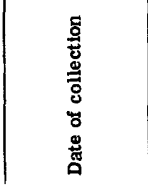 & 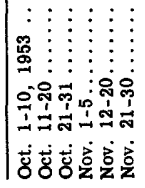 & 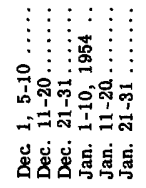 & 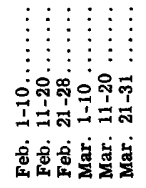 & 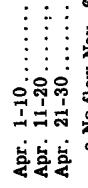 \\
\hline
\end{tabular}




\begin{tabular}{|c|c|c|c|c|c|}
\hline & 垫 & 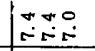 & 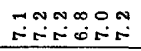 & 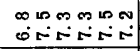 & 1 \\
\hline & 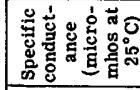 & 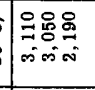 & 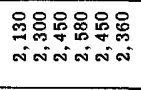 & 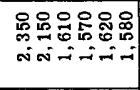 & 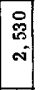 \\
\hline & 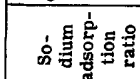 & a.0? & 900000 . & 0000000 & $\begin{array}{l}\infty \\
0 \\
0\end{array}$ \\
\hline & 咅哥宫息 & 으요 & $\exists=\simeq \cong \simeq \cong$ & $\cong=\infty 000$ & 우 \\
\hline & 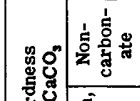 & 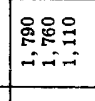 & 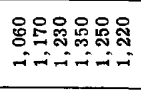 & 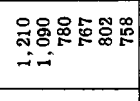 & $\stackrel{\circ}{\circ}$ \\
\hline & 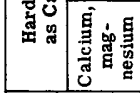 & 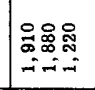 & 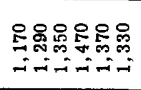 & 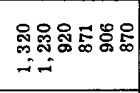 & 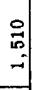 \\
\hline & 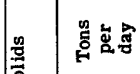 & 景尽嵒 & 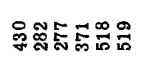 & ్ㅗㅇ잉미 & 员 \\
\hline $\begin{array}{l}0 \\
i \\
i \\
\dot{a}\end{array}$ & 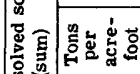 & 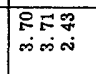 & 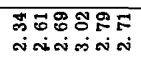 & 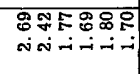 & 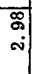 \\
\hline 焉 & 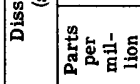 & 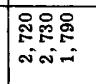 & 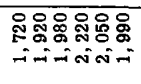 & 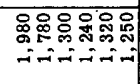 & : \\
\hline & 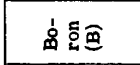 & & & & \\
\hline 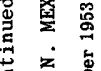 & 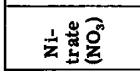 & $\stackrel{m}{i} \div$ & $9099 \%$ & 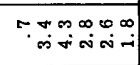 & $=$ \\
\hline 造 & 实茟国 & & & & \\
\hline 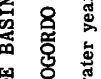 & 웛 & 蛋占邑 & 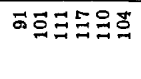 & 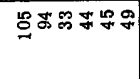 & 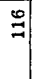 \\
\hline 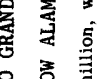 & 苛总 & 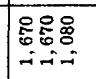 & 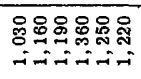 & 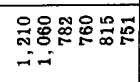 & $\begin{array}{l}0 \\
0 \\
0 \\
0 \\
-10\end{array}$ \\
\hline 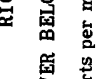 & 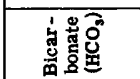 & 式吕怘 & 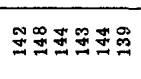 & 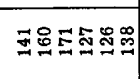 & 뭄 \\
\hline & 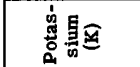 & & & & \\
\hline 兽蒂 & 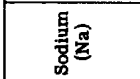 & Бర్లి & 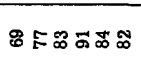 & 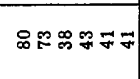 & : 2 \\
\hline 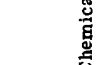 & 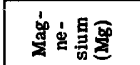 & $\mathscr{8}$ & 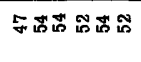 & 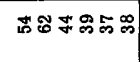 & $:$ \\
\hline & 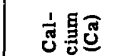 & 옹 & 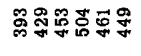 & ఈ & $\stackrel{\circ}{\circ}$ \\
\hline & 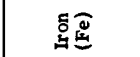 & & & & \\
\hline & 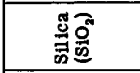 & 곡요 & ㅉำ & このレすのの & $\rightarrow$ \\
\hline & 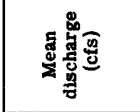 & 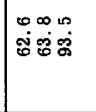 & 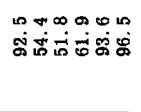 & 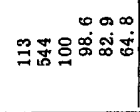 & 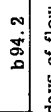 \\
\hline & 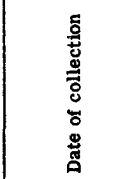 & 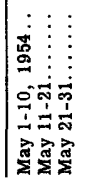 & 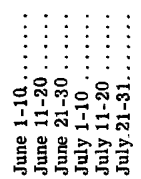 & 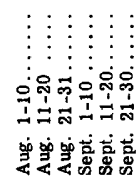 & 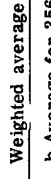 \\
\hline
\end{tabular}




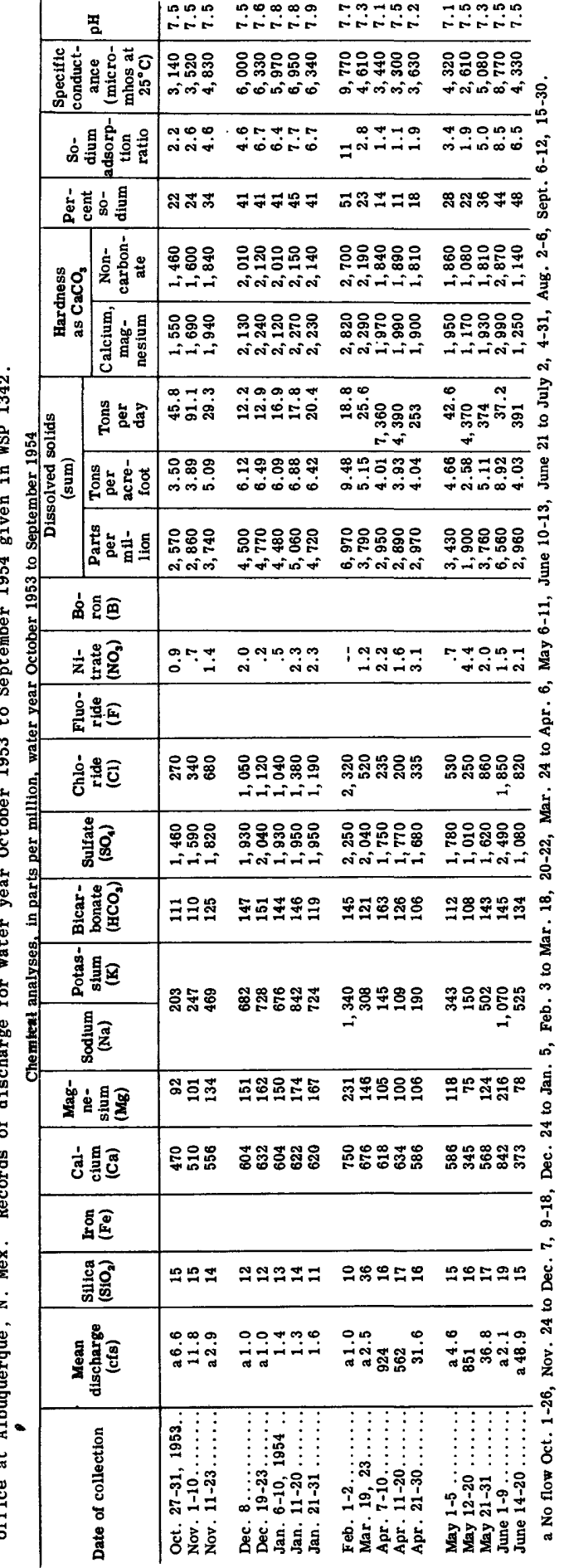




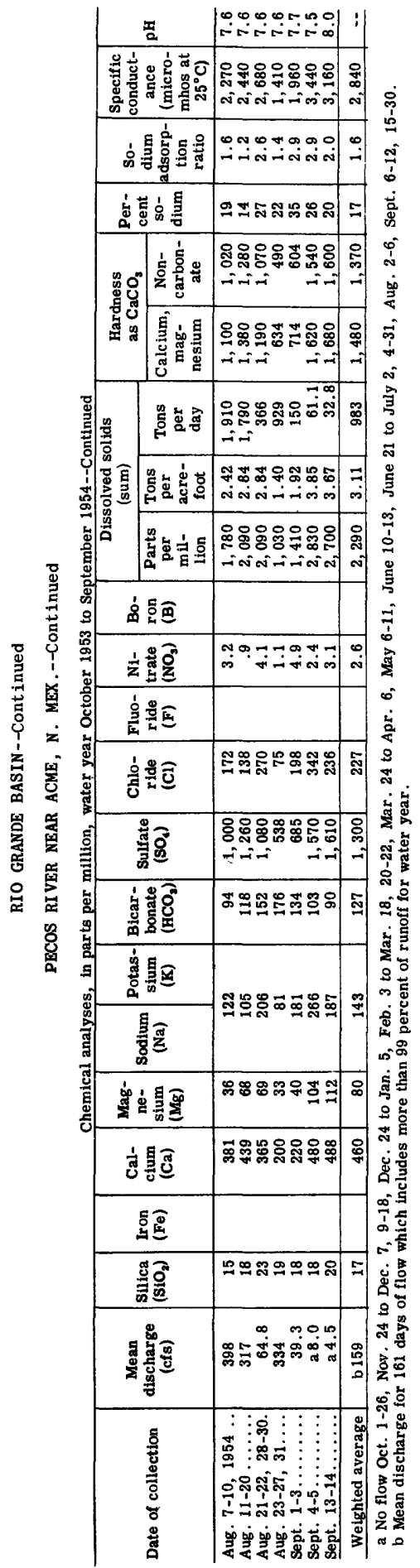


RIO GRANDE BASIN--Continued

PECOS RIVER NEAR ACME, N. MEX,--Continued

Temperature ( ${ }^{\circ} \mathrm{F}$ ) of water, water year October 1953 to September 1954 Once-daily measurement usually during daylight hours7

\begin{tabular}{|c|c|c|c|c|c|c|c|c|c|c|c|c|}
\hline Day & Oct. & Nov. & Dec. & Jan. & Feb. & Mar. & Apr. & May & June & July & Aug. & Sept. \\
\hline $\begin{array}{l}1 \\
2 \\
3 \\
4 \\
5\end{array}$ & $\begin{array}{l}-- \\
-- \\
-- \\
--\end{array}$ & $\begin{array}{l}-\overline{46} \\
47 \\
41 \\
38\end{array}$ & & & & & $\begin{array}{l}-- \\
-- \\
-\end{array}$ & $\begin{array}{l}69 \\
68 \\
-- \\
-2 \\
70\end{array}$ & $\begin{array}{l}82 \\
75 \\
73 \\
70 \\
77\end{array}$ & & $\begin{array}{l}= \\
-- \\
= \\
--\end{array}$ & $\begin{array}{l}82 \\
83 \\
80 \\
81 \\
75\end{array}$ \\
\hline $\begin{array}{r}6 \\
7 \\
8 \\
9 \\
10\end{array}$ & $\begin{array}{l}-- \\
-- \\
-- \\
-\end{array}$ & $\begin{array}{r}40 \\
38 \\
-- \\
39 \\
---\end{array}$ & & & & & $\begin{array}{l}- \\
-- \\
-- \\
--\end{array}$ & $\begin{array}{l}-- \\
-- \\
-- \\
-\end{array}$ & $\begin{array}{l}80 \\
70 \\
79 \\
-- \\
--\end{array}$ & & $\begin{array}{l}-- \\
-- \\
80 \\
80 \\
83\end{array}$ & $\begin{array}{l}-- \\
-- \\
-- \\
--\end{array}$ \\
\hline $\begin{array}{l}11 \\
12 \\
13 \\
14 \\
15\end{array}$ & $\begin{array}{l}-- \\
-- \\
-- \\
--\end{array}$ & $\begin{array}{l}38 \\
44 \\
40 \\
41 \\
38\end{array}$ & & & & & $\begin{array}{l}-- \\
55 \\
63 \\
67 \\
69\end{array}$ & $\begin{array}{l}-- \\
-- \\
73 \\
74 \\
77\end{array}$ & $\begin{array}{l}-- \\
-- \\
-- \\
-- \\
75\end{array}$ & & $\begin{array}{l}84 \\
82 \\
75 \\
87 \\
80\end{array}$ & $\begin{array}{l}-- \\
-- \\
83 \\
83 \\
--\end{array}$ \\
\hline $\begin{array}{l}16 \\
17 \\
18 \\
19 \\
20\end{array}$ & $\begin{array}{l}-- \\
-- \\
-- \\
--\end{array}$ & $\begin{array}{l}37 \\
-- \\
36 \\
-- \\
--\end{array}$ & & & & & $\begin{array}{l}69 \\
70 \\
73 \\
74 \\
70\end{array}$ & $\begin{array}{l}70 \\
82 \\
67 \\
77 \\
80\end{array}$ & $\begin{array}{l}70 \\
86 \\
85 \\
-2 \\
78\end{array}$ & & $\begin{array}{l}85 \\
85 \\
83 \\
78 \\
80\end{array}$ & $\begin{array}{l}-- \\
-- \\
-- \\
--\end{array}$ \\
\hline $\begin{array}{l}21 \\
22 \\
23 \\
24 \\
25\end{array}$ & $\begin{array}{l}-- \\
-- \\
-- \\
--\end{array}$ & $\begin{array}{l}-- \\
-- \\
-- \\
--\end{array}$ & & & & & $\begin{array}{l}69 \\
71 \\
68 \\
73 \\
75\end{array}$ & $\begin{array}{l}75 \\
70 \\
74 \\
65 \\
74\end{array}$ & $\begin{array}{l}-- \\
-- \\
-- \\
--\end{array}$ & & $\begin{array}{l}78 \\
76 \\
79 \\
80 \\
80\end{array}$ & $\begin{array}{l}-- \\
-- \\
-- \\
--\end{array}$ \\
\hline $\begin{array}{l}26 \\
27 \\
28 \\
29 \\
30 \\
31\end{array}$ & $\begin{array}{l}-- \\
45 \\
46 \\
44 \\
44 \\
36\end{array}$ & $\begin{array}{l}-- \\
-- \\
-- \\
-- \\
--\end{array}$ & & & & & $\begin{array}{l}70 \\
73 \\
75 \\
70 \\
67 \\
--\end{array}$ & $\begin{array}{l}76 \\
80 \\
82 \\
75 \\
80 \\
77\end{array}$ & $\begin{array}{l}-- \\
-- \\
-- \\
-- \\
--\end{array}$ & & $\begin{array}{l}80 \\
82 \\
82 \\
81 \\
82 \\
76\end{array}$ & $\begin{array}{l}-- \\
-- \\
-- \\
--\end{array}$ \\
\hline $\begin{array}{c}\text { Aver - } \\
\text { age }\end{array}$ & 43 & -- & & & & & 70 & 74 & 77 & & 81 & 81 \\
\hline
\end{tabular}




\section{RIO GRANDE BASIN--Continued}

RIO HONDO AT DI AMOND A RANCH, NEAR ROSWELL, N. MEX.

LOCATION. --At gaging station on downstream side of road bridge at Diamond A Ranch, $8 \mathrm{miles}$ upstream from Rocky Arroyo, and 18 miles west of Roswell, Chaves County.

DRAINAGE AREA. -960 squares miles (contributing area).

RECORDS AVAILABLE. --Water temperatures: September 1951 to September 1954.

Sediment records: September 1951 to September 1954

EXTREMES, 1953-54.--Water temperatures: Maximum observed, $85{ }^{\circ} \mathrm{F}$ June 28 ; minimum, not determined.

Sediment concentrations: Maximum daily, 60,000 ppm July 22; minimum daily, no flow on many days.

Sediment loads: Maximum daily, 68,000 tons Sept. 24 ; minimum daily, 0 tons on many days EXTREMES, 1951-54.--Water temperatures: Maximum observed, $86{ }^{\circ} \mathrm{F}$ July 24, 25, 1952 ; minimum, not determined.

Sediment concentrations: Maximum daily, not determined; minimum daily, no flow on many days.

Sediment loads: Maximum daily, 160,000 tons (estimated) July 13, 1953; minimum daily, 0 tons on many days.

REMARKS.--Maximum observed, sediment concentration during water year, 119,000 ppm July 23. No flow during January to March; tabulation omitted for this period. Records of discharge for water year October 1953 to September 1954 given in wSP 1342.

Temperature $\left({ }^{\circ} \mathrm{F}\right)$ of water, water year October 1953 to September 1954 [Önce-daily measurement, generallv between $11 \mathrm{a} . \mathrm{m}$. and $6 \mathrm{p} . \mathrm{m}$. No flow on many days

\begin{tabular}{|c|c|c|c|c|c|c|c|c|c|c|c|c|}
\hline Day & Oct. & Nov. & Dec. & Jan. & Feb. & Mar. & Apr. & May & June & July & Aug. & Sept. \\
\hline $\begin{array}{l}1 \\
2 \\
3 \\
4 \\
5\end{array}$ & & & & & & & & & $\begin{array}{l}-- \\
-- \\
-- \\
--\end{array}$ & $\begin{array}{r}82 \\
274 \\
-- \\
-- \\
--\end{array}$ & $\begin{array}{l}-- \\
-- \\
-- \\
--\end{array}$ & $\begin{array}{r}78 \\
\text { b78 } \\
80 \\
75\end{array}$ \\
\hline $\begin{array}{r}6 \\
7 \\
8 \\
9 \\
10\end{array}$ & & & & & & & & & $\begin{array}{l}-- \\
-- \\
-- \\
-- \\
--\end{array}$ & $\begin{array}{l}83 \\
84 \\
84 \\
--\end{array}$ & $\begin{array}{l}76 \\
76 \\
78 \\
80 \\
69\end{array}$ & $\begin{array}{r}\text { b76 } \\
78 \\
80 \\
80 \\
-\end{array}$ \\
\hline $\begin{array}{l}11 \\
12 \\
13 \\
14 \\
15\end{array}$ & & & & & & & & & $\begin{array}{l}-- \\
-- \\
-- \\
--\end{array}$ & $\begin{array}{l}-- \\
-- \\
-- \\
--\end{array}$ & $\begin{array}{l}80 \\
-- \\
-- \\
80 \\
--\end{array}$ & $\begin{array}{r}78 \\
76 \\
78 \\
77 \\
\mathbf{2} 69\end{array}$ \\
\hline $\begin{array}{l}16 \\
17 \\
18 \\
19 \\
20\end{array}$ & & & & & & & & 72 & $\begin{array}{l}-- \\
-- \\
-- \\
--\end{array}$ & $\begin{array}{l}-- \\
- \\
-- \\
--\end{array}$ & $\begin{array}{l}-- \\
-- \\
-- \\
82\end{array}$ & \begin{tabular}{r}
$\mathbf{6} 69$ \\
\hdashline- \\
-
\end{tabular} \\
\hline $\begin{array}{l}21 \\
22 \\
23 \\
24 \\
25\end{array}$ & & & & & & & & & $\begin{array}{l}-- \\
-- \\
-- \\
--\end{array}$ & $\begin{array}{r}79 \\
78 \\
278 \\
82\end{array}$ & $\begin{array}{l}-- \\
66 \\
78 \\
72 \\
74\end{array}$ & $\begin{array}{l}-- \\
-- \\
67\end{array}$ \\
\hline $\begin{array}{l}26 \\
27 \\
28 \\
29 \\
30 \\
31\end{array}$ & & & & & & & & & $\begin{array}{l}-- \\
-- \\
85 \\
82 \\
84 \\
--\end{array}$ & $\begin{array}{l}-- \\
-- \\
-- \\
-- \\
--\end{array}$ & $\begin{array}{l}78 \\
78 \\
80 \\
80 \\
80 \\
79 \\
\end{array}$ & $\begin{array}{l}-- \\
-- \\
-- \\
--\end{array}$ \\
\hline $\begin{array}{c}\text { Aver- } \\
\text { age }\end{array}$ & & & & & & & & - & 84 & $\cdots$ & 77 & - \\
\hline
\end{tabular}

a Measurement before 11 a. $\mathrm{m}$

b Measurement after 6 p.m. 
RIO GRANDE BASIN

RIO GRANDE BASIN--Continued

RIO HONDO AT DIAMOND A RANCH NEAR ROSWELL, N. MEX.--Continued

Suspended sediment, water year October 1953 to September 1954

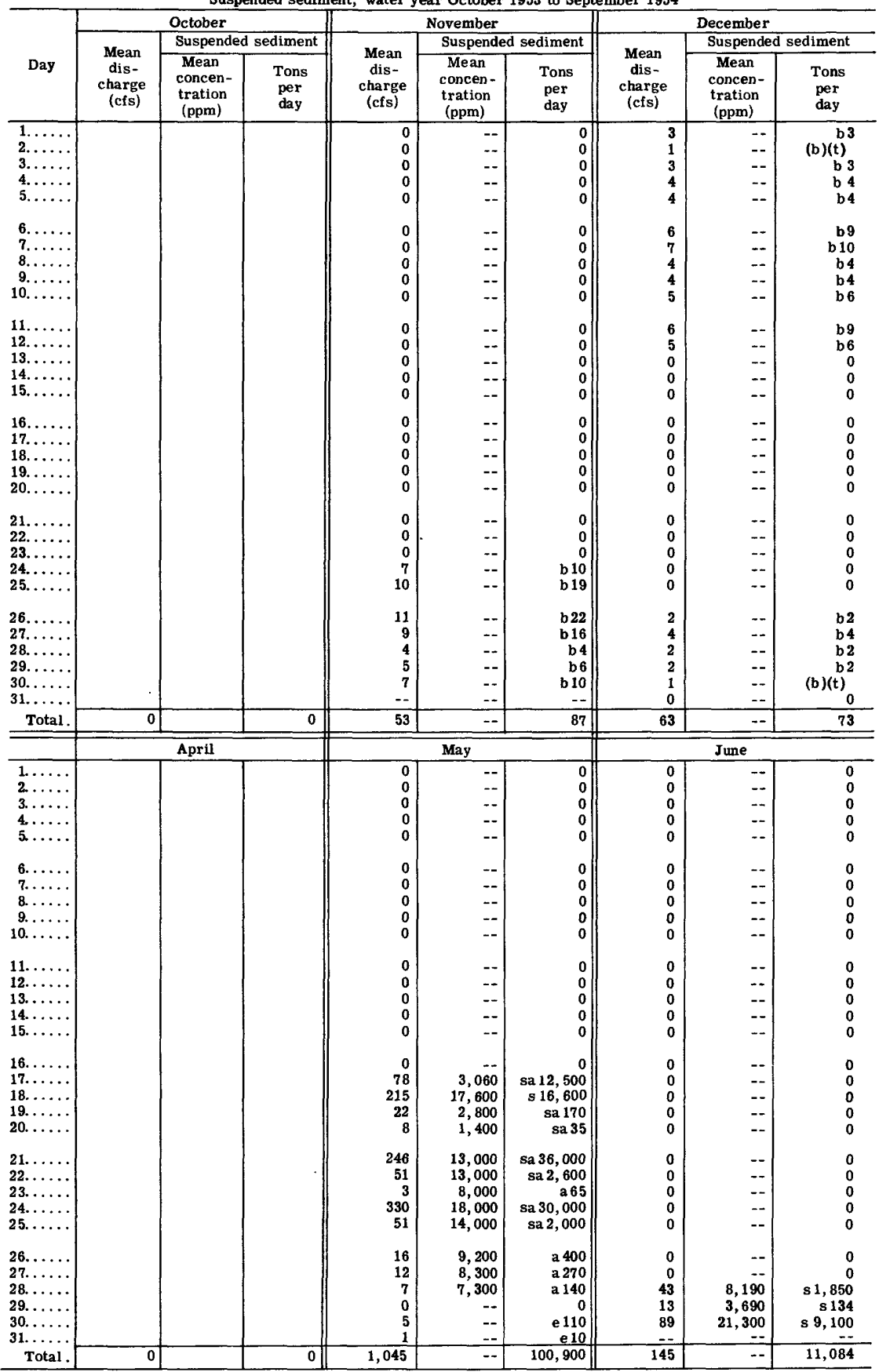

Estimated.

s Computed by subdividing day.

a Computed from estimated concentration graph.

$t$ Less than 0.50 ton.

Computed from water-sediment discharge relation. 
RIO GRANDE BASIN--Continued

RIO HONDO AT DIAMOND A RANCH NEAR ROSWELL, N. MEX.--Continued

\begin{tabular}{|c|c|c|c|c|c|c|c|c|c|}
\hline \multirow[b]{3}{*}{ Day } & \multicolumn{3}{|c|}{ July } & \multicolumn{3}{|c|}{ August } & \multicolumn{3}{|c|}{ September } \\
\hline & \multirow[b]{2}{*}{$\begin{array}{l}\text { Mean } \\
\text { dis- } \\
\text { charge } \\
\text { (cfs) }\end{array}$} & \multicolumn{2}{|c|}{ Suspended sediment } & \multirow[b]{2}{*}{$\begin{array}{l}\text { Mean } \\
\text { dis- } \\
\text { charge } \\
\text { (cfs) }\end{array}$} & \multicolumn{2}{|c|}{ Suspended sediment } & \multirow[b]{2}{*}{$\begin{array}{l}\text { Mean } \\
\text { dis- } \\
\text { charge } \\
\text { (cfs) }\end{array}$} & \multicolumn{2}{|c|}{ Suspended sediment } \\
\hline & & $\begin{array}{l}\text { Mean } \\
\text { concen- } \\
\text { tration } \\
(\mathrm{ppm})\end{array}$ & $\begin{array}{l}\text { Tons } \\
\text { per } \\
\text { day }\end{array}$ & & $\begin{array}{c}\text { Mean } \\
\text { concen- } \\
\text { tration } \\
\text { (ppm) }\end{array}$ & $\begin{array}{l}\text { Tons } \\
\text { per } \\
\text { day }\end{array}$ & & $\begin{array}{l}\text { Mean } \\
\text { concen- } \\
\text { tration } \\
\text { (ppm) }\end{array}$ & $\begin{array}{l}\text { Tons } \\
\text { per } \\
\text { day }\end{array}$ \\
\hline $\begin{array}{l}1 \ldots \ldots \\
2 \ldots \ldots \\
3 . \ldots \ldots \\
4 \ldots \ldots \\
5 . \ldots \ldots\end{array}$ & $\begin{array}{l}\mathbf{7} \\
\mathbf{7} \\
\mathbf{2} \\
0 \\
0\end{array}$ & $\begin{array}{r}10,000 \\
1,950 \\
700 \\
-- \\
--\end{array}$ & $\begin{array}{r}189 \\
37 \\
24 \\
0 \\
0\end{array}$ & $\begin{array}{l}0 \\
0 \\
0 \\
0 \\
0\end{array}$ & $\begin{array}{l}-- \\
- \\
-- \\
-- \\
--\end{array}$ & $\begin{array}{l}0 \\
0 \\
0 \\
0 \\
0\end{array}$ & $\begin{array}{r}9 \\
28 \\
32 \\
19 \\
19\end{array}$ & $\begin{array}{r}860 \\
3,520 \\
900 \\
340 \\
490\end{array}$ & $\begin{array}{r}21 \\
\text { s } 401 \\
\text { s } 97 \\
\text { a } 17 \\
25\end{array}$ \\
\hline $\begin{array}{r}6 . \ldots \ldots \\
7 \ldots \ldots \\
8 \ldots \ldots \\
9 . \ldots \ldots \\
10 \ldots \ldots\end{array}$ & $\begin{array}{r}0 \\
19 \\
8 \\
5 \\
4\end{array}$ & $\begin{array}{l}7,070 \\
5,600 \\
5,890 \\
5,500\end{array}$ & $\begin{array}{r}0 \\
\text { s724 } \\
\text { s } 130 \\
\text { sa } 136 \\
\text { sa 92 }\end{array}$ & $\begin{array}{r}5 \\
39 \\
7 \\
64 \\
371\end{array}$ & $\begin{array}{r}2,250 \\
9,820 \\
6,500 \\
2,300 \\
46,700\end{array}$ & $\begin{array}{r}\mathrm{s} 100 \\
\mathrm{~s} 1,710 \\
123 \\
397 \\
\mathrm{~s} 65,000\end{array}$ & $\begin{array}{l}5 \\
5 \\
2 \\
2 \\
0\end{array}$ & $\begin{array}{l}50 \\
50 \\
40 \\
30 \\
--\end{array}$ & $\begin{array}{lr} & 1 \\
\text { (t) } & \\
\text { (t) } & \\
& 0\end{array}$ \\
\hline $\begin{array}{l}11 \ldots \ldots \\
12 \ldots \ldots \\
13 \ldots \ldots \\
14 \ldots \ldots \\
15 . \ldots \ldots\end{array}$ & $\begin{array}{l}0 \\
0 \\
0 \\
0 \\
0\end{array}$ & $\begin{array}{l}-- \\
-- \\
-- \\
--\end{array}$ & $\begin{array}{l}0 \\
0 \\
0 \\
0 \\
0\end{array}$ & $\begin{array}{r}29 \\
11 \\
3 \\
10 \\
0\end{array}$ & $\begin{array}{r}11,400 \\
3,200 \\
1,200 \\
1,150 \\
--\end{array}$ & $\begin{array}{r}893 \\
95 \\
10 \\
\mathrm{~s} 49 \\
0\end{array}$ & $\begin{array}{r}8 \\
7 \\
36 \\
3 \\
3\end{array}$ & $\begin{array}{r}92 \\
310 \\
5,930 \\
1,000 \\
380\end{array}$ & $\begin{array}{r}\mathrm{s} 5 \\
6 \\
\mathrm{~s} 520 \\
8 \\
3\end{array}$ \\
\hline $\begin{array}{l}16 \ldots \ldots \\
17 \ldots \ldots \\
18 \ldots \ldots \\
19 . \ldots \ldots \\
20 . \ldots \ldots\end{array}$ & $\begin{array}{l}0 \\
0 \\
0 \\
0 \\
0\end{array}$ & $\begin{array}{l}-- \\
-- \\
-- \\
--\end{array}$ & $\begin{array}{l}0 \\
0 \\
0 \\
0 \\
0\end{array}$ & $\begin{array}{l}0 \\
0 \\
0 \\
3 \\
0\end{array}$ & $\begin{array}{r}-- \\
-- \\
570 \\
--\end{array}$ & $\begin{array}{r}0 \\
0 \\
0 \\
\text { sa } 13 \\
0\end{array}$ & $\begin{array}{l}2 \\
1 \\
1 \\
1 \\
1\end{array}$ & $\begin{array}{l}80 \\
70 \\
60 \\
50 \\
40\end{array}$ & $\begin{array}{c}(t) \\
(a)(t) \\
(a)(t) \\
(a)(t) \\
(a)(t)\end{array}$ \\
\hline $\begin{array}{l}21 \ldots \ldots \\
22 \ldots \ldots \\
23 \ldots \ldots \\
24 \ldots \ldots \\
25 . \ldots \ldots\end{array}$ & $\begin{array}{r}0 \\
87 \\
76 \\
11 \\
2\end{array}$ & $\begin{array}{r}60,000 \\
34,500 \\
5,700 \\
3,100\end{array}$ & $\begin{array}{r}0 \\
\text { s } 25,000 \\
\text { s } 8,510 \\
169 \\
17\end{array}$ & $\begin{array}{r}0 \\
61 \\
133 \\
408 \\
124\end{array}$ & $\begin{array}{r}-- \\
6,250 \\
18,900 \\
23,000 \\
9,500\end{array}$ & $\begin{array}{r}0 \\
\mathrm{~s} 849 \\
\mathrm{~s} 9,910 \\
\mathrm{~s} 39,600 \\
3,180\end{array}$ & $\begin{array}{r}1 \\
1 \\
1 \\
315 \\
171\end{array}$ & $\begin{array}{r}30 \\
30 \\
30 \\
10,900 \\
23,400\end{array}$ & $\begin{array}{c}(a)(t) \\
(a)(t) \\
(a)(t) \\
s a 68,000 \\
s 25,100\end{array}$ \\
\hline $\begin{array}{l}26 \ldots \ldots \\
27 . \ldots \ldots \\
28 . \ldots \ldots \\
29 \ldots \ldots \\
30 \ldots \ldots \\
31 \ldots \ldots\end{array}$ & $\begin{array}{l}0 \\
0 \\
0 \\
0 \\
0 \\
0\end{array}$ & $\begin{array}{l}-- \\
-- \\
-- \\
-- \\
--\end{array}$ & $\begin{array}{l}0 \\
0 \\
0 \\
0 \\
0 \\
0\end{array}$ & $\begin{array}{r}56 \\
12 \\
6 \\
5 \\
7 \\
12\end{array}$ & $\begin{array}{l}5,000 \\
4,480 \\
3,210 \\
2,320 \\
2,330 \\
1,690\end{array}$ & $\begin{array}{r}\text { s } 802 \\
145 \\
52 \\
31 \\
44 \\
55\end{array}$ & $\begin{array}{l}35 \\
27 \\
20 \\
14 \\
10 \\
--\end{array}$ & $\begin{array}{r}2,000 \\
200 \\
100 \\
80 \\
50 \\
--\end{array}$ & $\begin{array}{r}\text { a } 190 \\
\text { a } 15 \\
\text { a } 5 \\
\text { a } 3 \\
\text { a } 1 \\
--\end{array}$ \\
\hline Total. & 228 & - & 35,008 & 1,366 & -- & 123,058 & 779 & - & 94,421 \\
\hline
\end{tabular}

s Computed by subdividing day.

$t$ Less than 0.50 ton.

a Computed from estimated concentration graph. 
RIO GRANDE BASIN

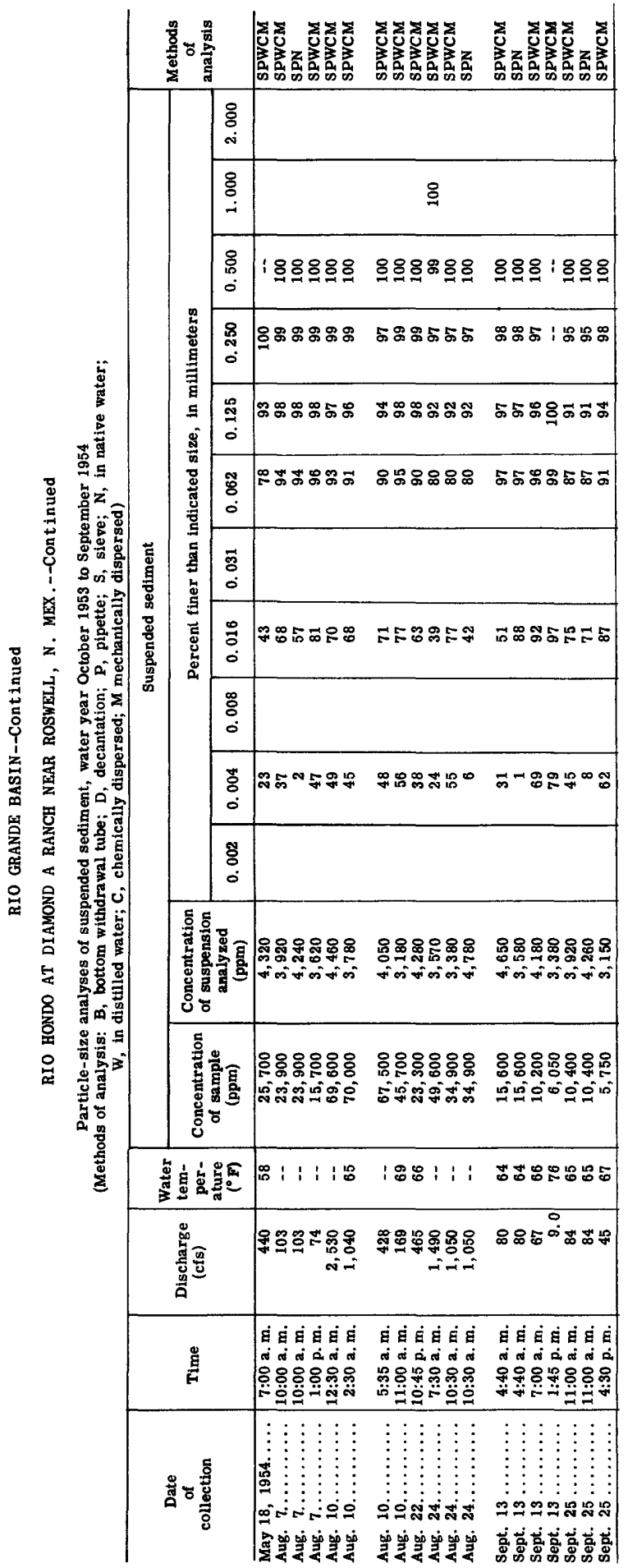




\begin{tabular}{|c|c|c|c|c|}
\hline \multicolumn{2}{|c|}{ 我 } & 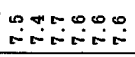 & 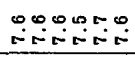 & 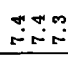 \\
\hline \multicolumn{2}{|c|}{ 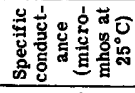 } & 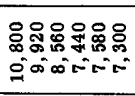 & 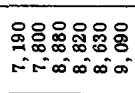 & 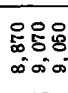 \\
\hline \multicolumn{2}{|c|}{ 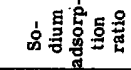 } & 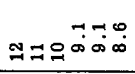 & 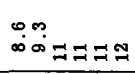 & $\exists \approx \approx$ \\
\hline \multicolumn{2}{|c|}{ 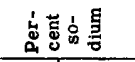 } & ำ 또ำ & 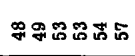 & 碑䓃芯 \\
\hline \multirow{2}{*}{ 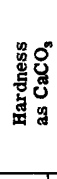 } & 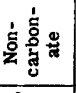 & 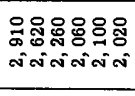 & 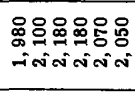 & 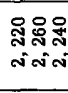 \\
\hline & 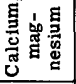 & 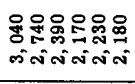 & 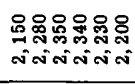 & 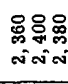 \\
\hline
\end{tabular}

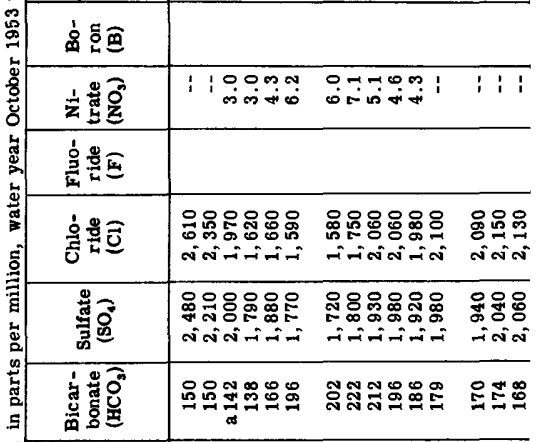

我 N

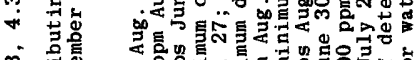

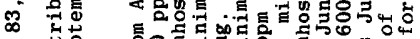

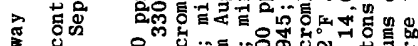

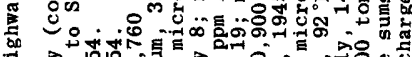

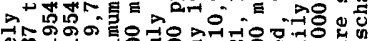

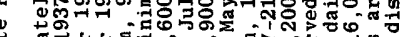
政 焉 1 。

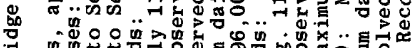
范 ๙ ร

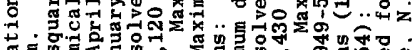

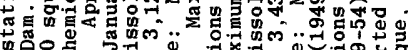

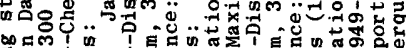

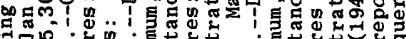

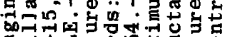

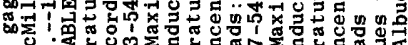

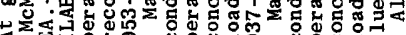
1

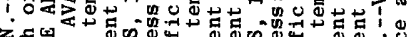

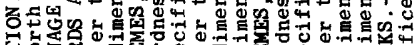

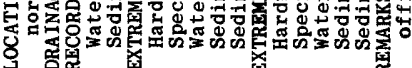

\begin{tabular}{|c|c|}
\hline 彭高 & \\
\hline $\begin{array}{ll} \\
\end{array}$ & 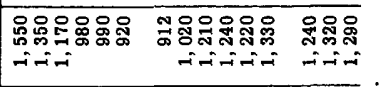 \\
\hline 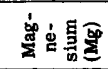 & 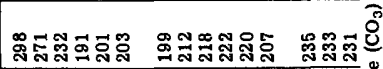 \\
\hline 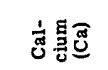 & 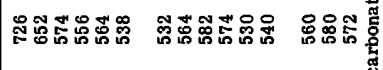 \\
\hline 焉要 & \\
\hline 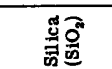 & 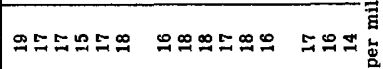 \\
\hline 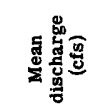 & 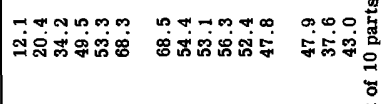 \\
\hline 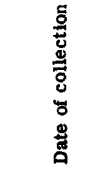 & 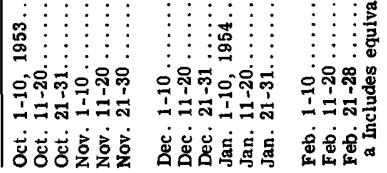 \\
\hline
\end{tabular}




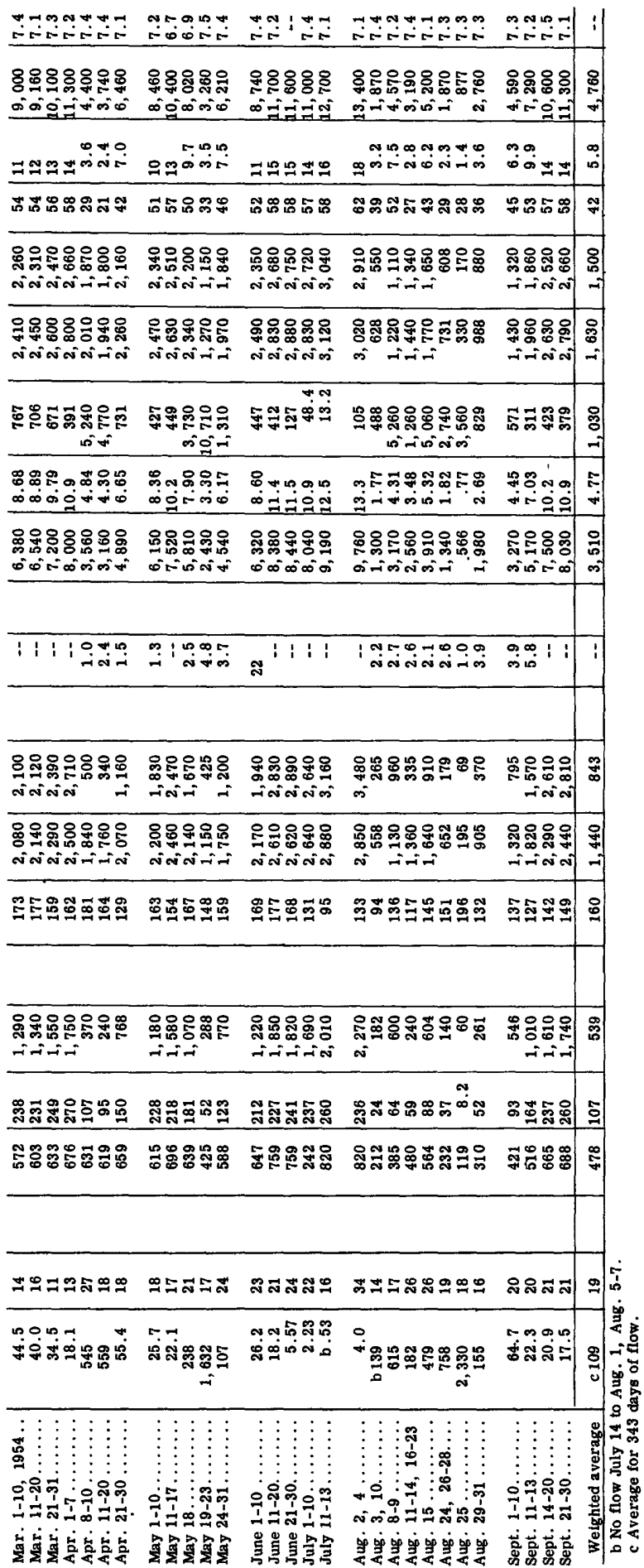


RIO GRANDE BASIN---Continued

PECOS RIVER NEAR ARTESIA, N. MEX.--Continued

Temperature $\left({ }^{\circ} \mathrm{F}\right)$ of water, water year October 1953 to September 1954 Once-daily measurement, generally between $11 \mathrm{a} . \mathrm{m}$. and $6 \mathrm{p} . \mathrm{m} .7$

\begin{tabular}{|c|c|c|c|c|c|c|c|c|c|c|c|c|}
\hline Day & Oct. & Nov. & Dec. & Jan. & Feb. & Mar. & Apr. & May & June & July & Aug. & Sept. \\
\hline $\begin{array}{l}1 \\
2 \\
3 \\
4 \\
5\end{array}$ & $\begin{array}{r}\text { a } 65 \\
\text { a } 70 \\
\text { a } 72 \\
67 \\
65\end{array}$ & $\begin{array}{r}\mathbf{6} 60 \\
64 \\
61 \\
\mathbf{2} 55 \\
55\end{array}$ & $\begin{array}{r}\text { a } 52 \\
53 \\
\text { a } 46 \\
38 \\
48\end{array}$ & $\begin{array}{r}\text { a } 40 \\
41 \\
\text { a } 38 \\
\text { a } 40 \\
47\end{array}$ & $\begin{array}{l}56 \\
-- \\
49 \\
-- \\
56\end{array}$ & $\begin{array}{r}52 \\
52 \\
\mathrm{a} 41 \\
\mathrm{a} 40 \\
44\end{array}$ & $\begin{array}{l}64 \\
69 \\
71 \\
72 \\
68\end{array}$ & $\begin{array}{r}65 \\
\mathrm{a} 67 \\
65 \\
63 \\
64\end{array}$ & $\begin{array}{r}268 \\
272 \\
76 \\
\mathrm{a} 70 \\
75\end{array}$ & $\begin{array}{l}82 \\
80 \\
81 \\
85 \\
85\end{array}$ & $\begin{array}{r}-- \\
79 \\
80 \\
\mathrm{a} 83 \\
--\end{array}$ & $\begin{array}{r}81 \\
82 \\
82 \\
82 \\
\mathrm{a} 77\end{array}$ \\
\hline $\begin{array}{r}6 \\
7 \\
8 \\
9 \\
10\end{array}$ & $\begin{array}{r}53 \\
66 \\
70 \\
\mathrm{a} 60 \\
\mathrm{a} 59\end{array}$ & $\begin{array}{r}\text { a } 54 \\
58 \\
\text { a } 50 \\
\text { a } 48 \\
\text { a } 46\end{array}$ & $\begin{array}{r}45 \\
43 \\
\text { b } 35 \\
\text { a } 38 \\
42\end{array}$ & $\begin{array}{r}48 \\
\mathrm{a} 41 \\
50 \\
\mathrm{a} 45 \\
\mathrm{2} 42\end{array}$ & $\begin{array}{r}54 \\
47 \\
51 \\
48 \\
\text { a } 52\end{array}$ & $\begin{array}{r}46 \\
50 \\
52 \\
62 \\
\text { b } 63\end{array}$ & $\begin{array}{r}72 \\
-- \\
66 \\
\mathrm{a} 59 \\
68\end{array}$ & $\begin{array}{r}74 \\
\mathrm{a} 65 \\
\mathrm{a} 74 \\
78 \\
75\end{array}$ & $\begin{array}{r}\mathbf{7 4} \\
78 \\
78 \\
78 \\
\mathrm{a} 76\end{array}$ & $\begin{array}{l}85 \\
78 \\
89 \\
78 \\
80\end{array}$ & $\begin{array}{r}-- \\
-- \\
-- \\
75 \\
\text { b } 79\end{array}$ & $\begin{array}{l}\text { a } 77 \\
\text { b } 80 \\
\text { a } 74 \\
\text { b } 78 \\
\text { a } 74\end{array}$ \\
\hline $\begin{array}{l}11 \\
12 \\
13 \\
14 \\
15\end{array}$ & $\begin{array}{r}68 \\
\mathrm{a} 60 \\
68 \\
70 \\
\mathrm{a} 63\end{array}$ & $\begin{array}{l}-- \\
-- \\
-- \\
55\end{array}$ & $\begin{array}{r}35 \\
\times 34 \\
\times 37 \\
40 \\
\times 35\end{array}$ & $\begin{array}{r}43 \\
\mathrm{a} 36 \\
38 \\
\mathrm{a} 37 \\
\mathrm{2} 40\end{array}$ & $\begin{array}{r}49 \\
\text { a } 45 \\
54 \\
\text { a } 50 \\
\text { 2 } 53\end{array}$ & $\begin{array}{l}58 \\
53 \\
45 \\
44 \\
45\end{array}$ & $\begin{array}{l}62 \\
57 \\
60 \\
59 \\
66\end{array}$ & $\begin{array}{r}70 \\
72 \\
72 \\
\text { a } 71 \\
\text { a } 71\end{array}$ & $\begin{array}{r}\mathrm{b} 80 \\
\mathrm{a} 80 \\
78 \\
\mathrm{a} 78 \\
80\end{array}$ & $\begin{array}{l}82 \\
80 \\
86 \\
-- \\
--\end{array}$ & $\begin{array}{r}\text { a } 78 \\
85 \\
\mathrm{a} 80 \\
83 \\
80\end{array}$ & $\begin{array}{r}80 \\
76 \\
\text { a } 72 \\
\text { a } 70 \\
78\end{array}$ \\
\hline $\begin{array}{l}16 \\
17 \\
18 \\
19 \\
20\end{array}$ & $\begin{array}{r}\text { a } 68 \\
\mathrm{a} 68 \\
63 \\
65 \\
\times 60\end{array}$ & $\begin{array}{r}\mathrm{a} 51 \\
53 \\
55 \\
\mathrm{a} 48 \\
48\end{array}$ & $\begin{array}{r}\text { a } 38 \\
43 \\
42 \\
45 \\
46\end{array}$ & $\begin{array}{r}\text { a } 38 \\
43 \\
\text { a } 44 \\
\text { a } 45 \\
45\end{array}$ & $\begin{array}{r}52 \\
49 \\
\mathrm{a} 44 \\
\mathrm{a} 45 \\
47\end{array}$ & $\begin{array}{r}52 \\
\text { b } 58 \\
51 \\
59 \\
\text { a } 52\end{array}$ & $\begin{array}{l}62 \\
69 \\
73 \\
73 \\
70\end{array}$ & $\begin{array}{r}70 \\
\text { a } 70 \\
\text { b } 68 \\
68 \\
72\end{array}$ & $\begin{array}{r}78 \\
\text { b8 } \\
80 \\
83\end{array}$ & $\begin{array}{l}-- \\
-- \\
-- \\
--\end{array}$ & $\begin{array}{r}\text { a } 78 \\
\text { b } 79 \\
\text { a } 73 \\
82 \\
\text { b } 82\end{array}$ & $\begin{array}{l}80 \\
77 \\
80 \\
80 \\
79\end{array}$ \\
\hline $\begin{array}{l}21 \\
22 \\
23 \\
24 \\
25\end{array}$ & $\begin{array}{l}65 \\
68 \\
60 \\
60 \\
59\end{array}$ & $\begin{array}{r}44 \\
\mathrm{a} 42 \\
48 \\
51 \\
\mathrm{a} 48\end{array}$ & $\begin{array}{r}\text { a } 44 \\
36 \\
34 \\
33 \\
\text { a } 36\end{array}$ & $\begin{array}{r}43 \\
\text { a } 38 \\
\text { a } 39 \\
\text { a } 41 \\
54\end{array}$ & $\begin{array}{r}\text { a } 48 \\
\text { a } 48 \\
52 \\
\text { a } 48 \\
\text { a } 49\end{array}$ & $\begin{array}{r}62 \\
60 \\
66 \\
62 \\
\mathbf{6} 51\end{array}$ & $\begin{array}{l}67 \\
70 \\
69 \\
71 \\
70\end{array}$ & $\begin{array}{r}70 \\
265 \\
74 \\
\times 62 \\
-\end{array}$ & $\begin{array}{r}\text { b } 84 \\
\text { b } 80 \\
83 \\
\text { a } 80 \\
b 80\end{array}$ & $\begin{array}{l}-- \\
-- \\
-- \\
-- \\
--\end{array}$ & $\begin{array}{r}\text { b } 80 \\
79 \\
78 \\
74 \\
75\end{array}$ & $\begin{array}{r}75 \\
73 \\
73 \\
\text { b } 68 \\
72\end{array}$ \\
\hline $\begin{array}{l}26 \\
27 \\
28 \\
29 \\
30 \\
31\end{array}$ & $\begin{array}{r}\text { b } 52 \\
\text { a } 51 \\
\text { a } 58 \\
\text { a } 58 \\
60 \\
62 \\
\end{array}$ & $\begin{array}{r}\text { a } 44 \\
\text { a } 48 \\
\text { a } 46 \\
\text { a } 47 \\
-- \\
-- \\
\end{array}$ & $\begin{array}{l}34 \\
35 \\
38 \\
43 \\
40 \\
36 \\
\end{array}$ & $\begin{array}{r}55 \\
53 \\
\mathrm{a} 48 \\
\mathrm{a} 51 \\
50 \\
51 \\
\end{array}$ & $\begin{array}{r}64 \\
54 \\
\times 46 \\
-- \\
-- \\
-- \\
\end{array}$ & $\begin{array}{r}61 \\
62 \\
60 \\
\mathrm{a} 60 \\
60 \\
64 \\
\end{array}$ & $\begin{array}{l}70 \\
75 \\
71 \\
64 \\
65 \\
-- \\
\end{array}$ & $\begin{array}{r}69 \\
-- \\
\text { a } 68 \\
75 \\
\text { a } 71 \\
\text { a } 74 \\
\end{array}$ & $\begin{array}{l}80 \\
83 \\
84 \\
84 \\
82 \\
-- \\
\end{array}$ & $\begin{array}{l}-- \\
-- \\
-- \\
-- \\
--\end{array}$ & $\begin{array}{r}78 \\
79 \\
\text { a } 78 \\
\text { b } 80 \\
80 \\
\mathrm{a} 80 \\
\end{array}$ & $\begin{array}{r}\mathbf{7} 70 \\
75 \\
75 \\
75 \\
77 \\
- \\
\end{array}$ \\
\hline $\begin{array}{c}\text { Aver- } \\
\text { age }\end{array}$ & 63 & 51 & 40 & 44 & 50 & 54 & 67 & 70 & 79 & 82 & 79 & 76 \\
\hline
\end{tabular}

Measurement before $11 \mathrm{a} . \mathrm{m}$.

b Measurement after 6 p.m. 
RIO GRANDE BASIN--Continued

PECOS RIVER NEAR ARTESIA, N. MEX.--Continued

Suspended sediment, water year October 1953 to September 1954

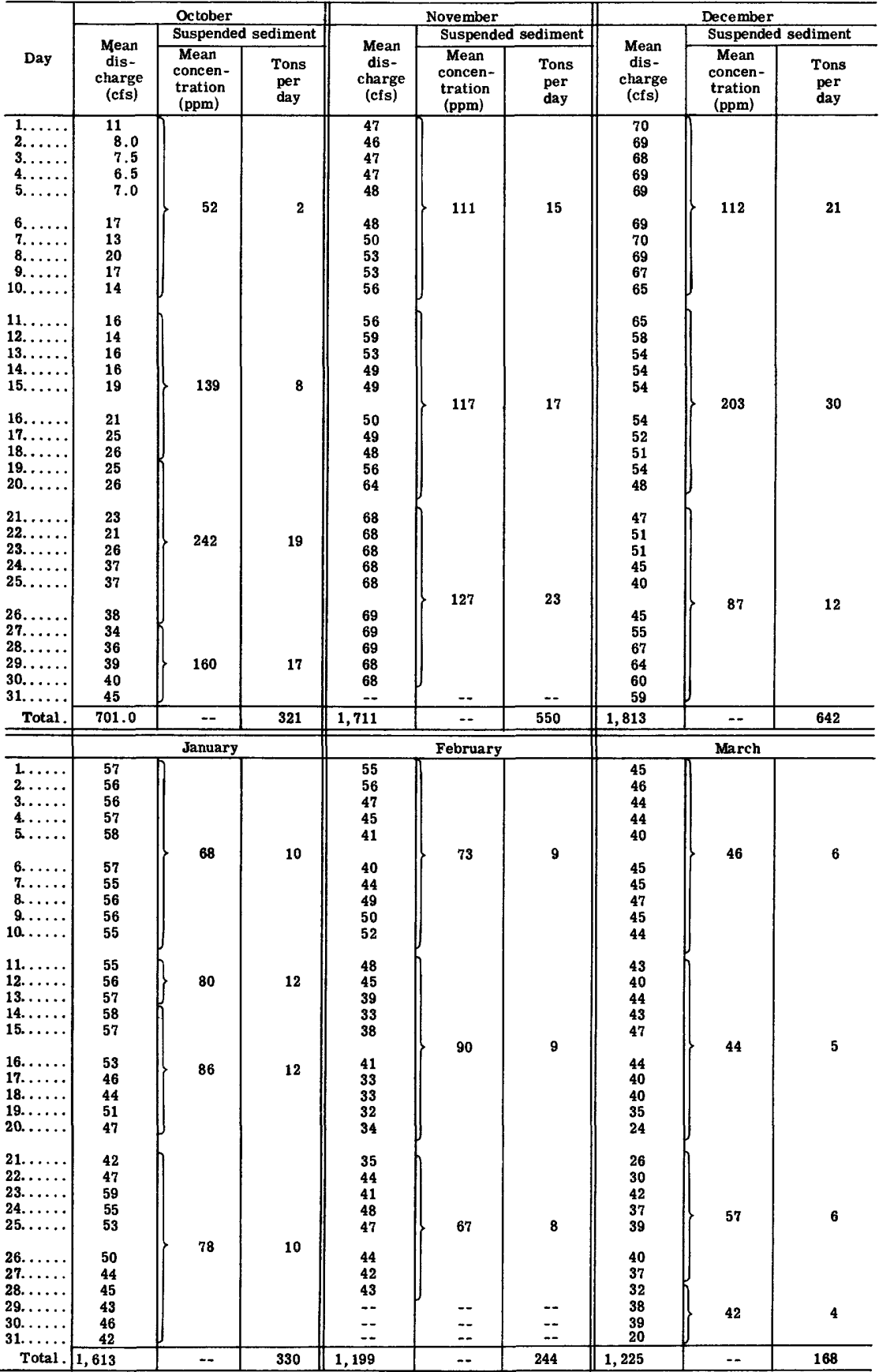

$4888170-59-31$ 
RIO GRANDE BASIN--Continued

PECOS RIVER NEAR ARTESIA, N. MEX.-- Continued

Suspended sediment, water year October 1953 to September 1954--Continued

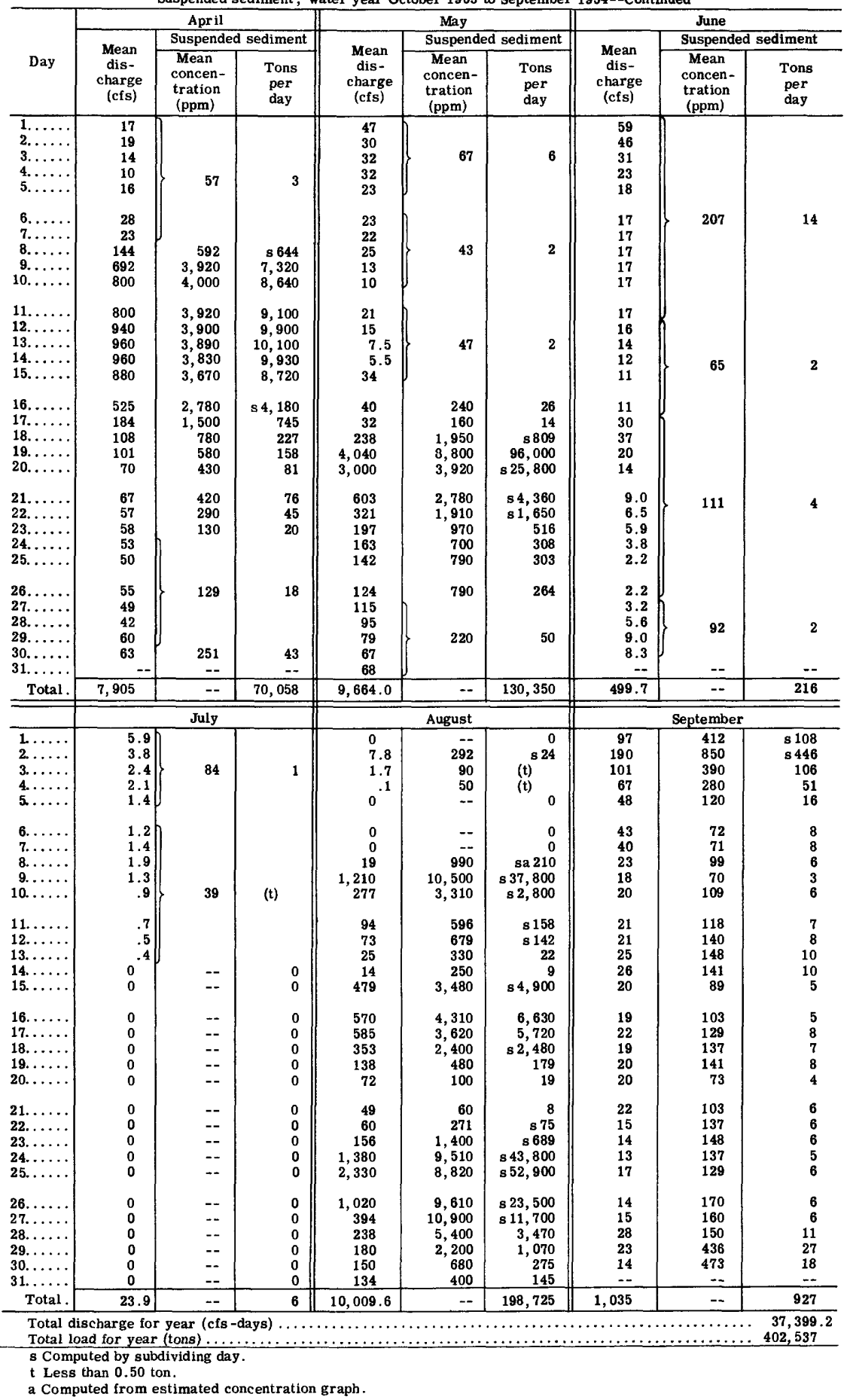




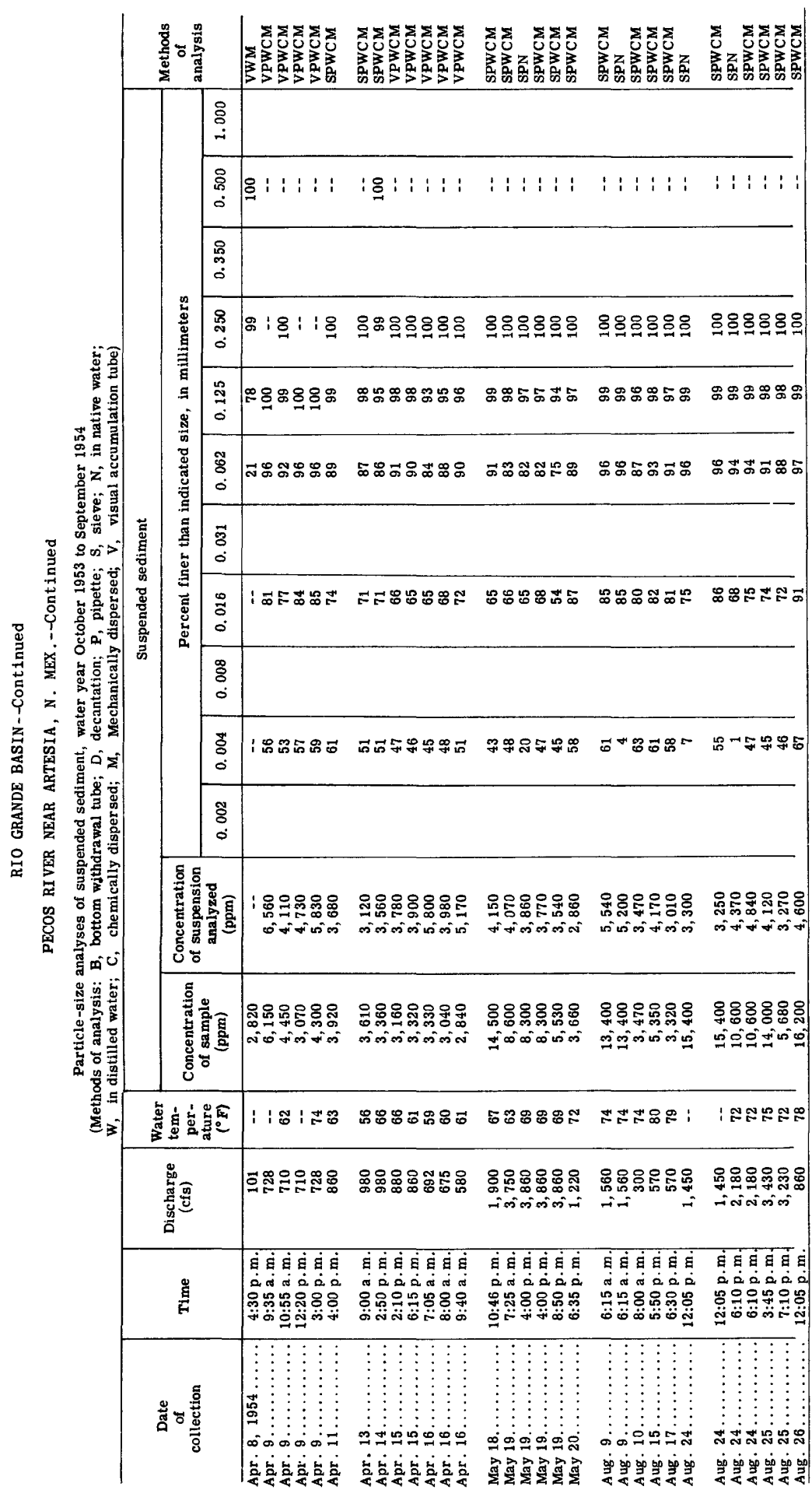


RIO PENASCO AT DAYTON, N. MEX.

(Formerly published as Rio Penasco near Dayton, N. Mex.)

LOCATION.--At gaging station 3 feet upstream from crest of abandoned diversion dam, 1 mile northeast of old Dayton railway station, 31 miles upstream from mouth, and 7 wiles southeast of Artesia, Eddy County.

DRAINAGE AREA. - 1, 070 square miles, approximately.

RECORDS AVAILABLE, --Water temperatures: September 1951 to September 1954.

Sediment records: September 1951 to September 1954.

EXTREMES, 1953-54. --Sediment concentrations: Maximum daily, 9,650 ppm Aug. 24; minimum daily, no flow on many days.

Sediment loads: Maximum daliy, 28,700 tons Aug. 24; minimum daily, 0 tons on many days.

EXTREMES, 1951-54:--Sediment concentrations: Maximum daily, 15,500 ppm June 18, 1953;

mintmum datly, no flow on many days.

Sediment loads: Maximum datly, 36,000 tons June 18, 1953 ; minimum daily, 0 tons on many days.

REMARKS.--Flow occured only on days indicated. Records of discharge for water year October 1953 to September 1954 given in WSP 1342.

Suspended sediment and temperature $\left({ }^{\circ} \mathrm{F}\right)$ of water, for water year October 1953 to September 1954 Once-dally temperature measurement, between 11 a. m. and 7 p. m.7

\begin{tabular}{|c|c|c|c|c|}
\hline \multirow[b]{2}{*}{ Day } & \multirow{2}{*}{$\begin{array}{l}\text { Mean } \\
\text { discharge } \\
\text { (cfs) }\end{array}$} & \multicolumn{2}{|c|}{ Suspended sediment } & \multirow[b]{2}{*}{$\begin{array}{c}\text { Temperature } \\
\left({ }^{\circ} \mathrm{F}\right)\end{array}$} \\
\hline & & $\begin{array}{c}\text { Mean } \\
\text { concentration } \\
\text { (ppm) }\end{array}$ & $\begin{array}{l}\text { Tons } \\
\text { per } \\
\text { day }\end{array}$ & \\
\hline 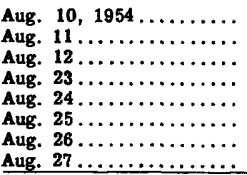 & $\begin{array}{r}100 \\
18 \\
2 \\
192 \\
910 \\
291 \\
17 \\
1\end{array}$ & $\begin{array}{r}\mathbf{5}, 220 \\
2,300 \\
300 \\
7,380 \\
9,650 \\
3,050 \\
1,300 \\
500\end{array}$ & $\begin{array}{r}\text { s 3,920 } \\
\text { s } 136 \\
1.6 \\
\text { s7, 050 } \\
\text { s } 28,700 \\
\text { s } 3,430 \\
\text { a } 60 \\
\text { a } 1.4 \\
\end{array}$ & $\begin{array}{r}74 \\
75 \\
\text { b } 65 \\
74 \\
73 \\
75 \\
-- \\
-- \\
\end{array}$ \\
\hline
\end{tabular}

s Computed by subdividing day.

a Computed from estimated concentration graph.

b Measurement at 9 a. m. 


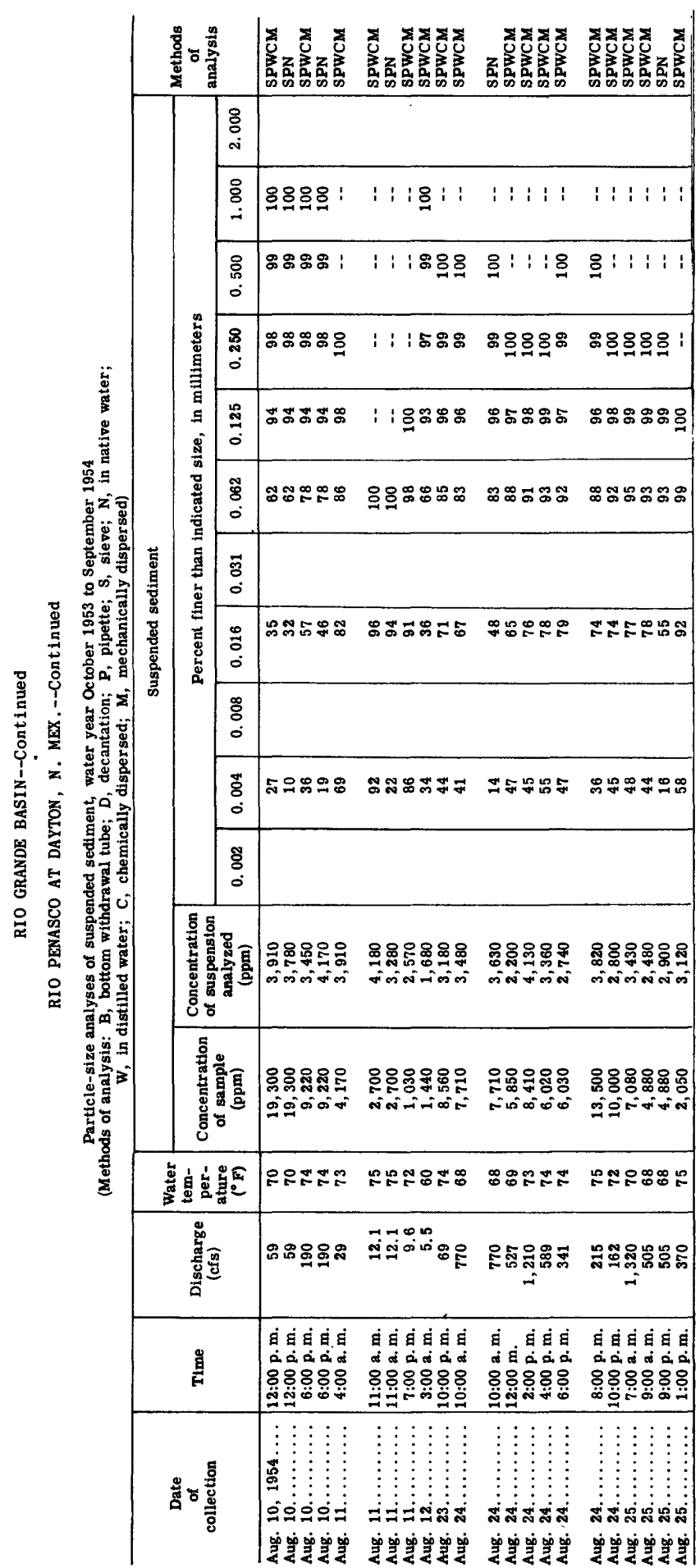


RIO GRANDE BASIN--Continued

PECOS RIVER AT DAM SITE 3, NEAR CARLSBAD, N. MEX.

LOCATION, --At gaging station at dam site 3 of Carlsbad project of Bureau of Reclamation, about 1 mile upstream from flow line of Lake Avalon, 1.3 miles downstream from Rocky Arroyo, and 8 miles northwest of Carlsbad, Eddy County.

DRAINAGE AREA,--17,620 square miles, approximately (contributing area).

REMARKS.--Samples collected at approximately weekly intervals. Records of discharge for water year October 1953 to September 1954 given in WSP 1342 .

Chemical analyses, in parts per million, water year October 1953 to September 1954

\begin{tabular}{|c|c|c|c|c|c|}
\hline Date of Collection & $\begin{array}{c}\text { Mean } \\
\text { discharge } \\
\text { (cfs) }\end{array}$ & $\begin{array}{l}\text { Bicar- } \\
\text { bonate } \\
\left(\mathrm{HCO}_{9}\right)\end{array}$ & $\begin{array}{r}\mathrm{Car}- \\
\text { bonate } \\
\left(\mathrm{CO}_{3}\right)\end{array}$ & $\begin{array}{c}\text { Chloride } \\
\text { (Cl) }\end{array}$ & $\begin{array}{c}\text { Specific } \\
\text { conductance } \\
\text { (micromhos) } \\
\text { at } 25^{\circ} \mathrm{C} \text { ) }\end{array}$ \\
\hline $\begin{array}{l}\text { Oct. } 8,1953 \ldots \\
\text { Oct. } 21 \ldots \ldots \ldots \\
\text { Oct. } 22 \ldots \ldots \ldots \\
\text { Oct. } 28 \ldots \ldots \ldots\end{array}$ & $\begin{array}{l}23 \\
21 \\
21 \\
37\end{array}$ & $\begin{array}{l}138 \\
143 \\
133 \\
119\end{array}$ & $\begin{array}{l}0 \\
0 \\
0 \\
0\end{array}$ & $\begin{array}{r}770 \\
780 \\
750 \\
1,330\end{array}$ & $\begin{array}{l}5,060 \\
5,100 \\
5,040 \\
6,980\end{array}$ \\
\hline $\begin{array}{l}\text { Nov. } 5 \ldots \ldots \ldots \\
\text { Nov. } 13 \ldots \ldots \ldots \\
\text { Nov. } 18 \ldots \ldots \\
\text { Nov. } 27 \ldots \ldots\end{array}$ & $\begin{array}{l}52 \\
62 \\
54 \\
79\end{array}$ & $\begin{array}{l}113 \\
115 \\
120 \\
122\end{array}$ & $\begin{array}{l}0 \\
0 \\
0 \\
9\end{array}$ & $\begin{array}{l}1,560 \\
1,470 \\
1,370 \\
1,390\end{array}$ & $\begin{array}{l}7,570 \\
7,280 \\
6,950 \\
6,850\end{array}$ \\
\hline $\begin{array}{l}\text { Dec. } 4 \ldots \ldots \ldots \\
\text { Dec. } 9 \ldots \ldots \ldots \\
\text { Dec. } 15 \ldots \ldots \\
\text { Dec. } 26 \ldots \ldots\end{array}$ & $\begin{array}{l}66 \\
64 \\
62 \\
45\end{array}$ & $\begin{array}{l}128 \\
140 \\
179 \\
143\end{array}$ & $\begin{array}{l}0 \\
0 \\
0 \\
0\end{array}$ & $\begin{array}{l}1,340 \\
1,420 \\
1,480 \\
1,550\end{array}$ & $\begin{array}{l}6,700 \\
6,820 \\
7,070 \\
7,150\end{array}$ \\
\hline $\begin{array}{l}\text { Jan. } 2,1954 \ldots \\
\text { Jan. } 8 \ldots \ldots \ldots \\
\text { Jan. } 11 \ldots \ldots \ldots \\
\text { Jan. } 14 \ldots \ldots \ldots\end{array}$ & $\begin{array}{l}72 \\
59 \\
49 \\
72\end{array}$ & $\begin{array}{r}155 \\
125 \\
117 \\
96\end{array}$ & $\begin{array}{l}0 \\
0 \\
0 \\
8\end{array}$ & $\begin{array}{l}1,740 \\
1,670 \\
1,670 \\
1,700\end{array}$ & $\begin{array}{l}7,930 \\
7,790 \\
7,750 \\
7,750\end{array}$ \\
\hline $\begin{array}{l}\text { Jan. } 18 \ldots \ldots \ldots \\
\text { Jan. } 30 \ldots \ldots \ldots \\
\text { Feb. } 3 \ldots \ldots \ldots \\
\text { Feb. } 8 \ldots \ldots\end{array}$ & $\begin{array}{l}49 \\
60 \\
67 \\
52\end{array}$ & $\begin{array}{r}106 \\
112 \\
73 \\
106\end{array}$ & $\begin{array}{r}0 \\
0 \\
12 \\
0\end{array}$ & $\begin{array}{l}1,680 \\
1,740 \\
1,840 \\
1,690\end{array}$ & $\begin{array}{l}7,740 \\
8,050 \\
8,220 \\
7,840\end{array}$ \\
\hline $\begin{array}{l}\text { Feb. } 23 \ldots \ldots \\
\text { Feb. } 24 \ldots \ldots \\
\text { Mar. } 2 \ldots \ldots \\
\text { Mar. } 9 \ldots \ldots\end{array}$ & $\begin{array}{l}49 \\
47 \\
47 \\
44\end{array}$ & $\begin{array}{r}80 \\
120 \\
138 \\
127\end{array}$ & $\begin{array}{l}7 \\
0 \\
0 \\
0\end{array}$ & $\begin{array}{l}1,850 \\
1,780 \\
1,830 \\
1,880\end{array}$ & $\begin{array}{l}8,430 \\
8,230 \\
8,450 \\
8,560\end{array}$ \\
\hline $\begin{array}{l}\text { Mar, } 16 \ldots \ldots \\
\text { Mar, } 24 \quad \ldots \ldots \\
\text { Apr. } 10 \ldots \ldots \\
\text { Apr. } 13 \ldots \ldots \\
\text { A } \ldots\end{array}$ & $\begin{array}{r}45 \\
25 \\
540 \\
718\end{array}$ & $\begin{array}{l}149 \\
132 \\
145 \\
145\end{array}$ & $\begin{array}{l}0 \\
0 \\
0 \\
0\end{array}$ & $\begin{array}{r}2,130 \\
1,870 \\
845 \\
340\end{array}$ & $\begin{array}{l}9,400 \\
8,670 \\
\mathbf{5}, 580 \\
\mathbf{3}, 760\end{array}$ \\
\hline 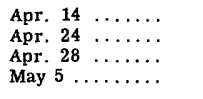 & $\begin{array}{r}830 \\
60 \\
48 \\
27\end{array}$ & $\begin{array}{l}175 \\
102 \\
111 \\
112\end{array}$ & $\begin{array}{l}0 \\
0 \\
0 \\
0\end{array}$ & $\begin{array}{r}290 \\
715 \\
1,080 \\
1,600\end{array}$ & $\begin{array}{l}3,540 \\
5,110 \\
6,420 \\
7,980\end{array}$ \\
\hline $\begin{array}{l}\text { May } 21 \ldots \ldots \\
\text { May } 27 \ldots \ldots \\
\text { June } 7 \ldots \ldots \ldots \\
\text { June } 14 \ldots \ldots\end{array}$ & $\begin{array}{r}1,250 \\
17 \\
21 \\
20\end{array}$ & $\begin{array}{l}124 \\
152 \\
146 \\
138\end{array}$ & $\begin{array}{l}0 \\
0 \\
0 \\
0\end{array}$ & $\begin{array}{r}330 \\
68 \\
800 \\
800\end{array}$ & $\begin{array}{r}3,090 \\
866 \\
5,190 \\
5,220\end{array}$ \\
\hline $\begin{array}{l}\text { June } 21 \ldots \ldots \\
\text { June } 27 \ldots \ldots \cdots \\
\text { June } 28 \ldots \ldots \\
\text { July } 3 \ldots \ldots\end{array}$ & $\begin{array}{l}18 \\
15 \\
14 \\
15\end{array}$ & $\begin{array}{l}109 \\
122 \\
102 \\
134\end{array}$ & $\begin{array}{l}0 \\
0 \\
0 \\
0\end{array}$ & $\begin{array}{r}810 \\
820 \\
820 \\
1,190\end{array}$ & $\begin{array}{l}5,300 \\
5,290 \\
5,310 \\
6,720\end{array}$ \\
\hline $\begin{array}{l}\text { July } 9 \ldots \ldots \ldots \\
\text { July } 16 \ldots \ldots \\
\text { July } 23 \ldots \ldots \\
\text { July } 30 \ldots \ldots\end{array}$ & $\begin{array}{r}13 \\
8.4 \\
6.9 \\
5.4\end{array}$ & $\begin{array}{l}129 \\
142 \\
117 \\
119\end{array}$ & $\begin{array}{l}0 \\
0 \\
0 \\
0\end{array}$ & $\begin{array}{l}940 \\
870 \\
840 \\
760\end{array}$ & $\begin{array}{l}5,760 \\
5,510 \\
5,350 \\
4,940\end{array}$ \\
\hline 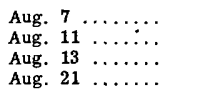 & $\begin{array}{l}4.8 \\
288 \\
32 \\
68\end{array}$ & $\begin{array}{r}130 \\
97 \\
117 \\
128\end{array}$ & $\begin{array}{l}0 \\
0 \\
0 \\
0\end{array}$ & $\begin{array}{l}455 \\
485 \\
445 \\
300\end{array}$ & $\begin{array}{l}3,340 \\
3,610 \\
3,270 \\
3,360\end{array}$ \\
\hline 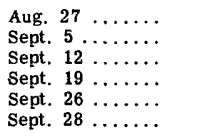 & $\begin{array}{r}21 \\
18 \\
312 \\
100 \\
30 \\
26\end{array}$ & $\begin{array}{r}122 \\
141 \\
98 \\
148 \\
154 \\
151\end{array}$ & $\begin{array}{l}0 \\
0 \\
0 \\
0 \\
0 \\
0\end{array}$ & $\begin{array}{l}102 \\
605 \\
360 \\
810 \\
780 \\
775\end{array}$ & $\begin{array}{l}1,100 \\
4,160 \\
2,720 \\
5,110 \\
5,040 \\
5,060\end{array}$ \\
\hline
\end{tabular}




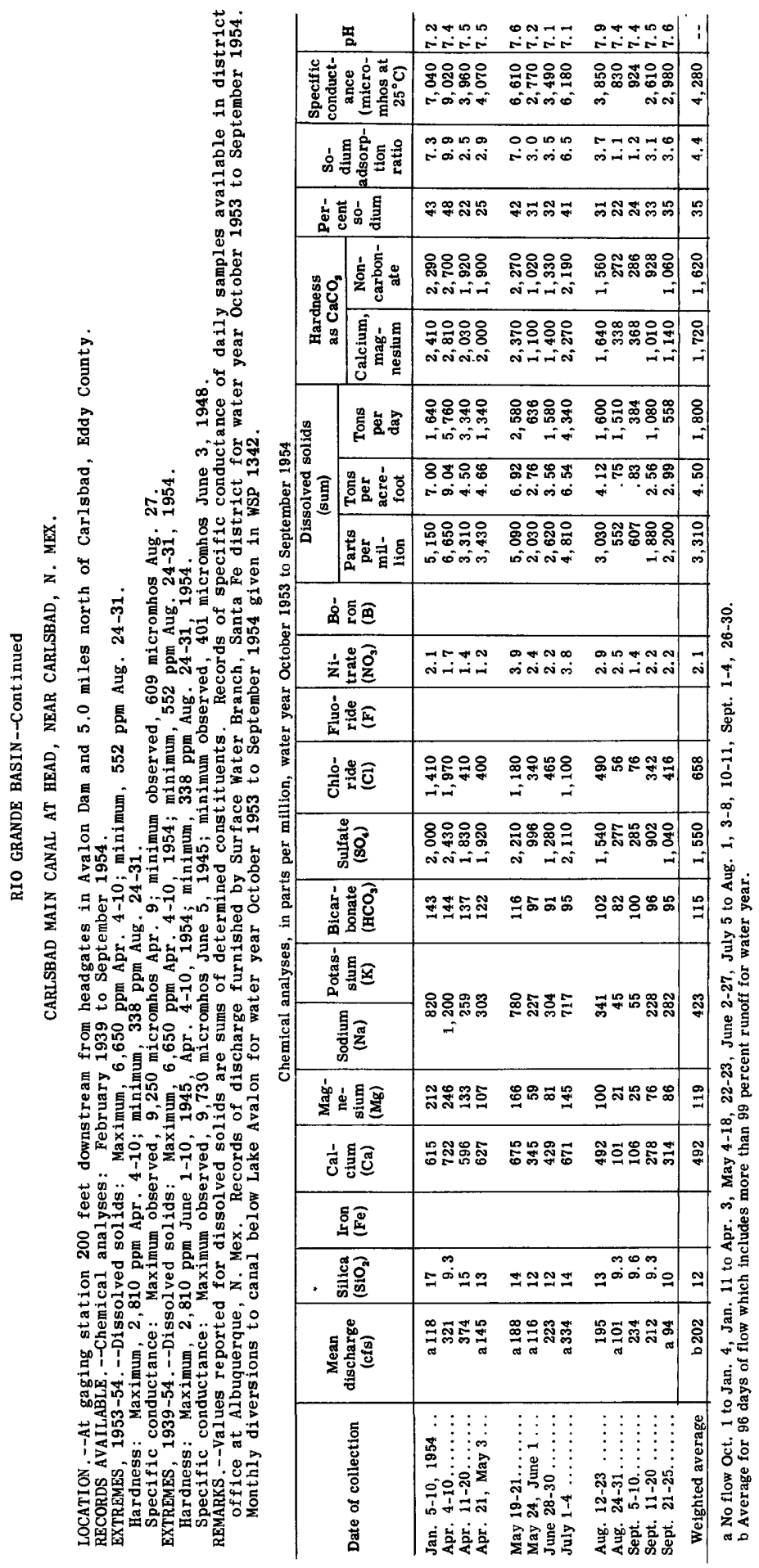




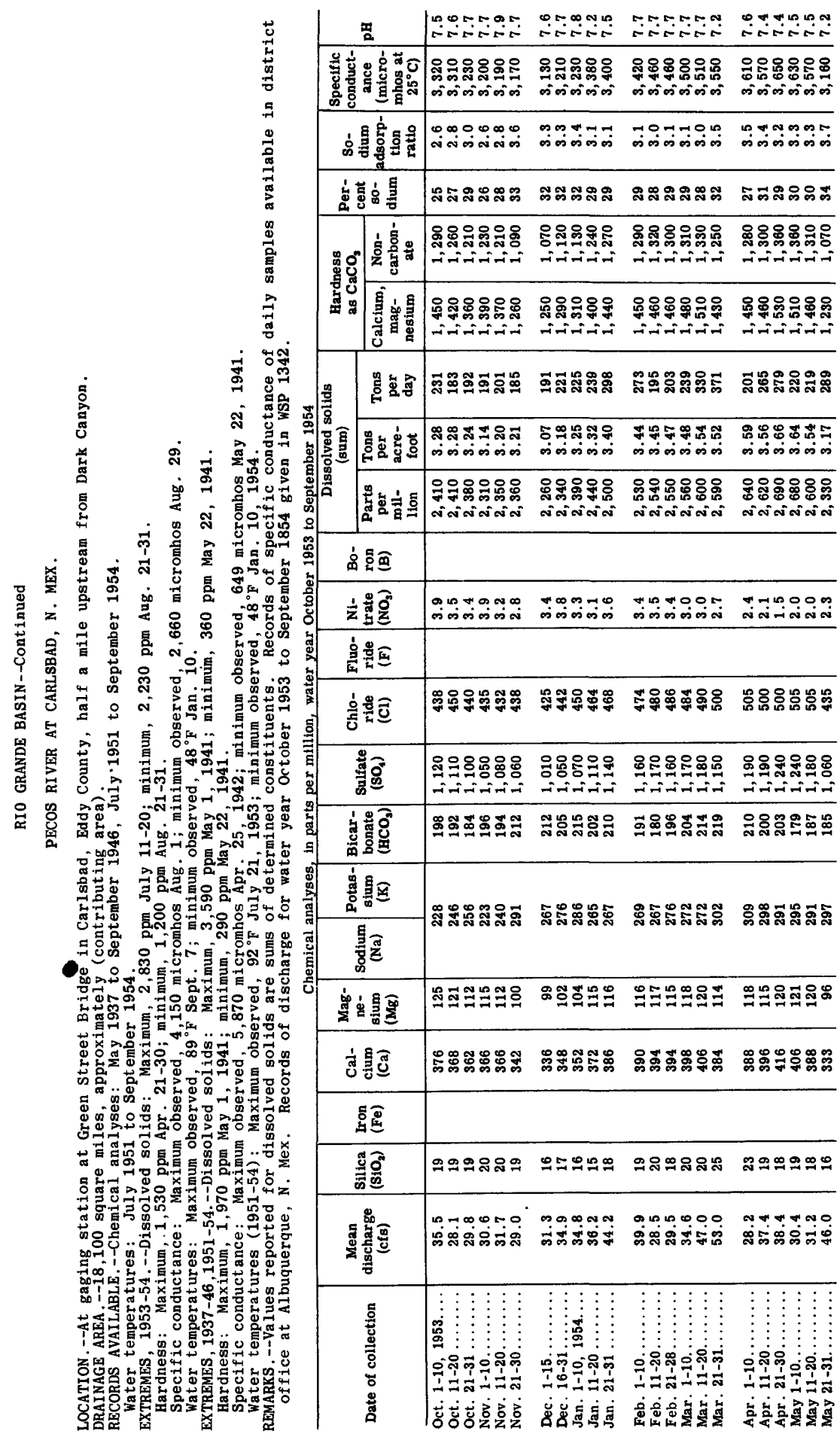




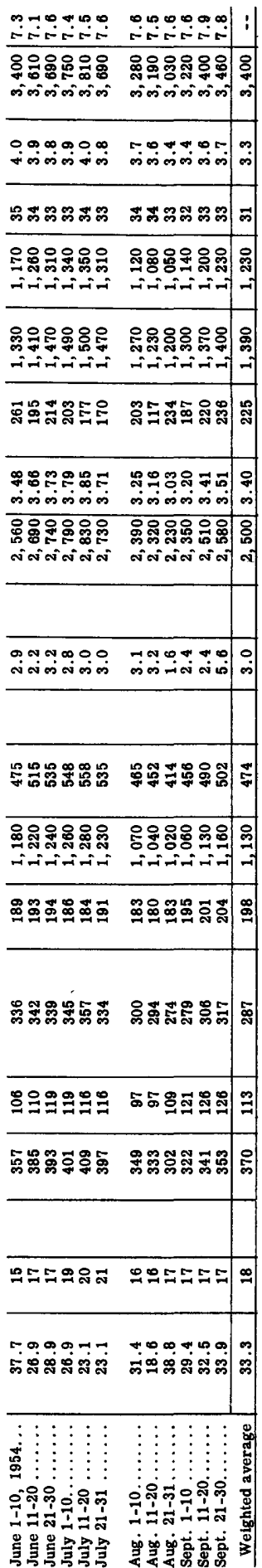


RIO GRANDE BASIN--Continued

PECOS RIVER AT CARLSBAD, N. MEX .--Continued

Temperature ( ${ }^{\circ} \mathrm{F}$ ) of water, water year October 1953 to September 1954

Once-daily measurement, usually between 5 p.m. and 7:30 p.m.7

\begin{tabular}{|c|c|c|c|c|c|c|c|c|c|c|c|c|}
\hline Day & Oct. & Nov. & Dec. & Jan. & Feb. & Mar. & Apr. & May & June & July & Aug. & Sept. \\
\hline $\begin{array}{r}1 \\
. \quad 2 \\
3 \\
4 \\
5\end{array}$ & $\begin{array}{l}75 \\
80 \\
72 \\
72 \\
75\end{array}$ & $\begin{array}{r}70 \\
-64 \\
68 \\
68 \\
64\end{array}$ & $\begin{array}{l}62 \\
61 \\
-- \\
59 \\
57\end{array}$ & $\begin{array}{l}53 \\
54 \\
58 \\
59 \\
60\end{array}$ & $\begin{array}{l}65 \\
64 \\
65 \\
67 \\
66\end{array}$ & $\begin{array}{l}60 \\
60 \\
53 \\
54 \\
58\end{array}$ & $\begin{array}{l}71 \\
70 \\
70 \\
74 \\
75\end{array}$ & $\begin{array}{l}79 \\
71 \\
66 \\
-- \\
72\end{array}$ & $\begin{array}{l}80 \\
82 \\
82 \\
80 \\
78\end{array}$ & $\begin{array}{l}84 \\
-- \\
85 \\
83 \\
83\end{array}$ & $\begin{array}{l}86 \\
83 \\
85 \\
83 \\
82\end{array}$ & $\begin{array}{l}85 \\
87 \\
86 \\
85 \\
83\end{array}$ \\
\hline $\begin{array}{r}6 \\
7 \\
8 \\
9 \\
10\end{array}$ & $\begin{array}{l}70 \\
72 \\
75 \\
77 \\
75\end{array}$ & $\begin{array}{l}68 \\
66 \\
68 \\
65 \\
64\end{array}$ & $\begin{array}{l}54 \\
57 \\
55 \\
58 \\
57\end{array}$ & $\begin{array}{l}58 \\
61 \\
60 \\
60 \\
48\end{array}$ & $\begin{array}{l}61 \\
62 \\
64 \\
64 \\
63\end{array}$ & $\begin{array}{l}59 \\
61 \\
61 \\
67 \\
70\end{array}$ & $\begin{array}{l}73 \\
71 \\
71 \\
75 \\
72\end{array}$ & $\begin{array}{l}76 \\
75 \\
76 \\
78 \\
75\end{array}$ & $\begin{array}{l}78 \\
83 \\
81 \\
84 \\
84\end{array}$ & $\begin{array}{l}85 \\
82 \\
86 \\
83 \\
82\end{array}$ & $\begin{array}{l}83 \\
79 \\
81 \\
83 \\
83\end{array}$ & $\begin{array}{l}86 \\
89 \\
87 \\
82 \\
85\end{array}$ \\
\hline $\begin{array}{l}11 \\
12 \\
13 \\
14 \\
15\end{array}$ & $\begin{array}{l}72 \\
74 \\
72 \\
74 \\
74\end{array}$ & $\begin{array}{l}68 \\
68 \\
65 \\
65 \\
67\end{array}$ & $\begin{array}{l}-- \\
52 \\
57 \\
57 \\
60\end{array}$ & $\begin{array}{l}55 \\
55 \\
52 \\
55 \\
58\end{array}$ & $\begin{array}{l}64 \\
60 \\
65 \\
65 \\
61\end{array}$ & $\begin{array}{l}64 \\
63 \\
63 \\
62 \\
60\end{array}$ & $\begin{array}{l}74 \\
71 \\
72 \\
75 \\
--\end{array}$ & $\begin{array}{l}75 \\
78 \\
-- \\
75 \\
--\end{array}$ & $\begin{array}{l}82 \\
82 \\
83 \\
80 \\
82\end{array}$ & $\begin{array}{l}85 \\
84 \\
86 \\
84 \\
83\end{array}$ & $\begin{array}{l}88 \\
87 \\
87 \\
85 \\
83\end{array}$ & $\begin{array}{l}86 \\
83 \\
85 \\
83 \\
85\end{array}$ \\
\hline $\begin{array}{l}16 \\
17 \\
18 \\
19 \\
20\end{array}$ & $\begin{array}{l}75 \\
75 \\
74 \\
74 \\
75\end{array}$ & $\begin{array}{l}68 \\
66 \\
65 \\
61 \\
62\end{array}$ & $\begin{array}{l}59 \\
59 \\
61 \\
61 \\
62\end{array}$ & $\begin{array}{l}\mathbf{5 8} \\
\mathbf{5 5} \\
58 \\
\mathbf{5 8} \\
\mathbf{5 6}\end{array}$ & $\begin{array}{l}63 \\
65 \\
59 \\
61 \\
61\end{array}$ & $\begin{array}{l}61 \\
65 \\
63 \\
69 \\
63\end{array}$ & $\begin{array}{l}-2 \\
76 \\
75 \\
75 \\
75\end{array}$ & $\begin{array}{l}79 \\
78 \\
72 \\
77 \\
79\end{array}$ & $\begin{array}{l}-- \\
84 \\
79 \\
85 \\
80\end{array}$ & $\begin{array}{l}82 \\
81 \\
82 \\
85 \\
84\end{array}$ & $\begin{array}{l}84 \\
83 \\
84 \\
83 \\
84\end{array}$ & $\begin{array}{l}84 \\
83 \\
85 \\
86 \\
84\end{array}$ \\
\hline $\begin{array}{l}21 \\
22 \\
23 \\
24 \\
25\end{array}$ & $\begin{array}{l}72 \\
71 \\
70 \\
69 \\
--\end{array}$ & $\begin{array}{l}60 \\
59 \\
61 \\
61 \\
62\end{array}$ & $\begin{array}{l}59 \\
49 \\
50 \\
50 \\
52\end{array}$ & $\begin{array}{l}57 \\
57 \\
59 \\
60 \\
61\end{array}$ & $\begin{array}{l}64 \\
63 \\
62 \\
61 \\
65\end{array}$ & $\begin{array}{l}66 \\
70 \\
71 \\
61 \\
62\end{array}$ & $\begin{array}{l}78 \\
76 \\
80 \\
-- \\
77\end{array}$ & $\begin{array}{l}76 \\
78 \\
78 \\
78 \\
75\end{array}$ & $\begin{array}{l}81 \\
83 \\
84 \\
84 \\
85\end{array}$ & $\begin{array}{l}85 \\
-2 \\
85 \\
87 \\
82\end{array}$ & $\begin{array}{l}82 \\
79 \\
80 \\
81 \\
82\end{array}$ & $\begin{array}{l}85 \\
81 \\
80 \\
80 \\
80\end{array}$ \\
\hline $\begin{array}{l}26 \\
27 \\
28 \\
29 \\
30 \\
31\end{array}$ & $\begin{array}{l}70 \\
70 \\
71 \\
65 \\
70 \\
70\end{array}$ & $\begin{array}{l}63 \\
60 \\
63 \\
64 \\
64 \\
--\end{array}$ & $\begin{array}{l}\mathbf{5 4} \\
55 \\
52 \\
56 \\
52 \\
57\end{array}$ & $\begin{array}{l}61 \\
60 \\
62 \\
65 \\
-- \\
65\end{array}$ & $\begin{array}{l}65 \\
60 \\
61 \\
-- \\
-- \\
--\end{array}$ & $\begin{array}{l}67 \\
-- \\
-- \\
65 \\
68 \\
72\end{array}$ & $\begin{array}{l}78 \\
-- \\
78 \\
70 \\
72 \\
--\end{array}$ & $\begin{array}{l}80 \\
81 \\
80 \\
-- \\
78 \\
80\end{array}$ & $\begin{array}{l}85 \\
84 \\
85 \\
-- \\
83 \\
--\end{array}$ & $\begin{array}{l}86 \\
88 \\
85 \\
84 \\
85 \\
87\end{array}$ & $\begin{array}{l}81 \\
87 \\
84 \\
85 \\
83 \\
87\end{array}$ & $\begin{array}{l}82 \\
82 \\
-- \\
83 \\
84 \\
--\end{array}$ \\
\hline $\begin{array}{c}\text { Aver- } \\
\text { age }\end{array}$ & 73 & 65 & 56 & 58 & 63 & 63 & 74 & 76 & 82 & 84 & 83 & 84 \\
\hline
\end{tabular}


RIO GRANDE BASIN--Continued

REFINERY INTAKE CANAL NEAR LOVING, $N$. MEX.

(Weekly samples taken from canal in sec. 13, T. 23 S., R. 28 E., representing water in Harroun Canal diverted from Pecos River at dam in sec. 11, T. 23 S., R. 28 E.)

\begin{tabular}{|c|c|c|}
\hline Date of collection & $\begin{array}{l}\text { Specific } \\
\text { conductance } \\
\text { (micromhos } \\
\text { at } 25^{\circ} \mathrm{C} \text { ) }\end{array}$ & $\begin{array}{l}\text { Chloride } \\
\text { (CI) } \\
\text { ppm }\end{array}$ \\
\hline $\begin{array}{l}\text { Oct. } 1,1953 \ldots \ldots \ldots \\
\text { Oct. } 8 \ldots \ldots \ldots \ldots \ldots \\
\text { Oct. } 15 \ldots \ldots \ldots \ldots \ldots \\
\text { Oct. } 22 \ldots \ldots \ldots \ldots \\
\text { Oct. } 29 \ldots \ldots \ldots \ldots \ldots\end{array}$ & $\begin{array}{l}4,270 \\
4,300 \\
4,480 \\
4,570 \\
1,880\end{array}$ & $\begin{array}{l}670 \\
680 \\
720 \\
720 \\
256\end{array}$ \\
\hline $\begin{array}{l}\text { Nov. } \begin{array}{l}5 \\
\text { Nov. } 12 \\
\text { Nov. } 19\end{array} \ldots \ldots \ldots \ldots \ldots \\
\text { Nov. } 26 \ldots \ldots\end{array}$ & $\begin{array}{l}4,100 \\
4,680 \\
4,790 \\
4,480\end{array}$ & $\begin{array}{l}680 \\
770 \\
790 \\
710\end{array}$ \\
\hline $\begin{array}{l}\text { Dec. }{ }^{3} \ldots \ldots \ldots \ldots \ldots \\
\text { Dec. } 10 \ldots \ldots \ldots \ldots \\
\text { Dec. } 17 \ldots \ldots \ldots \ldots \\
\text { Dec. } 24 \ldots \ldots \ldots \ldots\end{array}$ & $\begin{array}{l}4,270 \\
4,320 \\
4,320 \\
4,360\end{array}$ & $\begin{array}{l}660 \\
680 \\
670 \\
690\end{array}$ \\
\hline $\begin{array}{l}\text { Jan. } 7,1954 \ldots \ldots \ldots \\
\text { Jan. } 14 \quad \ldots \ldots \ldots \ldots \ldots \\
\text { Jan. } 21 \\
\text { Jan. } 28 \ldots \ldots \ldots \ldots \\
\text { Jan }\end{array}$ & $\begin{array}{l}4,050 \\
4,000 \\
4,160 \\
4,140\end{array}$ & $\begin{array}{l}610 \\
620 \\
635 \\
625\end{array}$ \\
\hline $\begin{array}{l}\text { Feb. } 4 \quad \ldots \ldots \ldots \ldots \ldots \\
\text { Feb. } 10 \ldots \ldots \ldots \ldots \\
\text { Feb. } 18 \ldots \ldots \ldots \\
\text { Feb. } 25 \quad \ldots \ldots \ldots \ldots\end{array}$ & $\begin{array}{l}4,170 \\
4,130 \\
4,570 \\
4,420\end{array}$ & $\begin{array}{l}640 \\
650 \\
740 \\
735\end{array}$ \\
\hline $\begin{array}{l}\text { Mar. } 4 \ldots \ldots \ldots \ldots \ldots \\
\text { Mar. } 11 \ldots \ldots \ldots \ldots \ldots \\
\text { Mar. } 18 \ldots \ldots \ldots \ldots \ldots \\
\text { Mar. } 25 \ldots \ldots \ldots \ldots\end{array}$ & $\begin{array}{l}4,230 \\
4,220 \\
4,270 \\
4,400\end{array}$ & $\begin{array}{l}655 \\
665 \\
675 \\
710\end{array}$ \\
\hline $\begin{array}{l}\text { Apr. } 1 \ldots \ldots \ldots \ldots \\
\text { Apr. } 8 \ldots \ldots \ldots \ldots \\
\text { Apr. } 15 \ldots \ldots \ldots \ldots \\
\text { Apr. } 22 \ldots \ldots \ldots \cdots \\
\text { Apr. } 29 \ldots \ldots \ldots \ldots\end{array}$ & $\begin{array}{l}4,420 \\
4,320 \\
4,330 \\
4,310 \\
4,400\end{array}$ & $\begin{array}{l}710 \\
665 \\
680 \\
675 \\
690\end{array}$ \\
\hline $\begin{array}{l}\text { May } 6 \ldots \ldots \ldots \ldots \ldots \\
\text { May } 13 . \ldots \ldots \ldots \ldots \ldots \\
\text { May } 20 \ldots \ldots \ldots \ldots \\
\text { May } 27 \ldots \ldots \ldots \ldots\end{array}$ & $\begin{array}{l}4,560 \\
4,820 \\
4,730 \\
4,400\end{array}$ & $\begin{array}{l}735 \\
790 \\
760 \\
680\end{array}$ \\
\hline $\begin{array}{l}\text { June } 5 \ldots \ldots \ldots \ldots \\
\text { June } 10 \ldots \ldots \ldots \ldots \\
\text { June } 17 \ldots \ldots \ldots \ldots \\
\text { June } 24 \ldots \ldots \ldots \ldots\end{array}$ & $\begin{array}{l}3,960 \\
4,020 \\
4,180 \\
4,320\end{array}$ & $\begin{array}{l}615 \\
620 \\
655 \\
680\end{array}$ \\
\hline $\begin{array}{l}\text { July } 8 \ldots \ldots \ldots \ldots \\
\text { July } 15 \ldots \ldots \ldots \\
\text { July } 24 \ldots \ldots \ldots \ldots \\
\text { July } 29 \ldots \ldots \ldots\end{array}$ & $\begin{array}{l}4,620 \\
4,630 \\
5,970 \\
6,410\end{array}$ & $\begin{array}{r}765 \\
760 \\
1,100 \\
1,300\end{array}$ \\
\hline $\begin{array}{l}\text { Aug. } 5 \ldots \ldots \ldots \ldots \\
\text { Aug. } 14 \ldots \ldots \ldots \ldots \\
\text { Aug. } 19 \ldots \ldots \ldots \\
\text { Aug. } 26 \ldots \ldots \ldots\end{array}$ & $\begin{array}{l}5,470 \\
5,910 \\
4,640 \\
1,570\end{array}$ & $\begin{array}{r}955 \\
1,140 \\
750 \\
205\end{array}$ \\
\hline $\begin{array}{l}\text { Sept. } 2 \ldots \ldots \ldots \ldots \ldots \\
\text { Sept. } 9 \ldots \ldots \ldots \ldots \ldots \\
\text { Sept. } 16 \ldots \ldots \ldots \ldots \\
\text { Sept. } 23 \ldots \ldots \ldots \ldots \\
\text { Sept. } 30 \ldots \ldots \ldots \ldots\end{array}$ & $\begin{array}{l}1,730 \\
2,730 \\
3,660 \\
4,140 \\
4,360\end{array}$ & $\begin{array}{l}245 \\
405 \\
580 \\
665 \\
705\end{array}$ \\
\hline
\end{tabular}




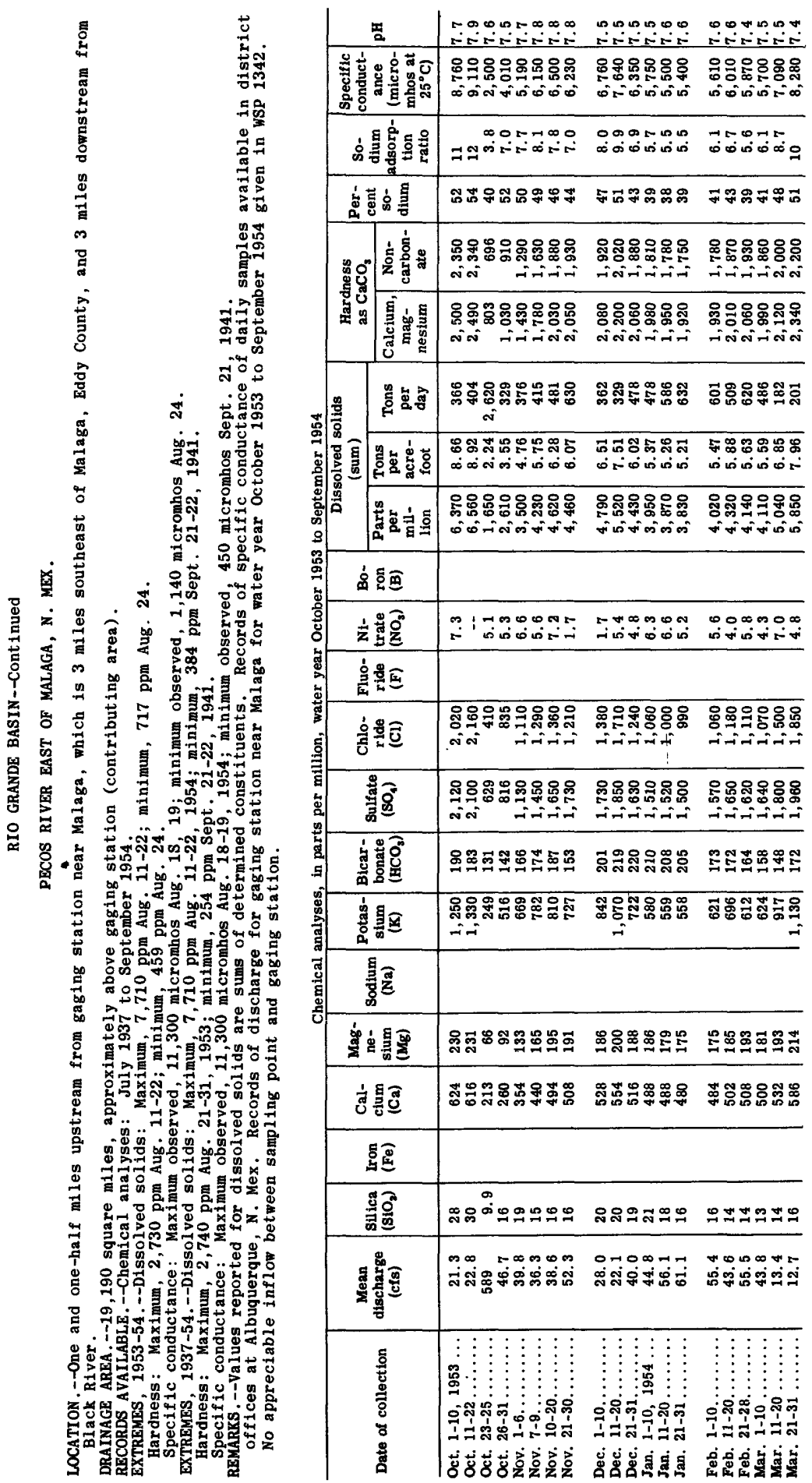




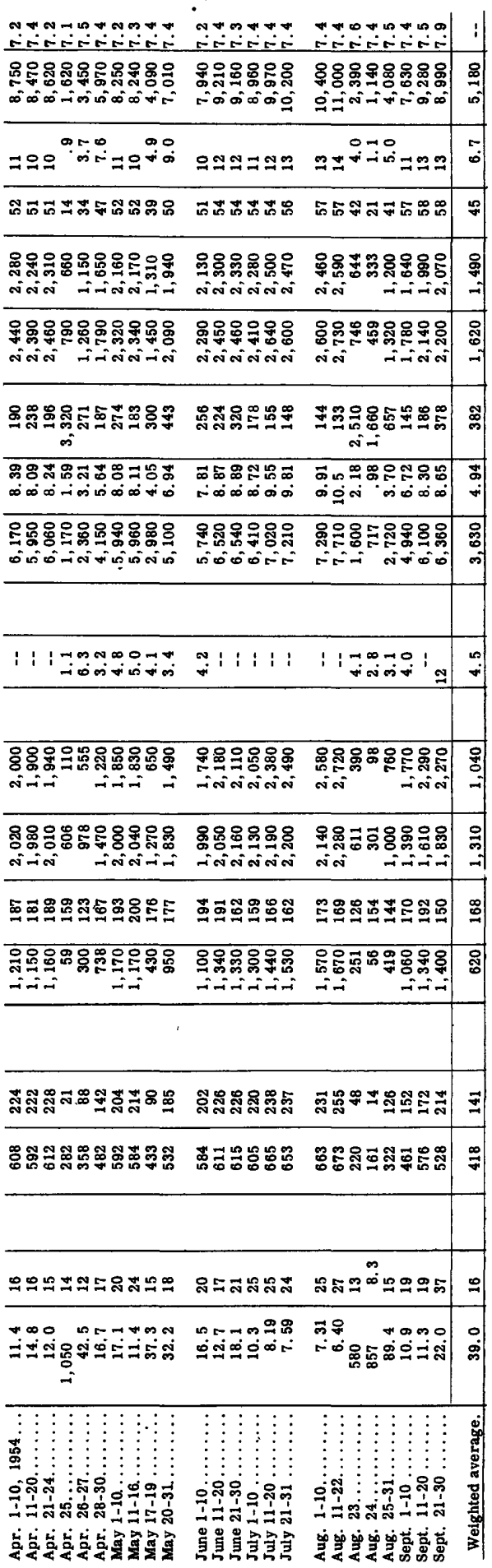




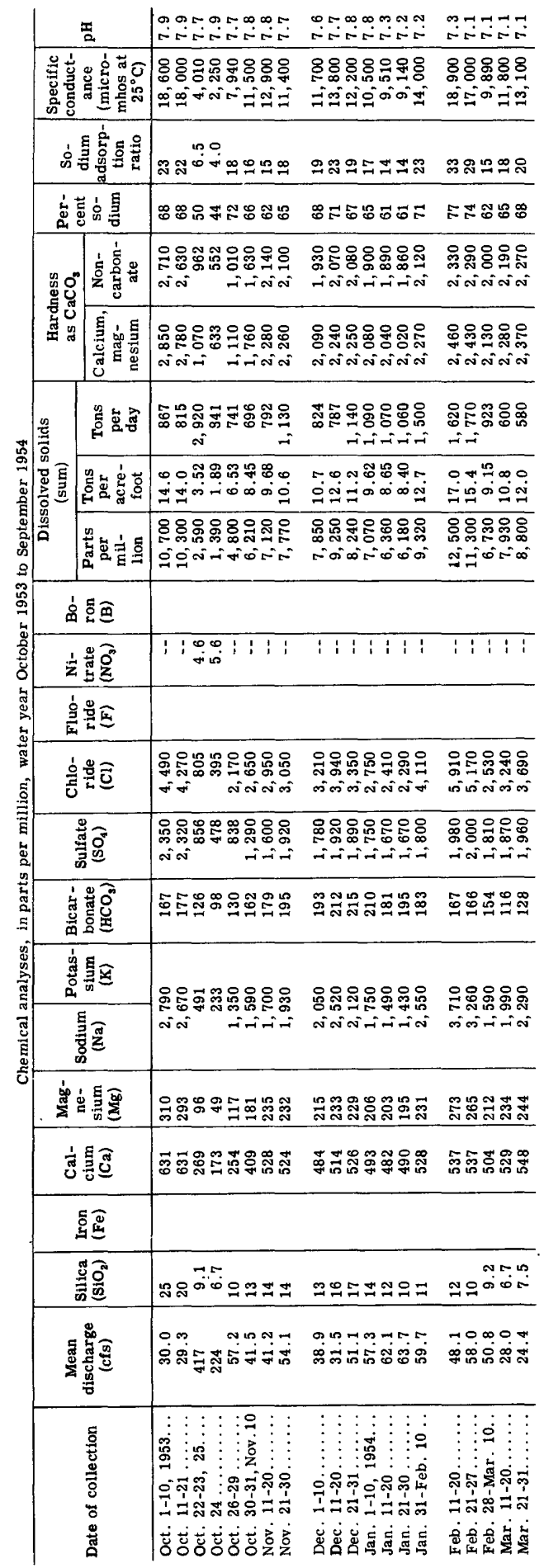




\begin{tabular}{|c|c|c|c|}
\hline 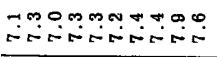 & 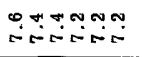 & 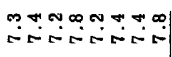 & il \\
\hline 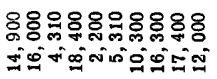 & 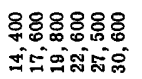 & 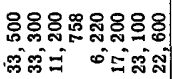 & $\begin{array}{l}8 \\
\text { +1 } \\
-1\end{array}$ \\
\hline 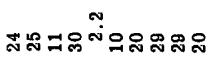 & 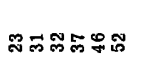 & 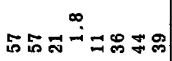 & 오 \\
\hline 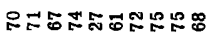 & $\approx \mathscr{N}$ & 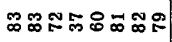 & $\mathbb{D}$ \\
\hline 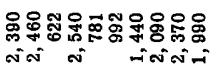 & 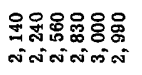 & 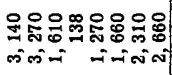 & -1 \\
\hline 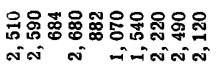 & 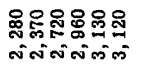 & 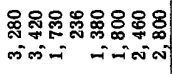 & $\begin{array}{c}0 \\
0 \\
0 \\
-1\end{array}$ \\
\hline 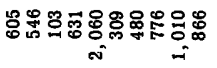 & 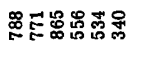 & 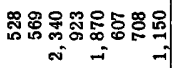 & $\stackrel{\infty}{\infty}$ \\
\hline ஈ & 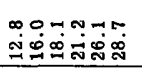 & 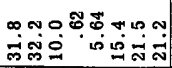 & $\stackrel{-}{0}$ \\
\hline 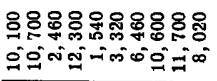 & 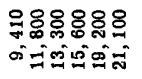 & 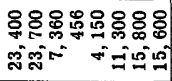 & in \\
\hline I I & $1: 1: 1:$ & ' ' & i) \\
\hline 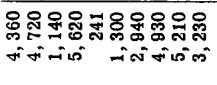 & 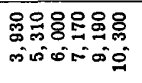 & 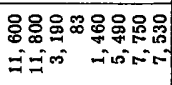 & 号 \\
\hline 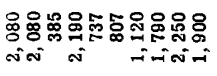 & 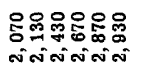 & 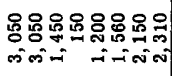 & 욤 \\
\hline 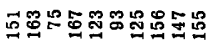 & 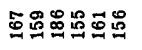 & 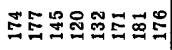 & 임 \\
\hline 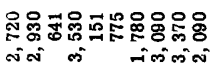 & 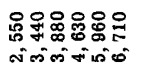 & 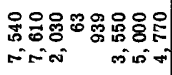 & $\begin{array}{l}8 \\
8 \\
\text { N }\end{array}$ \\
\hline 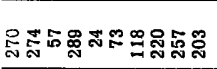 & 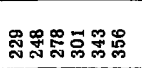 & 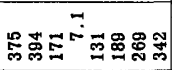 & $\stackrel{-1}{-\infty}$ \\
\hline 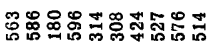 & 두ㅇㅠㅛ요요용 & 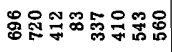 & ถึ) \\
\hline$\stackrel{+}{\infty}=$ & -1 & สำ & 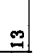 \\
\hline ஸ & 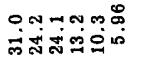 & $\begin{array}{l}\infty \\
\infty \infty \\
\infty \\
\infty\end{array}$ & จ \\
\hline 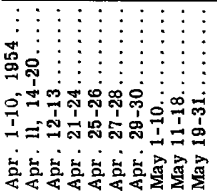 & 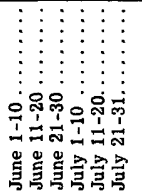 & 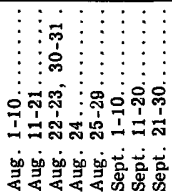 & 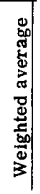 \\
\hline
\end{tabular}


RIO GRANDE BASIN--Continued

PECOS RIVER AT PIERCE CANYON CROSSING, NEAR MALAGA, N. MEX.--Continued

Temperature $\left({ }^{\circ} \mathrm{F}\right)$ of water, wat er year October 1953 to September 1954 Once-daily measurement, usually during daylight hours.7

\begin{tabular}{|c|c|c|c|c|c|c|c|c|c|c|c|c|}
\hline Day & Oct. & Nov. & Dec. & Jan. & Feb. & Mar. & Apr. & May & June & July & Aug. & Sept \\
\hline $\begin{array}{l}1 \\
2 \\
3 \\
4 \\
5\end{array}$ & $\begin{array}{l}73 \\
75 \\
69 \\
77 \\
69\end{array}$ & $\begin{array}{l}61 \\
-- \\
60 \\
--\end{array}$ & $\begin{array}{l}55 \\
55 \\
51 \\
50 \\
46\end{array}$ & $\begin{array}{l}43 \\
47 \\
44 \\
49 \\
49\end{array}$ & $\begin{array}{l}\mathbf{5 4} \\
57 \\
58 \\
58 \\
55\end{array}$ & $\begin{array}{l}55 \\
51 \\
48 \\
47 \\
45\end{array}$ & $\begin{array}{l}59 \\
68 \\
64 \\
68 \\
65\end{array}$ & $\begin{array}{l}67 \\
66 \\
63 \\
68 \\
67\end{array}$ & $\begin{array}{l}81 \\
80 \\
74 \\
80 \\
80\end{array}$ & $\begin{array}{l}80 \\
78 \\
81 \\
80 \\
79\end{array}$ & $\begin{array}{l}84 \\
85 \\
82 \\
86 \\
88\end{array}$ & $\begin{array}{l}84 \\
83 \\
82 \\
80 \\
79\end{array}$ \\
\hline $\begin{array}{r}6 \\
.7 \\
8 \\
9 \\
10\end{array}$ & $\begin{array}{l}71 \\
65 \\
65 \\
65 \\
65\end{array}$ & $\begin{array}{l}59 \\
60 \\
61 \\
54 \\
57\end{array}$ & $\begin{array}{l}45 \\
49 \\
47 \\
43 \\
47\end{array}$ & $\begin{array}{l}45 \\
49 \\
52 \\
52 \\
48\end{array}$ & $\begin{array}{l}\mathbf{5 5} \\
\mathbf{5 2} \\
\mathbf{5 1} \\
\mathbf{5 5} \\
\mathbf{5 7}\end{array}$ & $\begin{array}{l}50 \\
49 \\
52 \\
57 \\
61\end{array}$ & $\begin{array}{l}72 \\
70 \\
67 \\
70 \\
76\end{array}$ & $\begin{array}{l}67 \\
70 \\
77 \\
75 \\
77\end{array}$ & $\begin{array}{l}79 \\
78 \\
78 \\
82 \\
84\end{array}$ & $\begin{array}{l}80 \\
81 \\
83 \\
80 \\
83\end{array}$ & $\begin{array}{l}85 \\
85 \\
82 \\
80 \\
82\end{array}$ & $\begin{array}{l}80 \\
79 \\
83 \\
-- \\
80\end{array}$ \\
\hline $\begin{array}{l}11 \\
12 \\
13 \\
14 \\
15\end{array}$ & $\begin{array}{l}65 \\
65 \\
65 \\
67 \\
65\end{array}$ & $\begin{array}{l}\mathbf{5 8} \\
\mathbf{5 9} \\
\mathbf{5 4} \\
\mathbf{5 4} \\
\mathbf{5 4}\end{array}$ & $\begin{array}{l}44 \\
45 \\
39 \\
46 \\
46\end{array}$ & $\begin{array}{l}45 \\
39 \\
43 \\
44 \\
45\end{array}$ & $\begin{array}{l}55 \\
56 \\
54 \\
56 \\
58\end{array}$ & $\begin{array}{l}59 \\
56 \\
53 \\
54 \\
51\end{array}$ & $\begin{array}{l}67 \\
63 \\
67 \\
73 \\
72\end{array}$ & $\begin{array}{l}77 \\
75 \\
73 \\
72 \\
73\end{array}$ & $\begin{array}{l}84 \\
81 \\
78 \\
82 \\
79\end{array}$ & $\begin{array}{l}81 \\
81 \\
81 \\
80 \\
83\end{array}$ & $\begin{array}{l}88 \\
-- \\
79 \\
85 \\
80\end{array}$ & $\begin{array}{l}-- \\
78 \\
80 \\
81 \\
80\end{array}$ \\
\hline $\begin{array}{l}16 \\
17 \\
18 \\
19 \\
20\end{array}$ & $\begin{array}{l}65 \\
67 \\
69 \\
67 \\
67\end{array}$ & $\begin{array}{l}54 \\
55 \\
55 \\
56 \\
51\end{array}$ & $\begin{array}{l}44 \\
44 \\
47 \\
50 \\
46\end{array}$ & $\begin{array}{l}52 \\
48 \\
53 \\
49 \\
53\end{array}$ & $\begin{array}{l}56 \\
51 \\
58 \\
54 \\
56\end{array}$ & $\begin{array}{l}48 \\
51 \\
54 \\
55 \\
60\end{array}$ & $\begin{array}{l}73 \\
68 \\
70 \\
69 \\
75\end{array}$ & $\begin{array}{l}75 \\
74 \\
76 \\
76 \\
80\end{array}$ & $\begin{array}{l}79 \\
82 \\
83 \\
80 \\
81\end{array}$ & $\begin{array}{l}83 \\
80 \\
80 \\
83 \\
86\end{array}$ & $\begin{array}{l}82 \\
82 \\
80 \\
82 \\
82\end{array}$ & $\begin{array}{l}80 \\
73 \\
79 \\
78 \\
83\end{array}$ \\
\hline $\begin{array}{l}21 \\
22 \\
23 \\
24 \\
25\end{array}$ & $\begin{array}{l}70 \\
70 \\
63 \\
58 \\
61\end{array}$ & $\begin{array}{l}51 \\
50 \\
-- \\
53 \\
50\end{array}$ & $\begin{array}{l}50 \\
45 \\
39 \\
37 \\
39\end{array}$ & $\begin{array}{l}49 \\
50 \\
49 \\
49 \\
54\end{array}$ & $\begin{array}{l}52 \\
53 \\
58 \\
53 \\
62\end{array}$ & $\begin{array}{l}59 \\
61 \\
63 \\
64 \\
62\end{array}$ & $\begin{array}{l}73 \\
75 \\
72 \\
75 \\
54\end{array}$ & $\begin{array}{l}81 \\
82 \\
83 \\
72 \\
73\end{array}$ & $\begin{array}{l}80 \\
83 \\
85 \\
84 \\
83\end{array}$ & $\begin{array}{l}82 \\
83 \\
82 \\
90 \\
85\end{array}$ & $\begin{array}{l}80 \\
78 \\
79 \\
75 \\
--\end{array}$ & $\begin{array}{l}75 \\
75 \\
70 \\
73 \\
79\end{array}$ \\
\hline $\begin{array}{l}26 \\
27 \\
28 \\
29 \\
30 \\
31\end{array}$ & $\begin{array}{l}64 \\
-- \\
66 \\
61 \\
-- \\
-- \\
\end{array}$ & $\begin{array}{l}-- \\
-- \\
54 \\
51 \\
55 \\
--\end{array}$ & $\begin{array}{l}40 \\
39 \\
43 \\
44 \\
46 \\
46\end{array}$ & $\begin{array}{l}53 \\
54 \\
56 \\
54 \\
54 \\
54\end{array}$ & $\begin{array}{l}-- \\
57 \\
50 \\
-- \\
-- \\
--\end{array}$ & $\begin{array}{l}59 \\
60 \\
62 \\
61 \\
64 \\
62\end{array}$ & $\begin{array}{l}60 \\
62 \\
67 \\
71 \\
70 \\
--\end{array}$ & $\begin{array}{l}73 \\
76 \\
76 \\
74 \\
76 \\
80\end{array}$ & $\begin{array}{l}82 \\
78 \\
79 \\
-- \\
83 \\
--\end{array}$ & $\begin{array}{l}85 \\
80 \\
80 \\
83 \\
83 \\
83 \\
\end{array}$ & $\begin{array}{l}78 \\
82 \\
84 \\
85 \\
87 \\
83\end{array}$ & $\begin{array}{l}73 \\
75 \\
-- \\
77 \\
74 \\
-- \\
\end{array}$ \\
\hline $\begin{array}{c}\text { Aver- } \\
\text { age }\end{array}$ & 67 & 55 & 45 & 49 & 55 & 56 & 68 & 74 & 81 & 82 & 82 & 78 \\
\hline
\end{tabular}




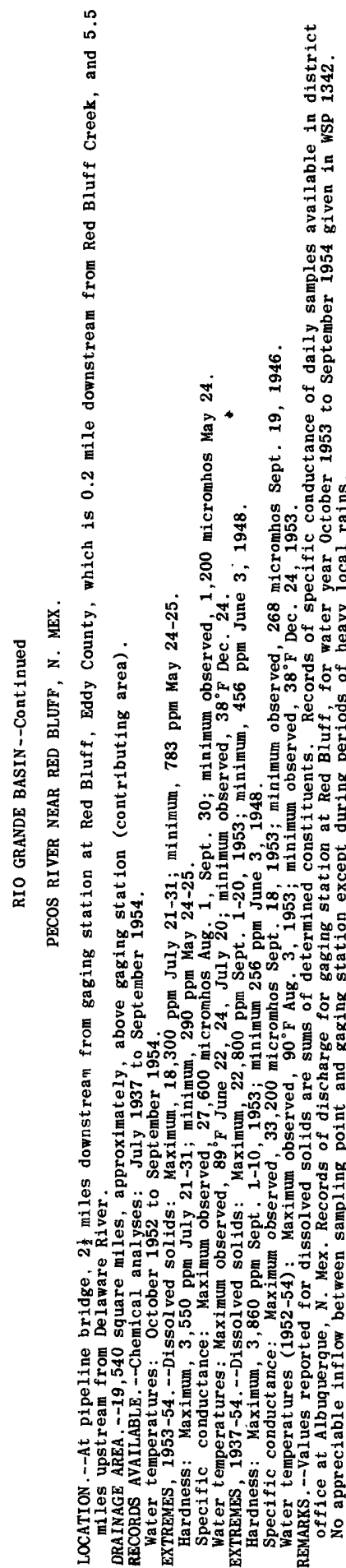

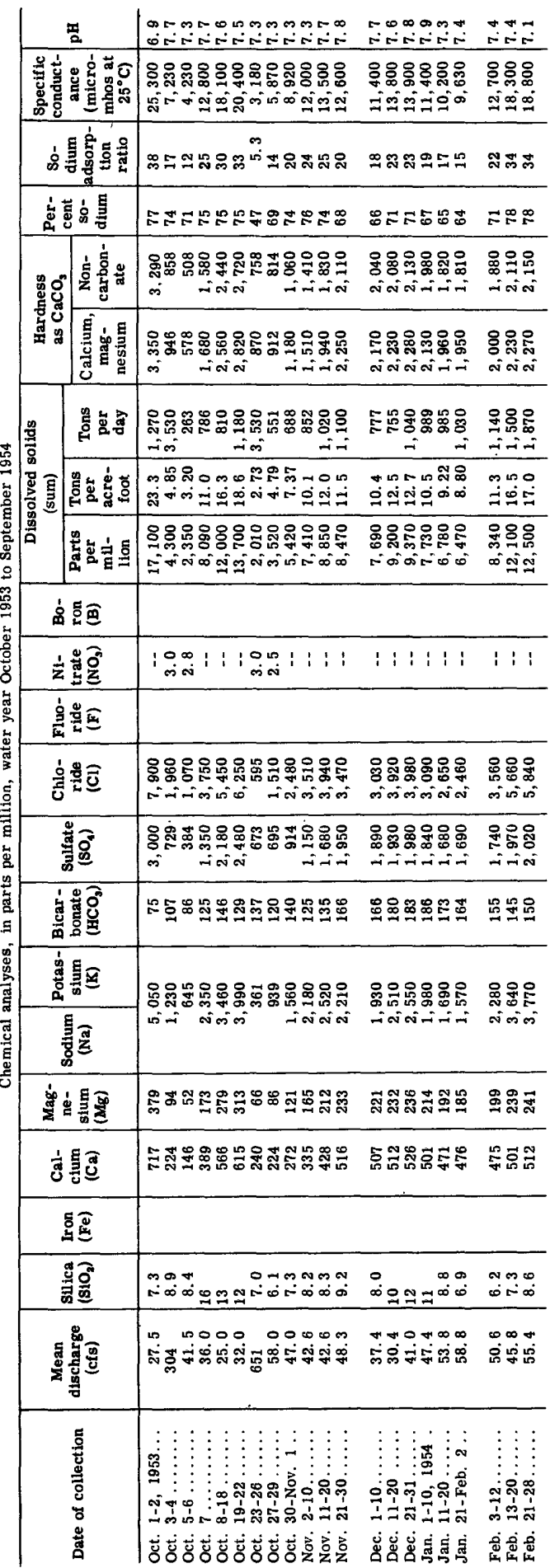

$4888170-59-32$ 


\begin{tabular}{|c|c|c|c|c|c|c|}
\hline & 뗨 & 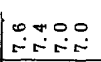 & 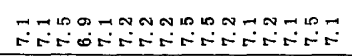 & 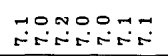 & 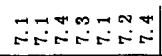 & $i$ \\
\hline & 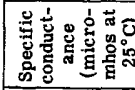 & 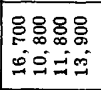 & 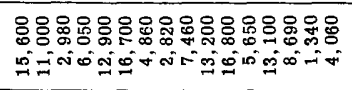 & 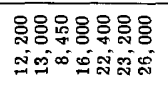 & 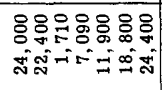 & $\mid$ \\
\hline & 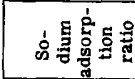 & 2도ำ & 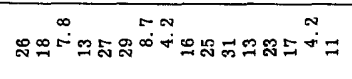 & 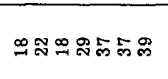 & 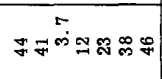 & $\stackrel{\infty}{-1}$ \\
\hline & 离葶宫意 & 몬 & 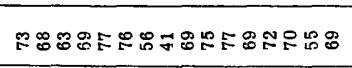 & 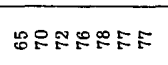 & 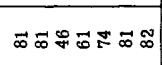 & 8 \\
\hline & 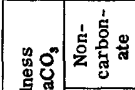 & 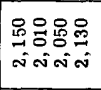 & 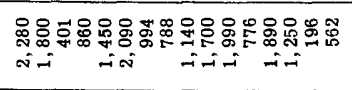 & 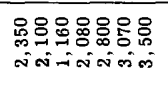 & 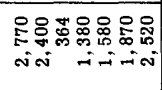 & 辛 \\
\hline & 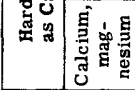 & 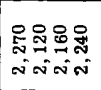 & 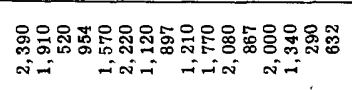 & 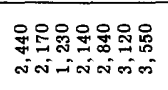 & 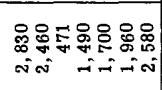 & $\mid$ \\
\hline & 总点新 & 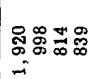 & 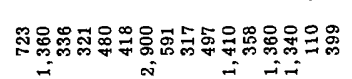 & 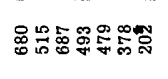 & 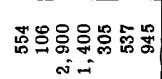 & : \\
\hline $\begin{array}{c}0 \\
\vdots \\
\vdots \\
o \\
o\end{array}$ & 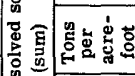 & 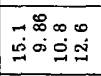 & 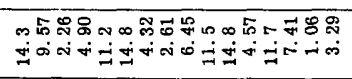 & 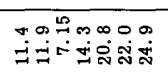 & 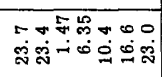 & $\Rightarrow$ \\
\hline : & 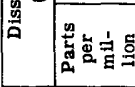 & 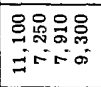 & 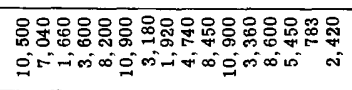 & 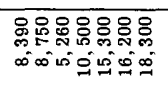 & 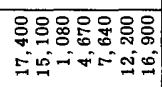 & \begin{tabular}{|c|}
0 \\
0 \\
$\infty$ \\
0
\end{tabular} \\
\hline & 官部鱼 & & & & & \\
\hline & 安农茛 & $1: 1: 1:$ & : : & : : : & 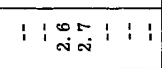 & 1 \\
\hline & 言要画 & & & & & \\
\hline 芴 & 영휼 & 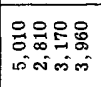 & 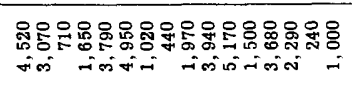 & 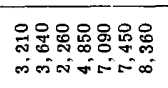 & 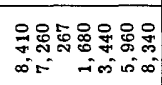 & 畩 \\
\hline 芠 & 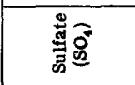 & 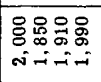 & 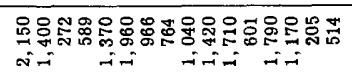 & 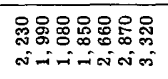 & 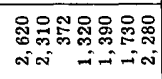 & 荡 \\
\hline 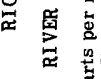 & 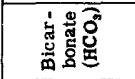 & 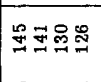 & 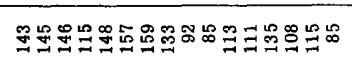 & 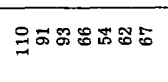 & 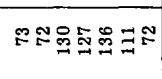 & $\mathscr{D}$ \\
\hline 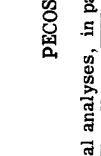 & 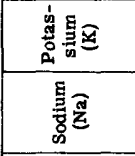 & 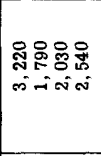 & 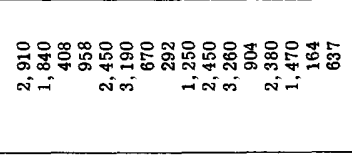 & 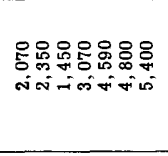 & 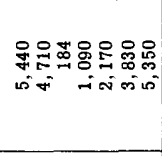 & $\mid \begin{array}{l}8 \\
8 \\
0 \\
-1\end{array}$ \\
\hline లే & 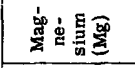 & ฟีสะสีส & 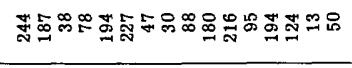 & 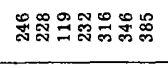 & 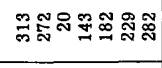 & 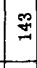 \\
\hline & 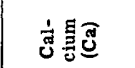 & ํㅗำ & 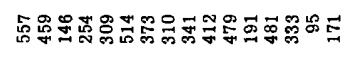 & 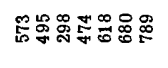 & 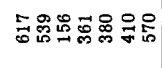 & $\overrightarrow{\mathrm{E}}$ \\
\hline & 递离 & & & & & \\
\hline & 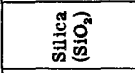 & $\begin{array}{l}\infty \\
\infty \\
\infty \\
\infty\end{array}$ & 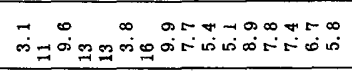 & 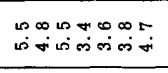 & 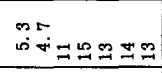 & $\begin{array}{ll}\infty \\
\infty \\
\infty\end{array}$ \\
\hline & 退 & 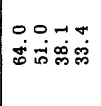 & 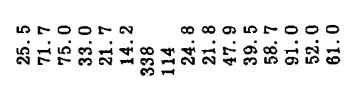 & 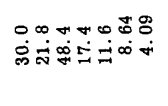 & 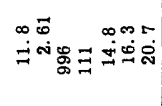 & $\mid \begin{array}{l}0 \\
\dot{b} \\
\dot{b}\end{array}$ \\
\hline & 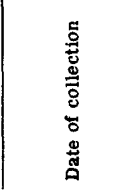 & 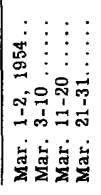 & 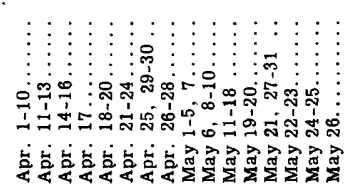 & 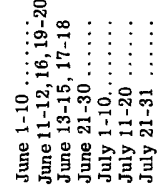 & 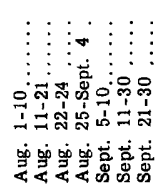 & 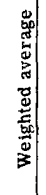 \\
\hline
\end{tabular}


RIO GRANDE BASIN--Cont inued

PECOS RIVER NEAR RED BLUFF, N. MEX.--Continued

Temperature $\left({ }^{\circ} \mathrm{F}\right)$ of water, water year October 1953 to September 1954 Once-daily measurement, usually between 4 p.m. and 6 p.m.7

\begin{tabular}{|c|c|c|c|c|c|c|c|c|c|c|c|c|}
\hline Day & Oct. & Nov. & Dec. & Jan. & Feb. & Mar. & Apr. & May & June & July & Aug. & Sept. \\
\hline $\begin{array}{l}1 \\
2 \\
3 \\
4 \\
5\end{array}$ & $\begin{array}{l}73 \\
76 \\
-- \\
69 \\
69\end{array}$ & $\begin{array}{l}66 \\
66 \\
64 \\
63 \\
60\end{array}$ & $\begin{array}{l}55 \\
54 \\
52 \\
50 \\
53\end{array}$ & $\begin{array}{l}41 \\
46 \\
48 \\
50 \\
52\end{array}$ & $\begin{array}{l}58 \\
57 \\
57 \\
58 \\
57\end{array}$ & $\begin{array}{l}57 \\
55 \\
48 \\
48 \\
47\end{array}$ & $\begin{array}{l}65 \\
70 \\
69 \\
70 \\
73\end{array}$ & $\begin{array}{l}74 \\
69 \\
66 \\
72 \\
77\end{array}$ & $\begin{array}{l}84 \\
83 \\
84 \\
80 \\
83\end{array}$ & $\begin{array}{c}82 \\
83 \\
83 \\
-- \\
83\end{array}$ & $\begin{array}{l}85 \\
84 \\
82 \\
88 \\
83\end{array}$ & $\begin{array}{l}86 \\
85 \\
84 \\
86 \\
85\end{array}$ \\
\hline $\begin{array}{r}6 \\
7 \\
8 \\
9 \\
10\end{array}$ & $\begin{array}{l}70 \\
70 \\
-- \\
72 \\
70\end{array}$ & $\begin{array}{l}58 \\
60 \\
61 \\
60 \\
58\end{array}$ & $\begin{array}{l}48 \\
48 \\
49 \\
47 \\
47\end{array}$ & $\begin{array}{l}50 \\
50 \\
50 \\
51 \\
48\end{array}$ & $\begin{array}{l}56 \\
58 \\
60 \\
-- \\
60\end{array}$ & $\begin{array}{l}53 \\
52 \\
57 \\
65 \\
65\end{array}$ & $\begin{array}{l}74 \\
70 \\
68 \\
70 \\
78\end{array}$ & $\begin{array}{l}79 \\
80 \\
78 \\
77 \\
79\end{array}$ & $\begin{array}{l}81 \\
80 \\
-- \\
83 \\
80\end{array}$ & $\begin{array}{l}84 \\
83 \\
-- \\
83 \\
87\end{array}$ & $\begin{array}{l}84 \\
86 \\
85 \\
88 \\
85\end{array}$ & $\begin{array}{l}85 \\
85 \\
85 \\
85 \\
--\end{array}$ \\
\hline $\begin{array}{l}11 \\
12 \\
13 \\
14 \\
15\end{array}$ & $\begin{array}{l}70 \\
70 \\
74 \\
73 \\
72\end{array}$ & $\begin{array}{l}60 \\
60 \\
58 \\
60 \\
58\end{array}$ & $\begin{array}{l}42 \\
45 \\
47 \\
45 \\
50\end{array}$ & $\begin{array}{l}45 \\
56 \\
63 \\
55 \\
50\end{array}$ & $\begin{array}{l}58 \\
-- \\
-- \\
60 \\
59\end{array}$ & $\begin{array}{l}62 \\
60 \\
55 \\
54 \\
50\end{array}$ & $\begin{array}{l}-2 \\
64 \\
66 \\
71 \\
75\end{array}$ & $\begin{array}{l}74 \\
75 \\
75 \\
74 \\
78\end{array}$ & $\begin{array}{l}84 \\
84 \\
-- \\
80 \\
83\end{array}$ & $\begin{array}{l}86 \\
84 \\
85 \\
80 \\
--\end{array}$ & $\begin{array}{l}-- \\
-- \\
-- \\
85 \\
85\end{array}$ & $\begin{array}{l}85 \\
80 \\
84 \\
85 \\
82\end{array}$ \\
\hline $\begin{array}{l}16 \\
17 \\
18 \\
19 \\
20\end{array}$ & $\begin{array}{l}73 \\
72 \\
70 \\
73 \\
73\end{array}$ & $\begin{array}{l}59 \\
60 \\
60 \\
57 \\
55\end{array}$ & $\begin{array}{l}43 \\
46 \\
48 \\
52 \\
52\end{array}$ & $\begin{array}{l}56 \\
48 \\
54 \\
54 \\
55\end{array}$ & $\begin{array}{l}60 \\
58 \\
60 \\
55 \\
59\end{array}$ & $\begin{array}{l}52 \\
59 \\
58 \\
63 \\
65\end{array}$ & $\begin{array}{l}72 \\
73 \\
77 \\
72 \\
73\end{array}$ & $\begin{array}{l}80 \\
76 \\
76 \\
79 \\
--\end{array}$ & $\begin{array}{l}79 \\
83 \\
87 \\
84 \\
81\end{array}$ & $\begin{array}{l}85 \\
85 \\
87 \\
86 \\
89\end{array}$ & $\begin{array}{l}85 \\
-- \\
-- \\
-- \\
--\end{array}$ & $\begin{array}{l}80 \\
80 \\
79 \\
81 \\
82\end{array}$ \\
\hline $\begin{array}{l}21 \\
22 \\
23 \\
24 \\
25\end{array}$ & $\begin{array}{l}71 \\
74 \\
64 \\
64 \\
65\end{array}$ & $\begin{array}{l}53 \\
57 \\
50 \\
56 \\
55\end{array}$ & $\begin{array}{l}52 \\
41 \\
42 \\
38 \\
40\end{array}$ & $\begin{array}{l}56 \\
51 \\
53 \\
53 \\
49\end{array}$ & $\begin{array}{l}58 \\
60 \\
59 \\
60 \\
--\end{array}$ & $\begin{array}{l}64 \\
65 \\
67 \\
64 \\
61\end{array}$ & $\begin{array}{l}74 \\
76 \\
74 \\
76 \\
64\end{array}$ & $\begin{array}{l}73 \\
80 \\
81 \\
70 \\
80\end{array}$ & $\begin{array}{l}84 \\
89 \\
87 \\
89 \\
83\end{array}$ & $\begin{array}{l}85 \\
87 \\
86 \\
88 \\
87\end{array}$ & $\begin{array}{l}-- \\
77 \\
75 \\
83 \\
83\end{array}$ & $\begin{array}{l}76 \\
74 \\
74 \\
76 \\
76\end{array}$ \\
\hline $\begin{array}{l}26 \\
27 \\
28 \\
29 \\
30 \\
31\end{array}$ & $\begin{array}{l}63 \\
65 \\
64 \\
64 \\
62 \\
65\end{array}$ & $\begin{array}{l}\mathbf{5 6} \\
\mathbf{5 2} \\
\mathbf{5 6} \\
\mathbf{5 6} \\
\mathbf{5 5} \\
--\end{array}$ & $\begin{array}{l}41 \\
40 \\
-- \\
45 \\
43 \\
47\end{array}$ & $\begin{array}{l}55 \\
55 \\
59 \\
59 \\
59 \\
51\end{array}$ & $\begin{array}{l}66 \\
55 \\
56 \\
-- \\
-- \\
--\end{array}$ & $\begin{array}{l}63 \\
65 \\
64 \\
68 \\
64 \\
64\end{array}$ & $\begin{array}{l}62 \\
72 \\
74 \\
70 \\
72 \\
--\end{array}$ & $\begin{array}{l}80 \\
84 \\
78 \\
81 \\
83 \\
84\end{array}$ & $\begin{array}{l}84 \\
85 \\
84 \\
78 \\
83 \\
--\end{array}$ & $\begin{array}{l}86 \\
-75 \\
84 \\
82 \\
83\end{array}$ & $\begin{array}{l}84 \\
86 \\
84 \\
86 \\
85 \\
85\end{array}$ & $\begin{array}{l}78 \\
78 \\
-- \\
75 \\
80 \\
--\end{array}$ \\
\hline $\begin{array}{c}\text { Aver - } \\
\text { age }\end{array}$ & 69 & 58 & 47 & $\mathbf{5 2}$ & 58 & 59 & 71 & 77 & 83 & 85 & $=$ & 81 \\
\hline
\end{tabular}




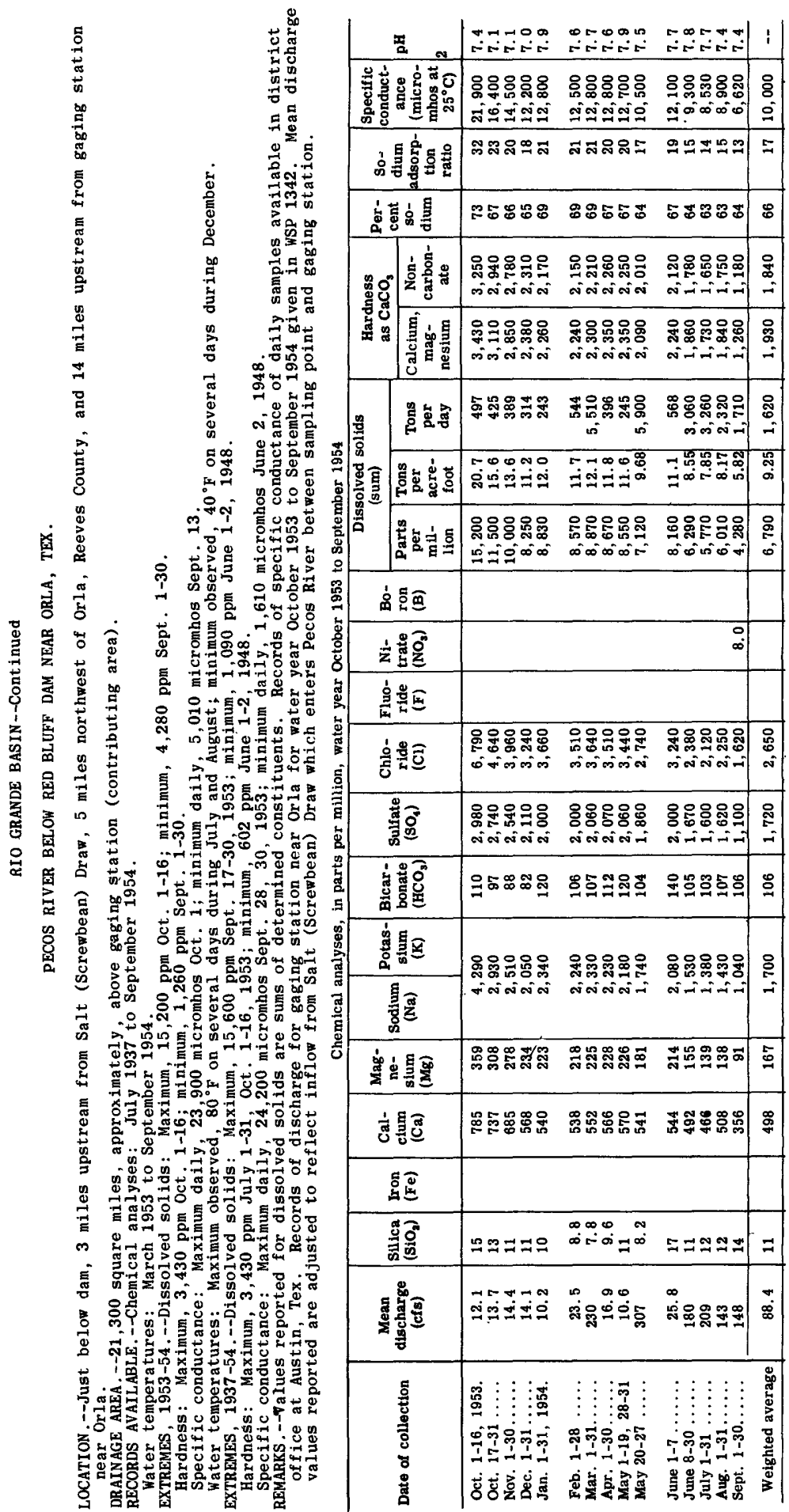


RIO GRANDE BASIN--Cont inued

PECOS RIVER BELOW RED BLUFF DAM NEAR ORLA, TEX .--Continued

Temperature $\left({ }^{\circ} \mathrm{F}\right)$ of water, water year October 1953 to September 1954

\begin{tabular}{|c|c|c|c|c|c|c|c|c|c|c|c|c|}
\hline Day & Oet. & Nov. & Dec. & Jan. & Feb. & Mar. & Apr. & May & June & July & Aug. & Sept. \\
\hline $\begin{array}{l}1 \\
2 \\
3 \\
4 \\
5\end{array}$ & $\begin{array}{l}73 \\
73 \\
74 \\
71 \\
72\end{array}$ & $\begin{array}{l}67 \\
67 \\
67 \\
67 \\
67\end{array}$ & $\begin{array}{l}55 \\
56 \\
55 \\
55 \\
55\end{array}$ & $\begin{array}{l}41 \\
41 \\
41 \\
42 \\
42\end{array}$ & $\begin{array}{l}48 \\
48 \\
49 \\
49 \\
50\end{array}$ & $\begin{array}{l}52 \\
52 \\
51 \\
51 \\
50\end{array}$ & $\begin{array}{l}57 \\
57 \\
57 \\
57 \\
57\end{array}$ & $\begin{array}{l}63 \\
62 \\
62 \\
62 \\
62\end{array}$ & $\begin{array}{l}65 \\
65 \\
64 \\
64 \\
65\end{array}$ & $\begin{array}{l}76 \\
76 \\
76 \\
76 \\
77\end{array}$ & $\begin{array}{l}79 \\
80 \\
80 \\
80 \\
80\end{array}$ & $\begin{array}{l}78 \\
78 \\
78 \\
77 \\
77\end{array}$ \\
\hline $\begin{array}{r}6 \\
7 \\
8 \\
9 \\
10\end{array}$ & $\begin{array}{l}71 \\
72 \\
72 \\
72 \\
72\end{array}$ & $\begin{array}{l}67 \\
67 \\
66 \\
66 \\
66\end{array}$ & $\begin{array}{l}52 \\
53 \\
53 \\
47 \\
46\end{array}$ & $\begin{array}{l}42 \\
42 \\
42 \\
43 \\
43\end{array}$ & $\begin{array}{l}50 \\
50 \\
50 \\
50 \\
50\end{array}$ & $\begin{array}{l}50 \\
50 \\
51 \\
51 \\
54\end{array}$ & $\begin{array}{l}57 \\
57 \\
57 \\
58 \\
59\end{array}$ & $\begin{array}{l}63 \\
63 \\
63 \\
63 \\
64\end{array}$ & $\begin{array}{l}65 \\
64 \\
70 \\
70 \\
71\end{array}$ & $\begin{array}{r}75 \\
75 \\
76 \\
75 \\
76\end{array}$ & $\begin{array}{l}80 \\
80 \\
79 \\
78 \\
79\end{array}$ & $\begin{array}{l}77 \\
77 \\
78 \\
77 \\
78\end{array}$ \\
\hline $\begin{array}{l}11 \\
12 \\
13 \\
14 \\
15\end{array}$ & $\begin{array}{l}72 \\
71 \\
71 \\
71 \\
71\end{array}$ & $\begin{array}{l}66 \\
66 \\
66 \\
66 \\
66\end{array}$ & $\begin{array}{l}46 \\
44 \\
44 \\
44 \\
44\end{array}$ & $\begin{array}{l}43 \\
43 \\
43 \\
43 \\
44\end{array}$ & $\begin{array}{l}51 \\
51 \\
51 \\
52 \\
52\end{array}$ & $\begin{array}{l}55 \\
54 \\
54 \\
52 \\
51\end{array}$ & $\begin{array}{l}59 \\
61 \\
61 \\
61 \\
60\end{array}$ & $\begin{array}{l}63 \\
-- \\
63 \\
63 \\
63\end{array}$ & $\begin{array}{l}71 \\
72 \\
72 \\
-2 \\
73\end{array}$ & $\begin{array}{l}75 \\
76 \\
76 \\
76 \\
76\end{array}$ & $\begin{array}{l}78 \\
78 \\
77 \\
78 \\
78\end{array}$ & $\begin{array}{l}77 \\
77 \\
76 \\
77 \\
77\end{array}$ \\
\hline $\begin{array}{l}16 \\
17 \\
18 \\
19 \\
20\end{array}$ & $\begin{array}{l}71 \\
71 \\
70 \\
70 \\
70\end{array}$ & $\begin{array}{l}65 \\
64 \\
65 \\
-- \\
--\end{array}$ & $\begin{array}{l}44 \\
44 \\
44 \\
44 \\
45\end{array}$ & $\begin{array}{l}44 \\
44 \\
44 \\
45 \\
45\end{array}$ & $\begin{array}{l}\mathbf{5 2} \\
\mathbf{5 2} \\
\mathbf{5 2} \\
\mathbf{5 1} \\
\mathbf{5 2}\end{array}$ & $\begin{array}{l}51 \\
51 \\
51 \\
52 \\
52\end{array}$ & $\begin{array}{l}61 \\
62 \\
62 \\
62 \\
63\end{array}$ & $\begin{array}{l}63 \\
63 \\
64 \\
64 \\
67\end{array}$ & $\begin{array}{l}72 \\
68 \\
68 \\
69 \\
69\end{array}$ & $\begin{array}{l}-- \\
76 \\
76 \\
76 \\
76\end{array}$ & $\begin{array}{l}78 \\
77 \\
77 \\
77 \\
77\end{array}$ & $\begin{array}{l}76 \\
76 \\
76 \\
76 \\
75\end{array}$ \\
\hline $\begin{array}{l}21 \\
22 \\
23 \\
24 \\
25\end{array}$ & $\begin{array}{l}70 \\
70 \\
69 \\
69 . \\
69\end{array}$ & $\begin{array}{l}-- \\
-- \\
-- \\
57 \\
56\end{array}$ & $\begin{array}{l}45 \\
45 \\
42 \\
40 \\
40\end{array}$ & $\begin{array}{l}45 \\
44 \\
44 \\
45 \\
45\end{array}$ & $\begin{array}{l}\mathbf{5 2} \\
\mathbf{5 2} \\
\mathbf{5 2} \\
\mathbf{5 2} \\
\mathbf{5 3}\end{array}$ & $\begin{array}{l}54 \\
55 \\
56 \\
57 \\
56\end{array}$ & $\begin{array}{l}62 \\
62 \\
63 \\
64 \\
64\end{array}$ & $\begin{array}{l}67 \\
68 \\
69 \\
70 \\
68\end{array}$ & $\begin{array}{l}70 \\
70 \\
70 \\
70 \\
70\end{array}$ & $\begin{array}{l}78 \\
79 \\
79 \\
79 \\
79\end{array}$ & $\begin{array}{l}78 \\
77 \\
77 \\
79 \\
78\end{array}$ & $\begin{array}{l}75 \\
77 \\
74 \\
74 \\
73\end{array}$ \\
\hline $\begin{array}{l}26 \\
27 \\
28 \\
29 \\
30 \\
31\end{array}$ & $\begin{array}{l}68 \\
67 \\
67 \\
67 \\
68 \\
67\end{array}$ & $\begin{array}{l}55 \\
55 \\
55 \\
55 \\
55 \\
--\end{array}$ & $\begin{array}{l}40 \\
40 \\
40 \\
40 \\
41 \\
41\end{array}$ & $\begin{array}{l}46 \\
47 \\
47 \\
47 \\
47 \\
47\end{array}$ & $\begin{array}{l}54 \\
54 \\
52 \\
-- \\
-- \\
--\end{array}$ & $\begin{array}{l}56 \\
56 \\
56 \\
56 \\
57 \\
57\end{array}$ & $\begin{array}{l}63 \\
63 \\
63 \\
63 \\
62 \\
--\end{array}$ & $\begin{array}{l}68 \\
68 \\
64 \\
64 \\
65 \\
65\end{array}$ & $\begin{array}{l}70 \\
76 \\
75 \\
75 \\
76 \\
--\end{array}$ & $\begin{array}{l}79 \\
79 \\
80 \\
79 \\
79 \\
80\end{array}$ & $\begin{array}{l}77 \\
77 \\
77 \\
77 \\
76 \\
77\end{array}$ & $\begin{array}{l}74 \\
73 \\
72 \\
72 \\
72 \\
--\end{array}$ \\
\hline $\begin{array}{c}\text { Aver- } \\
\text { age }\end{array}$ & 70 & 63 & 46 & 44 & 51 & 53 & 60 & 64 & 70 & 77 & 78 & 76 \\
\hline
\end{tabular}




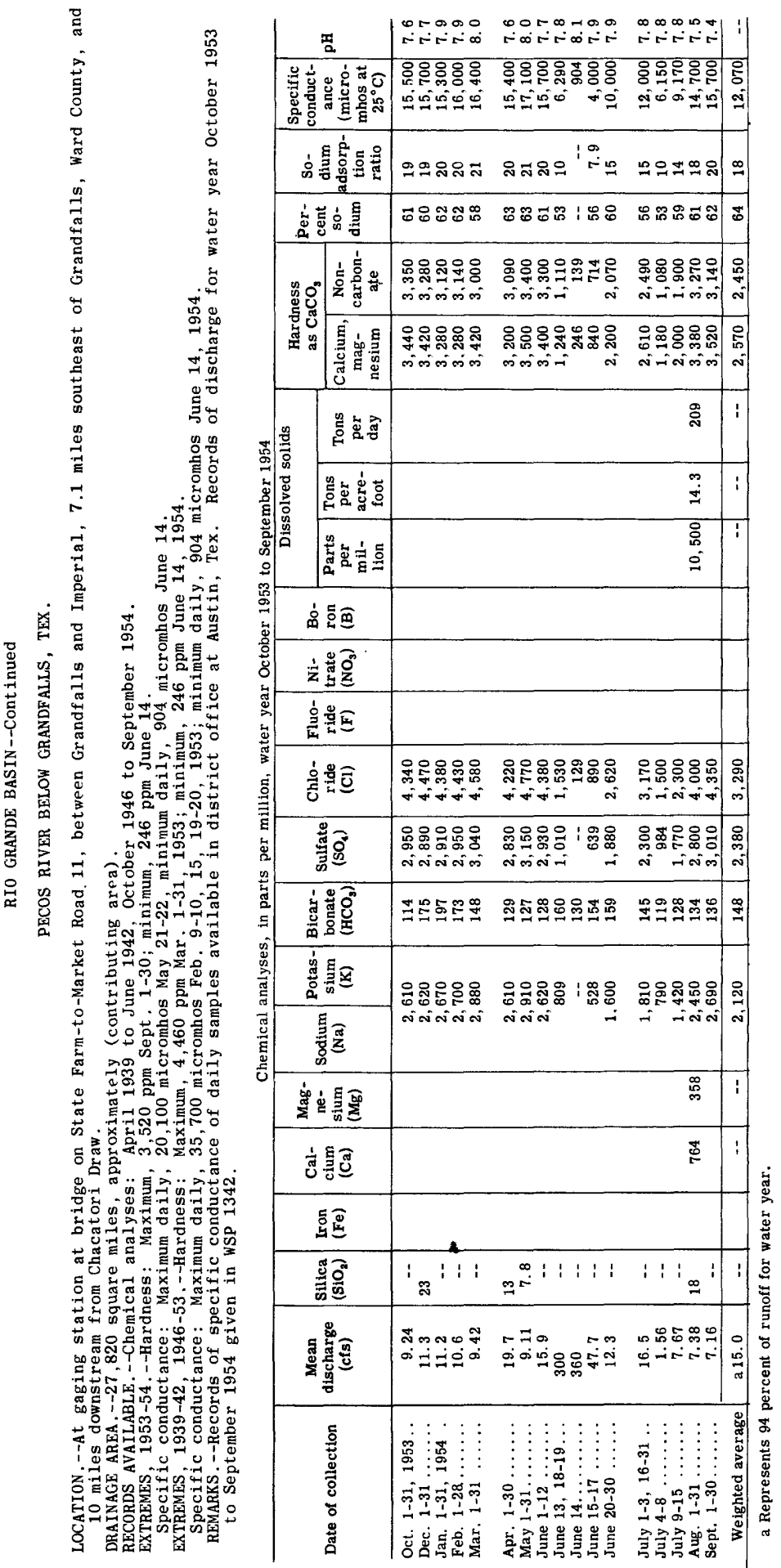


I

$\infty 00$ os in $\pi$

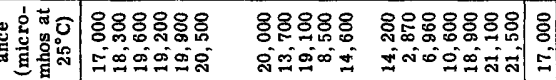

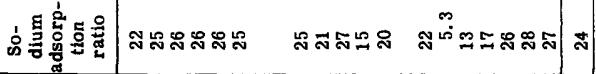

安著宫意

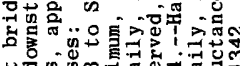

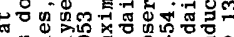
象 SOEE row क 今 Esto in

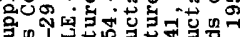

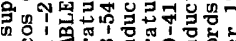

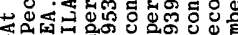
।

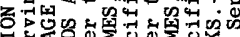

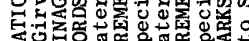

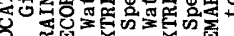

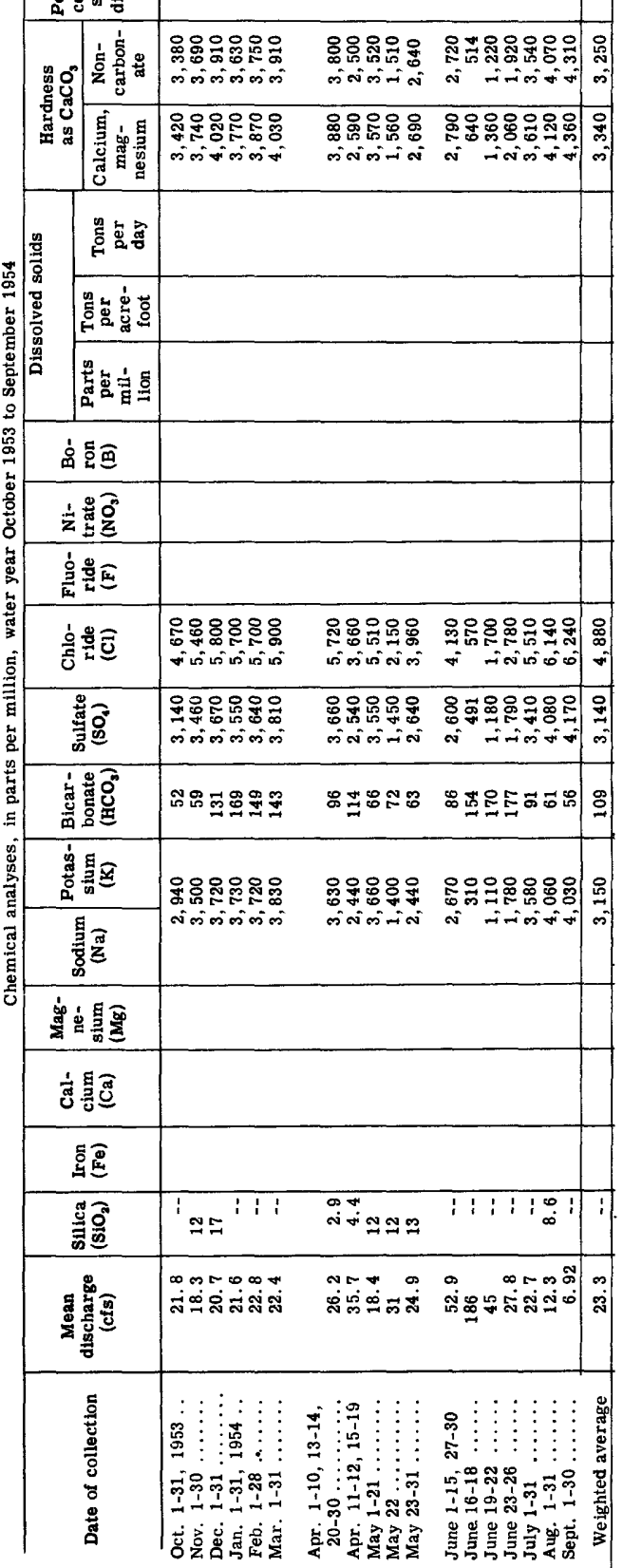


RIO GRANDE BASIN--Continued

PECOS RIVER NEAR GIRVIN, TEX.--Continued

Temperature $\left({ }^{\circ} \mathrm{F}\right)$ of water, water year October 1953 to September 1954

\begin{tabular}{|c|c|c|c|c|c|c|c|c|c|c|c|c|}
\hline Day & Oct. & Nov. & Dec. & Jan. & Feb. & Mar. & Apr. & May & June & July & Aug. & Sept. \\
\hline $\begin{array}{l}1 \\
2 \\
3 \\
4 \\
5\end{array}$ & $\begin{array}{l}-- \\
- \\
-- \\
--\end{array}$ & $\begin{array}{l}65 \\
65 \\
67 \\
67 \\
64\end{array}$ & $\begin{array}{l}60 \\
57 \\
53 \\
54 \\
52\end{array}$ & $\begin{array}{l}50 \\
-- \\
53 \\
53 \\
53\end{array}$ & $\begin{array}{l}51 \\
61 \\
60 \\
62 \\
60\end{array}$ & $\begin{array}{l}58 \\
56 \\
53 \\
50 \\
47\end{array}$ & $\begin{array}{l}69 \\
69 \\
73 \\
76 \\
79\end{array}$ & $\begin{array}{l}78 \\
75 \\
73 \\
73 \\
76\end{array}$ & $\begin{array}{l}93 \\
92 \\
89 \\
80 \\
-\end{array}$ & $\begin{array}{l}85 \\
86 \\
-- \\
85 \\
81\end{array}$ & $\begin{array}{l}88 \\
89 \\
87 \\
87 \\
88\end{array}$ & $\begin{array}{l}85 \\
86 \\
88 \\
87 \\
85\end{array}$ \\
\hline $\begin{array}{r}6 \\
7 \\
8 \\
9 \\
10\end{array}$ & $\begin{array}{l}-- \\
-- \\
-- \\
-- \\
--\end{array}$ & $\begin{array}{l}64 \\
62 \\
60 \\
60 \\
60\end{array}$ & $\begin{array}{l}52 \\
50 \\
52 \\
49 \\
49\end{array}$ & $\begin{array}{l}\mathbf{5 3} \\
\mathbf{5 3} \\
\mathbf{5 4} \\
\mathbf{5 5} \\
\mathbf{5 2}\end{array}$ & $\begin{array}{l}59 \\
57 \\
56 \\
55 \\
58\end{array}$ & $\begin{array}{l}49 \\
48 \\
60 \\
66 \\
64\end{array}$ & $\begin{array}{l}80 \\
81 \\
77 \\
74 \\
78\end{array}$ & $\begin{array}{l}77 \\
78 \\
79 \\
80 \\
79\end{array}$ & $\begin{array}{l}83 \\
85 \\
82 \\
84 \\
82\end{array}$ & $\begin{array}{l}87 \\
86 \\
88 \\
89 \\
90\end{array}$ & $\begin{array}{l}87 \\
87 \\
88 \\
88 \\
88\end{array}$ & $\begin{array}{l}85 \\
86 \\
85 \\
88 \\
87\end{array}$ \\
\hline $\begin{array}{l}11 \\
12 \\
13 \\
14 \\
15\end{array}$ & $\begin{array}{l}-- \\
73 \\
73 \\
76\end{array}$ & $\begin{array}{l}\mathbf{5 9} \\
\mathbf{6 0} \\
\mathbf{5 4} \\
\mathbf{5 8} \\
\mathbf{6 2}\end{array}$ & $\begin{array}{l}47 \\
-77 \\
42 \\
42\end{array}$ & $\begin{array}{l}43 \\
44 \\
44 \\
44 \\
44\end{array}$ & $\begin{array}{l}57 \\
59 \\
60 \\
65 \\
66\end{array}$ & $\begin{array}{l}61 \\
63 \\
54 \\
50 \\
57\end{array}$ & $\begin{array}{l}72 \\
66 \\
68 \\
71 \\
72\end{array}$ & $\begin{array}{l}79 \\
76 \\
78 \\
72 \\
74\end{array}$ & $\begin{array}{l}-= \\
85 \\
86 \\
81 \\
81\end{array}$ & $\begin{array}{l}87 \\
87 \\
85 \\
88 \\
86\end{array}$ & $\begin{array}{l}88 \\
88 \\
88 \\
87 \\
87\end{array}$ & $\begin{array}{l}84 \\
85 \\
83 \\
85 \\
84\end{array}$ \\
\hline $\begin{array}{l}16 \\
17 \\
18 \\
19 \\
20\end{array}$ & $\begin{array}{l}75 \\
75 \\
72 \\
71 \\
73\end{array}$ & $\begin{array}{l}\mathbf{5 8} \\
\mathbf{6 2} \\
\mathbf{6 6} \\
\mathbf{5 8} \\
\mathbf{5 7}\end{array}$ & $\begin{array}{l}44 \\
46 \\
47 \\
49 \\
48\end{array}$ & $\begin{array}{l}46 \\
48 \\
50 \\
52 \\
60\end{array}$ & $\begin{array}{l}59 \\
60 \\
59 \\
57 \\
58\end{array}$ & $\begin{array}{l}51 \\
60 \\
62 \\
59 \\
57\end{array}$ & $\begin{array}{l}71 \\
71 \\
68 \\
68 \\
78\end{array}$ & $\begin{array}{l}78 \\
79 \\
76 \\
77 \\
75\end{array}$ & $\begin{array}{l}84 \\
85 \\
85 \\
85 \\
86\end{array}$ & $\begin{array}{l}86 \\
87 \\
87 \\
87 \\
87\end{array}$ & $\begin{array}{l}86 \\
85 \\
87 \\
87 \\
87\end{array}$ & $\begin{array}{l}84 \\
81 \\
83 \\
81 \\
86\end{array}$ \\
\hline $\begin{array}{l}21 \\
22 \\
23 \\
24 \\
25\end{array}$ & $\begin{array}{l}72 \\
68 \\
65 \\
71 \\
66\end{array}$ & $\begin{array}{l}\mathbf{5 1} \\
50 \\
49 \\
49 \\
55\end{array}$ & $\begin{array}{l}49 \\
46 \\
44 \\
43 \\
41\end{array}$ & $\begin{array}{l}\mathbf{5 2} \\
\mathbf{5 5} \\
\mathbf{5 3} \\
\mathbf{5 3} \\
\mathbf{5 9}\end{array}$ & $\begin{array}{l}56 \\
61 \\
61 \\
58 \\
61\end{array}$ & $\begin{array}{l}65 \\
71 \\
68 \\
66 \\
71\end{array}$ & $\begin{array}{l}76 \\
69 \\
78 \\
79 \\
78\end{array}$ & $\begin{array}{l}81 \\
71 \\
78 \\
75 \\
79\end{array}$ & $\begin{array}{l}87 \\
86 \\
87 \\
87 \\
83\end{array}$ & $\begin{array}{l}87 \\
87 \\
87 \\
88 \\
89\end{array}$ & $\begin{array}{l}86 \\
85 \\
85 \\
85 \\
85\end{array}$ & $\begin{array}{l}84 \\
82 \\
80 \\
78 \\
80\end{array}$ \\
\hline $\begin{array}{l}26 \\
27 \\
28 \\
29 \\
30 \\
31\end{array}$ & $\begin{array}{l}65 \\
67 \\
66 \\
61 \\
65 \\
65\end{array}$ & $\begin{array}{l}57 \\
56 \\
54 \\
55 \\
58 \\
--\end{array}$ & $\begin{array}{l}43 \\
42 \\
45 \\
-- \\
42 \\
42\end{array}$ & $\begin{array}{l}61 \\
60 \\
62 \\
63 \\
58 \\
55\end{array}$ & $\begin{array}{l}61 \\
57 \\
59 \\
-- \\
-- \\
--\end{array}$ & $\begin{array}{l}70 \\
69 \\
69 \\
67 \\
73 \\
71\end{array}$ & $\begin{array}{l}80 \\
82 \\
84 \\
80 \\
75 \\
--\end{array}$ & $\begin{array}{l}81 \\
81 \\
84 \\
79 \\
75 \\
76\end{array}$ & $\begin{array}{l}85 \\
80 \\
83 \\
85 \\
85 \\
--\end{array}$ & $\begin{array}{l}88 \\
90 \\
90 \\
91 \\
90 \\
87\end{array}$ & $\begin{array}{l}87 \\
86 \\
88 \\
88 \\
88 \\
87\end{array}$ & $\begin{array}{l}81 \\
79 \\
82 \\
77 \\
74 \\
--\end{array}$ \\
\hline $\begin{array}{c}\text { Aver- } \\
\text { age }\end{array}$ & -- & 59 & 47 & 53 & 59 & 61 & 75 & 77 & 85 & 87 & 87 & 83 \\
\hline
\end{tabular}


RIO GRANDE BASINS--Continued

MISCELLANEOUS ANALYSES OF STREAMS IN RIO GRANDE BASIN IN NEW MEXICO

Chemical analyses, in parts per million, water year October 1953 to September 1954

\begin{tabular}{c|c|c|c|c|c|c}
\hline & Date of collection & $\begin{array}{c}\text { Discharge } \\
\text { (cfs) }\end{array}$ & $\begin{array}{c}\text { Bicarbonate } \\
\left(\mathrm{HCO}_{3}\right)\end{array}$ & $\begin{array}{c}\text { Carbonate } \\
\left(\mathrm{CO}_{3}\right)\end{array}$ & $\begin{array}{c}\text { Specific } \\
\text { Chloride } \\
\text { (C1) }\end{array}$ & $\begin{array}{c}\text { anduct- } \\
\text { ance } \\
\text { (micro- } \\
\text { mhos at } \\
\left.20^{\circ} \mathrm{C}\right)\end{array}$ \\
\hline
\end{tabular}

HAGERMAN CANAL AT DEXTER

\begin{tabular}{|c|c|c|c|c|}
\hline $\begin{array}{l}\text { Oct. } 20,1953 \ldots \ldots \\
\text { Nov. } 30 \ldots \ldots \ldots \ldots \\
\text { Jan. } 11,1954 \ldots \ldots \\
\text { Mar. } 4 \ldots \ldots \ldots \ldots \\
\text { Apr. } 12 \ldots \ldots \ldots \ldots \\
\text { May } 18 \ldots \ldots \ldots \ldots \\
\text { June } 28 \ldots \ldots \ldots \ldots \\
\text { Aug. } 11 \ldots \ldots \ldots \ldots \\
\text { Sept. } 27 \ldots \ldots \ldots \ldots\end{array}$ & $\begin{array}{l}187 \\
123 \\
245 \\
246 \\
248 \\
194 \\
264 \\
209 \\
229\end{array}$ & $\begin{array}{l}0 \\
7 \\
0 \\
0 \\
0 \\
0 \\
0 \\
0 \\
0\end{array}$ & $\begin{array}{r}1,190 \\
51 \\
1,130 \\
1,320 \\
1,270 \\
1,040 \\
1,340 \\
500 \\
1,260\end{array}$ & $\begin{array}{l}5,500 \\
1,350 \\
5,260 \\
5,900 \\
5,890 \\
4,940 \\
6,060 \\
3,020 \\
5,480\end{array}$ \\
\hline
\end{tabular}

LAKE MCMILLAN AT MCMILLAN DAM NEAR LAKEWOOD

\begin{tabular}{l|l|l|l|l|l|l|}
\hline Sept. $28,1954 \ldots \ldots$ & 81 & 0 & 3,350 & 12,900 \\
\hline
\end{tabular}

PECOS RIVER BELOW LAKE MCMILLAN DAM NEAR LAKEWOOD

\begin{tabular}{|c|c|c|c|c|}
\hline $\begin{array}{l}\text { Oct. } 22,1953 \ldots \ldots \\
\text { Nov. } 30 \\
\text { Jan. } 11,1954 \ldots \ldots \\
\text { Apr. } 13 \ldots \ldots \ldots \\
\text { Apr. } 24 \ldots \ldots \ldots \\
\text { May } 20 \ldots \ldots \ldots \ldots \\
\text { June } 28 \ldots \ldots \ldots \\
\text { Aug. } 11 \ldots \ldots \ldots \ldots \\
\end{array}$ & $\begin{array}{r}100 \\
62 \\
61 \\
136 \\
84 \\
140 \\
104 \\
129\end{array}$ & $\begin{array}{l}0 \\
0 \\
0 \\
0 \\
8 \\
0 \\
0 \\
0\end{array}$ & $\begin{array}{r}3,600 \\
1,730 \\
2,260 \\
310 \\
2,470 \\
370 \\
1,690 \\
390\end{array}$ & $\begin{array}{r}13,800 \\
7,840 \\
9,620 \\
3,630 \\
10,400 \\
3,380 \\
8,650 \\
3,070\end{array}$ \\
\hline
\end{tabular}

PECOS RIVER AT FORD CROSSING IN MAJOR JOHNSON SPRING AREA NEAR LAKEWOOD

\begin{tabular}{|c|c|c|c|c|c|}
\hline $\begin{array}{l}\text { Oct. } 22,1953 \ldots \ldots \\
\text { Dec. } 1 \ldots \ldots \ldots \ldots \\
\text { Jan. } 11,1954 \ldots \ldots \\
\text { Feb. } 24 \ldots \ldots \ldots \ldots \\
\text { Apr. } 13 \ldots \ldots \ldots \ldots \\
\text { May } 21 \ldots \ldots \ldots \ldots \ldots \\
\text { Aug. } 11 \ldots \ldots \ldots \ldots \\
\text { Sept. } 28 \ldots \ldots \ldots \ldots\end{array}$ & . & $\begin{array}{r}166 \\
87 \\
99 \\
124 \\
144 \\
124 \\
100 \\
200\end{array}$ & $\begin{array}{l}0 \\
0 \\
0 \\
0 \\
0 \\
0 \\
0 \\
0\end{array}$ & $\begin{array}{r}780 \\
1,670 \\
2,130 \\
2,310 \\
320 \\
310 \\
375 \\
1,040 \\
\end{array}$ & $\begin{array}{l}5,410 \\
7,610 \\
9,160 \\
9,750 \\
3,670 \\
2,970 \\
2,930 \\
6,010\end{array}$ \\
\hline
\end{tabular}

BLACK RIVER AT HARKEY CROSSING, SEC. 9, T. 24 S., R, 27 E., NEAR MALAGA

\begin{tabular}{|c|c|c|c|c|}
\hline $\begin{array}{l}\text { Dec. } 1, \quad 1953 \ldots \ldots \\
\text { Jan. } 12,1954 \ldots \ldots \\
\text { Feb. } 26 \ldots \ldots \ldots \ldots \\
\text { Apr. } 13 \ldots \ldots \ldots \ldots \\
\text { June } 29 \ldots \ldots \ldots \ldots \\
\text { July } 26 \ldots \ldots \ldots \ldots \\
\text { Aug. } 10 \ldots \ldots \ldots \ldots \\
\text { Sept. } 28 \ldots \ldots \ldots \ldots\end{array}$ & $\begin{array}{l}203 \\
206 \\
210 \\
199 \\
166 \\
166 \\
167 \\
186\end{array}$ & $\begin{array}{l}0 \\
0 \\
0 \\
0 \\
0 \\
0 \\
0 \\
0\end{array}$ & $\begin{array}{l}17 \\
24 \\
15 \\
21 \\
18 \\
12 \\
13 \\
13 \\
18\end{array}$ & $\begin{array}{l}1,720 \\
1,850 \\
1,730 \\
1,710 \\
1,640 \\
1,550 \\
1,530 \\
1,620\end{array}$ \\
\hline
\end{tabular}





\section{INDEX}

A

Page

A biquiu, N. Mex. , Rio Chama near. ... . . . 375-378 Acme, N. Mex., Pecos River near....... 461-463 Alamogordo Dam, N. Mex., Pecos River

below .................... 459-460

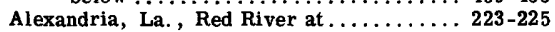

Altheiner, Ark. , Arkansas River near.... 152-155

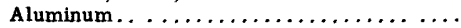

Amarillo, Tex., Canadian River near...... 103-105

Anahuac, Tex. , Trinity Bay near. . . . . . 331-334

Trinity River at. . . . . . . . . . . 329-330

Archer City, Tex., Little Wichita River near ....................... 186-189

Arkadelphia, Ark. , Ouachita River at. . . . 226-228

Arkansas River at Arkansas City, Kans .... 57-60 at Dardanelle, Ark ............. 143-147 at Little Rock, Ark. . . . . . . . . . . 148-151 at Ralston, Okla ................ 61-63 at Sand Springs Bridge near Tulsa, Okla. 75-79 at Van Buren, Ark .............. 135-139 below John Martin Reservoir, at Caddoa, Colo .......................

152-155

A rkansas River basin .............. 54-179

Artesia, N. Mex. , Pecos River near ..... 468-473

Atchafalaya River at Krotz Springs, La ... 282-284

Austin, Tex., Colorado River at ........ 358-359

\section{B}

Bancker's Ferry, La., Vermilion River at . 291-294

Bayou Bodcau near Sa repta, La ..........

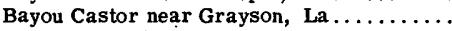

Bayou Cocodrie near Clearwater, La ...... 285-290

Bayou D'A rbonne near Dubach, La......... 263

Bayou De View near Brinkley, Ark ........

Bayou La Fourche near Crew Lake, La ....

Bayou Lapile near Strong, Ark . . . . . . . . . 246-249

Bayou Macon near Delhi, La . . . . . . . . . . .

Bear Creek near Fallis, Lincoln County,

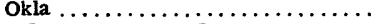

Beaver Creek near Kaw City, Kay County,

Okla ....................

near Waurika, Jefferson County, Okla .

Beckwith Creek near De Quincy, La .......

Beech Creek at Farm to Market Road 1013,

1 mile west of Spurger, Tex........

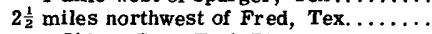

Beggs, Okla. , Deep Fork River near ......

Bellcow Creek at Chandler, Lincoln County,

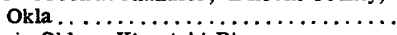

Belzoni, Okla. Kiamichi River near........ 208-209

Bernalillo, N. Mex., Rio Grande near ... . . 397-400

Bernardo, N. Mex., Rio Grande near .... 401-404

Rio Puerco near ............... 418-420

Berryville, Ark., Kings River near .......

Big Cabin Creek near Big Cabin, Craig County, Okla.

Big Turkey Creek, 6 miles southeast of

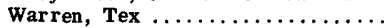

Black River at Harkey crossing, near

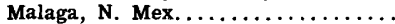

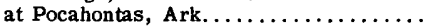

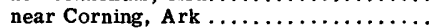

Blue Creek at Connerville, Johnston

Blue River near Blue, Bryan County, Okla.

Bơron.

Boughton A.................... 12

Brazos River at Possum Kingdom Dam

near Graford, Tex. . 337-338

at Richmond, Tex................. $342-344$

near Whitney, Tex ............... 339-341

Brazos River basin .............. 337-346
Bridgeport, Okla, Canadian River at . 106-109

Bueyeros, N. Mex., Ute Creek near.... 97-100 Buffalo Creek near Tiff City, McDonald

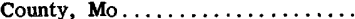
near Rush, Ark . . . . . . . . . . . near St. Joe, A rk .............. Bull Creek near Ira, Tex...........

\section{C}

Cabezon, N. Mex., Rio Puerco below. . 405-408 Cache Creek near Walters, Cotton County, Okla................

Cache River at Patterson, Ark........ Calcasieu River at Moss Bluff, La..... 299-301 Calcasieu River basin . . . . . . . . . . . 298-301

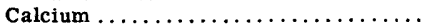
Calion, Ark. , Ouachita River at. ....... Canadian River at Bridgeport, Okla..... near Amarillo, Tex ............ 103-105 near Whitefield, Okla. ........... 128-133

Caney Lake at Red River Arsenal near

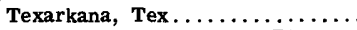
Canton, Okla., North Canadian River near ............................

Captain Creek near Wellston, Lincoln County, Okla...............

Carbonate and bicarbonate ........... Carlsbad Main Canal at head near

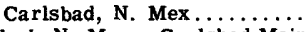

Carlsbad, N. Mex., Carlsbad Main Canal near. . . . . . . . . . . . Pecos River at $\ldots \ldots \ldots \ldots \ldots \ldots \ldots \ldots$

Pecos River near .............. Carnegie, Okla., Washita River at .... Carter, Okla., North Fork Red River

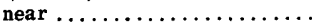

Cedar Creek near Carnegie, Caddo

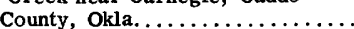

Chamita, N. Mex., Rio Chama near....

Chemical quality............... Chico Ar royo near Guadalupe, N. Mex.. Chikaskia River at Blackwell, Kay

County, Okla .............. 159-160

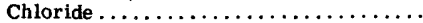

Cimarron River at Perkins, Okla...... near Guthrie, Logan County, Okla ... near Kenton, Cimarron County, Okla. near Mocane, Beaver County, Okla . . near Waynoka, Woods County, Okla. . Claremore, Okla., Verdigris River near Clarence, La., Saline Bayou near..... Clarendon, Ark., White river at ...... Clear Boggy Creek near Caney, Atoka

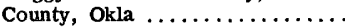

Clear Creek near May, Harper County, Okla . . . . . . . .

Clearwater, La., Bayou Cocodrie near. Coldwater Creek near Hardesty, Texas County, Okla.

279

$114-115$

175

11

477

477

478-480

476

198-201

183-185

270

379-382

3

409-411

69-74

166

161

161-162

163

83-85

221-222

46-48

275-276

173

285-290

172

3-6

Collection and examination of samples .

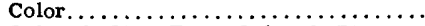
Colorado City, Tex. , Colorado River

at. .................... 349-351

Colorado River at Austin, Tex ....... 358-359 at Colorado City, Tex .......... $349-351$ at Wharton, Tex .............. 360-361 near San Saba, Tex. . . . . . . . . . 352-357 Colorado River basin............. 347-362 Commerce, Okla.; Neosho River near.. 90-92 Composition of surface waters ...... 8-16 Cooperation ................ 18-21 Cornie Creek near Junction City, Ark. . 254-257 
Page

Correo, N. Mex., San Jose River at. . . . 412-413

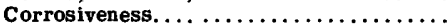

Cossatot River near De Queen, Ark......

Cotter, Ark., White River at .......... Cottonwood Creek near Guthrie, Logan

County, Okla ...............

Cove Creek near Lee Creek, Ark..........

Cove, Tex., Old River near............

Cow Bayou near Mauriceville, Tex.......

Crew Lake, La. , Bayou La Fourche near. .

Crooked Creek near Humphrey, Ark ......

Cypress Creek, I mile west of Kountze,

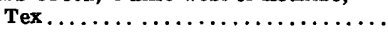

Dardanelle, Ark., Arkansas River at ....

Dayton, N. Mex., Rio Penasco at.

143-147

Deep Creek near Dunn, Tex............

Deep Fork River near Beggs, Okla. . . . . . . near Stroud, Lincoln County, Okla ..... near Welty, Creek County, Okla .......

Deep Red Run near Randlett, Cotton

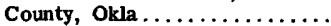

Deer Creek near Hydro, Caddo County,

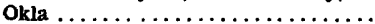

near Thomas, Custer County, Okla ....

Delhi, La., Bayou Macon near .......... Denison, Tex., Red River near..........

De Quincy, La. , Beckwith Creek near.....

Dissolved solids . . . . . . . . . . . . .

Division of work . . . . . . . . . . . . . .

Dixie, La. , Twelvemile Bayou near. ......

Domingo, N. Mex. , Galisteo Creek at. ....
Double Creek near Ramona, Washington

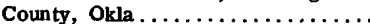

Double Mountain Fork Brazos River, 4.2 miles northeast of Slaton, Tex ..... near Lubbock Sewage Plant........... on State Highway 835, 4.3 miles southeast of Lubbock, Tex.............

on State Highway $835,7.8$ miles southeast of Lubbock, Tex. ............

on State Highway $400,5.5$ miles north of Slaton, Tex.

7.5 miles northwest of Slaton, Tex.... Dover, Ark., Piney Creek near .......... Dozier Creek near Wellington, Tex ........ Dubach, La. , Bayou D'Arbonne near ....... Dunn, Tex. , Deep Creek near........... Durwood, Okla., Washita River near...... Dutch Creek at Waltreak, Ark..........

Eagle Chief Creek at Cleo Springs, Major

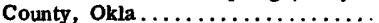
near Aline, Alfaifa County, Okla........ near Carmen, Alfalfa County, Okla......

Eleven Point River near Ravendon Springs, Ark . . . . . . . . . . . . . . . . .

Elk Creek near Hobart, Kiowa County,

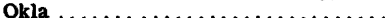
Elk River near Tiff City, McDonald County, Mo................

Elm Creek near Shamrock, Tex . ......... Embudo, N. Mex., Rio Grande at......... Emory, Tex. , Sabine River near ......... Evadale, Tex., Neches River at......... Expression of results...............

Felsenthal, Ark. , Ouachita River near ... 250-253 Finn Creek near Story, McClain County,

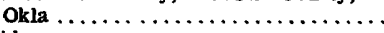
Fluoride . . . . . . . . . . . . . . . Fort Gibson, Okla. , Neosho River near ... Fourche La Fave River near Gravelly,

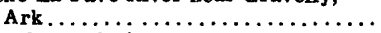

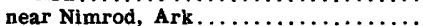
Frog Bayou near Rudy, Ark ........... Fulton, Ark., Red River at ...........

165

178

313

156

318

\section{5}

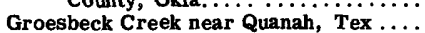
Guadalupe, N. Mex. , Chico Arroyo near Guadalupe River at Victoria, Tex....... Guadalupe River basin. . . . . . . . . . .

\section{H}

Hagerman Canal at Dexter, N. Mex .... Hardness . . . . . . . . . . . . . . . Helotes Creek, $1 \frac{1}{2}$ miles north of Helotes, Tex............... Henrietta, Tex., Little Wichita River

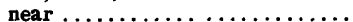

Hickory Creek at U. S. Highway 69 , $3 \frac{1}{2}$ miles south of Warren, Tex ...

$3 \frac{1}{2}$ miles west of War ren, Tex...... Hindsville, Ark. , War Eagle Creek near. . . . . . . . . . . . . . . Honey Creek near Turner Falls, Murray County, Okla............... Horatio, Ark., Little River near...... Hordes Creek Reservoir near Coleman,

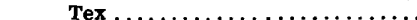
Horsepen Creek, 9 miles southwest of

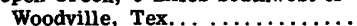

$9 \frac{1}{2}$ miles west of Woodville, Tex....

3 miles west of Warren, Tex. . ...... House Creek near Terlton, Pawnee, County, Okla............... Hoyle Creek near Ames, Major County,

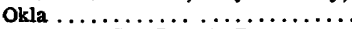
Huffman, Tex. , San Jacinto River near. Humphrey, Ark., Crooked Creek near. . Hurricane Creek near Sheridan, Ark ... Hydrogen-ion concentration ..........

194-197

389-392

493-494

101-102

$\mathbf{3 3 7}-\mathbf{3 3 8}$

170

492

266

170

277

409-411

363-365

363-366

\section{I}

Idabel, Okla. , Little River near ....... Illinois Bayou near Scotsville, Ark..... Illinois River at Tenkiller Reservoir

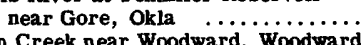
Indian Creek near Woodward, Woodward County, Okla.............. Imboden, Ark., Spring River at.......... Inola, Okla., Verdigris River near..... Introduction . . . . . . . . . . . . .

38

267

Ira, Tex., Bull Creek near.........

$\mathbf{J}$

Jamez Canyon Dam, N. Mex., Jemez River below............... Jemez River below Jemez Canyon Dam,$$
\text { N. Mex. }
$$

John Martin Reservoir, Colo. Arkansas River below

Junction City, Ark. , Cornie Creek

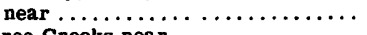

Three Creeks near ............

\section{$\mathbf{K}$}

Kiamichi River near Belzoni, Okla.... Kiowa Creek near Slapout, Beaver County, Okla

$$
\text { ................. }
$$

Kings River near Berryville, Ark. .... Krotz Springs, La. , Atchafalaya
208-209

$101-102$ 
$L$

Lagrue Bayou near Stuttgart, Ark.........

Lake Arthur, La., Mermentau River at ....

Lake J. B. Thomas near Ira, Tex .........

Lake Kemp near Seymour, Tex..........

Lake Kickapoo near Archer City, Tex......

Lake McMillan at McMillan Dam near

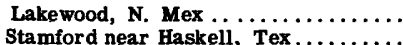

Lake Stamford near Haskell, Tex.........

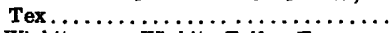

Lake Wichita near Wichita Falls, Tex......

Lampasas River at Fort Hood, Tex .........

Langley, Okla., Neosho River at ..........

Lebos Creek near Eldorado, Jackson

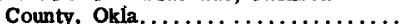

Lee Creek near Van Buren, Ark..........

Lelia Lake Creek near Hedley, Tex............

Lenapah, Okla., Verdigris River near ......

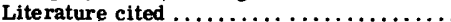

Little Beaver Creek near Duncan, Stephens County, Okla...................

Little Deep Fork Creek near Edna, Creek

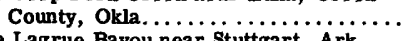

Little Lagrue Bayou near Stuttgart, Ark ...

Little Missouri River, at Narrows Dam near Murf reesboro, Ark...........

near Boughton, Ark ................

near Murfreesboro, Ark .............

Little River below Hog Creek near Norman, Okla ................... 110-113, 171

below Lukfata Creek, near Idabel, Okla....

171

Little Rock, Ark. , Arkansas River at....... 148-151

Little Washita River near Ninnekah, Grady

County, Okla..................

Little Wichita River near Archer City,

Tex ....................... 186-189

near Henrietta, Tex............... 190-193

Lobatos, Colo. , Rio Grande near........ 369-370

Lost Creek near Seneca, McDonald

County, Mo ........................

Lovell, Okla., Skelton Creek near........

near ........................

Lower Mississippi River basin .............

\section{$\mathbf{M}$}

Magnesium

laga, $N$ Mex, Pecos River east of .... . 482-483

Pecos River near ................ 484-486

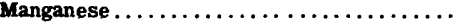

Marked Tree, Ark., St. Frances River at . .

Mathis, Tex., Nueces River near........ 367-368

Mauriceville, Tex. Cow Bayou near...... 311-313

Medina Lake near San Antonio, Tex.........

Mermentau River at Lake Arthur, La . . . . . 295 2957

Mermentau River basin. . . ............. 295-297

Mill Creek near Mill Creek, Johnston

County, Okla.................

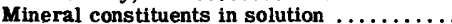

Mississippi River at St. Louis, Mo ........

- $23-26$

Mississippi River Delta ... . . . . . . . . . 282-294

Moss Bluff, La., Calcasieu River at. . . . . . 299-301

Moss Bluff, Tex., Trinity River near ...... 325-326

Muddy Boggy Creek near Farris, Atoka

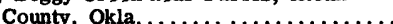

Muddy Fork Creek at Murfreesboro, Dam Site near Murfreesboro, Ark. ........

Mulber ry River near Mulberry, Ark .......

$\mathbf{N}$

Neches River at Evadale, Tex. at State Highway 103, west of Lufkin

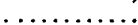

Neosho (Grand) River at Fort Gibson Reservair near Fort Gibson,

Okla .....................

at Pensacola Reservoir at Langley,

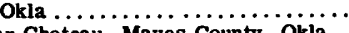

near Choteau, Mayes County, Okla..

Neosho River near Commerce, Okla. . .

Newport, Ark., White River at...... 40 40 42

Nitrate ..................... 12

Norfork, Ark. North Fork River near. 36

Norman, Okla., Little River near .. 110-113, 171

Norphlet, Ark., Smackover Creek

near .................. 231-234

North Canadian River at Canton

Reservoir near Canton, Okla. ... . 114-115

near Guymon, Texas County, Okla .. 172

near Seiling, Major County, Okla ... 174

near Wetumka, Okla . . . . . . . . . 119-123

near Yukon, Okla . . . . . . . . . . . . 116-118

North Fork Red River near Carter, Okla .................. 183-185

near Headrick, Jackson County,

Okla ................. 268

near Shamrock, Tex........... 277

near Texola, Beckham County, Okla. $\quad 267$

North Fork River at Norfork Dam near

Norfork Ark ...........................

36

North Fork Wichita River, $4 \frac{i}{2}$ miles

east of Truscott, Tex ......... 278

14 miles southeast of Paducah, Tex . 278

10 miles southeast of Paducah, Tex . 278

North Groesbeck Creek near North

Groesbeck, Okla..............

Nueces River near Mathis Tex. ..... $367-368$

Nueces River basin ............. 367-368

Oak Creek Reservoir near Blackwell,

Tex................. 362

Oakwood, Tex., Trinity River near.... 319-321

Old River near Cove, Tex. . . . . . . . 327-328

Orla, Tex., Pecos River near....... 490-491

Osage Creek near Elm Springs, Ark ... 178

Ouachita River, at Arkadelphia, Ark... 226-228

at Blakley Mountain Dam near Hot

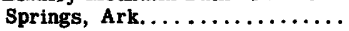

near Felsenthal Ark ....... 250-253

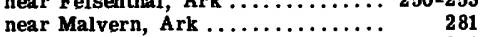

near Mount Ida, Ark ........... 280

Oxygen consumed ................ 13

\section{$\mathbf{P}$}

Palo Duro Creek near Range, Texas

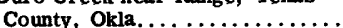

Patterson, Ark., Cache River at ......

Pecos River, at Carlsbad, N. Mex. . . . 478-480

at Dam Site 3 , near Carlsbad, $\mathbf{N}$.

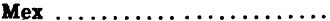

at ford crossing in Major Johnson

Spring area near Lakewood, $\mathbf{N}$.

Mex.

at Pierce Canyon Crossing near

Malaga, N. Mex ........... 484-486

at Puerto de Luna, N. Mex ....... 453-458

below Alamogordo Dam, N. Mex. ... 459-460

below Grandfalls, Tex ........... 492

below McMillan Dam near Lakewood,

N. Mex. . . . . . . . . . . . . . . 495

below Red Bluff Dam near Orla, Tex $490-491$

east of Malaga, N. Mex . . . . . . . . . 482-483

near Acme, N. Mex ........... 461-463

near Artesia, N. Mex. . . . . . . . 468-473

near Girvin, Tex. . . . . . . . . . . . 493-494

near Red Bluff, N. Mex . . . . . . . . . 487-489

Pennington Creek near Reagan,

Johnston County, Okla........... 274-275

Petit Jean Creek near Booneville, Ark . 178

near Waveland, Ark ........... 178

Percent sodium. .............. 15

Perkins, Okla, , Cimar ron River at.... 69-74 
Piney Creek near Dover, Ark .........

Piney Fork Strawberry River at Evening Shade, Ark ...............

Pond Creek near Fort Cobb, Caddo

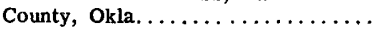
near Lamont, Grant County, Okla..... Poteau River at Cauthron, Ark ......... Poughkeepsie, Ark., Strawber ry River near.

Preacher Creek near Dover, Kingfisher County, Okla.

Properties and characteristics of water Pryor Creek near Pryor, Mayes County, Okla ..

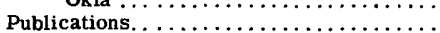

Puerto de Luna, N. Mex., Pecos River at

\section{Q}

Quapaw Creek near Meeker, Lincoln

County, Okla ..............

\section{$\mathbf{R}$}

Rainey Mountain Creek near Mountain View, Kiowa County, Okla ........ Ralston, Okla., Arkansas River at...... Ravendon Springs, Ark. , Eleven Point

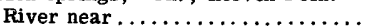

Red Bluff, N. Mex., Pecos River near... Red River at Alexandria, La.......... at Denison Dam near Denison, Tex.... at Fulton, Ark .................. at Index, Ark . . . . . . . . . . . . near Gainesville, Tex............

Red River basin

Red Rock Creek near Red Rock, Noble County, Okla.............................

Refinery intake canal near Loving, $\mathrm{N}$. Mex.

Richmond, Tex. Brazos River at $\ldots \ldots$

Rio Chama near Abiquiu, N. Mex....... near Chamita, N. Mex. . . . . . . . . . Rio Grande, above Culebra Creek near

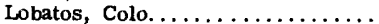

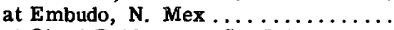
at Otowi Bridge near San Iidefonso,

N. Mex.

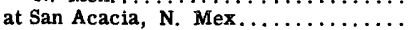
at San Antonio, N. Mex ............. conveyance channel at San Marcial,

N. Mex. ............... conveyance channel below heading,

near San Marcial, N. Mex.........

floodway at San Marcial, N. Mex...... near Bernalillo, N. Mex ............

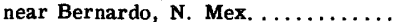
Tiffany Channel at San Marcial, $N$.

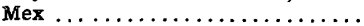

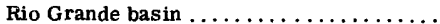

Rio Hondo at Diamond $A$ Ranch near

Roswell, N. Mex.............

Rio Penasco at Dayton, N. Mex.........

Rio Puerco below Cabezon, N. Mex...... at Rio Puerco, N. Mex............ near Bernardo, N. Mex...........

Rio Salado near San Acacia, N. Mex .....

Roaring Springs near Roaring Springs,

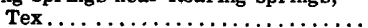

Rock Creek near Dougherty, Murray

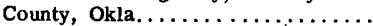

Rolling Fork River near De Queen, Ark .

Romayor, Tex., Trinity River at....... Round Springs Creek near Disney, Mayes County, Okla..................

Roswell, N. Mex., Rio Hondo near ..... Ruliff, Tex., Sabine River near ......... Rush Creek at Purdy, Garvin County,

Okla .......................... 4 miles northwest of Town Bluff, Tex.. near Maysville, Garvin County, Okla..

Rye, Ark., Saline River near ......... 244-245
Sabine River near Emory, Tex ....... 302-304 near Ruliff, Tex ............... 308-310 near Tatum, Tex............. 305-307 Sabine River basin .............. 302-313

St. Francis Bay near Riverfront, Ark. . $\quad 30$ St. Francis River at Lake City, Ark ... 30 at Marked Tree, Ark .......... 27-29 at Parkin, Ark.............. 30 at St. Francis, Ark............ 30 floodway near Marked Tree, Ark... $\quad 30$ St. Francis River basin. .......... 27-30 St. Joe, Ark., Buffalo River near ..... Saline Bayou near Clarence, La...... 221-222

Saline River near Dierks, Ark........ 280 near Rye, Ark ............... 244-245 Sallisaw Creek near Sallisaw, Sequoyah County, Okla............... 177

Salt Creek near Dewright, Seminole County, Okla................. 172 near Shidler County, Okla ......... 160 $6 \frac{1}{2}$ miles southeast of Paducah, Tex. 278 Salt Fork Arkansas River, at Tonkawa,

Kay County, Okla .............. 158-159 near Alva, Woods County, Okla..... near Jet, Alfalfa County, Okla ....... 157-158 Salt Fork Red River, at Mangum, Greer County, Okla ........... 267 near Vinson, Harmon County, Okla.. 267 near Wellington, Tex .......... 180-182 San Acacia, N. Mex., Rio Grande at... 424-429 Rio Salado near............... 421-422 Socor ro main canal north, at ...... 423 San Angelo Reservoir near San Angelo,

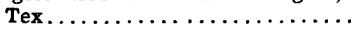
San Antonio, N .................. 430 San Indefonso, N. Mex., Rio Grande near .................... 383-384 San Jacinto River near Huff man, Tex... 335-338 San Jacinto River basin............ 335-336 San Jose River at Correo, N. Mex..... 412-413 San Marcial, N. Mex., Rio Grande conveyance channel at ........ 442-446 Rio Grande floodway at. .......... $447-452$ Rio Grande conveyance channel near 434-436 Rio Grande Tiffany Channel at ..... 437-441 San Saba, Tex., Colorado River near .. $352-357$ Sand Creek near Okesa, Osage County, Okla .................... 167 Sandy Creek on county road 10 miles southwest of Jasper, Tex....... 377 Sarepta, La., Bayou Bodcau near...... 220 Scottsville, Ark., Illinois Bayou near.. 142 Sediment. . . . . . $16 \ldots \ldots \ldots \ldots \ldots \ldots, 17$ Sheridan, Ark. , Hurricane Creek near. 240-243 Silica......................... Skedee Creek at Lake near Pawnee County, Okla............................ Smackover Creek near Norphlet, Ark...231-234 Socorro main canal north at San

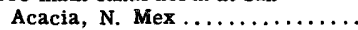
Sodium-adsorption-ratio ............... Sodium and potassium ................. South Fork of Ouachita River near Mount Ida, Ark .............. South Fork Wichita River 4 miles north

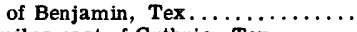
6 miles east of Guthrie, Tex......... South Fourche La Fave near Hollis,

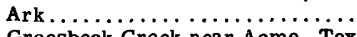
South Groesbeck Creek near Acme, Tex Spadra Creek near Clarksville, Ark.... Specific conductance ............... Spring River at Imboden, Ark .......... near Quapaw, Ottawa County, Okla.. Stinking Creek near Carnegie, Kiowa

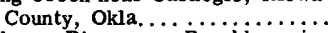
Strawberry River near Poughkeepsie,

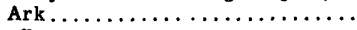
Streamflow...................... Strong Ark. Bayou Lapile near. ..... 246-249 
Stuttgart, Ark., Lagrue Bayou near ......

Little Lagrue Bayou near .............

Sugar Creek near Anadarko, Caddo

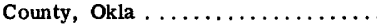

Sulfate $\ldots \ldots \ldots \ldots \ldots \ldots \ldots \ldots \ldots \ldots \ldots$

Suspended sediment $\ldots \ldots \ldots \ldots \ldots \ldots \ldots \ldots$

Sweetwater Creek near Texas line,

Beckham County, Okla ............

near Wheeler, Tex................

Sycamore Creek near Wyandotte, Ottawa

County, Okla..................

$\mathbf{T}$

Tatum, Tex. , Sabine River near. ....... 305-307

Temperature ....................

Theuvenins Creek, 7 miles southeast of Warren, Tex .................

Three Creeks near Junction City, Ark .... 258-262

Total acidity. ....................

Trinity Bay at mouth of Trinity River, near Anahuac, Tex

14-15

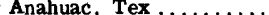

Trinity River, at Anahuac, Tex .............. at Romayor, Tex.................. near Moss Bluff, Tex.............

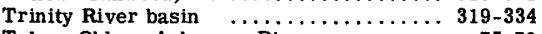

Tulsa, Okla. , Arkansas River near...... 75-79

Turkey Creek near Dover, Kingfisher

County, Okla. ................ near Drummond, Garfield County,

Okla.......................

near Olustee, Jackson County, Okla.....

Twelvemile Bayou near Dixie, La ........

\section{U}

Ute Creek near Bueyeros, N. Mex.

$97-100$

\section{$\mathbf{V}$}

Van Buren, Ark., Arkansas River at ... . 135-139

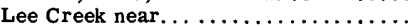

Verde Creek at Camp Verde, Tex........

Verdigris River near Claremore, Okla ... near Inola, Okla ................

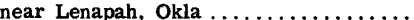

Vermilion River at Bancker's Ferry, La .. 291-294 Victoria, Tex., Guadalupe River at ..... 363-365

Village Creek at U. S. Highway 69 9 miles northwest of Kountze, Tex.

317

\section{Wellington, Tex. , Salt Fork Red River} near ................... 181-182

West Bitter Creek near Chickasha, Grady County, Okla ........... 271

West Cache Creek near Cookietown,

Cotton County, Okla ............

Wetumka, Okla., North Canadian River near ..................... 119-123

Wewoka Creek near Wetumka, Hughes

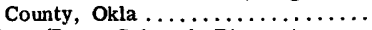

White River (Brazos River basin) at county road crossing, $4 \frac{1}{2}$ miles east of Crosbyton, Tex ......... 346

at U. S. Highway $82,4 \frac{1}{2}$ miles east of Crosbyton, Tex........... 346

White River (White River basin) at

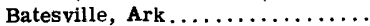

at Beaver, Ark . . . . . . . . . . . .

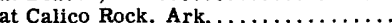

at Clarendon, Ark ..............

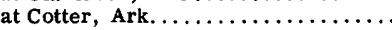

at De Valls Bluff, Ark............

at Newport, Ark................

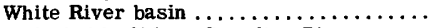

Whitefield, Okla., Canadian River

Whitney, Tex., Brazos River near...... 339-341

Wichita River near Seymour, Tex...... 279

Wildhorse Creek near Hoover, Garvin

Wolf Creek near Fort Supply, Woodward

6 miles nor thwest of Town Bluff, Tex ................. 317

Yukon, Okla., North Canadian River near ................... 128-133 County, Okla ............... 273 County, Okla ................ 173

$\mathbf{Y}$

52

52

$46-48$

$33-34$ near ....................... 
